

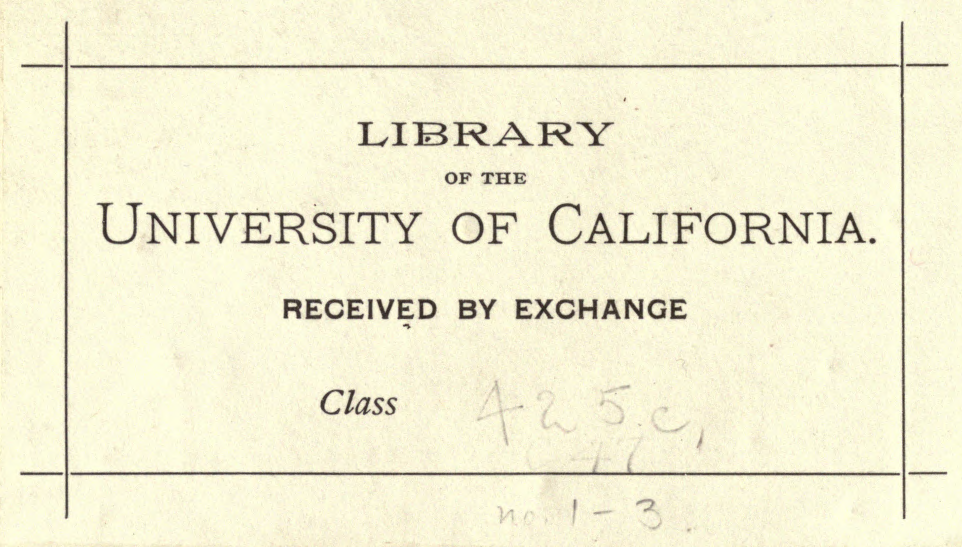


The GHicago ACADEmy of SCIENCES

SPEGIAL PUBLICATION NO. 3

\section{THE LYMNÆIDÆ OF \\ NORTH AND MIDDLE AMERICA RECENT AND FOSSIL}

$\mathrm{BY}$

FRANK COLLINS BAKER

CURATOR OF THE CYICAGO ACADEMY OF SOIENCES
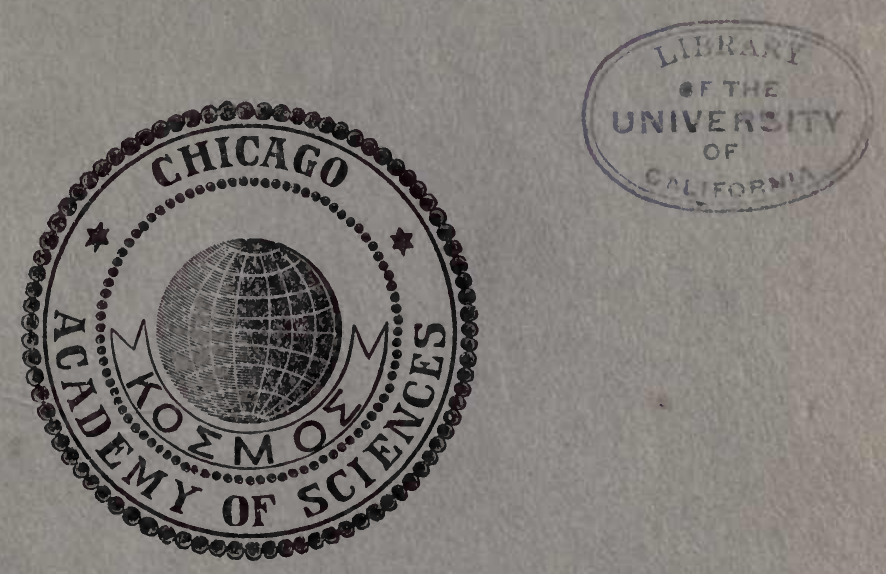

CHICAGO

Published by the Academy

February 15, 1911 



\title{
The Chicago Academy of Sciences
}

\author{
SPECIAL PUBLICATION NO. 3
}

\section{THE LYMNÆID压 OF}

\section{NORTH AND MIDDLE AMERICA} RECENT AND FOSSIL

By

\section{FRANK COLLINS BAKER}

CURATOR OF THE CHICAGO ACADEMY OF SCIENCES

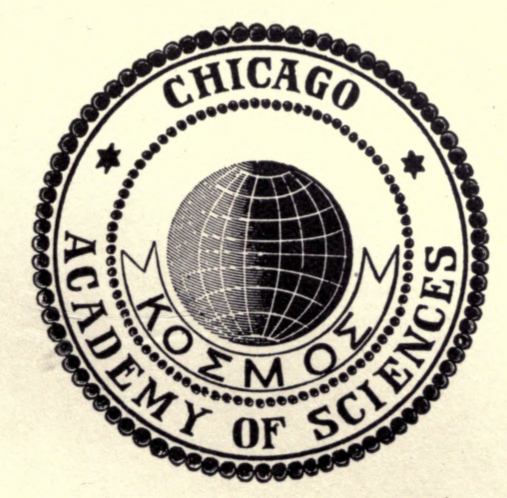

CHICAGO

Published by the Academy

February 15, 1911 
Peterson \& Kimball

COMPANY 
TO

DR. HENRY AUGUSTUS PILSBRY

IN GRATEFUL RECOGNITION OF

HIS HELPFUL ADVICE

AND FRIENDLY

INTEREST 



\section{PREFACE.}

The fresh-water snails embraced in the family Lymnæidæ form an important factor in the mollusk fauna of the more northern countries of the world. Say, Haldeman, Lea, Tryon, Binney and other early writers have described many species and several of these authors have essayed more or less complete monographs of the family. In 1865, W. G. Binney monographed the Lymnæas in the series of illustrated papers published in the Smithsonian Miscellaneous Collections under the litle of "Land and Fresh-Water Shells of North America." Binney was naturally very conservative and reduced the then known species and varieties (79) to about one-third this number (31). Though expressing his opinion that certain species were synonymous with certain other species, he was careful to include descriptions and figures of all known forms, leaving the matter to the judgment of American conchologists to weigh and test his conclusions. Unfortunately the American conchologists did not do this, but accepted Binney's conclusions as final, thus greatly complicating the literature and rendering the use of the latter for geographic purposes almost impossible.

The present monograph was begun as a revision of Binney's work; but, as the matter progressed, it became evident that the old classifications and methods of presentation needed an almost complete revolition to meet the requirements of modern standards. The meager descriptions needed to be much more extensive, the exact geographic and geologic distribution needed to be indicated, the ecology as well as other items demanded attention, and the project has thus grown to many times its original dimensions. It was also evident that to adeciuately present the subject a large number of figures would be necessary and these have accordingly been made from authentic or type material. It is obvious that until a group in any branch of Zoology is placed upon a sound basis and the limits of the species accurately defined, no discussions of zoögeographic questions can be of any value. This fact has been clearly demonstrated in the course of the present work.

It is the purpose of this volume to furnish to students of this family of fresh-water mollusks a reliable guide to a knowledge of the species, of their habitat relations and their geographic range. To this end chapters more or less extensive, have been introduced briefly 
outlining their general morphology, their ecological relations and their geologic and geographic distribution. A new classification is also proposed, based on characters of the internal organs as well as upon the shells. During the progress of the work several visits have been made to Washington and Philadelphia to consult the extensive collections in the Smithsonian Institution and in the Academy of Natural Sciences of Philadelphia and also to examine and describe the types in these institutions. Upward of 100,000 specimens have been examined, covering the entire continent of North America. Specimens have been freely placed at the writer's disposal by almost every student of the Mollusca in the United States and Canada, and to their generosity, credit is due in large measure. A collection embracing the majority of the species, and numbering some 20,000 specimens (about 1,500 lots) has been built up in the Chicago Academy of Sciences, from which the majority of the figures used to illustrate this work have been made. For the kenefit of future workers, the catalog numbers of these specimens have been indicated in the descriptions of the plates.

\section{ACKNOWLEDGMENTS.}

The success of the present work is largely due to the kind help and encouragement of a group of American conchologists who have cheerfully given counsel and assistance, besides the loan of collections, during the eight years of its preparation. Chief among these the author is indebted to Mr. Bryant Walker, of Detroit, Michigan, at whose suggestion the work was undertaken; to Dr. Henry A. Pilsbry Curator of Mollusks in the Academy of Natural Sciences of Philadelphia, and to Dr. William H. Dall, Curator of Mollusks in the United States National Museum, especial acknowledgments are due; my thanks are also due to Dr. Paul Bartsch of the National Museum and to Mr. E. G. Vanatta of the Philadelphia Academy, for material assistance while examining specimens in these two institutions. Recognition is due Mr. Edgar A. Smith of the British Museum, and the late Dr. J. F. Whiteaves, of the Canadian Geological Survey, for the loan of type material. Special mention should be made of the careful work of my assistant, Mr. Frank M. Woodruff, who prepared the excellent photographs which accompany this work. Acknowledgment is due the Smithsonian Institution for the loan of specimens and for certain photographs of type material; to the Academy of Natural Sciences of Philadelphia, for the loan of critical material; and to Dr. S. A. Forbes, Director Illinois State Laboratory of Natural History, Urbana, Ill., for the loan of the following plates: L, LI, LII, fig. 1, LIV, fig. 1. 
Also to the John Crerar Library, Chicago, and the Library of the University of Chicago, for assistance in the preparation of the bibliography.

The author is under great obligations to the following persons who have generously placed at his disposal their collections and, in many cases, have also presented to the Chicago Academy of Sciences a large amount of material for investigation, for which he wishes to express his gratitude:

Adams, Charles Christopher, Illinois State University.

Allen, John A., Cleveland, Ohio.

Armstrong, Edward H., Providence, R. I.

Arnold, Ralph, U. S, Geol. Survey, Washington, D. C.

Ashmun, E. H., Weiser, Idaho (deceased).

Bain, H. Foster, Urbana, Ills.

Baker, Mrs. Frank C., Chicago, Ill.

Berry, S. Stillman, Stanford University, California.

Brown, C. E., Milwaukee, Wis.

Button, Fred L., Oakland, California.

Calkins, W. W., Chicago, Ills.

Cass, Charles L., Pacific Beach, Cal.

Chase, Virginius H., Wady Petra, Ills.

Clapp, George H., Pittsburg, Penn.

Clarke, John M., Director, New York State Museum, Albany, N. Y.

Cockerell, T. D. A., University of Colorado, Boulder, Colo.

Conner, Charles H., Philadelphia, Penn.

Daniels, L. E., La Porte, Indiana.

Elrod, Morton J., University of Montana, Missoula, Mont.

Ferriss, James H., Joliet, Ills.

Forbes, S. A., Illinois State Laboratory of Natural History, Urbana, Ills.

Frierson, L. S., Frierson, La.

Gannett, Henry, Washington, D. C.

Gratacap, L. P., American Museum of Natural History, New York City.

Greenicher, S., Milwaukee, Wis.

Handwerk, J. H., Joliet, Ills.

Hanna, G. Dallas, Lawrence, Kans.

Hannibal, Harold, San Jose, Cal.

Hart, Charles A., Illinois State Laboratory of Natural History, Urbana, Ills.

Hemphill, Henry, San Diego, Cal.

Henderson, John B., Jr., Washington, D. C.

Henderson, Junius, University of Colorado, Boulder, Colo.

Hinkley, Anson A., Du Bois, Ills.

Hood, J. D., State Laboratory of Natural History, Urbana, Ills.

Iseley, F. B., Tonkawa, Oklahoma. Mass.

Johnson, Charles W., Curator, Boston Society of Natural History, Boston,

Keep, Josiah, Mills College, Cal.

Kirkland, Reynold J., Grand Rapids, Mich.

Latchford, F. R., Ottawa, Ontario, Canada. 
Latham, V. A., Chicago, Ills.

Lermond, N. W., Thomaston, Me.

Letson, Miss E. J., Buffalo Society of Natural History, Buffalo, N. Y. (Now Mrs. W. A. Bryan, of Honolulu.)

Lyon, Howard N., Chicago, Ills.

MacCurdy, H. A., Alma, Mich.

Marsh, Wm. A., Sr., Aledo, Ills.

Mazyck, William G., Charleston, S. C.

Morse, Edward S., Director, Peabody Museum, Salem, Mass.

Nason, William A., Algonquin, Ills.

Nylander, Olof. O., Caribou, Me.

Ortmann, A. E., Carnegie Museum, Pittsburg, Penn.

Over, W. H., Date, South Dakota.

Pease, A. S., University of Michigan, Ann Arbor, Mich.

Rathbun, Richard, U. S. National Museum, Washington, D. C.

Sargent, H. E., Grand Rapids, Mich.

Selden, Charles W., Valley City, North Dakota.

Simpson, Charles T., Little River, Florida.

Southwick, James M., Roger Williams Park Museum, Providence, R. I. (Deceased.)

Stearns, Robert E. C., Los Angeles, Cal. (Deceased.)

Sterki, Victor, New Philadelphia, Ohio.

Streng, L. H., Grand Rapids, Mich.

Strode, W. S., Lewistown, Ills.

Van Hyning, T., Des Moines, Iowa.

Wagner, George, University of Wisconsin, Madison, Wis.

Walker, Bryant, Detroit, Mich.

Walker, Miss Mary, Buffalo, N. Y.

Walter, H. E., Brown University, Providence, R. I.

Ward, F. H., State Museum, Albany, N. Y.

Weller, Stuart, University of Chicago, Chicago, Ills.

Wiswall, Mrs. E. C., Madison, Wis.

Woodruff, Frank M., Chicago Academy of Sciences, Chicago, Ills.

Youngren, Emil W., Chicago, Ills.

Zetek, James, State Laboratory of Natural History, Urbana, Ills.

SUMMARY.

The work is divided into chapters, each chapter dealing with a distinct phase of the subject. The morphology (I) is necessarily brief, and is intended simply to outline the gross anatomy of the Lymnæas in such a manner as to convey a clear idea of the structure of these animals. Under Ecology (II) is given a brief account of the habitat relations of the family, as well as notes on food, reproduction, respiration, æstivation, locomotion, etc., which it is hoped may prove useful to those interested in the modern science of animal ecology. It is believed that the photographs of typical habitats will aid not a little in the understanding of this subject. Exact data concerning the habitat relations of our fresh-water shells is very meager and there 
is a wide field for much valuable work in this direction. In Chapter III the geographical distribution of the family is discussed and a new division of North America into faunal areas is proposed. The tables of comparative distribution will doubtless prove of interest to students of this phase of the subject. The discussion of the post- and pre-glacial distribution is far from being as full or complete as could be wished, but seems to be the best that can be presented in the light of our present knowledge of pre-glacial Lymnæas.

In Chapter IV an effort has been made to summarize our present knowledge concerning the extinct species of American Lymnæas, and it is believed that the correlation of the fossil species with those of recent times will prove of interest. The majority of the fossil species are illustrated by the original figures. The list of fossil Lymnæas is believed to be fairly exhaustive. Chapter $\mathrm{V}$ contains an historical sketch of previous monographs. In Chapter VI a new classification is proposed, based on the comparative characters of shell, radula and genitalia. Many malacologists will not agree with the author in thus subdividing this group; in so doing he has only followed the trend of modern taxonomy. Chapter VII embraces a consideration of the nomenclature. It is believed that the instructions for collecting and preparing Lymnæas for dry and anatomical study, in Chapter VIII, will prove helpful to those having little experience in this subject.

Chapter IX includes the systematic discussion of the Lymnæas of Middle and North America. Each species is discussed under the following heads:

Bibliography.

Description of shells with measurements.

Location, number, and catalog number of type specimens.

Type locality.

Description of Animal.

Description of Jaw.

Description of Radula.

Description of Genitalia.

Range or Geographical Distribution.

Records of authentic localities arranged alphabetically by states.

Geological Range.

Records of fossil specimens.

Ecology.

Remarks. 
The bibliography includes every reference to the species under discussion, which the writer has been able to secure. When the species has been cited erroneously under another name, that fact is stated, if known. The descriptions of the shells have been made as full as possible; it will be noted that the measurements of the spire includes that portion of the shell from aperture to apex, in this respect differing from those of many writers, who included in the spire all but the body whorl. Measurements are given of several specimens from different localities. It is believed that the location, number, and catalog entries of the types will prove of value to future students of the family. The same is true of the type locality which is given in each case. With few exceptions, the types of all American Lymnæas have been seen and examined. The descriptions of the anatomical features have been made with great care; each drawing represents the combined examinations of many different individuals in order to check the results. No great difference was found in the genitalia at different seasons of the year. The organs, when at rest, appeared the same in the breeding as in other seasons. The figures of the radulæ have been made with exceptional care as the cusps are difficult to see and errors are easily made.

The distribution maps, both recent and fossil, are arranged by means of symbols to show at a glance the range of the species in the different river systems. The large symbols represent actual records while the small dots indicate the probable range of the species. Records outside these areas are to be viewed with suspicion until verified by competent malacologists. The list of records is arranged alphabetically by states and will doubtless be found of use to those malacologists who may be working up state lists. In a few cases (palustris, stagnalis, etc.) it has not seemed necessary to include these records, as the species are universally distributed over a large area. Under ecology is given all available information concerning the habitat relations of the species. This is a subject which has received scant attention and there is a wide field for excellent work in this direction. Large collections should be made from restricted areas and exact notes on habitat relations as well as photographs should be secured. Much light will be thrown on the exact relationship of several obscure species by studies of this kind. Under remarks considerable information is given concerning the species as well as comparative notes indicating the specific or varietal differences. The figures on the plates illustrate the species as it appears in different localities and at different ages. They also indicate something of the range of variation. 
Chapter $\mathrm{X}$ includes the bibliography, which is comparatively exhaustive, although a few references have doubtless been overlooked. It is believed to contain all of the important references to the subject.

Of the 211 names occurring in the literature, 95 are herein admitted as worthy of recognition as species or races. 6 names are used for the first time. 35 fossil species have been recorded, of which 24 are here recognized. One new race is described. The absence of keys for the determination of the species may lead some readers to suppose that the author places no value on aids of this. character. Such is not the case, and many attempts have been made to prepare a satisfactory key to aid beginners, but without success. In a group like the Lymnæas, where variation is paralleled in so many of the species, it is obviously impossible to prepare a key which will be intelligible to any save those well versed in the subject, and for this class no key is necessary. It is believed that with the figures and descriptions no one will have serious difficulty in determining the majority of the species of American Lymnæas.

It is fully realized, in presenting this monograph, that there is much contained therein which is faulty and incomplete. In a few cases adequate material has not been available for a satisfactory treatment of the species. There are many records which have not been substantiated and have been omitted, therefore, from the records and distribution maps. In a number of cases the soft parts have been lacking and a definite placing of the species has been impossible. With all its shortcomings, however, the author believes that it is a step in advance of previous efforts, and that it will prove an aid to all students. of this interesting family.

Should this volume meet with the approval of the conchological public, it is in the mind of the author to prepare companion volumes. on Planorbis, Physa and related genera.

Frank Colimins Baker.

Chicago, Illinois, January, 1911. 


\section{TABLE OF CONTENTS.}

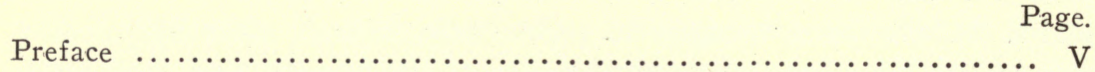

I. General Morphology of the Lymnæas...................... 1

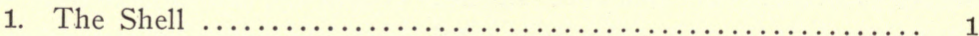

2. External Appearance of the Animal................... 5

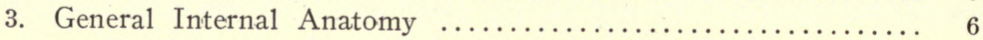

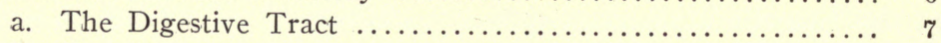

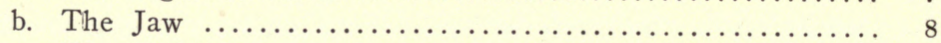

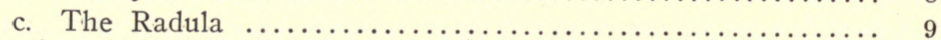

d. The Reproductive System....................... 10

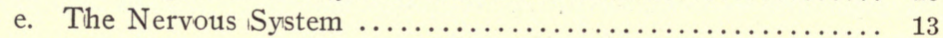

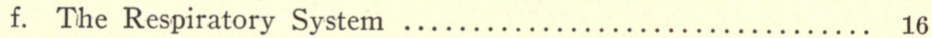

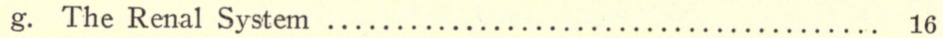

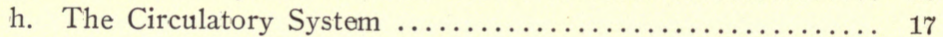

i. The Muscular System ......................... 17

4. Bibliography of Works Consulted....................... 18

II. Ecology of the Lymnæas............................... 19

a. General Environmental Conditions................. 19

b. Variation of the Lymnæid Shell in Different Environments. . 29

c. Locomotion .................................. 32

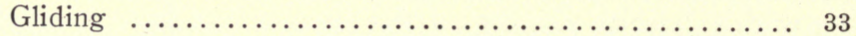

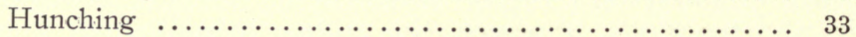

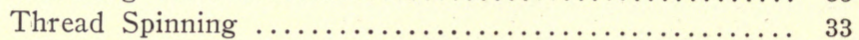

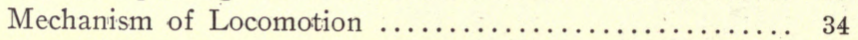

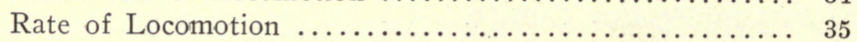

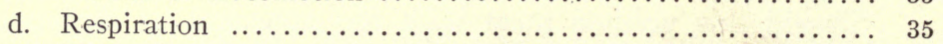

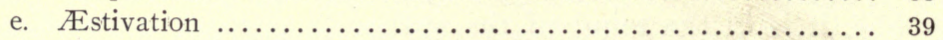

f. Abnormalities .............................. 40

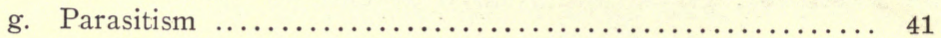

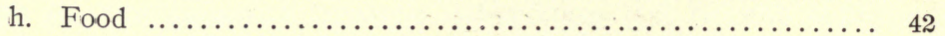

i. Food for Other Animals....................... 44

j. Reproduction and Nidification.................... 45

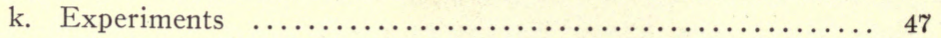

1. Length of Life ................................ 51

m. Bibliography of Works Consulted................ 51

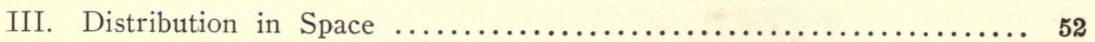

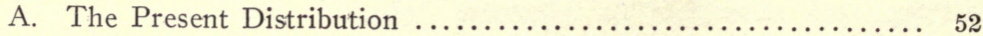

Eighteen Zoological Regions..................... 56

Table of Distribution of American Lymnæas............. 61

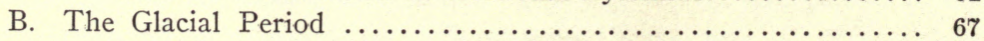

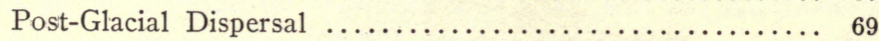

Tertiary Lakes of the Great Basin.................. 73 
Effect of the Glacial Period on the Lymnæid Fauna of America ................................ ${ }_{75}$

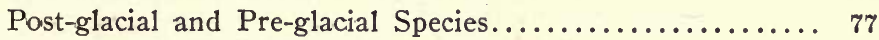

C. Bibliography of Works Consulted................... 79

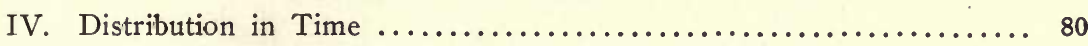

A. General Discussion ............................... 80

Systematic Table of Extinct American Lymnæas......... 85

Stratigraphical Table of Extinct American Lymnæas....... 86

B. Descriptions of American Fossil Lymnæas.............. 87

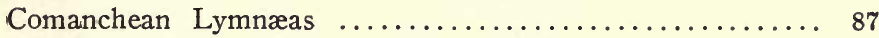

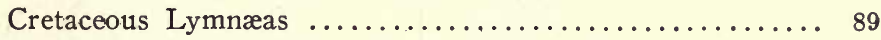

Lower Eocene Lymnæas ........................ 95

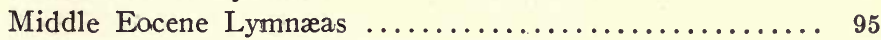

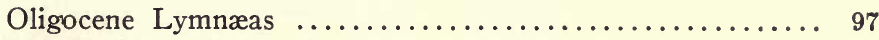

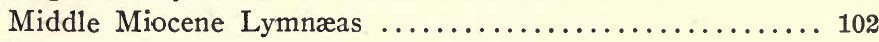

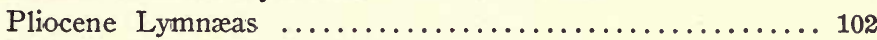

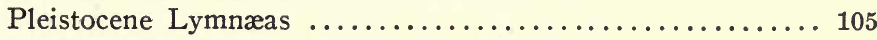

Doubtful Lymnæas and Species wrongly referred to this

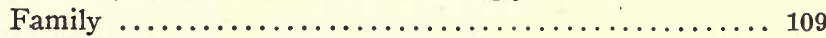

C. Bibliography of American Fossil Lymnæas.............. 111

V. Historical Sketch of Previous Monographs.................. 117

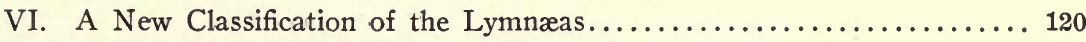

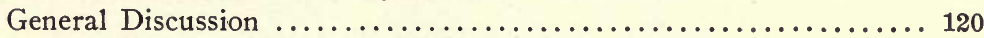

Key to Genera and Subgenera of Recent American Lymnæas...... 125

Extralimital Groups of Lymnæinæ.................... 127

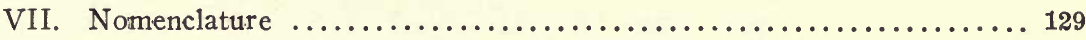

VIII. Instructions for Collecting and Preparing Lymnæas............. 131

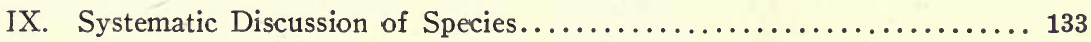

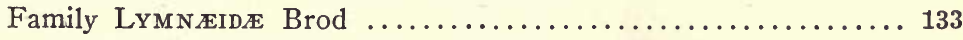

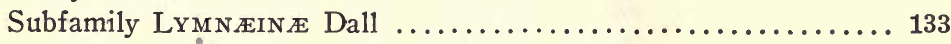

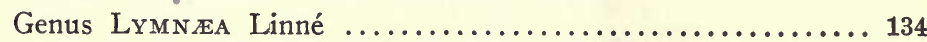

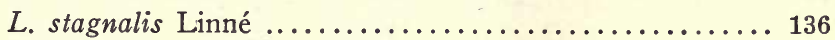

L. stagnalis appressa Say .................. 137

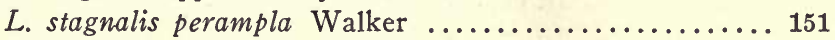

L. stagnalis wasatchensis Hemphill ............. 152

L. stagnalis lilliane Baker .................... 153

L. stagnalis sanctcmarice Walker ............... 156

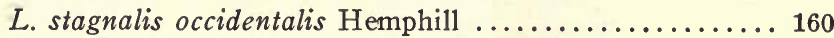

L. lepida Gould .......................... 161

Genus Pseudosuccinea Baker .................... 162

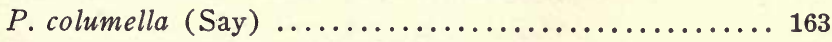

$P$. columella chalybea (Gould) ................ 171

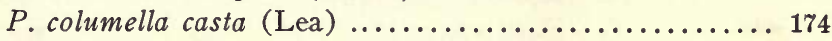

$P$. columella championi (Von Martens)........... 175

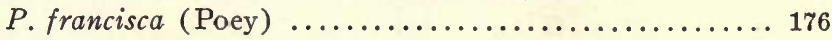

Genus RAdix Montfort ......................... 178

$R$. auricularia (Linné) $\ldots \ldots \ldots \ldots \ldots \ldots \ldots \ldots \ldots \ldots \ldots \ldots$ 


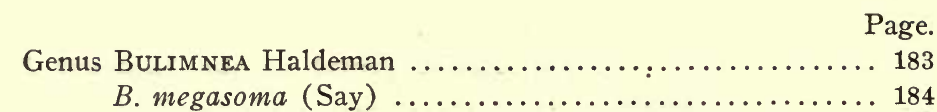

Genus Acella Haldeman ......................... 191

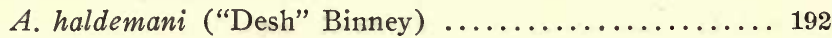

Genus Pleurolimn жa Meek ........................ 198

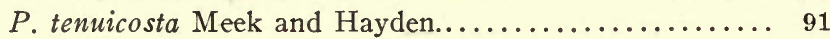

Genus Galba Schrank ............................. 199

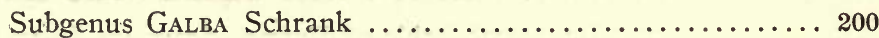

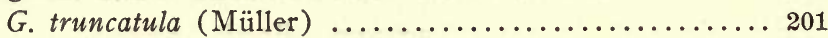

G. doddsi Baker ............................. 203

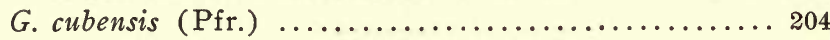

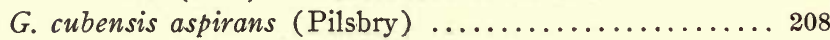

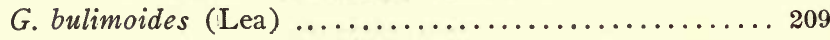

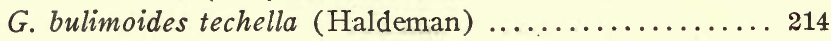

G. bulimoides cockerelli (Pilsbry \& Ferriss).......... 217

G. bulimoides cassi Baker .........................221

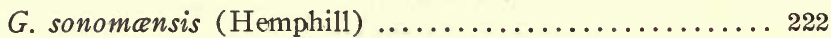

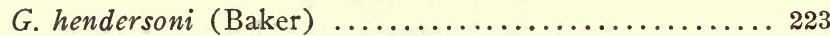

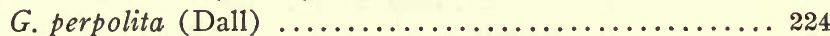

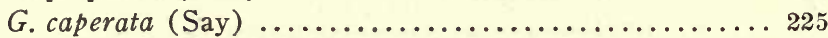

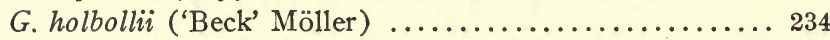

Subgenus Simpsonia Baker ..................... 236

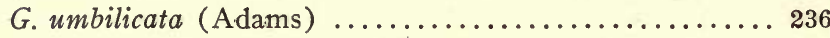

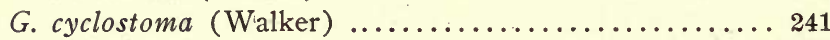

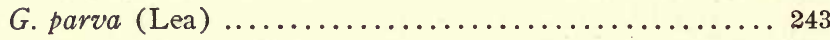

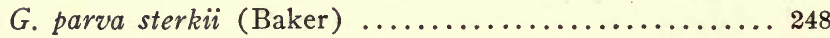

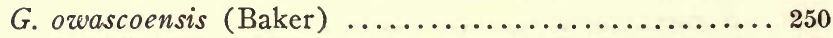

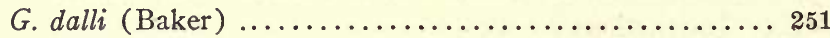

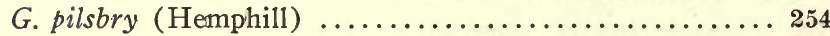

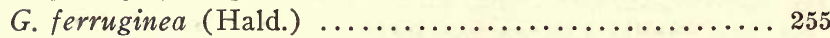

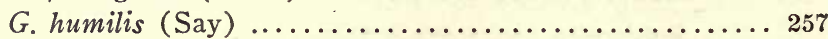

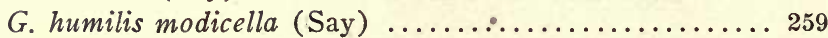

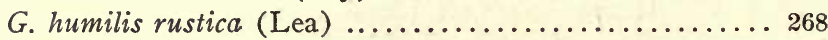

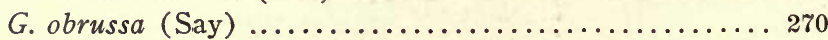

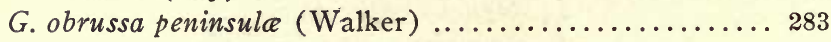

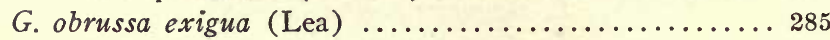

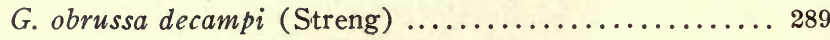

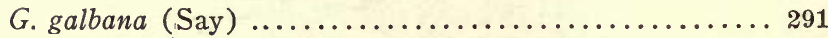

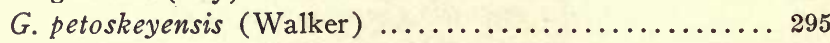

Subgenus Stagnicola Leach ...................... 296

Group of palustris......................... 298

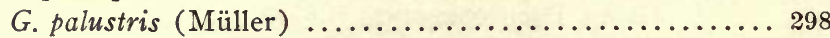

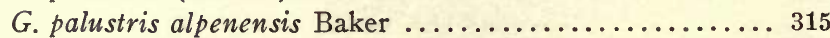

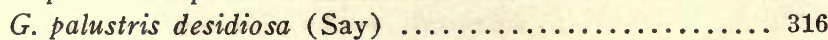

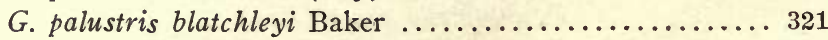

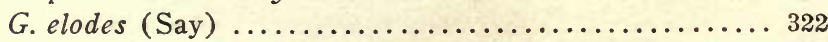

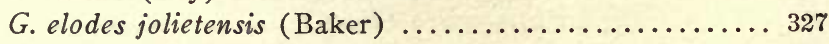

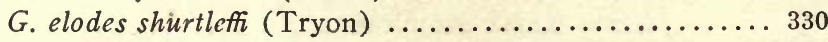

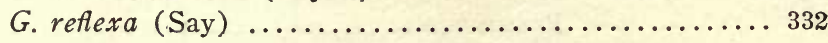


Page.

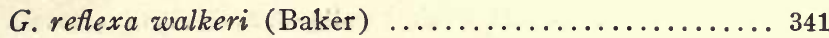

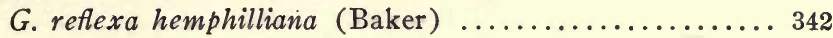

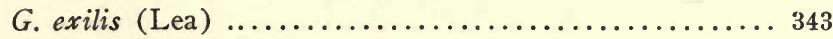

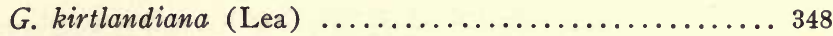

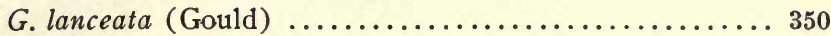

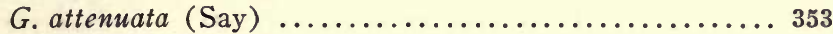

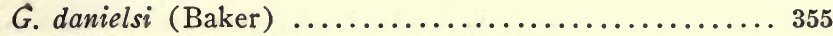

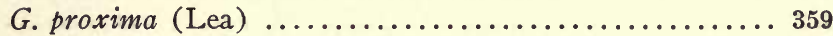

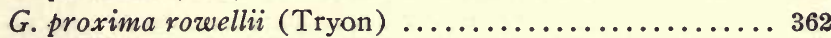

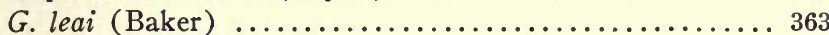

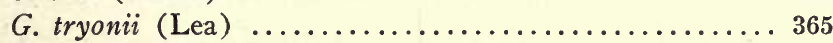

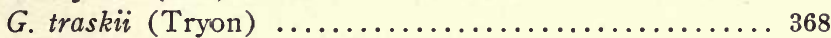

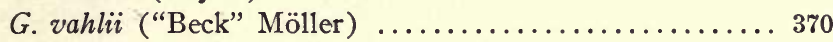

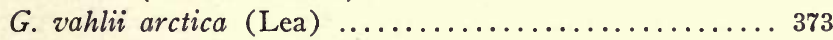

G. vahlii pingellii ("Beck" Möller).............. 374

G. neopalustris Baker ..................... 376

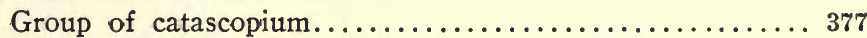

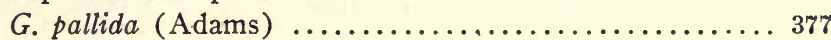

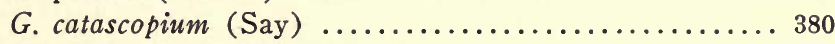

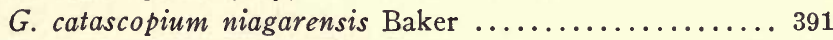

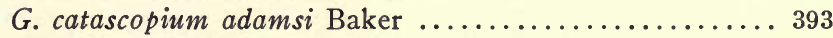

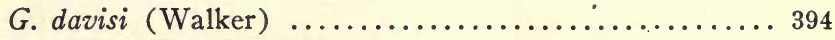

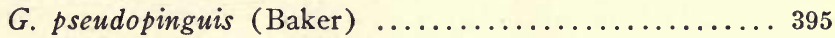

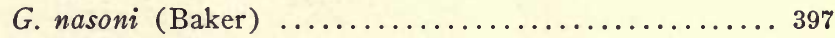

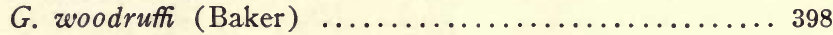

G. decollata (Mighels) .........................400

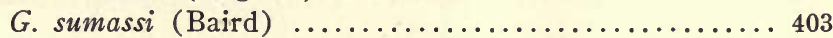

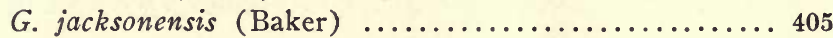

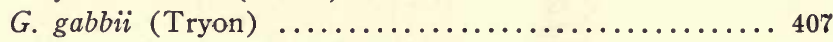

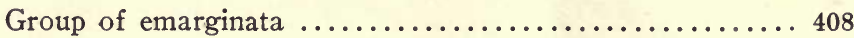

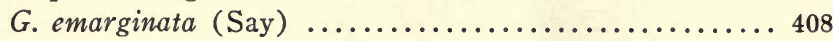

G. emarginata mighelsi (Binney) ................ 416

G. emarginata angulata (Sowb.)................ 421

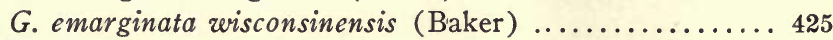

G. emarginata canadensis (Sowb.) ............. 427

G. emarginata ontariensis ("Muhlf." Küster)........ 432

G. contracta (Currier) ........................ 433

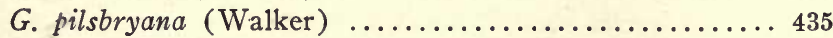

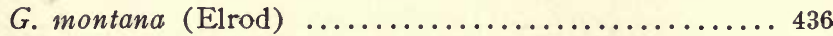

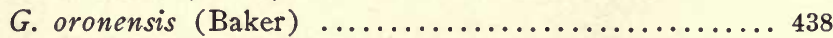

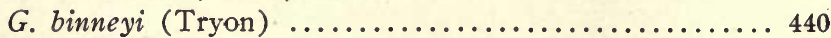

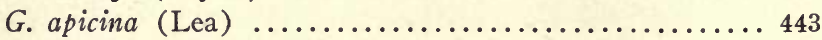

G. apicina solida (Lea) ...................... 448

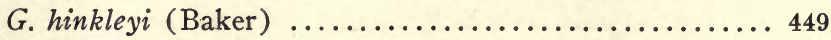

G. preblei (Dall) ........................ 450

G. randolphi (Baker) ..................... 452

G. alaskensis Baker ...................... 455

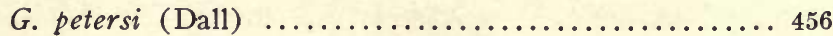


Page.

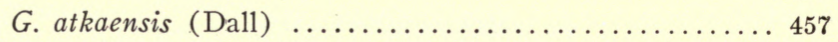

Subgenus Polyrhytis Meek .................... 458

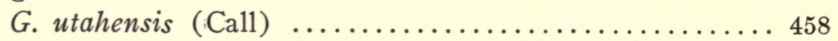

Subgenus Leptolimnæa Swainson ................ 460

Spurious and Unidentifiable Species....................... 462

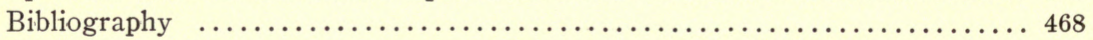

Description of Plates.................................... 511

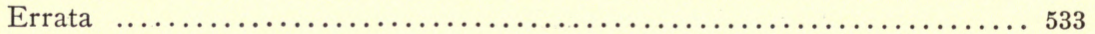

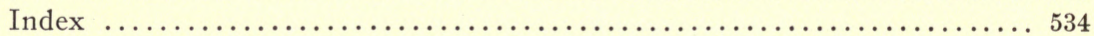




\section{GENERAL MORPHOLOGY OF THE LYMNÆAS.}

\section{THE SHELL (PLATE II, FIGURE A).}

The SHell in the Lymnæids is typically elongated, with a pointed spire and more or less turreted whorls. The shell may be as thin as paper, (haldemani, columella) or, thick and solid (megasoma, cockerelli). It is usually higher than wide. The whorls are tightly coiled about a central axis, forming a characteristic columella. The contour of the shell varies from distinctly globose (sonomansis, emarginata wisconsinensis) to very much elongated (haldemani, reflexa). This varying contour is well shown in several species, two of which are mentioned below.

Elongated.

bulimoides techella

Depressed.

Globose. bulimoides cockerelli (var.)

emarginata canadensis emarginata mighelsi bulimoides cockerelli (typical).

The shell is normally dextral in America, but in the Hawaiian Islands several sinistral species occur. Rarely a sinistral individual will be found, one such having been seen in the collection of Mr. Henry Hemphill (Galba obrussa), and one in the collection of Dr. W. A. Nason (palustris).

Size: The size ranges from the tiny Galba dalli, which is 4 millimeters in length, to the giant Lymncea stagnalis, which attains a length of 60 millimeters.

The SPIre (1) varies in the different species, in many being acutely pointed and elongated, in some acute and depressed, in others broadly dome-shaped and in a few flatly depressed. All gradations occur between these extremes.

THE WhORLS (3) may be very flat sided, as in exilis and haldemani, or very convex and obese as in techella cockerelli and emarginata wisconsinensis. The Sutures (4) vary accordingly, being just perceptible in some species (haldemani) and deeply impressed or even channeled in others (auricularia, randolphi).

The APFRTURE (2) is usually ovate, elongate-ovate or rounded, but in a few species is much elongated and narrow. There are no teeth or other obstructions, but a strong plait is frequently developed on the columella. The aperture may be long and narrow, with parallel 
margins, as in haldemani, or wide, rounded and even patulous, as in columella and auricularia. It varies from one-fourth to four-fifths the length of the entire shell. The aperture is usually angulate above and may be rounded, ovate or effuse below.

The OUTER LIP ( $y$ ) is always thin at the margin, but in many species develops a heavy varix just within the aperture, a trifling distance from the edge. This is (apparently) notably developed only in those species which bury themselves in the mud during times of drought. These varices show on the outside of the shell as white or black longitudinal bands, and they vary in number from two to six or more. They may be observed in such species as caperata, palustris, clodes, reflexa, parva, etc.

The INNER LIP (6) is reflected over the columellar region, a portion being closely appressed to the parietal wall (5) while the lower part may be tightly appressed to the columella, thus forming a distinct ascending columellar plait (stagnalis, auricularia, palustris), tightly appressed but not forming a plait (megasoma, haldemani, colusnella) or reflected and turned back, forming a broad expansion which overhangs the umbilicus (bulimoides, techella, caperata, emarginata).

The Axis or PILlar (in the upper whorls) may be gyrate or twisted in the form of a spiral (stagnalis), or it may form a straight smooth column, as in bulimoides and obrussa. All gradations occur between these two extremes.

The Umbilicus (8) may be a mere chink or narrow slit behind the reflected inner lip, or it may be a wide and deep hole, overhung or emargined by the expanded inner lip. In no case is it a hollow tube, as in many of the groups of fresh-water and land shells. In one species (Galba randolphi) a bristle may be passed to the penultimate whorl, but not beyond, except in abnormal specimens. In almost all individuals the umbilical opening is closed by the columellar axis of the preceding whorl. A difference should be made between the umbilical chink, which includes those shells in which the hole is but one whorl deep, and the true umbilicus in which the whorls revolve around a hollow tube, open to the apex. The Lymnæas belong to the former type.

The Nucleus or Protoconch is a small rounded knob of from $11 / 4$ to $1 \frac{1}{2}$ whorls, and is without distinct sculpturing. Under a glass the surface appears to have a satin-finish appearance. The nucleus varies slightly in form in many of the species (see plate XLIX). In a few species (umbilicata, for example) the nuclear whorls appear to be very faintly substriate. 
The Sculpture (9) in the Lymnæas falls under two rather distinct types, which, however, intergrade more or less in some species. First, the longitudinal lines of growth and second, the combination of these growth lines with more or less strongly marked spiral lines. The first type is largely confined to the smaller Lymnæas, while the latter includes nearly all of the larger species.

1. Longitudinal growth lines. (pl. III, fig. E.) These may be so fine and inconspicuous as to cause the shell to appear smooth until examined with a lens. In many shells, however, these lines are raised to form more or less equidistant ribs or costæ, as may be seen in some specimens of megasoma, palustris, emarginata, etc. A single specimen of megasoma in the collection of the Chicago Academy of Sciences has this form of sculpture so marked as to appear almost costate (23097) on the last whorl. This characteristic is developed to such an extent in two groups of Lymnæas as to cause the erection of two genera for their reception (Pleurolimncea and Polyrhytis). In not a few cases these ribs form extensive bulgings, causing the shell to assume a pathological aspect. The cause of this costate appearance is said by some to be due to a varying food supply, but may be equally as well ascribed to peculiarities of environment, such as alkalinity or salinity of the water, excessive cold or the presence of some acid in the fluid medium, which also causes many shells in certain localities to be eroded at the spire. The peculiar sculpture called malleation, which causes the surface to assume the aspect of hammered brass, is also due to environmental causes. That this malleation is due to causes which may be of a transient character is proven by the existence of numerous specimens (megasoma, palustris), in which this characteristic is developed on only a part of the shell, the upper whorls and the last portion of the body whorl being without this feature.

Dr. R. E. C. Stearns ${ }^{1}$ writes as follows concerning this feature of the sculpture of Lymnæas:

"The partially or wholly malleated surface so often met with in the Limnæids regardless of altitude or the salinity of the water, and less frequently in the Physas, is explainable by the character of the lake or pond bed in which these dinted forms occur. The character of the bottom, even in a pond of limited size, often exhibits very considerable differences in the matter of compactness or density; alluvial mud, clayey mud, clay or sand, with fine or coarse gravel intermixed with fragments of aquatic plants and plant stems in varying propor-

${ }^{1}$ Proc. U. S. Nat. Mus., XXIV, p. 291. 
tions. The habits of these mollusks include, if not properly speaking burrowing, wallowing or submersion, and moving as they do with somewhat of a rotating motion, this, combined with the moderate impact of the surrounding matter, contributes to produce the malleated or dinted surface, which frequently exhibits a somewhat spiral arrangement."

The writer believes that Dr. Stearn's theory is correct, as it is borne out by the ecological study of such species as palustris, reflexa and bulimoides techella. These species, with some of their varieties, are inhabitants of ponds and streams which dry up during a part of the year, compelling the animal to burrow in cracks, crawfish holes and under debris of various kinds. The newly formed shell is frequently added while the animal is wallowing in a few inches of water and thus takes the form of the surface upon which it is resting, which is usually very uneven. It is a significant fact that a malleated shell taken from the environment of a summer dry pond and placed under uniform conditions in an aquarium where there is an abundance of water, continues its shell growth without a trace of malleation. It is also noticeable that the malleated individual lives in more or less shallow ponds and pools among all sorts of debris, while those individuals without malleation and with smooth shells live in deeper waters of a less transient nature. Lymnæas from rivers and large lakes are seldom malleated, as may be seen in most individuals of catascopium and stagnalis. Dr. James Lewis believed that malleation was due to a rapid growth in warm water, which caused the shell to solidify unevenly. ${ }^{i}$ Dr. Lewis seems to have laid great stress on the temperature of the water, instead of on the mechanical action of the environment, which seems, from present data, to have been the primal cause of this feature. Temperature does influence growth in other directions, however, as may be seen in almost all species which have a wide northern range.

2. Spiral sculpture. The presence of spiral, more or less wavy, incised grooves has been frequently noted by many observers. This sculpture is characteristic of the majority of the species of Lymnæidæ, and, in fact, may be called typical. It is developed to a high degree in catascopium, the shell of which appears as though engraved with a tool. Stagnalis also exhibits the same appearance, although the lines are finer. Under the compound microscope these so-called spiral lines are seen to be caused by the elevation of the growth lines to form an infinite number of small costæ which are interrupted more or less regularly; these breaks between the ends of the costæ giving the appearance

${ }^{1}$ Am. Jour. Conch. VI, p. 85. 
of spiral impressed lines (pl. III, fig. F). These costæ may be either convex, in which case the spiral lines are impressed, or concave, causing the spiral lines to form pseudo-threads. The distance between these spiral lines varies considerably in the different species as well as in the same species and on the same individual. This beautiful sculpture is repeated among the land shells, where it is notably developed in the Polygyras.

Epidermis or Periostracum: The epidermis of the Lymnæids is usually very thick and in many cases may be peeled off when the shell becomes dry. It is deposited by the margin or collar of the mantle. Breaks made in the shell are repaired by the visceral mantle, but they lack the epidermal covering, which is secreted only by the edge of the mantle. In one species (caperata) the epidermis is hispid and stands erect in the spiral lines, causing the surface to assume the aspect of having rows of hairs. This may be observed only in fresh specimens. The color of the shell is in the epidermis and becomes chalky and lifeless when this is removed.

COLOR: The normal color of the shell is light yellowish horn. The color is affected very largely by the environment. Those species which live among aquatic vegetation generally have clear, translucent, yellowish shells, while those which inhabit muddy bottoms where there is an excess of decaying animal or vegetal matter have dark-colored or even black shells. Bulimnea megasoma has a brownish shell which is streaked with yellow, green and mauve. Some species from upper Michigan have a shell of a white, waxy color which is beautifully translucent. Dark brown is characteristic of the species of certain localities, while some individuals have a more or less pearly luster. When the animals live in a shallow pond or other body of water in which the bottom is covered with decaying vegetation, a shell is produced which is longitudinally striped in zebra fashion. the light zones being narrow and the darker ones wide. In Rock Run, near Joliet, some of the Lymnæas are marked spirally instead of longitudinally, producing a peculiarly marked surface.

\section{EXTERNAL APPEARANCE OF THE ANIMAL.}

Plate III, figures $\mathrm{H}-\mathrm{K}$.

Lymnæa is provided with a broad, oval or elongated foot which is squarely truncated or broadly rounded before, rounded behind, and much flattened at the margins. The head is separated from the foot and occupies the vela area (which is retained from the larval stage), which is short and wide, ranging in form from semi-circular to quad- 
rate, the lateral margins being pointed. The tentacles are large, triangular and placed on top of the head just above the junction of the vela area with the foot. The black eyes are placed on small swellings at the inner base of the tentacles. The mantle fits closely to the aperture of the shell, but does not extend beyond the margin of the outer lip or the edge of the reflected inner lip. The respiratory orifice is placed near the posterior angle of the shell, where a portion of the mantle is modified to form a so-called siphon which is capable of great expansion when the animal is taking in air. The pulmonary cavity fills about half of the body whorl and is usually colorless and transparent as seen through the shell. The heart may be distinctly seen through the thin tissues and its pulsations easily counted.

The heart pulsations of several specimens are tabulated below:

Lymnaa stagnalis ................. 37- 48 per minute.

Pseudosuccinea columella...............53-60" "

Galba obrussa ......................150-155 " "

Galba humilis modicella..................140-146 " "

Galba caperata......................129-133 “ "

Galba palustris...................... $80-81$ " "

The smaller species appear to have a higher pulse than the larger ones, stagnalis, the largest species, having $37-48$ pulsations, while obrussa, one of the smaller species, has 150-155 pulsations per minute.

There are no grooves on the body as in the helices, and the texture is smooth instead of being granular. The shell is carried, as a rule, in a direction parallel with the foot, although it may at times be swung around until it rests obliquely or even at right angles to the foot. (Fig. H.) In color the animals vary from yellowish, flecked with whitish or yellowish spots, to jet black. Frequently the black dashes, spots or blotches of the mantle may be seen through the transparent shell, causing the latter to appear mottled. The foot and tentacles vary to some extent among the different species, the variation being in the length of these organs.

\section{GENERAL INTERNAL ANATOMY. 1}

If a large specimen of Lymnæa be opened on the back and the organs be carefully separated and spread out (as in plate I), the relations and characteristics of the various anatomical features may be easily made out. In the plate, the genitalia are turned to the left, while the digestive and respiratory systems are turned to the right.

${ }^{1}$ This topic is treated in a somewhat superficial manner, the yurpose being simply to point out the more obvious characteristics of the various organs. The common American Lymnaeid, Galba reflexa Say, has been selected for this
purpose.

( = pabertess 


\section{a. THE Digestive tract. Plate I.}

The alimentary tract is similar in general form and structure to the other Pulmonata, differing, however, in some details. The mouth is placed at the anterior end of the buccal sac, into which it opens; the buccal sac (1) is somewhat pear-shaped, or long-ovate, when viewed dorsally; it is very stout, being composed of strong muscle fibers, and contains the jaw and odontophore; the posterior side bears the two buccal or stomato-gastric ganglia; the œșophagus leaves the buc$\mathrm{cal} \mathrm{sac}$ at the dorsal part of the posterior end (2), passing between the various ganglia composing the nervous ring, and proceeds to the crop in almost a straight line. The buccal sac is bluish in color, and the œsophagus is dark brown or black. Just posterior to the buccal sac the two salivary glands are placed; they are bright yellow in color, irregular or ramose in shape, and are connected with the buccal sac by four ducts (11) which enter the latter near the osophagus.

The region of the stomach is peculiar and was first correctly noted in American Lymnæas by Dr. R. P. Whitfield (op. cit.) in Bulimnea megasoma. The œsophagus first enters the pyriform or elongate oval crop (4), the stomach follows, and at first lies between two very muscular organs, the bilobed gizzard (3) and then widens into the pyloric portion (6), which gradually tapers to the intestine. The crop and stomach are yellowish in color, while the gizzard is almost black. The latter organ is very large, about the size of a small pea in species the size of reflexa, stagnalis and palustris, and composed of two concavoconvex portions, almost surrounding the stomach, as described above. They are more or less elliptical in outline, and their extremities are connected by a number of stout muscle fibers of a silvery luster, as recorded by Dr. Whitfield (op. cit.). The interior is hard and wrinkled, and much resembles the gizzard of a fowl. The gizzard is as hard as a pea, but the crop and stomach are soft and fleshy. A number of gizzards were cut open; in freshly killed specimens, which had been in captivity several months, the gizzards were empty, while in alcoholic specimens they contained particles of siliceous matter. The figure of the digestive system of Bulimnea megasoma in Prof. Wetherby's article $^{1}$ shows this gizzard, although its correct relation to the crop and stomach is not mentioned. The walls of the stomach, crop and gizzard are made up of strong muscle fibers.

The intestine (5) is very long, and is marked by but one pronounced flexure; it makes one complete turn after leaving the stomach, then follows the course of the last whorl and a half, bends upon itself,

1Journ. Cin. Soc. Nat. Hist., Vol. II, 1879, p. 95, fig. 1. 
and finds an exit in the anus (8) within the mantle cavity not far from the orifice of the vagina. The last part of the intestine is somewhat enlarged to form the rectum ( 7$)$. The digestive gland is very large, filling completely all but the last whorl of the shell, and is dark brown in color. It is composed of two lobes, one occupying the apical whorls and the other (larger) filling the last whorl just behind the heart. It opens by a number of large ducts into the intestine, and into the pyloric portion of the stomach. The digestive gland (9) is well supplied with blood vessels, which ramify in every direction, forming a complicated plexus. The digestive gland is scarcely analogous to the liver of vertebrate animals, as it contains a diastatic ferment, which converts starchy matter into glucose. It is probably comparable to the pancreas in the vertebrate animals.

In general the alimentary tract agrees with the figures published by European authors. The figure of the general anatomy of Lymnca stagnalis in Keferstein (taf. ciii, fig. 7) shows this tract very like that of the present species, except that no division into crop, stomach and gizzard is indicated. Moquin-Tandon's figure (pl. xxxiii, fig. 25) of Radix auricularia is almost identical, but his figure of Lymnca stagnalis (pl. xxxiv, fig. 18) differs in the form of the stomach, which does not show the divisions indicated above.

There appears to be little variation in the digestive system of the Lymnæas.

\section{b. THE JAW. Plate VI.}

The mouth of Lymnæa is somewhat T-shaped when in repose, The upper portion is armed with a strong, horny organ called the superior jaw (A, 1) which is wide and low, arched dorsally and trilobed ventrally, the center lobe being more or less acute, while that on either side is simply rounded. The ends of the jaw are frequently somewhat produced. The anterior face is striated and the whole jaw is generally brownish in color. The jaw is fastened to a short cartilage and is protracted and retracted by a set of muscles.

The lateral jaws (A, 2) emargine the sides of the mouth and are very long and narrow and curved at the superior end, where they are attached to a wide cartilage. Before being spread out, as in the figure, the lateral jaws appear as a narrow black edging to the mouth, the cartilaginous portion of the upper part being bent backward within the mouth. Butterell (1880) mentions certain filaments which cover the lateral jaws in Lymnca stagnalis. No such filaments, however, have been observed on the lateral jaws of American Lymnæas.

There appears to be little variation in the type of jaw among 
American Lymnæas. The median projection may be wide (as in $o b-$ russa (F) and caperata (L)) or very narrow and acute (as in humilis $(\mathrm{H})$ and catascopium $(\mathrm{K}))$. The jaw also varies somewhat with age and wear (compare catascopium (K) with a worn jaw of the same species (M) ). The lateral margins are also more produced in some species $(\mathrm{K})$ than in others $(\mathrm{B})$.

\section{c. THE RAdUla. Plate III.}

The radula in Lymnæa is strap-like or ribbon-like, as in the other groups of the Pulmonata, the basis of attachment being subquadrate or quadrate in shape. It is important to remember the law of mesometamorphosis in the study of the radulæ of Lymnæa. This law, as recorded by Dr. Pilsbry, is as follows: "All modifications in the teeth proceed from the median line of the radula outwards toward the edges, the outer marginal teeth being the last to be modified."'

The following remarks of Dr. Pilsbry are also of interest in connection with the study of the Lymnæid radula: "A study of the marginal teeth, therefore, gives a clue in many cases to the ancestral condition of a much modified radula; although in certain groups the change has been so long established and has proceeded so far that even the outermost teeth no longer retain their primitive form. In such cases recourse must be had to the radulæ of young individuals or embryos still unhatched, which sometimes retain an ancestral type of teeth. (See also Sterki, 1893, plate X.)

"The evident reason why the order of tooth-changes stated above should obtain is that the median portion of the radula is the part most used on account of its position and the convex boss-like shape of the subradular cushion."

The marginal teeth of the Lymneas are always multicuspid or serrated, showing a descent from the Tectibranchiate stock of marine mollusks. The Lymnæid type of radula is thus a good example of the law of mesometamorphosis, as explained above.

In the Lymnæas the teeth are divisible into two distinct series, the laterals and the marginals. Between these two series there is a third, which combines the characteristics of both laterals and marginals, which are called intermediate teeth (pl. III, fig. A). There are generally from eighty to over a hundred rows of these teeth, which overlap in the usual pulmonate manner (fig. B).

The radulæ of the Lymnæas fall into two main types: First, those species with bicuspid laterals (as stagnalis, reflexa), and, second, those species with tricuspid laterals (as columella, auricularia). The

${ }^{1}$ Guide to Study of Helices, p. xiil. 
marginals show no variation, all being of the usual multicuspid type. The center tooth is generally quite uniform in shape, the reflection being more or less trilobed with a spade-shaped cutting point. The cutting point is difficult to see except with high powers, the opaque portion standing out clearly and causing the tooth to appear trilobed or tricuspid, thus causing the errors mentioned below. The central tooth is very difficult to observe clearly, owing to its small size. It has been figured as tricuspid, trilobed and simply ovate by different authors. In the Cambridge Natural History, Mollusca (Cooke, 1895, p. 235) it is figured as tricuspid, the cusps being as large as those of the lateral teeth, unquestionably an' error, as no Lymnæid has this type of central tooth.

In studying these radulæ it is important to consider only the newer perfect teeth, as the older teeth near the mouth are usually much worn and hence give a false idea of the true form of the cusps. Figure D, plate III, shows two of these worn teeth. Compare these teeth with the same numbered teeth in figure $\mathrm{A}$ of the same plate. On plates VII, VIII and IX the radulæ of the various species are figured. ${ }^{1}$

\section{d. the Reproductive system. Plates I, III, IV.}

Like all pulmonates, the Lymnæas are hermaphrodites. The male and female systems are, however, separated for the most part, the opening of the male being behind the right tentacle, while that of the female is at the base of the neck near the respiratory cavity. (P1. III, fig. G).

The organs of the fresh-water pulmonates divide naturally into three groups, as follows:

Male organs ..... $\left\{\begin{array}{l}\text { penis. } \\ \text { penis-sac. } \\ \text { vas deferens. } \\ \text { prostate. } \\ \text { prostate duct. }\end{array}\right.$

Female organs.... $\left\{\begin{array}{l}\text { vagina. } \\ \text { oviduct. } \\ \text { uterine portion of oviduct. } \\ \text { receptaculum seminis or spermatheca. } \\ \text { duct of same. } \\ \text { albuminiparous gland. } \\ \text { first and second accessory albuminiparous glands. }\end{array}\right.$

Common to both.. $\left\{\begin{array}{l}\text { ovotestis. } \\ \text { hermaphorodite duct. }\end{array}\right.$ 
Male organs. The penis-sac (13) is very large, cylindrical, rather wide at the external opening and gradually contracting at the distal end where the penis is attached; it is grooved along its upper surface where a part of the prostate gland and the receptaculum seminis fit against it in their natural position. The penis (17) is variable in length but is always a tube-like body about the diameter of the vas deferens and terminating in a more or less rounded head. The penis and the upper portion of the penis-sac are bent back upon the latter at right angles. The vas deferens (14) is a narrow white tube of varying length; in its natural position it lies in two loops which run longitudinally with the penis-sac; at the right side of the penial aperture it enters the muscular tissue of the body wall where it runs in an irregular course and emerges near the vaginal aperture as the duct of the prostate (31); this duct makes a long loop between the penis-sac and the proximal portion of the oviduct; as it nears the prostate it enlarges somewhat and enters that organ in a central depression. The prostate $(30)$ is usually a somewhat sac-like organ, flatly cylindrical and lies in a groove on the posterior portion of the penis-sac. The oviduct and the duct of the spermatheca pass over its inferior surface in a groove; the first accessory albuminiparous gland lies below it and the receptaculum seminis lies posteriorly to and covers a portion of it. The outer surface is very rugose and the interior is divided into many small tubes. The posterior portion of the prostate (29) narrows to form a ribbon-like organ, often called the male portion of the hermaphrodite duct. This portion connects posteriorly with the oviduct, with which it unites to form the ovisperm duct.

The penis-sac is protracted by two sets of muscles, one of which (anterior, 15) is attached to the dorsal wall of the fore part of the body, while the other (postcrior, 16) is attached to the columella muscle. There is a penis-sac retractor (19) and a penis retractor (18) which have their insertions in the columella muscle. The male system is innervated by a nerve from the cerebral ganglion which consists of two branches, one extending to the head of the penis while the other innervates the penis-sac. The penis-sac is a large tube with muscular walls, somewhat corrugated within, where there are also one or two distinct folds (plate IV, fig. $\mathrm{H}$ ).

Female organs. The oviduct begins at the ovisperm duct where it becomes much convoluted to form the so-called uterus (2\%). The point of its commencement is underneath the anterior end of the albuminiparous gland. Near the second albuminiparous gland it becomes smooth and rounded (26), is later embraced by the large first 
albuminiparous gland and finally narrows and unites with the duct of the receptaculum seminis to form the vagina (21). The receptaculum seminis or spermatheca (also called swammerdamian vesicle, 23 ) is a more or less bulbous or pyriform sac of large size, which is connected with the oviduct by a long duct (22). This sac is usually yellowish or orange in color and occupies a position in the body to the left of and behind the prostate. The duct in some cases proceeds from the right hemisphere of the receptaculum seminis, but in others it proceeds directly from the apex of this inverted pear-shaped organ; it passes over the upper posterior portion of the prostate and then runs in a groove on the posterior face of the penis-sac. The upper part of the duct also lays in the anterior portion of a groove on the dorsal surface of the first accessory albuminiparous gland.

The albuminiparous gland (28) is a more or less linguiform or elongately rounded body, occupying a position in the body anterior to the crop. It lies across the center of the second accessory albuminiparous gland and is tightly fixed to that organ by connective tissue. There are two glands, called the accessory albuminiparous glands, of somewhat questionable use, which are attached to the oviduct. These lie just beneath the respiratory cavity and are separated from the prostate by a distinct diaphram of strong connective tissue, which must be cut away to observe the female organs.

The second accessory albuminiparous gland (25) is a small rounded body placed on the oviduct posterior to the first accessory albuminiparous gland. It is entirely free from the oviduct except on one side where it is attached. The first accessory albuminiparous gland (24) is very large, pyriform or ovate in shape and completely embraces the oviduct, forming a peculiar organ of unknown function, although by some anatomists believed to act as a reservoir for the ova. These accessory glands are yellowish or whitish in color and become swollen and flocculent when placed in water. The female organs are innervated by a nerve which proceeds from the abdominal and the right visceral ganglia (pl. IV, fig. D).

ORGANS COMMON to вотH SYSTEMS. The ovotestis or hermaphrodite gland (33) occupies the upper whorls of the body and is embedded in the digestive gland. The hermaphrodite gland is made up of a large number of rounded or lobulated follicles. The ovisperm duct (32) is a convoluted tube of pure white color, which passes from the ovotestis to the under side of the albuminiparous gland where it receives a duct from that gland, runs along its under surface a short distance and finally divides to form the oviduct and the posterior portion of the 
prostate. Both ova and sperm are produced in the same follicle of the ovotestis, the sperm ripening first and being stored in the spermatheca to await the expulsion of the ova.

There is considerable modification of the form of the sexual organs among the various species of. Lymnæas. Curiously enough this modification is confined almost entirely to the male system, the female system remaining practically unchanged. The penis and penis-sac exhibit many modifications as does also the prostate. These modifications being constant and uniform in certain groups of species, have been found very useful in preparing a classification of the pond snails. The comparative length of penis and penis-sac, for example, varies from one-quarter in Lymnea stagnalis to one and one-quarter in Radix auricularia. (P1. IV, fig. 1.) Care must be used in making these comparisons to be certain that the penis is pulled out to its fullest extent. Frequently it is partly inverted in the penis-sac and presents an appearance as shown in figure $G$, plate IV. The retracter and protractor muscles exhibit great variation, even in individuals of the same species (see plates XIV, XV).

If the opinion now held by leading malacologists is true that the hermaphrodite condition is secondary, then the Lymnæas must be considered of very ancient lineage and older in time than the Pulmonata Stylommatophora, in which the male organs have been more completely superimposed upon the female individual and in which there is a common genital orifice ${ }^{1}$. A comparative study of the genitalia of all the Pulmonata Basommatophora would doubtless reveal many modifications of the sexual organs bearing on this point. A more detailed discussion of the modifications of the genitalia will be found in the chapter on classification.

\section{e. The nervous system, Plates I and V.}

The nerve centers of Lymnæa with their connections belong to the type of nervous system known as Euthyneurous, in which the visceral nerve cords remain straight. The nerve centers form a ring or nervous collar surrounding the cesophagus, immediately posterior to the buccal sac (plate I, 47). In this nerve ring the two cerebral ganglia are above the œsophagus and all of the others are below. There are nine main nerve centers, as follows: two CEREBRAL, two PLEURAL, two VISCERAL, two PEDAL and one ABDOMINAL. In addition there are other 
minor nerve centers such as the BUCCAL GANGLIA, OSPHRADIUM, etc. All but the abdominal ganglion are paired. These ganglia, with their nerves and commissures, may be briefly described as follows:

The CEREBRAL GANGLIA (1) are situated above or a little to the side of the oesophagus and are joined to each other, to the pedal ganglia and to the pleural ganglia by short, thick commissures. These ganglia are made up of a number of small lobes, each of which is probably the center for some particular nervous direction. The right cerebral ganglion sends a nerve to the male generative organ which divides before reaching that organ, one branch going to the penis (15) and the other, which again subdivides, innervating the penis-sac (14). The cerebral ganglia also send nerves to the tentacles (12), optic nerves to eyes $(10,11)$, nerves to the front of the head $(9)$, labial nerves to the region of the mouth (1\%) and a pair of nerves to the buccal sac. These latter or cerebral commissures enlarge on the buccal sac to form the buccal or stomato-gastric ganglia. A small nerve (13) arises from the posterior lobe of the right cerebral ganglion and innervates the region of the neck. Two nerves (32) supply the labial arteries. These ganglia also send out a number of small nerves which innervate the buccal sac and the manducatory organs. Branches are also sent to the salivary glands.

The PEDAL GANGLIA ( $\%$ ) are very large, lie directly beneath the œesophagus, and are connected with the cerebral and pleural ganglia by short, thick commissures. These ganglia send off two sets of nerves of three each, the first, inferior and superior cervical and columellar neries $(16,18,19,26,2 \%)$ to the posterior part, and the second, supcrior, inferior and central pedal nerves $(28,29,30)$ to the anterior part of the foot. There are several other short, minute nerves invervating the fore part of the body. The otocysts (31) are placed in the posterior part of the pedal ganglia, and are connected with some of the other ganglia by fine nerves.

The Pleural GANGlia $(2,6)$ lie below the œsophagus, and are connected by short, thick commissures with the pedal, cerebral and visceral ganglia. They apparently send off no nerve cords.

The viscekal ganglia $(3,5)$ lie behind, and a little above the pleural ganglia, and are connected with the latter and the abdominal ganglia by short commissures. The right ganglion sends off a long nerve ( 24 , right pallial ncrve) which innervates the female genital orifice, a portion of the respiratory cavity and the right posterior part of the mouth. Near the end of this nerve an enlargement forms the olfactory organ or osphradium (25). A shorter nerve (33, anterior pallial), 
leaves the right visceral ganglion near the right pallial nerve, and shortly joins a similar one from the abdominal ganglion, the combined nerve passing to the vagina, the anterior part of the mantle and the respiratory cavity. The left ganglion sends off a single long nerve which innervates the mantle along its sides (20).

The ABDOMINAL GANGLION (4), which is really two ganglia fused together, lies behind and somewhat below the visceral ganglia, is connected with the latter by two short, thick commissures, and sends off four nerves. One of these has already been described under the right visceral ganglion. The central nerve (23) is the longest and innervates the pericardium, aorta, part of the genitalia, the rectum, digestive gland and respiratory cavity. A somewhat shorter nerve on the right of this (22) furnishes nerve force to the posterior part of the aorta and a part of the genitalia. To the left of the central nerve a small nerve, arising apparently at a point between the abdominal and left visceral ganglia, supplies the anterior part of the mantle (21). The nerves of the abdominal and visceral ganglia also innervate different portions of the digestive system.

In a living specimen the ganglia are of a very bright orange color, and in alcoholic specimens they are yellowish or yellowish white. The eyes are as usual in androgynous Pulmonata. The sclerotic membrane, choroid, cornea, etc., are well developed, and the optic nerve is very large.

In working out the foregoing Lacaze Duthiers' article in Archiv. de Zool. Exp., has been followed as a guide. The nervous system of the present species may be said to be almost identical with that of Lymnaa pereger described and figured by Lacaze Duthiers (pl. 1\%, fig. 2). Spengel's figure of Lymnaa stagnalis is also the same (taf. xvii, fig. 11), excepting that the nerves to the penis and vagina are not shown. Moquin Tandon's figures are different, his Lymncea palustris (pl. 34, fig. 2\%) showing a fused condition of the abdominal and visceral ganglia. In his figure of Lymncea auricularia the pleural and visceral ganglia appear to be fused and the nerves are insufficiently shown. No figures, excepting those of Lacaze Duthiers', show the innervation of the male and female genitalia.

The special organs of sense in Lymnæa are those of TOUCH, SIGHT, SMELL and HEARING. The ORGANS OF TOUCH are the flat, triangular tentacles which may be repeatedly observed performing this function. The organs of SIGHT are the eyes which are well developed. Nothing definite is known concerning the powers of sight in the fresh-water pulmonates. Many Lymnæas are known from experiment to love the 
light and their visual powers must be developed to a considerable degree. The SENSE OF SMELL is centered in the ganglion known as the osphradium (25). The SENSE OF HEARING is centered in the paired ganglia known as otocysts (31). These equilibrating organs consist of a sac filled with a fluid secretion, in which are suspended a greater or less number of calcareous bodies called otoliths, which are kept in a constant state of vibration by means of minute cilia. As many as a hundred ctoliths have been found in adult Lymnæas and as few as seven in the young individual. In Lymnæa the otocysts are connected with the cerebral ganglia by a short nerve. It is not known definitely whether or not a special SENSE OF TASTE is present, although there is no reason for doubting the existence of this sense, at least to a limited degree.

\section{f. THE RESPiRAtory system. Plate I.}

The RESPIRATORY CAVITY occupies nearly half of the last whorl (plate I, 39). It is longer than wide and is supplied with a network of blood vessels. These connect with the branchial artery or pulmonary vein (37), which conducts the aeriated blood into the auricle and from this organ into the ventricle $(34,35)$. The respiratory cavity is situated on the right side of the body and is closed by a lobe of the mantle, which forms a sort of siphon.

\section{g. the renal system. Plate I.}

The KIDNEY Or RENAL ORGAN (excretory) in Lymnæa is of extraordinary size, occupying the greater part of the respiratory cavity. It is somewhat pyriform in shape, very wide, and in its natural position appears like a large bag. It may be divided into two parts, a glandular portion (plate I, 40), which appears as a long yellowish organ which is filled with many small, rounded bodies, easily forced out by pressure and a second portion, appearing grayish-black in color, which is plentifully supplied with blood vessels (plate I, 38). The pulmonary vein lies between these two lobes. The ureter is very short and wide, and passes in a straight line to the anterior border of the respiratory cavity, where it has its opening not far from the rectum. (Plate I, 41.)

The direct passage of the ureter without flexure is another evidence of the antiquity of the fresh-water pulmonates, showing that they probably preceded such land forms as Partula and Achatinella, which also have the direct type of ureter, and which are less modified than the higher group (Sigmurethra) with the sigmoid ureter. The kidney in Lymnæa is very uniform in the different species, varying 
only in the general shape of width and length. The ureter in some species (as stagnalis ${ }^{1}$ ) is a trifle longer than in others (as reflexa).

\section{h. THE CIRCUlatory SYSTEM.}

The circulatory system does not differ materially from that of the pulmonates in general, being similar to the descriptions and figures published by Keferstein, Leidy and Simpson.

The heart is on the left side of the animal, at the apex of the respiratory cavity, and lies laterally between the osophagus and the rectum, and not far from the stomach. The ventricle and auricle lie in a large oblong pericardium $(34,35,36)$. The large aorta divides into the two branches (cephalica and visceralis) as in the other Pulmonata. The respiratory, circulatory and renal systems are closely related, both in structure and function.

Some of the Lymnæas, especially stagnalis, have been seen to discharge a quantity of a pale violet colored fluid when irritated; this color is so intense in some specimens as to tinge the water with violet when the animal is placed in scalding water. ${ }^{2}$ The fluid has been called hamocyanin by Williams. ${ }^{3}$ It is colorless when unoxidized, but becomes bluish when oxidized by the air. The hæmolymph of the animal contains this fluid, which is a respiratory substance consisting of copper united with a proteid. It is probable that some sudden shock causes the rupture of the veins containing the fluid. It has also been obscrved in a number of the American stagnalis appressa.

\section{i. the muscular system. Plates I and IV.}

Besides the columella muscle and the muscular tissue forming th: walls of the different organs, there are a number of free muscles of great importance. These are the RETRACTORS of the buccal body, and the RETRACTORS and FroTrACTORS of the sexual organs. The tentacles, not being retractile, have no free muscles of importance.

The buccal sac is retracted by two long muscles which are attached distally to the columella muscle at some distance from each other. In the Pulmonata Stylommatophora the two branches of the buccal re.tractors unite to form one muscular band before being inserted in the: columella muscle, thus differing radically from the Basommatophora. (P1. IV, fig. F. 2; pl. I, fig. 52.) Several small muscles protract and depress the buccal body. (P1. IV, fig. F, 5.)

\footnotetext{
${ }^{1}$ See Pilsbry, Proc. Phil. Acad., 1900, plate XVII, fig. 2, for a figure of the kidney of stagnalis.

2See Nelson, Quart. Jour. Conch. 1877, no. 11, p. 216.

Journ. Conch., VI, p. 122, 1889.
} 
The penis and penis-sac are each retracted by a powerful muscle which is inserted near the attachment of the right buccal retractor, the penis-sac retractor being the larger. (P1. IV, F, 3, 4; pl. I, figs. 18, 19.) The penis-sac is protracted by two sets of muscles, one, anterior, being attached to the dorsal surface of the body and the other, posterior, to the columella muscle. The former set consists of a wide band of muscular tissue, made up of many smaller muscles, while the latter set may be composed of as many as six distinct muscles or as few as one muscle. (P1. I, figs. 15, 16.) There may also be two penis-sac retractors. The female organs have no free muscles. The retractors of the foot are attached to the columella muscle, as in most spiral shells.

\section{BIBLIOCRAPHY. 1}

The following works have been consulted in the preparation of chapter I:

Baker, F. C., 1900, b.; 1905, f.-Baudelot, M., 1863.-Butterell, J. D., 1880Cooke, A. H., 1895.-Cuvier, G., 1816.-Dybowski, W., 1884.-Eisig, H., 1869.Keferstein, W., 1862-66.-Lacaze-Duthiers, Henri de, 1872.-Lankester, E. Ray, 1891.-Lewis, James, 1870.-Moquin-Tandon, A., 1855.-Nelson, William, 1877.Pilsbry, H. A., 1894, b.; 1900, b.-Spengel, Dr. J. W., 1881.-Stearns, R. E. C., 1891, b.; 1901.-Sterki, Dr. V., 1893.-Tryon, G. W., 1882.-Wetherby, A. G., 1879.-Whitfield, R. P., 1882.-Williams, J. W., 1889.

'See the bibliography at the end of this volume. 


\section{ECOLOGY OF THE LYMNÆAS.}

\section{a. GENERAL ENVIRONMENTAL CONDITIONS.}

The Lymnæas inhabit all varieties of bodies of water, from the small transient pool to the great lakes. While the family as a whole is thus widely distributed, many of the species are quite restricted in their habitat. Some species (stagnalis appressa, for example) live in marshy, reed-bordered lakes and ponds, preferring open patches of water near the shore in early spring and venturing out into the larger body of water in the fall. Another group of species represented by palustris prefers stagnant ponds where there is considerable decaying vegetation. They may be found crawling over the bottom of the pond or pool, on the vegetation or on any other submerged object. Some of the species, like caperata, live in small running streams, in stagnant overflows of creeks, or in small pools which dry up in periods of drought. The small species, like parva and humilis modicella, live on the margins of streams, ponds and creeks, on the mud bordering the shore or on sticks, stones and various kinds of débris. These species are seldom found in the water, unless recently submerged by a rise of the water, their natural habitat seeming to be just above high-water mark. When kept in captivity they invariably crawl out of the aquarium and may be found on tables, chairs or even the floor. A few Lymnæas, like apicina and emarginata, prefer a rocky habitat, either in running water or where there is a decided wave action as on the beach of Lake Superior in Ontonagon County, Michigan, and on the sandy shores of the larger inland lakes, like Tomahawk Lake, Wisconsin. So important has it become that exact data should be secured concerning the environmental relations of animal groups that it has been thought necessary to illustrate a few of the more typical and noteworthy habitats of a few species of Lymnæa. As the central United States is the metropolis of this family in North America, the illustrations and examples are mostly taken from this region. ${ }^{1}$

Galba Caperata (Say). Plates L; LI, figure 1.

This species, in company with Aplexa hypnorum and Spharium occidentale, lives in small streams, overflowed portions of small rivers and creeks, and in small transient pools in the woods. (Plate LI.) In the summer and fall these

IIt is not to be supposed that the different species occupy only stations like those pictured. They will be found in any locality furnishing a more or less similar set of conditions. 
species may be.found in hollows, under leaves, where they have crawled to secure the last drop of moisture. This character of habitat causes the animal to form a varix inside the inner lip, behind which an epiphragm is produced, to protect the mollusk until the area becomes wet again. These varices may be seen to the number of five or six on large shells of caperata.

Galba Reflexa (Say). Plate LI, figure 2 ; plate LII, figure 1.

This species prefers larger ponds in which vegetation occurs, either reeds or cat-tails, upon the stems of which it hibernates in times of drought, when the water becomes low or entirely evaporates. Occasionally found in muddy bayous, as at Des Moines, Iowa.

Reflexa is an inhabitant in many places of transient pools which are well filled with water in the spring, but which wholly or partially dry up in the summer. They, like Galba caperata, form a varix and an epiphragm and hibernate during dry seasons, renewing their activities when the pond or pool ag:in becomes moist. Such mollusks as Physa gyrina, Segmentina armigera and Musculium truncatum also live in this kind of a habitat. Galba exilis is also characteristic of such a habitat.

\section{Galba lanceata (Gould). Plate LII, figure 2; plate LIII, figure 1.}

Lanceata usually occupies such habitats as quiet inlets of larger lakes, where there is a quantity of debris, also considerable vegetation. Occasionally it will be found in a marshy portion of the shore of a large lake, as shown in figure 2. Planorbis binncyi is associated with lanceata in figure 2 (plate LII) while Planorbis trivolvis is found with it in the locality figured in 1 on plate LIII.

Galba parva (Lea). Plate LIV, figures 1 and 2.

Semi-aquatic species like parva, humilis, humilis modicella, parva sterkii, dalli, etc., freqent the edges of streams (figure 1) and large rivers, especially in those localities where there is a muddy flat. In some places they may be found in débris of various kinds on the margin of large inland lakes (figure 2) or of canals (as the Erie Canal in New York).

\section{Bulimnea megasoma (Hald.). Plate LIII, figure 2.}

This fine species lives in very quiet water where the environment is more or less boggy or miry. In Wisconsin this species has been found in miry bayous adjoining the Wisconsin River and tributary streams, near large marshes where the water is from six inches to a foot in depth and the soft, miry mud is from five to six feet in depth. In marshy thoroughfares between the larger lakes, or in small bays where pond lilies are abundant, megasoma may be found near the shore either on the muddy bottom or on drift-wood or floating logs. The bottom of such localities is composed of soft, impalpable mud composed largely of vegetable decomposition.

Lymnea stagnalis appressa Say. Plate LV, figure 1.

Lymnca stagnalis appressa is typical of quiet bodies of water of a more or less stagnant character. Here it may be found either near the reed-bordered shore or floating in the quiet waters of the bay among Spirogyra or other floating vegetation. 
Lymnea stagnalis lilliane Baker. Plate LV, figure 2.

Stagnalis appressa lives in quiet waters but this race, characterized by the shortened up spire and large aperture, is an inhabitant of exposed lake shores where it is frequently subjected to very rough usage by the heavy seas caused by storms and high winds. In Tomahawk Lake, Wisconsin, this race lives on a sandy shore fully exposed to the violence of the waves. In Isle Royale, in Washington Harbor, Lymnea stagnalis sanctamaria is found attached to the rocks, and is not readily removed by the waves. ${ }^{1}$

This race (stagnalis lilliane) has been produced by the change of environment from the quiet waters of protected bays to the rough waters of lakes. A parallel case may be cited in the palustris of Alpena, Michigan, where a change of habitat from quiet, marshy waters to the exposed pools of a lake beach has produced a quite distinct race.

Galba emarginata wisconsinensis Baker, also lives on an exposed beach in the Wisconsin lakes, associated with stagnalis lilliana.

Galba woodruffi (Baker). Plate LVI, figure 1.

At Millers, Indiana, this species is found abundantly on a sandy beach, fully exposed to the violence of the waves. Although no living specimens have been found, it is probable that the species lives not far from shore, as the dead shells are found in abundance all along the southern shore of Lake Michigan. Associated with this Lymnæid are species of Spharium, Valvata, Amnicola and Lampsilis.

\section{Galba Catascopium (Say). Plate LVI, figure 2; LVII, figure 1.}

This species is typically an inhabitant of the shore of quiet rivers or lakes where it may browse among the algæ along the shore. In the Genesee River and in the Erie Canal (figure 2) at Rochester, N. Y., this species may be found by countless thousands along the quiet shores of these streams. Some forms, by change of habit to the exposed shore of a large lake or bay, as at Pine Lake, near Charlevoix, Michigan, have developed a smaller, more solid shell than those individuals inhabiting the quiet areas mentioned above. Along the shore of Lake Ontario, where pools of water have collected behind breakwaters (due to rough water), this species lives in large numbers on the mud flats in shallow water (pl. LVII, fig. 1). In the Delaware River, catascopium lives between tides and is subject to all the influences of the littoral marine species.

Galba palustris (Müller). Plate LVII, figure 2.

Palustris is characteristic of stagnant ponds and swampy pools, where there is a quantity of vegetation, both living and dead. The edge of a Typha latifolia plant society is almost always a favorite resort of this species (pl. LV, fig. 1).

\section{Pseudosuccinea columella (Say). Plate LVIII, figure 1.}

This fragile Lymnæa lives in a quiet, stagnant habitat, usually among cattails $\left(T_{y} p h a\right)$. The surface of the water is usually covered with pond scum (Spirogyra) or other floating vegetation. A pond filled more or less with lilypads also affords a typical habitat for this ispecies (pl. LIII, fig. 2).

When the habitat is a rapidly flowing stream, the shell tends to become solid and to produce a large aperture to enable it to withstand

1c. f. Adams, Ecol. Surv. Mich., p. 97. 
the steady pull of the rapidly flowing water. Examples of Lymnæas living in this kind of a habitat are Galba apicina, in Union River, Michigan, and Galba reflexa in a rapidly flowing stream near Lockport, Illinois.

That the ecological study of nature is of great value in the separation of species and races has been clearly demonstrated by the exhaustive examination of local areas, which has shown that the variation of the individual is in direct ratio to the variation of the environment. A case in point is recorded by Dr. W. A. Nason, who thus describes the molluscan habitats near Alpena, Michigan: ${ }^{1}$

"Thunder Bay Island is one mile east of the north point of Thunder Bay. Here I found the shells in pools of water in ledges of limestone which are accessible to the waves of the lake during storms or high water. Sugar Island is a low island between Thunder Bay Island and the mainland, a little to the north.

"Sulphur Island is a small, low island near the southern point of Thunder Bay, about eight miles from the city of Alpena. Long Lake is about twelve or fifteen miles north of Alpena, and its shores are mainly limestone rock and low bluffs, except at the outlet of the creek which flows into Thunder Bay River. The shells were mainly collected on a broad, sandy beach about the outlet, and in from six inches to a foot of water.

"The change of localities gave the shells a difference in development which is very interesting. The contrast between the solid forms of Thunder Bay Island, where the waves and cool water of Lake Huron was almost daily forced into the pools where the shells developed, and the still, swampy pool where the Sugar Island Lymnæas lived, where the shores were low, but protected from the rough storms of the lake, give a hint of conditions very interesting, biologically."

Mr. A. G. Ruthven describes a somewhat similar habitat which cccurs on the shore of Lake Superior, Ontonagon County, Michigan, inhabited by Galba apicina. ${ }^{2}$

There is an interesting habitat at the southern end of Cayuga Lake, New York, in which a clear brook flows through the center of a swamp. The still, stagnant pools are inhabited by Galba palustris, to which location they are confined. The running stream is tenanted only by Physa and Galba umbilicata, the latter being scattered over the surface of the mud bordering the stream.

Mr. Junius Henderson, of the University of Colorado, thus describes the ecological features of Colorado: 
"The originally dry plains of the eastern part of the state are almost unbroken up to their very abrupt meeting with the foothills of the Front Range, at least from Colorado Springs to the northern boundary of the state. Through the plains run occasional streams, along which were originally some cottonwoods, willows, etc., but, generally speaking, except close to the borders of the streams, the country is semi-arid, with occasional shallow lagoons or lakes, often of considerable area but seldom of any depth, many of them being dry through a large part of the year, but filling up during the spring rains and run-off from the snows. These lakes are believed to be largely wind-formed, though that is not at all certain in many cases. At any rate, they are not of glacial origin, as the glaciers in this region did not extend below the $7000-8000$ foot line, while the plains meet the foothills at from 5000 to 6000 feet.

"Wherever the water from the streams can be economically carried in open ditches, by going upstream far enough to get sufficient head, a great change has been wrought in the character of the country in the last forty years, much of it within the last twenty. Many of the lakes have been enlarged and deepened by the building up of their dams, other reservoirs have been formed, dotting the plains everywhere within convenient reach of the streams, and ditches extending in all directions. Seepage water from ditches and reservoirs form many smaller pools, which are apt to be dry except during the irrigation season, just as the numerous pools formerly formed by overflow water along the streams during the spring run-off dry up later in the season. Many of the lakes are choked with vegetation usually found in such situations, while others are quite free therefrom. The bottom is apt to be of fine mud. In the mountains above 8000 feet there are numerous lakes, the origin of some of the lower ones being in doubt, but all the higher lakes being of glacial origin. The lower lakes, the only ones in which I have found Lymnæas, are usually very shallow lagoons, choked up by vegetation, including sedges, etc., and nearly or quite drying up in late summer."

Dr. Henry A. Gleason has recently ${ }^{1}$ made an interesting ecological survey of Isle Royale, Michigan, and his remarks on the ecological relations of the Lymnæas of this area are of great value. He says:

"Tonkin Bay is a small inlet about a half a kilometer long, opening to the east upon the lake, and with steep, approximately parallel sides. It is narrowed half way up by two beaches lying perpendicular to its length. By this the wave action on the upper part is reduced, but

\footnotetext{
${ }^{1}$ An. Rep. Ecol. Surv. Mich., 1908, pp. 60-62.
} 
still may sometimes be sufficient to wash heavy driftwood upon the beach. In the outer half the wave action is but slightly less than on the lake itself, and no shells are found. In the inner or upper half, Limnaa stagnalis lillianc, Limnea emarginata and Physa sayii Tap. live along both sides, where the bottom is rock, but not across the ends. They live only on a rock substratum, which may be either horizontal or vertical, and in water up to $45 \mathrm{~cm}$. in depth. The larger species, Limnea stagnalis lilliane, is more abundant in the deeper water, and only the smaller species live at a depth less than $15 \mathrm{~cm}$. They then prefer the vertical walls to the horizontal or flat bottom.

"Conglomerate Bay is a rocky inlet similar to the one just described and about $1.6 \mathrm{~km}$. long. Being wider at its mouth than Tonkin Bay, the force of the wave action is felt farther up the bay. Near the end the waves have little effect, as is evidenced by a sandy beach, almost without driftwood. At the upper end of this bay, along the north side, Limnea emarginata and Physa sayii Tap. are found in water $15-45 \mathrm{~cm}$. deep, in the deeper water on the tops of flat rocks, in the shallower water, also on the vertical sides and in small crevices. They never occur on the sand or gravel deposited around the rocks, as is frequently the case near the sand beach at the upper end of the bay. The distance to which they extend from shore is greatest opposite the concavities of the shore line and least opposite the small rocky headlands. Their distribution in both Tonkin Bay and Conglomerate Bay seems to be regulated mostly by the wave action, since they seek the most protected places and avoid the shallow water where the waves would strike them most, and do not live on loose or small rocks, gravel or sand which would easily be dislodged. The fact that the smaller shells are found at the least depth, while the larger Limnca emarginata inhabits the-deeper water, would indicate that the small size of the former renders them less easily dislodged by the waves. Again, their greater abundance on the north side suggests the possibility of a light relation.

"Siskowit Lake, with its rocky shores and large area, offers essentially the same condition as Lake Superior itself, and the shells have the same general distribution. Along the very gently sloping rocky shore near the outlet Limnea sanctamaria occurs in abundance, always at a depth of $10-40 \mathrm{~cm}$. Along the south side of a large island near the south shore, where they are sheltered from waves in every direction, the same species is abundant. They live on rocks in the full sun in water $10-45 \mathrm{~cm}$. deep, with the optimum depth at $20-25 \mathrm{~cm}$. They may occur on the tops or sides of rocks, but never on the sand between 
them. Associated with the Limncia, but much less abundant, are Planorbis bicarinatus royalensis Walker, P. campanulatus Say, Lampsilis lutcolus (Lam.), Anodonta marginata Say, and Anodonta grandis footiana Lea.

"Opportunity was given to observe the behavior of Limnca sanctemarice in waves of some size near a small circular island half a kilometer out in the lake. The bottom was gently sloping, and either of solid rock or of large rounded fragments. There were no overhanging trees, so the shells were found in uniform abundance in the usual depth of water on all sides of the island. At the time the island was visited a strong wind was blowing, and the waves were probably nearly as high as they ever become on Siskowit Lake. One or two shells were seen which had been washed loose and, of course, would be unable to reattach themselves until the waves abated. It would be expected that in such cases the shells might be crushed or broken or the animal killed. That such may happen was evidenced by finding a few live shells which had been cracked and then healed, leaving an irregular surface. Their occurrence here and elsewhere only upon rocks of considrable size shows that they require a firm substratum, and where the rocks are free from any coating of slime they can certainly endure higher waves. Around the island under discussion the rocks were washed perfectly clean.

"The beach in front of the camp at Siskowit Bay was inhabited by large numbers of Physa sayii, Physa sp., Limnaa sanctamaria and Limnca emarginata, so that more detailed observations of them could be made, and a few experiments carried out to show their sensitiveness to the depth, or bathytropism, as it has been termed. The beach here is of rock with a gentle slope of about one in five, corresponding to the dip, except where blocks have worn off, leaving low vertical walls. The wave action here is very light, its force being cut off by a series of islands lying between the beach and the main body of Siskowit Bay. This was well shown by the conditions on August 2, when there was scarcely a ripple inside the islands, although the bay outside was covered with whitecaps. The beach is covered with a thin coat of slime formed mostly of excrement from the snails.

"On such a beach snails may live close to the edge of the water, but the larger Limnæas still occupy their usual depth of 1.5 to 4.5 decimeters. About 10 a. m., on August 3, all the shells to a depth of about 1 decimeter were gathered from a strip of the beach about 10 meters long. They were comprised in the following species: Limnca sanctcmaria, Limnca cmarginata, Physa sayii Tapp., and Physa sp. 
The smaller Physas were especially abundant and about 200 of then were taken. Four hours later, at 2 p. m., 60 shells, all of the smaller species, had migrated upon the same strip. The only evidence concerning the way that they came is that one shell of Limnea sanctemarice was seen to drift up over a low wall into the shallow zone. This method could hardly account for 60 of the smaller ones, however, appearing in so short a space of time. It may be taken as indicating a general and continued migration in all directions within their bathytropic limits.

"It was noticeable that the large Limnea emarginata and Limnea sanctamaric, aside from the one specimen mentioned above, live at an average depth of $3 \mathrm{dm}$. and never deeper than 4.5 or $5 \mathrm{dm}$. To test their bathytropism, six of them were picked out of the deeper water by hand and held in contact with the bottom in the shallow zone until they extended their feet and attached themselves. At this time the water was very quiet, moving just enough to cause a faint sound on the beach. But the size of the shell of the two Limnæas is so large that they offer considerable surface to the water and are consequently casily washed loose. Two of the six swung a little from side to side and were then washed off and carried by the undertow into water 3 $\mathrm{dm}$. deep, where they again attached themselves. A third, without being shaken by the waves, clung to the rock for some time, then suddenly let go of its hold.and drifted over a low ledge into the deeper water. Two others immediately started to crawl down the slope, and one in about fifteen minutes, the other in about half an hour, had crawled over the ledge into water $3 \mathrm{dm}$. deep, where they both remained stationary. The sixth remained attached, and in three hours had crawled $2 \mathrm{dm}$. parallel to the shore, keeping at the same depth. The next morning, twelve hours later, it had disappeared and, of course, could not be recognized in the deeper water.

"On August 4 two shells of Limnaa appeared in the shallow zone, but it is not known whether they drifted or crawled up. They were there at least three hours. After they were last observed a fresh breeze sprang up from the east and the slight wave action caused by it probably washed them down.

"The level of the lake varies somewhat with the direction and intensity of the wind, so that in front of the camp a strip of beach up to $5 \mathrm{dm}$. in width may or may not be covered with water. The smaller shells, Physa sayii Tapp. and Physa sp., live in this zone in spite of the fact that they are sometimes out of water. So far as observed, they are never exposed for any considerable length of time, 
so that they do not become dry. Then again, the weathering of the rock has left bowl-shaped hollows a centimeter or so across and about the same depth, and the snails usually get into them.

"To summarize, the known facts bearing on the distribution of these four species are as follows:

"1. Their lower limit is 4.5 to $5 \mathrm{dm}$. depth of water, governed possibly by the water pressure or the food supply.

"2. The upper limit is, for Limncea sanctemarice and Limnea emarginata, $1.5 \mathrm{dm}$. of water, for Physa sayii and Physa sp., the shoreline. The cleaner the rock and the less the wave action, the shallower the water which they may inhabit.

"3. Their horizontal distribution is controlled by (a) full exposure to the sun ; (b) a rock bottom ; (c) a certain minimum of wave action."

These examples of environmental conditions might be vastly increased in number, but enough have been given to illustrate the conditions under which this group of mollusks live.

The Lyninæas are able to live under many and diverse conditions. In altitude they have been recorded from sea-level to a height of 10,000 feet or more; they also live in fresh, brackish and in salt water, in thermal springs and in ice-cold waters, at or near the surface of the water and at great depths in the largest and deepest lakes.

Some of the records of the altitudes at which Lymnæas have been found are given below:

LYMNÆA STAGNALIS.

Outlet Lake Tahoe, Placer County, California, 6247 feet altitude (Cooper).

GALBA OBRUSSA.

La Grulla, San Pedro Mountains, 7000 feet altitude (Nelson and Godman).

GALBA BULIMOIDES.

Outlet Lake Tahoe, Placer County, California, 6247 feet altitude (Cooper).

GALBA HUMILIS MODICELLA.

Big Payette Lake, Idaho, 5000 feet altitude (Ashmun).

GALBA PALUSTRIS.

Bear Lake, San Bernardino Mountains, 6700 feet (Stephens).

San Bernardino Mountains, Bluff Lake, 7500 feet altitude (Berry).

Walker Lake, San Francisco Mountains, Coconino County, Arizona, in crater of extinct volcano, 8250 feet altitude (Merriam). derson).

Goshen, near Boulder, Boulder County, Colorado, 8000 feet altitude (Hen- 
Magnolia, Boulder County, Colorado, 9000 feet altitude (Henderson).

In creek, Uintah Mountains, 10,000 feet altitude ${ }^{1}$ (Bailey; Dall).

Mt. Leidy, in stagnant pond at 10,000 feet altitude (Dall).

No exact data is available on the bathymetrical range of the American Lymnæas; it is quite probable that several species live at considerable depths in the great lakes, notably woodruffi, the animal of which has never been seen. Some of the smaller lakes undoubtedly have a deep-water Lymnæid fauna, but records of such have not been found.

In Europe considerable attention has been given to this subject, Forel's work on the deep-water fauna of Lac Leman, Switzerland, being classic. ${ }^{5}$

Among the European records the following are of special interest:

Lymnca stagnalis, Lake Geneva, Switzerland, 250 meters (Forel).

Lymnaa auricularia, Lake Constance, Switzerland, 70 meters (Siebold).

Lymnaa auricularia, Lake Geneva, Switzerland, 40 meters (Andre).

Lymnca abyssicola, Lac Leman, Switzerland, 25-250 meters (Forel).

Many Lymnæas, as well as other pulmonates, have been found in thermal springs; thus, Lymnaa percgra and Physa acuta live in the thermal waters at Barbatan, France, where the temperature reaches $86^{\circ}$. Lymnca peregra var. geiscrcola lives in the hot water of the geysers of Iceland (vide Mörch).

Lymnæa is also known to live in brackish or even salt water. Friedel ${ }^{2}$ records the living together in brackish water of Lymnca and Neritina with small specimens of Mya arenaria, Cardium edule, Cardium rusticum, Rissoa and Littorina. In the area of the Quaternary lakes Bonneville and Lahontan, several species of Lymnæids live in more or less brackish or alkaline waters, notably Galba palustris.

The Lymnæids are able to withstand a very low as well as a high temperature. It is recorded that Lymnca auricularia ${ }^{3}$ has been frozen in a solid mass of ice and has subsequently revived after being thawed out. Lymnæas have also been seen to crawl about on the under surface of a coating of ice. ${ }^{4}$

A number of observations have been made on the effect of infected or contaminated water, such as sewage, oil and chemicals, on fresh-water mollusks. Crosse and Fisher ${ }^{6}$ record that Sphcrium,

${ }^{1}$ At Iskardo and Nubra, in Tibet. Lymnaea hookeri lives at an altitude of 18,000 feet. (Woodward, P. Z. S., 1856 , p. 185.)

${ }^{2}$ Mal. Blatt, XVII, p. 56 ; Jordan, 1883, p. 236.

${ }^{3}$ Bull. Soc. Linn. Nord.. Abbeville, 1840, p. 150

${ }^{4}$ Cooke, Mollusca, p. 27.

'Bull. Soc. Vaudoise des Sci. Nat., X, p. 217, 1869; XIII, p. 1, 1874; Andre, Journ. Malac., VIII, p. $35,1901$.

'Journ. de Conch, XXII, p. 332. 
Pisidium and Planorbis resisted the effect better than Lymnaa. At Rochester, N. Y., the sewage has been discharged into the Genesee River for the past ten or fifteen years and at the present time is of the consistency of dirty, greasy dish water, yet Galba catascopium and Planorbis trivolvis live and thrive by thousands in this seemingly unfavorable environment. (Pl. LVIII, fig. 2. $)^{2}$ The writer's observations have been that chemicals and oil are deadly to molluscan life, while sewage does not materially affect them.

Recently Dr. A. E. Ortmann has made a detailed study of this subject in a study of the waters of western Pennsylvania. He found that sewage, excepting in a highly concentrated form, had little effect on the fresh-water fauna, excepting that it rather tended to increase than decrease certain forms of life. On the other hand, the chemicals discharged from the coal mines, oil wells and other industrial plants proved fatal, as is most clearly shown on the map accompanying Dr. Ortmann's paper, where large areas of the Allegheny, Ohio and Monongahela rivers have been rendered unfit for life. ${ }^{3}$

b. VARIATION OF THE LYMNAEID SHELL IN DIFFERENT ENVIRONMENTS.

The variation in the form of the shell in Lymnæa may be due to many causes; that relating to the environment only will be here considered. The effect of heat and cold has already been noted (page $2 \dot{8}$ ). Differences in environment have a marked effect upon the form of the shell. In many cases the variation is individual, but in not a few it is common to all the individuals inhabiting certain areas, and hence produces, oftentimes, characteristics of specific or racial value. Those Lymnæas which inhabit alkaline waters always produce a peculiar shell, as, for example, the Polyrhytis utahensis of Call, inhabiting Lake Utah, which has developed a series of longitudinal ribs. Galba palustris, when occupying a saline or alkaline water habitat, produces a shell on the average of from eleven to fifteen per cent smaller than in a fresh-water habitat, showing that salinity produces a dwarfing of the shell.

Many of the peculiar species of fresh-water pulmonates, which formerly lived in the waters of the Quaternary Lake Lahontan and Lake Bonneville, were produced by the struggle of the mollusks to become adapted to a changing environment. These fresh-water deposits show the gradual changes which took place in the mollusk fauna, as the conditions became more and more severe, until, at the top of

\footnotetext{
${ }^{2}$ Since writing the above the sewage in the Genesee River has become (1910) of such a highly concentrated form that the mollusks have all disappeared in the river for a mile or two below the point of the discharge of sewage into the river.

${ }^{3}$ See Ortmann, pp. 97-98; also Irrigation Papers, no. 186, 219, 226.
} 
the series, molluscan life disappears altogether. The evaporation of the water caused an increase in its alkalinity, and this condition of the environment is reflected in the shell, which becomes more solid, smaller, and ribbed or corrugated. ${ }^{1}$

Some years ago Dr. W. H. Dall ${ }^{2}$ penned the following lines, which admirably describe the effect of unfavorable environments on freshwater shells :

"The extra development of plicate sculpture is generally associated in arid regions with the dryness, and in moist regions with the presence of some alkaline salt, which accentuates the action of those factors in the organism which are concerned in the formation of the minor irregularities of the shell surface. The manner in which this is brought about is one of the prettiest illustrations of the direct action of the environment which I know, and seems to be sufficiently established by both geological and physiological evidence.

"In the arid region of the far West, especially in the desiccated lake basins of Utah, Nevada and California, it has long been observed by the writer, Dr. R. E. C. Stearns and others, that in the successive beds of fresh-water marl, which the now dried-up lakes deposited in Pliocene and Pleistocene times, the shells indicate a progressive change in surface characters as the alkalinity of the water increased, until at last the amount of alkali became so great that the mollusks were exterminated or found a precarious refuge in the fresh-water streams which fell into the basins in question. The shells, without regard to genus or systematic relations, showed a unanimous tendency to become ridged, plicated or rugose; the regularity of the gastropod coil was interfered with, abnormalities became more common, and, toward the last, almost general. Projecting sculpture, spiral threading, carinæ, riblets, etc., were exaggerated; size generally diminished, the height of the spire relatively to the diameter became less, and general degeneration curiously combined with extreme accentuation and irregularity of surface characters. Something of the same sort is visible at the present time in the shells of fresh-water gastropods in the irrigating ditches of farms in the alkaline arid region; those shells, in the ditches where the water has leached out alkaline matter from the soil, showing evidences of change in the same direction in surface sculpture, as I have personally observed in the Honey Lake Valley, Nevada.

"The dynamical origin of these changes may be explained by considering the origin of the surface characters of the shell. The de-

${ }^{1}$ See Call. Bull. U. S. Geol. Surv., no. 11; Stearns, Proc. U. S. Nat. Mus., $\mathrm{XXIV}$, p. 271.

2'Proc. Phil. Acad., 1896, pp. 407-409. 
position of the shell substance and epidermis takes place from the surface and the edge of the mantle. The process is not absolutely continuous, but is carried on at more or less frequent intervals when the animal is in a state of rest. At times when deposition is going on, the margin of the mantle is in a more extended state than usual, reaching to a point where the extremely thin and delicate membrane is in contact with the extremest margin of the already formed shell. The glandular epithelium of the edge of the mantle secretes less lime than that of the surface behind it, and is chiefly responsible for the periostracum of the shell, while the rest of the mantle has the task of secreting the more limy matter which makes up the bulk of the calcified shell. As the margin expands or contacts over the still viscous secretion, the ornamentation of the mantle edge, cilia, papillæ, fringes, etc., everything which by its form or bulk varies the flatness of the filmy membrane itself, mechanically influences the form of the surface over which it passes, as the teeth of a rake leave shallow furrows over the gravel of a garden walk. Essentially in this way are the spiral striæ, the revolving threads and similar ornamentation developed on the surface of a fresh water gastropod. The transverse sculpture, usually known as incremental lines, arises from the periodicity of secretion, while ribbing or spinose ornamentation originates in a periodic turgidity of the mantle (how induced normally is not known) which rhythmically affects that organ, and by its tidal rise and subsidence causes the shell secreted during such epochs to be more inflated or capacious than at the corresponding intervals. These features and modes of growth can be observed in an aquarium with the more common fresh water gastropods."

Dr. R. E. C. Stearns ${ }^{2}$ has recorded the case of a locality in Minnesota known as Eagle Lake, of which he says, "The testimony of the numerous examples of Lymnea emarginata from Eagle Lake points to considerable fluctuation in the volume of the water one season compared with another, and the more northerly Eagle Lake to the influence of extreme cold, or alterations of temperature conditions as related to volume of water in some seasons or years, as well as possibly alkalinity or some chemical fluctuation due to diminished volume of water at times, or briefly, to fluctuations in the quantity and temperature of the water and the chemical quantity, or proportions of the same."

The Galba emarginata from Eagle Lake are very variable, the spire being long or short, the body whorl rounded or shouldered, aperture rounded or patulous, surface malleated or simply lirate, and sutures

${ }^{2}$ Proc. U. S. Nat. Mus. XXII, p. 135. 
deep or shallow. Specimens of Galba emarginata mighelsi from Aroostook County, Maine, exhibit similar fluctuations, as do also examples from some of the lakes of Michigan and Wisconsin. Cooke ${ }^{4}$ cites examples of the European Lymnaa peregra and Lymnca stagnalis from the salt marshes near the sea of Aral which show the effect of a changing environment. These lakes are salt for several months of the year and comparatively fresh during the remainder of the year. The effect is to dwarf and otherwise modify the form of the shell.

In many localities in which the habitat consists of a rapidly flowing river or a wave beaten, rocky shore, the spire is shortened up and the aperture is greatly increased in size. This increase in the size of the aperture is in direct response to the character of the environment, the roughness of the water causing the animal to develop a larger foot, and hence, a larger aperture, in order to overcome the pushing and pulling power of the water; in other words, a larger foot surface is essential in this kind of a habitat, for the preservation of the species.

A change of habitat is thought by some conchologists to produce some species. Hazay, for example, records Lymnaa peregra from the ova of ovata, and ovata from the ova of peregra, by placing one species in running water and the other in still water. ${ }^{1}$

Dr. Lewis many years ago $^{2}$ asserted that Galba palustris in the Erie Canal became Galba catascopium when transferred to the Genesee River.

Variation in Lymnæa may be summed up as due to one or more of the following external causes:

Quality and quantity of food.

Station in stagnant or quiet water.

Station in rapid current or on wave beaten shore.

Temperature.

Chemical nature of fluid medium.

The foregoing remarks clearly indicate that the environment plays a notable part in the variation of the Lymnæas and hence in the formation of species, and it seems almost needless to state that when collections are made great care should be exercised in carefully noting the ecological data. ${ }^{3}$

\section{c. LOCOMOTION.}

Locomotion in Lymnæa is accomplished by three principal methods. These may be called gliding, hunching and thread spinning.

\footnotetext{
${ }^{1}$ Cooke, op. cit., p. 93.

${ }^{2}$ Amer. Journ. Conch., IV, pp. 2-4, 1868.

3See Semper's Animal Life, p. 439 , for a discussion of variation under various conditions.

${ }^{4}$ Mollusca, p. 85.
} 
GLIDING: By this method of locomotion the animal appears to slip over the surface of an object in the same manner that a boat glides through the water or a skater glides over the surface of the ice. The foot remains uniform in shape during this process, the shell being carried in one position; this mode of locomotion is more characteristic of Physa than of Lymnca, but may be observed in many species, as stagnalis, catascopium, haldemani, etc. A characteristic method of locomotion in Lymnaa is to glide over the under side of the surface film, the shell hanging downward. It has been observed that the animal leaves a path or track of mucus behind it as is the case when the snail is crawling over a solid surface. The production of this mucus path seems to be a necessary condition for successful locomotion; this statement has been verified by experiments in which the animal was allowed to crawl over an absorbent surface until its mucus supply was temporarily exhausted and then returned to the water. ${ }^{1}$ It was observed that the animal was obliged to rest quietly for a considerable time before the flow of mucus was again started. The same experiments demonstrated that each snail must prepare its own mucus track, the mucus path of neighboring snails not being used.

Hunching. This method of locomotion is common in such species as obrussa, parva, etc., and may also be observed in some of the large species. By this method the animal moves forward by muscular contractions of the foot and then pulls the shell after it with a jerk. This variety of locomotion is most notable when the animal is out of the water, which is the normal condition of the smaller species mentioned. A phenomenon frequently noted is that of twisting the shell from side to side by a sudden jerking motion. This motion is generally used when the animal is partly entangled in vegetation or is imprisoned in any manner.

Thread Spinning. Many, if not all species of Lymnaa, are able to spin a thread of mucus and to hang by it suspended from some object or even from the surface film of the water. Frequently a snail may be seen to attach a thread of mucus to the bottom and rise to the surface by this improvised ladder, the foot being rolled into a tube. The same snail may fill its lung with air, and with the aid of a few air bubbles to lighten the body, descend the ladder, reeling up the mucus thread as it descends. During locomotion by this means, the foot is extended from the shell to a considerable degree and the animal spends a large amount of time in twisting about.

${ }^{1}$ Walter, Cold Spring Harb. Mon., VI, p. 7. 
Two other means of locomotion may be observed. One is that of rising suddenly from the bottom to the surface of the water, and the other is that of dropping suddenly from the surface to the bottom. These are both caused by the ability of the animal to increase or decrease its specific gravity by the presence or absence of air in or on its body or shell.

Mechanism of Locomotion. The mechanism by means of which locomotion in snails is performed has been the subject of dispute and the question is far from being answered in a satisfactory manner. Walter (1. c., p. 8) has prepared a resumé of the subject, which is repeated below :

"Blainville, as quoted by Moquin-Tandon, rather indefinitely suggested that locomotion was caused by an undulatory muscular motion resembling somewhat that of a snake, but quite dissimilar in origin.

“" C'est plutôt un glissement du disque abdominal produit par des ondulations extrêment fines de tous les petits faisceaux longitudinaux qui composent cet empatement.' "'

"Quatrefages in 1850 assigned the cause to the motion of the cilia clothing the foot rather than to any particular motion of the foot itself. Simroth advanced the hypothesis of 'extensile muscles' which continuously lengthen anteriorly' and shorten posteriorly; while Maria Grafin von Linden has in mind a wave-like motion ('Wellenspiel') when she says: 'Die kleinen wellenformigen Bewegungen auf dassen Sohle genügen um eine Ortsveränderung hervorzubringen.' Sochaczewer considered the locomotive force to be the blood flow in the cavernous tissue of the foot. To quote his words: 'Die Fasern selbst werden durch die einstromende Flüssigkeit gedehnt und wirken erst nach reflektorischen Anreiz treibend auf die Maschen anschwellende Blutmenge.' Car came to the conclusion through anatomical studies that locomotion is due to a combination of contractions and relaxations of longitudinal and dorso-ventral muscles, but Simroth, returning to the controversy, pointed out that other forms than Lymnæus which have no dorso-ventral muscles at all, progress over the surface of the water equally as well.

"Jordan advances a theory based on the pressure of isolated bodies of visceral fluid or blood which is somewhat similar to that of Sochaczewer, and finally Carlson finds that certain land pulmonates appear to progress by waves of relaxation and contraction wherein the musculature of the dorsal and lateral walls of the body cavity act in such a way that the whole foot is not in intimate contact with the substratum at the same time. The contraction of the longitudinal muscles 
in those regions between the parts of the foot that are fixed to the substratum serves to advance the animal.

"The presence of cilia on the surface of the foot has been repeatedly demonstrated. These cilia may be easily seen on young snails by means of the microscope. In this connection it is interesting to note that a young Physa primeana, ten days old, showed cilia in motion not only around the edge of the foot, but over the tentacles as well."

RAte of Locomotion. The Lymnæas are usually sluggish creatures, content to browse slowly over the surface or to remain hunched at or above the surface of the water. Mr. Walter (1. c., p. 13) has experimented with Lymnæa with the following result:

Number of seconds required to go 1 inch. $70^{1}$ Number of trials.

78 60

The average time was found to be 106 seconds.

\section{d. RESPIRATION.}

Respiration in Lymnæa is carried on normally by means of a socalled lung, which is a fold of the mantle occupying the last part of the body whorl. This forms a sac or cavity into which the ais is taken through a modified portion of the mantle which forms a tube or siphon. This cavity is well supplied with blood vessels, the air taken into the lung æriating the blood in these veins before it enters the heart, after it has circulated through the body.

To obtain the air for respiratory purposes, Lymnæa visits the surface of the water periodically. When the surface is reached, the body is swung around to the right and the siphon opens above the surface with a distinct clicking sound. Apparently the snail is not aware that the surface has been reached until the tip of one, or both tentacles are in contact with the surface film, at which instant the siphon is brought into position. This peculiarity has been observed in a number of species of Lymnæa and is mentioned by Walter and others. The individual, after filling the respiratory chamber with air,

The following experiment by Walter is of interest:

"To demonstrate that the rate of progress of a single snail changes when the latter is forced to make repeated attempts to reach the surface, a single instance, which is typical of the behavior of all the snails that were subjected to experiment, is given. In the 60 trials of Lymnaeus the escape from the two-inch circle for the first 20 trials took, on the average, 45 seconds. The second 20 trials averaged 63 seconds, while the average for the last 20 trials was 101 seconds. This slowing down may have been simply the effect of fatigue. but more likely it was due to the gradual exhaustion of the mucus supply.; 
closes and draws the siphon from the air and turns about, usually in search of food.

The power of Lymnæa to live for great lengths of time without air has been noted by many conchologists. As has already been stated, Lymnæa and other fresh-water pulmonates normally come to the surface at more or less regular intervals to obtain a fresh supply of air for the respiratory cavity. It has been noted that visits to the surface are more frequent in water which is poor in oxygen than in water in which the normal amount is present. Several zoologists have made experiments with Lymnæa regarding their respiration, among others Mr. A. Pauly ${ }^{4}$ who noted that the animals came to the surface for air at intervals varying from a few minutes to several hours. In no case did he find that water was allowed to enter the respiratory cavity, even in individuals which were kept from air for ninety days, in which case respiration was accomplished by the skin and not by the lung. It is suggested by Pauly that those Lymnæas living at great depths in lakes may retain the primitive use of the lung to respire air from the water, as is the case with all young Lymnæas for a considerable period after being hatched (about ten days). Where bubbles of air are present, as in shallow water containing air plants, Lymnæa has been noted to use them for obtaining air, thus obviating the necessity for coming to the surface. Forel and Brot, while investigating Lymnaa abyssicola, found that the pulmonary chamber of this species contained no air at the moment it was taken from the water, but when placed in a jar it immediately fell into the habits of its shallow-water relatives, coming to the surface for air and also passing considerable periods out of water.

Forel $^{1}$, Siebold, Clessin and others believe that in some cases Lymnæa breathes directly from water introduced into the respiratory cavity, if compelled to remain away from the air for any great length of time. Clessin expresses his opinion ${ }^{2}$ that Lymnæa normally respires water and only comes to the air when compelled to do so by an unusually high temperature. Walter ${ }^{3}$ has conducted some very suggestive and interesting experiments on the breathing habits of Lymnæa, the results of which seem of enough importance to reproduce.

"Pauly states that the intervals between atmospheric breathing are directly dependent upon the course over which the snail travels to reach the surface, and he supports this conclusion with a table giving sixteen observations on four snails.

'Sitzungs, der Mat. Phys. Classe der K. Bayer. Akad. der Wissen., 1875, pp. $39-54$

'Mai. Blatt., XXIV, p. 175.

${ }^{3}$ Cold Spring Harbor Mon., VI., p. 14

"Uber die Wasserathruna der Limnaeiden, 1877. 
"Undoubtedly a snail sometimes takes a roundabout path to the surface, but it is fully as liable to arrive at the surface in a short interval of time as some other individual that has scarcely twice its own length to go. The important factor appears not to be so much the distance to be traveled as the animal's need of oxygen and its response to food stimulus. The 'need of oxygen' does not explain how breathing movements occur, but it may possibly give the clue to the cause.

"That different snails take in varying amounts of air may be shown by the number of bubbles they may be forced to give up after having been to the surface to breathe. A variation of 1 to 14 bubbles was demonstrated by experiments with the snails under consideration. Naturally a snail who has taken in 14 bubbles can remain under water longer than an individual who has taken in but one, provided other conditions are equal. The rate at which a snail travels to the surface is decidedly influenced also by the pasturage through which the latter passes on its way.

“Table VII summarizes 363 observations on 12 different snails, showing an average interval of 25 minutes. The actual intervals varied without uniformity from 15 seconds to several hours. For instance, on July 6 , No. 3 did not change its position at the bottom of the dish from 10 a. m. to 5 p. m., when the observation closed. How much greater the actdal interval may have been is not known.

"The twelve snails whose movements are tabulated above were all in the same dish, with an equal opportunity to reach the surface by any course, except No. 40 and No. 41, which were in a smaller dish together with a numerous company of Tubifex rivulorum. It will be noticed that No. 40 and No. 41 came to the surface at shorter intervals than the others. This was probably due not to the smaller size of the dish, but rather to the higher temperature of the water. It is undoubtedly true, as will be shown from evidence given later, that these snails obtain part of their oxygen through the skin from the water itself $-\mathrm{a}$ factor that must be borne in mind when considering the intervals between their visits to atmospheric air.

"The amount of visible breathing does not seem to be closely correlated with the amount of activity which the animal exhibits. For example, the details of the movements summarized in Table VII clearly show that snails which travel most are not necessarily the ones which come most frequently to the surface to breathe. In other words, dependence on atmospheric air does not seem to be a constant factor of paramount importance. 
TABLE VII.

Intervals between the breathing spells of Lymnaus palustris.

\begin{tabular}{|c|c|c|c|c|c|c|c|c|c|}
\hline \multirow{2}{*}{ 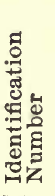 } & \multicolumn{6}{|c|}{ Time Under Observation. } & \multirow[b]{2}{*}{ 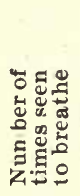 } & \multirow[b]{2}{*}{ 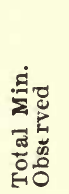 } & \multirow[b]{2}{*}{ 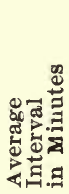 } \\
\hline & $\begin{array}{c}\text { July } 5 \\
335 \\
\text { Min. }\end{array}$ & $\begin{array}{c}\text { July } 6 \\
300 \\
\text { Min. }\end{array}$ & $\begin{array}{c}\text { July } 7 \\
125 \\
\text { Min. }\end{array}$ & $\begin{array}{c}\text { July } 8 \\
90 \\
\text { Min. }\end{array}$ & $\begin{array}{c}\text { July } 11 \\
220 \\
\text { Min. }\end{array}$ & $\begin{array}{c}\text { July } 12 \\
140 \\
\text { Min. }\end{array}$ & & & \\
\hline 1 & 2 & 8 & 0 & 3 & 9 & 10 & 32 & 825 & 27 \\
\hline 2 & 11 & 4 & 7 & 2 & 4 & 5 & 33 & 1215 & 37 \\
\hline 3 & 19 & 0 & 2 & 2 & 3 & 3 & 27 & 1215 & 42 \\
\hline 4 & 26 & 26 & 9 & 3 & 6 & 6 & 76 & 1215 & 16 \\
\hline 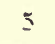 & 45 & 3 & 3 & . & . & . & 51 & 760 & 15 \\
\hline 36 & .. & .. & .. & .. & 13 & 16 & 29 & 360 & 12 \\
\hline 36 & .. & .. & . & .. & 3 & 1 & 4 & 360 & 9 \\
\hline 37 & .. & 10 & 5 & 8 & 12 & 3 & 38 & 880 & 23 \\
\hline 38 & .. & .. & . & . & 8 & 7 & 15 & 360 & 25 \\
\hline 39 & . & $\ldots$ & $\ldots$ & .. & 7 & 7 & 14 & 360 & 26 \\
\hline 40 & $\ldots$ & $\ldots$ & 18 & 7 & .. & $\ldots$ & 25 & 215 & 9 \\
\hline 41 & .. & .. & 14 & 5 & $\ldots$ & $\ldots$ & 19 & 215 & 11 \\
\hline
\end{tabular}

"The amount of atmopsheric air taken in by any individual during 24 hours depends not so much on the number of times it opens its respiratory tube at the surface as upon the length of time the tube remains open for inhalation. In this particular the 12 snails under observation exhibited decided individuality, some keeping the tube open only a fraction of a second, while others extended the period of inhalation even to 96 seconds. No. 4, Table VII, whose average interval was 16 seconds, kept the respiratory tube open noticeably longer than any other snail-40 and 50 seconds being its usual length of time, and 96 seconds the limit, while the average time of inhalation for the other snails was about 15 seconds."

Many Lymnæas have been observed to breathe without coming to the surface, and such respiration is considered abnormal. Pauly divides these abnormal breathers into three classes, as follows:

1.-Abyssal snails which cannot possibly reach the surface.

2.- Snails which make no attempt to reach the air though living in shallow water.

3.-Snails artificially restrained from securing atmospheric air.

The first class has already been discussed (see under bathymetrical range). Pauly cites a number of examples in which the animals secured air without visiting the surface of the water, and he explains as the reason for this change of habit, the ability of the snails to se- 
cure free air from bubbles which have become entangled in some objects below the surface. Pauly was able to observe a number of individuals actually secure the air from these bubbles, but Walter was not able to verify this observation during his studies on the behavior of the pond snails. (Walter, p. 20.) The author has frequently seen freshwater pulmonates in the vicinity of air bubbles and there is no reason to doubt the accuracy of Pauly's observations.

Pauly's third class of abnormal breathing, that of snails artificially deprived of air, bears upon a very interesting subject, that of the ability of Lymnæa to return to the ancestral habit of extracting the oxygen from the water, as observed in those snails living in very deep lakes and also in young Lymnæas. The observations of Moquin-Tandon, Saint-Simon, Pauly, Walter, etc., all tend to show that Lymnæa is unable to suddenly adapt itself to the water breathing habit. In some of the experiments Lymncea stagnalis and Lymncea elongata were used, Lymnce stagnalis surviving from 22 to 91 days, but finally succumbing. It is interesting to note that the deep water forms easily and readily adapt themselves to the surface-visiting habits of their shallow-water relatives:

\section{e. estivation.}

During seasons of drought when the ponds and streams dry up, the Lymnæas bury themselves in the mud to the depth of several inches, form a rib or varix within the outer lip and cover the aperture with an epiphragm like the hibernating helices. This is especially true of those species or races which inhabit intermittent streams or summer-dry ponds. Cooke ${ }^{1}$ records Lymncea peregra as burying itself to the depth of three inches, "when surprised by a sudden fall of water in the ditch on Coe Fen, behind Peterhouse, Cambridge." Galba truncatula has been found buried in hard dry mud to the depth of 18 inches. $^{2}$

Lymnæa is able to survive for considerable periods when deprived of water. Many of the smaller species (parva, humilis, obrussa) will voluntarily leave the water and remain for a considerable time on stones, sticks and other material on the land. Several of these species are sometimes found quite a distance from water. The European Galba truncatula has been reported by Jeffery ${ }^{4}$ as living far from water. The large species are not known to possess this habit, although they will live for a long time without water, if placed in wet moss or cotton. Wiedersheim ${ }^{3}$ has recorded the instance of Radix auricularia

Mollusca, p. 27.

2 Op. cit., p. 41.

ZZoologischer Anzeiger, II, p. 573, 1879.

"Journ. Conch., III, p. 305, 1882 . 
living for two months in fresh, wet moss. Clessin ${ }^{4}$ in commenting upon this statement, remarks that Lymnæa is naturally able to live for a considerable time in wet air, but doubts the possibility of accustoming them to this condition.

Pilsbry ${ }^{5}$ reports the following instance concerning the ability of Galba bulimoides cockerelli to resist drought "Specimens of a very short-spired form of this species were lately received from Mr. George H. Clapp, with the following note: 'They were collected by my cousin, George H. Pepper, from a water-hole that appeared to be dry most of the year, near Farmington, New Mexico, on September 20, 1896, and reached me, packed in cotton, on October 5 . On the 4th of this month (November) I dropped them into warm water to soak them loose from the cotton, and about two dozen out of 50 or more came to life. They had been out of water 45 days! The shells spend nearly as much time out of water as in it, frequently crawling to the top of the glass in which I keep them.' Out of 4 specimens sent alive, packed in dry cotton, one revived at once upon being placed in water, after an additional journey, dry, from the 6 th to the 9 th of November, The survivor has a translucent or almost water-colored body, closely peppered with opaque white; eyes black; tentacles opaque white; a dark stripe on back starting between tentacles. With the Limnæas were some of the little bivalve Phyllopod crustacean, Estheria mexicana Claus."

The author has frequently received living Lymnæas which had been packed in wet cotton or moss and which had been deprived of water for a week or ten days.

\section{f. ABNORMALITIES.}

The Lymnæas are subject to many forms of abnormal growth. The spire may be scalariform, a part of the last whorl may be detached from the body whorl or the aperture may be twisted out of shape. These abnormal conditions may be caused by disease, by accident or by parasitism. A particular case due to the latter cause is reported by Sykes ${ }^{1}$ from Davos Lake, Switzerland (5,000 feet alt.). The species was Radix auricularia and the shells were peculiarly constricted and channeled some distance from the edge of the outer lip. Brot $^{2}$ has recorded that nine-tenths of the Lymnca peregra inhabiting a pond near Geneva, Switzerland, were peculiarly malformed at the base of the columella. Singularly enough this deformity was coinci-

Mal. Blatt., (2). II, p. 199, 1880.

5Nautilus $X$, p. 96 .

JJourn. of Mal., III, p. 34.

${ }^{2}$ Proc. Verb. Soc. Mal. Belg., VI, p. xlviii. 
dent with the appearance of a large number of Hydra viridis in the pond. The Hydra disappeared the next season and the next generation of peregra was of the normal form. While this evidence is largely circumstantial, it is clearly evident that the Hydra was the cause of the malformation. The case cited by Sykes may be of the same character.

It is recorded by K. Hurlstom Jones ${ }^{1}$ and by Arthur G. Stubbs ${ }^{2}$ that Lymnca peregra has been known to leave its shell when diseased. This record requires further confirmation.

\section{g. PARASITISM.}

Various specimens of Lymnæa serve as host for different species of Trematode worms. The following European examples are cited by Cooke $^{3}$ :

Distoma endolabrum Duj. finds its first immediate host in Lymnea stagnalis and Lymnea ovata, its second in Lymncea stagnalis, or in one of the fresh-water shrimps and attains to sexular maturity in the common frog. Distoma ascidia v. Ben. passes, first through Lymnea stagnalis or Planorbis corneus; secondly, through certain flies and gnats (Ephemera, Perla, Chironomus) and finally matures in certain species of bats. Cooke records the following interesting notes on this subject:

"The common liver-fluke, which in the winter of $1879-1880$ cost Great Britain the lives of no less than three million sheep, is perhaps the best known of these remarkable parasitic forms of life. Its history shows us, in one important particular, how essential it is for the creature to meet, at certain stages of its existence, with the exact host to which it is accustomed. Unless the newly-hatched embryo finds a Limnca truncatula within about eight hours it becomes exhausted, sinks and dies. It has been tried with all the other common pond and river Mollusca, with Limncea peregra, palustris, auricularia, stagnalis, with Planorbis marginatus, carinatus, vortex, and spirorbis, with Physa fontinalis, Bithynia tentaculata, Paludina, Vivipara, as well as with Succinea putris, Limax agrestis and maximus, Arion ater and hortensis. Not one of them would it touch, except occasionally very young specimens of Limncea peregra, and in these its development was arrested at an early stage. But on touching a Limncea truncatula the embryo seems to know at once that it has got what it wants, and sets to work immediately to bore its way into the tissue of its involuntary host, making by preference for the branchial chamber; those

${ }^{1}$ Journ. Conch., IX, p. 164.

${ }^{21 .}$ c.. p. 112.

Moliusca, p. 61.

op. cit., pp. 61,62 . 
which enter the foot or other outlying parts of the Limnæa proceed no further."

The genitalia of Galba palustris from Braddocks Bay, N. Y., has been observed to be infested with thousands of a small parasite. These cases were all confined to individuals with malleated shells. It is probable that many of the American Lymnæas offer hosts for early stages of worms, but this subject does not appear to have been given much attention by American zoologists.

h. FOOD.

The normal food of the Lymnæas is vegetal; this, however, varies according to circumstances or individual preference. That the family is carnivorous at nearly all times is proven by the following table.

Deviations of Lymnæa from plant food. ${ }^{1}$

Authority.

Semper ${ }^{2}$

Ullyet $^{2}$

Cockerell $^{3}$

Cockerell $^{4}$

Baker $^{5}$

Sterki ${ }^{6}$

Brockmeier $^{2}$

Cooke $^{2}$
Species. stagnalis stagnalis stagnalis stagnalis palustris palustris peregra stagnalis
Food.

Living newt (plenty of plant food accessible). Living Stickleback.

Old fish head.

An old newspaper.

Dead carcasses of dogs, cats, etc.

A live leach.

Plankton caught in mucus trap.

Dytiscus larvæ, snails, minnows.

It would appear that many Lymnæas adopt a flesh diet from choice. Semper ${ }^{8}$ cites the case of several confined Lymnæas in which they attacked healthy living specimens of a large water newt (Tritontaniatus) and after overcoming them, devour them with evident relish, although there was an abundance of their favorite vegetable food growing near them. Living minnows have also served as an animal diet by preference. ${ }^{9}$

The vegetable food of Lymnæa consists largely of confervæ, the stems of water plants, diatoms, desmids, spirogyra and other pond scums. It is believed by some conchologists ${ }^{10}$ that the absence of vegetable food is the cause of the well-known habit in Lymnæa of eating the shell of its fellow captives when in captivity. Mr. Walter's remarks on the food of these animals are so pertinent that they are repeated below :

${ }^{1}$ After Walter, Cold Spring Harbor Mon., VI, p. 21.

${ }^{2}$ Cited by Cooke, Moll., p. 34 .

${ }^{3}$ Cooke, p. 37.

"Science Gossip, 1883, p. 163.

${ }^{5}$ Moll. Chi. Area, p. 285.

'Nautilus, V, p. 94.

'Forsch.-Ber. Biol. Stat., Plon. Th. 6, p. 165.

${ }^{8}$ Animal life, p. 59 .

${ }^{9}$ Cooke, p. 37.

${ }^{10}$ Clessin, Nach. Mal. Ges., V, p. 28, 1873. 
"Lymnceus elodes (palustris) feeds readily on dead flies, tadpoles and its own eggs, as well as on other snails when their shells have been crushed. It was also seen to engulf and retain the fæces of other snails. Brockmeier's observations of 'plankton fishing' in the case of Limnaus peregra were confirmed. 'Plankton fishing' may be described as follows: While the snail is floating attached to the surface film of the water it will sometimes depress its head-end a little below the water's surface, form a scoop out of the foot, and by means of this collect the microscopic organisms and other floating material at the posterior end, in a trap formed by the mucus which continues to flow out backward, even after the animal itself has become stationary. As soon as sufficient food has been collected, the snail twists its head around to the posterior end of the foot and quickly engulfs the 'catch', mucus and all. Turning now to the matter of plant food, snails were seen rasping off bits of Lemna and they seemed as well satisfied with dead or etiolated portions as with those which were still green. The way in which pond snails plow a clean path across the sides of an old aquarium that has become green with algal growths, is well known and a microscopic examination of the fæces of snails reveals the presence of a large amount of plant food, green cells, diatoms, etc. Rathay found that Pleurococcus can pass through a snail unassimilated. A couple of green apples which had been bitten into and thrown into the 'pump pool' were later found covered, wherever the skin was broken, with snails that were evidently feeding. The character of the fæces of these snails furnished confirmatory evidence that they had eaten greedily of the apples. It is reasonable, therefore, to conclude from such observations that snails are omnivorous, although they are probably most attracted to plant food. The part they play as natural scavengers renders their presence in water troughs and other sources of drinking water highly desirable.

"Some rough estimate of the amount of food ordinarily eaten by snails may be seen from the following experiment. A single snail, $8 \mathrm{~mm}$. in shell length, was isolated in a dish containing the usual food supply. After 48 hours its fæces, which are cylindrical and approximately of equal diameter, were measured and found to give a total of $230 \mathrm{~mm}$. This means that every 24 hours a snail gets rid of over fourteen times its own length in fæces.

"There seems to be no evidence of any struggle for the possession of food among these animals. Snails will gather around a dead tadpole, for example, until all the 'standing room' is taken and those that arrive late at the feast are unable to do anything aggressive. Un- 
der natural conditions the food of snails is so abundant and so universally distributed that apparently there has been no occasion for natural selection to act in this direction.

"Defecation is more frequently accomplished by snails while they are at rest than when they are in motion, and it is noticeably less in snails that have been placed in water which has been boiled. Snails in boiled water probably find very little to add to the contents of their digestive tracts, and this may be the reason why their fæces are longer rctained.

"It was repeatedly noted during the course of experiments in locomotion that a snail would cease moving in a manner quite inexplainable by the external factors known to be at work. After an interval of quiet defecation sometimes took place, a fact which appears to be an instance of interference with the action of external stimuli from within the organism itself. The physiological condition, or tonus, in which an animal happens to be when it is subjected to an external stimulus very largely determines the nature of its response. The greater the range of its physiological conditions the less it is possible to predict with accuracy what the animal will do under definitely known external stimuli."

As remarked by Walter, and confirmed by personal observation, there appears to be no struggle between individuals for the possession of food, each snail simply eating everything in its path without relation to its neighbors.

The jaws of Lymnæa serve to bite the small pieces of food while the radula tears or rasps it into smaller fragments. It has been observed while watching Lymnæa feed as it glided along the glass side of an aquarium, that the radula is thrust entirely out of the mouth, the motion approaching nearest to that of a cat lapping milk. The jaw and the radula appear to meet in the mouth, both seeming to gather the food.

\section{i. FOOD FOR OTHER ANIMALS.}

Lymnæas as well as other fresh-water mollusks form a staple food for other animals such as fish, birds and some mammals. The white fish of the Great Lakes feed largely upon Physa and Lymnaa. ${ }^{1}$ Cooke $^{2}$ cites the case of a Dytiscus in an aquarium which killed and devoured seven Lymnaa stagnalis in the course of an afternoon. These beetles also ate Lymnca peregra but seemed to prefer stagnalis, for 
when equal quantities of both species were placed in the aquarium, they chose the latter species first.

\section{j. REPRODUCTION AND NIDIFICATION.}

The Lymnæas are sexually hermaphrodites. Unlike the helices, they are capable of mutual union, each playing the part of male to the other. This is possible owing to the wide separation of the male and female orifices. Not only may two individuals perform the act of copulation at the same time but three or more individuals have been observed in coitu, one individual performing the part of both male and female with two other Lymnæas.

That Lymnæa is capable to some extent of self impregnation is apparently proven by Braun ${ }^{3}$ who isolated Radix auricularia when hatched. One year later each of three isolated individuals produced respectively one, four and five egg masses, several of which hatched out young auricularias.

The copulation of Lymnca stagnalis lilliance was recently observed and the following notes were made: The penis-sac is everted its whole length and appears as a very large, flat, elongate-triangular organ. When in coitu the male organ is firmly attached to the female, requiring a very strong pull to dislodge it. During the orgasm regular pulsations may be seen following the course of the vas deferens, the penis-sac being so transparent that this organ may be plainly seen occupying a long loop, folded longitudinally. The penis-sac is much more swollen during copulation than when observed in a dissected animal. During coition the male remains quiescent, with tentacles drawn inward and head much contracted. The female, ${ }^{4}$ however, seemingly pays little attention to the operation, but crawls about eating or examining the surroundings with her tentacles. When pulled apart and separated, the male immediately seeks the female again, if in the vicinity, or if placed near another individual, proceeds to search for the female opening at the base of the neck. The male is frequently found on the shell of the female.

Lymnca stagnalis lillianc, Galba emarginata and Galba lanceata have been observed copulating, and, curiously enough, emarginata, though a much larger animal, tried several times to copulate with lanceata, showing that at this period (the last of August) the sexual instinct is so strong that even distinction between species is lost. This was also observed to be the case with stagnalis and emarginata.

${ }^{8}$ Nach. Deutsch. Mal. Gesell., XV, p. 146.

"The terms male and female are here used simply to identify the immediate sex individuals, as Lymnaea is hermaphroditic, carrying the organs of both sexes in the body, as already explained. 
To what extent the penis is everted, could not be satisfactorily ascertained, but it is believed to be partly protruded. The penis-sac probably performs very largely the sexual functions during copulation, the penis being, in fact, but an enlargement of the vas deferens. The length of time of the coitus was not determined; Lymnæas were noted in coitu for more than a day, and it is possible that it may occupy several days.

Crosses between different species of Lymnæas have been observed. Heynemann ${ }^{1}$ records a cross between Radix auricularia and Lymnca peregra, the former acting the part of the female and the latter that of male. Chaster ${ }^{2}$ records a cross between Lymnca stagnalis and Radix auricularia, the former performing the function of the male. The specimens were taken in copulation by Mr. H. E. Craven at Litchfield, England. The union was not observed to be reciprocal. The progeny were good examples of peregra and the query is raised (by Chaster) as to whether peregra may not be the ancestral form of stagnalis and auricularia. Recently the writer has observed Lymnca stagnalis lilliance and Galba emarginata in coitu. As the specimens were not preserved to deposit their eggs, the result of the union is not known.

The eggs of Lymnæa are laid in irregularly elongate-ovate, gelatinous masses on stones, sticks, stems and leaves of water plants, on other shells, both dead and those occupied by the animal, and, in fact, on any kind of debris. The size of the egg masses varies considerably in the same species as do also the number of eggs in each mass. Three egg masses of Galba palustris from Colorado gave the following data:

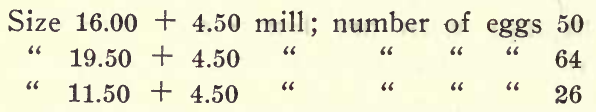

Galba reflexa from Chicago measured as follows:

Size $34.50+1.60$ mill; number of eggs 130

The embryology of the Lymnæas does not differ radically from that of other Pulmonata, excepting in some minor features, notably the retention of the velum in post embryonic life. In the trochosphere a ring is formed about the developing embryo, which becomes ciliated and is used as an organ of locomotion. This is termed the velum, and when fully developed the mollusk is said to be in the veliger stage. The mollusk retains this velum in post embryonic life, though it loses

${ }^{1}$ Nach. Mal. Gesell., I, p. 38.

${ }^{2}$ Journ. Conch., IX, p. $28 \dot{2}$. 
its fringe of cilia and its locomotor function (see plate II, figures C, D. $\left.{ }^{1}\right)$.

The young Lymnæa, just before it leaves the shell, is an interesting object, especially when viewed with a lower power (about $1 / 2$ inch objective) by the aid of which its spiral journeyings inside the egg may be observed (plate II, figure B). The shells at this time consist of a trifle less than two whorls, which are flat and helix-like, quite unlike the long-spired shell of the mature animal. ${ }^{2}$ The eggs of Lymnæa are easily obtained and the development of the embryo may be plainly seen and studied with ordinary powers of a compound microscope. Much good work may be done by anyone who will compare the development of some of the common species.

The effect of different colored lights and also the different densities of light on the developing eggs of Lymnæa has been interestingly shown in a series of experiments by $\mathrm{E}$. Young ${ }^{3}$ who records the following variations in the time of hatching: In violet light, 17 days; in blue light, 19 days; in yellow light, 25 days; in white light, 27 days; in red light, 36 days; and in darkness, 33 days.

\section{k. EXPERIMENTS.}

The genus Lymnæa has been frequently used in conducting experiments relative to the animal's power of resisting changing conditions of the environment. Whitfield's experiments on Bulimnea megasoma $a^{4}$ are well known. Specimens of this large Lymnæa were confined in an aquarium of small size and were bred to the fourth generation. Each succeeding generation was smaller than the one preceding, the last or fourth generation producing a shell about half the size of the first generation, with an elongated spire and generally narrow form, quite unlike the robust form of typical megasoma. Whitfield concluded that the volume of water bore a very close relation to the size and perfection of the shell. Certain interesting changes were also noted in the organs of the animal, such as the loss of the male sexual organs and a notable reduction in the size of the digestive glands. This degeneration is thought by Dall to be due rather to a concentration of salts, as the evaporated water was replenished without emptying the residual supply, causing an excess of salts to accumulate.

${ }^{1}$ See Lankester, Quart. Journ. Micr. Soc., Vol. XIV, p. 365, 1874, for an extended account of the development of Lymnaea.

${ }^{2}$ See an interesting account on this subject by Jabez Hogg, in Trans, Micr. Soc. London, II, p. 91, 1854.

${ }^{8}$ Arch. Zool. Exper., VII, pp. 273, 274.

${ }^{4}$ Bull. Amer. Mus. Nat. Hist., I, p. 29, 1881. 
Several European zoologists have experimented in the same manner, producing very interesting results. Thus, Semper ${ }^{1}$ bred specimens of Lymnca stagnalis from the same egg mass and placed them in aquaria of different volume varying from 100 to 2000 cubic centimeters. All of the essential conditions of life were kept as uniform as possible, especially the food supply. At the end of sixty-five days the specimens from the $100 \mathrm{c}$. c. aquarium measured 6 mill. in length, those from the 250 c. c. aquarium measured 9 mill. in length, while those from the largest aquarium, 2000 c. c. were 18 mill. long. Semper concluded from these experiments that the size of the shell varied in proportion to the volume of water, and that the effect was the same whether one or several individuals were confined in the same aquarium. The factor of temperature was accidentally shown in Semper's experiments; when the temperature fell to $55^{\circ}$. The aquaria were placed near a window through which the sun shone, raising the temperature of the smaller aquaria but having no effect upon the larger aquarium. The consequence was that the individuals in the 2000 c. c. vessel, which should have been 10 mill. in length when 25 days old, were but little longer than those individuals which were contained in the smaller aquaria, the water of which had been warmed by the rays of the sun.

De Varigny ${ }^{2}$ experimented in a similar manner by breeding snails in aquaria containing equal volumes of water, but with varying surface areas. The result was that the largest individuals were produced in those vessels having the greatest surface areas. De Varigny was led to the conclusion from the result of these experiments, that the chief factor in growth was an extensive surface area which permitted extended locomotion.

Willem, ${ }^{3}$ having in mind the experiments of Semper and DeVarigny, carried on two distinct sets of experiments. The first experiment consisted of two similar aquaria, one filled with stagnant water and the other with water into which a constant air stream was introduced. The result after three or four months was that the snails in the aeriated jars were very much larger than those in the aquarium containing stagnant water. In the second experiment two vessels of different sizes were used, the surface areas of which bore the ratio of 8 to 1 , the volumes of water being respectively 3110 and $310 \mathrm{c}$. c. An equal amount of air was kept passing through either jar, and at the end of three months the snails in the larger vessel were of the

${ }^{1}$ Arbeiten Zool.-Zoot. Inst., I, p. 137, 1874.

2Journ. Anat. Physiol., XXV, pp.147-188, 1894.

${ }^{3}$ Bull. Acad. Roy. Sci. Brussels, XXXII, p. 566. 
same size as those in the smaller, showing that neither volume nor exposed surface, but the presence of oxygen in the water was the important factor in determining growth in this case. ${ }^{2}$

A number of interesting experiments bearing on this subject were carried on by Walter ${ }^{3}$ as follows :

"A number of individuals were confined in a wide-mouthed bottle which was stoppered under water to exclude air bubbles. Twentyfour hours later they were all dead. To test whether increase in temperature or the exclusion of fresh microscopic food might have influenced this result, a similar number was placed in the same bottle with a mosquito netting covering the mouth. The bottle was then sunk in the 'cement tub' directly under the inflow of fresh water, eliminating these factors as far as possible. The snails thus imprisoned also died, although a few survived four days.

"In another experiment a film of kerosene was spread over the surface of an aquarium containing snails. Although able to pierce this film, the following day all were dead. Whether this was due to their inability to get a sufficient supply of air, which is probably the case with mosquito larvæ similarly treated with the oil film, or whether the oil itself had a direct effect on them, is not certain. In this connection it is interesting to learn that the 'pump-pool,' in which was found a numerous and thriving community of Lymnæids, had been treated with the oil film for the three preceding years in the effort to exterminate the mosquitoes breeding there.

"Pond snails when overcrowded in an aquarium visit the surface cftener than when only a few are present. This fact seems to offer evidence that Lymnæus absorbs a certain amount of its air directly from the water. In the case of gill-breathing snails which derive their total air-supply from the water, such a condition would naturally be expected, but if Lymnæus depends exclusively on the atmospheric air obtained at the surface, why should the scarcity of air in the water cxert any influence on its movements? That it cannot take all the air it requires in this manner is shown by the bottle experiments mentioned above.

"Continuing this line of observations, two similar vessels were selected, in each of which six snails were placed. One vessel was filled with fresh spring water and the other with water which had been boiled in order to drive off all the free air contained in it, before cooling in a sealed flask to prevent the ingress of fresh oxygen from the

${ }^{2}$ Walter, Cold Spring Harbor Mon., VI., p. 19.

${ }^{3} \mathrm{Op}$. cit., p. 17. 
atmosphere. Undoubtedly much air was absorbed by this boiled water during the experiment, but even so, it may be assumed with a fair degree of certainty that the water in this dish was poorer in oxygen than the spring water. The snails were observed for one hour, during which time those in spring water came to the surface to breathe 20 times, while those in the boiled water came up 44 times."

The results of these experiments show that when the Lymnæas are prevented from coming to the surface for atmospheric air they die.

Mr. H. S. Colton ${ }^{1}$ has conducted a number of interesting experiments on Pseudosuccinea columella, along the lines of those conducted by Semper, Willem, Walter, etc. His conclusions are interesting and agree for the most part with those of Walter. Some of the more interesting points not recorded in the previous pages are as follows (see op. cit., p. 446-44\%) :

"1. It was found that the presence of sand in the gizzard was necessary to enable the animal to assimilate plant tissue.

"2. The accumulation of fæcal matter, when washed and filtered had a beneficial effect on the growth of the animal; this is contrary to the result obtained by De Varigny.

" 3 . Calcium salts in the water seem on the whole beneficial to growth, calcium sulphate particularly so.

"4. Alternate Condition. Snails under unfavorable conditions when placed under favorable ones grow faster than if they were continuously in favorable conditions. It would seem that the change from unfavorable to favorable conditions of life acts as a stimulant for growth. However, this does not always mean that it surpasses the control size. It rarely does that.

"5. Not only does the environment affect growth, but it affects the number of eggs laid in a given time. This fact is very important, because it shows that the environment probably affects all the physiological processes and not one alone.

"6. This study reveals the fact that confinement influences the growth of aquatic animals in three ways-through the amount of food, through the amount of oxygen, and through the accumulations of the waste products of metabolism. The phenomenon is not a simple one, and each factor plays its own part."

Dr. Howard N. Lyon, a Chicago physician, has raised Galba reflexa from the egg in a four-quart battery jar, under equal conditions of heat and light, the brood being from a single egg capsule. Fifteen

1Proc. Phil. Acad., 1908, pp. 410-448. 
specimens were killed when seventeen weeks old, the smallest specimen being 4 mill. long and the largest 27 mill. No reason is apparent for the disparity in size.

\section{LENGTH OF LIFE.}

The duration of life in the family Lymnæidæ is from three to four years, full maturity being reached in about two years. Dr. Lyon has successfully raised Galba reflexa until fifty-two weeks old, the measurements at different stages of growth being as follows:

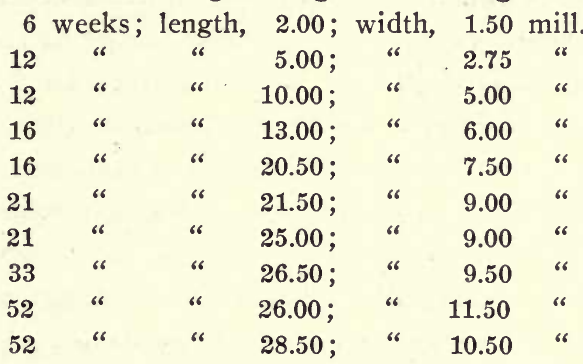

Radix auricularia was raised by Mr. Woodruff until four weeks old, with the following result:

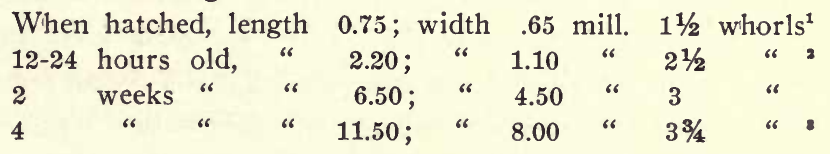

m. BIBLIOGRAPHY. ${ }^{1}$

The following works have been consulted in the preparation of chapter II : Adams, C. C., 1906.-Andre, Emile, 1901.-Baker, F. C., 1902; 1906, b.Braun, M., 1888.-Brot, A., 1877.-Bunker, Robert, 1880.-Call, R. E., 1884.Chaster, G. W., 1899.-Clessin, S., 1873, 1877, 1880.-Cockerell, T. D. A., 1885.Colton, H. S., 1908.-Cooke, A. H., 1895.-Crowther, H., 1896.-Dall, W. H., 1896.-DeVarigny, H., 1894.-Fischer and Crosse, 1874.-Fischer, Paul, 1883.Forel, S. F. A., 1869; 1874.-Friedel, Ernst, 1870.-Gleason, H. A., 1909.-Heynemann, D. F., 1868.-Hogg, Jabez, 1854; 1870.-Jeffery, W., 1882.-Jones, K. H., 1899.-Jordan, H., 1883; Jordan and Copeland, 1877.-Lankester, E. R., 1874.Leidy, J., 1887.-Lewis, J., 1868, a.-Linden, Maria, Grafin von, 1891.-Martens, E. von, 1899.-Ortmann, A. E., 1909.-Pauly, A., 1877.-Pilsbry, H. A., 1896.Ruthven, A. G., 1904.-Semper, Carl, 1874; 1881.-Siebold, C. Th. von, 1875.Sterki, V., 1891, a.-Stearns, R. E. C., 1900 ; 1901.-Stubbs, A. G., 1898.-Sykes, E. R., 1894.-Tryon, G. W., 1882.-Walter, H. E., 1906.-Whitfield, R. P., 1882.Wiedersheim, Prof., 1879.-Willem, V., 1896.-Woodword, S. P., 1856.-Young, E., 1878.

${ }^{1}$ Shell white, vitreous, transparent.

${ }^{2}$ Columellar plait very prominent.

${ }^{2}$ Last whorl wide and shell globular.

'See the bibliography at the end of the volume. 


\section{DISTRIBUTION IN SPACE.}

\section{A. THE PRESENT DISTRIBUTION.}

The family Lymnæidæ is widely and generally distributed over the North American continent from the Arctic Ocean to the Isthmus of Panama. In almost every body of water, large or small, some member of this family is almost sure to be found. In studying the geographical distribution of the family Lymnæidæ, the fact of the wide dispersal of many of the species is notably apparent. Thus, palustris, obrussa, stagnalis appressa, caperata and humilis modicella are of almost universal distribution and many of the other species, as catascopium, parva, apicina, binneyi, etc., cover a wide range of territory.

The evolution of the Lymnæas has been very slow compared with that of the vertebrates, or even with the land snails. The geologic study of the family shows it to be of great antiquity, undoubted species of Lymnæa having been found in the rocks of Lower Cretaceous age. As these Cretaceous Lymnæas do not differ greatly from the existing species, it is evident that the ancestors of the genus must be looked for in rocks of much earlier date, possibly Jurassic, or even an earlier formation.

In the distribution of this family we must, it seems evident, consider these early Cretaceous species as the precursors of the present Lymnæid fauna. When we study the distribution of the early Paleozoic rocks we are at once struck with the fact that from no other American source could the fauna have originated. ${ }^{1}$ The larger part of the Paleozoic rocks are of marine origin, and cover the greater part of the American continent east of the Rocky Mountains. Mr. C. A. White makes the following statement concerning the condition of the continent when the non-marine fauna first appeared." "East of west longitude $95^{\circ}$ (the western part of the Mississippi Valley), North America is mainly occupied by Paleozoic and Archæan rocks, as is also a large area which extends northward and southward through western North America, the eastern border of which is not far from the 113th meridian of west longitude. These two great areas are

${ }^{1}$ Verrill (Amer. Journ. Sci., iii, V, p. 467) asserts that the land and freshwater fauna originated in America.

${ }^{2}$ See Walker, Report Mich. Acad. Sci., p. 52, 1900, and also the various papers of Mr. White, listed in the bibliography appended to the chapter on Distribution in Time. 
taken to represent approximately the outline and extent of the principal portions of the North American continent that were above the level of the sea at the beginning of the Mesozoic time. A broad expanse of Mesozoic sea then stretched between these two continental factors, which were finally united by a general continental elevation and the consequent recedence of the sea. This elevation was not, properly speaking, catastrophal, but gradual and oscillatory."

Just how this dispersal was brought about, it might, perhaps, be difficult to state with certainty. It may have been by means of driftwood, freshets or by some of the birds or mammals. Much of the widening of the range was doubtless accomplished by the ordinary and natural means of locomotion. As the continent was gradually lifted above the sea, the interior basin became a large inland sea, then a brackish lake and was finally broken up into the large salt lakes now found in the western United States, the larger part of the water draining off or evaporating as the land rose higher and higher. The many rivers and streams which drain the country have formed ready avenues for the almost universal dispersal of the Limnæid fauna.

While it is probable, if not certain, that the American Lymnæid fauna originated in the fresh waters of this ancient land, it is also true that there was an admixture of Asiatic types of Lymnæa, which reached this region during Mesozoic and Cenozoic time via the land connection between the two continents at Bering Sea. That the Rocky Mountains, which have proven such an effectual barrier to the eastward migration of the Asiatic Helicidæ $æ^{1}$ and Unionidæ ${ }^{2}$ were not so effectual in checking the later dispersal of the Lymnæas is evidenced by the presence of such species as Galba binneyi, Galba apicina, Galba palustris, Galba obrussa, Galba humilis modicella and Lymnea stagnalis appressa, on both sides of the Rocky Mountains. The discovery of a large fossil Lymnæa (L. stearnsi) of the stagnalis type in the Middle Miocene beds of Oregon seems to indicate that at least some of the Lymnæas accompanied the Asiatic Helicidæ and Unionidæ in their Mesozoic migration along the Pacific Coast. A number of species, such as Lymncea lepida, Polyrhytis utahensis, Galba gabbi, Galba bulimoides, Galba ferruginea, Galba proxima, Galba traskii, and Galba sumassi, have, however, failed to cross the continental divide, but these are not typically Asiatic, as is the case with the Unionidæ and Helicidæ mentioned, but have apparently descended from some American ancestors. The truly Asiatic species, such as palustris and stag-

'Pilsbry, Guide to Study of Helices, p. XLIII, 1894.

${ }^{2}$ Walker, Proc. Mal. Soc., IX, p. $129,1910$. 
nalis have broken over every barrier and are widely distributed over the continent.

The northeastern Greenland-Iceland connection, so ably advocated by Dr. Scharff, does not appear to have been made use of by the Lymnæas, the characteristic European species stagnalis and palustris being absent from Greenland and northeastern America. A fact that bears strongly against the use of this land connection is the discovery, made by Mörch many years ago, that the Lymnæas of Greenland are related to the American fauna, while those of Iceland are related to the European fauna. The species vahlii and vahlii pingelii are found from Greenland to Alaska, which distribution seems to prove an Asiatic rather than an European origin.

The following table of comparative distribution seems to support the Asiatic origin of the circumboreal forms, The absence of any indication of the common species stagnalis or palustris in either Greenland or Iceland, especially as the former is not believed to have been rendered more uninhabitable along the coast than at the present time (in which case there should have been survivors of the fauna) is ample evidence that the fresh-water pulmonates migrated eastward across Europe and Siberia and entered America by way of the Bering Sea land connection, which has been available many times since Lower Cretaceous (Comanchean) time.

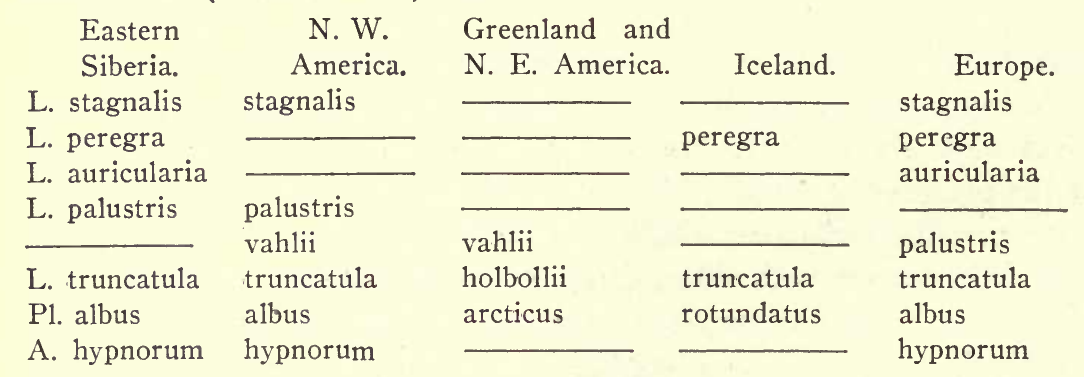

There have evidently been several Asiatic invasions in which some of the species accompanied the Helices and Uniones down the Pacific Coast, while other species, possibly at a later time, when there was a land connection between the two continental masses, migrated toward the southeast and into the central plains area.

The great Glacial Epoch, which occurred near the close of the Tertiary Period, has greatly influenced the present distribution of the fresh-water pulmonate Mollusca. The vast sheet of ice which covered the North American continent as far south as southern Illinois, Indiana and Ohio to the east and the extreme northern part of the United 
States to the west, absolutely destroyed all life north of the above limits. As the ice sheet receded, the remnants of the Lymnæid fauna again advanced and took possession of the newly formed lakes and rivers. That the preglacial Lymnæid fauna was nearly identical with that of the present fauna we believe from evidence afforded by the identity of fossils of interglacial ${ }^{1}$ and post-glacial deposits with the existing fauna. The question of the means by which the present Lymnæid fauna has become so widely distributed need not enter largely, however, into the present discussion, since its purpose is mainly to consider the present distribution of North American Lymnæas, drawing from this study any useful or interesting inferences which may present themselves.

The methods by which the Lymnæas have become so widely distributed are probably many and diverse. We know that they are carried by floods for great distances, attached to drift wood and to other objects, and the boats which ply up and down our rivers have doubtless helped to disperse these mollusks. The Erie Canal, in New York, is known to have been the highway for the dispersal of many mollusks. The veteran conchologist, Dr. Lewis, has stated on several occasions his belief that the transfer of species of Lymnæa from the canal to the rivers of New York state has produced some of the species of this genus (c. f. elodes and catascopium). While the author cannot agree with this theory, he still knows that Lymnæas and other fresh-water mollusks have been carried from one part of the canal to another by means of the canal boat, on several occasions mollusks having been observed clinging to the sides of these freighters. Water birds, especially ducks, are known to carry mollusks from one place to another, attached to their feet or some other part of the body; it is even recorded $^{2}$ that the eggs of Radix auricularia have passed through the digestive system of a swan without injury.

Various zoologists have divided the North American continent into zoögeographic regions, based on the distribution of the different species in latitude. Some early writers designated the country north of Mexico as the Nearctic region. Other authors have given the name Holarctic to the region including North America, Europe, northern Asia and Africa. Still others divide it into Arctic, Nearctic and Neotropical (see H. Jordan, 1883). While it is true that the fauna of this region is more or less uniform, it is also true that there are reasons

1See Coleman for a discussion of these deposits. Lymnæas recently discovered in deposits formed during the early stages of glacial lake Chicago are for the most part identical with recent species. (Science n. s., XXXI, p. 715.)

${ }^{2}$ Pascal, Journ. de Conch., XXXI, p. 9, 1891. 
for dividing this large area into a number of smaller ones. Thus, Binney ${ }^{1}$ divides North America into three major regions, I-The Pacific Province; II-The Central Province; and III-The Eastern Province, the latter being subdivided into (a) The Northern Region, (b) The Interior Region, and (c) The Southern Region. Simpson ${ }^{2}$ divides the area under consideration into the Palæarctic Region, west of the Rocky Mountains, the Mississippi Region, including the whole of the continent between the Rocky Mountains and the $80^{\circ}$ of longitude, the Atlantic Region, lying east of the $80^{\circ}$ of longitude and the Central American Region, including Mexico and Central America east of the Sierra Madre range.

Dr. C. Hart Merriam ${ }^{3}$ has divided the North American continent into life zones and this seems to be one of the best attempts which has thus far been made to divide this region into subregions. While this subdivision is admirably adapted for the mapping of some land forms, it is totally inadequate for the proper study of such aquatic forms as the Lymnæas, a single species of which may be equally distributed throughout the Boreal, Transition, Upper Austral and Lower Austral life zones. As Pilsbry has recently stated" "Transcontinental 'lifezones' have no necessary connection with the larger facts of faunal distribution, but define secondary divisions, parallel, so to speak, all over the world. For instance equal zones in the southern Alleghanies and Rocky Mountains might be spoken of as 'physically homologous,' but not faunally so." The distribution of the Lymnæid fauna of North America strongly substantiates Dr. Pilsbry's statement.

The geographic study of the Lymnæas has shown that an adequate and understandable division can be obtained only by a comparison of the different river systems, as has been suggested by Dr. Dall. ${ }^{5}$ The area under consideration has, therefore, been divided into regions embracing the natural drainage areas separated by divides. These may be characterized as follows (figure 1$){ }^{6}$

1. Labradorian. This region includes all of the drainage areas emptying into Ungava Bay and the Atlantic Ocean north of the Strait of Belle Isle. It includes the eastern part of Ungava, the extreme eastern end of Quebec, and the whole of Labrador.

${ }^{1}$ Man. Amer. Land Shells, Bull. U. S. Nat. Mus. No. 28, p. 18.

${ }^{2}$ Proc. Nat. Mus., XVIII, pl. 9; XXII, pl. 18.

${ }^{8}$ See North American Fauna No. 3, 1890; Bull. No. 10, Division Biol. Surv., 1898 ; A. O. U. check-list, 1910

'Proc. Phil. Acad., 1906, p. 530.

${ }^{5}$ Alaska Mollusks, p. 1; Popular Science Monthly, Vol. LXVI, p. 362.

${ }^{6}$ The majority of the northern regions are the same as those proposed by Dr. Dall, op. cit. 


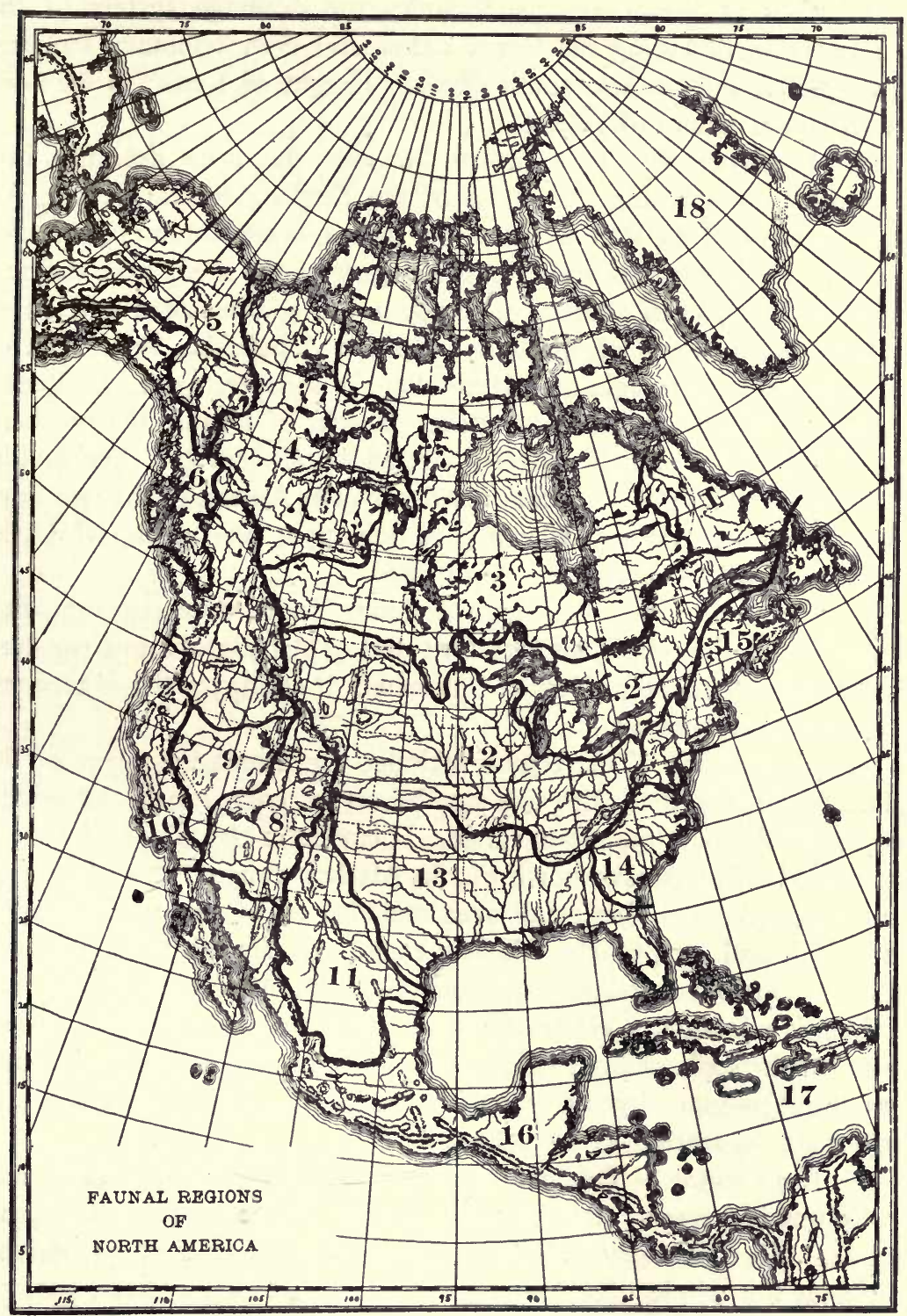

FIG. 1.

Map of North America showing faunal regions. 1, Labradorian; 2, Canadian ; 3, Hudsonian ; 4, Mackenzian ; 5, Yukonian; 6, Alaskan; 7, Columbian ; 8, Coloradoan; 9, Great Basin; 10, Californian; 11, Rio Grandian; 12, Upper Mississippian; 13, Lower Mississippian; 14, Carolinian; 15, Nova Scotian; 16, Central American; 17, West Indian; 18, Greenlandian. 
2. Canadian. This area includes the drainage system of the St. Lawrence, including the Great Lakes and their tributary streams. All of Quebec and Ontario south of the "Height of Land" is included as well as the Island of Anticosti.

3. Hudsonian. This region includes the area draining into Hudson Bay, embracing the basins of the English, Saskatchewan, A1bany, Severn and the Red River of the North, besides numerous minor streams. This territory, which is the largest of the areas here defined, embraces the western portion of Ungava, the southeastern portion of Mackenzie, the whole of Keewatin, eastern Athabaska, the whole of Saskatchewan, Assiniboia and Manitoba, the southern part of Alberta, Ontario and Quebec northwest of the "Height of Land," the northern part of Minnesota and the eastern part of North Dakota. The divide, known as the "Height of Land" divides North America into two huge areas, the rivers in the northern part flowing to the north, while the rivers south of this divide flow southward.

4. Mackenzian. This area includes the greater part of Mackenzie district, the central and western part of Athabaska, northwestern Alberta and northeastern British Columbia. It embraces the Mackenzie River and its tributaries.

5. Yukonian. This region includes the drainage system of the Yukon River, together with the smaller rivers lying north and northwest of the Alaskan mountain range. It embraces the whole of Yukon district and all of Alaska north of the Alaskan range.

6. Alaskan. This small area includes all of the coastal region lying south and west of the Alaskan range and the coast range as far south as Vancouver Island, and including the Alaska Peninsula and the Aleutian Islands. While this region is, as stated by Dall, closely related to the Columbian Region, its separation from that region and from the Yukonian by an extensive mountain chain would seem to warrant its separation as a regional division.

7. Columbian. This area includes the basins of the Fraser and the Columbia rivers, including the Snake River and its tributary streams. The territory embraces the southeastern part of British Columbia, the whole of Washington and Idaho, the western part of Montana and the eastern part of Oregon. The headwaters of tributary streams touch Wyoming and Nevada.

8. Coloradoan. This includes the entire drainage of the Colorado River, including the basin of the Gila River. Geographically it embraces the southern part of Nevada and Utah, the western parts of Colorado and New Mexico, the southwestern part of Wyoming, a 
part of southeastern California, the extreme northwestern part of Mexico and the whole of Arizona.

9. Great Basin. This includes the desert and arid regions of Nevada, Utah, Oregon and California. There is no outward drainage. A number of lakes occupy this basin, of which Great Salt Lake is the largest.

10. Californian. This area includes the coastal portions of Oregon and California, as well as that portion of the states west of the Sierra Nevada and Cascade ranges. The Sacramento and San Joaquin are the principal river systems. Its southern extension reaches the northern part of Lower California.

11. Rio Grandian. This includes the basins of the Rio Grande and the Pecos River, with their tributary streams. It embraces the southern part of Colorado, nearly the whole of New Mexico, the western part of Texas and the northern and central parts of Mexico drained by the tributaries of the Rio Grande. It includes the higher Mexican plateau.

12. Upper Mississippian. This area includes the territory drained by the upper Mississippi and Missouri rivers, including their tributary streams. It embraces the country south of the "Height of Land" in southern Canada and the Great Lakes, all of the territory between the Rocky Mountains on the west and the Appalachian Mountains on the east, and north of about the 35th parallel of north latitude. The drainage areas of the Arkansas and Tennessee rivers form the southern boundary of this area, and the line of the water partings varies from the 35 th to the 38 th parallels. The Ozark Mountains also. mark the southern limits of a portion of this region.

13. Lower Mississippian. This includes the region south of the Arkansas and Tennessee rivers. Its western limit is the Great Plains east of the Rio Grande drainage. Its eastern limit is somewhat indefinite, but would seem (judging by the distribution of certain Lymnæas) to be north of the St. Johns River in Florida, where a line drawn northward to the Appalachian range would separate the Lower Mississippian from the Carolinian region. This region embraces the lower drainage areas of the Mississippi River as well as all of the rivers flowing into the Gulf of Mexico, east of the Rio Grande. It includes also the entire peninsula of Florida.

14. Carolinian. This area includes all of the coastal strip east of the Appalachian range from southern New Jersey south to the St. Johns River, Florida. The drainage is into the Atlantic Ocean. Its northern limit is marked by the Potomac River, whence the line of 
demarcation extends northward across Maryland, including Delaware and New Jersey south of the 40th parallel.

15. Nova Scotian. This area includes the greater part of the New England states, the southeastern portion of New York, the eastcentral portion of Pennsylvania, northern New Jersey, Virginia, the greater part of Maryland, the whole of Nova Scotia, New Brunswick, and probably Newfoundland. The drainage is into the Atlantic Ocean. Its southern limit is the Potomac River and the 40th parallel in New Jersey.

16. Central American. This includes all of Central America from the Isthmus of Panama northward. It embraces all of Mexico excepting the higher tableland, including Lower California, taking in both the Pacific and Gulf coasts. The drainage is into the Pacific Ocean on the west and into the Gulf of Mexico and the Caribbean Sea on the east. It is possible that this area should be further subdivided, but too little is known of its aquatic pulmonate fauna to warrant such a course at present.

1\%. West Indian. For the present purpose the islands of the West Indies may constitute a single province, the Lymnæid fauna, so far as recorded, being apparently the same in the different islands.

18. Greenlandian. Little is definitely known concerning the distribution of the Lymnæas in the region known as Baffin Land, and the relation of this territory faunally to Greenland; whatever this relation may be ascertained to be, it seems advisable to institute a faunal region for Greenland, at least. 
The comparative distribution of American Lymnæas is shown in the following table:

TABLE OF DISTRIBUTION OF AMERICAN LYMN ÆAS.

stagnalis $\ldots \ldots \ldots \ldots$

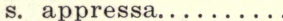

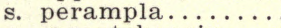

s. wasatchensis....

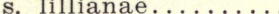

sanctaemariae ....

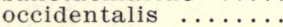

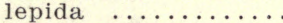

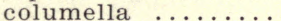

c. chalybea........

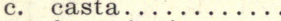

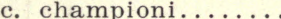

francisca .........

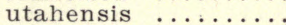

megasoma ........

haldemani ........

truncatula ........

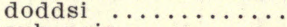

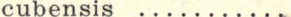

c. barbadensis......

bulimoides

b. techella

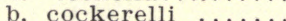

b. cassi...........

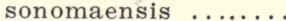

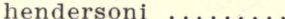

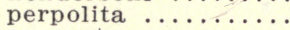

caperata

umbilicata ........

cyclostoma .......

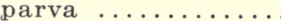

p. sterkii..........

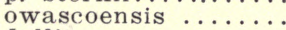

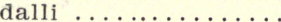

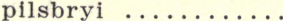

humilis $\ldots \ldots \ldots \ldots$

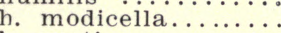

h. rustica.........

ferruginea ........

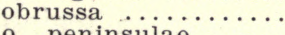

o. peninsulae......

o. exigua .........

o. decampi .........

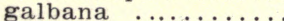

petoskeyensis .....

palustris .........

p. alpenensis.......

p. desidiosa.........

p. blatchleyi.......

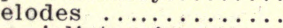

e. jolietensis.......

e. shurtleffi.........

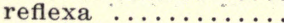

r. walkeri.........

r. hemphilliana....

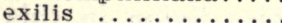

kirtlandiana $\ldots \ldots \ldots$

lanceata

attenuata

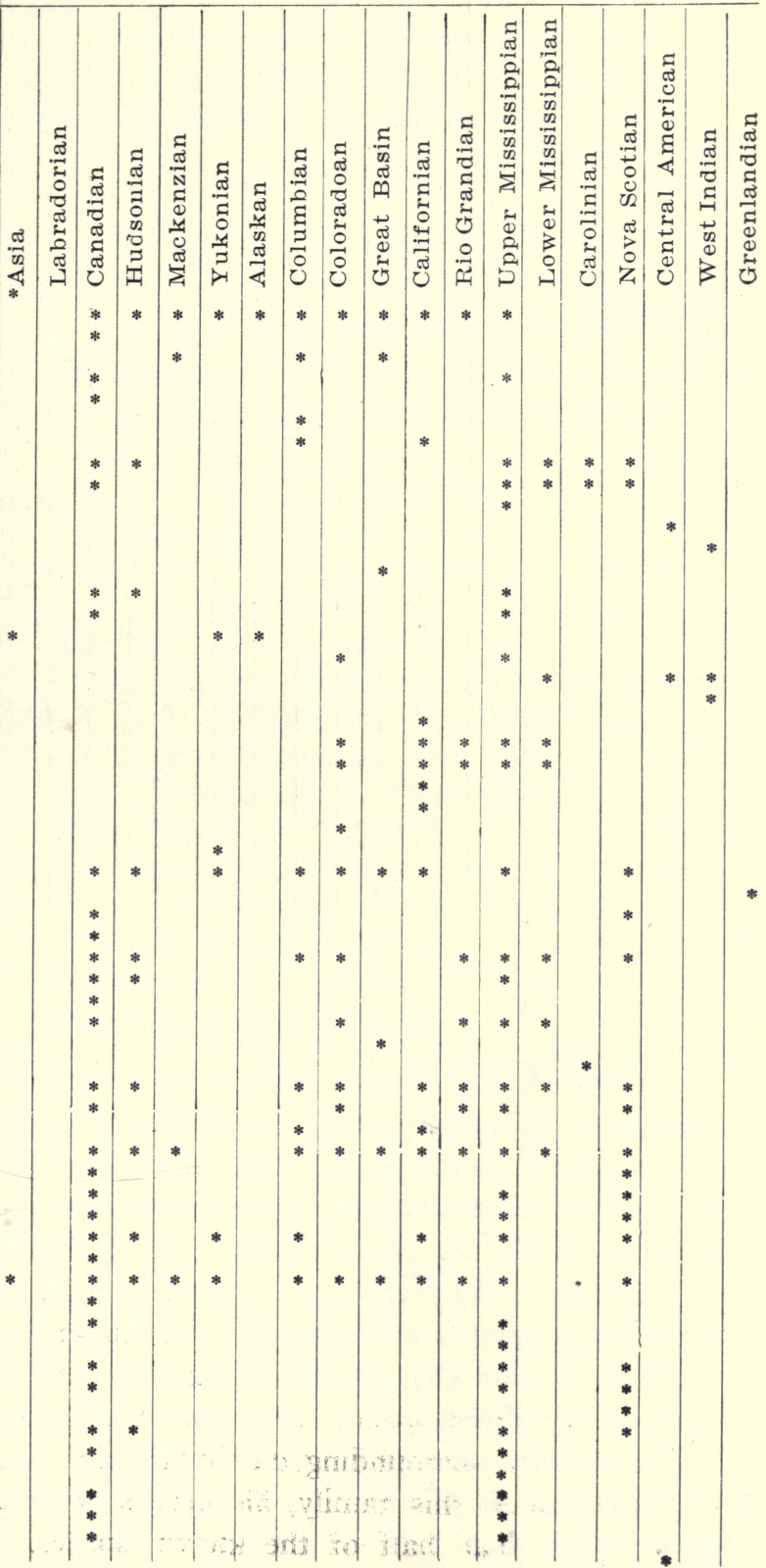




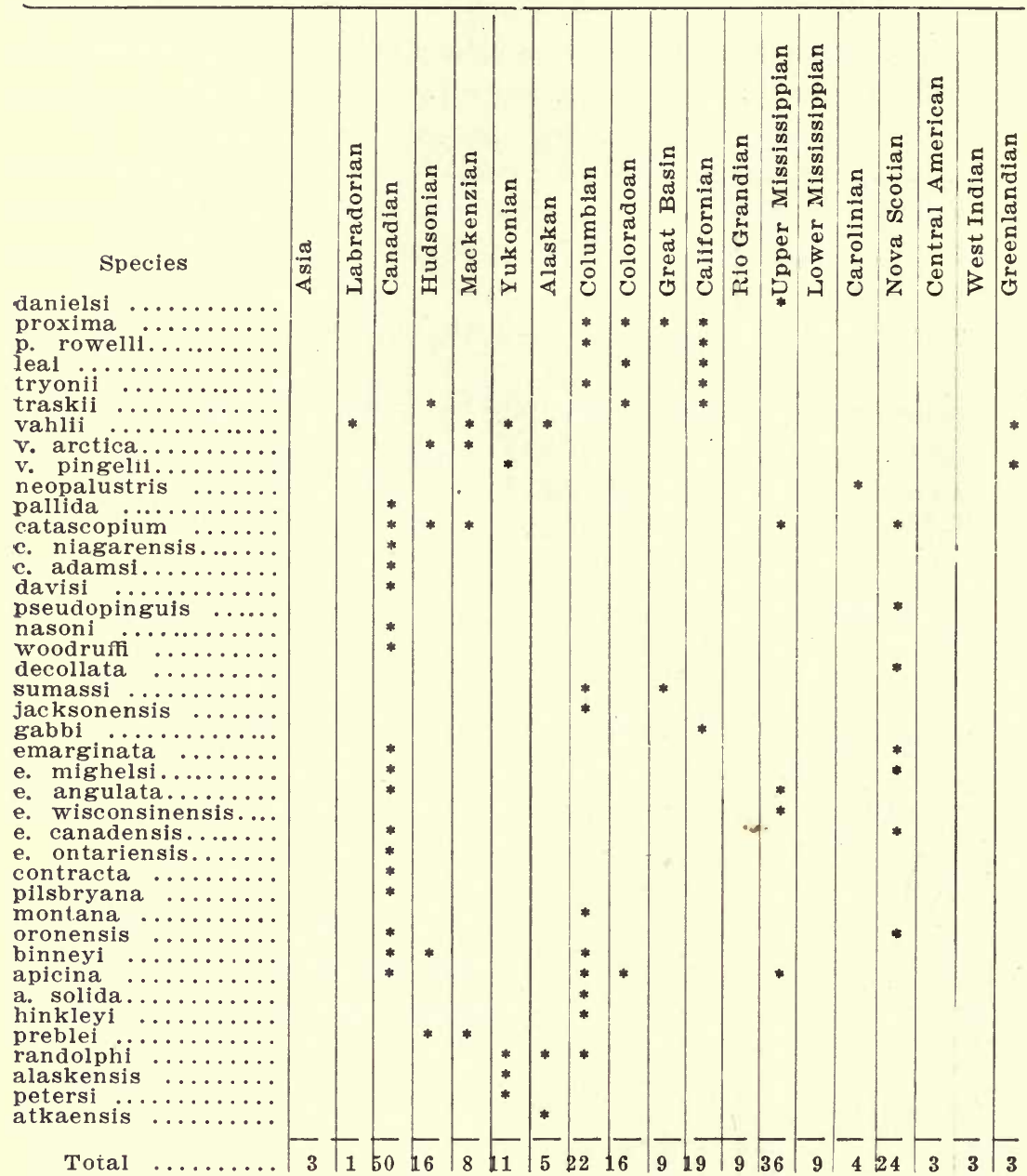

The above total reveals certain interesting facts. The Canadian region is the best represented, containing 50 species and varieties, or nearly one-half of the total fauna. The Upper Mississippian region is next in representation, 36 species and varieties being known. The Columbian (22), the Nova Scotian (24), the Californian (19) and the Hudsonian (16) regions also contain a high percentage of species. The poorly populated areas are the Carolinian (4), Central American (3), West Indian (3), Greenlandian (3) and the Labradorian (1) regions. Only three species are common to America and Asia.

The country surrounding the Great Lakes is at present the center of distribution of this family, 55 species and varieties living in this area, or more than half of the known species. Several species are 
universally distributed over the greater part of North America north of the $38^{\circ}$ of north latitude. These are shown in the subjoined table:

stagnalis appressa....... distributed throughout ten regions.

caperata ............ distributed throughout eight regions.

obrussa ............. distributed throughout eleven regions.

galbana .............. distributed throughout seven regions.

palustris ............ distributed throughout eleven regions.

Three species are universally distributed between the $30^{\circ}$ and $50^{\circ}$ of north latitude.

parva .............. distributed throughout seven regions.

humilis modicella....... distributed throughout nine regions.

obrussa .............. distributed throughout nine regions.

A number of species are peculiar to certain regions to which they are at present restricted. These are shown in the following tables:

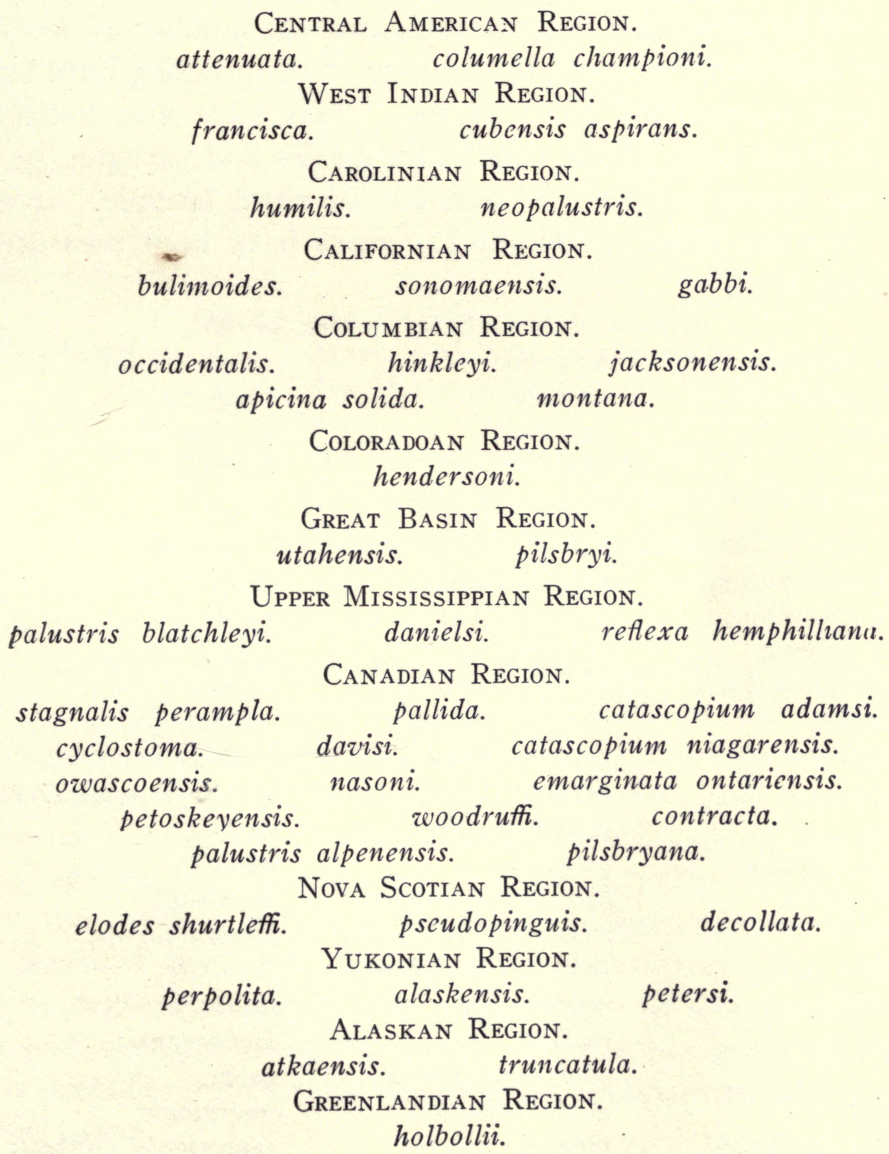


Of the above regions, the Canadian has produced the largest number of species (14). The Greenlandian region has but one peculiar species, and the West Indian, Carolinian and Alaskan regions have but two species peculiar to their areas.

A study of the distribution maps reveals certain interesting facts regarding the present dispersal of North American Lymnæas. The largest number of species is found between the 38 th and the 60 th degrees of north latitude. North and south of these parallels the number of species notably decrease.

TABLE SHOWING DISTRIBUTION IN LATITUDE.

Species and varieties north of $60^{\circ} \ldots \ldots \ldots \ldots \ldots \ldots \ldots$

Species and varieties between $38^{\circ}$ and $60^{\circ} \ldots \ldots \ldots \ldots \ldots$

Species and varieties south of $38^{\circ} \ldots \ldots \ldots \ldots \ldots \ldots \ldots 29$

Species and varieties south of $30^{\circ} \ldots \ldots \ldots \ldots \ldots \ldots \ldots \ldots$

Species and varieties south of $20^{\circ} \ldots \ldots \ldots \ldots \ldots \ldots \ldots \ldots$

It will be noted in the above table that the number of species first increases and then decreases, the number steadily falling until but three species are represented south of $20^{\circ}$. This table also indicates the northern distribution of the family, 85 species and varieties, or 85 per cent being found between $38^{\circ}$ and $60^{\circ}$ of north latitude. It is noteworthy that but three species of Lymnæas have been recorded from the tropical zone.

stagnalis appressa.

stagnalis wasatchensis.

truncatula.

perpolita.

stagnalis appressa.

stagnalis perampla.

stagnalis lilliana.

stagnalis wasatchensis.

sanctemarice.

occidentalis.

lepida.

columella.

columella chalybea.

columella casta.

utahensis.

megasoma.

haldemani.

truncatula.

doddsi.

bulimoides.

bulimoides cockerelli.
SPECIFS AND VARIETIES NORTH OF $60^{\circ}$.

holbollii.

obrussa.

palustris.

vahlii.

vahlii pingelli.

vahlii arctica.

randolphi.

alaskensis.

petersi.

SPECIES AND VARIETIES BETWEEN $38^{\circ}$ AND $60^{\circ}$.

humilis rustica.

ferruginea.

obrussa.

obrussa peninsula.

obrussa exigua.

obrussa decampi

galbana.

petoskeyensis.

palustris.

palustris alpenensis.

palustris blatchleyi.

palustris desidiosa.

neopalustris.

elodes.

elodes jolietensis.

elodes shurtleffi.

reflexa. traskii.

vahlii.

vahlii arctica.

pallida.

catascopium.

catascopium adamsi.

catascopium niagarensis.

davisi.

nasoni.

woodruffi.

pseudopinguis.

decollata.

sumassi.

jacksonensis.

gabbi.

emarginata.

emarginata mighelsi. 
sonomansis.

hendersoni.

caperata.

umbilicata.

cyclostoma.

parva.

parva sterkii.

owascoensis.

dalli.

pilsbryi.

humilis.

humilis modicella. reflexa walkeri.

reflexa hemphilliana.

exilis.

kirtlandiana.

danielsi.

proxima.

proxima rowelli.

leai.

tryonii. emarginata angulata.

emarginata wisconsinensis.

cmarginata canadensis.

emarginata ontariensis.

contracta.

pilsbryana.

montana.

oronensis.

binneyi.

apicina.

apicina solida.

hinkleyi.

randolphi.

SPECIES AND VARIETIES SOUTH OF $38^{\circ}$.

bulimoides cassi. obrussa exigua.

caperata.

parva.

parva sterkii.

dalli.

humilis.

humilis modicella.

ferruginea.

obrussa. galbana.

palustris.

proxima.

proxima rowelli.

tryonii.

leai.

traskii.

gabbii.

bulimoides.

bulimoides techella.

bulimoides cockerelli.

SPECIES AND VARIETIES SOUTH OF $30^{\circ}$.

columella championi.

cubensis.

francisca.

cubensis aspirans.

attenuata.

bulimoides techella.

obrussa.

SPECIES AND VARIETIES SOUTH OF $20^{\circ}$.

cubensis. cubensis aspirans.

columella championi.

The 105 th degree of west longitude (exclusive of Mexico, Central America and the West Indies) may be taken roughly as a dividing line between a western and an eastern Lymnæid fauna. As a matter of fact, the $105^{\circ}$ marks the eastern boundary of this faunal region from the 35 th to the 42 nd parallel, from whence the boundary is marked by the Rocky Mountain Chain, which extends northwesterly through British America and Alaska. 44 species and varieties have. been recorded west, and 70 species and varieties east of this dividing line. 17 species and varieties are common to both. 26 are thus peculiar to the western, and 53 to the eastern region. In the Mississippi Valley south of the 42 nd parallel, the region between the 100 th and the 105th degrees is almost void of members of this family, only 9 species and varieties being recorded. This is the great plains area, which is probably unfavorable to the usual luxuriant development of a Lymnæid fauna. 


\section{SPECIES AND VARIETIES WEST OF $105^{\circ}$ LONGITUDE.}

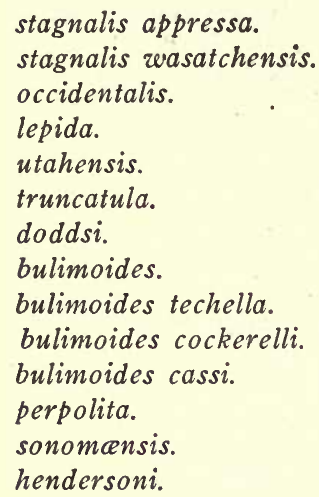

caperata.

parva.

dalli.

pilsbryi.

humilis modicella.

humilis rustica.

ferruginea.

obrussa.

galbana.

palustris.

proxima.

proxima rowelli.

leai.

tryonii.

traskii.

SPECIES AN.D VARIETIES EAST OF vahlii.

vahlii arctica.

vahlii pingclii.

sumassi.

jacksonensis.

gabbii.

montana.

binneyi.

apicina.

apicina solida.

hinkleyi.

randolphi.

alaskensis.

petersi.

atkaensis. stagnalis perampla.

stagnalis appressa.

stagnalis lilliana.

stagnalis wasatchensis.

sanctemaria.

columella.

columella chalybea.

columella casta.

megasoma.

haldemani.

cubensis.

bulimoides techella.

bulimoides cockerelli.

caperata.

holbollii.

umbilicata.

cyclostoma.

parva.

parva sterkii.

owascoensis.

dalli.

humilis.

humilis modicella. humilis rustica.

obrussa.

obrussa peninsula.

obrussa exigua.

obrussa decampi.

galbana.

petoskeyensis.

palustris.

palustris alpenensis. palustris blachleyi. palustris desidiosa. neopalustris.

elodes.

elodes jolietensis. elodes shurtlefi. reflexa.

reflexa walkeri. reflexa hemphilliana. exilis.

kirtlandiana.

lanceata.

\section{$105^{\circ}$ LONGITUDE.}

danielsi.

rahlii.

vahlii arctica.

vahlii pingelli.

neopalustris.

pallida.

catascopium.

catascopium adamsi.

catascopium niagarensis.

davisi.

pseudopinguis.

nasoni.

woodruffi.

decollata.

emarginata.

emarginata mighelsi.

emarginata angulata.

emarginata wisconsinensis.

emarginata canadensis.

emarginata ontariensis.

contracta.

pilsbryana.

oronensis.

binneyi.

apicina.

preblei.

SPECIES COMMON TO BOTH SIDES OF $100^{\circ}$ LONGITUDE.

stagnalis appressa.

stagnalis wasatchensis.

bulimoides techella.

bulimoides cockerelli. caperata.

parva.

dalli.

humilis modicella. vahlii.

vahlii arctica. vahlii pingelli.

binneyi. 
humilis rustica.

apicina.

obrussa.

galbana.

palustris.

It is noteworthy that the species living in tropical and semi-tropical regions are more uniform in size, shape and sculpture than are those species living in northern and colder climates, where variation is marked and apparently endless. The family is characteristic of boreal and temporate regions and the number of species grow less toward the warm climate of the south and the individuals become smaller:

\section{B. THE GLACIAL PERIOD.}

The Glacial Period, with its successive stages of extended glaciation, undoubtedly caused the absolute extinction of all molluscan life in that area occupied by the great ice sheet. The Lymnæid fauna must have been gradually driven south until it occupied the territory south of the Ohio and Missouri rivers (figure 2). A single ice sheet invaded the northern Mississippi Valley region as far south as southern Illinois, driving the Lymnæas into the lower Mississippi drainage. Just what effect the driftless area in Wisconsin may have had on the fauna is not known, but as it is believed that the ice failed to cover this region, which was several thousand square miles in extent, and as there must have been an abundance of water, it is not at all improbable that many of the species of Lymnæas may have retreated to this area and thus survived to aid in the repopulation of the north after the recession of the ice sheet.

Before considering the post-glacial dispersion of the Lymnæid fauna it would seem necessary to review briefly the fauna previous to the Glacial Period and note its derivation. It has been shown in the chapter on Distribution in Time that up to the Pliocene Period there existed a more or less varied Lymnæid fauna consisting of nearly all of the present generic types. Some of these types may have arisen independently, as they are found in both Europe, Asia and America; but a few of the types, as, for example, the typical Lymnæas represented by stagnalis, undoubtedly reached America by way of Asia, before the final separation of the two continents by Bering Strait. It will thus be seen that previous to the extended englaciation the Lymnæid type was quite fully developed, including, probably, a large number of species. It is also probable that the preglacial fauna was about as it is today, if we may judge from the few inter-glacial and post-glacial fossils obtained and from fossil remains found beyond the area of the drift. 
The process of the extinction and involuntary southward migration of life during the glacial period is thus graphically described by Dr. T. C. Chamberlin : ${ }^{1}$

"A distinguishing feature of the effects of the ice invasions on the life of the glacial period in northern latitudes was an enforced oscillatory migration in latitude. With every advance of the ice, the whole fauna and flora of the affected region was forced to migrate in front of it, or suffer extinction. The Arctic species immediately adjacent to the ice border crowded upon the sub-arctic forms next south of them, the sub-arctic forms crowded upon the cold-temperate forms, and these in turn upon the warm-temperate types, and so on. It is not unlikely that the limits of the tropical zones even were shifted, and the torrid belt appreciably constricted. With the succeeding deglaciation of the inter-glacial stages, a reversed migration followed. Present evidence seems to warrant the belief that five or six such toand-fro migrations were experienced in America and Europe, and that the southward and northward swing of these movements was several hundred miles in extent, in some cases perhaps one to two thousand miles. Some of the inter-glacial epochs saw a northward extension of mild-temperate forms greater than that of today, from which it is inferred that the inter-glacial climates were milder than the present, and hence that the ice-sheets were at least as much reduced as now. There is in this also ground for the inference that the northern tracts were at least as extensively peopled by plants and animals as they are today. This carries the conclusion that the migratory swing in these more pronounced cases was at least 2000 miles in North America, and more than 1000 miles in Europe. As indicated in the physical description, the geological evidences drawn from erosion, weathering, and organic accumulation warrant the belief that the inter-glacial intervals were long enough to permit a complete northern return, and the fossil evidence supports the conclusion that the climates were congenial enough to invite it.

"The forced migrations must, in their nature, have been peculiarly effective in bringing to bear a severe struggle for existence, and in calling into play the full resources of the plastic adaptation of the life. Forms previously specialized to meet local conditions were put to a most adverse test, for the invading ice forced every form within the glaciated area to move on, while the fringing zones of depressed temperature encircling each ice-sheet forced plant and animal life, even beyond the ice border, to seek new fields and new relations, both

${ }^{1}$ Geology, Vol. III, p. 485 . 
physical and organic. An incidental result of this wholesale migration was an unwonted commingling of plants and animals, for every aggressive form pushed forward in the van of the advancing zone, and hence came into new organic environment, while every laggard form fell behind, and was overtaken by the less reluctant migrants."

\section{POST-GLACIAL DISPERSAL.}

To understand the extent of the post-glacial dispersal of the Lymnæas and their reoccupancy of the territory from which they had been driven by the ice sheet, it will be necessary to bear in mind the condition of the North American continent at the end of the maximum extension of the ice sheet (figure 2). A study of the map shows that there were probably four main areas which could supply the biota for this purpose. These were: (1) that part of the United States lying south of Illinois and Ohio, west of the Alleghany Mountains, and of the Missouri River Valley, and east of the Rocky Mountains, including the lower drainage area of the Mississippi Valley and the adjacent prairies and plains; (2) an area south of British Columbia and Assiniboia, including Montana, Idaho and Washington and embracing the lipper drainage areas of the Missouri and the Columbia rivers; (3) the whole of northern and western Alaska, embracing the Yukon River $\checkmark$ alley, besides other smaller stream valleys; and (4) the driftless area in southern Wisconsin bordering the Mississippi River. A possible fifth region of survival is found in New Jersey and Pennsylvania east of the Appalachian chain, and south of New York. ${ }^{1}$

From these five centers, the Lymnæid fauna has been dispersed until at the present time there is scarcely a part of the glaciated territory which does not support one or more species of this interesting family. In fact, the metropolis of the family is in the territory immediately surrounding the Great Lakes, and from here the largest number of species has been recorded. (See page 62.)

In considering the routes by which the Lymnæas have reoccupied the englaciated territory, it must be remembered that, unlike the land forms, the post-glacial dispersal of which has been so ably discussed by Dr. C. C. Adams (Biol. Bull. IX, No. 1, 1905), the Lymnæas were more or less dependent upon the natural drainage of rivers and streams, although other agencies probably contributed to this means; but it is to the natural progress of locomotion that we must look for the spread-

1There is reason to believe that favorable conditions for the survival of many boreal mollusks existed in Greenland, Newfoundland, Anticosti and other places along the Atlantic coast, and also along the Pacific coast. (Vide Scharff,
1907, and Adams, 1905.) 


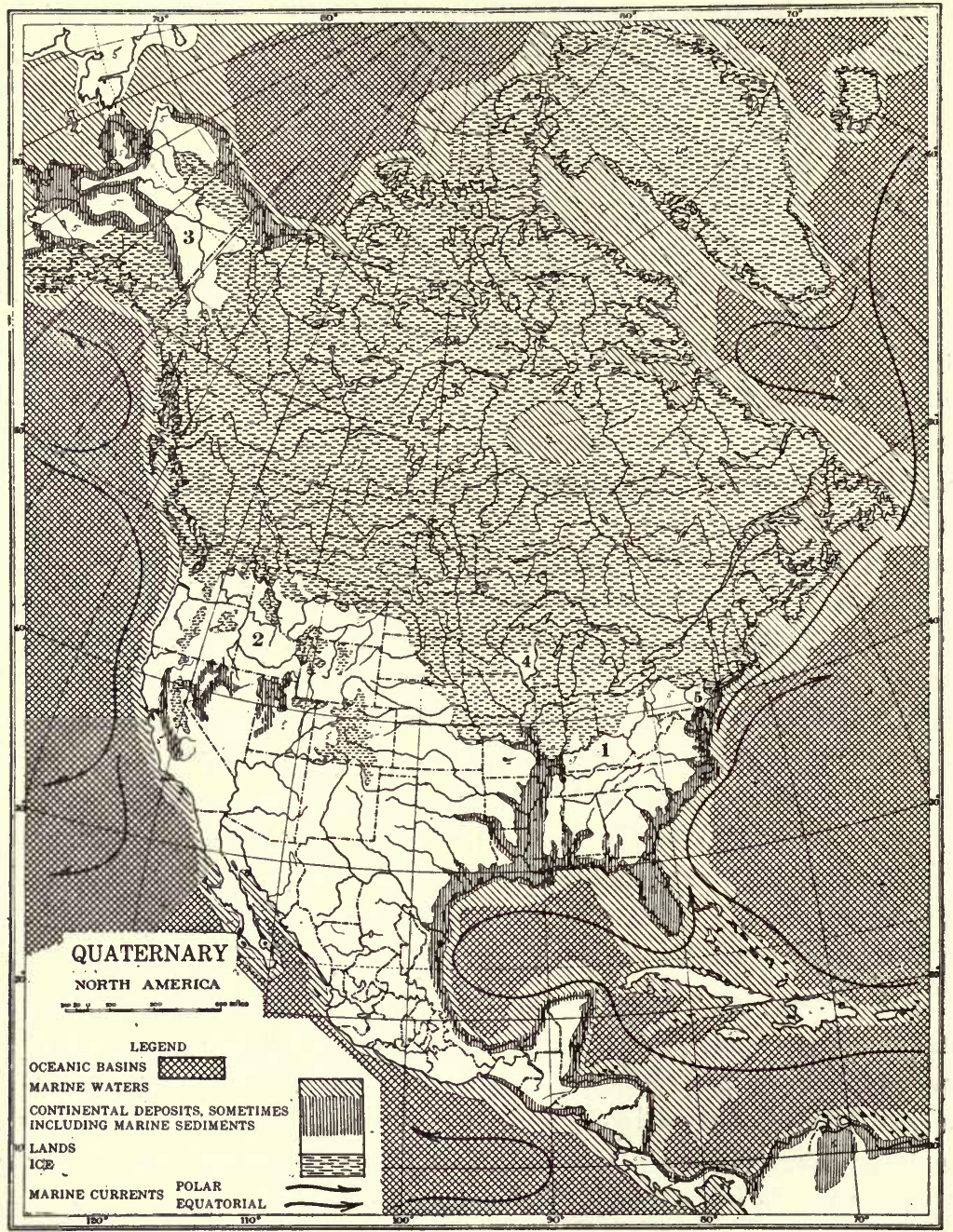

FIG. 2.

Map of North America showing maximum development of the ice sheet and indicating $(1,2,3,4,5)$ probable areas in which the life of the englaciated territory was preserved during the Ice Age. Willis, Journal of Geology, XVII, p. 601.

ing of the fauna over this immense territory. It must also be borne in mind that in the region immediately south of the ice sheet the faunas of several types of country were crowded together-arctic, subarctic, temperate- and as the ice receded, the mirgation northward was in the reverse order of the southward migration, the arctic forms following 
the ice closely, the subarctic forms following as conditions became favorable, and the more temperate fauna occupying the area near the edge of and a little to the north of the maximum extension of the ice cap.

Briefly considered, the dispersal of the family from the four areas outlined above was doubtless about as follows:

(1) As the ice receded in the Mississippi Valley (figure 3), several large bodies of water were formed which drained into the Mississippi

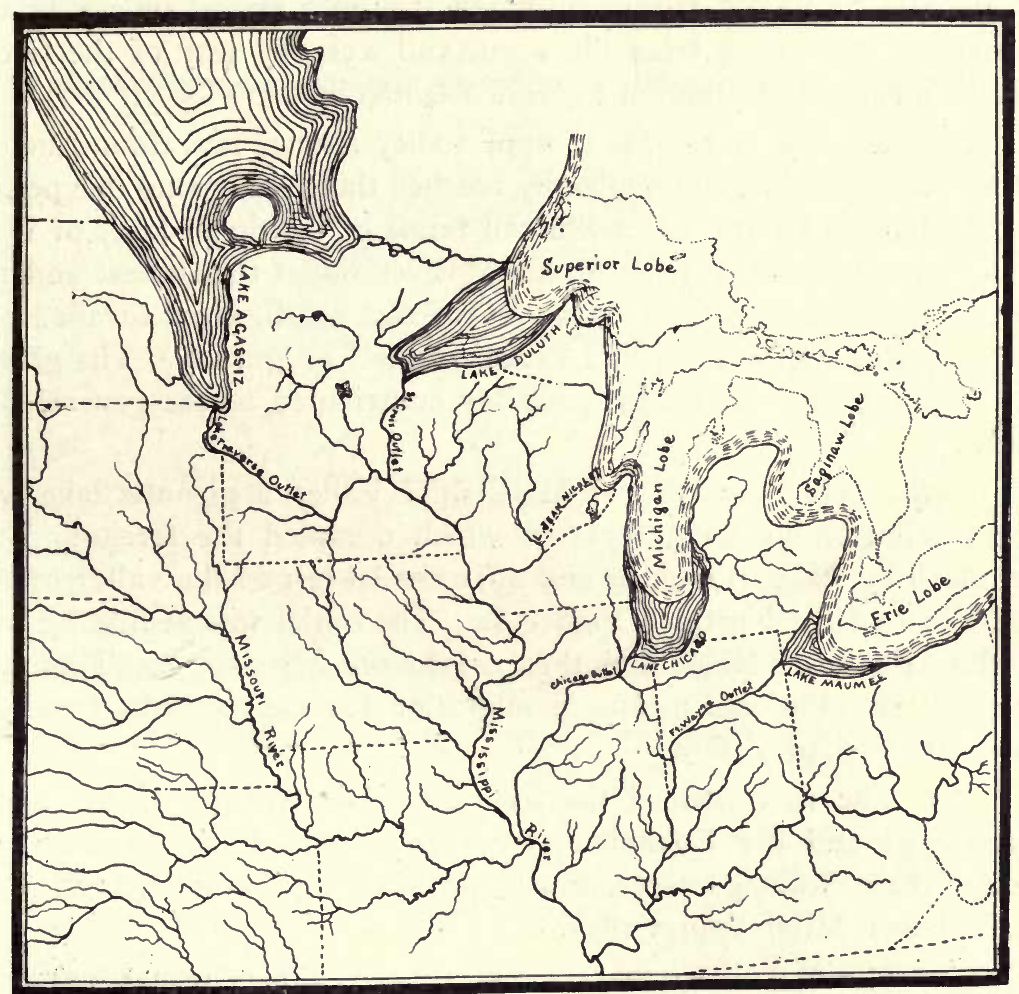

FIG. 3.

Glacial Lakes in Upper Mississippi Valley, showing early outlets into Mississippi River. The Glacial Lake Agassiz is shown at a later stage than lakes Duluth, Chicago and Maumee. (Compiled from Leverett and Upham.)

River-one at the west end of Lake Erie, draining through the Maumee and Wabash rivers; one at the southern end of Lake Michigan, draining through the Desplaines and Illinois rivers; and one at the west end of Lake Superior, draining through the. St. Croix River. A small lake (Jean Nicolet) is believed to have formed southwest of Green Bay, 
draining by way of the Wisconsin River. These drainage areas formed a natural means of migration for the mollusks, several of which continued until the Mohawk and St. Lawrence outlets were opened. The connection between Lake Chicago and Lake Saginaw contributed not a little to the eastward dispersal of the Lymnæas.

A small area of dispersal possibly existed in the northern part of Pennsylvania in the headwaters of the Genesee River; the Alleghany River was probably used as an avenue for the northeasterly dispersal of Mississippi Valley forms, although the inter-glacial invasions are believed to have been from the north and west, by way of the Great Lakes, during the formation to Lake Algonquin. ${ }^{1}$

The majority of the Mississippi Valley species now found in the St. Lawrence drainage undoubtedly reached this area during this period and established the present molluscan fauna of the finger lakes of New York, from whence, via the Mohawk River outlet to the east and the Chemung-Susquehanna River outlet to the south, they invaded the eastern part of New York and Pennsylvania. ${ }^{2}$ (Figure 4.) The glacial lake Passaic, in New Jersey, probably contributed to the general dispersal.

In the upper part of the Mississippi Valley a gigantic lake was formed, known as Lake Agassiz, which occupied the territory now embraced by Lake Winnipeg and adjacent lakes and the valley of the Red River of the North. (Figure 3.) The outlet was at first by way of the Minnesota River and thence into the Mississippi. This lake provided an additional means of migration for the mollusks from the lower Mississippi Valley. ${ }^{3}$

(2) The recession of the ice opened the valleys of the upper Mississippi and the Columbia rivers and enabled the Lymnæas to occupy these drainage areas, thus supplementing the work carried on in the lower Mississippi Valley.

(3) The Yukon River probably afforded the principal means of dispersal from Alaska, from which area a large part of the region lying west of the Canadian Rocky Mountains was doubtless supplied.

(4) The driftless area in Wisconsin undoubtedly contributed to some extent in re-establishing the molluscan fauna in the englaciated territory. This area was doubtless like that immediately south of the ice invasion, and the ice-bordered lakes and the numerous streams

'See Coleman, Maury, etc., op. cit.

${ }^{2}$ See Fairchild, Glacial Waters in Central New York, plate 35, etc.

'See Upham, Glacial Lake Agassiz, Mon. XXV, U. S. Geol. Surv. 
doubtless afforded ample havens for the mollusks which were driven from the frozen territory. ${ }^{3}$

To adequately understand the rapidity with which the newly opened territory was occupied by the Lymnæas, it must be borne in mind that these mollusks are able to withstand a very low temperature. Many of the species today live in ice-cold water and may be collected in ponds and streams when the surface of the water is frozen over. They were thus enabled to follow the retreating ice very closely and so to quickly occupy the new territory as it became available. This

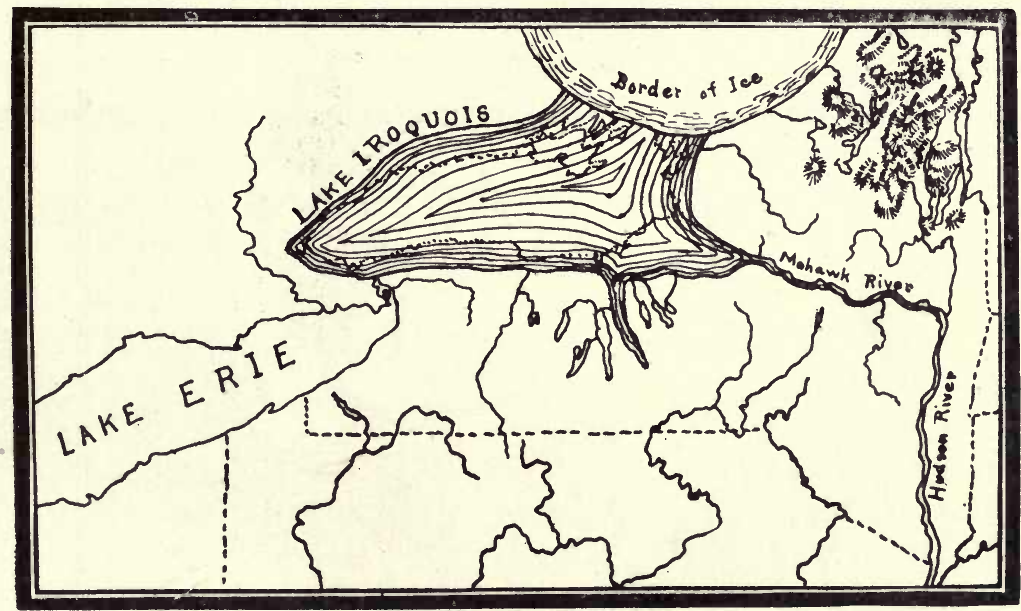

FIG. 4. Geol. Surv.)

Glacial Lake Iroquois showing Mohawk River outlet. (After Gilbert, U. S

is clearly indicated by the discovery of the remains of Lymnæas, as well as of other boreal mollusks, in various inter-glacial deposits, as at Cayuga Lake $^{1}$ and in the Don Valley at Toronto. ${ }^{2}$ As there is believed to have been a period between each ice sheet, during which time there was a comparatively mild climate, it is to be supposed that the Lymnæas migrated into this territory, which they occupied at each successive inter-glacial period.

TERTIARY LAKES OF THE GREAT basin. Figures 2 and 5 .

During the Glacial Period the western area known as the Great Basin again developed several large lakes, the largest known as Lake Bonneville, attaining a maximum depth of 1000 feet and an area of

${ }^{3}$ See Chamberlain, Geol. of Wis., Vol. 1, plates 9 and 10.

'Maury, Journ. Geol. XVI, p. 565, 1908.

${ }^{2}$ Coleman, Interglacial Periods in Canada, 1906. Also, Journal Geol. IX, p. 285, 1901; Amer. Geol., XIII, p. 85, 1894 . 
19,000 square miles. The waters of this lake fluctuated in depth, finally becoming so high that an outlet was effected to the north into the Snake River. The western lake, Lake Lahontan, did not attain the size of

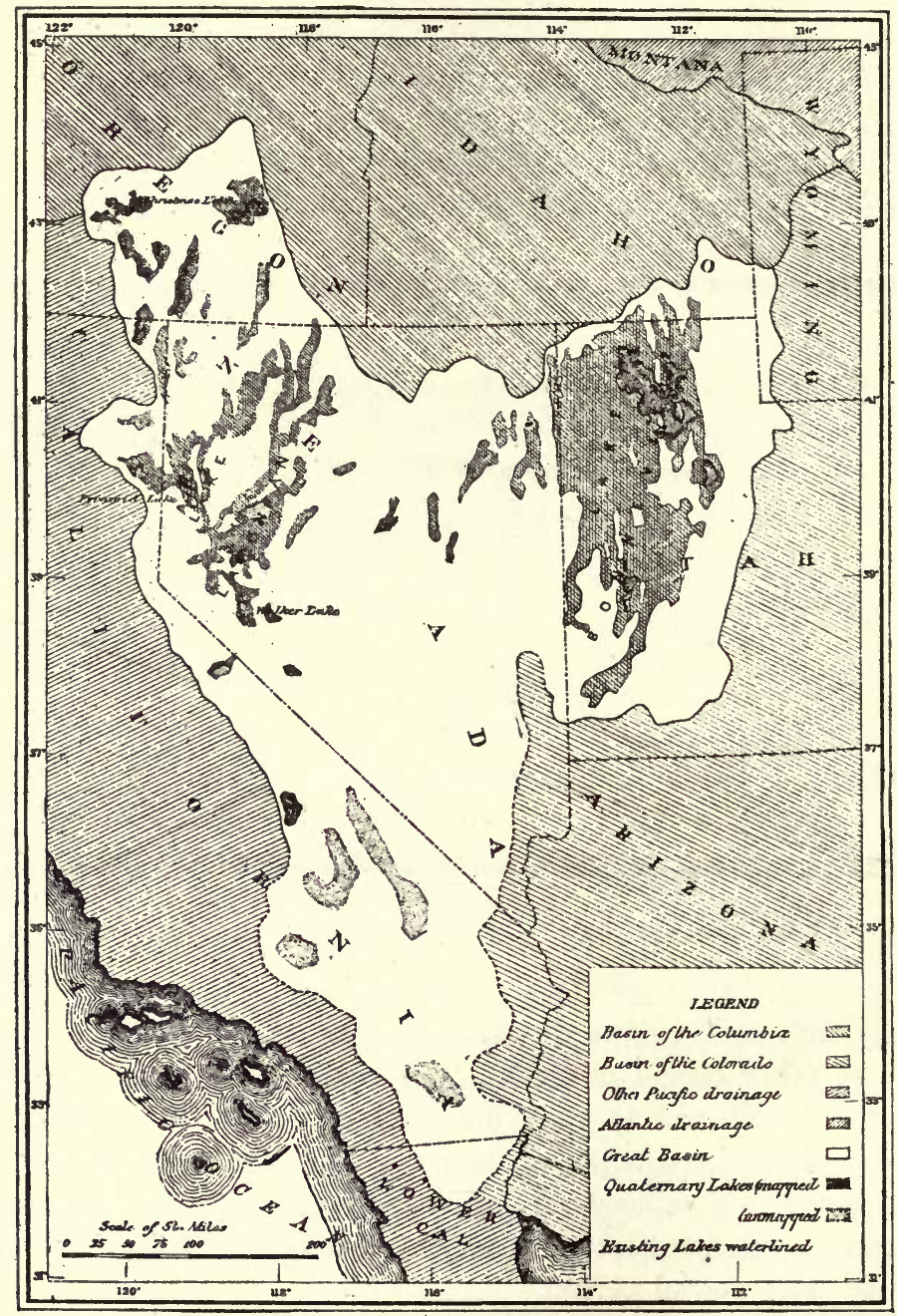

FIG. 5.

The Great Basin of Utah, showing Quaternary Lakes. Bull. U. S. Geol. Surv., No. 11, pl. 1.

Lake Bonneville (reaching an area only of 9000 square miles) and was without an outlet. Numerous smaller lakes also developed, most of which have long since disappeared. Great Salt Lake and Servier 
Lake are the descendants of Lake Bonneville, while Humboldt, Walker, Pyramid, Carson and other small lakes in western Nevada are the descendants of Lake Lahontan. ${ }^{3}$

How much of a factor these Quaternary Lakes may have been in providing a haven for the Lymnæas which were driven southward is not known. The connection with the Snake River might have provided a highway for the entrance into Lake Bonneville of such species. as stagnalis appressa, caperata, obrussa and palustris, which now occupy the area of the Great Basin. The streams of this area now have no outlet to the sea, but either flow into small lakes or are lost in the desert. The Great Basin, therefore, should be separated as a distinct. faunal region.

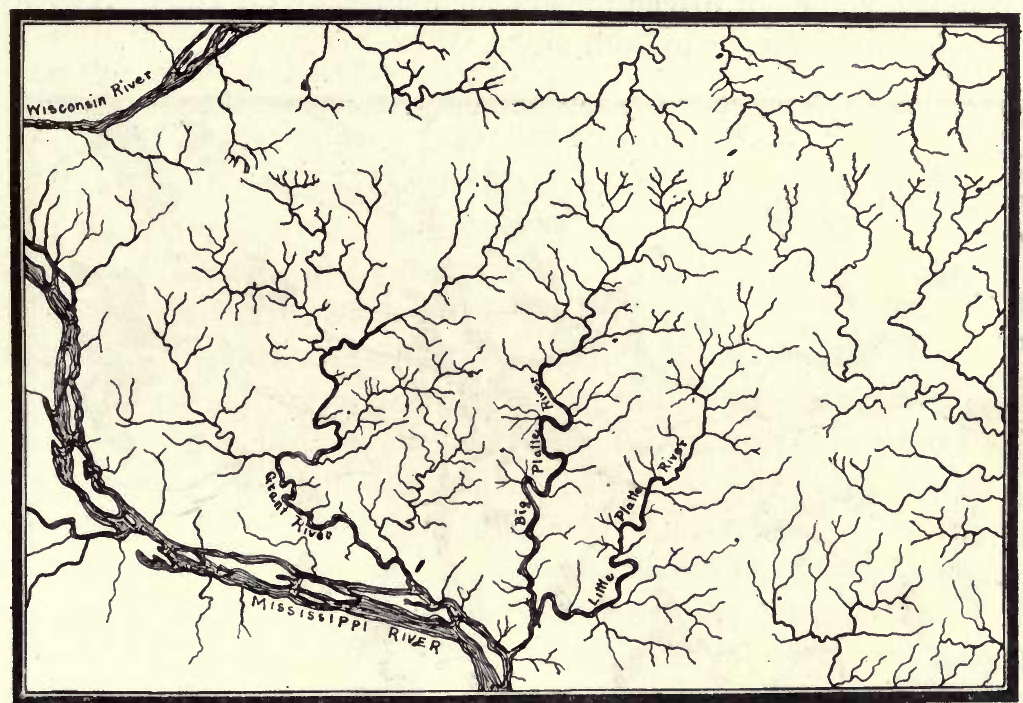

FIG. 6.

Portion of driftless area in Wisconsin, showing regular erosion in typicall unglaciated country. (From map published by Geological Survey of Wisconsin.)

EFFECT OF THE GLACIAL PERIOD ON THE I,YMN

The effect of the various ice invasions of the northern part of North America has been to produce a territory in which there are more lakes, large and small, than in all of the rest of the world combined. The Lymnæas are pre-eminently lake and pond inhabiting organisms and the habitats thus provided for them have been utilized

${ }^{8}$ See Chapter IV, page 82, for further discussion of this region; see also Monograph U. S. Geol. Surv. I, 1890. 
until scarcely a body of water in this area can be found which does not contain one or more species. The diversity of habitat thus formed has resulted in a considerable increase in the number of species since the Glacial Period. It is noteworthy that the glaciated territory now produces the larger number of species, and this numerical superiority is easily understood when the characteristics of the two regions-the glaciated and the unglaciated-are compared. The latter consists of regular river valleys and tributaries formed by simple erosion (figure 6 ), while the former is made up of rivers, lakes and swamps, forming a perfect network (figure 7 ). Comparison of the figures will render this statement clear. A comparison of the existing Lymnæid fauna shows that sixty species and varieties inhabit the glaciated ${ }^{1}$ portion of the country, while but fifteen inhabit the unglaciated portion. Twentysix species are common to both areas.

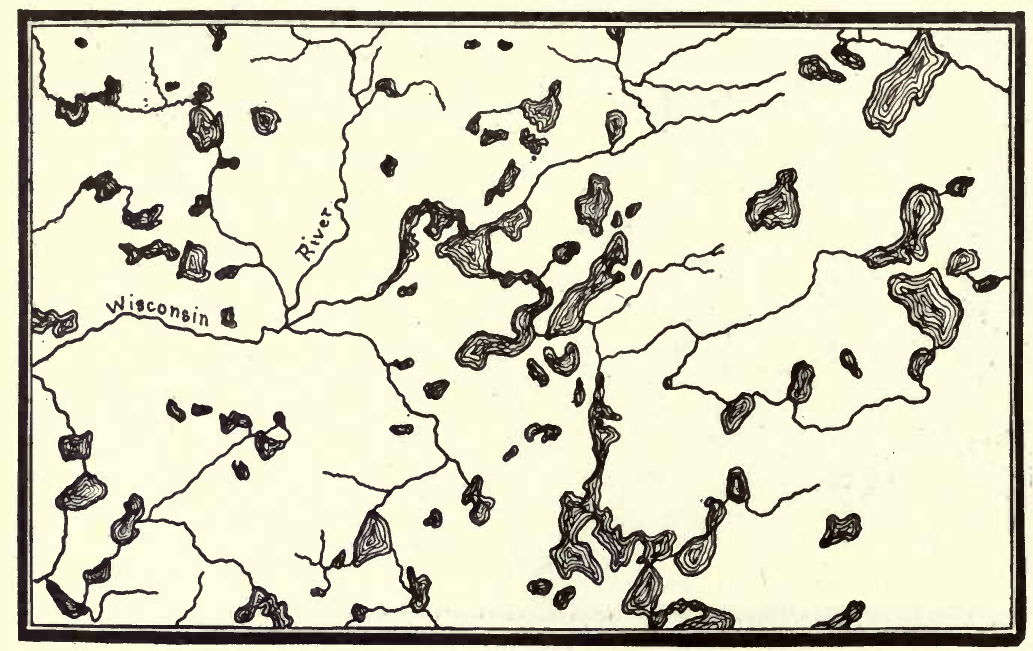

FIG. 7.

Portion of Vilas and Oneida counties, Wisconsin, showing topographic conditions in a typical glaciated country. (From map published by Chicago and Northwestern Railroad Company.)

The courses of many streams were changed during the several ice invasions, and it is probable that many streams were captured and beheaded, especially in the upper Mississippi Valley, as suggested by General Warren a number of years ago, and the Lymnæid fauna was doubtless thus enabled to enter more northern drainages. Interesting cases of change of drainage are found in Tight's paper (referred to in

Including the local mountain glaciers of the Rocky Mountains. 
the bibliography), in which a portion of the Ohio River is shown to have drained into Lake Erie in preglacial times. Leverett also describes several drainage changes, besides identifying numerous preglacial valleys in his several papers. The famous "Two Ocean Pass" at the summit of the continental divide in Wyoming is a good example of a route by which certain species of Lymnæas may have passed from one drainage to another. Atlantic Creek flows eastward to Yellowstone River. Pacific Creek flows southward to Snake River. The two creeks are connected in wet weather. (See Jordan and Kellogg, p. 309.)

It is to be noted that the species inhabiting the territory south of the englaciated region were affected but little by the ice invasion, unless it be by the added struggle for existence which the addition of the northern types may have caused, and also by the more crowded condition due to the decrease of territory.

POST-GLACIAL AND PRE-GLACIAL SPECIES.

The record of pre-glacial Lymnæas is obviously very imperfect. With the exception of a few species recorded from the inter-glacial deposits of Toronto and Cayuga Lake, all of the fossil records from within the glaciated area are referrable to post-glacial times. In the unglaciated regions a few records occur which are pre-glacial. One species (obrussa) has been found in deposits supposed to be Pliocene (Tassajora Lake bed, Alameda County, California). We have every reason to believe that a large number of the existing species originated prior to the Glacial Period, and the lack of records is due to the difficulty of reaching undoubted pre-glacial deposits, which are buried under the material left by the successive ice invasions. The territory outside the glaciated area, as well as the driftless area of Wisconsin, should produce a number of records which would doubtless prove the pre-glacial existence of many recent species. Misidentifications as well as references to the older composite species also render the glacial records quite incomplete. Our knowledge of fossil representatives of recent species may be tabulated as follows:

SPECIES IN DEPOSITS OF ENGLACIATED AREA. MARL DEPOSITS.

stagnalis appressa. dalli.

humilis modicella. humilis rustica.

stagnalis appressa. megasoma. obrussa.

obrussa exigua.

obrussa decampi. galbana.

CLAY DEPOSITS.

caperata.

humilis modicella. palustris.

reflexa.

emarginata canadensis. 
stagnalis appressa. columella.

obrussa decampi.

humilis modicella.

stagnalis appressa. columella chalybea. caperata.

humilis modicella.

\section{SPECIES IN}

stagnalis appressa.

obrussa.

parva.

\section{DISTRIBUTION}

Marl Deposits.

Clay Deposits.

Sand and Gravel Deposits. New York, Illinois, Ontario.

Florencia Deposits.

Loess Deposits.

Interglacial Deposits.
SAND AND GRAVEL DEPOSITS.

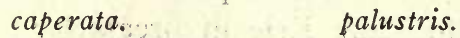

FLORENCIA FORMATION.

\begin{tabular}{ll}
\multicolumn{1}{c}{ LOESS. $^{1}$} & obrussa. \\
parva. & palustris. \\
humilis modicella. & reflexa.
\end{tabular}

SPECIES IN DEPOSITS

ASSOCIATED WITH MASTODON REMAINS.

caperata.

obrussa.

\section{DEPOSITS OUTSIDE ENGLACIATED AREA.} MARL DEPOSITS.

humilis modicella. obrussa. palustris.

CHARCOAL ZONE, NEW MEXICO.

bulimoides cockerelli.

INTERGLACIAL BEDS.

(Don Valley and Cayuga Lake.) palustris. catascopium.

PLIOCENE BEDS.

obrussa.

\section{UNCLASSIFIED DEPOSITS.}

humilis modicella. obrussa.

palustris. 
UNGLACIATED AREA.

Marl Deposits.

Charcoal Zone.

Dry Salt Lake.

Sandy Clay.

Pliocene.

Unclassified.
Lakes Bonneville and Lahontan, Nevada and Utah; Coconino Co., Arizona.

New Mexico (Arroyo Pecos).

New Mexico (near Eddy).

Texas (Howard Co.).

Tassajora Lake Bed, Alameda Co., Cal.

Contra Costa and Alameda Counties, Cal.; South Platte River.

\section{SUMMARY.}

Species and varieties in englaciated area.............. 17

Species and varieties in unglaciated area............ 7

Found only in englaciated area................... 10

Common to both areas......................... 6

\section{BIBLIOGRAPHY.}

The following works have been consulted in the preparation of Chapter III : (See Bibliography at end of volume.)

Adams, C. C., 1901; 1902, a ; 1902 ; 1905.-Baker, F. C., 1910, d.-Binney, 1885.-Chamberlin, T. C., 1883; 1906.-Coleman, A. P., 1901; 1906.-Cooke, A. H., 1895.-Dall, W. H., 1905, a, 1905, b.-Fairchild, H. L., 1899; 1909.-Gilbert, G. K., 1890.-Jordan and Kellogg, 1907.-Jordan, Hermann, 1883.-Leverett, Frank, 1895 ; 1899; 1902.-Maury, C. J., 1908.-Merriam, C. H., 1890; 1898; 1910.-Pascal, L., 1891.-Pilsbry, H. A., 1906.-Salisbury, R. D., 1902.-Scharff, R. F., 1907 ; 1909.-Simpson, C. T., 1895 ; 1900.-Tight, W. G., 1903.-Todd, J. E., 1896.-Tryon, J. W., 1882.-Upham, W., 1895.-Verrill, A. E., 1873.-Walker B., 1900, b.-Warren, G. K., 1875.-Wegemann, C. H., 1909. 


\section{DISTRIBUTION IN TIME.}

\section{A. GENERAL DISCUSSION.}

The American Lymnæas are geologically of considerable antiquity, the earliest species occurring in the fresh-water strata of the lower Cretaceous (Comanchean) ${ }^{1}$ Period. Dr. C. A. White ${ }^{2}$ thus writes of the origin and antiquity of the family: "In the Laramie Group, we find the family represented by all the principal genera that are known among living Limnæidæ, ${ }^{3}$ as well as the greater part of the subordinate sections of the genera which constitute the family. These facts necessarily point back to a period much more remote than the Laramie, for the origin of the family, and, although we lack the positive evidence of the fact, we cannot doubt that it not only had its origin as early as the beginning of Mesozoic time, but it had then become well established."

Several years after Dr. White penned the above, three Lymnæas were discovered in strata then believed to be late Jurassic but now referred to the Comanchean Period, thus carrying the family still farther back in Mesozoic time. A compilation of the literature relating to the extinct species of this family at once points to the fact that our knowledge of the geological distribution of American freshwater pulmonates is very imperfect. As ponds, swamps and streams are believed to have existed in early Mesozoic Time, and also in late Paleozoic Time, it is quite probable that the ancestors of the Lymnæas lived and flourished at a much earlier period than their discovered remains would indicate. There is no apparent reason why Lymnæas could not have lived during the Upper Carboniferous (Pennsylvanian) Period, as there is already evidence of a well-defined pulmonate fauna. ${ }^{*}$ The presence of spiders, scorpions, myriopods and insects, besides amphibians, which suggest a fresh or brackish water habitat, all point to the existence of conditions not at all unfavorable to the presence of Lymnæas and other fresh-water pulmonates, and it is confidently believed by the present writer that such evidence will be found at no far distant time. ${ }^{5}$

Mr. J. B. Woodworth ${ }^{6}$ has made certain pertinent observations which will perhaps bear repeating. He says: "We have to note that

\footnotetext{
${ }^{1}$ Bull. 29 U. S. Geol. Surv.; Chamberlin and Salisbury, Geology, Vol. III, pp. 66,119 .

'An. Rep. U. S. Geol. Surv., III, p. 444, 1883.

${ }^{3}$ This statement includes Planorbis and some other genera.

'Pupa vetusta from the Nova Scotia coal measures, Pupa vermilionensis and Dawsonella meeki from Illinois.

SSee Chamberlin and Sallsbury, op. clt., vol. II, p. 611.

Amer. Geol., XIV, p. 224.
} 
the fresh-water Mollusca of North America attained approximately their present characters during the period of evolution of the baseleveled lowlands, and that they have undergone little modification in the succeeding periods until now. 'To so great a degree had this differentiation then attained,' states Dr. C. A. White in his report on the Cretaceous invertebrates of the Plateau Provinces, 'that the species of Unio, Helix, Physa, etc., seem to have been as diversified and well cieveloped as they are at the present time. Indeed, the species of these genera are so closely like some of those now living that they need only the fresh condition of recent shells to remove all suspicion of their great antiquity from the mind of the casual observer.' "

It is interesting to note that in the earlier Cretaceous beds the mollusks are, with one exception, either naiades or aquatic pulmonates, while in the Laramie beds of the Upper Cretaceous the fauna has increased to such an extent as to include a large percentage of the existing families of American fresh-water mollusks as well as several families of land shells. The difficulty of assigning these fossil species to the proper genus is well illustrated by the history of the following species :

In 1878 Dr. White published the description of a mollusk under the name of Acclla haldemani, which was supposed to be congeneric with Acclla gracilis Hald., a recent mollusk, which the fossil shell markedly resembled in form. ${ }^{3}$ Later, ${ }^{4}$ by the examination of additional material and by improved methods of preservation, it was found that the columella of this species bore two distinct plaits. This discovery necessitated the removal of the species from the Lymnæas, no species of which has ever been seen with two columella plaits, and, as there was no available group in which to place this peculiar shell, a new genus was erected by Dr. White for its reception, which he called Tortacella, and which he placed in the family Auriculidæ. Lymnaa micronema, of the same author, is doubtful and will perhaps be found to belong to the same genus as haldemani. There are one or two other species of doubtful affinity, owing to their imperfect state of preservation.

Dr. White says ${ }^{1}$ in "reviewing the collections which represent the fossil faunæ herein discussed, so many familiar forms are seen that it is difficult to realize the fact that a large proportion of them, including those especially which have been mentioned by name in this article,

Ann. Rep. Geol. \& Geog. Surv. Terr., XII, pt. I, p. 84, pl. 30, fig. 9, 1878.

'Bull. U. S Geol. Surv., 128, p. 44, pl. 5, figs. 8-12, 1895.

${ }^{1}$ Amer. Journ. Scl., ser. 1il, Vol. XX, p. $48,1880$. 
were living contemporaneously with the last of the Dinosaurs. Yet such is the fact, and the shells of the former are often found commingled with the bones of the latter. What were the successive steps in the history of the transmission of these types from that remote time to the present we are unfortunately without the means of knowing with certainty, because of the remarkable paucity of molluscan remains in all the deposits of the great interior region later than the Eocene. All the molluscan remains which have been found in these later deposits belong to familiar living types, although of extinct species."

A glance at the accompanying map (figure 8) shows that the American Lymnæas originated, so far as the present records show, in the Rocky Mountain region, and that they continued to live in this region until Pliocene and Pleistocene Time. It is noteworthy that as fast as the new land was exposed and became suitably provided with fresh or brackish water lakes, the Lymnæas migrated eastward and westward and occupied these areas. The region in which these early Lymnæas are found is believed to have contained vast inland lakes, which, says Dr. White, "for magnitude have now no equal upon the earth." Mr. Clarence King ${ }^{1}$ has named these Tertiary lakes as follows : ${ }^{2}$

TERTIARY LAKES.

EOCENE.

Middle. Province.

Ute Lake (Vermilion Creek Group, King; Wahsatch Group, Hayden).

Gosiute Lake (Green River Group, Hayden; Elko Group, King).

Washakie Lake (Bridger Group).

Uinta Lake (Uinta Group, Emmons and Marsh).

MIOCENE.

Contemporaneous.

Province of Nevada and Oregon.

Province of the Great Plains.

Pah-Ute Lake (Truckee Group,

King; John Day Group, Marsh).

Sioux Lake (White River Group, Hayden).

PLIOCENE.

Contemporaneous.

Province of the Great Middle Province.

Province of the Great

Basin.

North Park Lake

Plains,

Shoshone Lake (Hum-

(North Park Group,

Cheyenne Lake (Nio-

boldt Group, King).

Hague and Hayden).

${ }^{1}$ Geology 40th Parallel., Vol. I, p. 408-458; see Chamberlin \& Salisbury's Geology for the present relations of these strata. These Tertiary lakes were recognized at an earlier date by Hayden and Newberry, later by Powell, Gilbert, Cope, Marsh and other geologists. See Davis. Proc. Amer. Acad. Arts. \& Sci., XXXV, p. 345, for a resume of this subject. Also Paleogeographic man by Willis, Journ. Geol., XVII, p. 504.

2op. cit., p. 458 . 


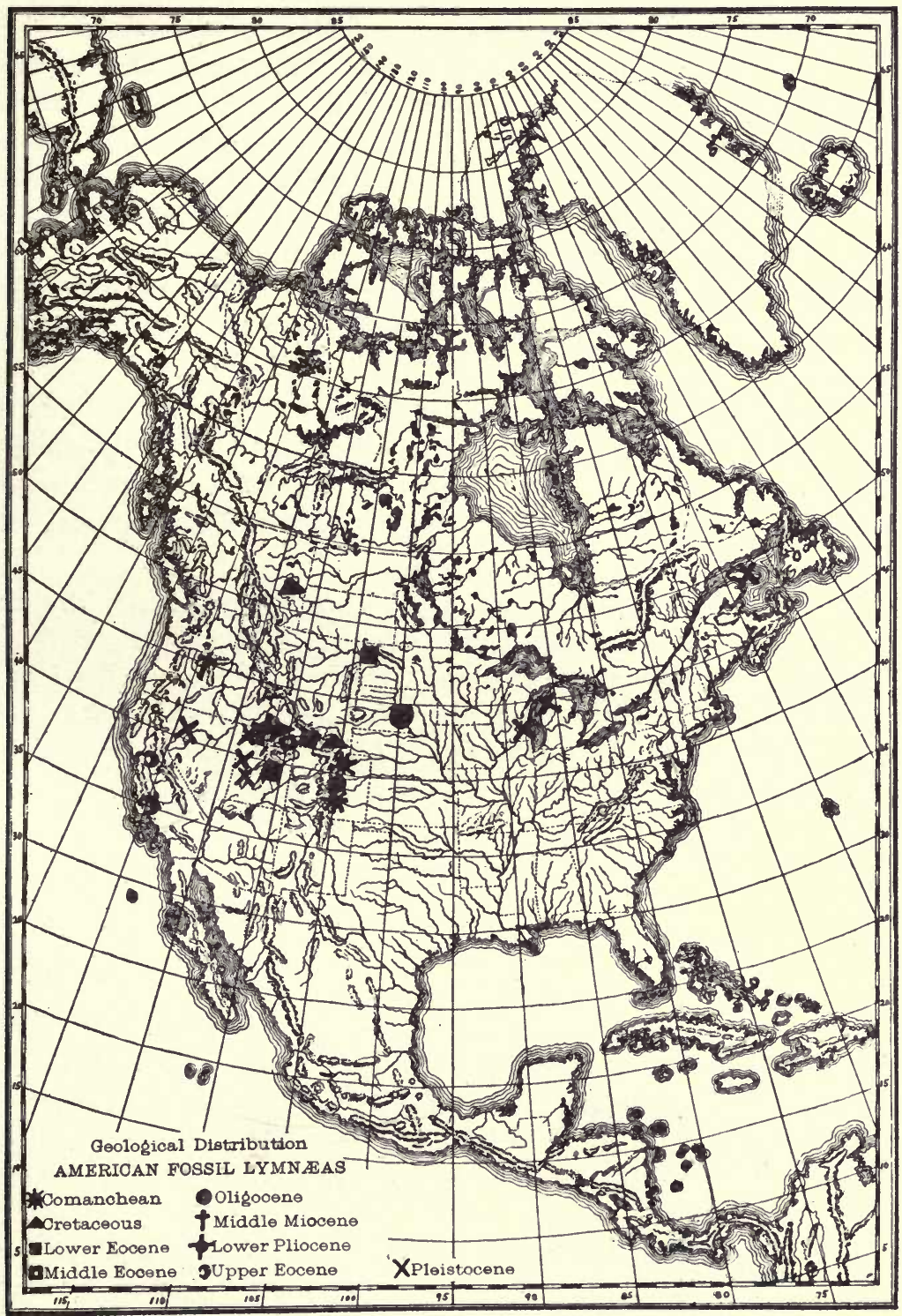

FIG. 8.

Map showing distribution of American Fossil Lymnæas. 
It would appear that since early Eocene Time this plateau region, known later as the Great Basin, had been the scene of some of the most stupendous physical changes in the history of the earth. At the close of the Mesozoic Era this region was notably subjected to warpings and faultings which elevated much of the land, producing irregular mountainous tracts capable of rapid erosion. Basins were formed here and there in which lakes of large size developed. ${ }^{1}$ It seems not unlikely that from this time (the Lower Eocene Period) to the present there existed in the area of the Great Basin a continuous series of lakes, large and small, of which the Pleistocene lakes Lahontan and Bonneville were the last, and of which Great Salt Lake is a diminishing descendant.

That the fresh-water faunas contemporaneous with the Lymnæas were relatively large and varied in character is attested by the presence of the genera Unio, Auricula, Tortacella, Planorbis, Physa, Neritina, Pachymelania, Pyrgulifera, Hydrobia, Vivipara and Campeloma. Numerous forms of land shells also occur. ${ }^{2}$

It also seems possible, if not probable, that the present Lymnæid fauna of this region is a direct descendant from these early times. It seems not at all improbable that the smaller Lymnæas of the United States (techella, desidiosa, etc.) originated here, as well, also, as some of the larger species. That the recent Lymnea utahensis of Call is a lineal descendant of Meek's Polyrhytis kingi seems evident. Lymnca stearnsi is also an early form of Lymnea stagnalis.

It also seems apparent that the Lymnæas of American origin spread from this region, following the river systems as they were formed, and finally mingled with the Asiatic emigrants which reached the plain area by the way of the lowlands of Alaska and British America. This combined fauna worked its way to the higher regions of the Rocky Mountains, where it is found today intermingled with the remnants of the original American stock. It is not believed by the writer that the supposed land connection with Europe via Greenland contributed to any extent in the formation of the present Lymnæid fauna.

In the following pages an attempt has been made to bring together all references to extinct American Lymnæas, together with the original descriptions and figures. No attempt has been made to critically revise the species, but remarks are introduced wherever an opportunity has

${ }^{1}$ Chamberlin and Salisbury, op. cit., III, p. 204, etc.

'See the interesting paper by Dr. Stearns on the Colorado Desert, which doubtless once formed a part of the Great Basin system. Proc. U. S. Nat. Mus., XXIV, pp. 271-299. 
presented itself. An endeavor has been made in Table I to place the extinct species in their proper genus or subordinate group. This has been difficult in many cases because of the necessary lack of anatomical details, upon which data the classification of the recent species is based. It is thought that the result may not be without value from a taxonomic point of view. It will be noted that nearly all of the groups of the recent species are represented.

Table II illustrates the stratigraphical relations of the various species. It will be noted that the number for the entire series from Cretaceous to Pleistocene is but twenty-five; adding the six undetermined species, we have a grand total of thirty-one species. Comparing the faunas of the successive formations, it will be apparent at once that the Lymnæid fauna, as shown by the records, has been neither abundant nor diversified as compared with that of the present time. This may be, and probably is, due to lack of extended exploration in the localities in which the strata occur. The largest number of species is from the White River beds of the Oligocene, in which four species have been found. Future research will doubtless extend our knowledge of the fresh-water Pulmonata to such a degree that a continuous record will be established from the earliest period of appearance to the present time. The hope is also entertained that the history of the family may be carried back to Paleozoic strata and that data may be secured bearing on the origin of this family from some marine or brackish water form.

\section{SYSTEMATIC TABLE OF EXTINCT AMERICAN LYMN EAS.} Family LYMNÆIDÆ Keferstein.

Genus LYMNÆA Lamarck.

Lymnaa stearnsi Hannibal.

Middle Miocene.

Genus PLEUROLIMNÆA Meek.

Pleurolimnaa tenuicosta (M. \& H.).

Cretaceous.

Pleurolimna tenuicosta whitcavesi Baker.

Cretaceous.

Genus GALBA SCHRANK.

Subgenus GALBA (typical).

Galba ativuncula (White).

Comanchean.

Cretaceous.

Galba minuscula (White).

Lower Eocene.

Galba scudderi (Cockerell).

Oligocene.

Galba sicucrti (Cockerell).

Oligocene.

Galba anticostiana (Dall).

Pleistocene.

Subgenus STAGNICOLA Leach.

Galba compactilis (Meek).

Galba consortis (White).

Cretaceous.

Comanchean.

Galba vetusta (Meek).

Middle Eocene. 
Galba similis (Meek).

Galba diaphana (E. \& S.).

Galba nebrascensis (E. \& S.).

Galba meekiana (E. \& S.).

Galba shumardi (Meek).

Galba florissantica (Cockerell).

Galba contracosta (Cooper).

Galba alamosensis (Arnold).

Galba bonnevillensis (Call).

Galba bakeri (Walker).

Galba nashotahensis (Baker).

Galba accelerata (White).

Subgenus POLYRHYTIS Meek.
Middle Eocene.

Oligocene.

Oligocene.

Oligocene.

Oligocene.

Oligocene.

Pliocene.

Pliocene.

Pliocene.

Pliocene.

Pliocene.

Comanchean.

Galba kingi Meek.

Lower Pliocene.

II. STRATIGRAPHICAL TABLE OF EXTINCT AMERICAN LYMNÆAS.

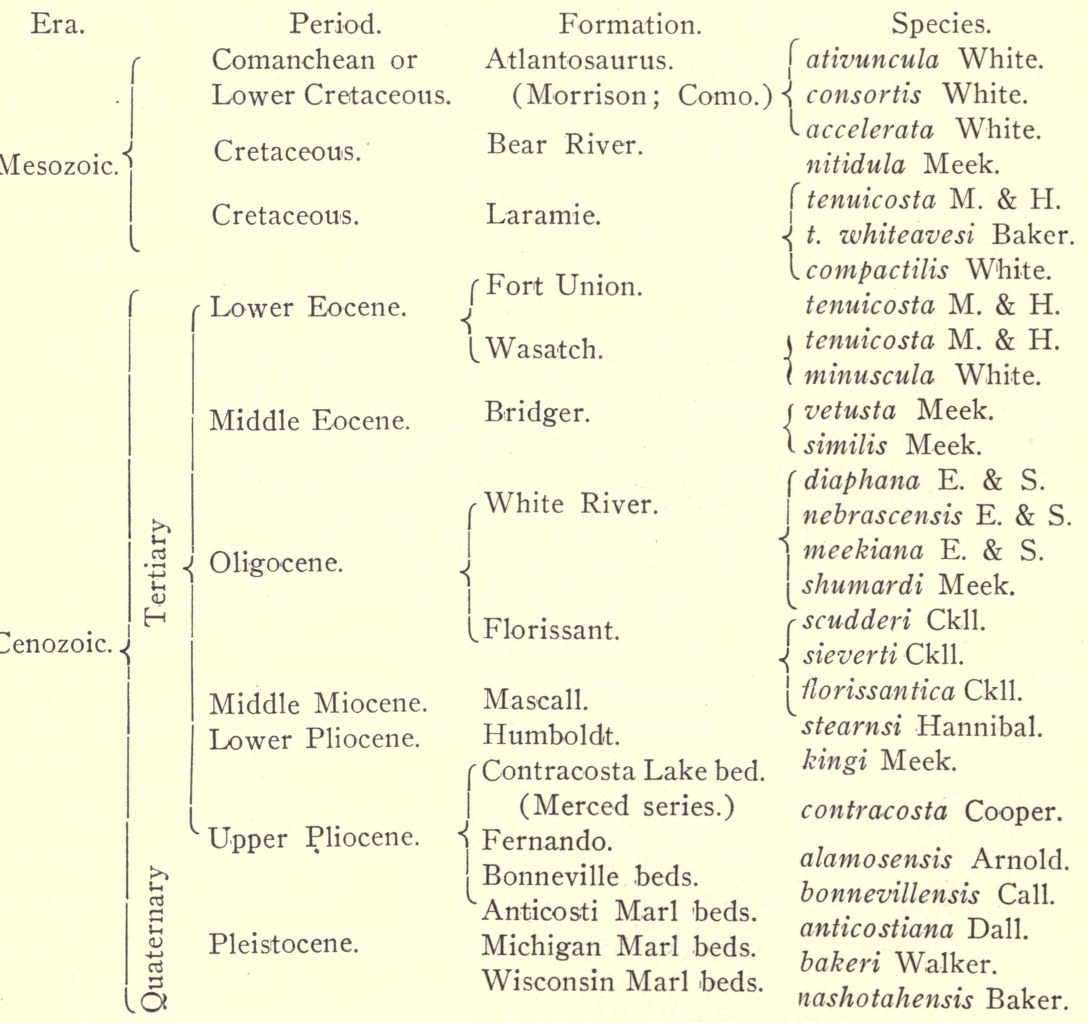




\section{B. DESCRIPTIONS OF AMERICAN FOSSIL LYMN ÆAS. COMANCHEAN LYMNAEAS.}

Galba ativuncula (White). Plate XVI, figures 1, 2.

Limnca ativuncula White, Bull. U. S. Geol. Surv., no. 29, p. 20, pl. 4, figs. 10-11, 1886 ; Proc. Amer. A. A. Sci., XXXIV, p. 241, 1890; Bull. U. S. Geol. Surv., no. 128, p. 71, 1895.-BoyLe, Bull. U. S. Geol. Surv., no. 102, p. 167, 1893.-Schuchert, Bull. U. S. Nat. Mus., no. 53, i, p. 355, 1905.

"Shell small, spire moderately slender; volutions about six in number, convex, the last one enlarged and somewhat longer than the spire. Surface marked by the usual lines of growth.

"Length of the largest example in the collection, 8 millimeters; but their average length is considerably less" (White).

Type: U. S. Nat. Mus. no. 20054.

Horizon: Atlantosaurus beds, Comanchean Period.

Locality: Eight miles north of Canyon City, Fremont County, Colorado.

REMARKs: "The younger examples of this species are more slender than the adult specimens on account of the proportionally greater enlargement of the last volution upon reaching maturity. These younger examples are so slender as to suggest their reference to Acella, but the older shells have more the shape of true Limnæa" (White).

From the figures, this species most nearly resembles certain recent Lymnæas which Lea described as rustica. It certainly falls in the group with obrussa, rustica, plica and parva, and could scarcely be distinguished from certain individuals of these species had the specimens the fresh appearance of recent shells. Occurring as it does in the oldest strata from which American Lymnæas have been secured, the parallel in resemblance is all the more remarkable, showing clearly, as remarked by Dr. White, that the Lymnæid fauna was well established at this period. ${ }^{1}$

Galba consortis (White). Plate XVI, figures 3, 4.

Limncea consortis White, Bull. U. S. Geol. Surv., no. 29, p. 20, pl. 4, figs. 8-9, 1886 ; Bull. U. S. Geol. Surv., no. 128, p. 71, 1895.-BoyLE, Bull. U. S. Geol. Surv., no. 102, p. 167, 1893.-SchucherT, Bull. U. S. Nat. Mus., 53, i, p. 356, 1905.

"Shell moderately small; spire short; volutions about five in number, convex, the last one inflated and much longer than the spire. Surface marked by the usual lines of growth.

"Length of largest example, 10 milimeters; breadth of the last volution, 5 millimeters" (White).

${ }^{1}$ Amer. Journ. Scl., iii, vol. XX, p. 44. 
TyPe: U. S. Nat. Mus. no. 20055.

Horizon: Atlantosaurus beds, Comanchean Period.

Locality: Eight miles north of Canyon City, Fremont County, Colorado.

Remarks: "This species, although small, is somewhat larger than the one last described, and it is also more robust than is usual with species of this genus, approaching Physa in that respect" (White).

Consortis resembles the short-spired forms of Galba catascopium more than any other recent species. The shell has a superficial resemblance to young examples of Radix auricularia, but differs in the form of the inner lip and columella. No perfect specimens have been found and the form of the outer lip is, therefore, unknown. No undoubted representative of Radix, either recent or fossil, has been found in America.

Galba accelerata (White). Plate XVI, figures 5-8.

Limncea? accelerata White, Bull. U. S. Geol. Surv., no. 29, p. 21, pl. 4, figs. 12-15, 1886 ; Bull. U. S. Geol. Surv., no. 128, p. 71, 1895.-BoyLE, Bull. U. S. Geol. Surv., no. 102, p. 167, 1893.-Schuchert, Bull. U. S. Nat. Mus., 53, i, p. 355, 1905.-Darton, Bull. Geol. Soc. Amer., XIX, p. 446, 1908.-Darton \& Siebenthal, Bull. U. S. Geol. Surv., 364, p. 30, 1909.

"SHell elongate ovoid; aperture a little shorter than the spire in adult shells; sides of the spire convex, rounding in more or less abruptly toward the apex, but when perfect the extreme apex is small and prominent; volutions convex, seven or eight in number when the shells have reached adult size, those near the apex being narrower and more transverse than the last two, during the production of which the axial extension of the shell was proportionately more rapid than in its earlier stages. Surface plain, being marked only by fine lines of growth.

"Length, 20 millimeters; diameter of the last volution, 7 millimeters" (White).

TYPE: U. S. Nat. Mus, no. 20056.

Horizon: Atlantosaurus beds, Comanchean Period.

Locality: Eight miles north of Canyon City, Fremont County, Colorado; Como Ridge, Albany County, Wyoming.

REMARKS: "It is apparent at a glance that this shell is not a typical Limncea; but after careful comparison with several other generic forms which have a similar facies I have not been able to refer it to them satisfactorily, and I therefore place it provisionally under Limncea. Some of the specimens show a considerable deposit of callus upon the inner lip, in which case the flexure of the lower portion of the columella has something of the appearance of a fold such as some of the 
smooth forms usually referred to Melanopsis possess. That feature also suggests the relationship of this shell to Stolidoma, but there is no evidence that the axis of the spire has been absorbed, as is usually the case with the Auriculidæ. The character of the aperture also seems to render its reference to any of the Bulimidæ improper.

"The collection contains a considerable number of small examples, which I at first regarded as belonging to another species; but, after comparing them with the apical portion of the form here described, I am quite convinced that they are the young of this species and represent the apical portion of the adult shell" (White).

This is a peculiar species, unlike any living or fossil form. It approaches some forms of the emarginata group, especially Galba contracta. The cylindrical whorls and narrow aperture are peculiar. It is tentatively referred to the subgenus Stagnicola.

The two small specimens figured by White $(5,6$, plate XVI) seem scarcely to belong to the same species, the sutures being much deeper and the whorls consequently much rounder than in accelerata. A study of additional material should be made to throw more light on the relationship of these small specimens to accelerata. They may possibly be immature specimens.

\section{CRETACEOUS LYMNAEAS.}

Galba nitidula (Meek). Plate XVI, figures 20-22.

Melania? nitidula MeEk, Proc. Acad. Nat. Sci. Phil., p. 314, 1860.

Limnaa nitidula CoNRAD, Eocene Smithsonian check-list, p. 9, 1866.MeEk, Simpson's Rep. Great Basin, Utah, pp. 363, 373, pl. 5, fig. 14, 1876; Bull. U. S. Geol. \& Geog. Surv. Terr., III, p. 610, 1877.-Miller, Mes. and Cænoz. Geol., p. 72, 1881; Journ. Cin. Soc. N. H., III, p. 82, 1880.-White, 3rd An. Rep. U. S. Geol. Surv., p. 445, pl. 6, figs. 15-16, 1883 ; An. Rep. U. S. Geol. and Geog. Surv. Terr., XII, pt. I, p. 84, 1884.-Boyle, Bull. U. S. Geol. Surv. no. 102, pp. 167, 168, 1893.-White, Bull. U. S. Geol. Surv., no. 128, pp. 45, 64, pl. 6, fig. 3, 1895 (nec. fig. 1-2).-SchucherT, Bull. U. S. Nat. Mus., 53, i, p. 356, 1905.

Limnaa (Limnophysa) nitidula MEEK, U. S. Geol. Surv. 40th Parallel, Vol. IV, p. 181, pl. 17, fig. 5, 1877.-White, An. Rep. U. S. Geol. and Geog. Surv. Terr., XI, pp. 241, 243, 255, 1879.-MArcou, Proc. Nat. Mus., VIII, p. 330, 1885.

Limnophysa nitidula Whrte, Am. Journ. Sci. and Arts., ser. iii, XX, p. 45, 1880 ; An. Mag. N. H., ser. v, VI, p. 249, 1880.

Limnaa sp., Whiтe, Geol. Uinta Mts., p. 100, 1876.

"Shell small, ovate-subfusiform; spire conical, moderately elevated; volutions about six and a half, convex, last one forming twothirds of the entire length; suture well defined; aperture subovate, narrowly rounded below and angular above, scarcely equaling one-half the length of the shell; columella apparently with only a very small 
fold, and showing by the side of the inner lip below, appearances of a small umbilical indentation. Surface marked by fine, rather obscure lines of growth, with (on some specimens) exceedingly faint traces of microscopical revolving striæ.

"Length, 0.40 inch; breadth, 0.20 inch; apical angle convex, divergence $40^{\circ}$ " (Meek).

TyPe: U. S. Nat. Mus. no. 685 ; no. 23116 ; plesiotypes no. 12500.

Horizon: Bear River formation, ${ }^{1}$ Cretaceous Period.

Locality: Bear River, near mouth of Sulphur Creek, Uinta County, Wyoming; Mellis Station, Bear River Valley; 20 miles north of Cokeville, Uinta County, southwestern Wyoming, embedded in thin layers of impure limestone.

REMARKS: "Among recent species, this may be compared with L. humilis and the several forms regarded by Mr. Binney as varieties of this species. It is a decidedly more slender shell, with a less expanded aperture and less developed inner lip than Mr. Binney's figure (p. 63, fig. 99, Land and Fresh-Water Shells) of an authentic specimen of that species. It agrees, however, more nearly in form with some of those figured by Mr. Binney as varieties of L. humilis, but still differs from them all in other details" (Meek).

As stated by Meek, this species bears a close resemblance to the recent Galba humilis (Say), ${ }^{2}$ and it undoubtedly groups with that species. There seems to be some confusion regarding this species. In his discussion of the Bear River formation, Dr. White remarks as follows : ${ }^{3}$

"Ever since the first publication of this species, more or less doubt has prevailed as regards its specific and generic characters, the locality and formation from which it was first obtained, and the identity of the type specimens. I have hitherto been somewhat disposed to regard it as identical with the form which is described on a following page under the name of Charydrobia stachei, and I should, therefore, have rejected it from this summary of the fauna of the Bear River formation if it were not that a considerable number of specimens have lately been obtained which conform well to the original description as published by Mr. Meek. The specimens believed to be those which were thus originally used by him are figured on plate VI. They are preserved in the collections of the United States National Museum,

${ }^{1}$ The writer agrees with Dr. White that the fauna of the so called Bear River formation is sufficiently distinct from that of the Laramie to justify its separation on this ground even though its stratigraphical relations may not Justify such a procedure.

${ }^{2}$ The resemblance to $\mathrm{G}$. humilis modicella is remarkable.

${ }^{2}$ Bull. 128, U. S. Geol. Surv., p. 45. 
accompanied by a label in Mr. Meek's handwriting, referring them to this species. The examples figured by Mr. Meek in volume IV of the report of the United States Geological Exploration of the Fortieth Parallel, and copied by me in the Third Annual Report of the United States Geological Survey, are unlike these specimens, and unlike any form known to me in the Bear River fauna, and they do not answer to Mr. Meek's description."

White's reference of the species to Charydrobia stachei is quite erroneous, as he correctly states on page 58 of the same work. The resemblance of the two species is scarcely superficial. A careful study of all the figures of nitidula seems to point to the conclusion that Dr. White was in error in referring figures 1 and 2 on plate VI to nitidula. These figures seem to be the same as those used for Lymncea similis by White in the Third Annual Report, plate 29, figures 20, 21.

Referring to the literature, we find that Meek's figure of the species in Simpson's Utah Report (pl. 5, fig. 14) agrees perfectly with his description. The next published figures are in the Fortieth Parallel Report, IV, pl. 17, figs. 5, 5a. These certainly agree with both the original figure and description of Meek. White refigures these in the Third Annual Report of the Geological Survey, pl. 6, figs. 15, 16. In Bull. 128, Dr. White figures what are said to be copies of Mr. Meek's unpublished figures (figs. 1, 2) and also a view of one of the type specimens (fig. 3). This last figure corresponds in every way with Meek's figures in the Fortieth Parallel Report, but does not at all agree with figures 1 and 2 of White's paper, nor do these figures answer to the description of Meek. It is also a curious fact that Meek's unpublished figures as published by White are an exact duplication of the figures of Lymnca similis Meek as figured in the Third Annual Report, pl. 29, figs. 20, 21. It would appear that some error had been made by Meek in labeling his unpublished figures, which certainly do not represent his nitidula as described and figured.

Pleurolimnæa tenuicosta (Meek and Hayden). Plate XVI, figures $9-11$; Plate XVII, figure 4.

Limnca tenuicosta Meek and Hayden, Proc. Phil. Acad., p. 119, 1856 ; Amer. Jour. Sci., ii, XXII, p. 428, 1856.-Miller, Jour. Cin. Soc. N. H., III, p. 21, 1880; Mes. and Caen. Geol., p. 57, 1881.

Limncea tenuicosta Meek and Hayden, Proc. Phil. Acad., p. 278, 1856.

Limnca (Acella) tenuicostata Meex and Hayden, Proc. Phil. Acad., p. 431, 1860 .

Limnca tenuicostatus Binney, L. and F. W. Sh. N. A., II, p. 72, 1865.

Limnea tenuicostata Binney, Journ. de Conch., XV, p. 428, 1867.-White, 3rd An. Rep. U. S. Geol. Surv., p. 445, pl. 23, fig. 24, 1883.-Fischer, Man. de 
Conch., p. 506, 1883.-Tryon, Struct. and Syst. Conch., III, p. 101, 1884.Whiteaves, Geol. \& Nat. Hist. Surv. Canada, Cont. Can. Paleont., I, pt. 1, p. 13, 1885.-Tyrrel.l, Rep. Geol. \& Nat. Hist. Surv. Can., 1886, n. ser. II, p. 68 E, p. 136, E, 1887.-Boyle, Bull. U. S. Geol. Surv., no. 102, p. 168, 1893.

Limnaa (Pleurolimnaa) tenuicostata Conrad, Smith. Check-list, p. 9, 1886.Meek, U. S. Geol. Surv. Terr., IX, p. 534, pl. 44, fig. 13, 1876.-White, Bull. U. S. Geol. \& Geog. Surv. Terr., III, p. 613, 1877 ; Amer. Journ. Sci. \& Arts, iii, XX, p. 45, 1880 ; An. Mag. N. H., v, VI, p. 248, 1880 ; An. Rep. U. S. Geol. \& Geog. Surv. Terr., XII, p. 84, 1883.-Marcou, Proc. Nat. Mus., VIII, p. 330, 1885.-White, Bull. U. S. Geol. Surv., no. 128, p. 75, 1895.-Schuchert, Bull. U. S. Nat. Mus. 53, p. 357, 1905.-BAKer, Science, N. S., XXVII, p. 943, 1908.

Lymnaa (Pleurolimnaa) tenuicostata Dall, Alaska Mollusks, p. 64, 1905.

Acella sp. White, Proc. U. S. Nat. Mus., III, p. 160, 1880.

Acella micronema White, Bull. U. S. Geol. Surv., 34, pp. 11, 22, pl. 2, fig. 14, 1886.-Schuchert, Bull. U. S. Nat. Mus., 53, p. 20, 1905.

"Shell very small, slender, thin and fragile; spire turreted, acute, about equaling the length of the aperture; volutions four to four and a half, convex, increasing rather rapidly in length, but not in breadth; last one not ventricose, narrowing and produced below; suture deep; surface-costæ regularly disposed, a little flexuous, arranged parallel to the minute striæ of growth, and numbering about eight to twelve on the last turn.

"Length, 0.30 inch; breadth, 0.08 inch; apical angle regular, divergence about $21^{\circ}$ " (Meek).

Type: Nat. Mus. no. 12488, tenuicosta; no. 20066, micronema.

Horizon: Laramie formation, Cretaceous Period.

Fort Union formation, Lower Eocene Period.

Wasatch formation, Lower Eocene Period.

Locality: Cretaceous (Laramie). Mouth of the Blind Man River, Township 39, Range 27, west of the Fourth Principal Meridian; Blind Man or Paskapoo River; three-quarters of a mile upstream from the Red Deer a six-inch seam of coal crops out forty feet above the bed of the stream, underlain by a thin bed of marl sand, in which the fossils occur (Alberta).

Lower Eocene (Fort Union). Three miles below Fort Union (Fort Buford), Williams County, North Dakota.

Lower Eocene (Wasatch). Wales, Sanpete County, Utah, near junction of Wasatch and Green River formations; three miles east of rable Rock station, southern Wyoming.

REMARks: "This species will be distinguished at a glance from all the others known in our Upper Missouri rocks. Indeed, I am not acquainted with any other form, either among recent or fossil shells, with which it is liable to be confounded. Its most marked features 
are its small size, slender form, and costate surface. With the exception of the last-mentioned character, it is evidently related to Limnea subulata of Sowerby, which, however, is described as having the surface smooth.

"It is possible that a distinct genus should be established for the reception of this little shell, though I have concluded to range it provisionally as the type of a subgenus under Limnaa" (Meek).

As remarked by Meek, this species is not likely to be confounded with any other form of Lymnca, either recent or extinct. The regular costæ are peculiar, as are also the long and narrow upper whorls. It resembles the recent genus Acella Haldeman; the presence of the regular costæ provide a character of generic importance, as does also its peculiar shape. Meek placed it in a separate group, which he called Pleurolimncea.

The species was first called temicosta, which name was changed in 1860 to temuicostata, for no apparent reason except, perhaps, that of euphony, which is not recognized in specific nomenclature. The writer has, therefore, restored the first spelling.

It is interesting to note that this species extends from the Cretaceous into the Lower Eocene. The Wasatch shell was distinguished as micronema by White, but recently Mr. T. W. Stanton has expressed the opinion that it is the same as Meek's tenuicosta. A comparison of White's outline figure (pl. XVII, fig. 4) with Meek's figure of tenuicosta easily leads the student to the same conclusion. This species is also noteworthy for its wide geographical range, the most extensive of any known fossil species.

Pleurolimnæa tenuicosta whiteavesi. Nov. Var.

Limnaa tenuicostata Whiteaves, Rep. Geol. \& Nat. Hist. Surv. Can., 1886, n. ser., ii, p. 163 E, 1887.

Dr. Whiteaves has recorded a variety of tenuicosta from the Canadian Laramie, which should bear a name, as it is sufficiently distinct from the typical form of the species. The new variety has from 18 to 20 fine ribs or costæ on the outer whorl, instead of 8 to 12 as in typical tenuicosta. As this discrepancy would scarcely exist in specimens of the same species, it is proposed to give the name whiteavesi to the variety in honor of Dr. Whiteaves, the eminent Canadian paleontologist, new deceased.

A careful comparison should be made between this variety and the specimens from the vicinity of Township 39 referred to tenuicosta, to see if they may not all be of the multicostate form and so referable to the variety rather than to the typical form. 
Type: Canadian Geological Survey.

Horizon: Laramie, Cretaceous Period.

Locality: Blind Man River, Township 40, Range 1, west of the Fifth Principal Meridian, Saskatchewan.

Galba compactilis (Meek). Plate XVI, figure 23.

Limnca (Limnophysa?) compactilis MeEK, 6th An. Rep. U. S. Geol. Surv. Terr., p. 517, 1873; Bull. U. S. Geol. \& Geog. Surv. Terr., III, p. 611, 1877.White, 3rd An. Rep. U. S. Geol. Surv., p. 445, pl. 26, fig. 14, 1883.

Limnaa compactilis Miller, Journ. Cin. Soc. N. H., IV, p. 101, 1881; Mes. \& Cænoz. Geol., p. 243, 1881.

Limnaa? compactilis Marcou, Proc. Nat. Mus., VIII, p. 330, 1885.-Boyle, Bull. U. S. Geol. Surv., no. 102, pp. 167, 168, 1893.-Schuchert, Bull. U. S. Nat. Mus., 53, i, p. 355, 1905.

"Shell rather small, slender, subfusiform; spiral conical, a little longer than the aperture; volutions about six, very little convex, and (for a Limnæa) compactly wound together; last one not ventricose, but rather produced below; suture distinct though shallow, and but little oblique; aperture narrow subovate, very narrowly rounded below, and acutely angular above; outer lip not dilated; columella a little twisted, and apparently so as to form a small oblique plication. Surface smooth.

"Length of a medium-size specimen, 0.50 inch; breadth, 0.20 inch; length of aperture, 0.22 inch; breadth of aperture, 0.10 inch" (Meek).

Type: U. S. Nat. Mus. no. 820\%.

Horizon: Laramie, Cretaceous Period.

Locality: Separation Station, Union Pacific Railroad, Carbon County, southern Wyoming.

REMARKS: "I have not seen specimens of this little shell showing the columella clearly enough to be sure that it belongs to the genus Limnca. There is a compactness in the rolling together of the volutions of the spire, and a want of obliquity and deepness observable in the suture, they are not often seen in that genus, and remind one of some forms referred to sections of the old genus Bulimus, such, for instance, as B. (Thaumastus) californicus" (Meek).

This is a doubtful representative of Lymnaa. It is said by Dr. White to "probably belong to the genus Thaumastus, and not to Limnaa." The figures of White do show a close resemblance to recent species of Thaumastus, and it may, as suggested, belong to that genus rather than to Lymnca. The figures also bear a close resemblance to certain half-grown Lymnæas of the subgenus Stagnicola (reflexa, palustris, exilis, etc.), and it is included here to complete the list of extinct Lymnæas. Future research may place the species in Than- 
mastus or some allied genus. Dr. White does not mention this species in his list of Laramie mollusks in Bulletin 128, U. S. Geological Survey.

\section{LOWER EOCENE LYMNÆAS.}

Pleurolimnæa tenuicosta (M. \& H.). Plate XVI, figures 9-11. figures 9-11.

This species occurs in the Fort Union and Wasatch formations of the Lower Eocene Period. See ante, page 92.

Galba minuscula (White). Plate XVI, figures 16, $1 \%$.

Limnea minuscula White, Proc. U. S. Nat. Mus., III, p. 160, 1880.Miller, Journ. Cin. Soc. N. H., IV, p. 133, 1881; Mes. \& Cænoz. Geol., p. 275, 1881.-White, 3rd An. Rep. U. S. Geol. Surv., p. 445, pl. 29, figs. 24-25, 1882; Bull. U. S. Geol. Surv., no. 128, p. $80,1895$.

Limncea (Leptolimncea?) minuscula White, Amer. Journ. Sci. \& Arts, 3 ser., XX, p. 45, 1880 ; An. Mag. N. H., ser, 5, VI, p. 248, 1880 ; Bull. U. S. Geol. Surv., no. 34, pp. 11, 22, pl. 11, figs. 10-12, 1886.

"Shell rather small, moderately attenuate; spire much longer than the aperture; volutions six or seven, moderately convex, the distal border very narrowly appressed against each preceding coil; aperture small, elongate, subovate; columellar fold distinct, but not large. Surface marked by distinct lines of growth, but no revolving lines have been detected.

"The only two examples of this species that have been discovered are broken, but the full length of the larger one is estimated at 9 millimeters; diameter of last volution, 3 millimeters; length of aperture, $3 \mathrm{~T} / 2$ millimeters" (White).

Types: Cotypes, no. $890 \%$. Plesiotype, no. 20065, U. S. Nat. Mus.

Horizon: Wasatch, Lower Eocene Period; on the confines of the Green River (Bridger) and Wasatch formations.

Locality: Three miles east of Table Rock Station, Sweetwater County, southern Wyoming; Wales, Utah.

Remarks: This species is placed in Leptolimncea by White, but this disposition seems scarcely correct, as the whorls are not quite cylindrical enough to be typical of the group. It resembles elongate forms of the recent caperata Say and particularly the Pleistocene species anticostiana Dall. Its best disposition would seem to be in the subgenus Galba of the genus Galba.

MIDDLE EOCENE LYMNÆAS.

Galba vetusta (Meek). Plate XVI, figures 12, 13.

Limnaa vetusta Meek, Proc. Phil. Acad., p. 314, 1860.-Binney, L. \& F. W. Sh. N. A., II, p. 72, 1865.-Conrad, Smith. Check List, p. 9, 1866.-Meek, Simpson's Report, Great Basin, Utah, pp. 367, 373, pl. 5, fig. 3, 1876; Bull. U. S. Geol. \& Geog. Surv. Terr., III, p. 611, 1877.-White, Amer. Journ. Sci. \& Arts, ser. 3, XX, p. 45, 1880.-Miller, Jour. Cin. Soc. N. H., III, p. 82, 1880; Mes. 
\& Cænoz. Geol., p. 72, 1881.-White, 3rd An. Rep. U. S. Geol. Surv., p. 445, pl. 29, figs. 22-23, 1882 ; Bull. U. S. Geol. Surv., no. 128, p. 80, 1895.-Schuchert, Bull. U. S. Nat. Mus., 53, i, p. 357, 1905.

Limnaa (Limnophysa) vctusta MeEk, U. S. Geol. Surv. 40th Parallel, IV, p. 191, pl. 17, fig. 4, 1877.-Marcou, Proc. Nat. Mus., VIII, p. 337, 1885.

Lymnophysa vetusta White, An. Mag. Nat. Hist., ser. 5, VI, p. 249, 1880.

"SHELl small, elongate-subovate, or subfusiform; spire moderately prominent, conical, scarcely as long as the aperture; volutions five and a half to six, compressed-convex; last one not very ventricose, sometimes almost subcylindrical; suture well defined, with comparatively little obliquity; surface showing only obscure lines of growth; aperture very narrow, subovate; columella with a moderately distinct fold.

"Length, 0.56 inch; breadth, 0.26 inch" (Meek).

Type: U. S. Nat. Mus., no. 693.

Horizon: Bridger formation, Middle Eocene Period.

Locality: Ham's Fork, north of Fort Bridger, Uinta County, southwestern Wyoming.

REMARKS: "Among existing species this may be compared with L. decidiosa of Say, some varieties of which it quite nearly resembles. Its body volution, however, is less ventricose, and its aperture less expanded, than we see in any of the several forms that have been supposed to be varieties of that species. It is, perhaps, more nearly allied to some of the real or supposed varieties of L. humilis, Say; though not exactly agreeing with any of them. It varies much in form" (Meek).

$V$ etusta belongs in the subgenus Stagnicola. It closely resembles some of the recent species of the palustris-reflexa groups.

Galba similis (Meek). Plate XVI, figures 14, 15, 18, 19.

Limnaa similis Meek, Proc. Phil. Acad., p. 314, 1860--Binney, L. \& F. W. Sh. N. A., II, p. 72, 1865.-Conrad, Smith. Check List, p. 9, 1866.-MeEk, Simpson's Rep. Great Basin Utah, pp. 367, 373, pl. 5, fig. 2, 1876.-White, Bull. U. S. Geol. \& Geog. Surv. Terr., III, p. 611, 1877.-MeEk, U. S. Geol. Surv. 40th Parallel, IV, p. 191, pl. 17, fig. 3, 1877.-Whire; Amer. Journ. Sci. \& Arts, ser. 3, XX, p. 45, 1880.-Miller, Journ. Cin. Soc. N. H., III, p. 82, 1880.; Mes. \& Cænoz. Geol., p. 72, 1881.-White, 3rd An. Rep. U. S. Geol. Surv., p. 445, pl. 29, figs. 20-21, 1882.-Marcou, Proc. Nat. Mus., VIII, p. 337, 1885.-White, Bull. U. S. Geol. Surv., no. 128, p. 80, 1895.-Schuchert, Bull. U. S. Nat. Mus., 53, i, p. 356, 1905.

Limnophysa similis White, An. Mag. N. H., Ser. 5, VI, p. 249, 1880.

"SHELl small, narrow-subovate, approaching subfusiform; spire rather prominent, nearly as long as the aperture; volutions five and a half to six, convex; suture rather deep and oblique; surface showing only fine, obscure lines of growth, scarcely visible without the aid of 
a lens; aperture subovate, rather narrowly rounded below, and acutely angular above; columella twisted into a moderately prominent fold.

"Length, 0.39 inch; breadth, 0.19 inch; apical angle slightly convex, divergence about $38^{\circ}$ " (Meek).

TyPE: U. S. Nat. Mus., nos. $692,694$.

Horizon: Bridger formation, Middle Eocene Period.

Locality: Ham's Fork, north of Fort Bridger, Uinta County, southwestern Wyoming.

REMARKS: "This variable form is so closely allied to the last that I am nearly satisfied that it is only a variety of the same. Its chief difference consists in having the volutions of its spire a little more convex, and more drawn out, as it were, so as to give decidedly greater obliquity to the suture. It seems to be even more nearly allied to some of the more slender forms regarded by Mr. Binney as varieties of L. humilis of Say; though it is a decidedly more attenuated, less compact shell than that represented by Mr. Binney's figure of $L$. $h u$ milis, given on page 63 of his 'Land and Fresh-Water Shells,' published by the Smithsonian Institution. There is scarcely any probability, however, that our shell is identical with any of the existing species" (Meek).

Meek calls attention to the similarity between this species and vetusta; there is, however, considerable difference, not only in size, but in the general shape of the whorls. Its generic affinities seem to be with Stagnicola.

There seems to be some discrepancy between the figures of this species in Simpson's Utah report and in the Fortieth Parallel report. The latter agree better with the description, in some respects, than do the former, which fail to show the columella fold and deep sutures mentioned by Meek. The figures from both reports are shown on plate XVI. Figures 18-19 are the same as those used by White in Bulletin 128, U. S. Geol. Surv. (See ante, p. 91.) It is possible that these figures represent a third species.

\section{OLIGOCENE LYMN瓜AS.}

Galba diaphana (Evans \& Shumard). Unfigured.

Lymnea diaphana Evans \& Shumard, Proc. Phil. Acad., p. 165, 1854.Hayden, Proc. Phil. Acad., p. 158, 1857.

Limnea diaphana M. \& H., Proc. Phil. Acad., 1856, p. 278.

Limnaa diaphana MeEk, Smithsonian Check List, p. 13, 1864.-Binney, L. \& F. W. Sh. N. A., II, p. 72, 1865.-White, Bull. U. S. Geol. \& Geog. Surv. Terr., III, p. 613, 1877.-Miller, Journ. Cin. Soc. N. H., III, p. 272, 1880; Mes. \& Cænoz. Geol., p. 174, 1881. 
"Shell small, oblong, ovate-conic; whorls five, convex, crossed by delicate lines of growth, spire short, acute at apex; aperture oval, slightly dilated, rather larger than half the length of the shell; columella rather delicate and sinuate, umbilicus minute.

"Length, $21 / 2$ lines; width, $1 \frac{1}{4}$ lines ; length of aperture, $1 \frac{1}{2}$ lines" (Evans and Shumard).

TyPE: Location not ascertained.

Horizon: White River formation, Oligocene Period.

Locality: Peno Creek, a tributary of the Little Missouri River, South Dakota, about ninety miles from Pierre Chateau (now Pierre).

REMARKs: It is unfortunate that this species has never been figured. From the description it would seem to have group affinities with Stagnicola.

Galba nebrascensis (Evans \& Shumard). Unfigured.

Lymnea nebrascensis Evans and Shumard, Proc. Phil. Acad., p. 165, 1854. -HAyden, Proc. Phil. Acad., p. 158, 1857.

Limnea nebrascensis M. \& H., Proc. Phil. Acad., p. 278, 1856.

Limnaa nebrascensis MeEK, Smithsonian Check List, p. 13, 1864.-Binney, L. \& F. W. Sh. N. A., II, p. 72, 1865.-WhiтE, Bull. U. S. Geol. \& Geog. Surv. Terr., III, p. 613, 1877.-Miller, Journ. Cin. Soc. N. H., III, p. 272, 1880; Mes. \& Cænoz. Geol., p. 174, 1881.

"Shell ovate, sub-conic; volutions five, convex, crossed by minute, elevated lines of growth; body whorl ventricose, more than twice the length of spire; spire short, apex pointed, suture not deeply impressed; lip. produced in front.

"Length, 5 $5 / 2$ lines; length of body whorl, 4 lines; width, about $21 / 2$ lines" (Evans and Shumard).

TYPE: Location not ascertained.

Horizon: White River formation, Oligocene Period.

Locality: Peno Creek, about ninety miles from Pierre Chateau (now Pierre), South Dakota.

REMARKS: "All the specimens in our possession are very much compressed and otherwise mutilated, so that the form and character of the aperture cannot be determined. It is very similar to the preceding species, from which it is distinguished by its greater size and its numerous crowded striæ" (Evans and Shumard).

The same opinion applies to nebrascensis as that expressed above for diaphana. 25 .

Galba meekiana (Evans \& Shumard). Plate XVI, figures 24,

Limnca meekiana Evans \& Shumard, Ms.-Meek and Hayden, Proc. Phil. Acad., p. 431, 1860; Meek, Smithsonian Check List, p. 13, 1964.-Binney, 
L. \& F. W. Sh. N. A., II, p. 72, 1865.-MeEk, U. S. Geol. Surv. Terr., IX, p. 598, pl. 45, fig. 5, 1876.-White, Bull. U. S. Geol. \& Geog. Surv., Terr., III, p. 613, 1877; 3rd An. Rep. U. S. Geol. Surv., p. 446, pl. 32, figs. 26-27, 1882.

Lymnaa meekii Cockerell, Nautilus, XXII, p. 70, 1908.

"Shell rather large, conical-subovate; spire less than half the length of the shell, acutely pointed at the apex; volutions five and a half to six, convex, last one ventricose, and comparatively large; suture well defined. Aperture rather narrow-ovate, angular above and rounded below; lip slightly dilated at the lower part of the columella; surface marked by moderately distinct lines of growth.

"Length, 1.15 inches; breadth, 0.66 inch; apical angle nearly regular, divergence $54^{\circ}$." (Meek.)

TYPE: Location not ascertained.

Horizon: White River formation, Oligocene Period.

Locality: Pinot's Creek, South Dakota.

REMARKS: "This fine Limnea is quite similar to several of the species figured by Edwards in his Monograph of the Eocene Mollusca of England, published by the Palæontographical Society, but seems to present well-defined specific differences from them all." (Meek.)

Meekiana is strongly suggestive of some specimens of the recent Galba catascopium Say. It is one of the largest of the fossil Lymnæas (excepting Stearn's maxima) as well as one of the most characteristic. For some reason not apparent to the writer, Dr. White used the specific name meekii in his report on the non-marine Mollusca, instead of the original name meckiana. There seems to be no warrant for changing the name, other than that of classical purity, which, as remarked before, cannot be taken into account in systematic nomenclature, where stability is of the first importance.

Galba shumardi (Meek). Plate XVI, figures 26;2\%.

Limnca shumardi MeEK, U. S. Geol. Surv. Terr., IX, p. 599, pl. 45, fig. 6, 1876.-White, Bull. U. S. Geol. \& Geog. Surv. Terr., III, p. 613, 1877.-Miller, Journ. Cin. Soc. Nat. H., IV, p. 111, 1881; Mes. \& Cænoz. Geol., p. 253, 1881.White, 3rd An. Rep. U. S. Geol. Surv., p. 446, pl. 32, figs. 28-29, 1883.Marcou, Proc. U. S. Nat. Mus., VIII, p. 340, 1885.-Schuchert, Bull. U. S. Mus., 53, i, p. 356, 1905.

Lymnaa shumardi Cockerell, Nautilus, XXII, p. 70, 1908.

"SHELl rhombic-subovate; spire less than half the entire length, very acute at the apex; volutions five and a half, convex, last one not ventricose, rather oblique; suture moderately well defined; surface marked by distinct lines of growth, and sometimes having, on the upper part of the body-whorl, a few broad, obscure, vertical or oblique folds; aperture ovate, rounded below, and angular above. 
"Length, 0.81 inch; breadth, 0.51 inch; length of aperture, 0.49 inch; breadth of same, 0.26 inch; apical angle nearly regular, divergence $54^{\circ} . "$ (Meek.)

Type: U. S. Nat. Mus. no. 2119 (Holotype).

Horizon: White River formation, Oligocene Period.

Locality: Pinot's Creek, South Dakota.

Remarks: "It is possible that this may not be distinct from the last, though I have not yet seen intermediate gradations between these forms. The shell here under consideration differs from the preceding in being smaller and proportionally more slender; while its body-whorl is much less ventricose and more oblique. It also differs in sometimes showing a tendency to form obscure folds on the upper part of the last volution. It is named in honor of the late Dr. B. F. Shumard, formerly State Geologist of Texas.” (Meek.)

As remarked by Meek, this species may be a variety of the preceding. It strongly resembles meekiana in the general form of the shell, but the aperture is differently shaped. A large series might show some interesting gradations.

Galba scudderi (Cockerell). Plate XVII, figure 13.

Lymnca scudderi Cockerell, Bull. Amer. Mus. Nat. Hist., XXII, p. 461, fig. 4, a, b, 1906; Nautilus, XXII, p. 70, 1908.-Bather, Proc. Geol. Assoc., XXI, pt. 3, p. 161, 1909.

"Shell: Length, about $6 \mathrm{~mm}$.; breadth, about 4 ; the spire short, about $1 \mathrm{r} / 2 \mathrm{~mm}$.; smooth and shining, without any strong sculpture; apex obtuse.

"Florissant, Station I (Rohwer) and Station 14 (W. P. Cockerell); not uncommon.

"Var. a. Smaller and more slender; long. 5, lat. $3 \mathrm{~mm}$.; length of aperture about $3 \mathrm{~mm}$; whorls only slightly convex. Station 12 (W. P. Cockerell). Station 12 is on the west side of Fossil Stump Hill." (Ckll.)

Type: University of Colorado.

Horizon: Florissant formation, Oligocene Period.

Locality: Stations 1, 12 and 14, vicinity of Florissant, Teller County, Colorado.

Remarks: This little species appears to group with the cubensistechella group of Lymnæas and may have been the ancestral stock from which these species sprang. Their imperfect condition renders their group affinities difficult to place with any degree of accuracy. 
"The species is named in honor of Mr. Scudder, who first indicated the presence of Mollusca in these beds." (Ckll.)

Galba sieverti (Cockrell). Plate XVII, figure 14.

Lymnaa sieverti Cockerell, Bull. Amer. Mus. Nat. Hist., XXII, p. 461, fig. 3, 1906; Nautilus, XXII, p. 70, 1908.

"Shell: "Long. $8 \mathrm{~mm}$., lat. 4r/4, with about five rounded whorls; length of aperture about $5 \mathrm{~mm}$.; sutures impressed; sculpture weak; aperture. contracted." (Ckll.)

TYPE: University of Colorado.

Horizon: Florissant formation; Oligocene Period.

Locality: Station 1, vicinity of Florissant, Teller County, Colorado.

Remarks: "This has the pointed spire of L. meekii Evans and Shumard, of the White River group, but it is much smaller and has more rounded whorls. The elongate narrow aperture is more like that of L. meekii than of L. shumardi Meek and Hayden. The much more convex whorls distinguish it from $L$. similis Meek, and L. vetusta Meek, from the Bridger Eocene.

"The specimen shows the interior of the shell, and the outside of a portion near the mouth. It is of course dextral, though from the manner of its preservation the aperture shows on the left side." (Ckll.)

Sieverti is a neat little species, having affinities, apparently, with the truncatula group of Lymnæas.

Galba florissantica (Cockerell). Plate XVII, figure 5.

Lymnaa florissantica CockerelL, Nautilus XXII, p. 69, November, 1908.

"Shell: "Length, $21 \mathrm{~mm}$.; diameter, about 101/2; spire short, scarcely over $5 \mathrm{~mm}$. long, the whorls moderately convex; body-whorl not very convex, with coarse, shallow, vertical grooves." (Ckll.)

TyPE: University of Colorado.

Horizon: Florissant formation, Oligocene Period.

Locality: Station 1, near Florissant, Teller County, Colorado.

Remarks: Prof. Cockerell (op. cit.) believes that this species is a Miocene representative of Galba emarginata. Emarginata is, however, quite different (see the figures and descriptions in the systematic portion of this work) and, in fact, is a modern species, possibly differentiated since the Glacial Period. The general shape of the fossil, so far as that can be made out from the photograph of the rather imperfect specimen kindly provided by Prof. Cockerell, would seem to place it in the palustris group of Lymnæas. It is quite unlike the other described species of the Oligocene Period. 


\section{MIDDLE MIOCENE LYMNAAS.}

Lymnæa stearnsi Hannibal, Ms. Plate XVII, figure 11.

Limnaa maxima Stearns, Science, N. S., XX, p. 154, 1902; Univ. Cal. Pub., Geology, V, p. 70, fig. 1, 1906. (Not Limncea stagnalis var maxima CoLLIN, Ann. Soc. Mal. Belg., VII, p. 94, 1872.)

"Partly exposed in portions of a fine compressed sediment of lacustrine origin are several casts of a very large Limnca, suggestive in a general way of the circumboreal stagnalis, but so much distorted as to preclude a more definite description." (Stearns.)

TyPE: Uni. Cal., Coll. Invert., no. 10002.

Horizon: Mascall beds, Middle Miocene Period.

Locality: Three-quarters of a mile east of Belshaw's ranch, Grant County, John Day Valley, Oregon.

REMARKS: The known specimens of stearnsi are so imperfect as to preclude an accurate discussion of the relationship of the species. Apparently it was a species similar to the recent stagnalis, judging by the size and form of the casts, and there is good reason to believe that it is a representative of the early Asiatic invasion and, hence, an ancestor of the recent Lymnaa stagnalis. More material is highly desirable, especially those showing the external character of the shell. Of the known fossil Lymnæas, stearnsi is the nearest approach to the typical genus, containing the circumboreal stagnalis.

\section{PLIOCENE LYMNAEAS. \\ Polyrhytis kingii (Meek). Plate XVII, figures 1, 2.}

Limncea (Polyrhytis) kingii MeEk, U. S. Geol. Surv. Terr., IX, p. 532, 1876; U. S. Geol. Surv. 40th Parallel, IV, p. 192, figs. 6, 7, 1877.-White, Bull. U. S. Geol. \& Geog. Surv., III, p. 614, 1877.-Marcou, Proc. Nat. Mus., VIII, p. 340, 1885.-Schuchert, Bull. U. S. Nat. Mus., 53, i, p. 356, 1905.

Limnca kingi, Miller, Journ. Cin. Soc. Nat. H., IV, p. 121, 1881.-White, 3rd An. Rep. U. S. Geol. Surv., p. 446, pl. 32, figs. 30-31, 1883.-TRYon, Struct. and Syst. Conch., III, p. 101, 1884.-BAKER, Science, n. s., XXVII, p. 943, 1908.

Lymnca, sp., King, U, S. Geol. Surv: 40th Parallel,.I, p. 436, 1878.

"Shell: Ovate; spire short; volutions about four, convex, rapidly increasing in size, last one very large and ventricose; suture well defined; aperture large, subovate; columella apparently with a moderately well-developed fold; surface ornamented by regular, distinct vrtical costæ, that are strongly defined on the body-volution, but more obscure or nearly obsolete on the spire.

"Length, 0.73 inch; breadth, about 0.43 inch." (Meek.)

Type: U. S. Nat. Mus., no. 8097 (Holotype). 
Horizon: Cache Valley beds, Humboldt Group, Pliocene Period. Locality: Cache Valley, Cache County, Utah.

REMARKS: "This species is remarkable for having its surface ornamented by a very regular, vertical costæ, quite strongly defined on its body-volution. This character will readily distinguish it from any other species, either recent or fossil, known to me, and, with its other characters, forbid its reference to any of the established subgenera. In the possession of ribs, it agrees with Pleurolimncea, but it differs extremely in form from that type. I have therefore proposed for its reception a new subgenus under the name Polyrhytis.

"I have seen but a single specimen of this shell, consisting of a well-defined mould, from which a gutta-percha cast has been taken, and from this the figures and description were prepared. The specific name is given in honor of Clarence King, Esq., the geologist-in-charge of the Survey of the Fortieth Parallel." (Meek.)

Lymnca kingii and Lymnca tenuicosta were, until recently, unique among Lymnæas, living or extinct, in the possession of strong longitudinal ribs. Meek (op. cit. 1876) erected the subgenus Polyrhytis for this species, giving the principal diagnostic character as "much like the last (Radix) in form, but bearing distinct regular, vertical costæ." In $1884,{ }^{1} \mathrm{R}$. E. Call described a recent Lymnca (Lymnca ampla var. utahensis) from Lehi, Lake Utah, which is certainly congeneric with kingii and which may well be the descendant of the Pliocene fossil, having the shape of that species as well as the peculiar longitudinal costæ. Call's figures are not good and do not correctly represent the species. A good series of kingii is a desideratum in order that comparison may be made with the recent species.

It is thought by geologists ${ }^{2}$ that the area of the Great Basin, in Utah, has formed in ages past a huge lake (Lake Shoshone), and it seems not at all unlikely that this unique Lymnæid is the lineal ancestor of Call's utahensis.

Galba contracosta (Cooper). Plate XVII, figure 12.

Limnaa contracosta J. G. Cooper, Proc. Cal. Acad. Sci., ii, IV, p. 169, pl. 14, fig. 12, 1894.-Merria m, Bull. Dept. Geol., Univ. Cal., 1, p. 363, 1896.Lawson and Palache, 1. c., II, p. 391, 1902.

Limnea contracosta J. G. Cooper, Bull. Cal. State Mining Bureau, IV, p. 36, pl. 5, fig. 59, 1894.

Shell: "Form broadly ovate, whorls five, rapidly enlarging from an obtuse apex, and with convex outlines to the very large body whorl,

1Bul, U. S. Geol, Surv, no. 11, p. 47.

'King, Geol. 40th Parallel, Vol. I, p. 359-458. 
which forms three-fourths of the total length; no umbilical fissure visible. Length, 1.20 inches; breadth, 0.75 ; spire, $0.30 . "$

TYPE: Location not ascertained.

Horizon : Contra Costa Lake bed, Merced series, Pliocene Period.

Locality: California. In thin stratum of Lignite on a small branch of San Pablo Creek, on the road going east to Lafayette, Contra Costa County (Cooper); top of Eureka Hill, Berkeley Hills; north base of Baldy Hill, Berkeley Hills, Alameda County (Hannibal).

"Specimens found with the two next species in a bed of laminated lignite, discovered about 1868, along the westerly branch of San Pablo Creek, on the state road just south of Rocky Mound. A thin stratum of lignite underlies several square miles around that locality, but its exact age is still unsettled. On the east are deposits of marine Miocene fossils, on the west altered Cretaceous rocks with 'Aucella piochii.' The lignite may, therefore, be a deposit formed in a Pliocene lake. None of the other Tertiary fresh-water deposits yet examined in California contain fossils like this. The coal strata have evidently been uplifted to an angle unusual in Pliocene deposits, but there is nothing to fix the date of the volcanic outburst which is seen in Rocky Mound, three and a half miles distant." Cooper also says: "The shells were crushed flat, but their outlines were so perfect and white in contrast with the black shale that I had no difficulty in making perfect tracings of them. The figures are of natural size."

The figure resembles a land shell (Bulimulus?) more than it does a Lymnaa; if a Lymnaa, it is exceedingly difficult to place in one of the modern groups. It somewhat resembles the recent Galba apicina.

Galba alamosensis (Arnold). Plate XVII, figures 9, 10.

Lymnaa alamosensis Arnold and Anderson, Bull. U. S. Geol. Surv., no. 322, p. 59, pl. XXI, figs. 6, 7, 1907.

Lymnaa alamosensis Arnold, Smith. Mis. Coll., L, p. 430, pl. 54, figs. 6, 7, 1908 ; Nautilus, XXII, p. 36, 1908.

"Adult shell averaging about 6 or 7 millimeters in altitude, broadly spindle-shaped, spire elevated, apex rounded. Whorls four, bulging, more convex posteriorly than anteriorly; outline of body whorl regularly arcuate; a faint ridge crowns the posterior margin of each whorl where it presses against the antecedent whorl. Suture appressed, slightly sinuous, distinct; sculpture consisting of numerous microscopic incremental lines, which are somewhat better developed on the posterior portion of the whorl, and occasional faint spiral striæ; a hard, glossy epidermis is preserved on some of the specimens. Aperture suboval, narrowing posteriorly; outer lip protruding anteriorly, thickened into 
overhanging flange internally, and flaring from posterior extremity as far around as umbilical region; a minute umbilical chink is visible in most specimens.

"Dimensions: Altitude, $6 \mathrm{~mm}$. ; latitude, $3 \mathrm{~mm}$. ; altitude of body whorl, $4.9 \mathrm{~mm}$.; longitude of aperture, $3 \mathrm{~mm}$.; latitude of aperture, $1.5 \mathrm{~mm}$. (Arnold.)

Type: U. S. Nat. Mus. no. 165426 ; cotypes, two specimens, Chicago Academy of Sciences, no. 24678.

Horizon: Fernando formation, Pliocene Period; fresh-water portion at top.

Locality: One mile southeast of bench-mark 425, Los Alamos Valley, Santa Barbara County, California.

Remarks: "This unique little fossil occurs in a peculiar finegrained gray clay in the upper portion of the Fernando formation, where, at the type locality, near Los Alamos, it is quite abundant. No other fresh-water species were found associated with it." (Arnold.)

This is a peculiar little species recalling some forms of the recent Galba capcrata (Say). It also resembles immature individuals of Galba catascopium (Say), especially certain specimens from Ottawa, Ontario, Canada. The species is, however, quite unlike any west coast Lymnæid living at the present time. It may possibly be an immature stage of a much larger species. It is placed tentatively in Stagnicola. Additional material will probably settle the question of its affinities.

PLEISTOCENE LYMN EAS.

Galba bonnevillensis (Call). Plate XVII, figures 6-8.

Limncea catascopium? Hayden, Prel. Rep. U. S. Geol. Surv. Wyoming, p. $170,1871$.

Limnophysa bonnevillensis CALL, Bull. U. S. Geol. Surv., no. 11, pp. 18, 24, 28, 48, pl. 6, figs. 10-13, 1884 ; Proc. Daven. Acad. Sci., V, p. 6, pl. 1, figs. 10-13, 1886,-Gilbert, Mon., U. S. Geol. Surv., I, pp. 210, 298, 1890.

Limnaa bonnevillensis Stearns, Proc. Nat. Mus., XXIV, p. 291, 1901.

"Shell umbilicated, elongate, ventricose or bullate, somewhat solid, faintly striate and very minutely reticulated, below the suture the last whorl bearing faint longitudinal ridges or costæ; spire elevated, acute; suture deeply impressed; whorls 4 to $4 \frac{1}{2} 2$, very much rounded, sometimes tending to geniculation above, the last whorl equal to threefourths the whole length of the shell, rapidly increasing in size, much swollen, somewhat expanded at base; columella somewhat plicate, slightly callous, regularly arcuate; columella and peristome continuous ; peristome simple, margins joined by a heavy callous which is con- 
tinuous and so reflexed as to partially close the umbilicus; aperture broadly ovate, often patulous, equal to one-half the entire length of the shell, oblique, angled slightly behind." (Call.)

$\begin{array}{rccccc}\text { Length. } & \text { Width. } & \begin{array}{c}\text { Aperture } \\ \text { Length. }\end{array} & \text { Width. Mill. } & \text { (Call.) } \\ 15.00 & 7.80 & & & & \\ 9.40 & 5.20 & & & & \\ 18.50 & 6.00 & & & \text { " } & \\ 12.50 & 7.50 & 6.50 & 3.10 & \text { Servier Lake } \\ 11.50 & 8.00 & 6.25 & .3 .50 & \text { " } & \text { " }\end{array}$

TyPes: Smithsonian Institution, 7 specimens (No. 53672); cotypes, Acad. Nat. Sci. Phil., (No. 73738).

Horizon: Upper Bonneville and Lahontan beds, Pleistocene Period. In white marl.

Locality: Bonneville beds; Bear Lake, Rich County; Kelton, Box Elder County; Fish Spring Valley and Willow Springs, Juab County; Servier Lake, Millard County; Ancient Lake Terrace, Salt Lake County, Utah. Lahontan beds; Rye Patch, Humboldt County, Nevada.

Remarks: Bonnevillensis is a peculiar little species bearing no particular resemblance to any recent species excepting, perhaps, certain forms of catascopium. Some specimens recall the recent Galba apicina although the spire is longer and the shell slenderer. Call's figures are not good and give a rather false idea of the species, being rather too short and wide. Some specimens resemble certain forms of the recently described Jacksonensis Baker. The form of the shell varies, in some individuals being long and somewhat scalariform, while in others it is short and quite globose. The Lake Servier shells appear to be variations of bonnevillensis and are not referable to catascopium. The shells mentioned by Hayden as catascopium are also probably this species.

Some of the Lymnæas mentioned by Gilbert in the survey west of the 100 th meridian probably refer to this species, as specimens of bonnevillensis in the Smithsonian collection refer to this expedition.

Galba anticostiana (Dall). Plate XLVI, figures 16, $1 \%$.

Limnca acuta BeLL, Can. Nat. \& Geol., IV, p. 213, 1859 (not of Lea).

Lymnaa (Stagnicola) anticostiana DAll, Alaska Moll., p. 79, p1. 2, figs. $4,5,1905$.

Lymnea anticostiana PILSBRy, Nautilus, XIX, p. 95, 1905.

SHell: Slender, very acutely conical, turreted; color pure white (fossil specimens); lines of growth fine, cloṣe set, irregularly raised to form elevated ridges; spiral striation well marked; some specimens 
are somewhat malleated and in a few cases there are a few obscure revolving ridges; whorls \%, convex, very slowly increasing in size, the body whorl slightly compressed laterally in the majority of specimens; nucleus reddish, flattened; spire very acutely conical, $11 / 2$ times the length of the aperture; sutures deeply impressed; aperture elongateovate, continuous; outer lip thin on the edge, but thickened within by a well marked, heavy varix; inner lip reflected over but not closing the umbilicus, leaving a well-marked chink; parietal callus rather heavy and tightly appressed; the columella is covered by a distinct fold, somewhat resembling a tooth.

$\begin{array}{ccccl}\text { Length. } & \text { Width. } & \begin{array}{c}\text { Aperture } \\ \text { Length. }\end{array} & \text { Width. } & \\ 19.00 & 7.00 & 7.00 & 4.50 \mathrm{mill} . & \text { type. } \\ 15.10 & 6.25 & 6.00 & 2.50 \% & \text { cotype. } \\ 13.50 & 5.50 & 5.50 & 2.50 " & \text { cotype. }\end{array}$

TyPES: Smithsonian Institution, 5 specimens, No. 162\%21.

Cotypes: Two specimens Chicago Acad. Sci., No. 23875.

Horizon: Pleistocene marls.

Locality: Marl Lake, Anticosti Island, Canada.

Remarks: Anticostiana is a very distinct species, exactly comparable with no other species of American Lymnæid. It has a faint resemblance to some forms of desidiosa and also to elongated forms of obrussa. It is, however, distinct from both these species. It is probably an extinct species, as nothing like it has been seen in the multitude of specimens examined during the preparation of this monograph. This is undoubtedly the shell mentioned by Bell (op. cit.) as "the most abundant species in the shell marl from Marl Lake, Anticosti."

Galba bakeri (Walker). Plate IV, figure C.

Lymnca bakeri WaLKer, Nautilus, XXII, p. 18, pl. ii, figs. 11-12, June, 1908.

"Shell: Slender, elongate, perforate; whorls 5; spire elongated, turreted; apex acute; body whorl narrow, elongated, compressed below ; suture deeply impressed; lines of growth fine and regular with fine subobsolete, revolving, spiral lines; aperture narrow, elongated, within the flare of the lip, the sides are nearly parallel, and about equally rounded above and below; lip thin, sharp, suddenly and broadly expanded, subreflected, continuous, not appressed to the parietal wall, and roundly reflected over the perforation, columella straight, without a fold; axis round and smooth.

“Alt. 16.5, diam. 7.5, length ap. 8.5, width $4.5 \mathrm{~mm} . "$ (Walker).

TYPE: Coll. Bryant Walker, No. 9353.

Horizon: Pleistocene Marls of Michigan.

Locality: Pine Lake, Charlevoix County, Michigan. 
REMARKs: "This remarkable species was dredged from the marl bottom of Pine Lake. No living specimens were found, and in all probability it is extinct. In its external characteristics it is more nearly related to $L$. jayi Dunker (gracilis Jay) than to any other of the described species, but the resemblance is a general one only, the two species differing in nearly every detail. The continuous, free lip and straight columella are exceedingly like those of jayi, and would naturally cause it to be referred to the subgenus Acella. But the axis is not gyrate, as in that group, but is rounded and without a fold, as in Galba.

"The young shell is subcylindrical, and with its heavily shouldered, turreted whorls and narrow aperture reminds one of the curious $L$. contracta Currier from Houghton Lake. I take pleasure in dedicating this very peculiar species to Mr. Frank C. Baker, of the Chicago Academy of Sciences, who has made a special study of the North American Lymnæas."

Galba nashotahensis (Baker). Plate XLVI, figures 18-24.

Lymncea nashotahensis BAKER, Nautilus, XXIII, p. 19, June, 1909.

SHELL: Elongated, somewhat pyramidal; surface dull, growth lines conspicuous, crossed by fine impressed spiral lines; whorls 6$6 \mathrm{I} / 2$, rather rapidly increasing in diameter, flatly rounded, the body whorl very large and quite convex, or even gibbous; spire broadly pyramidal or conic, longer than the aperture; sutures well marked; aperture elongate ovate, much narrowed above, generally wide and flaring below; outer lip with varical thickening; inner lip rather broad, reflected over the umbilical region, forming a conspicuous expansion and leaving a well marked umbilical chink; parietal callus wide and rather thick, in some specimens rendering the aperture continuous; axis twisted; the columella is plicate in the immature shell but in adult or old specimens the inner lip is raised over the umbilicus, somewhat as in emarginata.

$\begin{array}{cccc}\text { Length. } & \text { Breadth. } & \text { Aperture Length. } & \text { Breadth. } \\ 33.50 & 13.00 & 14.00 & 7.00 \text { mill. } \\ 29.00 & 13.00 & 15.00 & 6.75 \text { " } \\ 28.75 & 13.50 & 15.75 & 7.00 \text { " } \\ 25.00 & 12.00 & 14.00 & 7.25 \text { " } \\ 21.00 & 10.00 & 12.00 & 6.00 \text { " } \\ 24.00 & 10.00 & 11.00 & 5.00 \text { " } \\ 18.25 & 8.25 & 10.00 & 4.25 \text { " }\end{array}$

Types: The Chicago Academy of Sciences, 7 specimens, No. 24539 ; Cotypes, Academy of Natural Sciences, Philadelphia.

Horizon: Pleistocene Marls of Wisconsin. 
Locality: Nashotah, Waukesha County, Wisconsin.

REMARKS: Nashotahensis was at first thought to be a form of Galba daniclsi; it differs markedly from that species, however, in several particulars-the spire is broader and not so acute, the body whorl is larger and inclined to be gibbous, there is a conspicuous umbilical chink (danielsi is usually imperforate) and the columella is not noticeably plicate. In nashotahensis the aperture is elongate ovate, narrowed above and broadened below where it is often patulous. The upper whorls are strongly suggestive of Galba reflexa, the penultimate whorl having the swollen appearance so characteristic of reflexa.

Young specimens somewhat resemble Galba catascopium, differing in being narrower, with a more elongate aperture, longer and less rounded whorls and a less distinctly plicate columella. There is also an umbilical chink which is usually absent in catascopium. Certain specimens from the marl beds at Kegobic, Michigan, seem referable to this species. Nashotahensis was probably contemporaneous with one of the glacial stages of the Great Lakes.

Like Walker's Galba bakeri from Michigan, nashotahensis is an extinct species peculiar to the marl deposits. The specimens were secured by Mr. F. M. Woodruff.

DOUBTFUL LYMNAAS AND SPECIES WRONGLY REFERRED TO THIS FAMILY.

There have been a number of references to the occurrence of Lymnaa in Mesozoic and Tertiary strata, where the determinations apparently have never been made. There are also several cases in which the species, on more careful examination with additional material, have been found to belong to another family of mollusks. These are listed below.

\section{Lymnæa Sp.}

Limnaa? Upper Kanab, Utah; White, Rep. Geol. Uinta Mts., p. 100, 1876.

\section{Lymnæa Sp.}

Limncea sp.? Pliocene, Cache Valley; Peale, An. Rep. U. S. Geol. \& Geog. Surv. Terr., XI, p. 640, 1879 (possibly the same as Meek's Kingi).

\section{Lymnæa Sp.}

Limncea sp., Darton, Bull. Geol. Soc. Amer., XIX, p. 446, 1908.-Darton and Siebenthal, Bull. U. S. Geol. Surv., 364, p. 30, 1909.

Horizon: Morrison, Comanchean Period.

Locality: West of Downey Lakes, in the N. W. $1 / 4$, Sec. 15, T. 13 N., R. 75 W., Southern Wyoming.

\section{Lymnæa Sp.}

Acella $s p$. Whiteaves, Con. Can. Pal., I, p. 13, 1885.

"A few fragments of an Acella were collected by Dr. G. M. Dawson in 1874 and 1881 . Dr. C. A. White, to whom these specimens 
were sent, regards them as distinct from his $A$. haldemani, but they are too imperfect to admit of an accurate description of their characters." (Whiteaves.)

TyPe: Canadian Geological Survey.

Horizon : St. Mary River series, Laramie, Cretaceous Period.

Locality: North or second branch of Milk River, Alberta.

Remarks: This indeterminable Lymnæid may prove to belong to White's auriculoid genus Tortacella. As its generic affinities are uncertain, it is included here.

\section{Lymnæa Sp.}

Limnca sp.? Stanton and Knowlton, Bull. Geol. Soc. Amer., VIII, pp. 131, 135, 1897.-Stanton, Proc. Wash. Acad. Sci., XI, p. 244, 1909; 1. c. XI, p. 260, 1909.-Knowlton, Proc. Wash. Acad. Sci., XI, p. 227, 1909.

Horizon: Ceratops beds, Laramie, Cretaceous Period.

Locality: One and one-half miles south of U-L ranch, Converse County, Wyoming; northeast of George Moore's ranch, Section 16, Township 6, Sweetgrass County, Montana.

Remarks: This Lymnæid has not been identified, so far as known, and its generic affinities are of course unknown.

Lymnæa Sp. Plate XVII, figure 3.

Limnca?? Whiтe, Bull. U. S. Geol. Surv., 34, pp. 11, 22, pl. 2, fig. 13, 1886.

"A single imperfect example was found at the Wales locality, which evidently belongs to the genus Limnca and the general aspect of which is like that of the living species, L. columella. No species of Limnaa is yet known from either the Laramie or the Wasatch Group, to which this form can be properly referred; but it is possible that it is only a variety of the $L$. similis of Meek, from the Bridger Group of Southern Wyoming. This specimen is too imperfect to allow of a satisfactory specific description" (White).

Horizon: Wasatch formation, Lower Eocene Period.

Locality: Wales, Utah.

Remarks: Dr. White compares this Lymnæid with the recent columella, but it seems to be more nearly like some species of the recent catascopium group, and hence a Stagnicola. It also seems quite different from Meek's similis. What its true affinities really are can only be accurately determined by the study of additional material.

Acella haldemani (White).

Acella haldemani WhiтE, Bull. U. S. Geol. Surv. Terr., IV, p. 714, $1878=$ Tortacella haldemani, a genus of Auriculidx.

Bear River formation (Cretaceous). 
Limnæa? multistriata (Meek and Hayden).

Limnca? multistriata MeeK and Hayden, Proc. Phil. Acad., p. 431, $1860=$ Melania multistriata, M. \& H., 1. c. 1857, p. 124 = Campeloma multistriata.

Laramie formation (Cretaceous).

\section{BIBLIOGRAPHY OF AMERICAN FOSSIL LYMNÆAS.}

The following bibliography is believed to be measurably complete. As references to fossil Lymnæas are so widely scattered, many of them being in inaccessible publications, absolute completeness cannot be claimed, but it is thought that all of the more important references are here included. ${ }^{1}$

Anderson, Robert.

1907. See Arnold, Ralph.

Arnold, Ralph and Anderson, Robert.

1907. Geology and Oil Resources of the Santa Maria Oil District, Santa Barbara County, California. Bull. U. S. Geol. Surv., No. 322, 1907. Arnold, Ralph.

1908. New and Characteristic Species of Fossil Mollusks from the Oilbearing Tertiary Formation of Santa Barbara County, California. Smith. Mis. Coll., L, p. 419, 1908.

Aughey, Samuel.

(Review in Nautilus, XXII, p. 36.)

1876. The Superficial Deposits of Nebraska. An. Rep. U. S. Geol. and Geog. Surv. Colo. and Adjoining Territory, 1874, pp. 243-269.

1880. Sketches of the Physical Geography and Geology of Nebraska. p. 326.

Bather, F. A.

1909. Visit to the Florissant Exhibit in the British Museum (Natural History). Proc. Geologist's Association, XXI, pt. 3, pp. 159-165, 1909.

Bell, Robert.

1859. On the Natural History of the Gulf of St. Lawrence, and the Distribution of the Mollusca of Eastern Canada. Canadian Naturalist and Geologist, IV, p. 197.

Binney, W. G.

1865. Land and Fresh-Water Shells of North America. Part II, Pulmonata Limnophila and Thalassophila, p. 72, Smithsonian Miscellaneous Collections, No, 143, 1865.

Boyle, Cornelius Breckenridge.

1893. A Catalogue and Bibliography of North American Mesozoic Invertebrata. Bull. U. S. Geol. Surv., No. 102, 1893.

Call, R. Ellsworth.

1884. On the Quaternary and Recent Mollusca of the Great Basin with Descriptions of New Forms. Bull. U. S. Geol. Surv., XI, 1884.

1886. On Certain Recent, Quaternary, and New Fresh-Water Mollusca: Proc. Daven. Acad. Sci., V. p. 1, 1886.

Chamberlin, Thos. C. and Salisbury, Rollin D.

1906. Geology, Volumes II and III, 1906.

1I is to be noted that the references to Pleistocene species are also included in the bibllography of the recent species. 
Cockerell, T. D. A.

1906. The Fossil Mollusca of Florissant Colorado. Bull. Amer. Mus. Nat. Hist., XXII, p. 459, 1906.

1908. The Miocene Species of Lymnæa. Nautilus XXII, p. 96, 1908.

Conrad, T. A.

1866. Check List of the Invertebrate Fossils of North America. Eocene and Oligocene. Smith. Mis. Coll., No. 200, 1866.

Cooper, J. G.

1894. On some Pliocene Fresh-Water Fossils of California. Proc. Cal. Acad. Sci., ii, IV, p. 166, 1894.

1894. Descriptions and Figures of New Species of Cretaceous and Cretaceous B (or Eocene) Fossils of California, with Notes on Tertiary Species. Bull. Cal. State Mining Bureau, iv, pp. 36-65, 1894.

Dall, William Healy.

1905. Land and Fresh-Water Mollusks. Harriman Alaska Expedition, XIII, 1905 .

Dall, W. H. and Harris, G. D.

1892. Correlation Papers. Neocene. Bull. U. S. Geol. Surv., No. 84 (p. 286).

Darton, N. H.

1908. Paleozoic and Mesozoic of Central Wyoming. Bull. Geol. Soc. Amer., XIX, p. 403, 1908.

Darton, N. H. and Siebenthal, C. E.

1909. Geology and Mineral Resources of the Laramie Basin, Wyoming. Bull. U. S. Geol. Surv., p. 364, 1909.

Davis, W. M.

1900. The Fresh-Water Tertiary Formations of the Rocky Mountain Region. Proc. Amer. Acad. Arts and Sciences, XXXV, p. 345, 1900.

Dawson, George Mercer.

1875. Report on the Geology and Resources of the Region in the Vicinity of the Forty-ninth Parallel, etc. British North American Boundary Com., 1875.

Engelmann, Henry.

1876. Report on the Geology of the Country between Fort Leavenworth, K. I., and the Sierra Nevada near Carson Valley. Appendix I, Simpson's Exploration across the Great Basin of Utah in 1859, p. 243, 1876.

Evans, John and Shumard, B. F.

1854. Descriptions of New Fossil Species from the Fresh-Water Tertiary Formation of Nebraska, Collected by the North Pacific Railroad Expedition under Gov. J. J. Stevens. Proc. Acad. Nat. Sci. Phil., 1854, p. 164.

Fischer, Dr. Paul.

1883. Manuel de Conchiliologie, Paris.

Geike, Sir Archibald.

1903. Text-Book of Geology, Volume II, Fourth Edition. London. 
Gilbert, G. K.

1875. Report upon the Geology of Portions of Nevada, Utah, California and Arizona; Examined in the Years 1871 and 1872. Explorations and Surveys West of 100th Meridian, III, p. 21, 1875.

1875. Report on the Geology of Portions of New Mexico and Arizona. 1. c., III, p. 503,1875 .

Harris, G. D.

1890. Lake Bonneville. Mon. U. S. Geol. Surv. No. 1, 1890.

1892. See Dall, W. H.

Hayden, F. V.

1856. See Meek, F. B.

1857. Notes on the Geology of the Mauvaises Terres of White River, Nebraska. Proc. Phil. Acad., 1857, p. 151.

1860. See Meek, F. B.

1871. Preliminary Report of the United States Geological Survey of Wyoming and Portions of Contiguous Territories.

Hayden, F. V. and Meek, F. B.

1861. Descriptions of New Lower Silurian (Primordial), Jurassic, Cretaceous and Tertiary Fossils, Collected in Nebraska, by the Exploring Expedition under the Command of Capt. Wm. F. Raynolds, U. S. Top. Engrs.; with some Remarks on the Rocks from which King, Clarence. they were obtained. Proc. Acad. Nat. Sci. Phil., 1861, p. 415 (433).

1878. Systematic Geology. U. S. Geol. Surv. 40th Parallel, I, 1878.

Knowlton, F. H.

1897. See Stanton, T. W.

1909. The Stratigraphic Relations and Paleontology of the "Hell Creek Beds," "Ceratops Beds" and Equivalents, and their Reference to the Fort Union Formation. Proc. Wash. Acad. Sciences, XI, pp. 179238.

Lawson, Andrew C. and Palache, Charles.

1902. The Berkeley Hills. A Detail of Coast Range Geology. Bull. Geology, Univ. of California, II, pp. 349-450.

Marcou, John Belknap.

1885. A List of the Mesozoic and Cenozoic Types in the Collections of the U. S. National Museum. Proc. U. S. Nat. Mus., VIII, p. 290, 1885 .

Meek, F. B.

1860. Descriptions of Fossil Remains Collected in Nebraska and Utah, by the -Exploring Expedition under the Command of Capt. J. H. Simpson of U.' S. Topographical Engineers (extracted from that officer's forthcoming report.) Proc. Phil. Acad. Sci., p. 308.

1864. Check List of the Invertebrate Fossils of North America. Miocene. Smithsonian Miscellaneous Collections, No. 183.

1866. Conrad's Eocene Smithsonian Check List, p. 9.

1873. Preliminary Palæontological Report, Consisting of Lists and Descriptions of Fossils, with Remarks on the Ages of the Rocks in which they were Found, etc., etc. Sixth An. Rep. U. S. Geol. Surv. Terr., p. 431, 1873. 
1876. Report on the Palæontological Collections of the Expedition. Report of Exploration across the Great Basin of the Territory of Utah, etc. Report of Capt. J. H. Simpson, 1876. Appendix J, p. 339.

1876. A Report on the Invertebrate Cretaceous and Tertiary Fossils of the Upper Missouri Country. U. S. Geol. Surv. Terr., IX.

1877. Paleontology. U. S. Geol. Surv. 40th Parallel, IV, p. 181.

Meek, F. B. and Hayden, F. V.

1856. Descriptions of New Species of Acephala and Gasteropoda, from the Tertiary Formations of Nebraska Territory, with some General Remarks on the Geology of the Country about the Sources of the Missouri River. Proc. Acad. Nat. Sci. Phil., p. 111, 1856; also in Amer. Jour. Sci. \& Arts, Ser. ii, XXII, p. 423, 1856.

1856. Descriptions of New Fossil Species of Mollusca Collected by Dr. F. V. Hayden in Nebraska Territory; together with a Complete Catalogue of all the Remains of Invertebrata hitherto Described and Identified from the Cretaceous and Tertiary Formations of that Region. Proc. Acad. Nat. Sci. Phil., 1856, p. 265.

1860. Systematic Catalogue with Synonyma, etc., of Jurassic, Cretaceous and Tertiary Fossils Collected in Nebraska by the Exploring Expeditions under the Command of Lieut. G. K. Warren, of U. S. Topographic Engineers. Proc. Acad. Nat. Sci. Phil., p. 417.

Merriam, John C.

1896. Sigmogomphius Le Contei. A New Castoroid Rodent from the Pliocene near Berkeley, California. Bull. Geol. Dept., Univ. of Cal. I, pp. 363-370.

Miller, S. A.

1880-81. North American Mesozoic and Cænozoic Geology and Palæontology. Journ. Cin. Soc. Nat. Hist., III, pp. 9, 79, 245; IV, p. 93.

1881. North American Mesozoic and Cænozoic Geology and Palæontology, etc. Cincinnati, 1881.

Palache, Charles.

1902. See Lawson, Andrew C.

Peale, A. C.

1879. Report on the Geology of the Green River District. An. Report U. S. Geol. \& Geog. Surv. Terr., XI, p. 511, 1879.

Pilsbry, H. A.

1905. Review of Dall's Alaska Mollusks, Nautilus, XIX, p. 95.

Russell, Israel C.

1884. A Geological Reconnaissance in Southern Oregon. An. Rep. U. S. Geol. Surv. IV, p. 431, 1884.

Russell,, Frances W.

1891. Preliminary Notes on the Geology of Central Nebraska. Amer. Geol., VII, p. 38, 1891.

1892. Notes upon Nebraska Tertiary. Amer. Geol., IX, p. 178, 1892.

Salisbury, R. D.

1906. See Chamberlin, T. C. 
Schuchert, Charles.

1905. Catalogue of the Type Specimens of Fossil Invertebrates in the Department of Geology, United States National Museum. Bull. U. S. Nat. Mus., No. 53, part 1, 1905.

Siebenthal, C. E.

1909. See Darton, N. H.

Stanton, T. W. and Knowlton, F. H.

1897. Stratigraphy and Palæontology of the Laramie and Related Formations in Wyoming. Bull. Geol. Soc. Amer., VIII, p. 127, 1897.

Stanton, T. W.

1909. The Age and Stratigraphic Relations of the "Ceratops Beds" of Wyoming and Montana. Proc. Wash. Acad. Sci., XI, pp. 239-293.

Stearns, R. E. C.

1901. The Fresh-Water Shells of the Colorado Desert, their Distribution, Environment, and Variation. Proc. U. S. Nat. Mus., XXIV, p. 271, 1901.

1902. Fossil Shells of the John Day Region. Science, n. s., XV, p. 153, 1902.

1906. Fossil Mollusca from the John Day Mascall Beds of Oregon. Univ. of Cal. Publication, Geology, V, p. 67, 1906.

Tryon, Geo. W., Jr.

1884. Structural and Systematic Conchology. An Introduction to the Study of the Mollusca, III, Philadelphia, Pa., 1884.

Tyrrell, J. B.

1887. Report on a Part of Northern Alberta and Portions of Adjacent Districts of Assiniboia and Saskatchewan. Rep. Geol. \& Nat. Hist. Surv. Canada, N. S., II, E, 1887.

Walker, Bryant.

1908. New Michigan Lymnæas, Nautilus, XXII, p. 16, 1908.

White, C. A.

1876. Invertebrate Paleontology. of the Plateau Province. Powell's Rep. Geol. Uinta Mts., p. 74.

1877. Paleontological Papers No. 3.-Catalogue of the Invertebrate Fossils hitherto Published from the Fresh- and Brackish-Water Deposits of the Western Portion of North America. Bull. U. S. Geol. \& Geog. Surv. Terr., III, p. 607.

1878. Paleontological Papers No. 6; Descriptions of New Species of Invertebrate Fossils from the Laramie Group. Bull. U. S. Geol. Surv. Terr., IV, p. 707.

1879. Report on the Paleontological Field-work for the Season of 1377. An. Rep. U. S. Geol. \& Geog. Surv. Terr., XI, p. 161.

1880. On the Antiquity of Certain Subordinate Types of Fresi-water and Land Mollusca. Amer. Journ. Sci. and Arts., Ser. 3, XX, p. 44, 1880. Also Ann. Mag. N. H., ser. 5, VI, p. 247.

1880. Descriptions of New Invertebrate Fossils from the Mejozoic and Cenozoic Rocks of Arkansas, Wyoming, Colorado and Utah. Proc. U. S. Nat. Mus., III, p. 157.

1883. A Review of the Non-Marine Fossil Mollusca of North America. 3rd An. Rep. U. S. Geol. Surv., p. 403. 
1883. Contributions to Invertebrate Paleontology No. 4; Fossils of the Laramie Group. 12th An. Rep. U. S. Geol. and Geog. Surv. Terr., pt. 1, p. 49 .

1886. On the Fresh-Water Invertebrates of the North American Jurassic. Bull. U. S. Geol. Surv., No. 29.

1886. On the Relation of the Laramie Molluscan Fauna to that of the Succeeding Fresh-water Eocene and other Groups. Bull. U. S. Geol. Surv., No. 34 .

1890. On the Biological and Geological Significance of Closely Similar Fossil Forms. Proc. Am. A. A. Sci., XXXIX, p. 239.

1895. The Bear River Formation and Its Characteristic Fauna. Bull. U. S. Geol. 'Surv., No. 128.

Whiteaves, J. F.

1885. Report on the Invertebrata of the Laramie and Cretaceous Rocks of the Vicinity of the Bow and Belly Rivers and Adjacent Localities in the North-West. Territory. Geol. and Nat. Hist. Surv. Can., Cont. Can. Paleont., I, pt. 1, p. 1.

1887. On Some Fossils from the Cretaceous and Laramie Rocks of the Saskatchewan and its Tributaries Collected by Mr. J. B. Tyrrell in 1885 and 1886. Rep. Geol. \& Nat. Hist. Surv. Can., n. s., II, Appendix, p. $153 \mathrm{E}$.

Woodworth, J. B.

1894. The Relation between Baseleveling and Organic Evolution. Amer. Geol., XIV, p. 209.

Willis, Bailey.

1909. Paleogeographic Maps of North America. Journ. of Geol., XVII, Nos. 5, 6, 7. 


\section{HISTORICAL SKETCH OF PREVIOUS MONOGRAPHS.}

The fresh-water Pulmonata have been written upon to a greater extent than almost any other group of mollusks, excepting perhaps, the land snails. Scarcely a paper has been published on inland mollusks that did not mention some member of the group, hence the literature is extensive. Of illustrated monographs and other papers of a monographic character dealing with American Lymnæas, upwards of sixteen have been published that are especially notable. These may be summarized as follows :

I. 1832-34. Thomas Say. In his American Conchology, Say, the father of American Conchology, enumerates and figures 6 species of the genus. The Journal of the Academy of Natural Science of Philadelphia also contains descriptions of many species, published between the years 1817 and 1825 . The article "Conchology"' in the American edition of Nicholson's Encyclopedia of Arts and Sciences, contains 2 species of Lymnæa.

II. 1841. Augustus A. Gould. In the Invertebrata of Massachusetts, Dr. Gould lists and figures for the most part 7 species and 1 variety of Lymnæa from New England. This report was reprinted in 1870 under the editorship of Mr. W. G. Binney.

III. 1842. S. S. Haldeman. This is one of the best of the monographs of Lymnæa, the figures being superb, exceeding in this respect those of any other monograph. 24 species are described and figured. An attempt is here made to divide the American Lymnæas into subgeneric groups, five of which are recognized, two being described as new.

IV. 1843. James E. DeKay. In the Zoology of New York 23 species of Lymnæa are mentioned, 15 of which are figured.

V. 1858. W. G. Binney. In Binney's edition of the complete writings of Thomas Say on the Conchology of the United States 16 species are described, many of them being figured.

VI. 1862 And 1886. H. C. Kuster and S. Clessin. •H. C. Küster began a monograph of Lymnæa in the Conchylien Cabinet of Martini and Chemnitz in 1862 which was completed by S. Clessin in 1886. 40 American species are described and figured in the two parts of this monograph. 
VII. 1865. W. G. Binney. Land and Fresh-Water Shells of North America. This is the most complete and pretentious monograph of American Lymnæas which has yet been published and has been constantly referred to by all workers on this group of snails. Its great drawback has been the extreme conservatism with which the author treated the species, placing many names in the synonymy of other species which, upon recent critical study, have been found to be worthy of recognition. 31 species are considered valid by Binney. Figures (mostly outline) are given of all the species of American Lymnæas, which had been described at that time, some 80 in all.

VIII. 1872. Geo. W. Tryon, JR. Continuation of Haldeman's Monograph of the Fresh-Water Univalve Mollusca of the United States. In this monograph 37 species are recognized, 32 figures being given on three plates. An attempt is made to utilize a number of group names in a subgeneric sense. While not as conservative as Binney, Tryon's work nevertheless shows that little critical study was given to the smaller species of the genus.

IX. 1872. G. B. Sowerby in Reeves' Conchologica Iconica. In this monograph, which is fairly well illustrated, 40 species of American Lymnæas are recognized and figured.

X. 1880. Fischer, Paul and Crosse, H. In the Mission Scientifique au Mexique et dans l'Amerique Central, these gentlemen describe 4 and figure 2 species of southern Lymnæids.

XI. 1874. W. D. Hartman and Ezra Michener, in Conchologia Cestrica, figure and describe 8 species of Lymnæa from the eastern part of the United States.

XII. 1899. EdUARD von Martens. In the Biologia Centrali Americana, Mollusca, this author describes 6 species of Lymnæids principally from the Central American region.

XIII. 1900. R. E. CALL. In his report on the Mollusca of Indiana, this author describes and figures 5 species.

XIV. 1902. F. C. BAker. In the Mollusca of the Chicago Area, Part II, this author describes and figures 10 species of Lymnæas which inhabit northern Illinois.

XV. 1904. Josiah Keep. In West American Shells, this author describes 9 and figures 4 species of west coast Lymnæas.

XVI. 1906. W. H. Dall. In the Land and Fresh-Water Mollusks of Alaska, this author figures 26 species of Lymnæas as occurring in the northern part of the United States and in British America. This essay is the first attempt to place the classification of this group of fresh-water shells on a modern basis. 
A large number of valuable papers have been published which describe and illustrate various species of Lymnæas but the ones mentioned above are the most extensive and the nearest approach to a monographic treatment. Of these, the monograph by Binney is the most complete.

In much of the previous work on this group of mollusks it is apparent that little attention has been given to a critical examination of type material, without which it is impossible to accurately determine the relations of the different species. Many of the figures and descriptions are poor and quite unrecognizable without an examination of type or authentic material. In the preparation of the present monograph, nearly all of the types of American Lymnæas have been examined and it is believed that, in most cases, the species have been satisfactorily elucidated. The illustrations are photographs of authentic specimens. 


\section{A NEW CLASSIFICATION OF THE LYMNÆAS.}

\section{GENERAL DISCUSSION.}

The history of previous classifications of the Lymnæas shows that they have all been based on characteristics of the shell, the internal organs have been almost totally neglected in providing data for this purpose. The shell is more directly and easily modified by external influences than are the internal organs and, hence, is a more variable and less stable criterion for purposes of nomenclature. This is especially true of fresh-water mollusks, and is notably apparent in Lym$n \in a$ where a single species in a given locality may present variations characteristic of the majority of the recognized groups which have been founded upon shell characters.

Classifications based on the modifications of a single organ, as the shell, jaw or radula, are predestined to failure, because of the great changes which have taken place in these organs in closely related groups. It has been well stated by Dr. Pilsbry" that "a classification which takes cognizance of several totally diverse, uncorrelated organs, is more reliable than one based upon a single organ; for the reason that while some one organ or system of directly correlated organs, may independently assume similar forms in members of different stocks or phyla, when they are subjected to similar conditions of life, the probabilities are remote that several organs not directly correlated will be simultaneously so modified. Again, the ancestral form of a certain organ may be retained in several groups widely diverse in other respects; and moreover, the taxonomic value of a given structure varies widely in different families and genera." This statement, it would seem, applies quite as well to the fresh-water pulmonates as to the land mollusks.

Pilsbry has also stated that a natural classification of the pulmonates should be based on the following organs: ${ }^{2}$

Organs of protection (shell, mouth, integument of body).

Organs of locomotion (foot with pedal-grooves, tail gland, etc.).

Organs of reproduction (genitalia, comparative size of eggs, etc.). Organs of nutrition (jaw and teeth, intestinal tract, kidney). 
Nervous system (including sense organs such as tentacles, etc.).

Muscle system.

While the Stylommatophorous and Basommatophorous pulmonates differ rather widely in details, it would seem that the above criteria apply with equal force in formulating a natural classification of the fresh-water pulmonates and it has accordingly been followed as far as practicable. In the treatment of the genera of the Lymnæas the shell, radula, jaw and genitalia have been considered of principal importance and have been comparatively studied. In the case of the subgenera, the shell and radula have been relied upon to furnish data.

During the past thirty years the fresh-water pulmonates have been gradually undergoing the splitting process so notably carried out in the land snails by Dr. Pilsbry. In the middle of the past century the family Lymnæidæ contained the genera Lymnea, Amphipeplea, Physa, Aplexa, Chilina, Pompholyx, Carinifex, Planorbis, Ancylus and Gundlachia as well as several other genera. Ancylus, Physa and Chilina with several allied genera have been raised to family rank, each characterized by peculiarities of shell, foot, radula, jaw, genitalia and other organs. Of the old Lymnæidæ there remain Lymncea and Planorbis, with several associated genera, each falling into a subfamily. A study of these two groups seems to point to their inevitable further separation into two families, Lymnæidæ and Planorbidæ. The criteria upon which this opinion is based may be tabulated as follows:

\section{LYMN无ID压.}

Shell: long-spired.

TentaCles: flat, triangular.

Genitalia: male organ with distinct penis and penis-sac, the former with a distinct, heavy retractor muscle; penis-sac with a strong retractor muscle, inserted distally near the penis retractor. Numerous protractor muscles present. Vas deferens inserted in head of penis. Genitalia on right side.

Radula: Central tooth unicuspid; lateral teeth bi- or tri- cuspid.

KIDNEY: Very wide, short, somewhat pear-shaped.

\section{PLANORBID压.}

Shell: discoidal.

TENTACles: long, filiform.

Genitalia : male organ with a large cylindrical appendage attached to the apex of the penis. The vas deferens enters the distal end of the appendage, reappears at the junction of the appendage with the penis, and enters the penis in a depression on the side. Penis with wide retractor and protractor muscles. Genitalia on left side.

Radula: Central tooth bicuspid; lateral teeth tricuspid.

KidNEY: Very long, narrow.

The male system of Planorbis is very peculiar in the possession of the cylindrical appendage attached to the penis. (Plate XIII, A, 2.) This was at first thought to be the penis, but the insertion of the vas 
deferens in a depression on the side of the large sac below (which is believed to be the penis) would seem to indicate that it could not be co regarded. The vas deferens forms a loop exterior to the male organ, one end entering the penis in a depression on the side, the other end entering at the junction of the penis and the appendage, reappearing at the apex of the latter, whence its course is the same as in Lymncea, directly to the penial opening. There is no division of muscles retracting the male organ in Planorbis as in Lymnea, the penis in Planorbis being retracted by a wide, thin band of muscular tissue which is inserted in the columella muscle near the left buccal retractor, the characteristic penis retractor of Lymnea (pl. X, A, RM) being absent. It would be of great interest and value to know precisely the office of this peculiar appendage, but whether it prove to be the true penis (and the organ below the penis sac) or an appendage of the penis, does not alter the fact that its position on the penis and the peculiar insertions of the vas deferens provide a characteristic difference from Lymnaa which is of family value. The principal characters which differentiate Planorbidæ from Lymnæidæ are the peculiarities of the male organs, the bicuspid central tooth (plate XIII, B) the planorboid, discordal shell and the filiform tentacies.

The taxonomic value of the groups Camptocerinæ and Pompholaginæ of Dall, cannot be predicated at the present time, fresh material not being available. Dall's figure of the. genitalia of Pompholy $x^{1}$ is not in sufficient detail to allow of an opinion. The central tooth is bicuspid, which indicates relationship with Planorbis.

As thus restricted, the Lymnæidæ present a homogeneous group of snails which may be divided into several genera and subgenera. Before entering upon a discussion of the data upon which these groups are based it may be of interest to review briefly some of the previous classifications of the Lymnæids which bear directly upon the American fauna. All of these have been based on shell characters.

In 1840, S. S. Haldeman monographed the genus Lymnæa, including as subgenera Limnea, Radix, Leptolimnea, Bulimnea and Acella, the last two being described as new.

In $1865 \mathrm{~W}$. G. Binney monographed the genus, recognizing the following groups as subgenera:

Limncea Lam., Radix Montf., Bulimnea Hald., Limnophysa Fitz., Leptolimnea Swains., Acella Hald.

${ }^{1}$ Ann. Lyc. Nat. Hist., IX, pl. 2. 
In $18 \% 1$, W. H. Dall published a revision of the Lymnæids, and under the subfamily Limnæinæ recognized the following genera and subgenera :

\author{
Genus Limnca Lam. \\ Subgenus Radix Mont. \\ Subgenus Limnophysa Fitz. \\ Subgenus Bulimnea Hald. \\ Subgenus Acella Hald. \\ Subgenus Pleurolimnca Meek. \\ Subgenus Limnea Lam. \\ Genus Amphipeplea Nils. \\ Genus Erinna H. and A. Adams.
}

In $1872, \mathrm{G} . \mathrm{W}$. Tryon continued Haldeman's monograph of Lymnæa, recognizing the following groups:

Genus Limnca Lam.

Subgenus Auricula Klein.

Subgenus Bulimnea Hald.

Subgenus Limnophysa Fitz.

Subgenus Leptolimnea Swains.

Subgenus Acella Hald.

In 1884, the same author arranged the Lymnæids as follows in his Structural and Systematic Conchology:

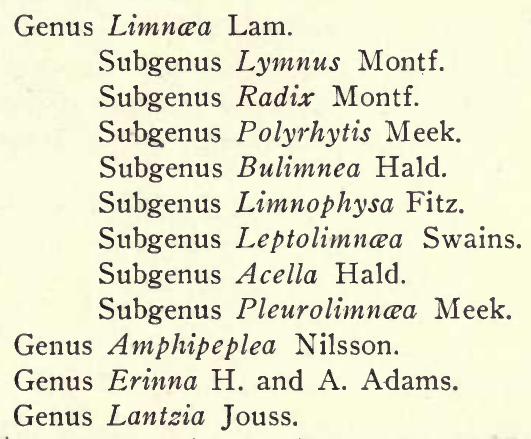

The treatment of the Lymnæids in the works of $\mathrm{H}$. and A. Adams, Fischer, Gray, Küster, Clessin, Westerlund and other European writers does not differ materially from that cited above.

In 1905, W. H. Dall revised the Lymnæids of the northern part of North America and presented the following synopsis which is, without doubt, the best treatment this group has received:

Genus Lymnca Lamarck.

Subgenus Lymnaa S. S.

Section Lymnaa S. S.

Section Bulimnea Haldeman.

Section Radix Montfort.

Section Cyclolimnca Dall. 
Section Polyrhytis Meek.

Section Acella Haldeman.

Section Pleurolimnaa Meek.

Section Galba Schrank.

Subgenus Stagnicola Leach.

Section Stagnicola S. S.

Section Leptolimnea Swanison

Section Physastra Tapp-Can.

Genus Erinna Adams.

In $1903^{1}$ Dybowski proposed a classification of the fresh-water pulmonates in which six families were recognized, as follows:

\author{
Limnæidæ \\ Limnophysidæ \\ Amphipeplidæ \\ Planorbidæ \\ Ancylidæ \\ Physidæ
}

This author thus tabulates the characters of the several groups:

I. Mantel mit einem über das Gehäuse aufgeschlagmen Anhänge.

1. Zahnplatten mit einem flugelartigen Anhänge, alle gleichformig gestaltet.

Family Physide.

2. Zahnplatten ohne Anhäng, der Gestalt nach drei Gruppen beldend

Family AmpHIPEPLIDE.

II. Mantel normal, ohne Anhänge.

1. Gehäuse in die Länge gestrickt.

(a) Letzter Umgang sehr gross, bauchig aufgetrieben; Schale unregemassig quergestreift; Glasur weisslich; Lippe fehlt.

Family LIMNAIDE.

(b) Letzter Umgang ausgezogen, wenig gewölbt; Schale sehr fein und ziertich längs und quergestreift; Glasur rötlich; Lippe rotbraun. Family Lim NOPHyside.

2. Gehäuse in die Quere gestrickt.

(a) Gehäuse scheibenförmig.

(b) Gehäuse mutzenformig.

Family Planorbide.

Family AnCylide.

In the above classification only the shell, mantle and radula are used as diagnostic factors. It is probable, however, that a study of the genitalia, nervous system and pallial organs will bear out the grouping substantially as proposed by Dybowski. The separation of Limnophysa from Lymnæidæ as a family is, however, not borne out by present studies, there being no distinguishing features by which the group can be separated from the other Limnæidæ, except as a genus.

In the present monograph it is proposed to classify the Lymnæids by the characters of the shell, genitalia (shape of prostate, relative size and form of penis and penis-sac) and radula. The study of

1Nach. Deutsch. Mal. Ges., XXXV, pp. 130-144. 
these organs indicates that the subgeneric groups, such as Radix, Bulimnea, Galba and Acella, which were founded on shell characters may also be distinguished by differences in the genitalia and radula. Only the North American species have been critically examined. ${ }^{1}$ The application of the above criteria results in the classification presented below. ${ }^{2}$

Family LymnæID E Broderip, 1839.

Subfamily Lymnжin ж Dall, $18 \%$.

Mantle margins retained within margin of shell.

Subfamily Amphipeplein e Dybowski, 1903.

Mantle margins enlarged, covering a portion of the shell.

The latter subfamily contains the following genera; neither of which occur in the North American fauna.

Genus Amphipeplea Nilsson, 1822.

Amphipeplea Nilsson, Moll. Suec. Ter. et Fluv., p. 58, 1822.-Dall, Ann. Lyc. N. H., IX, p. 350.-Tryon, S. \& S. Conch., III, p. 102, 1884. Type, Buccinum glutinosum MULLER.

"Shell: Globular, thin and transparent; spire very broad, depressed, short; aperture occupying nearly five-sixths of the entire length of the shell, very broadly expanded; outer lip thin, simple; columella without a fold.

"Animal with large mantle lobes which partly cover the shell. According to Forbes, Van Beneden found a peculiar modification of the nervous system correlated with the expanded mantle" (Dall).

Genus Cyclolimnea Dall, 1905.

Lymnea, section Cyclolimnca DALL, Alaska Moll., p. 64, 1905. Type Lymnaa involuta HANLEY.

"Shell: Thin, involute, the last whorl as long as the shell, the outer lip thin, simple, not expanded, the inner lip appressed, the axis not plicate, but with a small umbilical chink" (Dall).

The mantle covers a portion of the shell as in Amphipeplea.

This subfamily will doubtless show anatomical peculiarities distinctive from those of Lymnæinæ.

KEY TO GENERA AND SUBGENERA OF RECENT AMERICAN LYMN AEAS.

Prostate bulbous, penis less than half the length of penis-sac; lateral teeth bicuspid; shell with strongly gyrate columella.

Genus LymnæeA Lamarck.

\footnotetext{
${ }^{1}$ Several foreign genera are not here included, as their anatomy is unknown. It is not thought that a study of these genera will materially change trie classification here presented 1908.

'This outline was published in Sclence, n. s., vol. XXVII, No. 702, p. 942,
} 
Prostate long, narrowly cylindrical, with slightly bulbous termination; penis thick, about half as long as penis-sac; lateral teeth tricuspid; shell succineiform, axis slightly gyrate.

Genus Pseudosuccinea Baker.

Prostate short, pear-shaped when viewed laterally; penis very slender, longer than penis-sac; first lateral tooth tricuspid, balance bicuspid; shell with depressed spire and large body whorl, the axis gyrate.

Genus RAdix Montfort.

Prostate very large, irregularly elongate-ovate; penis very large, one-fourth longer than penis-sac, gradually enlarging in diameter toward the distal end; lateral teeth tricuspid; shell large, bulimiform, highly colored, axis twisted, with a sharp fold.

Genus Bulimnea Haldeman.

Prostate large, flatly cylindrical; penis thick, about four-sevenths the length of penis-sac; lateral teeth bicuspid; the mesocone with a distinct entoconic swelling; shell very slender, the apical whorls much longer than wide, the whorls very flat-sided; axis gyrate.

Genus Acella Haldeman.

Prostate very large, long-ovate or elongate-pyriform; penis shorter than penis-sac, usually very thick.

Genus Galba Schrank.

a. Prostate long-ovate; penis a trifle shorter than penis-sac, of narrow diameter; lateral teeth bicuspid; shell small, usually without spiral sculpture and with a flat, expanded inner lip, without a fold on the columella, the axis being hour-glass shaped.

Subgenus GALbA Schrank.

b. Genitalia as in (a); lateral teeth tricuspid; shell usually small, without strong spiral sculpture; axis as in (a); inner lip not typically expanded as in (a).

Subgenus Simpsonia Baker.

c. Prostate elongate-pyriform; penis from three-fourths to four-fifths the length of penis-sac, very thick; lateral teeth bicuspid; shell large, with marked spiral sculpture, the columella strongly plicate.

Subgenus Stagnicola Swainson.

d. Shell elongated with cylindrical whorls; details of animal not recorded.

Subgenús Leptolimnea Swainson. 
e. Shell with well-marked longitudinal folds or ribs; genitalia and radula not recorded.

Subgenus PoLYRhytis Meek.

\section{EXTRALIMITAL GROUPS OF LYMNEIN E.}

Several names appear in European works which cannot be definitely placed in the present classification. Dr. W. Dybowski ${ }^{1}$ has recently instituted a subgenus Omphalobulimus for a species of Lymnæa with a narrow shell, a raised and expended inner lip and a large umbilical chink. Dybowski compares his type species (Lymncea lagorii) with Lymncea vulgaris WEST. and also with Galba truncatula, calling attention to the similarity of the axis and inner lip to Limnophysa $(=$ Galba $)$. Without an examination of the genitalia and radula it is, of course, impossible to definitly postulate the correct position of this group, although its affinities would appear, from the published figures (which strongly resemble certain examples of palustris from New York and Colorado) to be with Stagnicola. It is scarcely a form of the typical Lymnæas.

We agree with Dr. Dall, that the names proposed by Servain in his Lake Balaton paper ${ }^{2}$ are not entitled to recognition in systematic nomenclature. These group names represent simply degrees of mutation which may be found in the inhabitants of any large body of water. Hazay is right in considering them physiological. Similar mutations may be seen in such American species as emarginata, catascopium, palustris and obrussa.

The name Tanousia Bourguignat appears in Servain's Lake Balaton papers and is founded on a Pleistocene fossil of Dalmatia. (Lymnea zrmanje BRUSINA). It may be thus described: "Shell small, ovate, conic, closely and almost involutely coiled; the last whorl inflated, subcarinate behind, the aperture contracted" (Dall). This description recalls such Pleistocene species as Galba obrussa decampi and Galba galbana, which lived in the icy waters of the Glacial Epoch. According to Westerlund, this group was christened by BRUsina under the name of Sandria, in 1885.

The following groups have no representatives in America, so far as known:

Zagrabica Brusina, Beitr. Pal. Oest.-Ung., 1884.-Westerlund, Acta Acad. Sci. Slav. Merid., CLI, p. 119, 1902.-DALL, Alaska Mollusks, p. 65, 1905.

${ }^{1}$ Nach. Mal. Ges., XXXV, Sept.-Oct., p. 143, 1903; Bull. Acad. Imp. des Sc1., St. Petersb., XVIII, p. 113, 1903.-Dall, Alaska Moll., pp. 61, 63, 1905.

${ }^{2}$ Hist. Mal. der Lac Balaton, 1881. 
"Shell ventricose, with a short acute spire and few rounded whorls, rugose, umbilicate, the last whorl ample, with a rotund transverse aperture, and continuous peristome appressed on the columellar margin; the outer lip simple" (Dall).

The type is Zagrabica naticoides Brusina, a Pleistocene fossil. According to Dr. Dall, Dybowski has referred to this group a recent species from the Caspian Sea under the name of $Z$. brusiniana. As remarked by Dall, this group appears from the description to be related to Radix.

Velutinopsis Sandberger, Land und süssev. Conch. d. Vorwelt, p. 700, 1875. -Tryon, S. \& S. Conch., III, p. 101, 1884.-DAll, Alaska Moll., p. 63, 1905.

"Shell almost planorboid, with but few, rounded, rapidly increasing whorls; the aperture simple, suborbicular, the peristome sharp, simple, not reflected; the pillar lip broad, not appressed; the axis umbilicate" (Dall). Type, Lymnca velutina Deshayes, from the Pliocene of the Crimea.

As remarked by Dr. Dall, this fossil genus looks like Choanomphalus, and it probably belongs with Pompholyx and Carinifex, and not to the Lymnæidæ.

Erinna H. and H. Adams, Gen. Rec. Moll., II, p. 644, 1858.-Dall, Ann. Lyc. N. H., IX, p. 350, 1870.-TRYoN, S. \& S. Conch., III, p. 102, 1884.-DALL, Alaska Moll., p. 63, 1905.

"Shell small, with a short spire, a large final whorl; the aperture with a continuous peristome which passes behind a broad, somewhat excavated pillar; axis imperforate and the pillar plicate" (Dall). Type, Erinna newcombi AdAMs, from the Hawaiian Islands.

This group has been modified, as stated by Dr. Dall, by its habit of living on rocks in swiftly running water or in waterfalls; this modification causing the spire to shorten up, the aperture to become expanded and the inner lip to be continued over the body whorl, providing a flat basal surface enabling the animal to cling tightly to its rocky support.

Physastra Tapparone-Canefri; Ann. Mus. Genov., XIX, p. 245, 1883.Dall, Alaska Moll., p. 64, 1905.

"Shell like Stagnicola, but with a coarse dehiscent periostracum, and coiled sinistrally" (Dall). Type, Physastra vestita TApparoneC.ANEFri, from New Guinea.

The reversed Lymnæids from Polynesia will probably fall into this genus, which will doubtless be found to possess distinctive characters in the genitalia and radula. 


\section{NOMENCLATURE.}

In preparing the generic nomenclature of the Lymnæas, constant reference has been made to Dr. W. H. Dall's recent work on the Land and Fresh-Water Mollusks of Alaska, and his conclusions have been accepted, in the main, and incorporated in the present work. So far as specific nomenclature is concerned, the ruling recognized by Pilsbry and other recent zoologists, of "Once a synonym, always a synonym," is the only safe and satisfactory disposition of duplicated names, even though the species are here placed in different genera.

Regarding specific limitations, a wide difference of opinion exists. Dr. Pilsbry well says: "The conception of species in such sedentary animals as snails is far from simple. A 'species' comprises a multitude of colonies or communities which at any one time are isolated one from the other by the existing topographic and other surface features of the country. This is and always has been the case, even with the common, widespread forms of the more level part of the country; but the colonies there have always been subject to frequent mixture with their neighboring colonies, by the ever slightly fluctuating conditions of woodland and local moisture, so that their network over the country has been here and there made practically complete within comparatively short periods. As a consequence, we have in many cases no tangible difference between individuals from colonies hundreds of miles apart."

The above paragraph, while relating to land mollusks, seems to apply equally as well to the Lymnæidæ, although the degree of differentiation is manifestly not as great among the fresh-water pulmonates as in the land pulmonates. The same rule, however, holds true for both. Land shells are more often differentiated by isolation than are the fresh-water pulmonates, but it is true, nevertheless, that isolation has played an important part in species formation among the Lymnæas.

Great care has been used in determining the specific limits of the Lymnæas herein recorded. In nearly all cases the types have been examined and no name has been placed in the synonomy unless there were valid reasons for considering it a synonym. It may be thought that too much liberality has been shown in thus recognizing many old species long considered synonyms by Binney, Tryon, Dall and other competent malacologists, and likewise the addition of such a large 
number of new species may be thought to be ill advised. Our modern conceptions of species, based on studies in ecology and evolution, have made it plain, it would seem, that a species is simply an assemblage of individuals which combine certain characteristics not shared by any other similar group of individuals. With this concept in mind, it is not difficult to comprehend that in a territory as large as North America, with its diversity of environment, there should have been evolved an hundred species and races of Lymnæids.

The question of species and varieties or subspecies has been determined as follows: Names are admitted as specific where it is clearly evident that no intermediate forms are now living; in other words, there is a break in the line of evolution; subspecies or races are admitted when the name covers a group of individuals combining certain characteristics which intergrade more or less with what is believed to be the parent species. In many cases there is apparently less difference between some closely related species than between certain species and races which seem to manifest wide differences (as emarginata), but in these cases, although the differences are slight, they are uniform and no intergradations occur. 


\section{INSTRUCTIONS FOR COLLECTING AND PREPARING LYMNÆAS.}

Collecting. Lymnæas may be collected in bottles, cans, or almost any receptacle. A wire scoop attached to a long handle is a good utensil to use in picking up floating individuals or for scooping up those species inhabiting the deeper water.

Preparation for Dry Study. The shell may be prepared by placing the animal in boiling water, which kills it, after which the soft parts are easily withdrawn with a pin or needle. The shell may then be washed and dried and is ready for the cabinet. In case the shell is encrusted with lime or some other matter, a judicious use of oxalic acid may be necessary to clean it well.

Preparation for Anatomical Study. Lymnæas may be killed by placing them in boiling water, after which they may be preserved in $60 \%$ alcohol. They should never be placed directly in alcohol, as this causes too much contraction for subsequent work. Should these facilities not be available, it is permissible to preserve specimens in alcohol, as any kind of a specimen is better than none, especially in the case of those species which live in little frequented parts of the country. Plunging in alcohol does not affect the Lymnæas as much as it does the land shells. On no account use formolyn (formaldehyde), as this medium makes the animal brittle, besides ruining the eyesight of the one studying the material.

Dissecting. The dissecting of Lymnæas is not difficult. All that is necessary is a dissecting microscope, a shallow pan with a cork or wax bottom into which pins may be stuck, a pair of fine-pointed scissors and plenty of fine-pointed pins (insect pins are the best). If care be observed, the genitalia, the digestive system, the central nerve mass and the respiratory and renal organs may be spread out and easily studied. (See plate 1.) The animal, after removal from its shell, may be opened by making an incision from the top of the back to the upper coils of the body and the flaps of the cut mantle turned aside and pinned to the bottom of the tray. In this position, with the head toward the observer, the genitalia will be seen to the left, the buccal sac and general digestive tract in the center, and the respiratory cavity and renal organ to the right. If the incision be made to the left of 
the center along the line of the columellar muscle, the respiratory tract may be examined entire. The central nerve mass will be observed just behind the buccal sac. Care must be used in separating the different organs, in order not to tear them. This is especially true of the genitalia. The jaw and radula may be extracted from the front end of the buccal sac and mounted in Canada balsam or glycerine jelly for study. The writer has frequently used a two-inch and one-inch objective for working out the details of anatomy, and has found it very satisfactory in many cases, the only drawback being the inability to use both hands in separating the organs. Dissected specimens may be permanently preserved in $75 \%$ alcohol.

A large amount of work is badly needed to provide additional information relating to the anatomical features of the fresh-water pulmonates, and almost any careful student may add valuable data concerning the affinities of the different species. There are a number of species which cannot be definitely placed, owing to lack of knowledge concerning the radula, jaw and genitalia. Too much emphasis cannot be placed on the admonition to be accurate in studies of this kind, because serious errors have been made by a too hasty statement regarding some anatomical feature. 


\section{SYSTEMATIC DISCUSSION OF SPECIES.}

Family LYMNÆID无 Broderip, 1839.

Subfamily Lymnæinæ Dall, 1870.

Shell: Normally dextral, rarely sinistral, ovately-oblong or elongate; spire more or less attenuated; columellar axis thickened by a shelly deposit and typically gyrate or twisted; peristome thin, sharp; shell covered with a corneous periostracum or epidermis.

Animal: With a short, wide, rounded foot; head supporting a velum which is retained from the larval state; tentacles flattened, triangular, the eyes sessile upon their inner base; a large superior and two smaller, narrow, lateral jaws present; central tooth unicuspid, lateral teeth bi- or tri-cuspid, marginals serrated; kidney very large, wide, pear-shaped; ureter proceeding directly forward without flexure; buccal retractors two in number, very long, inserted distally in the columellar muscle, the right retractor near the penis retractors and the left retractor some distance from this point; genitalia with the genital apertures separated, that of the male being behind the right tentacle, while that of the female is at the base of the neck near the pulmonary opening; the male organs consist of penis, penis-sac, vas deferentia, and prostate; the female organs consist of vagina, oviduct, receptaculum seminis and one albuminiparous gland with two accessory glands; an ovotestis and ovisperm duct are common to both male and female systems. The penis and penis-sac are retracted by one or more powerful muscles which are inserted in the columellar muscle. The body of the animal is striated, not granulose as in the helices.

Distribution: Worldwide, but more numerous in the north temperate zone.

Geological Range: Upper Jura (Purbeck) to recent fauna. Maximum development in late Tertiary times. In America the family ranges as far back as the Comanchean Period.

As restricted above, the Lymnæinæ form a markedly uniform and well-characterized group of the fresh-water Pulmonata. 


\section{Genus LYMNAA Lamarck, $1799 .^{1}$}

1746. Limnea cochlea Linne, Fauna Svecica, ed. I, pp. 374, 376, 1746 (not binomial).

1797. Vesica (ex parte) Anonymous, Mus. Calon., p. 58, 1797; Helix stagnalis (and amarula) Linné.

1798. Helix ( $s p$. ) Linne, Gmelin, Bolton in Mus. Bolt., p. 109, 1798.

1799. Lymncea Lamarck, Prodr. Nouv. Clas. Coq., p. 75, 1799 (Helix stagnalis L.)

1801. Lymnca Lamarck, Syst. des An. s. Vert., p. 91, 1801. (Helix stagnalis L.)

1801. Limneus Draparnaud, Tableau, pp. 30, 47, 1801 (no type cited).

1805. Limneus Draparnaud, Hist., pp. 25, 28, 48, 1805.

1805. Lymncea Rorssy, Hist. Nat. Moll., V, p. 345, 1805.

1810. Lymnus Montfort, Conch. Syst., p. 262, 1810. (L. stagnalis L.)

1812. Limncea Desmarest, Rapp., Soc. Philom. Paris, 1812.

1815. Lymneus Brard, Hist. des Coq. Terr. et. Fluv. Paris, p. 133, pl. 5, 1815.

1816. Lymnca Lamarck, Encycl. Meth., pl. 459, 1816.

1817. Lymnca Schumacher, Essai, p. 199, 1817.

1817. Lymnaus Cuvier, Regne An., II, p. 412, 1817.

1819. Lymnula Rafinesque, Journ. de Phys., LXXXVIII, p. 423, 1819 ; = Lymnea of Authors, fide RAFINESQUE.

1821. Lymneus Say, Journ. Acad. Nat. Sci. Phil., II, p. 167, 1821.

1822. Lymnca LAMARCK, An. S. Vert., VI, p. 157, 1822.

1825. Limncea Blainville, Malac., I, p. 448, 1825.

1828. Limnea Fleming, Hist. Brit. An., p. 273, 1828.

1831. Limneus Turton, Man., p. 127, 1831 (type L. stagnalis L.).

1832. Limneus SAY, American Conchology, 1832.

1833. Leachia Jeffreys, Linn. Trans., XVI, III, p. 519, 1833 (not Risso, 1829, or LeSUEUR, 1821), L. stagnalis Linné.

1838. Limncea BECK, Index, p. 110, 1838.

1841. Limnea Haldeman, Mon., p. 1, 1841.

1843. Limnea Dekay (Part.), Moll. N. Y., p. 67, 1843.

1854. Limneus Gosse, Nat. Hist. Moll., p. 86, 1854.

1855. Limnea Moguin-Tandon, Hist. Nat. Moll. France, II, p. 458, 1855.

1856. Limncea Woodward, Man. Moll., p. 170, 1856.

1858. Lymneus Binney, Reprint Say's Conchology, p. 60, 1858.

1865. Limnca Binney, L. \& F. W. Sh. N. A., II, p. 24, 1865.

1870. Limncea Gould, Binney's Ed., p. 470.

1870. Limnea Cooper, Proc. Cal. Acad. Sci., IV, p. 95, 1870.

1870. Limncea Dals, Ann. N. Y. Lyc. Nat. Hist., IX, p. 350, 1870.

1872. Auricula Krein, Tryon, Con. Hald. Mon., p. 86, 1872.

1875. Eulimneus, SandBerger, Land und. Süssw. Conch. d. Vorwelt, pp. 787, 844, 1875 ; sole example cited L. stagnalis (Linné).

${ }^{1}$ The writer is largely indebted to the work of Dr. W. H. Dall, Alaska Land and Fresh-Water Shells, for a large proportion of the references in the generic portions of this monograph. A number of references, principally frcm American sources, have been added, where the work is of a systematic diagnostic character. The majority of the rather numerous European references have been omitted, as they have not been deemed pertinent to the subject in hand. 
1874. Limnca Hartman and Michener, Conchologia Cestrica, p. 62.

1876. Limnaa Meek, U. S. Geol. Surv. Terr., final Report, IV, p. 532, 1876.

1884. Lymnus $\mathrm{T}_{\mathrm{RYON}}$, S. \& S. Conch., III, p. 101, 1884.

1902. Limnca BAKer, Moll. Chi. Area, II, p. 259, 1902.

1903. Limnus Dyвowski, Bull. Acad. Imp. Sci. St. Petersb., XVIII, p. 113, 1903.

1905. Lymnca Dall, L. \& F. W. Moll. Alaska, pp. 59, 63, 1906.

1908. Lymnca BAKer, Science, n. s., XXVII, No. 703, p. 943.

Shell: Ovately-oblong or elongated, generally thin and brittle; spire more or less attenuated; last whorl expanded; peristome thin, somewhat flaring, without internal varical thickening; aperture ovate or oblong-ovate, sometimes rounded; axis gyrate, forming a sharp, ascending columellar plait; no true umbilicus, but there is occasionally a very small chink; columellar callus closely appressed to the body of the last whorl, forming a wide deposit; surface marked by numerous fine impressed spiral lines and close-set longitudinal growth lines, forming a finely decussated pattern; a horny periostracum or epidermis is present. (Pl. XVIII, fig. \%.)

Animal: With a short, wide, rounded foot; head with the usual bilobed vela area; surface of body finely striated, presenting a smooth appearance; tentacles, eyes and other characters as in the family.

Jaws: Superior jaw much wider than high; dorsal margin rounded, ventral margin with a central more or less acutely rounded projection; lateral jaws triangular, the lower angle produced into a long tongue-like projection. (P1. VI, fig. A.)

RAdUla:. With unicuspid central tooth and bicuspid lateral teeth; marginal teeth serrated. (P1. VII, fig. A.)

Genital System: Penis-sac very large, penis very short (about one-quarter the length of penis-sac); penis-sac retractors normally two in number, very large; protractors of penis-sac very large, massive; prostate forming a bulb-like enlargement at the entrance of the prostate duct; the distal portion of the prostate is constricted behind the enlarged portion and is somewhat fusiform in shape; receptaculum seminis rounded, its duct of rather smail diameter; lower portion of oviduct very long; first accessory albuminiparous gland rounded. (Pl. $\mathrm{X}$, fig. A.)

Type: Helix stagnalis Linné.

Distribution: Holarctic region of America, Europe and Asia.

The genus Lymnca is here restricted to include those species having a bulb-shaped anterior termination of the prostate, differing in this character from all known groups of Lymnæidæ. The penis-sac retractors are normally two in number and are very massive. The 
shells are thin and brittle, with a more or less flaring aperture, a gyrate and imperforate axis and a simple peristome.

The genus Lymnea has been credited to several authors (Bruguiere, Draparnaud, Montfort, etc.), but is clearly due to Lamarck, who correctly diagnosed the genus in 1799. Bruguiere has frequently been quoted as its author, although the reference in the Encyclopédie Méthodique is clearly referable to Lamarck, Bruguiere, as Dr. Dall remarks, "having nothing to do with it." The name Lymnca has been spelled in six different ways-Lymnea, Lymnaa, Lymncus, Limnea, Limncea and Limneus. Etymologically the name should be spelled Limnca, but there seems to be no valid reason why Lamarck's original spelling should not be used. If the law of priority is to be adhered to strictly, there is then no other course. Some of the early American conchologists spelled the name correctly, but during the last forty or fifty years the name has been almost universally spelled Limnæa. Dr. Pilsbry (Nautilus, XVIII, p. 63, 1906) was the first modern zoologist to revise the original spelling, which has been generally accepted among American conchologists. The name Limnæa was used by Poli in 1791 for a heterogeneous assemblage of pelecypods, but his curious quadrinomal system does not enter into systematic nomenclature.

Lymnæa stagnalis (Linné). Plate XIX, figures 1-3.

Helix stagnalis LINNE, Syst. Nat., Ed. X, p. 774, 1758; Ed. XII, p. 1249, 1767.-BAKER, Science, n. s., YXVII, p. 943, 1908.

Lymncea stagnalis LAMARCK, Prodr., p. 75, 1799.

Shell: Elongated (or oval), ventricose at the anterior end, thin; periostracum yellowish-horn to brownish-black; surface shining, growth lines numerous, crowded, more or less elevated, crossed by numerous fine, impressed spiral lines; apex smooth, brownish horn color; whorls six to seven, rapidly increasing, all but the last two rather flat sided; last whorl very large, considerably dilated and inflated, inclining to form a shoulder; spire long, pointed, acute, occupying about half the length of the entire shell; sutures distinct, sometimes impressed; aperture large, broadly ovate, dilated, particularly at the upper part; peristome thin, acute, anterior part rounded; parietal wall with a rather wide, spreading callus which is closely appressed to the body and either completely closes the umbilicus or leaves a very small chink; pillar of the columella gyrate, usually forming a more or less heavy, oblique, ascending plait.

Aperture

Length. Breadth. length. $\begin{array}{lll}49.00 & 24.00 & 27.00\end{array}$

$\begin{array}{lll}51.00 & 23.00 & 27.00\end{array}$

Breadth.

14.00 mill. Baden, Germany.

13.00

66 
$\begin{array}{rrrrrr}52.00 & 31.00 & 32.50 & 20.00 & \text { “ } & \text { Elba River, Germany. } \\ 38.00 & 19.00 & 21.50 & 9.00 & \text { " } & \text { “ }\end{array}$

RANGE: Circumboreal; North America north of about the 40th parallel; Europe, the Caucasus, northern and western Asia.

REMARKs: Stagnalis is one of the most characteristic as it is the largest of the Lymnæas. No examples approaching the typical form as found in Europe have been seen by the writer except several specimens in the Smithsonian Institution from Slave River, 25 miles below Peace River, Athabaska (No. 180204) and from Lake Harrison, lat. $70^{\circ}$ north (No. 25913). These specimens are scarcely typical enough to be retained under stagnalis, however, and would seem to more logically range under the variety appressa of Say, to which the majority of American stagnalis should be referred. The specimens from the United States and Canada are easily referred to appressa, but those occurring in the northwestern part of British America and in Alaska are more like the typical form, showing the influence of the Siberian fauna and clearly indicating that stagnalis is a migrant from Asia via the ancient land connection at Bering Strait. The American specimens differ from the typical form in the shape of the body whorl and in the form of the spire, besides in other minor points.

Lymnæa stagnalis appressa (Say). Plate XIX, figures 4-10; plate XX, figures 1-6; plate XXII, figures 1-3.

Lymnaus appressus SAy, Journ. Phil. Acad., II, p. 168, 1818; Binney's Reprint, p. 66, 1858.

Lymnaa appressa Gould, Lamarck's Genera, p. 69, 1833.-LeA, Proc. Amer. Phil. Soc., IX, p. 8, 1841.-Wheatley, Cat. Sh. U. S., p. 23, 1845.LEA., obs., IV, p. 8, 1848.-JAY, Cat. ed. 4, p. 268, 1852.-Lewis, Proc. Phil. Acad., 1856, p. 259.-ReEve, Elements of Conch., p. 178, 1860.-Lewis, Proc. Phil. Acad., 1860, p. 17.-Morse, Amer. Nat., III, p. 651, pl. 11, fig. 2, 1870.-SCudDER, Bull. U. S. Nat. Mus., 23, p. $200,1885$.

Lymnea stagnalis appressa BAKER, Amer. Nat. XXXIX, p. 667, figs, 3, 4, 1905; Trans. St. Louis Acad., XVI, p. 10, 1906; Bull. Ill. State Lab. N. H., VII, p. 102, 1906.-Henderson, Univ. Colo. Studies, IV, pp. 93, 179, 1907.-Daniels, Nautilus, XXII, p. 120, 1909.-WALKeR, An. Rep. Geol. Surv. Mich., 1908, p. 289, pl. 63, fig. 4, 1909.

Lymnea appressa Dekay, Cat. N. Y. Animals, p. 32, 1839.-CURRIER, Shells Grand River, Mich., 1859.

Limnea appressa Haldeman, Mon. Limn., p. 18, p1. 5, 1842.-Dekay, Moll. N. Y., p. 74, 1843.-MILES, Geol. Surv. Mich., p. 237, 1860.-Cat. Nat. Hist. Eth. Prov. Mus. Victoria, p. 95, 1898.

Limncea appressa Beck, Index, p. 113, 1837.-AdAms, Amer. Journ. Sci., i, XL, p. 267, 1841; Thomp. Hist. Ver., pt. 1, p. 153, 1842.-STimpson, Shells of New England, p. 52, 1851.-MoQ.-TAND., Moll. France, II, p. 471, 1855.-Binney, Check List, p. 12, 1860; Proc. Phil. Acad., 
p. 330, 1861; Land and F. W. Sh. N. A., II, p. 25, fig. 28, 1865.Currier., Kent. Sci. Inst., Mis. Pub., No. 1, 1868.-Ck. \& Fisch., Moll. Mex., II, p. 41, 1870.-Bland \& Binnex, Amer. Jour. Conch., VII, p. 161, 1871.-Koвelt, Mal. Blatt., XVIII, p. 115, 1871.

Limncea appressa SowB., Conch. Icon., XVIII, Lim. sp. 20, Pl. 3, fig. 20, 1872.-Calkins, Cin. Quart. Journ. Sci., p. 323, 1874; Cin. Quart. Journ. Sci., 1, p. 243, 1874.-HAzAy, Mal. Blatt, n. s., III, p. 16, 162 ; IV, pl. 3, fig. 3, 1881.-Osborn, Pop. Sci., XXXIII, pp. 3, 4, 1899.

Limnaa stagnalis appressa BAKER, Moll. Chi. Area, p. 283, text. figs. 92, 93, pl. 34, fig. 1, 1902.-Blatchley \& Daniels, Rep. Dept. Geol. \& Nat. Res. Ind., XXVII, p. 596, pl. 1, fig. 10, 1902.-Daniels, Rep. Dept. Geol. \& Nat. Res. Ind., XXVII, p. 636, 1902.-Elrod, Bull. Univ. Mont., Biol. Series No. 3, p. 173, 1902 ; Nautilus, XV, p. 110, 1902.CKLl., Nautilus, XVI, p. 96, 1903.-KeEP, West. Amer. Sh., p. 313, 1904.-Whiteaves, Ottawa Nat., XIX, pp. 63, 65, 1905 ; Rep. Geol. Surv. Canada, 1904, p. 163A, 1906 ; Nautilus, XIX, pp. 3, 4, 1905.Chadwick, Nautilus, XX, p. 22, 1906 ; Bull. Wis. Soc. N. H., n. s., IV, p. 80, 1906.

Limnaus appressus Kuster, Conch. Cab. p. 4, taf. 1, figs. 8, 9, 1862.

Lymnca jugularis SaY, Art. Conchology, Nicholson's Eñcyc., I (no pagination), 1817; 3rd ed., p. 6, 1819.-Wheatley, Cat. U. S. Shells, p. 23, 1845.-JAY, Cat. p. 269, 1852.-SAY, BinnEY, Reprint, p. 46, 1858.Cooper, Pacific R. R. Rep., XII, p. 378, 1860.

Lymnca stagnalis jugularis BAKER, Amer. Nat., XXXIX, p. 669, fig. 2, 1905 ; Trans., St. Louis Acad., XVI, p. 10, 1906.

Limnea jugularis Haldeman, Mon. Lim., p. 16, pl. 4, 1841.-Dekay, Moll. N. Y., p. 74, pl. V, fig. 81, 1843.-Haldeman, Bos. Journ. Nat. Hist., IV, p. 468, 1844.-Anthony, L. \& F. W. Sh., Cin., 1848.-Gould, Agassiz's Lake Superior, p. 244, 1850.-Newberry, Proc. A. Ass. Ad. Sci., V, p. 105, 1851.-Lapham, Trans. Wis. State Ag. Soc., II, p. 368, 1852.-Miles, Geol. Surv. Mich, p. 237, 1860.

Limnaus jugularis Kuster, Conch. Cab., p. 3, taf. 1, fig. 7, 1862.

Limnaa jugularis HubBard, Cat.-Jackson, Proc. Bost. Soc. N. H., 1, p. 198, 1844.-S $\Lambda$ Y, Binney's Ed. p. 46, 1858.-Bell, Can. Nat. \& Geol., IV, p. 213, 1859.-Lapham, Proc. Phil. Acad., 1860, p. 155.-BinNEY, Check List, p. 12, 1860; Proc. Phil. Acad., p. 330, 1861.Whitfield, Can. Nat. \& Geol., VI, p. 458, 1861.-Bell, Can. Nat. \& Geol., VI, p. 43, 1861.-Binney, L. F.-W. Sh. N. A., II, p. 27, figs. 29, 32, 1865.-CARPENTER, Moll. West. N. Am., p. 599, 1864.Sowb., Conch. Icon., XVIII, Lim. sp. 24, a. b., 1872 (poor figure).Calkins, Cin. Quart. Journ. Sci., 1, p. 243, 1874.-Carpenter, Smith. Mis. Coll., X, p. 85, 1873.-HAzAy, Mal. Blatt., Ser. 2, III, p. 16, 1881.-Westerlund, Vega. Exped., IV, p. 165, 1883.

Limnaa stagnalis jugularis WALKeR, Nautilus, VI, p. 31, p1. 1, figs. 1-3, 1892 ; Rev. Moll. Fauna Mich., p. 17, 1895.

Limnaus speciosus Ziegler, Icon., I, pt. 2, p. 96, pl. 2, fig. 50, 1835.

Limnea speciosa Anthony, List L. F.-W. Sh. Cin., 1843.

Limnea speciosa Binney, Land and F.-W. Sh. N. A., II, p. 27, fig. 31, 1865. Lymnea speciosa JAY, Cat., p. 269, 1852. 
Lymncea stagnalis Kirtland, Amer. Journ. Sci., i, XXXI, p. 35, fig. 10, 1837 (pathologic specimen).-LEA, Proc. Amer. Phil. Soc., IX, p. 8, 1841; Obs., p. 8, 1848.-Lewis, Proc. Phil. Acad., p. 102, 1872.Scudner, Bull. Nat. Mus., 23, p. 201, 1885.-Dall, Land and F.-W. Moll., p. 65, fig. 42, 1905.-PIlsBry, Nautilus, XIX, p. 94, 1905.Smith, Nautilus, XX, p. 91, 1907.-Strerki, Proc. Ohio State Acad. Sci., IV, p. 381, 1907.

Lymnea stagnalis ShepPard, Trans. Lit. Hist. Soc. Quebec, I, p. 196, 1829.LoRD, Nat. in Brit. Col., II, p. 363, 1866.

Lymneus stagnalis CoOPER, Rep. Schoolcraft, Exped., p. 154, 1834.-SAGER, Geol. Surv. Mich., p. 15, 1839.-KIrTland, Rep. Zool. Ohio, p. 174, 1838.

Limnaus stagnalis Forbes, Rep. Brit. Asso., VI, p. 146, 1840.-PACKARD, Amer. Nat., IX, p. 301, 1875. (Embryology.)

Limnca stagnalis Gould, Bost. Journ Nat. Hist., III, p. 488, 1841.-CPR., Rep. Brit. Asso., p. 222, 1856.-Woodward, P. Z. S., p. 185, 1856.Gray, Ann. Nat. Hist., XIX, p. 408, 1857.-Can. Nat. \& Geol., II, p. 196, 1857.-Bell, Geol. Surv. Can., Rep. Prog., p. 252, 1859; Can. Nat. \& Geol., VI, pp. 43, 46, 1861.-Williamson, Can. Journ., n. s., VI, p. 327, 1861.-Whiteaves, Can. Nat. \& Geol., VIII, pp. 51, 102, 1863.-Carpenter, Moll. West. N. Am., pp. 607, 673, 1864.-Com. Geol. du Canada, p. 969, 1864.-Binney, Land \& F.-W. Shells, N. A., II, pp. 25, 27, 155, figs. 30, 257, 1865.-Currier, Am. J. Conch., 1, p. 294, 1865.-Tryon, Am. J. Conch., I, p. 68, 1865; Am. J. Conch., I, p. 247, 1865.-Currier, Kent. Sci. Inst., Miscel. Pub., No. 1, 1868.-Tryon, Con. Hald. Mon., p. 92 (66), pl. 16, fig. 11, 1870.Cooper, Proc. Cal. Acad. Sci., IV, p. 95, 1870.-Dall, Ann. Lyc. Nat. Hist., IX, pp. 340, 350, 1870.-Tryon, Proc. Phil. Acad., 1873, p. 286.-Sмiтн, U. S. Fish Com. Report, 1874, pp. 701, 707.INGersoll, Rep. U. S. Geol. \& Geog. Surv., Colo., etc., 1874, p. 405.Lewis, Bull. Buf. Soc. N. H., II, p. 135, 1874.-Calkins, Cin. Quart. Journ. Sci., 1, p. 323, 1874.-YARRow, U. S. Surv. West. 100th Merid., V, p. 941, 1875.-Dawson, Brit. N. Amer. Bound. Com., pp. 347, 348, 1875.-Walker \& Beecher, Proc. Ann. Arb. Sci. Ass., p. 45, 1876.-Aughey, An. Rep. U. S. Geol. \& Geog. Surv. Col. \& Adj. Terr., p. 268, 1876.-WALKer, Journ. Conch., II, p. 330, 1879.Bell, Rep. Prog. Geol. Surv. Can., 1878-79, c, p. 62, 1980.-Stein, Ind. Dept. Stat. \& Geol., 1880, p. 458.-Heron, Trans. Ott. Field Nat. Club., 1, pp. 37, 39, 1880.-Decamp, Kent. Sci. Inst., Miscel. Pub., No. 5, p. 7, 1881.-Bell, Rep. Geol. \& Nat. Hist. Surv. Canada, $1879-80$, p. 75 c. 1881 .-Amer. Nat. XVII, p. 203, 1883.-JoRDAN, Nova Acta Ksl.-Leop.-Carol. Deutsch. Akad. Natur., XLV, p. 282, 1883.-LATch Ford, Amer. Nat., XVIII, pp. 1051, 1052, 1884.Call, Bull. U. S. Geol. Surv., II, pp. 371, 378, 1884.-Trans. Ottawa Nat. Field Club., 1, p. 132, 1884.-Standard Nat. Hist., 1, p. 307, fig. 355, 1884.-Christy, Journ. Conch., IV, p. 346, 1885.-Trans. Ottawa Nat. Field Club, II, 263, 1885.-Beauchamp, Shells of N. Y., p. 3, 1886.-Grant, An. Rep. Geol. \& Nat. Hist. Surv. Minn., XIV, p. 122, 1886.-KEEP, West Coast Shells, p. 123, fig. 112, 1887.- 
Shimek, Bull. Lab. Nat. Hist. State Univ. Iowa, I, p. 67, 1888.Keyes, Bull. Essex Inst., XX, p. 70, 1888.-Grant, An. Rep. Geol. \& Nat. Hist. Surv. Minn., XVI, p. 483, 1888.-Holzinger, An. Rep. Geol. \& Nat. Hist. Surv. Minn., XVI, p. 490, 1888.-CкLl., Journ. Conch., VI, p. 64, 1889.--Gilbert, Mon. U. S. Geol. Surv., I, pp. 210, 298, 1890.-Sнгмек, Bull. Lab. Nat. Hist. Univ. Iowa, I, p. 67, 1890.-Pilsbry, Proc. Phil. Acad., pl. XVII, fig. 2, 1890.-Cooper, Proc. Cal. Acad. Sci., ii, III, p. 70, 1890.-Ottawa Nat., IV, p. 55, 1890.-Stearns, Proc. Nat. Mus., XIV, p. 100, 1891.-Walton, Proc. Roch. Acad. Sci., II, p. 11, pl. 6, fig. 9, 1891.-LATchFord, Ottawa Nat., VI, p. 118, 1892.-Taylor, Ottawa Nat., VI, p. 35, 1892.-WALKer, Nautilus, VI, p. 31, pl. 1, fig. 6, 1892.-MArShall, An. Rep. N. Y. State Mus., XLVII, p. 63, 1893.-LAtchford, Ottawa Nat., VII, p. 115, 1893.-WALKER, Nautilus, VII, p. 128, 1894.Marshall, Report Exhib. N. Y. World's Fair, p. 511, 1894.BAKer, Science, n. s., II, p. 179, 1895.-WALKer, Rev. Moll. Fauna Mich., p. 17, 1895.-TAYloR, Ottawa Nat., IX, p. 174, 1895.-SARGENT, Nautilus, IX, p. 127, 1896.-SNyder, The Museum, III, p. 12, 1896.-BAKer, Journ. Cin. Soc. N. H., XIX, p. 84, 1897; The Museum, III, p. 155, 1897.-WISWALl, Nat. Sci. Journal, 1, No. 2, p. 47, 1897.-BAKer, Journ. Cin. Soc. N. H., XIX, p. 78, 1897.-Ami., Ottawa Nat., XI, p. 26, 1897.-BAKER, Chicago Moll., p. 23, 1898; Trans. Acad. Sci. St. Louis, VIII, p. 88, 1898.-Walton, The Museum, IV, p. 132, 1898.-WALkER, Nautilus, XI, p. 122, 1898.Hanham, Nautilus, XIII, p. 5, 1899.-Mitchell, Nautilus, XIII, p. 88, 1899.-Pilsbry, Nautilus, XIII, p. 64, 1899.-Osborn, Pop. Sci., XXXIII, p. 3, 1899.-W Wh Ker, Nautilus, XIII, p. 35, 1899.Leverett, Mon. U. S. Geol. Surv., XXXVIII, p. 174, 1899.-Baker, Nautilus, XIV, p. 69, 1900.-Walker \& Lane, Geol. Surv. Mich., VII., pt. ii, p. 251, 1900.-Blatchley \& Ashley, Rep. Geol. \& Nat. Res. Ind., XXV, p. 248, 1901.-BAKER, Trans. Acad. Sci. St. Louis, XI, p. 21, fig. 12, pl. 1, fig. 15, 1901.-Stearns, Science, XV, p. 153, 1902.-Whiteaves, Ottawa Nat., XVI, p. 91, 1902.-Elrod, Bull. Univ. Mont., Biol. Ser., No. 3, pp. 112, 160, 1902.-Ckll., Nautilus, XVI, p. 96, 1903.-W -Wlker, Geol. Surv. Mich., VIII, pt. iii, p. 101, 1903.-BAKer, Shells of Land \& Water, p. 11, fig., pl. fig. 18, 1903. -KeeP, W.est. Amer. Shells, pp. 148, 313, fig. 127, 1904.-Letson, Bull. N. Y. State Mus., LXXXVIII, p. 51, 1905.-Whiteaves, Ottawa Nat., XIX, pp. 31, 32, 1905.-Letson, Bull. Buf. Soc. Nat. Sci., IX, p. 242, 1909.

Limnea stagnalis Haldeman, Bost. Journ. Nat. Hist., IV, p. 468, 1844.-

Carlton, Proc. Cal. Acad. Sci., i, IV, pp. 51, 57, 1869.-Froebel, Proc. Lyc. Nat. Hist., I, p. 72, 1870.-Ingersoll, Bull. U. S. G. \& G. Surv., I, p. 138, 1875 ; Proc. Daven. Acad. Sci., II, p. 132, 1877.

Limnca lanceata, Ottawa Nat., I, p. 58, 1882 ; IV, p. 58, 1890.

Limnca lepida, Ottawa Nat., I, p. 58; IV, p. 56, 1890; VI, p. 33, 1892.

SHELL: Differing from stagnalis in being more regularly fusiform, having a less angulated and more gracefully rounded body whorl and a more pronounced twist of the axis. The spire in typical stagnalis 
has a somewhat pinched-in appearance, and the body whorl is distinctly shouldered; nuclear whorls $1 \frac{1}{4}$, the texture resembling satin finish; in outline the first part of the whorl is a small rounded knob about one-fourth the size of the second part, which is wider than high; in color it is shining yellowish-brown. (P1. XLIX, figs. A, B.)

\section{Aperture}

$\begin{array}{ccrrll}\text { Length. } & \text { Breadth. } & \text { length. } & \text { Breadth. } & \\ 42.00 & 17.00 & 21.50 & 10.25 & \text { mill. } & \text { Say's Type. } \\ 40.50 & 16.00 & 21.00 & 9.50 & \text { “ } & \text { " } \\ 50.00 & 25.00 & 27.00 & 15.50 & \text { “ } & \text { Lake Ontario. } \\ 49.00 & 14.50 & 27.50 & 14.00 & \text { “ } & \text { “ } \\ 47.00 & 25.00 & 27.00 & 17.00 & \text { “ } & \text { Niagara River, N. Y. } \\ 41.00 & 19.00 & 22.00 & 13.00 & \text { “ } & \text { Bear Lake, Mich. } \\ 46.00 & 20.00 & 19.00 & 11.00 & \text { “ } & \text { Romeo, Ill. } \\ 46.00 & 20.00 & 22.00 & 11.00 & \text { “ } & \text { Pigeon Lake, Ont. } \\ 57.50 & 24.50 & 29.00 & 13.00 & \text { “ } & \text { Lake Calumet, Ill. } \\ 49.00 & 20.50 & 24.50 & 11.00 & \text { " } & \text { Erie Canal. } \\ 43.50 & 19.75 & 21.00 & 10.50 & \text { “ } & \text { Bitter Root River, Mont. } \\ 46.50 & 22.50 & 24.50 & 12.50 & \text { “ } & \text { St. Lawrence River. }\end{array}$

TyPe: Appressa; Academy of Natural Sciences of Philadelphia, two specimens. Jugularis, types not in existance.

Type Locality: Appressa, Lake Superior; jugularis, original locality not stated by Say.

Animal: Light or dark horn colored, tinged with bluish on the foot; tentacles triangular, flat, rather long and tapering; foot short and wide, truncated before and roundly pointed behind, 20 mill. long and 9 mill. wide in an individual of ordinary size.

JAws (Pl. VI, fig. A): The superior jaw arched, very wide and low, its cutting edge with a narrow, somewhat acute swelling in the middle, with a larger, convex swelling on each side; lateral jaws somewhat triangular, the lower point of the triangle produced, long and tongue-like, directed downward and outward when the jaws are pressed out flat. The cutting edge of the jaws is very dark chestnut colored, almost black in some specimens. The form of the superior jaw differs considerably from the figures given in some European works, where the lower median portion is shown as concave with a slight median swelling. This may be due to the figure having been drawn from a different position. Cooke (Moll., p. 211) figures the jaws as they appear in the American specimens examined.

Radula : Formula (Pl. VII, fig. A)

$$
\frac{2}{3}-\frac{4}{4}+\frac{3}{3}+\frac{19}{2}+\frac{1}{1}+\frac{19}{2}+\frac{3}{3}+\frac{24}{3-\frac{4}{4}+}
$$

(46-1-46). Central tooth with a single spade-shaped cusp; first to nineteenth lateral teeth bicuspid; the mesocone very large, rather 
narrow and acute, the ectocone short, spade-shaped and placed rather high on the reflection; the sixteenth to nineteenth teeth develop a very small cusp just above the ectocone; intermediate teeth three in number, the entocone arising by a splitting of the mesocone $(20,21)$, the ectocone becoming very small and a second cusp developing on the reflection just above it. First marginal teeth 4-5 serrate distally, with a small ectocone. The typical marginal teeth are narrow and elongated with very small cusps $(32,34)$. The extreme outer marginals are small, narrow and indistinctly serrated distally $(38,44)$. The number of teeth seems to vary in different individuals. The writer has counted from $46-1-46$ to 54-1-54; Binney (L. and F. W. Sh., p. 28) gives 40-1-40 and (p. 155) 47-1-47 teeth; Bland and Binney (Am. Journ. Conch., VII, p. 161) gives $40-1-40$. It is probable that the membrane having $54-1-54$ teeth was abnormal. $46-1-46$ is the number generally counted by the writer.

The radula of the American stagnalis does not agree in all respects with European figures. Dybowski ${ }^{1}$ figures the first lateral with a very small entocone, which has not been seen in any American specimen. Otherwise the figures are the same. Cooke ${ }^{2}$ figures the central tooth as distinctly tricuspid and of the same size as the lateral teeth, obviously an error, as no Lymnaa has this type of central tooth. Binney and Bland ${ }^{3}$ figure the laterals as they appear in this monograph, but the teeth are too aculeate and too much curved, a feature probably due to the use of photography, which does not produce accurate results in these small radulæ.

Genitalia (P1. X, fig. A): Male organs: Penis-sac very large, cylindrical, wide at penial opening and tapering toward the distal end; penis short, about one-quarter the length of the penis-sac; vas deferens five times the length of the penis-sac; prostate duct about half as long as vas deferens; it is a very narrow tube until it enters the prostate, where it becomes pyriform; proximal portion of prostate large, bulbshaped, constricted behind to form a narrow, ribbon-like organ, which gradually enlarges and then decreases in size where it joins the uterine portion of the oviduct; protractor muscles five to eight in number, two to five posterior and three anterior; these muscles are split at their extremities into many small branches where they enter the body wall, columella muscle and penis-sac; retractor muscles one to three in number, inserted in the columellar muscle; the penis retractor is inserted in the posterior retractor of penis-sac and the penis nerve enters this muscle. In two specimens examined but one retractor was found.

${ }^{1}$ Bull. Soc. Imp. Nat. Moscou, LIX, p. 256, tab. V, 1884.

${ }^{2}$ Mollusca, p. 255, fig. 141.

${ }^{3}$ op. cit., pl. 12 . 
The muscles of the penis-sac in stagnalis are unusually large and strong.

Female organs: Vagina very short and wide; oviduct very long, rounded at its lower portion, but much convoluted at its upper portion, where it forms the uterine portion; receptaculum seminis roundly pearshaped, its duct narrow and as long as the penis-sac, about a third as long as the prostate portion of the vas deferens and as long as the free portion of the oviduct; this duct enlarges at its junction with the oviduct to form the vagina; albuminiparous gland a large linqueform body; first accessory albuminiparous gland very large, flatly rounded, firmly attached to and embracing the oviduct; second albuminiparous gland small, almost round, attached to but not embracing the oviduct.

Hermaphrodite organs: The ovotestis is embedded in the digestive gland; its duct is at first a narrow tube which divides to form the uterine portion of the oviduct and the prostate.

The organs are brightly colored, the albuminiparous gland, ovotestis, first accessory albuminiparous gland and receptaculum seminis being orange, the prostate orange shading into black, the vagina dirty white and the penis-sac flesh-colored. The muscles, vas deferens and other ducts are white. The colors are somewhat variable.

The muscles of the penis-sac exhibit considerable variation (pl. $\mathrm{XIV}$, fig. A). The retractors vary from one to three in number, although two seem to be the normal number present; the anterior protractors appear quite constant in form and number, but the posterior protractors vary from one to five. It is noteworthy that where a number are present they are much smaller and narrower than is the case where only one or two are present. This increase in number is probably due to a splitting of the large muscles. The posterior protractors may be attached to the right border of the columellar muscle or they may be attached to the numerous small transverse muscles of the columellar region $(1, \mathrm{M})$. The penis retractor varies to some extent; normally it arises directly as a branch of the penis-sac retractor (pl. XIV, A., 2, 3), but it is sometimes split into two branches at its junction with the penis-sac retractor, as shown in figure A, 1.

The measurements of the genital organs are quite uniform; four are shown in the following table: ${ }^{1}$

\begin{tabular}{|c|c|c|c|c|c|c|c|c|}
\hline Penis. & $\begin{array}{c}\text { Penis- } \\
\text { sac. }\end{array}$ & $\begin{array}{l}\text { Rec. } \\
\text { sem. } \\
\text { duct. }\end{array}$ & $\begin{array}{c}\text { Prostate } \\
\text { duct. }\end{array}$ & $\begin{array}{l}\text { Vas. } \\
\text { def. }\end{array}$ & $\begin{array}{l}\text { Penis- } \\
\text { sac } \\
\text { tractor. }\end{array}$ & Shell. & Locality. & \\
\hline 2.50 & 9.00 & 8.50 & 29.00 & 45.00 & 5.25 & 50.00 & Rochester, & N. \\
\hline 2.50 & 9.00 & 9.00 & 29.00 & 45.00 & 5.00 & 50.00 & “ & “ \\
\hline 2.25 & 9.00 & 9.00 & 29.00 & 46.00 & 4.00 & 48.00 & “ & “ \\
\hline 2.00 & 7.00 & 9.00 & 29.00 & 32.00 & 4.00 & 48.00 & “ & “ \\
\hline
\end{tabular}

${ }^{1}$ Dissections 23023, 23024, 23042. 
The genitalia of the American stagnalis seem to be almost identical with those of the European form as figured by Baudelot, Prasch, Cooke and Keferstein. The figure by Baudelot (pl. 4, fig. 1) approaches nearest to our race. Cooke ${ }^{1}$ figures the penis-sac as enormously enlarged and of a totally different shape from anything found in the American form. No variation in the shape of this organ has been noted, in the American species, in the different seasons. There would seem to be no stable characters in the genitalia by which to separate the American from the European varieties of stagnalis. The characteristic features of the genitalia of stagnalis are the peculiar bulbshaped form of the prostate, the small size of the penis as compared with the penis-sac, the great length of the vas deferens, and the position and insertion of the retractor muscles of the male organ.

Range (Figure 9): North America from about the 37th (Colorado) and 41st (Illinois, Ohio ${ }^{1}$ ) parallels of north latitude to the Arctic Ocean. A glance at the map shows that stagnalis appressa is an inhabitant principally of the lake basins extending in a northwesterly direction from the great lakes to the Yukon River; it also inhabits a second large territory from southern Utah and Colorado northward between the Rocky Mountains and the Cascade Mountains, and the Sierra Nevadas. These two areas cover the regions of the great lakes left by the retreat of the ice sheet and also the Quaternary lake basins west of the Rocky Mountains. The absence of stagnalis from the waters of the great plains of the Dakotas and Nebraska is noteworthy, and indicates that the species is primarily a great lake form.

Comparing the distribution map with the regional map (figure 1), we find that stagnalis occupies the Canadian, Hudsonian, Mackenzian, Yukonian, Alaskan, Columbian and a part of the Californian, Coloradoan, Upper Mississippian and the Great Basin regions. It is absent from the Labradorian, the eastern part of the Hudsonian and the Nova Scotian regions. It is also absent, apparently, from the territory west of the Canadian Rocky Mountain chain. Its extension in the Mississippian region is confined to the upper part. This species is one which prefers cold or temperate climates. Its northwesterly extension is strongly suggestive of its Asiatic origin, a fact further emphasized by its apparent absence from the northeastern part of North America.

Compared with Merriam's zone map, stagnalis is found to occupy

${ }^{1}$ op. cit., p. 144 , fig. 55 .

${ }^{1}$ Anthony records stagnalis appressa from Cincinnati, but this was probably an error, as it has not been substantiated by specimens. 


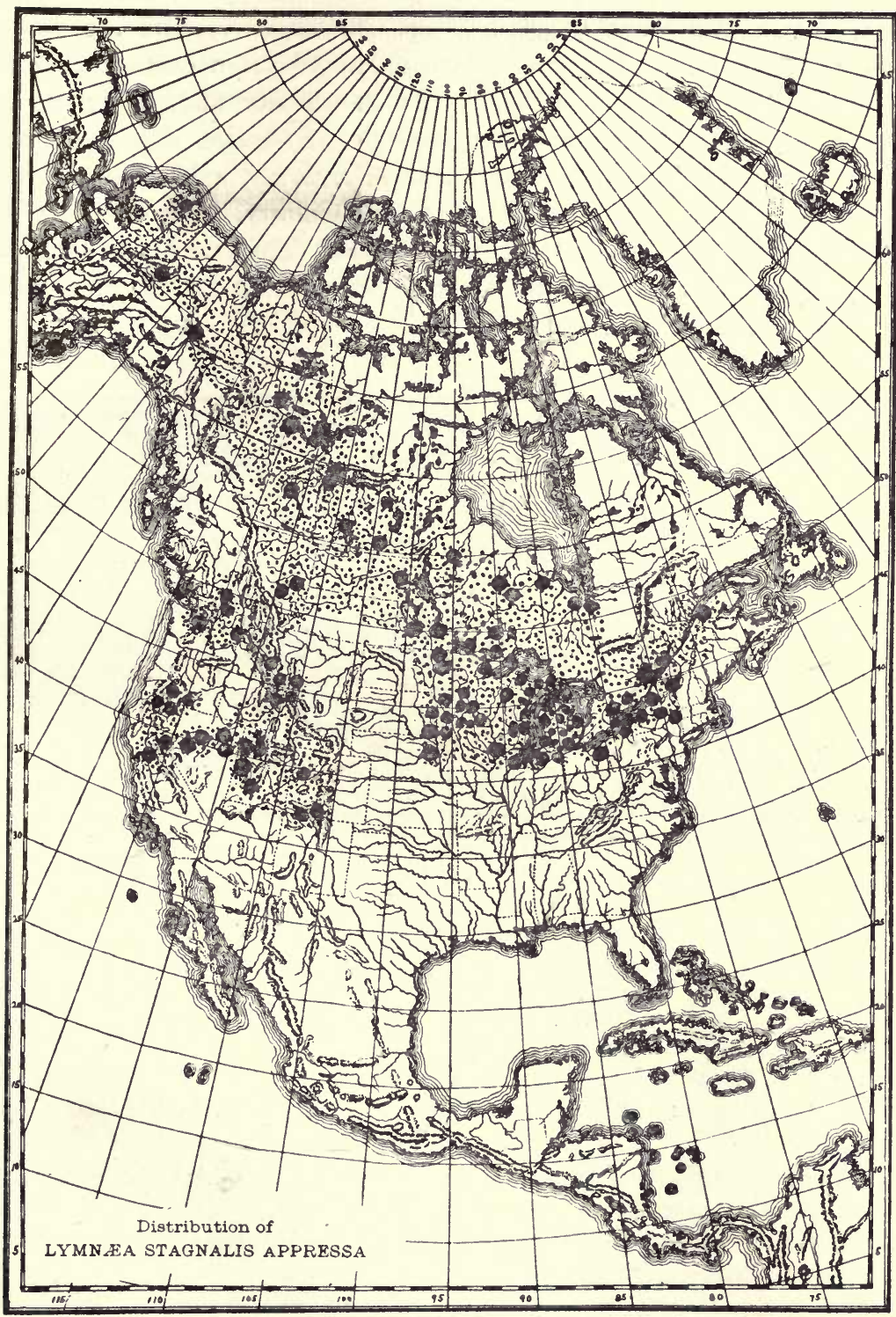

FIG. 9. 
a portion of the Arctic, the Hudsonian, Canadian, Transition and the extreme northern portion of the Upper Austral life zones.

Geological Range (Figure 10): Pleistocene. The records of fossil stagnalis show that the species extended from eastern Ontario west to Nevada. The records are few in number and, being mostly post-glacial, no generalizations are nocsihle. Stagnalis doubtless lived in Pliocene or earlier times, and Lymnaa stearnsi, a Middle Miocene fossil found in the Mascall beds of Grant County, John Day Valley, Oregon, is probably an ancestor of appressa. The specimens thus far obtained, however, are too imperfect to afford a basis for comnarison with the recent species.

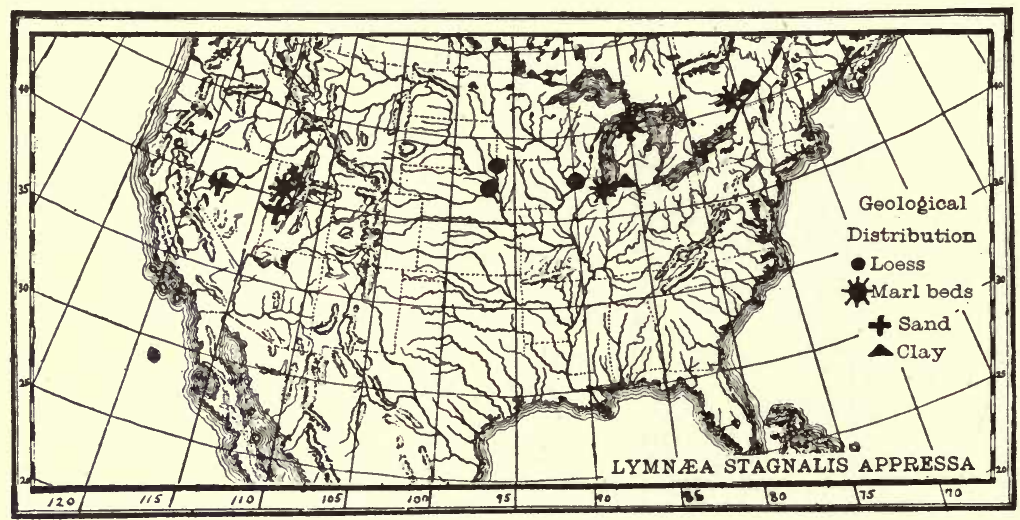

FIG. 10.

\section{RECORDS.}

LOESS.

IllinoIS: Base of Loess in bluff of Mill Creek, about five miles north of Milan, Rock Island Co. (Leverett; Shimek; Udden).

Nebraska: Washington Co. (Aughey).

South Dakota: Otis Mill, Union Co. (Darton coll., Smith. Inst.).

MARL BEDS.

Illinors: Clay and marl, Cook Co., various localities (Baker); marl beds, Clyde Ave. near Austin Ave., Chicago (Scharf).

Michigan : Crooked Lake, Oden, Emmet Co. (Slocum).

UтAн: White marl, Lake Bonneville (Gilbert).

Ontario, Canada: Hemlock Lake, near Edinburgh, east of Ottawa, in soft white calcareo-argillaceous matrix (Ami. Ottawa Nat., XI, p. 20, 1897).

SAND AND GRAVEL PITS, CLAY, ETC.

Illınors: Bowmanville, Cook Co. (Baker).

Michigan: Found with mastodon remains in Niles, Berrien Co., from muck beneath the mastodon (Walker, Nautilus, XI, p. 121, 1898). 
Nevada: Rare specimens are found semi-fossil in the Humboldt sink in the Lahontan area (Call).

Ontario, Canada: Sand and gravel pits, Niagara Falls; Leda clay, ten miles below Ottawa city (Bell).

Utaн: It abounds, as a semi-fossil, in Sevier Desert (Call, Mollusca of Great Basin).

EcolOGY: Found usually in more or less stagnant spots of ponds and rivers about decaying vegetation. In ponds it may be found floating among pond weeds with its foot applied to the surface of the water. A shore bordered with reeds and cat-tails is a favorite locality. Also - found on, and in the vicinity of, rotten fruit and vegetables, and frequently seen feeding on the dead bodies of various animals. In the small bays and inlets of Lake Ontario, this species is very abundant. It has been noted that early in the year, about May or June, stagnalis is found only in small patches of water near the shore, while later in the year, in August or September, it may be found in abundance floating in the open water of these bays, particularly in the vegetation which is so common at this time of the year. It breeds in the fall.

"In a small pool along Bitter Root River. A large spring supplies the pool with clear, fresh water. (Elrod, Montana.)

"In lakes, feeding upon weeds. (Sargent, Minnesota.)

"Outlet of Lake Tahoe, Placer County, Cal., 6247 ft. alt. (Cooper.)

"The specimens from the prairie region are often very well grown and robust, the shell being thick and showing strong growth lines. Some specimens from pools at Dufferin measured 56 by 26 mill." (Dawson, Manitoba.)

Although generally supposed to be a vegetable feeder, stagnalis is known not only to feed upon dead animals, but instances are on record of its attacking living animals, especially fish (stickleback) which have been confined with them in the aquarium. ${ }^{1}$. The writer has observer it adhering to rotting vegetables, dead dogs, cats and other animals in the Erie Canal, at Rochester, N. Y. Mr. William Nelson ${ }^{2}$ records the presence of a pale violet liquid, which is discharged by the animal when irritated and sometimes when lifted from the water. The same phenomenon has been observed by the writer in many of the American forms.

Some interesting experiments in raising appressa from the egg have been made by Dr. H. A. Pilsbry at the Academy of Natural Sciences of Philadelphia. The specimen from which the eggs were obtained was a large, fat individual of five whorls, from Buffalo, N. Y.,

${ }^{1}$ Uliyett, Sci. Gossip, XXII, p. 24, 1886.

${ }^{2}$ Journ. Conch. I, p. 216, 1878 . 
and measured as follows: Length, 54.00 ; breadth, 20.50 ; aperture length, 29.50 ; breadth, 16.00 mill. (No. $703 \%$ ). The progeny at eight months were very narrow, quite unlike the parent shell.

An albino stagnalis is reported by Mr. F. R. Latchford from Chilcotts' Lake, Masham, Ontario, in the Ottawa Naturalist, VI, p. 118. The shell is described as being as "white as pearl." Albinism in this species is also reported by several European authors.

Lymncea stagnalis is the host of several species of cercariæ (larvæ of trematode worms) which infest the pulmonary cavity. They seem to occasion no especial inconvenience to the animal. ${ }^{3}$

Remarks: A thorough revision and a careful study of a large collection of American stagnalis has made it evident that Say's jugularis (as defined by Haldeman and Binney) cannot be separated from appressa when large numbers of individuals are examined from various localities. When compared singly such forms as figure 9 , plate XIX, seem quite distinct from jugularis as shown in figure 6 , but when several hundred specimens are examined from the same locality these differences disappear and no line can be drawn between them. Both forms occur in the same geographic area and are almost always found associated together. They offer no anatomical differences. Say's types of appressa closely resemble Binney's figure 28, and this form must be taken as the type of the race appressa. Haldeman's figured specimens of both appressa and jugularis are faithfully portrayed on his plates 4 and 5. A specimen of his jugularis measures as follows:

Length, 44.00 ; breadth, 21.00 ; aperture length, 25.50 ; breadth, 12.00 mill.

It is unfortunate that Say's types of jugularis cannot be found. The name was doubtless founded on immature material, as the size given by Say is but one inch. Immature individuals of appressa of $51 / 2$ or 6 whorls measure about an inch and correspond in every way with Say's description. Say's reference to a specimen from the West Indies is, of course, quite erroneous; the only Lymnæa from this region resembling stagnalis is Pseudosuccinea francisca, from Cuba, which is much smaller and of a different shape.

Stagnalis appressa is a characteristic Lymnea, easily known wherever found. It differs from typical stagnalis principally in its more graceful, fusiform shape. The aperture is more oval and not so angular and the columellar callus is more closely appressed to the parietal wall, giving the axis a conspicuous twist which is absent in most specimens

${ }^{3}$ See Hogg, Trans. Roy. Micr. Sec. III, p. 232, 1870 for description of Cercaria furcata. 
of typical stagnalis. The spire is also more regular in form, that of stagnalis having a more or less pinched-in appearance.

Prof. Cockerell has suggested (Nautilus, XVI, p. 96) that the American shells might be included in the Helix fragilis of Linné. After an examination of European and American specimens, I am not inclined to adopt this course, particularly as the English conchologists consider the fragilis to be a smaller form than appressa. The description of Linné is as follows and might apply to our shells so far as the general characters go:

"H testa imperforata, ovato-subulata tereti, pellucida, aperturaoblonga” (Syst. Nat., ed. 12, p. 1249, 1767). Haldeman (Mon., p. 20) refers fragilis to palustris. Moquin-Tandon (Hist. Moll., II, p. 471) makes it a variety of stagnalis, and Louis Germain in a recent publication (Bull. Soc. Sci. Nat. L'Ouest France, ii, Tome III, p. 154) raises it to the rank of a species, but says: "Test mince, fragile, corné clair ou brun. Haut: 8-25 m.; diam., 4-9 m." Locard and Westerlund also consider it a small form. Moquin-Tandon (Moll. France, II, p. 471) makes appressa a synonym of stagnalis var. roseolabiata Wolf. Kobelt (Mal. Blatt., XVIII, p. 108, 1871) thinks appressa is a synonym of fragilis Linné, and includes bicolor Ziegler, roseolabiatus Wolf and subula Pareyss. The figure of subula (fig. 9) given by Kobelt seems almost identical with appressa. The raphidia of Bourg. (Spic. Mal., pl. II, fig. II) resembles appressa, although Westerlund (Synopsis Moll. Ext. Scan., p. 91) refers this and subula Pareyss to his subulata. Var. elegans Leach also resembles the American shell. (See Martens, Sitz.-Ber., Gess. Natur. Freunde, Berlin, 1899, p. 203.) Hazay (Mal. Blatt., n. s. III, p. 162) makes appressa a species, with subulata West., vulgaris West. and ampliata Clessin as varieties. His variegata (Mal. Blatt., IV, pl. 2, fig. 7) looks not unlike jugularis Say as figured by Haldeman. In view of the general confusion and uncertainty concerning just what the Helix fragilis of Linné really is, it would seem the best course to adopt for the American variety a name about which there is no uncertainty. There are a number of forms found in Europe which closely resemble those of America, but as they are undoubtedly cases of parallel development, they need not be considered in a study of the American fauna.

Some peculiar forms of stagnalis (pl. XXII, figs. 1-3) are figured by Mr. Bryant Walker on plate 1, volume VI, of the Nautilus. They are characterized by a rather short spire and a rather wide expansion of lip. Some of these may be pathological examples (pl. XXII, fig. 3, for example, which has the general aspect of var. sanctamaria), and 
all have been subjected to some peculiarly unfavorable influence. The specimens from Black Lake are a pure translucent white. If the forms figured on the plate referred to (pl. XXII, figs. 1, 2) were constant they would constitute a marked variety of stagnalis. Mr. Walker says of these, in a recent letter, that they vary toward the normal form and that in his opinion they are not entitled to be given varietal rank. He also says: "The set I have varies greatly in shape and several of them are deformed. Another has the edge of the lip completely revolute. Figs. 2 and 3 are the most regular." In the Smithsonian Institution there are three specimens similar to those figured by $\mathrm{Mr}$. Walker. These measure as follows:

\begin{tabular}{cccccc}
\multicolumn{5}{c}{ Aperture } \\
Length. & Breadth. & length. & Breadth. \\
33.00 & 16.50 & 22.00 & 10.25 & mill. & Lake Erie \\
22.00 & 14.25 & 19.25 & 8.00 & “ & Ruby Valley. \\
29.00 & 15.00 & 18.50 & $9.00 \quad$ “ & “ “
\end{tabular}

The Lake Erie specimen (No. 41716) was collected by Dr. Dall and the Ruby Valley specimens (No. 27953) by Capt. Simpson. This form is similar to var. acuminata Lam., clammys Bens., and succinea Desh., which are peculiar to India.

In the Niagara River at Squaw Island, near Buffalo, N. Y., occurs a form of appressa with a much expanded aperture, recalling some of the mutations named by European conchologists. Some specimens have the upper part of the aperture much flattened. It is upon just such material as this that some of the French conchologists have made two score or more species and varieties of Lymnaa stagnalis. The shell of stagnalis is frequently distorted, the whorls becoming scalariform and developing a marked shoulder. Such specimens have been seen from Spoonbill Slough, Deuel County, South Dakota.

Lymnæa stagnalis var. Plate XXII, figure 4.

Limnca stagnalis var. bottnica? WALKER, Nautilus, IX, p. 3, 1895 .

"Among the fresh-water pulmonates many interesting forms occurred. The most noteworthy of them was a single example of a deep-water form of Limnæa stagnalis L., dredged from ten meters depth in Lake Michigan, at High Island Harbor, in the Beaver Island. It is about $23 \mathrm{~mm}$. in length, exceedingly fragile, of a pure translucent white, and, though somewhat larger and differently proportioned, appears to be analagous to the var. bottnica of Clessin from Sweden." (Walker, Nautilus, p. 3.)

This is a peculiar shell and additional material may prove it to represent a recognizable race of stagnalis. Mr. Walker says of it: "The white form of L. stagnalis mentioned in Nautilus IX, p. 3, was 
a single small, pure white shell dredged from deep water. The lower part was smashed by the dredge. The animal was pure white and consequently the black eyes were very conspicuous" (in letter).

Future search will doubtless determine whether this peculiar shell is simply a case of albinism or an abyssal race of stagnalis.

Lymnæa stagnalis perampla (Walker). Plate XX, figures 7-9; pl. XXII, figure 5 .

Limnaa stagnalis WaLKeR, Nautilus, VI, p. 31, pl. 1, fig. 6, July, 1892.

Lymnaa stagnalis v. perampla WaLKer, Nautilus, XXII, No. 1, p. 8. pl. II, figs. 5, 6, May, 1908.

This variety differs from the usual North American form, var. appressa Say, by its shorter, rapidly accuminating spire and larger, strongly shouldered body whorl; the first three whorls of the spire are slender and increase regularly in size; the penultimate whorl is disproportionately enlarged, swollen and subangulated by the flattening of the upper part of the whorl, which in the body whorl develops into a prominent shoulder (Walker).

\section{Aperture}

\begin{tabular}{|c|c|c|c|}
\hline $\begin{array}{l}\text { Length. } \\
45.50\end{array}$ & $\begin{array}{c}\text { Breadth. } \\
26.00\end{array}$ & $\begin{array}{l}\text { length. } \\
28.00\end{array}$ & $\begin{array}{l}\text { Breadth. } \\
\quad 18.00 \text { mill: }\end{array}$ \\
\hline 45.00 & 23.75 & 26.00 & 17.00 " \\
\hline 49.00 & 26.50 & 30.00 & 15.50 \\
\hline
\end{tabular}

Types: No. 1834, coll. Bryant Walker; cotype, Chi. Acad. Sci., 1 specimen No. 23924.

Type Locality: Houghton Lake, Roscommon County, Mich.

Animal, Jaw, Radula and Genitalia: Not examined.

RANGE: Michigan. A race of the Canadian region and of the Canadian life zone.

\section{RECORDS.}

Michigan: Douglas Lake, Cheboygan Co. (Ferriss; Velie; Walker); Houghton Lake, Roscommon Co. (Walker).

Geological Range: Unknown.

Ecology: "All the specimens of stagnalis from Houghton Lake that I have seen, more than thirty, are of this peculiar form, which is apparently a well marked race" (Walker).

It is interesting to note that in Marl Lake a small enlargement of Marl River, which connects Higgins and Houghton Lakes, the typical stagnalis appressa was the only form found.

REMARks: As remarked by Walker, this variety seems to be a well marked race, easily separable from typical stagnalis appressa. It will probably be found in other localities in northern Michigan, and possibly in parts of Minnesota, Wisconsin and northern Ontario. 
Lymnæa stagnalis wasatchensis (Hemphill). Ms. Plate XX, figures 10-12.

Shell: Much elongated, narrow, thin; color light yellowish horn; surface with the characteristic sculpture of stagnalis; whorls $61 / 2$ flatly rounded, increasing slowly in size; last whorl small, generally not inflated, but well rounded; spire very long, acutely pointed, occupying more than half the length of the shell; sutures well marked, aperture small, roundly ovate; inner lip appressed tightly to the parietal wall and to the columellar region; there is no umbilical chink; axis with a strong plait as in stagnalis appressa.

\begin{tabular}{cccc} 
Length. & Breadth. Aperture length. & \multicolumn{2}{c}{ Breadth. } \\
42.00 & 17.00 & 19.00 & $12.00 \mathrm{mill}$. \\
38.00 & 16.00 & 17.50 & 11.00 “" \\
32.50 & 14.00 & 15.00 & 9.50 " \\
37.00 & 18.00 & 19.00 & 12.00 “ \\
45.00 & 20.00 & 22.00 & 13.00 “
\end{tabular}

Type: Coll. Henry Hemphill.

Type Locality: Near Salt Lake, Utah.

Animal, Jaw, Radila and Genitalia: Unknown.

Range: (Figure 11) Western and Northwestern America.

RECORDS.

The records give a peculiar distribution for this species, showing an area of about 1500 miles between the most northern record and that from Alberta. The northern record seems authentic, the specimens agreeing well with wasatchensis. The race probably inhabits most of the region north of the 40th parallel and west of the 110th meridian.

UNITED STATES.

Uтан: Near Salt Lake; near Logan, Cache Co. (Hemphill); Pangeritch Lake, 25 miles north of Salt Lake, Tooele Co. (Wheeler expedition, Phil Acad.).

Washington: Near Spokane Falls, Spokane Co. (Button); East of Colville (Smithsonian coll.).

BRITISH AMERICA.

Alberta : Devil's Lake, near Banff (Woodruff).

Mackenzie: Near Fort Anderson, N. lat. $68^{\circ}$ (McFarland).

GEOLOGical RANGe: Unknown.

ECOLOGY: No records have been seen detailing the habitat relations of this race.

Remarks: Wasatchensis appears to be a strongly marked race of stagnalis. Its chief characteristics are its long tapering spire, its roundly ovate aperture and the general rotundity of the last whorl. It may be at once distinguished from appressa by its more rounded aperture and last whorl, appressa having more flat sided whorls. This 
is the most elongate race of stagnalis in America and were it not for certain intermediate examples might easily rank as a species.

Westerlund's subulata (Expose. Crit., 18\%1) is similar to wasatchensis, but has 8-9 whorls and the aperture is more oblong. In the Smithsonian collection there is a peculiar form from near Fort Colville, Washington (No. 9322) which may be regarded as an extreme form of wasatchensis. The spire whorls are long and tapering, but the body whorl suddenly expands to about double the diameter of the penultimate whorl and is notably flat sided near the suture. A char-

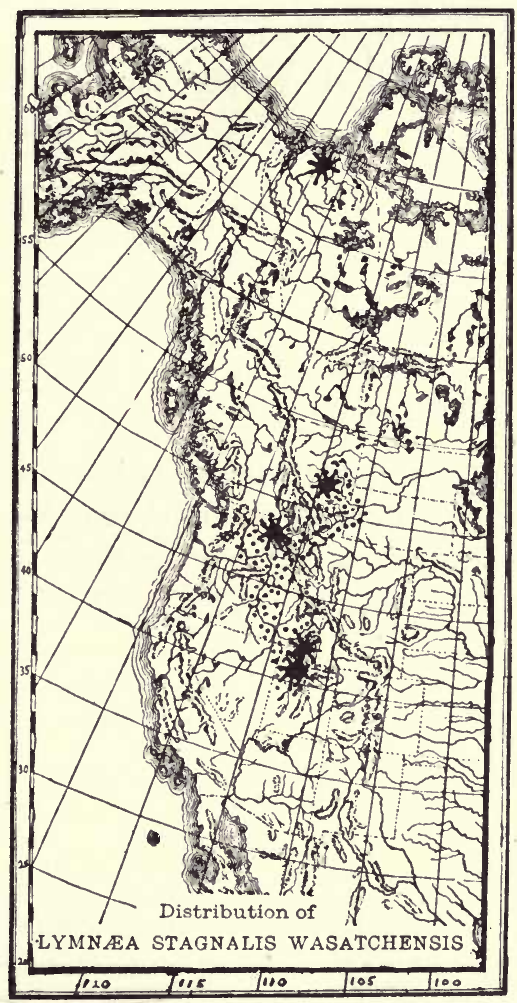

FIG. 11.

acteristic specimen measures: Height, 42.00 ; breadth, 18.50 ; aperture height, 19.50 ; breadth, 10.50 mill. The breadth of the last whorl is 18.50 mill. while that of the preceding is but 9.00 mill. The specimens from Fort Anderson, though far removed from the original locality, seem to be good examples of the race.

Lymnæa stagnalis lillianæ (Baker). Plate XXI, figures 8-12; plate XXII, figure 6 . 
Lymnaa stagnalis lilliance BAKER, Natitilus, XXIII, p. 112, February, 1910. Lymnaa stagnalis var. DANIELs, Nautilus XXII, p. 120, 1909.

Lymnaa stagnalis var. Walker, An. Rep. Mich. Geol. Surv. 1908, p. 289, fig. 63, No. 1, 1909.

Limnca stagnalis Adams, Rep. Geol. Surv. Mich., 1908, pp. 16, 17, 18, 21, 1909.

SHell: Elongate-ovate, with short spire and elongated, narrow aperture, which is typically longer than the spire; whorls flattened, elongated, very flat-sided and sloping, especially the body whorl which is cylindrical; spire sharply accuminated; whorls $5 \mathrm{r} / 2$ to 6 ; body whorl elongated, flattened, roundly shouldered; aperture long and narrow, slightly expanded; axis strongly gyrate; umbilical region with a very minute, narrow chink; sculpture and nuclear whorls as in stagnalis appressa.

\begin{tabular}{ccccc} 
Length. & Breadth. Aperture length. & \multicolumn{2}{c}{ Breadth. } \\
42.00 & 22.00 & .26 .00 & 13.00 mill. \\
40.00 & 19.50 & 23.50 & 11.75 " \\
39.00 & 20.00 & 24.50 & 11.00 " \\
37.50 & 19.50 & 23.75 & 12.00 " \\
28.00 & 13.00 & 17.50 & 8.50 "
\end{tabular}

Types: Chicago Academy of Sciences, 5 specimens, No. 24554.

Type locality: Tomahawk Lake, Oneida County, Wisconsin.

Animal: Similar to that of stagnalis appressa in form; in color varying from yellow to jet black (see ante, page 45 for notes on the animal of this race).

JAw: Similar to that of stagnalis appressa.

Radula: Formula $\frac{16}{4-5}+\frac{8}{3}-\frac{1}{4}+\frac{15}{2}+\frac{1}{1}+\frac{15}{2}+\frac{8}{3-4}+\frac{18}{4-4}$ (39-1-39); the teeth are similar in form to those of stagnalis appressa; there are but fifteen laterals, in this respect differing from both appressa and sanctemaria which have respectively nineteen and eighteen laterals; the intermediate teeth are double those of stagnalis and sanctemarice, and the total number of teeth is less.

Genitalia : Similar to those of stagnalis appressa; the penis-sac retractors are two in number, the penis retractor inserted in the posterior retractor, as figured on plate XIV, figure $\mathrm{A}, 2$; this arrangement of the retractor muscles allies this race with appressa rather than with sanctcmarice, in which there is a distinct penis retractor (see plate XIV, figure B). A specimen gave the following measurements (dissection No. 24552) :

Penis. Penis-sac. Vas. def. Prost. duct. Ret. mus. Rec. sem. Shell.

$\begin{array}{lllllll}4.00 & 14.00 & 47.00 & 22.00 & 5.50 & 9.50 & 43.50 \mathrm{mill} .\end{array}$


RANGE: Michigan to Minnesota north of the 45th parallel of north latitude. A species of the Canadian and Upper Mississippian regions and of the Canadian and Transition life zones.

\section{RECORDS.}

Michigan: Isle Royale; various localities (Adams; Gleason; Walker).

Minnesota: Lake Harriet, near Minneapolis, Hennepin Co. (Daniels).

Wisconsin: Quynoch Point, Eagle Bay, and other portions of Tomahawk Lake, Oneida Co. (Baker).

Geological Range: Unknown.

ECoLogy: Lilliance is typically an inhabitant of sandy shores, in shallow water, where it is subjected to heavy wave action; only once was a specimen found in a still-water habitat, and this instance was undoubtedly caused by drifting from its normal habitat. When any number of specimens were found, the habitat was invariably an exposed beach. Associated with lilliance were Galba emarginata zuisconsinensis and Planorbis binneyi. Individuals were observed crawling over the sandy beach or attached to water-soaked logs or other shore debris. The animal of this race exhibits two color modifications, one bright yellow and the other black or grayish-black. No cause for this color dimorphism was apparent. It is not protective, as both forms occupy the same area of white sandy beach. See the introduction, (page 45) for a discussion of the breeding habits of this race.

Remarks: Lilliance may be known by its short spire, long and narrow aperture, and compressed body-whorl. It was at first thought to be a form of sanctamarice but a comparison with that species shows it to be uniformly narrower with compressed body-zohorl, and more acute spire. In sanctcmarice the body-whorl is usually very rotund; the aperture is also roundly ovate, while in lilliance it is clongate-ovate. The musculature of the male organ is also quite different from sanctamarice, and similar to that of appressa. Lilliance differs from appressa in its short spire, flattened and compressed body-z'horl and elongated aperture. It appears to be a distinguishable race of stagnalis. No true appressa were found associated with this race in Tomahawk Lake. There were a few specimens with spires and aperture of equal length, showing clearly that the race is a modification of the appressa type, caused, doubtless, by a change of environment.

At Isle Royale, in Lake Superior, a form of stagnalis occurs which at first sight appears quite distinct. A number of individuals, however, approach very closely to var. lilliance and they may be referred provisionally to this race. Judging from the material at hand, this is a transition form between appressa and lillianc, representing, perhaps, one of the stages in the evolution of the race. The Isle Royale 
form "is characteristic of the quieter waters of the long, narrow harbors which are such a remarkable feature of the island" (Walker). Typical lilliance lives on a wave-beaten shore, and this precarious environment has caused the aperture to become enlarged to provide for the larger foot to enable it to retain its hold on submerged objects. The Isle Royale form, living in quieter water, has not developed the large aperture of the Tomahawk Lake shell.

The Tomahawk Lake shells vary to some extent, those inhabiting the quieter bays having a longer spire and a smaller aperture. These shells closely resemble the Isle Royale specimens and also clearly indicate relationship with appressa. Specimens referable to appressa were collected at one station in Tomahawk Lake, the habitat being marshy in character. Some pathologic forms occur in the Wisconsin shells, the abnormalities being confined principally to the last whorl and aperture. Specimens from Lake Harriet, Minnesota, collected by Mr. L. E. Daniels, are also referable to this race. In the course of time this race will probably assume specific characteristics, a fact foretold by its remarkable uniformity.

The race is dedicated to my wife, Mrs. Lillian M. Baker, who assisted in the discovery of the type specimens.

Lymnæa stagnalis sanctæmariæ (Walker). Plate XXI, figures 1-7; plate XXII, figures 7, 8; plate XXIII, figures 1-3.

Limnaa stagnalis sanctamarice WALKER, Nautilus, VI, p. 31, pl. 1, figs. 4, 5, 1892; Rev. Moll. Faun. Mich, pp. 7, 17, 1895.

Lymnea stagnalis var. sanctamarice WALKER, An. Rep. Mich. Geol. Surv., 1908, p. 289, fig. 63, No. 2, 1909.

Limnae stagnalis var. sanctamarice Cockereld, Science Gossip, No. 388, p. 27, Feb. 1893.

Limnca stagnalis higleyi BAKER, Nautilus, XVIII, p. 142, 1905.

Lymnaa stagnalis var. higleyi WaLker, An. Rep. Mich. Geol. Surv. 1908, p. 289, fig. 63, No. 5, 1909.-GLEASON, 1. c., pp. 6-64, 1909.

Limnaa stagnalis var., WaLKer \& Ruthven, Rep. Geol. Surv. Mịch., 1905, pp. 97, 98, 1906.

Lymnaa stagnalis var., WalKer, An. Rep. Mich. Acad. Sci., 1908, p. 289, fig. 63, Nos. 3, 6, 1909.

Limnca jugularis Sowb., Conch. Icon., XVIII, Lim. pl. 4, fig. 24, 1872.

Limnca stagnalis Adams, Rep. Geol. Surv. Mich., 1908, p. 10, 1909.

Shell: Broadly ovate, with short spire and widely expanded aperture, which is usually twice the length of the spire; spire whorls flattened, producing a mammilliform appearance; spire rapidly accuminating; whorls, $5 \mathrm{~T} / 2$; body whorl very large, rounded or even globular, slightly shouldered in some specimens; aperture large, somewhat flaring, expanded; axis typically strongly gyrate; the umbilical region 
is generally tightly closed, but in some specimens there is a small chink; sculpture usually strong. Nuclear whorls as in stagnalis appressa.

\begin{tabular}{|c|c|c|c|c|c|}
\hline $\begin{array}{c}\text { Length. } \\
33.00\end{array}$ & $\begin{array}{l}\text { Width. } \\
18.50\end{array}$ & $\begin{array}{c}\text { Aperture } \\
\text { length. } \\
20.00\end{array}$ & $\begin{array}{r}\text { Wic } \\
11.00\end{array}$ & & Michipicoten Island \\
\hline 50.00 & 30.00 & 32.00 & 22.00 & “ & higleyi. \\
\hline 42.00 & 27.00 & 27.00 & 19.00 & “ & " \\
\hline 38.00 & 22.00 & 25.00 & 17.00 & “ & “ (type). \\
\hline 49.50 & 29.50 & 32.00 & 17.50 & “ & Siskowit Lake. \\
\hline 45.50 & 27.00 & 31.50 & 17.00 & “ & " \\
\hline 32.50 & 17.00 & 19.50 & 10.50 & “ & Sault St. Marie. \\
\hline 34.50 & 18.50 & 21.00 & 11.50 & “ & " " " \\
\hline 34.00 & 20.00 & 22.00 & 13.00 & “ & “ \\
\hline 31.75 & 21.00 & 20.00 & 13.00 & “ & “ \\
\hline
\end{tabular}

Types: Sanctamaria, 2 specimers, No. 2682, Coll. Bryant Walker; higleyi, 1 specimen, No. 23050, Coll. Chicago Academy of Sciences; cotypes, Coll. J. H. Ferriss.

Type Locality: Sanctcmaria, Neebish Rapids, St. Mary's River, Michigan; higleyi, Michipicoten Island, north shore Lake Superior.

Animal: Similar to stagnalis appressa.

JAw (P1. VI. fig. B): Superior jaw higher than stagnalis appressa, with a more acute central swelling; lateral jaws not differing from those of stagnalis appressa.

RAdUla: Similar to that of stagnalis, but with eighteen laterals, the intermediate teeth beginning on the nineteenth tooth.

Genitalia: Similar in general to that of stagnalis appressa, but differing in details of the penis retractors. (P1. XIV, fig. B.) The penis retractor, instead of being inserted in the penis-sac retractor, as in appressa (pl. XIV. fig. A) is inserted in the columella muscle close to the insertion of the penis-sac retractor. In addition, there are two or three short muscles connecting the penis retractor with the penis-sac retractor. In one specimen the penis-sac retractor was split to form two muscles, the lower muscle being very heavy, with many insertions at its juncture with the penis-sac. (B, 2.) A specimen from Sault Ste. Marie had the two retractors fused to form a broad band of tissue for about half their length to the insertion in the columella muscle. All of the muscles of the male system in sanctemarice are heavier than those of stagnalis appressa.

Some characteristic measurements of the genitalia are given in the table below (dissection No. 23919) (Sault St. Marie) No. 23918 (Siskowit Bay) : 
Penis- Rec. sem. Prostate Vas. Penis-

Penis. sac. duct. duct. def. retractor. Shell. Locality.

\begin{tabular}{|c|c|c|c|c|c|c|c|c|}
\hline 2.00 & 7.50 & 6.50 & 10.00 & 28.00 & 2.25 & 34.00 & Sault St & t. Marie \\
\hline 2.00 & 6.50 & 6.50 & 8.00 & 30.00 & 2.25 & 33.00 & “ & “ \\
\hline 2.00 & 6.50 & 6.50 & 6.50 & 29.00 & 2.25 & 28.00 & “ & “" \\
\hline 00 & 8.00 & 12.50 & 28.00 & 78.00 & 9.00 & 50.00 & Siskowit & Lake. \\
\hline & 9.00 & 12.00 & 26.00 & 75.00 & 8.50 & 45.50 & “ & \\
\hline
\end{tabular}

It will be noted that there is a marked difference in the comparative lengths of the vas deferens and the prostate duct between the Sault St. Marie and the Siskowit Lake specimens. This may be accounted for by the size, the latter individuals being a third larger than the former.

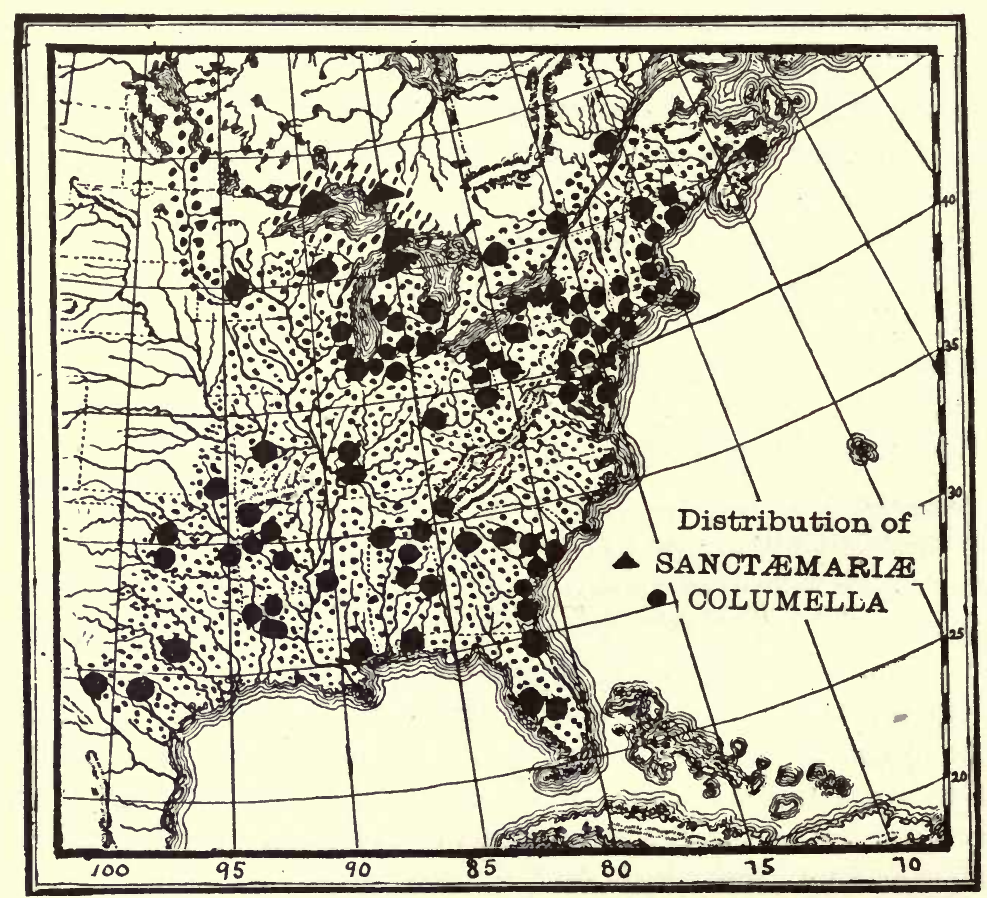

FIG. 12.

RANGE: (Figure 12) Northern Michigan and Lake Superior. It has not been found outside of the area of Lake Superior and the northern part of Lake Michigan. It is probably peculiar to the great iakes and hence an inhabitant of the Canadian region and life zone. 


\section{RECORDS.}

UNITED STATES.

Michigan: Neebish Rapids, St. Mary's River, Chippewa Co.; Sault St. Marie, Chippewa Co.; Black Lake, Presque Isle Co.; shore of Lake Superior, and Siskowit Lake, Isle Royale, Lake Superior (Walker).

\section{BRITISH AMERICA.}

Ontario: Michipicoten Bay, Thunder Bay District (Brown); north shore Lake Superior (Ferriss); Lake Superior (Newberry).

\section{Geological Range: Unknown.}

Ecology: "Attached to the larger rocks that are not readily moved by the action of the surf." (Walker and Ruthven, Isle Royale.) From the records of Ruthven and Adams, this race would seem to be typically an inhabitant of a region under the influence of clear, shore waters in situations where there is considerable action of the waves. In this respect it differs widely from stagnalis appressa, which is a lover of quiet waters subject to more or less stagnation. In the St. Mary's River it inhabits the Neebish Rapids, which provides an environment similar to that afforded by the wave action of the Lake Superior stations.

Sanctcmarice exhibits beautifully the correlation of the animal with its environment. In Isle Royale the form living on an exposed lake beach is rather small with a thick shell. The form living in Siskowit Bay, where the water is quiet, is the largest of any North American Lymnea, and the shell is thin and brittle. There is usually little variation in general form; rarely a specimen occurs in which the body whorl is compressed and the spire lengthened (Pl. XXI, figure 2; pl. XXIII, fig. 2). These forms approach some individuals of $L$. stagnalis lilliance, but are doubtless cases of parallel development. See Chapter II, p. 24 for a more detailed discussion of the ecological relations of this race.

REMARKs: This rather distinct race may be known by its very short spire, rotund body-whorl and wide, somewhat patulous aperture. It appears to be a northern race which reaches its maximum development in the cold waters of Lake Superior.

The name sanctemarice was apparently founded on immature specimens; higleyi is the fully mature form, and must fall into the synonymy. Specimens from Sault Ste. Marie have a coarse dark brown epidermis and many of the specimens seen by the writer appear to have suffered an injury to the last third of the body whorl, which is joined to the body of the shell in such a manner as to leave a deep channel at the suture. This portion of the last whorl is also disposed to be malleated. 
Sanctemarice has a superficial resemblance to Hemphill's occidentalis, but differs in lacking the decided shoulder so characteristic of the latter race. Prof. Cockerell (op. cit.) refers sanctcmarice to his var. compressa (fig. 9, p. 79, Williams "Shell-Collectors' Handbook.") The figure, however, is quite different from sanctcmarice and does not particularly resemble any of our American species. Several European Lymnæas somewhat resemble sanctcmarice. Thus Lymncea doriana Bourg. (Spic. Mal., p. 100, pl. 12, figs. 9-10) seems similar but the whorls in the American race are not so rounded and the body whorl is more flattened at its posterior extremity. Cockerell's variety expansa (Science Gossip, XXI, p. 179, fig. 121, 1885 non expansa Hald. 1842) is somewhat similar in form. These are all apparently cases of parallel development.

Lymnæa stagnalis occidentalis Hemphill. Plate XXIII, figures 4-5.

Limnaa stagnalis var. occidentalis HemphiLl, Nautilus, IV, p. 26, 1890.KeEP, West Amer. Sh., p. 313, 1904.

Shell: Quadrangularly inflated, thin, fragile; color light horn; spire short and acute, set abruptly on the body whorl, which is very large and quadrangularly inflated; suture impressed; the whorls are considerably shouldered, especially the body whorl; aperture longovate, more than twice the length of the spire; axis strongly gyrate. forming a well-marked plait; callus closely appressed to the parietal wall; whorls five; sculpture of the usual character, and often marked by strong spiral and longitudinal raised ridges, giving the surface a malleated aspect; a small umbilical chink is sometimes present.

\begin{tabular}{ccccc} 
Length. & Breadth. Aperture length. & \multicolumn{2}{c}{ Breadth. } \\
35.00 & 21.00 & 23.00 & 14.00 mill. Type. \\
33.00 & 21.00 & 22.00 & 15.00 “ & “ \\
35.00 & 21.00 & 22.00 & 14.00 " & "
\end{tabular}

Type: Coll. Henry Hemphill.

Type Locality: Lake Whatcom, Washington.

Animal, Jaw, Radula and Genitalia: Unknown. It is exceedingly unfortunate that $\mathrm{Mr}$. Hemphill did not think of the carnivorous propensities of Circinaria vancouverensis when he placed the two living specimens of this species in the box with them, because the anatomy of occidentalis is now a desideratum.

RANGE: State of Washington, from whence it is only known at present.

\section{RECORDS.}

Washington: Lake Whatcom, Whatcom Co. (Hemphill).

Geological Range: Unknown. 
Ecology: Not recorded. Hemphill says: "Found on the shores of the above lake in November, 1889. I found two living specimens in the lake."

Remarks: Occidentalis is one of the most characteristic of the American races of Lymnca. The short, acute spire with its peculiar shoulder just above the suture, the suddenly expanded body whorl with its pronounced shoulder, easily distinguishes it. Its nearest relative is sanctcmarice, in which the whorls are not angular and the spire is longer. There is some distortion in the aperture, especially in the anterior margin; the spire also varies in height.

Occidentalis is strongly suggestive of some individuals of the European lacustris Stud., but in occidentalis the spire is longer and more acute and the shoulders of the whorls are sharper than in the specimens of lacustris which the writer has examined. Some of the short-spired forms of European stagnalis are beautifully illustrated by Nordenskiöld in Bihang till Kong. Svenska Vetenskaps-Akademiens Handlingar, Band 26, Afd. IV, No. 11, Tafl. 1. The plate well illustrates the large amount of variation to which stagnalis is subject.

Lymnæa lepida Gould. Plate XXIII, figures 6-\%.

Limnaa lepida Gould, Proc. Bos. Soc. N. H., II, p. 211, 1847; Moll. Wilkes Exp., p. 121, figs. 141, 141a, 1852.-Binney, Check List, p. 12, 1860.-Cpr., Rep. Brit. Ass., 1864, p. 673.-TRYon, Amer. Journ. Conch., I, p. 247, 1865.-BinneY, L. \& F.-W. Sh. N. A., II, p. 29, fig. 33, 1865.-Cooper, Proc. Cal. Acad. Sci., IV, p. 95, 1870.-TRYoN, Con. Hald. Mon., p. 93 (67), pl. 16, figs. 12, 13, 1872.CPr., Smith. Mis. Coll., p. 159, 1872.-Stearns, Proc. Nat. Mus., XIV, pp. 101, 102, 1891; N. Am. Fauna, VII, p. 275, 1893; Proc. Nat. Mus., XXIV, p. 291 , 1901.-KeEp, West. Amer. Sh., p. 314, 1904.

Lymnca lepida DaLL, Land \& Fresh-Water Moll., p. 67, fig. 43, 1905.

Limnea lepida Gould, Otia. p. 41, 1862.-CARLton, Proc. Cal. Acad. Sci., IV, p. 51, 1869.

SHELl: "Very fragile, elongated, very acutely conical, subumbilicate, pale horn color; whorls five, oblique, moderately convex, forming an accuminated spire; suture moderately impressed; surface smooth and shining, lines of growth faint, and when examined by a magnifier they are found to be rendered somewhat zigzag by distant, revolving furrows, which cross them. Aperture large and expanded, nearly semicircular, half the length of the shell; outer lip expanded; columella having a very strongly marked sharp fold, and broadly covered with thin callus, which not being closely appressed at the umbilical region, leaves a small chink. Length, $3 / 5$, breadth $1 / 4$ inch." (Gould.)

Length. Breadth. Aperture length.

Breadth.

12.00 5.25 6.00

12.00 6.00 ....

2.75 mill. Type .... " Gould.

(5541). 
TyPE: Smithsonian Institution, one broken specimen (No. 5541); two specimens (Binney's two original specimens) No. $85 \% 1$.

Animal, Jaw, Radula and Genitalia: Unknown.

Range: Idaho to Washington, north to central California. Pacific coast drainage of the Columbian and Californian regions, and the Transition and Upper Austral Life zones.

RECORDS.

UNITED STATES.

California: Antioch, Contra Costa Co. (Cooper).

IрAно: Near Challis, Custer Co. (Dall; Merriam; Stearns).

Washington: Lake Vancouver, Clarke Co. (Gould; Wilkes).

Geological Distribution: Unknown.

ECology: Not recorded.

Remarks: Lepida appears to be a rare species, and has not been seen by the writer in any collection excepting that of the Smithsonian Institution, where Gould's original specimens are deposited. As suggested by Cooper (Pr. Cal. Acad., IV, p. 51), it is very like a diminutive stagnalis and the figures published are strongly suggestive of the immature state of that species. The record from Meech's Lake, Ontario (Trans. Ott. Nat. Field Club, I. p. 58), though said to have been verified by Tryon, is erroneous, the specimens being young stagnalis. A good series of this species from the original locality might prove it to be the young or a diminutive variety of stagnalis. Additional information is greatly needed. Gould's observation concerning its resemblance to pallida and desidiosa (obrussa) is not borne out by an examination of his type specimens.

\section{Genus PSEUDOSUCCINEA Baker, 1908.}

Pseudosuccinea BAKer, Science, n. s., XXVII, p. 943, June, 1908.

Radix of authors.

TYPE: Lymnaa columella Say.

Shell: Of medium size, succineiform; spire generally short and somewhat dome-shaped; last whorl very large, expanded; axis gyrate and imperforate; columellar plait not well marked; outer lip sharp. (Plate XVIII, fig. 5.)

JAW: Wide and low, with a bluntly rounded median projection. (Plate VI, fig. C.)

RADUla: With tricuspid lateral teeth; marginals serrated.

Genitalia: Prostate very small, cylindrical, with rounded termination; penis-sac retractors two in number; penis retractors inserted in posterior penis-sac retractor; penis short and thick, less than onehalf the length of the penis-sac; penis nerve inserted in head of penis. (Plate X, fig. B.) 
Distribution: North and middle America. Principally south of Canada and east of the great plains. ${ }^{1}$

The Succinea-like shells of Lymnca columella have been usually placed in Radix on account of the large, somewhat flaring aperture. Dr. Dall, in his Alaska Mollusca, has expressed the opinion that it belongs to Stagnicola. A study of the anatomy shows that it differs markedly from Stagnicola in its genitalia and in its radula. The peculiar shape and small size of the prostate, the number and position of the retractor muscles of the male organ and the Succinea-like form of the shell have led the author to erect a new genus for the reception of these peculiar shells.

Pseudosuccinea columella (Say). Plate XXIII, figures 8-20; plate XXIV, figures 1-4.

Lymnaa columella SAy, Journ. Phil. Acad., I, p. 14, 1817.-Earle, Report on Geol. Zool. Mass., p. 558, 1833,-Gould, Lamarck's Genera, p. 69, 1833.Ravenel, Cat. Sh. Cab. Ravenel, p. 11, 1834.-Earle, Geol. Zool. Mass., p. 23, 1835.-Hitch., Geol. Zool. Mass., p. 27, 1835.-Gould, Rep. Geol. State Maine, I, p. 119, 1837.-Lea, Trans. Amer. Phil. Soc., IX, pp. 11, 12, 1841.-Linsley, Amer. Journ. Sci., XLVIII, p. 282, 1845.-Wheatley, Cat. U. S. Shells, p. 23, 1845.-LeA, Obs., IV, pp. 11, 12, 1848.-JAY, Cat. 4th ed., p. 268, 1852.-Lewis, Proc. Phil. Acad., 1856, p. 259.-SAY, Binney, Reprint, pp. 56, 60, 1858.-Morse, Amer. Nat., III, p. 651, pl. 11, fig. 17, 1870.-Lewis, Proc. Phil. Acad., 1872, p. 109 ; Proc. Phil. Acad., 1872, p. 101.-ScudDer, Bull. Nat. Mus., 23, p. 200, 1885.RhoADS, Nautilus, XVIII, p. 66, 1904.-DalL, Land \& F.-W. Sh., p. 70, fig. 47, 1905.-Pilsbry \& Ferriss, Proc. Phil. Acad., 1906, p. 161.-Baker, Bull. Ill. State Lab. N. H., VII, p. 103, 1906.-HinkLEY, Nautilus, XV, p. 40, 1906.Pilsbry \& Ferriss, Proc. Phil. Acad., p. 564, 1906.-Smith, Nautilus, XX, p. 91, 1907.-Sterki, Proc. Ohio State Acad. Sci., IV, p. 382, 1907.-Henderson, Nautilus, XXI, p. 7, 1907.-JACKson, Nautilus, XXI, p. 143, 1908.-BAKER, Science, n. s., XX்VII, p. 943, 1908.-Lermond, Shells of Maine, p. 37, 1908.Colton, Proc. Phil. Acad., 1908, pp. 413, 422, 446.-BAker, Nautilus, XXIV, p. $69,1910$.

Lymnea columella Girard, Proc. Nat. Inst., I, p. 81, 1856.-Currier, Sh. Grand River, Mich., 1859.-Lewis, Proc. Phil. Acad., 1860, p. 18.-Couper, Cat., p. 4.

Limnaus columella Grbses, App. Geol. Car., p. XX, 1848.-Küster, Conch. Cab., p. 44, taf. 8, figs. 3-5, 1862.

Lymnceus columellus Say, Journ. Phil. Acad., II, p. 167, 1821.-SAger, Geol. Surv. Mich., p. 15, 1839.-SAy, Binney, Reprint, p. 65, 1858.

Limnaa columella SAY, Nich. Encyc., IV, p. 56, 1819 (reprint).-BECK, Index, p. 113, 1837.-Potiez \& Michaud, Galerie, I, p. 216, pl. 22, figs. 15-16, 1838. - Taylor \& Shiverick, Cat., 1840.-Gould, Invert. Mass., p. 215, fig. 144, 1841.-Prescott, Sh. Mass., No. 191, 1842.-Read, Cat., 1845.-Russell, Journ. Essex Co., Nat. Hist. Soc., p. 130, 1852.-Chickering, List Sh. Portland, Me.,

${ }^{1}$ Until the anatomy of the European and other exotic species is known it is impossible to assign any of them to this group, although several species have similar shells. 
1855 to 1856.-Lewis, Proc. Bos. Soc. N. H., VI, p. 2, 1856.-Tufts, Proc. Essex Inst., I, p. 30, 1856; Can. Nat. \& Geol., II, p. 197, figure, 1857.-TRUe, Proc. Essex Inst., II, p. 195, 1857.-Binney, Check List, p. 12, 1860.-Reeve, Elements of Conch., p. 178, 1860.-LAPham, Proc. Phil. Acad., 1860, p. 155.Whiteaves, Can. Nat. \& Geol., VI, p. 453, 1861 ; Can. Nat. \& Geol., VI, p. 458, 1861.-GABb, Proc. Phil. Acad., 1861, p. 309.-Whiteaves, Can. Nat. \& Geol., VIII, p. 102, 1863.-Tryon, Proc. Phil. Acad., 1861, p. 398.-Binney, Land \& F.-W. Sh. N. A., II, p. 32, fig. 38, 1865.-Hubbard \& Sмith, Ann. N. Y. Lyc. N. H., VIII, p. 152, 1867.-Tryon, Amer. Journ. Conch., III, p. 196, 1867.Currier, Kent. Sci. Inst., Mis. Pub., No. 1, 1868.-Gould, Invert. Mass., Bin. Ed., p. 471, fig. 723, 1870.-Smith \& Prime, Ann. Lyc. N. H., IX, p. 402, 1870.Dall, Proc. Bos. Soc. N. H., XIII, p. 248, 1870.-Tryon, Con. Hald. Mon., p. 88 (62), 1872 (fig. 1, pl. 16 of Succinea pellucida Lea). Byrnes, L. \& F.-W. Sh. Cin., p. 1, 1872.-Sowв., Conch. Icon., XVIII, Lim. sp. 36, pl. 10, fig. 36 b., 1872.-Jefrreys, Ann. Mag. N. H., iv., X, p. 247, 1872.-Smith, Rep. U. S. Fish Com., pp. 701, 707, 1874.-Jefrreys, Journ. Conch., I, p. 16, 1874.-WALKeR and Beecher, Proc. Ann Arb. Sci. Asso., p. 45, 1876.-Jones, Moll. Nova Scotia, p. 10, 1877.-Walker, Journ. Conch., II, p. 330, 1879.-Heron, Ottawa Nat., I, p. 39, 1880 ; 35th Rep. N. Y. State Mus., p. 112, 1882.-Jordan, Nova Acta Ksl.-Leop.-Carol. Deutsch. Akad. Natur., XLV, p. 367, 1883.-Ottawa Nat. I, p. 132, 1884.-Westerlund, Vega. Expd., IV, p. 166, 1885.-Sampson, Bull., Sedalia N. H. Soc., No. 1, pp. 22, 23, 24, 1885.-Beauchamp, Sh. N. Y. State, p. 3, 1886.-Heillprin, Trans. Wagner Inst., I, pp. 38, 49, 50, 1887.-SAmpson, Amer. Nat. XXI, p. 85, 1887.-H. F. Carpenter, Sh. bear. Moll. R. I., 2nd ed., p. 5, 1889.-TAYLOR, Journ. Conch., VI, pp. 284, 287, 1890.-Ottawa Nat., IV, p. 55, 1890.-Pilsbry, Nautilus, IV, p. 47, 1890.-Stearns, Proc. Nat. Mus., XIV, p. 101, 1891.-Walton, Proc. Roch. Acad. Sci., II, p. 12, pl. 6, figs. 3, 4, 1891.Sampson, Ann. Rep. Ark. Geol. Surv., II, 1891, p. 194.-Pilsbry, Proc. Phil. Acad., p. 406, 1891.-TAylor, Ottawa Nat., VI, p. 35, 1892.-WAlker, Nautilus, VI, p. 33, 1892.-Dean, Amer. Nat., XXVI, p. 11, 1892.-Sampson, Nautilus, VII, p. 33, 1893.-VAughan, Amer. Nat., XXVII, p. 952, 1893.-Marshall, Rep. N. Y. State Mus., XLVII, p. 64, 1893; Rep. N. Y. Exhibits World's Fair, p. 510, 1893.-Pilsbry, Proc. Phil. Acad., 1894, p. 24.-Singley, An. Rep. Geol. Surv. Texas, IV, p. 313, 1893.-Stupakoff, Nautilus, VII, p. 135, 1894.Walker, Rev. Moll. Fauna Mich., p. 18, 1894.-Shick, Nautilus, VIII, p. 137, 1895.-Sargent, Nautilus, IX, p. 127, 1896.-Pilsbry and Rhoads, Proc. Phil. Acad., 1896, p. 493.-BAKer, Journ. Cin. Soc. N. H., XIX, p. 78, 1897; Trans. Acad. Sci. St. Louis, VIII, p. 88, 1898.-MAUry, Chautauqua Lake Shells, p. 25, pl. 3, fig. 22, 1898.-Rhoads, Nautilus, XII, p. 138, 1899.-Sterki, Ann. Rep. Ohio St. Acad. Sci., VIII, p. 34, 1900.-Stearns, Proc. Nat. Mus., XXIV, p. 291, 1901.-Letson, Bull. Buf. Soc. N. Sci. VII, No. I, p. 244, 1901; Bull., N. Y. State Mus., IX, No. 45, p. 244, 1901.-BAKer, Trans. Acad. Sci. St. Louis, XI, p. 2, pl. 1, fig. 13, 1901; Moll. Chi. Area, p. 260, figs. 82, 83, pl. 30, fig. 26, 1902.Daniels, Rep. Dept. Geol. and Nat. Res., Ind., XXVII, p. 636, 1902.-BlatchleY and Daniels, Rep. Dept. Geol. and Nat. Res., Ind., XXVII, p. 598, pl. 1, fig. 15, 1902.-Pilsbry, Proc. Phil. Acad., p. 776, 1903.-Hinkley, Nautilus, XVIII, p. 45, 1904.-Letson, Bull. N. Y. Sitate Mụs., LXXXVIII, p. 52, 1905.-ChaDwick, Nautilus, XX p. 22, 1906 ; Bull. Wis. Soc. N. H., N. S., IV, p. 81, 1906.Letson, Bull. Buf. Soc. Nat. Sci., IX, p. 242, 1909. 
Limnea columella Hald., Mon. Limn., p. 38, pl. 12, figs. 10-15, 1842.Mighels, Bost. Journ. N. H., IV, p. 337, 1843.-Sowerby, Faun. Bor- Amer., p. 316, 1836.-Dekay, Zool. N. Y., p. 72, pl. 4, fig. 75, 1843.-Anthony, L. F-W. Sh. Cin., 1843.-Stimpson, Sh. N. Eng., p. 52, 1851.-Lapham, Tran's. Wis. State Ag. Soc., II, p. 368, 1852.-Tufts, Cat. Mass. State Cab., p. 87, 1859.Miles, Geol. Surv. Mich., 1860, p. 237.-25 Ann. Rep. N. Y. State Mus., p. 37, 1871.-Walton, The Museum, IV, p. 133, 1898.-Hubbard, Cat. (No date).Hartman, Cat. Moll. Chester Co. (No. date).-Henderson, Nautilus, XX, p. 98, 1907.-Wheat, Bull. Brook. Conch. Club, I, p. 10, 1907.

Radix columella Morse, Journ. Port. Soc., I, p. 42. 1864.-Lewis, Bull. Buf. Soc. N. H., II, p. 135, 1874.-Hartman and Michener, Conchologia Cestrica, p. 63, figs. 117, 118, 119, 1874.-Prime, Forest and Stream, XV, p. 245, 1880.-Decamp, Kent Sci. Inst., Mis. Pub., No. 5, p. 7, 1881.-Call, Bull. Wash. Coll. Lab. N. H., I, p. 180, 1886.

Limnca (Radix) columella H. F. CARPENTER, Random Notes N. H., III, p. 78, 1886.-Harper, Journ. Cin. Soc. N. H., XVIII, p. 95, 1895.

Neristoma columella Currier, Amer. Journ Conch., I, p. 294, 1865.Tryon, Amer. Journ. Conch., I, p. 248, 1865. -Perkins, Proc. Bos. Soc. N. H., XIII, p. 133, 1869 .

Limnophysa columella Call, Proc. Ind. Acad. Sci., 1893, p. 150.-BAKer, Journ. Cin. Soc. N. H., XIX, pp. 82. 83., 1897.

Lymnea columellaris C. B. Ad., Amer. Journ. Sci., XXXVI, p. 392, 1839 (Abssq. descr.).

Limnaa columellaris Binney, Journ. de Conch., XV, p. 427, 1867.

Limnca navicula VAL., Rec. Obs., II, p. 251, 1833.-Fer., Bull. Zool., p. 33, 1835.-Binney, L. and F. W. Sh. N. A., II, p. 35, 1865 ; Journ. de Conch., XV, p. 427, 1867.-Sowb, Conch. Icon., XVIII, Lim., sp. 49, 1872. (Not fig.)

Limnea succiniformis Adams, teste Haldeman, Mon., p. 40, 1842.

Succinea pellucida LEA, Proc. Phil. Acad., p. 109, 1864; LEA, Journ. Phil. Acad., VI, p. 178, pl. 24, fig. 106, 1866 ; obs., XI, p. 134, pl. 24, f. 106, 1867.Binney, L. \& F. W. Sh. N. A., I, p. 271, fig. 488, 1869 ; Man. Amer. Land Sh., p. 344, fig. 371 a, 1885.-TRYon, Con. Hald. Mon. p. 88 (62), pl. 16, fig. 1, 1872.Binney, Terr. Moll. U. S., V, 1878.-Scudder, Bull. Nat. Mus., 23, pp. 150, 226, 1885.-Cooper, Proc. Cal. Acad. Sci., iv, V, p. 168, 1895.

Succinea wrilsoni LEA, Proc. Phil. Acad., p. 109, 1864 ; Journal of same, VI, pp. 177, 179, pl. 24, fig. 105, 1866.-Obs., XI, pp. 133, 135, pl. XXIV, fig. 105, 1867. -Binney, L. \& F. W. Sh. N. Am., I, p. 260, fig. 464, 1869.-Tryon, Amer. Journ. Conch., II, p. 238, pl. 2, fig. 27, 1866.-Binney, Terr. Moll. U. S., V, 1878; Man. Amer. Land Sh., p. 344, fig. 372d, 1885.-Scudder, Bull. Nat. Mus., 23, pp. 150, 226, 1885.-Cooper, Proc. Cal. Acad. Sci., IV, V, p. 168, 1895.

Lymnaus macrostomus SAY, Journ. Phil. Acad., II, p. 170, 1821; Binney, Reprint, p. 67, 1858.

Limnceus macrostoma Gibbes, App., Geol. S. Car., p. XX, 1848.

Limnceus macrostomus Küster, Conch., Cab., p. 43 taf. 8, figs. 1, 2, 1862.

Lymnca macrostoma Gould, Lamarck's Genera, p. 69, 1833.-Amer. Journ. Sci., XXXI, p. 36, 1837.-Wheatley, Cat. U. S. Shells, p. 23, 1845.-Linsley, Amer. Journ. Sci., XLVIII, p. 282, 1845. 
Limnea columella var. macrostoma Whiteaves, Can. Nat. \& Geol., VI, p. 458, 1861 ; Can. Nat. \& Geol., VIII, p. 102, 1863.

Lymnca columella var macrostoma JAY, Cat., Ed. 4, p. 261, 1852.-Morse, Amer. Nat., III, pl. 3, fig. 16, 1870.-Lermond, Shells of Maine, p. 37, 1908.

Lymnea macrostoma Dekay, Cat. An. N. Y., p. 32, 1839.-Girard, Proc. Nat. Inst., p. 81, 1856.-Tryon, Amer. Journ. Conch., II, p. 11, 1866.

Limnaa macrostoma Gould, Invert. Mass., p. 217, fig. 148, 1841.-TAYLOR and Shiverick, Cat., 1840.-Prescott, Sh. Mass., No. 196, 1842.-Read, Cat., 1845.-Russell, Journ. Essex Co. Nat. Hist. Soc., p. 130, 1852.-Tufts, Proc. Essex Inst., I, p. 30, 1856.-True, Proc. Essex Inst., II, p. 195, 1857.-Can. Nat. \& Geol., II, p. 198, figure, 1857.-ReEve, Elements of Conch., p. 179, 1860.Binney, Land \& F. W. Sh. N. A., II, p. 34, fig. 39, 1865.-Tryon, Amer. Journ. Conch., III, p. 196, 1867.-Gould, Invert. Mass., ed. Binney, p. 472, f. 724, 1870.Tryon, Con. Hald. Mon., p. 88 (62) pl. 16, fig. 2, 1872.-Sowb., Conch. Icon., XVIII, Lim., sp. 43, pl. 6, fig. 36, 1872.-CR. and Fisch., Mis. Scient. Mex., Moll., II, p. 52, 1880 .

Limnea macrostoma Hald, Mon. Limn., pl. 12, figs. 1-8, 1842.-LAPHAM, Trans. Wis. State Ag. Soc., II, p. 368, 1852.-Tufts, Cat. Mass. State Cab., p. $87,1859$.

Limnaa merostoma Ravenel, Cat. Sh. Cab. Ravenel, p. 11, 1834.

Radix macrostoma Hartman and Michener, Conchologia Cestrica, p. 63, fig. 120,1874 .

Neristoma macrostoma Tryon, Amer. Journ. Conch., I, p. 248, 1865.

Radix columella var. macrostoma PRIME, Forest \& Stream, XV, p. 245, 1880.

Limnca acuminata C. B. Ads., Amer. Journ. Sci., XXXIX, p. 374, 1840.

Lymnaa columella var. acuminata JAY, Cat., ed. 4, p. 268, 1852.

SHell: Ovate, somewhat pointed, thin, fragile, transparent ; color light greenish or yellowish horn; surface shining, covered with rather coarse growth lines, and encircled by heavily impressed spiral lines; whorls four, well rounded, rapidly enlarging, the last one three times the size of the rest of the shell; spire sharply conic, rather short; apex small, very dark brown; sutures tightly appressed; a ridge is frequently formed at the suture where the lines of growth meet the whorl above; aperture ovate, dilated, expanded at the lower part; peristome thin, acute; inner lip closely appressed to the body whorl and reflected over the umbilicus, either completely closing the latter or leaving a small, narrow chink; axis slightly twisted; the columellar region is so narrow and so peculiarly arched that a view may be taken from the base nearly to the apex, as in Succinea retusa; this is especially noticeable in the wide shells called macrostoma. The nuclear whorls do not differ in outline from those of Lymnaa stagnalis. The nucleus consists of about $1 \frac{1}{4}$ smooth whorls. The growth lines are very heavy at the beginning of the post nuclear shell. 


\begin{tabular}{|c|c|c|c|c|c|}
\hline $\begin{array}{l}\text { Length. } \\
21.50\end{array}$ & $\begin{array}{l}\text { Breadth. } \\
12.00\end{array}$ & $\begin{array}{c}\text { Aperture length. } \\
14.00\end{array}$ & $\begin{array}{l}\text { Brea } \\
7.00\end{array}$ & $\begin{array}{l}\text { dth. } \\
\text { mill. }\end{array}$ & columella \\
\hline 19.00 & 12.00 & 14.50 & 8.50 & “ & Type macrostoma \\
\hline 16.00 & 8.50 & 11.40 & 6.00 & “ & Chicago. \\
\hline 14.00 & 7.75 & 9.50 & 5.60 & “ & " \\
\hline 21.00 & 11.00 & 15.50 & 9.50 & “ & Washington, D. C. \\
\hline 13.00 & 7.00 & 9.00 & 5.50 & “ & " " \\
\hline 10.00 & 6.50 & 7.00 & 4.50 & “ & Manatee Co., Fla. \\
\hline 19.00 & 11.00 & 14.00 & 8.00 & “ & Concord, Tenn. \\
\hline 12.00 & 7.50 & 9.00 & 6.00 & “ & Pass Christian, Miss. \\
\hline 20.50 & 12.00 & 15.00 & 9.00 & “ & Branford, Conn. \\
\hline 14.00 & 8.00 & 10.00 & 6.50 & “ & “ \\
\hline
\end{tabular}

Types: Columella Say, Academy of Natural Sciences, Philadelphia, three specimens, No. 58791 ; columellaris C. B. Adams, Amherst College; navicula Val., location unknown; Succinea pellucida Lea, eight specimens, No. 117913, and Succinea wilsoni Lea, one specimen, No. 121066, Smithsonian Institution; macrostoma Say, Academy of Natural Sciences, Philadelphia, three specimens, No. 58582; acuminata C. B. Adams, Amherst College.

Type Locality: Columella Say, type locality not mentioned by Say (probably near Philadelphia); macrostoma Say, Cayuga Lake, N. Y.; acuminata Adams, New Bedford, Mass.; navicula Val., Philadelphia, Penn; Succinea wilsoni, Darien, Ga. ; Succinea pellucida, type locality not given.

Animal: Almost transparent, with a short, wide foot, bluntly rounded behind; head separated from foot by a constriction; tentacles short, thick, triangular, transparent; color dirty white, darker on the body, which is covered with white spots, seen through the transparent shell; edge of mantle transparent; head above lilac-tinted; the head is not much in advance of the edge of the shell when the animal is in motion; the animal appears much too large for the shell. Length of foot, 8.00 ; width, 5.50 mill.

JAws: Median jaw wide and low, arched, about three times as wide as high; lower margin with a wide, bluntly rounded median projection. (P1. VI, fig. C.)

RAdula: Formula (plate VII, fig. B) : $\frac{23}{5}+\frac{2}{4}+\frac{10}{3}+\frac{1}{1}+\frac{10}{3}+\frac{2}{4}+\frac{23}{5}+$ (35-1-35); central tooth with a wide reflection, the cutting point broadly spade-shaped; lateral teeth with a quadrate base of attachment; reflection rather wide, reaching below the base of attachment, tricuspid, the mesocone the largest; all cusps wide and spade-shaped; the second lateral has the entocone nearer the distal extremity, the ectocone becoming higher on the reflected portion; the eleventh and twelfth teeth are morlified and connect the lateral with the marginal teeth, a second 
small cusp appearing on the outer edge of the reflection above the ectocone in the eleventh tooth; marginal teeth beginning abruptly, much longer than wide, multicuspid, the distal extremity becoming serrated.

The marginals show great variation in the number, shape and position of the distal cusps. In the Mollusca of the Chicago area the lateral teeth are described as bicuspid, but this is an error, as all subsequent examinations have shown the radula to be tricuspid. In one membrane the first lateral was abnormal in having two small cusps above the entocone. Nearly all of the first laterals in this membrane were of this abnormal form.

Genitalia: (Plate X, fig. B) Male organs: Penis-sac large, cylindrical; penis short, less than one-half the length of the penis-sac; vas deferens twice the length of the penis-sac; prostate portion of vas deferens about half as long as vas deferens, enlarged at its point of junction with the prostate; prostate long, narrowly cylindrical, proximal portion globular, with a scarcely perceptible constriction behind, where it again enlarges to form the cylindrical portion; this becomes narrower and forms a short ribbon-like body which connects with the uterine portion of the oviduct; protractor muscles always five in number (seven specimens examined), two posterior and three anterior; retractor muscles three in number (generally uniform), inserted in the columellar muscle; the penis retractor is inserted in the posterior retractor of the penis-sac, generally near its insertion in the columellar muscle; in several cases short muscles connect the penis and penis-sac. The penis nerve enters the head of the penis near the insertion of the penis retractor.

Female organs: Vagina very short; lower portion of oviduct very wide; receptaculum seminis roundly pear-shaped, its duct very narrow and nearly as long as the vas deferens, and much longer than the free portion of the oviduct; albuminiparous gland and second accessory albuminiparous gland not essentially different from these organs in Lymnea stagnalis; first accessory albuminiparous gland very large, rounded and much wrinkled. The organs are usually yellowish or whitish; the receptaculum seminis is bright orange in color.

The retractor muscles of the penis exhibit some variation (plate XIV, fig. C), especially in the location of the insertion of the penis retractor in the posterior penis-sac retractor, which location may be near the penis (4) or near the columellar muscle (1). One specimen (2) had the termination of the anterior retractor inserted in the posterior retractor near its junction with the penis-sac. In a third indi- 
vidual (3) the posterior retractor was entirely separated from the anterior, the penis retractor being inserted at both ends; in another specimen (plate X, B) the penis retractor was entirely separated from the posterior penis-sac retractor, with many fine muscles connecting with the penis-sac.

\begin{tabular}{|c|c|c|c|c|c|c|c|}
\hline $\begin{array}{l}\text { Penis. } \\
1.00\end{array}$ & $\begin{array}{l}\text { Penis- } \\
\text { sac. } \\
2.25\end{array}$ & $\begin{array}{l}\text { Rec. sem. } \\
\text { duct. } \\
3.00\end{array}$ & $\begin{array}{l}\text { Pros- } \\
\text { tate } \\
\text { duct. } \\
1.50\end{array}$ & $\begin{array}{l}\text { Vas. } \\
\text { def. } \\
3.00\end{array}$ & $\begin{array}{c}\text { Penis- } \\
\text { sac } \\
\text { retractor. } \\
1.00\end{array}$ & $\begin{array}{r}\text { Shell. } \\
19.50\end{array}$ & $\begin{array}{l}\text { Locality. } \\
\text { Rochester, N. Y. }\end{array}$ \\
\hline 1.00 & 2.00 & 3.00 & 2.00 & 4.00 & 1.00 & 18.50 & " \\
\hline 1.00 & 2.25 & 3.00 & 1.50 & 4.00 & 1.00 & 19.00 & “ \\
\hline 0.75 & 1.75 & 3.00 & 1.50 & 3.50 & 0.75 & 19.00 & La Porte, Ind. \\
\hline
\end{tabular}

Dissection No. 23066; Shells Nos. 23078, 23079, 23059.

The characteristic features of the genitalia of columella are the cylindrical form of the prostate, the larger size of the penis, the number of the penis-sac retractors and the insertion of the penis retractors on the posterior penis-sac retractor.

Range: (Figure 12) Nova Scotia west to Minnesota, eastern Kansas and central Texas; Manitoba and Quebec (N. Lat. $52^{\circ}$ ) south to Texas and Florida (N. Lat. $27^{\circ}$ ).

The records show that columella has a wide range throughout the eastern part of the United States. It does not occur in the great plains, its western extension seeming to be bounded by the edge of the prairie region of the Mississippi Valley (about longitude $100^{\circ}$ ). It is also absent (apparently) from the Appalachian Mountains. It is not a typical species of the great lakes, its center of distribution being at about the 40th parallel. Additional records are needed to establish its northern as well as its extreme southern range. Comparing the distribution with the regional map, we find that columella is found in the Canadian, Upper and Lower Mississippian, Nova Scotian, Carolinian, and Rio Grandian regions. A single record from the Hudsonian region and one from Lake Superior (Dall) show that the species has a considerable range in this region. The records indicate that a rather wide area between northern Minnesota and Wisconsin, and Manitoba (Lake Winnipeg ${ }^{1}$ ), is badly in need of exploration. There is perhaps little reason for doubting the Manitoba records, but it would be very reassuring to have them confirmed by additional collections from this and adjacent territory.

Columella occupies the drainage areas of two great river systems, the Mississippi and the St. Lawrence, as well as the various streams

${ }^{1} \mathrm{No}$ exact locality is given for this record and it is therefore not ind1cated on the distribution map. 
emptying into the Atlantic Ocean. Its northward extension to Lake Winnipeg is easily accounted for by the glacial Lake Agassiz and the Pleistocene connection of the Red River of the North with the Minnesota River. Columella extends throughout the humid divisions of the Lower Austral, Upper Austral and Transition life zones and just over the border of the Canadian zone.

Geological Range: Pleistocene. Goat Island Gravel Pits, Niagara River, N. Y. (Letson). This was the only record found referring to the geological range of columella.

Ecology: Columella is an inhabitant of ponds and streams where the water is more or less stagnant; a locality with an abundance of lily pads is particularly favorable; it is found also along the shore in shallow water in the vicinity of cat-tails (Typha) and other reeds, upon which it is often found, mimicking the situs of the pulmonate genus Succinea. Rarely found in running water. Columella is a lover of shallow bays and small ponds or creeks, where it may browse in the pond scum and on bits of rotting stems of water plants. It has been collected by the writer associated with Lymnea stagnalis appressa, Galba obrussa and Galba palustris. Brook flowing from Crawford's into seven-tree pond (Lermond, Maine).

The following note is interesting, as it illustrates another of the almost unaccountable instances of distribution:

"The L. macrostoma which I send you requires a note. It comes as near a case of spontaneous generation as anything within my observation. It was found in a little pool about twenty feet in diameter, entirely cut off from streams. and fed by a spring. I had for years frequented it for desmidia, etc., in which it was very rich. One season, and one only, appeared these Limnace, which do not occur elsewhere, as far as I now know, within twenty miles. The pond dried up that season and destroyed the locality." (Dr. T. R. Ingalls in Binney, p. 3\%.)

Remarks: Columella may easily be known by its Succinea-like shell, resembling very closely specimens of Succinca ovalis Say. It is subject to considerable variation, especially in the height of the spire and in the size of the aperture; the whorls also vary in convexity. There is also some variation in consistency, some shells being heavy and thick, with a rather rough surface, while others are very thin, delicate and shining. The species is so unlike the other Lymnæas, however, that it need never be confounded with any species.

A form (pl. XXIV, figs. 1-3) occurs in the southern states which is considerably smaller than typical columella, averaging about two- 
thirds the size of the more northern forms. Typical specimens of this small form, which does not seem important enough to receive a name, measure as follows:

Length. Breadth. Aperture length. Breadth.

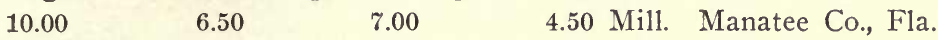

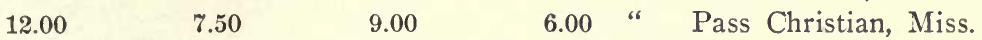

All of the Succinea-like Lymnæas have been united with columella by most recent authors, but there are strong reasons for admitting several varieties. It was thought at one time that two distinct species could be recognized, but the large amount of material examined shows so many connecting links that a satisfactory specific diagnosis is impossible. There are three fairly well marked varieties, however, which should be recognized.

Say's macrostoma cannot be separated from columella when a large series of specimens is examined. As Haldeman remarks, it is a columella until it assumes the macrostomous form in the large expanded body whorl, which in typical macrostoma is flaring and quite patulous. The figures on the plate well illustrate the variation in the body whorl. (P1. XXIII, figs. 8, 10, 11, for example.) Von Martens questions the Mexican reference to this species in the Biologia Centrali Americana, but the records of Cooper and Rhoads confirm its concurrence in Mexico. These records, however, should probably be referred to the race called championi.

Pseudosuccinea columella chalybea (Gould). Plate XXIV, figures 5-13.

Limncea chalybea A. A. Gould, Amer. Journ. Sci., XXXVIII, p. 196, 1840.Gould, Invert., Ed. Binney, p. 472, 1870.-Sowв., Conch. Icon., XVIII, Limn., sp. 52 , pl. 8 , fig. 52 , a. b., 1872 .

Limnea chalybea HaLd., Mon. Limn., p. 40, pl. 12, fig. 9, 1842.-Anthony, L. F-W. Sh. Cin., Ed. 2, 1848.-Gould, Otia, p. 180, 1862.

Lymnea chalybea Linsley, Amer. Journ. Sci., XLVIII, p. 282, 1845.Wheatley, Cat. U. S. Shells, p. 23, 1845.-MórSe, Amer. Nat. III, pl. 11, fig. 18, 1870.-27 Ann. Rep. N. Y. State Mus., p. 53, 1875.

Limnea columella var. chalybea Mighels, Bost. Journ. N. H., IV, p. 336, 1843.-Gould, Invert. Mass., p. 210, fig. 149, 1841.-PREscotr, Sh. Mass., No. 192, 1842.-Read, Cat., 1845.-Can. Nat. \& Geol., II, p. 197, figure, 1857.-Binney, Land \& F. W. Sh. N. A., II, p. 34, fig. 40, 1865.-JAY, Cat. Ed. 4, p. 268, 1852.

Lymnaa columella chalybea BAKER, Bull. Ill. Lab. N. H., VII, p. 103, 1906.Sterki, Proc. Ohio State Acad. Sci., IV, p. 382, 1907.-Hanna, Nautilus, XXIII, p. $96,1909$.

Lymnaa columella var chalybea LeRmond, Shells of Maine, p. 37, 1908.

Lymnea strigosa LEA, Proc. Amer. Phil. Soc., II, p. 33, 1841; Trans. Amer. Phil. Soc., IX. p. 12, 1844; Obs., IV, p. 12, 1848.

Lymnaa strigosa Wheatley, Cat. U. S. Shells, p. 23, 1845.-Morse, Amer. Nat., III, pl. 11, fig. 19, 1870.-ScudDER, Bull. Nat. Mus., 23, pp. 33, 44, 201, 1885. 
Limnca strigosa Binney, Check-list, p. 12, 1860; Land \& F. W. Sh. N. A., II, p. 35, fig. 41, 1865 ; Journ. de Conch., XV, p. 427, 1867.-Tryon, Con. Hald. Mon., p. 89 (63), pl. 16, fig. 4, 1872.

Lymnea coarctata LeA, Proc. Amer. Phil. Soc., II, p. 33, 1841; 'Trans. Amer. Phil. Soc., IX, pp. 11, 12, 1844. Obs., IV, pp. 11, 12, 1848.

Lymncea coarctata, Wheatley, Cat. U. S. Shells, p. 23, 1845.-Morsé, Amer. Nat. III, pl. 11, fig. 14, 1870.-Scudder, Bull. Nat. Mus., 23, pp. 33, 200, 1885.

Limnaa coarctata Binney, Check-list, p. 12, 1860 ; Land \& F. W. Sh., N. A., II, p. 35, fig. 42, 1865.-TRYoN, Con. Hald. Mon., p. 89 (63), pl. 16, fig. 5, 1872.Sowb., Conch. Icon., XVIII, Limnæa, sp. 36, pl. X, fig. 36 b., 1872.

Neristoma coarctata TRYON, Amer. Journ. Conch., I, p. 249, 1865.

Lymnca columella var. coarctata, JAY, Cat., Ed. 4, p. 268, 1852.

?Lymncus columellus var. a. SAY, Journ. Acad. Nat. Sci. Phil., I, p. 14, 1817.-Binney, Reprint, p. 65, 1858; L. \& F. W. Sh. N. A., II, p. 33, 1865.

Limnaa columella var. casta Simpson, Proc. Daven. Acad. Sci., V, p. 69, 1886.

SHell: Elongate-ovate, compressed, thin but generally not fragile; color light greenish to black; sculpture as in columella; whorls $4-4 \frac{1}{2}$, flat-sided and compressed; body whorl occupying about fourfifths of the length of the shell; spire short, acutely pyramidal; in some specimens a channel is developed in the suture of the whorl; aperture elongate-ovate, rounded anteriorly and angled posteriorly; it is generally very effuse anteriorly and typically somewhat expanded; inner lip strongly appressed to the parietal wall, where a thin, spreading callus is developed; the lower part of the columella is deeply excavated and rolled upwards, permitting an anterior view of the shell almost to the apex; axis feebly gyrate, but columellar plait well marked; the umbilicus is generally tightly closed.

$\begin{array}{cccccc}\text { Length. } & \text { Breadth. Aperture length. } & \text { Breadth. } \\ 15.00 & 8.00 & 11.00 & 6.00 & \text { Mill. } & \text { Chalybea type } \\ 11.00 & 7.00 & 10.00 & 6.00 & \text { " } & \text { “ } \\ 14.25 & 7.50 & 9.00 & 4.10 & \text { " } & \text { Coarctata " } \\ 18.75 & 10.00 & 12.25 & 6.00 & \text { " } & \text { Strigosa " } \\ 17.00 & 9.00 & 12.00 & 7.25 & \text { " } & \text { Cambridge, Mass. } \\ 16.50 & 8.50 & 11.00 & 7.00 & \text { " } & \text { “ } \\ 16.50 & 8.00 & 12.00 & 6.75 & \text { " } & \text { Kent, Ohio. } \\ 17.50 & 10.00 & 12.75 & 6.50 & \text { " } & \text { Blount Co., Tenn. } \\ 22.25 & 11.25 & 15.00 & 9.00 & \text { " New York. } \\ 20.50 & 10.00 & 14.00 & 8.25 & & \text { " }\end{array}$

Types: Chalybea Gould, 14 specimens, N. Y. State Museum, Albany, No. 301, Gould, No. A3039; strigosa Lea, 3 specimens, Lea. Coll., Smithsonian No. 118648, Lea's figured specimen measured above; ioarctata Lea, 3 specimens. Lea Coll., Smithsonian No. 118665. Measured specimen is Lea's original figured example and also Binney's figure 42 . 
Type Locality: Chalybea, Cambridge, Mass; strigosa, near Cincinnati, Ohio; coarctata, Newport, R. I.

Animal, Jaw, Radula and Genitalia: Not examined.

RANGE (Figure 13): Chalybea covers about the same range as typical columella. Its range is principally confined to the eastern part of the United States, and embraces the Carolinian and Nova Scotian regions, the southern part of the Canadian region and the eastern half of the Mississippian regions; in Texas it lies on the border of the Rio Grandian region. Its absence from Louisiana, Mississippi, etc., can

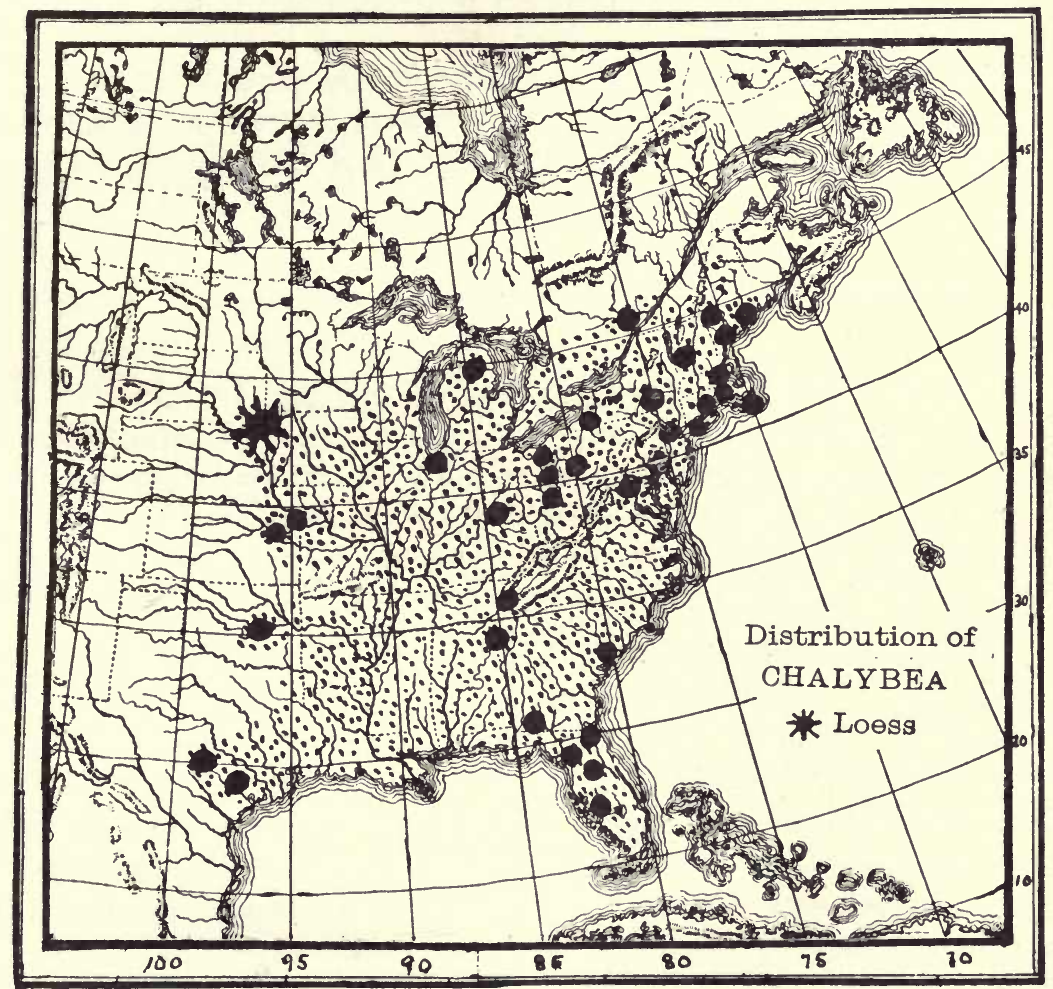

FIG. 13.

be accounted for only by lack of records. It seems to be an inhabitant of deciduous forest areas. A fossil specimen has been seen from Union County, South Dakota, and future search may discover the variety in this part of the prairie region. Its northern range may also be somewhat extended when it is differentiated from typical columella. 
Geological Range: Pleistocene. Loess. Otis Mill, Union County, South Dakota (Smith Coll.).

Ecology: Probably the same as for typical columella; mud pool in old lime quarry (Lermond, Maine).

Remarks: Chalybea is distinguished by its narrow shell, compressed acuminate spire, flattened body whorl and narrow and very effuse aperture. The cxcavated and arched columella is peculiar and will easily distinguish this variety from any form of typical columella. The spire is compressed and the aperture varies from elongate-ôvate to expanded or even flaring. The columellar plait is very pronounced in this variety. The names included in the synonyms all seem minor variations of one form, although coarctata seems to stand midway between chalybea and casta. Its peculiar columella seems to ally it rather with chalybea. Chalybea is not as narrow as casta, from which it is also distinguished by its deeply cxcavated and strongly arched columella. In some localities the variety chalybea takes the place of typical columella.

Pseudosuccinea columella casta (Lea). Plate XXIV, figures 14-19.

Lymnea casta LeA, Proc. Amer. Phil. Soc., II, p. 33, 1841; Trans. Amer. Phil. Soc., IX, pp. 10, 11, 1844; Obs., IV, pp. 10, 11, 1848.

Lymnca casta Wheatley, Cat. U. S. Shells, p. 23, 1845.-Morse, Amer. Nat., III, pl. 11, fig. 15, 1870.-Scudder, Bull. Nat. Mus., 23, pp. 33, 43, 200, 1885.

Limnaa casta Binney, Check List, p. 12, 1860; Land \& F. W. Sh. N. A., II, p. 26, fig. 43, 1865.-Tryon, Con. Hald. Mon., p. 89 (63), pl. 16, fig. 3, 1872 (figure not good).-MArsh, Conch. Ex., II, p. 110, 1887.-DEAN, Amer. Nat., XXVI, p. 11, 1892.

Neristoma casta Tryon, Amer. Journ. Conch., I, p. 249, 1865.

SHELL: Very elongate, somewhat fusiform, much compressed, inclining to obliquity; whorls $4-4 \mathrm{I} / 2$, flat-sided and compressed; body whorl occupying from three-quarters to four-fifths the length of the shell; spire short, very acute, narrow; aperture strongly elongateovate, compressed in the center, the margins parallel in many specimens, rounded anteriorly and roundly angled posteriorly; it is somewhat effuse anteriorly and occasionally a little expanded; inner lip straight in most examples, the lip somewhat erect, the columellar callus closely appressed to the parietal wall, but leaving, in most specimens, a small chink; axis gyrate.

Length. Breadth. Aperture length. Breadth.

\begin{tabular}{lrrrrrrr}
18.50 & 9.00 & 12.50 & 5.10 & mill. & \multicolumn{3}{c}{ Type } \\
24.00 & 11.00 & 17.50 & 8.00 & " & Bass & Lake, Ind. \\
20.50 & 10.50 & 14.00 & 7.00 & “ & “ & " & " \\
18.50 & 8.50 & 13.50 & 7.00 & " & “ & " & " \\
18.50 & 9.00 & 15.00 & 7.50 & " & “ & & "
\end{tabular}


Type: One specimen. Lea Colln., Smithsonian Institution No. 118670 .

Type Locality: Poland, Ohio.

Animal: Not seen.

Jaw, Radula And Genitalia: Not examined.

RANGE: The range of variety casta is unsatisfactorily known, owing probably to its being confused with typical columella. In view of this fact, generalities must be dispensed with. It is not known at present outside of Illinois, Indiana and Ohio, and is hence confined entirely to the Upper Mississippian region and drainage, and to the humid division of the Upper Austral life zone.

Illinois :-Mercer Co. (Marsh).

RECORDS.

UNITED STATES.

Indiana: La Porte, La Porte Co. (Daniels); Bass Lake, Starke Co. (Daniels; Woodruff).

Оніо: Poland, Mahoning Co. (Lea); Kent, Portage Co. (Dean, Sterki; Walker).

Geological Range: Unknown.

Ecology: Similar to columella.

Remarks: Casta may be distinguished from chalybea by its very narrow, elongated, somewhat oblique shell, pointed spire, long and narrow aperture and particularly by its almost straight inner lip margin (Compare fig. 13 with fig. 14). The shells from Bass Lake contain an occasional specimen which has the chalybean form of aperture, but this is rare, the majority of specimens conforming closely to the casta type with an almost straight inner lip margin. This variety is one of the most beautiful of the columclla group; the color is a rich, shining yellowish horn and the surface is marked by raised growth lines, which are crossed by fine impressed spiral lines, giving the surface the appearance of engraved steel. Were it not for the presence of occasional intermediate forms, this variety might be raised to specific rank.

Lea gives six whorls in his description, but his type specimen does not show this number, nor do any of the Bass Lake specimens. It is probable that both variety casta and variety chalybea have been included in some of the records of columella, but this cannot be determined without an examination of the original specimens, which is quite impossible in most instances.

Pseudosuccinea columella championi (Von Martens). Plate XXIV, figure 20.

Limnca columella var. championi Martens, Biol. Cent. Amer., Moll., p. 379, pl. 19, fig. 12, 1899. 
Limnaa columella Cooper, Proc. Cal. Acad. Sci., ii, V, p. 168, 1895.-PilsBRY, Proc. Phil. Acad., p. 776, 1903.

Limnca macrostoma Martens, Biol. Cent. Amer., Moll., p. 379, 1899.

"Shell: Oblong-ovate, thin, irregularly striate, fawn-colored; whorls four, moderately increasing, the upper ones very convex, the last oblong, less convex; aperture very slightly oblique, occupying twothirds of the whole length, narrowly oval, not very acute above; its outer margin not much arcuated; basal margin rounded; columellar margin almost vertically ascending, thin, triangularly reflexed above, having a small umbilical slit in some specimens." (Martens.)

$\begin{array}{ccccc}\text { Length. } & \text { Breadth. Aperture length. } & \text { Breadth. } & \\ 12.00 & 6.00 & 8.00 & 4.00 \mathrm{mill} \text {. } & \text { (Martens). } \\ 13.50 & 8.00 & 9.00 & 5.00 \text { “ } & \text { “ } \\ 16.00 & 8.00 & 10.00 & 6.00 \text { “ } & \text { (Coll. Walker). }\end{array}$

Types: Location not ascertained.

Type Locality: Bigabo, South Panama.

Animal, Jaw, Radula and Genitalia: Unknown.

RANGe: Central America and Mexico. Variety championi appears to be a race of the tropical life zone. It undoubtedly inhabits a large part of Central America, but records are wanting, except from two localities :

Tepic: Tepic (Cooper).

MEXICO.

Michoacan: Lake near Urupam (Rhoads; Pilsbry; Walker).

Mexico: Mexico (Von Martens; Dr. Berendt).

Nicaragua: Palvon (Walker).

CENTRAL AMERICA.

Panama: Bigabo, South Panama (Martens; Champion).

Geological Range: Unknown.

ECOLOGY: Not recorded.

Remarks: Championi is a form in which the spire is sharply attemuated, the aperture is gracefully rounded as in typical columella and the columella has the chalybea-like excavation, although Martens describes the columellar margin as "almost vertically ascending," a feature not shown in specimens from Central America or in the original figure. It is not as compressed as casta and also lacks the obliquity of that race. This race will undoubtedly prove to be a widely distributed form in Central America when that region is more thoroughly explored. The Mexican references of Cooper and Rhoads seem to be referable to this race.

Pseudosuccinea francisca (Poey). Plate XXIV, figure 21.

Limncea francisca Poey, Mem. Hist. Nat. Cuba, II, p. 32, 1858.-Pfr., Mal. Blatt, V, p. 11, 1858.-Arango, Rep. Fisico-Nat. Cuba, I, p. 137, 1865; II, p. 87, 1866.-Crosse, Journ. de Conch., XXXVIII, p. 260, 1890. 
Shell: Thin, oblong-ovate, elongate-ovate or fusiform, much compressed; surface sculpture as in columella; color brownish horn; whorls $4-4 \frac{1}{2}$, very flat-sided, especially the body whorl, which is very long and much compressed; spire moderately short, acute, narrow; aperture elongate-ovate, the sides almost parallel in the center, broadly rounded anteriorly and bluntly angled posteriorly; inner lip narrow, thin, almost straight, the columellar callus forming a rather thick deposit on the parietal wall; there is a very small umbilical chink; axis feebly gyrate.

\begin{tabular}{ccccccc} 
Length. & Breadth. Aperture length. & \multicolumn{3}{c}{ Breadth. } \\
$8-9$ & 4.50 & $\ldots .$. & $\ldots$. & mill. & Poey & \\
13.00 & 5.75 & 8.00 & 4.10 & “ & Pinar del Rio \\
13.00 & 6.00 & 8.25 & 3.25 & “ & “ & “ \\
13.00 & 6.00 & 8.00 & 3.50 & “ & “ & "
\end{tabular}

TyPES: Location not ascertained.

Type Locality: Lagunas del Potrero, Omoa en Guines, Havana Province.

Animal, Jaw, Radula and Genitalia: Unknown.

RANGE: Island of Cuba. A tropical species of the West Indian region.

\section{RECORDS.}

Cuba: Guines, Havana Province (Arango; Poey).-Pinar del Rio Province (Palmer and Riley).

Geological Range: Unknown.

ECOLOGY: Not recorded.

REMARKS: This Cuban columella was at first thought to be referable to Von Martens' championi, but a comparison of specimens in the Smithsonian Institution from Pinar del Rio, which have been compared with undoubted championi from Central America, reveals considerable difference, the Cuban species being narrower, with a more clongate aperture, a longer spire, and a perfectly straight columellar margin. Von Martens describes his species as with a columella "almost vertically ascending." This feature is not exhibited in his figure (Biol. Cent. Amer., pl. 19, fig. 12), nor is it shown in specimens from Nicaragua (plate XXIV, figure 20). The general shape of the Cuban shell, which in outline strongly resembles some forms of obrussa and which is quite unlike the usual form of columella and its varieties, leads the writer to consider it a valid species.

In 1858 Poey described a shell from Guines; Cuba, which has been almost entirely overlooked by modern writers. A study of his description indicates a shell of the columella group, and there seems to be no question but that the shell herein described is the one named by Poey. His original description is as follows: 
"Testa imperforata, ovato-oblonga, tenuis, pallide fusca, subtiliter striata, striis spiralibus confertis regulariter decussata (italics are the author's); spira conica et acutiuscula; anfr. 4 convexiusculi, utlimus maximus; apertura elliptica, antice amplior, $5 / 8$ out $5 / 9$ longitudinis aequans; columella brevissime intorta; peritr. acutum. Long. $8 / 9$, diam. $41 / 2$ mill. Succinæformis, parum nitida."

This interesting little species will doubtless be found to be a common inhabitant of the ponds and lagoons of Cuba.

\section{Genus RADIX Montfort. 1810.}

1810. Radix Montfort, Conch. Syst., II, p. 266. Type Helix auricularia L. (sole example).

1819. Gulnaria, LeACH, Proofsheets, pp. 146, 148; fide Turton, Man., p. 117, 1831.

1840. Gulnaria, Gray's Turton, p. 232 (type L. auricularia Linné).

1847. Gulnaria Gray, P. Z. S., p. 180 (type L. auricularia, Linné).

1855. Neritostoma H. \& A. Adams, Genera Rec. Moll., II, p. 253, 1st sp. L. auricularia (Linné). Not of Mörch, 1864.

1864. Radix Morch, Vidensk. Meddel. Kjöb., p. 302.

1865. Radix Binney (part), L. \& F. W. Sh. N. A., II, p. 30.

1870. Radix Dall, Ann. Lyc. Nat. Hist., N. Y., IX, p. 349.

1874. Radix Hartman and Michener, Conchologia cestrica, p. 62.

1876. Radix MEEK, U. S. Geol. Surv. Terr., IX, p. 532.

1880. Radix CR. \& Fisch., Mis. Scient. Mex., II, p. 52.

1884. Radix Tryon, S. \& S. Conch., III, p. 101.

1905. Radix Dall, Alaska Mollusks, p. 64.

1908. Radix BAKER, Science, N.-S., XXVII, p. 943.

Shell: Broadly ovate or rounded; spire generally short, last whorl very large, globose, somewhat expanded or even campanulate; outer lip simple, without internal thickening; columella strongly twisted in the earlier whorls, but the twisting frequently concealed by a reflexed inner lip, which may be conspicuously elevated and form a large, open umbilical chink; sculpture as in Lymncea (p1. XVIII, fig. 9).

Animal: Not differing essentially from Lymncea externally.

JAw: Wide and low with a heavy, broadly rounded median projection on the ventral surface (pl. VI, fig. D).

RAdUla: First laterals tricuspid; balance bicuspid (pl. VII, fig. C).

Genitalia: The penis-sac is large, the penis is longer than the penis-sac and does not exceed the vas deferens in diameter; there is one penis-sac retractor which enters the penis-sac by a large, bifid splitting of the muscle; penis retractor narrow, about as long as the penis-sac retractor; it enters the columella muscle near the point of insertion of the penis-sac retractor; prostate not large, regularly pyri- 
form, the posterior portion long, narrow and ribbon-like. Female organs not differing materially from those of Lymnaa (pl. X, fig. C).

Distribution: Holarctic region of Europe; introduced into America. ${ }^{2}$

This genus differs from all other known groups of Lymnæidæ in the very long and narrow penis which can scarcely be differentiated from the vas deferens. There is a different disposition of the retractor muscles, especially in the form of the penis-sac insertions, and the prostate is more regularly pyriform and totally unlike any of the other groups. The vas deferens is also very long. The shell is peculiar in its strongly twisted columella and in its ample and expanded body whorl and its perforated (often wide) umbilical chink. Until the anatomy of more of the Lymnæas is known, the position of some species must remain doubtful. Lymnca randolphi Baker has been placed by Dr. Dall in Radix and the shell certainly has many characteristics in common with auricularia, but its position will remain doubtful until the animal is examined. Its position at the present time is thought to be with Stagnicola.

${ }^{1}$ Radix auricularia (Linné). Plate XXII, figures 12-15.

Helix auricularia Linne, Syst. Nat., Ed. X, p. 774, 1758.-BAKER, Science, n. s., XXVIII, p. 943, 1908.

Limncea auricularia MoQ.-TAND., Hist. Moll. Fr., II, p. 462, pl. 33, fig. 21-31, 1855.-Cpr. Rep. Brit. Ass., 1856, p. 222,-Binney, L. \& F. W. Sh. N. A., II, p. 31, fig. 35, 1865.-BAKer, Nautilus, XV, p. 59, 1901.-Nautilus, XVI, p. 58, 1902; Moll. Chi. Area, II, p. 408, fig. 138, 1902.-Call., Science, XVI, p. 65, 1902.-Letson, Bull. N. Y. State Mus., LXXXVIII, p. 52, 1905.-Wheat, Bull. Brook. Conch. Club, I, p. 10, 1907.

Lymncea auricularia BAKER, Amer. Nat., XXIX, p. 675, fig. 10, 1905; Bull. III. State Lab. N. H., VII, p. 102, 1906.

SHell: Roundly ovate, inflated, thin; periostracum horn-color to pale gold; surface shining, lines of growth fine, wavy, crowded, with occasionally a heavy ridge representing a rest period; spiral, impressed lines present but very fine; whorls four, convex, inflated, the last large and spreading; spire short, conic, very small compared with the body whorl; sutures deeply impressed, channeled in some specimens; aperture very large, ovate, occupying four-fifths of the length of the entire shell, rounded above and flaring below in old specimens; peristome thin, sharp; columella sigmoid, the axis strongly twisted forming an erect, sharp ascending plait; callus very thin, closely appressed to the

${ }^{2}$ Until the anatomy of all the American species is known, the distribution of Radix must remain uncertain. At present, no American species is known which can be placed in this group.

Although this species is not native to America, it has been thought best to include a full description as it is the type of the genus and has also been introduced into a number of our greenhouses. No attempt has been made to include the European synonymy. 
body whorl; inner lip reflected and widely spreading in old specimens; umbilical chink very small in young or half grown individuals, but wide and deep in fully adult specimens. The epidermis is somewhat marked by light and dark lines of color, alternating. Nucleus of about $1 \mathrm{I} / 4$ hyaline whorls, not differing in outline from those of Lymnca stagnalis appressa.

$\begin{array}{cccrll}\text { Length. } & \text { Breadth. Aperture length. } & \text { Breadth. } & \\ 23.00 & 17.00 & 18.00 & 11.00 \mathrm{mill} & \\ 20.00 & 15.50 & 15.50 & 9.50 & & \\ 31.00 & 24.00 & 24.50 & 16.50 & \text { “ } & \\ 26.50 & 21.50 & 24.50 & 14.00 & \text { “ } & \\ 18.00 & 12.25 & 13.00 & 8.00 & \text { “ } & \text { (Half grown) } \\ 15.00 & 10.00 & 11.00 & 7.00 & \text { “ } & \text { “ “ }\end{array}$

TyPE: Location unknown.

Type Locality: Not known to the writer.

Animal: Body flecked with small white spots; mantle marked by many black, irregular spots which show through the shell; head broad, auriculate; tentacles very long, narrow, tapering; foot broadly rounded anteriorly and acutely rounded posteriorly; 18 by 11 mill. in a specimen of good size.

Jaws: Superior jaw low and very wide, strongly arched, about one-quarter as high as wide with a distinct rounded median projection about one-third the length of the entire jaw; lateral jaws not Giffering from those of Lymnea stagnalis (P1. VI, fig. D).

Radula: Formula: $\frac{32}{4}+\frac{4}{4}+\frac{5}{3}+\frac{8}{2}+\frac{1}{3}+\frac{1}{1}+\frac{1}{3}+\frac{8}{2}+\frac{5}{3}+\frac{4}{4}+\frac{32}{4}+$ (P1. VII, fig. C) (50-1-50). Central tooth narrow, with a long acute mesocone $(\mathrm{C})$; first lateral tooth very broad, tricuspid, the mesocone very wide, the entocone and ectocone small; second to ninth lateral teeth broad, bicuspid, the mesocone very wide, the ectocone small and rather narrow; the tenth tooth becomes tricuspid by the splitting of the mesocone to form a small spade-shaped entocone; the eleventh to thirteenth teeth are similar in form, the entocone, however, approaching more nearly to the distal end of the reflection in the twelfth and thirteenth teeth; the fourteenth to eighteenth teeth have a very long and narrow reflection, with two spade-shaped cusps at their extremity and two small outer cusps about midway of the reflection; the nineteenth to twenty-first teeth are similar, excepting that the cusps at the distal end vary from two to four in number; the marginals from the twenty-third to the edge of the membrane are long and narrow, with small cusps at their distal ends, and two small cusps on the outer margin. There are from eighty to ninety rows of teeth. 
The shape of the teeth vary somewhat in different membranes and also in the same membrane in different positions. The radula of the Lincoln Park specimens does not agree with the figure given by Hazay (Mal. Blatt., N. S., VII, pl. 1, fig. 1) of European specimens, the laterals being distinctly bicuspid in the Lincoln Park specimens. Many examinations have been made of the radulæ of these specimens with powers ranging from 500 to 600 diameters and in no case could a tricuspid tooth be found after the first or previous to the tenth tooth as here figured. It is possible that there are two or more species of this group distinguishable by difference in the number of the cusps of the lateral teeth. The second to the ninth marginal teeth exhibit a peculiar swelling on the inner edge of the mesocone, which might be taken for a third cusp, if care is not used in making the examination. The figure on plate VI is drawn from fresh, unworn teeth. In one membrane, several of the lateral teeth exhibit a number of small serrations on the inner margin of the mesocone.

The radula of auricularia is peculiar in the aculeate cusp of the central tooth and the tricuspid first lateral, the bicuspid laterals following with the rounded swelling on the inner side of the mesocone. No other species at present known has this peculiar combination of characters.

Genitalia (Plate X, Fig. C): Male organs: Penis-sac cylindrical, six mill. long and two mill. wide, diminishing in diameter toward the distal end, where it swells slightly before receiving the vas deferens; penis very slender, eight mill. in length, with a rounded head; vas deferens seventeen mill. in length; vas deferens to prostate six mill. long, enlarging slightly as it enters the prostate; prostate roundly pyriform at its proximal end, receiving the vas deferens in a little depression; the prostate narrows behind the pyriform portion and forms a rather long ribbon-like organ which unites with the oviduct under the albuminiparous gland; retractor muscles of penis two in number, one for the penis-sac, which widens and forms a long double insertion as it joins the sac, and one narrow ribbon-like muscle which extends from the columella muscle to the head of the penis; the latter is strongly reflected by this muscle; protractor muscles four in number, two narrow muscles on the posterior face and two larger muscles with many branches on the anterior face.

Female organs: Oviduct short and wide, the anterior two-thirds simple and cylindrical, the posterior third, forming the uterine portion much convoluted; receptaculum seminis large, elongate-pyriform in outline, with a duct 6.50 mill. long, joining the oviduct one mill. from 
the vaginal opening, the two organs forming the short vagina; albuminiparous gland large, oval, very tightly bound down to the oviduct; first accessory albuminiparous gland very large, embracing the oviduct; second accessory albuminiparous gland small, round, attached to the oviduct a very short distance above the first albuminiparous gland.

The organs are colored as follows: Albuminiparous gland bright yellow, prostate black shading into dirty white, oviduct yellowish or dirty white, receptaculum seminis flesh-colored on its lower part, bright orange on its upper part; penis-sac yellowish; the other organs white.

The measurements of the genitalia may be tabulated as follows:

\begin{tabular}{|c|c|c|c|c|c|c|c|}
\hline Penis. & Penis-sac. & $\begin{array}{l}\text { Rec. sem. } \\
\text { duct. }\end{array}$ & $\begin{array}{l}\text { Prostaite } \\
\text { duct. }\end{array}$ & Vas. def. & $\begin{array}{l}\text { Penis-sac } \\
\text { retractor. }\end{array}$ & $\begin{array}{l}\text { Penis } \\
\text { retractor. }\end{array}$ & Shell. \\
\hline 7.50 & 6.00 & 6.50 & 6.50 & 17.00 & 2.10 & 2.15 & 29.00 \\
\hline 9.00 & 6.00 & 6.00 & 5.50 & 15.00 & 4.50 & 5.00 & 31.00 \\
\hline 9.00 & 7.00 & 6.00 & 7.00 & 15.00 & 4.50 & 5.00 & 31.50 \\
\hline
\end{tabular}

The penis-sac retractor is peculiar (pl. XII, fig. F) ; for about half of its length it is a narrow band of muscle; at this point it suddenly enlarges, forming a thick pad-like structure, which bifurcates unequally, continuing to the penis-sac in two wide, flat bands of muscle, which enter the penis-sac by several branches. (Dissection No. 23085 and 23086.)

The genitalia of the Lincoln Park auricularia is similar to Eisig's figure (Zeitsch. Wissen. Zool., XIX, p. 29), the organs, however, not being shown in much detail in his figure, but their relative shapes are similar. Moquin-Tandon's figure (Hist. Nat. Mol. Ter. Fluv. Fr.) shows the organs apparently as in their natural position and the female organs as they appear when swollen with water. None of these figures show the male organs and their muscles in a clearly defined manner.

RANGE: Europe and northern Asia; North America (introduced).

Records: Lincoln Park, Chicago, Ills., in greenhouse (Baker); Flatbush, Brooklyn, N. Y. (Call; Smith).

Geological Range: Not recorded.

ECOLOGY: Auricularia is a mollusk which prefers slow-moving bodies of water like lakes, ponds and the still parts of rivers. In captivity it remains near the bottom of the aquarium, rarely coming to the surface. It is rather active, moving about the aquarium with a steady gliding motion.

REMARKS: The specimens of auricularia from the greenhouse in Lincoln Park seem typical, though some old specimens approach var. i'entricosa Hartm. The old specimens differ greatly from the halfgrown ones, the outer lip widely expanding and forming a peculiar extension of the aperture at its posterior end, like a rude canal. Some specimens recall Radix ampla Hartm. 
The species was first found in the greenhouse by $\mathrm{Mr}$. Herbert $\mathrm{E}$. Walter, the instructor in Biology in the Robert A. Waller High School, Chicago, in 1901. It was imported on plants from Belgium and has thrived well in captivity, increasing to such an extent as to furnish an abundance of material for the biology classes in the above named high school. It has also been found in a lily pond in the park, the water of which was artificially heated to $90^{\circ} \mathrm{Fahr}$. The mantle shows conspicuously through the shell in irregular patches of dark and light spots. It will probably be found in other greenhouses in the United States and there is no reason why it would not thrive in the ponds and rivers of certain favorable sections of the country. The Brooklyn colony has evidently become well established in the open, and, if the environment is favorable, it may become a recognized part of the molluscan fauna.

\section{Genus BULIMNEA Haldeman. 1841.}

1841. Bulimnea Haldeman, Mon. Limn., part 3, p. 6, July, 1841. Type Limnea megasoma SAY. (Not of $\mathrm{H}$. A. Adams.)

1865. Bulimnea Binney, L. and F. W. Sh. N. Amer., II, p. 37.

1870. Bulminea Dall, Ann. Lyc. Nat. Hist., N. Y., IX, p. 349.

1872. Bulimnea Tryon, Con. Hald. Mon., p. 86 (60).

1876. Bulimnea MeEk, U. S. Geol. Sur. Terr., IX, p. 532.

1880. Bulimnea CR. \& Fisch., Mis. Scient. Mex., II, p. 51.

1884. Bulimnea Tryon, S. and S. Conch., III, p. 101.

1905. Bulimnea DALL, Alaska Mollusks, p. 63.

1908. Bulimnea BAKER, Science, N. S., XXVII, No. 703, p. 943, 1908.

SHell: Bulimiform, very solid, generally richly colored; spire and aperture about equal in length; outer lip simple; axis twisted, inclining to gyrate, the fold quite sharp; inner lip expanded and folded back, completely closing the umbilicus. (P1. XVIII, fig. 8.) fig. E.)

JAw: With a wide, slightly convex median swelling. (P1. VI,

Radula: With tricuspid lateral teeth. (P1. VII, fig. D.)

Genitalia: Penis-sac large, the penis one-fourth longer than the penis-sac and enlarging gradually to the end, which is club-shaped and not rounded, as in the other members of the family; penis-sac retractors one or two in number, penis-sac protractors very numerous; prostate very large, long, irregularly flattened, the posterior portion short ; first accessory albuminiparous gland roundly knob-shaped, tapering toward the vaginal opening; the oviduct emerges from this gland some distance from the termination of the rounded portion. (P1. X, fig. D.)

Distribution: Nearctic. 
Bulimnea differs generically from the rest of the family in its peculiar bulimiform, darkly colored shell, its long, club-shaped penis, and large and irregular prostate. The penis is very peculiar, being very long, and gradually increasing in diameter to the end, which is cut off almost squarely and not rounded as in other Lymnæas; the end is more than double the diameter of the organ as it leaves the penis-sac; the protractor muscles of the penis-sac are also more numerous than in any groups excepting Lymncea.

\section{Bulimnea megasoma (Say). Plate XXV, figures 1-6.}

Lymnaus megasomus SAY, Rep. Long's Exp., II, p. 263, pl. 15, fig. 10, 1824 ; Binney, reprint, p. 129, 1858.

Limnaus megasomus Küster, Conch. Cab., ed. ii, p. 36, taf. 6, figs. 20, 21, 1862.

Limnea megasoma Haldeman, Mon. Limn., p. 13, pl. 3, figs. 1-3, 1841.DeKay, Zool. N. Y., p. 70, pl. 4, fig. 70, 1843.-Lapham, Trans. Wis. St. Agr. Soc., II, p. 368, 1852.-Kirtland, Trans. Clev. Acad. Nat. Sci., II, p. 6, 1854.Beauchamp, L. and F. W. Sh. N. Y., p. 9, 1886.

Limnea megasoma C. B. AdAms, Amer. Journ. Sci., XL, p. 267, 1841.Bell, Can. Nat. and Geol., IV, p. 213, 1859.-C. B. Adams, Thomp. Hist. Vt., p. 153, 1842 (nec. fig.) ; pamphlet, p. 3.-Stimpson, Sh. N. Eng., p. 52, 1851.Binney, Check List, p. 12, 1860.-Laphum, Proc. Phil. Acad., p. 155, 1860.Bell, Can. Nat. and Geol., VI, p. 43, 1861.-Whiteaves, Can. Nat. and Geol., VIII, p. 102, 1863.-Binney, L. and F. W. Sh. N. A., II, p. 37, fig. 46, 1865.Currier, Kent. Sci. Inst., Mis. Pub., No. 1, 1868.-Gould, Binney's ed., p. 470, fig. 722, 1870.-Bland and Binney, Amer. Journ. Conch., VII, p. 162, 1871.Tryon, Con. Hald. Mon., p. 94 (68), 1872.-Sмith, Rep. U. S. Fish Com., p. 701, 1874.-Walker, Journ. Conch., II, p. 330, 1879.-CR. and Fisch., Moll. Mex., II, p. 41, 1880.-Hyatr, Amer. Nat., XIV, p. 51, 1880.-Dall, Bull. Phil. Soc. Wash., III, p. 75, 1881; Smith. Mis. Coll., XX, p. 75, 1881.-Trans. Ottawa Nat. Field Club, I, p. 58, 1882; I, p. 74, 1883.-Fischer, Man. Conch., p. 506, 1883.-Tryon, S. and S. Conch., III, p. 101, pl. 103, fig. 5, 1884.-Standard Nat. Hist., I, p. 308, fig. 356, 1884.-Christy, Journ. Conch., IV, p. 346, 1885.Trans. Ottawa Nat. Field Club, II, p. 351, 1886.-Sнiмeк, Bull. Lab. Nat. Hist., Univ. Iowa, I, p. 68, 1888.-Ottawa Nat. IV, p. 56, 1890.-WAlker, Nautilus, VI, p. 32, 1892.-Taylor, Ottawa Nat., VI, p. 35, 1892.-Marshall, Rep. N. Y. State Mus., XLVIII, p. 63, 1893.-Latchford, Ottawa Nat., VII, p. 115, 1893.-Walker, Rev. Moll. Fauna Mich., p. 17, 1894.-Marshall, Rep. N. Y. at World's Fair, p. 510, 1894.-SArgent, Nautilus IX, p. 127, 1896.-HAn ham, Nautilus, XIII, p. 5, 1899.-BAKer, Shells of Land and Water, pl. and fig. p. 18, 1903.-Whiteaves, Rep. Geol. Surv. Canada, p. 163A, 1905.-Letson, Bull. N. Y. State Mus., LXXXVIII, p. 52, 1905.-СнAdwick, Nautilus XX, p. 22, 1906 ; Bull. Wils. Nat. Hist. Soc., N. S., IV, p. 81, 1906.-BAKer, Science, N. S., XXVII, p. 943, 1908.-Adams, Rep. Geol. Surv. Mich., 1908, p. 20, 1909.

Limnaa megastoma ReEve, Elements of Conch., p. 79, 1860.-Sowerby, Conch. Icon., XVIII, Limn., sp., 11, p1. 2, fig. 121, 1872. (Error in plate, note, p1. 2, fig. 12, not fig. 11.) 
Limnaa (Bulimnea) megasoma BeLl, Rep. Geol. and Nat. Hist. Surv. Canada, 1879-1880, p. 75, 1881.

?Lymnea megasoma LoRD, Nat. in Brit. Col., II, p. 363, 1866.

Lymnaa megasoma Wheatley, Cat. Sh. U. S., p. 23, 1845.-JAY, Cat., ed. 4, p. 270, 1852.-Morse, Amer. Nat., III, p. 651, pl. 11, fig. 1, 1870.-HYatT, Amer. Nat. XIV, p. 71, 1880.-Whitfield, Bull. Amer. Mus. Nat. Hist., I, p. 29, 1881.-Dall, Land and F. W. Moll., p. 67, fig. 44, 1905.-BAKer, Amer. Nat., XXXIX, p. 676, 1905; Nautilus, XX, p. 36, 1906.-LATchrord, Nautilus, XX, p. 83, 1906.-Sterki, Proc. Ohio State Acad. Sci., IV, p. 381, 1907.Walker, An. Rep. Geol. Surv. Mich., 1908, p. 290, 1909.-Colton, Proc. Phil. Acad., 1908, p. 421.

Limnaa megalosoma SAndberger, Conch. de Urw., p. 581, 1873.

Bulimnea megasoma Chenu, Man. Conch., II, p. 480, fig. 3543, 1862.Lewis, Bull. Buf. Soc. Nat. Hist., II, p. 135, 1874.-Wetherby, Journ. Cin. Soc. Nat. Hist., II, p. 93, 1879.-Grant, Rep. Nat. Hist. Surv. Minn., XIV, p. 122, 1886; XVI, p. 483, 1888.-Keyes, Bull. Essex Inst., XX, p. 70, 1888.

Bulimnca megasoma Tryon, Amer. Journ. Conch., I, p. 249, 1865.-Dall, Ann. Lyc. Nat. Hist., IX, p. 349, 1870.-Decamp, Kent. Sci. Inst., Mis. Pub., No. 5, p. 7, 1881-Call, Bull. U. S. Geol. Surv., II, p. 383, 1884.

Shell: Large, ovate, inflated, bulimiform; periostracum brownish, greenish or olive, with, in many specimens, longitudinal streaks of green, orange, purple or ochraceous; surface strongly marked with growth lines, which are raised to form wide, flat ridges in some specimens; the spiral, wavy lines of the Lymnæas are present, but are rather faint; some specimens are strongly malleated; nuclear whorls $1 \mathrm{I} / 4$ in number, dark chestnut colored in some specimens, light yellowish horn in others; outline of second whorl shouldered near the suture of the first whorl; texture that of satin finish (pl. XLIX, fig. B); whorls $5-5 \mathrm{~L} / 2$, rounded, somewhat flattened at the previous sutures; spire varying from rather pointed to depressed dome-shaped; sutures well impressed; aperture large, subovate, inflated, chestnut brown or dark purple within, occupying from half to two-thirds the length of the entire shell; peristome thin; parietal wall with a thin wash of callus which is tightly appressed to the body whorl, completely closing the axis; pillar twisted, forming a raised, prominent ascending plait.

$\begin{array}{cccccc}\text { Length. } & \text { Breadth. Aperture length. } & \text { Breadth. } & \\ 43.25 & 22.50 & 26.25 & 12.10 & \text { mill. Type. } \\ 35.50 & 20.50 & 22.75 & 10.50 & \text { “ } & \text { " } \\ 36.00 & 21.00 & 22.50 & 12.25 & \text { " } & \\ 40.50 & 22.00 & 24.50 & 13.00 & & \\ 41.00 & 23.50 & 24.50 & 14.00 & & \\ 44.00 & 21.00 & 24.50 & 12.50 & & \\ 41.00 & 21.00 & 24.00 & 12.00 & & \\ 47.00 & 27.00 & 21.00 & 14.00 & \end{array}$

Type: Academy of Natural Sciences of Philadelphia, 2 specimens, No. 58388. 
Type Locality: Bois Blanc Lake, Manitoba.

Animal: "Blackish, the head and tentacles marked with small yellow spots which give a brownish color on close inspection, and when the animal is in motion the surface has the appearance of being covered with a superficial bloom of a russet color; foot of blackish gray, lighter beneath; mantle bluish gray, slightly tinged with yellow toward the posterior angle of the shell aperture. Head broadly semi-circular, spreading below, obtusely angular at the posterior lateral margins and slightly emarginate in front. Foot disc broadly rounded in front and tapering behind to an obtusely rounded point; about fiveeighths of an inch wide near the anterior end, and together with the head measures about one inch and five-eighths in length when the animal is in motion. Tentacles broad and thin, more than half an inch long, slightly curved inward and irregularly tapering to an obtuse point. Eye spots small, situated at the inner base of the tentacles; yellow in color, with a black center. Respiratory orifice of the pulmonary sac situated a little less than half an inch from the posterior angle of the shell aperture, and when dilated, as in the act of receiving air, is about one-fourth of an inch in its greatest diameter, and regularly oval in outline." (Whitfield. See plate XXV, figs. 1-2.)

JAws (plate VI, fig. E): Median jaw about three times as wide as high, with a broad convex median projection on the cutting edge; lateral jaws very long, triangular, the cutting edges somewhat irregular.

RAdula (plate VII, fig. D): Formula: $\frac{31}{5}+\frac{3}{4}+\frac{14}{3}+\frac{1}{1}+\frac{14}{3}+\frac{3}{4}+\frac{31}{5}+$ (48-1-48). Central tooth with a broad, short cutting point; lateral teeth rather short, quadrate, broad, tricuspid, the second to tenth teeth narrow, the entocone placed nearer the distal end of the reflection; several of the lateral teeth show a tendency to a splitting of the mesocone, a small accessory cusp resulting, as figured by Whitfield; eleventh to fourteenth laterals becoming narrower toward the marginal teeth, which begin at about the eighteenth tooth, the reflection being narrow, with three or more cusps at or near the distal end and one or more higher upon the outer margin; outer marginals very narrow, irregularly tri-, quardi- or penta-cuspid. The fifteenth to seventeenth teeth are intermediate, the entocone moving upward and becoming larger; the eighteenth tooth is a typical marginal.

The radula differs somewhat from Whitfield's figure (Bull. Amer. Mus. N. H., I, pl. v, fig. 10), in which the lateral teeth are wider, with a longer, more acute mesocone. No example of megasoma has been seen with a radula exactly comparable with the figures of the lateral teeth as shown by Whitfield. 
Genitalia (plate X, fig. D): Male organs: Penis-sac cylindrical, eight mill. long and two mill. wide, enlarging slightly at the distal end; penis very long (10 mill.) and gradually enlarging toward the head-end; the whole penis is somewhat club-shaped; the penis-sac; as well as the penis, is made up of strong circular and longitudinal muscular tissue; vas deferens very long ( 42 mill.) ; prostate duct rather short (10 mill.), not much dilated where it enters the prostate; prostate irregularly cylindrical, somewhat folded, contracted posteriorly to form a narrow, irregularly convoluted tube; retractor muscles two or three in number, one penis retractor and one or two penis-sac retractors; protractor muscles numerous, six or more on the posterior face and one very large muscle on the anterior face, which is made up of about six smaller muscles. The muscles of the penis-sac show much variation in position ( $\mathrm{pl}$. XIV, fig. D), the posterior protractors being widely separated (2) or close together and joined by small branches (1) ; there is normally one penis-sac retractor, but two may be present, as shown in figure 2 .

Female organs: Oviduct rather long, the convoluted uterine portion very large; receptaculum seminis very large, round, its duct ten mill. long, joining the oviduct two mill. from the vaginal opening; albuminiparous gland of usual form; first accessory albuminiparous gland rather large, somewhat pyriform or roundly knob-shaped, its walls very thick; second albuminiparous gland very small, rounded.

The organs are colored as follows: Penis, flesh; penis-sac, blackish; prostate, bright orange; receptaculum seminis, mottled flesh and yellowish; albuminiparous gland, purplish and flesh; accessory glands, light flesh; uterine portion of oviduct, yellowish and whitish.

The peculiarities of the genitalia of megasoma are the shape of the penis and its size in relation to the penis-sac. The prostate also differs in form from that of any other species. The number and position of the retractor and protractor muscles of the male organ are also noteworthy. The length of the vas deferens is equaled only by that of stagnalis.

The genitalia of two specimens measure as follows (dissection No. 23101):

\begin{tabular}{ccccccccc} 
& & Rec. & Pros- & \multicolumn{5}{c}{$\begin{array}{c}\text { Penis } \\
\text { Penis- }\end{array}$} \\
Penis. & $\begin{array}{c}\text { Penis- } \\
\text { sac. }\end{array}$ & $\begin{array}{l}\text { sem. } \\
\text { duct. }\end{array}$ & $\begin{array}{c}\text { tate } \\
\text { duct. }\end{array}$ & $\begin{array}{c}\text { Vas. } \\
\text { def. }\end{array}$ & $\begin{array}{c}\text { re- } \\
\text { tractor. }\end{array}$ tractor. & Shell. & \\
10.20 & 8.75 & 9.00 & 8.00 & 41.00 & 6.50 & 5.50 & 45.00 & Canada \\
10.00 & 8.00 & 8.50 & 7.10 & 44.00 & 5.00 & 5.00 & 41.00 & "
\end{tabular}


RANGe (figure 14): Northern New England (Vermont) west to Minnesota, Iowa and Manitoba; northern Ohio, latitude $41^{\circ}$, northward in British America to north latitude 5\% .

Megasoma is confined to the Canadian and Hudsonian regions and the northern part of the Upper Mississippian region. It thus occupies the drainage areas of the St. Lawrence River, the Mississippi River and the waters of the western part of the Hudson Bay area. The center of distribution is the Great Lake region, from whence the species has spread to the areas east, west and north. The northward

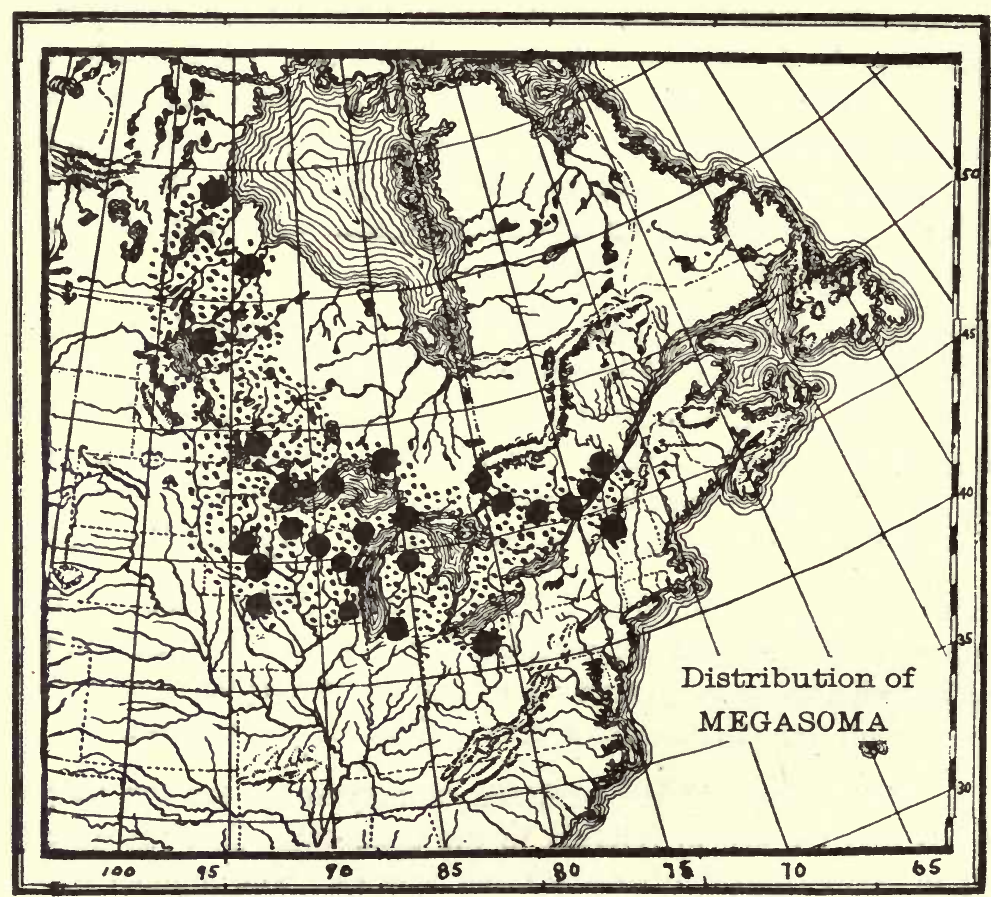

FIG. 14.

extension in Keewatin was made possible by the glacial Lake Agassiz via the Minnesota-Red River connection. The Ohio record is the most southern.

Mcgasoma is essentially a boreal species, though extending into the transition life zone; the southern records in Ohio, Wisconsin and Iowa are at the southernmost extension of the Alleghanian division of the Transition zone, while the northern limit seems to be in the Hudsonian area of the Boreal zone. The range extends through the 
Canadian area of this zone. It is exceedingly doubtful if this species really lives in any area south of the Transition zone. Referring to its distribution in relation to the forest areas, we find that its center of dispersal is in the coniferous regions of the northern United States and Canada. In the southeast and south of this area it extends into the region of deciduous forests and on the southwest into the prairie region of the Mississippi Valley. Its range is probably between the 41 st and 60 th degrees of north latitude and between the $73 \mathrm{rd}$ and the 100th degrees of west longitude. Lord ${ }^{1}$ records megasoma from Lake Osoyoos, British Columbia, but this is undoubtedly a case of misidentification, as the species has never been reported so far west, except in this instance.

\section{RECORDS.}

UNITED STATES.

IowA: Winnebago and adjoining counties (Keyes); pond near Forest City, Winnebago Co. (Shimek).

LAKe Superior: Lake Superior (Newberry; Chicago Academy of Sciences).

Massachusetts: Massachusetts? ${ }^{2}$

Michigan: St. Joseph River, Berrien Co. (Smith. Coll.); Drummond's Island and St. Mary's River, Chippewa Co.; Lake Huron; Higgins River and Marl Lake, Roscommon Co.; Green Bay, Menominee Co.; Isle Royale (Walker).

Minnesota: Lake Minnetonka, Hennepin Co. (Miss A. A. Abbott); Elk River, Sherburne Co. (Bailey); S.t. Louis and Lake Counties (Grant); Duluth, St. Louis Co. (Leidy); Minnesota (Chicago Academy of Sciences).

Онго: Alliance, Mahoning River, Stark Co. (Kirtland; Sterki; Ulrich).

Vermont: Burlington, Crittenden Co. (Smith. Coll.) ; near Lake Champlain (Hudson; Marshall; Stimpson).

Wisconsin: Tomahawk Lake and Wisconsin River, Oneida Co. (Baker); Moles Creek, between Two Rivers and Two Creeks, Manitowoc Co. (C. E. Brown; C. H. Chadwick) ; Lake Koshkonong, Jefferson Co. (Chadwick) ; West Superior (Conrad); West side Green Bay (Crawford; Wetherby) ; St. Croix River, Douglas Co. (Dr. S. Grænicher) ; Oconto, Oconto Co. (Geo. T. Marston); Green Bay (Smith. Coll.) ; Oconto, Oconto Co., in marsh (Mrs. E. C. Wiswall).

\section{BRITISH AMERICA.}

KeEwatin: Vermilion Lake to Echinamish Lake, in lat. $57^{\circ}$ n., between the Nelson and the Height of Land (Bell); Echinamish River (Bell; Hanham).

Manitoba: Bois Blanc Lake (Bigsby, Say).

Ontario: Pic River, Lake Superior (Agassiz); Vermilion Lake, Rainy River District; Creek near Hawksbury, Prescott Dist. (Bell) ; Bonnechere River (Billings) ; Meech's Lake, near Ottawa, Carleton Dist. (Latchford); Georgian

${ }^{1}$ Nat. in. Brit. Col., II, p. 356.

${ }^{2}$ A tray of this species marked Massachusetts (Stearns' collection, No. $63460)$ is in the collection of the Smithsonian Institution, but the locality needs confirmation. No authentic record has been seen from any New England state excepting Vermont. (Lake Champlain.) 
Bay; French River; Lake Nipissing; Lake Temagami and Lake Temiskaming, Nipissing Dist.; "doubtless occurs in suitable waters from Albany River to Lake Abittibi” (Latchford) ; Cobalt Lake, Nipissing Dist. (Latchford).

QuebeC: Nun's Island, near Montreal, Hochelaga Dist. (Whiteaves); McGoey's Lake, in the Laurentides, near Chelsea (Trans. Ottawa Nat. Field Club).

Geological Range: Leda clay, ten miles below Ottawa City, Ontario (Bell).

Ecology: In rivers, lakes, sloughs and ponds. "A small lily pond in the bed of the Mississippi River just below St. Cloud. The snails are to be seen floating on the surface or feeding upon the lily leaves. They are shy, sinking almost instantly when alarmed" (Sargent). "The animal is sluggish in its haibits and excessively timid, the slightest disturbance of the water causing it to instantly draw itself into the shell. Though it feeds upon algæ in confinement my specimens also devour the animals of land snails and of fresh-water mussels with great greediness" (Wetherby). "Common in ponds and pools" (Keyes). "Not uncommon on floating masses of vegetation in some of the ponds and lakes in the northern part of the state" (of Iowa) (Shimek). "The waters of Lake Cobalt, Ontario, Canada, are so impregnated with arsenic as to cause serious intestinal trouble to those who use it. L. megasoma, however, lives and thrives, attaining large size and preserving to a ripe old age the beautiful epidermis characteristic of young shells" (Latchford).

At Tomahawk Lake, Wisconsin, megasoma lives in swampy portions of sheltered bays where the water is quiet. The bottom of such a habitat is boggy and the water is so shallow that frequently little boggy islands are formed, and on these megasoma may be found, one or two specimens on each island. In other parts of this habitat they may be found near the shore, clinging to logs and other debris. A small, swampy slough, lying between the Wisconsin River and Gilmore Creek, Oneida County, afforded the best habitat for megasoma, where they lived in considerable number. This slough is about a quarter of a mile long and two or three hundred feet wide; the water is (in summer) but a few inches in depth, but the mud, which is about the consistency of mush, is from six to ten feet in depth. Megasoma lives on the surface of the mud and on old logs which the lumbermen have left in the swamp. It would seem that the characteristic habitat of megasoma is a swamp or marshy pond or bay (Baker).

A single large, but dead, specimen was found in a pond-like bayou which was connected with Tobin Harbor by a very narrow and short outlet (Walker, Isle Royale). 
Remarks: Megasoma is our finest American Lymnæa, not even rivalled by stagnalis. It seems fairly common in its range, which is decidedly northern. There is considerable variation in the height of the spire, some shells having a rather high, broadly conic spire, while others have a short, dome-shaped spire. These differences, as well as certain variation in color, are very trivial and are but individual modifications. This species cannot be mistaken for any other. A number of interesting experiments have been performed with these animals, mention of which has been made in Chapter II (see p. 47). In the spring of 1868 Dr. Whitfield introduced living megasoma into several ponds and streams about Albany. In $18 \% 1$ he records the finding of one specimen in a pond. As no subsequent records have been seen, it seems probable that the various colonies died out, possibly because of unfavorable environment.

\section{Genus ACELLA Haldeman. 1841.}

1841. Acella Haldeman, Mon. Limn., part 3, p. 6, July, 1841. Type, Lymnca gracilis Jay.

1865. Acella Binney, L. and F. W. Sh. N. A., II, p. 69.

1870. Acella Dall, Ann. Lyc. Nat. Hist. N. Y., IX, p. 349.

1872. Acella Tryon, Con. Hald. Mon. Limn., p. 87 (61).

1876. Acella MEeK, Rep. U. S. Geol. Sur. Terr., IX, p. 533.

1884. Acella Tryon, S. and S. Conch., III, p. 101.

1905. Acella Dall, Alaska Moll., p. 64.

1908. Acella Baker, Science, N. S., XXVII, p. 943.

Shell: Thin, acute, with slender spire; outer lip slightly expanded at the margin, simple; axis gyrate; columella not plicate ; sculpture of growth lines only (pl. XVIII, fig. 1).

JAw : Very high, with a strong, prominent median swelling.

RAdula: With bicuspid lateral teeth, the mesocones of which are strongly modified by a large swelling on the inner side, corresponding in position to an entocone. Intermediate teeth strongly tricuspid (pl. VIII, fig. E).

Genitalia: Penis-sac long, cylindrical, the penis thick, 4/6 to $4 / 7$ the length of penis-sac; prostate large, flatly-cylindrical (pl. XI, fig. F).

Distribution : Nearctic; recent fauna only.

Acella differs generically from all other Lymnæidæ in its shell, all the whorls of which are very long in proportion to their width, even the nuclear whorls, a condition not shared by any other American Lymnæas (see pl. XLIX, fig. E). The prostate differs in being long and regularly cylindrical. The radula is the most peculiar of any Lymnaid yet examined, the mesocone of the lateral teeth having a 
very decided swelling on the inner side, which is probably a modified entocone. The ninth tooth (transition) is distinctly tricuspid, while the tenth tooth is a typical marginal, the transition being very abrupt.

The only radula of Lymnaa known which is at all comparable with this species is Lymnaa hawaicnsis ${ }^{1}$ Pilsbry, described from Hawaii, in which the laterals are modified in much the same manner. This species is very small and of a wholly different character and should probably be made the type of a distinct group of Lymnæas. The combination of the characters of the shell, radula and genitalia gives to this species a higher rank than a subgenus or section and entitles it to full generic consideration.

Acella haldemani ("Deshayes," Binney). Plate XVIII, figure 1; Plate XXVI, figures 1-4.

Lymnaa gracilis JAY, Cat., Ed. 3, p. 112, pl. i, figs. 10, 11, 1839, (non Ziethen, 1830).-Wheatley, Sh. U. S., p. 23, 1845.-Jay, Cat. Ed. 4, p. 269, 1852.Lewis, Proc. Phil. Acad., 1856, p. 259; 1860, p. 18.-Reeve, Elements of Conch., p. 179, 1860.-Lewis, Proc. Bost. Soc. N. H., IX, p. 160, 1862.-Morse, Amer. Nat., p. 651, pl. 11, fig. 6, 1870.-Lewis, Proc. Phil. Acad., 1872, p. 102.-Sмiтh, Nautilus, XX, p. 91, 1907.-WALker, Nautilus, XXII, p. 18, 1908; Journ. Conch., XII, p. 240, 1909.

Lymnea gracilis DeKay, Cat. An. N. Y., p. 32, 1839.-JAY, Ann. N. Y. Lyc. N. H., IV, p. 170, 1846.-Currier, Sh. Grand. Riv., Mich., 1859.-WhittiMORE, Proc. Bos. Soc. N. H., VII, p. 151, 1859.

Limnaa gracilis C. B. Adams, Am. Journ. Sci., XL, p. 267, 1841; Thomp. Hist. Vt., pt. I, p. 153, 1842.-Stimpson, Sh. N. Eng., p. 52, 1851.-Lewis, Proc. Bost. Soc. N. H., V, p. 296, 1856 ; Proc. Bost. Soc. N. H., VI, p. 2, 1856.Binney, Check List, p. 12, 1860.-Lapham, Proc. Phil. Acad., 1860, p. 155.Binney, L. and F. W. Sh. N. A., II, p. 69, figts. 113, 114, 1865 ; Journ. de Conch., XV, p. 427, 1867.-Currier, Kent Sci. Inst. Mis. Pub., No. 1, 1868.-Sowerby, Conch. Icon., XVIII, Limn. sp., 19, pl. 3, fig. 19, a, b, 1872.-Tryon, Con. Hald. Mon., p. 114, 1872; Heron, Ottawa Nat., I, p. 39, pl. 11, fig. 4, 1880.-Fischer, Man. de Conch., p. 506, 1883.-Tryon, S. and S. Conch., III, p. 101, pl. 103, fig. 8, 1884.-Beauchamp, L. and F. W. Sh. N. Y., p. 9, 1886.-Ottawa Nat., IV., p. 56, 1890.-TAYlor, Ottawa Nat. VI, p. 35, 1892.-W ALker, Nautilus, VI, p. 34, 1892.Marshall, Rep. N. Y. State Mus., XlVII, p. 65, 1893.-Walker, Rev. Moll. Mich., p. 18, 1894.-Marshall, Rep. N. Y. Col. Exp., p. 512, 1894.-Sargent, Nautilus, IX, p. 127, 1896.-W AlKer, Nautilus, XII, pp. 119, 131, 1899.-LeTson, Bull. N. Y. State Mus., LXXXVIII, p. 56, 1905.-Chadwick, Bull. Wis. Soc. N. H., N. S. IV, p. 83, 1906.-BAKer, Science, N. S., XXVII, p. 943, 1908.Letson, Bull. Buf. Soc. Nat. Sci., IX, p. 242, 1909.

Limnea gracilis Haldeman, Mon. Limn., p. 50, pl. 13, fig. 21, 1842.-Newberry, Proc. A. A. A. Sci., V, p. 105, 1851.-Lapham, Trans. Wis. State Agr. Soc., II, p. 368, 1852.-DeKay, Zool. N. Y., p. 70, pl. 4, fig. 73, 1843.-Miles, Geol. Surv. Mich., 1860, p. 237.

Limnaus gracilis KüsteR, Conch. Cab., p. 50, taf. 11, figs. 9, 10, 1862.

${ }^{1}$ See Proc. Phil. Acad., 1903, p. 791, for figures. 
Acella gracilis Tryon, Amer. Journ. Conch., I, p. 257, 1865.-Currier, Amer. Journ. Conch., I, p. 294, 1865.-Dall, Ann. Lyc. Nat. Hist., IX, pp. 340, 349, 1870.-Lewis, Bull. Buf. Soc. N. H., II, p. 135, 1874.-Decamp, Kent Sci. Inst., Pub. No. 5, 1881.-Grant, Rep. Nat. Hist. Surv. Minn., XVI, p. 483, 1888.-Chenu, Man. de Conch., II, p. 480, fig. 3545.

Limnaa haldemani Deshayes, Binney, Journ. de Conch., VII, No. 4, Oct., 1867.-Tryon, Con. Hald. Mon., p. 114 (88), 1872.-BAKer, Bull. Ills. State Lab. N.' H., VII, p. 103, 1906.-Sterki, Proc. Ohio State Acad. Sci., IV, p. $382,1907$.

\section{Limnca jayi Dunker, Walker, Nautilus, XXII, p. 18, 1908.}

SHell: Very slender, thin and fragile; color of periostracum yellowish-white; surface generally dull, growth lines closely set, fine; no spiral sculpture; nucleus consisting of about one whorl which is long-oval in outline and resembles the end of a bullet; when turned to one side the outline of the nuclear and first post-nuclear whorls resembles a liberty cap (pl. XLIX, fig. E) ; whorls $5 \frac{1}{2} 2$, very oblique and flat-sided; spire very slender and acute, much longer than the aperture; sutures heavily impressed, bordered by a narrow band indicating the position of the previous connected lips; aperture long-ovate, elongated and narrowed, made continuous by the heavy and raised inner lip; peristome thin, acute, inner lip elevated in some specimens and causing the aperture to be continuous; in other individuals it is attached but not appressed to the parietal wall; the aperture is also twisted to the left and narrowed at its junction with the body whorl; axis gyrate; there is a small umbilical chink; there is no plait on the columella, which is almost straight.

\begin{tabular}{ccccc} 
Length. & Breadth. Aperture length. & \multicolumn{2}{c}{ Breadth. } \\
18.50 & 3.50 & 7.25 & 2.25 mill. \\
20.00 & 3.75 & 8.00 & 2.75 “" \\
19.00 & 4.00 & 7.50 & 2.50 " \\
25.00 & 5.00 & 10.50 & 3.00 " \\
24.00 & 5.00 & 10.00 & 3.00 "
\end{tabular}

Types: Not in Jay collection (vide letter from Mr. L. P. Gratacap, Amer. Mus. Nat. Hist.).

Type Locality: Lake Champlain.

Animal: Yellowish, flecked with fine white dots, which become larger on sides of body and edge of mantle; under side of foot bordered by a dark margin; tentacles small; foot broadly long-ovate and shorter than aperture, one specimen measuring as follows: shell, 22.50 mill., aperture 11.00 mill., foot $\% .00$ mill.; the shell and animal are in life almost transparent, the organs showing plainly through the shell, especially those of the digestive system. 
JAw: About twice as wide as high, with squarish ends and a heavy convex median swelling. The jaw resembles that of Galba palustris (see pl. VI, fig I).

Radula: (Plate VIII, fig. E) Formula: $\frac{12}{6-8}+\frac{1}{3}+\frac{8}{2}+\frac{1}{1}+\frac{8}{2}+\frac{1}{3}+\frac{12}{6}-\frac{2}{8}$ (21-1-21). Central tooth with a sharp, spade-shaped cusp, the opaque portion of the reflection strongly trilobate; lateral teeth eight in number, bicuspid, the mesocone very broad and modified on the inner side by a strong swelling which probably corresponds in position to an entocone; ectocone small, broad, placed rather high up on the reflection; the seventh and eighth teeth are narrower than those preceding; the ninth tooth is intermediate and is strongly tricuspid, the entocone being very sharp, wide, and placed rather high upon the inner side of the tooth; marginal teeth beginning abruptly with the tenth tooth and six to eight cuspid, acquired by splitting of the ectocone being high up on the outer margin of the tooth; the mesocone persists throughout the marginal teeth as a rather large cusp, while the entocone splits up into several small denticles. The first lateral on one side in one membrane had a double cuspid ectocone. There are about 80 rows of teeth.

The radula of haldemani differs widely from that of any other known species of this family and is approached only by Lymncea haz'aiensis Pilsbry, as mentioned on a previous page.

Genitalia: (pl. XI, fig. F) Male organs; penis-sac cylindrical, 2.25 to 2.60 mill. long and about .90 mill. wide; penis short, thick, 1.50 to 2.00 mill. long ( $4 / 6$ to $4 / 7$ the length of penis-sac); vas deferens 6.00 to 6.50 mill. in length; prostate duct 2.80 to 2.90 mill. long, entering the prostate by a slight enlargement; prostate flatly cylindrical, 1.60 by .60 mill., its ends broadly rounded, the posterior portion very narrow; penis and penis-sac retractors equal in length (each 1.65 in alcoholic specimen and 3.00 in fresh specimen), attached distally to the columellar muscle; protractors of penis-sac three to four in number, two posterior and one small or two large anterior; each muscle is very slender and enters the penis-sac by several terminations.

Female organs; receptaculum seminis large, rounded, with a duct three mill. long, which enters the oviduct by an enlargement; first accessory albuminiparous gland large, ovate; second accessory albuminiparous gland very small; free portion of oviduct large, short; the other organs not differing from those of the other Lymnæidæ.

The penis-sac retractor muscles exhibit some variation in their insertion in the penis-sac (pl. XV, fig. E). In two examples (pl. XI, $\mathrm{F}$; pl. XV, E, 2) the muscle is split to form four rather widely sepa- 
rated insertions, while in the balance of the specimens examined ( $\mathrm{pl}$. $\mathrm{XV}$, fig. E, 1, 3) there is a single band of tissue with two small insertions. In several cases the retractors of penis and penis-sac were joined and formed one band of muscle as it entered the columella muscle. The measurements of the genitalia may be tabulated as follows:

$\begin{array}{cccccccl}\text { Penis. } & \begin{array}{c}\text { Penis- } \\ \text { sac. }\end{array} & \text { Vas. def. } & \begin{array}{c}\text { Prostate Rec. sem. Penis-sac } \\ \text { duct. }\end{array} & \begin{array}{c}\text { Penis } \\ \text { duct. }\end{array} & \text { retractor. retractor. } & \text { Shell. } \\ 2.00 & 2.25 & 6.00 & 2.80 & 3.00 & 1.60 & 1.65 & 24.50 \\ 1.50^{1} & 2.60 & 6.50 & 2.90 & 3.00 & 3.00 & 3.00 & 26.00 \\ 1.60 & 2.25 & 6.50 & 2.90 & 3.00 & 1.75 & 1.75 & 23.50 \\ 1.50^{1} & 2.50 & 6.00 & 2.80 & 3.00 & 2.00 & 2.00 & 26.00\end{array}$

The genitalia of Acella haldemani differ from those of the other Lymnæidæ in the long, flatly. cylindrical prostate.

RANGE: (Figure 15) Vermont and eastern Ontario west to northern Minnesota, south to northern Illinois and northern Ohio.

The range of haldemani lies on the confines of the Canadian and the upper Mississippian regions, and does not extend for any great distance into either. It is confined to the drainage of the St. Lawrence-Great Lakes and the upper part of the Mississippi River. With the exception of the Minnesota records, the distribution lies within the drainage area of the Great Lakes. It is characteristic of the transition life zone. The records indicate that the species did not take advantage of the Lake Agassiz connection with the Minnesota River; it is possible that it is a new type developed since the Glacial Period. Information is needed concerning the range of this species in northern Michigan, Wisconsin and Minnesota and in Canada.

\section{RECORDS.}

UNITED STATES.

Illinors: Cedar Lake, Lake Co. (State Laboratory).

Mrchigan: Lakes near Grand Rapids and lakes in Grattan, Kent Co. (Currier); Grand Rapids (J. A. McNeil); Reeds Lake, Kent Co. (Kirtland; Walker); Kent and Eaton Counties (Walker).

Minnesota: Vermilion Lake, Dakota Co. (Grant); Pelican Lake, Crow Wing Co. (Nason); Belle Lake and Heath Lake, Wright Co. (Sargent).

New York: Buffalo, Erie Co. (Buffalo Soc. N. H.) ; Strawberry Island, Buffalo (Letson) ; Squaw Island, Niagara River, Erie Co. (Lewis); Mohawk, Herkimer Co. (Lewis); Little Lakes, Otsego Co. (Lewis; Lea); Schuyler's Lake, Otsego Co. (Am. Mus. N. H.; Lewis; Binney's fig. 113) ; Lake Canadarago, Otsego Co., previous to 1870 (Smith).

Oнго: Congress Lake, between Portage and Stark Counties (Bland; Newberry; Sterki); Sandusky Bay, Erie Co. (Sterki; Walker).

1These were fresh specimens, the balance were alcoholic. Dissections
No. 23908 . 
Vermont: Lake Champlain (Am. Mus. N. H.; Dall; Ingalls; Lea; Call; Emmons; Jay).

Wisconsin: Milwaukee, Milwaukee Co. (Lapham).

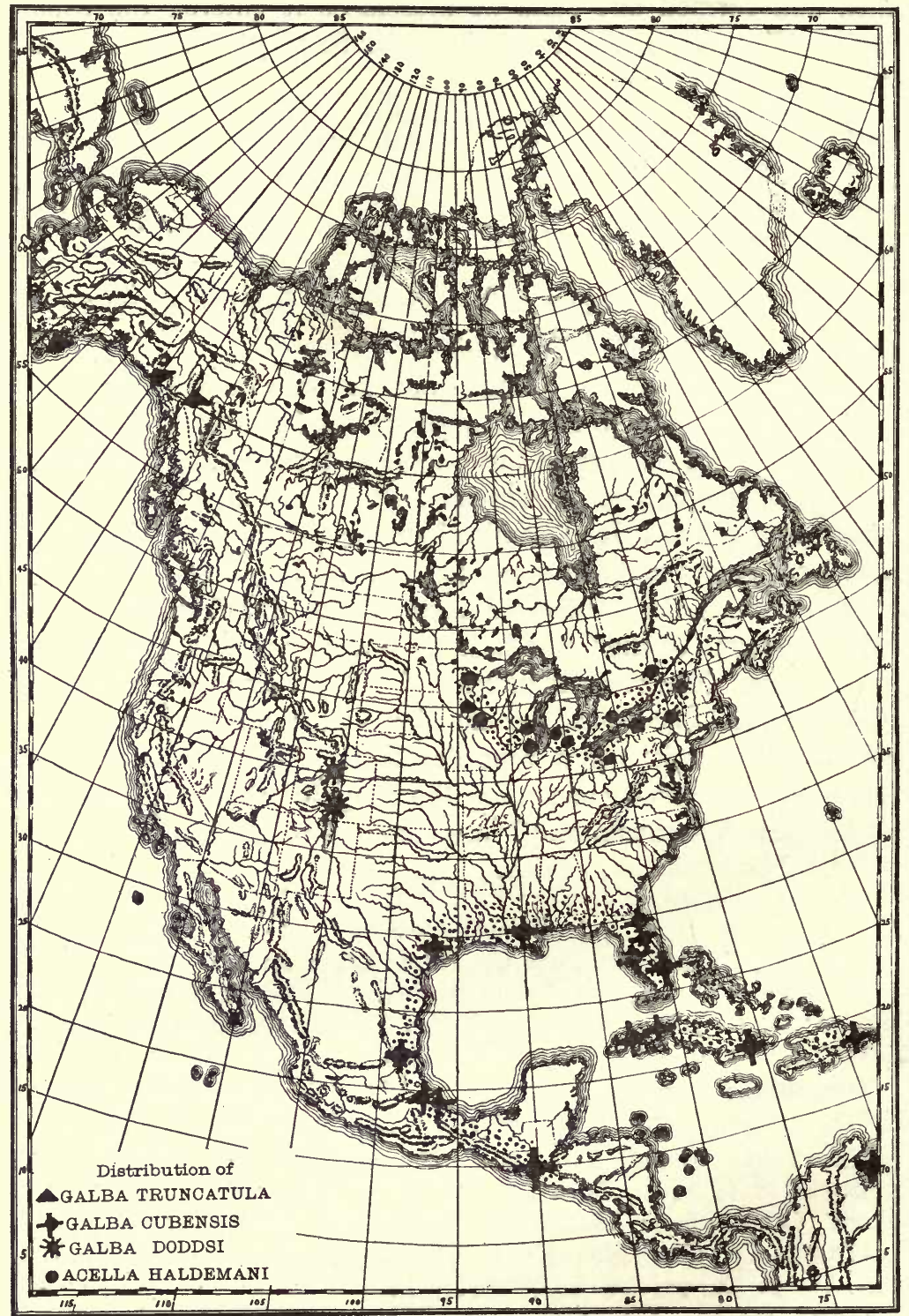

FIG. 15. 
BRITISH AMERICA.

\section{(Walton). \\ Geological Distribution: Unknown.}

Ontario: Ottawa, Carleton Dist. (Heron); Hamilton, Wentworth Dist.

Ecology: But few collectors have studied the habitat relations of this beautiful species and the writer takes great pleasure in quoting the following account by Dr. Reynold J. Kirkland, of Grand Rapids, Michigan:

"On Thanksgiving Day, 189\%, a collecting trip to Reed's Lake was made. The day was bright, cold and windless; the surface of the water covered with a thin sheet of ice, not thick enough to greatly interfere with wading. My quest was particularly for Pisidia. On clearing my scoop, while standing in about two feet of water, I was greatly surprised to find two examples of $L$. gracilis amongst the little bivalves at the bottom. They had evidently been dislodged from the rushes and had fallen into the scoop as it was being brought to the surface. Further search for Pisidia was abandoned, and the following several hours were spent in sweeping the rushes with my scoop. The result was over eighty specimens of this exquisite mollusk, a fine sauce for the cold turkey that awaited my return home at dark.

"Each fall save one since then, from one to a dozen trips have been made to this spot, with varying success. One year four trips yielded but five individuals; while a single visit another year resulted in a bag of nearly two hundred.

"This is a deep water species, which migrates shoreward in the fall, doubtless for spawning purposes, as adults only have been captured, but this should be verified by dissection. September 25th is the earliest date they have been taken, and they remain until ice forms, how much longer is not known. They are gregarious, or at least live in colonies. This colony has occupied an area of not more than a few square rods any one year; and the location of this area has not varied a hundred feet in either direction during the ten years of its observation. Rushes grow along about two miles of the shore line of this lake. Systematic examination of perhaps a half mile of this distance has failed to disclose another colony. The home of this mollusk is on the rushes or reeds common to all our inland waters; in water from one to three feet deep; and invariably from six to eight inches from the bottom, on the side of the reed facing deep water, the apex of the shell pointing downwards,-though in a few instances the apex has been upwards, as if in the act of descending. Incidentally, it may be remarked that Ancylus fuscus is abundant on these same 
reeds, but never more than four inches from the base, while $A$. parallclus, though rather scare, is found from ten to eighteen inches above base.

"Unlike other Lymnæas, gracilis attaches itself very firmly to its resting place. Unless a gentle, sliding movement is made in removing it, the delicate lip is apt to become broken in the operation. If traction is made along the long axis of the shell, the empty shell will be found between thumb and finger, the animal clinging to the reed having suffered a rupture of its attaching muscle to occur rather than relax its hold" (Kirkland).

"After finding dead specimens of this beautiful species in Belle Lake, I was told by Prof. Hubbard that he took it alive in Heath Lake in the previous fall, upon the under side of lily leaves. Later a thorough search was made for them in the same locality, but only two dead specimens were found. Query,-where do they keep themselves in summer?" (Sargent, Minnesota habitat.)

In captivity the animal moves about slowly in the aquarium and will also rest for hours with half its shell out of the water, the animal being attached to the glass side of the aquarium.

Remarks: Haldcmani is the slenderest of our Lymnæas, its height beng five times its breadth. It is also very thin and fragile. It cannot be mistaken for any other species, its graceful, oblique whorls and slender form at once distinguishing it. From the reports of those who have collected this species it would seem to inhabit the deeper water generally, coming toward the shore at different seasons. It is very common in some localities and rather rare in others. The Lake Champlain specimens average rather smaller than the western forms.

The very appropriate name of gracilis is preoccupied by Ziethen, and in 1867 Binney used the name haldemani, as suggested by Deshayes.

\section{Genus PLEUROLIMNÆA Meek, 1866.}

1866. Pleurolimnaa Mesk, Check List N. Amer. Fos. Eocene, pp. 9, 34 (type, Limnaa tenuicostata Meek and Hayden, Eocene).

1870. Pleurolimnca Dall, Ann. Lyc. Nat. Hist. N. Y., IX, p. 349.

1876. Pleurolimnaa Meek, Rep. U. S. Geol. Surv. Terr., IX, p. 533.

1883. Pleurolimnaa Fischer, Man. Conch., p. 506.

1884. Pleurolimnaca Tryon, S. and S. Conchology, III, p. 101.

1905. Pleurolimnaa Dall, Alaska Mollusks, p. 64.

1908. Pleurolimnca BAKer, Science, N. S., XXVII, p. 943.

RANGE: Eocene period.

Shell: "Differing from the last (Acella) in having small, regular surface-costæ parallel with the lines of growth, the aperture narrowed or subangular, instead of rounded anteriorly" (Meek). 
The writer has followed the suggestion made by Meek in 18\%6, that this group should be raised to full generic rank. The strong axial ribs, which are equidistant, are very distinctive. It is not particularly related to Acella, although the shape of the shell has led several authors to place it in close relationship with the slender Acella haldemani. The nuclear and first post-nuclear whorls of haldemani are very different, as is also the general shape of the body whorl.

The only species of the genus (which is extinct) is described in the chapter on fossil Lymnæas, page 91.

\section{Genus GALBA Schrank, 1803.}

Galba Schrank, Fauna Boica, III, pt. 2, pp. 262, 285. Sole example Buccinum truncatulum Müller (vide Dall).

Shell: Turreted or elongated, whorls gradually increasing in size, the last whorl generally of moderate size; spire usually long and pointed; outer lip typically not expanded, usually a thick rib being developed just within the edge in the adult; $;^{1}$ axis not gyrate, forming an almost straight pillar from spire to umbilicus; the columella is strongly plicate in one group but entirely smooth typically; axis with perforation or imperforate; the inner lip frequently forms a heavy spreading callus.

Animal: Not differing essentially externally from the other Lymnæas.

JAw: Superior jaw wide and low, arched, with a median swelling on the ventral surface. Lateral jaws very long.

RADULA: Lateral teeth bi-or tricuspid.

Genitalia: Penis always shorter than penis-sac; prostate longovate or elongate-pyriform, very large, its duct generally short.

Distribution: Holarctic and Palearctic.

A close study of the groups Galba and Stagnicola has convinced the writer that they both represent the same type of Lymnaa. The pillar is nearly straight in both groups (the difference of the axis not heing of generic value) and old individuals of both groups form a varical thickening within the outer lip. ${ }^{2}$ The genitalia are also of the same type. The characters mentioned are quite different from those of any of the preceding groups and at once differentiate this type of Lymnæid from Lymnea, Radix, Acella and Bulimnea.

The genus naturally splits into three (possibly four) groups, Galba sensu stricto, with usually a smooth shell, a non-plicate colum-

${ }^{1}$ Stagnicola. In Galba and Simpsonia it is not usually developed to so great a degree.

${ }^{2}$ This has been seen in obrussa, parva and modicella and may be observed in some individuals of any large series. 
ella and bicuspid lateral teeth; Simpsonia, with tricuspid lateral teeth; and Stagnicola, with a strong spirally lined shell, a plicate columella and a characteristic radula and genitalia.

The name Galba was given by Schrank to a species of Lymnaa which has been referred to both the Buccinum truncatulum and the Buccinum palustre of Müller. Dr. Dall is probably right in selecting truncatulum as the type, the description of both shell and animal agreeing very closely with truncatula. The name Stagnicola would be preferable for the genus name were it not that Galba has priority and must be retained for the genus; Stagnicola, however, may be used as a subgenus for the large shells with impressed spiral lines and plicate columella.

The name Limnophysa has been almost universally used for the large, palustris-like Lymnæas, but this is an absolute synonym of Stagnicola, which was published three years earlier. Leptolimnea may be retained for those shells with a cylindrical shell, numerous whorls, and a small aperture. The anatomy of this group is unknown.

Galba includes the large majority of the species of our Lymnæids. The shells are generally long and graceful, and some one of the species is invariably a characteristic member of the fauna of almost any locality in North America. They occur in almost countless thousands in some localities.

\section{Subgenus GALBA Schrank, 1803.}

1803. Galba Schrank, Fauna Boica, III, pt. 2, pp. 262, 285. (Sole example Buccinum truncatulum Müller, vide Dall).

1865. Limnophysa Binney (part), L. and F. W. Sh. N. A., II, p. 38.

1870. Limnophysa Dall (part), Ann. N. Y. Lyc. N. H., IX, p. 349.

1870. Limnophysa Cooper (part), Proc. Cal. Acad., Ser. i, IV, p. 96.

1872. Limnophysa Tryon (part), Con. Hald. Mon., p. 87 (61).

1872. Limnaa Tryon (part), Con. Hald. Mon., p. 87 (61).

1876. Limnophysa MeEK (part), Rep. U. S. Geol. Surv. Terr., IX, p. 533.

1884. Limnophysa Tryon (part), S. and S. Conch., III, p. 101.

1885. Fossaria Westerlund, Fauna Pal. Reg., V, p. 49. (L. truncatula Müller).

1902. Fossaria Westerlund, Acta Soc. Sci. Slav. Merid., CLI, p. 118.

1905. Galba Dall, Alaska Mollusks, p. 64.

1908. Galba BAKer, Science, N. S., XXVII, p. 943.

SHELL: Generally small, turreted, surface usually without spiral lines; axis not twisted, forming a series of smooth, almost round pillars from apex to umbilicus; columella without a plait; inner lip usually forming a wide, smooth, spreading callus, which is turned back against the parietal wall; umbilicus a small chink or roundly open; outer lip thin, sharp, rarely forming, when adult, an internal rib just within the edge (pl. XVIII, fig. 2). 


\section{Radula: With bicuspid lateral teeth (pl. VI, fig. N).}

Genitalia: Penis shorter than penis-sac; prostate short, elongate-ovate, its proximal portion rather roundly pointed as it joins the duct; receptaculum seminis generally ovate, rarely round; the first accessory albuminiparous gland is ovate and is placed lower down on the oviduct than in Stagnicola (pl. XI, fig. A).

This subgenus contains the smaller Lymnæas which have a shell without strong spiral sculpture. They exhibit terrestrial habits to a much larger extent than do any of the other groups of Lymnæas, being found usually on wet banks or bars of mud, quite out of the water. 'The formation of the inner lip is quite peculiar and will at once distinguish these small species from their larger relatives. The subgenus is widely distributed, being found from the West Indies and southern Mexico to the Arctic regions. Its maximum development is reached in the southwestern portion of the United States.

Galba truncatula (Müller). Plate XXVII, figures 1-4.

Buccinum truncatulum MüLLER, Verm. Terr. et Fluv., II, p. 130 , 1774.BAKER, Science, N. S., XXVII, p. 943, 1908.

Limneus minutus Draparnaud, Tableau, p. 51, 1801; Hist., p. 53, pl. 3, figs. 5, 6, 1805 .

Limnea truncatulus Haldeman, Bos. Journ. N. H., IV, p. 468, 1844.

Limnca truncatula WoodWard, P. Z. S., 1856, p. 185; Manual, p. 399, 1856.-Carpenter, Rep. Brit. Ass., 1856, p. 222.-Gray, Ann. Nat. Hist., XIX, p. 408, 1857.-Mовсн, Amer. Journ. Sci., IV, p. 33, 1868.-Gibвons, Journ. Conch., II, p. 129, 1879.-Clessin, Mal. Blatt., N. S., I, p. 20, 1879; Mal. Blatt., N. S., III, p. 77, 1881.-JoRDAN, Nova Acta Ksl. Leop. Carol.-Deutschen Akad. Natur., XLV, p. $367,1883$.

Lymnca (Galba) truncatula Dall, Land and Fr. W. Moll., p. 72, fig. 49, 1905 (part).

Limnca humilis Dall, Proc. Nat. Mus., VII, p. 343, 1884; Rep. Seal. Inves., III, p. 544, $1899{ }^{1}$

Shell: Small, turreted, ovate-conic or oblong-conic, rather solid; periostracum light yellowish-horn, sometimes darker; surface shining, lines of growth close-set, conspicuous; spiral striation absent or only very slightly developed; nuclear whorls $1 \mathrm{x} / 4$ in number, light horn colored; in outline the first whorl is very small, while the second is very large, flattened, wide, and convex; the sculpture is minutely substriate under a very high power but appears of a satin finish character under a low power (pl. XLIX, fig. D); whorls 5-6, convex, roundly inflated, roundly shouldered above, gradually increasing in diameter; body whorl occupying about half the length of the shell, somewhat ventricose; spire conic, turreted, more or less acute; sutures

${ }^{1}$ Only a few references, chiefly from American sources, are included above. European citations would occupy several pages. 
strongly impressed; aperture ovate or roundly-ovate, generally evenly rounded at the lower extremity and somewhat angled above; outer lip thin, sharp; inner lip reflected to form a rather broad, flat, excavated projection over the umbilicus, there being a moderately open chink; parietal callus very thin; the inner lip is rolled over and appressed rather closely to the columellar region; axis forming a series of smooth, hour-glass-shaped pillars.

\begin{tabular}{|c|c|c|c|c|c|c|}
\hline Length. & Breadth. & Aperture length. & Brea & & & \\
\hline 10.50 & 5.00 & 5.00 & 2.50 & mill. & European & spec. \\
\hline 11.50 & 6.00 & 5.75 & 3.00 & “ & " & “ \\
\hline 7.50 & 4.25 & 3.50 & 2.00 & “ & " & “" \\
\hline 7.50 & 4.00 & 3.50 & 1.75 & “ & “ & " \\
\hline 6.00 & 3.50 & 3.00 & 1.50 & “ & “ & “ \\
\hline 7.00 & 4.50 & 3.50 & 2.00 & “ & “ & “ \\
\hline
\end{tabular}

Types: Location not ascertained.

Type Locality: Not known.

Animal: Not examined.

Jaw, Radula and Genitalia: Not examined.

RANGE: (Figure 15) Europe, northern Asia and portions of Alaska and Yukon Territory.

The presence of true truncatula in America, except in portions of Alaska, Yukon and the Aleutian Islands, is seriously to be questioned. The majority of the specimens examined have been referable to Galba paria Lea. Further investigation, however, may discover it in other portions of northwestern North America.

\section{RECORDS.}

Alaska: Ponds near Yukutat Bay (Kincaid); Ladyginsk, Behring Island (Stejneger); Kadiak (Jeffreys).

Yukon, BRITish America: Lake Marsh (Ranidolph).

Geological Range: Pleistocene. There are no American records.

Ecology: Inhabits marshes, ditches, muddy streams, etc.

REMARKS: Truncatula may be distinguished by its turreted whorls rather narrow shell and ovate aperture. It resembles humilis and parva, but these species are quite distinct, having a differently shaped spire and inner lip.

It is closely allied to cubensis, having somewhat the same form of inner lip, but may be distinguished by its narrower shell, more attenuate spire and less rotund body whorl. The inner lip is not as roundly folded in truncatula as in cubensis, being rather a little excavated in the middle; the umbilical chink is also smaller in truncatula. 
Clessin (op. cit.) discusses the group of Lymnea truncatula, placing humilis, desidiosa (=obrussa) curta, cubensis, galbana, etc., in it. $\mathrm{He}$ also places solida, pallida and traski in the same group, clearly showing that he did not understand these species.

The Liver-fluke (Fasciola hepatica) has been found parasitic on Lymncea truncatula (Journ. Conch., III, p. 329, 1882).

Galba doddsi Sp. Nov. Plate XXVII, figures 5-8.

Limnca truncatula Cockerell, Journ. Conch., VI, p. 63, 1889; Nautilus, III, p. 9, 1889 (part).

Limnca humilis Henderson, Univ. Col. Studies, IV, p. 179, 1907 (part).

SHell: Elongated, turreted; color brownish horn; surface with very heavy growth lines, giving the shell a rough aspect; whorls $5 \mathrm{~T} / 2$, plano-convex, the body whorl slightly ventricose; spire turreted, a trifle longer than the aperture; sutures impressed; aperture ovate or roundly ovate; inner lip reflexed to form a projecting shelf, which is not tightly appressed to the parietal wall, but is erect and emargines the umbilical chink, which is large and conspicuous.

$\begin{array}{cccccc}\text { Length. } & \text { Breadth. Aperture length. } & \text { Breadth. } \\ 9.00 & 4.50 & 4.25 & 2.50 \text { mill. } & \text { Type. } \\ 8.00 & 4.00 & 3.75 & 2.25 & \text { " } & \text { " } \\ 6.50 & 3.75 & 3.00 & 2.00 & \text { “ } & \text { " } \\ 6.50 & 3.50 & 3.00 & 2.00 \text { " } & \text { " }\end{array}$

Types: The Chicago Academy of Sciences, four specimens. No. $2393 \%$.

Type Locality: Hot Sulphur Springs, Colorado.

JAW: Not differing materially from that of cubensis.

RAdula: (Pl. VI, fig. N). Formula: $\frac{17}{5}-6+\frac{2}{4}+\frac{2}{3}+\frac{4}{2}+\frac{1}{1}+\frac{4}{2}+\frac{2}{3}+\frac{2}{4}+\frac{17}{5}-6$ (25-1-25); central tooth with long, spade-shaped cusp; lateral teeth bicuspid, the mesocone very large, pointed, the ectocone smaller, prominent, placed rather high up on the reflection; there are two sets of intermediate teeth; the fifth and sixth teeth are tricuspid, the entocone arising on the lower part of the mesocone and being rather small; the seventh and eighth teeth have the mesocone almost subequal, the ectocone splitting into two teeth which become smaller; the marginal teeth begin on the ninth tooth, the entocone splitting into two or three small cusps. There are over seventy rows of teeth. The radula of $d o d d s i$ is very uniform, exhibiting little or no variation among the individual teeth. In one ribbon 26-1-26 were counted.

Genitalia: Resembling closely those of Galba cubensis.

Male organs: The penis-sac is twice the length of the penis, which is short and rather thick; the vas deferens is six times the length of the penis; the prostate is large, oblong-ovate, contracted at the proxi- 
mal (anterior) end, where it narrows to receive the duct, which is 1.50 mill. in length; the retractors of the penis and penis-sac are subequal, each being 1.00 mill. in length; they are very slender.

Female organs: Receptaculum seminis very large, roundly pyriform, the duct 2.00 mill. long; free portion of oviduct short, very thick; first accessory albuminiparous gland very large, ovate.

A large specimen gave the following measurements:1

\begin{tabular}{|c|c|c|c|c|c|c|c|}
\hline Pen & $\begin{array}{l}\text { Penis- } \\
\text { sac. } \\
2.00\end{array}$ & $\begin{array}{c}\text { Vas. def. } \\
6.00\end{array}$ & $\begin{array}{c}\text { Prostate } \\
\text { duct. } \\
1.50\end{array}$ & $\begin{array}{l}\text { Rec. sem. } \\
\text { duct. } \\
2.00\end{array}$ & $\begin{array}{c}\text { Penis } \\
\text { retractor. } \\
1.00\end{array}$ & $\begin{array}{c}\text { Penis-sac } \\
\text { retractor. } \\
1.00\end{array}$ & \\
\hline
\end{tabular}

Range: (Figure 15) South-central Colorado. So far as known this species is confined to the Canadian life zone and the Coloradoan and Upper Mississippian regions. It will probably be found in other parts of Colorado.

\section{RECORDS.}

Colorado: West Cliff, Custer Co. (Cockerell); Hot Sulphur Springs, Grand Co. (G. S. Dodds; Henderson).

Geological Range: Unknown.

ECOLOGY: Not recorded.

Remarks: Doddsi may be distinguished from truncatula by its generally less rounded whorls and aperture, and particularly by the formation of the inner lip, which is raised and overhangs the umbilical chink forming a broad, even expansion. In truncatula the inner lip rolls over into the umbilical chink nearly closing the perforation while in doddsi it is rolled upward leaving a distinct umbilical chink.

This is the shell recorded by Prof. Cockerell as truncatula and hy Mr. Henderson as humilis. It bears a strong resemblance, when young, to juvenile specimens of Galba cubensis aspirans, but its smaller size, more turreted spire and rounder aperture will easily distinguish it. There is some variation in the amount of compression of the inner lip. It may be distinguished from parva by its narrower body whorl and wider columellar expansion, which is not as erect as in parva.

It is named in honor of Mr. G. S. Dodds, who collected the type specimens.

Galba cubensis (Pfeiffer). Plate XXVII, figures 9-16.

Limnaa cubensis PFeiffer, in Wiegm. Arch., I, p. 354, 1839.-Hjal. and Pfr., Mal. Blatt., V, p. 135, 1858.-Pfeiffer, Mal. Blatt., V, p. 154, 1858.Arango, in Poey, Rep. Fisico.-Nat. Cuba, I, p. 137, 1865.-Presas, in Poey, Rep. Fisico.-Nat. Cuba, I, p. 264, 1865.-Poey, Rep. Fisico.-Nat. Cuba, II, p. 270, 1866.-Arango, in Poey, Rep. Fisico.-Nat. Cuba, II, p. 87, 1866.Sowerby, Conch. Icon., XVIII, Limn. sp., 48, pl. 8, fig. 48, a, b, 1872 (figures not good).-Strebel, Natur. Ver., Hamburg, VI, p. 58, taf. 4, fig. 33, 1873.Martens, Jahrb. IV, p. 353, 1877.-Clesssin, Mal. Blatt., N. S., I, p. 27, 1879.-

${ }^{1}$ Dissection No. 23939. 
Gibbons, Journ. Conch., II, p. 129, 1879.-CR. and Fisch., Moll. Mex., II, pp. 47, 50, pl. 27, figs. 12, 12a, 1880.-Clessin, Mal. Blatt., N. S., III, p. 83, 1881.Crosse, Journ. de Conch., XXXVIII, p. 260,1890.-Pilsbry, Proc. Phil. Acad., 1891, p. 320.-Crosse, Journ. de Conch., XXXIX, p. 157, 1891; XL, p. 35, 1892.Simpson, Proc. Nat. Mus., XVII, pp. 438, 444, 1894.-Rhoads, Nautilus, XIII, p. 47, 1899.-Martens, Biol. Cent. Amer. Moll., p. 378, 1898.-Dall and Simpson, Bull. U. S. Fish Com., XX, pt. 1, 369, 1900.-Fisch. and Crosse, Mis. Scient. Mex. Moll., I, taf. 27, figs. 32, 32a; II, p. 50, 1880.

Lymneus cubensis Shuttleworth, Mitt. Natur. Ges., Bern, I, 1854, p. 98.

Limnaus cubensis Küster, Conch. Cab., p. 32, taf. 6, figs. 6, 7, 8, 1862.

Lymnea cubensis Tryon, Amer. Journ. Conch., II, p. 11, 1866.

Lymnca cubensis Hinkley, Nautilus, XXI, p. 78, 1907.-WALKER, Nautilus, XXII, pp. 7, 8, pl. II, fig. 3, 1908; Ottawa Nat., XXII, pp. 89, 90, 1908.

Limnaa humilis Simpson, Proc. Dav. Acad. Sci., V, p. 69, 1896.-Johnson, Nautilus; III, p. 139, 1890.

?Limnaa umbilicata, C. B. Adams, Proc. Bost. Soc. Nat. Hist., II, p. 134, 1846 ; Contributions to Conchology, p. 45, 1849 ; Ann. N. Y. Lyc. N. H., V, p. 111, 1852 ; Contr. to Conch., No. 9, p. 187, 1852.

Limnea umbilicata Henderson (on Adams), Nautilus, VIII, p. 33, 1894.

?Limnea umbilicata CRANdall, Nautilus, VI, p. 103, 1893.

Lymncea lecontii LeA, Proc. Phil. Acad., 1864, p. 113; Journ. Phil. Acad., VI, p. 162, pl. 24, fig. 79, 1866 ; Obs., XI, p. 118, pl. 24, fig. 79, 1867.-Scudder, Buill. Nat. Mus., 23, pp. 148, 201, 1885.

Limnophysa lecontii Tryon, Amer. Journ. Conch., I, p. 255, 1865.

Limnca lecontii Tryon, Con. Hald., Mon., p. 105 (79), pl. 18, fig. 4, 1872.

SHell: Small, ovate to roundly ovate; periostracum light horn, varying to pearl gray in some specimens; surface with close-set, rather rough and irregular lines of growth; spiral lines very faint; nuclear whorls similar in outline to those of truncatula; under a power of 100 diameters the apical whorls appear finely striate; whorls $5 \frac{1}{2}-6$, well rounded, rapidly increasing in size; the whorls are usually inclined to be shouldered; spire of medium length, broadly pyramidal or acute, about as long as the aperture; sutures well impressed; aperture roundly cvate, somewhat angled above; periostome thin, acute; inner lip folded backward and forming a broad, flat, somewhat triangular expansion, leaving a well marked umbilical chink; there is a very thin wash of callus on the parietal wall; the axis is not twisted but forms a large, wide, smooth, hour-glass-shaped column.

\begin{tabular}{rccccc} 
Length. & Breadth. Aperture length. & Width. & \multicolumn{2}{c}{ Locality. } \\
9.00 & 5.00 & 5.00 & 3.00 & mill. & Havana, Cuba \\
8.00 & 5.50 & 4.50 & 3.00 & “ & “ \\
7.00 & 4.50 & 4.00 & 2.30 & “ & “ \\
11.25 & 7.25 & 6.25 & 3.25 & " & Cuba \\
7.50 & 5.00 & 4.00 & 2.50 & " & Mexico \\
10.50 & 6.00 & 5.50 & 3.00 & " & " \\
7.50 & 4.50 & 4.00 & 2.50 & " lecontii
\end{tabular}


Types: Cubcnsis, location not ascertained; lecontii, Smithsonian institution one specimen, No. 121503. Specimen figured by Tryon in Con. Hald.

Type Locality: Cubensis, Cuba; lecontii, Georgia.

ANimal: Not examined.

JAW : (P1. VI, fig. G) Wide and low, with acutely rounded ends and a narrow median swelling on the ventral border.

Radula: (Plate VII, fig. F), Formula: $: \frac{14}{4}+\frac{3}{3}+\frac{6}{2}+\frac{1}{1}+\frac{6}{2}+\frac{3}{3}+\frac{1}{4}+$ (22-1-22) ; central tooth with a long, acute cusp; lateral teeth bicuspid, the mesocone very large, the ectocone much smaller; the first marginals (intermediate teeth) become tricuspid (seventh tooth) by the appearance of a rather large entocone about midway of the inner border of the mesocone; the eighth tooth has the entocone placed nearer the distal end of the mesocone, while in the ninth tooth it is placed higher up, but is much larger; at the tenth tooth the true marginals begin, the cusps becoming simple serrations. About ninety rows of teeth were counted. In one membrane the first tricuspid intermediate appeared at the seventh tooth on the left side and at the eighth tooth on the right side. The radula is similar to that of doddsi, the principal difference being that the intermediate teeth begin at the seventh instead of the fifth tooth.

Genitalia: (P1. XI, fig. A) Male organs: Penis-sac from 1.00 to 1.50 mill. long; penis slender, 0.75 to 1.00 mill. long, or about $2 / 3$ to $3 / 4$ the length of the penis-sac; vas deferens 2.50 to 3.00 mill. long; vas deferens to prostate 1.00 mill. long; prostate long-ovate, flattened, rounded at the extremities, narrowed at the proximal end where it joins the prostate duct; retractor of penis 0.75 mill. long and penissac retractor about the same length, the insertion being close together in the columella muscle; protractor muscles eight in number, three posterior and five anterior; the retractor muscles are large and powerful.

Female organs: Receptaculum seminis elongate pear-shaped, the duct 2 mill. in length; first accessory albuminiparous gland somewhat pcar-shaped; the receptaculum seminis is a delicate salmon color.

The genital organs of cubensis are quite uniform. They resemble those of modicella more than any other species. Four specimens gave the following measurements (dissection Nos. 23320, 23321) :

\begin{tabular}{cccccccr} 
& & \multicolumn{3}{c}{ Pros. } & \multicolumn{3}{c}{ Penis-sac. } \\
Penis. & Penis-sac. Vas. def. & duct. & Rec. sem. & Penis ret. & ret. & Shell. \\
0.75 & 1.00 & 2.50 & 1.00 & 2.00 & 0.75 & 0.75 & 7.50 \\
0.75 & 1.00 & 2.50 & 1.00 & 2.00 & 0.75 & 0.75 & 6.50 \\
1.00 & 1.50 & 2.50 & 1.00 & 2.00 & 0.75 & 0.75 & 7.00 \\
1.00 & 1.50 & 3.00 & 1.00 & 2.00 & 0.75 & 0.75 & 7.50
\end{tabular}


RANGE: (Figure 15) Southern United States, from southern Texas to Florida; south to Mexico, Guatemala and northern Venezuela; east throughout the West Indies to St. Croix; and west to southern Lower California.

Cubensis is typically a tropical species, which, judging by the records, has extended its range northward into the Austroriparian division of the Lower Austral life zone. It is typical of the Central American and West Indian regions. The records are rather widely separated and several of them have not been substantiated by the study of authentic material. The California records which have been examined have proven to be techella. Further records are needed to accurately establish the range of this species. It is quite probable that cubensis has hitherto been confounded with techella.

\section{RECORDS.}

UNITED STATES.

Florida: Anastasia Island, St. Johns Co. (Johnson); Head of Miami River, Dade Co. (Rhoods); Terraceia Island; ponds south of Manatee River, Manatee Co.; near Tampa, Hillsboro Co. (Simpson); Enterprise, Volusia Co. (Walker).

Georgia: Georgia (Lea; LeConte), exact locality not stated.

Louisiana: New Orleans, Orleans Co. (Pilsbry).

Texas: Garcitas Creek, Victoria Co. (J. D. Mitchell).

CENTRAL AMERICA.

Guatemala: Antigua, Sacatepequez Dept., in rivulets (Morelet).

MEXICO.

State of Vera Cruz: Orizaba (Baker and Heilprin); City of Vera Cruz, in ditches near the railway; Rio Tenoya, Vera Cruz (Strebel); El Abra and Valles, San Luis Potosi (Hinkley).

Lower California: Sanzal, Todos Santos Bay (Orcutt).

WEST INDIES.

CubA: Havana, Havana Province (Arango; Baker); Marianceo and Caramelo, Havana (Rhoads) ; Santiago, Santiago Province (J. H. Redfield); Punta de la Jaula, Pinar del Rio Province (C. Wright); Cuba (Pfeiffer); Cape San Antonio, Pinar del Rio Province (Poey) ; River Nivaja, near Santiago (Hjohnarson and Pfr.); all the rivers and lakes of the island (Arango).

Jamaica : (Stearns; Adams; Simpson).

Porto Rico: (Blanner; Chamberlain; Simpson); numerous localities (Crosse).

St. Croix: (Phil. Acad.; S. G. Marton; Simpson.)

Santo Domingo: (Phil. Acad.)

SOUTH AMERICA.

Venezuela: Caracas, Miranda District (Gollmer, in Mus. Berol, vide Biol. Cent. Am.).

Geological RANGe: Not recorded.

ECology: In rivulets and small streams. Found in cow tracks 
on the outer edge of Pujal Lake and under a thorny bush near Valles, Mexico (Hinkley). No other records of the ecological relations of this species have been seen by the writer.

Remarks: Cubensis is the most common Lymnæid in Mexico, Cuba and certain of the West Indies. It varies somewhat in corpulency and in the height and acuteness of the spire. It is easily known by its generally rotund shell, rather short broad spire, large rounded aperture, rounded, somewhat turban-shaped whorls and by its triangular, roundiy folded inner lip. This last character will easily separate it from umbilicata and aspirans. Truncatula rather closely resembles cubensis, but the spire in cubensis is shorter, the whorls are wider and more rotund, the aperture is rounder and the inner lip is differently reflected.

In specimens from Mexico the inner lip may be rolled over into the umbilical chink or rolled upward, somewhat as in the race aspirans. Cuban specimens average somewhat more obese than specimens from Mexico and Florida.

Both Clessin and Gibbons have called attention to the similarity of certain forms of truncatula to cubensis. This similarity is due, undoubtedly, to parallel development. The life zones of the two species are widely separated and there is little fear of confusion in the identity of cubensis. Galba humilis has been mixed with cubensis and may be separated by its more elongated and sharper spire, less rounded whorls and differently shaped inner lip.

It is believed by the writer that the references to Lymnaa umbilicata by Adams, from Jamaica, are founded on specimens of cubensis. See under Galba umbilicata for a discussion of this subject. The single specimen of Lea's lecontii seems referable to cubensis, specimens from Mexico being almost identical with it in form.

Galba cubensis aspirans (Pilsbry). Plate XXVII, figures 1\%-19. Lymncea cubensis aspirans PILsbry, Nautilus, XXIII, p. 120, February, 1910. Lymnaa cubensis Brown, Journ. Conch., X, p. 266, 1903.

Shell: Elongate-ovate or fusiform, solid; periostracum light yellowish to reddish horn; surface shining, growth lines heavy, conspicuous; spiral lines absent, or if present, almost indistinguishable; nuclear whorls similar to those of techella; whorls $5 \mathrm{x} / 2$ to 6 convex, the body whorl ovately ventricose; spire acutely conical, wide, about equal to the aperture in length; sutures well impressed; aperture elongateovate; outer lip simple; inner lip reflexed to form a flat shelf which is narrow and is not compressed at the junction of the columella with the parietal wall; parietal callus thin, white; umbilical chink very large, deep, overhung by the inner lip which emargines it; axis as in cubensis. 


$\begin{array}{ccccc}\text { Length. } & \text { Breadth. Aperture length. Breadth. } & \\ 10.50 & 6.00 & 5.50 & 2.60 & \text { Barbadoes } \\ 11.10 & 5.75 & 5.00 & 2.50 & \text { “ }\end{array}$

Types: Academy of Natural Sciences, Philadelphia, No. 85455.

Type Locality: Barbadoes.

Animal, Jaw and Genitalia: Not examined.

RANGE: West Indies. As this race has been confounded with cubensis it is impossible, without an examination of specimens, to separate the two forms in the records from Cuba. Aspirans probably inhabits a number of the West Indian Islands.

\section{RECORDS.}

Barbadoes: Barbadoes (L. B. Brown ; Walker).

St. Croix : St. Croix (I. I. Brown).

Geological Range: Unknown.

ECOLOGY: Not recorded.

Remarks: Aspirans may at once be distinguished from cubensis by the form of the inner lip which is narrow and stands crect, while in cubensis the inner lip is more triangular and is rolled over toward the umbilical chink. The shell in aspirans is more uniformly ovate as is also the aperture. The shell is also larger than cubensis, the spire is usually longer, the whorls are rounder and the umbilical chink is usually more conspicuous. It has heretofore been called cubensis, but the characters outlined above seem sufficient to distinguish it as a race.

Galba bulimoides (Lea). Plate XXVII, figures 20-29.

Lymnea bulimoides LeA, Proc. Am. Phil. Soc., II, p. 33, 1841; Trans. Amer. Phil. Soc., IX, pp. 9, 12, 1844; Obs., IX., pp. 9, 12, 1848; Journ. Phil. Acad., VI, pp. 162, 163, 1866; Obs., XI, pp. 118, 119, 1867.

Limnea bulimoides HALD., Mon. Lim., p. 44, pl. 13, figs. 9, 10, 1842.-DeKAY, Zool., p. 75, 1843.-INGersoll, Rep. U. S. Geol. \& Geog. Surv. Terr., 1874, p. 406; Bull. U. S. Geol. \& Geog. Surv., I, p. 139, 1875 ; var., Proc. Daven. Acad. Sci., II, p. 132, 1877.*

Limnaa bulimoides Binney, Check List, p. 12, 1860.-CPr., Rep. Brit. Asso., 1864, p. 674 ; Rep. Brit. Asso., 1864, p. 630.-Binney, L. \& F.-W. Sh. N. A., II, p. 61, 1865.-Cooper, Proc. Cal. Acad. Sci., IV, p. 96, 1870.-Tryon, Con. Hald. Mon,, p. 85 (111), 1872 (part).-CPr., Smith. Miscel. Coll., 1872, p. 116.SowB., Conch. Icon., XVIII, sp. 77, pl. 12, fig. 77, a, b, 1872*. (The figures are not good and do not correctly represent the species.)-CPr., Smith. Miscel. Coll., 1872, p. 160.-Chessin, Mal. Blatt., N. S., III, p. 82, 1881.-WALKeR, Nautilus, VI, p. 34, 1892*; Rev. Moll. Mich., p. 18, 1894.*-TAYLoR, Ottawa Nat., VIII, p. 148, 1895*; ?Ottawa Nat., IX, p. 176, 1895*-KeEp, West. Am. Sh., p. 314, 1904 (part).

Limnaus bulimoides Küster, Conch. Cab., p. 49, taf. 11, figs. 5, 6, 7, 8, 1862* (the figures are not typical).-Clessin, Küster, Conch. cab., p. 387, taf. 53, fig. 1, 1886.

*The references with an asterisk probably refer to some one of the forms of techella or cockerelli. 
Limnophysa bulimoides TRYoN, Amer. Journ. Conch., I, p. 256, 1865.Cartton, Proc. Cal. Acad. Sci., IV, p. 57, 1869.-Cooper, Proc. Cal. Acad. Sci., IV, pp. 173, 174, 1872.*-DeCamp, Kent. Sci. Inst., Mis. Pub., No. 5, p. 8, 1881.*Call, Bull. U. S. Geol. Surv., II, p. 372, 1884 (part).-Russell, An. Rep. U. S. Geol. Surv., IV, p. 460, 1884.*-KeEP, West Coast Shells, p. 122, 1887 (part).— Cooper, An. Rep. Cal. State Min. Bu., VII, p. 245, 1888 (part) ; Proc. Cal. Acad. Sci. ii, III, p. 70, 1890.-Gilbert, Mon. U. S. Geol. Surv., I, pp. 290, 395, 1890.*

Lymncea bulimoides Wheatley, Cat. Sh. U. S., Ed. 2, p. 23, 1845.-Cooper, Amer. Nat., II, p. 486, 1868*; Am. Nat., III, p. 297, 1869.*-Scudder, Bull. Nat. Mus., 23, pp. 33, 43, 200, 1885.-Henderson, Univ. Col. Studies, IV, pp. 93, 179, 1907.*-WALKer, Nautilus, XX, p. 108, 1907.

Lymnaa (Stagnicola) bulimoides DALl, Alaska Moll., p. 79, 1905.

Limneus cubensis var. bulimoides PILSBRy, Proc. Phil. Acad., 1891, p. 320.*

Limnca humilis RandolPh, Nautilus, IX, p. 102, 1896.

Lymnca bryanti BAKer, Nautilus, XVIII, p. 141, April, 1905.

Lymnca humilis modicella BERRY, Nautilus, XXIII, p. 77, 1909.

Limnca adelince Tryon, Proc. Phil. Acad., 1863, p. 148, pl. 1, fig. 12.Cpr., Rep. Brit. Asso., 1864, p. 674.-Binney, L. \& F. W. Sh. N. A., II, p. 59, fig. 92, 1865.-Cooper, Proc. Cal. Acad. Sci., IV, p. 96, 1870.-Cpr., Smith. Mis. Coll., 1872, p. 160.-Tryon, Con. Hald. Mon., p. 108 (82), pl. 18, fig. 6, 1872.Roper, Nautilus, III, p. 78, 1889.-Wood, Nautilus, V, p. 56, 1891.-STEarns, Proc. Nat. Mus., XIV, pp. 101, 102, 1891.-Taylor, Ottawa Nat., VI, p. 35, 1892.Pilsbry, Nautilus, XVII, p. 84, 1903.-KeEP, West. Amer. Sh., pp. 149, 314, 1904.

Limnea adeline, Cat. Coll. Nat. Hist. Eth. Prov. Museum Victoria, p. 95, 1898.

Limnophysa adelince Tryon, Amer. Journ. Conch., 1, p. 254, 1865.-CAll, Bull. U. S. Geol. Surv., II, p. 403, 1884.-KeEP, West Coast Shells, p. 122, 1887.

Limnaus adelince Clessin, Küster, Conch. Cab., p. 404, 1886.

Lymnaa (Stagnicola) adelince DALl, Alaska Moll., p. 78, fig. 61, 1905.

Limnophysa gabbi var. adelince COoper, ZoE, I, p. 196, 1890.

SHell: Thin to robust, regularly ovate-conic in outline; periostracum yellowish-horn color; surface generally polished, semi-transparent, growth lines very fine, crossed by a few inconspicuous spiral lines; the last whorl is malleated in some specimens; whorls $5 \mathrm{I} / 2$, rather regularly and rapidly increasing in size, flatly rounded, the body whorl usually convex; spire turreted, broadly-acutely conical, about as long as the aperture; nuclear whorls $1 \frac{1}{4}$, the second whorl very wide and low, resembling in outline that of Galba jacksonensis; sutures well impressed; aperture ovate or roundly-ovate, broadly and evenly rounded below, narrowed and angulated above; outer lip thin; inner lip triangular, reflected and rolled over into the umbilical region, leaving a very small chink; parietal callus very thin. 


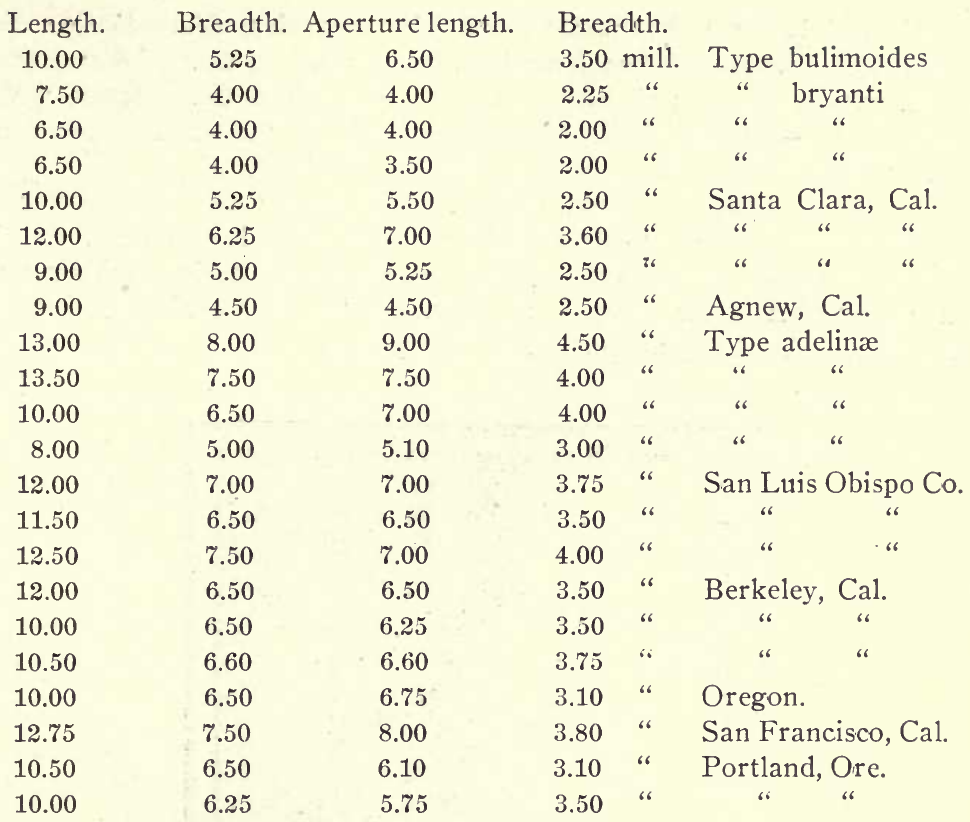

Types: Bulimoides, Smithsonian Institution, seven specimens, No. 11864\%; bryanti, coll. Bryant Walker, seven specimens, No. 1352; cotypes, Chicago Academy of Sciences, one specimen, No. 23335; adelince, Academy of Natural Sciences, Philadelphia, twenty-two specimens, No. 58525.

Type Locality: Bulimoides, Oregon; bryanti, Alameda County, California; adelince, San Francisco, California.

Animal, Jaw, Radula and Genitalia: Not examined.

Range: (Figure 16) Pacific coast, from Vancouver Island south to southern California.

Bulimoides is characteristic of the Californian and Columbian regions, judging by the authentic records. But few of the published references can be relied upon, as it has been universally mixed with G. bulimoides techella and G. b. cockerelli. It will probably be found to extend well into the Columbian region. Records east of the Rocky Mountains all seem referable to techella or cockerelli.

\section{RECORDS.}

California: Agnew, Santa Clara Co.; Redlands, San Bernardino Co.; Pajaro Valley (Berry); Berkeley, Alameda Co. (Berry; Hannibal); Haywards, Alameda Co. (Button); Truckee River, Nevada Co. (Carleton); Los Angeles, Los Angeles Co. (Cooper; Hannibal); outlet of Lake Tahoe, Placer Co., alt. 6247 feet (Cooper) ; Alameda, Alameda Co. (Dall); Menton Ranch, Santa Clara Co. (Hannibal) ; Santa Barbara, Santa Barbara Co.; line between San Diego 
Co., Cal., and Lower Cal.; Oakland and West Berkeley, Alameda Co.; Fulton, Sonoma Co. (Hemphill); San Francisco, San Francisco Co. (Gabb; Hemphill; Lea; Raymond; Rowell; Stearns; Tryon) ; San Diego Co. (Roper) ; Merced Lake, Merced Co. (Smith. Coll.) ; Sausalito, Marin Co.; Alameda Co. (Stearns) ; San Luis Obispo Co.; Alameda Co. (Orcutt; Walker).

Oregon: Johnson's Creek, Portland, Multnomah Co. (Benedict) ; Portland (Ferriss); Oregon (Lea; Nuttall); East Pontland (Walker).

Washington: Vancouver (Gabb) ; Seattle, King Co., in greenhouse (Randolph); Columbia River, near Vancouver, Clarke Co. (Smith. Coll.); Grand Coulee, Blue Lake, Douglas Co. (R. S. Snodgrass).

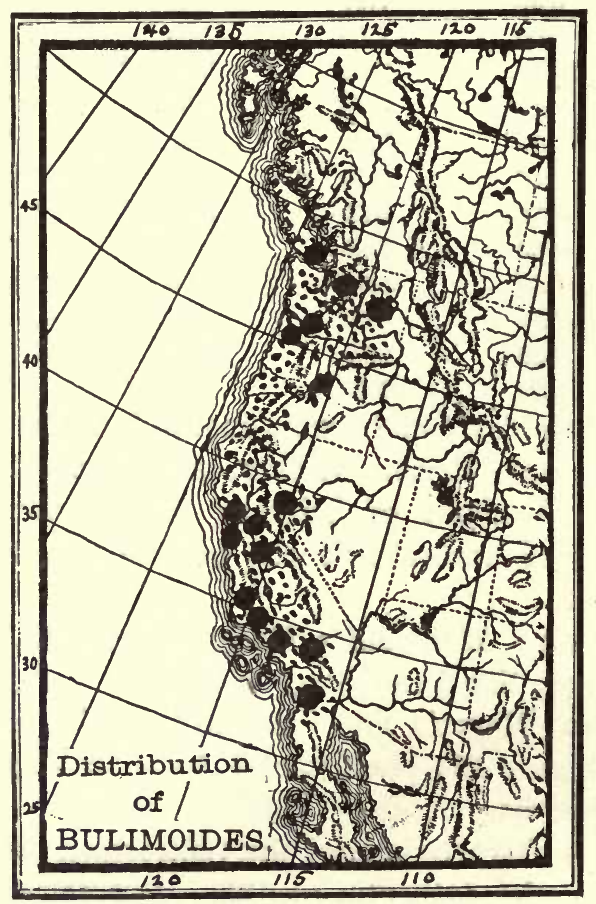

FIG. 16.

BRITISH AMERICA.

British Columbia: Victoria, Victoria District, Vancouver Island (Phila. Acad.).

Geological Distribution: Unknown.

Ecology: Not recorded. Shells believed to be this species have been found at the outlet of Lake Tahoe, California, at an altitude of 6247 feet.

Animal, Jaw, Radula and Genitalia: Not examined. 
Remarks: Bulimoides may be distinguished from techella and other races by its more regularly ovate shape, less globose body-whorl, more elongate-ovate aperture and by the different manner in which the inner lip is appressed to the columellar region. There is considerable variation in the rotundity of the whorls and in the length and acuteness of the spire. The inner lip also varies greatly, in some specimens being rolled or folded over into the umbilical region while in others it is expanded, approaching the techella form. Bulimoides somewhat resembles cubensis, differing in its nearly closed umbilical chink, folded inner lip, shorter and broader spire and its ovate shell. The whorls of cubensis are also rounder and more distinctly shouldered than are those of bulimoides.

Judging by Lea's types of bulimoides, most authors have confused this species with techclla and cockerelli. The figure in Binney is not good, representing, probably, cockerclli. Haldeman's figùres are good and fairly represent the species. The types in the Lea collection at Washington are rather small, long and narrow, regularly ovate-conic with a flat sided body whorl and with the inner lip reflected and appressed to the umbilical region, leaving a small chink. Of the seven type specimens three are apparently nearly full grown and four are immature.

In mapping the distribution of the typical form, great difficulty has been experienced in harmonizing some of the literature. In references from the southwestern states it is impossible to know whether true bulimoides or some of its varieties is intended. Call's record in Bull. Wash. Coll. Lab. N. H., I, p. 118, is very doubtful, especially in view of his reference to Binney's figure 86 , which does not represent bulimoides. Only an examination of the specimens will settle the status of these doubtful records. Bulimoides is reported by DeCamp from Michigan "greenhouses, probably introduced on plants" (Walker, Nautilus, VI, p. 34). One of the type specimens of bulimoides is figured on pl. XXVII, fig. 25. (No. 118647 Smith. Inst.) Compare this figure with the figures in Binney and Tryon.

In Dr. Pilsbry's excellent discussion of the techella group of Lymnæas ${ }^{1}$ typical bulimoides was not redefined although techella, cockerelli and sonomensis were made races of this species. The triangular and rolled over form of the inner lip and the less rotund shape of the body whorl will separate bulimoides from techella and cockerelli. Lymnaa bryanti is a synonym of bulimoides; it was founded on immature specimens.

${ }^{1}$ Proc. Phil. Acad., p. 162, 1906. 
Dr. Dall (Alaska Mollusks, p. 78) suggests the identity of adelince and bulimoides. An examination of the types of both species shows that Dall was right in thus associating the two forms. Tryon's types show a wide range of variation, principally in the form of the body whorl, which may be regularly ovate or somewhat widely expanded (compare the figures on plate XXVII). The figures of both forms have been very poor, and the descriptions have been totally inadequate. Tryon's figure in continuation of Haldeman's monograph is of an extremely wide specimen, scarcely to be considered as typical. Many specimens vary toward techclla, the inner lip being wider and the umbilical chink more widely open. Adeline (=bulimoides) has frequently been confounded with gabbi, but that species is almost imperforate, has a columellar plait and belongs to a different group of Lymnæas.

Galba bulimoides techella (Haldeman). Plate XXVII, figures 30-35; plate XXVIII, figures 1-3, 8.

Limnce techella Haldeman, Amer. Journ. Conch., III, p. 194, pl. 6, fig. 4, 1867.-Tryon, Con. Hald. Mon., p. 112 (86), pl. 18, fig. 9, 1872.-Pilsbry, Proc. Phil. Acad., 1891, p. 320.

Lymnaa techella? Ferriss, Nautilus, XX, p. 17, 1906.-BAker, Nautilus, XXIII, p. 94.-Hanna, 1. c., p. 96, 1909.

Lymnaa bulimoides techella Pilsbry and Ferriss, Proc. Phil. Acad., 1906, p. 163, figs. 20-23.-Henderson, Univ. Col. Studies, IV, pp. 81, 83, 93, 180, 1907.Walker, Nautilus, XX, p. 108, 1907.-Strecker, Nautilus, XXII, p. 65, 1908.Henderson, Nautilus, XXIII, p. 144, 1910.

Limnaa bulimoides Singley, Rep. Geol. Surv. Tex., IV, pp. 188, 1892; p. 313, 1893.-Dall, Proc. Nat. Mus., XIX, p. 368, 1897.-And of authors generally.

Lymnca caperata Hinklex, Nautilus, XX, p. 40, 1906.

Shell: Varying from obtuse to subfusiform; periostracum yellowish in color; surface dull to shining, growth lines rather coarse, with but faint indications of spiral lines; the body whorl is frequently malleated, "the flattened facets obliquely descending;" nuclear whorls $1 / 4$ wide and low, with a surface sculpture resembling satin finish (pl. XLIX, fig. C) ; whorls six, convex, usually somewhat shouldered; last whorl large, generally very ventricose; spire acutely conic, of variable length; sutures well impressed; aperture roundly ovate, from $1 / 2$ to $3 / 5$ the length of the entire shell; inner lip broadly and flatly expanded and reflected, without a fold; the anterior extremity of the aperture is produced or effuse; umbilical chink large, rather widely open; outer lip simple, sharp; axis consisting of a series of smooth, round, hour-glass-shaped columns. 
Length. Breadth. Aperture length. Breadth.

\begin{tabular}{rrrrrc}
8.00 & 5.10 & 4.90 & & mill. & \multicolumn{2}{c}{ Cotype. } \\
8.50 & 5.10 & 5.10 & & & San Marcos, Texas \\
13.00 & 7.60 & 6.70 & & & " \\
14.00 & 9.00 & 8.80 & & & " \\
10.00 & 6.75 & 5.10 & 2.50 & " & Rockwell Co., Texas. \\
12.00 & 6.50 & 5.50 & 3.50 & " & Albuquerque, N. M. \\
11.00 & 6.00 & 6.00 & 3.00 & " & “ \\
12.00 & 7.00 & 7.00 & 4.00 & " & Pacific Grove, Cal. \\
11.00 & 6.50 & 6.50 & 3.75 & " & " \\
9.00 & 6.00 & 6.00 & $3.50^{\circ}$ & " & "
\end{tabular}

Types: Location not ascertained; Cotypes, Academy of Natural Sciences of Philadelphia, five specimens, No. 59604.

Type Locality: Texas.

Animal, Jaw, Radula and Genitalia: Not examined.

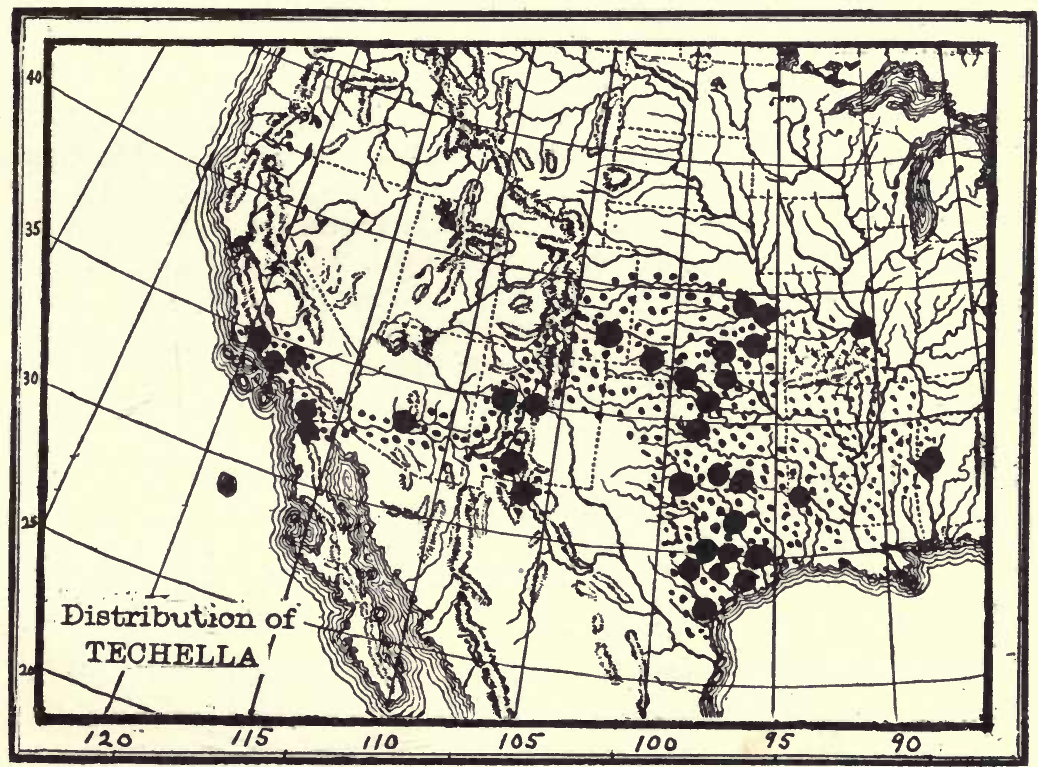

FIG. 17.

Range (Figure 17): Southern United States from Kansas, Missouri and Colorado to southern Texas; Alabama west to southern California and northern Mexico. Techella is a race characteristic of the Lower Mississippian, Ric Grandian and Coloradoan regions. Its center of distribution would seem to be the great plains region of Texas, where it is abundant and widely distributed. This 
group of Lymnæas has been so recently differentiated that generalizations may well be reserved until a future time, when more definite information is available concerning the distribution of the different races.

\section{RECORDS.}

UNITED STATES.

Alabama: Boligee, Greene Co. (Hinkley).

Arizona: Salt River at Tempe, Maricopa Co. (Ashmun).

California: Bardsdale, Ventura Co. (S. S. Berry); Warner, San Diego Co. (F. W. Bryant) ; Los Angeles Co. (Mrs. A. E. Brush); Morena, San Diego Co. (Cass) ; Bixby, Los Angeles Co.; Baird's Lake, Ventura Co. (Hannibal) ; pond about artesian well, ten miles north of Ontario, San Bernardino, Cal. (Henderson).

Colorado: La Junta, Otero Co. (G. S. Dodds; Henderson).

Missouri: St. Louis, St. Louis Co. (G. D. Linol).

Kansas: Verdigris River, Greenwood Co. (Lea); Topeka, Shawnee Co. (Stearns) ; Nickerson, Reno Co.; Lawrence, Douglas Co.; Manhattan, Riley Co.; Arkalon, Seward Co. (Hanna).

Louisiana: Grand Cane, De Soto Co. (Vaughan).

New Mexico: Albuquerque, Bernalillo Co. (Ashmun); McCartys, Vallencia Co. (Ashmun; Walker) ; Ria Grande, Paraje, Socoro Co.; Rio Grande, Mesilla, Donna Ana Co. (Cockerell).

Oklahoma: Oklahoma City, Oklahoma Co. (Ferriss); Cache Creek, S. W. Oklahoma; Tonkawa, Kay Co. (Isley); Woodward, Woodward Co. (Vaughan).

Texas: Dallas, Dallas Co. (E. Hall); Greenville, Hunt Co. (Hanna); Houston, Harris Co.; Dallas, Dallas Co. (Hemphill) ; Rockwall Co. (Ferriss) ; San Marcos, Hays Co. (Pilsbry and Ferriss) ; San Antonio, Bexar Co.; Houston, Harris Co. (Pilsbry) ; Royse, Rockwall Co. (G. H. Ragsdale) ; Fort Worth, Tarrant Co. (Sampson; Walker); Sabine River, Hunt Co.; Brazos River, Fort Bend Co.; Colorado River and tributaries, Travis Co.; mouth of Nueces River, Nueces Co. (Singley) ; Rio Grande, near El Paso, El Paso Co.; Bouldin Creek, Travis Co.; New Braunfels, Comal Co.; Cala Creek, Throckmorton Co.; Jackson Co. (Smith. Coll.); McLennan Co. (Strecker); Western Texas (Walker).

MEXICO.

Lower California: Near San Diego Co., Cal. (Orcutt).

Geological Range: Not recorded.

Ecology: No definite records have been seen regarding the ecology of this variety. It probably inhabits to a large extent the intermittent streams of the great plains, which are dry for a great part of the year, compelling the Lymnæas to hibernate. See note under variety cockerelli.

Remarks: Techella may be known by its acutely conic spire, obese body whorl, broadly dilated and flattened inner lip and wide and deep umbilical chink. Cubensis has a narrower, more triangular and less broadly reflected inner lip and a narrower umbilical chink. The 
shell is also narrower and the upper whorls are rounder and more turban-shaped. There is considerable variation in the form of the shell of techella, the last whorl being either simply convex or disproportionately swollen. The inner lip varies greatly in the extent to which it is expanded or compressed. The spire also varies in height, as do the sutures in their degree of impression. Some specimens somewhat closely resemble var. cockerelli, in which, however, the spire is always very short. There is also great variation in size, individuals from some localities being about half the size of those from other localities.

Old specimens have the last whorl distinctly malleated, but this character is not apparent on shells of younger growth, which are smooth and polished, with a comparatively short spire. The type lot have the majority of the specimens with the spire eroded, for which reason and on account of the insufficient figures of both Haldeman and Tryon, the species has been misunderstood by most conchologists and has been confounded with both bulimoides and cubensis. Dr. Pilsbry (loc. cit.) was the first conchologist to correctly describe and figure this form, which is one of the neatest of the American Lymnæas.

Techella and cockerelli were once thought to be specifically separable from bulimoides, but the examination of a large series of both forms has proven conclusively that techella is but a race of bulimoides. Techella, while normally possessing a broadly dilated inner lip, is sometimes seen with a folded inner lip as in bulimoides, but with the sharp spire and obese body whorl of techella. Again, the inner lip may be broadly expanded and the body whorl may be compressed as in bulimoides. The latter also exhibits parallel cases of variation.

Galba bulimoides cockerelli (Pilsbry and Ferriss). Plate XXVI, figures 5-7; plate XXVIII, figures 4-7.

Lymnaa bulimoides cockerelli PILsBry, Nautilus, XIX, p. 30, March, 1906.Pilsbry and Ferriss, Proc. Phil. Acad., p. 162, figs. 13-17, 1906.-Henderson, Univ. Col. Stud., IV, pp. 93, 180, 1809.-WALKER, Nautilus, XX, p. 108, 1907.PIlsbry and Ferriss, Nautilus, XXII, p. 104, 1909 ; Proc. Phil. Acad., p. 144, 1910.

Limnaa bulimoides Bland and Gooper, Ann. N. Y. Lyc. N. H., VII, p. 370, 1862.-Binney, L. and F. W. Sh. N. A., II, p. 61, fig. 96, 1865 (nec. desc.).Stearns, N. Am. Fauna, VIII, p. 275, 1893.-SQuyer, Nautilus, VIII, p. 65, 1894.-Pilsbry, Nautilus, X, p. 96, 1896.-Stearns, Proc. Nat. Mus., XXIV, p. 288, 1901.-Elrod, Bull. Univ. Mont., Biol. Ser., No. 3, p. 172, 1902.

Lymnaa (Stagnicola) bulimoides Dall, Alaska Moll., fig. 62, 1906.-HenDERson, Univ. Col. Studies, IV, p. 179, fig. 36, 1907.

Lymncea bulimoides BERRY, Nautilus, XXIII, p. 77, 1909.

Limnophysa bulimoides CALL, Bull. Wash. Lab. N. H., I, p. 118, 1885. ${ }^{1}$

${ }^{1}$ From Call's description and his reference to Binney's figure 86 , there would seem to be little question that his specimens were cockerelli. 
SHeLl: Subglobose, rather thick; color pale horn; surface dull to shining; growth lines fine, coarser on the last whorl, which is sometimes malleated near the aperture; nucleus very small, rounded; whorls $4 \mathrm{r} / 2$, very convex, rapidly enlarging; spire very short and broad; last whorl very large, globose; sutures impressed; aperture varying from ovate to roundly ovate, occupying from two-thirds to two-fifths the length of the shell; inner lip broadly expanded, arched over the umbilical chink, which is widely open.

\begin{tabular}{|c|c|c|c|c|c|c|}
\hline $\begin{array}{l}\text { Length. } \\
10.00\end{array}$ & $\begin{array}{c}\text { Breadth. } \\
7.20\end{array}$ & $\begin{array}{c}\text { Aperture length. } \\
6.70\end{array}$ & Brea & & Type Las Vegas, & N. M. \\
\hline 8.30 & 6.00 & 5.30 & & “ & " & $“$ \\
\hline 8.00 & 6.20 & 6.00 & & “ & “ & “ \\
\hline 9.00 & 6.00 & 5.75 & 3.00 & “ & \multirow{3}{*}{$\begin{array}{l}\text { Ogalalla, Neb. } \\
\text { New Mexico. } \\
\text { “ }\end{array}$} & \\
\hline 10.00 & 6.50 & 6.00 & 3.50 & “ & & \\
\hline 11.00 & 7.50 & 6.00 & 3.75 & “ & & \\
\hline 12.50 & 9.50 & 8.00 & 5.00 & “ & \multirow{2}{*}{\multicolumn{2}{|c|}{ Rio Puerco, N. M. }} \\
\hline 13.50 & 9.50 & 8.25 & 5.00 & 6 & & \\
\hline
\end{tabular}

Types: Academy of Natural Sciences, Philadelphia, four specimens, No. $8428 \%$.

Type Locality: Las Vegas, New Mexico.

Animal: Not examined alive.

JAw: Like that of cubensis.

RADULA: Formula: $\frac{10}{6-7}+\frac{4}{3}+\frac{7}{2}+\frac{1}{1}+\frac{7}{2}+\frac{4}{3}+\frac{10}{6}-7$ (21-1-21) ; similar to that of cubensis. (See pl. VII, fig. F.) The marginals are more generally serrated than in cubensis, otherwise the teeth are the same. In cubensis, however, the intermediate teeth begin on the seventh tooth, while in cockerelli they begin on the eighth tooth. In one specimen the tenth tooth had a bifid entocone.

Genitalia: In almost all respects similar to those of cubensis. (See pl. XI, fig. A.) The penis is a trifle stouter than in cubensis.

\section{TABLE OF MEASUREMENTS. ${ }^{1}$}

$\begin{array}{cccccccr}\text { Penis. } & \text { Penis-sac. Vas. def. } & \begin{array}{r}\text { Prost. } \\ \text { duct. }\end{array} & \text { Rec. sem. Pen. ret. } & \begin{array}{l}\text { Penis- } \\ \text { sac. ret. }\end{array} & \text { Shell. } \\ 1.00 & 1.50 & 6.75 & 1.50 & 1.75 & .60 & .75 & 6.00\end{array}$

RANGE (Figure 18): Montana south to southern Texas; South Dakota and eastern Texas west to California.

The range of cockerelli includes portions of the Upper and Lower Mississippian, Rio Grandian, Coloradoan and Californian regions. It also appears to inhabit nearly the whole of the great plains area penetrating into the prairie region on the eastern border of its range to the 95th degree of longitude. The range of cockerelli overlaps that of techella on the south; it has the most northern range of any member of 
the cubensis group. As in the case of techella, future investigation will doubtless add much information concerning the range of this race. At present it is known to occupy the drainage areas of three great river systems-the Mississippi, the Rio Grande and the Colorado.

\section{RECORDS.}

\section{UNITED STATES.}

Arizona: Holbrook, Navajo Co. (Ashmun); Midway between the Chiricahua and Peloncillo ranges (Pilsbry).

California: Bardsdale, Ventura Co. (Berry); in lake, 25 miles west of Susanville, Lassen Co. (Hannibal); near Daggett, Mojave River, San Ber-

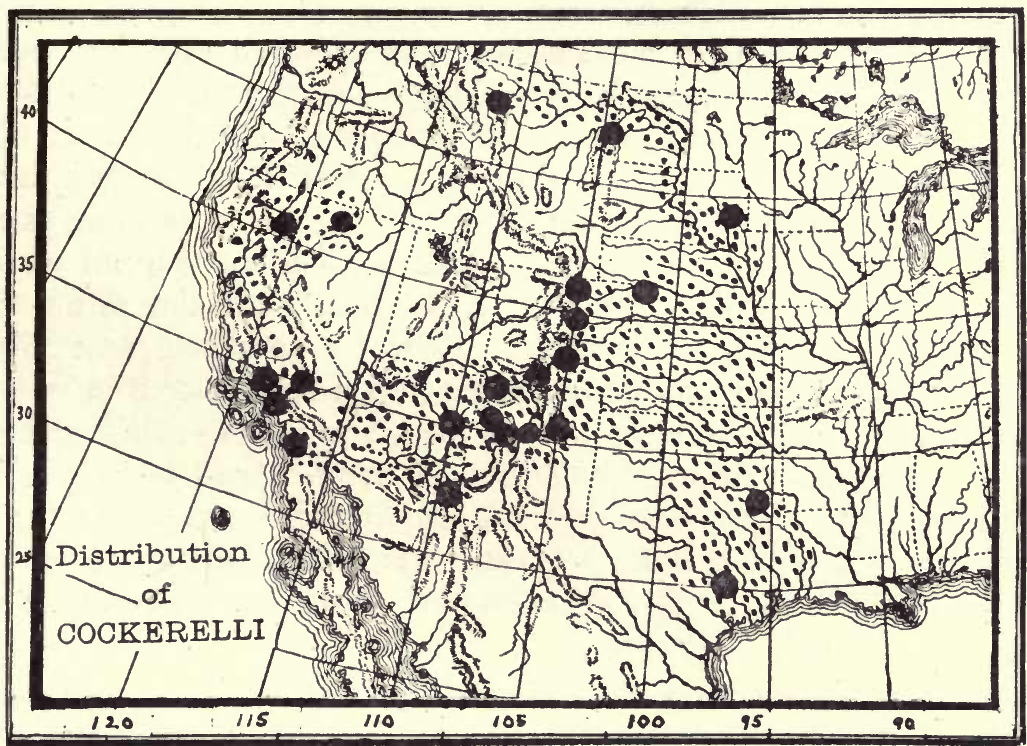

FIG. 18.

nardino Co. (Smith. Coll.) ; San Diego, San Diego Co. (Newberry) ; Bixby, Los Angeles Co. (Hemphill; Walker).

Colorado: Fossil Ridge, six miles south of Ft. Collins, Larimer Co. (Henderson); Florence, Fremont Co. (Henderson; A. Kenyon); Lake, San Luis Valley, Costilla Co. (Ingersoll); pool, southeast of Denver, Arapahoe Co. (J. D. Putnam).

Montana: Missouri River above the Falls (Bland \& Cooper); Mingusville, Dawson Co.; spring, five miles south of Wilbaux, Dawson.Co. (Squyer).

Nebraska: Ogallala, Keith Co. (Ferriss; Simpson).

Nevada: Quinn River crossing, Humboldt Co., alt. 4100 ft. (Berry; C. H. Richardson, Jr.).

New Mexico: Gallup, Bernalillo Co. (Ashmun); Chaco Canyon, alt. 6500 feet, San Juan Co. (Geo. H. Clapp; Geo. H. Pepper) ; Farmington, San Juan Co. 
(Geo. H. Pepper); Las Vegas, San Miguel Co. (Miss Mary Cooper); Grant, Valencia Co. (Pilsbry); Albuquerque, Bernalillo Co. (Pilsbry and Ferriss).

South Dakota: Lake Herman, Lake Co. (P. C. Freeman); Date, Perkins Co. (Over).

Texas: Sabine River, Greenville, Hunt Co. (Smith. Coll.); Rutterville, Fayette Co. (Lea).

Geological Range: Charcoal zone of the Pleistocene of Arroyo Pecos, New Mexico (Cockerell).

Ecology: In the Nautilus, Vol. X, p. 96, I find the following note: "Limnæa bulimoides resisting drought.-Specimens of a very short-spired form of this species were lately received from Mr. George H. Clapp, with the following note: 'They were collected by my cousin, George H. Pepper, from a water-hole that appeared to be dry most of the year, near Farmington, New Mexico, on September 20, 1896, and reached me, packed in cotton, on October 5. On the 4 th of this month (November) I dropped them into warm water to soak them loose from the cotton, and about two dozen out of 50 or more came to life. They had been out of water 45 days! The shells spend nearly as much time out of the water as in it, frequently crawling to the top of the glass in which I keep them.' Out of 4 specimens sent alive, packed in dry cotton, one revived at once upon being placed in water, after an additional journey, dry, from the 6 th to the 9 th of November. The survivor has a translucent or almost water-colored body, closely peppered with opaque white; eyes black; tentacles opaque white; a lark stripe on back starting between tentacles. With the Lymnæas were some of the little bivalve Phyllopod crustacean, Estheria mexiinna Claus." (H. A. Pilsbry.)

REMARKs: Cockerclli may be distinguished by its icry globose form, short and very broad spirc and by the wide cxpansion of the inner lip, which is not folded but broadly expanded, producing a large, acep umbilical chink. It is a very characteristic and usually an easily separable variety of bulimoides. Some specimens are narrower and higher in the spire than the types (especially in specimens from Ogallala, Neb. (pl. XXVIII, fig. 4), but all agree in having the open umbilical chink, expanded columellar region and dome-shaped spire. The aperture varies somewhat in rotundity. It is probable that some of the references under bulimoides and adcline belong here, as both this form and techclla have been recorded as bulimoides. Specimens from Ventura County, California, show a tendency to vary toward the techella form of shell, clearly showing that the cockerelli race is an offshoot of techella. (Compare plate XXVII, figures 33-35, with plate XXVIII, figures 6-\%.) 
Binney's figure 96 seems to belong to cockerelli rather than to bulimoides.

Galba bulimoides cassi Nov. Sp. Plate XXVIII, figures 9-11.

SHell: Ovate, elongated, solid; periostracum light yellowishhorn; surface shining, growth lines heavy, conspicuous; spiral lines absent; body whorl without malleation; nuclear whorls similar to those of techella; whorls $5-5 \mathrm{t} / 2$, flatly convex, the body whorl ovate in outline; spire acutely conical, rapidly acuminating; sutures impressed; aperture ovate, rounded anteriorly and angled posteriorly, as long as, or longer than, the spire; outer lip simple; inner lip reflexed to form a flat shelf which is broad with parallel margins and stands almost erect, overhanging the umbilical chink which is widely open.

$\begin{array}{cccccc}\text { Length. } & \text { Breadth. Aperture length. } & \text { Breadth. } \\ 7.50 & 4.50 & 4.00 & 2.50 \text { mill. } & \text { Type } \\ 8.50 & 5.00 & 4.50 & 3.00 & \text { “ } & \text { “ } \\ 7.50 & 4.50 & 4.50 & 2.50 & \text { “ } & \text { “ } \\ 8.50 & 5.25 & 5.00 & 3.00 & \text { “ } & \end{array}$

Types: Chicago Academy of Sciences, seven specimens, No. 23948.

Type Locality: Rose Canyon, near Pacific Grove, San Diego, County, California.

Animal, Jaw, Radula and Genitalia: Not examined.

RANGE: Southern California and northern Lower California. Cassi occupies the southern portion of the Californian region. Its area of distribution will probably be greatly widened by more extensive collecting.

\title{
RECORDS.
}

\author{
UNited STATES.
} Cass).

California: Rose Canyon, near Pacific Grove, San Diego Co. (C. L.

\section{MEXICO.}

Lower California: Near Alamo (Orcutt).

Geological Range: Unknown.

ECology: "In intermittent stream which runs but two months of each year; in summer overflow of drinking tank of cattle" (Cass).

Remarks: Cassi may be distinguished from techella, which it closely resembles, by its more ovate shell and aperture and by its inner lip which stands erect instead of being broadly reflected. In techella the inner lip is usually appressed at its junction with the parietal wall, while in cassi it is not appressed at this point, but forms a continuous, cvenly curved projection, which, in many cases, produces a continuous aperture. 
This race was at first thought to be a distinct species, but the presence of intermediate forms, though few in number, indicate its relationship with techclla and, hence, with bulimoides. Some specimens from New Mexico approach cassi in the general form of the shell, but the spire and aperture relate them to techella. In Pilsbry's revision of the bulimoides group, this race was apparently included in techella, but an abundant series of specimens prove its distinctness. Cassi has doubtless been confused with cubensis, bulimoides and techella heretofore. The race is dedicated to Mr. C. L. Cass of Pacific Grove, California.

Galba sonomænsis (Hemphill). Plate XXVIII, figures 12-14.

Lymnaa bulimoides sonomansis Hemphill, Pilsbry, Proc. Phil. Acad., p. 162, figs. 18, 19, 1906.

Limncea ampla KeEp, West Coast Shells, p. 123, 1887.

Radix ampla var. utahensis KeEP, West American Shells, p. 149, 1904. (Not of Call.)

Lymnaa perpolita? DaLL, Alaska Shells, p. 79, 1905.

Shell: Rather small, globose, very thin; color light yellowishhorn; surface dull to shining, lines of growth distinct; whorls $31 / 2$ to 4 , rounded, the body whorl very globose; spire very short and roundly depressed; sutures not markedly impressed; aperture rounded, expanded, somewhat effuse; inner lip evenly reflected over the columellar region, forming a long, somewhat triangular expansion which is closely appressed to the columellar region; umbilical chink very narrow; the parietal wall is covered with a thin callus.

\begin{tabular}{|c|c|c|c|c|c|}
\hline Length. & Breadth. & Aperture length. & Bread & & \\
\hline 10.00 & 6.00 & 6.50 & & & (Hemphill) \\
\hline 9.00 & 6.75 & 6.50 & 4.00 & “ & “ \\
\hline 6.00 & 5.00 & 4.50 & 3.00 & “ & “ \\
\hline 6.50 & 4.50 & 4.50 & 2.50 & “ & " \\
\hline
\end{tabular}

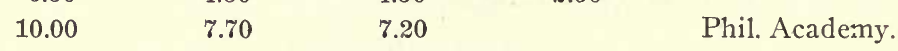

Types: Academy of Natural Sciences of Philadelphia, seven specimens, No. 59999; cotype, Chicago Academy of Sciences, one specimen, No. 23229.

Type Locality: Sonoma County, California.

Animal, Jaw, Radula and Genitalia: Not examined.

Range: Western California. Apparently confined to the Californian region.

\section{RECORDS.}

California: Sonoma and Lake counties, California (Hemphill).

Geological Range: Not recorded.

Ecology: Not recorded. 
Remarks: Sonomansis is related to bulimoides. Its distinguishing characteristics are its short, dome-shaped spire, globose form and tather rapidly expanding last whorl. The aperture also is somewhat patulous. The columella is narrower and more heavily appressed to the columellar region than in Galba bulimoides cockerelli; the umbilicus is a narrow chink, while in cockerelli it is rather widely open.

This species has been variously referred to ampla Migh., ampla utahensis Call and to perpolita Dall, but it is not related to any one of these save, perhaps, the last, which seems to be related to bulimoides.

Galba hendersoni (Baker). Plate XXVIII, figures 15-18.

Lymnea hendersoni BAKER, Nautilus, XXII, p. 140, April, 1909.

SHell: Globose, very thin and fragile; periostracum light yellowish or brownish horn; surface dull; sculpture of fine growth lines, without spiral lines; whorls $3 \frac{1}{2}$, very rapidly increasing in diameter, the body whorl seven-eighths the length of the entire shell, very globose; spire very short, depressed, dome-like, the first two whorls flat and coiled in the same plane, so that a profile view shows only two full whorls. Nuclear whorl flat, partly concealed by the volutions of the spire; sutures impressed; aperture round or roundly elliptical; cuter lip thin; inner lip broad, triangular, reflected over the columellar region, but leaving a deep, well-marked chink; the inner edge of the inner lip is usually bent downward near the body whorl, partly concealing the umbilical chink; parietal callus thin; axis smooth, hourglass-shaped.

$\begin{array}{ccccc}\text { Length. } & \text { Breadth. } & \text { Aperture length. } & \text { Breadth. } \\ 7.00 & 5.50 & 4.75 & 3.00 \text { mill. } & \text { Type } \\ 6.25 & 5.00 & 4.00 & 2.50 \text { “ } & \text { “" } \\ 6.75 & 5.00 & 4.80 & 3.00 \text { “ } & \text { “ } \\ 5.50 & 4.10 & 4.00 & 2.50 \text { " } & \end{array}$

Types: Chicago Academy of Sciences, six specimens, No. 24537; cotypes, University of Colorado, Boulder, Colorado.

Type Locality: West of Fort Collins, Colorado.

Animal (in alcohol): With a very broad, short foot, 4.00 by 3.00 mill.; tentacles very large, broadly triangular. The animal seems to be large for the size of the shell.

JAw: Resembling that of Galba bulimoides techella.

Radula (plate VI, figure P) : Formula: $\frac{14}{5}-\frac{4}{7}+\frac{2}{3-4}+\frac{7}{2}+\frac{1}{1}+\frac{7}{2}+\frac{2}{3}-\frac{4}{5}+\frac{14}{5}-\frac{7}{7}$ (23-1-23); the teeth are similar to those of techella. The marginals begin quite abruptly, the entocone splitting into two acute points on the ninth (second intermediate) and into three points on the tenth (lirst marginal) tooth. The cusps of the marginal teeth are very long and acute. There are over 110 rows of teeth. 
Genitalia: In almost all respects like those of cubensis and techella. Measurements are as follows:

\begin{tabular}{cccccccc} 
& & \multicolumn{3}{c}{ Prost. } & \multicolumn{3}{c}{ Penis-sac } \\
Penis. & Penis-sac. Vas. def. & $\begin{array}{c}\text { duct. } \\
\text { duct. }\end{array}$ & Rec. sem. Penis ret. & ret. & Shell. \\
1.25 & 2.00 & 8.00 & 2.00 & 2.00 & 1.10 & 1.50 & 7.00
\end{tabular}

The penis-sac retractor is much enlarged as it enters the penis-sac, the whole muscle forming a broad band of tissue; the penis retractor is long and narrow, and enters the columellar muscle at the same point as the penis-sac retractor. The receptaculum seminis is ovate-quadrangular in outline.

Range: Colorado. A species of the Coloradoan region.

RECORDS.

Colorado: West of Fort Collins, Larimer Co. (Henderson).

ECOLOGY: Inhabits lagoons and intermittent bodies of water. $\mathrm{Mr}$. Henderson writes of the habitat as follows: "I am informed that there had been no water in the lagoon for many months, probably not sinee liast summer or autumn. The ground was cracked to a depth of several inches and the mollusks were found down in the cracks and in the mud. Therefore, it seems to be another species capable of aestivating."

Remarks: This species was at first thought to be Galba sonomcensis Hemphill, but a comparison with that species shows that the present species differs not only from sonomansis but from all related species in the form of the spire and aperture. The first two whorls cf the spire are coiled in the same plane, producing a sharply truncated appearance. The outline of the shell is also more ovate than in sonomansis and the aperture is not expanded. The inner lip is also rolled over to a greater extent than in the Sonoma species, and approaches closely to some individuals of bulimoides. The only Lymnæid likely to be confounded with hendersoni is sonomensis, which differs in the form of the spire and inner lip.

I take great pleasure in dedicating this interesting species to Judge Junius Henderson, of the University of Colorado.

Galba perpolita (Dall). Plate XXVIII, figure 19.

Lymncea (Stagnicola) perpolita DALL, Alaska Moll., p. 78, pl. 2, figs. 6, 8, 1905.

Lymnaa perpolita PILSBRY, Nautilus, XIX, p. 95, 1905.

"Shell: Small, translucent, dark amber color, with a darker line at resting stages; smooth, except for fine lines of growth, brilliantly polished; whorls four, tumid, rapidly increasing, separated by a pronounced suture; spire short, rather obtuse; aperture ovate, longer than the spire, with a very thin wash of callus on the spire, the pillar lip 
slightly reflected, with a small perforate umbilicus behind it; pillar straight, with no twist or fold, outer lip thin, sharp." (Dall.)

$\begin{array}{cccc}\text { Length. } & \text { Breadth. Aperture length. } & \text { Breadth. } \\ 11.00 & 8.50 & 7.00 & 4.50 \text { mill }\end{array}$

Type: Smithsonian Institution, one specimen, No. $17555 \%$.

Type Locality: Nushagak, Bristol Bay, Alaska.

Animal, Jaw, Radula and Genitalia: Unknown.

RANGE: Alaska. Evidently typically a boreal species of the Hudsonian life zone.

\section{RECORDS,}

Alaska: Nushagak, Bristol Bay (Dall).

Geological Range: Unknown.

Ecology: Not recorded.

REMARKS: "This shell is so elegantly polished that it may be an Amphipeplea. It has the rich dark amber color of some Succineas. No other American species has an equally polished surface, so far as I have observed." (Dall.)

An examination of the type specimen of this species shows that it is allied to the cubensis group, having the same arrangement of inner lip as well as the smooth, polished surface. It is not the same as the Sonoma County shells collected by Hemphill, as suggested by Dr. Dall, these being a distinct species (sonomensis). A series of specimens of this species is very desirable.

Galba caperata (Say). Piate XXVIII, figures 20-33; plate XXIX, figures 1-3.

Lymnceus caperatus SAY, New Harmony Dis., II, p. 230, 1829.

Lymneus caperatus SAY, Binney's Ed., p. 148, 1858.

Limnaus caperatus Küster, Conch. Cab., p. 47, taf. 8, figs. 27-30, 1862.

Lymncea caperata Wheatley, Cat. Sh. U. S., Ed. 2, p. 23, 1845.-Linsley, Am. Journ. Sci., LXVIII, p. 282, 1845.-JAY, Cat., Ed. 4, p. 268, 1852.-LEA, Journ. Phil. Acad., VI, p. 160, 1866; Obs., XI, p. 116, 1867.-ScudDER, Bull. Nat. Mus., 23, p. 200, 1885.-DALL, Alaska Moll., p. 79, fig. 63, 1905.-BAKER, Bull. Ill. State Lab. N. H., VII, p. 104, 1906.-WALkER, Nautilus, XX, p. 82, 1906.Henderson, Univ. Colo. Studies, IV, pp. 81, 93, 158, 180, fig. 39, 1907.-STERKI, Proc. Ohio State Acad. Sci., IV, p. 382, 1907.-Walker, Ottawa Nat., XXII, pp. 89, 90, fig. 2, 1908.-Lermond, Shells of Maine, p. 38, 1908.-DANiels, Nautilus, XXII, p. 121, 1909.-Berry, Nautilus, XXIII, p. 77, 1909.-Henderson, Univ. Col. Studies, VII, p. 126, 1909.-Baker, Bull. Ill. State Lab. N. H., VIII, p. 492 , et seq., 1910.

Lymnea caperata Girard, Proc. Nat. Inst., I, No. 2, p. 81, 1856.-Dawson, Can. Nat. and Geol., n. s. VI, p. 387, 1872.

Limnca caperata C. B. Ad., Amer. Journ. Sci., XL, p. 268, 1841; Thomp. Hist. Vt., pt. 1, p. 154, 1842.-Anthony, List Sh. Cin., 1843.-Stimpson, Sh. N. Eng., p. 52, 1851.-Adams, Exp. Red River, p. 244, 1854.-Higgins, Cat. Sh. Columbus, p. 6, 1858.-Bell, Can. Nat. and Geol., IV, p. 213, 1859; Geol. Surv. 
Can. Rep. Prog., p. 252, 1859.-Binney, Check List, p. 12, 1860.-?Lapham, Proc. Phil. Acad., 1860, p. 155.-?Binney, Proc. Phil. Acad., p. 330, 1861. ${ }^{1}$ Bell, Can. Nat. \& Geol., VI, pp. 42, 46, 1861.-Whiteaves, Can. Nat. \& Geol., VIII, p. 103, 1863.-Tryon, Proc. Phil. Acad., 1863, p. 149.-Conn. Geol. Can., pp. 969, 985, 1864.-Binney, L. \& F. W. Sh. N. A., II, p. 56, fig. 87, 1865.Currier, Kent. Sci. Inst., Mis. Pub., No. 1, 1868.-Smith and Prime, Ann. Lyc. N. H., IX, p. 378, 1870.-Gould, Invert. Mass., Ed. Binney, p. 481, fig. 732, 1870.-Sowerby, Conch. Icon., XVIII, Lim., sp. 53, pl. 8, fig. 53, 1872.-Tryon, Con. Hald. Mon., p. 106 (80), 1872.-Calkins, Proc. Ottawa Acad. Sci., p. 25, 1874 ; Cin. Quart. Journ. Sci., I, pp. 243, 323, 1874.-Sмıтн, U. S. Fish Com. Rep., 1872-73, p. 702, 1874.-YArRow, U. S. Geog. Surv. 100th Merid., V, p. 944, 1875.-Dawson, British N. A. Bound. Com., p. 349, 1875.-Pratt, Proc. Daven. Acad. Sci., I, p. 166, 1876.-Witter, Journ. Conch., I, p. 387, 1878.-WALKer, Journ Conch., II, p. 330, 1879.-Heron, Ottawa Nat., I, p. 39, 1880.-Stein, Ind. Dept. of Stat. \& Geol., 1880, p. 458.-Call, Amer. Nat., XV, p. 586, 1881.Christy, Journ. Conch., IV, p. 347, 1885.-Ottawa Nat., II, p. 264, 1885.-BEAUChamp, L. \& F.-W. Sh. N. Y., p. 3, 1886.-H. F. CPr., Random Notes N. H., III, p. 79, 1886.-MARSH, Conch. Exch., II, p. 104, 1887.-Shimek, Bull. Lab. N. H. Univ. Iowa, I, pp. 68, 208, 1888; Amer. Geol., I, p. 151, 1888.-H. F. CPR., Cat. Sh. R. I., Ed. 2, p. 5, 1889.-Ottawa Nat., IV, p. 55, 1890.-Shimek, Bull. Lab. Nat. Hist. Univ. Iowa, I, p. 200, 1890.-Walton, Proc. Roch. Acad. Sci., II, p. 12, 1891.-Stearns, Proc. Nat. Mus., XIV, p. 101, 1891.-Pilsbry, Proc. Phil. Acad., 1891, p. 320.-McGee, Rep. U. S. Geol. Surv., XI, p. 461, 1891.TAylor, Ottawa Nat., VI, p. 33, 1892.-WALker, Nautilus, VI, p. 34, 1892.Dean, Amer. Nat., XXVI, p. 11, 1892.-Marshall, Rep. N. Y. State Mus., XlVII, p. 65, 1893.-Stearns, N. A. Fauna, VII, p. 274, 1893.-Marshall, N. Y. at World's Col. Exp., p. 512, 1894.-Walker, Rev. Moll. Mich., 1894, p. 17.-Pilsbry, Proc. Phil. Acad., 1894, p. 24.-Souyer, Nautilus, VIII, p. 65, 1894.-TAylor, Ottawa Nat., IX, p. 175, 1895.-Ottawa Nat., IX, p. 156, 1895.Sargent, Nautilus, IX, p. 127, 1896.-Wiswall, Nat. Sci. Journ., I, p. 45, 1897.Shimek, Proc. Iowa Acad. Sci., V, pp. 35, 44, 1898.-BAker, The Museum, III, p. 154, 1897; Journ. Cin. Soc. N. H., XIX, p. 78, 1897; Nautilus, XII, p. 65, 1898; Trans. Acad. Sci. S.t. Louis, VIII, p. 89, 1898.-Topd, Proc. Iowa Acad., VI, pp. 124, 125, 1898.-Walton, The Museum, IV, p. 133, 1898.-Baker, Moll. Chi. Area., pp. 23, 24, 1898.-HanhaM, Nautilus, XIII, p. 5, 1899.-Leverett, Mon. U. S. Geol. Surv., XXXVIII, pp. 173, 174, 1899.-ClapP, Nautilus, XIV, p. 64, 1900.-Stearns, Proc. Nat. Mus., XXII, p. 135, 1900.-Baker, Trans. Acad. Sci. St. Louis, XI, p. 10, pl. 1, fig. 11, 1901.-Shrmek, Bull. Lab. N. H. Univ. Iowa, V, p. 207, 1901; Amer. Geol., XXVIII, p. 353, 1901.-Stearns, Proc. Nat. Mus., XXIV, p. 291, 1901.-BAKer, Amer. Nat., XXXV, p. 662, 1901.Shimek, Geol. Surv. Iowa, p. 264, 1901.-Elrod, Bull. Univ. Mont., Biol. Ser., No. 3, p. 173, 1902.-Sterki, Ohio Nat., II, p. 286, 1902.-Daniels, Rep. Dept. Geol. \& Nat. Res. Ind., XXVII, p. 636, 1902.-BAKer, Moll. Chi. Area., p. 270, pl. 30, fig. 18, text fig. 87, 1902; Shells of Land and Water, p. 43, fig. 1903; Nautilus, XVII, p. 113, 1904.-Shimek, Bull. Lab. N. H. Univ. Iowa, V, p. 379, 1904.-Letson, Bull. N. Y. State Mus., LXXXVIII, p. 55, 1905.-Chadwick, Bull. Wis. Nat. Hist. Soc., n. s., IV, p. 82, 1906.-Nautilus, XX, p. 22, 1906.

Limnea caperata HALD., Mon. Limn., p. 34, pl. 11, figs. 1-8, 1842.-DEKAY, p. 69, pl. 4, figs. 66, 69, pl. 5, fig. 79, 1843.-Haldeman, Rupps. Hist. Lanc. Co., 
p. 480, 1844.-Gould, Agassiz's Lake Sup., p. 244, 1850.-Lapham, Trans. Wis. State Ag. Soc., II, p. 368, 1852.-Miles, Geol. Surv. Mich., p. 237, 1860.-Dean, Amer. Nat., XXVI, p. 18, 1892.-Huetr, Nat. Hist. La Salle Co., p. 104, 1898.Tond, Proc. Iowa Acad. Sci., VI, pp. 124, 125, 1899.-Hartmann, Cat. Moll. Chester Co.-HubBard, Cat.

Limnophysa caperata Morse, Journ. Port. Soc. N. H., p. 42, 1864.-Tryon, Amer. Journ. Conch., I, p. 254, 1865.-Currier, Amer. Journ. Conch., I, p. 294, 1865.-Hartmann and Michener, Conchologia cestrica, p. 66, fig. 127, 1974.Prime, Forest \& Stream, XV, p. 245, 1880.-DeCamp, Kent. Sci. Inst., Mis. Pub., No. 5, p. 8, 1881.-Call, Bull. Wash. Coll. Lab. N. H., I, p. 118, 1885.Grant, Rep. Nat. Hist. Surv., Minn., XIV, p. 122, 1886.-Call, Bull. Wash. Coll. Lab. N. H., II, p. 17, 1887.-KEEP, West Coast Shells, p. 122, fig. 110, 1887.Keyes, Bull. Essex. Inst., XX, p. 71, 1888; Bull. Essex. Inst., XX, p. 83, 1888.Gilbert, Mon. U. S. Geol. Surv., I, p. 299. 1890.-Call, Proc. Ind. Acad. Sci., 1893, p. 150, 1893; Proc. Ind. Acad. Sci., 1895, p. 138; Proc. Ind. Acad. Sci., p. 250, 1895 ; Proc. Ind. Acad. Sci., 1896, p. 250 ; Proc. Ind. Acad. Sci., 1896, p. 254.-Baker, Journ. Cin. Soc. N. H., XIX, pp. 83, 84, 1897.-Call, Rep. Dept. Geol. \& Nat. Res. Ind., XXIV, p. 407, pl. 8, fig. 7, 1899.-Norris, Proc. Ind. Acad. Sci., p. 118, 1901.-Blatchley and Ashley, Rep. Geol. \& Nat. Res. Ind., XXV, p. 176, 1901.-Keep, West. Amer. Sh., pp. 149, 314, fig. 129, 1904.

Limnea umbilicata Lapham, Trans. Wis. State Ag. Soc., II, p. 368, 1852.Miles, Geol. Surv. Mich., p. 237, 1860.

Lymnea umbilicata Currier, Sh. Grand Riv., Mich., 1859.

Lymnca umbilicata Lewis, Proc. Phil. Acad., p. 18, 1860 ; Proc. Phil. Acad., 1872 , p. 102

Limnophysa umbilicata Lewis, Bull. Buff. Soc. N. Sci., II, p. 135, 1874.

Limncea umbilicata D’URban, ${ }^{1}$ Geol. Surv. Can., Rep. Prog., p. 242, 1859.Bell, ${ }^{1}$ Geol. Surv. Can., Rep. Prog., p. 252, 1859.-Currier, Kent. Sci. Inst., Mis. Pub., No. 1, 1868.-Aldrich, Rep. N. Y. State Cab. N. H., XXII, p. 23, 1868.-Jeffrey's Ann. Mag. N. H., Ser. 4, X, p. 247, 1872 (part) ; Journ. Conch., I, p. 8, 1874 (part).-Beauchamp, L. \& F.-W. Sh. N. Y., p. 3, 1886.-Marshall, Rep. N. Y. State Mus., XLVIII, p. 642, 1895.-Sterki, Ohio Nat., II, p. 286, 1902.

Limnaa caperata var. umbilicata, Ottawa Nat., I, p. 58, 1882. ${ }^{1}$-Ottawa ${ }^{1}$ Nat., IV, p. 56, 1890.

Limncea caperata umbilicata Blatch. \& Daniels, Rep. Dept. Geol. \& Nat. Res., Ind., XXVII, p. 597, pl. 1, fig. 13, 1902.-Daniels, Rep Dept Geo.. \& Na.. Res. Ind., XXVII, p. 636, 1902.-BAKer, Moll. Chi. Area., II, p. 272, pl. 30, fig. 19, text fig. 88, 1902.-С p. 82, 1906; Nautilus, XX, p. 22, 1906.

Lymncea caperata umbilicata BAKer, Bull. Ill. State Lab. N. H., p. 105, 1906.

Limnaa cubensis BAKer, The Museum, III, p. 154, 1897; Moll. Chi. Area., p. 23, 1898; Trans. Acad. Sci. St. Louis, XI, p. 12, pl. 1, fig. 10, 1901.

Limnophysa cubensis BAKER (non. Pfr.), Journ. Cin. Sci. N. H., XIX, p. 83, 1897.

Limncea ferrissi Baker, Moll. Chi. Area, p. 277, pl. 31, fig. 26, 1902.

Lymnaa smithsoniana LeA, Proc. Phil. Acad., 1864, p. 113; Journ. Phil.

${ }^{1}$ These references may have been based on the true umbilicata but in the absence of the specimens, these records are left under caperata, for the present. 
Acad., VI, p. 161, pl. 24, fig. 76, 1866 ; Obs., XI, p. 117, pl. 24, fig. 76, 1867.-ScuDDER, Bull. Nat. Mus., 23, pp. 149, 201, 1885.

Limncea smithsoniana TryoN, Con. Hald. Mon., p. 103 (77), pl. 18, fig. 2, 1872.

Limnophysa smithsoniana TRYoN, Amer. Journ. Conch., I, p. 255, 1865.

SHell: Ovately-elongated, turreted, rather solid; color yellowish horn to brown, sometimes black; surface dull to shining; lines of growth very fine, crowded, irregular; shell encircled by numerous equidistant, heavily impressed spiral lines which give the shell a rather latticed or wavy appearance; these spiral lines appear at first to be elevated, this effect being caused by the epidermis standing erect in the otherwise impressed spiral lines; this epidermis may be scraped or brushed off, after which the surface resembles the other Lymnæas with spiral lines; whorls $6-6 \frac{1}{2}$, very convex; spire acutely conic, generally longer than the aperture; nucleus consisting of one and a third whorls, in outline resembling the nucleus of Galba bulimoides techella (pl. XLIX, fig. C), sculpture of satin finish and color generally deep wine or brown; sutures very heavily impressed; aperture ovate, its terminations more or less rounded, frequently reddish or purplish within; peristome thin, sharp, thickened by an internal rib, which is edged with dark purple; inner lip reflected over the umbilicus to form a wide, smooth, triangular expansion, without a columellar plait; parietal callus very thin; axis thickened but not twisted; umbilical chink open, generally rather wide and deep. The surface of the shell is frequently marked by two, three or more rest periods, showing as heavy yellowish longitudinal bands; the spiral lines are so heavy that they may be plainly seen on the inner whorls of the shell when broken open.

\begin{tabular}{|c|c|c|c|c|c|}
\hline $\begin{array}{l}\text { Length. } \\
12.00\end{array}$ & $\begin{array}{l}\text { Width. } \\
5.00\end{array}$ & $\begin{array}{c}\text { Aperture length. } \\
5.00\end{array}$ & $\begin{array}{l}\mathrm{Wi} \\
3.00\end{array}$ & $\begin{array}{l}\text { dth. } \\
\text { mill. }\end{array}$ & Say's specimen \\
\hline 11.50 & 6.25 & 5.50 & 3.00 & $“$ & Type Smithsoniana \\
\hline 11.00 & 5.50 & 4.50 & 3.00 & “ & Type ferrissi \\
\hline 17.00 & 7.50 & 7.00 & 4.00 & “ & Lake Albert Lea \\
\hline 15.75 & 7.50 & 6.50 & 3.50 & “ & Des Moines, Iowa \\
\hline 16.75 & 8.25 & 7.00 & 3.90 & “ & “ $\quad$ " \\
\hline 13.75 & 7.00 & 6.50 & 3.25 & “ & “ \\
\hline 13.50 & 6.50 & 5.80 & 3.00 & “ & Joliet, Ill. \\
\hline 13.75 & 6.75 & 6.25 & 3.30 & “ & Moran, Iowa \\
\hline 14.50 & 6.50 & 6.25 & 3.50 & “ & Emerson, Manitoba \\
\hline 14.00 & 7.00 & 6.25 & 3.50 & “ & Boulder, Colo. \\
\hline 13.00 & 7.00 & 6.00 & 3.00 & “ & " 6 \\
\hline 9.00 & 5.00 & 4.25 & 2.50 & “ & Marsh Lake, Yukon Terr. \\
\hline 13.10 & 6.50 & 6.00 & 3.10 & “ & N. Platte City, Neb. \\
\hline 14.90 & 8.00 & 7.50 & 4.00 & “ & " " " \\
\hline 12.50 & 6.00 & 5.50 & 2.90 & “ & Platte River \\
\hline 9.00 & 5.25 & 4.50 & 2.50 & “ & “ 6 \\
\hline
\end{tabular}


Types: Say's type cannot be found. A specimen received from Say is No. 58824 in the collection of the Academy of Natural Sciences, Philadelphia; smithsoniana Lea, six specimens, Smithsonian Institution, No. 118700 ; ferrissi, one specimen, Chicago Academy of Sciences, No. 3458 .

Type Locality: Indiana for caperata; Loup Fork of the Platte River for smithsoniana; Rock Run, Joliet, Illinois, for ferrissi.

Animal: Black or bluish black, lighter below and minutely flecked with small, whitish dots, which are scarcely visible except on the top of the head; head distinct; tentacles short, flat, triangular; foot short and wide, 8 mill. long and 3 mill. wide. The animal is very rapid and decisive in its movements.

JAW (pl. VI, fig. L) : Wide and rather high, the median swelling occupying about one-third of the width; ends rather bluntly rounded.

RADULA (plate IX, figure J) : Formula: ${ }_{5}^{2}-\frac{0}{7}+\frac{4}{3}-4+\frac{8}{2}+1+\frac{1}{1}+\frac{8}{2}+\frac{4}{3}-\frac{4}{4}+\frac{20}{5}-7$ (32-1-32) ; central tooth with a rather broad, spade-shaped cusp; lateral teeth bicuspid, the mesocone very broad, the ectocone very small and placed rather high; intermediate teeth tricuspid, the entocone of the ninth, tenth and eleventh teeth very small and acute, placed high on the mesocone, which is smaller than in the lateral teeth; the twelfth tooth is very much modified, with the three cusps about equal in size; marginal teeth claw-like, the entocone split to form from three to four small cusps, the mesocone and ectocone reduced in size and a small cusp appearing prominently above the ectocone. There are over eightyfive rows of teeth.

In the Mollusca of the Chicago Area, the writer figured a radula with but seven laterals, but the normal number is eight. The radula figured on page 272 for the short-spired caperata is incorrect, no specimens being subsequently studied which gave such a formula.

Genitalia (plate XIII, figure D): Male organs: Penis short, two-thirds the length of the penis-sac, which is large and cylindrical; vas deferens a trifle longer than penis and penis-sac combined; prostate duct about the length of penis and penis-sac; prostate large, ovately cylindrical, rounded at both ends; retractor muscle of penis enlarged at its insertion in the columellar muscle; penis-sac retractor enlarged at its junction with the penis-sac, about three-fourths the length of the penis retractor; the two retractors are joined at their insertion in the columellar muscle.

Female organs: Lower portion of oviduct narrow, short; first accessory albuminiparous gland very large, bulbous; receptaculum 


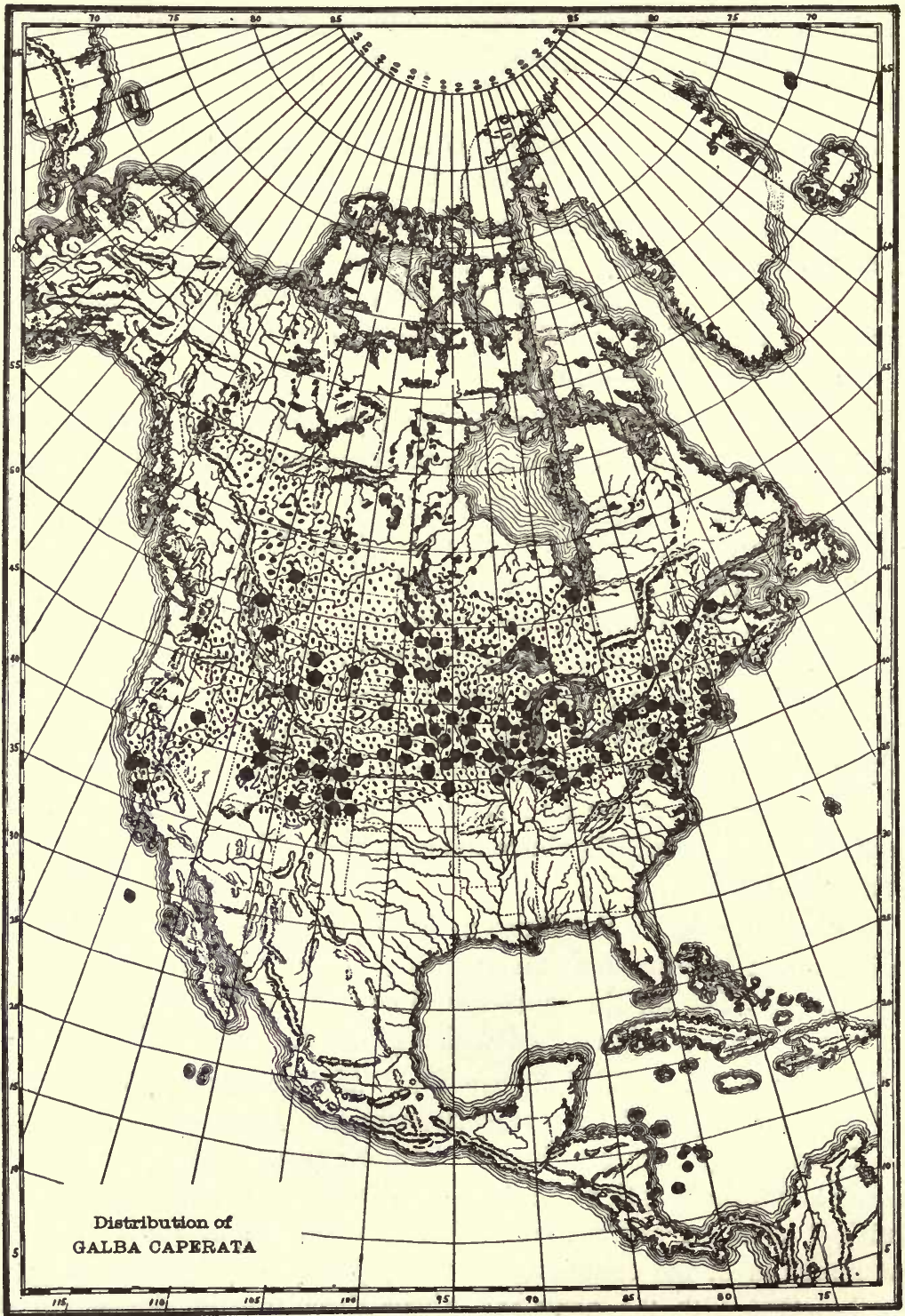

$\mathrm{F}_{1 \mathrm{G}}, 19$. 
seminis small, rounded, its duct one-fourth longer than the penis-sac; vagina rather long.

The comparative measurements may be tabulated as follows : ${ }^{1}$

\begin{tabular}{cccccccc} 
& & & \multicolumn{4}{c}{ Penis-sac } \\
Penis. & Penis-sac. Vas. def. & Prost. & duct. & Rec. sem. & Penis retr. & retr. & Shell. \\
2.00 & 3.00 & 7.00 & 5.00 & 4.00 & 2.00 & 1.50 & 14.90 \\
2.00 & 3.00 & 7.00 & 6.00 & 4.00 & 2.00 & 1.50 & 13.00 \\
2.00 & 3.00 & 7.00 & 6.00 & 4.00 & 3.00 & 2.00 & 14.00
\end{tabular}

There is very little variation in the genitalia of caperata, the size and shape of the different organs being quite uniform.

RANGe (Figure 19): From Quebec and Massachusetts west to California; Yukon Territory and James Bay south to Maryland, Indiana, Colorado and California.

Caperata is a species of northern distribution, occupying portions of the Canadian, Hudsonian, Mackenzian, Yukonian, Columbian, Coloradoan, Californian, Great Basin, Upper Mississippian and Nova Scotian regions. Its center of distribution embraces a broad belt across the center of North America from about the 38th to the 52nd degree c.f north latitude, the belt being, therefore, about fourteen degrees in width. Caperata is a characteristic species of the Upper Mississippi Valley, from whence it has migrated to other parts of the country. So far as the forests are concerned, it seems to extend only slightly into the deciduous area in the southeastern part of its range, but occupies a large part of the coniferous area, as well as of the plain and prairie areas. ${ }^{2}$ It extends through the Hudsonian, Canadian and Transition life zones.

The range of caperata has been restricted by some conchologists to the country east of the Rocky. Mountains, but the records from California, Utah and Washington are authentic and there is no doubt of the range of this species to the Pacific Coast. Further records are needed from the western states and especially from British America, where the records indicate a northwesterly range to Alaska.

\footnotetext{
${ }^{1}$ Dissection No. 23907. : Dissection made in July, from Joliet, Illinois, specimens.

${ }_{2}$ There are several records of this species from Louisiana and Texas, but no specimens have been seen from any state south of Indiana and Colorado: these records are believed to have been founded on some forms of the cubensis group, possibly Galba bulimoides techella or Galba cubensis, both of which bear some resemblance to caperata. The references and localities are as follows:

Adams, Sh. Red Riv. Louis., p. 244, 1854

Singley, An. Rep. Geol. Surv. Texas., IV, p. 188, 1892; p. 313, 1893.

Frierson, Nautllus, XIV, p. $68,1900$.

The first locality is near Cache Creek, Oklahoma; the Texas localities are in Hardeman, Gillespin, Baylor, Reeves, Swisher, Cottle and Stonewall counties; Frierson records a small species from the great raft in the Red River, doubtfully as caperata. The writer has not been able to secure specimens from these localities for the verification of the records. Call's records from Cimarron River, Oklahoma, and from Elk Creek, Barber County, Kansas, need confirmation. We suspect these to have been based on a variety of bulimoldes.
} 
Geological Range (Figure 20): Pleistocene. The geologica! range of caperata is not as extensive, judged by the records, as is its recent range. The records are sufficiently numerous, however, to indicate a wide extension in the Upper Mississippian and Canadian regions. None of the records are preglacial. It is a characteristic Lœss fossil owing to its peculiar habitat. Further Lœss researches will doubtless largely extend the range herein indicated.

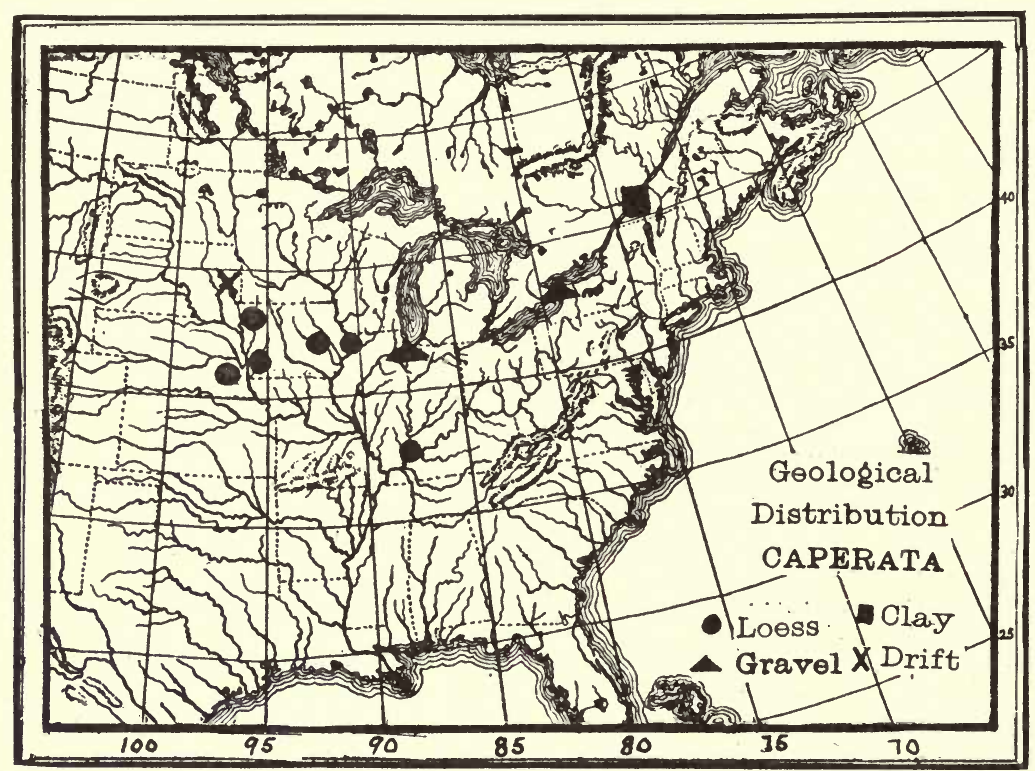

FIG. 20.

LOESS.

IowA: Fremont and Mills Counties, Iowa, in bluffs bordering the Missouri River (Call); Lœss of Iowa (Keyes; Shimek) ; Lœss of Iowa City, Johnson Co. (McGee, smaller than living form; Shimek); Bluff above Hershey Avenue, Muscatine, Muscatine Co.; Division; St. Davenport, Scott Co., near base of Lœss (Leverett; Shimek; Udden) ; $2 \frac{1}{2} 2$ miles north-east of Minden, Pottawattamie Co.; Nebraska City, Fremont Co., and Sioux City, Woodbury Co.; Scott and Johnson Counties (Shimek).

Indiana: New Harmony, Posey Co. (Daniels; Weller.)

Nebraska: Lancaster Co. (Shimek).

SAND AND GRAVEL DEPOSITS.

ILLiNois: Sand banks along Lake Michigan shore, north of Graceland Avenue, Chicago (Jensen).

Canada: Sand and gravel pits near Niagara Falls (Bell; Can. Geol. Surv.). 
CLAY DEPOSITS.

Canada: Mr. Peel's clay pits near Montreal (Bell); Pleistocene fossil, Montreal (Dawson).

DRIFT.

South Dakota: Sioux Falls, Minnehaha Co. (Todd).

Ecology: "Lymnea caperata I have found almost invariably in ditches and sloughs which are dry during part of the year, with nearly always a fine mud bottom; often in ditches entirely free from vegetation, with obrussa, and again in sloughs containing much swamp grass, filled by spring overflow of streams." (Henderson, for Colorado specimens.) Among grass in marsh (Humboldt County, Nevada; Richardson).

In the Mississippi Valley this species seems to almost invariably occupy intermittent streams or small pools, ponds and ditches which dry up in the summer. In Illinois it is usually found in association with Aplexa hypnorum and Spherium occidentale, either in small streams, pools or sloughs, or in spring pools in the woods which become completely dry in late spring and summer. The species hibernates to a greater degree than any of the other Lymnæas, a fact attested by the many rest varices observed on the shell of large individuals. In these dry ponds living specimens may frequently be found by digging into the mud under leaves and other debris. The reports of Van Hyning for Iowa, Walker for Michigan, Baker for New York and Sterki for Ohio show the same ecological relations of this species.

REMARKS: Although the statement has been-made that caperata may prove a heterogeneous-assemblage of different forms, it is nevertheless true that it is one of the most distinct and uniform of American Lymnæas. The striking manner in which the epidermis stands erect in the impressed spiral lines is peculiar to this species and will always distinguish it when the specimens are fresh. Some small specimens resemble individuals of cubensis and humilis, and have been thus reported by various collectors. Caperata is one of the commonest of American Lymnæas and is found over a very wide stretch of country. It varies somewhat in the length of the spire and in the rotundity of the whorls, but this variation is not marked or uniform. (Plate XXVIII.) Specimens from Iowa, Illinois and Indiana are very large and robust. Many specimens are quite scalar and the color variation is wide. The shell is sometimes quite thin, though generally very solid. Individuals from Yukon Territory are smaller and paler than typical caperata, but offer no other tangible characters. They were compared with Say's specimen by Dr. H. A. Pilsbry, who pronounced them identical. Some specimens from California and Wyoming resemble buli- 
moides in general form and may be distinguished by the presence of the heavy impressed spiral lines.

Half-grown specimens with short spire have been identified as umbilicata by many students and have been so reported from various parts of the country. A study of Adams' specimen of umbilicata has shown, however, that these authors were in error, Adams' specimens being quite a different shell. (See umbilicata.) Caperata was at first thought to range under stagnicola, but its wide, flat inner lip, and the shape of the prostate, places it rather in typical Galba, with cubensis and truncatula.

Say's type of capcrata is not in existence. A somewhat worn specimen with long, scalar spire is preserved in the collection of the Academy of Natural Sciences of Philadelphia (No. 58824), marked as follows, in MS.: "Lymnca caperata Say. Illinois. N. H. Disseminator, Vol. 2, p. 230. Ex. Auct." This specimen differs but slightly from Binney's figure $8 \%$, being a trifle more scalariform. It agrees well with Haldeman's figure 3 on plate 11 of his monograph. Smithsoniana Lea is an absolute synonym of caperata, differing only in size, in its shorter spire and in its darker color. Lea's types in the Smithsonian Institution do not differ from caperata as found in Indiana and Illinois. Specimens recently collected in the south branch of the Platte River near Fort Morgan by H. W. Clatworthy (Ex. Mr. Junius Henderson) are identical with Lea's types. Ferrissi Baker is simply a markedly scalariform example of caperata. (Plate XXIX, figure 3.)

Caperata has been kept in an aquarium in the writer's study for many months at a time. While in confinement many specimens ate holes in each others' shells for the lime needed to build their own shells. An egg mass of this species was laid March 16, 189\%. It contained 45 eggs, distinctly nucleated, and in a jelly-like mass measuring 11 by 2 mill. On March 18 a second egg mass was laid and on the 19th three more masses. On the 22nd three individuals were seen in coitu, each one endeavoring to play the active part. Of the five egg masses laid each contained the following number of eggs: $42,42,35,45,28$. The eggs were spherical in shape and very distinctly nucleated.

Galba holbollii ( (Beck) Möller). Plate XXIX, figure 4.

Limnca (Limnophysa) holbollii Beck, Index, p. 111, 1838. (Nude name.)

Limnaa holbollii Morch, Moll. Grön., p. 76, 1857.-Binney, Check List, p. 12,1860 ; L. \& F.-W. Sh. N. A., II, p. 59, fig. 91, 1865.-MorCH, Amer. Journ. Sci., IV, p. 36, pl. 4, fig. 8, 1868.-Tryon, Con. Hald. Mon., p. 101 (75), pl. 17, fig. 11, 1872.-Sowв., Conch. Icon., XVIII, sp. 22, pl. 4, fig. 22, 1872.-STeenSTrup, Mal. Blatt., n. s. I, p. 17, 1879.-West., Vega Exp., IV, pp. 167, 169, 170, 1885. 
Lymnaa holbollii Molder, Ind. Moll. Groen., p. 5, 1842.-Reeve, Voy. Assistance, p. 392, 1855.-DALl, Moll. Alaska, p. 74, fig. 53, 1905.

Limnaus holbollii Küster, Conch. Cab., p. 28, taf. 5, figs. 13, 14, 15, 1862.

Limnophysa holbollii b. minor, BEck., p. 111, 1838.

Limnophysa holbollii, a major, Beck., p. 111, 1838.

Limnophysa holbollii Tryon, Amer. Journ. Conch., I, p. 254, 1865.

SHELl: Small, elongate-ovate, conic, thin, more or less scalar; color greenish horn; surface dull to shining, lines of growth very fine, crossed by microscopic impressed spiral lines; whorls 5, well rounded, not rapidly increasing in diameter; spire acutely conical, much longer than the aperture; sutures well impressed; aperture roundly-ovate, in some specimens almost continuous; outer lip thin, no varical thickening observed in the specimens examined; inner lip rather wide, triangular, reflected over but not covering the umbilicus, which is rather widely open; parietal callus thin; axis slightly twisted; varical bands on the shell four or five in number.

\begin{tabular}{|c|c|c|c|c|}
\hline $\begin{array}{c}\text { Length. } \\
14.00\end{array}$ & $\begin{array}{c}\text { Width. } \\
\ldots .\end{array}$ & $\begin{array}{c}\text { Aperture length. } \\
7.00\end{array}$ & $\begin{array}{l}\text { Width. } \\
\text {... mill. }\end{array}$ & Vide Mörch \\
\hline 12.00 & 6.50 & 5.75 & 3.10 & Greenland \\
\hline 11.50 & 6.00 & 5.75 & 3.25 & “ \\
\hline 11.00 & 6.00 & 5.00 & $2.75^{\circ}$ & " \\
\hline
\end{tabular}

Types: Museum of University of Copenhagen, Denmark.

Type Locality: Godthaab, Greenland.

Animal: "Dark yellowish-gray; tentacula narrower and more pointed than L. vahlii." (Möller.)

Jaw, Radula and Genitalia: Unknown.

RANGe: Greenlandian region. A typical boreal species, not known to live outside of Greenland.

\section{RECORDS.}

Greenland: Greenland (Walker); Godthaab (Möller).

Geological Range: Unknown.

Ecology: Found in a little tank in the mountains of Godthaab (Möller).

Remarks: Holbollii may be known by its small size, long, acute spire, short, roundly-ovate aperture and large umbilical chink. The whorls are evenly rounded and the inner lip is quite expanded. It differs from truncatula in its more regularly acutely-conic spire and less compressed and more triangular inner lip. It greatly resembles some specimens of caperata, but lacks the decided sculpture of that species, besides having less rotund whorls and a differently shaped inner lip. By most conchologists, holbollii has been ranged with vahlii under Stagnicola, but its affinities seem rather to be with truncatula under Galba. 
Subgenus SIMPSONIA Nov. Subgen.

\section{Type: Limnca humilis Say.}

SHell: Similar in general form to that of Galba.

RAdula: With tricuspid lateral teeth.

Genitalia: Similar to Galba.

This group of small Lymnæas is separated from the subgenus Galba mainly on account of the radula, which has tricuspid instead of bicuspid laterals. The shell offers no definite characters of group value by which to separate Simpsonia from Galba. The subgenus contains the humilis-obrussa-parva group of Lymnæas, in which the shell is usually small and without marked spiral sculpture. It is mainly confined to the northern part of the United States and Canada.

Galba umbilicata (C. B. Adams). Plate XXX, figures 1-\%.

Limnaa umbilicata C. B Adams, Amer. Journ. Sci., i, XXXIX, p. 374, 1840.-Bost. Journ. Nat. Hist., III, p. 325, pl. iii, fig. 14, 1840.-TAYLOR and Shiverick, Cat., 1840.-Gould, Invert. Mass., p. 218, fig. 149, 1841.-Prescott, Cat. Sh. Mass., No. 198, 1842.-Reed, Cat., 1845.-Russell, Journ. Essex Co. Nat. Hist. Soc., p. 130, 1852.-Lewis, Proc. Bos. Soc. N. H., VI, p. 2, 1856 (part).-Turts, Proc. Essex. Institute, I, p. 30, 1856.-True, Proc. Essex Inst., II, p. 195, 1857.-Whiteaves, Can. Nat., VIII, p. 103, 1863.-Binney, L. \& F. W. Sh. N. Am., II, p. 57, fig. 88, 1865.-Gould, Binney Ed., Inv. Mass., p. 480, fig. 731, 1870.-Jeffreys, Ann. Mag. N. H., ser. IV, X, p. 247, 1872 (part); Journ. Conch., I, p. 8, 1874 (part).-H. F. Carpenter, Random Notes, III, p. 86, 1886.-Pilsbry, Proc. Phil. Acad., p. 320, 1891.

Lymnaa umbilicata LeA, Journ. Phil. Acad., VI, pp. 161, 162, 1866; Obs., XI, pp. 117, 118, 1867.-Scudder, Bull. Nat. Mus., 23, p. 201, 1885.-Walker, Nautilus, XXII, pp. 7, 8, figure 1, pl. 2, figs. 1, 2, 1908; Ottawa Nat., XXII, pp. 90-91, fig. 3, 1908.-Lermond, Shells of Maine, p. 37, 1909.-BAKer, Nautilus, XXIII, p. 80, 1909.

Lymnca caperata var. umbilicata JAY, Cat. Ed. 4, p. 268, 1852.

Limnea umbilicata Hald., Mon. Limn., p. 34, pl. 11, fig. 9, 1842.

Limneus umbilicatus Clessin, Mal. Blatt., n. s., III, p. 83, 1881.

Limnaa umbilicata JAckson, Nautilus, XXI, p. 142, 1908.

Limnaa humilis Heron, Ottawa Nat, I, p. 39, 1880.-Nylander, Nautilus, VIII, p. 126, 1895; XIII, p. 104, 1900.-Lermond, Shells of Maine, p. 38, 1908 (part).

Lymnea griffithiana LEA, Proc. Amer. Phil. Soc., II, p. 33, 1841; Trans. Amer. Phil. Soc., IX, p. 8, 1844 ; Obs., IV, p. 8, 1848.

Lymnaa griffithiana Wheatley, Cat. Sh. U. S., Ed. 2, p. 23, 1845.-ScudDER, Bull. Nat. Mus., 23, pp. 43, 201, 1885.

Limnca griffithiana Binney, Check List, p. 12, 1860; Land and F. W. Sh. N. A., II, p. 66, fig. 107, 1865.-Tryon, Amer. Journ. Conch., III, p. 196, 1867 ; Con. Hald. Mon., p. 105 (79), pl. 18, fig. 5, 1872.-Clessin, Mal. Blatt., n. s. III, p. 81, 1881. PFr.).

Limnaa cubensis Crosse \& Fischer, Pilsbry, Von Martens, etc. (not 
SHELL: Small, rather solid, varying from ovate to elongate-ovate; color light yellowish or brownish; surface shining, with heavy growth lines crossed by very fine, almost microscopic spiral impressed lines; nuclear whorls as in cubensis; whorls $5-5 \mathrm{~T} / 2$, well rounded, the spire whorls inclining to become shouldered, the body whorl very convex; spire attenuated, broadly conical, about as long as the aperture; sutures well impressed; aperture ovate or roundly ovate, its axis nearly parallel with that of the shell; outer lip thin, with an internal varix edged with violet; inner lip reflected and turned back over the umbilical region, forming a narrow, somewhat elevated expansion; parietal wall with marked callus; umbilical chink large and conspicuous; axis of the whorls as in cubensis.

\begin{tabular}{cccccc} 
Length. & Breadth. Aperture length. & \multicolumn{2}{c}{ Breadth. } \\
7.00 & 4.50 & $\ldots$. & $\ldots$. & mill. & Adams \\
6.75 & 4.00 & 3.50 & 2.10 & “ & Rhode Island. \\
6.00 & 3.40 & 3.00 & 1.90 & “ & “ \\
7.75 & 4.00 & 3.75 & 2.00 & " & Maine. \\
7.00 & 3.00 & 3.50 & 2.00 & “ & “ \\
7.00 & 4.00 & 3.50 & 2.00 & " & “ \\
6.00 & 3.50 & 2.75 & 1.25 & & Griffithiana
\end{tabular}

Types: Umbilicata, Amherst College. Cotypes: Phil. Acad. Sci. (eight specimens, No. 58507) ; Smithsonian Institution, No. 28158 (Binney's No. 8249); Museum of Middlebury College, Vermont; griffithiana, Smithsonian Institution, two specimens, No. 11946\%.

Type Locality: New Bedford, Massachusetts, for umbilicata; Charlotte Lake, Columbia County, New York, for griffithiana.

Animal: Not differing from the other small Lymnæas.

JAw (plate VI, fig $\mathrm{H}$ ): Wide and low, much arched with a narrow, acute median projection on the ventral margin.

Radul $\Lambda$ (plate VIII, figs. A, B) : Formula: $\frac{16}{5}-\frac{6}{7}+\frac{2}{3}+\frac{4}{3}+\frac{1}{1}+\frac{4}{3}+\frac{2}{3}+\frac{16}{5}-7$ (22-1-22) ; central tooth with rather wide cusp; lateral teeth tricuspid, the mesecone very long and wide, the entocone and ectocone smaller; the fourth and fifth laterals become elongated, the entocone moves toward the distal end and becomes larger and the mesocone becomes smaller; the true marginals begin at the seventh tooth and consist of a long and narrow, bifid entocone, a larger mesocone and a smaller cctocone; one or two very small serrations appear on the reflection above the ectocone; the outer marginals become claw-like with from three to five serrations at the distal end and several smaller serrations on the outer margin. There are about 90 rows of teeth. The teeth are quite uniform, little variation being seen in several membranes examined. In one membrane the seventh tooth (transition) was dis- 
tinctly tricuspid, the cusps being subequal (fig. B). In specimens from New Jersey the marginals began at the ninth tooth, the seventh and eighth teeth being transitional.

Genitalia (plàte XI, fig. B): Male organs: Penis-sac wide, rather long; penis very narrow, from four-fifths to seven-eighths the length of the penis-sac; penis retractor and penis-sac retractor of about equal length (as long as penis), separate, entering the columellar muscle in close proximity; protractor muscles four in number, two very narrow muscles posterior and two wide, powerful muscles anterior; vas deferens a little longer than penis and penis-sac; prostate

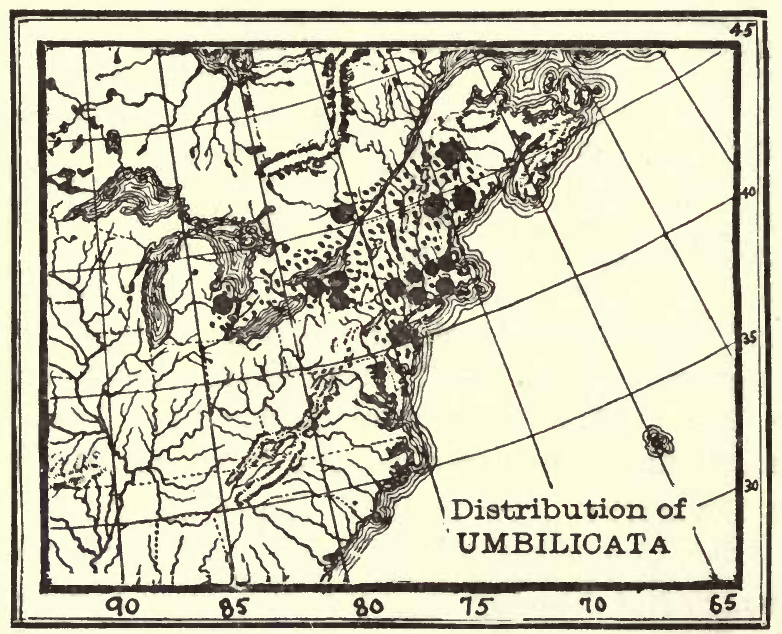

FIG. 21.

duct as long as penis; prostate long, ovate, flattened with rounded extremities, entering the prostate duct by a narrow construction; posterior portion of prostate very narrow.

Female organs: First accessory albuminiparous gland very large, pyriform; lower portion of oviduct short and thick; receptaculum seminis ovate, its duct very narrow and about half as long as the vas deferens. The other organs as usual. The receptaculum seminis is salmon colored, but the other organs are flesh-colored or whitish.

The genital organs, with the exception of the penis muscles, are very uniform in this species. In two specimens examined the penis retractor was attached to the penis-sac retractor about midway of the latter, and in one specimen one of the posterior protractor muscles of the penis-sac was attached to the latter at the same point as the penis- 
sac retractor. (P1. XIV, fig. F.) The normal form and position of the retractor and protractor muscles appears to be as shown in (1) of Fig. F.

Several measurements of the genitalia are given below. (Dissections Nos. 23151, 23165, 23166):

\begin{tabular}{|c|c|c|c|c|c|c|c|c|}
\hline $\begin{array}{c}\text { Penis. } \\
1.00\end{array}$ & $\begin{array}{l}\text { Penis- } \\
\text { sac. } \\
1.25\end{array}$ & $\begin{array}{l}\text { Rec. } \\
\text { sem. } \\
1.50\end{array}$ & $\begin{array}{l}\text { Prost. } \\
\text { duct. } \\
1.00\end{array}$ & $\begin{array}{l}\text { Vas. } \\
\text { def. } \\
2.50\end{array}$ & $\begin{array}{l}\text { Penis } \\
\text { ret. } \\
1.00\end{array}$ & $\begin{array}{c}\text { Penis- } \\
\text { sac. ret. } \\
1.00\end{array}$ & $\begin{array}{c}\text { Shell. } \\
6.00\end{array}$ & $\begin{array}{c}\text { Locality. } \\
\text { Cayuga Lake }\end{array}$ \\
\hline 1.75 & 2.10 & 1.50 & 1.00 & 3.00 & 1.50 & 1.00 & 7.00 & " " \\
\hline 1.00 & 1.10 & 1.50 & 1.00 & 3.50 & 1.50 & 1.50 & 7.00 & “ \\
\hline 1.40 & 1.60 & 1.80 & 1.40 & 4.00 & 1.00 & 1.00 & 8.00 & Maine \\
\hline 1.00 & 1.10 & 1.50 & 1.00 & 3.00 & 1.00 & 1.00 & 6.20 & \\
\hline
\end{tabular}

In some specimens the penis is slightly enlarged toward the head. (Plate XI, fig. B, 1.)

The genitalia of umbilicata closely resemble those of parva.

RANGE (Figure 21): Northern Maine and southern Ontario to Rhode Island and New Jersey, west to New York and southeastern Michigan.

The range of umbilicata is imperfectly known, as it has probably been identified as humilis, which it somewhat resembles. The records at present known show it to range from Maine to Michigan and south to New York and New Jersey, which indicates that it is an inhabitant of the Canadian and Nova Scotian regions. It is characteristic of the humid divisions of the Canadian and Transition life zones. Until more specimens have been examined from different parts of the United States no generalizations can be made. Umbilicata probably inhabits a large portion of the northern part of the United States.

\section{RECORDS.}

UNITED STATES.

Connecticut: Small stream emptying into Farmington River, Unionville, Hartford Co. (Baker).

Maine: Buckfield, Oxford Co. (J. A. Allen); Woodland, Aroostook Co. (Nylander); Fox Island, Penobscot River, Knox Co. (Jackson).

Massachusetrs: New Bedford, Bristol Co. (Adams); Brook near Cabot's Park, Newton; Charles River above Watertown, Middlesex Co. (Baker); Swampscott, near Lynn, Essex Co. (Tufts); Southborough, Worcester Co. (Bos. Soc. N. H.) ; Salem, Essex Co. (True); Essex Co. (Russell) ; Westfield, Hampden Co. (Smith. Coll.).

Michigan: Otter Lake, Lapeer Co. (Walker).

NEW JERSEY: Drainage ditches east of Burlington, Burlington Co. (Baker; Pilsbry).

NEW YoRK: South end Cayuga Lake, near Ithaca, Tompkins Co.; Erie Canal; Maplewood Park, Rochester, Monroe Co.; 4 miles south of Cayuga, Cayuga Co. (Baker); Charlotte Lake, Columbia Co. (Lea).

Rhode Island: The Fountain, Pawtucket, Providence Co. (H. F. Carpenter); Rhode Island (Walker). 
BRITISH AMERICA.

Ontario: Ottawa, Carleton Dist. (Heron); Carleton Co. (Walker).

Geological Range: Unknown.

Ecology: Abundant in still water in sheltered borders of rivers, in small brooks, ditches and streams and in shallow overflows. Clings to dead leaves or other submerged debris or crawls over the muddy bottom of its habitat, in shallow water. Associated with Galba obrussa, Aplexa hypnorum and the small planorbes (Baker). In ditches and brooks in pastures (True). Common in damp places and in ditches along roads where water collects only in rainy weather (Nylander).

REMARKS: The shell of umbilicata may be distinguished from cubensis by its smaller size, longer spire, less globose body whorl, rounder spire whorls and by the less triangular and more erect inner lip, which is peculiarly rolled over in cubensis. In half-grown specimens the spire is a trifle shorter than the aperture, but in mature individuals the spire is as long, or even a trifle longer, than the aperture. In umbilicata the center of rotundity of the body whorl is nearer the anterior end than in cubensis, the latter being decidedly effusive anteriorly. Specimens are occasionally found with a pink columella. Umbilicata differs from humilis in the shape of the inner lip, which forms a broad, flat, rolled up shelf, while in humilis it is narrow and the margin is rolled in instead of up. The shell of umbilicata is also more elongate and regularly long-ovate than that of humilis.

For the past eighteen or twenty years Adams' Lymncea umbilicata has been a puzzle to students of the Mollusca, and a number of very diverse opinions have been published concerning it. By some it has been considered a synonym of caperata, by others a variety of the same species, and by a few a synonym of cubensis Pfeiffer. The history of the treatment of umbilicata is interesting. Adams described the species in 1840 in the American Journal of Science and figured it in the Boston Journal of Science. Haldeman, in his monograph, in 1842, considered it a synonym of caperata. The earlier students-Lewis, Tufts, True, Currier, Beauchamp, etc.-considered it a distinct species. Tryon, in his Catalogue (American Journ. Conch., 1, p. 255), placed it in the synonymy of caperata. Binney placed it under caperata in his monograph, but treated it as possibly distinct in Binney's Gould. Baker and Daniels, in their papers on the Mollusca of Illinois and Indiana, have considered it a variety of caperata with short spire and bulbous whorls. Dall, in his Alaska Molluska, places it in the synonymy of caperata.

In 1891, Pilsbry (Proc. Phil. Acad., 1891, p. 321) stated as follows: "The L. umbilicata C. B. Ad. is completely synonymous with 
L. cubensis. Havana specimens of the latter are absolutely indistinguishable from Vermont L. umbilicata in our collection, received from Prof. Adams himself." Dr. Pilsbry's opinion was based on an authentic lot of umbilicata received from Prof. Adams, as stated above. It is interesting to note that both Crosse and Fischer, as well as Von Martens, have considered umbilicata a synonym of cubensis. Later Mr. Bryant Walker examined a cotype deposited by Adams in the Museum of Middlebury College. This specimen has been compared with material from Rhode Island and from Aroostook County, Maine, and the distinction of the species is beyond question. Pilsbry (op. cit., p. 321) suggested its relation to techella when he remarked: "L. techella Hald. is nearly identical with umbilicata." To Mr. Walker belongs the credit of finally settling the question of the standing of this neat little species, although he did not sufficiently differentiate it from cubensis.

Adams' reference of the species to Jamaica shows that he confused his species with cubensis, described a year earlier, and indicates the relationship of the two species. At one time it was the positive opinion of the writer that Adams had mixed his shells with the Jamaica material collected by him, but later researches have proven this opinion to be erroneous.

The Maine specimens, referred previously to humilis, are quite typical and, indeed, may be taken as the type of the fully mature form. They accurately correspond with the description of Adams, showing the inflated body whorl, the faintly impressed spiral lines and the short spire. In outline these shells strongly resemble a miniature caperata and it is no wonder that conchologists have so generally mistaken this species for the widely distributed caperata, when half grown.

Umbilicata was at first thought to group with cubensis, as pointed out by Pilsbry and Walker, but its radula has tricuspid lateral teeth, while in the cubensis group the laterals are bicuspid. This structure of the radula allies umbilicata with the humilis group, in which the laterals are tricuspid. Upon close inspection the shell is seen to be of the same general form as parva, sterkii, etc. Lea's griffithiana is absolutely synonymous with umbilicata, his shell, as well as others collected in New York state, being indistinguishable from the shells from Rhode Island and Maine. Many of the references to humilis from the Eastern and Middle states probably refer to this species.

Galba cyclostoma (Walker). Plate XXX, figure 8.

Limnaa cubensis Walker, Rev. Moll. Mich., p. 17, 1894. 1908.

Lymnaa cyclostoma WALKER, Nautilus XXII, No. 1, p. 7, pl. II, fig. 4, May, 
"Shell: Ovate, conic, turreted, umbilicate, light yellowish horncolored, shining; lines of growth fine, irregular, subobsolete on the body whorl, stronger on the apical whorls, reticulated by indistinct revolving, impressed spiral lines. Spire elongated, apex subacute; whorls 5, very convex, those of the spire somewhat shouldered, suture deeply impressed; body whorl large, inflated, very convex. Aperture broad, oval, subcircular, rounded above and below. Columella broadly reflected over the round, deep umbilicus, convex, smooth with no fold, parietal wall with a thin transparent callus. Lip sharp, but thickened within by a heavy white callus."

Length. Breadth. Aperture length. Breadth.

$\begin{array}{lllll}7.50 & 3.25 & \ldots . & \ldots . & \text { Type (Walker) } \\ 7.75 & 4.25 & 3.80 & 2.50 & \text { Cotype }\end{array}$

Types: Collection Bryant Walker, three specimens, No. 13599.

Type Locality: Indian Creek, Kent County, Michigan.

Animal, Jaw, Radula and Genitalia: Unknown.

Range: Michigan to New York. A species of the Canadian region and of the Transition life zone.

\section{RECORDS.}

Michigan: Indian Creek, Kent Co., Alma, Gratiot Co. (Walker).

New York: Ellicott Creek, Williamsville, Erie Co. (Miss. Walker).

Geological Range: Unknown.

Ecology: Not recorded.

REMARKs: Cyclostoma may be known by its peculiar cyclostomoid aperture and very obese body whorl. It combines characteristics of both umbilicata and parva and has been derived, doubtless, from the same stock. It approaches closer to parva in its rounded whorls and acute spire. It strongly resembles certain forms from Des Moines, Iowa (pl. XXIX, figs. 5-7), differing in the form of the aperture, the body whorl and the inner lip, as well as in sculpture.

"This very distinct little species was first collected by Dr. R. J. Kirkland, of Grand Rapids, Michigan, and was listed as L. cubensis Pfr. (umbilicata C. B. Ads.) in my Review of the Moll. Fauna of Michigan (1894). Through the courtesy of Mr. E. A. Burt, curator of the Museum of Middlebury College, I have been able to examine the specimens of L. umbilicata deposited in that museum by Adams. The two species are so obviously distinct that verbal comparison is hardly necessary. L. cyclostoma differs in its more elevated, turreted spire, more broadly reflected columella and thickened white lip. It resembles umbilicata, however, in the sculpture, and is no doubt derived from the same stock." Cyclostoma will probably be found in many collections, labeled humilis or parva. 
Galba parva (Lea). Plate XXIX, figures 5-14; plate XXX, figures $9-12$.

Lymnea parza Lea, Proc. Amer. Phil. Soc., II, p. 33, 1841; Trans. Amer. Phil. Soc., IX, p. 11, 1844 ; Obs., IV, p. 11, 1848.-HANnA, Nautilus, XXIII, p. 96, 1909.-Scudder, Bull. Nat. Mus., 23, pp. 33, 44, 201, 1885.

Lymnca parva Wheatley, Cat. U. S. Shells, p. 23, 1845.-Wolf, Amer. Journ. Conch., VI, p. 28, 1870.-BAKER, Nautilus, XVIII, p. 126, 1905; Bull. Ill. State Lab. N. H., VII, p. 104, 1906.-WALKer, Journ. Conch., XII, p. 240, 1909.Lermond, Shells of Maine, p. 38, 1908.-BAKER, Nautilus, XXIII, p. 94.-PILsbry and Ferris, Proc. Phil. Acad., 1909, p. 515, 1910.

Lymnaa parvus Henderson, Univ. Col. Studies, IV, pp. 93, 179, fig. 32, 1907.-Sterki, Proc. Ohio State Acad. Sci., IV, p. 382, 1907.

Limnaa parva Bell, Geol. Surv. Can., Rep. Prog., p. 252, 1859.-Binney, Check List, p. 12, 1860 ; L. \& F. W. Sh. N. A., II, p. 64, fig. 102, 1865.-Tryon, Amer. Journ. Conch., III, p. 196, 1867.-Clessin, Mal. Blatt, n. s., III, p. 81, 1881.-Marsh, Conch. Exch., II, p. 110, 1887.-Clapp, Nautilus, VIII, p. 116, 1895.-Сhadwick, Bull. Wis. Nat. H. Soc., n. s., IV, p. 83, 1906.

Limnea parva Anthony, List. L. \& F. W. Sh. Cin., 1843.

Limnaa humilis parva Sнiмeк, Bull. Lab. N. H. Univ. Iowa, I, pp. 209, 210, 211, 1890; Bull. Lab. N. H. Univ. Iowa, II, p. 90, 1893.

Limnophysa.humilis McGeE and Call, Amer. Journ. Sci., iii, XXIX, p. 208, 1882 (part).

Lymnca humilis var. parva? JAY, Cat., p. 269, 1852.

Lymnea humilis var. parva Todd, Proc. A. A. A. S., XXVII, p. 235, 1878.

Lymnea curta LeA, Proc. Amer. Phil. Soc., II, p. 33, 1841; Trans. Amer. Phil. Soc., IX, p. 11, 1844 ; Obs., IV, p. 11, 1848; Journ. Phil. Acad., VI, p. 163, 1866 ; Obs., XI, p. 119, 1867.-Scudder, Bull. Nat. Mus., 23, pp. 33, 44, 200, 1885.

Lymnaa curta Wheatley, Cat. U. S. Sh., p. 23, 1845.-Wolf, Amer. Journ. Conch., VI, p. 28, 1870.

Limnaa curta Binney, Check List, p. 12, 1860 ; Land \& F. W. Sh. N. A., II, p. 64, fig. 101, 1865.-Tryon, Amer. Journ. Conch., III, p. 196, 1867.-Clessin, Mal. Blatt., n. s., III, p. 81, 1881.

Limnaa truncatula Whiteaves, Nautilus, XIX, p. 4, 1905 ; Ottawa Nat., XIX, p. 66, 1905.

Limncea tazezuelliana Wolf, Amer. Journ. Conch., V, p. 198, pl. 17, fig. 2, 1869.-BAKer, Bull. Ill. State Lab., N. H., VII, p. 103, 1906.

SHELL: Small, rather solid, turreted, translucent; periostracum light horn or yellowish white, pellucid; surface shining, growth lines close set and well marked, sometimes elevated so as to roughen the surface of the last whorl; spiral lines very fine or absent; whorls $5-5 \mathrm{~T} / 2$, very convex, regularly increasing in size; nucleus of $1 \mathrm{I} / 4$ whorls, smooth, with satin-finish sculpture; in outline the nucleus is rounded, the first whorl being very large; the sculpture begins abruptly; as shown in figure $H$, plate XLIX. Spire elevated, forming an acute pyramid, generally longer than the aperture; sutures deeply impressed; 
aperture roundly and regularly elliptical, continuous in many specimens, a trifle effusive at the lower end; outer lip thin, sometimes developing it white deposit or varix a short distance from the edge; inner lip markedly and broadly reflected over the umbilicus, forming a broad, even expansion; parietal callus well marked, thick; umbilical chink well marked, open, axis straight, not twisted, thickened by shelly deposit.

\begin{tabular}{|c|c|c|c|c|c|c|}
\hline $\begin{array}{l}\text { Length. } \\
4.50\end{array}$ & $\begin{array}{l}\text { Breadth. } \\
2.50\end{array}$ & $\begin{array}{c}\text { Aperture length. } \\
1.50\end{array}$ & $\begin{array}{c}\text { Brea } \\
.50\end{array}$ & $\begin{array}{l}\text { dth. } \\
\text { mill. }\end{array}$ & Type parva & \\
\hline 7.75 & 4.10 & 3.50 & 1.50 & “ & Type curta & \\
\hline 6.00 & 3.00 & 2.50 & 1.25 & “ & Allegheny Co., & , Penn. \\
\hline 5.00 & 2.75 & 2.25 & 1.50 & “" & Dyer, Indiana & \\
\hline 9.00 & 4.50 & 3.80 & 2.00 & “ & Des Moines, I & Iowa \\
\hline 8.00 & 4.00 & 3.80 & 1.90 & “ & “ & “ \\
\hline 7.50 & 4.00 & 3.50 & 1.75 & “ & “ & “ \\
\hline 7.25 & 3.75 & 3.00 & 1.50 & “ & “ & “ \\
\hline 6.25 & 3.10 & 2.90 & 1.50 & “ & “ & “ \\
\hline
\end{tabular}

Types: Smithsonian Institution; parva, fourteen specimens; No. 119418, all immature; curta, four specimens, No. 118632; tazewelliana, location unknown.

Type Locality: Parva and curta, Cincinnati, Ohio; tazewelliana, Tazewell shore, Illinois River, Illinois.

Animal: Color blackish, very thickly dotted with fine white dots. The upper whorls are pinkish in the living animal, and the spotted mantle shows through the almost transparent shell. A specimen with head and foot protruded, measured as follows:

Length of foot and head. Width of foot. Length of shell.
4.25
2.00
7.00 mill

JAW : Superior jaw a trifle more than three times as wide as high, not notably arched, with a small median swelling on the ventral margin; the jaw resembles that of umbilicata.

RADUla: Formula : $\frac{18}{4}++^{\frac{2}{4}}+\frac{4}{3}+\frac{1}{1}+\frac{4}{3}+\frac{2}{4}+\frac{1}{4}+8(24-1-24)$; central tooth with a rather long cusp; lateral teeth tricuspid, very wide, the small entocone forming by a splitting of the large mesocone; ectocone rather large; the marginal teeth commence at the seventh tooth, in which the entocone and mesocone are about equal in size and appear at the distal end of the reflection; the typical marginal teeth begin with the tenth tooth, the distal end of the reflection becoming serrated, while the outer edge develops several small serrations. The marginal teeth are long and narrow, and there is considerable variation in the number and position of the individual cusps. Eighty-two to ninety-five rows ci: teeth were counted. The general form of the teeth are not different from those of umbilicata (pl. VIII, fig. A). 
Genitalia (pl. XI, fig. D): Male organs: Penis small, narrow, with rounded head, two-thirds as long as penis-sac, which is of large diameter; retractor muscles of penis one mill. in length, very slender; penis-sac retractor 1.25 mill. long and about twice as wide as the penis retractor; these muscles have their insertion close together in the columellar muscle; protractor muscles four in number, two wide, powerful anterior muscles entering the penis-sac by several branches, and two narrow posterior protractors; vas deferens four mill. in length; prostate, elongate, ovate, flattened, rounded at both ends; the anterior end gradually narrows to meet the prostate duct, which is about one mill. in length.

Female organs: Receptaculum seminis roundly pyriform, rather large, its duct 1.75 mill. in length; first accessory albuminiparous gland long-ovate, placed near the vaginal opening.

The organs of parva are very uniform. In several specimens examined, only one showed any variation and in this one the penis retractor was attached to the penis-sac retractor a short distance from its insertion in the columella muscle. (Pl. XIV, fig. E, 2.)

Three specimens gave the following measurements:

\begin{tabular}{|c|c|c|c|c|c|c|c|c|}
\hline $\begin{array}{c}\text { Penis. } \\
1.00\end{array}$ & $\begin{array}{c}\text { Penis- } \\
\text { sac. } \\
1.50\end{array}$ & $\begin{array}{c}\text { Penis } \\
\text { ret. } \\
1.00\end{array}$ & $\begin{array}{l}\text { Penis- } \\
\text { sac. ret. } \\
1.25\end{array}$ & $\begin{array}{l}\text { Rec. } \\
\text { sem. } \\
1.75\end{array}$ & $\begin{array}{l}\text { Prost. } \\
\text { duct. } \\
1.00\end{array}$ & $\begin{array}{l}\text { Vas. } \\
\text { def. } \\
4.00\end{array}$ & $\begin{array}{l}\text { Shell. } \\
8.10\end{array}$ & Des Moines \\
\hline 1.00 & 1.50 & 1.00 & 1.25 & 1.75 & 1.00 & 3.00 & 7.00 & " \\
\hline 1.00 & 1.50 & 1.00 & 1.15 & 1.75 & 1.00 & 4.00 & 6.80 & “ \\
\hline
\end{tabular}

The measurements show great uniformity. In one specimen (No. 2) the prostate duct was longer and the vas deferens shorter than in the other specimens examined. (Dissections Nos. 23133 and 23132.) The genitalia of parva are almost identical with those of umbilicata.

RANGE (Figure 22): Connecticut west to Idaho; James Bay and Montana south to Maryland, Kentucky, Oklahoma, southern New Miexico and Arizona.

Parva is a characteristic species of the Upper Mississippian region, from whence it has migrated into the Canadian, Hudsonian, Columbian (via the Missouri-Columbia drainages), Coloradoan and Rio Grandian regions. In the East it has penetrated into the Nova Scotian region. Farva occupies a large part of the Canadian, Transition and Upper Austral life zones. It is absent, apparently, from the Gulf and South Atlantic states. Its metropolis appears to be the Upper Mississippi Valley and the Great Lakes region. It has been universally confused with humilis and modicclla. When it is differentiated from these species it will doubtless be found to be widely distributed.

Geological Range: Pleistocene. 
LOESS.

Iowa : Des Moines, Polk Co. (McGee and Call; Van Hyning; Walker); Turkey Creek, Johnson Co.; common in Lœss with humilis (modicella) and caperata (Shimek); Lœss of Iowa (Todd).

GENERAL PLEISTOCENE.

Colorado: South Platte River, Arapahoe Co. (Henderson).

IllinoIs: Tazewell shore, Illinois River, Tazewell Co. (Wolf).

Recently Mr. Junius Henderson sent the writer a specimen of a small Lymnæa which seems to be a form of parva. It has a pointed spire, well-rounded whorls, deep sutures, a well-marked umbilicus, a long ovate aperture and the inner lip erect. The last whorl is much contracted, but this may be a malformation. It measures as follows:

Length. Width. Aperture length. Width.

$\begin{array}{llll}5.50 & 3.00 & 2.00 & 1.25 \mathrm{mill}\end{array}$

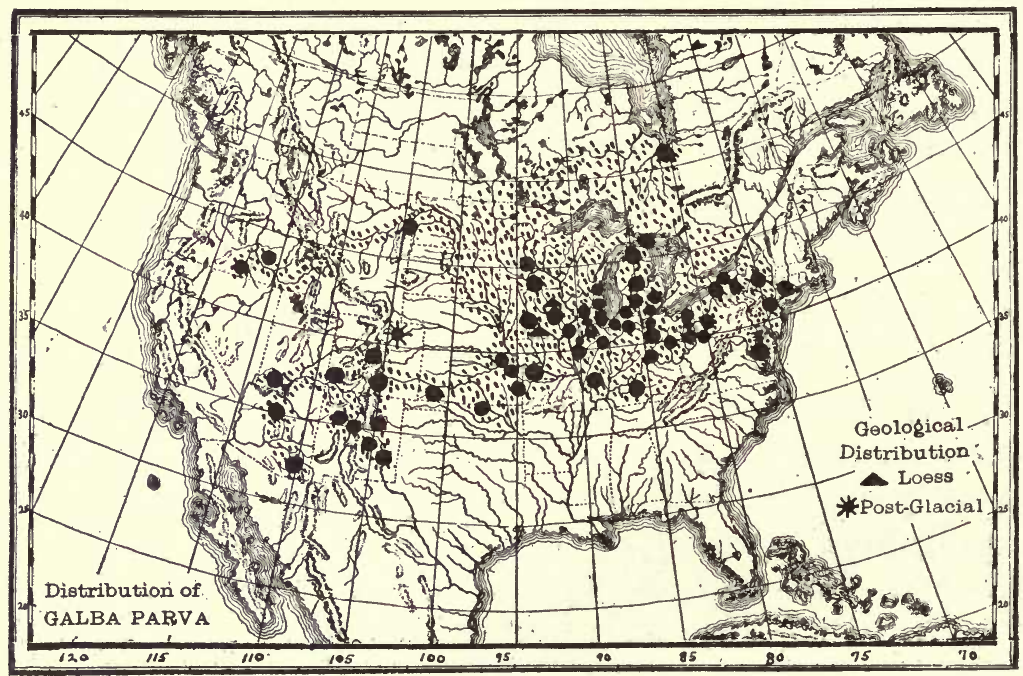

FIG. 22.

"I am sending you for examination a specimen of a small species of Limnæa of the identity of which I am not certain. I found two or three, but the material when freshly exposed was very fragile and this seems to be the only one which arrived home in recognizable condition. This shell is interesting to me and may be to you in your work on the Limncas, because it was found in what I at present consider Pleistocene deposits containing in the same horizon the following:

This form of Lymnæa was found in deposits supposed to be Pleistocene, which are thus described by Mr. Henderson: 
Pupilla muscorum, Succinea grosvenori, Vallonia gracilicosta and Planorbis parvus. Numerous exposures. disclose the recent geological history of the region to perfection. The South Platte first excavated a rather deep valley with steep bluffs along the northwest edge, then it refilled that valley with perfectly stratified deposits for the most part of fine material, with some local gravel beds. It is in a stratum of the fine material that these shells have been found."

Ecology: Parva is to be searched for in wet, marshy places, generally out of the water, on sticks, stones or muddy flats. The animal is more prone to leave the water than any other of the Lymnæas.

Remarks: Parva may be known by its peculiar bulimoid appearance. It is more slender than humilis, has a longer, more turreted spire, a more regularly elliptical aperture and a differently shaped inner lip, which is roundly and broadly reflected over the umbilicus. Some specimens resemble in outline a miniature Campeloma as recorded by Lea in his description of curta. Occasionally specimens will be found in which the whorls are more or less shouldered, the umbilicus is more widely open and the sutures are more deeply impressed. (P1. XXIX, fig. 8.) The sculpture of the surface varies, in some examples the shell being smooth while in others there are very fine revolving lines. Parva also resembles umbilicata, but may be known from that species by the shape of the inner lip, which stands erect in parva while it is flattened out and excavated, especially at its junction with the parietal wall, in umbilicata. The spire is longer and narrower, the sutures are more deeply impressed and the whorls rounder in parva. Parva is a common species and will probably prove to be widely distributed. When adult and perfectly formed it is one of the most graceful and handsome of Lymnæas, with its rounded whorls, deep sutures and elliptical aperture. It varies somewhat in corpulency, some specimens heing narrow while others are quite robust. The aperture varies from almost round to long-ovate.

Parva resembles truncatula somewhat, but is easily distinguished by its more elliptical aperture and longer, more attenuated spire. The umbilical region and columella are also different. Though resembling Inumilis, it is quite distinct and was erroneously placed in the synonym of that species by Binney. It is probable that a number of the records of humilis were founded on parva, but as it is impossible to examine the original specimens upon which the records were made, their authenticity cannot be verified.

The types of Lea's parva are all small, immature specimens. His curta is large and robust, representing the adult form of parva. A 
collection of several thousand specimens of parva+curta, sent for examination by Mr. T. Van Hyning of Des Moines, Iowa, proves beyond a question that the two forms are the same species. The statement in the Nautilus (XXIX, p. 52, 1905) is erroneous, the specimens there considered parva being a totally distinct species. (See dalli, page 251.) Limnca tazewelliana, described from Pleistocene deposits of the Illinois River, is undoubtedly the same as parva. Specimens from Des Moines, identified as tazewelliana by Dr. Pilsbry, are the same as Lea's parva in the Smithsonian collection, and the figure and description of tazewelliana agree perfectly with the Des Moines specimens. Wolf's figure is probably too obese in the body whorl, however. The type of tazewelliana was thought to be in the Philadelphia Academy, but a careful search failed to reveal it in the collection. The Wolf collection was presented to the high school at Canton, Illinois, but efforts to secure information concerning Wolf's types were fruitless.

Galba parva sterkii (Baker). Plate XXIX, figures 15-22.

Lymncea sterkii BAKeR, Nautilus, XIX, p. 51, Sept. 1905; Bull. I11. State Lab. N. H., VII, p. 104, 1906.-Srerki, Proc. Ohio State Acad. Sci., IV, p. 382, 1907.Daniels, Nautilus, XXII, p. 121, 1909.

Lymnaa parva sterkii BAKER, Bull. Ill. State Lab: N. H., VIII, p. 492, pl. 25, fig. 21, 1910 .

Shell: Small, elongated, turreted, rather thin ; color light yellowish horn, darker in some specimens; surface dull to shining, marked by distinct, crowded, raised growth lines generally without spiral lines; nucleus small, rounded, about the same size and shape as that of parva; whorls $51 / 2-6$, very convex, somewhat shouldered, especially the last; spire narrow, rather acute, turreted, generally longer than the aperture, sutures very deeply impressed; aperture ovate, much expanded anteriorly; outer lip sharp, thin; inner lip forming a very broad, flatly concave expansion reflected over the umbilicus, which it emargins; there is a thin wash of callus on the parietal wall; umbilical chink narr Jw but deep; axis thickened, straight.

\begin{tabular}{|c|c|c|c|c|c|}
\hline Length. & Breadth. & Aperture length. & Bre & adth. & \\
\hline 7.75 & 3.50 & 3.50 & 1.75 & mill. & Type \\
\hline 7.75 & 4.00 & 3.25 & 2.00 & “ & "] \\
\hline 8.00 & 3.50 & 3.50 & 2.00 & “ & “ \\
\hline 7.00 & 3.50 & 3.25 & 2.00 & “ & “ \\
\hline 10.00 & 4.75 & 4.75 & 2.50 & “ & Canton, I11. \\
\hline 9.00 & 4.50 & 4.60 & 3.00 & " & \\
\hline
\end{tabular}

Types: The Chicago Academy of Sciences, five specimens, Nos. 23155, 23156 ; cotypes, Philadelphia Academy of Sciences, No. 90177; coll. Sterki. 
Type Locality: Twelve miles west of Cleveland, Ohio.

Animal, Jaw, Radula and Genitalia: Unknown.

Range (figure 23): Central New York to Minnesota, south to Tennessee. Sterkii is typically a species of the Carolinian division of the Upper Austral life zone, extending northward in Minnesota and New York into the Alleghanian division of the Transition zone. This range may be greatly extended when the species becomes well known and special search is carried on for it. Thus far it has been seen only from Illinois, Minnesota, New York, Ohio and Tennessee, and appears, therefore, to be characteristic of the Upper Mississippian, Hudsonian and Canadian regions.

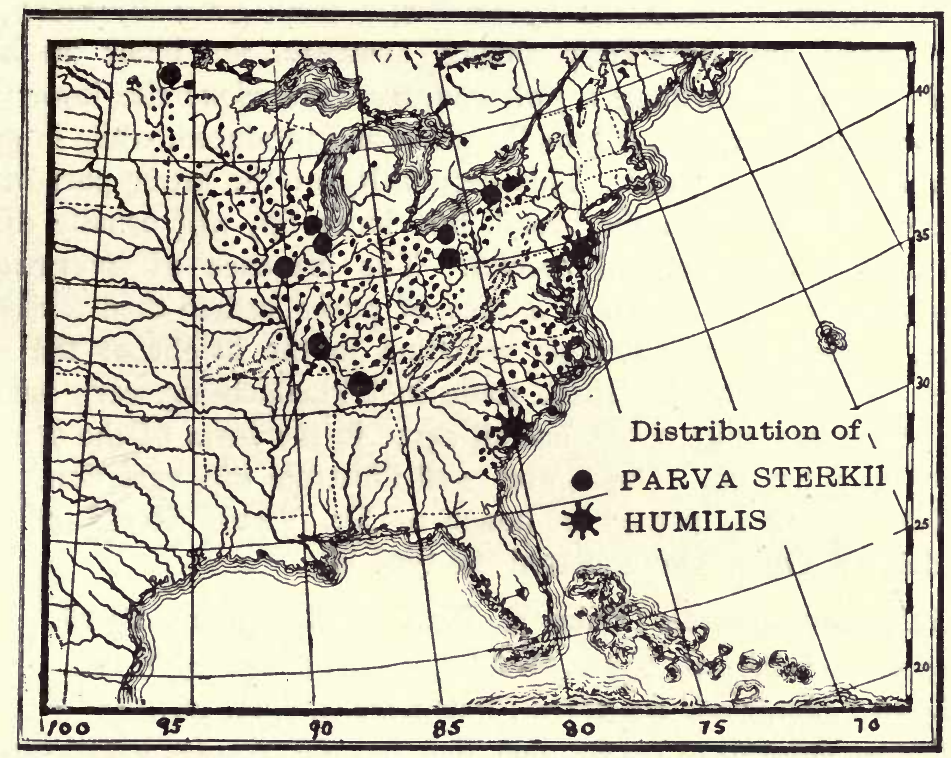

FIG. 23.

\section{RECORDS.}

IllinoIs: Glencoe, Cook Co. (Baker); Greenhouse, Lincoln Park, Chicago (Fry) ; Canton, Fulton Co. (Nason) ; Algonquin, McHenry Co. (Nason) ; Morgan Park, Cook Co.; Fountain Bluff, Jackson Co. (Woodruff).

Minnesota: Thief River Falls, Red Lake Co. (Daniels).

New YoRK: Road near Tichnor's Point, Canandaigua Lake, Ontario Co. (Baker).

Онго: Twelve miles west of Cleveland, in a small, swampy brook, Cuyahoga Co.; Blicktown, near New Philadelphia and Goshen, three miles southeast of New Philadelphia, Tuscarawas Co.; near Doner, Cuyahoga Co. (Sterki). 
Tennessee: Hickman Co. (Hinkley).

Geological Range: Unknown.

Ecology: In more or less swampy brooks and streams, in situations similar to those in which Galba parva is found.

Remarks: This curious Lymnæid was at first thought to be Lea's exigua, but his description does not cover the present species and the figure in Binney is totally unlike it. The type of exigua is not in existence, so that no direct comparison is possible. Sterkii bears a superficial resemblance to owascoensis, but in that species the whorls are decidedly and strongly shouldered, causing them to appear like boxes of diminishing size set one upon another, the whorls being very flat-sided. The inner lip is also very different in sterkii. It may be distinguished from parva by its larger shell, generally more flatsided whorls and differently shaped aperture, the inner lip being broadly reflected, forming a flat, concave expansion; the lower part of the aperture in sterkii is broadly effuse and produced, while in parva it is very evenly elliptical. This peculiarity of the lower part of the aperture, together with the broad, flat, inner lip, will usually distinguish sterkii from related species. The presence of intermediate forms suggests that sterkii is a race of parva rather than a distinct species. There is considerable variation in the height of the spire and in the width of the shell, some individuals being very narrow, while others are quite obese, but all agree in the form of the aperture and of the inner lip. The figures well illustrate this variation.

The variety is named in honor of Dr. Victor Sterki, of New Philadelphia, Ohio, who collected the type lot.

Galba owascoensis (Baker). Plate XXIX, figures 23-25.

Lymnca orwascoensis BAKER, Nautilus, XVIII, p. 141, April, 1905.

Limnea owascoensis Henderson, Nautilus, XX, p. 98, 1907.

Limnca owascoensis Letson, Bull. Buf. Soc. Nat. Sci., IX, p. 242, 1909.

Shell: Small, elongate, turreted, rather thin; color light yellowish horn; surface shining, marked by close-set lines of growth; in some specimens there is a tendency to become malleated; nucleus small, round, of the same color as the rest of the shell, in form similar to that of Galba parva, the first whorl being smaller; whorls six, strongly shouldered, rather flat-sided; spire elongated, sharply conical; sutures deeply impressed; aperture roundly ovate, almost continuous, about one-third as long as the entire shell; outer lip thin, sharp; inner lip reflected over the umbilicus to form a rather wide, flat projection; which is almost erect and strongly emargines the umbilical chink; the callus on the parietal wall is generally rather thin, but when heavy 
causes the aperture to be continuous; umbilical chink round, wide and deep, exhibiting one or more volutions; the base of the shell is roundly flattened.

\begin{tabular}{|c|c|c|c|c|}
\hline Length. & Breadth. & Aperture length. & Breadth. & \\
\hline 8.50 & 3.50 & 3.50 & 2.00 mill. & Type \\
\hline 8.75 & 4.00 & 3.50 & 2.00 & “ \\
\hline 7.60 & 3.50 & 3.00 & 2.00 & \\
\hline
\end{tabular}

Types: The Chicago Academy of Sciences, four specimens, No. $2315 \%$; cotypes, Philadelphia Academy of Sciences, No. 89172.

Type Locality: Owasco Lake, New York.

Animal, Jaw, Radula and Genitalia: Unknown.

RANGe: New York state. A species of the Alleghanian division of the Transition life zone and of the Canadian region.

RECORDS.

New York: Cazenovia, Madison Co. (Henderson); Owasco Lake, Cayuga Co. (H. N. Lyon); Cazenovia, Madison Co., and Williamsville, Erie Co. (Walker).

Geological Range: Unknown.

Ecology: Along the shore on debris, such as sticks, reeds, etc., or on stones and submerged vegetation.

REMARKS: Owascoensis may be known by its elongated, narrow sfire, turreted, flat-sided whorls and large, round, open umbilical chink. The whorls appear, when viewed in outline, like boxes of diminishing size set one upon another. The shape of the aperture is also peculiar. Its nearest ally is parva, from which it may be distinguished by its flat-sided and shouldered whorls, its generally compressed outline and its more open, round and deep umbilical chink which exhibits the last volution.

Galba dalli (Baker). Plate XXX, figures 13-18.

Lymnaa parva BAKer, Nautilus, XIX, p. 52, 1905 (not of Lea).

Lymnaa dalli BAKer, Bull. Ill. State Lab. N. H., VII, p. 104, 1906; Nautilus, XX, p. 125, 1907 (description).-Hanna, Nautilus, XXIII, p. 96, 1909.

SHELL: Very small, thin, ovate-conic, turreted; color greenish or whitish horn; surface dull to shining, marked by heavy, crowded growth lines which are elevated into indistinct ridges in some specimens; nucleus very small, flatly rounded, light horn-colored, similar in form to that of Galba parva. Whorls $4 \frac{1}{2}-5$, rounded and distinctly shouldered; spire generally obtusely conic, turreted, a trifle longer than the aperture; sutures very deeply impressed; aperture elongate ovate or elliptical, continuous in many specimens; outer lip acute; inner lip forming a rather flat erect extension over the umbilical region, leaving a pronounced chink; the lower part of the aperture is somewhat effusive; the columellar extension of the inner lip is sometimes 
so appressed at its junction with the parietal wall as to form a pseudoplait; the inner edge of the outer lip frequently forms a rib-like varix in very old specimens.

\begin{tabular}{|c|c|c|c|c|c|c|c|}
\hline $\begin{array}{c}\text { Length. } \\
3.25\end{array}$ & $\begin{array}{c}\text { Breadth. } \\
2.00\end{array}$ & $\begin{array}{c}\text { Aperture. } \\
1.50\end{array}$ & $\begin{array}{l}\text { Brea } \\
1.00\end{array}$ & $\begin{array}{l}\text { dth. } \\
\text { mill. }\end{array}$ & (Lake & James) & Type \\
\hline 4.00 & 2.00 & 2.00 & 1.00 & "6 & “ & 6 & 6 \\
\hline 3.00 & 2.00 & 1.25 & .90 & “" & “ & 6 & $" 6$ \\
\hline 4.25 & 2.00 & 1.75 & 1.00 & “6 & “ & " & “ \\
\hline 4.50 & 2.50 & 2.00 & 1.10 & “ & (Scala & riform) & \\
\hline 3.75 & 2.75 & 2.00 & 1.25 & & Rockf & rd & \\
\hline 4.00 & 2.10 & 2.00 & 1.10 & & 66 & & \\
\hline
\end{tabular}

Types: Chicago Academy of Sciences, No. 23125; cotypes, Academy of Natural Sciences, Philadelphia; Smithsonian Institution, Washington.

Type Locality: Marsh, west side Lake James, Steuben County, Indiana.

Animal, Jaw, Radula and Genitalia: Not examined.

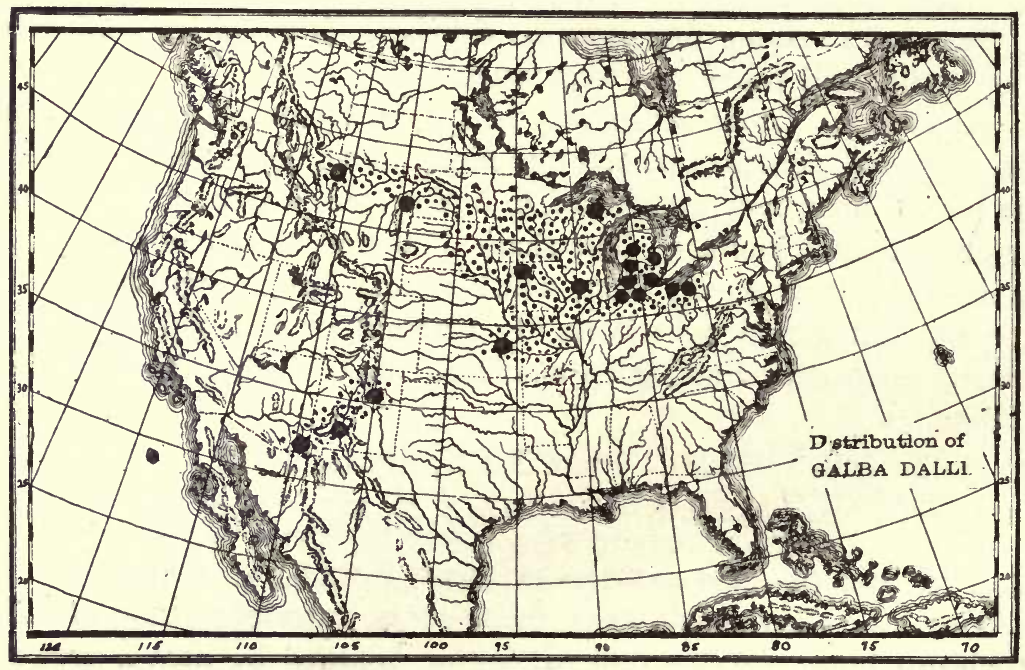

FIG. 24.

RANGe (Figure 24): Ohio to northern Michigan and Montana, south to Kansas and Arizona.

In general, dalli occupies a large part of the Transition and Upper Austral life zones; it reaches the Canadian zone in Michigan. It is typically an inhabitant of the Upper Mississippian region, reaching here its greatest degree of perfection. It has migrated south and west into the Coloradoan region. So little is known concerning the distri- 
bution of this tiny species that no generalization can be made at this time. It may ultimately be found to inhabit the greater part of the United States east of the Rocky Mountains and west of the Alleghanies, and to be coextensive with Galba parva.

RECORDS.

Arizona: Ash Canyon, Huachuca Mts., 5000 ft. alt., Cochise Co. (Ferriss and Daniels).

Illinois: Rockford, Winnebago Co. (Hinkley); Copperas Creek (E. Hall); Northern Illinois, in drift (Sterki).

Indiana: Lake Maxinkuckee, Marshall Co. (Bartsch); Arlington, Marshall Co.; Waterford and Little Kankakee River, La Porte Co.; Marsh, west side Lake James, Steuben Co. (Daniels).

IowA : Lost Island Lake and swamps, Ruthven, Palo Alto Co. (Walker).

Kansas: Lawrence, Douglas Co., in greenhouse; Tecumseh, Shawnee Co. (Hanna).

Michigan : Gratiot, Isabella, Kent, Marquette, Montcalm, St. Joseph, Tuscola and Washtenaw Counties (Walker).

Montana: Great Falls, Cascade Co. (Bailey); Beaver Creek, Mingusville and Wibaux, Dawson Co. (Squyer).

New Mexico: Flood debris, Arroya Pecos, Las Vegas, San Miguel Co. (Cockerell); drift of Rio Grande, Paraje, Socorro Co. (Cockerell).

Онго: Between Dover and Rocky River, near Cleveland, Cuyahoga Co.; Put-in-Bay Island (J. A. Allen); Cartalea, Erie Co., in creek near depot (Sterki).

Geological Range: Pleistocene.

Marl beds of Arnolds Lake, Washtenaw Co., Michigan (Walker).

Ecology: Found in situations similar to those occupied by Galba parva.

Remarks: This little species, the smallest of our American Lymnæas, is related to Galba parva, appearing at first sight to be a small example of that species. It differs from parva in its smaller size, rounder and more turreted whorls, slenderer outline, longer and narrower aperture and smaller and less conspicuous umbilicus. The whorls are inclined to be shouldered, also, a feature not emphasized in parva. There is some variation in the length of the spire, many specimens having a rather long spire, while in others the spire is much depressed and the whorls are humped, this last being in slightly abnormal forms. The inner lip of dalli is different from that of parva, being generally more crect; in dalli there is also a denting in or constriction at the point of juncture of the inner lip and the parietal wall which is not notably apparent in parva.

In the Nautilus (XX, p. 52) this species was described as the Barva of Lea, but a careful study of Lea's types in the Smithsonian. Institution makes it evident that it is not that species, but a new one 
hitherto unnoticed. Young specimens of parva are similar to dalli, but may be distinguished by the less number of whorls in shells of the same size and in the different shape of the whorls. The two species, parva and dalli, are related, but are easily separated when attention is given to the details of size and form. This peculiar little species is named in honor of Dr. William H. Dall, curator of the division of Mollusks of the Smithsonian Institution.

Galba pilsbryi (Hemphill). Plate IV, figures A, B.

Limnca (Leptolimnaa) pilsbryi HeмphilL, Nautilus, IV, p. 25, June, 1890.

Limncea pilsbryi KeEP, West Amer. Shells, pp. 149, 314, 1904.

SHell: Elongated, narrow, somewhat solid; periostracum light horn colored; surface sculpture of fine growth lines without spiral lines; whorls $6-61 / 2$, well rounded, slowly increasing in diameter, the body whorl much flattened in the middle; spire narrow, attenuated, over twice the length of the aperture; the spire whorls are well rounded and inclined to be shouldered; sutures deeply indented; aperture longoval, a trifle oblique; outer lip thin; inner lip narrow, reflexed to form a smooth, rounded expansion; parietal callus thin; umbilical chink small, slightly emargined by the inner lip; columella smooth, without a plait.

Length. Breadth. Aperture length. Breadth.

$\begin{array}{lllll}8.00 & 3.00 & 2.10 & 1.10 & \text { Type }\end{array}$

Types: Academy of Natural Sciences, Philadelphia, three specimens, No. 62293.

Type Locality: Fish Spring, Nye County, Nevada.

Animal, Jaw, Radula and Genitalia: Unknown.

RANGe: Nevada. A species of the Great Basin region.

RECORDS.

Nevada: Fish Springs, Nye Co., in approximately lat. 38.45, long. 116.30 (Hemphil1).

Geological Distribution: Unknown.

ECology: Not recorded.

Remarks: Pilsbryi is one of the most distinctive of American I.ymnæas, being unlike any other species. Its affinities seem to be with obrussa, the whorls of the spire resembling closely those of Galba owascoensis. The cylindrical shell, shouldered whorls, with their deep sutures and the small, oblique aperture, will at once distinguish pilsbryn from any other species. It was at first placed in the subgenus Leptolimnea, but a comparison with Galba glabra (Müller), the type of that group, shows that this disposition is not correct, the shape of the whorls and especially the inner lip being quite different. (See Plate XLVIII, figure 4.) 
Of this species Hemphill says: "I collected a few specimens of this interesting shell in the month of June, 1868, at this locality, after a long and hard day's ride of 40 miles horseback. Another long ride next day of 50 miles to water compelled an early start, and thus the opportunity to secure more specimens was lost."

It is very desirable that additional specimens be secured alive that the anatomy may be examined.

Galba ferruginea (Haldeman). Plate XXXI, figures 15-19.

Limnea ferruginea Haldeman, Mon. Lim., pt. 3, third page of cover, March, 1841 ; pt. 4, p. 49, pl. 13, figs. 19, 20, 1842.-DEKAY, Zool. N. Y., p. 75, 1843.Carlton, Proc. Cal. Acad. Sci., IV, p. 51, 1869.-?Ingersoll, Rep. U. S. Geol. \& Geog. Surv. Terr., p. 406, 1876; Bull. U. S. Geol. \& Geog. Surv. I, p. 139, $1875 .{ }^{1}$

Limnaa ferruginea CPR., Rep. Brit. Ass., 1856, pp. 265, 316.-Binnex, Check List, p. 12, 1860.-CPR., Rep. Brit. Ass., 1864, p. 674.-Binney, Land \& F. W. Sh. N. A., II, p. 67, fig. 110, 1865.-Sowв., Conch. Icon., XVIII, Lim. sp. 80, pl. 12, fig. 80, a, b, 1872.-Cpr., Smith. Mis. Coll., 1873, p. 160.-Trरon, Con. Hald. Mon., p. 103 (77), 1872.-Clessin, Mal. Blatt., n. s., III, p. 82, 1881.-CkLL., Journ. Conch., VI, p. 64, 1889.

Lymncea ferruginea JAY, Cat., ed. 4, p. 269, 1852.-?Henderson, Univ. Colo. Studies, IV, p. 185, 1907. 1862.

Limnaus ferrugineus Küster, Conch. Cab., p. 52, taf. 11, figs. 22, 23, 24,

Limnophysa ferruginea TrYon, Amer. Jour. Conch., 1, p. 257, 1865.

Limnae humilis var. ferruginea Cooper, Proc. Cal. Acad. Sci., IV, p. 96, 1870.-Wood, Nautilus, V, p. 56, 1891.-KeEp, West Amer. Sh., p. 314, 1904.

Lymncea truncatula DALL, Moll. Alaska, p. 73, 1905.

Shell: Small, ovate-conic, thin, more or less diaphaneous; color yellowish or brownish horn, sometimes reddish; surface shining, lines of growth rather coarse, prominent, without spiral lines; whorls 5, rounded, the body-whorl quite convex; spire acutely conic, about as long as the aperture, generally rather strongly shouldered near the suture; sutures well impressed, constricting the whorls; aperture ovate; outer lip thin; inner lip narrow, somewhat triangular, rolled over and appressed tightly to the umbilical region, either tightly closing the umbilicus or else leaving a very small chink; parietal callus very thin; columella twisted in some individuals so as to form a distinct, ascending plait, but in others it is flatly excavated.

$\begin{array}{ccccc}\text { Length. } & \text { Width. } & \text { Aperture length. } & \text { Width. } & \\ 7.00 & 3.50 & 3.75 & 2.00 & \text { Type } \\ 7.00 & 3.00 & 3.50 & 2.00 & \text { “ } \\ 7.50 & 3.75 & 4.10 & 2.10 & \text { Washington } \\ 8.00 & 4.00 & 4.00 & 2.30 & \text { " } \\ 7.00 & 4.00 & 3.75 & 2.10 & \text { " }\end{array}$

${ }^{1}$ These references are extremely doubtful. The two specimens mentioned by Ingersoll could not be found in the Smithsonian collection. 
Types: Academy of Natural Sciences, Philadelphia, two specimens (No. 58606).

Type Locality: Oregon.

Animal, Jaw, Radula and Genitalia: Unknown.

RANGE (Figure 2\%): Oregon, Washington and California.

A species of the Columbian and Californian regions, occupying the territory west of the Sierra Nevada range. It appears to be confined to the Transition life zone.

\section{RECORDS.}

California: Antioch, Contra Costa Co. (Carlton); San Francisco Co. (Wood and Raymond).

OrEGon: Oregon (Nuttall).

Washington: Upper valley of Nesqually River, near Ashford, Pierce Co. (O. D. Allen).

Geological Range: Unknown.

ECOLOGY: Not recorded.

REMARKS: Ferruginea has not been understood by students of our fresh-water shells, and has been made a synonym of both humilis and truncatula, principally for the reason that neither the types nor cuthentic specimens have been examined. The two specimens figured and described by Haldeman are preserved in the Academy of Natural Sciences of Philadelphia and an examination of these shows that ferruginea is a perfectly recognizable species, not closely related to either of the species mentioned above, although apparently belonging to the same group as humilis. The inner lip and columella are totally different from those of humilis, being triangular and closely appressed to the umbilical region, leaving a very small chink. It differs from truncatula in being almost imperforate and in having a slightly plicate columella. The spire is regularly conic, the whorls scarcely disturbing a straight line on either side drawn from apex to body whorl or aperture. The sutures are much constricted, the whorls are flatly rounded and are more or less strongly shouldered near the suture. The body whorl is well rounded and in this respect resembles humilis.

Haldeman's figures are very good, while Binney's figure is very poor and was not correctly copied, being too much elongated. The specimens figured on plate XXXI are similar to the types. Over fifty specimens of this species have been examined and the characteristics are very uniform, particularly the form of the columella. The shells vary somewhat in width and in the height of the spire, and the aperture varies correspondingly. The inward roll of the edge of the inner lip, in some specimens, is very peculiar. Ferruginea will undoubtedly be 
found in the cabinets of western conchologists reposing under the name of Lymnca humilis.

Galba humilis (Say). Plate XXIX, figures 26-30; plate XXX, figures 19-20.

Lymneus humilis SAY, Journ. Phil. Acad., II, p. 378, 1822; Binney, Reprint, p. $110,1858$.

Lymnca humilis Gould, Lamarck's Genera, p. 69, 1833.-JAY, Cat., Ed. IV, p. 269, 1852.-REEvE, Elements of Conch., p. 179, 1860.-DALl, Alaska Moll., p. 73, fig. 50, 1905 (part).-Henderson, Univ. Colo. Studies, IV, fig. 33, 1907.

Limncea humilis Binney, Check List, p. 12, 1860; Land \& F.-W. Sh. N. A., II, p. 63, fig. 99, 1865.-Gould, Invert. Mass., Binney's ed., fig. 151, 1870.-SowB., Conch. Icon., XVIII, Limn., sp. 78, pl. 12, figs. 70, a, b, 1872 (the figures are scarcely characteristic).-TrYoN, Con. Hald. Mon., p. 105 (79), 1872 (part).Clessin, Mal. Blatt., n. s., I, p. 27, 1879 (part); III, p. 81, 1881 (part).

Limnea humilis Hald., Mon. Limn., p. 41, pl. 13, fig. 1, 1842.-DeKay, Zool. N. Y., p. 71, 1843 (part).

Limnophysa humilis BeCK, Index, p. 112, 1837.-TRYon, Amer. Journ. Conch., I, p. 256, 1865 (part).-Hartman and Michener, Conch. Cestrica, fig. 126, 1874.-Call, An. Rep. Dept. Geol. Nat. Res. Ind., XXIV, pl. 8, fig. 9, 1899.

Limnaus humilis GibBs, App. Geol. So. Car., p. XX, 1848.-KÜster, Conch., Cab., p. 51, taf. 11, figs. 15, 16, 17, 18, 1862 (figures are not typical).

Shell: Small, ovate-conic; periostracum light yellowish horn; surface shining, sometimes polished; lines of growth crowded, prominent; spiral sculpture absent or but slightly indicated; apex as in Galba humilis modicella; whorls $5-5 \mathrm{~T} / 2$, convex, rather rapidly increasing in diameter, the body whorl quite obese; spire conic, turreted, about as long as the aperture; sutures well impressed; aperture ovate or roundly ovate; peristome lip thin; inner lip reflected to form a narrow, somewhat triangular expansion which may be rolled in toward the umbilical chink or stand more or less erect; umbilical chink small and narrow, emarginated by the inner lip; parietal callus well marked; axis smooth, forming a column as in Galba cubensis.

\begin{tabular}{|c|c|c|c|c|c|}
\hline $\begin{array}{l}\text { Length. } \\
8.50\end{array}$ & $\begin{array}{l}\text { Breadth. } \\
4.50\end{array}$ & $\begin{array}{c}\text { Aperture length. } \\
4.50\end{array}$ & $\begin{array}{l}\text { Brea } \\
2.50 \mathrm{r}\end{array}$ & & Say's type. \\
\hline 8.50 & 5.00 & & & “ & \\
\hline 6.00 & 3.50 & 2.75 & 2.00 & “ & Charleston, S. C. \\
\hline 6.00 & 3.75 & 3.00 & 2.00 & “ & \\
\hline 8.00 & 4.75 & 4.50 & 2.50 & “ & (Walker Coll.) \\
\hline 8.00 & 4.50 & 4.00 & 2.25 & “ & “ \\
\hline
\end{tabular}

Types: Academy of Natural Sciences, Philadelphia, two specimens, No. $58 \% 54$.

Type Locality: South Carolina.

Animal, Jaw, Radula and Genitalia: Not examined.

Range (Figure 24): Southeastern United States. So far as at present known, humilis is confined to the Upper and Lower Austral 
life zones, east of the Appalachian Mountains. It is characteristic of the Carolinian region. Like many plants, it has extended its range into southern New Jersey.

\section{RECORDS.}

New Jersey: Mouth of Woodbury Creek, and in tide meadow ditch at Washington Park near Gloucester, Camden Co. (J. A. Allen).

South Carolina: South Carolina (Gibbs; Say) ; Charleston, S. C. (Lewis; Walker); Charleston, S. C., collected in 1865 in a low lot in Alexander Street near Chapel, only four or five blocks from the center of the city (now filled up and destroyed); Sullivan's Island, four miles from the city (Mazyck).

Geological Range: Unknown.

Ecology: In tide meadow ditch and at mouth of creek (Allen, New Jersey); in vacant lots and in ditches (Mazyck, South Carolina).

Remarks: Humilis may be known by its acute spire, convex whorls, obese body whorl and narrow, somewhat triangular inner lip, which is not notably appressed at its junction with the parietal wall but forms an evenly rounded expansion. It greatly resembles umbilicata, but may be distinguished by the inner lip which, in umbilicata, forms a broad, triangular excavated expansion reaching to the base of the aperture, while in humilis the lower part of the inner lip is turned upward and not backward. Humilis has also a more obese body whorl. The formation of the inner lip of the two species is quite different and no difficulty will be encountered in distinguishing the two forms if this point is observed. The shape of the inner lip is also different in parva, sterkii and the other related species.

Until recently Say's humilis was believed to be one of the best known as well as one of the commonest of American Lymnæas. At present it may be said to be one of the rarest and least known. Mr. Bryant Walker was the first conchologist to call attention (in a letter to the writer) to the relation of certain northern forms placed in humilis to umbilicata, and also to the relation of modicella to humilis. A careful study of all available material, including Say's types, following Mr. Walker's suggestion, revealed the fact that typical humilis was not authentically known outside of the region east of the Appalachian Mountains. The fact also became apparent that modicella was simply a northern form of humilis, thus, in part, corroborating Binney's opinion expressed in 1865. (See remarks under modicella.) Some of the records of humilis from Louisiana, New Mexico and Texas may have been founded on the true humilis, but in the new aspect of the case it has seemed best to restrict the records to those which are known to have been founded on Say's South Carolina form. Special search should be carried on for this species, which may be 
known from modicella by the greater obesity of the body whorl, which produces a more acutely conic spire.

Say's types are like the two specimens figured on plate XXIX. The species is not well figured by either Binney or Haldeman, the former not showing well the obese character of the body whorl, while the latter does not well illustrate the conic, turreted spire. The figures on the plate, from specimens in the collection of Mr. Bryant Walker, show well the rotund whorls. Mr. William G. Mazyck, of Charleston, South Carolina, sent several specimens to the writer, which are figured on plate XXX. The New Jersey record is somewhat of a surprise; the specimens, however, are quite typical. Humilis has been made to embrace almost all of the small forms of the Lymnæas in the United States, as many as eight species being included under this all-embracing name. As species go in Lymnæa, these are well characterized and easily known when attention is given to the details of structure.

Galba humilis modicella (Say). Plate XXIX, figures 31-3\%; plate XXXI, figures 1-9.

Lymnaus modicellus SAY, Journ. Phil. Acad., V, p. 122, 1825 ; Binney's Ed., p. $113,1858$.

Lymnca modicella Gould, Lamarck's Genera, p. 69, 1833.-Wheatley, Cat. Sh. U. S., p. 23, 1843.-Scudder, Bull. Nat. Mus., 23, p. 201, 1885.-WaLKer, Ottawa Nat., XXII, p. 91, 1908.

Lymnaa modicellus Linsley, Amer. Journ. Sci., XLVIII, p. 283, 1845.

Lymnca humilis var. modicella, JAY, Cat., p. 269, 1852.

Lymncea humilis modicelle BeRRY, Nautilus, XXIV, p. 62, 1910.

Lymnea modicellus DeKay, An. N. Y., p. 32, 1839.-Girard, Proc. Nat. Inst., I, No. 2, p. 81, 1856.-Currier, Sh. Grand River, Mich., 1859.

Limnea modicellus Hald., Mon. Lim., p. 42, pl. 13, figs. 2-8, 1842.-TRUe, Proc. Essex Inst., II, p. 195, 1857.-Turrs, Cat. Sh. Mass., p. 87, 1859.-Miles, Geol. Surv. Mich., 1860, p. 237.

Limncea modicellus Gould, Invert. Mass., p. 218, fig. 151, 1841.-PREscotT, Cat. Sh. Mass., No. 197, 1842.-Read, Cat., 1843.-Russell, Journ. Essex Co. Nat. Hist. Soc., p. 130, 1852.-CurRIer, Kent. Sci. Inst., Mis. Pub., No. 1, 1868.

Limnaa modicella Bell, Geol. Surv. Can. Rep. Prog., p. 252, 1859.-BinNEY, Land and F. W. Sh. N. A., II, p. 64, fig. 100, 1865.-Tryon, Amer. Journ. Conch., III, p. 196, 1867.-Sowb., Conch. Icon., XVIII, sp. 83, pl. 12, fig. 83, 1872.-Clessin, Mal. Blatt., n. s., III, p. 81, 1881.-Jordan, Nova Acta Ksl.-Leop. Carol. Deutsch Akad. Natur., XLV, p. 367, 1883.-CKLl., Journ. Conch., VI, p. 61, 1889.-Singley, An. Rep. Geol. Surv. Texas, IV, p. 188, 1892; p. 313, 1893.

Lymncea desidiosa var. modicella BAKER, Nautilus, XVIII, p. 127, 1905.LERMOND, Shells of Maine, p. 38, 1908.

Lymnaa desidiosa modicella Sterki, Proc. Ohio State Acad. Sci., IV, p. 382, 1907. 
Lymnaa obrussa modicella BAKeR, Bull. Ill. State Lab. N. H., VII, p. 103, 1906.-Henderson, Univ. Col. Studies, IV, p. 93, 179, fig. 35, 1907.-Daniels, Nautilus, XXII, p. 121, 1909.

Lymnca humilis $^{1}$ Wheatley, Cat. Sh. U S., Ed. 2, p. 23, 1845.-Lewis, Proc. Phil. Acad., 1856, p. 260.-Cooper, Amer. Nat., II, p. 486, 1868.-Wolf, Amer. Journ. Conch., VI, p. 28, 1870.-Lewis, Proc. Phil. Acad., 1872, p. 102 ; Proc. Phil. Acad., 1872, p. 109.-Rhoads, Nautilus, XVIII, p. 66, 1904.-BAKer, Nautilus, XVIII, p. 125, 1905 ; Amer. Nat., XXXIX, p. 673, 1905.-DALl, Alaska Moll., p. 72, 1905 (part).-Pilsbry and Ferriss, Proc. Phil. Acad., 1906, p. 161 (?). -Baker, Bull. Ill. State Lab. N. H., VII, p. 104, 1906.-Henderson, Univ. Colo. Studies, IV, pp. 93, 179, 1907.-Sterki, Proc. Ohio Acad. Sci., IV, p. 382, 1907.JACKson, Nautilus, XXI, p. 143, 1908.-WALker, Ottawa Nat., XXII, p. 90, fig 1, 1908.-Lermond, Shells of Maine, p. 38, 1908 (part).

Lymnea humilis DeKay, Cat. An. N. Y., p. 32, 1839.-Girard, Proc. Nat. Inst., I, No. 2, p. 81, 1856.-LeA, Exp. in Neb., II, pt. 3, p. 724, 1859.-RoberTs, Rep. U. S. Geol. Surv. Wyoming, 1870, p. 468.-Todd, Proc. Am. A. A. Sci., XXVII, p. 235, 1878.-WALker and Coolidge, Nautilus, XXII, p. 32, 1908.

Limnaa humilis Mighels, Bost. Journ. Nat. Hist., IV, p. 336, 1843.Stimpson, Sh. N. Eng., p. 52, 1851.-Chickering, List. Sh. Portland, Me., 1855 or 1856.-Lewis, Proc. Bos. Soc. N. H., VI, p. 2, 1856.-Higgins, Cat. Sh. Columbus, p. 6, 1858.-Bland and Cooper, Ann. N. Y. Lyc. N. H., VII, p. 370, 1862.Whiteaves, Can. Nat. \& Geol., VIII, p. 103, 1863.-Cpr., Rep. Brit. Asso., 1864, p. 630.-Hubbard and Smith, Ann. N. Y. Lyc. N. H., VIII, p. 152, 1867.Tryon, Amer. Journ. Conch., III, p. 196, 1867.-Aldrich, Rep. N. Y. State Col. N. H., XXII, p. 23, 1868.-Currier, Kent. Sci. Inst. Mis. Pub. No. 1, 1868.Dall, Proc. Bost. Soc. N. H., XIII, p. 248, 1870.-Smith and Prime, Ann. Lyc. N. H., IX, p. 402, 1870.-Cooper, Proc. Cal. Acad. Sci., IV, p. 96, 1870.-Gould, Binney's Ed. Inv. Mass., p. 482, 1870.-CPR., Smith. Mis. Coll., 1872, p. 116.Jefrereys, Ann. Mag. N. H., ser. 4, X, p. 247, 1872.-Byrnes, L. \& F.-W. Sh. Cin., p. 1, 1872.-Tryon, Con. Hald. Mon., p. 105 (79), 1872 (part).-Jeffreys, Journ. Conch., I, p. 16, 1874.-Sмiтh, Rep. U. S. Fish. Com., 1874, p. 702.Calkins, Proc. Ottawa Acad. Sci., 1874, p. 25 ; Cin. Quart. Journ. Sci., 1, p. 323, 1874.-Yarrow, U. S. Geol. Surv. 100th Merid., V, p. 945, 1875.-Dawson, British N. A. Bound. Com., p. 349, 1875.-Walker and Beecher, Proc. Ann. Arb. Sci. Asso., p. 45, 1876.-Pop. Sci. Mon., X, p. 248, 1876.-Jones, Moll. of Nova Scotia, p. 10, 1877.-WALker, Journ. Conch., II, p. 330, 1879.-Gibbons, Journ. Conch., II, p. 133, 1879.-Clessin, Mal. Blatt., n. s. I, p. 27, 1879 (part). —Stein, Ind. Dept. Stat. \& Geol., 1880, p. 458.-Call, Amer. Nat., XV, p. 586, 1881.-Clessin, Mal. Blatt., n. s. III, p. 81, 1881 (part).-Jordan, Nova Acta Ksl.-Leop.-Carol Deutsch Akad. Natur., XLV, p. 367, 1883.-Sampson, Bull. Sedalia N. H. Soc., No. 1, p. 24, 1885.-Moore and Butler, Bull. Brookville Soc. N. H., No. 1, p. 43, 1885.-Christy, Journ. Conch., IV, p. 347, 1885.-WEst., Vega Exped., IV, pp. 166, 220, 1885.-STerki, Nach. Mal. Gesell., XVIII, p. 19, 1886.-Beauchamp, Sh. N. Y., p. 4, 1886.-H. F. Carpenter, Random Notes, III, p. 86, 1886.-Marsh, Conch. Exch., II, p. 110, 1887.-Sampson, Amer. Nat.,

${ }^{1}$ As there is no possible means of knowing just what these records of humilis were founded on, they are all assumed to refer to the northern form which is here called modicella. By this treatment all of the references are brought together. Several references from the south (Louisiana, Texas, New Mexico) may have been founded on the true humilis, but the author has not been able to verify them. 
XXI, p. 83, 1887.-CkLl., Ann. Mag. N. H., ser. 5, XIX, p. 176, 1887.-Sнiмeк, Amer. Geol., I, p. 151, 1888; Bull. Lab. N. H., Univ. Iowa, I, p. 69, 1888; Bull. Lab. N. H. Univ. Iowa, I, p. 209, 1888.-Holzinger, Rep. Nat. Hist. Surv. Minn., XVI, p. 490, 1888.-CPR., Cat. Moll. R. I., Ed. 2, p. 5, 1889.-Sнімек, Bull. Lab. N. H. Univ. Iowa, I, pp. 209-212, 1890.-Ottawa Nat., IV, p. 56, 1890.-Wood, Nautilus, V, p. 56, 1891.-SAmpson, Ann. Rep. Geol. Surv. Ark., II, p. 193, 1891.-Fox, Nautilus, IV, p. 114, 1891.-McGeE, Rep. U. S. Geol. Surv., XI, pp. 461, 471, 1891.-Pleas, Nautilus, IV, p. 131, 1891.-Taylor, Ottawa Nat., VI, p. 35, 1892.-Singley, Rep. Geol. Surv. Texas, IV, p. 188, 1892; p. 313, 1893.Dean, Amer. Nat., XXVI, p. 18, 1892.-Walker, Nautilus, VI, p. 34, 1892.Marshall, Rep. N. Y. State Mus., XlVII, p. 65, 1893.-Vaughan, Amer. Nat., XXVII, p. 944, 1893.-Sampson, Nautilus, VII, p. 33, 1893.-Stearns, N. Am. Fauna, VII, p. 275, 1893.-Pilsbry, Proc. Phil. Acad., 1894, p. 24.-SQuver, Nautilus, VIII, p. 65, 1894.-Stupakoff, Nautilus, VII, p.: 135, 1894.-Walker, Rev. Mol. Mich., p. 17, 1894.-MarshalL, Rep. N. Y. World's Fair, p. 512, 1894; Rep. N. Y. State Mus., XLVIII, p. 642, 1895.-Shick, Nautilus, VIII, p. 138, 1895.-Harper, Journ. Cin. Soc. N. H., XVIII, p. 95, 1895.-Whiteaves, Ottawa Nat., IX, p. 22, 1895.-SArgent, Nautilus, IX, p. 127, 1896.-DANA, Geology, p. 966, 1896.-Pilsbry and Rhoads, Proc. Phil. Acad., 1896, p. 493.-Udden, Proc. Iowa Acad., V, p. 103, 1897.-Baker, Nautilus, XI, p. 30, 1897.-Wiswall, Nat. Sci. Journ., I, p. 47, 1897.-Shiмeк, Proc. Iowa Acad. Sci., V, pp. 35, 44, 1897.Hershey, Amer. Journ. Sci., iv, IV, p. 96, 1897.-Pilsbry, Amer. Jouril. Sci., iv, V, p. 233, 1898.-Todi, Proc. Iowa Acad., VI, p. 127, 1898.-Baker, Trans. Acad. Sci. St. Louis, VIII, p. 89, 1898; Nautilus, XII, p. 65, 1898.-WALKer, Nautilus, XI, p. 122, 1898.-Beyer, Proc. Iowa Acad., VI, p. 118, 1898.-PilsBRY, Nautilus, XIII, p. 65, 1899 ; Nautilus, XIII, p. 79, 1899.-Sмiтн, Nautilus, XIII, p. 35, 1899.-BAKer, Nautilus, XIII, p. 30, 1899.-Hanham, Nautilus, XIII, p. 6, 1899.-Leverett, Mon. U. S. Geol. Surv., XXXVIII, pp. 169, 170, 171, 172, 1899.-Todd, Proc. Iowa Acad. Sci., VI, p. 127, 1899.-STERKI, An. Rep. Ohio State Acad. Sci., VIII, p. 34, 1900.-Pilsbry, Nautilus, XIV, p. 10, 1900.-Price, Nautilus, XIV, p. 76, 1900.-PILs. \& Cock., Nautilus, XIV, p. 86, 1900.-Stearns, Nautilus, XIII, p. 101, 1900 ; Nautilus, XIII, p. 132, 1900.-Shimek, Amer. Geol., XXVIII, p. 354, 1901; Geol. Surv. Iowa, p. 264, 1901; Bull. Lab. N. H. Univ. Iowa, V, p. 208, 1901.-Stearns, Proc: Nat. Mus., XXIV, p. 288, 1901.-Ba Ker, Trans. Acad. Sci. St. Louis, XI, p. 9, pl. 1, fig. 14, 1901.-Sterki, An. Rep. Geol. Surv. Tex., III, p. 263, 1901.-Daniels, An. Rep. Dept. Geol. Nat. Res. Ind., XXVII, p. 637, 1902.-Elrod., Bull. Univ. Mont. Biol., ser. No. 3, p. 172, 1902.Baker, Moll. Chi. Area, p. 268, pl. 30, fig. 21, text fig. 86, 1902.-Shimek, Geol. Surv. Iowa, 1902, pp. 171, 172.-W Alker, Geol. Surv. Mich., VIII, pt. 3, p. 101, 1903.-Baker, Nautilus, XVII, p. 39, 1903.-Fuller \& Clapp, Bull. Geol. Soc. Amer., XIV, p. 162, 1903.-Sнiмек, Bull. Lab. N. H. Univ. Iowa, V, p. 379, 1904. -BAKer, Nautilus, XVII, p. 113, 1904.-KeEP, West. Amer. Sh., p. 314, 1904.Baker, Trans. Acad. Sci. St. Louis, XIV, p. 103, 1904.-Letson, Bull. N. Y. State Mus., LXXXVIII, p. 56, 1905.-Chadwick, Bull. Wis. Nat. Hist. Soc., n. s., iv, p. 82, 1906 ; Nautilus, XX, p. 22, 1906.-Wheat, Bull. Brook. Conch. Club., I, p. 10, 1907.-Letson, Bull. Buf. Soc. Nat. Sci., IX, p. 24ุ2, 1909.

Limnea humilis DEKAY, Zool. N. Y., p. 71, pl. 4, figs. 71, a. b., 1843.Mighels, Bost. Journ. N. H., IV, p. 336, 1843.-Haldeman, Rupp's Hist. Lanc. Co., p. 480, 1844.-Anthony, L. \& F.-W. Sh. Cin., 1848.-Gould, Agassiz's Lake 
Sup., p. 244, 1850.-Carlton, Proc. Cal. Acad. Sci., IV, p. 51, 1869.-An. Rep., N. Y. State Mus., XXV, p. 37, 1871.-Ingersoll, Rep. U. S. Geol. \& Geog. Surv. Terr., 1874, p. 406; Bull. U. S. Geol. \& Geog. Surv., I, p. 139, 1875.-Tond, Proc. A. A. A. Sci., XXVII, p. 234, 1878.-Huert, Nat. Hist. La Salle Co., p. 104, 1898.-Hubbard, Cat.-Hartman, Cat. Moll. Chester Co.-Sterki, An. Rep. Geol. Surv. Texas, III, p. 263, 1891.-Henderson, Nautilus, XX, p. 98, 1907.-Cat. Coll. Nat. Hist. Eth. Prov. Mus. Victoria, p. 95, 1898.

Limnophysa humilis Morse, Journ. Port. Soc. N. H., I, p. 42, 1864.Currier, Amer. Journ. Conch., I, p. 294, 1865.-Tryon, Amer. Journ. Conch., 1, p. 256, 1865 (part).-Cooper, Proc. Cal. Acad. Sci., IV, p. 153, 1870.-Cooprer, Proc. Cal. Acad. Sci., IV, p. 174, 1872.-Lewis, Bull. Buf. Soc. N. Sci., II, p. 135, 1874.-Hartman and Michener, Conch. Cestrica, p. 65, 1874.-Prime, Forest \& Stream, XV, p. 245, 1880.-CALl, Amer. Nat., XV, p. 784, 1881.McGee \& Call, Amer. Journ. Sci. iii, XXIX, p. 208, et sq., pl. V, figs. 5-11, 1882. ${ }^{1}$-Sampson, Kas. City Rev. Sci., May, 1883, p. 23.-Call, Bull. U. S. Geol. Surv., II, p. 372, 1884.-Chamiserlin \& Salisbury, An. Rep. U. S. Geol. Surv., VI, p. 286, 1885.-Call, Bull. Wash. Coll. Lab. N. H., I, p. 53, 1885.-Cooper, An. Rep. Cal. State Min. Bu., VI, p. 245, 1886.-KeEP, West Coast Sliells; p. 122, 1887.-Keyes, Bull. Essex Inst., XX, p. 71, 1888; Bull. Essex Inst., XX, p. 83, 1888.-Cooper, An. Rep. Cal. State Min. Bu., VII, p. 245, 1888; Zoe, I, p. 196, 1890.-Gilbert, Mon. U. S. Geol. Surv., I, p. 298, 1890.-McGee, Rep. U. S. Geol. Surv., XI, p. 448, 1891.-Cooper, Proc. Cal. Acad. Sci., (ii) III, p. 217, 1892 ; Zoe., III, p. 20, 1892.-Call, Proc. Ind. Acad. Sci., 1893, p. 150.Cooper, Proc. Cal. Acad. Sci., Ser. 2, IV, p. 170, 1894-Call, Proc. Ind. Acad. Sci., 1895, pp. 138, 250 ; Proc. Ind. Acad. Sci., 1896, p. 250.--DanA, Geology, p. 966, 1896.-Baker, Journ. Cin. Soc. N. H., XIX, p. 83, 1897.-Call, An. Rep. Dept. Geol. Nat. Res. Ind., XXIV, p. 408, 1899.-?Beyer, Proc. Iowa Acad. Sci., VI, p. 118, 1899.-Leverett, Mon. U. S. Geol. Surv., XXXVIII, p. 166, 1899.-Blatchley and Asbury, An. Rep. Dept. Geol. \& Nat. Res. Ind., XXV, pp. 176, 226, 304, 1901.-Norris, Proc. Ind. Acad. Sci., 1901, p. 118.

Limncea desidiosa BAKer, Moll. Chi. Area, p. 265, pl. XXI, fig. 7, 1902; Trans. Acad. Sci. St. Louis, XVI, p. 13, 1906.

Lymnca jamesii LeA, Proc. Phil. Acad., 1864, p. 113; Journ. Phil. Acad., VI, p. 161, pl. 24, fig. 77, 1866; Obs., XI, p. 117, pl. 24, fig. 77, 1867.-ScUdDer. Bull. Nat. Mus., 23, pp. 149, 201, 1885.

Limnaa jamesii Tryon, Amer. Journ. Conch., III, p. 196, 1867.-Con. Hald. Mon., p. 104 (78), pl. 18, fig. 3, 1872.

Limnophysa jamesii 'Tryon, Amer. Journ. Conch., I, p. 255, 1865.

SHELl: Of medium size, elongate-ovate or fusiform; periostracum light yellowish horn; surface shining, with distinct, rather coarse lines of growth and frequently very fine spiral lines; whorls $4 \frac{1}{2}$ to 5 , convex, the body whorl very large, flatly rounded; spire generally short, broadly or acutely conic, sometimes dome-shaped; sutures well impressed; nuclear whorls $1 \frac{1}{4}$, resembling those of Galba cubensis in outline, the first whorl very small, the second very large, the sculpture of the post-nuclear whorls beginning gradually; aperture ovate or

'Some of these should probably be referred to parva rather than to modicella. 
elongate ovate, somewhat narrowed above; peristome thin; inner lip narrow, reflexed over the umbilical' region, rolled over and appressed at the point of contact with the parietal wall, but standing more erect at the lower part; umbilical chink small, narrow but distinct; axis as in Galba humilis.

\begin{tabular}{|c|c|c|c|c|c|}
\hline $\begin{array}{c}\text { Length. } \\
8.50\end{array}$ & $\begin{array}{c}\text { Breadth. } \\
4.25\end{array}$ & $\begin{array}{c}\text { Aperture length. } \\
4.75\end{array}$ & \multicolumn{2}{|c|}{ Breadth. } & Say's type \\
\hline 8.50 & 4.50 & 4.00 & 2.00 & “ & jamesii \\
\hline 7.75 & 3.25 & 4.50 & 2.25 & “ & Chicago \\
\hline 7.00 & 3.50 & 4.50 & 2.00 & “ & \\
\hline 8.50 & 5.00 & 5.00 & 2.75 & “ & Oakland Co., Mich. \\
\hline 7.00 & 4.00 & 4.00 & 2.00 & “ & " \\
\hline 9.50 & 4.90 & 5.00 & 3.00 & “ & Macomb Co., Mich. \\
\hline 8.25 & 4.50 & 4.50 & 2.50 & “ & " \\
\hline 12.00 & 6.00 & 5.30 & 3.00 & “ & Alpena, Mich. \\
\hline 10.25 & 5.00 & 5.00 & 2.75 & “ & \\
\hline 10.50 & 5.75 & 5.75 & 3.00 & “ & Hamilton Co., Ohio. \\
\hline
\end{tabular}

Types: Modicella, Academy of Natural Sciences, Philadelphia, two specimens, No. 58790 ; jamesii, one specimen, Smithsonian Institution, No. 29106.

Type Locality: Owego, Tioga County, New York, on the Susquehanna River, ${ }^{1}$ for modicella; ponds near Cincinnati, Ohio, for jamesii.

Animal: Similar externally to obrussa; color light brownish or blackish, lighter on the foot.

JAw : Similar to that of obrussa.

RAdULA : Formula : $\frac{18}{5--6}+\frac{1}{4}+\frac{6}{3}+\frac{1}{1}+\frac{6}{3}+\frac{1}{4}+\frac{18}{5-6}(25-1-25)$; lateral teeth tricuspid; the seventh tooth transitional; marginals beginning abruptly on the eighth tooth. The shape of the teeth do not differ from those of obrussa and its varieties.

Genitalia: Similar to those of obrussa.

Range (Figure 25): Eastern Quebec, Nova Scotia and New Jersey west to Vancouver Island; Manitoba south to southern California, Arizona, Texas and Alabama.

Modicella is one of the most widely distributed of the smaller Lymnæas, its range embracing practically the whole of the United States, north and west of the Alleghany Mountains. It is, therefore, found in the Boreal, Transition, and Upper and Lower Austral life zones. It seems to be absent from the gulf strip of the Austro-riparian division of the Lower Austral life zone, as well as from the Atlantic Coast strip of the Lower Austral, its place here being taken by typical

${ }^{1}$ In Binney's monograph this locality is spelled Oswego. 
humilis. On the north it barely enters the Boreal (Canadian) life zone. It occupies all of the Canadian, Upper Mississippian and Nova Scotian regions, and a large part of the Columbian, Coloradoan, Californian and Rio Grandian regions. It barely enters the Hudsonian region on the north. Its absence from the Great Plains area is noteworthy, but may be due to lack of records.

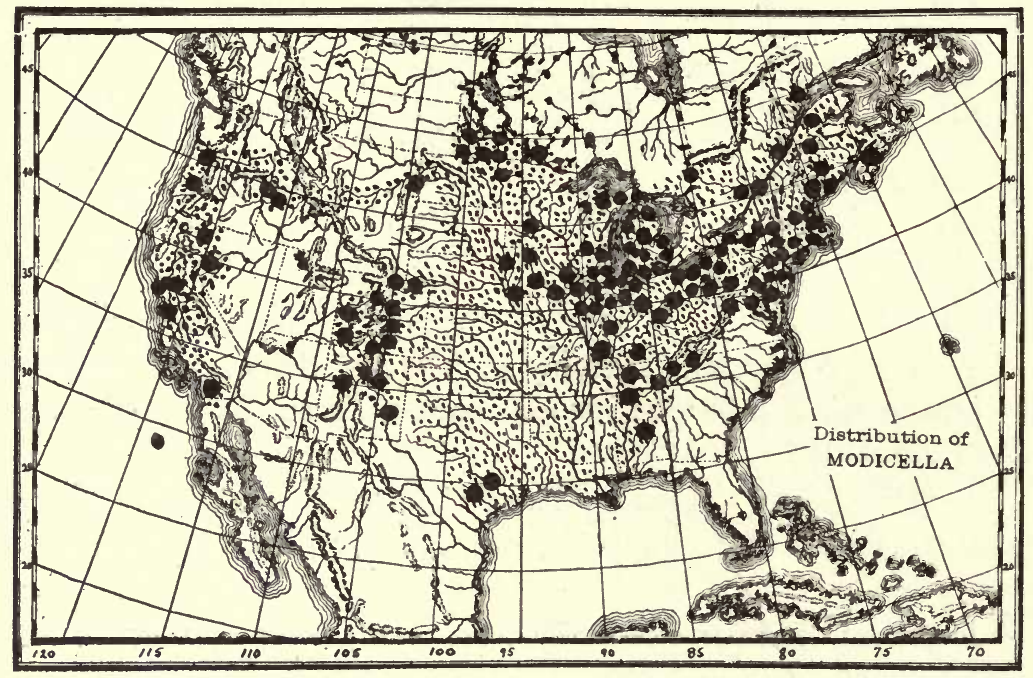

FIG. 25.

${ }^{1}$ Lower California: Common in the ponds of Sierra Laguna, at some height. Before known as far south as latitude $31^{\circ} 51^{\prime}$ (Cooper).

Geological Range ${ }^{2}$ (Figure 26): Pleistocene.

Comparing the geological distribution of modicella with the recent distribution, we find that it covers about the same territory. To the south the recent distribution extends farther into the Lower Austral life zone and to the north it penetrates the Boreal life zone. It is noteworthy that no fossils have been recorded from deposits in the latter zone, the species in Pleistocene time seeming to keep within the Transition life zone. This restriction of distribution may be, and

${ }^{1}$ This record is doubtful as no specimens of true modicella have been seen from Mexico or Lower California. The specimens were probably Galba bulimoides cassi, which somewhat resembles modicella. As the record has not been substantiated, it is excluded from the map, though recorded here for completeness. The original specimens were lost in the earthquake which destroyed the Museum of the California Academy of Sciences.

${ }^{2}$ It is probable that a number of records here listed were really based on Galba parva or some one of the related species, as all of the smaller Lymnæas have been lumped under humilis. It has been impossible to verify the majority of these records and they are, therefore, listed under modicella. 
probably is, due to lack of records, or to lack of care in identifying material.

\section{RECORDS.}

\section{LESS.}

Illinois: Galena, Jo Daviess Co. (Chamberlin and Salisbury; McGee); Freeport, Stephenson Co. (Hershey; Leverett); Virginia, Cass Co. (Leverett; Snyder); Fulton, Whiteside Co. (McGee); Rock Island, Rock Island Co. (Udden).

IowA: Washington Township, along Clear and Walnut Creeks, Story Co. (Beyer); Bluffs of Missouri, Fremont and Mills Counties (Call); Des Moines, Polk Co. (Call and McGee); Jefferson, Clayton Co., southeast quarter, Section 20 (Chamberlin \& Salisbury); Lœss of Iowa (Keyes); Muscatine, Muscatine Co. (Leverett; McGee; Shimek; Witter); Iowa City, Johnson Co. (McGee; Pilsbry; Shimek); Fremont Co., terraces (?) base of Missouri bluffs, Scott Township; near Nishnabatna River; Scott and Johnson Counties; Pottawattamie Co., three miles west of Avoca; west of Minden (Shimek); Lœss of Iowa (Todd).

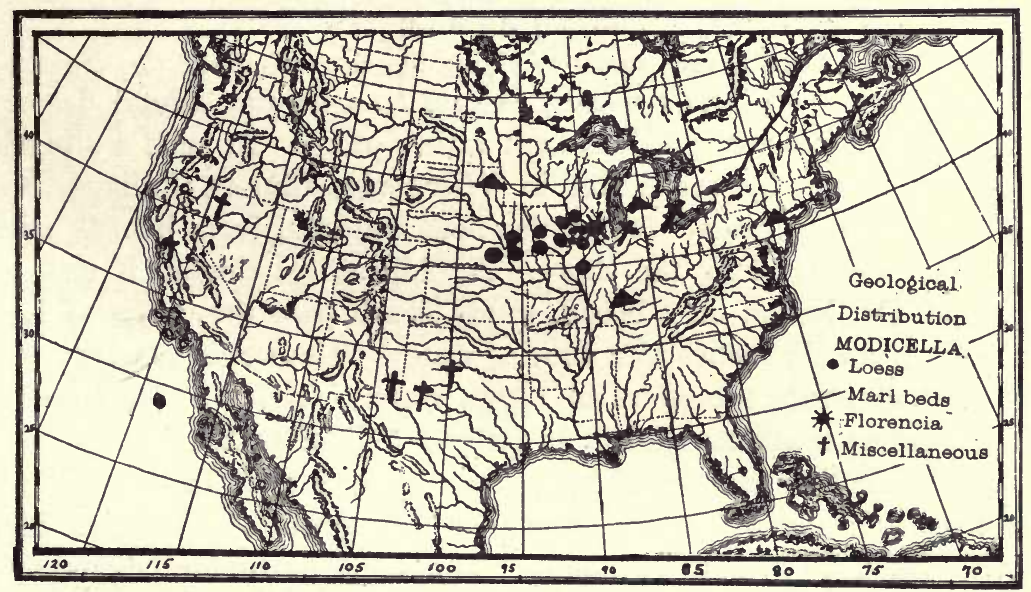

FIG. 26.

Nebraska: Lancaster Co. (Shimek).

Wisconsin: Prairie du Chien, Crawford Co. (Chamberlin; Leverett); Bridgeport, Crawford Co., mouth of Wisconsin River, higher terraces (Chamberlin and Salisbury).

MARL DEPOSITS.

Indiana: Stewardsville, Posey Co.; west of Mounts, Gibson Co. (Fuller and Clapp).

Michigan: 'One-quarter mile east of Cedar Lake Station, Montcalm Co. (Walker).

New Jersey: White Pond, Sussex Co. (Baker; Leidy; Weller).

South Dakota: Bradley, Clark Co. (Todd). 
FLORENCIA FORMATION.

Illinors: Indian Garden, Pecatonica River Valley, Stephenson Co. (Hershey).

\section{Various Pleistocene Formations.} UNITED STATES.

California: Walnut Creek, Contra Costa Co.; Tassajora Lake Bed? deposit near Walnut Creek, Alameda Co., north of Livermore. (Cooper).

IowA: Drift of Iowa. (Udden).

Mrchigan: Near Buchanan, Berrien Co., with Mastodon remains (Smith); with Mastodon remains, Niles, Berrien Co. (Walker).

Nevada: Upper Lahontan beds, Rye Patch, Humboldt Co. (Call).

New Mexico: Dry Salt Lake, near Eddy, Eddy Co. (Sterki). Co.;

TEXAs: Forks of Groesbeck Creek, three miles west of Quanah, Hardeman

"Rush's pasture, Wild Horse Creek, northeast of Big Spring, Howard Co., northwest Texas, from bed of sandy clay, twenty feet above present bed of creek. The bed rests upon a conglomerate composed of small silicious pebbles. Found with mammalian remains" (Singley).

\section{BRITISH AMERICA.}

Ontario: Fossiliferous sands overlying the clays of Essex Co. (Stearns).

Ecology: Modicella usually selects as a habitat a mud flat or a strip of muddy beach which is kept rather moist. In such a situation il has been seen by the writer in Wisconsin, Illinois, Indiana, New York and Pennsylvania. It has also been collected from boards, sticks and other debris along the shore. At Alpena, Michigan, it was collected by Dr. Nason on a broad, sandy beach near the outlet of Long Lake, in from six inches to a foot of water. The shells are very thick and well illustrate the effect of rough water. Mr. Woodruff records the habitat in southern Illinois as follows (Nautilus XI, p. 28) :

"The shells were found in a rocky glen or cleft in the center of the chain of high precipices known by the names of Fountain Bluff, Devil's Bake Oven and Backbone. This cleft or ravine begins about three-quarters of a mile from the face of the cliff and gradually descends in a northwesterly direction until the bottom is reached, and one may stand upon a broad shelf of rock ten feet from the ground, with high overhanging cliffs of bare rock on both sides. A stream of clear spring water flows down this ravine and, falling over the high shelves of rock, has formed numerous round pools or basins. I was surprised to find no shells in the stream, and could only collect a few specimens of Limnca humilis, which I found clinging to the wet moss under the falls."

REMARKS: Modicella is closely related to humilis, differing in having a longer and narrower aperture and a less obese body whorl; in the majority of individuals the upper extremity of the lip where 
it joins the parietal wall is somewhat abruptly curved in. The columella is also straighter than in humilis. These distinctions hold good in the presence of the rather large series of humilis examined. Some specimens of modicella, however, closely approach humilis, especially in the form of the inner lip, which sometimes wholly lacks the peculiar compression at its junction with the parietal wall. (See plate XXIX, fig. 35 ; pl. XXXI, fig. 4.) The South Carolina specimens of humilis also vary in this respect. (Compare the figures on plate XXIX.) The rounder aperture, more obese body whorl and broadly conic spire of humilis appear, however, to be constant. Modicella may be distinguished as a race occupying the whole of the United States except the southeastern states bordering the Atlantic Ocean and the Gulf of Mexico. Some forms of Galba bulimoides cassi somewhat resemble modicella, but may be distinguished by the form of the inner lip. Parva and sterkii also differ in the form of the inner lip. Obrussa has a differently shaped aperture and the inner lip is notably compressed and bent inward at its junction with the parietal wall. Galbana is similar in some of its forms, but is typically shorter, more corpulent and with a more depressed spire, more shouldered whorls and a rounder aperture. Young specimens of Galba bulimoides from California have been mistaken for modicella. A form of modicella occurs at La Porte, Indiana, which has a strongly zebra-marked shell, the narrow white stripes standing out vividly against the dark brown background. As many as fourteen stripes may be counted on the last whorl of one specimen.

The spire in modicella varies greatly in length, the short-spired individuals being the form commonly known as humilis. No line can be drawn between the short and long-spired specimens, as every kind of intermediate form occurs. (See the figures on plate XXIX.) From the records it would appear that Say at first considered the narrower form the same as his humilis, for he says in his description: "A variety of it, sometimes quite black, was found by Dr. McEwen, at Owego, on the Susquehanna." Under modicella he writes: "It was found by Dr. McEwen at Owego, on the Susquehanna River, near the state of New York." There is no question, I think, but that modicclla was founded on the same specimens spoken of under humilis, and it also seems evident that Say considered them distinct from his North Carolina humilis. The types of modicella are preserved in the Philadelphia Academy and conform closely to Binney's figure and to the shells figured on plates XXIX and XXXI of this monograph.

Lea's jamesii (pl. XXXI, fig. 1), of which the cotype is in the 
Smithsonian collection, is a form of modicella. The cotype has a narrow reflection of the inner lip which leaves a rather small umbilical chink. A comparison of the figure on plate XXXI, which is a photograph of the cotype, with Tryon's figure 3 , plate 18 , of his continuation of Haldeman's Monograph, will serve to show how little dependence can be placed upon a figure made by the ordinary artist in correctly repicting the shells of mollusks.

Galba humilis rustica (Lea). Plate XXXI, figures 10-14.

Lymnea rustica LeA, Proc. Amer. Phil. Soc., II, p. 33, 1841; Trans. Amer. Phil. Soc., IX, p. 10, 1844; Obs., IV, p. 10, 1848.-Scudder, Bull. Nat. Mus., 23, pp. 33, 44, 201, 1885.

Lymnca rustica Wheatley, Cat. Sh. U. S., p. 23, 1843.

Limnaa rustica Binney, Check List, p. 12, 1860; L. \& F.-W. Sh. N. A., II, p. 65, fig. 106, 1865.-Clessin, Mal. Blatt., n. s., III, p. 81, 1881.-CKLL.; Ann. Mag. N. H., Ser. 5, XIX, p. 176, 1887.

Shell: Small, elongated, subfusiform; periostracum light yellowish horn, darker in some specimens; surface shining, growth lines coarse, spiral lines absent or very faint; whorls 5 to $5 \mathrm{x} / 2$, convex, rather slowly increasing in diameter, the body whorl suddenly enlarging; spire long, very acute, generally a trifle longer than the aperture; nuclear whorls resembling those of modicella; sutures impressed; aperture usually narrowly elliptical; outer lip thin, sometimes with a varix; inner lip narrow, reflected, the lower part turned up, the upper part at its junction with the parietal wall impressed and flattened, forming a slight plait; umbilical chink usually very narrow, in some specimens nearly closed; axis as in modicella.

\begin{tabular}{|c|c|c|c|c|c|}
\hline $\begin{array}{c}\text { Length. } \\
7.50\end{array}$ & $\begin{array}{c}\text { Breadth. } \\
4.00\end{array}$ & $\begin{array}{c}\text { Aperture length. } \\
3.75\end{array}$ & $\begin{array}{l}\text { Brea } \\
1.50\end{array}$ & $\begin{array}{l}\text { dth. } \\
\text { mill. }\end{array}$ & Smithsonian specimen \\
\hline 8.75 & 4.00 & 4.50 & 2.10 & “ & Mohawk, N. Y. \\
\hline 8.50 & 4.00 & 4.00 & 2.00 & “ & " 6 \\
\hline 9.75 & 4.50 & 5.00 & 2.50 & “ & Albuquerque, N. M. \\
\hline 10.50 & 4.75 & 5.50 & 2.50 & “ & “ \\
\hline 8.50 & 4.00 & 4.00 & 2.00 & “ & $a$ \\
\hline 7.75 & 4.00 & 4.00 & 2.00 & “ & Joliet, Ill: \\
\hline 8.50 & 4.25 & 4.50 & 2.25 & “ & “ 4 \\
\hline 9.75 & 4.75 & 4.90 & 2.25 & “ & Alpena, Mich. \\
\hline 9.00 & 4.00 & 4.00 & 2.50 & “ & Cedar Lake, Mich. \\
\hline 10.00 & 4.80 & 4.50 & 2.50 & " & “ “ “ \\
\hline
\end{tabular}

Types: Not in existence; autotype, one specimen, Smith. Inst., No. 118652.

Type Locality: Poland, Ohio.

Animal: Not differing externally from modicella.

JAw: As in modicella. 
Radula : Formula: $\frac{12}{4-6}+\frac{2}{3}-4+\frac{6}{3}+\frac{1}{1}+\frac{6}{3}+\frac{2}{3}-\frac{1}{4}+\frac{12}{4-6} \quad(20-1-20)$; the teeth are similar in all respects to those of modicella.

Genitalia: Not differing from those of modicclla.

RANGE (Figure 27): New York west to Utah, Nebraska south to New Mexico.

The scattering records of rustica indicate that it is an inhabitant of the Boreal, Transition and Austral life zones. The larger part of the records are confined to the humid divisions of the Transition and Upper Austral life zones. Future records will doubtless extend the range of this race, which is now known from the Canadian, Upper Mississippian and Rio Grandian regions. Its range is probably coextensive with that of Galba humilis modicclla.

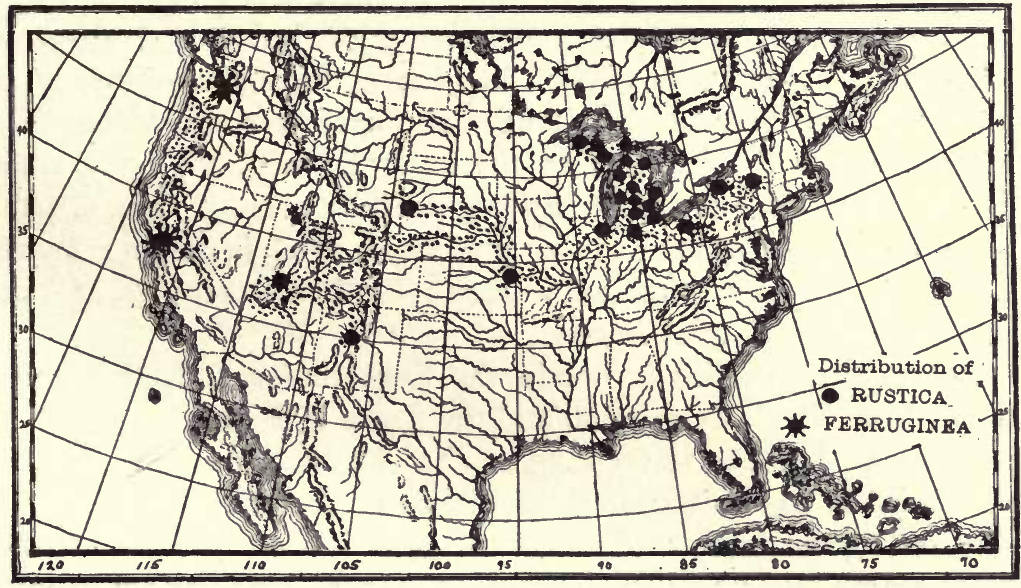

FIG. 27.

\section{RECORDS.}

UNITED STATES.

IllinoIs: Joliet, Will Co. (Ferriss).

Indiana: Lake James, Steuben Co. (Daniels).

Kansas: Lawrence, Douglass Co. (Hanna).

Michigan: Whitefish Point, Alpena, Alpena Co. (Nason); Cedar Lake, Montcalm Co.; Benzie, Chippewa, Eaton, Emmet, Grand Traverse, Gratiot, Ingham, Isabella, Kent, Marquette, Menominee, Monroe, Montcalm, Muskegon, Ontonagon, Tuscola and Washtenaw Counties (Walker).

Nebraska: Squaw Canyon, Sioux Co. (O. A. Peterson; Ortmann).

New Mexico: Albuquerque, Bernalillo Co. (Ashmun).

New York: Irondequoit Bay; Wide Waters, Erie Canal, Rochester, Monroe Co. (Baker); Mohawk, Herkimer Co. (Nason).

Онго: Poland, Mahoning Co. (Lea). 
UтAн: Deception Lake, 8 miles from Kanab, Kane Co. (Daniels and Ferriss).

Geological Distribution: Pleistocene.

\section{RECORDS.}

Michigan: Kegomic, Emmet Co., in marl beds (Slocum).

Ecology: On damp mud flats and in other situations similar to those under which modicella is found.

REMARKS: Rustica appears to be a modification of the humilis type of shell, characterized principally by its long, very acute spire and ovate aperture. Its long, pointed spire will distinguish it from any form of modicella. It is liable to be confounded with forms of Galba obrussa exigua, but in that race the aperture is longer and narrower and inclined to be squarish, while in rustica it is more acutely rounded at the extremities. The spire in rustica is longer and more acute than in exigua, the spire whorls being less inflated. Half-grown specimens of obrussa are similar in general form, but differ in the form of the aperture, which is longer and narrower and forms a distinct shoulder at the junction of the outer lip with the body whorl, while in rustica this part of the lip is gracefully curved. The aperture is sometimes almost round and the spire varies much in height. Rustica is evidently more nearly related to modicella than to obrussa and may be considered a variety of humilis.

The type of rustica is not in the Smithsonian collection and is probably lost. Lea's description and the figure in Binney's work, however, leave no doubt as to the kind of sheil Lea had in mind. A single specimen in the Lea collection in the Smithsonian Institution is marked rustica and agrees fairly well with Lea's description. It is No. 118652. Careful search will undoubtedly reveal this neat little variety in many collections, labeled humilis or obrussa.

Galba obrussa (Say). Plate XXVT, figures 8-13; plate XXXI, figures 20-3\%.

Lymneus obrussus SAY, Journ. Phil. Acad., V, p. 123, 1825 ; Binney's Ed., p. $113,1858$.

Lymnca obrussa Gould, Lamarck's Genera, p. 69, 1833.-Wheatley, Cat. Sh. U. S., p. 23, 1843.-JAY, Cat., p. 270, 1852.-DAll, Land \& F. W. Sh., p. 73, fig. 51, 1905.-BaKer, Bull. Ill. State Lab., VII, p. 103, 1906.-Henderson, Univ. Col. Studies, IV, pp. 93, 179, fig. 34, 1907; Univ. Col. Studies, IV, p. 158, 1907.-Daniels, Nautilus, XXII, p. 120, 1909.-Walker, An. Rep. Mich. Geol. Surv., 1908, p. 290, 1909.-BAKer, Nautilus, XXIII, p. 94.-Berry, Nautilus, XXIV, p. 62, 1910.

Limnaus obrussa Küster, Conch. Cab., p. 51, taf. 11, fig. 19-21, 1862.

Limnaa obrussa BinneY, Check List, p. 12, 1860; Land \& F. W. Sh. N. A., II, p. 49, fig. 69, 1865.-Tryon, Amer. Journ. Conch., III, p. 196, 1867.-Wood, Nautilus, V, p. 54, 1891.-KEEP, West. Amer. Sh., p. 314, 1904. 
Limnea obrussa HALD., Mon. Limn., p. 48, pl. 13, figs. 16-18, 1842.-DEKAY, Zool. N. Y., p. 75, 1843.-Ingersoll, Rep. U. S. Geol. \& Geog. Surv. Terr., 1874, p. 406.-Hanna, Nautilus, XXIII, p. 96, 1909.

Limnophysa obrussa Tryon, Amer. Journ. Conch., I, p. 252, 1865.-Cooper, Proc. Cal. Acad. Sci., IV, pp. 90, 154, 1870; p. 173, 1872; Zoe, I, p. 196, 1890.

Lymnaa desidiosa (Authors, non Say).

Lymneus desidiosus Sager, Geol. Surv. Mich., p. 15, 1839.

Limnaus desidiosus Küster, Conch. Cab., p. 47, taf. 8, figs. 22-26, 1862.

Limnea desidiosa Haldeman, Mon. Limn., p. 31, pl. X, 1842.-DeKay, Zool. N. Y., p. 73, pl. 5, fig. 78, 1843.-Mighels, Bost. Journ. N. H., IV, p. 337, 1843.-Haldeman, Rupp's Hist. Lanc. Co., p. 480, 1844.-Anthony, L. \& F. W. Sh. Cin., 1848.-Gould, Agassiz's Lake Sup., p. 244, 1850.-Tufts, Cat. Sh. Mass., p. 87, 1859.-Miles, Geol. Surv. Mich., 1860, p. 237.-Carlton, Proc. Cal. Acad., Sci., IV, p. 51, 1869.-Sмiтh \& Prime, Ann. Lyc. N. H., IX, p. 402, 1870.-Rep. N. Y. State Mus., XXV, p. 37, 1871.-Ingersoll, Rep. U. S. Geol. \& Geog. Surv. Terr., 1874, p. 406; Bull. U. S. Geog. Surv., I, p. 138, 1875.Huetr, Nat. Hist. La Salle Co., p. 104, 1898.-Henderson, Nautilus, XX, p. 98, 1907.-Hartman, Cat. Mol. Chester Co.-Hubbard, Cat.

Lymnea desidiosa DeKay, An. N. Y., p. 32, 1839.-Currier, Sh. Grand River, Mich., 1859.-Girard, Proc. Nat. Inst., I, No. 2, p. 81, 1856.-Lewis, Proc. Phil. Acad., p. 18, 1860.-Roberts, Rep. U. S. Geol. Surv. Wyoming, p. 468, 1870.-Shaffer, List Sh. Cin. (no date).

Lymnca desidiosa Gould, Lamarck's Genera, p. 69, 1833.-Amer. Journ. Sci., XXXI, p. 36, 1837.-Linsley, Amer. Journ Sci., XLVIII, p. 282, 1845.JAy, Cat., p. 269, 1852.-Lewis, Proc. Phil. Acad., p. 260, 1856.-Reeve, Elements of Conch, p. 178, 1860.-Cooper, Amer. Nat., II, p. 486, 1868.-Morse, Amer. Nat., III, p. 651, 1870 (nec. fig.).-Wolf, Amer. J. Conch., VI, p. 28, 18\%0.Lewis, Proc. Phil. Acad., 1872, p. 109; Proc. Phil. Acad., 1872, p. 101.-Rhoads, Nautilus, XVIII, p. 66, 1904.-BAKER, Nautilus, XIX, p. 28, 1905 ; Amer. Nat. XXXIX, p. 672, fig. 8, 1905.-DAll, Land \& F. W. Moll., p. 73, 1905.-Pilsbry \& Ferriss, Proc. Phil. Acad., 1906, p. 161.-Hinkley, Nautilus, XX, p. 40, 1906.Walker, Nautilus, XX, p. 82, 1906.-Pilsbry \& Ferriss, Proc. Phil. A.cad., p. 564, 1906.-Sterki, Proc. Ohio State Acad. Sci., IV, p. 382, 1907.-JAckson, Nautilus, XXI, p. 143, 1908.-Lermond, Shells of Maine, p. 37, 1908.-WaLker, Nautilus, XXII, p. 6, pl. 1, fig. 4, 1908; XXII, p. 17, pl. 11, fig. 8, 1908.-NyLANDER, Nautilus, XXII, p. 105, 1909.-Johnson, Nautilus, XXIV, p. 72, 1910.

Limnaa desidiosa Adams, Amer. Journ. Sci., XL, p. 268, 1841.-Gould, Invert. Mass., p. 219, fig. 150, 1841.-ADAms, Thomp..Hist. Vt., p. 154, 1842.Prescott, Cat. Sh. Mass., No. 195, 1842.-Mighels, Bos. Journ. Nat. Hist., IV, p. 337, 1843.-Read, Cat., 1845.-Adams, Cat. Sh. in Cab. C. B. Ad., p. 32, 1847. -Reeve, P. Z. S., 1850, p. 49.-Stimpson, Sh. N. Eng., p. 52, 1851.-ChickerING, List. Sh. Portland, Me., 1855 or 1856.-Lewis, Proc. Bost. Soc. N. H., VI, p. 2, 1856.-Can. Nat. \& Geol., II, p. 198, fig. 1857.-Higgins, Cat. Sh. Columbus, p. 6, 1858.-Binney, Check Lis.t, p. 12, 1860.-Whiteaves, Can. Nat. \& Geol., VIII, p. 103, 1863.-?, Carpenter, Rep. Brit. Ass., p. 607, 1864 ; Rep. Brit. Asso., 1864, p. 630.-Hubbard \& Smith, Ann. N. Y. Lyc. N. H., VII, p. 152, 1867.Pratt, Proc. Daven. Acad. Sci., I, p. 166, 1867.-Tryon, Amer. Journ. Conch., III, p. 196, 1867.-Currier, Kent. Sci. Inst., Mis. Pub. No. 1, 1868.-Rep. N. Y. State Mus., XXII, p. 23, 1868.-MöRCH, Amer. Journ. Conch., IV, p. 35, 1868.- 
Cooper, Amer. Nat., III, p. 297, 1869.-Dall, Proc. Bos. Soc. N. H., XIII, p. 248, 1870.-Gould, Ed. Binney, p. 478, fig. 729, 1870.-Froebel, Proc. Lyc. N. H., I, p. 72, 1870.-?Verrell \& Smith, Amer. Journ. Sci., II, p. 448, 1871.-HayDEN, Prelim. Rep. U. S. Geol. Surv. Wyoming, p. 170, 1871.-Tryon, Con. Hald. Mon., p. 104 (78), 1872.-Carpenter, Smith. Mis. Coll., X, pp. 93, 116, 1872.Byrnes, List. Sh. Cin., p. 2, 1872.-Jefrrey's, Ann. Mag. N. H., Ser. 4, X, p. 247, 1872.-Tryon, Proc. Phil. Acad., 1873, p. 286 ; Journ. Conch., I, p. 16, 1874.-Calkins, Cin. Quart. Journ. Sci., I, p. 323, 1874; Proc. Ottawa Acad. Sci., 1874, p. 25.-Sмiтh, Rep. U. S. Fish. Com., 1874, p. 702.-Yarrow, U. S. Geog. Surv. West 100th Merid., V, p. 944, 1875.-Gilbert, U. S. Geol. Surv. West 100th Merid., III, pp. 99, 100, 1875.-Walker \& Beecher, Proc. Ann. Arb. Sci. Asso., p. 45, 1876.-Pop. Sci. Mon., X, p. 248, 1876.-Bland \& Cooper, Ann. N. Y. Lyc. N. H., VII, p. 370, 1876.-Ingersoll, Proc. Daven. Acad. Sci., II, p. 132, 1877.-KInG, U. S. Geol. Surv. 40th Parallel, I, p. 494, 1878.-Witter, Journ. Conch., I, p. 386, 1878.-WALKer, Journ. Conch., II, p. 330, 1879.-Stein, Ind. Dept. Stat. \& Geol., 1880, p. 458.-Heron, Ottawa Naturalist, I, p. 39, 1880.Home \& Science Gossip, 1881.-Ottawa Nat., II, p. 263, 1885.-Christy, Journ. Conch., IV, pp. 3, 47, 1885.-Sampson, Bull. Sedalia N. H. Soc., No. 1, p. 24, 1885.-Beauchamp, Land and F. W. Sh. N. Y., p. 3, 1886.-Sterki, Nach. Mall. Ges., XVIII, p. 19, 1886.-Keyes, Bull. Essex Inst., XX, p. 71, 1888.-WebSter, Amer. Nat. XXII, p. 419, 1888.-H. F. CPR., Cat. Sh. R. I., p. 5, 1889.Marsh, Conch. Exch., II, p. 103, 1888.-CKLl., Journ. Conch., VI, p. 64, 1889.Ottawa Nat., IV, p. 56, 1890.-ShimeK, Bull. Lab. N. H., Univ. Iowa, I, p. 68, 1890.-Sterki, An. Rep. Geol. Surv. Tex., III, pp. 263, 265, 1891.-Walton, Proc. Roch. Acad. Sci., II, p. 12, pl. 6, figs. 7, 8, 1891.-McGeE, Rep. U. S. Geol. Surv., XL, p. 461, 1891.-WALker, Nautilus, VI, p. 34, 1892.-TAYlor, Ottawa Nat., VI, p. 35, 1892.-DeAn, Amer. Nat., XXVI, p. 11, 1892.-MARShall, Rep. N. Y. State Mus., XlVII, p. 64, 1893.-Singley, An. Rep. Geol. Surv. Texas, IV, p. 313, 1893.-WALker, Rev. Fauna Mich., p. 17, 1894.-SARGent, Nautilus, VII, p. 121, 1894.-Stupakoff, Nautilus, VII, p. 135, 1894.Marshall, Rep. N. Y. World's Fair, p. 511, 1894.-Pilsbry, Proc. Phil. Acad., 1894, p. 23.-Nylander, VIII, p. 125, 1895.-Whiteaves, Ottawa Nat., IX, p. 22, 1895.-Shick, Nautilus, VIII, p. 138, 1895.-Walker, Nautilus, IX, p. 5, 1895.-Taylor, Ottawa Nat., IX, pp. 175, 176, 1895.-Marshall, Rep. N. Y. State Mus., XlVIII, p. 642, 1895.-Ward, Bull. Mich. Fish. Com., No. 5, p. 65, 1895.-Snyder, The Museum, III, p. 12, 1896.-Pilsbry, Proc. Phil. Acad., 1896, p. 493.-DanA, Man. Geology, p. 966, 1896.-Hershey, Amer. Journ. Sci., iv, IV, p. 96, 1867.-Амi, Ottawa Nat., XI, p. 26, 1897.-Dall, Proc. Nat. Mus., XIX, p. 368, 1897.-Nylánder, Nautilus, XI, p. 10, 1897.-Shimek, Proc. Iowa Acad. Sci., V, pp. 35, 44, 1897.-BAKer, Journ. Cin. Soc. N. H., XIX, p. 78, 1897 ; Nautilus, XII, p. 65, 1898.-WALKER, Nautilus, XI, p. 122, 1898.-Walton, The Museum, IV, p. 133, 1898.-Baker, Trans. Acad. Sci. St. Louis, VII, p. 89, 1898.-PIlsbry, Amer. Journal Sci., iv, V, p. 233, 1898.-Pilsbry, Nautilus, XIII, p. 65, 1899.-BAKer, Nautilus, XIII, p. 30, 1899.-Sмiтh, Nautilus, XIII, p. 35, 1899.-Baker, Nautilus, XIII, p. 58, 1899.-Hanнaм, Nautilus, XIII. p. 6, 1899. - Sterki, An. Rep. Ohio State Acad. Sci., VIII, p. 34, 1900.-Pilsbry, Proc. Phil. Acad., 1900, p. 457.-WAlker, Geol. Surv. Mich., VII, pt. 2, p. 251, 1900.Nylander, Nautilus, XIII, p. 104, 1900.-Baker, Journ. Cin. Soc. N. H., XIX, p. 176, 1900.-Stearns, Proc. Nat. Mus., XXII, p. 136, 1900.-Letson, Bull. Buff. 
Soc. Nat. Sci., VII, No. 1, p. 244, 1901; Bull. N. Y. State Mus., IX, No. 45, p. 244, 1901.-Nylander, Nautilus, XIV, pp. 103, 104, 1901.-Shimek, Bull. Lab. N. H. Univ. Iowa, V, p. 208; 1901.-BAker, Trans. Acad. Sci. St. Louis, XI, p. 6, pl. 1, fig. 8, 1901.-Needham \& Belten, Bull. N. Y. State Mus., XLVII, p. 402, 1901.-? ?himeк, Amer. Geol., XXVIII, p. 344, 1901.-Baker, Moll. Chi. Area., p. 265, pl. 30, fig. 20, text fig. 84.-Daniels, Rep. Dept. Geol. Nat. Res. Ind., XXVII, p. 637, 1902.-WALkeR, Geol. Surv. Mich., VII, pl. 3, p. 101, 1903.Pilsbry, Proc. Phil. Acad., 1903, p. 777.-Wright, Rep. State Board Geol. Surv. Mich., 1903, p. 42.-BAKeR, Shells of Land and Water, p. 11, fig., 1903.-HinkLey, Nautilus, XVIII, p. 45, 1904.-BAker, Trans. St. Louis Acad. Sci., XIV, p. 103, 1904.-Letson, Bull. N. Y. State Mus., LXXXVIII, p. 54, 1905.-CHADwick, Nautilus, XX, p. 22, 1906; Bull. Wis. Nat. Hist. Soc., n. s., IV, p. 82, 1906.-Whitenves, Ottawa Nat., XX, p. 117, 1906.-Wheat, Bull. Brook. Conch. Club., I, p. 10, 1907.-Hankinson, Rep. Geol. Surv. Mich., 1907, p. 235, 1908.-HiLBERT, Schriften Phys. Okon. Gesell., Konigsberg, LXIX, p. 400, 1909.-Letson, Bull. Buf. Soc. Nat. Sci., IX, p. 242, 1909.

Limnophysa desidiosa BECK, Index, p. 111, 1837.-Morse, Journ. Port. Soc. N. H., I, p. 41, 1864.-Currier, Amer. Journ. Conch., I, p. 294, 1865.Tryon, Amer. Journ. Conch., I, p. 252, 1865.-Perkins, Proc. Bos. Soc. N. H., XIII, p. 132, 1869.-Cooper, Proc. Cal. Acad. Sci., IV, pp. 90, 153, 1870.-Lewis, Buff. Soc. N. H., 1874, p. 135.-Hartman and Michener, Conch. Cestrica, p. 65, figs. 116, 125, 1874.-Prime, Forest \& Stream, XV, p. 245, 1880.-?CAlL; Amer. Nat., XV, p. 784, 1881.-McGeE \& Call, Amer. Journ. Sci., iii, XXIV, p. 209, et seq., pl. V, figs. 1-4, 1882.-DeCamp, Kent. Sci. Inst., Mis. Pub., No. 5, p. 8, 1881.-Call, Bull. Wash. Coll. Lab. N. H., I, p. 118, 1885.-Cooper, Ann. Rep. Cal. State Min. Bu., VI, p. 245, 1886.-KeEP, West Coast Shells, p. 121, 1887.-Keyes, Bull. Essex Inst., XX, p. 83, 1888; Amer. Nat., XXII, p. 1052, 1888.-Cooper, An. Rep. Cal. State Min. Bu., VII, p. 245, 1888.-Gilbert, Mon. U. S. Geol. Surv., I, pp. 210, 298, 1890.-McGee, Rep. U. S. Geol. Surv., XI, p. 448, 1891.-Call, Proc. Ind. Acad. Sci., 1893, p. 150.-Cooper, Proc. Cal. Acad. Sci, ii, IV, p. 170, 1894.-CAll, Proc. Ind. Acad. Sci., pp. 250, 253, 1896.Baker, Journ. Cin. Soc. N. H., XIX, p. 83, 1897.-Call, Rep. Dept. Geol. and Nat. Res. Ind., XXIV, p. 407, 1899 (nec. fig.).-Blatchley and Ashley, An. Rep. Dept. Geol. \& Nat. Res. Ind., XXV, pp. 226, 248, 304, 1901.

Limnophysa decidiosa Todd, Bull. U. S. Geol. Surv., No. 158, p. 70, 1899.

Lymneus decidiosus Kirtland, Zool. Ohio, p. 174, 1838.

Limnea decidiosa DeAn, Amer. Nat., XXVI, p. 17, 1892.

Limncea decidiosa GabB, Proc. Phil. Acad., 1861, p. 309.-Tryon, Proc. Phil. Acad., 1861, p. 398.-Mörch, Amer. Journ. Conch., IV, p. 33, 1868.-Journ. Geol. IX, p. 292, 1903.-White, Proc. Amer. A. A. Sci., XXXIX, p. 241, 1890.Coleman, Interglacial Periods in Canada, p. 16, 1906.

Lymnca desidiosa (Variety?) Strecker, Nautilus, XXII, p. 65, 1908.

Limncea (Limnophysa) decidiosa HARPer, Journ. Cin. Soc. N. H., XVIII, p. $95,1895$.

Lymnaa decidiosa Wheatley, Cat. Sh. U. S., p. 23, 1843.-Scudder, Bull. Nat. Mus., 23, p. 200, 1885.

Limnea adeline, Nautilus, XII, p. 60, 1898.

Lymnea philadelphica LeA, Proc. Amer. Phil. Soc., II, p. 33, 1841; Trans. 
Amer. Phil. Soc., IX, p. 9, 1844; Obs., IV, p. 9, 1848; Expl. in Neb., II, pt. 3, p. 724,1859

Lymnaa philadelphica Wheatley, Cat. Sh. U. S., p. 24, 1843.-Scudder, Bull. Nat. Mus., 23, pp. 33, 43, 201, 1885.

Limnea philadelphica HALD., Mon. Limn., p. 33, pl. X, fig. 10, 1842.Anthony, L. \& F.-W. Sh. Cin., 1848.

Limncea philadelphica Binney, Land \& F. W. Sh. N. A., II, p. 50, fig. 71, 1865.-Tryon, Amer. Journ. Conch., III, p. 196, 1867.-Sowb., Conch. Icon., XVIII, Sp. 82, pl. 12, fig. 82, 1872.

Lymncea galbana var. philadelphica DALL, Alaska Moll., p. 74, fig. 52, 1905.

Lymncea desidiosa var. philadelphica JAY, Cat., p. 269, 1852.

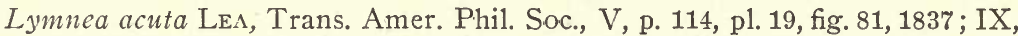
p. 12, 1841; Obs., I, p. 226, 1837.-LeA, Proc. Phil. Acad., 1860, p. 147.

Lymncea acuta Wheatley, Cat. Sh. U. S., p. 23, 1845.-Scudder, Bull. Nat. Mus., 23, pp. 14, 200, 1885.

Limnea acuta Hald., Mon. Limn., p. 33, pl. 10, fig. 14, 1842.-Anthony, L. \& F.-W. Sh. Cin., 1848.

Limnca acuta Bell, Geol. Surv. Canada, Rep. Prog., p. 252, 1859.-Binney, Land \& F.-W. Sh. N. A., II, p. 5, fig. 70, 1865.-Tryon, Amer. Journ. Conch., III, p. $196,186 \%$.

Lymncea desidiosa var. acuta JAY, Cat., p. 269, 1852.

Limnca pallida (not of Adams) CPr., Rep. Brit. Asso., pp. 209, 213, 1856.Whiteaves, Can. Nat. \& Geol., VI, p. 458, 1861.-Crr., Can. Nat. \& Geol., VI, p. 458, 1861; Smith. Mis. Coll., pp. 120, 160, 1872.-Calkins, Proc. Ottawa Acad. Sci., p. 25, 1874; Cin. Quart. Journ. Sci., I, p. 323, 1874.-?DAwson, British N. A., Bound Com., p. 349, 1875.-Walton, Proc. Roch. Acad. Sci., II, p. 12, pl. 6, figs. 12, 13, 1891.-Currier, Kent. Sci. Inst. Mis. Pub., No. 1, 1868.Walker, Journ. Conch., II, p. 330, 1879.-Shimek, Bull. Lab. N. H., Univ. Iowa, I, p. 68, 1888.-Walker, Nautilus, VI, p. 34, 1892; Rev. Moll. Mich., p. 17, 1894.-Walton, The Museum, IV, p. 133, 1894.-Baker, Trans. Acad. Sci. St. Louis, VIII, p. 89, 1898.-Huetr, Nat. Hist. La Salle Co., p. 104, 1898.-Letson, Bull. N. Y. State Mus., LXXXVIII, p. 55, 1905 (pąrt).

Lymnca pallida LeA, Proc. Phil. Acad., p. 81, 1856.-Currier, Sh. Grand River, Mich., 1859.-BAKer, Bull. I11. State Lab., VII, p. 105, 1906.

Limnca pallida Letson, Bull. Buf. Soc. Nat. Sci., IX, p. 242, 1909.

Limnea pallida Miles, Geol. Surv., Mich., 1860, p. 237, 1861.

Limnophysa pallida DeCamp, Kent. Sci. Inst., Mis. Pub., No. 5, p. 8, 1881.Keyes, Bull. Essex Inst., XX, p. 71, 1888.

?Limnca truncatula Woodward, Man., p. 399

Shell: Subconic, pointed, oblong, rather thin, frequently somewhat inflated; periostracum generally light yellowish horn color; surface shining, covered with numerous coarse lines of growth; under a strong lens very fine spiral lines may be seen; whorls $5 \mathrm{~T} / 2$, rounded, somewhat shouldered, the shoulder being near the suture; the last whorl is very large, half the length of the entire shell, generally compressed but quite obese in some specimens; spire acute, sharply-conical; nuclear whorls $1 \frac{1}{4}$, resembling those of Galba parva in outline and 
sculpture (see pl. XLIX, fig. H) ; sutures deeply indented; aperture very elongate-ovate, somewhat produced anteriorly; peristome thin, acute; inner lip reflected over the umbilical chink to form a thin, narrow expansion, which is usually appressed to the umbilical region, giving the axis a slight twist; parietal callus very thin; umbilical chink varying from distinctly open to scarcely observable; the surface of the shell is frequently malleated.

\begin{tabular}{|c|c|c|c|c|}
\hline $\begin{array}{c}\text { Length. } \\
9.50\end{array}$ & $\begin{array}{c}\text { Breadth. } \\
4.50\end{array}$ & $\begin{array}{c}\text { Aperture length. } \\
5.00\end{array}$ & $\begin{array}{c}\text { Breadth. } \\
2.50\end{array}$ & $\begin{array}{l}\text { Locality. } \\
\text { Type of obrussa }\end{array}$ \\
\hline 8.00 & 4.50 & 4.00 & 2.00 & “ philadelphica \\
\hline 9.00 & 5.00 & 4.50 & 2.00 & " \\
\hline 15.00 & 6.00 & 7.00 & 2.75 & acuta \\
\hline 14.00 & 6.00 & 6.50 & 3.00 & “ \\
\hline 18.00 & 7.75 & 9.00 & 3.75 & " $\quad$ " \\
\hline 17.00 & 8.00 & 10.00 & 4.00 & Haldeman's figure 14 \\
\hline 19.50 & 12.50 & 12.50 & 7.28 & $\begin{array}{lll}* & & \end{array}$ \\
\hline 18.25 & 9.00 & 10.00 & 5.00 & $\begin{array}{lll}\text { " } & \text { " } & 2\end{array}$ \\
\hline 14.00 & 6.00 & $\cdot 7.15$ & 3.25 & Owasco Lake, N. Y. \\
\hline 13.50 & 6.50 & 7.00 & 3.50 & \\
\hline 11.00 & 5.00 & 6.00 & 3.00 & Joliet, Ill. \\
\hline 13.25 & 7.25 & 7.25 & 4.00 & “ “ “ \\
\hline 12.00 & 5.50 & 6.25 & 3.25 & " " \\
\hline 12.50 & 6.50 & 6.50 & 3.50 & Des Moines, Ia. \\
\hline 11.00 & 5.00 & 5.75 & $3.25^{\circ}$ & " \\
\hline 12.00 & 6.00 & 6.00 & 3.00 & Chicago, Ill. \\
\hline 13.00 & 5.75 & 7.50 & 4.00 & \\
\hline 12.00 & 7.10 & 7.00 & 4.00 & Lemont, Ill. \\
\hline 13.00 & 6.50 & 7.00 & 3.50 & 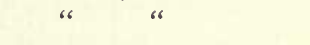 \\
\hline 17.50 & 8.00 & 8.50 & 4.50 & Bethlehem, $\mathrm{Pa}$. \\
\hline 16.00 & 8.00 & 9.00 & 5.00 & Lebanon, $\mathrm{Pa}$. \\
\hline 17.75 & 7.75 & 9.00 & 5.00 & " 6 \\
\hline
\end{tabular}

Types: Obrussa Say, two specimens, Acad. Nat. Sci Phil., No. $58 \% 00$; philadelphica Lea, Smithsonian Institution, three specimens, No. $11868 \%$; acuta Lea, three specimens, Smithsonian Institution, Lea Coll., No. 118643.

Type Localities: Obrussa, Harrowgate, Philadelphia County, Pennsylvania; philadelphica, River Schuylkill, near Philadelphia; acuta, pond four miles north of Philadelphia.

Animal: With a very small, more or less oblong foot, when viewed from the base, the anterior and posterior borders rounded; color dark gray or blackish, lighter below, sometimes yellowish, the whole surface is dotted with whitish or yellowish, which is specially noticeable about the eyes; tentacles triangular, flat, short, more or less transparent; the black eyes are placed on prominences at the inner base of the tentacles; respiratory orifice on the right side, near the angle 
of the peristome and body whorl. Length of foot 5.00, width 3.00 mill. Portions of the body frequently appear pinkish through the shell. When the animal is drawing in air through its siphon, it will withstand quite a violent jar before closing the respiratory orifice. In a number of experiments, no instance was noted in which water entered the respiratory cavity owing to these violent shocks.

JAw: About three times as wide as high, much arched, with rounded ends and a wide, flatly convex median swelling. (Pl. VI, fig. F.)

Radula (plate VII, fig. E) : Formula : $\frac{16}{4-7}+\frac{2}{3}-\frac{2}{4}+\frac{8}{3}+\frac{1}{1}+\frac{8}{3}+\frac{2}{3}-\frac{1}{4}+\frac{16}{4}-7$ (26-1-26) ; central tooth with a rather pointed cusp; lateral teeth tricuspid, with a subquadrate base of attachment, the reflection very broad, the entocone short and rather small, the mesocone long and wide, reaching below the lower margin of the base of attachment, the ectocone large and placed rather high up on the reflection; the ninth and tenth teeth are modified laterals and. are intermediate between laterals and marginals; they are rather narrow with two unequal cusps at the distal end and a third cusp placed higher up on the reflection; a small cusp is frequently developed very high up on the outer side of the reflection; marginals at first long and narrow, four to seven cuspid with one or more small denticles high up on the outer side of the reflection. The cusps vary widely in number, size and position on the marginal teeth, but are usually four in number; extreme cuter marginals narrow with four or more denticulations at the distal end. The examination of a small, narrow form of obrussa from Des Moines, Iowa, gave 25-1-25 teeth, the intermediate teeth beginning with the seventh tooth, the ninth tooth being a true marginal. A specimen from Maine had seven laterals, the marginals beginning abruptly with the eighth tooth. Obrussa seems more variable in the number and position of the lingual tooth than any of the other small Lymnæas. There are more than seventy rows of teeth. ${ }^{1}$

Genitalia (Plate XI, fig. C): Male organs: Penis-sac cylindrical, long and narrow, 2.00 mill, long, 0.75 mill. wide; penis very long and slender, 2.00 to 3.00 mill. long, or as long as, or somewhat longer than, the penis-sac; vas deferens 5.00 mill. long; vas deferens to prostate 1.00 mill. long, entering the prostate without marked enlargement; prostate small, rather short, flattened, somewhat long-ovate when viewed from the front, and very elongate-cylindrical when seen

\footnotetext{
${ }^{1}$ The radula described and figured by the writer in Mollusca of the Chicago Area, page 267 , is erroneous. The specimen from which the radula was. extracted was not preserved, and it is now impossible to determine just what species was represented.
} 
from the side; retractor muscles of penis two in number, very long and narrow, ribbon-like; one muscle enters the penis-sac and one the head of the penis; protractor muscles very small, five in number, three on the posterior and two on the anterior face of the penis-sac.

Female organs: Oviduct not differing from that organ as found in other Lymnæas; receptaculum seminis not remarkably large, ovate or pyriform, with a duct 3.00 mill. long joining the oviduct .25 mill. from the vaginal opening; albuminiparous gland of the usual form; first accessory albuminiparous gland large, pyriform, a little elongated, its proximal end narrowing suddenly toward the vaginal portion of the oviduct. The receptaculum seminis is orange in color and the albuminiparous gland is yellowish.

The genitalia exhibit some variation. The retractor muscle of the male organ may be separated or the penis retractor may enter the penis-sac retractor about half its length from the columellar muscle. (P1. XIV, fig. G, 1, 2.) The first albuminiparous gland also varied in one specimen, being irregularly quadrate instead of regularly pyriform. In another specimen the prostate was flattened and broadly pyriform when viewed from above, but elongated when viewed from the side. (P1. XII, fig. C.) The majority of specimens examined, however, were as shown in figure $\mathrm{C}$, plate XI.

Several measurements of the genitalia gave the following results. (Dissections Nos. 23167, 23168, 23169, 23170, 2317\%, 23178, 23179.) The uniformity of the majority of the measurements is noteworthy.

\begin{tabular}{|c|c|c|c|c|c|c|c|c|}
\hline Penis. & $\begin{array}{l}\text { Penis- } \\
\text { sac. }\end{array}$ & $\begin{array}{l}\text { Rec. } \\
\text { sem. }\end{array}$ & $\begin{array}{l}\text { Prost. } \\
\text { duct. }\end{array}$ & $\begin{array}{l}\text { Vas. } \\
\text { def. }\end{array}$ & $\begin{array}{l}\text { et. mus. } \\
\text { Penis. }\end{array}$ & $\begin{array}{l}\text { Ret. mus. } \\
\text { Penis-sac. }\end{array}$ & Shell. & \\
\hline 2.75 & 2.00 & 3.00 & 1.00 & 5.00 & 1.10 & 1.75 & 9.50 & Cayuga Lake \\
\hline 2.00 & 1.90 & 3.25 & 1.00 & 5.00 & 1.10 & 1.75 & 11.50 & $\pi$ \\
\hline 2.00 & 1.90 & 3.25 & 1.00 & 5.00 & 1.10 & 1.75 & 10.50 & Sea Breeze ${ }^{1}$ \\
\hline 3.00 & 2.00 & 3.00 & 1.00 & 5.00 & 1.10 & 1.75 & 11.50 & " 1 \\
\hline 2.75 & 2.00 & 3.00 & 1.00 & 5.00 & 1.10 & 1.75 & 11.50 & Des Moines \\
\hline 3.00 & 2.25 & 3.00 & 1.00 & 5.00 & 1.25 & 1.50 & 13.00 & " \\
\hline 2.00 & 2.00 & 3.00 & 1.00 & 5.00 & 1.10 & 1.50 & 11.50 & “ \\
\hline 2.00 & 2.00 & 3.00 & 1.00 & 5.00 & 1.10 & 1.50 & 12.00 & Narrow form \\
\hline 1.10 & 1.10 & 3.00 & 1.00 & 3.00 & 1.10 & 1.00 & 9.00 & “ \\
\hline 1.75 & 1.50 & 3.00 & 1.00 & 3.00 & 1.10 & 1.50 & 10.00 & “ \\
\hline
\end{tabular}

On May 15, 190\%, several egg masses were laid by this species in an aquarium; the measurements of the masses and the number of eggs in each are given below:

$800 \times 2.00$ mill., 30 eggs; $7.50 \times 2.50$ mill., 45 eggs.

Range (Figure 28): From the Atlantic to the Pacific oceans, 


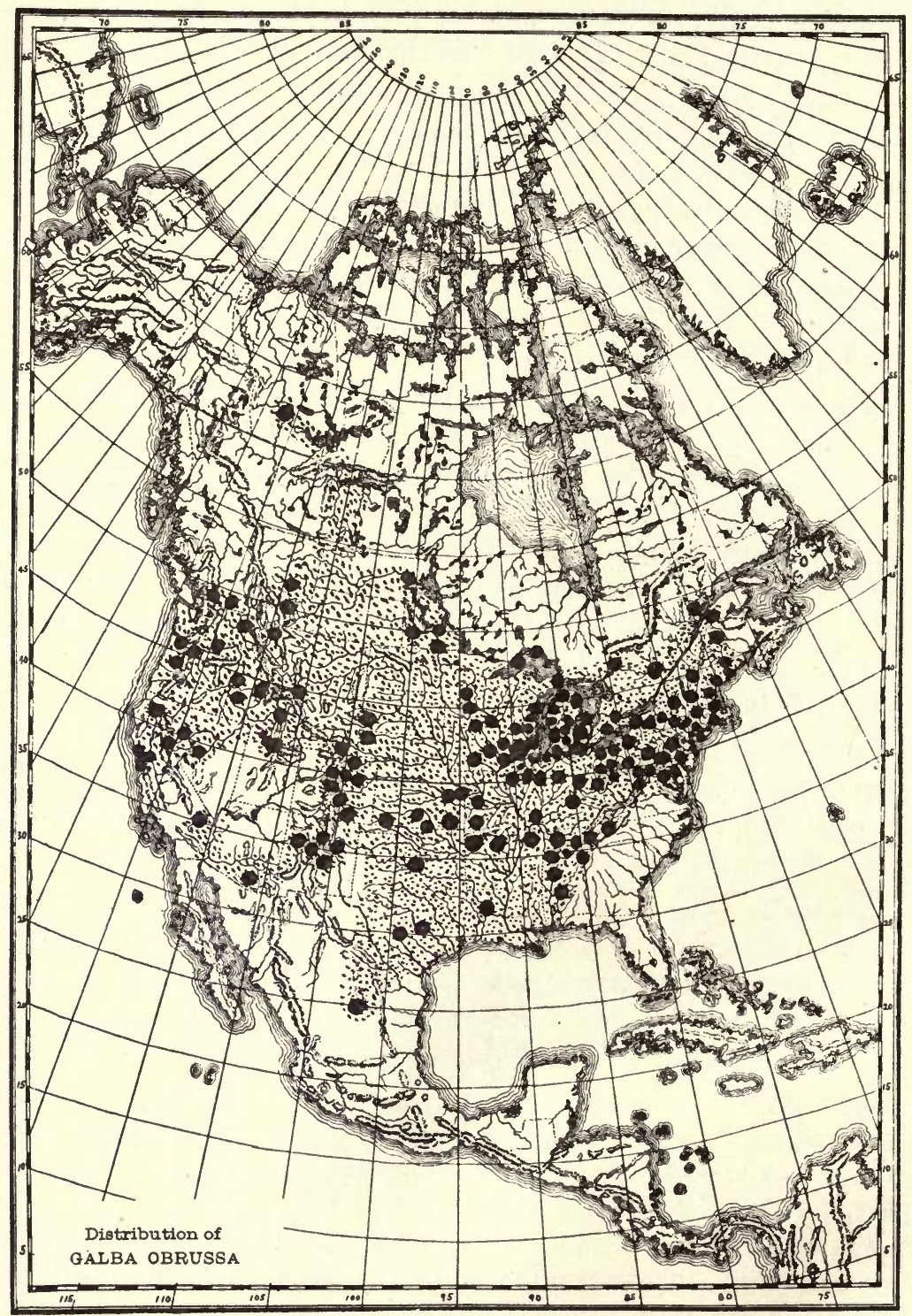

FrG. 28. 
and from Mackenzie Territory and Quebec south to Arizona and northern Mexico.

Obrussa covers a wide range, including all of North America excepting the Labradorian, Yukonian, Alaskan, Central American and Carolinian regions. It is well distributed throughout the Boreal, Transition and Upper and Lower Austral life zones. Like Galba humilis modicella, it is absent from that portion of the Lower Austral (Austroriparian) which borders the Atlantic Ocean and the Gulf of Mexico. It ranges from the sea level to a height of some 10,000 feet in Colorado. It is quite probable that additional records will greatly extend, besides adding to, the records from British America. Records are also needed from the area of the Great Plains.

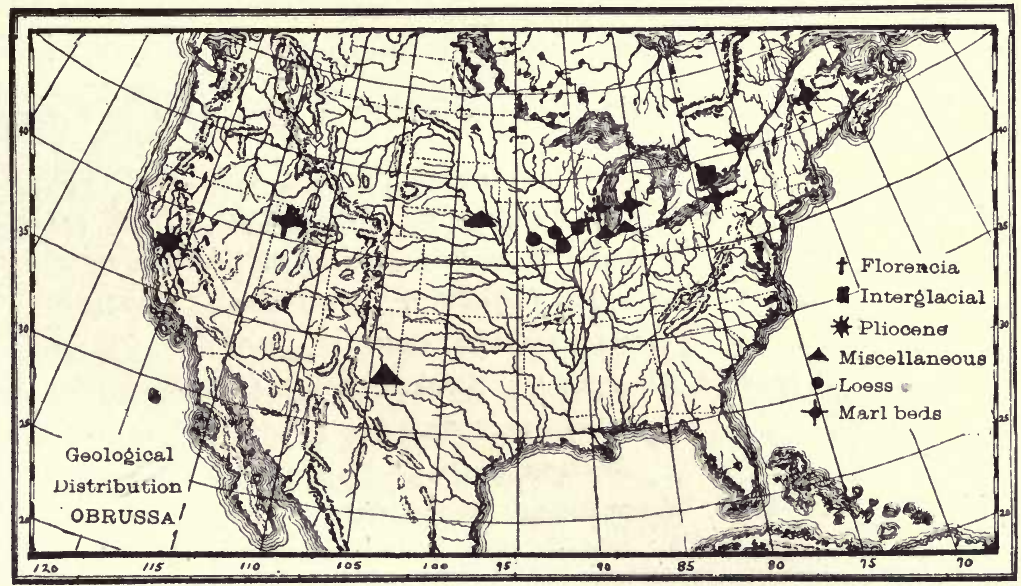

FIG. 29.

The range of this species is remarkable in that it covers a territory 35 degrees long and about 60 degrees wide. It is evident that the species has taken advantage of all the post-glacial water connections to extend its range. Next to palustris, it is the most universally distributed of the American Lymnæas.

Geological Range (Figure 29): Pliocene to Pleistocene. As in the case of Galba humilis modicella, the records of the occurrence of this species in geological strata are not numerous enough to indicate with any degree of exactness the past distribution of obrussa. Records from the Lœss give it a wide range in northern Illinois, Iowa and Nebraska, while the marl records include the territory from Maine to Wisconsin. The marl records are in the Alleghanian division of 
the Transition life zone, while the Lœss records are confined to the Carolinian division. 'The New Mexico record is probably to be considered from subfossil strata.

\section{Cooper's record is as follows: ${ }^{1}$}

"Along a small branch of Walnut Creek, in Alameda County, north of Livermore, is a deposit which contains chiefly living species, and was formerly called Quaternary, but one extinct species has been described from there, and its high elevation, nearly corresponding with the bed last described, makes it probable that it may better be called Pliocene."

Further records will be of great interest in the light of recent elucidation of the smaller species and varieties.

\section{RECORDS. \\ LÆSS.}

Illinors: Galena, Jo Daviess Co. (McGee); two miles south of Freeport, Stephenson Co. (Smith. Inst.).

Iowa: Lœss of Iowa; North Hill, Burlington, Des Moines Co. (Keyes); Des Moines, Polk Co. (McGee and Call); Iowa City, Johnson Co. (McGee; Pilsbry; Shimek); Lœss of Iowa (Shimek); Johnson Co. (Webster).

Nebraska: Lœess of Nebraska (Shimek).

FLORENCIA FORMATION.

ILlinors: Pecatonica River Valley, Stephenson Co. (Hershey).

MARL DEPOSITS.

United States.

Maine: Mud Lake, Westmanland, Aroostook Co. (Nylander).

Michigan : Huron Co.; cascade near Grand Rapids, Kent Co.; Pickerel and Fremont lakes, Newaygo Co.; near Cedar Lake Station. Montcalm Co. (Walker).

Utah: Lake Bonneville (Gilbert).

Wisconsin: Milwaukee, Milwaukee Co. (Baker; Slocum).

British America.

Ontario: Hemlock Lake, near Edinburgh, east of Ottawa, Carleton Co., in soft, white, calcareo-argillaceous matrix (Ami); near Ottawa (Heron).

GRAVEL BEDS.

New York: Goose Island, Niagara River, Erie Co. (Letson).

VARIOUS PLEISTOCENE DEPOSITS.

United States.

Illinors: Old lake beach, Rockwell Street near Belmont Avenue, Chicago, in sand (Jensen).

. Michigan : Two miles west of village of Buchanan, Berrien Co., in Bakertown Marsh, associated with Mastodon remains (Smith); Niles, Berrien Co., associated with Mastodon remains (Walker).

${ }^{1}$ Proc. Cal. Acad. Sci. i, IV, p. 166. 
Nebraska: Five or six miles southwest of Santee Agency, Knox Co., in stratum of laminated clay (Todd).

New Mexico: Dry salt lake, near Eddy, Eddy Co. (Sterki).

\section{British America.} man).

Ontario: Interglacial beds, Don Valley, near Toronto, York Co. (ColePLIOCENE.

CALifornia: Tassajora Lake bed, along small branch of Walnut Creek, Alameda Co. (Cooper).

Ecology: Found generally in small bodies of water, as creeks, ponds, sloughs, bays and marshy spots along river banks. Frequently inhabits abandoned quarries which have become filled with water. Like Galba humilis modicclla and Galba parra, this species is at home on sticks, stones and exposed muddy surfaces (Baker); in warm water streams from Hot Springs, Hill City, Black Hills (Ulke); on weeds, Owasco Lake, New York (Lyon); "obrussa is abundant at Boulder, in overflow ditches, in mud, the channels free from vegetation and, I believe, in no case have I found it where water stands or flows the year round" (Henderson); dredged in Lake Superior at a depth of eight to fifteen fathoms (U. S. Fish Com).

Remarks: Obrussa is one of the most widely distributed, as it is one of the most variable, of the American Lymnæas, not even excepting the circumboreal palustris. The spire may be long or short, pointed or wide, and strongly shouldered. The whorls may be slender, scalar or wide and corpulent, while the aperture varies from almost round to long and narrow. The umbilicus may be rather widely open or it may be reduced to a minute chink, depending upon whether the inner lip is closely appressed to the axis or is raised over the umbilical region. Imperforate specimens are, however, very rare. The fine spiral sculpture can only be seen when the shell is examined with the aid of a powerful lens; in some specimens these lines are very distinct, while in others they are scarcely discernable. Typically, obrussa may be known by its pointed spire, compressed body rohorl and elongated and shouldered aperture, which is also strongly effuse at the anterior end; the inner lip is appressed to the body whorl about the middle of the apcrture. The shape of the shell, of the aperture and of the inner lip is quite different from Galba humilis modicella, the shell being larger and more elongated, the last whorl not so convex; the aperture is longer and narrower and much more effuse, besides forming a distinct shoulder at its junction with the body whorl; the inner lip is more compressed in the middle where it joins the parietal wall. In 
shells of the same size, modicella has five whorls, while obrussa has four whorls; in form the young of obrussa, especially of the variety plica, somewhat approach modicella. The shell is, typically, much larger than modicella, parva and the other members of the humilis group. Within certain limits, obrussa is very easily recognized and need not be confounded with any other species.

The types of obrussa, two specimens, are preserved in the Academy of Natural Sciences of Philadelphia, No. 58\%00. They are both broken, but one specimen is sufficiently perfect to settle the question of its specific identity. This specimen corresponds with Say's description and is fairly represented by Binney's figure 69 . The types of Lea's philadelphica in the Lea collection (No. 118687) are identical with common forms of obrussa. They have five whorls, which are somewhat shouldered, the sutures are compressed and there is a small umbilical chink. The specimens are from Center City, Pa. Dr. Dall, in his Alaska Mollusks, makes philadelphica a variety of galbana, but Lea's specimens belong unquestionably to obrussa and have only a superficial resemblance to galbana. Some small individuals resemble galbana in general form, but have a more acute spire and a differently shaped inner lip and aperture. The series of figures on plate XXXI illustrate this similarity in form and also show the general transition into typical obrussa. In galbana the spire is always short and wide, the outer lip is much more arched at the upper part, and the inner lip lacks the impressed character as it meets the parietal wall, a feature very marked in obrussa. Lea's acuta was at first thought to be a recognizable variety of obrussa, but the study of extensive series from different localities shows that it is a minor variation of obrussa. This form is typically of a pronounced fusiform shape, with elongated spire and aperture, the latter being notably effusive at the anterior end. Lea's types comprise three specimens, of which the largest was figured by Binney. (Fig. 70.) There are six full whorls and the columellar plait is quite heavy. Several lots of obrussa have been examined in which the variations may be traced from a short rounded shell to the fusiform aspect called acuta by Lea. As these forms are all associated together in colonies spreading over a territory scarcely a yard in area, they can scarcely be regarded as varieties. This variation has been observed in sets of shells from Des Moines, Iowa; Lemont and Joliet, Illinois, and Aroostook County, Maine. Some of these variations are figured on plate XXXI (especially fig. 20 and fig. 33, which are good examples of acuta). Certain large, robust specimens of obrussa have been identified as pallida Adams. (See under pallida.) 
A peculiar form of obrussa occurs at La Porte, Indiana (in Clear Lake), which when half grown has the general form of Galba humilis modicella and the spire has the rounded whorls of Galba obrussa plica. (P1. XXXI, figs. 35-3\%.) The adult shells, however, are typical obrussa. This fact illustrates the supreme importance and value of studying a large series from each locality. At Lebanon, Pennsylvania, a form occurs with a very acute spire and a much expanded aperture, resembling in outline Galba davisi (Walker). (See plate XXVI, figures 11-13.) This form approaches Galba obrussa peninsula in the acuteness of the spire, but the body whorl is quite convex. A somewhat similar form occurs in Monocacy Creek, Bethlehem, Pennsylvania, differing in the aperture, which is purely of the obrussa type. (Figs. 8-10.) These variations are not stable and are all sports or mutations.

Haldeman's figures on plate 10 of his monograph are all founded on true obrussa, although figure $\gamma$ is abnormal. The specimens are preserved in the Philadelphia Academy, No. 58\%02. Figure 14 represents the acuta of Lea. All of the forms figured on Haldeman's plate have been collected by the writer, excepting the one represented by figure $\%$, which is probably unique. (Compare Haldeman's figures with those on plate XXXI.) Binney's figure 68 is questionable, though it may represent an elongated form of obrussa.

This species has long been known under the name of desidiosa, but that name should be applied to a totally different species, a fact made clear by an examination of autotypes in the Philadelphia Academy. See under palustris.

Galba obrussa peninsulæ (Walker). Plate XXXII, figures 1-6.

Limnaa desidiosa Ruthven, Rep. Mich. Acad. Sci., VI, p. 190, 1904.Walker and Ruthyen, Rep. Geol. Surv. Mich., 1905, p. 95, 1906.

Lymnca desidiosa var. peninsula Walker, Nautilus, XXII, p. 9, 163, pl. ii, fig. 7, May, 1908.

Shell: Of good size, slender, elongated; periostracum yellowish or brownish horn; surface dull to shining, growth lines rather coarse and heavy, spiral lines faintly impressed on some specimens, very heavily impressed on others; whorls 6 , very convex, body whorl subcylindrical, somewhat compressed; spire long and acute, subturreted to turreted; sutures deeply impressed; aperture oval, not notably expanded; outer lip thin; inner lip narrowly reflected, forming a triangular expansion, narrow and erect at the lower part of the aperture, wide and flatly appressed to the parietal wall at the upper part; umbilical chink very narrow. 


$\begin{array}{cccccc}\text { Length. } & \text { Breadth. } & \text { Aperture length. } & \text { Breadth. } & \\ 13.50 & 6.25 & 7.00 & 3.10 \text { mill. } & \text { Type } \\ 15.00 & 6.00 & 6.00 & 3.50 & \text { “ } & \\ 14.00 & 6.00 & 6.50 & 3.50 & \\ 13.75 & 6.00 & 6.50 & 3.25 & \\ 12.50 & 6.00 & 6.50 & 3.00 & \\ 13.50 & 6.00 & 6.50 & 3.00 & \text { " } & \text { Cotypes } \\ 12.75 & 6.00 & 6.25 & 3.00 & \text { " } & \text { " } \\ 13.50 & 6.25 & 6.50 & 3.50 & \text { " } & \text { Maine }\end{array}$

Types: Coll. Bryant Walker, eight specimens, No. 20040; cotypes, Chicago Academy of Sciences, five specimens, No. 23968; Academy of Natural Sciences, Philadelphia.

Type Locality: Headwaters of the Union River, Ontonagon County, Michigan.

Animal: Not differing from that of obrussa.

Jaw and Radula: Same as those of obrussa.

Genitalia: Similar to those of obrussa (Maine specimen). The retractor muscle of the penis-sac differs in being much larger, fanshaped, with numerous branches at either end. (P1. XIV, fig. G, 3.) A specimen measured as follows:

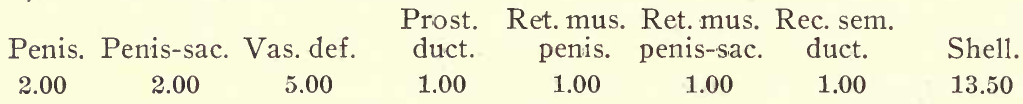

RANGe: Northern Maine to northern Michigan. Southern Boreai and northern Transition (Alleghanian) life zones. Canadian and Nova Scotian regions. Further search will probably reveal this variety in many other localities in the northern part of the United States.

\section{RECORDS.}

Maine: Unity, Waldo Co. (Berry); Thomaston, Knox Co. (Lermond).

Michigan: Union River and Little Iron River, Ontonagon Co.; Salmon Trout River, Marquette Co.; St. Mary's River, Sault Ste. Marie, Chippewa Co. (Walker); rock pools of Middle Branch, Lake Superior, Ontonagon Co. (Walker and Ruthven).

Geological Distribution: Unknown.

Ecology: "Occurs quite numerously in the rock pools of the middle Beach.” (Walker and Ruthven.)

REMARKs: This variety differs from typical obrussa in being more slender, with a longer, more turreted spire, deeper sutures and a more oval aperture. The body whorl is more cylindrical than in the typical form. Mr. Walker says: "It is apparently characteristic of the small rivers tributary to Lake Superior. With the exception of a few specimens from Sault Ste. Marie, the typical form has not been as yet found in the upper peninsula at all. As a characteristic loca! form of a large region, it seems worthy of a name." The specimens 
from Thomaston and Unity, Maine, seem referable to this variety. A form of obrussa occurs at Castle Hill, Aroostook County, which somewhat resembles this variety, differing in having a larger aperture and a narrower body whorl. These are probably transition forms. Peninsulce will probably be found in collections labeled desidiosa.

Galba obrussa exigua (Lea). Plate XXXII, figures \%-14.

Lymnea exigua LEA, Proc. Amer. Phil. Soc., II, p. 33, 1841; Trans. Amer. Phil. Soc., IX, pp. 9, 10, 1844 ; Obs., IV, pp. 9, 10, 1848 ; Proc. Phil. Acad., VIII, p. 81, 1856 ; Journ. Phil. Acad., VI, pp. 155, 162, 1866 ; Obs., XI, pp. 111, 118, 1867.

Lymnaa exigua Wheatley, Cat. Sh. U. S., p. 23, 1843.-LeA, Proc. Phil. Acad., 1856, p. 81.-CPR., Rep. Brit. Asso., 1864, p. 634.-Wolf, Amer. Journ. Conch., VI, p. 28, 1870.-CPR., Smith. Mis. Pub., 1872, p. 120.-Scudder, Bull. Nat. Mus., 23, pp. 33, 43, 201, 1885.

Limnaa cxigua D’Urban, Geol. Surv. Can. Rep. Prog., p. 242, 1859.-BinNEY, Check List, p. 12, 1860 ; L. \& F.-W. Sh. N. A., II, p. 65, fig. 105, 1865.Whiteaves, Can. Nat. \& Geol., VIII, p. 103, 1863.-Tryon, Amer. Journ. Conch., III, p. 196, 1867.-Clessin, Mal. Blatt., n. s., III, p. 81, 1881.

Limnophysa humilis var. exigua Cooper, Proc. Cal. Acad. Sci., IV, p. 96, 1870.

Lymnea plica LeA, Proc. Amer. Phil. Soc., II, p. 33, 1841; Trans. Amer. Phil. Soc., IX, pp. 8, 9, 10, 1844; Obs., IV, pp. 8, 9, 10, 1848; XI, p. 118, 1867; Journ. Phil. Acad., VI, p. 162, 1866.

Lymnca plica Wheatley, Cat. Sh. U. S., p. 23, 1843.-Scudder, Bull. Nat. Mus., 23, pp. 33, 44, 201, 1885.

Limnca plica Binney, Check List, p. 12, 1860 ; L. \& F.-W. Sh. N. A., II, p. 65, fig. 103, 1865.-TrYon, Amer. Journ. Conch., III, p. 196, 1867.-Clessin, Mal. Blatt., n. s., III, p. 81, 1881.

Limnaa plicata D’Urban, Geol. Surv. Can., Rep. Prog., p. 242, 1859.

Lymnaa obrussa plica Baker, Bull. Ill. State Lab. N. H., VII, p. 103, 1906.

Lymnea planulata LeA, Proc. Amer. Phil. Soc., II, p. 33, 1841; Trans. Amer. Phil. Soc., IX, p. 9, 1844; Obs., IV, p. 9, 1848.

Lymnaa planulata WheAtley, Cat. Sh. U. S., p. 23, 1843.-Scudder, I.'! Nat. Mus., 23, pp. 33, 44, 201, 1885.

Limnca planulata Binney, Check List, p. 12, 1860 ; L. \& F.-W. Sh. N. A., II, p. 65, fig. 104, 1865.-Clessin, Mal. Blatt., n. s., III, p. 81, 1881.

SHell: Small, turreted, subfusiform, generally narrow; surface dull to shining, growth lines coarse, elevated, crowded; spiral lines sometimes present; whorls 5, generally well rounded, slowly increasing in diameter; spire wide, elevated, turreted, generally longer than the aperture; nuclear whorls as in obrussa; sutures deeply impressed; body whorl generally compressed, subcylindrical; aperture ovate to elliptical, slightly effuse; outer lip thin; inner lip narrow, tightly appressed at its junction with the parietal wall, the lower part erect or turned upward; umbilical chink very small, frequently entirely closed. 


\begin{tabular}{cccccc} 
Length. & Breadth. Aperture length. & \multicolumn{2}{c}{ Breadth. } \\
9.10 & 4.25 & 4.10 & 1.75 & mill. & Plica \\
8.10 & 4.10 & 3.10 & 1.50 & " & Planulata \\
5.50 & 3.00 & 3.00 & 1.00 & " & “ \\
9.00 & 4.10 & 4.50 & 2.00 & " & Maine \\
8.75 & 3.90 & 4.00 & 2.00 & " & “ \\
8.00 & 3.50 & 3.75 & 2.00 & " & " \\
8.50 & 3.50 & 4.00 & 2.00 & " & " \\
11.50 & 5.50 & 5.25 & 2.60 & " & Iowa \\
9.50 & 4.50 & 4.10 & 2.10 & " & " \\
8.50 & 4.75 & 4.25 & 2.00 & " & " \\
9.50 & 4.00 & 4.75 & 2.00 & "
\end{tabular}

Types: Plica, Smithsonian Institution, one specimen, No. 119485; plamulata, Smith. Inst., six specimens, No. 118676 ; the types of exigua are not in existence.

Type Locality: Plica, Tennessee; plamulata, White Sulphur Springs, West Virginia; exigua, Tennessee.

Animal: Similar to obrussa externally.

JAw: Not differing in general form from that of obrussa.

Radula (Plate VIII, fig. C, D) : Formula : $\frac{18}{4}-7+\frac{1}{4}+{ }_{3}^{6}+11+\frac{1}{3}+\frac{1}{4}+\frac{18}{4-7}$ (25-1-25); central tooth like that of obrussa; lateral teeth tricuspid, the reflection quite broad, the entocone small, the mesocone very large and the ectocone small; the laterals become narrower at the third tooth, the entocone approaching the distal end; the seventh tooth is intermediate, the entocone becoming larger, so that it and the mesocone are subequal in size; the true marginals begin at the eighth tooth and are claw-like. The eighth tooth varies somewhat in the form of the denticulations. (See pl. VIII, fig. C.) In one specimen from Des Moines, Iowa, the seventh tooth possessed three small, very acute denticles on the upper part of the outer margin; this probably indicated a splitting of the ectocone; the entocone was very large and very acute. (P1. VI, fig. 0.) There are over sixty rows of teeth. The teeth of exigua are very uniform. The radula differs from that of obrussa in having but six laterals and in the true marginals commencing on the seventh instead of the eleventh tooth. In form the teeth of both radulæ are very similar.

Genitalia: The genitalia of exigua are in all respects similar to those of obrussa. A typical measurement is as follows (No. 23292):

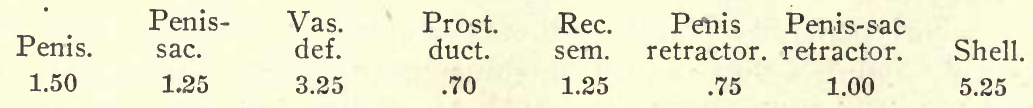

There are two posterior and two anterior protractor muscles of the penis-sac. 
Range (Figure 30): Maine west to Iowa and Minnesota, northern Michigan south to Tennessee.

Exigua has a wide range, embracing a larger part of the Alleginanian and Carolinian divisions of the Transition and the Upper Austral life zones. To the north and northeast (Michigan and Maine) it penetrates the Boreal (Canadian) life zone. A characteristic race of the Canadian, Upper Mississippian and Nova Scotian regions.

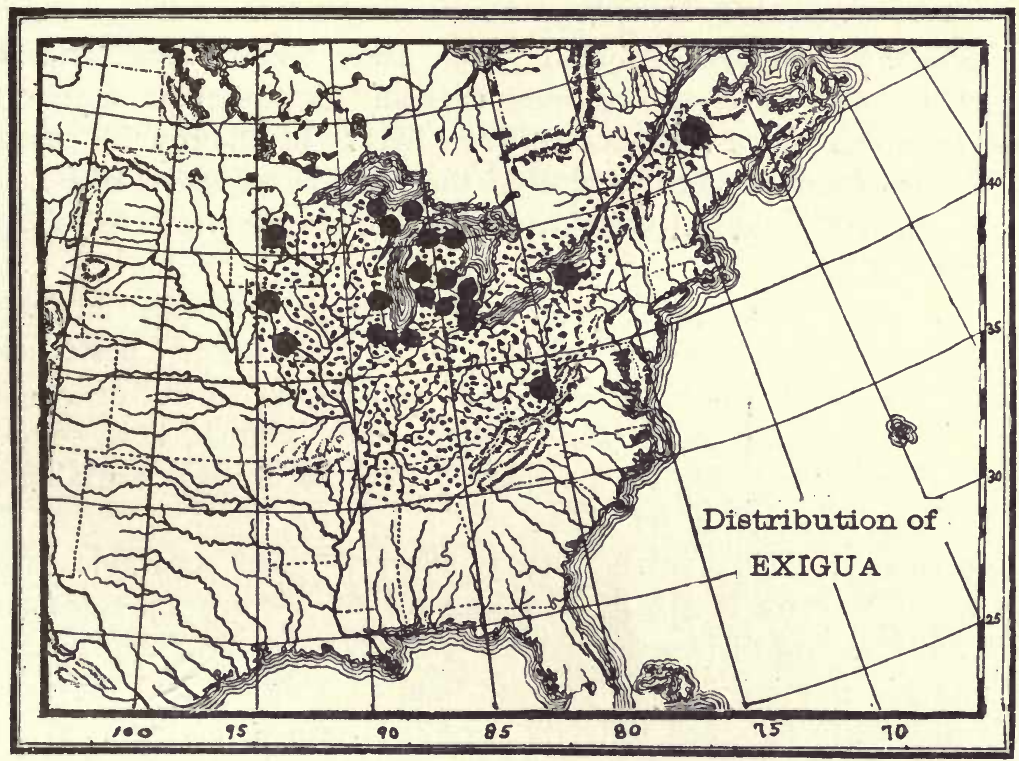

FIG. 30 .

\section{RECORDS.}

UNITED STATES.

Illinors: In ditches, N. W. end Calumet Lake, Cook Co. (Baker) ; Drummond, Will Co. (Ferriss); Stony Island, Cook Co. (Hood).

Indiana: Little Kankakee River, near La Porte, Indiana (Daniels).

Iowa: Bayou below Valley Junction, Des Moines, Polk Co.; pond No. 1 and pond No. 3 above dam, Des Moines; pond No. 3, old Zoo, Des Moines; pond below Chesterfield, near Des Moines (Van Hyning) Elk Lake, Ruthven, Palo Alto Co. (Walker).

MaIne: Aroostook River, Caribou, Aroostook Co.; Caribou Stream, Woodland, Aroostook Co. (Nylander).

Michigan: West Twin Lake, Charlevoix Co.; Pere Marquette River, Lake Co.; Carlton, Monroe Co.; Alger, Alpena, Charlevoix, Dickinson, Eaton, Gratiot, Kent, Lake, Marquette, Monroe, Montcalm, Ottawa, Shiawassee and Washtenaw Counties (Walker). 
Minnesota: Mississippi River, Stearns Co. (Walker).

New York: Erie Canal, Lock 65, Rochester; Round Pond, near Charlotte; Sea Breeze, Irondequoit Bay; Monroe County (Baker).

Tennessee: Tennessee (Lea; Troost).

West Virginia: White Sulphur Springs, Greenbrier County (Lea; Nicklin).

Wisconsin: Milwaukee, Milwaukee Co. (Smith. Inst.).

Geological Range: Pleistocene.

MARL BEDS

Michigan: Arnolds Lake, Washtenaw County (Walker).

Ecology: In bayous, small ponds, lakes and streams, and the protected shores of rivers, on mud flats and in situations similar to those in which Galba humilis modicella lives. In Illinois the species is generally found in ditches and on the margins of small lakes. In New York it is found in swampy places and on the protected shores of lakes and bays.

Mr. Van Hyning, of Des Moines, Iowa, has recorded an interesting case of protective resemblance. In a pond below Chesterfield, near Des Moines, Iowa, rather small, narrow specimens of exigua occur. Those living on a sandy bottom have whitish, horn-colored shells, while those living on a muddy bottom or in moss are almost, and in some cases quite, jet black.

REMARKS: This small variety appears quite separable from obrussa. The spire is usually long and the whorls are flat-sided and compressed, giving their upper parts a strongly shouldered appearance; the aperture is more regularly ovate than in obrussa, and the inner lip is peculiarly flattened near the umbilical region, giving rise to a pseudo-plait. The most noteworthy feature is the very deep suture, which is almost channeled in many specimens, causing the whorls to be turban-shaped. This feature is present in the majority of the individuals examined. This race will probably be found in many collections under the names of desidiosa or humilis. Specimens from Des Moines are striped in zebra fashion.

This neat little variety is usually easily separated from obrussa. At Des Moines, Iowa, the variety is connected with obrussa by intermediate forms, but in most of the lots examined the variety is very constant. Exigua is liable to be confounded with Galba humilis rustica, hut in that race the spire is acutely conical, the whorls regularly increase, the body whorl is not compressed in the middle, and the aperture is roundly ovate, while in exigua the spire is broadly turreted, the whorls are disproportionate in size and the body whorl is very cylindrical. (See the figures on plate XXXII.) 
Lea's type of plica is preserved in the Smithsonian Institution. The single specimen is undoubtedly the small form of obrussa herein described. Plica is described as imperforate, but the type has a very small chink which is emarginated by the inner lip, which is impressed in the manner shown on plate XXXII. Planulata, of which the type lot of six specimens is preserved, is also the same; this flattening of the whorls is well shown in figure 9 on plate XXXII. The type of cxigua is not in existence. The three forms described by Lea, of which cxigua is first mentioned, constitute a distinct and easily recognizable variety of obrussa.

Galba obrussa decampi (Streng). Plate XXXII, figures 15-22.

Limncea desidiosa var. decampi Streng, Nautilus, IX, p. 123, text figure, March, 1906.-WALker, Geol. Surv. Mich., VII, pl. 3, p. 101, 1903.

Limnca desidiosa BAKer, Journ. Cin. Soc. N. H., XIX, p. 176, 1900.Nylander, Nautilus, XIX, p. 162, 1901.

Lymnca obrussa decampi BAKer, Bull. Ill. Lab. N. H., VII, p. 103, 1906.

Lymncea obrussa var. decampii Lermond, Shells of Maine, p. 37, 1908.

SHELl: Small, oblong or subfusiform, somewhat inflated, subconic, rather solid; periostracum pale horn; surface rather dull, growth lines distinct but not coarse, spiral striation generally absent; whorls 5, rather rapidly enlarging, the spire whorls convex, and distinctly shouldered near the suture, the body whorl very much flattened in the middle ; spire short, broadly conic, turreted, about as long as the aperture; nuclear whorls as in obrussa; sutures deeply impressed, forming a distinct shoulder; aperture very long and narrow, somewhat elliptical, rounded below and forming a prominent shoulder at the upper part; inner lip narrowly reflected, forming an expansion which is not much compressed at its junction with the parietal wall; the lower part of the inner lip stands quite erect; umbilical chink large and conspicuous, emargined by the inner lip.

\begin{tabular}{|c|c|c|c|c|c|}
\hline $\begin{array}{l}\text { Length. } \\
5.00\end{array}$ & $\begin{array}{c}\text { Breadth. } \\
2.50\end{array}$ & $\begin{array}{c}\text { Aperture length. } \\
\ldots .\end{array}$ & $\begin{array}{l}\text { Brea } \\
\ldots\end{array}$ & $\begin{array}{l}\text { dth. } \\
\text { mill. }\end{array}$ & Type \\
\hline 11.00 & 5.50 & 6.00 & 2.75 & “ & Maine \\
\hline 8.50 & 4.00 & 4.50 & 2.00 & “ & " \\
\hline 10.00 & 5.00 & 5.25 & 2.50 & “ & Illinois \\
\hline 9.75 & 5.25 & 5.50 & 2.50 & “ & Michigar \\
\hline
\end{tabular}

Types: Coll. L. H. Streng, Grand Rapids, Michigan; cotypes, Coll. Bryant Walker, Detroit, Michigan; Acad. Nat. Sci., Philadelphia, No. 67805 .

Type Locality: Brook's Lake, Newaygo County, Michigan.

Animal, Jaw, Radula and Genitalia: Unknown. 
Range (Figure 31): Maine west to Wisconsin, northern Michigan south to northern Illinois.

This variety occupies a large part of the Alleghanian division of the Transition life zone; it enters the Carolinian division of the Upper Austral life zone on the south and the Boreal (Canadian) life zone on the north. This area of distribution will probably be greatly extended when the variety becomes known. It has been confounded with obrussa heretofore. The geological range is at present much wider than the present range (the race has not been observed living outside of Illinois and Michigan), probably showing that the variety is ap-

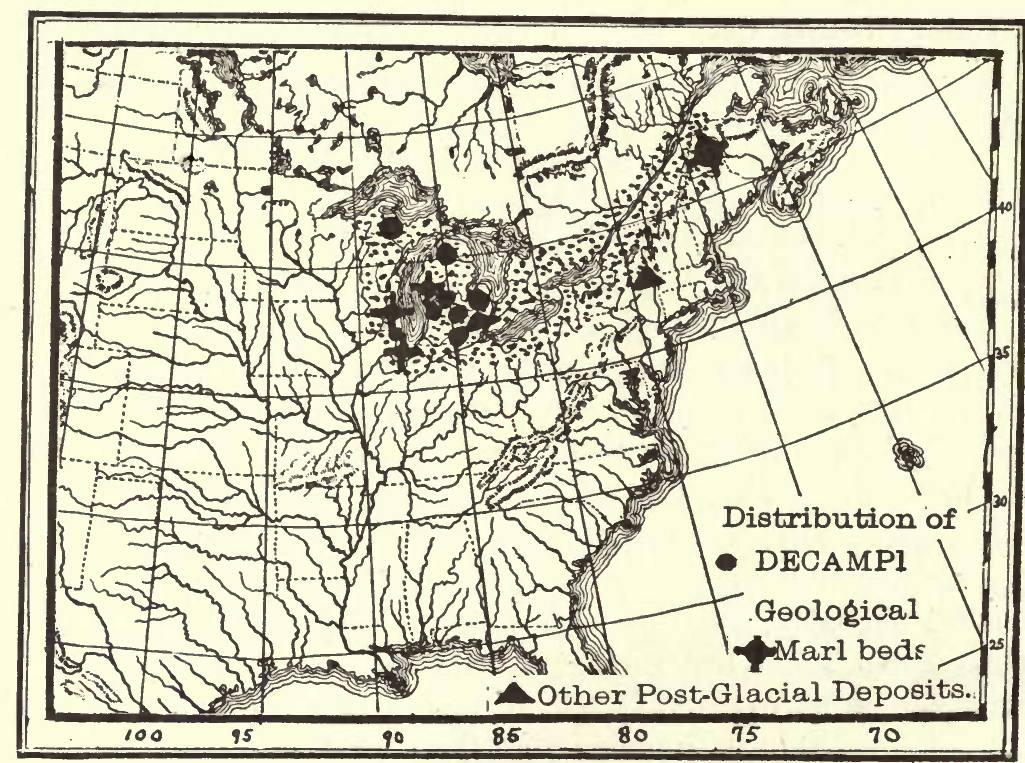

FIG. 31.

proaching extinction. As a marl fossil it is one of the most abundant of the Lymnæas, and a characteristic mollusk of the Canadian and Nova Scotian regions.

\section{RECORDS. \\ UNITED STATES.}

IllinoIs: Fox Lake, Lake Co. (Baker) ; Silver Lake and Algonquin, McHenry Co. (Nason); Cedar Lake and Long Lake, Lake Co. (State Laboratory).

Michigan: Brook's Lake, Newaygo Co. (Streng; Walker) ; Charlevoix, Hillsdale, Jackson, Lake, Marquette, Muskegon, Newaygo, Shiawassee and Tuscola Counties (Walker ${ }^{1}$ ).

Geological Distribution: Pleistocene.

${ }^{1} \mathrm{~A}$ number of these records refer to fossil or subfossil specimens. 


\section{RECORDS. \\ United States. \\ MARL DEPOSITS.}

Illinors: Chicago, Clyde Avenue, near Austin Avenue, six feet beneath surface, Cook Co. (Scharf).

Maine: Barren Brook, Caribou, Aroostook Co. (Nylander).

Michigan: Pickerell Lake, Newaygo Co.; Marsh north side of Cedar Lake, Cedar Lake Station, Montcalm Co. (Walker).

Wisconsin: Milwaukee, Milwaukee Co. (Baker; Slocum). OTHER POST-GLACIAL DEPOSITS.

Michigan: Celery Swamp, Ann Arbor, Washtenaw Co. (Walker).

New York: West Chartton, Saratoga Co., in extinct lake, under six feet of muck (H. B. McWilliams).

Ecology: The habitat of decampi is probably the same as that of obrussa.

REMARKS: Dccampi is a very distinct and characteristic variety of obrussa, known at once by its strongly shouldered whorls and the peculiar manner in which the outer lip is arched at its junction with the body whorl. It appears to be one of the most common of the Pleistocene species and no doubt lived, with galbana, in the more or less icy waters of Post-Glacial Times. Small specimens may be confused with galbana, but that species does not have the elongate aperture nor the distinctly shouldered whorls of decampi, the aperture being rounder and the shell much heavier and more robust in galbana. Decampi varies greatly in the comparative height of the spire; examples from the same locality will embrace individuals with a long, slender spire and with a short, dome-shaped spire. The aperture also varies somewhat. The figures on plate XXXII illustrate this variation.

Galba galbana (Say). Plate XXXII, figures 23-36.

Lymneus galbanus SAY, Journ. Phil. Acad., V, p. 123, 1825; Binney's Ed., p. $114,1858$.

Lymnaa galbana Gould, Lamarck's Genera, p. 69, 1833.-BAker, Trans. St. Louis Acad., XVI, p. 13, 1906.-WALKer, Rep. Geol. Surv. Mich., 1905, p. 465, 1906.

Limnceus galbanus Leidy, Proc. Phil. Acad., II, p. 281, 1845.

Limnea galbana Haldeman, Mon. Limn., p. 51, pl. 13, figs. 22, 23, 1842.

Limnca galbanus D’Urban, Geo. Surv. Can., Rep. Prog., p. 242, 1859.Whiteaves, Can. Nat. \& Geol., VIII, p. 103, 1863.

Limnaa galbana Binney, Check List, p. 12, 1860 ; Land \& F. W. Sh. N. A., II, p. 72, fig. 117, 1865.-Currier, Kent. Sci. Inst., Mis. Pub., No. 1, 1868.Sowb., Conch. Icon., XVIII, Lim. sp. 107, pl. 15, fig. 107, a, b, 1872.-Clessin, Mal. Blatt., n, s., III, p. 82, 1881.-WALker, Nautilus, VI, p. 34, 1892 ; Rev. Moll. Mich., 1894, p. 18.-TAYlor, Ottawa Nat., VIII, p. 147, 1895.-Ami., Ottawa Nat., XI, p. 26, 1897.-Baker, Nautilus, XVII, p. 39, 1903.-Whiteaves, Rep. Geol. Surv. Can., p. 163, 1905. 
Acella galbana Lewis, Bull. Buff. Soc. N. H., 1874, p. 135.

Limnca traskii Martens, Mal. Blatt., XIX, p. 78, 1872. (?)

Shell: Small, subovate, rather inflated, thick; periostracum whitish or yellowish; surface shining, growth lines coarse, prominent, without spiral lines; whorls 5, convex, roundly shouldered, rapidly increasing in diameter, the body whorl very large and somewhat flattened on the periphery; nucleus small, flatly rounded, dark colored, similar in form to that of obrussa; spire usually short, broadly acutely conical, generally occupying about half the length of the shell; sutures rather deeply impressed; aperture ovate, generally rounded above and below; outer lip simple, acute; inner lip erect, forming a rather broad, fat reflection over the umbilical region which emargins the umbilical chink and which is without plait-like thickening; there is a thin wash of callus on the parietal wall; umbilical chink narrowly open; specimens are frequently imperforate.

\begin{tabular}{|c|c|c|c|c|c|}
\hline $\begin{array}{l}\text { Length. } \\
8.00\end{array}$ & $\begin{array}{c}\text { Breadth. } \\
4.50\end{array}$ & $\begin{array}{c}\text { Aperture length. } \\
4.25\end{array}$ & $\begin{array}{l}\text { Brea } \\
2.00\end{array}$ & $\begin{array}{l}\text { dth. } \\
\text { mill. }\end{array}$ & Say's type \\
\hline 8.50 & 5.00 & 4.75 & 2.50 & “ & Alpena, Mich. \\
\hline 8.50 & 5.00 & 5.00 & 2.75 & “ & “ “ \\
\hline 8.00 & 3.75 & 4.00 & 2.00 & “ & White Pond, N. J. \\
\hline 7.00 & 3.75 & 3.00 & 1.75 & “ & " . “ \\
\hline 7.00 & 4.00 & 3.75 & 2.00 & “ & “ \\
\hline 10.00 & 5.00 & 5.50 & 2.75 & “ & Squaw Island, N. Y. \\
\hline 9.00 & 4.90 & 6.00 & 2.50 & “ & " " \\
\hline 8.50 & 4.90 & 5.00 & 2.50 & “ & “ \\
\hline 9.00 & 5.00 & 5.50 & 3.15 & “ & “ \\
\hline 7.50 & 4.50 & 4.75 & 2.50 & “ & “ \\
\hline
\end{tabular}

TyPE: Academy of Natural Sciences, Philadelphia, one specimen, No. 58821.

Type Locality: Marl pit near Franklin, New Jersey.

Animal, Jaw, Radula and Genitalia: Unknown.

Range (Figure 32): From New Brunswick and Anticosti Island west to Washington, Alaska south to southern Indiana and southern California.

Galbana is not found at present farther south than the Transition life zone, though it ranges north well into the Boreal life zone. The marl deposits, however, show that in Post-Glacial Times it ranged south in Indiana (Upper Austral) and extended as far north as the Arctic circle. It is exceedingly abundant in the marl deposits of New Tersey, New York, Michigan and Indiana, and must have been at one time one of the commonest of the smaller Lymnæas. The wide gaps in its distribution show that much work is yet to be done before its 


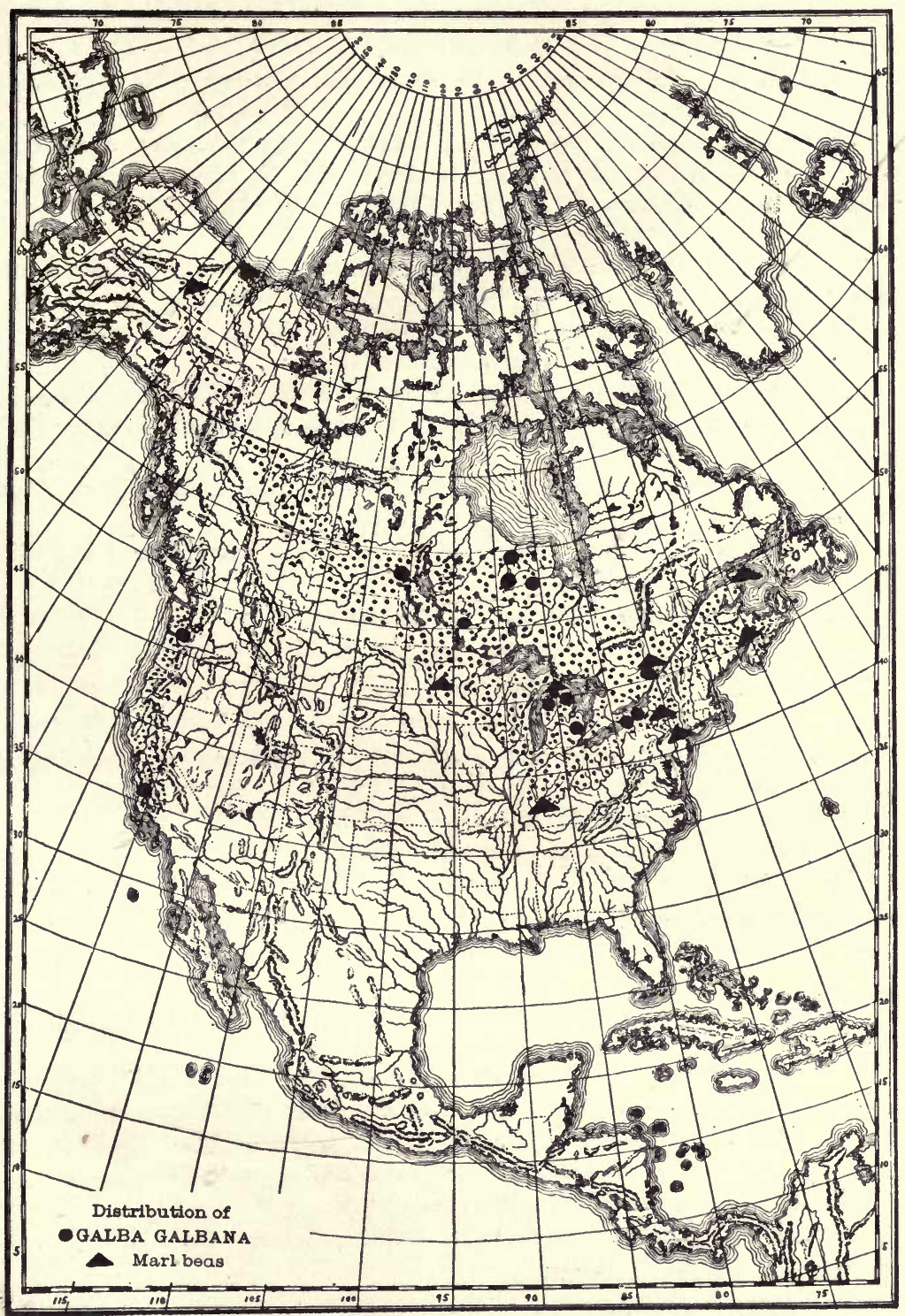

FIG. 32. 
history is complete. It now inhabits the Nova Scotian, Canadian. Hudsonian, Californian and Columbian regions.

RECORDS.

UNITED STATES.

California: Pacific Grove, Monterey Co. (Berry); near Monterey, Monterey Co. (Dall).

Michigan: Alpena, Alpena Co. (Nason); Crooked Lake, Emmet Co.; Pine Lake, eight metres, Charlevoix, Charlevoix Co. (Walker); Emmet, Grand Traverse, Alpena, Macomb and Oakland Counties; generally distributed over the state (Walker).

New York: Braddock's Bay, near Manitau, Monroe Co., Lake Ontario (Baker); Squaw Island, near Buffalo, Erie Co. (Miss Walker).

Washington: Columbia River, Vancouver, Clarke Co. (Dall). BRITISH AMERICA.

KeEwatin: Attawapiskat River (Dall); Kawinogans Lake and Kanuchuan River, Attawapiskat River; Ozhiski Lake; Wapicopa Lake, Winisk River (Whiteaves).

Ontario: Ottawa, Carleton Dist. (Billings, Lea Coll.); Fort Francis, Winnipeg River, Rainy River Dist. (Latchford).

Saskatchewan: Grand Rapids of Saskatchewan River, near Lake Winnipeg (Dall).

Geological Distribution: Pleistocene.

\section{RECORDS. United States MARL DEPOSIT}

Indiana: Three-fourths mile southwest of Stewartsville, Posey Co.; one and one-half miles northwest of Petersburg, Pike Co. (Smith. Inst.).

Michigan: Kegomic, Emmet Co. (Slocum).

Minnesota: Fergus Falls, Otter-tail Co. (E. P. Berkey).

New Jersey: White Pond, Sussex Co. (Pilsbry and Rhoads; Weller); near Franklin, Sussex Co. (Say).

NEW YoRK: Herkimer Co., in calcareous tufa (Lewis).

$$
\text { Alaska. }
$$

Alaska: Left bank of Yukon River, below old Fort Yukon (Dall). British AMERICA.

New Brunswick: Sawler's Lake, St. John, St. John Dist. (Dall).

Ontario: Hemlock Lake, New Edinburg, east of Ottawa, in soft white calcareous-argillaceous matrix (Ami); Ottawa, Carleton Dist. (Dall); Eagle's Nest Lake, Lower Canada (D’Urban; Whiteaves).

Quebec: Anticosti Island (Dall; Schmidt).

Ecology: Galbana prefers a habitat where the water is clear and in more or less movement.

REMARKS: Galbana is very little understood among conchologists, probably on account of its being first described as a fossil. Is is very common in many localities, has a wide range and is remarkably uniform. It has been mistaken for both Galba humilis and Galba humilis modicella, but it is a much more solid shell. It is a more robust shell 
than humilis, with shouldered whorls and a larger aperture in comparison with the rest of the shell; the aperture is also larger and rounder in galbana. Obrussa decampi has a superficial resemblance, but is a much narrower shell with elongated aperture and squarely shouldered whorls. The inner lip is also differently appressed than either humilis, modicella or decampi. Galbana may be known by its solid shell, its swollen and somewhat shouldered last whorl, its short, generally dome-shaped spire and its broadly reflected inner lip which emargins the umbilical chink. The spire varies somewhat in height, as cioes also the aperture. (See plate XXXIf.) In the Michigan specimens the sutures are not as much compressed as in the New Jersey specimens.

Like its congener, Galba obrussa decampi, galbana lived in the icy waters of Post-Glacial Time, to which environment its peculiar form is undoubtedly due. As remarked by Dr. Dall, the recent shells are less variable, on the average, than are the fossil forms. Galbana will probably be found to be one of our commonest species when it becomes fully recognized; in many cabinets it now reposes, without doubt, under the names of desidiosa and humilis. I cannot agree with Dr. Dall (op. cit., p. 74) in making traski Tryon a synonym of galbana. It scems to me to be related to proxima. Its size of 16 mill. is far greater than any galbana I have seen, and its shape, as figured and described by Tryon and as shown by his type, is totally different.

Galba petoskeyensis (Walker). Plate XXVI, figures 14-16.

Lymncea petoskeyensis Walker, Nautilus, XXII, p. 6, pl. i, figs. 3, 5-7, May, 1908.

Shell: Elongated, compressed, thin; periostracum light yellowish horn; the shell is almost white and translucent; surface shining, growth lines prominent, crossed by impressed spiral lines, giving the surface the wavy appearance of the typical Lymnæas; the last whorl is sometimes malleated; whorls $6-6 \mathrm{~T} / 2$, rather flat,sided, shouldered at the periphery on the spire whorls, the last whorl somewhat roundly compressed; nucleus very small, rounded; hyaline; the first whorl is very minute, the second is very large ( $\mathrm{pl}$. XLIX, fig. G) ; spire acutely conical, generally a trifle longer than the aperture; sutures well impressed; aperture an elongated oval, rounded and somewhat effuse anteriorly; the posterior portion of the aperture forms an acute angle; outer lip thin, with a white internal thickening or varix within the edge; inner lip broadly reflected, flattened and emarginating the conspicuously open umbilicus; parietal callus rather thick; at the junction of the inner lip with the parietal wall, the former is abruptly pressed 
in, forming a distinct furrow and giving the columella the appearance of a plait; this is apparent in all of the specimens examined; pillar round and smooth, as in obrussa, nearly cylindrical, "the base of the preceding whorl abruptly flattened around the insertion of the upper end of the pillar."”

$\begin{array}{cccccc}\text { Length. } & \text { Width. } & \text { Aperture length. } & \text { Width. } & \\ 23.50 & 11.25 & 13.00 & 8.00 & \text { mill. } & \text { Type } \\ 24.50^{\circ} & 11.00 & 13.50 & 7.50 & \text { “ } & \text { “ } \\ 25.00 & 10.50 & 12.00 & 7.00 & \text { “ } & \text { “ } \\ 22.75 & 10.25 & 13.00 & 5.10 & \text { “ } & \text { Cotype } \\ 21.50 & 9.50 & 11.00 & 5.10 & \text { “ } & \text { “ } \\ 20.50 & 9.00 & 9.75 & 4.50 & \text { “ } & \text { “ } \\ 19.50 & 8.10 & 9.50 & 4.10 & \text { “ } & \text { " }\end{array}$

Types: Collection Bryant Walker, thirteen specimens, No. 14347; cotypes, Academy of Natural Sciences, Philadelphia; the Chicago Academy of Sciences, three specimens, No. 23316.

Type Locality: In small spring-brook flowing into Little Traverse Bay, Petoskey, Michigan.

Animal, Jaw, Radula and Genitalia: Unknown.

Range: Michigan. Apparently an inhabitant of the Boreal (Canadian) life zone and of the Canadian region.

\section{RECORDS.}

Michigan: Brook, Petoskey, Emmet Co. (Walker).

Geological Distribution: Unknown.

Ecology: Inhabits a small spring-brook flowing into Little Traverse Bay.

Remarks: Pctoskcyensis is the largest species of the obrussa group of Lymnæas. It is at once known by its peculiar inner lip and iarge umbilical chink, and by its large size and heavy spiral sculpture. Mr. Walker says of it: "This species was at first supposed to be a very thin, fragile form of the elongate variety of L. catascopium, characteristic of the lake region. But upon cutting into the shell, the peculiar shape of the axis forbode its reference to that species." (See Nautilus, p. 6.)

Petoskeyensis is a very distinct species, not at all likely to be confounded with any other. It is very desirable that the anatomy should be examined in order that its correct systematic position may be known. It is provisionally placed in Simpsonia, but an anatomical examination may place it in Stagnicola with catascopium or emarginata.

Subgenus STAGNICOLA Leach, 1830.

1819. Stagnicola LEACH, Proof-sheets, pp. 141, 145.

1819. Omphiscola Rafinesque, Journ. de Phys., LXXXVIII, p. 423. 
1826. Lymnea Risso, Hist. Nat. Eur. Mer., IV, p. 94, first sp. L. pereger (Müller). Not Lymnea Rafinesque, Pisces, 1815.

1830. Stagnicola Jefrreys, Linn. Trans., XVI, ii, p. 376, May 29 (type L. palustris (Müller)).

1831. Stagnicola Turton, Man., pp. 121-124, Oct., 1831.

1833. Limnophysa Fitzinger, Syst. Verz., p. 112 (type L. palustris (Müller)).

1838. Limnophysa BECK, Index, p. 110.

1840. Stagnicola Gray's Turton, pp. 237-242.

1864. Limnophysa Mörch, Vidensk. Meddel. Kjob., p. 298.

1865. Limnophysa Binney, L. \& F. W. Sh. N. A., II, p. 38.

1865. Omphiscola Binney, L. \& F. W. Sh., N. A., II, p. 70.

1870. Limnophysa Dall, Ann. Lyc. N. H., IX, p. 349.

1870. Limnophysa Cooper, Proc. Cal. Acad. Sci., IV, p. 96.

1872. Limnophysa Tryon, Con. Hald. Mon., p. 87 (61).

1874. Limnophysa Hartman and Michener, Conch. Cestrica, p. 64.

1876. Limnophysa Meek, Rep. U. S. Geol. Surv. Terr., IX, p. 533.

1876. Omphalia 'Raf.' Meek, Rep. U. S. Geol. Surv. Terr., IX, p. 532, in Syn.; ere. pro. Omphiscola Raf.

1880. Limnophysa CR. \& Fisch., Mis. Cient. Mex., II, p. 49.

1881. Lymnophysa (Fitzinger) HazAy, Mal. Blatt., III, p. 163.

1884. Limnophysa Tryon, S. \& S. Conch., III, p. 101.

1905. Stagnicola DALL, Alaska Moll., p. 64.

1908. Stagnicola BAKER, Science, n. s., XXVII, p. 943.

1909. Lymnca H. B. Baker, An. Rep. Mich. Acad. Sci., p. 138.

SHELL: Elongated, with gradually increasing whorls; outer lip with (usually) a heavy varical thickening just within the aperture, representing a period of rest in the growth of the shell; these varices may be retained as white bands on the earlier whorls of the spire; pillar slightly twisted and plicated; inner lip appressed to the columiellar region, forming an impervious or narrowly open axis; sculpture of strong growth lines and equally strong spirally impressed lines, forming a notably decussated pattern. (P1. XVIII, figs. 4, 10.)

RADULA: With bicuspid lateral teeth.

Genitalia: With the penis generally shorter than penis-sac; lower portion of oviduct (below first accessory albuminiparous gland) very long and narrow; prostate rather long, flatly rounded, broadly rounded anteriorly and gradually narrowed posteriorly.

Stagnicola differs from Simpsonia in its generally more pronouncedly sculptured shell, the presence of a plait on the slightly twisted axis, and in the heavier rib or varix within the aperture which marks periods of rest from shell making. The genitalia differ but little, the prostate being longer, with a more broadly rounded proximal end; the lower portion of the oviduct is also longer and narrower. The radula differs 
in having bicuspid lateral teeth. The habitat of Stagnicola is quite different as a rule from that of the smaller Lymnæas, which prefer the banks of small streams and shore debris, where they may crawl out of water and remain in the air, while Stagnicola is partial to stagrant pools, ponds and lakes, and is seldom found out of the water.

The name Stagnicola was first used by Leach in 1819 in his proofsheets. Jeffreys subsequently cited the name, in 1830, in Linn. Trans., using Limnaa palustris as the type. In 1833 Fitzinger, in his Syst. Verz., established the name Limnophysa, but as he used the same type (L. palustris) as that selected for Stagnicola, Leach's name must stand. Brehm used the name in Ornithology in December, 1830, but as Jeffrey's paper was published in May, Brehm's name becomes obsolete. The name Omphiscola was used by Rafinesque in 1819 for a group of shells which are thus described: "Differs from Lymnula (Lymnea Auct.) by its inferior lip being detached from the columella and divided from it by a long umbilicus. Family of Limnidæ. Many lacustrine and fluviatile species." As many of the species of Stagnicola are frequently found with the inner lip thus separated (particularly reflexa), I quite agree with Dr. Dall that Omphiscola is the same as Stagnicola. As no type was cited by Rafinesque and as he lists no species under the genus, the name cannot be used, although it is older than either Stagnicola or Limnophysa. The characters used by Rafinesque have no importance, even specifically.

\section{GROUP OF GALBA PALUSTRIS.}

Galba palustris (Müller). Plate XXVI, figures 17-37; plate XXXIII, figures 1-25; plate XXXIV, figure 20.

Buccinum palustre MülleR, Verm. Terr., II, p. 131, 1774.-BAKER, Science, n. s., XXVII, p. 943, 1908.

Helix palustris Gemlin, Syst. Nat., p. 3658.

Limnea palustris SowB., Tank. Cat., p. 42, 1826.-Goul.D, Bost. Journ. Nat. Hist., III, p. 488, 1841.-Haldeman, Bost. Journ. N. H., IV, p. 468, 1844 ; Rupp's Hist. Lancas. Co., p. 480, 1844.-CPR., Rep. Brit. Asso., 1856, p. 222.Binney, Check List, p. 12, 1860; Proc. Phil. Acad., 1861, p. 330.-Whiteaves, Can. Nat. \& Geol., VI, p. 458, 1861.-Williamson, Can. Journ., n. s., VI, p. 327, 1861.-Whiteaves, Can. Nat. \& Geo., VIII, p. 51, 1863.-Commis. Geol. Can., p. 966, 1864.-CPr., Rep. Brit. Asso., 1864, p. 674.-Binney, L. \& F. W. Sh. N. A., II, p. 45, figs. 61, 65, 66, 1865.-TrYoN, Amer. Journ. Conch., III, p. 196, 1867 ; Amer. Journ. Conch., IV, p. 151, 1868.-Currier, Kent. Sci. Inst., Mis. Pub., No. 1, 1868.-Cooper, Amer. Nat., III, p. 297, 1869.-Dall, Ann. Lyc. Nat. Hist., IX, p. 340, 1870.-Byrnes, Land \& F. W. Sh. Cin., p. 2, 1872.-CPr., Smith. Mis. Coll., 1872, p. 160.-Tryon, Con. Hald. Mon., p. 97 (71), 1872; Proc. Phil. Acad., 1873, p. 286.-Sмith, Rep. U. S. Fish. Com., p. 701, 1874.Calkins, Cin. Quart. Journ. Sci., I, pp. 243, 323, 1874.-Yarrow, U. S. Geog. Surv. West 100th Merid., V, p. 942, 1875.-Gilberr, 1. c., III, p. 100, 1875.- 
Pop. Sci. Mon., X, p. 248, 1876.-Aughey, An. Rep. U. S. Geol. \& Geog. Surv. Col., p. 268, 1876.-Walker and Beecher, Proc. Ann. Arb. Sci. Asso., 1876, p. 45.-Ingersoll, Proc. Daven. Acad. Sci., II, p. 132, 1877.-Kobelr, Nach. Mal. Ges., XII, p. 32, 1880.-Stein, Ind. Dept. Stat. \& Geo., 1880, p. 458.-Bell, Rep. Geol. \& Nat. Hist. Surv. Canada, 1879-80, p. 75. c, 1881.-Amer. Nat., XVII, p. 203, 1883.-Jordan, Nova Acta Ksl.-Leop.-Carol.-Deutsch. Akad. Natur., XLV, pp. 282, 368, 1883.-Ottawa Nat., II, 132, 1884.-Latch Ford, Amer. Nat., XVIII, p. 1052, 1884.-Christy, Journ. Conch., IV, p. 347, 1885.-Ottawa Nat., II, p. 264, 1885.-Moore and Butler, Bull. Brookville Soc. N. H., No. 1, p. 43, 1885.-Shimek, Bull. Lab. N. H. Univ., I, p. 68, 1888.-Holzinger, Rep. Nat. Hist. Surv. Minn., XVI, p. 490, 1888.-CKLl., Journ. Conch., VI, p. 63, 1889.-Ottawa Nat., IV, p. 55, 1890.-Wood, Nautilus, V, p. 56, 1891.-Stearns, Proc. Nat. Mus., XIV, p. 100, 1891.-Walker, Nautilus, VI, p. 33, 1892.-SNIGLEy, Rep. Geol. Surv. Texas, IV, p. 188, 1892 ; p. 313, 1893.-Dean, Amer. Nat., XXVI, p. 18, 1892.-TAYlor, Ottawa Nat., VI, p. 35, 1892.-Stearns, N. Am. Fauna, VII, p. 274, 1893.-TAYLor, Nautilus, VII, p. 85, 1893.-SQUYer, Nautilus, VIII, p. 65, 1894.-Walker, Nautilus, VII, p. 128, 1894.-Walker, Rev. Moll. Mich., p. 18, 1894.-Stupa Koff, Nautilus, VII, p. 135, 1894.-Ottawa Nat., IX, p. 156, 1895.-TAYlor, Ottawa Nat., IX, pp. 174, 176, 1895.-SNyder, The Museum, III, p. 12, 1896.-RANDolPh, Nautilus, IX, p. 102, 1896.-SARGENT, Nautilus, IX, p. 127, 1896.-BAKer, The Museum, III, p. 154, 1897.-Shimek, Proc. Iowa Acad. Sci., V, pp. 35, 44, 1898.-Wiswall, Nat. Sci. Journ., I, p. 48, 1897.BAKer, Journ. Cin. Soc. N. H., XIX, p. 78, 1897; Nautilus, XII, p. 65, 1898; Trans. Acad. Sci. St. Louis, VIII, pp. 88, 89, 1898; Moll. Chi. Area., pp. 23, 24, 1898.-Randolph, Nautilus, XII, p. 111, 1899.-Hanham, Nautilus, XIII, p. 5, 1899.-BAKer, Nautilus, XIII, p. 58, 1899.-Mitchell, Nautilus, XIII, p. 88, 1899.-Leverett, Mon. U. S. Geol. Surv., XXXVIII, p. 173, 1899.-Sterki, An. Rep. Ohio State Acad. Sci., VIII, p. 34, 1900.-Walker and Lane, Geol. Surv. Mich., VII, pt. 2, p. 251, 1900.-Stearns, Proc. Nat. Mus., XXII, p. 135, 1900.-BAKer, Journ. Cin. Soc. N. H., XIX, p. 176, 1900; Nautilus, XIV, pp. 69-71, 1900; Nautilus, XIII, p. 112, 1900.-Stearns, Proc. Nat. Mus., XXIV, p. 291, 1901.-BAKer, Amer. Nat., XXXV, p. 662, 1901; Trans. Acad. Sci. St. Louis, XI, p. 14, pl. 1, figs. 1, 2, text figs. 8-9, 1901.-Everman and GoldsBorough, Rep. U. S. Fish. Com. for 1901, p. 175, 1902.-Baker, Moll. Chi. Area., II, p. 273, text figs. 89,90 , pl. 32, fig. 1, 1902.-ELrod, Nautilus, XV, p. 111, 1902 ; Bull. Univ. Mont., Biol. Ser., III, pp. 124, 172, 1902.-Whiteaves, Ottawa Nat., XVI, p. 91, 1902.-CKL., Nautilus, XVI, p. 96, 1902.-Daniels, Rep. Dept. Geol. \& Nat. Res. Ind., XXVII, p. 636, 1903.-Elrod, Bull. Univ. Mont., Biol. Ser., V, p. 257, 1903.-Sнiмек, Nat. Hist. Bull. Univ. Iowa, V, p. 279, 1904.KeEP, West. Amer. Sh., pp. 148, 314, fig. 128, 1904.-Whiteaves, Ottawa Naturalist, XIX, pp. 3, 65, 1905.-Letson, Bull. N. Y. State Mus., LXXXVIII, p. 53, 1905.-Chadwick, Nautilus, XX, p. 22, 1906; Bull. Wis. Nat. Hist. Soc., IV, p. 81, 1906.-Whiteaves, Ottawa Nat., XX, p. 116, 1906.-Maury, Journ. Geol., XVI, p. 566, 1908.-Letson, Bull. Buf. Soc. Nat. Sci., IX, p. 242, 1909.

Limnea palustris Sowb., Faun. Bor.-Amer., p. 316, 1836.-HAld., Mon. Lim., p. 55, pl. 15, fig. 2, 1842.-Chapman, Can. Journ., n. s., VI, p. 497, 1861.?Carlton, Proc. Cal. Acad. Sci., IV, p. 51, 1869.-Ingersoll, Bull. U. S. Geol. and Geog. Surv, I, p. 138, 1875; Rep. U. S. Geol. \& Geog. Surv. Terr., 1876, p. 406.-?Coleman, Trans. Can. Inst., VI, p. 37, 1899.-Henderson, Nautilus, XX, p. $98,1907$. 
Limnaus palustris Drap., Hist., p. 52, pl. ii, figs. 40-42, iii, figs. 1-2, 1805.Rossmassler, Icon., I, p. 96, 1835.-Fokbes, Rep. Brit. Asso., VI, p. 146, 1840.Forbes and Hanley, Hist. Brit. Moll., IV, p. 180, pl. 124, fig. 2, 1853.

Lymnea palustris Sheppard, Trans. Lit. Hist. Soc. Quebec, I, p. 196, 1829.Roberts, Rep. U. S. Geol. Surv. Wyoming, 1871, p. 468.

Lymnaa palustris CoOper, Amer. Nat., II, p. 468, 1868.-BAKer, Amer. Nat., XXXIX, p. 669, fig. 9, 1905.-DAll, Alaska Moll., p. 76, figs. 56, 57, 1905.Baker, Amer. Nat. XL, p. 328, figs. 1, 2, 1906; Trans. Acad. Sci. St. Louis, XVI, p. 11, 1906; Bull. I1l. State Lab. Nat. Hist., VII, p. 105, 1906.-Walker, Nautilus, XX, p. 82, 1906.-Henderson, Univ. Col. Studies, IV, pp. 93, 158, 180, fig. 37, 1907.-Sмiтh, Nautilus, XX, p. 91, 1907.-Sterki, Proc. Ohio State Acad. Sci., IV, p. 381, 1907.-Nylander, Nautilus, XXII, p. 19, 1908.-Berry, Nautilus, XXI, p. 122, 1908.-Hannibal, Nautilus, XXII, p. 33, 1908.-Lermond, Shells of Maine, p. 38, 1908.-Daniels, Nautilus, XXII, p. 121, 1909.Berry, Nautilus, XXIII, pp. 76, 77, 1909.-Baker, An. Rep. Mich. Acad. Sci., p. 138, 1909.-Henderson, Univ. Col. Studies, VII, p. 126, 1909.-Berry, Nautilus, XXIV, p. 62, 1910.

Limnophysa palustris BECK, Index, Moll., p. 110, 1837.-Tryon, Amer. Journ. Conch., I, pp. 68, 251, 1865.-DAll, Ann. Lyc. N. H., IX, p. 349, 1870.-Prime, Forest \& Stream, XV, p. 245, 1880.-DeCamp, Kent. Sci. Inst. Mis. Pub., No. 5, p. 8, 1881.-Call, Bull. Geol. Surv., II, pp. 371, 383, 388, 389, 1884; Bull. Wash. Coll. Lab. N. H., I, p. 52, 1885.-Grant, Rep. Nat. Hist. Surv. Minn., XIV, p. 122, 1886.-KeEP, West Coast Shells, p. 123, fig. III, 1887.-Cooper, An. Rep. Cal. State Min. Bu., VII, p. 245, 1888.-Keyes, Bull. Essex. Inst., XX, p. 70, 1888.-Gilbert, Mon. U. S. Geol. Surv., I, pp. 210, 300, 1890.-Cooper, Zoe. I, p. 196, 1890.-Call, Proc. Ind. Acad. Sci., for 1893, p. 150, 1894.-Cooper, Proc. Cal. Acad. Sci., ii, IV, p. 170, 1894.-Call, Proc. Ind. Acad. Sci., p. 250, 1896.-Baker, Journ. Cin. Soc. N. H., XIX, p. 84, 1897.-Call, Rep. Dept. Geol. Nat. Res. Ind., XXIV, p. 406 (not fig.), 1900.-Blatchley \& Ashley, An. Rep. Geol. \& Nat. Res. Ind., XXV, pp. 176, 190, 248, 304, 1901.

268, 1841.

Limnaa plebeia Gouln (nude name) in Adams, Am. Journ. Sci., XL, p.

Limnea umbrosa Hald. (non Say), Mon. Lim., pl. 7, figs. 4, 5, 1842.

Limnaa elodes of authors, not of Say. ${ }^{1}$

Lymneus élodes Kirtland, Zool. Ohio, p. 174, 1838.-Sayer, Geol. Surv. Mich., 1839, p. 15.

Limnaus clodes Küster, Conch. Cab., I, p. 42, taf. 7, figs. 17-21, 1862 (part). -Walter, Cold Spring Harbor Mon., VI, 1906.

Lymnea elodes DeKay, Cat. N. Y. Animals, p. 32, 1839.-LeA, Hayden's Exp. Neb., p. 724, 1859.-Roberts, Rep. U. S. Geol. Surv. Wyoming, 1870, p. 468.-Dawson, Can. Nat. \& Geol., n. s., VI, p. 307, 1872.-Shaffer, Shells Cin., Ohio (no date).

Lymnaa elodes, Amer. Journ. Sci., XXXI, p. 36, 1837.-Linsley, Amer. Journ. Sci., XLVIII, p. 282, 1845.-ReEve, P. Z. S., 1850, p. 49.-Dawson, Can. Nat. \& Geol., II, p. 422, 1857.-Currier, Shells of Grand River, 1859.-?DAwson, Can. Nat. \& Geol., IV, p. 36, 1859.-Lewis, Proc. Phil. Acad., 1860, p. 18 ; Amer. Journ. Conch., IV, p. 4, 1868.-Morse, Amer. Nat., III, p. 651, pl. 11, figs.

${ }^{1}$ Some of these references may include the true elodes of Say, but it is impossible to verify them and they are, therefore, all included under palustris. 
7-12, 1870.-Lewis, Amer: Journ. Conch., VI, p. 86, 1870 ; Proc. Phil. Acad., 1872, p. 101.-Bunker, Amer. Nat., XIV, p. 522, 1880.-Col.ton, Proc. Phil. Acad., 1908 , p. 424 ,

Limnea elodes Hald., Bost. Journ. Nat. Hist., IV, p. 468, 1844.-Plum mer, Amer. Journ. Sci., XLVIII, p. 96, 1844.-Lapham, Trans. Wis. State Ag. Soc., II, p. 368, 1852.-True, Proc. Essex Inst., II, p. 195, 1857; Tufts. Cat. Mass. State Cab., p. 87, 1859.-Miles, Geol. Surv. Mich., 1860, p. 237, 1861.-HubBard, Cat.

Limnaa elodes Gould, Inver. Mass., p. 221, figs. 146, 147, 1841.-AdAMS, Amer. Journ. Sci., XI, p. 268, 1841.-Prescott, Cat. Shells, Mass., 1842.Adams, Thomp., Vt., p. 153, 1842.-Hald., Bost. Journ. Nat. Hist., IV, p. 468, 1844.-Read, Cat., 1845.-Stimpson, Shells New Eng., p. 52, 1851.-Russell, Journ. Essex Co. Nat. Hist. Soc., p. 130, 1852.-Tufrs., Proc. Essex Inst., I, p. 30, 1853.-Lewis, Proc. Bost. Soc. N. H., V, p. 123, 1855 ; Proc. Bost. Soc. N. H., VI, p. 2, 1856.-Can. Nat. \& Geol., II, p. 199, figure, 1857.-Bell, Can. Nat. \& Geol., IV, p. 213, 1859.-Whiteaves, Can. Nat. \& Geol., VI, p. 458, 1861; Can. Nat. \& Geol., VIII, p. 103, 1863.-Commis. Geol. Can., p. 985, 1864.-CurRIER, Kent. Sci. Inst., Mis. Pub., No. 1, 1868.-Mörch, Amer. Journ. Conch., IV, p. 33, 1868.-Aldrich, Rep. N. Y. State Cab. N. H., XXII, p. 23, 1869.-Dall, Proc. Bos. Soc., XIII, p. 240, 1870.-Sмiтh \& Prime, Ann. Lyc. Nat. Hist., IX, p. 379, 1870.-Gould, Inv. Mass., Ed. Binney, p. 475, fig. 728, 1870.-Cooper, Proc. Cal. Acad. Sci., IV, p. 96, 1870.-Kobelt, Mal. Blatt., XVIII, p. 115, 1871.-Jeffreys, Ann. Mag. N. H., ser. 4, X, p. 247, 1872.-Sowb., Conch. Icon., XVIII, Limn. sp. 29, pl. 5, fig. 29, pl. 9, fig. 29 b, 1872.-Jefrreys, Journ. Conch., I, p. 16, 1874.-Dawson, British N. A., Bound Com., p. 348, 1875.-Leidy, Proc. Phil. Acad., 1877, p. 201.-Jones, Moll. of Nova Scotia, p. 10, 1877.-Heron, Ottawa Nat., I, p. 39, 1880.-Standard Nat. Hist., I, pp. 304, 307, figs. 347, 354, 1884.-Christy, Journ. Conch., IV, p. 347, 1885.-West, Vega-Exp., IV, p. 166, 1885.-Beauchamp, Land \& F. W. Sh., N. Y., p. 3, 1886.-H. F. Carpenter, Random Notes N. H., III, p. 85, 1886; Cat. Moll. R. I., p. 5, 1889.-Walton, Proc. Roch. Acad. Sci., II, p. 12, pl. 6, figs. 1, 2, 1891.-Marshall, An. Rep. N. Y. State Mus., XLVII, p. 64, 1893; N. Y. at World's Fair, p. 511, 1894; An. Rep. N. Y. State Mus., XlVIII, p. 643, 1895.-Walton, The Museum, IV, p. 132, 1898.-Maury, Chautauqua Lake Shells, p. 1, fig. 1, 1898.-STearns, Proc. Nat. Mus., XXIV, p. 291, 1901; Journ. Geol., IX, p. 292, 1903.-Coleman, Interglac. Periods of Canada, p. 16, 1906.-MAury, Journ. Geol., XVI, p. 566, 1908.-Letson, Bull. Buf. Soc. Nat. Sci., IX, p. 242, 1909.

Limnaa elodes, var., Ingersoll, Proc. Daven. Acad. Sci., II, p. 132, 1877.

Limnophysa elodes BEcK, Index Moll., p. 111, 1837.—a major, BECK, Index Moll., p. 111, 1837; b. minor, Index Moll., p. 111, 1837.-Morse, Journ. Bost. Soc. N. H., I, p. 41, 1864.-Lewis, Bull. Buf. Soc. N. Sci., p. 135, 1874.

Limnaa palustris var. elodes Stein, Ind. Dept. Stat. \& Geol., 1880, p. 458, Limnca palustris var. septentrionalis Chessin, Kobelt, Nach. Mal.' Ges., XII, p. 32, 1880 .

Lymnca palustris clodes Henderson, Univ. Col. Studies, IV, pp. 93, 180, 1907.

Limnea expansa Hald., Suppl. to part 1, p. 2, 1840; Mon. Lim., p. 29, pl. 9, figs. 6-8, 1842.-DeKAY, Moll. N. Y., p. 75, 1843.

Limnaa expansa Binney, Check List, p. 12, 1860 ; L. \& F. W. Sh. N. A., II, p. 46, fig. 63, 1865.-Sowв., Conch. Icon., XVIII, Lim., sp. 79, pl. 12, fig. 79, 
1872.-Adams, Thomp. Vt., p. 169, 1842.-MöRCH, Ameł. Journ. Conch., IV, p. 33, 1868.

Limnaus expansus Küster, Conch. Cab., I, p. 39, taf. 7, figs. 6, 7, 1862.

Limnophysa expansa TRYoN, Amer. Journ. Conch., I, p. 251, 1865.

Lymnca expansa Wheatley, Cat. U. S. Shells, p. 23, 1845.-JAy, Cat., p. $269,1852$.

Limnaa palustris expansa CKLL., Nautilus, XVI, p. 96, 1902.-BAKER, Moll. Chi. Area, II, p. 277, 1902.

Limnceus sufflatus Calkins, Ms. Baker, Moll. Chi. Area., p. 277, pl. 32, fig. 2, 1902 .

Limnea fragilis Haldeman, Mon. Lim., p. 20, pl. 6, pl. 15, fig. 1, 1842 (not of Linné).-DeKay, Moll. N. Y., p. 68, pl. 4, fig. 68, 1843.-Lapham, Trans. Wis. State Ag. Soc., II, p. 368, 1853.-Kennicott, Trans. Ill. State Ag. Soc., I, p. 595, 1855.-НАмвасн, Bull. Geol. Surv. Mis., I, p. 60, 1890.

Lymnaa fragilis JAY, Cat., p. 269, 1852.

Limnea fragilis UlfFers, Trans. I11. State Ag. Soc., I, p. 612, 1855.Swallow, An. Rep. Geol. Surv. Missouri, II, p. 215, 1855.-Lapham, Proc. Phil. Acad., 1860, p. 155.-GabB., Proc. Phil. Acad., 1861, p. 309.-Bland \& Cooper, Ann. N. Y. Lyc. N. H., VII, p. 370, 1862.-Tryon, Proc. Phil. Acad., 1863, p. 149.-Cpr., Rep. Brit. Asso., 1864, p. 630.-Currier, Kent. Sci. Inst., Mis. Pub. No. 1, 1868.-Lewis, Amer. Journ. Conch., VI, p. 86, 1870.-Cpr., Smith. Mis. Coll., 1873, p. 116.-Hartman, Moll. Chester Co., Penn.

Limnophysa fragilis DeCamp, Kent. Sci. Inst., Mis. Pub., No. 5, p. 8, 1881.

Lymnca fragilis var. corvus PARR., JAY, Cat., ed. 4, p. 269, 1852.

Lymnea nuttalliana LEA, Proc. Amer. Phil. Soc., II, p. 33, 1841; Trans. Amer. Phil. Soc., IX, p. 9, 1844; Obs., IV, p. 9, 1848; Hayden's expl. Neb., p. 724, 1859 ; Journ. Phil. Acad., VI, p. 160, 1866; Obs., XI, p. 116, 1867.

Lymnca nuttalliana Wheatley, Cat. U. S. Shells, p. 23, 1845.-JAY, Cat., p. 270, 1852.-Scudder, Bull. Nat. Mus., 23, pp. 33, 43, 201, 1885.-Baker, Amer. Nat., XL, pp. 329, 330, 1906.

Limnca nuttalliana CARpenter, Rep. Brit. Asso,, 1856, p. 198, 316.-CPr., P. Z. S., 1856, pp. 209, 220.-Binney, L. \& F. W. Sh., N. A., II, p. 45, fig. 62, 1865.-Tryon, Amer. Journ. Conch., III, p. 196, 1867.-Cooper, Proc. Cal. Acad. Sci., IV, p. 96, 1870.-Sowb., Conch. Icon., XVIII, Lim. sp. 70, p1. 11, figs. 70, a, b, 1872 (the figures look like rowelli Tryon).-Sнiмек, Bull. Lab. N. H. Iowa Univ., I, p. 68, 1888.-Stearns, Proc. Nat. Mus., XIV, p. 101, 1891; N. Am. Fauna, VII, p. 274, 1893.-TAYlor, Ottawa Nat., VIII, p. 148, 1895.-STEARns, Proc. Nat. Mus., XXIV, p. 291, 1901.-Elrod., Nautilus, XV, p. 111, 1902; Bull. Univ. Mont., Biol. Series, No. 3, p. 173, 1902.-PILSBry, Nautilus, XVII, p. 84, 1903.

Limnceus nuttallianus Küster, Conch. Cab., I, p. 38, pl. 7, fig. 5, 1862.

Limnea nuttalliana Carlton, Proc. Cal. Acad. Sci., IV, p. 51, 1869.-Cat. Coll. Nat. Hist. Eth. Prov. Mus. Victoria, p. 95, 1898.

Limnophysa nuttalliana Tryon, Amer. Journ. Conch., I, p. 250, 1865.Cooper, Proc. Cal. Acad., IV, p. 153, 1870.-Call, Bull. Wash. Coll. Lab. N. H., I, p. 52, 1885.-Keyes, Bull. Essex Inst., XX, p. 70, 1888.

Limnaa palustris nuttalliana BAKER, Moll. Chi. Area, II, p. 276, pl. 31, fig. 6,1902 . 
Limnca palustris var. nuttalliana Woop, Nautilus, p. 56, 1891.-KeEP, West. Amer. Sh., p. 314, 1904.

Limnophysa palustris var. nuttalliana Cooper, Zoe., I, p. 196, 1890.

Lymnca palustris. var. nuttalliana DALL, Alaska Moll., p. 76, fig. 57, 1905.

Lymnaa palustris nuttalliana BERRY, Nautilus, XXI, p. 123, 1908.

Lymnea haydeni LEA, Proc. Phil. Acad., 1858, p. 166; Exp. in Nebraska, II, pt. 3, p. 724, 1859.-Journ. Phil. Acad., VI, pp. 159, 161, pl. 34, fig. 73, 1866 ; Obs., pp. 115, 117, pl. 34, fig. 73, 1867.-Scudder Bull. Nat. Mus., 23, pp. 82, 149, 201, 1885.-Roberts, Rep. U. S. Geol. Surv. Wyoming, 1871, p. 468.

Limnea haydeni Ingersol, Bull. U. S. Geol. \& Geog. Surv., I, p. 138, 1875; Rep. U. S. Geol. \& Geog. Surv. Terr., 1876, p. 405.

Limnaa haydeni Binney, Check List, p. 12, 1860 ; L. \& F. W. Sh. N. A., II, p. 44, fig. 59, 1865.-Tryon, Con. Hald. Mon., p. 98 (72), pl. 17, fig. 6, 1872.Walker, Nautilus, VI, p. 33, 1892; Rev. Moll. Mich., 1894,-pp. 18, 22.

Limnophysa haydeni Tryon, Amer. Journ. Conch., I, p. 251, 1865.-Call, Bull. Wash. Coll. Lab. N. H., I, p. 52, 1885.

Limnaus haydeni Clessin, Küster, Conch. Cab., p. 390, taf. 53, p1. 10, 1886.

Limncea sumassi Tryon, Con. Hald. Mon., p. 97 (71), pl. 17, fig. 5, 1872.Ingersoll, Bull. U. S. Geol. \& Geog. Surv., I, p. 138, 1875; Rep. U. S. Geol. \& Geog. Surv. Terr., 1874, p. 405, 1876.

Limnaa near sumassi Pilsbry, Nautilus, XVII, p. 84, 1903. (?)

Limnophysa sumassi Call, Bull. U. S. Geol. Surv., II, pp. 371, 403, 1884 ; Bull. Wash. Coll. Lab. N. H., I, p. 52, 1885.-Gilbert, Mon. U. S. Geol. Surv., I, pp. 210, 300, 1890.

Lymnaa sumassi Henderson, Univ. Col. Studies, IV, p. 180, 1907.

Limnophysa palustris var. sumassi Cooper, An. Rep. Cal. State Min. Bu., VI, p. 245, 1888.

Lymnaa catascopium var. sumassi DalL, Alaska Moll., p. 78, 1905 (part).

Limnea ${ }^{1}$ ?Ingersoll, Bull. U. S. Geol. \& Geog. Surv., I, p. 138, 1875 ; Rep. U. S. Geol. \& Geog. Surv. Terr., 1874, p. 405, 1876.

Limnca rowelli CKLl., Journ. Conch., VI, p. 64, 1889.

Limnca vahlii ?Whiteaves, Ottawa Nat., XX, p. 117, 1906.

Lymnca rowelli Henderson, Univ. Col. Studies, IV, p. 184, 1907.

Limnaa tryoniana ?Singlex, Rep. Geol. Surv. Texas, IV, p. 188, 1892; p. 314, 1893.

Limnaa palustris michiganensis BAKer, Trans. Acad. Sci. St. Louis, XI, p. 17, pl. i, fig. 5, 1901 (part).-Moll. Chi. Area, p. 276, pl. 32, fig. 5, 1902 (part). -Blatchley and Daniels, 27 Rep. Dept. Geol. Nat. Res. Ind., p. 596, 1903 (part).-Daniels, 1. c., p. 636 (part).

Limnaus sordidus Küster, in Mart. \& Chemn., Syst. Conch. Cab., ed. 2, Limnæus, p. 58, taf. 12, figs. 15, 16, 1862.-Von Martens, Biol. Cent. Amer. Moll., p. 379, 1899.

Limnca zebra TAYLOR (non TRYON), vide WALKer, in letter.

SHELL: Varying from elongate to elongate-ovate, usually rather thin; color varying from pale brown to almost jet black; surface dull

\footnotetext{
'Ingersoll says "near L. Rowelli Tryon, 'Dr. James Lewis in letter':" These were probably narrow forms of palustris, or possibly elodes. Rowelli has not been recorded authentically from Colorado. The same may be said of the record of Prof. Cockerell.
} 
to shining, covered with numerous crowded growth lines crossed by several elevated spiral lines and by numerous very fine impressed spiral lines; in many specimens the last whorl, and frequently the whole shell, is heavily malleated; the whorls are sometimes encircled by coarse wrinkles, and frequently the epidermis is so arranged as to show longitudinal stripes of white and horn color, alternating; whorls seven, rounded, the last varying in its rotundity but usually quite obese; spire sharp and pointed, varying from over half to three-fifths the length of the entire shell; sutures well impressed; aperture varying from roundly-ovate to long-ovate, more or less expanded; peristome thin, acute, sometimes expanded, in old specimens or at resting stages thickened by a heavy deposit or varix within; the peristome is white and there is a band of very dark brown which edges the varix; inner lip closely appressed to the parietal wall, forming a heavy callus, which in some specimens is so extensive as to make an almost continuous aperture; axis twisted, forming a rather heavy, ascending columellar piait; umbilical chink generally very narrowly open, but sometimes closed.

\begin{tabular}{|c|c|c|c|c|c|}
\hline $\begin{array}{l}\text { Length. } \\
20.00\end{array}$ & $\begin{array}{l}\text { Breadth. } \\
10.00\end{array}$ & $\begin{array}{c}\text { Aperture length. } \\
10.10\end{array}$ & $\begin{array}{l}\text { Brea } \\
5.00\end{array}$ & & Type nuttalliana \\
\hline 20.50 & 10.00 & 10.00 & 5.00 & “ & " haydeni \\
\hline 23.00 & 11.50 & 13.25 & 6.50 & “ & " expansa \\
\hline 24.00 & 11.50 & 13.50 & 5.50 & “ & “ “ \\
\hline 23.50 & 11.00 & 12.50 & 6.00 & “ & “ sufflatus \\
\hline 32.00 & 11.50 & 14.50 & 7.00 & “ & Alpena, Mich. \\
\hline 31.50 & 14.00 & 15.50 & 7.00 & “ & “ \\
\hline 27.00 & 12.00 & 13.50 & 6.80 & “ & “ \\
\hline 21.50 & 10.00 & 11.00 & 5.25 & “ & " \\
\hline 24.50 & 12.00 & 12.50 & 6.25 & “ & California. \\
\hline 28.00 & 12.50 & 14.00 & 6.50 & “ & Owasco Lake, N. Y. \\
\hline 31.50 & 14.00 & 15.50 & 7.50 & “ & “ $\quad “$ \\
\hline 21.00 & 11.00 & 10.00 & 5.10 & “ & “ \\
\hline 21.00 & 10.50 & 11.00 & 6.00 & “ & Halma, Minn. \\
\hline 24.00 & 11.50 & 12.00 & 5.50 & “ & “ “ \\
\hline 32.00 & 10.00 & 10.50 & 5.50 & “ & “ ، \\
\hline 22.00 & 8.50 & 10.00 & 4.50 & “ & " $"$ \\
\hline 28.00 & 11.00 & 12.50 & 6.00 & “ & Braddock's Bay, N. Y. \\
\hline 28.00 & 12.00 & 15.00 & 7.00 & “ & " \\
\hline 23.00 & 11.00 & 11.75 & 6.00 & “ & Seattle, Wash. \\
\hline 9.50 & 4.50 & 5.00 & 2.20 & “ & Indiana. \\
\hline 11.00 & 5.00 & 5.00 & 2.50 & “ & Alpena, Mich. \\
\hline 10.75 & 5.00 & 5.50 & 2.40 & “ & Joliet, Ill. \\
\hline 11.25 & 4.90 & 5.25 & 2.00 & “ & “ “ “ \\
\hline
\end{tabular}

Types: Expansa Hald., Academy of Natural Sciences, Philadelphia, two specimens, No. 58533; nuttalliana Lea, Smithsonian Insti- 
tution, three specimens, No. 118649 ; haydeni Lea, Smithsonian Institution, two specimens (one figured type), No. 121505 ; sufflatus Calkins, Chicago Academy of Sciences, two specimens (one figured specimen), No. 8375 ; plebeia Gould, location, if any, not ascertained; sordidus Küster and septentrionalis Clessin, location not ascertained.

Type Localities: Expansa, Vermont; muttalliana, Oregon; haydeni, Yellowstone River; sufflatus, Chicago, Illinois; plebeia, Massachusetts; septentrionalis, North America; sordidus, unknown.

Animal: Black, lighter below, the body spotted with white which shows through the shell; foot wide and short, rounded before and behind; tentacles short and rather wide.

JAw (Plate VI, fig. I): Wide and rather high, with a rounded median swelling on the ventral margin about one-third the diameter of the jaw in width.

RAdUla (Plate VIII, fig. F) : Formula: $\frac{21}{4-6}+\frac{4}{3}+\frac{9}{2}+\frac{1}{1}+\frac{9}{2}+\frac{4}{3}+\frac{21}{4-6}$ (34-1-34) ; central tooth with a rather long, sharp cusp; lateral teeth (9) narrow, bicuspid, the mesocone long and narrow, the ectocone short, rather wide and placed high up on the reflection; transition teeth (10-13) narrow, tricuspid, the mesocone very long and narrow, the entocone very small and placed a little below the middle of the mesocone; the entocone first appears on the tenth tooth and gradually becomes larger until in the fourteenth tooth it is as large as the mesocone; marginal teeth long and very narrow, tri-, quadri or penta-cuspid, the cusps at the distal end of unequal size; there are two outer cusps, one placed about midway of the reflection and one, smaller, placed some distance above this; the marginals gradually become smaller toward the edge of the membrane, and the distal end of the reflections become serrated by three or four cusps of equal size. In one membrane examined, the first lateral to the right of the central tooth had a bifid ectocone. This was observed on all the first laterals in this membrane. (P1. VIII, fig. H.) There are one hundred rows of teeth.

In specimens of palustris from Colorado, the transition teeth began at the ninth tooth, while radulæ from California specimens gave the same result as those from Illinois and New York.

Crosse and Fischer have referred to the lateral teeth of palustris as being tricuspid, but in a large number of examinations of American specimens, from many parts of the country, all have been bicuspid. (See Mis. Scient. Mex., II, p. 41, 1870.) All of the palustris-emarginata-catascopium groups have bicuspid lateral teeth.

Genitalia (Plate XI, fig. E): Male organs: Penis-sac cylindrical, 4.50 mill. long, 1.50 mill. greatest diameter; penis 3.00 mill. long, 
round, of equal diameter throughout; vas deferens 15.00 mill. long; penis retractor very long and very narrow; penis-sac retractor very long, wide, ribbon-like; penis-sac protractors usually six in number, three anterior and three posterior. The anterior protractors are largest and are frequently fused; prostate duct 5.00 mill. long, slightly enlarging as it enters the prostate; prostate flattened, much elongated, rounded at either end, the larger end receiving the prostate duct; the prostate gradually tapers to the narrow portion which joins the uterine portion of the oviduct.

Female organs: Receptaculum seminis large, pear-shaped, connected with the oviduct by a duct 7.00 mill. long, which enters the oviduct 1.25 mill. from the vaginal opening; the first accessory albuminiparous gland is very elongate-ovate, narrowing suddenly at both ends; it is markedly creased in the center, longitudinally, where the prostate is attached; second albuminiparous gland very small, rounded; albuminiparous gland not differing from those already described; the lower portion of the oviduct is long and very narrow.

The organs are colored as follows: Penis-sac, blackish; penis, yellowish flesh; prostate, flesh; receptaculum seminis, yellowish; albuminiparous glands, yellowish. The musculature of the penis-sac varies considerably. The posterior protractors may be one or four in number. while the anterior protractors vary in number and in position. There are several very small muscles close to the penial opening, which vary in number. In specimens from Florissant, Colorado, the posterior protractor muscles varied in number from two to four, while the anterior protractors were almost invariably a constant of four. (Pl. $\mathrm{XV}$, fig. C.) In one specimen $(\mathrm{C}, 3)$ the penis retractor had a small branch extending to a point in the penis-sac just above the penis-sac retractor. In another specimen $(\mathrm{C}, 1)$ the two retractors were joined as they entered the columellar muscle.

The comparative measurements of the genitalia of several individuals are as follows (dissections Nos. 23454 to $2345 \%, 23500,23596$ ) :

\begin{tabular}{|c|c|c|c|c|c|c|c|c|}
\hline $\begin{array}{c}\text { Penis. } \\
2.75\end{array}$ & $\begin{array}{c}\text { Penis- } \\
\text { sac. } \\
3.80\end{array}$ & $\begin{array}{c}\text { Penis } \\
\text { ret. } \\
3.75\end{array}$ & $\begin{array}{l}\text { Penis-sac } \\
\text { ret. } \\
4.00\end{array}$ & $\begin{array}{l}\text { Vas. } \\
\text { def. } \\
7.10\end{array}$ & $\begin{array}{r}\text { Prost. } \\
\text { duct. } \\
16.50\end{array}$ & $\begin{array}{l}\text { Rec. } \\
\text { sem. } \\
3.00\end{array}$ & $\begin{array}{r}\text { Shell. } \\
20.75\end{array}$ & California. \\
\hline 2.90 & 3.50 & 3.50 & 3.50 & 5.50 & 15.00 & 4.80 & 21.00 & New York. \\
\hline 3.00 & 4.50 & 3.75 & 4.50 & 5.00 & 15.00 & 7.00 & 31.50 & " \\
\hline 2.50 & 3.00 & 2.00 & 3.00 & 4.00 & 18.00 & 5.00 & $\ldots \ldots$ & California. \\
\hline 2.00 & 4.00 & 1.50 & 2.50 & 8.10 & 18.00 & 4.50 & 24.00 & Colorado. \\
\hline 2.00 & 3.75 & 2.10 & 2.90 & 5.50 & 15.50 & 4.15 & 20.00 & \\
\hline 2.00 & 3.50 & 1.50 & 1.75 & $\ldots$ & $\ldots \ldots$ & 4.00 & 19.00 & “ \\
\hline 3.00 & 4.75 & 1.50 & 2.25 & 8.25 & 19.00 & 6.00 & 21.00 & " \\
\hline
\end{tabular}


The above table shows that there is some variation in the measurements of the different organs. The genitalia of palustris differ from those of the smaller Lymnæas (Galba) in the form of the prostate, which is ovate in Galba while in Stagnicola it is squarely rounded at the anterior end and gradually tapers toward the posterior end. The penis is also thicker and larger in Stagnicola.

The size and number of eggs in the egg-capsules of Galba palustris are as follows:

\begin{tabular}{cccc} 
Length. & \multicolumn{2}{c}{ Width. } & Eggs. \\
12.50 mill. & 3.50 mill. & 82 & Illinois. \\
13.00 " & 3.50 “ & 68 & " \\
16.00 " & 4.50 " & 50 & Colorado. \\
19.50 " & 4.50 " & 64 & " \\
11.50 " & 4.50 “ & 26 & "
\end{tabular}

Range (Figure 33): Circumboreal. Northern Asia and Europe. North America from the Atlantic to the Pacific Ocean, and from Alaska south to New Mexico.

Palustris probably inhabits nearly the whole of North America from the Arctic Circle to southern California and New Mexico. It appears to be absent from the Lower Austral (Austro-riparian division). It may be said to be characteristic of the Boreal and Transition life zones, from whence it has penetrated into the Upper Austral life zone. Its absence from Labrador, Ungava and the northern part of this region may be accounted for by lack of records. Although reported from these regions by Dall (Alaska Moll., p. 76), no specimens from these areas have been examined by the writer, nor have any definite rcords been seen. It is possible that its place in this region, as well as in Greenland, is taken by Galba vahlii. West and northwest of Hudson Bay it is common and widely distributed. Its hypsometric distribution extends to 9000 feet in Colorado, $7 \% 60$ feet in southern California, and 10,000 feet in the Uinta Mountains, Utah.

Comparing the range of palustris with the drainage regions, we find it absent from the Labradorian, Alaskan, Carolinian, Lower Mississippian and Central American regions. It enters the Rio Grandian. The neighborhood of the 40 th parallel marks the southern boundary in this region, excepting a small portion of Illinois. In the west, palustris extends almost to the 30th parallel, the altitude providing the temperate climate of the northern portion of the Mississippi Valley. The general northwesterly extension of the distribution indicates apparently the origin of the species in America, it being an emigrant from Asia via Bering Strait. Additional records will doubtless establish an unbroken route from the Arctic shores of Alaska to the Great 


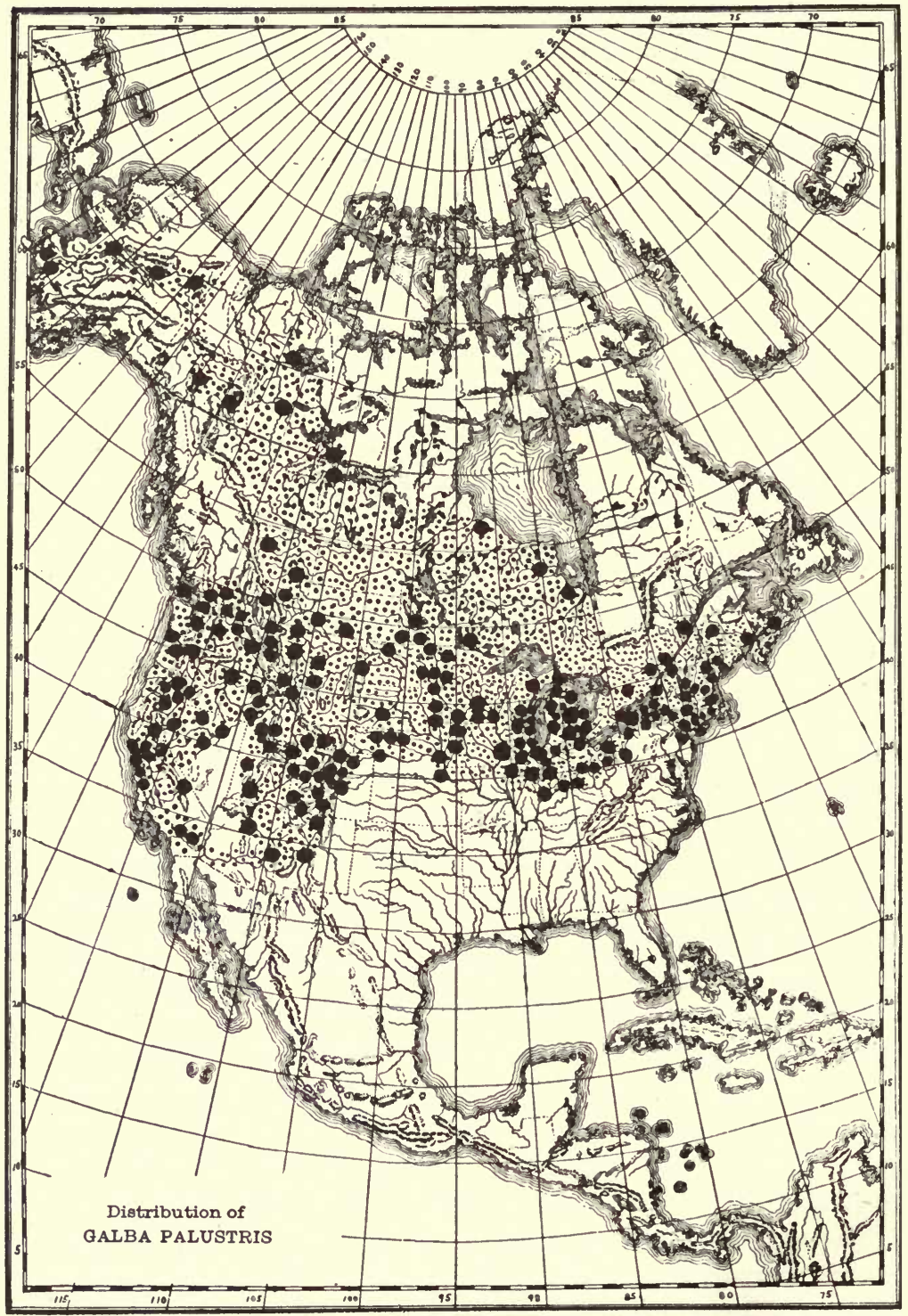

FIG. 33. 
Lakes and the Rocky Mountains. Its route of dispersal in Post-Glacial Time is plainly indicated on the map, via the ancient waterways connected with Lake Agassiz, Lake Warren and Lake Chicago. A small colony doubtless found refuge in Alaska during the Ice Age, and was subsequently scattered over the northwestern portion of British America via the Yukon River.

Geological Range (Figure 34): Pleistocene. Palustris has been found in various Pleistocene and recent deposits. It is rare in the Lœss, but very common in certain sand, gravel and lacustrine deposits. Call mentions it as an abundant post-Lahontan fossil ranging downward to the Middle Lahontan, Nevada. It is abundantly distributed throughout the Bonneville area in Utah. In the inter-glacial

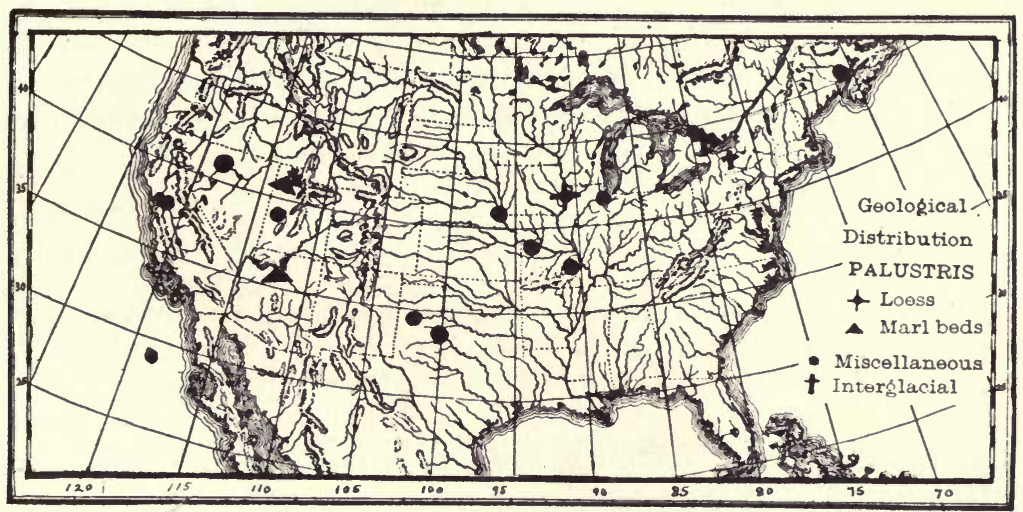

FIG. 34 .

deposits of the Don Valley, near Toronto, and in those of the western shore of Cayuga Lake, in New York, it is also abundant. Geographically the geological range is from New Brunswick to California, forming a belt about ten degrees in width. The Missouri, and especially the Texas and Arizona records, indicate that the species formerly ranged well into the Lower Mississippian region. No recent specimens have been seen from Texas, and the descriptions of the deposits lead to the opinion that they are of considerable antiquity, perhaps pre-glacial.

\section{RECORDS.}

UNITED STATES.

LESS.

Iowa: Division Street, Davenport, Scott Co., near the base of the Lœss (Leverett; Shimek; Udden). 
MARL.

Arizona: Coconino Co. (Dall).

UтAн: Lake Bonneville, in white marl (Gilbert); near Salt Springs Creek (Call).

INTERGLACIAL BEDS.

New York: West side Cayuga Lake, Tompkins Co. (Murray).

Ontario: Don Valley, near Toronto (Coleman).

VARIOUS DEPOSITS.

UNITED STATES.

CAlifornia: Branch of Walnut Creek, near Livermore, Alameda Co.; Walnut Creek, Contra Costa Co. (Cooper).

Illinors: Worth, Cook Co., in old lake deposit (Baker); In beach at Evanston (Marcy).

Mrssouri : Belleview, Iron Co., and Lexington, La Fayette Co. (Swallow).

Nebraska: Along banks of Missouri River, in lacustrine deposits (Aughey); Bluff City landing, below mouth of Platte (Swallow).

NevadA: In estuary of highest Lahontan beach; Brown's, Washoe Co.; stratified gravels of Mill City, Humboldt Co.; Middle Lahontan (Call).

Texas: Three miles east of Kiowa Peak, Stonewall $\mathrm{Co}^{2}$; forks of Groesbeck Creek, Hardeman Co., ${ }^{1}$; Tule Canyon, Swisher Co. (Singley).

Uтан: Surface of Sevier Desert, Millard Co. (Call).

\section{BRITISH AMERICA.}

New Brunswick: Sawler's Lake, St. John, St. John Dist. (Dall).

Ontario: Upper drift deposits, Nottawasaga River, near Angus Station, Simcoe Dist. (Chapman) ; Iroquois Beach, from dune-like sand plain near Toronto, York Dist. (Coleman).

${ }^{1}$ As these records are apparently outslde of the present range of the species, the full description of the localities is appended. (See Geol. Surv. Texas, IV, pp. 184, 185.)

1"This locality is about three miles west of the town of Quanah, in Hardeman County. Groesbeck is a tributary of the South Fork of Red River. The south fork of the creek heads southwestward from the town of Quanah, and, after forming a junction with the north fork, flows into the river a few miles northeast of that town. The north branch has its source a little west of Quanah, and flows almost east to its confluence with the south branch. Both streams are fed by constantly flowing springs, rising from the massive gypsum beds which underlle the whole country.

"The limestone hills on both sides of the creek, near the junction of the two branches, rise to the height of forty or fifty feet above the creek valley, which is in places a mile or more in width. The creek has cut a channel through this valley, which was the former flood plain, down into the massive gypsum to the depth of twenty-five feet, and this channel, which is about 100 feet wide, now constitutes the flood plain of the stream, the water belng confined to a still deeper and narrower channel except at flood times.

"At the top of the old flood plain, twenty-five feet above the present stream, is the horizon at which the material was taken containing the shells mentjoned as coming from the Forks of Groesbeck. The bed also contains parts of fossil vertebrates, among which may be mentioned an elephant, horse, and beaver, with others not yet determined.

"It is evident that at one time there was much more water flowing down this valley than at present, and that it spread out in a broad sheet. This must have continued for quite a while as the drift material is often ten to twelve feet thick. This locality is west of the Seymour plateau.

${ }_{2}$ "This locality is in the northeastern corner of Stonewall County, on the east side of the Brazos River, and near the road at the crossing of the river. r'he bluff on the river at this place, on the east slde, is about thirty feet high, composed of drift material. The beds from which the shells were taken is a bluish clay, situated about ten feet below the top of the bluff and extending saveral hundred yards along a hollow running back from the river. I also saw the same clay in several other gulches running into the river. This material was different from that composing the bluff of the river, which is a red sandy loam, and seems to have been deposited against the older blue clay bed." 
Quebec: Saxicava Sand, Packenham Mills, 266 feet above Lake St. Peter, St. Lawrence Valley (Dawson. Probably drifted into sea by fresh-water streams).

ECOLOGY : Found plentifully in bodies of water of greater or less size, on floating sticks and submerged vegetation, on stones and on the muddy bottom. Inhabits both clear and stagnant water, but prefers a habitat in which the water is not in motion. Seldom found out of the water, as is the case with the smaller species of the subgenus Galba. The more distinctly malleated forms inhabit stagnant pools where the bottom is muddy, with more or less decaying vegetation present. The food of palustris is made up of both animal and vegetable matter, the species being literally vegetiferous, scavengiferous and carnivorous. The writer has noted it feeding upon the dead carcasses of dogs, cats, rats, etc., upon rotting vegetables and decaying fruit. Dr. Sterki (Nautilus V, p. 94) has seen it in the act of eating a living leech. The animal of palustris is very rapid in movement. When crawling, the shell is frequently moved rapidly from side to side, and is carried at all conceivable angles. It is a very rapid feeder and will soon clear up the sides of an aquarium. Like other species of the genus, palustris has the habit of rising very suddenly from the bottom to the top of the water, where it will then float, shell downward. (Baker.) lander.)

"In small brook on farm near Caribou Village, Maine." ( $\mathrm{Ny}-$

"L. palustris I have found only in lakes except some unusually large specimens from a small ditch connecting two lakes on the plains near Fort Collins, and found none in either of the lakes, but it was when the lakes were full, at which time it is usually harder to find Mollusca along the shores of our fluctuating lakes. In the valleys I have found them in lakes containing some vegetation but not choked therewith except around the inlets. In the mountains I have found them only in sedge-choked, very shallow lakes which nearly dry up in the late summer. At Lake George, altitude about 8000 feet, I found it in very shallow water with fine mud bottom at the head of the lake, and in a seepage pool with fine mud bottom just below the lake. This lake is purely artificial, formed by throwing a dam across the South Platte at a point where the canyon widens out into a broad valley, so I presume these shells may have been brought down the river from some lake nearer its source. There is no vegetation in either the lake or the pool. It is interesting to note that the Lymnæas occupied the same region in Tertiary time (L. sieverti, L. scudderi, Ckll., Bull. Am. Mus. Nat. Hist., Vol. 22, p. 461), but the lake in which they lived 
was drained ages ago by the cutting down of the barrier." (Henderson, Colorado. )

In a still, swampy pool, protected from the waves of Lake Huron. (Nason, Alpena, Mich.)

"Taken from a pond near Bitter Root River. Quite abundant, several hundred specimens taken. Also taken in abundance in standing and quiet waters in the creeks on Flathead Indian reservation. At the upper end of Flathead Lake there is a great deal of marshy country tributary to the lake and to Flathead River. In the lowland bordering on the lake, which had been overflowed and later dried off, large quantities of dead shells were observed. Indeed, the shells were so abundant one could not walk without mashing large numbers. In still other places the shells were yet alive in the sloughs, in great abundance. Along the Bitter Root River the shells were living in the same waters with Aplexa hypnorum.”. (Elrod, Montana.)

"A few days ago, while collecting tresh-water shells in the dry bed of a pond near Alum Rock Park, San José, the author found several live specimens of a form of Lymnaa palustris (Müller) lying on the dry mud surface with the aperture sealed down by a thick dried mucus and withdrawn into their shells half a whorl. The pond usually contains water at least half the year, but on account of the dry spring has contained none since April 1st at least. The bed is thinly covered with tall tulas, so that the shells were not in the direct rays of the sun. This form is the only one which occurs in the lake, and dead shells up to barely mature are abundant, and some larger." (Hannibal, California.)

"Young, hatched in August, in a small aquarium, were fully grown by midwinter." (Sterki, Ohio.)

Quinn River crossing, Humboldt County, Nevada, altitude 4100 feet. In pools, Yellowstone Park. (Berry.)

Remarks: Palustris is one of the commonest and most variable of the Lymnæas, being equaled in this respect only by Galba obrussa. The large, more or less corpulent shell, with its coarse, generally malleated sculpture and heavy columella plait, will easily distinguish it from related species. The whorls in typical palustris are always well rounded, especially the body whorl, which may be quite robust. The aperture and spire are generally equal in length and the whorls are much wider than high, a character which will help to separate the narrow forms from reflexa and elodes. The principal variation is in the form of the spire, which in some specimens is long and narrow while in others it is short and corpulent. This variation does not seem 
to be confined to any particular locality, but is found in any considerable lot of shells from any locality. (See the figures on the plates.) It is evident from a study of the figures of palustris in European works (Forbes and Hanley, Sowerby, Martini and Chemnitz, etc.) that the large, rather corpulent form is to be considered as typical. This form is absolutely identical with American specimens, series from both continents being indistinguishable when mixed. There are, however, several varieties or races which seem recognizable. Very distinct variations are frequently seen in shells from different parts of the same body of water, as notably illustrated by the palustris in Owasco Lake, N. Y., where specimens from the west shore are very large and thin (pl. XXXIII, figs. 2-y) while those from the north end are smaller and very solid, in some individuals recalling both Galba catascopium and Galba palustris desidiosa (P1. XXXIII, figs. 8-10).

A study of the types of Lea's Lymnæas in the Smithsonian Institution conclusively proves that nuttalliana (pl. XXXIII, figs. 22-23) and haydeni (pl. XXXIII, fig. 25) are absolute synonyms of palustris, haydeni being a slight modification of the nuttalliana form. The characteristics of a corpulent shell or a strongly plicate columella are of no consequence whatever when a series is examined, such as is shown on plate XXVI, where figs. 20 and 17 seem very distinct when placed side by side, but are seen to be easily and gradually connected with each other in a large series. (Compare also fig. 21 with fig. 26.) These mutations are very interesting, but are not of taxonomic importance, being simply individual variations. Lymnaa expansa Hald. is a form in which the outer lip is expanded; the same is true of sufflatus Calkins. Plebeia Gould, a nude name, is an absolute synonym of palustris. Limnaus sordidus Küster, is a synonym of palustris, judging by Von Martens' references to Haldeman, plate 6, figure 1 . The locality "Central America" is an error as no member of the palustris group (except attemuata) is found south of the Rio Grande. It is probably a case of mixing labels. Specimens in Dunker's collection, now in Berlin, are said by Von Martens to be like Haldeman's figure 5 on plate \%. These are marked "Central America."

Unlike the Lymnæas previously considered (excepting caperata) palustris forms several distinct ribs or rest varices in its shell, as many as four being distinctly seen in some specimens, although three seem to be the normal number. In the majority of specimens one varix is formed on the third whorl, one on the fifth whorl and one on the margin of the aperture. Whether these varices are formed yearly or simply mark periods of hibernation when the animal is buried in the 
mud, the author cannot state positively, but his opinion is that it marks periods of hibernation and has nothing to do with the annual growth of the shell. The presence of this varix is not, however, a sign of maturity as has been stated, for it may be found in a shell of three whorls. One specimen from Halma, Minnesota, has four varices placed close together on the body whorl.

Fully adult palustris has seven full whorls; the majority of specimens, however, have from four to six whorls. Individuals of four whorls are frequently seen with the aperture and spire about equal, which appear at first sight distinct from palustris. In some specimens the body-whorl is flattened and a heavy varix is formed. These shells are two-thirds grown having formed the varix preceding the formation of the last body-whorl. A form of palustris occurs in Lake George, Florissant, Colorado (pl. XXXIII, figs. 14-18) which is remarkably flattened from front to back, and the inner lip in the mature shell is reflected in such a manner as to form a broad, smooth projection which emargins the unibilicus, leaving a conspicuous chink. The spire and aperture are about equal in length. These shells were eroneously identified by the writer as sumassi Baird. Some of the specimens in this lot are heavily malleated. The genitalia and radula do not differ from those of palustris.

The surface of many of the large, fragile forms, as at Alpena and in Owasco Lake, is strongly malleated. These shells may be taken as typical palustris. The shells of palustris vary considerably in their thickness, some being as thin as paper while others are quite thick and solid. The columellar plait also varies markedly in prominence in different individuals. Specimens from California (pl. XXXIII, fig. 24) are frequently very wide and corpulent, the body whorl being almost globose. Such a form is shown by Binney in his fig. 61 . Several specimens have been seen which have the first five whorls jet black while the last two are rich horn-colored, the line of demarcation between the two being very strong. A collection from Deuel County, South Dakota, contains a number of individuals which are heavily striped in zebra fashion. A single reversed specimen has been collected by Dr. William A. Nason, at Stony Point, near Alpena, Michigan. It consists of four whorls and measures 9.50 mill. in length.

No attempt has been made to correlate the European varieties of palustris with those of America. They have been developed along parallel lines, but cannot be said to be identical, though resembling each other very closely. The varieties corvus, turricula. decollata (Jeff.), roseolabiata, fusca and many others have their counterpart in 
the American shells. It may be noted in passing, that until some European author revises the nomenclature of the European varieties and so called species it will be absolutely impossible to make any intelligible comparisons. The tendency of some of the students of freshwater shells is to make every mutation a species or variety. A similar course practiced on our American palustris would produce several hundred of these "species."

Galba palustris alpenensis Nov. Var. Plate XXXIII, figures 26-33.

Lymncea palustris BAKER, Trans. Acad. Sci. St. Louis, XVI, p. 10, 1906. (part).

Lymnaa palustris michiganensis BAKER, Trans. St. Louis Acad. Sci., XVI, p. $12,1906$.

SHell: Elongated, narrow, very solid; periostracum light horncoiored; sculpture as in palustris; whorls six to seven, well rounded, the body whorl somewhat obese; spire long and acutely conical, usually considerably longer than the aperture; sutures well impressed; aperture regularly oval; outer lip thickened internally by a well marked varix; inner lip rather wide, reflected over the umbilical region, either completely closing the perforation or else leaving a very small chink; the parietal callus heavy, producing a continuous aperture in many specimens; there is in some specimens a more or less distinctly marked plait, but the majority of specimens are without a distinct columellar plait, though the axis is distinctly twisted.

\begin{tabular}{|c|c|c|c|c|c|}
\hline $\begin{array}{l}\text { Length. } \\
24.25\end{array}$ & $\begin{array}{c}\text { Breadth } \\
10.50\end{array}$ & $\begin{array}{c}\text { Aperture length. } \\
11.00\end{array}$ & $\begin{array}{l}\text { Bre } \\
5.50\end{array}$ & $\begin{array}{l}\text { adth. } \\
\text { mill. }\end{array}$ & Type \\
\hline 23.00 & 10.00 & 10.50 & 5.25 & “ & \\
\hline 22.00 & 10.00 & 10.00 & 5.00 & “ & “ \\
\hline 19.75 & 9.00 & 9.50 & 4.00 & “ & \\
\hline 21.00 & 10.00 & 10.50 & 5.00 & “ & \\
\hline 16.25 & 8.00 & 9.00 & 4.50 & “ & \\
\hline
\end{tabular}

Types: Chicago Academy of Sciences, eight specimens, No. 23486.

Type Locality: Thunder Bay Island, near Alpena, Alpena Co., Michigan.

Animal, Jaw, Radula and Genitalia: Unknown.

RANGE: Michigan. A race of the Canadian region. RECORDS.

Michigan: Thunder Bay Island; Long Lake; Whitefish Point; Sugar Island, all near Alpena, Alpena Co. (Nason).

Geological Distribution: Unknown.

Ecology: This race lives on an exposed shore in pools on limestone ledges where the waters of Lake Huron dash in, producing a 
precarious environment. The specimens from Thunder Bay Island exhibit admirably the effect of the heavy seas of Lake Huron.

REMARKS: Alpenensis may be distinguished by its solid, narrow shell, long, acute spire, rounded whorls, with well rounded body whorl and particularly by its inner lip, which is wide and raised from the columellar region, producing an emarginate condition very similar to that in Galba cmarginata. The solidity of the shell and particularly of the inner lip, which is nearly always continuous will also serve to aid in the identification of this race. Some small specimens somewhat resemble Galba palustris dcsidiosa, but that race is smaller, thinner, the spire is regularly turreted, the body whorl is proportionally wider and more obese and the inner lip is appressed to the parietal wall, producing a distinct plait. Galba elodes has a narrower shell with more flat-sided whorls and a more elongate aperture.

This form is so numerous in individuals and so constant in character that it seems necessary to bestow a name upon it as a race of palustris. Typical palustris from this locality lives in a still, swampy area which is protected from the rough waters of Lake Huron by a low shore. This quiet, peaceful habitat produces a large, thin shelled form quite unlike the race which lives on the exposed shore (see plate XXVI, figures 17-20; compare with figures on plate XXXIII). The environment in this case has produced a shell which is uniformly so distinct as to be as easily distinguished as are any of the species of Lymnea. At Halma, Minnesota, a narrow shell occurs, but this is connected by insensible degrees with the large corpulent form of typical palustris ( see plate XXVI, figures 21-26). In Owasco Lake, N. Y., a narrow, long spired form occurs, but here again the variation runs into the typical form without a break. In alpencnsis, the peculiarities are quite uniform and there is no decided variation towards the large, corpulent form. Young shells have a short spire and elongate-ovate shape, but the fully adult shell is always as figured on the plate. The shells were collected by Dr. William A. Nason of Algonquin, Illinois.

Galba palustris desidiosa ${ }^{1}$ (Say). Plate XXXIV, figures 1-12. Lymneus desidiosus SAY, Journ. Phil. Acad., II, p. 169, 1821; Long's Exped., II, p. 264, 1824 ; Binney's Ed., pp. 66, 130, 1858.

Limneus desidiosus SAY, Amer. Conch., VI, p. 211, pl. 55, fig. 3, 1834; Binney's Ed., p. 211, 1858.

Limnca desidiosa Binney, L. \& F. W. Sh. N. A., II, p. 48, 1865.-Gould, Inv. Mass., p. 219, 1841 (part) ; Binney's Ed., p. 470, 1870 (part).

${ }^{1}$ Only those references are here given which are believed to refer to the true desidiosa. Several references listed under obrussa may belong here, but tliere appears to be no way of verifying them. 
Lymnaa desidiosa Morse, Amer. Nat., III, p. 651, 1870 (part).-BAKeR, Nautilus, XXII, p. 20, pl. III, figs. 1-2, 1908.

SHELL: Of medium size, solid, ovate to elongated in form; periostracum pale horn colored, darker in some specimens; surface dull, lines of growth crowded, conspicuous, crossed by fine impressed spiral lines; the body whorl is frequently malleated; whorls five to six, regularly and rapidly increasing in size, well rounded, the body whorl quite convex; spire acutely conic or elongated, as long as or a little longer than the aperture; sutures well impressed, rather deeply in some specimens; nuclear whorls $1 \frac{1}{2}$ in number, brownish horn in color, and in outline like those of palustris; aperture ovate or roundly ovate, rounded below and slightly angled above; outer lip with an internal varix; inner lip narrow, triangular, reflected over the umbilical region, leaving a small chink; the callus on the parietal wall is heavy and sometimes causes the aperture to be continuous; there is a columellar plait and the axis is slightly twisted.

\begin{tabular}{|c|c|c|c|c|c|}
\hline Length. & Breadth. & Aperture length. & Brea & dth. & \\
\hline 15.00 & 7.50 & 8.00 & 3.00 & mill. & Say's autotype \\
\hline 14.25 & 7.50 & 7.75 & 3.50 & “ & “ \\
\hline 15.00 & 8.00 & 8.00 & 4.00 & “ & Williamsville, N. Y. \\
\hline 14.00 & 8.00 & 8.00 & 3.50 & “ & “ \\
\hline 17.00 & 8.00 & 7.50 & 4.00 & “ & Seneca Lake, N. Y. \\
\hline 15.50 & 7.50 & 6.50 & 3.50 & “ & “ $\quad$ “ \\
\hline
\end{tabular}

Types: Autotypes, Acad. Nat. Sci., Philadelphia, two specimens, No. 58\%31.

Type Locality: Cayuga Lake, N. Y.

Animal: Not examined alive, but alcoholic specimens appear externally like palustris.

JAW: As in palustris.

Radula (Pl. VIII, fig. I.) : Formula $\frac{21}{5-6}+\frac{4}{3}+\frac{9}{2}+\frac{1}{1}+\frac{9}{2}+\frac{4}{3}+\frac{21}{5}-\frac{1}{6}$ (34-1-34) ; the teeth are in all essential respects like those of palustris; the marginals of desidiosa begin more abruptly than is the case with palustris.

Genitalia: Not differing from those of palustris; one specimen gave the following measurements:

\begin{tabular}{cccccccc}
\multicolumn{7}{c}{ Penis- } & \multicolumn{5}{c}{ Prost. } & Penis Penis-sac \\
Penis. & sac. & Vas. def. & duct. & ret. & ret. & Shell. & Locality. \\
1.50 & 2.75 & 10.00 & 3.50 & 2.25 & 2.00 & 14.00 & New York.
\end{tabular}

RANGE: New York to Indiana. A species of the humid division of the Transition and Upper Austral life zones, and of the Canadian and the Upper Mississippian regions. The specimens examined have all been from the Carolinian division of the Upper Austral of western New York. The Indiana record is that of Say on page 211 of his 
American Conchology. No specimens have been seen from this locality. When better understood, desidiosa will probably be found to inhabit a much wider range than here indicated.

\section{RECORDS.}

Indiana: New Harmony, Posey Co. (Leseuer, Say).

NEW YoRK: Small stream under Erie Canal, Western Wide Waters, Rochester, Monroe ,Co.; near Geneva, north end Seneca Lake, Ontario Co. (Baker); Cayuga Lake; Falls of Niagara, Erie Co. (Say); Young's Quarry, Williamsville, Erie Co. (Miss Walker).

Pennsylvania: Pennsylvania (Say).

Geological Distribution: Unknown.

Ecology: Dead specimens were found along a marshy reedbordered shore in Seneca Lake; Miss Waiker found it in an old quarry at Williamsville.

REMARKS: An examination of Say's specimens of desidiosa in the Academy of Natural Sciences of Philadelphia reveals the fact that all subsequent naturalists have misunderstood this species and have given the name to a species belonging to a different group of Lymnæas. The true desidiosa is a member of the palustris group, as shown by Say's specimens and by a close study of Say's description and figures. The two specimens in the Philadelphia Academy may be described as follows : 1

Shell oblong-ovate, rather solid, color pale horn; surface dull, lines of growth crowded, conspicuous, crossed by impressed spiral lines; whorls $51 / 2$, convex; the body whorl is quite convex; spire acutely conic, about as long as the aperture; sutures well impressed; apex of $1 \mathrm{I} / 2$ whorls, brownish horn; aperture long-ovate; outer lip thin, with an internal rib or varix; inner lip reflected over and appressed to the parietal wall, leaving a small umbilical chink; columellar axis with a distinct, thick plait.

$\begin{array}{cccc}\text { Length. } & \text { Breadth. Aperture length. } & \text { Breadth. } \\ 15.00 & 7.50 & 8.00 & 3.00 \mathrm{mill} \\ 14.25 & 7.50 & 7.75 & 3.50 \text { " }\end{array}$

The specimens bear the following label in the original handwriting: Lymnea desidiosa Say. Journ. Acad. V. 2, p. 169. T. Say, Penn.? (No. 58731.)

The figure in Binney (fig. 68) is said to be from an authentic specimen in the Philadelphia Academy, but no such specimen is now in existence, nor are the specimens mentioned from Cayuga Lake to be found. In the absence of any other authentic material, it would seem that Say's specimens must be taken as typical of desidiosa. A

'The specimens are somewhat narrower than Say's figures in Amer. Conch. 
close analysis of Say's description would seem to indicate that he did not have the shell before him which has so long borne the name of desidiosa. He says ${ }^{1}$ (italics the author's): "It is closely allied to clodes, but the whorls are more convex, one less in number, and the two terminal ones are proportionately smaller." This statement is repeated in the American Conchology. This comparison with elodes would scarcely have been made by Say, who possessed a peculiarly discriminating sense of minute differences between shells, if he had been describing the shell historically known as desidiosa. The size of the Philadelphia specimens ( 15 mill.) also corresponds pretty well with the size given by Say ( $7 / 10$ of an inch $=$ about 17 mill.). The most convincing fact to the writer is the presence of a specimen of "desidiosa" (authors) in the Philadelphia Academy marked "Lymnæa......, Canandaigua Lake. T. Say" (No. 58732), showing that the form usually called desidiosa is not the one so called by Say. Prof. Edward S. Morse, who made the drawings for Binney's work, has been unable to add to our knowledge concerning the specimen figured by Binney.

During the summer of $190 \%$ the writer made three trips to Cayuga Lake, one to the south end at Ithaca, and two to the north end at the town of Cayuga, with the hope of securing specimens which would correspond with Say's specimens. Three whole days were spent in exploring several miles of the shore and the small creeks, and while specimens of both palustris and obrussa were obtained, not a single specimen was found which agreed with Say's desidiosa. The palustris were the large, thin-shelled form and the obrussa were rather small specimens, not at all like the description or specimens of desidiosa. As Say gave no particular part of Cayuga Lake as the identical spot in which the types were collected, it renders the task of finding locotypes well nigh impossible, since the lake is thirty-eight miles in length.

Recently, Miss Mary Walker, of Buffalo, New York, sent the writer a number of shells from Young's Quarry, Williamsville, New York, which are identical with Say's specimens of desidiosa, having the same number of whorls and almost the same measurements. These are given for comparison.

\begin{tabular}{cccccc} 
Length. & Breadth. Aperture length. & \multicolumn{2}{c}{ Breadth. } \\
15.00 & 7.50 & 8.00 & 3.00 mill. & Say's specimens \\
14.25 & 7.50 & 7.75 & 3.50 & “ & “ \\
15.00 & 8.00 & 8.00 & 4.00 & “ & Miss Walker's \\
14.00 & 8.00 & 8.00 & 3.50 & “ & “
\end{tabular}

Say's figure in the American Conchology (plate 55, fig. 3). corresponds with the specimens from Williamsville, all having the peculiar

'Journ. Acad. Nat. Scl., II, p. 169. 
obese body whorl. Say himself identifies desidiosa from western New York in Long's Expedition, II, p. 263, where he says, "Lymnceus desidiosus nob. Falls of Niagara." Some of these specimens, as well as others from Seneca Lake, agree fairly well with Binney's figure 68, and also with Say's specimens. Binney's figure 68 is also unlike the historical desidiosa, which rarely has such a uniformly oval aperture. There are, however, occasional specimens of obrussa which compare as favorably with Binney's figure 68 as do the specimens mentioned above, and for this reason it seems best to refer it to obrussa with a query. (Compare figures 10 and 11, plate XXVI, with Binney's figure 68.) Another significant fact is that when Say described obrussa, in 1825 , he made no reference to desidiosa, which was described four years earlier (1821). This fact, together with his comparison with clodes, is to the author conclusive evidence of the distinction of these two species.

The history of desidiosa in the American monographs is interesting and clearly indicates that since Say's time little attention has been given to closely analyzing this species. In all of his references, Say distinctly indicates a shell of the palustris type. Haldeman describes and figures the form here distinguished as obrussa and not the true desidiosa. (Compare his plate with Say's fig. 3.) Many of Haldeman's figures are abnormal and do not represent obrussa as it is usually developed. Tryon, in his continuation of Haldeman's work (p. 104), states that many of the figures on this plate are not desidiosa, but a form of columella (macrostoma). In this statement Tryon is wrong and could scarcely have seen Haldeman's specimens, for a recent examination proved them all to be referable to obrussa (desidiosa of authors), although, as stated above, several of the specimens are abnormal. The writer has collected many specimens similar to those figured on Haldeman's plate. Binney, in his Land and Fresh-Water Shells of North America, part II, makes obrussa a synonym of desidiosa, thus showing that he considered the latter the small, smooth form and not the true desidiosa of Say, and his figure 68 is questionable for this reason. In Baker's Mollusca of the Chicago Area, obrussa is described and figured as desidiosa. Recently, Dr. W. H. Dall, in his Alaska Mollusca (p. 73, fig. 51), figures Say's obrussa under desidiosa, but also refers, in his synonymy, to Binney's figure 68 . The European monographs have given figures referable to obrussa rather than to desidiosa.

Amidst the uncertainties caused by the absence of Say's types we must look for a shell which is closely allied to elodes, but is smaller, with more convex whorls, and possesses 5 instead of 6 whorls. Such 
a shell is found in the autotypes of desidiosa in the Philadelphia Academy and this type of shell occurs in localities in the eastern part of the United States, and is easily separable from any other known species or variety. The spire varies considerably, being short or long or even scalariform. There are from 2 to 5 rest varices on the whorls.

Desidiosa, then, differs from obrussa (desidiosa of authors) in its generally larger and more solid shell, longer and more turreted spire, more pronounced and heavier sculpture and more convex whorls, with deeper sutures; in having a distinct internal rib inside the outer lip and in the presence of a fold on the columella. Compared with palustris, desidiosa is smaller, usually more solid and with a more obese body-whorl and a more dilated aperture. The spire, too, is more sharply conic and the whorls are more tightly coiled, producing a deeper suture. The inner lip is also more expanded, producing a heavier callus. The shells called elodes by Say are larger, more flat-sided, with a longer spire, and the whorls are not so rounded and are more oblique. If we accept the evidence afforded by Say's specimens, and there seems to the writer to be no other course, then the shells usually called $d e-$ sidiosa must bear the name of obrussa, which is the first available name, and the name desidiosa must be used for the shells so called by Say.

There is some variation among the specimens referred to desidiosa, especially in the lot from the small stream near the Erie Canal, but all have the peculiar pot-bellied aspect of the body whorl, so markedly emphasized in Say's figure (pl. XXXIV, figs. 8-9). Specimens from Seneca Lake vary toward palustris alpenensis (pl. XXXIV, figs. 1012). Desidiosa appears to be a depauperate variety of palustris.

Galba palustris blatchleyi Nov. Var. Plate XXXIII, figures 34-36.

Limnea palustris michiganensis Blatchley and Daniels (non Walker), 27 An. Rep. Dept. of Geol and Nat. Res. Ind., 1902, p. 596, 1903 (part).-DANIELS, 1. c., p. 636, 1903 (part).

SHELl: Elongated, rather solid, periostracum very light-yellowish horn; surface polished; sculpture as in palustris; whorls 6 to $6 \mathrm{x} / 2$, rounded, the body whorl subglobose; spire acute, longer than the aperture; sutures well impressed; aperture long-oval; outer lip with heavy internal varix; inner lip narrow, triangular, either tightly appressed to the columellar region and forming a plait or broadly reflected and leaving a narrow chink; axis twisted.

$\begin{array}{ccccc}\text { Length. } & \text { Breadth. } & \text { Aperture length. } & \text { Width. } & \\ 20.00 & 8.00 & 8.50 & 4.00 \text { mill. } & \text { Types } \\ 17.00 & 8.25 & 7.75 & 4.00 \text { " } & \text { " } \\ 16.50 & 7.00 & 8.00 & 3.80 \text { “ } & \text { " } \\ 16.50 & 7.00 & 7.60 & 3.50 \text { “ } & \text { " }\end{array}$


Types: Chicago Academy of Sciences, four specimens, No. 23626 ; cotypes, coll. L. E. Daniels, La Porte, Indiana; Phil. Acad. Sci., Penn. Type Locality: Turkey Lake, Kosciusko County, Indiana.

Animal, Jaw, Radula and Genitalia: Not examined.

RANGE: Indiana. A race of the Upper Mississippian region. RECORDS.

Indiana: Turkey Lake, Kosciusko Co. (Daniels).

Geological Distribution: Unknown.

Ecology: Not recorded.

REMARKS: Blatchleyi may be known by its long spire, regularly increasing whorls and rounded body whorl. It is smaller than typical palustris and differs markedly in its spire and aperture, palustris having a large, corpulent shell with large aperture. The present race differs from Galba elodes and Galba elodes jolietensis in its more rounded and more regularly increasing whorls. Alpenensis has a broader shell with a differently shaped inner lip and spire.

Efforts to include this form with the described varieties of palustris have proven futile. It lives in Turkey Lake in large numbers, is very uniform in shape and size and is certainly entitled to a name. I take great pleasure in dedicating this interesting race to Mr. Blatchley, State Geologist of Indiana. The shells were discovered and collected by Mr. L. E. Daniels, and were previously reported as Lymnca palustris michiganensis, which small specimens somewhat resemble.

Galba elodes $\left(\mathrm{Say}^{1}\right)$. Plate XXX, figures $32-34$; plate XXXIV, figures 14-19, 21-24.

Journ. Phil. Acad., II, p. 169, 1821.-Forbes and Hanley, Hist. Brit. Moll., IV, p. 182, 1853.-SAY, Binney's Ed., p. 66, 1858.

Limneus elodes SAY, Amer. Conch., IV, p. 188, pl. 31, fig. 3, 1832.-LEIdy, Proc. Phil. Acad., II, p. 281, 1845.-Binney's Ed., p. 188, 1858.-Küster, Conch. Cab., I, p. 42, 1862 (part).

Limnaa palustris BinNeY, L. \& F. W. Sh. N. A., II, p. 44, fig. 60, 1865.

Lymnaa elodes Gould, Lamarck's Genera, p. 69, 1833.-WheAtley, Cat. U. S. Shells, p. 23, 1845.-JAY, Cat., p. 269, 1852.-ReEve, Elements of Conch., p. 178, 1860.-ScudDer, Bull. Nat. Mus., 23, p. 201, 1885.

Limncea elodes Jordan, Nova Acta Ksl.-Leop.-Carol. Deutsch Akad. Natur., XLV, p. 368, 1883.-Hanna, Nautilus, XXIII, p. 96, 1909.

Limnophysa elodes Hartman and Michener, Conch. Cestrica, p. 64, fig. 123.

Lymnaus elongatus SAY, Journ. Phil. Acad., II, p. 167, 1821 (not of Draparnaud, 1805) ; Long's Narrative, p. 264, 1824; reprint, p. 130; Binney's ed., pp. $65,130,1858$.

'In the synonymy only the references to Say's original elodes (besides one or two others) are included, as most authors have used the name to cover the majority of the palustris-like forms of America. Under palustris all of the remaining references to elodes are given. 
Lymnea elongata Gould, Lamarck's Genera, p. 69, 1833.-JAY, Cat., p. 269, 1852.-REEVE, Elements of Conch., p. 178, 1860.

Lymnaus elodes SAY, Chenu, Bib. Conch., p. 44, pl. 8, figs. 3, 3a, 1845.

Lymnophysa elongata BECK, Index Moll., p. 111, 1837.

Limneus elongatus Binney, L. \& F. W. Sh. N. A., II, p. 40, fig. 49, 1865.

Limneus umbrosus ${ }^{1}$ SAY, Amer. Conch., IV, p. 187, pl. 31, fig. 1, 1832.BinNeY's Ed., p. 187, 1858.

Limnaus umbrosus Forbes \& Hanley, Hist. Brit. Moll., IV, p. 182, 1853.Küster, Conch. Cab., I, p. 41, taf. 7, figs. 13-16, 1862 (figures not typical).

Lymnaus umbrosus Cooper, Schoolcraft Exped., p. 153, 1834.-SAY, Chenu, Bib. Conch., p. 43, pl. 7, figs. 5, 5a, 1845.

Lymneus umbrosus Kirtland, Zool. Ohio, p. 174, 1838.

Limnaa umbrosa Adams, Amer. Journ. Sci., XI, p. 268, 1841 (?).-Gould, Wilkes U. S. Exp. Exped., p. 122, 1852.-CPR., Rep. Brit. Asso., pp. 210, 316, 1857.-Higgins, Cat. Moll. Col. Ohio, p. 6, 1858.-Bell, Can. Nat. \& Geol., IV, p. 213, 1859; Geol. Surv. Can., Rep. Prog., p. 252, 1859.-Lapham, Proc. Phil. Acad., 1860, p. 155.-Bell, Can. Nat. \& Geol., VI, pp. 43, 50, 1861.-Whiteaves, Can. Nat. \& Geol., VIII, p. 102, 1863.-Commis. Geol. Can., pp. 967, 985, 1864.Cpr., Rep. Brit. Assoc., p. 599, 1864.-Tryon, Amer. Journ. Conch., III, p. 196, 1867.-Sowb., Conch. Icon., XVIII, Lim., Sp. 6, pl. 1, fig. 6, 1872.-Cpr., Smith. Mis. Coll., p. 85, 1872.-Calkins, Cin. Quart. Journ. Sci., I, pp. 243, 323, 1874.Heron, Ottawa Nat., I, p. 39, 1880.-Jordan, Nova Acta Ksl.-Leop.-Carol. Deutsch Akad. Natur., XLV, p. 368, 1883.-Beauchamp, Land \& F. W. Sh. N. Y., p. 3, 1886.-Ckll., Journ. Conch., VI, p. 257, 1890.-Stearns, Proc. Nat. Mus., XXIV, p. 291, 1901.

Limnea umbrosa Hubbard, Cat.-Haldeman, Mon. Lim., p. 24, pl. 7, figs. 1, 2, 3, 6, 7, 8, 1842.-DeKay, Moll. N. Y., p. 68, pl. 4, fig. 76, 1843.-Anthony, List. L. \& F.-W. Sh. Cin., 1843.-Lapham, Trans. Wis. State Ag. Soc., II, p. 368, 1852.-?Swallow, An. Rep. Geol. Surv. Mo., II, p. 215, 1855.-Miles, Geol. Surv. Mich., 1860, p. 237, 1861.-Намвасн, Bull. Geol. Surv. Mis., I, p. 60, 1890.-Henderson, Nautilus, XX, p. 98, 1907.

Lymnca umbrosa Wheatley, Cat. Sh. U. S., Ed. 2, p. 24, 1845.-JAY, Cat., p. 271, 1852.-Currier, Shells of Grand River, 1859.-REeve, Elements of Conch., p. 179, 1860.-Tryon, Amer. Journ. Conch., II, p. 112, 1866.-Wolf, Amer. Journ. Conch., VI, p. 28, 1870.-Scudder, Bull. Nat. Mus., 23, p. 201, 1885.

Lymnea umbrosa LeA, Hayden's Expl. Neb., p. 724, 1859.-RoberTs, Rep. U. S. Geol. Surv. Wyoming, 1871, p. 468.-Dawson, Can. Nat. \& Geol., n. s., VI, p. $387,1872$.

Limnophysa umbrosa Tryon, Amer. Journ. Conch., I, p. 250, 1865.-CuRRier, Amer. Journ. Conch., I, p. 294, 1865.-Perkins, Proc. Bos. Soc. N. H., XIII, p. 132, 1869.-DeCamp, Kent. Sci. Inst., Mis. Pub., No. 5, p. 8, 1881.

Limnaa elodes var. umbrosa Christy, Journ. Conch., p. 347, 1885.

Limnaa reflexa Letson, Bull. Buf. Soc. Nat. Sci., IX, p. 242, 1909.

Limnca reflexa var. DeKay, Moll. N. Y., p. 71, pl. IV, fig. 65, 1843.

Limnaa reflexa umbrosa Letson, Bull. N. Y. State Mus., LXXXVIII, p. 53, 1905.

${ }^{1}$ Some of the references to umbrosa may have been founded on short sfrecimens of reflexa, but as there is no way of authenticating the majority of the records all references to umbrosa are listed here. The California references are based on rowellil Tryon. 
Limnea palustris michiganensis WALKER, Nautilus, VI, p. 33, pl. 1, figs. 9, 10, 1892; Rev. Moll. Mich., pp. 7, 18, 1894.-Baker, Trans. Acad. Sci. St. Louis, XL, p. 17, 1901 (part) ; Moll. Chi. Area, II, p. 276, pl. 31, fig. 25, 1902 (part).-Daniels, Rep. Dept. Geol. Nat. Res. Ind., p. 636, 1902.-Blatch. \& Daniels, Rep. Dept. Geol. Nat. Res. Ind., XXVII, p. 596, pl. 1, fig. 12, 1902.

Limnophysa palustris michiganensis BAKER, Journ. Cin. Soc. N. H., XIX, p. 84,1897 .

Limnaa palustris var. michiganensis CHadwick, Bull. Wis. Nat. Hist. Soc., IV, p. 81, 1906; Nautilus, XX, p. 22, 1906.

Lymnca palustris michiganensis BAKER, Bull. Ill. State Lab. N. H., VII, p. $105,1906$.

SHELl: Elongated, narrow, attenuated, rather thin ; periostracum light yellowish horn, frequently jet black; occasionally longitudinally striped; surface dull to shining; sculpture as in palustris; whorls 6 to 7 , rather evenly increasing in size, typically flatly rounded, especially the body whorl; spire long and very much attenuated; sutures usually less impressed than in palustris; aperture elongate-ovate, generally much shorter than the spire; peristome with heavy varical thickening; inner lip narrow, reflected and appressed to the columellar region, forming a distinct plait and usually completely closing the umbilicus; parietal callus rather wide, heavy.

\begin{tabular}{|c|c|c|c|c|c|c|}
\hline Length. & Breadth. & Aperture length. & Brea & dth. & \multirow{3}{*}{\multicolumn{2}{|c|}{$\begin{array}{c}\text { Type umbrosa } \\
\text { “ elodes }\end{array}$}} \\
\hline 30.00 & 12.00 & 13.00 & 5.00 & mill. & & \\
\hline 32.00 & 12.00 & 14.00 & 6.50 & “ & & \\
\hline 31.00 & 10.50 & 12.00 & 6.00 & “ & White Co., & Ind. \\
\hline 30.00 & 11.00 & 12.00 & 6.00 & “ & “ & “ \\
\hline 30.00 & 10.50 & 11.50 & 5.50 & “ & “ & “ \\
\hline 30.00 & 11.00 & 12.50 & 6.25 & “ & “ & “ \\
\hline 26.00 & 9.50 & 11.50 & 5.50 & “ & “ & “ \\
\hline 21.00 & 8.50 & 11.00 & 4.50 & “ & “ & “ \\
\hline 28.25 & 9.00 & 11.90 & 5.50 & “ & Lockport, & I11. \\
\hline 28.00 & 9.00 & 11.00 & 5.00 & “ & “ & $“$ \\
\hline 37.00 & 14.00 & 16.00 & 8.00 & “ & Lake Menc & dota, \\
\hline
\end{tabular}

Types: Academy of Natural Sciences, Philadelphia; elodes, one specimen, No. 58638 ; umbrosa, two specimens, No. 58504 ; michiganensis, Walker, coll. Bryant Walker; cotypes, Acad. Nat. Sci. Phil., No. 58690.

Type Locality: Canandaigua Lake, New York, for elodes; waters of the Missouri, near Council Bluffs, Iowa, for umbrosa; Ecorse and Greenfield, Wayne County, Michigan, for michiganensis.

Animal: Not differing externally from palustris.

Jaw, Radula and Genitalia: Not differing essentially from palustris.

RANGE (Figure 35): Connecticut to South Dakota; Rainy Lake, Ontario, south to northern Kansas and southern Ohio. 
Elodes is a characteristic species of the humid portions of the Transition and Upper Austral life zones. The records from the Boreal (Canadian) life zone are few in number. This paucity of records is doubtless due to the mixing of elodes with palustris or reflexa. With the execption of a few records from the Nova Scotian region, elodes is confined to the Canadian and Upper Mississippian regions, and to the drainage areas of the St. Lawrence and Mississippi rivers.

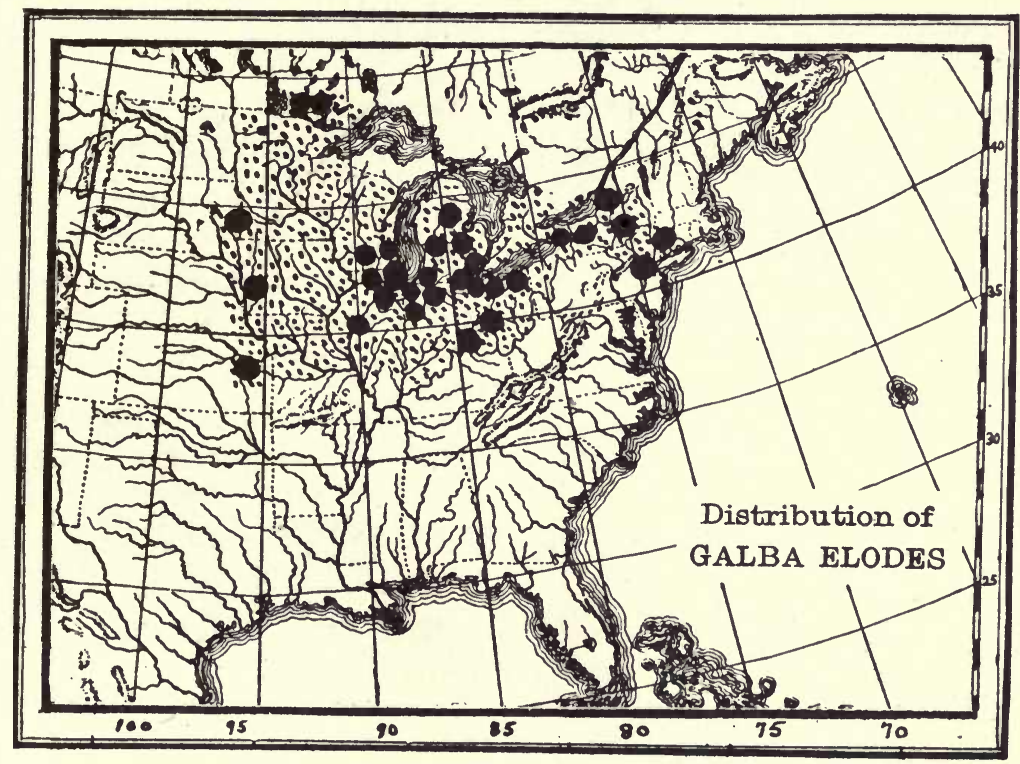

FIG. 35.

\section{RECORDS. ${ }^{1}$}

Connecticut: Weatogue, Hartford Co. (Shurtleff; Tryon).

Illınors: Lake Villa, Cedar Lake, Lake Co.; Bowmanville, Cook Co. (Baker); Joliet, Will Co. (Ferriss); sloughs in Winnebago Co. (Hinkley); Wolf Lake, near Chicago; North Branch Chicago River, Chicago (Jensen); Mason Co. (Nason); Quiver Creek, Mason Co. (State Laboratory); Bristol, Kendall Co. (Walcott) ; Havana, Mason Co. (Walker) ; Northwest end Calumet Lake, in ditches, Cook Co.; creek near Bangs Lake, Wauconda, Lake Co. (Woodruff).

Indiana: Millers, Lake Co.; Roby, Lake Co. (Baker); Tippecanoe Lake, Kosciusco Co.; Brookston and Carr's Slough, White Co.; La Porte, La Porte Co. (Daniels); Pine Station, Lake Co. (Higley).

Kansas: Lawrence, Douglass Co. (Hanna).

${ }^{1}$ Only those records have been admitted which are known to have been founded on undoubted elodes. Nearly all of these have been personally verifled. 
IowA: Missouri River, in the vicinity of Council Bluffs, Pattawattamie Co. (Say).

Michigan: Grand Rapids, Kent Co. (Currier; McNeil); Stoney Creek, Monroe Co. (Sister Mary Katherine) ; East Saginaw, Saginaw Co. (Lathrop); Ecorse and Greenfield, Wayne Co.; Higgins River, Roscommon Co. (Walker); Galien River, New Buffalo, Berrien Co. (Webster).

Minnesota: Ponds, southern Minnesata (Shimek).

New Jersey: White Pond, Sussex Co. (Pilsbry and Rhoads).

New York: South Ogden Street pond, Buffalo, Erie Co. (Letson) ; Chippewa Creek, Erie Co. (Letson; Miss Walker) ; Sacketts Harbor, Jefferson Co., Lake Ontario (Phil. Acad); Canandaigua Lake, Ontario Co. (Say) ; Litchfield, Herkimer Co. (Walker).

Оніо: Shore of Johnson's Island, near Sandusky, Erie Co.; pool at Linndale, near Cleveland, Cuyahoga Co. (J. A. Allen); Cincinnati, Hamilton Co. (Anthony; Shaffer) ; Toledo, Lucas Co. (F. A. Bossard) ; Columbus, Franklin Co. (H. Moores); Miami Canal, Lockland, Hamilton Co. (Walker).

South Dakota: Brookings Co. (P. C. Truman).

Wisconsin: In pool, Johnson's woods, near National Soldiers' Home, Milwaukee, Milwaukee Co. (C. E. Brown); Lake Mendota, Dane Co. (C. Judey); Madison, Dane Co.; Kenosha, Kenosha Co. (Mrs. Wiswall).

BRITISH AMERICA.

Ontario: Rainy Lake and Seine River, Rainy River Dist. (Say).

Geological Range: Not differentiated by authors from that of palustris.

ECOLOGY: Inhabits ponds and sloughs which become more or less àry in summer.

REMARKS: Elodes differs from palustris in having more loosely coiled whorls and in being narrower and more attenuated, with more fiat-sided whorls. The spire is very narrow and considerably longer than the aperture. In narrow specimens of both species, elodes is seen to have a longer and more compressed body whorl and a narrower and longer aperture. In the majority of cases elodes is easily separable from palustris, the whorls of elodes being comparably longer than in palustris, though not as long as in reflexa.

This is the form which is frequently confounded with reflexa and which has caused the statement to be so frequently made by writers that "palustris runs into reflexa." In reflexa the body-whorl and the penultimate whorl are normally very long in comparison with their height; they are usually (in the typical form) flatly rounded and oblique; the first to the fourth whorls are very small and regularly increase, while the fifth to seventh whorls increase disproportionately in size; in clodes all of the whorls have usually a regular increase. The upper whorls of reflexa also have a puffy appearance, while those of clodes are more evenly rounded. The aperture in reflexa is very different, being strongly reflexed and "bayed" just below the columellar 
callus. Attention to these points will usually separate the two forms. Immature specimens of both species are sometimes difficult to distinguish, but there is little difficulty in the case of fully adult shells. In some individuals of elodes the spire is shortened, the specimens of this kind resembling small, narrow forms of palustris.

The figure of elodes in Binney is very poor, scarcely representing this form correctly, judging by the type, being too wide across the body whorl. Say may have included the wider, long-spired palustrislike forms in his elodes, but there is no question concerning the identity of the typical elodes. Say's figure in the American Conchology (plate $\mathrm{XXX}$, figure 34 , of this volume) does not exactly fit the type specimen in the Philadelphia Academy, which is narrower and like the figures on plate XXXIV, and similar to Haldeman's figure 2 on plate \%. DeKay's figure 76 on plate 4 correctly represents certain forms of elodes. Say's umbrosa is undoubtedly a synonym of elodes (see Say's figures on plate XXX, figures 32, 33), the two type specimens in the Philadelphia Academy being almost indistinguishable from the type of elodes. It has generally been placed in refle $x a$, but it lacks the characteristic twist, besides the peculiarities of the spire whorls mentioned above. A comparison of Say's original figures on plate XXX with the figures on plate XXXIV will show this relation clearly. Haldeman plainly indicates the differences between reflexa and umbrosa, but places elodes in the synonymy of palustris, in which he has been followed by Binney and later writers. Michiganensis appears to be the immature state of elodes, which has seven full whorls, while michiganensis has but five. It agrees in all particulars with juvenile specimens collected with mature elodes. (See plate XXXIV, figures $17,18,19)$. It was at one time thought that michiganensis was the young of reflexa, but the receipt of adult specimens from the type locality shows conclusively that it is immature elodes.

Elodes exhibits less variation, on the average, than does palustris. The internal varix of the outer lip is usually very heavy and the surface of the shell is frequently heavily malleated, a condition due to its characteristic habitat in ponds and streams which dry up in the summer.

Galba elodes jolietensis (Baker). Plate XXXIV, figures 25-30; plate XXXV, figures 1-2.

Limnca reflexa jolietensis BAKER, Nautilus, XV, p. 17, 1901; Moll. Chi. Area, II, p. 280, pl. 32, fig. 4, 1902.

Lymnaa reflexa jolietensis BAKER, Bull. Ill. State Lab. N. H., VII, p. 106, 1906.

Limnaa reflexa attenuata BAKer, Trans. Acad. Sci. St. Louis, XI, p. 20, pl. 1, fig. 4, 1901 (non Say). 
Shell: Attenuated, more or less scalar, periostracum light yellowish horn; sculpture as in palustris; whorls 6 to $\%$, loosely coiled, generally quite convex; spire long, attenuated, pointed, somewhat scalar; sutures typically very deeply impressed; aperture elongateovate or lunate, about one-third the length of the shell; peristome thin, bordered by a heavy varix which is edged with dark red or chestnut; inner lip thin, narrow, reflected over and nearly closing the umbilicus, leaving a very small chink; columella with a distinct, ascending plait; axis strongly twisted. The surface is sometimes malleated.

$\begin{array}{ccccccc}\text { Length. } & \text { Width. } & \text { Aperture length. } & \text { Width. } & & \\ 24.00 & 8.00 & 9.50 & 5.25 & \text { mill. } & \text { Joliet, } & \text { Ill. Type } \\ 23.00 & 7.75 & 9.00 & 5.00 & \text { “ } & \text { “ } & \text { “ } \\ 22.00 & 7.00 & 8.75 & 4.75 \text { “ } & \text { “ } & \text { “ } & \text { “ }\end{array}$

Types: Chicago Academy of Sciences, four specimens, No. 23606 ; cotypes, Academy of Natural Sciences, Philadelphia, No. $8155 \%$.

Type Locality: Rock Run, Joliet, Illinois.

Animal: Not differing from typical palustris.

JAw: As in palustris.

Radula (P1. VIII, fig. G) : Formula $\frac{22}{4-6}+\frac{2}{3}+\frac{8}{2}+\frac{1}{1}+\frac{8}{2}+\frac{2}{3}+\frac{22}{4-6}$ (32-1-32); the teeth do not differ materially from those of palustris; the transition teeth begin at the ninth tooth and the marginal teeth begin at the eleventh tooth. There are over eighty rows of teeth. The intermediate teeth sometimes begin at the tenth tooth.

GENitAlia: In all respects like those of typical palustris. The retractors of the male organ vary slightly in size, but otherwise the organs are very uniform. (P1. XV, fig. G.)

Several dissections gave the following result (dissection No. 23597 and No. 2361\%), which is markedly uniform:

\begin{tabular}{|c|c|c|c|c|c|c|c|}
\hline $\begin{array}{l}\text { Penis. } \\
2.50\end{array}$ & $\begin{array}{c}\text { Penis-sac. } \\
2.10\end{array}$ & $\begin{array}{c}\text { Ret. } \\
\text { penis. } \\
2.00\end{array}$ & $\begin{array}{c}\text { Ret. } \\
\text { penis-sac. } \\
1.00\end{array}$ & $\begin{array}{c}\text { Rec. sem. } \\
4.00\end{array}$ & $\begin{array}{r}\text { Prost. } \\
\text { duct. } \\
5.00\end{array}$ & $\begin{array}{c}\text { Vas. def. } \\
13.25\end{array}$ & $\begin{array}{l}\text { Shell. } \\
19.00\end{array}$ \\
\hline 2.60 & 2.10 & 1.25 & 1.25 & 4.00 & 5.00 & 13.00 & 19.00 \\
\hline 2.60 & 2.10 & 1.50 & 1.50 & 4.00 & 5.00 & 14.50 & 19.00 \\
\hline
\end{tabular}

Range (Figure 36): Southern Wisconsin to eastern New York; central Michigan south to northern Illinois and northern Ohio.

Jolietensis occupies an area along the borders of the humid divisions of the Transition and Upper Austral life zones. It appears to be typical of the drainage of the Great Lakes, being confined to the area bordering the Canadian and Upper Mississippian regions.

RECORDS.

UNITED STATES.

Illinors: Rock Run, Joliet, Will Co. (Ferriss); Berry Lake, Cook Co. (Higley); south of Wolf Lake, Cook Co. (Jensen); Elgin, Kane Co.; Crystal Lake, McHenry Co. (Nason). 
Michigan: Saginaw River, Saginaw Co. (Walker).

NEW YoRK: Mohawk, Herkimer Co. (Nason).

Оніо: Poland, Mahoning Co.; La Grange, Lorain Co. (Walker) ; Akron, Summit Co. (Walker).

Wisconsin: Milwaukee, Milwaukee Co. (Lea).

Geological Range: Unknown.

ECOLOGY: In small creeks, ditches and along the shores of rivers; habits similar to those of elodes.

Remarks: Galba elodes jolietensis may be known by its sharp, attenuated spire, very convex whorls and elongated aperture. It varies

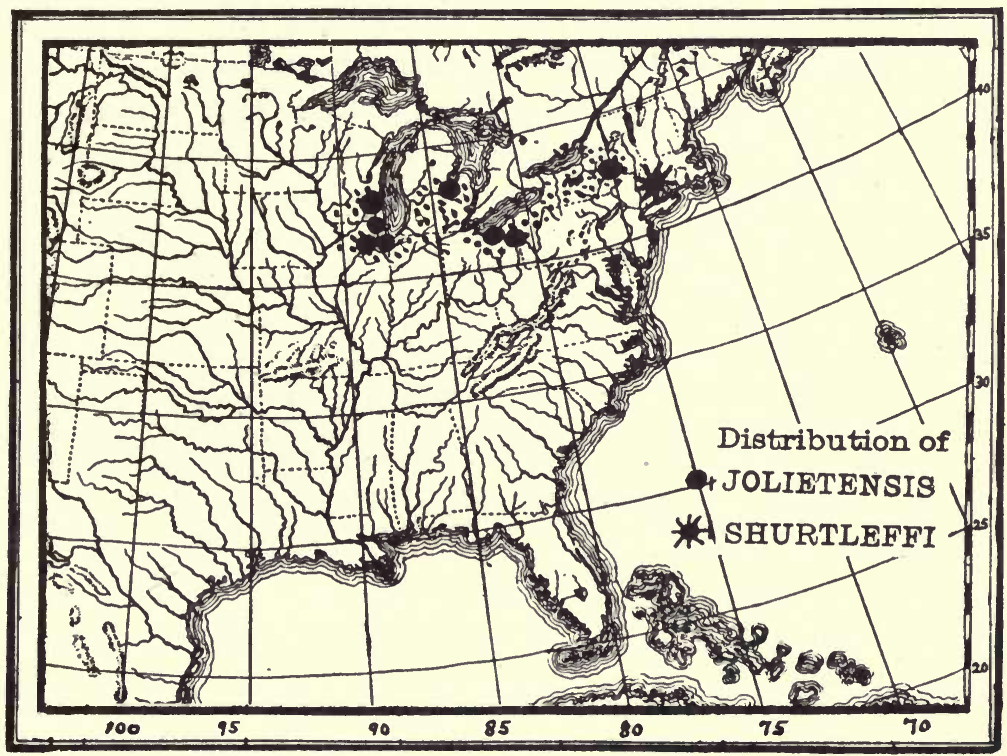

FIG. 36.

somewhat, some specimens having flatter whorls than the types, with shallow sutures. From Lea's description, and from some specimens named by him, it was at first thought to be a form of kirtlandiana, but an examination of Lea's type in the Smithsonian Institution shows that it is not that species.

This race was first described as a variety of reflexa, but an examination of additional material shows it to be related rather to elodes. Some of the Joliet specimens are much wider than the type, with less conspicuous sutures, clearly showing the relationship of the race to elodes. (See plate XXXIV, figures 29-30.) Jolietensis is a neat little 
race which seems reasonably distinct from clodes and which is an abundant mollusk in certain localities.

Galba elodes shurtleffi (Tryon). Plate XXXIV, figure 13.

Limnca (Limnophysa) shurtleffi Tryon, Amer. Journ. Conch., II, p. 111, p1. 10 , figs. $4,5,1866$.

Limnea shurtleffi TRYoN, Con. Hald. Mon., p. 98 (72), pl. 17, figs. 7, 8, 1872.

Lymnaa shurtleffi BAKER, Amer. Nat., XL, p. 331, et sq., fig. 4, 1906.

Shell: Ovate, cylindrical, robust; periostracum yellowish horn, surface shining, growth lines heavy, coarse, close-set, crossed by fine impressed spiral lines; whorls 5 to 6 , flatly convex, the last subcylindrical and considerably compressed or flattened on the sides; spire depressed, though more elevated in some specimens, acutely conical; nuclear whorls brown, smooth, in outline like those of palustris; sutures impressed, bordered by a rather heavy white callus; aperture elongateovate, contracted, somewhat ear-shaped; outer lip thickened within and bordered by a purplish band; columella with a heavy callus, which is reflected so as to nearly cover the umbilicus, leaving a small chink; axis slightly twisted.

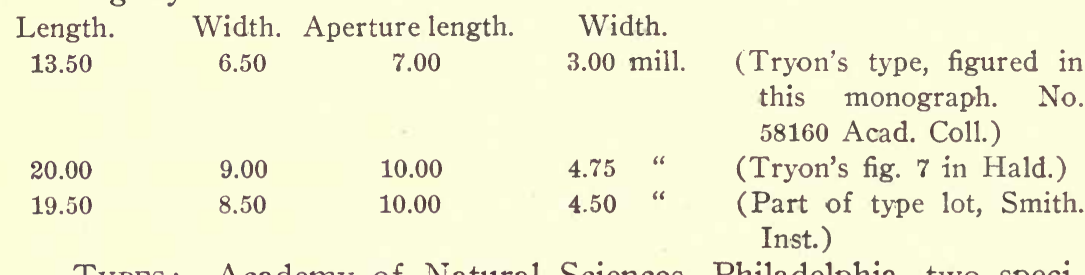

Types: Academy of Natural Sciences, Philadelphia, two specimens, No. 58160.

Type Locality: Weatogue, Conn.

Animal, Jaw, Radula and Genitalia: Unknown.

RAnge (Figure 36): Connecticut.

RECORDS.

Weatogue, Hartford Co., Conn. (Shurtleff; Lea; Tryon).

Geological Range: Unknown.

ECOlOGY: In artificial pond.

REMARKs: Shurtleffi is a form of elodes in which the upper spire whorls are shortened and the body and aperture are compressed. The specimens in Philadelphia and Washington are wonderfully uniform. This Lymnæa was found under rather peculiar circumstances, seeming to be a case of mutation, as outlined by de Vries, and the account given by Tryon and Shurtleff is not without interest, and is certainly very 
suggestive. Mr. Tryon writes as follows:" "The circumstances under which this and the following species were found are so peculiar that it is with great hesitation that I have ventured on a description of either of them. That new species of these shells should exist undetected in sections of the United States which have been so well explored by assiduous naturalists would be surprising; but in the present instance the almost irresistible supposition is that these species are of very recent origin (italics the writer's) - in fact, contemporaneous with that of the body of water which they inhabit. I have looked in vain for some evidence upon the specimens themselves of the effect of some strong local influence. The species are so distinct that they afford no clew to a possible derivation from others.

"In conclusion, I present the following interesting particulars:

"Extract from a letter from the late Dr. S. Shurtleff to Isaac Lea, Esq., Weatogue, Hartford County, Connecticut, November 22, 1865.

"In the summer of 1860 I made an excavation some two rods below a spring that flows about eight months in the year. The spring comes from a neighboring hill. The overlying rock is New Red Sandstone. From the time of the excavation till the summer of 1864 there was water in the artificial pond. It was dry in 1864, but I did not examine for shells, as before the excavation I had repeatedly examined the spring, but never found shells of any description.

"After my return from Pennsylvania, in September, 1865, accidentally crossing the pond, which was dry, I noticed quantities of shells clustered in the hollows. I gathered a few and laid them by for leisure examination; when I came to look at them again I found L. umbrosa, as I supposed, as well as a nondescript species. I immediately went to the pond and secured all the Lymnæans I could findsome alive and many dead; and, fearing the dry season would destroy them all, I put many of the living shells into a pond that I have since made, that will never dry up. I may have collected 50 specimens of L. umbrosa (?) and of other specimens a half-pint.

"How these shells came into the pond is as much a matter of surprise to me as it is to you. I have no knowledge that there was ever a shell put into the pond.

"One fact more. The spring and pond are perfectly isolated, as the overflow disappears at the edge of a sandy plain in less than ten rods from its fountain head, and there is no stream of perpetual running water within one mile of it. The Farmington River is about a

${ }^{1}$ Amer. Journ. Conch. II, p. 112, 1866. 
mile distant in the valley below, and here the only species yet found are Lymnea columella Say, Physa heterostropha Say, Planorbis bicarinatus Say, Vivipara decisa Say, Unio complanatus Solander, and Unio radiatus Lamarck.

"The pond is two hundred feet above the bed of Farmington River."

Tryon says: "Besides the above two species I found a single specimen of Lymncea umbrosa Say, and several of L. desidiosa Say."

From the foregoing account it would appear that shurtleffi was a mutant of elodes, that being the only other species present (save $d e$ sidiosa, which belongs to quite another group of Lymnæas). The short, acute spire, subcylindrical, compressed body whorl, the partly open umbilicus, and the long and narrow aperture are the principal characteristics of the race, which has not been seen from any other part of America.

Galba reflexa ${ }^{1}$ (Say). Plate XXX, figures 30,31 ; plate XXXV, figures 3, 5-22 ; plate XXXVI., figures 1-11; plate XVIII, figure 10.

Lymneus reflexus SaY, Journ. Phil. Acad., II, p. 167, 1821.-Cooper, Sh. Schoolcraft Exped., p. 154, 1834.-Kirtland, Zool. Ohio, p. 174, 1838.-SaY, Binney Ed., p. 65, 1858.

Limneus reflexus SAY, Amer. Conch., IV, pl. 31, fig. 2, 1832.-Binney, Reprint, p. 188, pl. 31, fig. 2, 1858.

Limnaus reflexus SAY, Chenu, Bib. Conch., III, p. 44, pl. 7, fig. 4, 4a, 1845.Küster, Conch. Cab., p. 41, taf. 7, figs. 10-12, 1862.

Limnaus reflexa Forbes \& Hanley, Hist. Brit. Moll., IV, p. 182, 1853.

Limnaa reflexa Kennicotr, Trans. Ill. State Ag. Soc., I, p. 595, 1855.Ulffrers, Trans. I11. State Ag. Soc., I, p. 612, 1855.-D’Urban, Geol. Surv. Can., Rep. Prog., p. 242, 1859._Bell, Geol. Surv. Can., Rep. Prog., p. 252, 1859.Binney, Check List, p. 12, 1860.-Whiteaves, Can. Nat. \& Geol., VIII, p. 102, 1863.-Carpenter, Rep. Brit. Assoc., p. 673, 1864 (part).-Binney, L. \& F. W. Sh. N. A., II, p. 38, fig. 48, 1865.-TRYoN, Amer. Journ. Conch., III, p. 196, 1867.-Aldrich, N. Y. State Cab. N. H., XXII, p. 19, 23, 1868.-CurRier, Kent. Sci. Inst., Mis. Pub., No. 1, 1868.-Tryon, Con. Hald. Mon., p. 94 (68), 1872.Byrnes, L. \& F. W. Sh. Cin., p. 2, 1872.-Sowв., Conch. Icon., XVIII, Lim., sp. 32, pl. 15, 1872 (not fig.).-Carpenter, Smith. Mis. Coll., p. 159, 1872.-Calkins, Proc. Ottawa Acad. Sci., 1874, p. 26; Cin. Quart. Journ. Sci., I, p. 243, 1874; Cin. Quart. Journ. Sci., I, p. 323, 1874.-Y ARRow, U. S. Geol. Surv., W. 100th Merid., V, p. 942, 1875.-Aughey, An. Rep. U. S. Geol. \& Geog. Surv. Col., p. 268, 1876.-PRAtT, Proc. Daven. Acad. Sci., I, p. 166, 1876.-WitTer, Quart. Journ. Conch., I, p. 386, 1878.-WALKer, Journ. Conch., II, p. 330, 1879.-Stein, Ind. Dept. Stat. \& Geol., 1880, p. 458.-HAZAY, Mal. Blatt., ii, III, p. 17, 160, 1881.-

${ }_{1}^{1}$ Many of the following references to reflexa undoubtedly include also such species and varieties as elodes, exilis and kirtlandiana, as well as others of this group, but there is no way of verifying the majority of them. 
Call, Amer. Nat., XV, p. 586, 1881.-Jordan, Nova Acta Ksl.-Leop.-Carol. Deutsch Akad. Natur., XLV, p. 368, 1883.-TRYoN, S. \& S. Conch., III, p. 101, pl. 103, fig. 7, 1884.-Marsh, Conch. Exch., II, p. 103, 1887.-Sнiмek, Bull. Lab. Nat. Hist. Univ, Iowa, I, p. 68, 1888.-Walton, Proc. Roch. Acad. Sci., II, p. 12, pl. 6, fig. 6, 1891.-Pilsbry, Proc. Phil. Acad., 1891, p. 320.-Dean, Amer. Nat., XXVI, p. 18, 1892.-WALKer, Nautilus, VI, p. 32, pl. I, fig. 8, 1892.Marshall, Rep. N. Y. State Mus., XlVII, p. 64, 1893.-Walker, Rev. Moll. Mich., pp. 7, 17, 1894; Nautilus, VII, p. 128, 1894-Marshall, Rep. N. Y., Col. Exp., p. 510, 1894.-TAYlor, Ottawa Nat., VIII, p. 148, 1895.-Marshall, Rep. N. Y. State Mus., XLVIII, p. 643, 1895.-TAylor, Ottawa Nat., IX, p. 175, 1895.-HARPER, Journ. Cin. Soc. N. H., XVIII, p. 95, 1895.-SNyder, The Museum, III, p. 12, 1896.-SARGENT, Nautilus, IX, p. 127, 1896.-Wiswall, Nat. Sci. Journ., I, p. 47, 1897.-Shimek, Proc. Iowa Acad. Sci., V, pp. 35, 44, 1898.-BAKER, The Museum, III, p. 155, 1897; Nautilus, XII, p. 65, 1898; Trans. Acad. Sci. St. Louis, VIII, p. 88, 1898.-Huetr, Nat. Hist. La Salle Co., Ill., p. 104, 1898.-Walton, The Museum, IV, p. 133, 1898.-Baker, Moll. Chi. Area, pp. 23, 24, 1898.-Leverett, Mon. U. S. Geol. Surv., XXXVIII, p. 174, 1899.-BAker, Journ. Cin. Soc. N. H., XIX, p. 176, 1900.-WAlKer \& LANe, Geol. Surv. Mich., VII, pt. 2, p. 251, 1900.-BAKer, Trans. Acad. Sci. St. Louis, XI, p. 17, pl. 1, fig. 6, 1901.-Shiмeк, Amer. Geol., XXVIII, p. 354, 1901; Bull. Lab. N. H. Univ. Iowa, V, p. 207, 1901.-BAKer, Moll. Chic. Area, II, p. 277, pl. 32, fig. 6, pl. 31, fig. I, 1902.-Daniels, Rep. Dept. Geol. \& Nat. Res. Ind., XXVII, p. 636, 1903.-BAKER, Shells of Land \& Water, p. 45, fig., 1903.Walker, Geol. Surv. Mich., VIII, pt. 3, p. 101, 1903.-Letson, Bull. N. Y. State Mus., LXXXVIII, p. 53, 1905.-CHADwick, Nautilus, XX, p. 22, 1906; Bull. Wis. Nat. Hist. Soc., n. s., IV, p. 81, 1906.

Limnca reflexis Higgins, Cat. Moll. Col. Ohio, p. 6, 1858.

Limnea reflexa Hubbard, Cat.-HAld., Mon. Lim., p. 26, pl. 8, 1842.DeKay, Moll. N. Y., p. 71, pl. 4, figs. 65, 72, a, b, 1843.-Anтнony, L. \& F.-W. Sh. Cin., 1843.-Kennicott, Trans. Ill. State Ag. Soc., I, p. 595, 1855.-Swallow, 2nd An. Rep. Geol. Surv. Mis., p. 215, 1855.-Miles, Rep. Geol. Surv. Mich., 1860, p. 237, 1861.-Намвасн, Bull. Geol. Surv. Mis., I, p. 60, 1890.-Kennedy, An. Rep. Geol. Surv. Texas, IV, p. 66, 1893.-Henderson, Nautilus, XX, p. 98, 1907.

Lymnea reflexa DeKay, Cat. An. N. Y., p. 32, 1839.-CurRIER, Sh. Grand River, 1859.-Morse, Amer. Nat., III, p. 651, pl. 11, fig. 3, 1870.-RoberTs, U. S. Geol. Surv., Wyoming, p. 468, 1871.-Hanna, Nautilus, XXIII, p. 96, 1909.

Limnophysa reflexa BECK, Index, p. 110, 1837.-TRYON, Amer. Journ. Conch., I, p. 68, 1865; Amer. Journ. Conch., I, p. 249, 1865.-Currier, Amer. Journ. Conch., I, p. 294, 1865.-Lewis, Bull. Buf. Soc. N. Sci., II, p. 135, 1874.Hartman and Michener, Conch. Cestrica, p. 65, fig. 124, 1874.-DeCAMP, Kent. Sci. Inst., Mis. Pub., No. 5, p. 8, 1881.-Call, Bull. Wash. Coll. Lab. N. H., I, p. 53, 1885 ; 1. c., I, pp. 124, 184, 1885.-Grant, Rep. Nat. Hist. Surv. Minn., XIV, p. 122, 1886.-Call, Bull. Wash. Coll. Lab. N. H., II, p. 17, 1887.Keyes, Bull. Essex Inst., XX, p. 70, 1889.-Call, Proc. Ind. Acad. Sci., 1893, p. 150,$1894 ; 1895$, p. 138,$1896 ; 1896$, p. 250,1897 ; 1896, p. 253, 1897.-BAKER, Journ. Cin. Soc. N. H., XIX, p. 84, 1897.-CALL, Rep. Dept. Geol. \& Nat. Res. Ind., XXIV, 1899, p. 406, pl. 8, fig. 8, 1900.-BAKER, Journ. Cin. Soc. N. H., XIX, p. 176, 1900. 
Lymnaa reflexa Gould, Lamarck's Genera, p. 69, 1833.-Amer. Journ. Sci., XXXI, p. 36, 1837.-Wheatley, Cat. Sh. U. S., p. 23, 1845.-JAy, Cat., p. 270, 1852.-ReEve, Elements of Conch., p. 179, 1860.-Wolf, Amer. Journ. Conch., VI, p. 28, 1870.-Scudder, Bull. Nat. Mus., 23, p. 201, 1885.-BAKer, Amer. Nat., XXXIX, p. 671, 1905.-DALL, Alaska Moll., p. 77, fig. 58, 1905.Baker, Bull. Ill. State Lab. N. H., VII, p. 105, 1906.-Walker, Nautilus, XX, p. 82, 1906.-Sterki, Proc. Ohio State Acad. Sci., IV, p. 382, 1907.-Baker, Bull. Ill. State Lab. N. H., VIII, p. 493, pl. 25, fig. 1, 1910.-H. BAKER, An. Rep. Mich. Acad. Sci., XII, p. 60, 1910.

Limnaa reflexa iowaensis BAKER, Nautilus, XVIII, p. 10, 1904; Bull. I1l. State Lab. N. H., VII, p. 106, 1906.

Limneus palustris var. distortus Rossmassler, Icon., I, p. 97, pl. 2, fig. 52, 1835.-Binney, L. \& F. W. Sh. N. A., II, p. 41, fig. 52, 1865.

Limnea distorta Jordan, Nova Acta Ksl.-Leop.-Carol. Deutsch Akad. Natur., XLV, p. 368, 1883.-CKLl., Journ. Conch., VI, p. 257, 1890.

Limnophysa palustris CALL, Indiana Mollusca, pl. 8, fig. 5, 1900.

Limnca reflexa crystalensis BAKER, Nautilus, XVIII, p. 11, 1904; Bull. I11. State Lab. N. H., VII, p. 106, 1906 ; VIII, p. 493, pl. 25, figs. 2, 3, 1910.

Lymnea reflexa crystalensis Hanna, Nautilus, XXIII, p. 96, 1909.

Lymnaa palustris michiganensis BAKER, Bull. Ill. State Lab. N. H., VIII, p. 493, pl. 25, figs. 4-8, 1910.

SHELl: Very much elongated, narrow, thin, sometimes scalar; color honey-yellow to black, sometimes obscurely longitudinally banded; surface shining, covered with numerous closely crowded growth lines, with fine impressed spiral lines which reticulate the surface; the growth lines are also wavy and elevated, in some specimens forming ridges of considerable size; nuclear whorls smooth, brownish or blackish, in form like those of palustris (pl. XLIX, fig. $\mathrm{K}$ ) ; whorls seven, flatly rounded, last whorl much compressed; the sixth and seventh whorls are much longer in comparison with their width than are any of the preceding whorls; spire very long and pointed, occupying nearly twothirds of the entire length of the shell; sutures impressed; aperture lunate or elongate-ovate, narrowed at the upper part, very oblique and effuse in some specimens; peristome thin, sharp, thickened by a heavy callus or varix on the inside, the varix chocolate or purplish in color; lower part of peristome dilated; inner lip narrow, reflected over the umbilical region, leaving a very small chink or entirely closing the umbilicus ; columella oblique, with a heavy plait across its center, running up into the whorl; the callus on the parietal wall varies from a very thin wash to an erect, thick inner lip which causes the aperture to be continuous; axis twisted. 


\begin{tabular}{|c|c|c|c|c|c|}
\hline $\begin{array}{l}\text { Length. } \\
34.00\end{array}$ & $\begin{array}{c}\text { Breadth. } \\
11.00\end{array}$ & $\begin{array}{c}\text { Aperture length. } \\
\qquad 14.50\end{array}$ & $\begin{array}{l}\text { Brea } \\
5.50\end{array}$ & $\begin{array}{l}\text { lth. } \\
\text { mill. }\end{array}$ & Say's type reflexa \\
\hline 31.00 & 9.50 & 13.00 & 4.50 & " & " \\
\hline 28.50 & 12.00 & 13.50 & 7.50 & “ & Baker's Iowaensis \\
\hline 45.00 & 16.00 & 18.00 & 7.50 & “ & Hald. Fig. 3 \\
\hline 47.00 & 15.00 & 18.00 & 9.50 & “ & Calumet River, Chicago \\
\hline 39.50 & 13.50 & 15.00 & 8.00 & “ & “ $\quad$ “ $\quad “$ \\
\hline 36.50 & 11.50 & 15.00 & 8.00 & “ & “ \\
\hline 32.00 & 12.50 & 15.00 & 7.50 & “ & " 64 \\
\hline 33.00 & 11.50 & 13.00 & 7.00 & “ & Lake Albert Lea, Minn. \\
\hline 33.00 & 11.50 & 14.00 & 7.75 & “ & Winnebago Co., Ill. \\
\hline 39.00 & 12.50 & 16.00 & 8.00 & “ & " $\quad$ " \\
\hline 37.00 & 12.50 & 14.50 & 7.00 & “ & Romeo, Ill. \\
\hline 31.00 & 11.50 & 14.00 & 7.00 & “ & “ " \\
\hline 31.50 & 10.00 & 12.50 & 5.50 & “ & Lockport, Ill. \\
\hline 27.50 & 10.50 & 12.50 & 6.50 & “ & “ “ “ \\
\hline 19.50 & 8.00 & 9.00 & 4.00 & “ & Crystal Lake, Ill. \\
\hline 21.00 & 8.00 & 10.00 & 5.00 & “ & " \\
\hline 23.00 & 8.50 & 10.50 & 5.00 & “ & " $"$ " $"$ \\
\hline 26.50 & 10.50 & 12.50 & 5.50 & “ & $"$ \\
\hline 28.00 & 10.00 & 12.00 & 6.00 & “ & $“$ \\
\hline
\end{tabular}

Types: Reflexa, Academy of Natural Sciences, Philadelphia, two specimens, No. 58639; iowaensis, coll. Bryant Walker, five specimens, No. 2223 ; cotype, Chicago Academy of Sciences, one specimen, No. 23520 ; crystalensis, Chi. Acad. Sci., eight specimens, No. 23634.

Type Locality: Reflexa, Lake Superior; iowaensis, Muscatine, Iowa; crystalensis Crystal Lake, McHenry County, Ill.

Animal: Similar to palustris; the foot of a medium-sized specimen measured 12.50 mill. long and 6.50 mill. wide.

JAw : Similar to that of palustris.

Radula: (Plate IX, figure A) Formula: $\frac{23}{4-6}+\frac{4}{3}-\frac{4}{4}+\frac{2}{2}+\frac{11}{2}+\frac{1}{1}+$ $\frac{11}{2}+\frac{2}{2}+{ }_{3}^{4}-\frac{4}{4}+\frac{23}{4}-6$ (40-1-40); lateral teeth bicuspid, the mesocone long and rather wide, the ectocone small and wide; the first lateral tooth is wider than those which follow; intermediate teeth four in number, tricuspid, the entocone small, placed toward the lower margin of the mesocone; a small cusp appears on the outer margin of the ectocone; marginal teeth long, narrow, oblique, 4 to 6 cuspid at the distal end, causing this part of the tooth to resemble a comb. The cusps are very irregular in size. There are over 100 rows of teeth. In one membrane examined, the first lateral to the right of the center tooth had a bifid ectocone. In another specimen there were 15 laterals on the right side of the central tooth and 14 laterals on the left side; in all membranes examined the last two (generally 12 and 13) laterals have 
the lower inner part of the mesocone slightly excavated, apparently a first indication of splitting to form an entocone. The radula of reflexa is similar to that of palustris, the teeth being, perhaps, a trifle wider. The radula figured in Mollusca of the Chicago Area (p. 279) for reflexa is probably palustris (or elodes), as it corresponds with these species, but not with reflexa, which has a larger number of laterals than palustris.

Genitalia (Plate XII, figures A, E): Male organs: Penis-sac large, cylindrical, 6.00 mill. long and about 1.50 mill. wide; penis 3.50 mill long, of rather large diameter, muscular, with large rounded head; vas deferens 24 to 27 mill. long; protractor muscles five to seven in number, three to five slender ones on the posterior face of the penissac, and two large, wide muscles on the anterior face; the protractors on the anterior face are made up of about six distinct bands joined together and attached to the penis-sac and to the roof of the body cavity by many branches or insertions; penis retractor muscle long, rounded; penis-sac retractor long, wide, band-like; this muscle becomes very wide, thin and transparent as it enters the penis-sac; duct of prostate small, 8 to 10 mill. long; prostate large, elongated, wide, gradually narrowing toward the posterior end.

Female organs: Receptaculum seminis very large, elongate-quadrate in outline, somewhat constricted in the middle, the duct attached to the large end; duct of receptaculum seminis 8.00 mill. long. The first accessory albuminiparous gland is very large and is ovate in shape. The organs are similar to those of palustris, and are colored as follows: Penis-sac, blackish; prostate, yellowish ; receptaculum seminis, purplishflesh; the rest of the organs are white or flesh-colored.

The muscles of the male organ vary widely in form and position. In specimens from Calumet Lake (pl. XV, fig. D), the retractor muscles of the penis-sac (2) and penis (3) have each an additional band of muscle; the posterior protractor muscles vary from two to four in number; the anterior protractors are quite uniform, however. The measurements of the various organs gave the following comparative results (dissections Nos. 23600 to 23604, 23538, 23555):

\begin{tabular}{|c|c|c|c|c|c|c|c|c|c|}
\hline Penis. & $\begin{array}{l}\text { Penis- } \\
\text { sac. }\end{array}$ & $\begin{array}{l}\text { Penis } \\
\text { ret. }\end{array}$ & $\begin{array}{l}\text { Penis- } \\
\text { sac } \\
\text { ret. }\end{array}$ & $\begin{array}{l}\text { Vas. } \\
\text { def. }\end{array}$ & $\begin{array}{l}\text { Prost. } \\
\text { duct. }\end{array}$ & $\begin{array}{l}\text { Rec. } \\
\text { sem. }\end{array}$ & Shell. & \multirow{4}{*}{\multicolumn{2}{|c|}{ 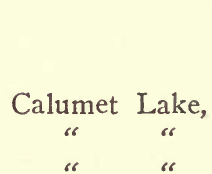 }} \\
\hline 3.00 & 5.80 & 4.50 & 3.25 & 24.00 & 10.00 & 8.50 & 32.00 & & \\
\hline 3.50 & 6.00 & 4.50 & 3.50 & 24.00 & 10.25 & 8.00 & 36.10 & & \\
\hline 3.50 & 6.00 & 4.50 & 3.50 & 27.00 & 10.00 & 8.00 & 37.25 & & \\
\hline 3.50 & 5.10 & 5.00 & 4.00 & 20.00 & 9.50 & 7.25 & 26.50 & Millers, & Ind. \\
\hline 3.50 & 5.00 & 3.50 & 4.75 & 20.00 & 8.00 & 6.00 & 26.00 & & \\
\hline 3.50 & 5.00 & 3.50 & 4.00 & 18.00 & 8.00 & 6.00 & 24.00 & “ & “ \\
\hline
\end{tabular}


The above figures show that the organs are somewhat variable in form. Some of the variation, however, is due to the contracted condition of the alcoholic specimens. In one individual, the receptaculum seminis was rounded instead of quadrangular (pl. XII, fig. E), but in all other specimens it was as in figure A.

In the immature form (called crystalensis) the retractors of the male organs vary considerably. (Pl. XV, fig. A.) One specimen (1) had the penis retractor attached to the penis-sac retractor; a second penis-sac retractor was present, its insertion in the columellar muscle being some distance from that of the posterior retractor. The posterior protractors also varied in position and number in one specimen (2), having their insertions in the columellar muscle, very close together. Three measurements of the immature individuals are given below:

$\begin{array}{cccccccc}\text { Penis. } & \text { Penis-sac. } & \begin{array}{c}\text { Penis } \\ \text { ret. }\end{array} & \begin{array}{c}\text { Penis-sac } \\ \text { ret. }\end{array} & \text { Vas. def. } & \begin{array}{c}\text { Prost. } \\ \text { duct. }\end{array} & \begin{array}{c}\text { Ret. sem. } \\ \text { duct. }\end{array} & \text { Shell. } \\ 3.50 & 4.00 & 2.00 & 1.50 & 11.00 & 5.00 & 4.00 & 21.00 \\ 3.00 & 4.00 & 2.00 & 1.75 & 13.00 & 5.00 & 4.50 & 21.00 \\ 3.00 & 4.00 & 2.00 & 1.25 & 16.00 & 6.00 & 6.50 & 27.00\end{array}$

An egg capsule, deposited in the pond of the zoological laboratory of the University of Chicago, measured 34.50 by 1.60 mill. and contained 130 eggs.

The chief characteristic of the genitalia of reflexa is the form of the receptaculum seminis; otherwise they do not differ markedly from those of palustris.

RANGe (Figure 37): Eastern Quebec $\left(65^{\circ}\right)$ to Nebraska $\left(100^{\circ}\right)$; Manitoba $\left(50^{\circ}\right)$ south to southern Illinois and southern Kansas $\left(37^{\circ}\right)$.

Reflexa is characteristic of the humid divisions of the Transition and Upper Austral life zones, extending northward into the Boreal (Canadian) life zone. It is not authentically known west of the 100th meridian, nor does it enter the Lower Austral, the 3\%th parallel marking its southern limit. Compared with the regional map, reflexa is seen to range through the Canadian and a large part of the Upper Mississippian regions, embracing the drainage areas of the Great Lakes, of the St. Lawrence River and of the upper portions of the Mississippi River. It reaches its greatest development in the prairie region of the central west. References to this species from localities west of the 100th meridian have all proved to be Galba proxima and var. rozvelli, which the immature reflexa greatly resembles. Binney (p. 41, Cat. Nos. 3523 and 8734) has confused the species with rozvelli. Taylor's reference of this species to Red Deer, Alberta, was probably founded on narrow forms of palustris. 
Geological Range (Figure 38): Pleistocene. Reflexa ranges through a number of Pleistocene deposits within its present distribution, but has not been found fossil as far north, east or south as it now ranges. Kennedy's record ${ }^{1}$ from the Brazos River valley, Robertson County, Texas, needs confirmation, as reflexa has not been authentically reported south of Illinois.

\section{RECORDS.}

LCES.

ILLINOIS: Base of Lœs in bluff of mill creek, about five miles south of Milan, Rock Island Co. (Leverett; Shimek; Udden).

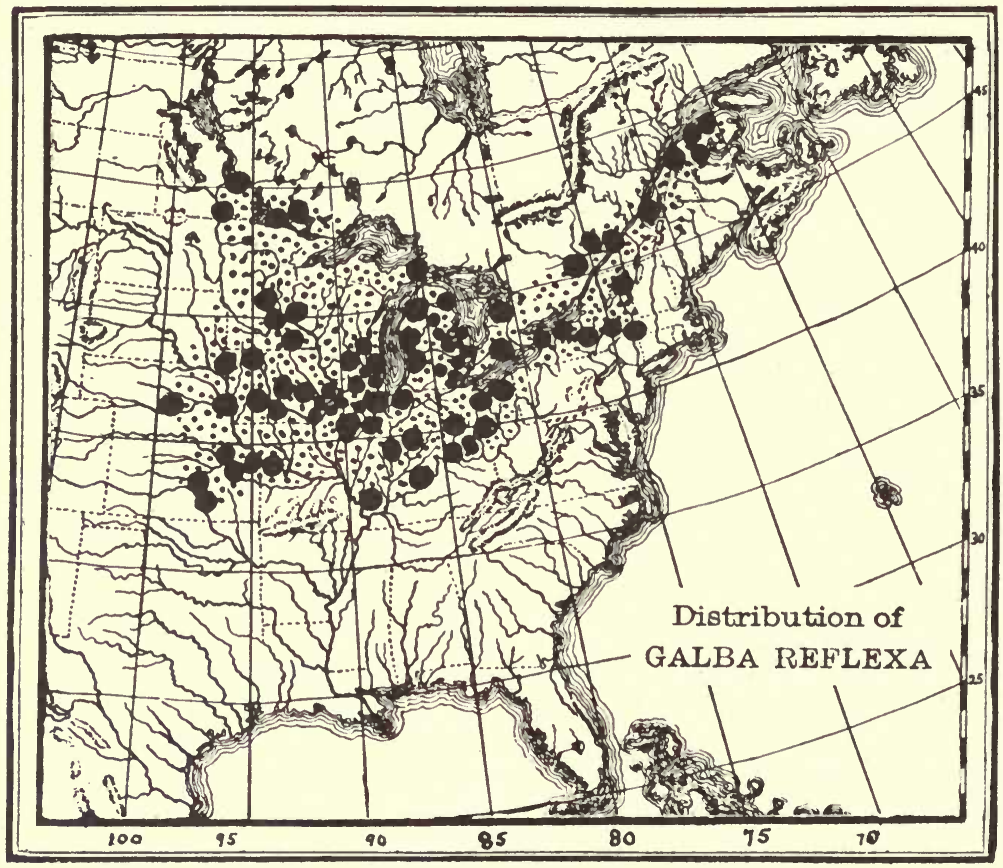

FIG. 37.

Iown: Bluffs bordering the Missouri River in the counties of Fremont and Mills (Call).

MARL DEPOSITS.

Illinors: Clyde Avenue, near Austin Avenue, Chicago, Cook Co. (Scharf).

Michigan: Cut between section 24 and 25, Spaulding Township, Saginaw

Co. (A. C. Lane).

Wisconsin: Milwaukee, Milwaukee Co. (Baker; Slocum).

CLAY DEPOSITS.

Illinors: Le Barnes' clay pit, South Evanston, Cook Co. (Walcott).

${ }^{1}$ An. Rep. Geol. Surv. Texas, IV, p. 66; p. 313, 1893. 
Ontario: Mr. Peel's clay pit near Montreal; found in bed of sand (Bell). LACUSTRINE DEPOSITS.

Illinors: In bed of Glacial Lake Chicago (Baker); in beach, Evanston, Cook Co. (Marcy).

Nebraska: Dakota and Dixon counties (Aughey); Bluff City landing, below mouth of Platte River; near mouth of Great Nemaha River, Nemaha Co. (Hambach; Swallow).

Ontario: Owen Sound, Grey District (Geol. Surv. Can.).

ECOLOGY: Found plentifully in creeks, ponds, lakes and rivers, in sheltered localities, attached to floating debris, submerged vegetation, stones, etc.; also found on decaying fruit, vegetables, etc. In many localities reflexa is found in small ponds, ditches, beside roads and railroad tracks and in sloughs and other bodies of water which dry

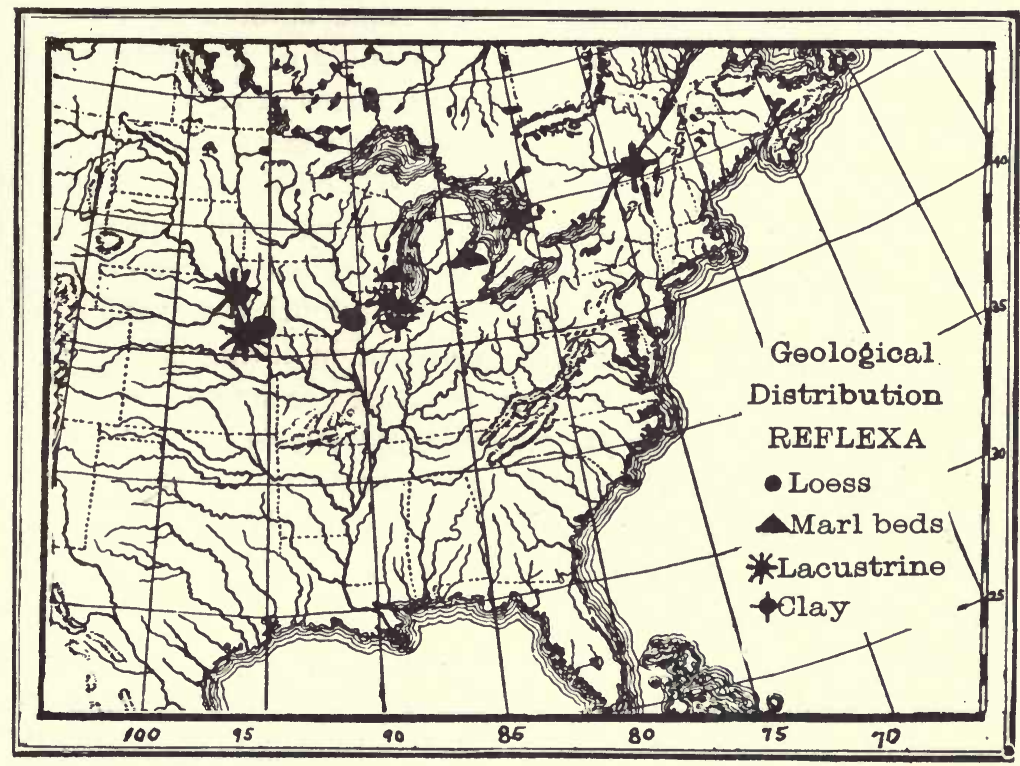

FIG. 38.

up more or less in the summer. In northern Illinois it is more often found in these summer-dry ponds than in larger bodies of water. The animal is generally rather sluggish in movement, but sometimes moves with considerable rapidity, especially when feeding. In Illinois the dead shells may be found in summer-dry ponds, scattered over the surface after the water has evaporated. In ponds containing cat-tails ( $T$ ypha) this species may be found adhering to the stems of the reeds after the water has evaporated. 
Remarks: Reflexa is one of the commonest of the Lymnæas in certain localities; it is very variable and is frequently confounded with long-spired specimens of Galba elodes. The spire of reflexa is always longer than the aperture, and may be twice as long. As a general rule, reflexa has higher whorls in comparison with their width than in elodes; the last two whorls are disproportionately larger and the penultimate whorl is usually large and has a "puffy" appearance (in elodes they usually taper gradually and regularly to a point); the whorls are also rounder, with deeper sutures. Moreover, reflexa is very rarely malleated, while elodes usually shows traces of malleation due to its wallowing habit. The aperture in reflexa is also more halfmoon-shaped and has a peculiar "twist." A close study of the shape of the whorls will almost invariably separate reflexa from elodes. Failure to note these points has caused some authors to assert that reflexa runs into palustris (elodes), but a study of abundant material does not bear out this statement; young specimens of reflexa and elodes resemble each other, the parallel between them being the same as between immature Polygyra thyroides and P. albolabris. Even halfgrown specimens of elodes can be distinguished from reflexa by the shape of the body whorl, which in the latter species is more compressed and flattened than in clodes. The majority of specimens of reflexa examined have been usually constant in form. The inner lip is sometimes raised so as to make the aperture continuous (pl. XXXV, fig. 15), and the epidermis is sometimes heavily zebra-marked, both spirally and longitudinally. The spire varies somewhat in height. Very old individuals which have survived until the third season are exceptionally large and the aperture is peculiarly oblique and reflexed. (P1. XXXV, fig. 8.)

Say's types of reflexa (two specimens) are still preserved in the Academy of Natural Sciences of Philadelphia (No. 58639). The shells consist of $61 / 2$ whorls, which are rounded and not flat-sided as in Say's figure published in Binney, but more like Say's figure in the American Conchology. (See plate XXX, figures 30,31 .) Haldeman's plate 8 is typical of the majority of specimens referred to reflexa. Crystalensis (plate XXXVI, figures $\%-11$ ) is the immature state of reflexa, a fact recently demonstrated by an ecological study of certain summerdry ponds or "swales" in northern Illinois. Both forms may be found associated together, the fully mature reflexa being a crystalensis of the third year. This immature form resembles elodes, from which it may be distinguished by its more tightly coiled upper whorls, its narrower aperture and more cylindrical whorls. 
Iowaensis Baker cannot be separated from reflexa in a large series, and must become a synonym (pl. XXXV, fig. 9) ; the characters relied upon in the diagnosis are not constant, being founded on an immature condition. In the Illinois and Michigan Canal at Joliet, Illinois, occurs a form of reflexa which is subject to many peculiar pathologic variations. These affect the spire and the aperture, and produce many strange forms. Plate XXXVI, figures 1 to 6 , illustrate a few of these variations, and several measurements are given below:

$\begin{array}{cccc}\text { Length. } & \text { Width. } & \text { Aperture length. } & \text { Width. } \\ 20.00 & 10.00 & 11.50 & 6.00 \mathrm{mill} \text {. } \\ 21.00 & 9.00 & 11.00 & 6.00 \text { " } \\ 22.50 & 10.00 & 11.00 & 6.00 \text { " } \\ 28.00 & 9.50 & 11.50 & 6.50 \text { " }\end{array}$

When at its best, reflexa is easily the handsomest Lymnæa of the American fauna, with its long, graceful spire and rich chestnut brown color.

Galba reflexa walkeri (Baker). Plate XXXVI, figures 12-18.

Limnéa reflexa scalaris WALKER, Nautilus, VI, p. 33, pl. 1, fig. 7, 1892 (not scalaris A. Braun, 1853, or Sowerby, 1872, or VAN DEN Broeck, 1872).WalKer, Rev. Moll. Mich., pp. 7, 17, 1894 ; Nautilus, VII, p. 128, 1894.-BAKER, Trans. Acad. Sci. St. Louis, XL, p. 21, pl. 1, fig. 7, 1901.-Walker \& Lane, Geol. Surv. Mich., VII, pt. 2, p. 251, 1900. 1902 .

Limnaa reflexa zealkeri BAKER, Moll. Chi. Area., II, p. 281, pl. 31, fig. 2, Lymnaa reflexa walkeri BAKER, Bull. Ill. State Lab. N. H., VII, p. 106, 1906.

Limnea reflexa var. distortus WALKER, Journ. Conch., II, p. 330, 1879.

Limnaa reflexa distortus WALKer, Rev. Moll. Mich., p. 17, 1894.

Shell: Much elongated, narrow, scalariform; color and surface sculpture as in reflexa; whorls 7 to $7 \mathrm{I} / 2$, rounded, very long; spire over twice as long as the aperture; sutures much indented; aperture narrower and longer than in reflexa, the inner lip frequently erect and the aperture continuous.

\begin{tabular}{|c|c|c|c|c|c|}
\hline $\begin{array}{l}\text { Length. } \\
37.00\end{array}$ & $\begin{array}{l}\text { Width. } \\
11.00\end{array}$ & $\begin{array}{c}\text { Aperture length. } \\
12.00\end{array}$ & & & Calumet-Lake, Ill. \\
\hline 35.50 & 9.50 & 12.50 & 5.00 & “" & “" “" \\
\hline 35.50 & 9.00 & 11.00 & 5.00 & “ & Joliet, Ill. \\
\hline 37.50 & 9.00 & 12.50 & 6.00 & “ & Algonquin, Ill. \\
\hline 37.00 & 10.00 & 13.00 & 5.50 & “ & Wolf Lake, Ill. \\
\hline 37.00 & 10.50 & 10.50 & 5.50 & “ & Calumet Lake, Ill. \\
\hline
\end{tabular}

Types: Collection Bryant Walker, Detroit, Mich., five specimens, No. 146.

Type Locality: Rouge River, Wayne County, Mich. Animal, Jaw, Radula and Genitalia: Not examined. 
RANGE: Illinois, Indiana, Michigan, Ohio. A form of the humid divisions of the Transition and Upper Austral life zones, and of the Canadian and Upper Mississippian regions. The range of walkeri will probably be found to be coexistent with that of typical reflexa. It has doubtless been recorded as reflcxa and labeled as such in collections. RECORDS.

UNITED STATES.

Illinors: Lake George and Calumet River, Cook Co. (Baker); Calumet Lake, Cook Co. (Calkins); Joliet, Will Co. (Ferriss); Wolf Lake, Cook Co. (Jensen) ; Kendall Co. (Hinkley); Algonquin and Silver Lake, McHenry Co.; Cook Co. (Nason); Stony Island, Chicago, Cook Co. (Zetek).

Indiana: Hessville, Lake Co. (Walcott).

Michigan: River Rouge, Wayne Co. (Walker); Saginaw Valley, Saginaw Co. (Walker); Detroit, Wayne Co. (Miss Walker).

Онго: Near Cincinnati, Hamilton Co. (Lea).

Geological Range: Unknown.

Ecology: Walkeri lives under much the same conditions as does reflexa.

REMARKS: Walkeri is distinguished by its very long, scalar spire and the narrowness of the shell compared with its length; the whorls are generally well rounded. While this variety is quite distinct in some localities, it is found in other places to gradually grade into typical reflexa. The variety is distinguishable from reflexa, the characteristics of the long, well-rounded whorls, narrow shell, deep sutures and the absence of the rapid enlargement of the last two whorls being sufficient to cause its immediate recognition. From an ecological point of view, as walkeri is the dominant form in some localities, it seems quite desirable to recognize it as a race. Specimens raised in the greenhouse of the University of Chicago were all referable to rwalkeri. It lacks the "puffy" aspect of the penultimate whorl, so markedly developed in typical reflexa. $19-20$.

Galba reflexa hemphilliana (Baker). Plate XXXVI, figures

Limnca reflexa hemphilliana BAKER, Nautilus, XVIII, p. 11, May, 1904.

SHell: Elongate-ovate, rather solid; color light horn; surface shining, with distinct spiral lines; whorls six, very flat-sided, somewhat oblique, loosely coiled; nuclear whorls very dark red; spire short, wide, acutely pyramidal, about as long as the aperture; sutures not deeply impressed; aperture ovate, or elongate-ovate; peristome thin, bordered by a red-banded internal rib; inner lip narrow, reflected and almost closing the umbilicus, leaving a very small chink; the columella is slightly twisted and there is a rather heavy ascending plait. The surface is lightly malleated. 


$\begin{array}{ccccc}\text { Length. } & \text { Width. } & \text { Aperture length. } & \text { Width. } & \\ 27.00 & 11.00 & 14.00 & 7.25 \text { mill. } & \text { Type } \\ 27.00 & 11.50 & 15.00 & 7.50 & \text { “ }\end{array}$

Types: Collection Bryant Walker, two specimens, No. $1403 \%$.

Type Locality: Lake Albert Lea, Minn.

Animal, Jaw, Radula and Genitalia: Unknown.

RANGE: Minnesota. A race of the Transition life zone (humid division) and of the Upper Mississippian region. It has probably been called either reflexa or palustris by most collectors and its range may be widely extended when its characteristics are once known.

\section{RECORDS.}

Minnesota: Lake Albert Lea, Freeborn Co. (Hemphill; Walker).

Geological Distribution: Unknown.

ECology: Not recorded.

Remarks: Hemphilliana is suggestive of a widened out and shortened up Galba exilis. The spire is flat-sided as in exilis, but the shell is wider and the aperture more expanded, as in reflexa. As far as known, it has been found only in Minnesota. Its chief characteristics are its short, wide, flat-sided spire and wide whorls. It somewhat resembles Galba lanceata Gould, but is wider with more flat-sided whorls and a longer, narrower and more oblique aperture. A good series of this race is a desideratum.

Galba exilis (Lea). Plate XXXV, figure 4; plate XXXVI, figures 21-22; plate XXXVII, figures 1-11.

Lymnaa exilis Lea, Trans. Amer. Phil. Soc., V, p. 114, pl. 19, fig. 82, 1837; Obs., 1, p. 226, pl. 19, fig. 82, 1837.-Wheatley, Cat. Sh. U. S., p. 23, 1845.-ScudDER, Bull. Nat. Mus., 23, pp. 14, 201, 1885.

Lymnea exilis Anthony, L. \& F.-W. Sh. Cin., 1848.-Shaffer, Shells Cin. Ohio (no date).

Lymneus exilis Kirtland, Zool. Ohio, p. 174, 1838.

Limnaus exilis Küster, Conch. Cab., p. 40, taf. 7, fig. 9, 1862.

Limnca exilis Binney, L. \& F.-W. Sh. N. A., II, p. 40, fig. 50, 1865.-Sowb., Conch. Icon., XVIII, Lim., sp. 72, pl. 11, fig. 72, 1872.-HAZAÝ, Mal. Blatt., ii, III, pp. 17, 164, 1881.-Jordan, Nova Acta Ksl.-Leop.-Carol. Deutsch. Akad. Natur., XLV, p. 368, 1883.

Lymncea reflexa var. exilis JAY, Cat., p. 270, 1852.

Limnea reflexa var. exilis WALKER, Journ. Conch., II, p. 330, 1879.

Limncea reflexa var. exilis Walker, Nautilus, VI, p. 32, 1892; Rev. Moll. Mich., p. 17, 1894.-BAKER, Moll. Chi. Area, II, p. 282, pl. 31, fig. 3; pl. 32, fig. 3, 1902.

Lymnca reflexa exilis BAKER, Bull. I11. State Lab. N. H., VII, p. 105, 1906. Limnophysa reflexa attenuata BAKER (non Say), Journ. Cin. Soc. N. H., XIX, p. 84, 1897.

Limncea reflexa Sowb., Reeve, Conch. Icon., pl. 5, sp. 32, b. 1872.-BAKer, Trans. Acad. Sci. St. Louis, XI, p. 17, pl. I, fig. 3, 1901. 
Limnaa zebra TRYon, Amer. Journ. Conch., I, p. 228, pl. 23, fig. 4, 1865; Amer. Journ. Conch., III, p. 196, 1867.-Currier, Kent. Sci. Inst., Mis. Pub., No. 1, 1868.-Tryon, Con. Hald. Mon., p. 94 (68), pl. 16, fig. 14, 1872.-Calkins, Cin. Quart. Journ. Sci., 1, p. 243, 1874 ; Cin. Quart. Journ. Sci., 1, p. 323, 1874.Tryon, Home \& Science Gossip, June 15, 1881.-Marsh., Conch. Exch., II, p. 104, 1887.-SNYder, The Museum, III, p. 12, 1896.

Limnophysa zebra CURRIER, Amer. Journ. Conch., I, p. 294, 1865.-Tryon, Amer. Journ. Conch., I, pp. 68, 70, 250, 1865.-Call, Bull. Wash. Coll. Lab. N. H., I, p. 53, 1885.-KeYes, Bull. Essex Inst., XX, p. 70, 1888.

Limnea reflexa var. zebra WiTter, Quart. Journ. Conch., I, p. 386, 1878.WALKer, Journ. Conch., II, p. 330, 1879.

Limnophysa reflexa var. zebra DeCamp, Kent. Sci. Inst., Mis. Pub., No. 5, p. $8,1881$.

Limnca reflexa zebra Walker, Nautilus, VI, p. 32, 1892 ; Rev. Moll. Mich., p. 7, 1894.-SARGent, Nautilus, IX, p. 127, 1896.

SHELL: Elongated, attenuated, thin; periostracum light corneous or honey-yellow, sometimes streaked zebra-like ; surface dull to shining, growth lines distinct, crowded, crossed by numerous very fine incremental striæ; nuclear whorls $1 \frac{1}{4}$, small, similar to those of palustris in outline, light corneous to very dark brown in color; whorls six to seven, very flat-sided, the last a little over one-third the length of the entire shell; spire long and very acutely attenuated, forming an almost unbroken, acute triangle in typical specimens; sutures impressed, frequently margined below by a white band edged with chestnut; aperture elongate-ovate, narrow, oblique, slightly contracted at the upper part; rounded at the lower part; peristome sharp, thin, a rather heavy callus within which is dark chestnut colored, the remainder of the aperture being brownish or horn color; this color shows on the outside as a light band in many specimens; inner lip very narrow, erect, reflected over the umbilicus, completely closing it the callus on the parietal wall is well marked and is so heavy in some specimens, especially when slightly raised, as to render the aperture continuous; the axis is slightly twisted, frequently somewhat gyrate.

\begin{tabular}{|c|c|c|c|c|c|}
\hline $\begin{array}{l}\text { Length. } \\
37.00\end{array}$ & $\begin{array}{l}\text { Width. } \\
11.50\end{array}$ & $\begin{array}{c}\text { Aperture length. } \\
14.00\end{array}$ & $\begin{array}{l}\text { Wid } \\
6.25\end{array}$ & $\begin{array}{l}\text { th. } \\
\text { mill. }\end{array}$ & Type exilis. \\
\hline 37.00 & 11.00 & 14.00 & 6.00 & “ & Chicago. \\
\hline 28.00 & 9.50 & 12.00 & 4.50 & “ & Type zebra. \\
\hline 30.00 & 9.00 & 13.00 & 5.00 & “ & Chicago. \\
\hline 24.00 & 7.50 & 10.50 & 4.50 & “ & “ \\
\hline 28.50 & 7.50 & 11.50 & 4.50 & “ & “ \\
\hline 28.00 & 7.50 & 11.00 & 5.00 & “ & Mercer Co., Ill. \\
\hline 33.00 & 9.50 & 12.50 & 5.50 & “ & Winnebago Co., Ill. \\
\hline 36.50 & 10.00 & 15.00 & 6.50 & “ & " $\quad$ " \\
\hline 28.00 & 9.00 & 13.00 & 5.50 & “ & Antrim Co., Mich. \\
\hline 39.00 & 11.00 & 16.00 & 6.00 & “ & Minneapolis, Minn. \\
\hline 30.10 & 9.10 & $12.1 n$ & 4.00 & “ & Poland, Ohio. \\
\hline
\end{tabular}


Types: Exilis Lea, one specimen, No. 119481, Smithsonian Institution; zebra Tryon, four specimens, Academy of Natural Science, Philadelphia, No. 58629.

Type Locality: Exilis, near Cincinnati, Ohio ; zebra, Minnesota.

Animal, Jaw, Radula and Genitalia: Not examined.

RANGE (Figure 39): Ohio to Kansas, northward to northern Minnesota and northern Michigan.

Exilis is typical of the humid divisions of the Transition and Upper Austral life zones, from whence it has crossed into the southern part of the Boreal (Canadian) life zone, in Minnesota and Michigan. It is a Mississippi Valley and Great Lakes species, common to the Canadian and Upper Mississippian regions. Its differentiation from reflexa will doubtless extend its range.

\section{RECORDS.}

UNITED STATES.

Illinors: Cook Co. (Baker); Calumet River and Calumet Lake, Cook Co. (Baker; Calkins; Walker); Mercer and Winnebago cos. (Ferriss); Berry Lake, Cook Co. (Higley); sloughs of Winnebago Co. (Hinkley; Walker); Will Co. (Marsh); Cedar Lake, Lake Co.; northern Illinois (State Laboratory); Aledo, Mercer Co. (Walker).

InDIANA: George Lake, Lake Co. (Woodruff).

IowA: Iowa River (Dall); Dallas Co.; Des Moines, Polk Co.; Burlington, Des Moines Co. (Keyes); pond near West Liberty, Muscatine Co.; north of Iowa City, Johnson Co. (Pilsbry) ; Spirit Lake, Dickinson Co.; Algona, Kossuth Co. (Shimek); Davenport, Scott Co. (Tryon); vicinity of Des Moines (Van Hyning); Boone Co.; Iowa River (Walker); Muscatine, Muscatine Co. (Witter).

Kansas: Lake Farland, McPherson Co. (Call; Cragin).

Michigan: In small lake, Antrim Co. (Walker).

Minnesota: Elk River, Sherburne Co. (Bailey); Lake Minnetonka, Hennepin Co. (Cope); Minneapolis, Hennepin Co. (Hemphill); Lake Albert Lea, Freborn Co. (Hemphill; Walker); Pelican Lake, Crow Wing Co. (Nason); Belle Lake, Wright Co. (Sargent); Lake Calhoun, Hennepin Co. (Walker).

Oн1о: Cincinnati, Hamilton Co. (Allan; Anthony; Lee; Shaffer); Poland, Mahoning Co. (Kirtland; Lea; Walker); pond near Congress Lake, Stark Co. (Walker).

Wisconsin: Milwaukee, Milwaukee Co. (Lapham); East River, Green Bay and DePere, Brown Co. (Marston; Wis. Nat. Hist. Surv.); Fox River and Green Bay (Walker).

Geological Distribution: Unknown.

ECOLOGY: Exilis is an inhabitant of sloughs, ponds and rivers which dry up more or less during a portion of the year.

REMARKS: This very characteristic and usually very distinct species is a common Lymnæa in the Upper Mississippi Valley streams and ponds. Its most pronounced distinguishing features are the long, 


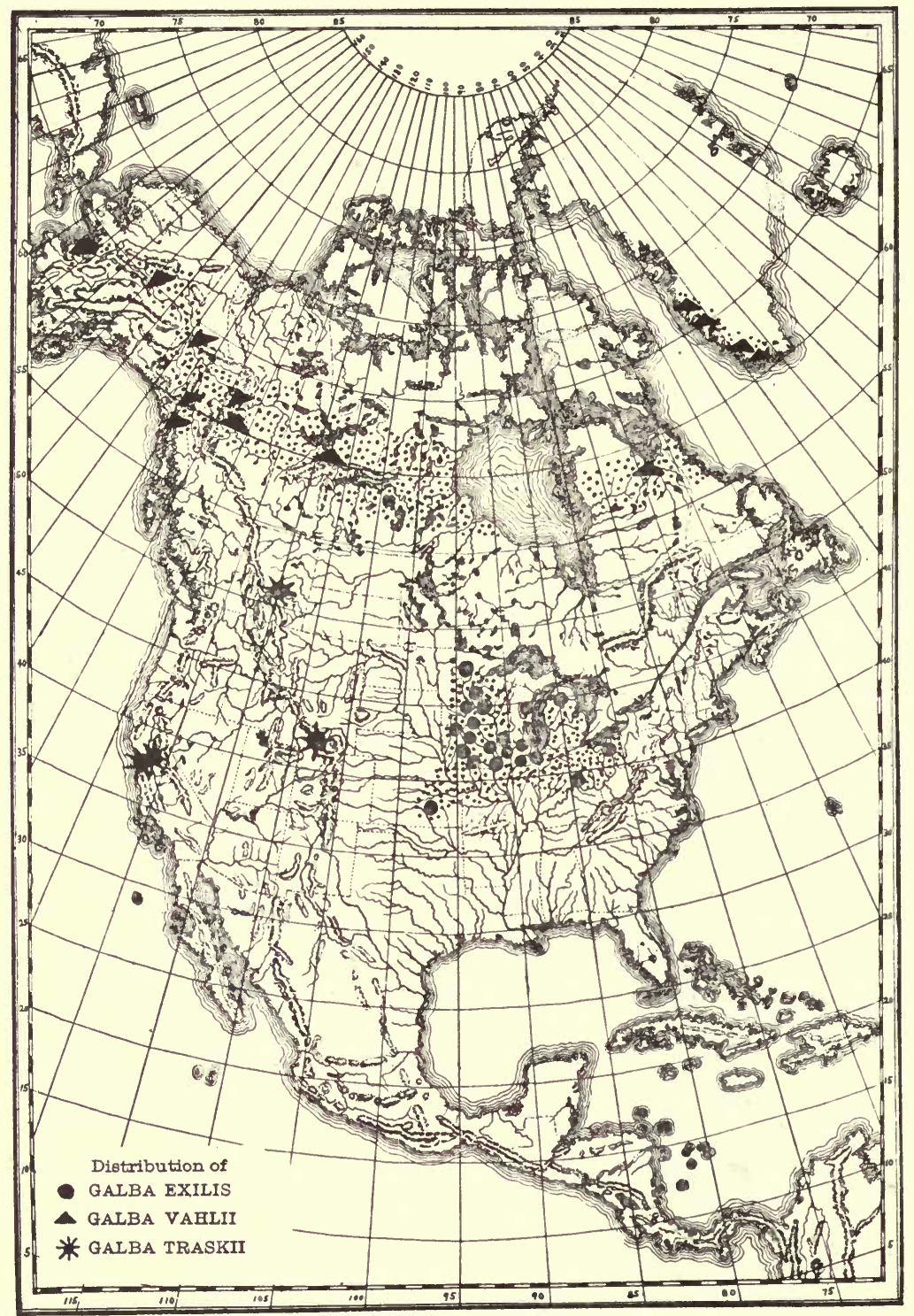

Fì IG. 39. 
fiat-sided whorls, the attenuated, steeple-shaped spire, the shallow sutures and the long, narrow aperture. Many specimens have zebra-like markings (the form named zebra by Tryon) and in not a few individuals the inner lip is erect and causes the whole aperture to stand out from the body-whorl. The axis has a distinct twist and some individuals have an almost gyrate axis. This fact has led some conchologists to place it in the genus Acella. The axis is not typically gyrate, a fact which may be verified by breaking open the whorls; the species is a typical Stagnicola. There is considerable variation in the shape of the aperture; in many specimens the twist, so characteristic in reflexa, is entirely absent, while in others, notably in old specimens, the tivist is markedly developed. The whorls also vary somewhat in rotundity.

Lea's type of exilis is a large shell, with flat-sided whorls and with the aperture entire and separated from the body whorl, a pathologic condition frequently seen in the reflexa group. It was collected near Cincinnati, Ohio. The figure of exilis in Binney is very poor and does not well represent this species. Figures 7 and 9 on plate XXXVII are good examples of exilis as shown by Lea's type specimen. There is some variation in the width of the body whorl $(1,2,7,8$, pl. XXXVII), but all have the very flat-sided, oblique whorls and long aperture, which will distinguish exilis from all related species. Its relation to lanceata is indicated in the remarks under that species. Tryon's zebra is a synonym of exilis, according to his types and published figures, although he seemed to make it cover any zebra-marked shell of the reflexa group, a fact borne out by his remarks in the American Journal of Conchology, volume I, page 228, where reference is made to Haldeman's figures of umbrosa and reflexa, to which the true zebra is not especially related. Of Tryon's type lot of four specimens, only one corresponds with his figure in the American Journal of Conchology, plate 23, figure 4, the others being true exilis. A peculiar, small form of cxilis occurs near Des Moines, Iowa, which is small and narrow, with a very heavy varix in the outer lip, showing that the animal at some time sustained a long period of æstivation. The body whorl is very much flattened. This form is frequently identified as kirtlandiana Lea. When perfect, exilis is one of the most graceful and beautiful of the Lymnæas.

Dr. Dall (Alaska Moll., p. 72) believes that cxilis should be included in the Acella group with Haldeman's gracilis (=haldemani). While there is a superficial resemblance to haldemani in the flatness of the whorls and in the general oblique and elongated shell, an exam- 
ination of haldemani shows a marked difference in the nuclear whorls. The genitalia and radula of haldemani are also peculiar and unlike those of any other American Lymnæid. The axis is not gyrate as stated, but plicate as in reflexa, although individual specimens may be of a gyrate character.

Galba kirtlandiana (Lea). Plate XXXVII, figures 12-16.

Lymnea kirtlandiana LeA, Proc. Amer. Phil. Soc., II, p. 33, 1841; Trans. Amer. Phil. Soc., IX, p. 12, 1844 ; Obs., IV, p. 12, 1848; Hayden's Report, II, pt. iii, p. 724, 1859.-Roberts, U. S. Geol. Surv., Wyoming, 1870, p. 468.

Lymnaa kirtlandiana Wheatley, Cat. Sh. U. S., p. 23, 1845.-Scudder, Bull. Nat. Mus., 23, pp. 33, 44, 201, 1885.—DALL, Alaska Moll., p. 72, fig. 48, 1905.

Limnaa kirtlandiana Binney, Check List, p. 12, 1860 ; L. \& F.-W. Sh. N. A., II, p. 67, fig. 111, 1865.-Tryon, Con. Hald. Mon., p. 112 (86), pl. 18, fig. 10, 1872.-Sterki, Ohio Nat., II, p. 286, 1902.-KeEP, West. Amer. Sh., p. 314, 1904.

Limnea kirtlandiana DeAn, Amer. Nat., XXVI, p. 18, 1892.

Leptolimnaa kirtlandiana Tryon, Amer. Journ. Conch., I, p. 257, 1865.

Limnaa reflexa kirtlandiana WALKeR, Nautilus, VI, p. 32, 1892; Rev. Moll. Mich., p. 17, 1894.-Baker, Moll. Chi. Area, p. 281, pl. XXXI, fig. 4, 1902.Blatch. \& Daniels, Rep. Dept., Geol. \& Nat. Res. Ind., XXVII, p. 596, pl. 1, fig. 11, 1902.-DANiels, 1. c., p. 636, 1902.

Limnaa reflexa Sowb., Reeve, Conch. Icon., pl. 5, sp. 32, a, 1872.-BAKER, Trans. Acad. Sci. St. Louis, XI, pl. 1, fig. 6, last two figures to right, 1901; Moll. Chi. Area, pl. XXXII, fig. 6, last two figures to right, 1902.

Lymnca reflexa kirtlandiana Sterki, Proc. Ohio State Acad. Sci., IV, p. $382,1907$.

Lymnaa reflexa exilis BAKER, Bull. Ill. State Lab. N. H., VII, p. 105, 1906 (part).

SHell: Much elongated, turreted, rather thin; periostracum pale horn color to dark brown; sculpture as in exilis; whorls 6 to 7 , slowly increasing in size, slightly convex, only a trifle oblique, the body whorl very flatly rounded; spire very long, acute, turreted; sutures impressed; aperture elongate-ovate or long elliptical, a trifle effusive and reflexed below; outer lip with a varical thickening; inner lip narrow, erect, tightly appressed to the body whorl, either entirely closing the umbilical opening or leaving a very narrow chink; parietal callus wide, thin; the columella is provided with a distinct ascending plait; the axis is slightly twisted.

\begin{tabular}{|c|c|c|c|c|c|}
\hline $\begin{array}{l}\text { Length. } \\
18.00\end{array}$ & $\begin{array}{c}\text { Breadth. } \\
6.50\end{array}$ & $\begin{array}{c}\text { Aperture length. } \\
7.00\end{array}$ & $\begin{array}{l}\text { Brea } \\
2.25\end{array}$ & $\begin{array}{l}\text { dth. } \\
\text { mill. }\end{array}$ & Type. \\
\hline 18.00 & 6.00 & 7.50 & 3.00 & “ & Topotype. \\
\hline 20.50 & 6.50 & 8.00 & 3.00 & “ & Crystal Lake, Ill. \\
\hline 19.00 & 6.50 & 7.00 & 3.00 & “ & Chicago. \\
\hline 20.25 & 6.75 & 8.50 & 3.50 & “ & “ \\
\hline 17.00 & 6.50 & 8.00 & 3.00 & “ & “ \\
\hline
\end{tabular}

TYPE: One specimen, Smithsonian Institution, No. 118662. 
Type Locality: Poland, Ohio.

Animal, Jaw, Radula and Genitalia: Not examined.

Range: (Figure 40) Ohio west to South Dakota, northern Michigan south to northern Illinois.

Kirtlandiana occupies a large part of the humid division of the Transition and Upper Austral life zones, extending northward into the Boreal (Canadian) life zone (in Michigan). Kirtlandiana appears to be of more northern distribution than exilis. It is confined to the Canadian and Upper Mississippian regions.

\section{RECORDS.}

Illinors: Mud Lake, Grand Crossing, Chicago, Cook Co. (Baker); Berry Lake, Cook Co. (Higley); Crystal Lake, McHenry Co. (Nason).

Michigan : St. Mary's River, Chippewa Co. (Walker).

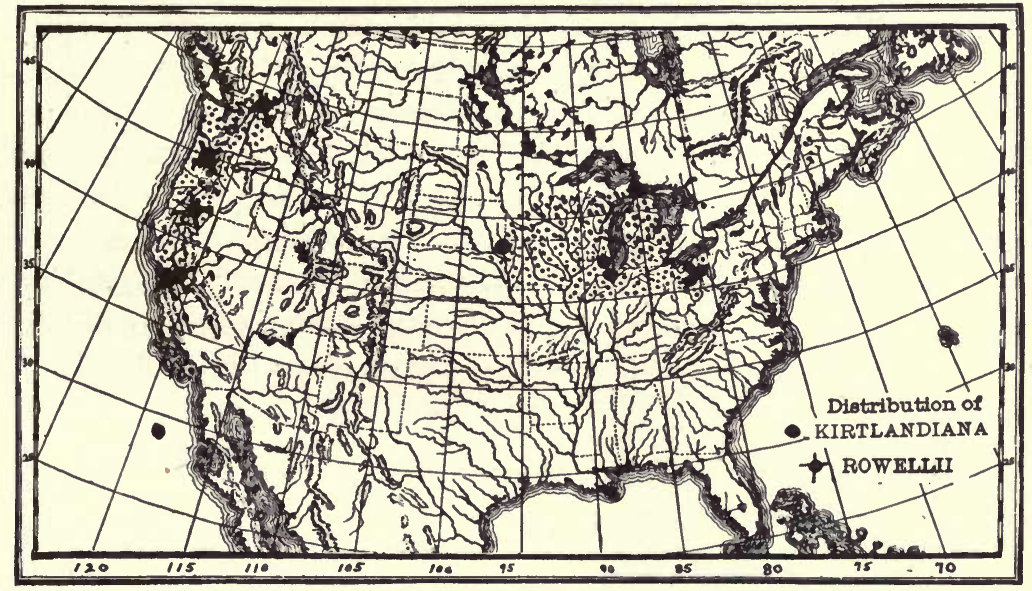

FIG. 40 .

Оніо: Portage Co. (Dean); Garrettsville, Portage Co. (Hinkley; Walker); Poland, Mahoning Co. (Kirtland; Lea; Walker); pond, Stone Creek, near New Philadelphia, Ohio, Tuscarawas Co. (Sterki).

South Dakota: Big Sioux River (Lea).

Geological Range: Unknown.

Ecology: Kirtlandiana is characteristic of small bodies of water, especially those that may become dry in the summer.

REMARKS: Kirtlandiana is related to several species, but appears tc be recognizable. The whorls are not as flat-sided nor as oblique as are those of exilis, nor has the aperture the distinct twist; it is also slightly perforate while exilis is not. It may be known from lanceata by its much narrower, more clongate shell, more turreted whorls, and 
much smaller aperature. It approaches nearest in general form to some individuals of Galba clodes jolietensis, from which it may be known by its narrower and flatter body whorl, its less rounded and more oblique whorls, and its longer and narrower aperture.

Kirtlandiana has been considered by many excellent conchologists a synonym of both cxilis and lanceata, from both of which it seems perfectly distinct. The type specimen in the Smithsonian Institution (No. 118662) agrees well with Binney's figure. Specimens of cxilis from Poland, Ohio, in the Lea collection, have doubtless been the cause of its reference to exilis. All of Lea's specimens which have been examined are immature; the adult shell is figured on plate XXXVII, figures 13-14. A specimen from the Lewis collection received from Lea, now in the possession of Mr. Bryant Walker, is identical with the type and agrees perfectly with the shells figured on plate XXXVII. Tryon's figure in Haldeman's monograph (pl. 18, fig. 10 ) is very poor, showing the whorls too flat-sided and too oblique, and particularly misrepresenting the shape of the body whorl. A peculiar flat-sided type of shell has been received from Iowa under the name of kirtlandiana, but this is referable to cxilis (see under cxilis; see also plate XXXVII, figure 11). Kirtlandiana, when understood and properly distinguished from cxilis and lanceata, will doubtless be found to occupy a large territory, in the states from Ohio to Nebraska and from the Lake Superior region southward to the vicinity of the 40th parallel.

\section{Galba lanceata (Gould). Plate XXXVII, figures 17-22.}

Limnca lanceata Gould, Proc. Bost. Soc. N. H., III, p. 64, 1848.-Binner, Check List, p. 12, 1860; L. \& F.-W. Sh. N. A., p. 68, fig. 112, 1865.-Currier, Kent. Sci. Inst., Mis. Pub., No. 1, 1868.-Tryon, Con. Hald. Mon., p. 113 (87), pl. 18, fig. 11, 1872.-Sмiтh, U. S. Fish Com. Rep. 1872-73, p. 702, 1874.Walker, Journ. Conch., II, p. 330, 1879.-Stearns, Proc. Nat. Mus., XIV, p. 101, 1891.-Walker, Nautilus, VI, p. 33, 1892.-Taylor, Ottawa Nat., VI, p. 35, 1892.-Walker, Rev. Moll. Mich., pp. 6, 18, 1894; Nautilus, IX, p. 4, 1895.Stearns, Proc. Nat. Mus., XXIV, p. 291, 1901.-Ruthven, Rep. Mich. Acad. Sci., VI, p. 190, 1904.

Limnea lanceata Gould, Agassiz's Lake Sup., p. 244, pl. 7, figs. 8, 9, 1850 ; Otia Conch., p. 206, 1862.

Lymnca lanceata Gould, Rep. N. Y. State Mus., XXVII, p. 53, 1875.

Acella lanceata Tryon, Amer. Journ. Conch., 1, p. 258, 1865.

Leptolimnea lanceata DeCamp, Kent. Sci. Inst., Mis. Pub., No. 5, p. 8, 1881.

SHell: Elongate-cylindrical, rather thin, compressed; periostracum light to very dark horn colored; surface dull to shining; growth lines and spiral lines very heavy producing a conspicuously marked reticulated appearance; whorls 6 to $61 / 2$, flatly rounded, slightly oblique, 
not rapidly increasing in diameter, the body whorl very long and much compressed; sutures well marked; spire acutely pyramidal, generally a trifle longer than the aperture; nuclear whorls like palustris in outline and number, very dark chestnut colored; aperture elongated, slightly oblique, rounded below and somewhat acutely angled above, where the outer lip is slightly arched, as it joins the body whorl; outer lip with a conspicuous varix, bordered by a dark chestnut band; inner lip very narrow, forming a sharp keel on the columella and a thick deposit of callus on the parietal wall; there is no evidence of an umbilical chink; the columella is marked by a distinct plait.

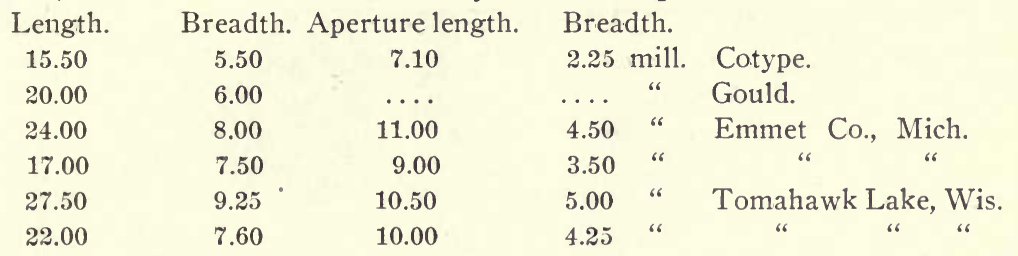

Type: New York State Museum, Albany, N. Y., three specimens; No. A, 3030, cotype, Smithsonian Institution one specimen, No. 9026. Type Locality: "Pic Lake," North Shore of Lake Superior.

Animal: Not differing from palustris. Two colors were observed, one yellow and the other black.

JAw : As in reflexa.

RAdUla: Formula: $\frac{18}{5-7}+\frac{3}{3}-\frac{3}{4}+\frac{9}{2}+\frac{1}{1}+\frac{9}{2}+\frac{3}{3}-\frac{1}{4}+\frac{18}{5-7} \quad(30-1-30)$; The teeth are similar in form to those of reflexa.

Genitalia: Similar in form and proportions to those of reflexa.

RANGE: (Figure 41). North shore of Lake Superior and eastern Ontario $\left(i 5^{\circ}\right)$ south to northern Ohio, west to Wisconsin.

The records show this species to be an inhabitant of the humid division (Alleghanian) of the Upper Austral life zone from whence it extends south into the northern part of the Lower Austral (Carolinian) life zone and north well into the Boreal (Canadian) life zone. It is characteristic of the Great Lake drainage and of the Canadian and Upper Mississippian regions.

\section{RECORDS. \\ United States.}

Michigan: Marquette, Marquette Co. (Downing); Lake Gogebic, Ontonagon Co. (Ruthven); Carp Lake, Emmet Co.; Bell Isle, Detroit River, Wayne Co.; High Island Harbor, Charlevoix Co.; Charlevoix, Chippewa; Emmet, Houghton, Marquette, Monroe, Ontonagon, Wayne and Wexford Counties (Walker).

Онго: Hudson, Summit Co. (Walker).

Wisconsin: Tomahawk Lake, Oneida Co. (Baker). 


\section{British America.}

Ontario: Pic Lake, Thunder Bay District (Agassiz; Dall; Gould) ; Lake Superior (Gould); Ottawa, Carleton Dist. (Latchford; Taylor).

Geological Distribution: Unknown.

Ecology: In Tomahawk Lake, Wisconsin, this species lives in swampy or quiet bays or pond-like bodies of water connecting with the lake. In quiet bays it may be found rarely on the sandy shore in shallow water. Its more usual habitat is in swampy areas where there is a quantity of vegetation such as Typha and the pond scums, in

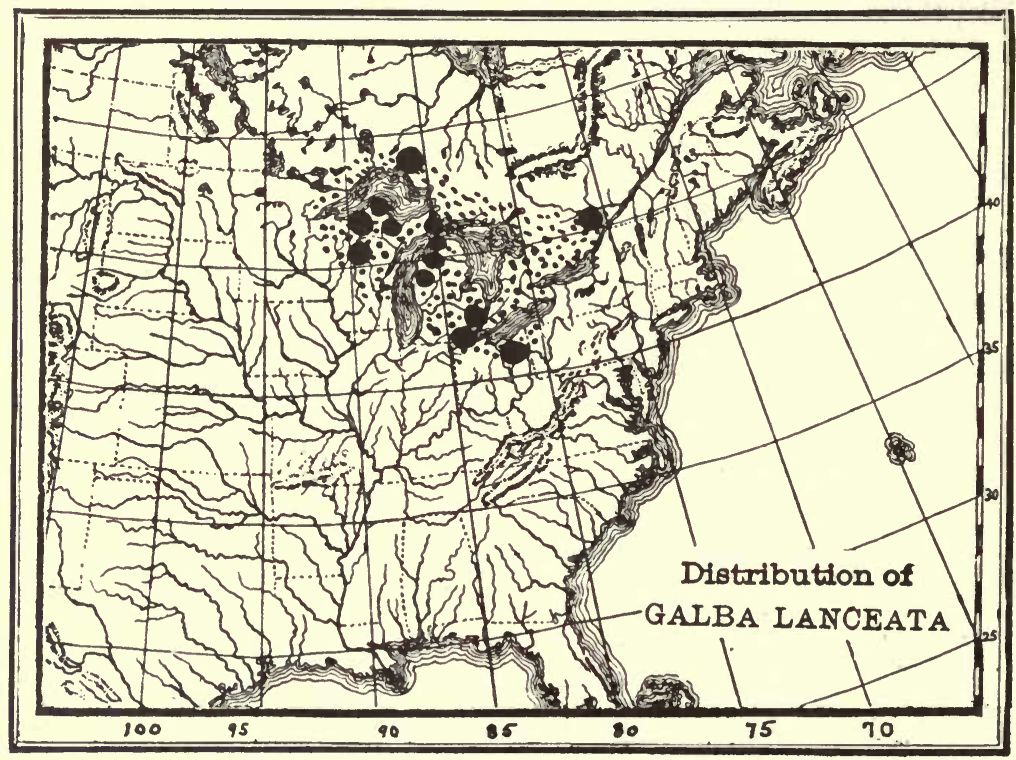

FIG. 41.

which situation it may be found on floating logs or in the vegetation. In this region it is typically an inhabitant of swampy, Typha bordered bogs, in which there is an accumulation of old logs.

REMARKS: Lanccata is one of the Lymnæas which has been much misunderstood for many years. By several authors it has been considered a synonym of kirtlandiana and exilis. Dr. Dall in his excellent report on Alaska Mollusks, page $\% 2$, refers it to kirtlandiana as an immature form. An examination of a cotype in the Smithsonian collection, and a study of Gould's figures and descriptions, aided by a collection of over one hundred specimens from the northern states shows that it is a good species. It is true that Binney's figure is very . poor, but the two figures in Agassiz's Lake Superior (pl. \%, figs. 8 
and 9) are excellent and answer exactly to Gould's description. These are almost identical with the figures on plate XXXVII, which illustrate the range of variation. Binney's figure of kirtlandiana bears some resemblance to lanceata but quite correctly typifies kirtlandiana in which the whorls are more oblique, a feature absent in lanceata. Tryon's figure in his continuation of Haldeman's Monograph, is very poor and looks more like a form of exilis than lanceata. (Hald. pl. 18, fig. 11).

Lanceata is liable to be confused with three forms of Lymnæa; exilis, which has a longer spire with more flat-sided oblique whorls, a narrower, more oblique aperture and a twist like that of reflexa; immature reflexa, which differs in the form of the penultimate whorl (which is disproportionately enlarged) and in the shape of the aperture, which is slightly oblique and reflexed; and elodes, which has a wider shell, wider spire whorls and a rounder aperture. With reasonable care there ought to be no difficulty in distinguishing lanceata from all related species. The spire whorls are only slightly oblique, notwithstanding the fact that Gould says in his description "quite oblique." The rectangular shape of the aperture and the flatly cylindrical form of the body whorl, will aid much in distinguishing lanceata.

Galba attenuata (Say). Plate XXXVII, figures 23, 24.

Lymnaus attenuatus SAY, New Harm. Dis., II, p. 244, 1829; Binney's Ed., p. 148 ; Discr., p. 23, 1858.

Lymnca attenuata JAY, Cat., Ed. 4, p. 268, 1852.

Limnaus attenuatus KüsṬE, Conch. Cab., p. 39, taf. 7, fig. 8, 1862.

Limnea attenuata HALD., Mon. Lim., p. 28, pl. 9, figs. 1-5, 1842.-DEKAY, Zool. N. Y., p. 75, 1843.

Limnaa attenuata Binney, Check List, p. 12, 1860 ; L. \& F. W. Sh. N. A., II, p. 42, fig. 53, 1865; Journ. de Conch., XV, p. 427, 1867.-Sowв., Conch. Icon., Lim., XVIII, pl. 13, fig. 32 c, 1872.-TRYon, Con. Hald. Mon., p. 95 (69), 1872.Streber, Ab. Natur. Ver., Hamb., VI, p. 57, taf. 5, figs. 32, 32 a, 1873.-Pilsbry, Proc. Phil. Acad., 1891, p. 320.-CR. \& Fisch., Miss. Scient. Mex., Moll., I, taf. 27, figs. 11, 11, a, b, II, p. 49, 1880.-BAKER, Nat. in Mexico, p. 103, 1895.-MARtens, Biol. Cent. Amer., Moll., p. 375, 1899.-Pilsbry, Proc. Phil. Acad. 1903, p. 776.

Leptolimnaa attenuata TrYon, Amer. Journ. Conch., 1, p. 257, 1865.

Omphiscola pugio BECK, Index Moll., p. 110, 1837 (sine descr.).

Limnaa emarginata Sowb. (non Say), Reeve's Conch. Icon., XVIII, Limnæa, pl. 6, fig. 35, 1872.

Limnaus turritus Philippi in coll. Dunker (vide Martens).

Limnaus mexicanus ZIEGLER, in coll. Dunker (vide Martens).

Limnaus subulatus DUNKer in Küster, Conch. Cab., Ed. 2, p. 24, taf. 4, fig. 24, 1862.-Von Martens, Mal. Blatt., XII, p. 58, 1865.-Clessin, MarT. \& Chemn., Conch. Cab., p. 395, taf. 16, figs. 1, 2, 1886. 
Limnaa subulata Binney, Check List, p. 12, 1861; L. \& F.-W. Sh. N. A., II, p. 42, fig. 54, 1865 ; Journ. de Conch., XV, p. 427, 1867.

Shell: Elongated, turreted, narrow, thin ; periostracum yellowish to reddish horn; surface shining, marked by close set lines of growth which are crossed by fine, wavy, impressed spiral lines; the growth lines are sometimes raised into fine ridges, especially on the last whorl; nuclear whorls $1 \frac{1}{2}$, smooth, round, dark colored, in outline like those of reflexa; whorls $6-7 \mathrm{I} / 2$, regularly increasing, flat-sided; spire long and attenuated; sutures not deeply impressed, sometimes bordered by a white line; aperture ovate, oblique, somewhat expanded in some specimens; peristome thin, the internal rib scarcely developed; inner lip narrow, reflected over and nearly closing the umbilicus, leaving a small chink; parietal callus wide and tightly appressed to the body whorl; columella with a distinct, strong, ascending plait; the aperture is sometimes a little reflexed as in some forms of reflexa; the axis is twisted.

\begin{tabular}{|c|c|c|c|c|c|c|}
\hline $\begin{array}{l}\text { Length. } \\
24.00\end{array}$ & $\begin{array}{c}\text { Width. } \\
8.00\end{array}$ & $\begin{array}{c}\text { Aperture length. } \\
9.00\end{array}$ & $\begin{array}{l}\text { Wid } \\
3.50\end{array}$ & $\begin{array}{l}\text { h. } \\
\text { nill. }\end{array}$ & \multirow{2}{*}{\multicolumn{2}{|c|}{$\underset{\text { Say's type. }}{\text { “. }}$}} \\
\hline 19.00 & 7.50 & 9.50 & 3.50 & “ & & \\
\hline 26.50 & 10.50 & 10.50 & 6.00 & “ & Mexic & o City. \\
\hline 18.50 & 7.00 & 9.00 & 9.00 & “ & “ & “ \\
\hline 18.00 & 6.00 & 7.00 & 7.00 & “ & “ & “ \\
\hline 22.00 & 9.00 & 10.00 & 4.00 & “ & " & " \\
\hline 21.25 & 7.00 & 8.00 & 3.00 & “ & “ & $"$ \\
\hline 34.50 & 14.50 & 13.00 & 5.50 & “ & Lake & Chalco. \\
\hline 35.00 & 12.00 & 12.50 & 5.00 & “ & & \\
\hline
\end{tabular}

Types: Attenuata, Academy of Natural Sciences, Philadelphia, two specimens, No. 58572. Subulata, turritus and mexicanus, location not ascertained.

Type Locality: Attemuata, Mexico City; subulata, Zimapan, Hidalgo; turritus and mexicanus, Mexico.

Animal, Jaw, Radula and Genitalia: Not examined.

RANGE: Mexican plateau. This species is found in the Lower Austral and Upper Austral life zones.

Hidalgo: Zimapan (Dunker).

\section{RECORDS.}

Mexico: Lake Chalco, City of Mexico (Baker; Heilprin; Strebel); Uhde, Lake of Mexico (Dunker); City of Mexico (Deppe and Schiede; Say); Lagos de Tezcuco, City of Mexico (Phil. Acad.); Tlalpam, City of Mexico (Pilsbry; Rhoads).

Geological Distribution: Unknown.

Ecology: Attenuata lives along the shores of the shallow lakes, in water from a few inches to a foot or more in depth; the shells are usually found on the muddy bottom or in shore vegetation. 
RemARKS: Galba attenuata resembles certain forms of reflexa, particularly reflexa walkeri. Its flat-sided, turreted whorls, elongated spire, heavy columellar plait and particularly the absence of the convex swollen penultimate whorl will distinguish it from reflexa. The body whorl is also more convex than in either reflexa or exilis. Galba exilis has more flat-sided whorls and a longer and narrower aperture. The aperture varies somewhat in some individuals being rather narrow while in others it is wider or even expanded and flaring. The flatness of the whorls varies also, in some individuals they are almost as flat as in exilis while in others they are almost as rounded as in typical reflexa. The whorls of attenuata are, however, always peculiarly flattened in the middle and rounded toward the sutures above, besides being more regular in their increase than in reflexa or exilis. Strebel figures several specimens which resemble some examples of Galba elodes jolietensis.

Say's types of attenuata are preserved in the Academy of Natural Sciences of Philadelphia. One specimen has seven whorls, which are flat-sided. Subulata Dunker is undoubtedly a synonym the spire whorls being wide and more flat-sided than typical attenuata. Mexicanus Ziegler is also a synonym. Haldeman's figures are excellent and correctly represent the species.

Galba danielsi (Baker). Plate XXXVIII, figures 1-8.

Limnophysa reflexa Blatch. and Ashley, Ind. Geol. \& Nat. Res., XXV, p. 248, 1901.

Lymnca danielsi BAKER, Nautilus, XX, p. 55, September, 1906.

SHELl: Elongated, attenuated, of medium thickness; periostracum ranging from very light-yellowish horn to dark chestnut or purple; surface shining, growth lines generally fine and close-set, but occasionally, as near the aperture, coarse and often raised into ridges; last whorl often malleated; spiral sculpture of fine impressed lines; nuclear whorls resembling those of reflexa in outline, spermaceti-white in color; whorls 7, flat-sided or slightly convex, slowly increasing in diameter; the body whorl is very large and much inflated; spire long and sharply attenuated, longer than the aperture; sutures impressed; aperture ovate or semi-lunate, often a little triangular, rounded below, acutely angled above, somewhat flaring; peristome sharp, simple, bordered by a dark purple or chocolate band in many specimens; parietal wall with a thin callus; inner lip narrow but wider than in reflexa, reflexed, generally closely appressed to the shell and almost closing the umbilical region, leaving a small chink; axis strongly twisted, almost gyrate, forming a heavy ascending plait; interior of aperture varying from white to dark purple. 


\begin{tabular}{ccccc} 
Length. & Breadth. Aperture length. & \multicolumn{2}{c}{ Breadth. } \\
28.50 & 12.00 & 14.00 & $6.50 \mathrm{~mm}$. \\
32.00 & 11.50 & 14.00 & 6.00 “ \\
30.50 & 13.50 & 13.25 & 7.50 " \\
27.50 & 11.50 & 12.50 & 6.00 " \\
29.00 & 11.25 & 13.00 & 6.00 “" \\
25.50 & 10.00 & 11.50 & 6.00 " \\
23.00 & 9.00 & 9.50 & 4.75 “ \\
20.00 & 10.00 & 10.50 & 5.50 "
\end{tabular}

Types: Chicago Academy of Sciences, two specimens, No. 23622; cotypes, five specimens, No. 23624; coll. L. E. Daniels; Academy of Natural Sciences of Philadelphia; Smithsonian Institution; State Museum, Indianapolis.

Type Locality: Lake Maxinkuckee, Indiana.

Animal: Resembling reflexa in form; color ranging from horn color to jet black; usually light yellowish flecked with white all over.

JAw: Superior jaw wider than high, much arched, the inferior margin with a strong, acute median projection; the anterior angles of the lower margin form two triangular projections. The jaw is in all respects like that of palustris (See Pl. VI, fig. 1).

Radula: (P1. IX, figs., B. C.) Formula: $\frac{17}{5}-\frac{7}{7}+\frac{2}{3}-\frac{4}{4}+\frac{9}{2}+\frac{1}{1}+\frac{9}{2}$ $+\frac{2}{3}-\frac{1}{4}+\frac{1}{5}-\frac{7}{7}(28-1-28)$; central tooth as in reflexa; lateral teeth bicuspid, the mesocone very large, acute, the ectocone small and wide; intermediate teeth tricuspid, the entocone small and placed near the lower end of the mesocone; the eleventh tooth has the entocone and mesocone of equal length; marginals long and narrow, claw-shaped, the distal end with from three to five denticles of variable length; the first four or five marginals have one or two small cusps on the outer margin. In one membrane the tenth tooth (first intermediate) had a swelling in place of an entocone (pl. IX, fig. C).

The transition from lateral to marginal teeth is very abrupt in danielsi, and the marginal teeth are very variable in the form and number of the denticles. There are about 110 rows of teeth.

Genitalia: (P1. XIII, fig. C) Male Organs: Penis short and thick, 2.50 mill. long, with a rounded head; penis-sac large, 3.50 mill. in length; penis retractor (3.00 mill. long) and penis-sac retractor (2.00 mill. long) flat, the latter inserted in penis-sac by about five small branches; protractor muscles seven in number, four posterior and three anterior, each bifurcated as it joins the penis-sac; vas deferens 18.00 to 20.00 mill. long, rather thick; prostate duct about 6.00 mill. in length, slightly enlarging as it enters the prostate; prostate very large, flattened, elongated, squarely rounded proximally and gradually 
narrowing distally, where it is attached to the first accessory albuminiparous gland.

Female Organs: Lower portion of oviduct long and narrow; receptaculum seminis very large, short, roundly-pear shaped, its duct large, 5.00 mill. long; first accessory albuminiparous gland very large, ovate.

The genitalia of danielsi are remarkably uniform. Four measurements gave the following results (Dissections No. 23599 and 23623).

$\begin{array}{cccccccc}\text { Penis. } & \begin{array}{c}\text { Penis- } \\ \text { sac. }\end{array} & \begin{array}{c}\text { Penis } \\ \text { retractor. }\end{array} \text { renis-sac } & \begin{array}{c}\text { Vas. } \\ \text { def. }\end{array} & \begin{array}{c}\text { Prost. } \\ \text { duct. }\end{array} & \begin{array}{c}\text { Rec. sem. } \\ \text { duct. }\end{array} & \text { Shell. } \\ 2.60 & 3.50 & 2.50 & 1.80 & 18.00 & 6.00 & 5.00 & 28.00 \\ 2.50 & 3.50 & 3.00 & 2.00 & 18.00 & 5.75 & 5.00 & 26.00 \\ 2.50 & 3.50 & 3.00 & 2.00 & 20.00 & 6.25 & 5.00 & 24.00 \\ 1.80 & 2.50 & \ldots . & \ldots . . & 8.00 & 2.50 & 3.00 & 13.50\end{array}$

The genitalia do not differ materially from those of palustris.

RANGE: (Figure 42). Indiana. A species of the humid division of the Upper Austral life zone, and of the Upper Mississippi region.

\section{RECORDS.}

Indiana: Lake Maxinkuckee, Marshall Co. (Bartsch; Daniels).

Geological Distribution: Unknown.

ECology: Probably lives in deep water as usually only dead shells are seen along the shore after storms. (Daniels).

Remarks: Danielsi may be known by its acutely pyramidal spire, large body whorl and flaring aperture. It somewhat resembles elongated forms of stagnalis but is smaller. Young forms of palustris somewhat resemble juvenile specimens of danielsi. The shells vary widely in color, some specimens being a rich chestnut brown while others are very light horn colored; nearly all specimens have a dark chocolate aperture, however. The light specimens outnumber the dark ones about two to one. A specimen collected by Mr. Bartsch is curiously deformed (pl. XXXVIII, fig. 3) the aperture being entire and separated from the body whorl.

The series of this species collected by Mr. Daniels is very uniform, showing that the species is quite stable. The last whorl is more convex and much wider than that of reflexa and the same may be said of palustris from which it also differs in its axis. A few curious variations occur in which the spire is shortened and the aperture is enlarged and expanded. In some specimens the columellar plait is exaggerated to such an extent that it forms a pseudo-tooth. In other specimens the lower part of the aperture is somewhat effuse. A few specimens are strongly scalariform. 


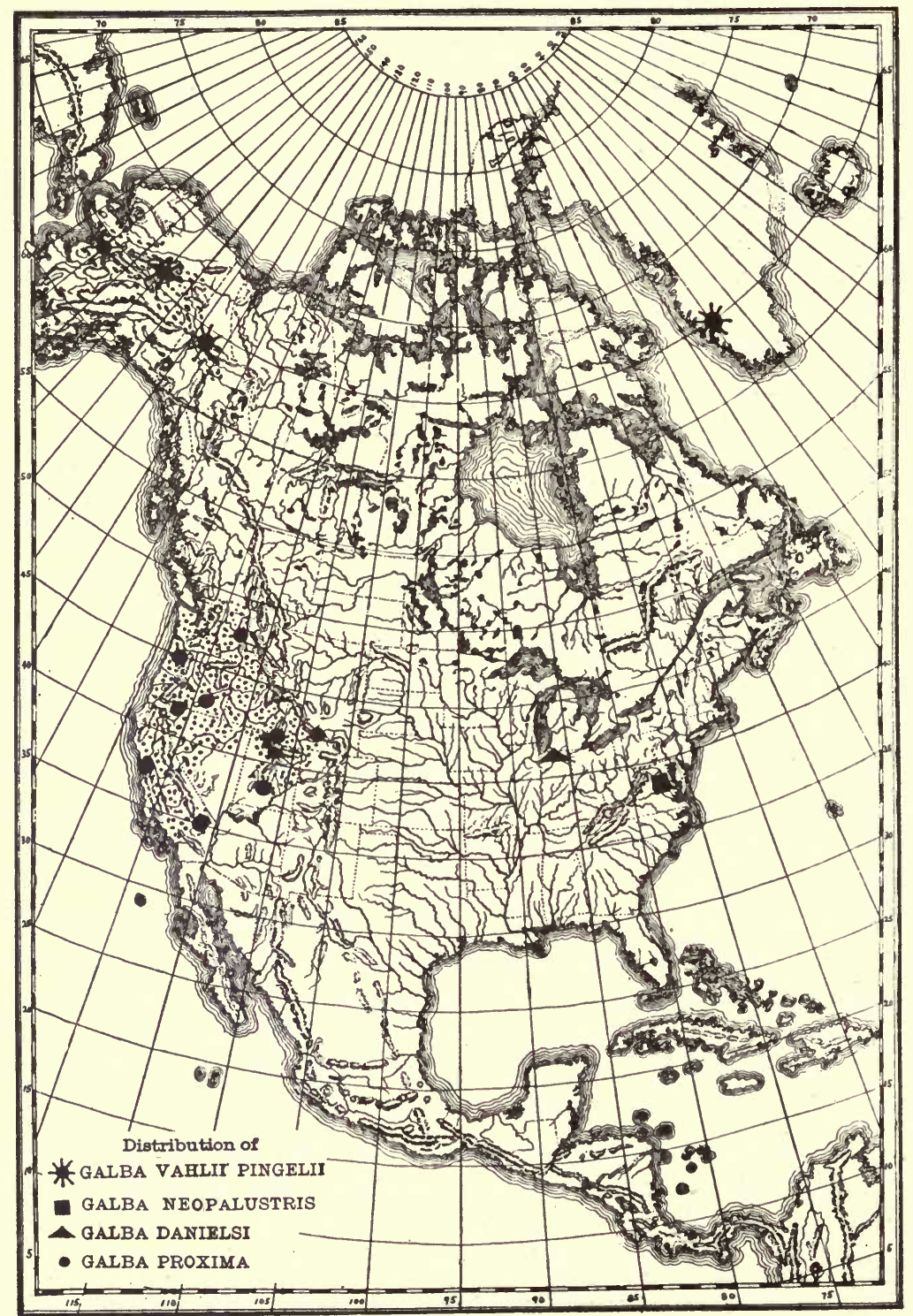

FIG. 42. 
Danielsi was at first thought to be a typical Lymncea, but an examination of the genitalia shows it to be a Galba closely allied to palustris and reflexa. The species is named in honor of Mr. L. E. Daniels of LaPorte, Indiana, who first made known this distinct and handsome species. It is an interesting circumstance that so large and distinct a Lymnæid should have been unnoticed in a region so thoroughly explored as the state of Indiana.

Galba proxima (Lea). Plate XXXVIII, figures 9-13.

Lymnaa proxima LeA, Proc. Phil. Acad., 1856, p. 80.-CpR., Rep. Brit. Assoc., 1864, p. 634.-LeA, Journ. Phil. Acad., VI, p. 160, pl. 24, fig. 74, 1866; Obs., XI, p. 116, pl. 24, fig. 74, 1867.-Morse, Amer. Nat., p. 651, pl. 11, fig. . 5, 1870.-CPR., Smith. Mis. Coll., 1872, p. 120.-ScudDER, Bull. Nat. Mus., 23, pp. 68,

Limnea proxima Binney, Check List, p. 12, 1860.-CPR., Rep. Brit. Assoc., 1864, p. 674.-Binney, L. \& F.-W. Sh. N. A., II, p. 48, fig. 67, 1865.-SowB., 149, 201, 1885.-DALL, Alaska Moll., p. 77, 1905.

Conch. Icon., XVIII, Lim., sp. 44, pl. 7, fig. 44a, 1872 (not true proxima).Crr., Smith. Mis. Coll., p. 160, 1872.-Tryon, Con. Hald. Mon., p. 96 (70), pl. 17, fig. 2, 1872 (fig. not typical).-Clessin, Küster, Conch. Cab., p. 389, taf. 53, fig. 7, 1886.-PILSBRY, Nautilus, XIII, p. 64, 1899.

Limnophysa proxima TrYon, Amer. Journ. Conch., 1, p. 251, 1865.-CALL, Bull. Wash. Coll. Lab. N. H., I, p. 52, 1885.-KeEp, West Coast Shells, p. 123, 1887; West Amer. Sh., p. 149, 1904.

Limnophysa palustris var. proxima Cooper, Zoe., I, p. 196, 1890.-KeEP, West Amer. Shells, p. 314, 1904.

Limnca palustris var. proxima Wood, Nautilus, V, p. 56, 1891.

Limnca elodes var. proxima Cooper, Proc. Cal. Acad. Sci., IV, p. 96, 1870.

Limncea palustris TRYON, Con. Hald. Mon., p. 97 (71), pl. 17, fig. 4, 1872 (monstrosity).

Limnaa californica Sowb., Conch. Icon., XVIII, Lim., sp. 67, pl. 10, figs. 67, a, b, 1872.

Limnaa interstriata SowB., Conch. Icon., XVIII, Lim., sp. 62, pl. 10, fig. 62, 1872.

Limnaa sumasii Sowb. (non Baird), Conch. Icon., XVIII, sp. 34, pl. 5, figs. 34, a, b, 1872.

Leptolimnaa kirtlandiana KeEP, West Coast Shells, p. 121, fig. 109, 1887.

Limnaa kirtlandiana KeEP, West Amer. Shells, p. 150, fig. 130, 1904.

SHell: Acutely conic, varying from thin to rather thick; periostracum light yellowish horn to black; surface dull to shining; sculpture consisting of rather heavy growth lines crossed by impressed spiral lines; very rarely malleated; whorls 6-\%, moderately convex, rapidly increasing in diameter, the body whorl usually somewhat obese; nuclear whorls dark chestnut, rounded, the first whorl somewhat larger than in palustris and reflexa; spire long and acutely conic; sutures well impressed, deeply so in many specimens, and sometimes bordered below by a dark band; aperture nearly elliptical, sometimes 
a trifle inflated, about two-fifths the length of the shell; peristome thin, sharp, with a slight internal rib, chestnut colored on the edge; inner lip narrow, reflected and appressed to the columellar region leaving a very narrow chink; the parietal callus is thin and narrow; a distinct, sharp but not heavy plait extends across the columella in an upward direction; the axis is slightly twisted.

$\begin{array}{ccccc}\text { Length. } & \text { Width. } & \text { Aperture length. } & \text { Width. } & \\ 21.00 & 8.50 & 8.50 & 4.00 \text { mill. } & \text { Type, proxima. } \\ 24.00 & 10.00 & 11.00 & 5.50 \text { “ } & \text { San Francisco, Cal. } \\ 27.50 & 11.50 & 12.00 & 6.50 \text { “ } & \text { San Mateo, Cal. } \\ 28.00 & 12.00 & 13.00 & 7.00 \text { “ } & \text { “ } \\ 18.00 & 8.00 & 7.50 & 4.00 \text { “ } & \text { Wyoming. }\end{array}$

Types: Proxima, Lea, two specimens, Smithsonian Institution, No. 29082 ; cotypes, Philadelphia Academy of Sciences, No. 58503; californica, Sowerby and interstriata, Sowb., British Museum of Natural History, London, England.

Type Locality: Proxima, Arroya, San Antonio, Cal. ; californica, California ; interstriata, California.

Animal, Jaw, Radula and Genitalia: Not examined.

RANGE: (Figure 42) California to Wyoming; Washington south to Southern California. The regional map shows that proxima is common to the Columbian, Coloradoan, Great Basin and Californian regions. It is also characteristic of two great river systems, the Columbia and the Colorado. The records show that proxima has a wide range in Western America from the 35th to the 48th degree of North latitude. It seems to thrive from near the sea level to a height of over $\%, 000$ feet.

\section{RECORDS.}

California: Mountain stream near San Francisco, San Francisco Co. (Button; Cooper; Nason; Rowell; Stearns; Walker); San Mateo Co. (Hemphill); South Fork Pitt River, Modoc Co. (McGregor); Arroya, San Antonio, San Bernardino Co. (Lea; Trask).

Oregon: Dallas, Polk Co. (Dall; Stearns); southeast Oregon (Gabb); Steins Valley, Harney Co. (Tryon).

UTAH: Near Salt Lake City, Salt Lake Co. (Hemphill); near Logan, Cache Co. (Hemphill; Keep; Walker); Beaver City, Beaver Co., high up in Wasatch Mountains (Palmer); Bear Lake, Rich Co. (Walker).

Washington: Spokane, Spokane Co. (Smith. Inst.); Columbia River (T. B. Wilson).

Wyoming: Alkali Springs, forty miles north of Almond, Sweetwater Co. (W. C. Knight).

Geological Distribution: Unknown.

ECOLOGY: In mountain streams or small lakes, generally at high altitudes. 
Remarks: Proxima resembles certain long-spired forms of palustris, from which it may be distinguished by its more convex bady whorl, longer and more regularly conic spire and rounder aperture, and more rapidly enlarging whorls. Long-spired palustris from the Mississippi Valley region have usually a more obese body whorl, but the California long-spired palustris have usually a less obese body whorl than proxima. The difference in the spire whorls, the aperture and the body whorl, is sufficient to distinguish proxima from palustris. It apparently replaces reflexa west of the Rocky Mountains, and has been named by collectors reflexa, elodes, palustris and umbrosa, from all of which it is quite distinct.

Lea's types of proxima agree with Binney's figure, and show well the rapid enlargement of the whorls which is so characteristic of this species. Tryon's figure in Continuation Haldeman, is not characteristic. Sowerby's californica as well as his interstriata are synonyms of proxima. An authentic specimen of californica, which has been compared with Sowerby's type in the British Museum, is figured on plate XXXVIII (ex. coll. Walker). For the sake of comparison, Sowerby's descriptions are appended:

"Limncea californica: Shell elongate, pyramidal, thin, semi-pellucid, pale horn colored; spire elevated, whorls five, oblong, moderately convex; aperture ear-shaped, short; inner lip single-plaited in the middle ; columellar fold twisted backward."

"Limnca interstriata: Shell pyramidal, acuminated, solid, yellowish chestnut; distantly slightly longitudinally riged, finely striated, longitudinally striated; spire elevated; whorls four, attenuated, rather convex; aperture subtrigonal, slightly orange; columella, white; columellar fold, thick, broad."

The angulate specimen figured by Tryon (Con. Hald. Mon., pl. $1 \%$, fig. 4), as a form of palustris, is probably a pathologic phase of proxima. The strongly angulated whorls make a very peculiar looking shell; Tryon's specimen (No. 58523 Acad. Nat. Sci. Phil.) measures as follows: Length, 22.00 ; width, 9.75 ; aperture length, 10.50 ; width, 5.25. It was collected in mountain lake near San Francisco by $\mathrm{Mr}$. Rowell. Typical proxima also inhabits this lake as well as its variety rowellii.

Proxima has been made a synonym or variety of palustris by many recent authors, but it would seem to be as much entitled to specific rank as almost any of the palustris-reflexa group. It possesses characteristic features which sufficiently distinguish it from its congeners. 
Galba proxima rowellii (Tryon). Plate XXXVIII, figures 1421.

Limnca rowellii Tryon, Amer. Journ. Conch., I, p. 228, pl. 23, fig. 1, 1865; Con. Hald. Mon., p. 95 (69), pl. 17, fig. 1, 1872.

Limnophysa rowellii Tryon, Amer. Journ. Conch., I, p. 250, 1865.

Limnca palustris var. rowellii Wood, Nautilus, V, p. 56, 1891.-KEEP, West Amer. Shells, p. 314, 1904.

Limnophysa palustris var. rowelii Cooper, Zoe, I, p. 196, 1890.

Lymnaa palustris var. rowelli DALL, Alaska Moll., p. 76, fig. 56 g, 1905.

Limnaa umbrosa var. rowelli Cooper, Proc. Cal. Acad. Sci., IV, p. 96, 1870.

Limnaa proxima Sowв., Conoh. Icon., Lim., pl. 7, fig. 44 b, 1872.

Limnaa reflexa Tryon, Proc. Phil. Acad., 1863, p. 149.

Limnophysa reflcxa KEEP, West Amer. Shells, p. 149, 1904.

Limnaa umbrosa Tryon, Proc. Phil. Acad., p. 149, 1863. ${ }^{1}$-Cooper, Proc. Cal. Acad. Sci., IV, p. 96, 1870.

Limnea umbrosa Gould, U. S. Exp. Exped., p. 122, 1852 (?).

Limnea palustris var. umbrosa Wood, Nautilus, V, p. 56, 1891.-KEEP, W. Amer. Sh., p. 314, 1904.

Limnea palustris michiganensis WaLkeR, Nautilus, VI, p. 33, 1892 (part?).

Lymnaa umbrosa Cooper, Pac. R. R., Rep., XII, pt. 2, p. 378, 1860.

Lymnaa proxima rowellii BAKer, Bull. State Lab. Nat. Hist., VIII, p. 493, 1910.

SHELL: Elongated, acute, rather thin; periostracum varying from light yellowish horn to almost black; surface dull to shining; sculpture as in proxima; lines of growth conspicuous on the body whorl; whorls six to seven, flatly rounded, somewhat oblique, loosely coiled, the body whorl flatly rounded, compressed; spire acute, elongated, generally longer than the aperture; sutures well marked, sometimes heavily impressed; aperture very elongate-ovate, varying from narrow to wide and flaring; peristome thin with a light chestnut-colored internal varix ; inner lip narrow, erect, the parietal callus closely appressed and thin or very thick; there is a narrow umbilical chink in some specimens; columella with a distinct, sometimes heavy, ascending plait; axis twisted as in palustris.

\begin{tabular}{cccccc} 
Length. & Width. & Aperture length. & \multicolumn{2}{c}{ Width. } \\
27.25 & 10.50 & 12.00 & $5.00 \mathrm{mill}$ & Type. \\
24.00 & 10.00 & 10.00 & 4.50 & " & " \\
24.50 & 10.00 & 10.50 & 5.00 & " & San Francisco Co., Cal. \\
22.50 & 9.00 & 10.00 & 4.50 & "San Francisco, Mt. Lake. \\
29.00 & 12.00 & 15.50 & 7.50 & " & " \\
32.00 & 14.00 & 15.50 & 8.50 & " & "
\end{tabular}

Types: Academy of Natural Sciences, Philadelphia, three specimens, No. 58588 .

${ }^{1}$ These references are believed to have been based on the different forms of rowelli, as the true umbrosa (=elodes) has not been seen from west of the Rocky Mountains. 
Type Locality: San Francisco, Cal.

Animal, Jaw, Radula and Genitalia: Not examined.

RANGE: (Figure 40) Washington south to California. A species of the Transition life zone and appears to be mainly restricted to the Californian and Columbian regions west of the Sierra Nevada range. It may have been recorded as palustris from the region between the latter and the Rocky Mountains, but no authentic specimens have been examined.

\section{RECORDS.}

California: Mountain lake near San Francisco, San Francisco Co. (Button; Cooper; Dall; Hemphill; Dr. Horning; Lea; Rowell; Stearns; Tryon; Wood); San Francisco; Lower Klamath Lake, Siskiyou Co. (Gabb); Contra Costa Co. (Hemphill); Oakland, Alameda Co. (Rowell).

Washington: Lake Osoyoos, Okanogan River, Okanogan Co. (Cooper). Oregon: Dallas, Polk Co. (Stearns).

Geological Distribution: Unknown.

ECology: Probably the same as that of proxima.

Remarks: Galba proxima rowellii appears to be a modification of the proxima type rather than of the palustris form. It is easily separated from proxima by its more flat-sided whorls and its more elongated and narrower aperture. (Compare the figures on the plate.) The sutures, also, are less heavily impressed. There are connecting links, however, which show its relation to proxima, a notable locality heing Mountain Lake, near San Francisco. It is liable to be confused with elodes, but that species has a rounder aperture and rounder and less oblique whorls. It is probable that western references to reflexa bavc been based on forms of this shell, as no authentic specimens of reflexa have been seen from west of the Rocky Mountains. Rowellii may be known from long spired specimens of palustris occupying the same area, by its more acute spire, with more flat-sided whorls, and by its less obese, flat-sided body whorl.

Tryon's types in the Philadelphia Academy of Sciences are well illustrated by his figures in American Journal of Conch. and in the continuation of Haldeman's Monograph. The material examined shows that the variety may be narrower or wider than figured by Tryon and the outer lip may flare markedly. (Pl. XXXVIII, figs. 15, 19.)

Galba leai (Baker). Plate XXXIX, figures 1-3.

Lymnaa leai BAKER, Nautilus, XX, p. 126, March, 1907.-Henderson, Univ. Colo. Studies, IV, pp. 167, 180, 1907.

?Limnaa nuttalliana INGersoll, Bull. U. S. Geol. Surv., I, p. 138, 1875; Rep. U. S. Geol. \& Geog. Surv. Ter., p. 406, 1876. 
SHELL: Large, ovate, thin; periostracum yellowish-horn; surface with fine lines of growth crossed by equally fine spiral lines; whorls six, flatly rounded, very rapidly increasing in diameter, the last whorl very large and somewhat elongated; spire short, broadly ovately conic; sutures well impressed; aperture elliptical or elongate-ovate, narrowed above, longer than the spire, effuse anteriorly; outer lip thin, only slightly thickened by a longitudinal varix; inner lip thin, narrow, appressed to the umbilical region so as to leave a well marked chink; callus on the parietal wall thin, wide, well marked; columella twisted, with a strongly developed, ascending plait.

$\begin{array}{ccccc}\text { Length. } & \text { Width. } & \text { Aperture length. } & \text { Width. } & \\ 30.00 & 13.50 & 18.00 & 8.50 \text { mill. } & \text { Type. } \\ 28.00 & 13.50 & 17.00 & 8.00 \text { " } & \text { “ } \\ 31.00 & 14.50 & 18.50 & 9.50 \text { “ } & \text { " }\end{array}$

Type: The Chicago Academy of Sciences, one specimen, No. 23653. Cotypes: Collection Illinois State University, two specimens.

Type Locality: Near San Francisco, California.

Animal, Jaw, Radula and Genitalia: Unknown.

RANGE: California to Colorado. A race of the Transition and Upper Sonoran life zones, confined to the Californian and Coloradoan regions.

\section{RECORDS.}

California: Near San Francisco, San Francisco Co. (Nason); San Joaquin River (Mrs. E. E. Rush); Merced Lake, Merced Co. (Dall; Stearns).

Colorado: Between Animas and La Plata rivers (Ingersoll).

Geological Distribution: Unknown.

Ecology: Not recorded.

Remarks: Leai seems to be a very distinct species easily recognized by its short spire, very large, narrow, aperture and heavy columellar plait. It is more nearly related to Galba proxima rowellin Tryon than to any other Lymnæa but seems to be distinct. It has probably been heretofore identified as a form of the protean species palustris, but it is unquestionably distinct from any form of that species. It differs from palustris in its larger and flatter body whorl, long, oblique and reflexed aperture and in the form of the columella. The aperture somewhat recalls reflexa.

Specimens from Colorado, deposited by Ingersoll in the Smithsonian collection appear to belong to this species although the localities are widely separated. Ingersoll's record of nuttalliana from Colorado "between Animas and La Plata rivers" was probably based on these specimens. The species is dedicated to one of America's best known pioneer conchologists, Dr. Isaac Lea. 
Galba tryonii (Lea). Plate XXXIX, figures 4-5.

Lymncea traskii LEA, Proc. Phil. Acad., p. 113, 1864 (not of Tryon, 1863).ScudDER, Bull. Nat. Mus., 23, pp. 149, 201, 1885.

Limncea traskii Tryon, Con. Hald Mon., p. 102 (76), pl. 18, fig. 1, 1872.

Limnophysa tryonii 'LEA' MS, Tryon, Amer. Journ. Conch., I, p. 251, 1865.

Limnaa tryonii RandolPh, Nautilus, IX, p. 102, 1896.-KeEP, West. Amer. Sh., p. 314, 1904.

Lymnea tryoniana LEA, Journ. Acad. Nat. Sci., VI, p. 162, pl. 24, fig. 78, 1866 ; Obs., XI, p. 118, pl. 24, fig. 78, 1867.

Limnea tryoniana CARLton, Proc. Cal. Acad. Sci., IV, p. 51, 1869.

Limnaa tryoniana Cooper, Proc. Cal. Acad. Sci., IV, p. 96, 1870.

Lymncea tryoniana ScudDER, Bull. Nat. Mus., 23, pp. 149, 201, 1885.

Shell: Small, subfusiform or subovate, sometimes slightly elongated, thin, semi-transparent, rather inflated; periostracum very light yellowish horn; surface shining, marked by numerous closeset, even lines of growth which are crossed by heavy impressed spiral lines, giving the surface a peculiarly engraved appearance; nucleus very dark red; whorls $51 / 2$ to 6 , convex, rapidly increasing in diameter, the body whorl slightly convex; spire conic, acute, about as long as the aperture; sutures well marked but not deeply impressed, bordered -below by a light band which is sometimes edged with dark purple, especially on the last whorl; aperture ovate to broadly ovate, with a broad, thick, brown-edged varix within; inner lip appressed to the umbilical region leaving a very small chink; callus on the parietal wall thin; columella with a sharp plait which gives the axis a slight twist.

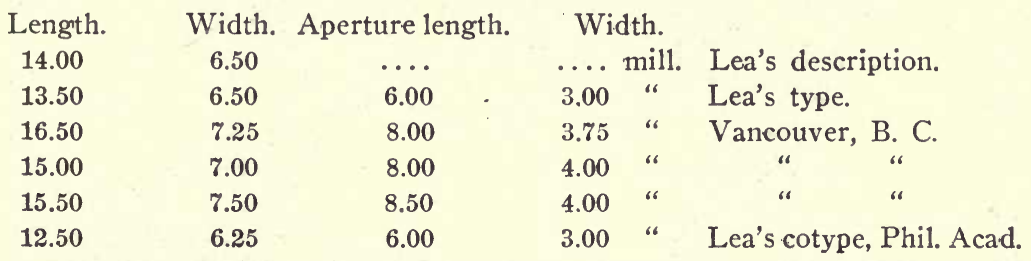

Types: Smithsonian Institution, three specimens, No. 121470; cotypes, Academy of Natural Sciences, Philadelphia, No. 58514.

Type Locality: Arroya, San Antonio, Cal.

Animal, Jaw, Radula and Genitalia: Not examined.

RANGE: (Figure 43) Vancouver Island south to southern California, west of the Sierra Nevadas. Tryonii is a species of the Transition and Upper Austral (Upper Sonoran division) life zones. It is common to the Californian and Columbian regions. It is probable that this species will be found very commonly distributed over the area west of the Sierra Nevadas, when it is distinguished from palustris, with which species it has been confused by nearly all recent students. 


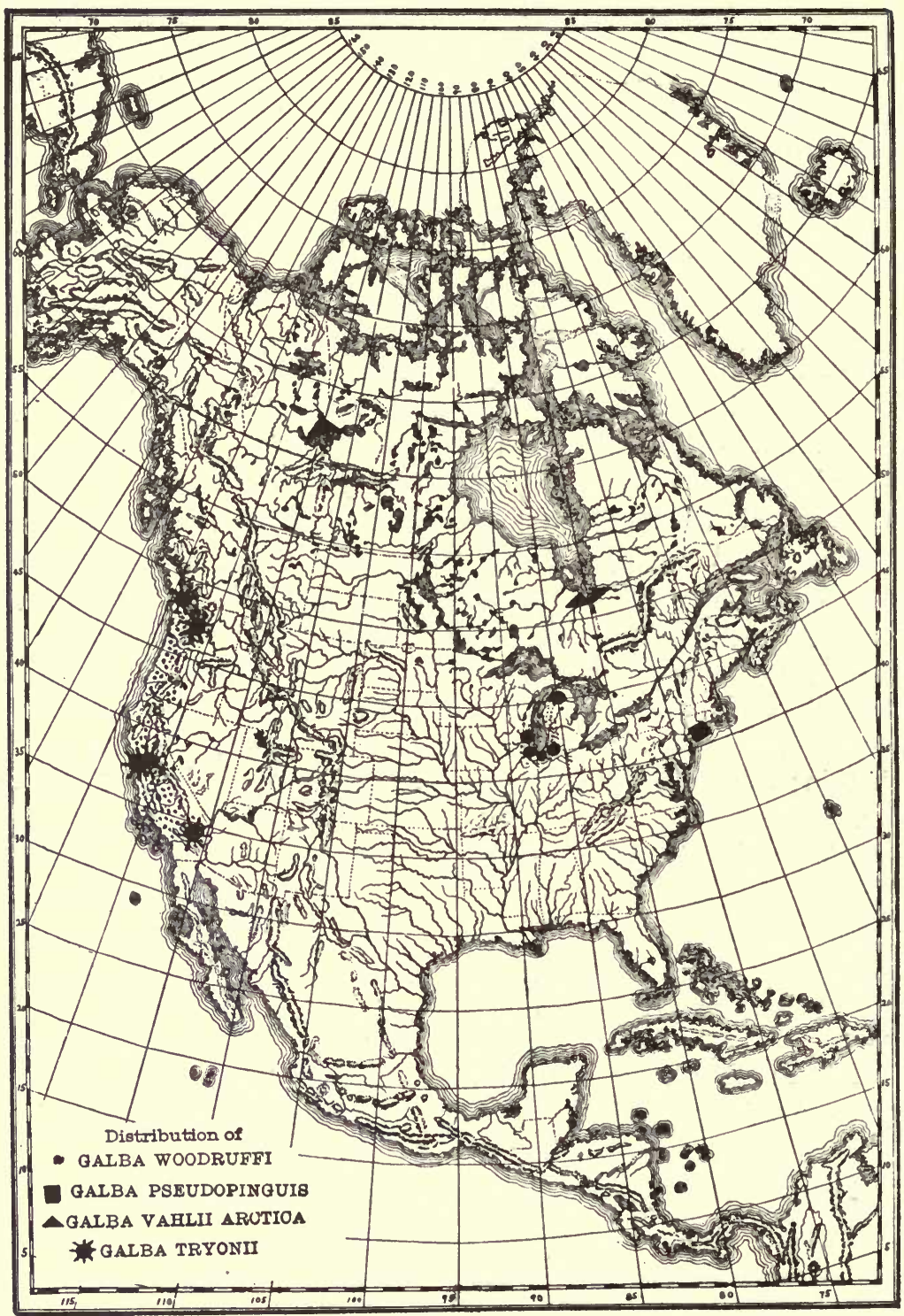

FIG. 43. 


\section{RECORDS.}

United States.

California: Antioch, Contra Costa Co. (Carlton); San Antonio, San Bernardino Co. (Lea); San Francisco, San Francisco Co. (Rowell); Alameda Co. (Walker).

Washington: Green Lake, Seattle, King Co. (Randolph).

\section{British America.}

British Columbia: Vancouver Island (Walker).

Geological Distribution: Unknown. ${ }^{1}$

ECOLOGY: Not recorded. The habitat relations of tryonii are probably similar to those of palustris.

REMARKS: Tryonii is quite a distinct little species, though related to proxima. It is always a smaller species than proxima though having about the same number of whorls, and the spire is not so elongated. The sutures, also, are shallower and the whorls are more flat-sided. It is not particularly related to palustris, being easily separated by its smaller size, regularly conical spire, flattened whorls and by its regularly ovate aperture. All of the specimens examined have a peculiarly delicate yet distinct sculpture like an engine-turned surface. The whorls vary somewhat in corpulency, and the aperture is more ovate in some specimens than in others. The columellar plait is quite prominent. Small specimens of palustris have been seen in various collections from localities east of the Sierra Nevadas, which have been labeled tryonii, but no authentic material has been seen from this area. It has doubtless been reported as palustris from the region west of the Rocky Mountains and a careful search through the collections will probably widely extend the distribution, besides filling in many blanks on the map.

Lea first named this species traskii but later changed the name to tryoniana on account of Tryon's traskii a distinct species named in the previous year. Tryon, however, used the name tryonii LEA, MS, in 1865 thus antedating Lea's name by a year. Lea's original specimens are in the Smithsonian collection and compare favorably with the specimens illustrated in this monograph. (P1. XXXIX, fig. 4, one of the type specimens, No. 1214\%0). The figure in Tryon's continuation of Haldeman is not good as will be seen by a comparison with the photograph of the type specimen.

IIn the fourth annual report of the Geological Survey of Texas (p. 188) Mr. Singley records tryonlana as a fossil or subfossil from Tule Canyon, Swisher County, Texas. He says of it "Nearer this than any other species. Well preserved shells, though bleached." The writer has not been able to examine these shells, and he seriously doubts their being tryonil, authentic specimens of which have not been seen from the great plains region. These specimens were probably small or immature forms of palustris, which species has been reported as a fossil from northern Texas. 
Galba traskii (Tryon ${ }^{1}$ ). Plate XXXIX, figures 6-10.

Limnca traskii Tryon, Proc. Phil. Acad., p. 149, pl. 1, fig. 13, 1863.-CPR., Rep. Brit. Asso., 1863, p. 674, 1864.-Binney, L. \& F.-W. Sh. N. A., II, p. 60, fig. 94, 1865.-Carlton, Proc. Cal. Acad. Sci., IV, p. 51, 1869.-Tryon, Con. Hald. Mon., p. 96 (70), pl. 17, fig. 3, 1872.-CPR., Smith. Mis. Coll., 1872, p. 160.Clessin, Mal. Blatt, n. S., III, p. 82, 1881.-?Westerlund, Vega Exp., IV, p. 163, 1883.-Ckll., Journ. Conch., VI, p. 258, 1890.

Lymnaa traski DALl, Alaska Moll., p. 74, 1905.

Limnaus traskii Clessin, Küster, Conch. Cab., p. 386, taf. 53, fig. 3, 1886 (fig. not good).

Limnophysa traskii Tryon, Amer. Journ. Conch., I, p. 254, 1865.

Limnaa elodes var. traskii Cooper, Proc. Cal. Acad. Sci., IV, p. 96, 1870.

Limnaa palustris var. traskii Wood, Nautilus, V, p. 56, 1891.-KEEP, West Amer. Sh., p. 314, 1904.

Shell: Ovate, acutely conical; periostracum light horn colored, surface dull to shining; growth lines very distinct, frequently raised to form ridges, crossed by distinct spiral lines; some of the upper whorls are frequently malleated; whorls 6 to $6 \mathrm{t} / 2$, well rounded, particularly the body whorl; spire short, but acutely conical, forming a rather broad pyramid; sutures very deeply impressed, constricted; aperture ovate or roundly ovate, a little less than half the length of the shell; outer lip thin, without pronounced varical thickening; inner lip flatly reflected over the umbilical region forming a rather broad expansion, leaving a very distinct umbilical chink; the callus on the parietal wall is sometimes thick and heavy, rendering the aperture continuous; the inner lip is flat and smooth (recalling in this respect the Galba groups of Lymnæas) and there is no distinct columellar plait, although in some specimens there is a thickening of the axis, which is slightly twisted.

\begin{tabular}{|c|c|c|c|c|c|c|}
\hline $\begin{array}{l}\text { Length. } \\
13.00\end{array}$ & $\begin{array}{c}\text { Width. } \\
7.00\end{array}$ & $\begin{array}{c}\text { Aperture length. } \\
5.50\end{array}$ & & $\begin{array}{l}\text { ith. } \\
\text { mill. }\end{array}$ & Type. & \\
\hline 16.00 & 9.00 & 8.00 & 6.25 & “ & San Francisco, & Cal. \\
\hline 20.00 . & 10.50 & 9.25 & 5.50 & “ & & \\
\hline 22.50 & 11.50 & 10.50 & 5.75 & “ & " & “ \\
\hline 21.25 & 10.00 & 9.50 & 4.50 & “ & “ & 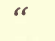 \\
\hline 23.00 & 11.00 & 10.50 & 5.50 & “ & " & " \\
\hline 16.00 & 8.00 & 7.00 & 5.00 & “ & Tryon. & \\
\hline 21.50 & 10.00 & 10.50 & 6.00 & " & Banff, Alberta. & \\
\hline
\end{tabular}

${ }^{1}$ The following references to traskii cannot be verified:

Limnea traski Ingersoll, Bull. U. S. Geol. \& Geog. Surv. I, p. 139, 1875; Rep. U. S. Geol. \& Geog. Surv. Terr., 1874, p. 406, 1876.

Lymnæa traski Henderson, Univ. Col. Studies, IV, p. 185, 1907.

Limnæa traskii Walker, Nautilus, VI, p. 33, 1892.

Limnæa traski, Walker, Rev. Moll. Mich., 1894, pp. 18, 22.

Ingersoll says, "Comes near to L. traski, but distinct."-Dr. James Lewis in letter. Henderson's remark that "we suspect a mixing of labels or mistaking abbreviation of California for Colorado," may possibly be true concerning this record. Walker simply says, "Cited by DeCamp from Houghton Lake." This may have been a form of palustris, which species lives in this lake. 
TyPE: Academy of Natural Sciences, Philadelphia, Pa., one specimen, No. 58519.

Type Locality: Mountain lake, California.

Animal, Jaw, Radula and Genitalia: Not examined.

RANGE: (Figure 39) California to Wyoming, north to southern Alberta. A species characteristic of the Upper Austral Transition and Boreal (Canadian) life zones and of the Californian, Coloradoan and Hudsonian regions. A careful search will doubtless fill the vacant territory between Wyoming, California and Alberta.

\section{RECORDS.}

\section{United States.}

California; Oakland and Berkeley, Alameda Co. (Cockerell); mountain lake near San Francisco, San Francisco Co. (Hemphill; Rowell; Tryon; Wood); Santa Clara Co. (Stearns).

Wyoming: Black Rock Butte, Sweetwater Co. (W. C. Knight; Walker).

\section{British America.}

Alberta: Banff (Bos. Soc. N. H.).

Geological Distribution: Unknown.

Ecology: Not recorded.

Remarks: Traskii may be known by its short spire, very large, rotund body whorl and distinct umbilical chink. The inner lip is broadly reflected and without a distinct plait, resembling in this respect such species as cubensis, galbana, etc. It is this resemblance which has led some conchologists to place traskii in the synonymy of galbana, an erroneous disposition as it is clearly a member of the subgenus Stagnicola and is closely related to proxima, which occasionally has a raised inner lip and a small chink. The flat, smooth expansion of the inner lip is not always a safe guide as this occurs in typical palustris (from Colorado) as well as in certain species of the emarginata group, which are undoubtedly members of the subgenus Stagnicola. ${ }^{1}$

The study of Tryon's type and of the material in Philadelphia, Washington and in certain private collections, renders it apparent that traskii is a distinct species and not a variety of proxima as thought by Tryon. No specimens have been seen which connect the two species although they occupy the same territory. The sudden enlargement of the body whorl, the wide, smooth inner lip, the conspicuous umbilical chink, and the short, almost shouldered spire, are characteristics which separate traskii from proxima. Von Martens cites the species from Alaska, but this record needs confirmation.

\footnotetext{
${ }^{1}$ An examination of the radula will at once settle the question of its proper position, Stagnicola having bicuspid laterals while the group of which galbana is a member has tricuspid laterals.
} 
Galba vahlii ("Beck" Möller). Plate XXXIX, figures 11-18.

Limnaa (Limnophysa) vahlii Beck, Index, p. 111, 1838 (Nude name).

Limnca vahlii Mörch, Moll. Grön., p. 76, 1857.-BINney, Check List, p. 12, 1860; L. \& F.-W. Sh. N. A., II, p. 57, fig. 89, 1865.-MörCH, Amer. Journ. Conch., IV, pp. 34, 36, pl. 4, figs. 1-5, 1868.-Sowb., Conch. Icon., XVIII, sp. 23, pl. 4, fig. 23, 1872.-Tryon, Con. Hald. Mon., p. 100 (74), pl. 17, fig. 10, 1872.Steenstrup, Mal. Blatt., n. s., I, p. 17, 1879.-Westerlund, Vega-Exp., IV, pp. 167, 169, 170, 1885.-Whiteaves, Nautilus, XIX, p. 3, 1905; Ottawa Nat., XIX, p. 65, 1905.-ScharfF, Proc. Roy. Irish Acad., XXVIII, Sect. B, p. 20, 1909.

Limncus vahlii Küster, Conch. Cab., p. 27, taf. 5, figs. 8, 9, 10, 1862.

Limnaus palustris var. vahlii Dald, Proc. Nat. Mus., IX, pp. 202, 208, 1886. -Whiteaves, Ottawa Nat., XIV, p. 222, 1901.

Limnophysa vahlii Tryon, Amer. Journ. Conch., I, p. 254, 1865.

Lymnca vahlii Möller, Index, Moll. Groen., p. 4, 1842.-JAY, Cat., Ed. 4, p. 271, 1852.-Reeve, Voy. Assistance, p. 392, 1855.-Dall, Alaska Moll., p. 74, fig. 54, 1905.

Limnca vahlii var. elongata MöLLER (MS), in Mörch, Am. Journ. Conch., IV, p. 40, pl. 4, fig. 1, 1868.

Limnaa vahlii var. leucostoma Mörch, Prod. Moll. Grön., p. 4, No. 11, B, 1842 ; Prod. Moll. Grön., p. 76, 1857.-Steenstrup, Mal. Blatt., n. s., I, p. 17, 1879 .

Limnaa leucostoma CPR., Rep. Brit. Asso., 1856, p. 222.-MöRCH, Amer. Journ. Conch., IV, p. 34, 1868.

Lininaa leucostoma, B. minor, Mörch, Amer. Journ. Conch., IV, p. 34, 1868.

Limnophysa vahlii, $b$. inaqualis BECK, Index, p. 111, 1838.

Limnophysa vahlii, a., lavigata BECK, Index, p. 111, 1838.

Limnaa mölleri BECK, Naturf. Vers. Kiel, p. 123, No. 4 (nude name); Gerstreldt, Land und Sussw. Conch., Sibiriens, p. 37, 1859.-MörCH, Amer. Journ. Conch., IV, p. 34, 1868.

Limnaa grönlandica (Beck MS.) JAY, Cat., p. 269, No. 6298, 1850.-BINNEY, Check List, p. 12, 1860.-Mörch, Amer. Journ. Conch., IV, p. 33, 18668.

Lymnaa grenlandica (Beck MS), JAY, Cat. Ed. 4, p. 269, 1852.

Limnophysa grcnlandica TrYoN, Amer. Journ. Conch., I, p. 254, 1865.

Limnaus grönlandicus ClessiN, Küster Conch. Cab., p. 396, taf. 16, figs. $8,9,1886$.

Limnca vahlii var. parva MöRch, Moll. Grön., p. 76, 1857.-SteenstruP, Mal. Blatt, n. s., I, p. 17, 1879.

Limnaa vahlii var. nitens Mörch, Moll. Grön., p. 76, 1857.-Steenstrup, Mal. Blatt., n. s., I, p. 17, 1879.

Limnaa palustris RAN DolPH, Nautilus, XII, pp. 109, 110, 1899 (part).

Lymnaa wormskioldi BEck, Naturf. Vers., Kiel, p. 123, No. 7 (nude name).

Limnca wormskioldii Mörch, Prod. Moll. Grön., p. 76, 1857.

Limnaa wormskioldi Mörch, Amer. Journ. Conch., IV, p. 35, pl. 4, fig. 6, 1868.-Binney, L. \& F.-W. Sh. N. A., II, p. 58, 1865.-West., Vega-Exp., IV, pp. 167, 170, 1885.-ScharfF, Proc. Roy. Irish Acad., XXVIII, sect. B, p. 20, 1909.

Limnca wormskjoldii Steenstrup, Mal. Blatt, n. s., I, p. 17, 1879. 
Limnophysa wormskioldi Tryon, Amer. Journ. Conch., I, p. 254, 1865.

Limnaa vahlii, Jun., Mörch, Prod. Moll. Grön., No. 135.

Limnaa senegalensis BECK, Index, p. 111, 1838 (nude name); Мörch, Amer. Journ. Conch., IV, p. 35, 1868 (footnote).

Limnaa vahlii var. malleata Mörch, Moll. Grön., p. 76, 1857.-SteEnstrup, Mal. Blatt., n. s., I, p. 17, 1879.-MörCH, Amer. Journ. Conch., IV, p. 35, 1868.

Shell: Thin, sometimes translucent, ovate-oblong or elongated; periostracum pale yellowish or greenish horn, sometimes reddish; surface shining, growth lines very fine, crossed by fine impressed-spiral lines giving the surface a delicately waved appearance; whorls $5 \mathrm{r} / 2$ to 6 , very convex, the body whorl very large and obese; sutures deeply impressed; spire acutely pyramidal, generally a trifle longer than the aperture; aperture elongate-ovate or elliptical, sometimes a trifle expanded, outer lip thin, with a slight varical thickening in adult shells; inner lip rather wide, spreading over the parietal wall in a wide, more or less heavy white callus; axis slightly twisted with a weak, oblique plait; there is a small, narrow, umbilical chink. In some scalar specimens the umbilicus is rather widely open; the varical bands on the shell number two or three.

\begin{tabular}{|c|c|c|c|c|c|}
\hline $\begin{array}{l}\text { Length. } \\
22.00\end{array}$ & $\begin{array}{c}\text { Width. } \\
9.00\end{array}$ & $\begin{array}{c}\text { Aperture length. } \\
11.00\end{array}$ & $\begin{array}{l}\text { Wi } \\
\ldots .\end{array}$ & $\begin{array}{l}\text { th. } \\
\text { mill. }\end{array}$ & (Mörch, typical). \\
\hline 18.50 & 9.00 & 9.00 & 4.50 & “ & St. Michaels. \\
\hline 15.50 & 7.50 & 7.00 & 3.50 & “ & Alaska. \\
\hline 16.00 & 7.50 & 9.00 & 4.50 & “ & “ \\
\hline 14.50 & 7.00 & 7.00 & 4.00 & “ & “ \\
\hline 16.00 & 6.50 & 6.00 & 3.25 & “ & (Scalariform). \\
\hline 18.25 & 9.00 & 9.10 & 4.75 & “ & Yukon Terr. \\
\hline 19.10 & 9.50 & 10.00 & 4.75 & “ & \\
\hline 11.00 & 5.50 & 5.50 & 2.75 & “ & Grönlandica ex Mörch. \\
\hline 15.00 & 7.00 & $\ldots$ & $\ldots$ & “ & Wormskioldi ex Mörch. \\
\hline 18.00 & 9.00 & $\ldots$ & $\ldots$ & “ & Malleata ex Mörch. \\
\hline 15.00 & 7.00 & $\ldots$ & $\ldots$ & “ & Solidula ex Mörch. \\
\hline
\end{tabular}

Types: The types of vahlii and its varieties are believed to be in the University Museum of Copenhagen.

Type Locality: Vahlii, Amaraglik; mölleri, Tunnundliarbik; wormskioldi, Wormskiold; solidula and malleata, exact locality not stated.

AnImal: "Animal grayish-green with minute yellow white dots" (Möller, teste Mörch).

Jaw, Radula and Genitalia: Not examined.

RANGE: (Figure 39) Greenland west to Alaska, south to Great Slave Lake and Ungava.

Vahlii is a Boreal species of wide distribution, extending northward from about the 58th degree of north latitude. It will probably 
be found to be common to the Greenlandian, Labradorian, Hudsonian, Mackenzian, Yukonian and Alaskan regions.

\section{RECORDS.}

Alaska.

Dall River, north of the Yukon River (Dall); flats near St. Michael (Randolph); Loring, southeast Alaska, on Behm Canal (U. S. Fish Com.).

GREENLAND.

Near Arsut; near Davis Strait (Mörch); Amaraglik (Möller; Mörch); Tunnundliarbik (Holböll; Mörch; Vahl); Inekusk (Morelet).

BRITISH America.

Mackenzie: Ft. Robinson, Great Slave Lake (Kennicott).

Ungava: Fort Chimo, Ungava Bay (Dall; Turner; Whiteaves).

Yukon: Stewart River (Dall); headwaters of the Laird River in lakes; Francis and Finlayson lakes (Dawson; Whiteaves); Lewis River; headwaters of the Yukon in Lakes Bennett, Marsh and Lindeman (Randolph).

Geological Distribution: Unknown.

ECOLOGY: "The occurance of the Greenland Limnæa is exceedingly local, thus, a species was found by Möller in a little hole between the mountains opposite to the colonial buildings of Godthaab and not a single specimen in any of the numerous other tanks, large or small, which are found in a continuous row of nearly one mile. Mö1ler tells that he took (July 30,1840 ) the wormenboat over to the clay bank of Kuksuk, and after much searching, at length found a tank with Limnca and Pisidium; but only single specimens were obtained, as they mostly walked on the bottom so far out that it was not possible to reach them. Holböll found Limnaa sitting on stones, even when the water was covered by ice $1 \frac{1}{2}$ inches thick." (Mörch, Amer. Journ. Conch., IV, p. 34).

In Alaska, Galba vahlii is found in small lakes in stations similar to those occupied by Galba pulustris.

Remarks: Vahlii is related to palustris, and doubtless sprang from that stock, but it seems to possess specific differences. It is a smaller, thinner shell, the sutures are, generally, more deeply impressed, and the inner lip and columella lack the heavy plait of palustris. The body whorl is also usually more globose. A comparison with shells of the same size shows that vahlii has a wider, more regularly conic spire, a rounder body whorl, a wider and more expanded inner lip and scarcely an indication of a columellar plait. The globose character of the body whorl at once distinguishes vahlii from tryonii as does also the shape of the inner lip. The species varies greatly in form, some specimens resembling pulustris with short spire equal to the aperture in length, while others are much elongated. Scalariform specimens occur with the spire twice as long as the aperture and with 
the whorls very convex (pl. XXXIX, fig. 13). The Alaska specimens do not differ materially from those collected in Greenland.

Galba vahlii was first mentioned by Beck in his index, but was not described. Möller described it in his index and Mörch both described and figured it in American Journal of Conchology, Volume IV. Authentic specimens received from Mörch have been examined both in the Academy of Natural Sciences of Philadelphia and in the Smithsonian Institution. These compare favorably with the specimens described and figured in this monograph.

It has not been possible to successfully differentiate the varieties indicated by Mörch in his review of the Greenland fresh-water mollusks, in the American Journal of Conchology. All seem to be minor variations of one type of shell. Variety leucostoma is said by Mörch (Amer. Journ. Conch., p. 34) to be "somewhat smaller and broader than the type, but differs chiefly by a thick layer of milk-white chalk, which covers all the inside and columella, giving the exterior of the shell a light straw color." This last character is not constant in any large series, besides being a physiologic character. The form minor of this variety (1. c., p. 34 ) is also a very trivial variation not worthy of a distinct name. The shell of vahlii is seen to vary from short to long spired when a number of specimens are examined. Varieties parva and nitens appear to be local mutations of vahlii as do also wormskioldi Beck and malleata Mörch.

An examination of the axis of vahlii shows it to be placate and a member of the Stagnicola group instead of the Galba group, as indicated by Dr. Dall.

Galba vahlii arctica (Lea). Plate XXXIX, figures 19-23.

Lymnaa arctica LEA, Proc. Phil. Acad., p. 113, 1864; Journ. Phil. Acad., VI, p. 160 , pl. 24, fig. 75 , 1866 ; Obs., XI, p. 116, pl. 24, fig. 75, 1867.-SCUDDER, Bull. Nat. Mus., 23, pp. 147, 200, 1885.

Limnaa arctica TryoN, Con. Hald. Mon., p. 100 (74), pl. 17, fig. 9, 1872.

Limnophysa arctica TRYoN, Amer. Journ. Conch., I, p. 255, 1865.

Limnaa vahlii Whiteaves, Nautilus, XIX, p. 4, 1905; Ottawa Nat., XIX, p. 66,1905 .

Shell: Thick and solid, opaque, oblong-ovate; periostracum dark horn or chestnut, sculpture as in vahlii; many of the specimens examined have a rather thick epidermis which hides the sculpture of the shell; whorls $5 \frac{1}{2}$, convex, rather rapidly increasing in size; sutures well marked but not deeply impressed; spire short, acutely pyramidal; about as long as the aperture; the spire whorls are inclined to be shouldered, and the fourth and fifth whorls are disproportionately enlarged; aperture ovate, dark colored within; outer lip thickened near 
the edge, white; inner lip reflected so as to nearly cover the umbilicus leaving a very small chink; parietal callus thick, wide, white, columella with a rather heavy thickening in the center which forms a conspicuous plait; the axis is very slightly twisted. The varical bands on the shells examined are obscured by the thickness of the shell.

\begin{tabular}{|c|c|c|c|c|c|c|}
\hline $\begin{array}{l}\text { Length. } \\
16.50\end{array}$ & $\begin{array}{c}\text { Width. } \\
8.50\end{array}$ & $\begin{array}{c}\text { Aperture length. } \\
8.10\end{array}$ & $\begin{array}{r}\mathrm{Wi} \\
4.50\end{array}$ & $\begin{array}{l}\text { dth. } \\
\text { mill. }\end{array}$ & James & Bay. \\
\hline 15.00 & 8.00 & 8.00 & 3.90 & “ & “ & " \\
\hline 14.25 & 7.50 & 7.10 & 3.50 & “ & “ & " \\
\hline 14.50 & 8.00 & 7.50 & 3.90 & “ & “ & " \\
\hline 11.50 & 6.10 & 6.10 & 3.25 & “ & “ & “ \\
\hline 10.00 & 6.00 & $\ldots$ & .... & “ & Arctic & a ex \\
\hline
\end{tabular}

TYPE: The type is not in the Smithsonian Institution.

Type Locality: Moose River, near Hudson Bay.

Animal, Jaw, Radula and Genitalia: Not recorded.

RANGE: (Figure 43) James Bay, northwest to Great Slave Lake. Arctica is typically a boreal form (Canadian division) which has not been found south of the fifty-first degree of north latitude and appears to be confined to the Hudsonian and Mackenzian regions. Additional records will doubtless fill in the blank territory on the map.

\section{RECORDS.}

Ontario: Moose River (Lea); Moose River, Hudson Bay (Drexler; Nason); Hudson Bay (Walker); two miles above mouth of Harricanaw River, Hannah Bay (O'Sullivan and Spreadborough; Whiteaves).

Mackenzie: Fort Rae, Great Slave Lake (S. Jones); in crop of duck, Great Slave Lake (Preble).

Geological Distribution: Unknown.

Ecology: Not recorded.

Remarks: Arctica may be recognized by its thick, heavy shell and heavy plaited, almost toothed columella. In most of the specimens examined the fourth whorl is disproportionately large, a feature not observed in vahlii or pingelii. A part of the original lot of arctica received from Drexler is figured on plate XXXIX, (figures 20-23). They agree perfectly with Lea's description. The figure given by Tryon in his continuation of Haldeman's Monograph is very poor and does not correctly represent this race. $24-2 \%$.

Galba vahlii pingelii ("Beck" Möller). Plate XXXIX, figures

Limnaa (Limnophysa) pingelii BECK, Index, p. 111, 1838.

Limnaa pingelii (Beck) Möller, Index Moll. Groen., p. 5, 1842.

Limnca pingelii Binney, Check List, p. 12, 1860; L. \& F.-W. Sh. N. A., II, p. 58, fig. 90, 1865.-Mörch, Amer. Journ. Conch., IV, pp. 35, 37, 1868.SowB., Conch. Icon., XVIII, sp. 98, pl. 14, fig. 98, 1872.

Lymnaa pingelii Scudder, Bull. Nat. Mus., 23, p. 201, 1885 
Limnophysa pingellii Tryòn, Amer. Journ. Conch., I, p. 254, 1865.

Limnaus pingellii Küster, Conch. Cab., p. 27, taf. 5, figs. 11, 12, 1862.

Lymnaa vahlii var. pingelii DALL, Alaska Moll., p. 75, fig. 55, 1905.

Limnaa vahlii var. nitida Mörch, Prod., No. 10 a, Amer. Journ. Conch., IV, p. 35, 1868.

Limnaa vahlii var. pingelii, aa solidula MöRCH, Amer. Journ. Conch., IV, p. $35,1868$.

Limnea arctica Whiteaves, Nautilus, XIX, p. 3, 1905; Ottawa Naturalist, XIX, p. 65, 1905.

Limnca palustris RANDOLPH, Nautilus, p. 109, 1899 (part).

Shell: Thin, cylindrical, ovate; periostracum dark reddish horn or brownish; sculpture as in vahlii; whorls 5-6, very convex; sutures deeply impressed; spire short, as long as, or shorter than, the aperture, the apex obtuse and generally decorticated; aperture ovate, somewhat dilated in some individuals; inner lip narrow; appressed to the umbilical region, leaving a small chink; columellar callus wide, thin, white; columella with a longitudinal thickening but with scarcely any twist. In some individuals the rest periods may be seen as light yellowish longitudinal streaks; from 3 to 5 of these streaks may be seen on each shell.

\begin{tabular}{cccccc} 
Length. & Width. & Aperture length. & \multicolumn{2}{c}{ Width. } \\
15.00 & $\ldots .$. & 8.00 & $\ldots .$. & mill. & Mörch. \\
13.75 & 7.75 & 6.50 & 3.50 & " & St. Michaels. \\
12.00 & 6.00 & 6.00 & 3.10 & " & " \\
12.50 & 7.25 & 7.50 & 4.00 & “ \\
12.50 & 7.10 & 6.50 & 4.00 & " & " \\
12.75 & 6.50 & 7.00 & 3.25 & " & " \\
10.00 & 5.50 & 4.50 & 5.00 & "
\end{tabular}

TyPE: Location not ascertained.

TyPE Locality: Tank on the northern shore of Baal's River, vicinity of Nepiset Sound, Greenland.

Animal, Jaw, Radula and Genitalia: Not recorded.

RANGE: (Figure 42). Western Greenland to western Alaska. A form of the Arctic and Hudsonian divisions of the Boreal life zone. Future research will doubtless connect the two widely separated areas on the map, and the race will probably be found to inhabit the $\mathrm{Yu}$ konian, Mackenzian, Hudsonian and Greenlandian regions.

\section{RECORDS.}

AlASKa.

St. Michaels (E. W. Nelson); flats near St. Michaels (Randolph); Dall River (Dr. I. T. White).

\section{British America.}

YUkon TERRITORY: Stewart River, near Mayo River (J. Keele; Whiteaves). 


\section{Greenland.}

Northern shore of Baal's River, near Nepiset Sound (Möller; Mörch).

Geological Distribution: Unknown.

Ecology: Artificial tank in Greenland (Möller).

REMARKS: Pingelii differs from vahlii in its smaller size, more cylindrical shell, shorter and blunter spire and in its more feebly developed inner lip; the aperture is generally more ovate and the umbilical chink is larger. The variety seems to occupy about the same range as vahlii and frequently occurs associated with it. Its short stumpy spire, which is almost always decollated, will invariably distinguish it from vahlii. Its dark color is also a distinguishing feature.

It resembles some forms of arctica Lea from which it may be known by the absence of the columellar plait and also by its thinner shell. The specimens referred to arctica by Whiteaves (Nautilus XIX, p. 3), upon examination seem to be referable rather to pingelii. They certainly do not agree with the shells brought from Hudson Bay by Dexter, and they do agree with the specimens referred to pingelii, as well as with the published descriptions and figures.

Galba neopalustris, Sp. nov. Plate XXXIX, figure 28.

SHELL: Small, thin, ovate-conic; color reddish brown; sculpture of fine growth lines crossed by distinct spiral lines; last whorl somewhat malleated and encircled by a number of heavy, equidistant spiral ridges; whorls 5-6 (the earlier ones usually eroded) rounded, roundly shouldered, the body whorl quite obese; the upper part of the whorls is somewhat flatly sloping; spire acutely conic, usually eroded to the third whorl, longer than the aperture; sutures well impressed; aperture roundly ovate; peristome thin, slightly thickened within; inner lip very narrow, the upper part, together with the parietal callus folded tightly over the parietal wall; there is a very minute umbilical chink; axis twisted.

$$
\begin{array}{cccc}
\text { Length. } & \text { Breadth. Aperture length. } & \text { Breadth. } \\
13.00 & 7.00 & 7.00 & 4.00 \text { mill. }
\end{array}
$$

Type: Chicago Academy of Sciences, one specimen, No. 24547; cotpyes, coll. Bryant Walker, No. 8250.

Type Locality: Orange, Orange Co., Virginia.

Animal, Jaw, Radula and Genitalia: Unknown.

RANGE: (Figure 42). Virginia in the drainage of the Rappahannock River. A species of the Carolinian region and of the Upper Austral (Carolinian division) life zone.

\section{RECORDS.}

Virginia: Orange, Orange Co. (Walker).

Geological Range: Unknown. 
Ecology: Not recorded.

REMARKs: This small and enigmatical Lymnæid has been a puzzle for several years. It was at first thought to be a small form of the protean palustris but that species does not range as far south as Virginia, and the present form is quite unlike the large shells of the northern states. It is apparently a new species, though belonging to the palustris group of the subgenus Stagnicola.

Neopalustris may be distinguished from palustris by its uniformly smaller size, its more obese body whorl, rounder aperture, narrower inner lip and particularly by the long, flat slope of the upper part of the whorls. It bears a superficial resemblance to some small forms of palustris from England. A special search should be made for this species in Virginia and adjacent states.

GROUP OF GALBA CATASCOPIUM.

Galba pallida (Adams). Plate XL, figures 1-5.

Limnca pallida Adams, Amer. Journ. Sci., i, XXXIX, p. 374, 1840; Bost. Journ. Nat. Hist., III, p. 324, pl. 3, fig. 13, 1840; Amer. Journ. Sci., i, XL, p. 268, 1841; Thomp. Hist. Vt., p. 153, 1842.-Bell, Geol. Surv. Can., Rep. Prog., p. 252, 1859.-BInney, Check List., p. 12, 1860; L. \& F.-W. Sh. N. A., II, p. 60, fig. 95, 1865.-Mörch, Amer. Journ. Conch., IV, p. 35, 1868.-Dall, Pror. Bost. Soc. N. H., XIII, p. 248, 1870.-Gould, Inv. Mass., Ed. Binney, p. 481, fig. 733, 1870.-Jeffreys, Ann. Mag. N. H., ser. iv, X, p. 247, 1872.-Sowb., Conch., Icon., XVIII. Lim., sp. 81, pl. 12, fig. 81 a, b, 1872.-TRYoN, Con. Hald. Mon., p. 106 (80), 1872.-Jefrreys, Journ. Conch., I, p. 16, 1874.-Clessin, Mal. Blatt., n. s., III, p. 82, 1881.-Marshall, Rep. N. Y. State Mus., XLVII, p. 64, 1893; New York at World's Fair, p. 512, 1894.-Letson, Bull. N. Y. State Mus., LXXXVIII, p. 55, 1905 (part).

Limnea pallida Hald., Mon. Lim., p. 45, pl. 13, figs. 11-13, 1842.-DeKAY, Zool. N. Y., p. 69, pl. 4, fig. 67, 1843.

Lymnca pallida Wheatley, Cat. Sh. U. S., p. 23, 1843.-JAY, Cat., p. 270, 1852.-SCudDer, Bull. Nat. Mus., 23, p. 201, 1885.

Limnophysa pallida TrYoN, Amer. Journ. Conch., I, p. 255, 1865.-Lewis, Bull. Buf., Soc. Nat. Sci., II, p. 135, 1874 (part).

Limnaus pallidus Küster, Conch. Cab., p. 49, taf. 11, figs. 1-4, 1862.

Limnaa pallida ${ }^{1}$ Whiteaves, Can. Nat. \& Geol., VIII, pp. 51 1, 103, 1863.Beauchamp, L. \& F.-W. Sh. Onondaga Co., p. 4, 1886.-CkL., Journ. Conch., VI, p. 257, 1890.-TAYLOR, Ottawa Nat., VIII, p. 148, 1895.

Lymncea pallida Lewis, Proc. Phil. Acad., p. 102, 1872.

SHELl: Ovate-fusiform, elongated, rather solid; periostracum pale yellowish horn, sometimes semi-transparent; surface shining, growth lines heavy and very well marked, crowded, crossed by fine impressed spiral lines; whorls 5 to $5 \mathrm{~T} / 2$, flatly convex, the body whorl

${ }^{1}$ The following references are very doubtful; it has not been possible to verify them as in most cases the original specimens have not been preserved. Some of the records may have been based on the true pallida, while. others undoubtedly refer to forms of obrussa, catascopium or palustris. 
a trifle tumid; spire acutely conic, a trifle longer than the aperture, nuclear whorls smooth, consisting of $11 / 4$ rounded, horn colored whorls, the second being about four times the size of the first (similar to those of catascopium); sutures impressed; aperture oblong-ovate, narrowed at both extremities; outer lip rather thin, regularly convex, bordered by a red-edged varix within; inner lip narrow, reflected over and rather tightly appressed to the columella, leaving a very small umbilical chink; there is a well-marked columellar plait. The aperture is produced anteriorly and the shell is frequently quite imperforate.

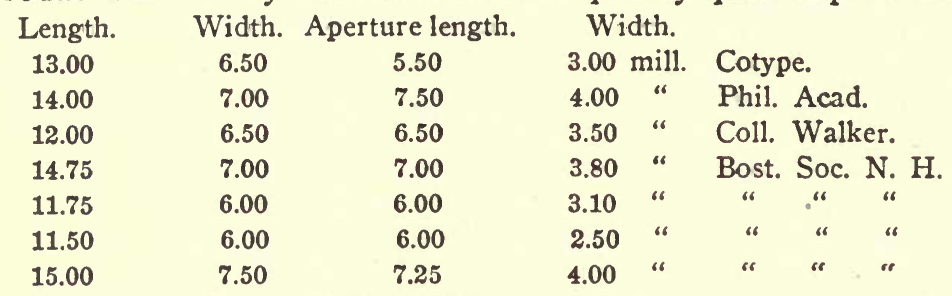

TYPE: Amherst College, Mass.; cotype, one specimen Smithsonian Institution, No. 8490.

TyPe Locality: Shoreham (Storeham, misprint), Lake Champlain, Vermont.

Animal, Jaw, Radula and Genitalia: Unknown.

RANGE: (Figure 44). Vermont to Michigan. A species of the Canadian region and of the Transition (Alleghanian) life zone. Future researches will doubtless greatly extend this range.

Michigan: Kent Co. (Walker).

\section{RECORDS. ${ }^{2}$}

Vermont: Shoreham, Lake Champlain, Addison Co. (Adams; Emmons; DeKay; Roper, B. S. N. H.) ; Lake Champlain (Lea; Walker; Dr. F. B. Wilson); Larrabee Island, Addison Co. (Dr. H. F. Perkins, B. S. N. H.); Higate, Lake Champlain, Franklin Co. (Walker).

Geological Distribution: Unknown.

Ecology: Clinging to rocks and stones on the shore of Lake Champlain (Adams).

Remarks: Pallida has been a puzzle to most conchologists, who have identified it with desidiosa, obrussa, catascopium and elodes. The receipt of a series of shells from the original locality ${ }^{1}$ together with a study of a cotype (now in the Smithsonian Collection) received from the author, enables the writer to clear up some of the uncertainty

'Only those records are here included which are known to have been founded on the true pallida. Several of the New York records and a few from Canada may eventually prove to have been based on true pallida. Until this fact is ascertained beyond a doubt, it seems best to restrict the range to the known authentic records. History.

'Submitted by Mr. C. W. Johnson, Curator of the Boston Soclety of Natural 
surrounding this species. It is closely related to catascopium, but is apparently distinct. It differs from catascopium in the form of the spire which is very acute, in the body whorl which is usually more globose and in the columella which is not so sharply plicated. The aperture is also rounder than is that of catascopium. It is distinguished from palustris by its smaller size, lighter color, more broadly conic and shorter spire, more solid shell and lack of a distinct twist in the columella. These are minor differences, perhaps, but they are ap-

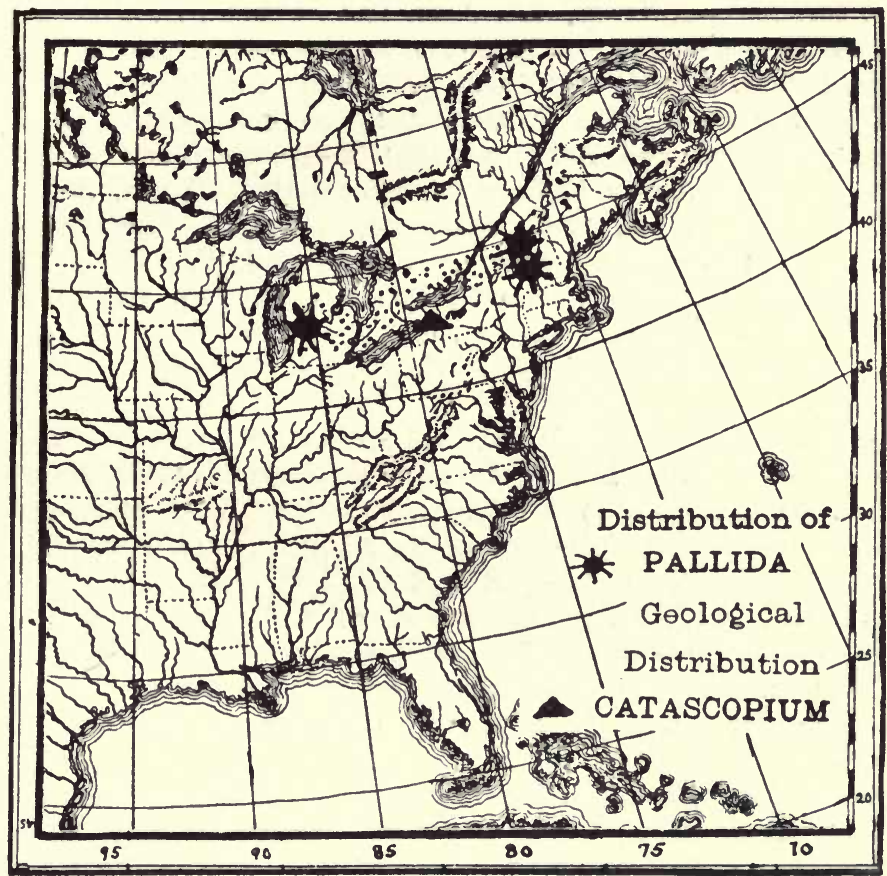

FIG. 44.

parently sufficient to distinguish pallida from palustris. The latter species occurs with pallida but is always darker in color and double the size when adult, besides being generally more fragile.

Pallida has been quoted from California, Michigan, Iowa, Illinois and other western states; many of these references have been found upon examination of the specimens, to have been based on forms of obrussa (desidiosa authors). The statement of Adams that the surface is "without revolving striæ" has misled many conchologists to hunt for a smooth shell like humilis. Adams evidently meant that the 
surface was without the distinct spiral striæ of such specimens as caperata. The outline figure in Binney's work is not particularly good, but Haldeman's figure 12 is very characteristic. The references to New York localities by Beauchamp and Lewis, as well as the Quebec records, need confirmation.

Galba catascopium (Say). Plate XXX, figures 25-6; plate XL, figures 6-35; plate LXI, figures 1-4; plate XLVII, figure 10.

Lymnca catascopium SAY, Nich. Encyc., Am. Ed. II, pl. 2, fig. 3, 1817 (no pagination).-Gould, Lamarck's Genera, p. 69, 1833.-EARLE, Geol. \& Zool. Mass., p. 558, 1833.-Ravenel, Cat., p. 11, 1834.-Hrtch., Geol. Zool. Mass., p. 558, 1835.-Wheatley, Cat. U. S. Sh., p. 23, 1845.-JAY, Cat., p. 268, 1852.Lewis, Proc. Bost. Soc. N. H., V, p. 27, 1854 ; Proc. Bost. Soc. N. H., V, p. 122, 1855.-SAy, Binney ed., p. 45, pl. 2, fig. 3, 1858.-Lewis, Amer. Journ. Conch., IV, p. 4, 1868; Proc. Phil. Acad., p. 101, 1872--BAker, Amer. Nat., XXXIX, p. 674, 1905.-DALL, Alaska Moll., p. 77, fig. 60, 1905.-BAKER, Bull. Ill. State Lab. N. H., VII, p. 104, 1906; Trans. Acad. Sci. St. Louis, XVI, p. 12, pl. 1, figs. 15-16, 1906.-Sterki, Proc. Ohio State Acad. Sci., XX, p. 382, 1907.Lermond, Shells of Maine, p. 38, 1908.-Walker, An. Rep. Geol. Surv. Mich., 1908, p. 290, 1909.-GLEASON, 1, c., p. 64, 1909.

Limneus catascopium SAY, Amer. Conch., VI, pl. 55, fig. 2, 1834; Binney's Ed., p. 211, 1858.

Lymneus catascopium Kirtland, Zool. Ohio, p. 174, 1838.

Lymnea catascopium DeKay, Cat. An. N. Y., p. 32, 1839.-Adams, Amer. Journ. Sci., XXXVI, p. 392, 1839.-Lewis, Proc. Phil. Acad., 1860, p. 19.

Limnea catascopium Sowb., Fauna Bor. Amer., p. 316, 1836.-HALD., Mon. Lim., p. 6, pl. I, figs. 1-8, 1842.-DeKAY, Zool. N. Y., p. 67, pl. 5, fig. 80, 1843.Gould, Agassiz's Lake Sup., p. 244, 1850.-Lapham, Trans. Wis. State Ag. Soc., II, p. 368, 1852.-Hartmann and Michener, Conchologia Cestrica, 1874.-INGeRSoll, Rep. U. S. Geol. \& Geog. Surv. Terr., 1874, p. 406 (part); Bull. U. S. Geol. \& Geog. Surv., I, p. 139, 1875 (part).-Henderson, Nautilus, XX, p. 98, 1907.

Limnaa catascopium Poт. \& Мich., Gal. des Moll., I, p. 216, pl. 22, figs. 3, 4, 1838.-Gould, Invert. Mass., p. 223, 1841.-Prescott, Cat. Sh. Mass., p. 188, 1842.-Read, Cat. 1845.-Reeve, P. Z. S., 1850, p. 49.-Gould, Proc. Bost. Soc. N. H., III, p. 181, 1850.-Stimpson, Sh. N. Eng., p. 52, 1851.-Can. Nat. \& Geol., II, p. 201, 1857.-Bell, Can. Nat. \& Geol., IV, p. 213, 1859; Geol. Surv. Can., Rep. Prog., p. 252, 1859.-Binney, Check List, p. 12, 1860.-Lapham, Proc. Phil Acad., 1860, p. 155.-Reeve, Elements of Conch., p. 179, 1860.-GABB., Proc. Phil. Acad., 1861, p. 309.-Tryon, Proc. Phil. Acad., 1861, p. 398.-WhiтEAves, Can. Nat. \& Geol., VI, p. 458, 1861; Can. Nat. \& Geol., VIII, pp. 51, 103, 1863.-Carpenter, Rep. Brit. Asso., 1864, p. 674 (part).-Binney, L. \& F. W. Sh. N. A., II, p. 53, figs. 80, 81, 82, 85, 1865.-Tryon, Amer. Journ. Conch., III, p. 196, 1867.-Mörch, Amer. Journ. Conch., IV, p. 34, 1868.-CurRIER, Kent Sci. Inst., Mis. Pub., No. 1, 1868.-Lewis, Amer. Journ. Conch., VI, p. 85, 1870.Dall, Proc. Bost. Soc. Nat. Hist., XIII, p. 248, 1870.-Smith \& Prime, Ann. Lyc. Nat. Hist., IX, p. 379, 1870.-Gould, Binney Ed., Invert. Mass., p. 479, fig. 730, 1870.-Koвelt, Mal. Blatt., XVIII, p. 115, 1871.-Sowв., Conch., Icon., Lim., XVIII, sp. 33, pl. 5, fig. 33, 1872.-CArpenter, Smith. Mis. Coll., X, p. 160, 
1872 (part).-TRyon, Con. Hald. Mon., p. 107 (81), 1872.-Jeffreys, Ann. Mag. N. H., iv, X, p. 247, 1872,-Verrill, Ann. Mag. N. H., ser. 4, XI, p. 209, 1873 ; Amer. Journ. Sci., iii, V, p. 468, 1873.-Jefrreys, Journ. Conch., I, p. 16, 1874.Calkins, Cin. Quart. Journ. Sci., I, p. 323, 1874.--Smith, Rep. U. S. Fish. Com., 1872-73, p. 702, 1874.-Dawson, Brit. N. A. Bound Com., p. 349, 1875.-Jones, Moll. of Nova Scotia, p. 10, 1877.-Walker, Journ. Conch., II, p. 330, 1879.Stein, Ind. Dept. Stat. \& Geol., p. 458, 1880.-Heron, Ottawa Nat. I, p. 39, 1880.-Bell, Rep. Geol. \& Nat. Hist. Surv. Canada, 1879-80, p. 75 c, 1881.Ottawa Nat., I, p. 58, 1882.-Christy, Journ. Conch., IV, p. 347, 1885.-Ottawa Nat., II, p. 264, 1885.-Sampson, Bull. Sedalia N. H. Soc., No. 1, p. 24, 1885.Beauchamp, L. \& F.-W. Sh. N. Y., p. 3, 1886.-TAylor, Ottawa Nat., IV, p. 55, 1890 ; Journ. Conch., VI, p. 284, 1890.-Walton, Proc. Roch. Acad. Sci., II, p. 12, pl. 6, figs. 10, 11, 1891.-Fox, Nautilus, IV, p. 114, 1891.-BaIley, Nautilus, V, p. 23, 1891.-TAYLOR, Ottawa Nat., VI, p. 35, 1892.-WALKer, Nautilus, VI, p. 34, 1892.-SAmpSon, Nautilus, VII, p. 33, 1893.-MArshalL, Rep. N. Y. State Mus., XLVII, p. 64, 1893; N. Y. Col. Exp., p. 511, 1894.Walker, Nautilus, VII, p. 128, 1894 (part); Rev. Fauna Mich.,..p. 17, 1894.Schick, Nautilus, VIII, p. 137, 1895.-WALkER,.. Nautilus, IX, p. 4, 1895.Ward, Bull. Mich. Fish. Com., No. 5, pp. 21, 65, 1895.-Marshall, Rep. N. Y. State Mus., XlVIII, p. 642, 1895.-SArgent, Nautilus, IX, p. 127, 1896. Walton, The Museum, IV, p. 132, 1898.-Baker, Trans. Acad. Sci. St. Louis, VIII, pp. 88, 89, 1898.-MAURY, Chautauqua Lake Shells, p. 25, pl. 1, fig. 3, 1898.-Hanham, Nautilus, XIII, p. 5, 1899.-Mitchell, Nautilus, XIII, p. 89, 1899.-Baker, Nautilus, XIV, p. 69, 1900.-WAlKer \& LANe, Geol. Surv. Mich., VIII, pt. 2, p. 251, 1900.-BAKeR, Trans. Acad. Sci. St. Louis, XI, p. 5, 1901 (non fig.).-Letson, Bull. Buff. Soc. Nat. Sci., VII, No. 1, p. 244, fig. 173, 1901; Bull. N. Y. State Mus., IX, No. 45, p. 244, fig. 173, 1901.-Stearns, Proc. Nat. Mus., XXIV, p. 291, 1901.-Baker, Trans. Acad. St. Louis, XI, p. 5, pl. 1, fig. 9, 1901; Amer. Nat., XXXV, p. 662, 1901; Moll. Chi. Area, II, p. 263, pl. 31, fig. 5, 1902.-Bцатсн. \& Daniels, Rep. Dept. Geol. Nat. Res. Ind., XXVII, p. 597, pl. 1, fig. 14, 1902.Whiteaves, Ottawa Nat., XVI, p. 92, 1902.-Daniels, Rep. Dept. Geol. Nat. Res. Ind., XXVII, p. 636, 1902.-Ottawa Nat., XVI, p. 205, 1903.-Whiteaves, Rep. Geol. Surv. Can., 1904, p. 164, A, 1905.-Ottawa Nat., XIX, pp. 31, 32, 1905.-LeTson, Bull. N. Y. State Mus., LXXXVIII, p. 55, 1905.-Снарwick, Bull. Wis. Nat. Hist. Soc. n. s. IV, p. 82, 1906; Nautilus, XX, p. 22, 1906.-Letson, Bull. Buf. Soc. Nat. Sci., IX, p. 242, 1909.-Adams, Rep. Geol. Surv. Mich., 1908, p. 20, 1909.

Limnaus catascopium Küster, Conch. Cab., I, p. 46, taf. 8, figs. 15-21, 1862.

Limnophysa catascopium Beck, Index Moll., p. 111, 1837.-Morse, Journ. Bost. Soc. N. H., I, p. 42, 1864.-TRYoN, Amer. Journ. Conch., I, p. 253, 1865.Lewis, Bull. Buf. Soc. N. Sci., II, p. 135, 1874.-Hartman and Michener, Conch. Cestrica, p. 64, figs. 121, 122, 1874.-BeI.L, Rep. Prog. Geol. Surv. Canada, 1878-79, C, p. 62, 1880.-DeCamp, Kent. Sci. Inst., Mis. Pub., No. 5, p. 8, 1881.Call, Bull. Wash. Coll. Lab. N. H., I, pp. 52, 124, 1885; Bull. Wash. Coll. Lab. N. H., II, p. 17, 1887.-KeEP, West Coast Shells, p. 122, 1887 (part).-BAKer, Amer. Nat., XXXV, p. 659, 1901.-KeeP, West Amer. Sh., p. 314, 1904 (part).

Limnca elodes var. catascopium Aldrich, Rep. N. Y. State Cab. N. H., XXII, pp. 19, 23, 1868.

Helix catascopium EAton, Text-book, p. 195, 1826. 
Limnea cornea Valenciennes, in Humboldt and Bonpland, Rec. d'obs. de Zool., II, p. 251, 1832.-Ferussac, Bull. Zool., 1835, p. 33.-Binney, L. \& F.-W. Sh. N. A., II, p. 54, 1865 ; Journ. de Conch., XV, p. 427, 1867.

Limnca sericata ZIEGLER, Rossmässler Icon., I, p. 98, 1837.

Lymnaus pinguis SAY, Journ. Phil. Acad., V, p. 123, 1825, ed. Binney, p. $114,1858$.

Lymnea pinguis DeKay, Cat. An. N. Y., p. 32, 1839.

Lymnca pinguis Gould, Lamarck's Genera, p. 69, 1833.-WheAtley, Cat. U. S. Sh., p. 24, 1845.

Limnaa pinguis Gould, Proc. Bost. Soc., N. H., III, p. 181, 1850.-Binney, L. \& F.-W. Sh. N. A., II, p. 54, fig. 83, 1865.-Tryon, Amer. Journ. Conch., III, p. 196, 1867.-Sowb., Conch. Icon., XVIII, Lim., pl. 8, fig. 49, 1872.-SowB., Conch. Icon., XVIII, Lim. sp. 18, pl. 3, fig. 18; pl. 9, fig. 18 b; pl. 15, fig. 18 c. distorted, 1872..$^{-}$-W ALKER, Nautilus, IX, p. 4, 1895.

Limnophysa pinguis TryoN, Amer. Journ. Conch., I, p. 253, 1865.

Limnca catascopium var. pinguis Dawson, British N. A. Bound Com., p. 349, 1875 (?).-Tryon, Con. Hald. Mon. p. 107 (81), 1872.

Lymnca catascopium var. pinguis JAY, Cat., p. 268, 1852.

Limnea catascopium var. pinguis Hald., Mon. Lim., p. 7, pl. 1, figs. 10-12, 1842.

Lymnaa catascopium pinguis BAKER, Moll. Chi. Area, II, p. 264, pl. 30, fig. 27, 1902 ; Bull. I11. State Lab. N. H., VII, p. 104, 1906.

Lymnaa linsleyi DeKAY, Moll. N. Y., p. 72, pl. 4, fig. 74 a, b, 1843.Linsley, Amer. Journ. Sci., i, XLVIII, p. 282, 1845.-JAY, Cat. Ed. 4, p. 270, 1852.

Limnca linsleyi Binney, Land \& F.-W. Sh. N. A., II, p. 66, fig. 108, 1865.Clessin, Mal. Blatt., n. s., III, p. 81, 1881.

Limnaa brozenii Tryon, Amer. Journ. Conch., I, p. 229, pl. 23, fig. 15, 1865 ; Amer. Journ. Conch., III, p. 196, 1867 ; Con. Hald. Mon., p. 110 (84), pl. 18, fig. 8, 1872.

Limnophysa brownii Tryon, Amer. Journ. Conch., I, p. 253, 1865.

Limnaa emarginata Mitchell, Nautilus, XIII, p. 88, 1899.

Limncea intertexta Currier, Kent. Sci. Inst., Mis. Pub. No. 1, 1868.WALKer, Journ. Conch., p. 330, 1879 ; Nautilus, VI, p. 33, 1892 ; Rev. Moll. Mich., pp. 18, 22, 1894.

Limnophysa intertexta DeCAMP, Kent Sci. Inst., Mis. Pub., No. 5, p. 8, 1881.

Limncea solida Whiteaves, Can. Nat. \& Geol., VI, p. 458, 1861; VIII, pp. 51, 103, 1863.

Limnaa opacina Bell, Geol. Surv. Canada, Rep. Prog., p. 252, 1859; Can. Nat. \& Geol., IV, p. 213, 1859:-DALL, Alaska Moll., p. 80, 1905.

SHELl: Varying from short-ovate to elongate-fusiform, thin to very thick and solid; periostracum light-horn to dark chestnut; surface dull to shining, in some specimens almost polished; lines of growth crowded, fine to coarse; spiral sculpture varying from faint to deeply incised, producing a wavy appearance, surface seldom mal-

Pl. 9, fig. $18 \mathrm{~b}$, is said by Sowerby to have been named strigata. This probably refers to strigosa Lea which is a variety of columella Say. 
leated; nuclear whorls $1 \frac{1}{4}$, small, well rounded, white or wine colored (pl. XLIX, fig. J) ; whorls 5 to 6 , well rounded, the body whorl typically very large and moderately convex; spire varying from short, depressed, dome-shaped to turreted, acutely conical or pyramidal; sutures impressed, in some specimens almost channeled; aperture ovate or long ovate, somewhat produced and effuse anteriorly, as long as, or longer than, the spire; peristome thickened within by a longitudinal varix edged with chestnut; inner lip narrow, reflected and appressed tightly to the columellar region, either completely closing the umbilicus or leaving a very small, narrow chink; columella with a heavy oblique plait causing the axis to be twisted; in specimens from some localities the shell is very solid and the inner lip and axis is covered by a heavy coating of white, shelly material. The parietal wall is covered by a more or less thickened callus.

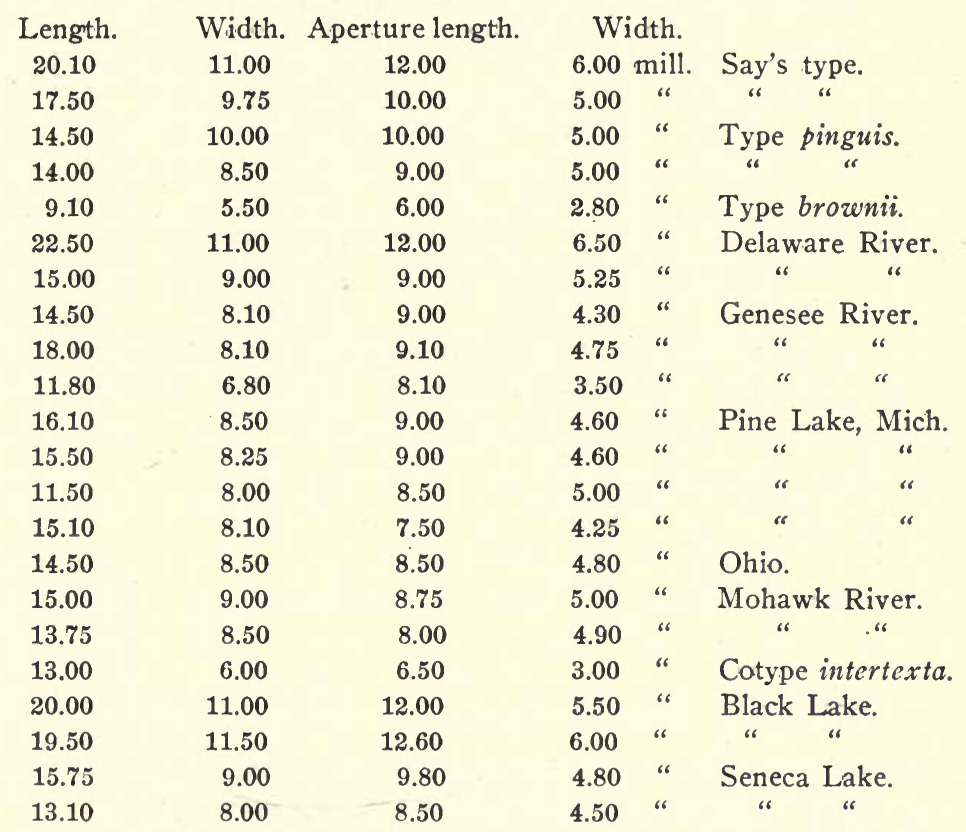

Types: Catascopium, two specimens, Academy of Natural Sciences, Philadelphia, No. 58486 ; pinguis, two specimens, Phil. Acad., No. 58571; brownii Tryon, one specimen, Phil. Acad., No. 58516; linsleyi DeKay, N. Y. State Museum, Albany; intertexta, Kent Scientific Museum, Grand Rapids, Mich.; cotypes, coll. Bryant Walker, No. 17358 ; cornea Val., location not ascertained.

Type Locality: Catascopium and pinguis, Delaware River, Philadelphia, Pa.; brownii, Elyria, Ohio ; linsleyi, Stratford, Conn.; cornea, 
environs of Philadelphia; intertexta, outlet of Black Lake, Holland, Michigan.

Animal: Yellowish or blackish, covered with small whitish flecks; foot about as long as the aperture, wide, rounded behind ; tentacles lighter colored at their tips.

Jaws: (P1. VI, figs. K., M.) Superior jaw arched, very wide, low; ends acutely rounded; central lobe narrow, acute.

RADULA: (P1. IX, fig. I). Formula: $\frac{22}{5}-7+\frac{4}{3}-\frac{4}{4}+\frac{9}{2}+\frac{1}{1}+\frac{9}{2}-1-\frac{4}{3}-\frac{4}{4}+\frac{2}{5}-\frac{2}{7}$ (35-1-35); central tooth with a rather long acute cusp; lateral teeth rather narrow, bicuspid, the mesocone very large, spade shaped, the ectocone small and rather wide; the tenth to twelfth (transition) teeth are wide and tricuspid, the entocone splitting off from the mesocone, and gradually becoming larger; the thirteenth tooth (transition) is very wide, the entocone and mesocone are subequal and very acute; the true marginals begin at the fourteenth tooth which develops two to three small cusps on the entocone; outer marginals irregularly 4 to 5 cuspid, the cusps being confined to the distal end of the tooth on the extreme outer teeth; the marginal teeth have one or two small cusps high up on the outer margin. The teeth are crowded on the membrane, fitting more closely than in Galba palustris. There are about 105 rows of teeth.

Catascopium exhibits some variation in the position of the lateral teeth. Normally the lateral teeth seem to be nine in number, but in one specimen there were ten laterals, in another eleven laterals; one specimen from the Genesee River, Rochester, N. Y., had a radula with fifteen laterals on the left side and twelve laterals on the right side. Binney (op. cit. p. 55) figures 17 laterals, but this is evidently an error, as no Stagnalis has been seen with so large a number of lateral teeth.

\section{Genitalia: (P1. XII, fig. B).}

Male organs: Penis slender, usually as long as the penis-sac, which has a much larger diameter than the penis; vas deferens about twice the length of the penis and penis-sac; penis retractor long (1.50 to 3.25 mill.) and slender; penis-sac retractor generally a trifle shorter ( $1.50^{\circ}$ to 2.10 mill.) and thicker than the penis retractor; both retractors are inserted at the same point in the columellar muscle; protractor muscles variable in number; the prostate is very large, flatly cylindrical, narrowing at the posterior end; the duct of the prostate is about half the length of the vas deferens, and enlarges slightly as it enters the prostate. 
Female organs: Receptaculum seminis large, globular, its duct slender, a trifle longer than the prostate duct; second accessory albuminiparous gland large, somewhat pear shaped; anterior portion of oviduct rather long, slender.

The protractor muscles (pl. XV, fig. F, 4-8) vary considerable in number and position. The penis retractor was unform in all specimens examined. The protractor muscles exhibited the greatest variation. The anterior protractor is made up of one very wide muscle, composed of from two to four branches which again subdivide as they enter the penis-sac. The posterior protractor muscles vary from one to four in number, and likewise vary in their relative positions, in one case (4) being rather widely separated, and in two cases $(5,6)$ being crowded together. In two examples there was but one anterior protractor. This variation was observed in specimens from Michigan and from two localities in New York.

Eleven specimens gave the following comparative measurements: Dissection Nos. 23900 to 23905 :

Length. Length. Length. Length. Length. Length. Length.

\begin{tabular}{|c|c|c|c|c|c|c|c|c|c|}
\hline $\begin{array}{c}\text { of } \\
\text { penis. } \\
3.00\end{array}$ & $\begin{array}{c}\text { of } \\
\text { p.-sac. } \\
3.00\end{array}$ & $\begin{array}{l}\text { of } \\
\text { r. sem. } \\
5.00\end{array}$ & $\begin{array}{l}\text { of } \\
\text { prost. } \\
7.00\end{array}$ & $\begin{array}{c}\text { ot } \\
\text { vas. def. } \\
12.00\end{array}$ & $\begin{array}{c}\text { of } \\
\text { pen. ret. } \\
1.50\end{array}$ & $\begin{array}{l}\text { of } \\
\text { p.-s. ret. } \\
1.50\end{array}$ & $\begin{array}{l}\text { Shell. } \\
17.00\end{array}$ & $\begin{array}{r}\text { Locality. } \\
\text { Genesee R., }\end{array}$ & N.Y. \\
\hline 2.75 & 3.00 & 5.00 & 4.50 & 13.00 & 1.50 & 1.50 & 16.00 & & 6 \\
\hline 3.50 & 3.50 & 5.50 & 7.00 & 13.00 & 3.00 & 1.50 & 17.50 & Canal, & , N. Y. \\
\hline 3.50 & 3.50 & 5.00 & 4.50 & 12.00 & 3.25 & 2.10 & 17.00 & “ & \\
\hline 3.25 & 3.25 & 5.00 & 5.50 & 13.00 & 2.00 & 1.50 & 18.00 & “ & " \\
\hline 2.00 & 2.50 & 4.50 & 5.50 & 14.00 & 2.00 & 1.75 & 17.50 & $\begin{array}{l}\text { Mackinaw } \\
\text { Mich. }\end{array}$ & City, \\
\hline 2.00 & 2.50 & 4.50 & 6.00 & 12.00 & 2.25 & 2.00 & 13.50 & $\begin{array}{c}\text { Mackinaw } \\
\text { Mich. }\end{array}$ & City, \\
\hline 2.00 & 2.00 & 4.25 & 4.50 & 10.00 & 2.00 & 2.00 & 19.50 & Adamsi. & \\
\hline 3.50 & 3.50 & 4.50 & 5.00 & 10.50 & 3.50 & 3.00 & 16.00 & “ & \\
\hline 2.00 & 2.00 & 4.50 & 5.75 & 12.00 & 3.25 & 3.25 & 18.00 & " & \\
\hline 2.00 & 2.50 & 4.00 & 5.75 & 11.00 & 3.25 & 3.25 & 16.00 & “ & \\
\hline
\end{tabular}

It will be noted that the greatest variation occurs in the retractor muscles of the male system, which may be due in a large measure to undue stretching, these muscles being very flexible. In two cases the prostate duct was of unusual length. The difference in length of the penis and penis-sac in several examples is due to the contracted condition of these organs. It will be noted that the ratios are about the same in all cases examined. So far as the genitalia are concerned, catascopium does not differ materially from palustris.

RANGE: (Figure 45). Eastern Canada and Nova Scotia west to North Dakota, Great Slave Lake south to Northern Iowa, Northern Ohio and Maryland. 
Catascopium occupies a large part of the Boreal (Canadian) and Transition life zones and enters the Upper Austral life zone on the south. In the United States it does not extend west of the humid division of the Transition and Upper Austral life zones. In British America it occupies the larger part of the Boreal (Canadian) life zone, east of the 115th degree of latitude and south and wêst of Hudson Bay, extending south into North Dakota. Its northern limit seems

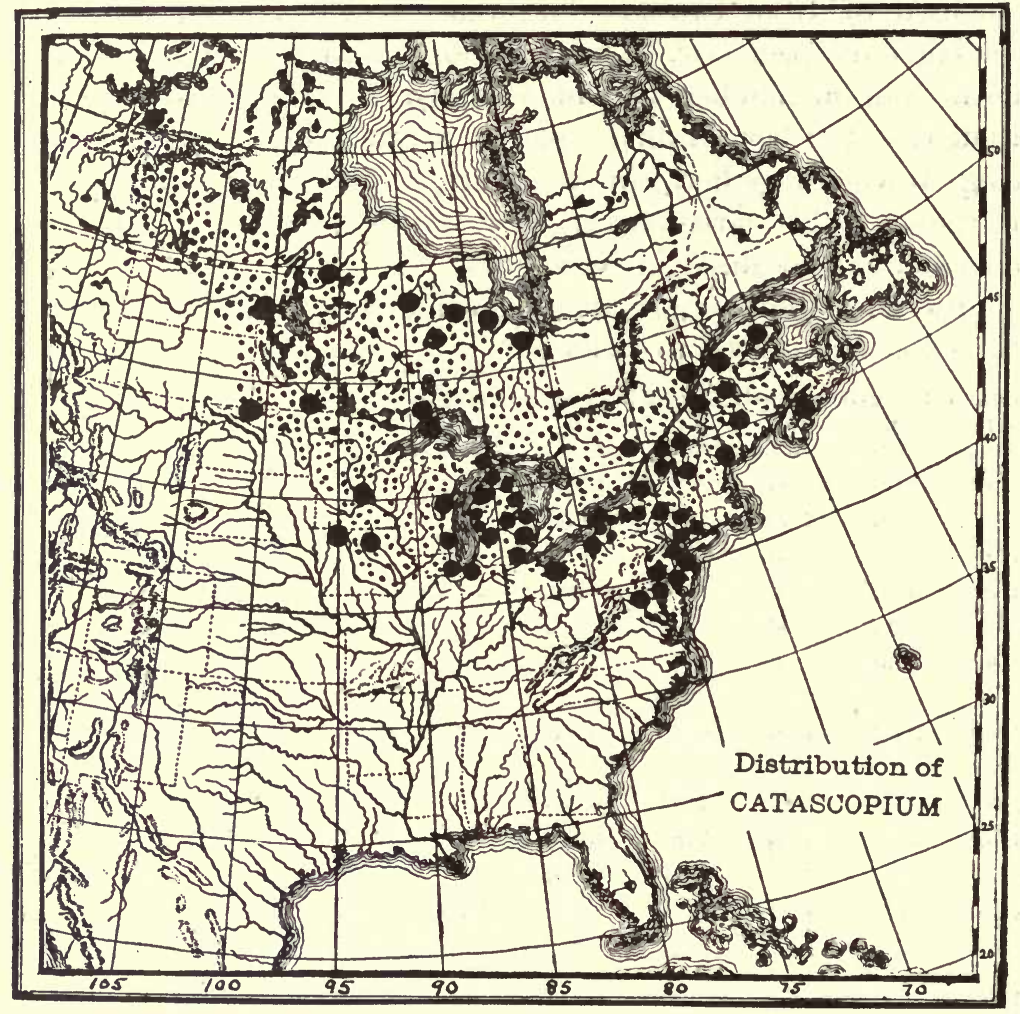

FIG. 45.

to be Great Slave Lake at about the 60th parallel. It probably inhabits some of the country to the east of Hudson Bay, but no specimens or authentic records have been seen; Dall reports it from Ungava and Labrador. Its center of distribution appears to be the Great Lake region lying to the southwest of Hudson Bay. It has not been found in the great plains area, but is common in the prairie regions of the central west. It is a common mollusk in the Canadian, Hud- 
sonian, Mackenzian, Nova Scotian and Upper Mississippian regions. Additional records are needed from the Mackenzian and Hudsonian regions, as well as from the northwestern part of the Upper Mississippian region, where the species has been confused with binneyi and apicina. In the United States (with the exception of the North Dakota record) no authentic specimens have been personally examined from west of the $95^{\circ}$ of longitude. ${ }^{1}$

\section{EXTREME RECORDS. ${ }^{1}$}

North Dakota: Riviere des Lacs, Ward Co. (Dawson).

KeEwatin: Oxford Lake; Great Playgreen Lake (Bell); Mistassin Lake, Attawapiskat River; Kawinogans River; Winisk River; Ozhiski Lake (McInnes; Whiteaves) ; Ekwan River; Knee Lake; Albany River and Trout Lake (Whiteaves).

Mackenzie: Fort Resolution, Great Slave Lake (Kennicott).

ManitoBa: Dufferin, Provancher Dist. (Dawson); Lake Manitoba (Hanham); Lake Winnipeg (Kennicott).

Ontario: Moose Factory, Moose River, Nipissing District (Drexler); Fort William and north shore Lake Superior, Thunder Bay Dist. (Gould).

Saskatchewan: Grand Rapids, Saskatchewan River, Lake Winnipeg, (Smith. Inst.).

Geological Distribution: (Figure 44). Pleistocene. The only records secured of the occurrence of this species in a fossil state have been from New York. It will undoubtedly be found fossil throughout a wide area when carefully searched for and correctly identified.

RECORDS.

GRAVEL DEPOSITS.

NEW YoRK: Gravel beds, Goat Island, Whirlpool and Foster's Flats, Niagara River (Letson).

INTERGLACIAL DRIFT.

NEW YoRK: Interglacial drift, Niagara Falls (A. Coleman).

Ecology: Catascopium is plentiful in large bodies of water, such as lakes, rivers and bays. It is especially abundant along the shore of the Genesee River, in Rochester, N. Y. This habitat is of especial interest in view of the fact that this river has been used for over ten years as receptacle for the sewage of the city. Catascopium, however, seems to thrive in this water which now has the consistency of dirty dish-water and is greasy to the touch. The effect of seven years of life in this environment is plainly seen by comparing collections

1Missouri: Flat Creek, Pettis Co. (Sampson). Newton).

Kansas: Erie, Neosho Co. (Call; Ferriss); Oswego; Labette Co. (Call;

These records, as well as Sampson's record in the Nautilus, VII, page 33, are to be viewed with suspicion until verified by the examination of specimens. No authentic material from as far south has been seen and it is quite probable that the records were based on short-spired shells of palustris. No mention of catascopium is made by Sampson in his report published in the Arkansas Geological Survey. Special search should be made for this species in this area. 
made in 1899 (plate XL, figures 11-12) with those made in 1906, which resemble figures 13 to 15 on the same plate. These figures are of catascopium which live between the upper and middle falls, where the water is badly polluted with chemicals. Strangely enough, the variation is toward a palustris-like shell. ${ }^{1}$ In the Erie Canal, at a point where it spreads out forming a lake-like expansion called the "Wide-Waters," catascopium is abundant along the stony shore, and is usually typical and very uniform (pl. XL, figures 6-10). Some interesting variations in the outer lip occur among the shells from this locality. In Seneca Lake, New York, this species lives on a fairly open shore in shallow water.

The original habitat in the Delaware River, near Philadelphia, is of special interest as it is in tide water, though not saline. The Lymnæas are subject to the ebb and flow of the tide in the same manner as the Littorinas, Purpuras and similar littoral forms. This ecological condition is interesting because of the fact that during regularly recurring periods the Lymnæids are out of the water and are subject to the rays of the sun. It may be that the heavy shell (which is much thicker than in specimens living in quiet, uniform waters, as in the Genesee River at Rochester) serves as a protection against too much drying during these periods of ebb tide. The animals inhabit a wide strip of beach between low water mark and half tide, in company with Physa ancillaria, Planorbis bicarinatus and Goniobasis virginica.

Mr. Bryant Walker, thus speaks of the habitat of certain forms of catascopium in Pine Lake, near Charlevoix, Michigan ${ }^{2}$ (see plate $\mathrm{XL}$, figures 16-22) :

"The Limnæidae of Pine Lake, which empties into Lake Michigan at Charlevoix, were also extremely interesting. The bottom of the lake is composed almost wholly of marl, except where it has been covered by a thin coating of sand washed in from the shores, and, as a consequence, both plant and animal life exist under very unfavorable circumstances. The level of the lake seems to have been lowered by the canal made by the U. S. Government to connect it with Lake Michigan, and the former lake terrace is now largely exposed, and, in many places, quite dry. In the numerous pools, however, which are left along the shore, the Limncea catascopium Say is found in great abundance and almost infinite variety. It varies in shape from the comparatively slender form usually found in the Great Lakes to the

1 A recent visit to the Genesee River (June, 1910) revealed the fact that the river had now become so flled with highly concentrated sewage that all traces of molluscan llfe had vanished.

${ }^{2}$ Nautilus, IX, p. 4. 
globose form described as $L$. pinguis by Say, and seems, in many cases, to run very close to that of $L$. ampla Migh. The Pine Lake examples have usually a very thick, solid opaque shell, and a large proportion are more or less distorted, the most common effect of their unfavorable environment being apparently to induce a very abrupt and rapid expansion of the outer lip, which, in most cases, is accompanied by a heavy callus deposit all around the aperture."

The thick opaque texture is characteristic of many of the species from the northern part of the lower peninsula of Michigan.

REMARKS: Catascopium is frequently confounded with palustris and emarginata. It differs from the latter in the manner in which the inner lip is appressed to the axis, and in having generally a narrower, more fusiform shell and a more elongated aperture. Emarginata is typically umbilicated and the inner lip is widened out to form a broad expansion, quite different from the narrow inner lip of typical catascopium. It differs from palustris in its shorter, wider and less acute spire, in having one whorl less and in having generally a wider, more fusiform shell and finer sculpture. The columellar plait is not generally as pronounced in catascopium as it is in typical palustris. Catascopium is, also, seldom malleated while palustris is frequently so marked. The more fusiform shape, wider shell, one less whorl and the less acute spire will serve to distinguish the majority of specimens of catascopium from palustris. It generally has a thicker shell than that of palustris.

Dr. James Lewis ${ }^{1}$ has advanced some suggestive theories in regard to the relationship of catascopium to clodes (=palustris). Dr. Lewis believed that "An equitable temperature, a moderate supply of food, limited supply of air, and frequent disturbances of the station of the animal by currents in the water, determines the form we call catascopium" while "a warmer station, abundance of food, unlimited access to the atmosphere, and quite stagnant water, favor the development called elodes." While this statement is true to a certain extent as regards the habitat of the two species, yet the writer has seen no evidences bearing out the theory advanced by Dr. Lewis that the eggs of catascopium will produce palustris when transferred to a different environment. The shell may be (and does) become somewhat elongated and simulate the palustris form, but it is still catascopium, as may be proven by examining the teeth and genitalia. The nearest approach seen by the author of catascopium to palustris is in a lot of shells from the north end of Owasco Lake, Cayuga Co., New York.

${ }^{1}$ Amer. Journ. Sci., IV, p. 4; VI, p. 85. 
These shells are very smooth, not malleated and some specimens are short and resemble catascopium, though lacking the tumid whorls and wide aperture. These small shells connect perfectly with the large forms which are undoubtedly palustris. Such sets of shells have undoubtedly been the cause of the statement made by some conchologists, that catascopium is only a form of palustris. Specimens of catascopium from the Erie Canal and the Genesee River, Rochester, New York, also somewhat resemble palustris in being thin-shelled and somewhat elongated. It has been suggested (Crandall and others) that perhaps these shells are hybrids, which fact might account for Dr. Lewis' belief.

Catascopium shows very beautifully the effect of environment on the shell; as found in the lower Genesee River, Rochester, N. Y., where the water is more or less quiet along the shore, the shells are quite thin, and exhibit a large amount of variation in the comparative length of the spire, the very short spired forms showing a tendency to approach the pinguis-like aspect. The spire varies from one-half the length of the aperture to more than equal its length. (P1. XL, figs. 6-10). The catascopium of Pine Lake, near Charlevoix, Michigan, are very solid and heavy, and vary in the length of the spire to even a more marked degree than do the Rochester specimens. (See plate $\mathrm{XL}$, figures 16-22).

Say's types of catascopium are still preserved in the Academy of Natural Sciences of Philadelphia. They are similar to Haldeman's figures, but the spire is not as acute as the figures of Say (see plate $\mathrm{XXX}$, figures 25-26) would indicate. Binney's figure 80 is not typical for the same reason. His figure 81 is better and fairly represents the species. Say's pinguis was at first thought to be a distinguishable race of catascopium, but the examination of large series of specimens from widely separated localities shows that no line can be drawn between the long and short spired forms. Topotypes from near the original locality are figured on plate XLI, figs. 2, 3, which show the variation in the height of the spire. Intermediate forms are plentiful in the Delaware and clearly indicate the unity of the two forms. Tryon's brownii is a small example intermediate between catascopium and pinguis. Of the two type specimens, one is caperata and the other is brownii, apparently not mature as there are but $4 \mathrm{~T} / 2$ whorls. An examination of certain specimens from the St. Lawrence River listed by Dr. Whiteaves as solida (=apicina) reveals the fact that they are short spired forms of catascopium. These specimens were first cited by Bell, who was followed by Whiteaves and others. Some of 
the individuals resemble solida in being roundish and having tumid whorls, but the resemblance is superficial, the shells having on the average, all the characteristics of catascopium. Several of these specimens are figured on plate XL (figures 23-26). Specimens of catascopium from Lake Champlain, near Burlington, Vermont, are very thin, with rather large shell, and somewhat resemble Lymnaa limosa Linné of Europe. Currier's intertexta is a synonyn of catascopium, the Black Lake specimens being almost identical (though thinner) with individuals from Philadelphia (see plate XL, figures 32-35). Currier's types (a cotype figured on plate XL) are scalariform in character, but are otherwise the same as typical catascopium.

Limnca linsleyi De Kay appears to be an immature form of catascopium. It has no relation to humilis, as may readily be seen by carefully reading the original description. DeKay especially compares it with pinguis. Catascopium includes in the synonomy six names, mostly founded on its various mutations: cornea, Val., sericata Ziegler, linsleyi DeKay, pinguis Say, intertexta Currier and brownii Tryon. With all of its variations, however, it cannot be mistaken for any other species when its characteristics are once understood.

Galba catascopium niagarensis Baker. Plate XLII, figures 1-4.

Lymnea fusiformis LeA, Proc. Amer. Phil. Soc., II, p. 33, 1841; Trans. Amer. Phil. Soc., IX, p. 10, 1844; Obs., IV, p. 10, 1848 (not Lymnaa fusiformis Sowb., Mineral Conchology, II, p. 155, pl. 169, 1818, an Oligocene fossil of the Isle of Wight).

Lymnea fusiformis Wheatley, Cat. Sh. U. S., p. 23, 1843.-Scudder, Bull. Nat. Mus., 23, pp. 33, 44, 201, 1885.

Lininea fusiformis Hald., cover p. 4, No. 6, 1843.

Limnaa fusiformis Binney, Check List, p. 12, 1860; Land \& F.-W. Sh. N. A., II, p. 50, fig. 72, 1865.-Tryon, Amer. Journ. Conch., III, p. 196, 1867.

Shell: Thick, solid, fusiform; periostracum yellowish horn; sculpture as in catascopium; whorls five to six, flat-sided, broad, rapidly increasing in diameter; spire short, broadly acute, the whorls flat-sided or only very slightly rounded; sutures slightly impressed; outer lip with internal varical thickening; aperture elliptical, narrow in some specimens, about as long as the spire; inner lip rather broad, tightly appressed to the columella, completely closing the umbilical region; parietal callus very heavy; columella with a distinct but not sharp fold, axis twisted. 


\begin{tabular}{ccccccc} 
Length. & Breadth. Aperture length. & \multicolumn{3}{c}{ Breadth. } \\
15.00 & 8.00 & 9.00 & 3.75 & mill. & Type. \\
11.50 & 6.00 & 5.50 & 2.25 & “ & “ & \\
14.00 & 7.00 & 8.50 & 3.50 & “ & Squaw & Island. \\
11.00 & 6.00 & 6.50 & 3.25 & “ & “ & “ \\
13.00 & 7.00 & 8.00 & 3.75 & “ & “ & " \\
13.50 & 7.00 & 7.50 & 3.50 & “ & “ & "
\end{tabular}

Types: Three specimens, Smithsonian Institution, No. 118664.

Type Locality: Niagara River, Lewiston, New York.

Animal, Jaw, Radula and Genitalia: Not examined.

RANGE: New York and Ontario. Fusiformis appears to be a characteristic race of the Great Lakes, no specimens having been seen from any locality outside of this drainage. It is, therefore, confined to the Canadian region.

\section{RECORDS.}

\section{United States.}

New York: Squaw Island, Niagara River, Erie Co. (Letson; Nason; Miss Walker); Lewiston, Niagara Co. (Lea; Nicklin) ; rapids above the American Falls, Niagara (Miss Walker).

\section{British America.}

\section{Ontario: Ottawa, Carleton District (Hinkley).}

Geological Range: Unknown.

Ecology: Not recorded. Evidently modified by the influence of rapid flowing or rough water.

REMARKS: Niagarenis differs from catascopium in its smaller size, generally more solid shell, more fusiform shape, less impressed sutures and hence more flat-sided whorls (especially the body whorl) and in its more elongated aperture; the columellar callus is heavier in adult specimens, but the columellar plait is much less conspicuous. This is a neat little shell, usually quite distinguishable from typical catascopium. Binney (p. 50) places fusiformis in the synonymy of desidiosa (obrussa) but in this he was in error, a fact made clear by an examination of Lea's types, which have the heavy spiral sculpture of catascopium. The umbilical chink is not always tightly closed, the immature shell frequently showing quite a chink. In the type lot, two specimens, immature, show a small umbilical chink, while one specimen, adult, is quite imperforate. The specimens from Squaw Island, illustrated on plate XLII, are the same as the type specimens and well illustrate the form of the race. Specimens from Niagara Falls are the same as are also certain very immature shells from Ottawa, Canada. Certain narrow forms of catascopium from Pine Lake, Charlevoix Co., Michigan, somewhat resembles niagarensis, but the whorls are rounder, the sutures deeper and the aperture is much rounder. Niagarenis 
appears to be a recognizable race of catascopium, characterized by an elongated, narrow shell, flat-sided whorls and a narrow aperture.

Galba catascopium adamsi, Var. Nov. Plate XLII, figures 5-8.

Lymnaa catascopium Walker, An. Rep. Geol. Surv. Mich., 1908, p. 291, 1909.-Gleason, 1. c., p. 64, 1909.

Shell: Thin, narrow, much elongated; periostracum yellowish or whitish horn; sculpture coarser than in typical catascopium; whorls 6-6 $1 / 2$ very flatly rounded, very slowly increasing in diameter but rapidly increasing in length; spire very long, usually longer than the aperture, narrow, acute, the whorls very flatly rounded; sutures shallow; outer lip but slightly thickened within; aperture narrow, very elongate-ovate, narrowed above and below and frequently sharply angled; inner lip rather wide, flatly reflected and tightly appressed to the columellar region, usually completely closing the umbilical chink; there is a distinct, oblique columellar plait and the parietal wall is covered with a heavy, wide callus; axis twisted.

$\begin{array}{cccc}\text { Length. } & \text { Breadth. Aperture length. } & \text { Breadth. } \\ 16.00 & 8.00 & 9.00 & 4.00 \text { mill. } \\ 15.00 & 7.00 & 7.50 & 3.00 \text { " } \\ 15.60 & 7.00 & 8.00 & 3.50 \text { " }\end{array}$

Types: Chicago Academy of Sciences, four specimens, No. 24511 ; cotypes, coll, Bryant Walker.

Type Locality: St. Clair flats, Detroit, Michigan.

Animal: Not differing from typical catascopium.

JAW: As in catascopium.

RADULA: Not differing from typical catascopium. There is little variation, there being nine laterals in all the specimens examined.

Genitalia: (Plate XV, fig. F, 1-3). Not differing essentially from these organs in typical catascopium. In one specimen from the St. Clair flats, the penis-sac retractor was double (3). The measurements of the genitalia will be found under typical catascopium (p. 385) where they are listed for comparison with the typical form.

RANGE: Adamsi has not been seen outside of the state of Michigan and is, hence, confined to the Canadian Region.

\section{RECORDS.}

Michigan: St. Clair flats, Wayne Co.; small island in Tobin Harbor, Isle Royale (Walker).

Ecology: "Apparently most frequent in shallow water in places sheltered from the waves." (Isle Royale) St. Clair flats (Detroit).

REMARKS: The race here separated from catascopium offers characters which easily separate it from the typical form, which is always wider, with a shorter, wider spire and a more ovate aperture. 
It was at first identified as niagarensis, but differs from that race in having a more elongated shell, a longer spire and hence longer spire whorls, and a more elongated and narrower aperture. The race is so characteristic that it cannot be mistaken for any other species or race. There is some variation in the shape and degree of impression of the inner lip and also of the aperture, but on the whole the race is unusually constant in general form. Several specimens have been seen in which the upper part of the whorls is distinctly shouldered.

The race is common on the St. Clair flats near Detroit. Walker's Michigan reference (op. cit. p 291), in which he says, "Associated with this form at Station IV, 6, (Small Island in Tobin Harbor, Isle Royale) was a very thin, elongated form with the characteristic sculpture of catascopium, which is closely related to, but much more fragile than, the elongated form which is characteristic of the lower Great Lakes," appears to be referable to this race.

The race is named in honor of Prof. Chas. C. Adams, of the University of Illinois, who has contributed many valuable notes to the ecology of Michigan Mollusca.

Galba davisi (Walker). Plate XLI, figure 5.

Lymnaa davisi WalkFe, Nautilus, XXII, p. 17, pl. ii, figs. 9-10, June 1908.

"Shell: Of medium size, globose-conic; perforate; light horncolor; whorls 5 ; the spire about one-third of the entire length of the shell, rapidly acuminating and with a minute, sharp apex; the whorls of the spire are flattened and but slightly convex, with a distinct, but not deeply impressed suture; body whorl large, inflated, ovate, flattened above and rounded below ; lines of growth distinct, fine and regular, minutely decussated with revolving spiral lines; aperture large, pear-shaped, acutely angled above and broadly rounded below, about three-fifths of the entire length, lip sharp, slightly thickened within, straight above, somewhat expanded below, broadly reflected over and nearly covering the small umbilical perforation; columella with a very slight fold; axis rather thick, round, scarcely if at all folded."

$\begin{array}{ccccc}\text { Length. } & \text { Breadth. } & \text { Aperture length. } & \text { Breadth. } & \\ 15.20 & 7.50 & 9.00 & 4.00 \text { mill. } & \text { Type. } \\ 15.00 & 7.50 & 9.50 & 4.50 \text { “ } & \text { “ }\end{array}$

Type: Collection Bryant Walker, Detroit, Michigan, two specimens, No. 20092.

Type Locality: Fish Point, Tuscola Co., Michigan.

Animal, Jaw, Radula and Genitalia: Unknown.

Range: Tuscola Co., Michigan. A species of the humid division of the Transition life zone and of the Canadian region. 
RECORDS.

Michigan : Fish Point, Saginaw Bay, Tuscola Co, (Davis; Walker).

Geological Distribution: Unknown.

ECOLOGY: Not recorded.

Remarks: Of this species Mr. Walker says: "This species is well characterized by its large, ovate body whorl and its very acute spire; the apical whorls are flattened and the straight line of spire is prolonged over the upper part of the body, giving a 'pot-bellied' appearance to the shell."

This is a peculiar little species, unlike any other. Its very acute spire, large body whorl and elongate-ovate aperture appear to be the chief features, which easily distinguish it from catascopium, its nearest relative. "Named in honor of Prof. Charles A. Davis, of Ann Arbor, its discoverer, in recognition of the many valuable contributions he has made to our knowledge of the distribution of the Mollusca in Michigan." (Walker).

Galba pseudopinguis Baker. Plate XLI, figures 6-7; plate XLII, figures 9-13.

Lymnca pseudopinguis BAKeR, Nautilus, XXI, p. 54, Sept., 1907.

SHELL: Elongate-ovate to subglobose, rather thin; periostracum very light corneous, inclining to yellowish or brownish; surface dull to shining, but not polished; growth lines very heavy and spiral lines deeply incised; whorls five to six, rounded, the body whorl globosely inflated; the whorls increase very rapidly in diameter; spire about as long as the aperture, broadly conic, the whorls very rapidly increasing in size; sutures well marked or deeply indented, bordered below by a wide, yellowish band; aperture ovate or roundly ovate, sometimes a trifle expanded and somewhat effuse anteriorly; inner lip rather broadly expanded, triangular, reflected over but not closing the umbilicus which is a conspicuous chink; the inner lip is much compressed and dented at its junction with the body whorl, forming a slight plait; the parietal callus is very thin or wholly lacking. The axis is but slightly twisted.

\begin{tabular}{|c|c|c|c|c|c|}
\hline $\begin{array}{l}\text { Length. } \\
9.00\end{array}$ & $\begin{array}{c}\text { Breadth. } \\
6.50\end{array}$ & $\begin{array}{c}\text { Aperture length. } \\
6.00\end{array}$ & $\begin{array}{l}\text { Bre } \\
3.50\end{array}$ & $\begin{array}{l}\text { adth. } \\
\text { mill. }\end{array}$ & Crystal Brook. \\
\hline 9.50 & 6.75 & 6.50 & 3.50 & “ & " \\
\hline 8.25 & 5.50 & 5.40 & 3.00 & “ & “ \\
\hline 14.00 & 8.00 & 8.00 & 4.30 & “ & “ \\
\hline 12.50 & 7.50 & 7.30 & 4.00 & “ & “ \\
\hline 11.00 & 7.00 & 7.00 & 3.50 & “ & $" 6$ \\
\hline 18.00 & 9.25 & 9.50 & 4.00 & “ & Canarsie. \\
\hline 12.00 & 6.00 & 6.50 & 3.00 & “ & " \\
\hline 7.25 & 5.00 & 5.00 & 3.00 & “ & Mt. Sinai. \\
\hline 7.50 & 5.00 & 5.00 & 2.50 & “ & " \\
\hline
\end{tabular}


Types: Chicago Academy of Sciences, four specimens, No. 23800; cotpyes, collection Miss Mary Walker, Buffalo, N. Y., Mr. Bryant Walker, Detroit, Mich., Academy of Natural Sciences of Philadelphia, and the Smithsonian Institution, Washington, D. C.

Type Locality: Crystal Brook, Long Island, N. Y.

Animal, Jaw, Radula and Genitalia: Unknown.

RANGE: (Figure 43). Long Island. A species of the Alleghanian division of the Transition life zone, and of the Nova Scotian region.

RECORDS.

Canarsie, King Co. (Ferriss; Weeks); Crystal Brook and Mt. Sinai, Suffolk Co., Long Island, N. Y. (Miss Walker and Bryant Walker).

Geological Range: Unknown.

HABITAT: In salt or brackish water "at low tide in shore of bay fed by springs" (Crystal Brook). In ice-cold spring (Mt. Sinai).

Remarks: This peculiar Lymnæa was at first thought to be a variety of catascopium but it differs from that species in its thinner shell, more globose whorls, especially the spire whorls, and particularly by its triangular, smooth, reflected inner lip and distinct umbilical chink. The form of the shell and of the inner lip resemble the techella group of Lymnæas of the subgenus Galba.

It is probably a variation of the catascopium stock, produced by changing conditions of the environment which have dwarfed the shell. It is a significant fact that the icy cold spring at Mt. Sinai has produced the same shell characteristics as the brackish water of Crystal Brook. There is considerable variation in the height of the spire among the numerous specimens examined, some individuals having an elongated spire a trifle longer than the aperture while in others the spire is less than half the length of the aperture. The shell also varies in corpulency. The short globose shells are all immature and are the specimens first described as typical. Additional specimens from Crystal Brook and also from Canarsie show the mature form to have a spire as long as the aperture with rounded whorls. A single specimen from Canarsie is distinctly scalariform (plate XLI, figure 6). The inner lip is peculiar and, together with the form of the shell, will easily separate this species from catascopium, its nearest ally. The short spired form was at first thought to be a variation of catascopium pinguis, hence the specific name pseudopinguis.

The shell was first brought to the notice of the writer by Miss Mary Walker of Buffalo, New York (who suggested its resemblance to bulimoides) and later by Mr. Bryant Walker of Detroit, Michigan. 
Galba nasoni (Baker). Plate XLII, figures 14-1\%.

Lymnca nasoni BAKER, Trans. Acad. Sci. St. Louis, XVI, p. 12, pl. 1, figs. 1-4, May, 1906.

SHell: Rather small, globosely inflated, solid; periostracum whitish, tinged with purple; surface dull, marked by rather coarse growth lines crossed by fine, impressed spiral lines; nuclear whorls small, rounded, very wide and low, flattened, dark brown in color; (plate XLIX, figure 0) ; whorls four, roundly inflated, tumid, the body whorl very large and bulbous; spire much depressed, very broadly acute; sutures slightly impressed; aperture broadly ovate, almost round in some specimens, sometimes somewhat expanded, rounded anteriorly, somewhat acutely angled posteriorly ; outer lip with a bluishwhite, longitudinal varix bordering its edge; inner lip narrow, appressed to the axis, leaving a very small chink and forming a distinct, ascending plait on the columella; the inner lip slightly emargins the umbilical chink; the callus on the parietal wall is thin; the interior of the aperture is brown in color.

\begin{tabular}{|c|c|c|c|c|c|}
\hline $\begin{array}{l}\text { Length. } \\
10.50\end{array}$ & $\begin{array}{c}\text { Width. } \\
6.75\end{array}$ & $\begin{array}{c}\text { Aperture length. } \\
7.00\end{array}$ & $\begin{array}{r}\mathrm{Wi} \\
4.25\end{array}$ & $\begin{array}{l}\text { idth. } \\
\text { mill. }\end{array}$ & Туре. \\
\hline 9.50 & 6.00 & 7.00 & 5.00 & . “ & “ \\
\hline 8.50 & 6.00 & 6.25 & 4.00 & $₫ 6$ & " \\
\hline 10.00 & 6.75 & 7.00 & 5.00 & "6 & “ \\
\hline
\end{tabular}

Types: The Chicago Academy of Sciences, four specimens, No. 23788. Cotypes, collection Illinois State University and Mr. Bryant Walker, Detroit, Michigan.

Type Locality: Thunder Bay Island, near Alpena, Michigan.

Animal, Jaw, Radula and Genitalia: Unknown.

RANGe: Michigan. A species of the Boreal life zone and of the Canadian region.

\section{RECORDS.}

Michigan: Thunder Bay Island, near Alpena, Alpena Co., Michigan (Nason).

Geological Distribution: Unknown.

Ecology: Exposed shore of Lake Huron, where the water is daily forced into the pools (Nason).

Remarks: Nasoni may be known by its small size, its short, bulbous, dome-shaped spire and wide-spreading aperture. It somewhat resembles certain forms of catascopium found in Pine Lake, Charlevoix, Michigan, but differs in the very short spire, broad and tumid last whorl, and in having one whorl less. The columellar plait is also more distinct. Woodruffi has a differently shaped shell and a totally different inner lip. Galba apicina is liable to be confused with 
nasoni, but that species is larger, has a more regularly globose shell, a longer spire and broader inner lip which emargins the umbilical chink. Nasoni belongs to the catascopium group, while apicina is a member of the emarginata group.

The species is named in honor of Dr. William A. Nason, of Alongquin, Illinois, who collected the specimens.

Galba woodruffi (Baker). Plate XLII, figures 18-22.

Limnca catascopium pinguis BAKER (non Say), Trans. Acad. Sci.; St. Louis, XI, p. 5, pl. 1, fig. 12, 1901.

Limncea woodruffi BAKer, Bull. Chi. Acad. Sci., II, p. 229, fig. 1901; Moll. Chi. Area, II, p. 264, pl. 31, fig. 8, 1902.-Blatchley \& Daniels, An. Rep. Dept. Geol. \& Nat. Res., Ind., XXVII, p. 598, pl. 1, fig. 16, 1902.-Daniels, 1. c., p. 636, 1902.-CKLl., Nautilus, XVI, p. 96, 1902.

Lymnaa woodruffi BAKer, Bull. Ill. State Lab. N. H., VII, p. 104, 1906.

SHELL: Small, ventricose, inflated, rather solid; periostracum greenish-horn or olivaceous; surface shining, growth lines crowded, very distinct, crossed by fine impressed spiral lines; nuclear whorls roundly inflated, light or dark horn colored similar in outline to those of jacksonensis; whorls $4-4 \mathrm{r} / 2$, convex, tumid, the body whorl very large, occupying more than two-thirds the length of the shell; spire generally much depressed, globose; sutures well impressed; aperture very large, long-ovate to roundly ovate, broadly rounded below, angulated above, occupying about two-thirds the total length of the shell; it is sometimes shouldered; outer lip thickened within by a heavy longitudinal varix ; inner lip rather wide, with parallel margins, spreading over the umbilicus which it slightly emargins and forming a wide, flattened expansion; an umbilical chink is usually present; the callus on the parietal wall is thick and heavy and is the same width as the inner lip; in some specimens the columella is thickened in the middle forming a distinct tubercle; a columellar plait is not developed, but the axis, especially in the upper whorls, is distinctly twisted.

$\begin{array}{rccccc}\text { Length. } & \text { Width. } & \text { Aperture length. } & \text { Width. } & \\ 11.80 & 8.50 & 8.50 & 5.50 & \text { mill. } & \text { Type. } \\ 10.50 & 7.25 & 8.50 & 4.75 & \text { “ } & \text { “ } \\ 10.50 & 7.00 & 8.00 & 5.00 & \text { “ } & \text { “ } \\ 9.00 & 5.25 & 6.00 & 3.50 & \text { “ } & \text { Millers. } \\ 9.50 & 6.00 & 6.75 & 3.50 & \text { “ } & \text { “ } \\ 13.75 & 8.00 & 9.50 & 4.50 & \text { " } & \text { Chicago. } \\ 11.50 & 7.50 & 8.25 & 4.25 & \text { “ } & \text { " }\end{array}$

Types: Five specimens, Chicago Academy of Sciences, 23\%89 and 3425 .

Type Locality: Lake Michigan, Oak Street, Chicago, Illinois. Animal, Jaw, Radula and Genitalia: Unknown. 
RANGE: (Figure 43). States bordering Lake Michigan. A species of the Canadian region and of the humid division of the Transition and Upper Austral life zones. It is apparently a species confined for, the most part to Lake Michigan; there is but one record (Lake Geneva, Wisconsin) away from Lake Michigan and it is possible that this record is due to a mixing of labels.

\section{RECORDS.}

IllıNors: Lake shore, Ravinia, Lake Co. (Baker); Lake Michigan, Oak Street, Chicago, Cook Co. (Lyon; Woodruff); lake shore, Lincoln Park, Chicago (Jensen; Walcott); Lake Michigan, Chicago (Nason); Evanston, Cook County (C. S. Raddin); Lake Michigan south of Graceland Avenue, Chicago (Walcott).

IndiANA: Lake Michigan, Millers, Lake Co. (Baker; Woodruff); Lake Michigan, Michigan City, La Porte Co. (Daniels).

Michigan: New Buffalo, Berrien Co. (Daniels; Walker); High Island Harbor, Charlevoix Co. (Walker).

Wisconsin: Lake Geneva, Walworth Co. (Illinois State Laboratory).

Geological Distribution: Unknown.

ECOLOGY: Woodruffi probably inhabits the deeper waters of Lake Michigan as only dead shells have been found along the shore.

REMARKs: Woodruffi may be known by its very short, broad spire, rapidly increasing and tumid whorls, its large, ovate or roundly ovate aperture and its broad, flat inner lip without a plait. It resembles emarginata in the form of its emarginate inner lip and catascopium in the general depressed form of the shell. The small size, large aperture and peculiar inner lip will distinguish woodruffi from both of these species. It somewhat resembles apicina but differs in the depressed spire and broad, flat inner lip, without a plait. The same feature will distinguish it from decollata. The shells vary somewhat in rotundity, some specimens being a trifle flattened on the body whorl and having the spire somewhat elevated. The shells vary somewhat in the degree of umbilication which may be marked or absent. The aperture may also be roundly ovate, oblong-ovate or elliptical. With all this variation, however, the species seems quite distinct and is very uniform in its specific features. Young shells are quite thin, but adult specimens are very thick and solid and show a tendency to hecome imperforate as well as to acquire a tubercle or swelling on the middle of the columella.

Since its discovery by Mr. F. M. Woodruff, in 1901, the species has been collected in large numbers all along the southern shores of Lake Michigan from Evanston, Illinois, to Michigan City, Indiana. This abundance of material is ample evidence that the species is living in goodly numbers somewhere in the deep water of the southern 
part of Lake Michigan. After a northerly storm the beaches along the lake are strewn with the dead shells of Galba woodruffi. This is especially true at Millers, Indiana, where the beach is very wide and evenly sloping, and in the line of beach debris, this Lymnæa may be found by thousands. It is very curious that not a single living specimen has as yet been found.

It has been suggested by Cockerell (Nautilus XVI, p. 96) that woodruffi might be a form of the European peregra, but a comparison with authentic specimens of that species shows it to be quite different. It is undoubtedly a native species.

Galba decollata (Mighels). Plate XLII, figures 23-26; plate XLI, figures 8-10.

Limnaa decollata Mighels, Proc. Bost. Soc. N. H., I, p. 49, 1841.Mighels \& Adams, Bost. Journ. Nat. H., IV, p. 45, pl. 4, fig. 13 (four views), 1842.-Mighels, Bost. Journ. Nat. H., IV, p. 337, 1843.-Stimpson, Sh. N. Eng., p. 52, 1851.-Chickering, List. Sh. Portland, Me., 1855 or 1856.-Bell, Geol. Surv. Can., Rep. Prog., p. 252, 1859.*-Binney, Check List, p. 12, 1860.-Whiтeaves, Can. Nat. \& Geol., VIII, p. 102, 1863.*-Binney, Land \& F.-W. Sh. N. A., II, p. 31, figs. 36, 37, 1865.-Dall, Proc. Bost. Soc. N. H., XIII, p. 240, 1870.Smith \& Prime, Ann. Lyc. N. H., IX, p. 378, 1870.*-Gould, Invert. Mass., Binney's Ed., p. 473, fig. 725, 1870.-Jefrreys, Ann. Mag. N. H., iv, X, p. 247, 1872.-Sowb., Conch. Icon., XVIII, Lim. sp. 42, pl. 6, fig. 42, 1872.-TrYon, Con. Hald., Mon., p. 90 (64), 1872.-Jefrreys, Journ. Conch., I, p. 16, 1874.Westerlund, Vega Exp., IV, p. 165, 1885.-Cham bers, Rep. Geol. \& Nat. Hist. Surv., Canada, 1882-84, p. 46, GG, 1885.*-Ottawa Nat., IV, p. 55, 1890.*-TAylor, Ottawa Nat., VI, p. 33, 1892.*-Stearns, Proc. Nat. Mus., XXIV, p. 291, 1901.

Limnea catascopium var. decollata Hartmann and Michener, Conchologia Cestrica, 1874 (part).

Lymnaa decollata Wheatley, Ca.t. U. S. Sh., Ed. 2, p. 23, 1845.-Linsley, Amer. Journ. Sci., XLVIII, p. 282, 1845.*-JAY, Cat., 4th Ed., p. 268, 1852.Morse, An̉er. Nat., III, p. 651, pl. 11, fig. 4, 1870.-DAll, Alaska Moll., p. 68, 1905.-Lermond, Shells of Maine, p. 38, 1908.-Berry, Nautilus, XXIV, p. 62, 1910.-WAlker, Journ. Conch., XII, p. 240, 1909.

Limnaus decollatus Küster, Conch. Cab., Ed. 2, p. 45, taf. 8, figs. 12, 14, 1862 (figs. $11 \& 13$ are not decollata).

Limnea decollata Haldeman, Mon. Limn., p. 52, pl. 14, figs. 1-3, 1842.

Radix decollata Morse, Journ. Bost. Soc. N. H., I, p. 42, 1864.

Neristoma decollata Tryon, Amer. Journ. Conch., I, p. 248, 1865.

Limnea catascopium? Haldeman, Mon. Lim., p. 52, 1842 (non Say).

Lymnaa mighelsi Dall, Alaska Moll., p. 68, fig. 45, 1905 (non Binney).

SHELL: More or less ventricose, subovate or irregularly rhomboid, thin to thick; periostracum olivaceous green color; some specimens are almost jet black; surface shining, growth lines crowded, fine in

*These records marked with an asterisk are very doubtful. They probably were based on short spired forms of catascopium. Specimens received from Mr. F. R. Latchford are referable to the short spired form of catascopium. 
some specimens and coarser in others, crossed by very indistinct spiral impressed lines; in old specimens the shell becomes very rough and eaten away by the excess of carbon dioxide in the, water; whorls $31 / 2$ in perfect specimens, but generally only 2 to $21 / 2$ remain intact, the tip of the spire being decollated; the whorls are rather flat sided on the spire, the body whorl alone being ventricose and sometimes roundly sloping above the periphery; apex light horn color, small, rounded; spire very short, broadly conic, generally decollated; sutures tightly appressed, in some specimens distinctly impressed; aperture large, ovate, occupying two-thirds the length of the shell, in old specimens distinctly campanulate; peristome thin, acute; the outer lip is inclined to thicken within the aperture and a transverse varix edged with reddish brown is sometimes formed; inner lip reflected over the parietal wall and umbilicus, tightly closing the latter; the axis is slightly twisted and there is a well marked fold.

Length. Breadth.

$15.00 \quad 12.50$ mill. (Mighels .6 by .5 inch.)

$15.00 \quad 10.50$ “ Tryon.

Aperture length. Breadth.

12.00

$8.00 \quad 9.00$

5.50 mill.

Walker, received from $\mathrm{Mi}$ ghels.

12.25

8.00

9.00

5.50 “

Walker, received from $\mathrm{Mi}$ ghels.

11.25

7.75

8.00

5.00 “

Walker, received from $\mathrm{Mi}$ ghels.

9.75

7.00

7.00

4.50 "

Walker, received from $\mathrm{Mi}$ ghels.

11.00

7.50

8.00

5.00

Walker (J. G. Anthony).

11.75

8.00

8.25

5.00

Phil. Acad. Sci.

12.00

8.50

8.50

4.50

Smith. Inst.

14.00

11.50

9.25

17.00

11.25

12.50

15.25

11.00

11.50

7.00

6.50

6.25

Bost. Soc. N. H.

Types: Destroyed in Portland fire of 1866. Specimens received from Mighels are in the collection of the Academy of Natural Sciences, Philadelphia, No. 58\%03; in the Boston Society of Natural History, No. 24192; the Chicago Academy of Sciences, No. 23811 and in the collection of Mr. Bryant Walker.

Type Locality: Lake Wininecook, Unity, Waldo Co., Maine.

Animal: "Dingy mouse-color, with a slight tinge of purple; covered with numerous microscopic, elongated white spots on every visible part of the surface, including the mouth and tentacula; foot of a chocolate color, rather broad, length rather greater than the aperture." (Mighels). 
Jaw, Radula and Genitalia: Unknown.

RANGE: Maine. A species of the Alleghanian division of the Transition life zone and of the Nova Scotian region. As the species has been so misunderstood and mixed with catascopium, apicina, etc., only those records are mapped which are known to be correct. No authentic records are known outside of the state of Maine. The Connecticut record of Linsley and the British American references by Bell and Whiteaves are believed to have been based on some form of catascopium.

\section{RECORDS.}

MAINE: Winnecook Lake, Waldo Co. (Berry); Maine (Anthony; Binney; Griffith; Haldeman; Lea; Lewis; Mighels; Walker) ; Portland, Cumberland Co. (Chickering); Unity, Waldo Co. (Adams; Mighels).

Geological Distribution: Unknown.

HaBitat: "Adhering to boulders just below the surface of the water." (Chambers).

Remarks: Decollata is a very distinctive species, easily known by its flatly sloping spire, tumid body zhorl, somewhat patulous aperture and very tightly closed umbilicus. It does not seem to be similar to any species, excepting, perhaps, some short-spired forms of catascopium which, however, have a differently shaped spire, aperture and umbilical region. The spire is decollated in a majority of the specimens examined.

Decollata seems to be little understood by most conchologists. It has been placed in both catascopium and emarginata, and has also been considered a variety of mighelsi. Specimens of apicina from northern Michigan and Lake Superior have been identified as decollata and specimens of emarginata angulata have also been so identified. This confusion has arisen from lack of authentic specimens for comparison. The specimen figured by Binney (fig. 3\%, ex Haldeman, Smith, No. 9132) is larger and much thinner than specimens believed to be typical. This specimen measures as follows: Length, 21.00 ; breadth, 15.00; aperture length, 14.00 ; breadth 10.00 mill. Mighel's original measurements are: length, 15.00 ; breadth, 12.50 mill. This specimen has all of the characteristics of decollata excepting that it is larger, thinner and has a more patulous aperture. It is not mighelsi, as may be seen by comparing the spire and body whorl with those of mighelsi, which are much broader, rounder and of a different shape (compare Binney's figure with figure 9 on plate XLI). Specimens in the Boston Society of Natural History (No. 24192) which were deposited by Mighels and may, indeed, be considered cotypes, agree well with Binney's figure 3\%. Two of these are figured on plate XLI, figures 8 ond 9. 
Specimens in the Lea collection (Smith. No. 118655) are similar to specimens in the Philadelphia Academy (No. 58703) which were received from Mighels, and which correspond with his figures and descriptions, and it is these forms which must be taken as correctly representing Mighels' species. Specimens in the collection of Mr. Bryant Walker, which were received from Mighels, are figured on plate XLII, figures 23-25. The material examined is very uniform and the species appear to be very distinct. An examination of the axis shows that decollata is a member of the catascopium group of the subgenus Stagnicola, and was not correctly placed in Radix by Binney, Dall, Tryon and other conchologists. The peculiar swelling out of the periphery of the body whorl in decollata will at once distinguish it from all related forms. The writer has not seen specimens from Connecticut or from different parts of Canada, and the records of Linsley, Bell and others in which decollata is cited from these localities is greatly to be questioned. They will probably be found to be forms of catascopium or oronensis.

Galba sumassi (Baird). Plate XLI, figures 11-1\%.

Limnaa sumassi BaIRd, Proc. Zool. Soc., p. 68, 1863.-CPR., Rep. Brit. Assoc., p. 673, 1864.-Binney, L. \& F.-W. Sh. N. A., II, p. 43, fig. 56, 1865.Tryon, Amer. Journ. Conch., III, p. 196, 1867.-CPR., Smith. Mis. Coll., p. 15:, 1872.-Sowb., Conch. Icon., XVIII, Limn., sp. 34, 1872.-Stearns, Proc. Nat. Mus., XIV, p. 101, 1891; XXIV, p. 291, 1901.-Whiteaves, Ottawa Nat., XX, p. $115,1906$.

Limnophysa sumassi Tryon, Amer. Journ. Conch., I, p. 251, 1865.-Call, Bull. U. S. Geol. Surv., II, p. 371, 1884 (part).

Lymnea sumassi LoRD, Nat. in Brit. Col., II, p. 363, 1866.

Limnceus sumassi Clessin, Küster, Conch. Cab., p. 387, taf. 53, fig. 4, 1886 (figure poor).

Limnca nuttalliana var. sumassi Cooper, Proc. Cal. Acad. Sci., IV, p. 96, 1870 (part).

Lymnca catascopium var. sumassi Dald, Alaska Moll., p. 78, 1905 (part).

Shell: Narrow, elongated, attenuated, fusiform in some specimens, varying from thin to rather solid; periostracum light, whitish horn, with two or three rest period bands; surface shining, lines of growth coarse and heavy, wrinkled and crowded about the aperture, crossed by very heavy impressed spiral lines; nuclear whorls rounded, smooth, dark brown color, in size about as in catascopium; whorls six, flatly rounded, slowly enlarging; last whorl somewhat flat-sided normally; spire rather long, pointed, a trifle longer than the aperture; sutures well impressed; aperture elongate-ovate, somewhat semi-lunate, a little effuse anteriorly; peristome thin, acute, bordered within by a narrow black band which marks a rest-varix; parietal wall with a 
rather wide, thick callus; inner lip narrow, reflected, nearly or quite closing the umbilicus; the columella is inclined to be twisted and is marked by a heavy plait. Some specimens are somewhat malleated.

$\begin{array}{cccccc}\text { Length. } & \text { Breadth. Aperture length. } & \text { Breadth. } & \\ 23.50 & 9.50 & 11.50 & 4.80 & \text { mill. } & \text { Cotype. } \\ 22.00 & 10.00 & 11.50 & 5.10 & \text { “ } & \text { “ } \\ 29.00 & 12.50 & \ldots . . & \ldots . & \text { “ } & \text { (Baird.) } \\ 15.50 & 7.50 & 7.60 & 3.10 & \text { " } & \text { Utah. } \\ 17.00 & 8.00 & 8.50 & 4.00 \text { “ } & \text { “ }\end{array}$

Types: British Museum, London, England.

Type Locality: Sumass Prairie, Frazer River, British Columbia.

Animal, Jaw, Radula and Genitalia: Unknown.

RANGE: British Columbia south to Northern Utah (41st parallel); a species of the Columbian and Great Basin regions and of the Canadian and Transition life zones. Sumassi doubtless occupies much of the territory between the two records cited, but it has been confused with palustris, jacksonensis and other western species and the records cannot be relied upon. Only two lots have been seen which are authentic, the type lot and one from Echo Canyon, Utah.

RECORDS.

United States.

Utah: Echo Canyon, Summit Co. (Hannibal).

\section{British America.}

British Columbia: Sumass Prairie, Frazer River, New Westminster District (Baird; Lord).

Geological Distribution: Unknown.

ECology: Not recorded.

Remarks: Sumassi has long been a puzzle to most American conchologists who have believed it to be a snyonym of palustris. The original description is quite inadequate and in no wise differentiates the species from palustris. Dr. Dall recently ${ }^{1}$ quoted it as a variety of catascopium, while the writer ${ }^{2}$ referred certain fragile Lymnæas from Lake George, near Florissant, Colorado, to it. Through the kindness of Mr. E. A. Smith, of the British Museum, the writer was enabled to examine and figure two specimens of sumassi from the original lot collected by Mr. J. K. Lord. These specimens are quite different from the Colorado specimens (which are a form of palustris) and show that Dr. Dall was right in associating sumassi with catascopium.

Sumassi closely resembles certain narrow forms of catascopium, especially examples from the Great Lake region, but it is usually nar-

${ }^{1}$ Alaska Moll., p. 78.

${ }^{2}$ Henderson, Moll. of Colorado, p. 180. 
rower, thinner, the aperture is generally more elongate, the spire is narrower and more acute, and the columellar plait is heavier. The aperture is also somewhat differently shaped. Catascopium adamsi approaches nearest to sumassi; it differs from this race in its rounder whorls, more ovate aperture and more decided columellar plait. It also occupies a widely separated area of the country. Sumassi differs from palustris in being lighter in color, with heavier sculpture, narrower shell, and differently shaped columella. It has the spermacetilike color of the catascopium group and not the brown color of palustris. Binney's figure 56 seems to be quite typical and accurately represents the two specimens from the British Museum but his figure $5 \%$ would seem to represent a different species, perhaps jacksonensis. This figure (5\%) has been used by Dall and others as typical of sumassi, but it does not agree with the description nor the cotypes in the British Museum. Compare figure 14, on plate XLI, with Binney's figure 56.

Many of the references to sumassi are based on narrow or fragile forms of palustris. Dr. Dall's reference to Snake River, Idaho, probably is based on Galba jacksonensis ${ }^{1}$ which is a much wider shell than sumassi. The Lake Washington, Seattle, specimens are a form of palustris. Sumassi replaces catascopium on the Pacific slope and will probably be found to be widely distributed in the northwest when its characters are understood and this territory is more thoroughly explored.

Galba jacksonensis (Baker). Plate XLII, figures 27-31.

Lymncea jacksonensis BAKER, Nautilus, XXI, p. 52, September, 1907.

Lymncea catascopium var. sumassi Dall, Alaska Moll., p. 78, 1905 (part).

?Limncea sumassi Binney, L. and F.-W. Sh., II, p. 43, fig. 57, 1865.

Shell: Ovately-fusiform, inflated, solid; periostracum very dark horn; surface shining, lines of growth coarse, crossed by deeply incised spiral lines sagrinating the surface; one or two rest periods are discernable as longitudinal bands on the body whorl and spire; nuclear. whorls $11 / 4$, very dark chestnut colored, much flatter and wider than those of catascopium (see plate XLIX, figure $\mathrm{N}$ ); whorls $5 \mathrm{~T} / 2$, rounded, rather rapidly increasing in size; body whorl large, ovatelyinflated; sutures well impressed; spire about equal to the aperture in length, broadly conical; aperture regularly elongate-ovate, narrowed at both ends, somewhat effuse anteriorly; outer lip with a chestnut bordered internal varix; inner lip in the adult rather broadly reflected over the umbilicus, leaving a small, narrow chink; parietal cal- 
lus rather heavy in some specimens in which case making a continuous aperture; axis very slightly twisted; columella with a well marked fold, more strikingly developed in immature than in very old specimens, and frequently indicated only by a tubercle-like swelling.

$\begin{array}{cccccc}\text { Length. } & \text { Width. } & \text { Aperture length. } & \text { Width. } & \\ 19.00 & 10.00 & 10.10 & 5.00 & \text { mill. } & \text { Type. } \\ 16.50 & 9.50 & 9.10 & 4.80 & \text { “ } & \text { “ } \\ 14.50 & 8.50 & 8.50 & 4.00 & \text { “ } & \text { " } \\ 14.00 & 7.50 & 7.50 & 3.40 & \text { " } & \text { " } \\ 12.50 & 7.50 & 8.00 & 3.50 & \text { " } & \text { " }\end{array}$

Types: Chicago Academy of Sciences, five specimens, No. 23806. Cotypes, collections of Academy of Natural Sciences, Philadelphia and A. A. Hinkley.

Type Locality: Jackson Lake, drained by the south fork of the Snake River, Wyoming.

Animal, Jaw, Radula and Genitalia: Unknown.

RANGE: Wyoming and Idaho. A species of the Boreal (Canadian) life zone and of the Columbian region.

\section{RECORDS.}

IDAHo: Snake River (Dall).

Wyoming: Jacksons Lake, drained by the south fork of the Snake River; Phelps Lake, eight miles south of Jacksons Lake (H. O. Hinkley; A. A. Hinkley).

Geological Range: Unknown.

Ecology: Not recorded.

Remarks: This species was received from Mr. A. A. Hinkley of DuBois, Illinois, under the name of binncyi. Comparison with Tryon's types showed at once that it was not that species which is larger, of a different color and with a differently shaped shell, inner lip, umbilicus, etc. It approaches gabbii Tryon, but the aperture is more regularly clongate-ovate, the whorls are rounder, the inner lip is broadcr, there is an umbilical chink and the whole shell is more fusiform. Comparison has been made with Tryon's types and with a set in the Chicago Academy of Sciences, from the original lot received from Tryon. It has some resemblance to catascopium, but the columella is quite dissimilar, there is an umbilical chink, the color of shell and aperture is different, and the aperture is differently shaped. Jacksonensis has a superficial resemblance to sumassi but differs in being shorter and wider, smaller (usually) and with a very different columella (compare the figures of these species on plates XLI and XLII). The reference by the writer in the Nautilus to Binney's figures of shells from Grindstone Creek was an error, as these figures refer to apicnia. Jackson- 
ensis has probably been recorded under the name of palustris, and in many collections may repose under the name of sumassi, binneyi or solida. It is, however, a distinct species related to the catascopium group. Mr. H. O. Hinkley collected the specimens.

Galba gabbii (Tryon). Plate XLII, figures 32-36.

Limnca gabbii Tryon, Amer. Journ. Conch., I, p. 229, pl. 23, fig. 2, 1865; Con. Hald. Mon., p. 109 (83), pl. 18, fig. 7, 1872.

Limnophysa gabbii TrYoN, Amer. Journ. Conch., I, p. 254, 1865.

Limnae adelina var. gabbii Cooper, Proc. Cal. Acad. Sci., IV, p. 96, 1870.

Limnophysa var. gabbii Cooper, Proc. Cal. Acad. Sci., IV, p. 173, 1870.

Shell: Small, rather thin, ovate; periostracum brownish, rather dark in some specimens; surface dull, with rather rough, close set growth lines and fine impressed spiral lines; surface frequently malleated; nuclear whorls $1 \mathrm{I} / 4$ rounded, smooth, almost jet black in color; similar in outline to those of jacksonensis; whorls 5, rapidly enlarging, flatly rounded; body whorl very large, flatly rounded; spire short, broadly acutely conical; sutures impressed but not deeply indented; aperture large, somewhat lunate, a trifle oblique, generally more than half the length of the entire shell; parietal wall with a thin callus; inner lip narrow, reflected, so as to cover the umbilical region leaving, rarely, a very small chink; outer lip with an internal varix; axis slightly twisted, causing a more or less distinctly marked plait.

\begin{tabular}{|c|c|c|c|c|c|}
\hline $\begin{array}{c}\text { Length. } \\
13.10\end{array}$ & $\begin{array}{c}\text { Width. } \\
7.10\end{array}$ & $\begin{array}{l}\text { Aperture length. } \\
\qquad 8.00\end{array}$ & $\begin{array}{r}W \\
4.00\end{array}$ & $\begin{array}{l}\text { idth. } \\
\text { mill. }\end{array}$ & Type. \\
\hline 16.25 & 9.10 & 9.75 & 4.75 & “ & “ \\
\hline 14.75 & 8.50 & 8.50 & 4.50 & “ & “ \\
\hline 14.00 & 7.00 & 8.50 & 4.50 & “ & Clear Lake, \\
\hline 11.00 & 6.00 & 6.50 & 3.00 & “ & “ \\
\hline
\end{tabular}

Types: Academy of Natural Sciences, Philadelphia, twelve specimens, No. 58526.

Type Locality: Clear Lake, California.

Animal, Jaw, Radula and Genitalia: Unknown.

RANGE: California. A species of the Californian region and of the Transition and Upper Austral (Upper Sonoran) life zones.

\section{RECORDS.}

California: Clear Lake, Modoc Co. (Button; Gabb; Hemphill; Tryon; Veatch); Sacramento Valley (Rowell); Islais Creek, San Francisco Co. (Cooper); San Francisco Co. (Hemphill).

Geological Distribution: Unknown.

Ecology: Not recorded.

Remarks: Gabbii somewhat resembles some forms of catascopium but differs in having a more acute, flat-sided spire, a more elongated aperture and a less distinctly marked plait on the columella. The 
body whorl is also more flat-sided and the inner lip is narrower. It differs from jacksonensis in its flat-sided whorls and narrower inner lip in addition to its longer aperture.

The types of gabbii show that the specific characters are fairly constant and do not connect it with any other species. Tryon's figure in the American Journal of Conchology is very good. Cooper (op. cit.) considered it a variety of both adclince and catascopium. The specimens examined show but little variation.

\section{GROUP OF GALBA EMARGINATA.}

Galba emarginata (Say). Plate XXX, figures 27-28; plate XLI, figures 18-24; plate XLIII, figures 1-12.

Lymnaus emarginatus SAY, Journ. Phil. Acad., II, p. 170, 1821; Long's Exp., II, p. 263, 1824 ; Binney's Ed., pp. 67, 130, 1858.

Limnaus emarginatus SAY, Amer. Conch., part VI, pl. 55, fig. 1, 1834; Binney's Ed., pp. 67, 140, 211, pl. 55, fig. 1, 1858.-KüsTer, Conch. Cab., I, p. 44, taf. 8, figs. 6-10, 1862 .

Limnea emarginata Haldeman, Mon. Lim., p. 10, pl. 2, figs. 1-5, 1842.DeKay, Zool. N. Y., p. 73, 1843 (part).-Gould, Agassiz's Lake Sup., p. 244, 1850.-Ingersoll, Bull. U. S. Geol. \& Geog. Surv., I, p. 139, 1875 (part); Rep. U. S. Geol. \& Geog. Surv. Terr., 1874, p. 406, 1876 (part).

Lymnea emarginata Gould, Lamarck's Genera, p. 69, 1833.-Ravenel, Cat. Sh., p. 11, 1834.-Wheatley, Cat. Sh. U. S., Ed. 2, p. 23, 1845.-Jay, Cat., Ed. 4, p. 268, 1852.-Reeve, Elements of Conch., p. 178, 1860--Baker, Amer. Nat., XXXIX, p. 671, figs. 6, 7, 1905.-DALL, Alaska Moll., p. 68, 1905 (part).-BAKER, Bull. Ill. State Lab., VII, 102, 1906.-WALKER, Nautilus, XXII, p. 18, pl. 1, fig. 1, 1908.-Lermond, Shells of Maine, p. 38, 1908.-Walker, An. Rep. Mich. Geol. Surv., 1908, p. 290, 1909.-Gleason, 1. c., pp. 60-62, 1908.

Limnaca emarginata Gould, Proc. Bost. Soc. N. H., III, p. 181, 1850.Stimpson, Sh. N. E., p. 52, 1851.-Ulffers, Trans. I11. State Ag. Soc., I, p. 612, 1855. ${ }^{1}-$ ReEve, P. Z. S., 1862, p. 105.-BinneX, L. \& F.-W. Sh. N. A., II, p. 51, figs. 75, 77, 79, 1865 (part).-CURrier, Kent. Sci. Inst., Pub. No. 1, 1868.-TrYon, Con. Hald. Mon., p. 110 (84), 1872.-Sowв., Conch. Icon., XVIII, Lim., sp. 35, pl. 7, figs. 35 , b, c, pl. 15 , fig. 47 a, 1872 (the figures are not all typical).-Sмiтн, Rep. U. S. Fish Com., 1872-73, p. 702, 1874.-Aughey, Bull. U. S. Geol. \& Geog. Surv., III, p. 700, $1877 .^{2}$-W WALKER, Journ. Conch. II, p. 330, 1879 (part).-Ottawa Nat., I, p. 58, 1882 (part).-LATch Ford, Amer. Nat., XVIII, p. 1052, 1884 (part). Ottawa Nat., II, p. 264, 1885 (part).-Ottawa Nat., IV, p. 55, 1890 (part).Walker, Nautilus, VI, p. 34, 1897 (part).-Taylor, Ottawa Nat., VI, p. 35, 1892 (part).-Walker, Rev. Moll. Mich., p. 17, 1894 (part) ; Nautilus, IX, p. 5, 1895.Nylander, Nautilus, VIII, p. 126, 1895.-TAylor, Ottawa Nat., VIII, p. 147, 1895 (part).-Nylander, Nautilus, XI, p. 10, 1897; Nautilus, XIII, p. 104, 1900; Nautilus, XV, p. 127, 1901; Destr. of L. Emarg., p. 3-4, 1901.-Stearns, Proc. Nat. Mus., XXIV, p. 291, 1901 (part)._Adams, Rep. Mich. Geol. Surv., 1908, p. 10, 1909.

${ }^{1}$ It is impossible to verify this record which was undoubtedly not based on the true emarginata.

${ }^{2}$ This record has not been substantiated. No specimens of emarginata or of its varieties have been seen from Nebraska. 
Limnophysa emarginata Beck, Index Moll., p. 111, 1837.-Tryon, Amer. Journ. Conch., I, p. 252, 1865 (part).-DeCamp, Kent Sci. Inst., Mis. Pub. No. 5, p. 8, 1881 (part).-Rep. N. Y. State Mus., XXV, p. 112, 1882.-Grant, Rep. Nat. Hist. Surv. Minn., XVI, p. 483, $1888^{8}$

Limnea serrata Haldeman, Mon. Lim., p. 12, pl. 2, figs. 6, 7, 8, 1842.

Limnca serrata Binney, L. \& F.-W. Sh. N. A., II, p. 52, fig. 78, 1865.Tryon, Amer. Journ. Conch., I, p. 253, 1865; Con. Hald. Mon., p. 110 (84), 1870.

Limnophysa ampla var., Rep. N. Y. State Mus., XXXV, p. 112, 1882?

Radix ampla Morse, Journ. Port. Soc. N. H., I, p. 42, 1864 (part); Bull. Essex Inst., XII, p. 172, 1880 (part).

Limnaa delicata 'SAY', Sowb., Conch. Icon., XVIII, Limn., sp. 76, pl. 12, figs. 76, a, b, 1872 (not described by Say).

Limnaa emarginata mighelsi NyLANDER, Nautilus, VIII, p. 126, 1896 ; XI, p. 10, 1897; XIII, p. 104, 1900 (part).-BAKer, Bull. Chi. Acad. Sci., II, p. 196, pl. 2, 1900 (part).-NyLANDER, Dist., pls. 2-4, 1901 (part).

Shell: Large, ranging from ovate to somewhat globose, inflated, usually rather thin, more or less translucent; periostracum corneous, varying from almost pure white to rather dark brown; the periostracum is sometimes ornamented by longitudinal lighter bands, much narrower than the ground color of the shell; frequently there will be a broad band of white on the last whorl, and the sutures are sometimes bordered by a white line; nuclear whorls $1 \frac{1}{2}$ large, wide and low, flattened, chestnut colored, in outline resembling those of Galba nasoni; surface dull to shining, lines of growth coarse, crowded, frequently wrinkled and sometimes crossed by several spiral ridges, in addition to the fine spiral impressed lines, giving the surface a malleated aspect; whorls 5 to $5 \mathrm{I} / 2$, convex to subglobose shouldered, more or less inflated, the last whorl large and usually quite convex, showing a tendency to expand and flare, and also to become shouldered; spire varying from broadly, acutely pyramidal to depressed globose or flattened, frequently eroded; sutures generally deeply impressed in some individuals markedly so; aperture ovate or somewhat rectangular, very large, somewhat expanded or flaring in some specimens, a trifle effuse anteriorly; the aperture occupying one-half to two-thirds of the length of the shell; aperture whitish to brownish or deep chocolate in color; peristome thin, with a thin whitish or brownish internal varix in fully adult specimens; inner lip white, wide, rather broadly reflected and forming a wide expansion which strongly emargins the umbilical chink; in the majority of specimens the parietal callus is very thick and is a trifle raised so as to make the aperture continuous; the columella varies from smooth to heavily plicated; the umbilicus varies from a small chink to a rather wide perforation, emargined by the inner lip; axis

${ }^{3}$ This record has not been verified. 
slightly twisted. There is generally a marked rest varix about midway of the body whorl, and in some specimens as many as five of these varices may be counted; in many individuals the lower part of the aperture becomes twisted to such an extent that it spreads far beyond the umbilical opening; axis twisted and slightly plicate. The juvenile shells are very globose, the strongly shouldered whorls appearing only in nearly adult or old individuals.

\begin{tabular}{cccrcl} 
Length. & Breadth. Aperture length. & \multicolumn{2}{c}{ Breadth. } \\
20.00 & $\ldots .$. & 12.50 & $\ldots .$. & mill. & Say. \\
19.50 & 11.50 & 11.00 & 5.75 & “ & Autotypes. \\
19.10 & 10.50 & 10.75 & 6.00 & “ & “ \\
21.50 & 13.10 & 11.75 & 8.00 & “ & Maine. \\
22.75 & 13.00 & 15.00 & 7.50 & “ & “ \\
28.00 & 18.00 & 18.50 & 10.50 & “ & “ \\
27.75 & 19.00 & 19.00 & 10.50 & “ & “ \\
30.00 & 21.00 & 21.00 & 11.50 & “ & “ \\
24.00 & 12.50 & 13.50 & 7.30 & “ & Lake Superior. \\
22.00 & 12.50 & 12.50 & 7.00 & “ & Isle Royale. \\
18.50 & 12.00 & 12.00 & 6.50 & " & "
\end{tabular}

Types: Not in existence; autotypes, from Saratoga Lake, three specimens, Philadelphia Academy of Sciences, No. 58463; Haldeman's serratus, Philadelphia Academy of Sciences, two specimens, No. 58470.

Type Locality: Lakes of Maine (emarginata); Northwest Territory (serratus).

ANimaL: Color generally blackish or bluish-black, head, tentacles and the greater part of the body flecked with white or yellowish white, giving the surface the appearance of being covered with a superficial bloom when the animal is in motion, as described by Dr. Whitfield for Bulimnea megasoma. ${ }^{1}$ Foot broadly rounded before, more acutely behind, very broad and much flattened on the margins; color bluish-black, lighter beneath and where it joins the body, flecked with yellowish white spots; the center of the sole is lighter than the edge. Head and velum rather short, ranging from semi-circular to very wide in form, with the lateral ends obtusely pointed, according as the animal is motionless or rapidly progressing; the vela area is very large in this species, and frequently assumes a bilobate form anteriorly. Mantle large and conspicuous, fitting closely to the aperture of the shell, bluish-black, flecked with whitish or yellowish. Tentacles broad, flat, thin, triangular and very large and conspicuous, obtusely pointed at their extremity, blackish flecked with yellowish white. Eyes black, surrounded by a yellowish-white zone, placed on rather large swellings at the inner base of the tentacles. Respiratory orifice placed near

${ }^{1}$ Bull. Amer. Mus. Nat. Hist., Vol. I, p. 30, 1881. 
the posterior angle of the shell; the so-called "Siphon" is capable of great expansion, and when taking in air at the surface of the water is sometimes extended to a length of nearly a third of an inch. The pulmonary cavity fills about half of the body whorl, and is colorless and transparent as seen through the shell, where the heart can also be seen pulsating.

Some animals are lighter than others, the extremes of light and dark being very great. The animal in alcohol is almost jet black, and the spots are sometimes scarcely visible. In a freshly-killed specimen the liver is yellowish-white, with bright yellow patches here and there, but in alcoholic specimens it turns brownish, as seen through the transparent mantle; the edge of the latter is greatly thickened and fleshy.

JAw : (Pl. VI, fig. J). Superior jaw, wide and low ; dorsal margin broadly arched, smooth; ventral margin with a narrow central projection; anterior face of jaw striated. The lower lateral margins are frequently produced into rounded prolongations. Color very dark brown; lateral jaws similar to those of auricularia. ${ }^{1}$

RADULA: (Pl. IX, figs. D, F). Formula: $\frac{23}{4-6}+\frac{2}{3}+\frac{10}{2}+\frac{1}{1}+\frac{10}{2}+\frac{2}{3}+\frac{23}{4-6}$ (35-1-35) ; central tooth unicuspid, the cusp long and narrow, the cutting point small and acute; lateral teeth bicuspid, wide, the mesocone wide, spade-shaped, the ectocone rather narrow; toward the intermediate teeth the laterals become narrower; intermediate teeth tricuspid, the entocone small and placed near the distal end of the mesocone; the ectocone is small and is placed about half way up the margin of the reflection; there is a small denticle above the ectocone; marginal teeth serrated, the distal extremity four to six cuspid, the inner margin frequently with two small denticles. There are over 100 rows of teeth. In a membrane from an Isle Royale specimen the. second intermediate tooth and the first two lateral teeth had the entocones broken up into from three to five long, sharp serrations. (P1. IX, fig. F.) In another specimen there were fourteen lateral teeth instead of the nornal number, ten.

Genitalia: (P1. XII, fig. G). Male organs: Penis-sac rather long, cylindrical, 4.50 mill. long, 1.00 mill. wide; penis 2.00 mill. long, or about half as long as penis-sac; retractor muscle of penis 1.75 to 2.25 mill. long, very slender; retractor muscle of penis-sac 1.50 to 2.25 mill. long, wide, band-like, enlarging as it approaches the penis-sac, to which it is attached by numerous small filament-like muscles; the two re-

1The statement made by the writer in his paper on the Gross Anatomy of Limnæa, that only the superior jaw is present in this species, was an error: no species of Lymnæa has been found without the characteristic lateral jaws. 
tractors meet in the columellar muscle where they form one attachment; frequently this attachment is split into two branches; protractor muscles normally five in number, two anterior and three posterior, the former being the largest and attached to the penis-sac by many small branches; vas-deferens 23.00 to 25.00 mill. in length; prostate duct 6.00 mill. in length enlarging slightly as it joins the prostate; prostate very large, flattened, elongated, squarely rounded anteriorly, gradually tapering posteriorly to form the long, narrow part which joins the uterine portion of the oviduct.

Female Organs: Receptaculum seminis large, rounded, its duct 6.00 mill. long; first accessory albuminiparous gland large, elongate, pear-shaped; the lower portion of the oviduct is rather long and narrow.

The musculature of the penis varies somewhat in different specimens; in two individuals from Isle Royale, Michigan, the distal end of the posterior protractor had shifted its position so that it became a second, inferior penis-sac retractor. (P1. XV, fig. B, 1, 2); this was noted also in a specimen of emarginata mighelsi from Maine. The cause of this shifting of muscles was not ascertained.

The measurements of the genitalia of specimens from Aroostook Co., Maine, and from Isle Royale, Michigan, are tabulated below. (Dissections No. 23661, 23662, 23663, 23664, 23666.)

\begin{tabular}{|c|c|c|c|c|c|c|c|c|}
\hline $\begin{array}{c}\text { Penis. } \\
2.00\end{array}$ & $\begin{array}{l}\text { Penis- } \\
\text { sac. } \\
4.50\end{array}$ & $\begin{array}{c}\text { Penis } \\
\text { ret. } \\
1.75\end{array}$ & $\begin{array}{c}\text { Penis- } \\
\text { sac. ret. } \\
1.50\end{array}$ & $\begin{array}{l}\text { Vas. } \\
\text { def. } \\
23.00\end{array}$ & $\begin{array}{l}\text { Prost. } \\
\text { duct. } \\
6.00\end{array}$ & $\begin{array}{l}\text { Rec. } \\
\text { sem. } \\
6.00\end{array}$ & & \\
\hline 2.10 & 4.25 & 2.25 & 2.25 & 25.00 & 6.00 & 6.00 & 22.00 & " \\
\hline 2.00 & 4.50 & 2.00 & 2.00 & 24.00 & 6.00 & 6.00 & 21.00 & “ \\
\hline 2.75 & 2.50 & 1.75 & 1.00 & 16.00 & 4.75 & 7.75 & 16.00 & Michigan \\
\hline 2.00 & 2.00 & 2.00 & 1.85 & 12.50 & 4.75 & 7.75 & ..... & \\
\hline
\end{tabular}

It will be noted that the Isle Royale specimens have a shorter penis-sac, a shorter vas deferens and prostate duct and a longer receptaculum seminis duct. The shells of the latter are smaller and the spire more pointed than the shells from Maine. The form and position of the different organs were generally the same in both lots.

RANGe: (Figure 46). Maine to western Ontario, south to the northern part of the southern peninsula of Michigan, and northern New York.

Typical emarginata appears to be a species of northern distribution, principally confined to the Boreal (Canadian) life zone and to the Canadian and Nova Scotian regions. No specimens of the typical form have been seen from outside this area. The range will doubtless be much extended when the typical form is differentiated from 
mighelsi, angulata, and the other races of this species. It should be found abundantly in the waters of northern Michigan, northern Maine and southeastern British America.

\section{RECORDS. \\ United States.}

Maine: Mud Lake (second Eagle Lake) on Fish River; Aroostook River; thoroughfare between Portage and Eagle lakes; Square Lake Inlet; Fish River, Fort Kent; Aroostook Co. (Nylander); Aroostook Co. (Nylander); Lakes of Maine (Say).

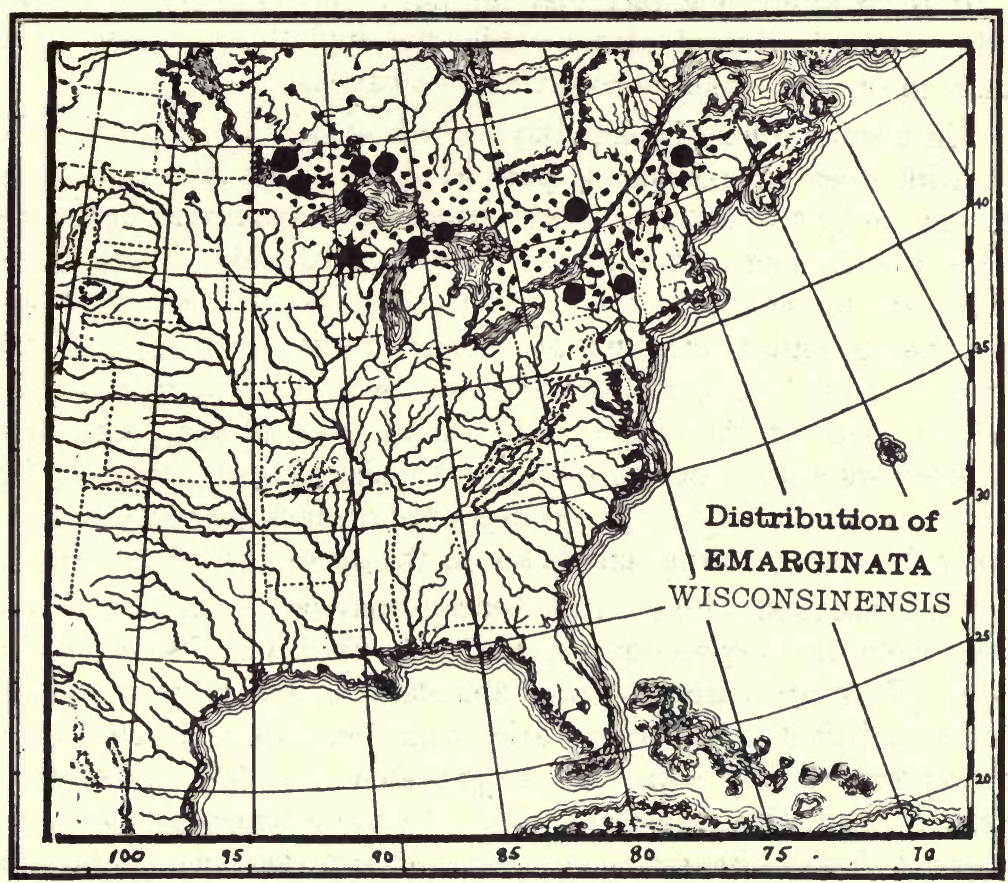

FIG. 46.

Michigan: Lake shore, Mackinac Island, Mackinac Co.; Sault St. Marie, Chippewa Co.; Tonkin, Conglomerate and Siskowit bays, Isle Royale (Walker).

New York: North end Seneca Lake, Ontario Co. (Baker); Saratoga Lake, Saratoga Co. (Say).

British AMERICA.

Ontario: Lake Superior (Ferriss; Newberry) ; Kettle Falls, Rainy Lake, Rainy River District; Nepigon River, Thunder Bay District; Rideau River, Ottawa Dist. (Latchford) ; Lake Namakin, Thunder Bay Dist. (Say); Lake of the Woods, Rainy River Dist. (Whiteaves).

Geological Distribution: Unknown. 
Ecology: "The specimens in this lake (Mud Lake) are small, light horn-colored, sometimes ornamented with revolving bands; the color of the animal varies. The specimens at the water's edge are bluish-black or gray, and those in deep water are very light and sometimes orange. Specimens are most common in water about three feet in depth, on a gravel bottom, where they feed on confervæ, growing on the rocks. In square lake it is always found at low water mark, on gravelly or stony bottom, or on a gravelly bar where there is a strong current from an inlet or thoroughfare." (Nylander, Maine.)

It is an interesting fact that the large variety mighelsi is found in the larger bodies of water, while the typical emarginata occurs usually in or near small thoroughfares or bayous.

"In a small inlet (Tonkin Bay) which opens to the east upon the lake, with steep, approximately parallel sides. This inlet is narrowed half way up by two beaches which reduce the wave action in the inlet. In this inlet Lymncea emarginata lives along both sides where the bottom is rock, but not across the ends. It lives only on a rock substratum, which may be either horizontal or vertical, and in water up to 45 centimeters in depth. In Conglomerate Bay emarginata lives in water in $15-45 \mathrm{~cm}$. deep, in the deeper water on the tops of flat rocks, in the shallower water, also, on the vertical sides and in small crevices. They never occur on the sand or gravel deposited around the rocks, as is frequently the case near the sand beach at the upper end of the bay.

"In connection with the rock beaches may be mentioned the beach pools, which are depressions in the rock filled with water by high waves. They are naturally most abundant on flat or gently sloping beaches, and their permanency varies with their size and depth, affecting evaporation, and with their height above the lake, affecting the frequency with which they are filled. In those which are permanent are found shells, Limnca emarginata Say and Planorbis parvus Say. (Gleason, Isle Royale).

Remarks: On page 69 of his Alaska Mollusks, Dr. Dall says: "After considerable study I have been forced to the conclusion that several species were identified under this name by Say himself, as well as others." Dr. Dall is right in this statement, excepting that I believe Say understood his species pretty thoroughly. There is no doubt that later students have mixed the true emarginata with forms of catascopium and palustris, besides confounding several varieties under this name. The original specimens came from Maine and it is to this state that we must look for typical emarginata. Such material has been abundantly collected by Mr. Olof O. Nylander in the lakes of Aroos- 
took Co. It is unfortunate that Say's type specimens from Maine have not been preserved. The two autotypes in the Philadelphia Academy are from Saratoga Lake, New York, and do not accurately represent the Maine form, being of a transition nature between typical emarginata and the race called canadensis. The autotypes are rather small and thin, have well rounded whorls, especially the body whorl, a conspicuous umbilical chink and a wide, erect inner lip which strongly emargins the umbilical region. Say's original figure in the American conchology (see P1. XXX, figures 27-28) represent the whorls as very globose and the spire as short and rather blunt. Haldeman's figures well represent the typical elongated form, though figures 4 and 5 approach the race called canadensis.

Authors generally have taken the small, narrow shell with sharp pointed spire as typical emarginata, but Say did not have this form in mind, although he may have included it in his species. Typical emarginata has a rather short, broadly pyramidal spire, the whorls being well rounded, the body whorl quite convex, the aperture ovate or almost round in some specimens, and the inner lip wide and broadly reflected, overhanging the large, conspicuous umbilical chink. The distinguishable features of the shell are the rounded, sub-globose shape of the last whorl, and the broad spire with the upper spire whorls broadly depressed and flattened. Say remarks in his original description that it is a larger and consderably wider shell than catascopium, and as he figures a wide shell for this species (see plate XXX, figures 25, 26) we must look for a still wider shell in emarginata, which is supplied by the Maine and Michigan shells. Catascopium may be at once distinguished from emarginata by its narrower shell, and especially by its inner lip which is narrow and closely appressed to the umbilical region leaving at most only a very small chink. There is also a distinct plait in catascopium.

In the Conch. Icon. Sowerby describes and figures a Limncea delicata Say, which appears to be the same as emarginata. Say, however, never described such a Lymnæa, and both the figure and description show it to refer to some form of cmarginata. The description is as follows:

"Shell subfusiform, subpellucid, horny, pale rose-milky, spirally slightly banded, spire elevated, slightly ladder-like; whorls four, convex, rather angular, last whorl rather short, excavated behind the columella; aperture subquadrate, posteriorly slightly angular, columella tortuous, somewhat curved backwards."

An examination of several thousand specimens of emarginata 
from Maine, Michigan, Wisconsin and Minnesota has demonstrated that the species is divisible into a number of fairly well-marked races. In all of these races there are some individuals which approach typical emarginata in general form showing that all have sprung from the same stock. Each race, however, expresses a certain facies which easily separates it from the typical form and from the other races. The relationship of these races may be expressed as follows:
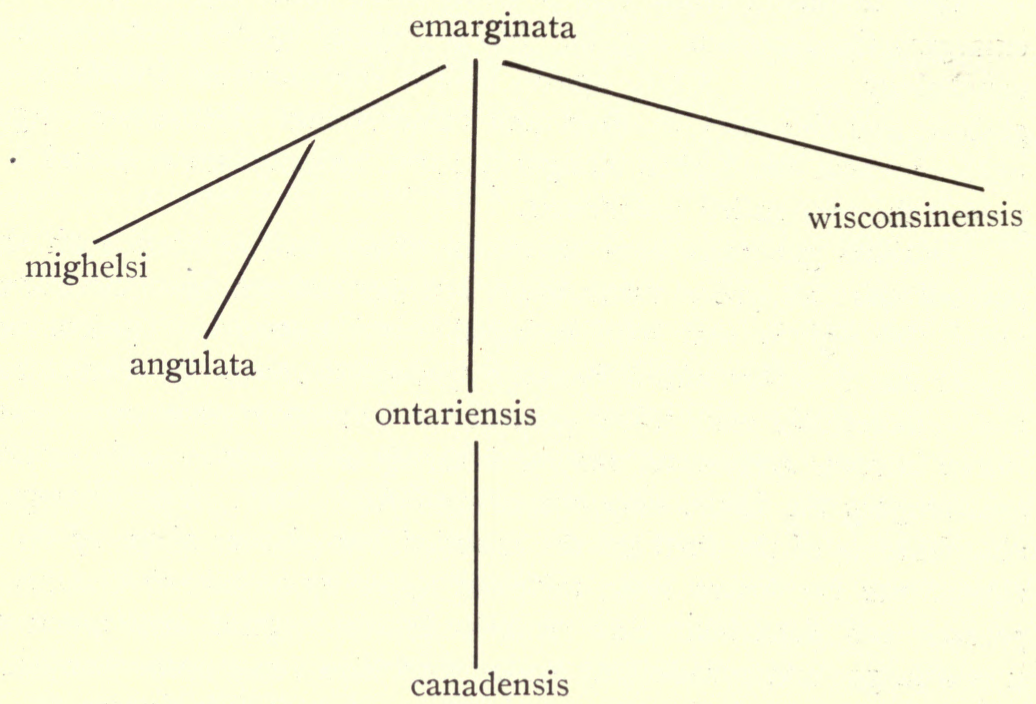

Wisconsinensis is somewhat related to mighelsi and angulata, but on the whole seems to present characters which place it as an independent branch of emarginata.

The Maine emarginata varies toward mighelsi, some individuals being of such a transition character that they cannot be definitely placed in either form (as figures 10-11 on plate XLIII). As a rule, however, the rounded aperture and more elevated spire will separate the two forms. The figures on plate XLIII well illustrate this variation. Emarginata from Michigan and New York are more uniform and less difficult to determine. Specimens from Western Ontario (especially Rainy Lake) vary towards mighelsi.

Galba emarginata mighelsi (W. G. Binney). Plate XLIII, figures 13-21 ; plate XLI, figure 25.

Limncea ampla Mighels, Bost. Journ. Nat. Hist., IV, p. 337, 1843; Bost. Journ. Nat. Hist., IV, p. 347, pl. 16, fig. 1 a to 1 c, April, 1843 (not of Hartmann $1842)$; Proc. Bost. Soc. N. H., 1, p. 129, 1843.-Stimpson, Sh. N. Eng., p. 52, 1851. -Whiteaves, Can. Nat. \& Geol., VIII, pp. 102, 112, fig. 11, 1863.-Binney, Check List, p. 12, 1860; Land \& F. W. Sh. N. A., II, p. 30, fig. 34, 1865.-Morse, Amer. 
Journ. Conch., I, p. 286, 1865.-TRYoN, Amer. Journ. Conch., III, p. 196, 1867.Gould, Ed. Binney, p. 474, figs. 726, 727, 1870.-Dall, Proc. Bost. Soc. N. H., XIII, p. 248, 1870.-Tryon, Con. Hald. Mon., p. 91 (65), pl. 16, figs. 6-8, 1872.Jefrereys, Ann. Mag. N. H., iv, X, p. 247, 1872 ; Journ. Conch., I, p. 16, 1874.Amer. Nat., XVII, p. 203, 1883.-West., Vega-Exp., IV, p. 165, 1885.-Stearns, Proc. Nat. Mus., XIV, p. 101, 1891.-TAylor, Ottawa Nat., VI, p. 35, 1892.Nylander, Nautilus, XV, p. 127, 1901 (part).

Neristoma ampla Tryon, Amer. Journ. Conch., I, p. 247, 1865.

Radix ampla Morse, Journ. Port. Soc. N. H., 1, p. 42, 1864 (part); Bull. Essex Inst., XII, p. 172, 1880 (part).

Limnea mighelsi Binney, Land \& F. W. Sh. N. A., II, p. 31, foot note, 1865.-BAKER, Shells of Land \& Water, p. 12, fig., p. 35, fig., 1903.

Lymnaa mighelsi BAKer, Amer. Nat., XXIX, p. 673, fig. 5, 1905.-LERMoNd, Shells of Maine, p. 38, 1908.

Lymnca (Radix) mighelsi Dall, Mollusks, p. 68, 1905 (part).

Limnaa emarginata mighelsi NyLANDER, Nautilus, VIII, p. 126, 1895 (part).

Limnea emarginata var. mighelsi Nylander, Nautilus, XI, p. 10, 1897 (part); Nautilus, XIII, p. 104, 1900 (part).-BAKer, Bull. Chi. Acad. Sci., II, p. 196, pls. 2-6, 1900 (part).-Nylander, Distr. of., pls. 2-4, 1901 (part).Baker, Moll. Chi. Area, pl. 33, 1902.

Limnaus mighelsianus Clessin, Küster, Conch. Cab., p. 401, 1886.

SHell: Large, generally rather thin, ranging from ovate to very globose, suboval, inflated, periostracum horny, olivaceous green or rich chestnut; the epidermis is frequently eaten away by the carbon dioxide ( $\left.\mathrm{CO}_{2}\right)$ in the water, and is sometimes streaked as in emarginata; nucleus consisting of $1 \mathrm{r} / 2$ chestnut or wine-colored whorls, smooth and rounded and rapidly increasing in size; surface dull to shining, sculpture as in emarginata; frequently, large specimens have a number of raised spiral ridges, and in very old specimens that last whorl is "humped" in several places; whorls $5-5 \mathrm{~T} / 2$, tumid, convex, inflated, shouldered, the last very large, flaring and strongly shouldered; spire flattened and much depressed; sutures strongly impressed, deeply channelled in some strongly shouldered forms; aperture very large, flaring, long-ovate, occupying from two-thirds to three-quarters the length of the shell, rounded below, and either rounded or square above when strongly shouldered, color varying from deep chocolate to bluishwhite; peristome sharp, thin, generally not flaring; inner lip elevated and reflected over the umbilicus, leaving a distinct umbilical opening which is strongly emargined by the inner lip; the columellar callus spreads over the parietal wall; the lower part of the aperture sometimes becomes so distorted that it spreads far beyond the umbilicus; axis twisted, forming a rather heavy plait. The juvenile shells are very globose and gracefully rounded, the strongly shouldered whorls only appearing in nearly adult or old individuals. 


$\begin{array}{cccc}\text { Length. } & \text { Width. } & \text { Aperture length. } & \text { Width. } \\ 36.00 & 29.00 & 27.00 & 17.50 \mathrm{mill} . \\ 32.00 & 25.00 & 24.50 & 17.50 \text { " } \\ 29.00 & 19.00 & 20.00 & 10.50 \text { " } \\ 76.00 & 19.00 & 21.00 & 11.00 \text { “ } \\ 26.50 & 19.00 & 19.00 & 10.00 \text { " } \\ 26.50 & 19.00 & 19.50 & 12.00 \text { " } \\ 25.00 & 18.50 & 19.00 & 10.00 \text { " } \\ 25.00 & 19.00 & 19.00 & 11.00 \text { " } \\ 22.50 & 17.50 & 17.50 & 9.50 \text { " }\end{array}$

Type: Destroyed in the Portland fire of 1866.

Type Locality: Second Eagle Lake, Aroostook Co., Maine.

Animal: Not differing externally from that of typical emarginata.

JAW: As in emarginata.

RADUla: (Pl. IX, fig. G). Formula: $\frac{22}{5}-\frac{2}{7}+\frac{2}{3}-\frac{4}{4}+\frac{11}{2}+\frac{1}{1}+\frac{11}{2}+\frac{2}{3}-\frac{2}{4}+{ }_{5}^{22}-\frac{2}{2}$ (35-1-35) in 130 rows; central tooth long, narrow, unicuspid; lateral teeth wide with a subquadrate base of attachment; reflection large, bicuspid, the mesocone very large, symmetrically rounded and terminating in a sharp point; the ectocone very small, rather wide, the extremity rather sharp and in some cases pointed inward toward the inner cusp; intermediate teeth tricuspid, the mesocone rather long, wide, the entocone large and placed near the distal end of the reflection, the ectocone smaller and placed higher up; the thirteenth tooth has a smaller denticle above the ectocone; the marginal teeth are long and narrow, the distal end of the reflection 3 to 4 cuspid with two denticles on the outer edge of the reflection. In one specimen examined the intermediate teeth began at the fifteenth tooth but this membrane was evidently abnormal.

Genitalia: The genitalia of mighelsi are in all respects like those of cmarginata. ${ }^{1}$ Specimens from Square Lake inlet measured as follows :

\begin{tabular}{|c|c|c|c|c|c|c|c|}
\hline $\begin{array}{c}\text { Penis. } \\
2.00\end{array}$ & $\begin{array}{l}\text { Penis- } \\
\text { sac. } \\
4.50\end{array}$ & $\begin{array}{l}\text { Ret. mus. } \\
\text { penis. } \\
1.50\end{array}$ & $\begin{array}{c}\text { Ret. mus. } \\
\text { penis-sac. } \\
1.50\end{array}$ & $\begin{array}{l}\text { Vas. } \\
\text { def. } \\
26.00\end{array}$ & $\begin{array}{r}\text { Prost. } \\
\text { duct. } \\
6.25\end{array}$ & $\begin{array}{c}\text { Rec. sem. } \\
6.00\end{array}$ & Shell. \\
\hline 2.00 & 5.00 & 2.50 & 3.00 & 24.50 & 6.25 & 6.00 & .00 \\
\hline 1.80 & 3.00 & 2.25 & 2.25 & 25.00 & 6.00 & 5.50 & \\
\hline
\end{tabular}

A study of the genitalia clearly indicates the close relationship between emarginata and mighelsi.

IIt will be noted that the figure of the genitalia of emarginata differs radically from those previously described by the writer. This is due to the fact that they were drawn in a different position (the former figures being from the side), the organs are separated and better magnifying glasses were used which more clearly indicated the shape and position of the different
organs. 
RANGE: (Figure 4\%). Maine and Southeastern Canada. So far as the writer has been able to determine, from an examination of specimens, this race is confined to the Nova Scotian and the eastern part of the Canadian regions and to the Boreal (Canadian) life zone.

\section{RECORDS.}

United States.

MaIne: Cross Lake, Eagle Lake, Portage Lake, Square Lake Inlet, Aroostook Co. (Cumings; Nylander); Second Eagle Lake (Longfellow; Mighels); Seabass Lake, ${ }^{1}$ fifteen miles from Portland, Cumberland Co. (Fuller; Morse; Putnam).

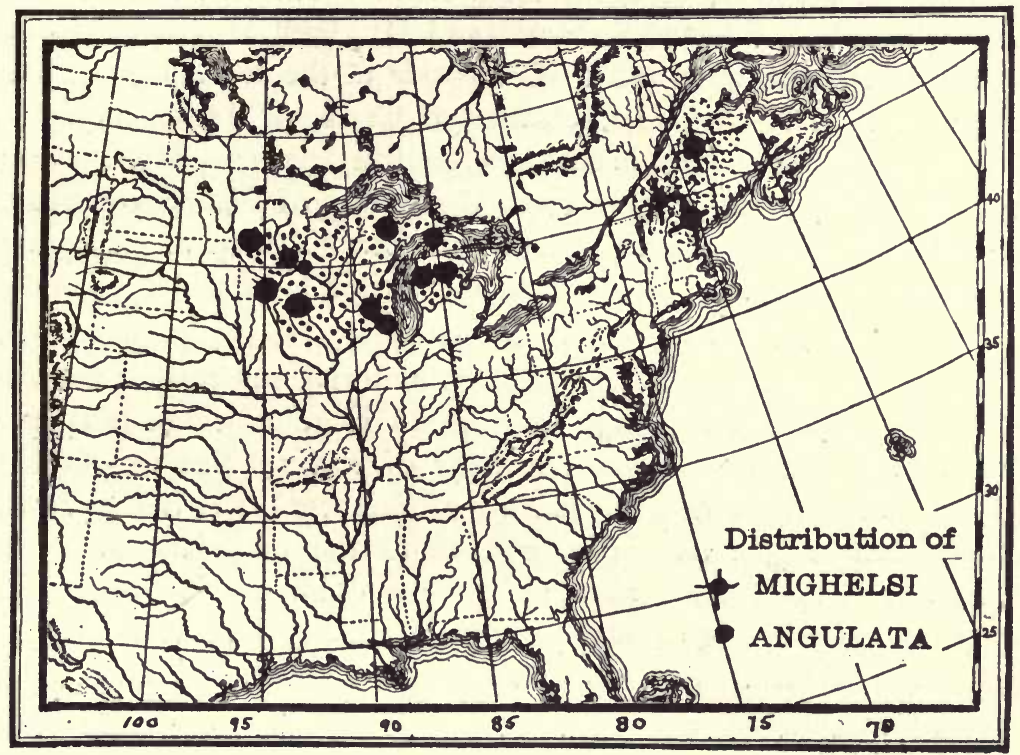

FIG. 47.

British America.

QueBeC: Brome Lake, Brome District (Latchford; Taylor; Whiteaves). Geological Distribution: Unknown.

ECOLOGY: "Mighelsi is found in the lake feeding on confervæ growing on the rocks. The majority of the young shells are somewhat elongated, while the old, senile forms are very broad. These old shells are probably very sluggish in habit and when once located on a large rock, find food plentiful and accordingly remain in this location all summer. The current in the lakes is not strong enough to dislodge

${ }^{1}$ This is evidently a typographical error for Sebago Lake. The record has not been verified by the examination of specimens and it is not definitely known whether this is the true mighelsi or a convex form of emarginata. 
them from their rocky support, but is strong enough to carry away muddy sediment brought from the thoroughfares. The colonies in Square Lake live on a shore sheltered form the surf of the strong and most prevailing (northwest) winds and always in a location where the bottom is rocky, or sandy with stones. They are more frequently found in the vicinity of an inlet or thoroughfare." (Nylander).

Remarks: In 1843, Mighels described and figured a large Lymnæa found in Second Eagle Lake on Fish River, Aroostook Co., Maine, as Limncea ampla. The shells were secured by Mr. Alexander W. Longfellow (a brother of the poet Longfellow) who obtained four specimens although he reported them as very common on the shores of the lake. Prof. Edward S. Morse and Mr. John M. Gould collected seven dead specimens in 1852. Previously to the extensive collecting carried on by $\mathrm{Mr}$. Olof $\mathrm{O}$. Nylander of Caribou, Maine, these were the only notes which had been made on this species. Mr. Nylander has made a very complete survey of the waters of Fish River and the adjacent lakes and the many excellent series obtained of this species has led both Dr. H. A. Pilsbry and the writer to consider mighelsi a variety of emarginata.

A careful study of this magnificent material, much of it from the original locality, Second Eagle (or Mud) Lake (a large portion of which he has presented to the Academy of Natural Sciences of Philadelphia and to the Chicago Academy of Sciences), has laid at rest all doubts which might be entertained as to the propriety of uniting mighelsi with emarginata as a race. The opinion expressed by the author several years ago (Bull. Chicago Acad. Sci. II, No. 3) has been amply corroborated. The Maine specimens show a perfect gradation from typical emarginata to mighelsi as will be seen by comparing the figures on the plates.

It is evident, however, that the name mighelsi has been made to cover many forms which should be included in other races of emarginata, a fact made clear by the examination of a large series from Wisconsin and Michigan. The race, as indicated by the original description and figures, has a very large, elongated aperture, and a very wide, much depressed spire, quite different from the rounded aperture and generally bulbous form of the specimens from Michigan and Wisconsin which have been referred to mighelsi (figure 1b of Mighels plate is a transition form between mighelsi and emarginata). True mighelsi has been seen only from Aroostook County, Maine, and Brome Lake, Quebec. In Maine it shows a perfect gradation from the narrow, long spired emarginata to the wide, flat spired mighelsi. The 
various lakes, ponds and rivers of this area exhibit examples for ecological study unsurpassed by any other single region in the United States. Many mutations retain certain individual characteristics which distinguish them from specimens of nearby localities. Thus typical emarginata from Eagle Lake is oval with a comparatively long spire. The Cross Lake specimens are quite globose, as are those from Aroostook River, Portage Lake and Fish River. The Square Lake Inlet specimens are the largest and finest, with short spire and wide aperture recalling Radix auricularia. The resemblance is, however, only apparent, for in auricularia the spire is very acute, while in mighelsi it is very broad and the whorls are tumid. The axis of auricularia is also much more strongly twisted and truly gyrate. The surface of mighelsi varies from the fine, delicate sculpturing so characteristic of the Lymnæas to a rough, malleated surface.

Specimens from Brome Lake, Quebec, (which were previously, but erroneously referred to wisconsinensis) are not quite typical, showing a tendency to vary toward angulata. Rarely a specimen resembles wisconsinensis, but in that race the aperture is normally round, while in the Brome Lake specimens it is quadrangular.

Mighelsi is unlike any other form of Lymnæa and its broad, depressed spire and large, elongated aperture are features sufficiently characteristic to cause its separation as a race. There is some variation in the height of spire, showing transition to emarginata. The ambilical chink varies somewhat, being almost closed in some specimens. Binney, Tryon, Dall and other conchologists have placed mighelsi in the section Radix of the typical Lymnæas, but an examination of the axis shows that it is plicate and not gyrate, the animal, besides, having anatomical features not embraced in Radix. Mighelsi is not related to decollata Mighels which belongs to the catascopium group.

Galba emarginata angulata (Sowerby). Plate XLIV, figures $1-9$.

Limnce angulata SowB., Conch. Icon., XVIII, Lim., No. 47, pl. 7, fig. 47, 1872.

Limncea ampla Currier, Kent Sci. Inst., Mis. Pub., No. 1, 1868.-Walker, Journ. Conch., II, p. 330, 1879.-DeCamp, Kent Sci. Inst., Mis. Pub., No. 5, p. 7, 1881.-Walker, Nautilus, VI, p. 32, 1892; Rev. Moll. Mich., p. 17, 1894; Nautilus, IX, p. 4, 1895.-Wiswall, Nat. Sci. Journ., I, p. 48, 1897.

Lymnaa binneyi Dall, Alaska Moll., p. 69, 1905 (part).

Lymnaa decollata DALL, Alaska Moll., p. 68, 1905 (part).

Limnaa binneyi Walker, Nautilus, VI, p. 33, 1892; Rev. Moll. Mich., pp. 18, 22, 1894 . 
Limnaa mighelsi WALKer, Nautilus, XIV, p. 8, 1900; XXI, p. 63, 1907.

Lymnaa emarginata mighelsi WALKer, Nautilus, XXIII, p. 9, 1909.

Limnea decollata Chadwick, Wis. Nat. H. Soc., IV, p. 80, 1906.

Limnaa emarginata Lapham, Proc. Phil. Acad., p. 155, 1860.-Binney, L. \& F. W. Sh., N. A., II, p. 53, 1865 (part).-Sargent, Nautilus, IX, p. 127, 1896.-Wiswall, Nat. Sci. Journ., I, p. 48, 1897.-Baker, Bull. Chi. Acad. Sci., II, p. 212, pl. 1, fig. D, 1900 ; Bull. Chi. Acad. Sci., II, p. 195, 1900 (part).Stearns, Proc. Nat. Mus., XXII, p. 136, 1900.-Chadwick, Bull. Wis. Nat. H. Soc., IV, p. 82, 1906.

Limnea emarginata Lapham, Trans. Wis. State Ag. Soc., II, p. 368, 1853.

Shell: Solid, rotund, tumid; periostracum, light horn, varying to brownish or purplish; sculpture as in emarginata, but growth lines coarse, the surface of the shell frequently raised into ridges, sometimes giving a malleated aspect; spiral lines rather conspicuous; nuclear whorls rather large, rounded, whitish, the outline resembling those of catascopium; whorls 5 to $5 \mathrm{r} / 2$, rounded, tumid, the body whorl usually very convex; the whorls increase very rapidly in size and are generally strongly angulated on the shoulders of the penultimate and body whorl; spire short, tumid, wide; sutures impressed; aperture ovate, langer than the spire, rounded and effuse anteriorly, angulated posteriorly; outer lip with a slight varical thickening within; inner lip broad, reflected, closely appressed to the shell, generally completely closing the umbilicus; the parietal callus is very thick and in old shells is raised so as to make the aperture continuous; the columella is much thickened and frequently develops a strong plait; axis slightly twisted.

\begin{tabular}{|c|c|c|c|c|c|}
\hline $\begin{array}{l}\text { Length. } \\
22.50\end{array}$ & $\begin{array}{l}\text { Width. } \\
14.10\end{array}$ & $\begin{array}{c}\text { Aperture length. } \\
14.00\end{array}$ & $\begin{array}{l}\text { Wic } \\
8.50\end{array}$ & & Lake Houghton \\
\hline 23.00 & 15.00 & 13.00 & 7.75 & “ & " \\
\hline 21.00 & 13.50 & 14.00 & 7.50 & “ & “ \\
\hline 19.00 & 13.00 & 11.50 & 7.50 & “ & " \\
\hline 18.00 & 13.50 & 11.50 & 8.00 & “ & “ \\
\hline 19.00 & 12.50 & 12.50 & 7.00 & “ & Madison, Wis. \\
\hline 25.50 & 15.50 & 16.00 & 8.25 & “ & Pine Lake, Mich. \\
\hline 23.50 & 16.00 & 17.00 & 8.50 & “ & “ \\
\hline 20.00 & 13.00 & 14.50 & 7.50 & “" & “" \\
\hline
\end{tabular}

Types: British Museum Natural History, London, England.

Type Locality: North America. (Probably founded on Michigan specimens).

Animal: Not examined alive.

JAW: As in emarginata.

RAdula : (Pl. IX, fig. H.) Formula $\frac{19}{5-7}+\frac{3}{3}-\frac{3}{4}+\frac{9}{2}+\frac{1}{1}+\frac{9}{2}+\frac{3}{3}-\frac{3}{4}+\frac{19}{5-7}$ (31-1-31); the teeth are in all respects like those of emarginata. In one specimen there were ten instead of nine full laterals, and the transition teeth began very abruptly. 
Genitalia: (P1. XII, fig. H). Male Organs: Penis-sac long and cylindrical, 3.50 to 5.00 mill. in length; penis short and thick, 2.00 to 3.00 mill. in length, or about one-half the length of the penis-sac; vas deferens 24.00 to 26.00 mill. in length, or about five times the length of the penis-sac; prostate portion of vas deferens 6 mill. long; prostate very large and somewhat quadrate, narrowing posteriorly to form a rounded tube as large in diameter as the oviduct; a side view of the prostate shows it to be very elongate-ovate; protractor muscles six to seven in number, four narrow, slender posterior muscles with numerous small branches entering the penis-sac and two to three large anterior muscles, with many branches entering the penis-sac. Penis retractor 3.00 mill. long, narrow; penis-sac retractor wide, ribbon-like, swollen in the middle and entering the penis-sac by many small branches. The retractors have a common insertion in the columellar muscle.

Female Organs: Similar to those of emarginata; the first accessory albuminiparous gland is somewhat pear shaped, elongated and very large; the second accessory albuminiparous gland is very small and rounded and placed rather high up on the oviduct; receptaculum seminis large, rounded, its duct 5.00 to 6.00 mill. in length and attached to the oviduct one mill. from the vaginal opening, by a bulbous termination.

The organs are colored as follows: Penis and penis-sac yellowish, prostate yellowish or amber-colored; ovotestis yellowish, albuminiparous gland greenish, receptaculum seminis pearly white, and the other organs yellowish.

The genitalia measure as follows: (Dissection No. 23667).

\begin{tabular}{|c|c|c|c|c|c|c|c|c|}
\hline $\begin{array}{c}\text { Penis. } \\
3.00\end{array}$ & $\begin{array}{l}\text { Penis- } \\
\text { sac. } \\
5.00\end{array}$ & $\begin{array}{l}\text { Ret. } \\
\text { mus. } \\
\text { penis. } \\
3.25\end{array}$ & $\begin{array}{l}\text { Ret. mus. } \\
\text { penis-sac. } \\
2.25\end{array}$ & $\begin{array}{l}\text { Vas. } \\
\text { def. } \\
24.00\end{array}$ & $\begin{array}{l}\text { Vas. } \\
\text { def. } \\
\text { prot. } \\
6.00\end{array}$ & $\begin{array}{l}\text { Rec. } \\
\text { sem. } \\
4.20\end{array}$ & $\begin{array}{r}\text { Shell. } \\
19.00\end{array}$ & Michigan. \\
\hline 2.75 & 3.50 & 3.00 & 2.00 & 24.00 & 6.00 & 6.00 & 20.00 & " \\
\hline 3.00 & 4.25 & 3.00 & 2.25 & 25.00 & 6.00 & 5.00 & 23.50 & “ \\
\hline
\end{tabular}

There is some variation in the lengths of the penis and penis-sac but otherwise the measurements are quite uniform. The form and position of the protactor and retractor muscles of the male organs are also very uniform.

The genitalia of angulata differ from those of emarginata principally in the form of the first accessory albuminiparous gland which is longer and more spindle shaped.

Range: (Figure 47). Michigan to Minnesota, Northern Michigan south to Southern Wisconsin. A race of the Transition (Caro- 
linian) and Boreal (Canadian) life zones and of the Canadian and Upper Mississippian regions. It occurs in both the Great Lakes and in the Mississippi River drainage.

\section{RECORDS. \\ United States.}

Michigan : Onekama, Manistee Co. (E. E. Hand); Crystal Lake, Benzie Co. (Kirtland; Walker); Higgins and Houghton Lakes, Roscommon Co.; Pine Lake, Marquette Co.; small lake on Beaver Island, Mackinac Co. (Walker); Douglas Lake, Cheboygan Co. (Pease).

Minnesota: Minnetonka Lake, Hennepin Co. (Helen Abbott); Eagle Lake, Jackson Co. (Bailey; Stearns); Ottertail Creek, Ottertail Co. (Kennicott); Clearwater Lake, Wright Co. (Sargent; Walton).

Wisconsin: First of four lakes, Madison, Dane Co. (Baker; Carpenter; Chadwick; Letson Wis. Nat. Hist. Surv.); Kenosha, Kenosha Co. (Chadwick; Wiswall).

Geological Distribution: Unknown.

ECOLOGY: Dr. R. J. Kirkland thus describes the habits of angulala (mighelsi Authors not Binney): "I made a visit to Crystal Lake, Benzie County, Mich., in July and again in October. Along the shores are thousands of dead Limnea mighelsi W. G. Binn., and though many hours were spent in July in searching for living ones, not one was found, until an improvised dredge brought them to view from a depth of about twelve feet. Hiring a couple of men to row, about two hundred were taken in half a day's work. This fall, however, I was surprised to see them in shallow water (one to three feet), and I collected over a thousand by wading and picking them up one by one. They were not in groups at all, but scattered irregularly in patches over the bottom. Some of them were half buried in the sand and the greater part resting with the head toward the shore, and where a track was visible, it was a line from deeper to shallower water. During the few days under observation, not a single individual was seen floating on the surface." (Nautilus XIV, p. 8, 1900).

Sargent records its ecology as follows: "Two quite distinct varieties of texture were taken. One corneous, the other nearly white, opaque and heavier, with much thickened margins. Both forms were plentiful and near together. One was found on the pebbles, the other on the sandy bottom."

Remarks: Angulata is very closely related to emarginata, the chief points of difference being the solid shell, tightly closed umbilicus, angulated whorls and depressed spire.

Sowerby's description is as follows: "Shell solid, pinky brown, rather square, spire short, whorls broad, angular, the last large; straight at the sides, excavated behind the columella; aperture subtrigonal, 
anteriorly a little accuminated; columella thick, straight, outer lip with a single chestnut band within." The Houghton Lake specimens were submitted by Mr. Walker to Mr. E. A. Smith of the British Museum, who compared them with Sowerby's types and pronounced them identical (see pl. XLIV. figs. 1-6). There is considerable variation in the form of the shell, as is the case with mighelsi, emarginata and canadensis, the variation being the long or short spire, but all agree, when adult, in the tightly closed umbilicus, coarse sculpture, solid shell and angulated whorls. The Madison, Wisconsin, shells show a strong variation toward emarginata, and certain individuals might be referred to that species were it not that the majority of the specimens are of the angulata type. The shells from Minnesota appear to group with angulata rather than with typical cmarginata, although isolated specimens might be referred to the typical form. Dr. Stearns (Proc. Nat. Mus. XXII, p. 136) records a large amount of variation in specimens from Eagle Lake, Minn., collected by Mr. Vernon Bailey. These vary in having a long or short spire, rounded or shouldered whorls, sutures deep or shallow, aperture patulous and distorted, surface malleated and shell rather solid or quite thin. The axis may be simple or rather strongly twisted. An examination of these shells, in the Smithsonian Institution shows them to belong to variety angulata, with a strong variation toward emarginata. Nearly all specimens agree in the tightly closed umbilicus although all are not angulated.

The Michigan shells have been referred to both decollata and mighelsi. They are totally unlike decollata. From mighelsi they differ in the generally longer and narrower spire, rounder aperture, more angulated whorls, closed umbilicus and heavier texture. Specimens occur which might be referred to mighelsi, but on the whole the race is distinct enough to be differentiated from mighelsi, which has not been seen outside of Maine. Each race of emarginata contains many mutations which connect it with the typical form, but this is to be expected in a group of mollusks where polymorphism is as marked as in the fresh-water pulmonates.

Galba emarginata wisconsinensis (Baker). Plate XLIV, figures $10-18$.

Galba emarginata BAKER, Nautilus, XXIII, p. 113, 1910. 1910.

Lymnaa emarginata wisconsinensis BAKER, Nautilus, XXIV, p. 58, Sept.,

Shell: Very large, varying from elongated to globose, inflated, usually rather thin; periostracum varying from light yellowish horn to chestnut; nuclear whorls as in emarginata; sculpture as in emarginata; 
many specimens have, in addition to the spiral impressed lines, a number of heavy, more or less equidistant spiral ridges encircling the body whorl; the last whorl may also be somewhat malleated; whorls 5 to $5 \mathrm{I} / 2$, globose, roundly shouldered, inflated, the body whorl very globose and disproportionately swollen; spire varying from broadly acute to depressed, usually about half the length of the entire shell; suture well marked, often deeply impressed; aperture roundly-ovate, rarely quadrate, seldom flaring; peristome with internal, varical thickening; inner lip wide, whitish, broadly reflected over the umbilical region producing a wide, flat expansion, which emarginates the umbilical chink, as in the typical form; umbilical chink usually very large and conspicuous; imperforate individuals are rare; the parietal callus is thick and wide producing a continuous aperture in some specimens; the lower part of the aperture is somewhat effuse in a few individuals.

$\begin{array}{cccc}\text { Length. } & \text { Breadth. Aperture length. } & \text { Breadth. } \\ 23.50 & 15.00 & 13.00 & 7.50 \mathrm{mill} . \\ 22.00 & 15.00 & 12.00 & 8.00 \text { " } \\ 24.00 & 16.00 & 13.50 & 9.00 \text { " } \\ 24.00 & 16.25 & 13.00 & 8.00 \text { " } \\ 26.50 & 19.50 & 16.50 & 11.00 \text { " } \\ 25.00 & 19.00 & 16.00 & 10.00 \text { " } \\ 26.00 & 19.00 & 16.50 & 10.00 \text { " }\end{array}$

Types: The Chicago Academy of Sciences, 19 specimens, No. 24504 ; cotypes, coll. Bryant Walker, Detroit, Mich.; Academy of Natural Sciences, Philadelphia.

Type Locality: East shore Tomahawk Lake, Oneida Co., Wis.

Animal: Similar to typical emarginata. The animals of the Tomahawk Lake race are of two very pronounced colors, black with white dots and bright yellow with white dots. This difference in the animal is quite conspicuous rendering the light colored specimens less noticeable than the dark colored individuals against the white sand of the shore.

Jaw, Radula and Genitalia: In all respects similar to those of emarginata.

RANGE: (Figure 46). Wisconsin.

Wisconsinensis has been only seen from the type locality. It doubtless lives in many lakes in Northern Wisconsin, and has probably been identified as mighelsi.

\section{RECORDS. ${ }^{1}$}

Wisconsin: Tomahawk Lake, Oneida Co. (Baker).

${ }^{1}$ The statement in the Nautilus vol. XXIV, p. 28, in which certain specimens from Brome Lake are referred to this race is erroneous. A series recently received from Mr. Latchford shows them to be referable to mighelsi. 


\section{Geological Distribution: Unknown.}

Ecology: In Tomahawk Lake, Wisconsin, this species is very abundant, the shore after storms being literally paved with dead shells. It lives on the sandy or pebbly shores, in water from a few inches to several feet in depth. By wading along the beach thousands may be collected. The localities in this lake are all on exposed points or in curved bays where the shore receives the full force of the waves. No specimens were found in sheltered places, where the water was at all stagnant. As recorded by Dr. Kirkland, for angulata, they were irregularly scattered over the surface, crawling over the sand, where a distinct track was left, or else lying half buried in the sand. The two different colors mentioned by Nylander as being characteristic of the Maine emarginata were also observed in the Tomahawk Lake specimens.

REMARKs: This race differs from all the other races of emarginata in its very globose body whorl and rounded aperture. The race is very variable, the variant being the spire which is elongated or depressed. Some individuals approach mighelsi but this is rare, the shell being usually much more globose than that race. Angulata differs in having a heavier shell, a much less globose body whorl, and an elongated and angulated, instead of rounded, aperture. The umbilicus is closed in angulata while it is usually open in wisconsinensis. The globose form will, however, separate this race from all others. The umbilical chink is usually conspicuous but may be so wide as to form a deep umbilicus or may be entirely closed.

Wisconsinensis is by far the most abundant shell in Tomahawk Lake, Wisconsin, where, in many places, it forms windrows of dead shells on the shore after a northwesterly storm. It was at first thought to be a variety of the mighelsi type of shell, but the globular form of the body whorl is so different from mighelsi and the shells are so numerous in the original locality as to render it quite as eligible to receive a name as are any of the races of Lymnæa.

Galba emarginata canadensis (Sowb.). Plate XLIV, figures 19-23 ; plate XLV, figures 1-20.

Limncea canadensis Sowb., Conch. Icon., XVIII, Limn., sp. 45, pl. 7, figs. 45 a, a, 1872 (not a, b, as stated on plate).-DALl, Alaska Moll., p. 69, 1905.

Limnea emarginata DeKAY, Zool. N. Y., p. 73, pl. 4, fig. 77, 1843 (part).?Kennicotr, Trans. Ill. State Ag. Soc., I, p. 595, 1855.-Henderson, Nautilus, $\mathrm{XX}$, p. $98,1907$.

Lymnaa emarginata Linstey, Amer. Journ. Sci., XLVIII, p. 282, 1845.Lewis, Proc. Phil. Acad., pp. 18, 19, 1860; Amer. Journ. Conch., VI, p. 86, 
1870.-DAll, Alaska Moll., p. 68, fig. 46, 1905.-BAKer, Trans. Acad. Sci. St. Louis, XVI, p. 12, 1906.

Limnaa emarginata Lewis, Proc. Bost. Soc. N. H., V, p. 124, 1855.-BinNEY, L. \& F.-W. Sh. N. A., II, p. 52, fig. 76, 1865.-WALKER, Journ. Conch., II, p. 330, 1879 (part).-Ottawa Nat., I, p. 58, 1882 (part).-LATchford, Amer. Nat., XVIII, p. 1052, 1884 (part).-Ottawa Nat., II, p. 264, 1885 (part).-BEAUснамP, L. \& F.-W. Sh. N. Y., p. 3, 1886.-Ottawa Nat., IV, p. 55, 1890 (part).Walker, Nautilus, VI, p. 34, 1892 (part).-TAYLoR, Ottawa Nat., VI, p. 35, 1892 (part).-Marshall, Rep. N. Y. State Mus., XlVII, p. 65, 1893; N. Y. World's Col. Exp., p. 510, 1894.-WALKer, Rev. Moll. Mich., p. 17, 1894 (part).TAYlor, Ottawa Nat., VIII, p. 147, 1895 (part).-MAURY, Chautauqua Lake Shells, p. 26, fig. 2, 1898.-BAKER, Nautilus, XIII, p. 58, 1899.-BAKER, Bull. Chi. Acad. Sci., II, p. 193, pl. 1, figs. A, E, 1900.-Walker \& Lane, Geol. Surv. Mich., VII, pt. 2, p. 251, 1900.-Stearns, Proc. Nat. Mus., XXIV, p. 291, 1901 (part).Letson, Bull. N. Y. State Mus., LXXXVIII, p. 54, 1905 (part).

Limnophysa emarginata Lewis, Bull. Buffalo Soc. N. Sci., II, p. 135, 1874.

Radix ampla Lewis, Bull. Buf. Soc. N. Sci., II, p. 135, 1874.

Limnca ampla Aldrich, Rep. N. Y. State Cab. N. H., XXII, pp. 19, 23, 1868. ${ }^{1}$-Beauchamp, L. \& F.-W. Sh. N. Y., p. 9, 1886.-Mitchell, Nautilus, XIII, p. 89, 1899.-Marshall, Rep. N. Y. State Mus., XLVIII, p. 643, 1895.Letson, Bull. N. Y. State Mus., LXXXVIII, p. 52, 1905.

Limnaa barbadensis Sowerby, Conch. Icon., XVIII, Limn. sp. 100, pl. 14, fig. 100, 1872.-CR. \& Fisch., Mis. Cient. Mex., II, p. 47, 1880.-PILsbry, Nautilus, XXIII, p. 120, 19 i0.

Limnaus barbadensis (BECK) Clessin, Conch. Cab. p. 379, taf. 50, fig. 2, 1886.

SHell: Elongated to ovate, varying from thin to rather thick; periostracum very light horn, sometimes. darker, pellucid; nuclear whorls small, smooth, rounded, consisting of $1 \mathrm{I} / 2$ white or horn colored whorls in outline similar to those of catascopium; surface and sculpture as in emarginata; whorls $5 \frac{1}{2}$ to 6 , rounded, convex, the body whorl quite convex; spire typically long, attenuated, but shorter and depressed in some individuals; sutures well impressed; aperture longcvate, occupying from half to three-fourths the length of the shell, much expanded and flaring in some forms; interior of the aperture varying from white to brownish; peristome thickened by a white varix; inner lip wide, raised, reflected over the umbilical region either entirely closing the perforation or leaving a small chink; the parietal callus is usually rather thick and sometimes becomes heavy and raised so as to render the aperture continuous; the umbilical chink is emargined as in the typical form; in some specimens the columella has a heavy, ascending plait; axis twisted.

${ }^{1}$ This record has not been verified. It may have been based on specimens of catascopium. 


\begin{tabular}{|c|c|c|c|c|c|c|}
\hline $\begin{array}{l}\text { Length. } \\
37.00\end{array}$ & $\begin{array}{l}\text { Width. } \\
\mathbf{1 5 . 5 0}\end{array}$ & $\begin{array}{c}\text { Aperture length. } \\
17.50\end{array}$ & $\begin{array}{l}\text { Wid } \\
7.75\end{array}$ & & (coll. Walke1.) & \\
\hline$\cdot 23.50$ & 11.00 & 12.50 & 6.50 & $“$ & Bear Lake, Mic & ch. \\
\hline 24.00 & 13.50 & 13.00 & 8.00 & “ & Crooked Lake, & Mich. \\
\hline 26.00 & 13.50 & 15.00 & 8.50 & “ & " & “ \\
\hline 24.00 & 11.75 & 11.50 & 6.50 & “ & “ & “ \\
\hline 20.00 & 11.75 & 11.60 & 7.00 & “ & “ & “ \\
\hline 19.50 & 11.50 & 11.00 & 6.00 & “ & " $\quad 6$ & “ \\
\hline 26.75 & 16.00 & 15.00 & 9.00 & “ & New York. & \\
\hline 23.00 & 15.50 & 14.00 & 10.50 & “ & “ & \\
\hline 19.75 & 10.50 & 11.00 & 7.00 & “ & “ & \\
\hline 21.00 & 11.00 & 11.00 & 7.00 & “ & “ & \\
\hline 18.50 & 11.50 & 11.50 & 8.00 & “ & “ & \\
\hline 16.00 & 10.00 & 10.75 & 7.00 & “ & “ & \\
\hline 15.00 & 10.00 & 10.50 & 7.25 & " & “ & \\
\hline 12.25 & 9.00 & 8.50 & 7.00 & “ & “ & \\
\hline
\end{tabular}

Types: British Museum, London, England.

Type Locality: Unknown; probably in Canada.

Animal, Jaw, Radula and Genitalia: Unknown.

RANGE: (Figure 48). Anticosti Island west to Eastern Wisconsin, south to Southern Michigan, Northern Pennsylvania and Southern New York. A race primarily of the Alleghanian division of the Transition life zone but extending southward into the Upper Austral (Carolinian) life zone and northward into the Boreal (Canadian) life zone. It is typical of the Great Lakes (the Canadian region) and of the streams draining into them and but few authentic specimens have been seen from outside this drainage area.

\section{RECORDS. \\ United States.}

Connecticut: Connecticut (Linsley). ${ }^{1}$

Michigan: Squaw Island, Alpena, Alpena Co. (Baker; Nason); Port Austin, Huron Co. (C. A. Davis); Crooked Lake, Emmet Co. (Ferriss; Slocum; Walker); Bear Lake, Charlevoix Co. (Ferriss); Lake Huron (Lathrop); south end, east arm, Grand Traverse Bay, Grand Traverse Co., on land spit (Mather); Grand Lake, Presque Isle Co. (S. L. Schrum; Walker); River Rouge, Detroit, Wayne Co.; Lake Michigan shore, Charlevoix Co. (Walker); Sault St. Marie, Chippewa Co. (Walker; Walton).

New York: Cross Lake, Onondaga Co. (Beauchamp); Oswego, Oswego Co. (Beauchamp; Marshall); Mohawk River (DeKay); Cazenovia, Madison Co. (Henderson) ; Owasco Lake (Lewis) ; Hayden's Mills; Owasco Lake and Owasco River, Cayuga Co. (Lyon); Lakewood, Chautauqua Lake, Chautauqua Co. (Maury); Skaneateles Lake, Onondaga Co. (Smith. Inst.); Moravia, Cayuga Co. (Geo. Scarborough); Owasco Lake (Miss Walker).

Wisconsin: Green Bay (Marston); Kenosha, Kenosha Co. (Wiswall).

${ }^{1}$ No specimens of emarginata or its varieties have been seen from Connecticut. This record needs confirmation. 
British AmericA.

Quebec: Chilcotts Lake, Masham, Ottawa District (Latchford); Jupiter River, Anticosti Island (Latchford; Macoun).

Geological Distribution: Pleistocene.

\section{RECORDS.}

Michigan : Marl beds, Crooked Lake, Oden, Emmet Co. (Slocum).

Ecology: Appears to inhabit chiefly the large inland lakes. In Owasco Lake it lives on a sandy bottom.

REMARKS: Canadensis differs from typical emarginata by having a narrozer and more flatly rounded body whorl, a longer, more acum-

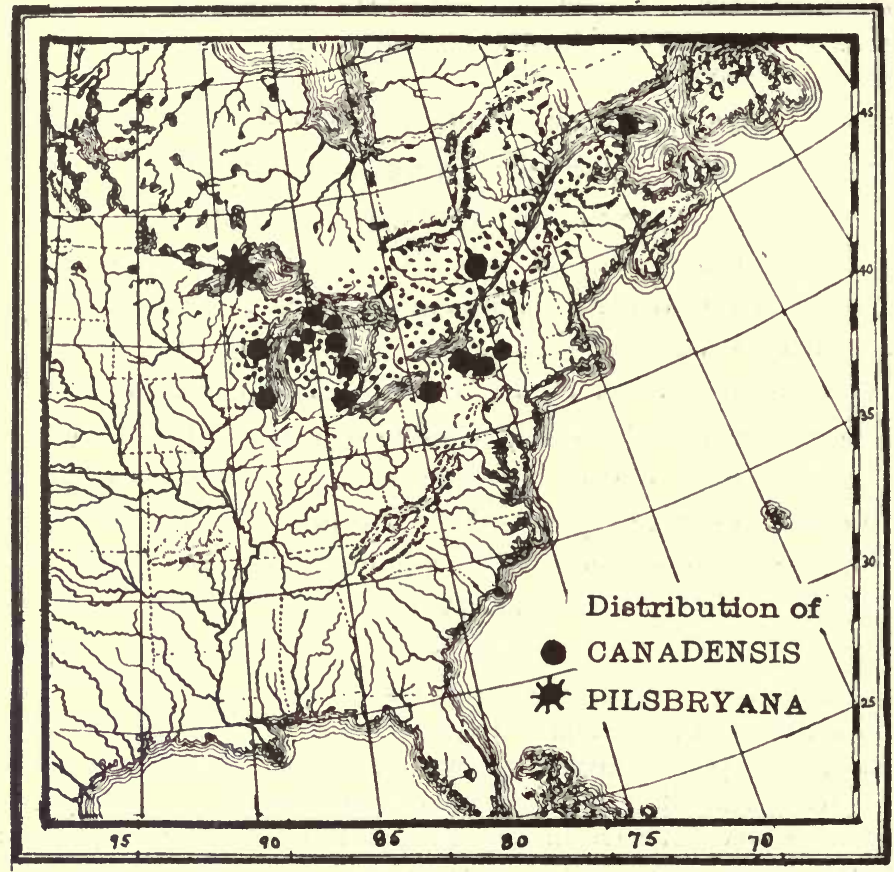

FIG. 48.

inate spire, narrower and more elongated spire whorls, an elongated instead of an ovate or rounded aperture and a more or less plicate instead of a simple columella. The shape of the penultimate whorl is very different in the two races, that of emarginata being very wide and low and notably convex, while that of canadensis is high and narrow, comparatively, and usually rather flatly rounded. The umbilical chink is usually either absent or is reduced to a very narrow slit. In individual specimens it may be widely open. Typically it is a very distinct race, but there are intermediate forms which show its relation to 
emarginata. In Owasco Lake, New York, this race occurs in vast numbers and great variety of form. The shells vary from rather long and narrow, with acuminate spire, to short and convex with very short spire. The columella is more or less plicate and the aperture varies from roundly ovate to elongate ovate.

This is the race which has usually been called typical emarginata; an examination of Maine and Wisconsin material, in connection with Say's original description, figures and autotypes, shows that the typ1cal form is not the one with the acuminate spire, but with the broad and depressed spire. Say's figure emphasizes the globoseness of the whorls. Certain specimens of this race may be confused with catascopium, and may be known from that species by their large size, wider and heavier inner lip, longer spire and (usually) absence of a plait.

Sowerby's description of his canadensis is as follows:

"Shell pyramidal, anteriorly inflated, rather thin, polished, horny; spire attenuated, whorls four, rather rounded, the last inflated; anteriorly slightly acuminated, a little excavated behind the columella; aperture auriform, inner lip broad, columella thick, strongly plicated; outer lip expanded, reflected, thickened within. Habitat Canada." Sowerby further adds, "Finding this shell in the British Museum without a name, and thinking it sufficiently distinct from $L$. stagnalis, the writer has given it a local name."

Sowerby has also described and figured a Limncea barbadensis which appears to be the same as canadensis, judging by the description and figure. It is not the type of shell that inhabits the West Indies and it is exactly like the shells of the emarginata group. A mixing of labels doubtless accounts for its description as a Barbadoes shell. It probably came from Canada or the northern part of the United States and there is little doubt of its being referable to canadensis.

Specimens of canadensis from Michigan have been compared.with Sowerby's types in the British Museum, and the shells referred to canadensis from New York, Michigan and Minnesota, conform closely to the form of these shells (see pl. XLIV, figures 19-23). Certain shells from Bear Lake, Michigan, are referred provisionally to variety canadensis (plate XLV, figures 18-20). These are very narrow with an elongated spire and compressed whorls. The four specimens figured are either bleached or fossil individuals and are evidently immature. Typical canadensis (plate XLV, figures 14-15) inhabits this lake and exhibits a variation of the body whorl from subglobose to narrow and compressed (plate XLV, figures 16-17). It is easy to connect these narrower forms with the very narrow specimens figured. These were 
once thought to be a form of Galba contracta, but the above disposition now appears to be the most logical.

Canadensis is a distinct race of emarginata and will doubtless be found to cover a wide range when it is sufficiently differentiated from the other races of emarginata. The name emarginata has been made to cover specimens of binneyi, catascopium, palustris and mighclsi, besides several other forms, and has been quoted from Maine to Alaska. So far as known no form of emarginata or its races, has been found west of Minnesota or south of Michigan and Wisconsin. It is a type of mollusk almost peculiar to the Great Lakes and the streams emptying into them. It is also abundantly represented in the upper waters of the Mississippi Valley drainage, in Wisconsin and Minnesota. The five races recorded in the present monograph seem to be well characterized representing five types of variation about each of which numerous mutations have formed.

Galba emarginata ontariensis ("Muhlfeldt" Küster). Plate XLV, figures 21-28.

Limnaus ontariensis Muhlfeldt in Lit., Küster, in Chemn., ed. 2, p. 45, 1862.

Limnaa emarginata var. A. ontariensis Binney, L. \& F.-W. Sh. N. A., II, p. 52, 1865.

Limnaa emarginata BAKer, Bull. Chi. Acad. Sci., II, pl. 1, fig. C, 1900.

Limnaa catascopium WALkeR, Nautilus, VII, p. 128, 1894 (part).

SHELl: Ovate-conic, rather thick; periostracum light yellowish horn or purplish white; surface sculptures as in cmarginata canadensis; there are from four to six rest varices on the shell; nuclear whorls as in canadensis; whorls $5 \mathrm{~T} / 2$, the spire whorls flatly sloping, the body whorl very convex; spire short, broadly acutely conic; sutures usually not much impressed; aperture semi-oval, broadly rounded below and much narrowed and angulated above, about as long as the spire; the aperture is frequently much expanded appearing to flare markedly; outer lip with an internal varix; inner lip broad, thick, closely appressed to the columellar region, completely closing the umbilicus; the parietal callus is usually well marked and is sometimes very heavy; the inner lip is usually compressed at its junction with the parietal wall forming a plait of variable distinctness; axis twisted.

\begin{tabular}{|c|c|c|c|c|c|}
\hline $\begin{array}{l}\text { Length. } \\
17.00\end{array}$ & $\begin{array}{l}\text { Width. } \\
10.00\end{array}$ & $\begin{array}{c}\text { Aperture length. } \\
10.50\end{array}$ & $\begin{array}{l}\text { Wic } \\
6.00\end{array}$ & $\begin{array}{l}\text { Ath. } \\
\text { mill. }\end{array}$ & Buffalo. \\
\hline 15.00 & 9.00 & 9.25 & 5.75 & “ & "6 \\
\hline 18.50 & 11.00 & 12.00 & 6.50 & “ & Fort Erie \\
\hline 17.00 & 9.00 & 9.75 & 4.75 & “ & “ \\
\hline 17.00 & 10.00 & 10.00 & 5.50 & “ & Saginaw \\
\hline 14.00 & 9.00 & 9.00 & 5.00 & “ & " \\
\hline 15.50 & 9.50 & 9.75 & 5.00 & " & “ \\
\hline
\end{tabular}


TyPES: Location not ascertained.

Type Locality: Not ascertained. Probably in Canada.

Animal, Jaw, Radula and Genitalia: Unknown.

Range: New York to Michigan, north to Central Ontario. A race of the Great Lakes drainage (Canadian region) characteristic of the Transition and Upper Austral life zones.

RECORDS.

United States.

Michigan: Saginaw Bay (Miles); Stoney Island, Saginaw Bay, Tuscola Co. (Walker); River Rouge, Detroit, Wayne Co. (Miss Walker).

New York: Rose Hill Cemetery, Buffalo; Fort Erie Grove, Erie Co. (Miss Walker).

British America.

Ontario: Pigeon Lake, Peterborough District (Clapp).

Geological Distribution: Unknown.

Ecology: Not recorded.

REMARKS: Ontariensis may be distinguished from canadensis, some forms of which it closely resembles, by its short, very acute spire, the whorls of which are very flat-sided, x line drawn from the periphery of the body whorl being scarcely interrupted by the convexity of the whorls, as is the case in canadensis. The aperture is also different, being triangularly ovate. It is also a smaller shell.

In 1862 Küster (op. cit.) placed in the synonymy of emarginata a shell which he called ontariensis and credited to Muhlfeldt in manuscript. This was said to be ovate-conic with an acuminate spire, convex whorls and a semioval aperture. It seems evident from this description that the shell herein recorded, and which was first brought to the attention of the writer by Mr. Bryant Walker, is the form which Muhlfeldt had in mind. In the absence of types or of typical specimens for comparison, and as this distinct little form is without a name, it would appear quite proper to use Küster's name. The shells vary somewhat, particularly in the convexity of the whorls, which resemble those of emarginata in some examples. The aperture flares markedly in some specimens. The immature shell has a strong, twisting columellar plait, but the adult has the usual wide, flattened inner lip of the emarginata group. This race has been called both emarginata and catascopium and is probably so labelled in many collections.

Galba contracta Currier. Plate XLVI, figures 1-4.

Limnaa contracta Currier, Kent. Sci. Inst., Mis. Pub., No. 1, 1868.-Sowb., Conch. Izon., XVIII, Lim., pl. 15, fig. 32 b, 1872.-WALker, Journ. Conch., II, p. 330, 1879; Nautilus, VI, p. 33, 1892 ; Rev. Moll. Mich., p. 18, 1894.

Limnophysa contracta Currier, Kent. Sci. Inst., Pub. No. 5, p. 14, pl. 1, fig. 1, 1881. 
SHell: Elongated, compressed, thin; color spermaceti white, sometimes brownish-white; surface shining, marked by heavy, raised close-set growth lines which are crossed by fine impressed spiral lines, the surface frequently malleated; whorls six or seven, strongly angulated at the shoulder and flattened on the side, the body whorl much contracted, strongly shouldered and flattened in the middle; spire long, turreted, tapering; nucleus small, ovate, smooth, resembling jacksonensis in outline; sutures well impressed; aperture long and narrow, contracted, in some specimens being almost continuous by the elevation of the inner lip; the aperture occupies a little less than half the entire length of the shell; outer lip thickened within by a longitudinal varix; inner lip rather broad, strongly reflected and appressed to the parietal wall and the umbilical region, usually leaving a very small chink but frequently entirely closing the perforation; the inner lip is tightly appressed at its junction with the parietal wall producing a wellmarked plait; in some specimens the inner lip emargins the umbilical chink, much as in cmarginata; axis twisted.

\begin{tabular}{ccccc} 
Length. & Width. & Aperture length. & \multicolumn{2}{c}{ Width. } \\
22.00 & 8.50 & 10.60 & 3.75 & mill. \\
19.25 & 8.00 & 9.75 & 4.50 & “ \\
16.75 & 7.50 & 8.50 & 3.25 & “ \\
16.50 & 6.50 & 9.00 & 2.75 “
\end{tabular}

Types: Collection Bryant Walker, No. 11995.

Type Locality: Higgins Lake, Michigan.

Animal, Jaw, Radula and Genitalia: Unknown,

RANGE: Michigan. A species of the Canadian region and of the Boreal (Canadian) life zone.

\section{RECORDS.}

Michigan: Higgins Lake, Roscommon Co. (Currier; Walker).

Geological Range: Unknown.

Ecology: "This species has never been found alive so far as I know. It is probably as inhabitant of deep water that only comes to shore occasionally and apparently no one as yet has been fortunate enough to strike the occasion." (Walker).

Remarks: Contracta is a distinct, easily recognized species, distinguished by its long, acute spire, shouldered whorls, compressed body whorl and heavily plaited columella. Its very narrow, compressed shell and very long and narrow aperture separate it from emarginata, to which it is related. It approaches some forms of emarginata canadensis, but is always narrower and thinner. The peculiarly contracted aperture, which is sometimes reduced to a mere slit, and its notably compressed and shouldered body whorl, are its principal distinctive 
features. The specimens examined show a little variation, some individuals having a regular tapering spire of rounded whorls, while others have the later whorls and body whorl shouldered. The shells range from smooth to strongly malleated and the inner lip varies in its emargination of the umblical chink. Contracta has not been detected outside of the State of Michigan.

Galba pilsbryana (Walker). Plate XLV, figures 29-31.

Limnaa sumassi ? Walker \& Ruthven, Rep. Geol. Surv. Mich., 1905, pp. 51, 52, 53, 97, 99, 1906.

Lymncea pilsbryana WALKER, Nautilus, XXII, pp. 4, 18, 19, pl. 1, figs. 2, 8-11, May, 1908; An. Rep. Mich. Geol. Surv., 1908, p. 290, 1909.

"Shell: Ovate-conic, slightly perforate; dark brownish-yellow, frequently tinged with purple, with a light line just below the suture; whorls 5, convex, with a deeply impressed suture, the three apical whorls small, forming a short conical apex, penultimate whorl twice as long as the three preceding, inflated and convex, body-whorl large and well rounded; lines of growth strong and regular, cut by numerous fine spiral lines giving a shagreened appearance to the surface, in some specimens the last half of the body whorl is obsoletely malleated; aperture broadly oval, somewhat more than one-half of the entire length of the shell, dark brownish-yellow within, with a liver colored band just within the lip; lip sharp, regularly rounded and slightly expanded toward the basal margin; columella thick, white with a strong fold, broadly reflected over and appressed to the axial region, leaving only a very small perforation, and connected with the upper insertion of the lip by a broad, white and rather thick (for the genus) callus; axis thick, solid, twisted." (Walker).

$\begin{array}{ccccc}\text { Length. } & \text { Breadth. } & \text { Aperture length. } & \text { Breadth. } & \\ 22.00 & 13.50 & 13.00 & 10.00 \text { mill. } & \text { Type. } \\ 24.00 & 14.00 & 14.00 & 10.00 \text { " } & \text { “ }\end{array}$

Type: Collection Bryant Walker, twenty specimens, No. 21345; cotypes, Chicago Ácademy of Sciences, two specimens, No. 23672; Academy of Natural Sciences, Philadelphia.

Type Locality: Washington Harbor, Isle Royale, Lake Superior, Michigan.

Animal, Jaw, Radula and Genitalia: Not recorded.

RANGE: (Figure 48). Isle Royale, Lake Superior. A species of the Canadian region and of the Boreal (Canadian) life zone.

RECORDS.

Michigan: Washington Harbor, Isle Royale, Lake Superior (Ruthven; Walker).

Geological Distribution: Unknown. 
Ecology: "This form is abundant in Washington Harbor, and with Limnea stagnalis constitutes the characteristic molluscan life of this station. The specimens collected were found clinging to the rocks under the same conditions as L. stagnalis. It was also found to occur commonly in the rock pools on the Minong Trap promontory (Adams; Ruthven).

Remarks: Pilsbryana differs from emarginata (as herein understood) by its less rotund shape and particularly by the entire absence of the inner lip emargination. It is, however, very closely allied to the conical race known as canadensis, differing, as indicated by Walker, by its darker color and more inflated spire whorls. The Isle Royale emarginata appear to be transitional forms between typical emarginata and the race canadensis, many specimens have a spire quite as wide as either emarginata or pilsbryana, while others have the sharp conical spire of canadensis. The characteristic of the inner lip will immediately distinguish pilsbryana from all related species.

Galba montana (Elrod). Plate XLVI, figures 5-8.

Limnea emarginata var. montana Elrod, Nautilus, XV, p. 111, 1901; Trans. Amer. Micr. Soc., XXII, p. 76, 1901 ; Bull. Univ. Mont., Biol. Ser., No. 3, pp. 112, 173, 1902.

Limnaa emarginata montana KeEP, West Amer. Sh., p. 314, 1904.

Shell: Rather large, elongated, thin; periostracum light brownish horn or pearl gray; surface shining; sculpture of heavy growth lines crossed by heavy impressed spiral lines, giving the shell a beautifully latticed appearance; rarely malleated; whorls $5 \frac{1}{2}$ to 6 , well rounded, rather obliquely coiled, body whorl obese; spire long, acutely pyramidal, a trifle longer than the aperture; nuclear whorls as in emarginata; sutures well impressed; aperture roundly ovate or elongate ovate; interior of aperture chocolate colored; peristome thin with a slight thickening within; inner lip reflected and forming a broad, flat expansion which emargins the large umbilical chink; parietal callus not generally notably heavy; columella thickened but not plicate; axis slightly twisted.

\begin{tabular}{|c|c|c|c|c|c|c|}
\hline $\begin{array}{l}\text { Length. } \\
27.00\end{array}$ & $\begin{array}{l}\text { Width. } \\
13.25\end{array}$ & $\begin{array}{c}\text { Aperture length. } \\
14.70\end{array}$ & $\begin{array}{l}\text { Wid } \\
10.25\end{array}$ & $\begin{array}{l}\text { th. } \\
\text { mill. }\end{array}$ & (Elrod.) & \\
\hline 29.50 & 14.25 & 14.50 & 8.50 & “ & Mission & Mountains. \\
\hline 28.50 & 14.00 & 13.00 & 8.00 & “ & " & " \\
\hline 31.00 & 15.00 & 14.00 & 8.75 & “ & “ & “ \\
\hline 24.50 & 14.00 & 12.50 & 9.00 & “ & “ & “ \\
\hline
\end{tabular}

Types: Collection Morton Elrod, University of Montana; topotypes, The Chicago Academy of Sciences, four specimens, No. $23 \% 09$. 
Type Locality: Sin-yale-a-min Lake, Mission Mountains, western Montana.

Animal, Jaw, Radula and Genitalia: Not examined.

RANGE: Western Montana. A species of the Columbian River drainage (Columbian region) occupying an extension of the Boreal (Canadian) life zone.

\section{RECORDS.}

Montana: McDonald and St. Mary's Lakes, Mission Mountains; Swan Lake and Sin-yale-a-min Lake, Mission Mountains (Elrod).

Geological Distribution: Unknown.

ECoLOGY: "The most noticeable snail, and the most difficult to secure, was Limnca emarginata, a small variety. The same species was found very abundantly in McDonald Lake, fifteen miles further to the north, and is also in Swan Lake across the range east. In Sinyaleamin Lake the shells are for the most part singly on stones in the bottom where the water is shallow, or along the bank. They are very light in color and very conspicuous. To secure them it is necessary to take a boat, row slowly where the water is shallow, and when one can be seen wait until the water becomes smooth and either pick it off by hand if not too deep, or by some other method. As there is much trouble to determine the depth of the water on such occasions, the task becomes quite difficult, and the result is often a wetting. Our best success was to take an insect net, and with this gently pull the shell off the rock by inserting the net under the snail, thus letting the animal fall into the net. Even this is slow work. The snails have the peculiar habit of letting all holds go when anything touches them, ialling to the bottom among the pebbles, where it is very difficult to see them. An entire afternoon was spent fishing for these specimens, a couple of dozen being the number secured, and many getting away. It is readily seen from this that a small bottle may hold the entire catch of an afternoon" (Elrod).

Collected in McDonald Lake along the rocks in the middle of the lake and at the outlet among grass and weeds in shallow water.

Remarks: Montana may be known by its long spire, obese body whorl and rather open umbilicus. The inner lip is turned over more than in emarginata, and the body whorl is more obese and the columella smoother than in var. canadensis. It is a very thin shell. The sculpture is the most pronounced of any of the American species of Lymnæa. A peculiarity of montana is found in the obese character of the penultimate whorl.

Montana seems to be entitled to specific rank, presenting a combination of characters not connected with emarginata by intermediate 
forms, besides occupying a wholly different drainage area. It is one of the handsomest of the American Lymnæas.

\section{Galba oronensis (Baker). Plate XLVII, figures 1-9.}

Limnaa emarginata BAKer, Bull. Chi. Acad. Sci., II, pl. I, fig. B, 1900.Nylander, Nautilus, XII, p. 104, 1900 (part) ; Distr., Lim. emarginata, p. 4, 1901 (part).

Lymnaa decollata Lermond, Shells of Maine, p. 38, 1908 (part).

Radix decollata Heron, Ottawa Nat., I, p. 39, 1880.

Lymnca decollata oronoensis BAKER, Nautilus, XVIII, p. 62, Oct., 1904.LERMOND, Shells of Maine, p. 38, 1908.

SHELL: Globose, inflated, solid; periostracum rich greenish horn or dark olivaceous, inclining to black in some specimens; surface shining, the growth lines somewhat elevated, sometimes producing indistinct, fine elevations; spiral sculpture of fine impressed lines, giving the surface a wavy appearance; nuclear whorls rounded, smooth, very dark horn colored, in outline resembling those of emarginata; whorls $4 \mathrm{I} / 2$ to 5 ; very convex, the body whorl almost globular, sometimes a little shouldered near the suture; spire broadly conic, depressed in some specimens; sutures impressed; aperture roundly ovate, produced anteriorly, occupying about two-thirds the length of the shell; it is somewhat narrowed at the posterior end; peristome thin and sharp; in old specimens the outer lip thickens within and forms a distinct varix; inner lip tightly appressed to the parietal wall where it forms a spreading callus; the umbilicus is either completely closed or (rarely) there is a very narrow chink; axis strongly twisted, forming a distinct, ascending plait; the interior of the aperture is brownish-red.

$\begin{array}{cccccc}\text { Length. } & \text { Breadth. Aperture length. } & \text { Breadth. } \\ 18.00 & 12.00 & 12.00 & 8.00 \text { mill. } & \text { Type. } \\ 17.00 & 11.50 & 11.00 & 7.00 & \text { “ } & \text { “ } \\ 16.00 & 10.00 & 10.00 & 6.00 & \text { “ } & \text { “ } \\ 12.00 & 9.00 & 8.75 & 5.50 & \text { “ } & \text { " } \\ 19.50 & 12.50 & 11.75 & 6.00 & \text { " } & \text { Caribou, Maine. } \\ 20.00 & 12.50 & 13.00 & 7.00 & \text { “ } & \text { “ } \\ 18.00 & 10.00 & 10.00 & 6.00 & \text { “ } & \text { “ }\end{array}$

Types: Collection, Bryant Walker, twelve specimens, No. 7912 ; cotype, Chicago Academy of Sciences, one specimen, No. 23784.

Type Locality: Orono, Penobscot Co., Maine.

RADUla : Formula : $\frac{22}{5}-7+\frac{6}{2}-4+\frac{8}{2}+\frac{1}{1}+\frac{8}{2}+\frac{6}{2}-4+\frac{1}{5}-7 \quad(36-1-36)$; the teeth are similar in shape to those of catascopium and emarginata, differing principally in the number of laterals, which are nine in the former and ten in the latter, while they number but eight in oronensis. The large number of transition teeth ( $\mathrm{six}$ ) in oronensis is noteworthy, there being but two in emarginata and four in catascopium. Laterals 
one to eight are very uniform in oronensis; the ninth lateral has a small indication of an entocone, the tenth and eleventh teeth are typical intermediates with well-developed entocone and ectocone; the twelfth tooth has usually a bifid entocone, while the thirteenth tooth is a normal intermediate. The fourteenth tooth and all which follows are typical marginals, with irregularly serrated margin; the mesocone persists in a few marginals, but all of the cusps become subequal at about the seventeenth tooth.

Genitalia : Not examined.

RANGE: (Figure 49). Maine to eastern Ontario. A species of the Canadian and Nova Scotian regions and of the Boreal (Canadian),

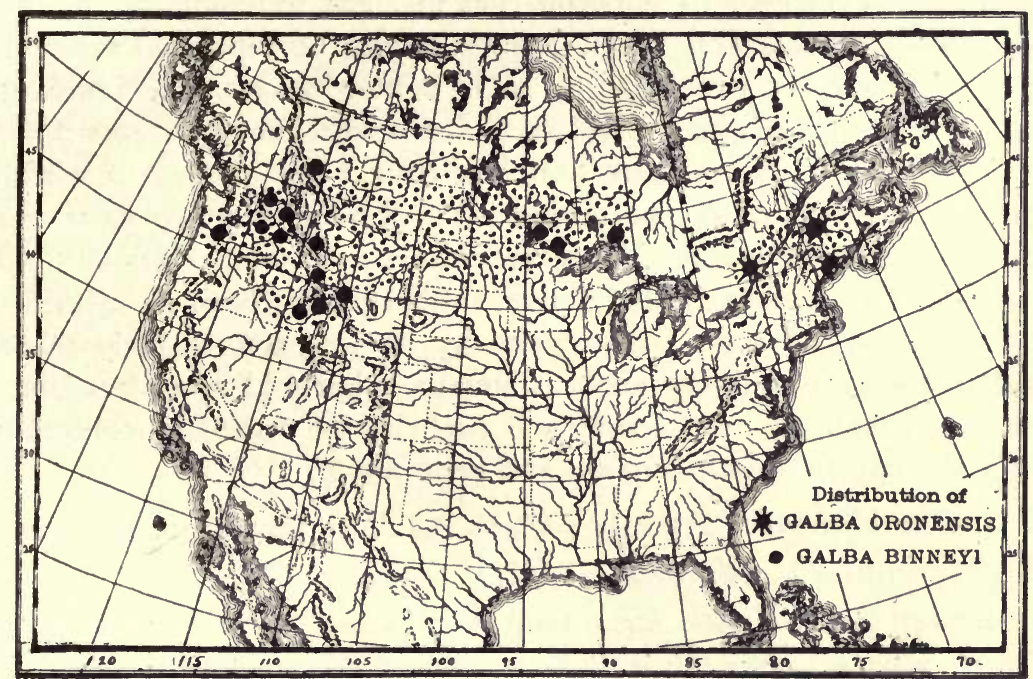

FIG. 49.

Transition and Upper Austral life zones; it is confined to the Atlantic drainage.

\section{RECORDS.}

United States.

Maine: Lincoln, Penobscot River, Penobscot Co. (Bost. Soc. N. H.); Orono, Penobscot Co. (Bolles; Stearns; Walker); Lake Auburn, Androscoggin Co. (Lermond); Caribou River, Aroostook Co. (Nylander).

British AMERICA.

Ontario: Ottawa, Carleton Dist. (Latchford; Heron; Walker).

Geological Distribution: Unknown.

Ecology: Not differentiated from emarginata. 
REMARKS: Oronensis is easily known by its rounded whorls, very globose form, imperforate axis, roundly ovate aperture and strongly plicate columella. It differs from catascopium in its broad shell, tumid, globose whorls, depressed spire and roundly ovate aperture. The columellar plait is also heavier than in catascopium and the inner lip is broader. It is more nearly related to emarginata but may be distinguished by the imperforate axis and plicate columella. It resembles some forms of emarginata canadensis, which race, however, has a more acute spire, a less globose body whorl and a wider and less plicate columella. The species does not seem to be closely related to either catascopium or emarginata though having affinities with both, standing nearer to emarginata, however, a fact shown by the wider inner lip and evidences of emargination in some individuals. Normal specimens from Caribou River, Maine, cannot be separated from the types of oronensis, excepting by their lighter color. The immature Caribou River specimens resemble juvenile specimens of emarginata mighelsi Binney, but are more solid and have a less number of whorls. They were referred to cmarginata by Nylander, but are more correctly placed in oronensis. Young specimens somewhat resemble Galba apicina and specimens from Ottawa, Canada, have been so identified. It may be known from that species by its less rotund body whorl, imperforate axis and very acute columellar plait which is placed on a narrower inner lip. Oronensis will probably be found in collections under the names of catascopium and emarginata.

Galba binneyi (Tryon). Plate XLVI, figures 9-12; plate XLVII, figures 11-18; plate XLVIII, figure 3.

Limnea binneyi TrYon, Amer. Journ. Conch., I, p. 229, pl. 23, fig. 3, 1865.Currier, Kent. Sci. Inst., Mis. Pub. No. 1, 1868.-Cooper, Proc. Cal. Acad. Sci., IV, p. 96, 1870.-Ingersold, Bull. U. S. Geog. \& Geol. Surv. I, p. 139, 1875; Rep. U. S. Geol. \& Geog. Surv. Terr., 1874, p. 406, 1876.

Limnophysa binneyi Tryon, Amer. Journ. Conch., I, p. 252, 1865.-Cooper, Proc. Cal. Acad. Sci., IV, p. 173, 1872 ; Proc. Cal. Acad. Sci., VI, p. 26, 1875.

Limnophysa caperata var. binneyi, KeEP, West Coast Shells, p. 122, 1887.

Limncea ampla TRYoN, Con. Hald. Mon., p. 91, pl. 16, fig. 9, 1872 (exparte, non Mighels).

Lymnaa (Radix) binneyi Dall, Alaska Moll., p. 69, 1905.

Limnea catascopium Gould, Agassiz's Lake Superior, p. 244, 1850 (part).

Limnaa palustris Stearns, Proc. U. S. Nat. Mus., XIV, p. 101, 1891 (part).

Lymncea emarginata Cooper, Pac. R. R. Rep., XII, pt. 2, p. 278, 1860.

Limncea emarginata CPR., Rep. British Asso., pp. 599, 674, 1864.-Smith. Mis. Coll., X, pp. 85, 160, 1872.

Limncea sumassi? Binney, L. \& F.-W. Sh. N. A., II, p. 43, fig. 58, 1865 (non Baird). 
Limnaa ampla? Tryon, Con. Hald. Mon., p. 91, pl. 16, fig. 10, 1872 (non Mighels).-Cat. Coll. Nat. Hist. Eth. Prov. Mus. Victoria, p. 95, 1898.

Limnaa randolphi? DaLl, Alaska Moll., p. 71, 1905.

Shell: Elongate-globose, inflated, generally rather solid; periostracum pale horn, darker in some specimens; surface shining, lines of growth coarse and close-set; spiral striation pronounced; apex wine colored; whorls $4 \frac{1}{2}$ to 5 , rapidly increasing in size, inflated, tumid; spire short, broadly conic; nuclear whorls $1 \frac{1}{2}$ in number, flattened, especially the first whorl which is very flat, sunken in the volution of the second whorl, and separated by a deep sutural channel (pl. XLIX, fig. P) ; sutures impressed; aperture ovate or elliptical, occupying more than half the length of the shell; outer lip convex, thickened within by a varix edged with brown; inner lip somewhat erect, reflocted over the parietal wall to form a thick callus and raised above the umbilicus forming a broad, flat projection partly hiding the umbilical chink; axis not much twisted, but the columella is slightly thickened and in some specimens the inner lip is appressed to such an extent as to form a rather well-marked plait; the umbilical chink varies from a small slit to a rather wide opening. The surface is sometimes malleated.

\begin{tabular}{|c|c|c|c|c|c|c|}
\hline Length. & Breadth. & Aperture length. & \multicolumn{2}{|c|}{ Breadth. } & \multirow{2}{*}{\multicolumn{2}{|c|}{ Tryon's type. }} \\
\hline $\begin{array}{l}19.00 \\
18.25\end{array}$ & $\begin{array}{l}12.00 \\
11.50\end{array}$ & $\begin{array}{l}12.25 \\
11.50\end{array}$ & $\begin{array}{l}0.25 \\
5.50\end{array}$ & mil. & & \\
\hline 20.50 & 12.20 & 12.60 & 7.00 & " & Lake & Superior. \\
\hline 28.00 & 18.00 & 17.50 & 10.10 & “ & . & " \\
\hline 22.50 & 12.75 & 13.50 & 7.50 & “ & " & " \\
\hline 19.50 & 13.25 & 12.50 & 8.10 & “ & “ & “ \\
\hline 19.75 & 11.50 & 10.50 & 7.50 & “ & “ & “ \\
\hline 16.00 & 9.30 & 9.80 & 5.50 & " & “ & " \\
\hline 17.00 & 10.00 & 10.00 & 5.50 & “ & “ & “ \\
\hline 22.75 & 13.00 & 13.00 & 7.50 & “ & “ & “ \\
\hline 29.00 & 19.50 & 19.50 & 11.50 & “ & Rainy & Lake. \\
\hline 25.00 & 16.50 & 19.50 & 11.50 & “ & “ & \\
\hline
\end{tabular}

Types: Two specimens, ex Gabb., Acad. Nat. Sci., Phil., No. 58506.

Type Locality: Hell Gate River, Montana.

Animal, Jaw, Radula and Genitalia: Not examined.

RANGE: (Figure 49). Western Ontario north of Lake Superior $\left(86^{\circ}\right)$ west to Washington, Alberta south to southern Idaho. Binneyi is a species of the Boreal (Canadian) and Transition life zones. It occupies both the Great Lakes drainage and that of the streams emptying into the Columbia River (Columbian and Canadian regions). There seems to be no question concerning the identity of the shells occupying these very diverse drainage areas. Specimens from Montana and Yellowstone Park indicate that the species occupies the upper drain- 
age of the Missouri River (Upper Mississippi region); and also from near Banff, Alberta indicating that it may occupy the Saskatchewan drainage (Hudsonian region). Further investigation will doubtless reveal the fact that this species has migrated from one part of its range to another via Two Ocean Pass in Yellowstone Park. The absence of records from the intervening area is due to the confusion of this species with catascopium, emarginata and palustris. A large collection covering the intermediate area is needed to throw further light on the range of this species.

\section{RECORDS.}

\section{United States.}

IрAно: Birch Creek, Fremont Co. (Cooper; Hemphill); Sawtooth Lake, Blaine Co. (Merriam).

Montana: Hell Gate River, Missoula Co. (Binney; Tryon); Madison Co. (Merrill).

Washington: East of Colville, Stevens Co. (Boundary Survey); Lake Oyosa, Okanogan River, Okanogan Co. $\left(\right.$ Cooper $\left.^{1}\right)$; Cascades of the Columbia River, Skamania Co. (Cooper; Dunn); Spokane, Spokane Co. (Hemphill); Fort Vancouver, Columbia River, Clarke Co. (Lea); Blue Lake, Grand Coulee Mountains, Douglass Co. (R. E. Snodgrass).

Wyoming: Madison River, Riverside, Yellowstone Park (Smith. Inst.).

British America.

Alberta: Lake Louise, near Banff (Mrs. Schaeffer \& Miss James).

Ontario: North shore Lake Superior, Thunder Bay District (Ferriss); Lake of the Woods, Rainy River District (Kennicott) ; Gull Rocks, Rainy Lake, Rainy River District (Latchford).

Geological Distribution: Unknown.

Ecology: Not recorded.

Remarks: Binneyi is related to both catascopium and emarginata. It is generally wider than catascopium, is (usually) umbilicate, has a shorter, broader spire and more tumid whorls. The columella is quite different, being broader, erect and lacking the plait and twist of that species. The spire is short and acute-conic, differing from both catascopium and emarginata. It may be known from emarginata by its more regularly ovate shell, less rotund body whorl, more acute spire and more ovate aperture. It differs from canadensis in its shorter, broader spire and widely open umbilical chink. Binneyi is related to apicina Lea, differing in its more acute spire, narrower shell, open umbilicus and more emarginate inner lip. Normally there is an entire absence of a columellar plait in binneyi while in apicina a plait is usually developed. When once recognized this species is very characteristic and easily distinguishable from all related species.

${ }^{1}$ Probably intended for Osoyoos Lake. 
Binneyi varies greatly in size as well as in the tumid character of the whorls. The majority of the specimens are uniform in size and do not vary markedly from Tryon's types, in the Philadelphia Academy of Natural Sciences. In the lot from Lake Superior, however, there are several individuals which are double the normal size, one specimen having a large patulous aperture (pl. XLVII, fig. 17). The spire also varies somewhat in height. The umbilical chink is usually (and normally) rather large and deep and is overhung or emargined by the inner lip somewhat as in cmarginata. Occasionally a specimen occurs in which the inner lip is so closely applied to the parietal wall as to nearly or quite close the umbilicus and form a conspicuous plait (pl. XLVII, fig. 1\%). The aperture varies from ovate to elliptical. Some specimens from Rainy Lake, Ontario, have a large aperture and a very short, broad spire. The majority of specimens from this locality are quite normal. Specimens from Lake Louise, near Banff, are narrower than typical binneyi, but are otherwise similar (plate XLVI, figures 911). An examination of the axis of this species shows that it is not gyrate nor particularly twisted, excepting in abnormal specimens, and it cannot therefore, be correctly placed in the section Radix.

The Lake Superior lot of binneyi is in all respects like Tryon's types from Hell Gate River, Montana, thus extending the range of this species many miles eastward. The western references to emarginata undoubtedly refer to this species as emarginata does not occur west of the Rocky Mountains, binneyi replacing it. A specimen labeled cmarginata in the Smithsonian collection (from Sawtooth Lake, Idaho) proved, upon examination, to be typical binneyi (pl. XLVI, fig. 12). Figure 15, on plate XLVII, is almost identical with Tryon's type as well as his figure. The specimen figured by Binney on page 43 (1. c.) is probably a scalariform individual of binneyi and not referable to randolphi. Specimens from the same lot examined recently are all referable to binneyi.

Galba apicina Lea. Plate XLVII, figures 19-29 ; plate XLVIII, figure 1.

Lymnaa apicina LeA, Trans. Amer. Phil. Soc., VI, p. 102, pl. 23, fig. 94, 1839 ; Obs., II, p. 102, 1839.-Wheatley, Sh. U. S., p. 23, 1845.-Scudder, Bull. Nat. Mus., 23, pp. 20, 200, 1885.

Limnea apicina Gould, Wilke’s Exped., p. 122, 1852.

Limnaa apicina CPR., Rep. Brit. Assoc., pp. 210, 216, 1856.-Binney, Check List, p. 12, 1860 ; L. \& F.-W. Sh. N. A., II, p. 62, fig. 98, 1865.

Limncas apicinus Troschel, Archiv. für Natur., II, p. 224, 1839.-Küster, Conch. Cab., p. 48, taf. 8, figs. 31-33, 1862. 
Limnca bulimoides var. apicina Cooper, Proc. Cal. Acad. Sci., IV, p. 96, 1870.

Limnea catascopium HAld., Mon. Limn., p. 8, pl. 1, fig. 9, 1842; Mon. Lim., p. 52 , pl. 14 , fig. 5,1842 .

Limnaa catascopium? Binney, L. \& F.-W. Sh. N. A., II, p. 56, fig. 86, 1865.

Lymnca catascopium BAKeR, Trans. Acad. Sci. St. Louis, XVI, p. 13, 1906.

Limnaa decollata Binney, L. \& F.-W. Sh. N. A., II, p. 32, 1865 (part).Currier, Kent. Sci. Inst., Mis. Pub., No. 1, 1865.-Dawson, British N. A. Bound. Com., p. 349, 1875.-WALKer, Journ. Conch., II, p. 330, 1879.-Christy, Journ. Conch., IV, p. 347, 1885.-Walker, Nautilus, VI, p. 32, 1892 ; Rev. Moll. Mich., 1894, p. 17.-Hanham, Nautilus, XIII, p. 5, 1899 (?).-Ruthven, Rep. Mich. Acad. Sci., VI, p. 190, 1904; Rep. Geol. Surv. Mich., 1905, pp. 23, 24, 35, 95, 1906.

Radix decollata DeCamp, Kent. Sci. Inst., Mis. Pub., No. 5, p. 7, 1881.

Limnca brownii TRYON, Amer. Journ. Conch., III, p. 196, 1867 (part).

Limncea solida TrYoN, Con. Hald. Mon., pp. 107 (81), 111 (85), 1872.

Limnea solida HAld., Mon. Limn., p. 38, pl..11, fig. 12, 1842.

SHELL: Globose or ovate, inflated, generally rather solid; periostracum pale horn, darker in some specimens; surface shining, almost polished, lines of growth coarse and close-set, spiral striation pronounced; nuclear whorls wine-colored, in outline resembling those of binneyi; whorls 4-5, rapidly increasing in size, inflated, tumid; spire short, generally very broad, dome-shaped, frequently much depressed; sutures impressed, frequently bordered by a white band; aperture ovate or roundly ovate, occupying usually more than half the length of the shell; outer lip very convex, with an internal transverse varix, edged with brown; inner lip triangular, rather narrow, tightly appressed to the umbilical region, leaving a very small chink; parietal callus very thin; axis twisted forming a distinct ascending plait.

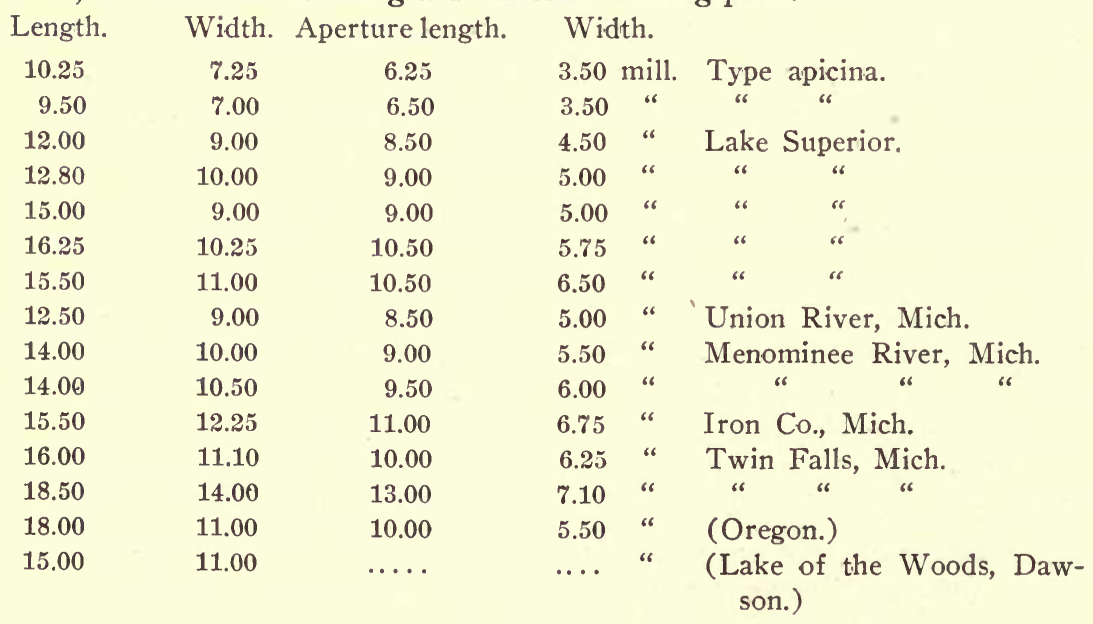


Types: Two specimens, Smith. Inst., No. 118626.

Type Locality: Willamette (Wahlamat) near its junction with the Columbia River, Oregon.

Animal, Jaw, Radula and Genitalia: Not examined.

RANGE: (Figure 50). Northern part of the lower peninsula of Michigan $\left(86^{\circ}\right)$ west to Western Washington; Ontario south to Southern Wyoming and South Dakota.

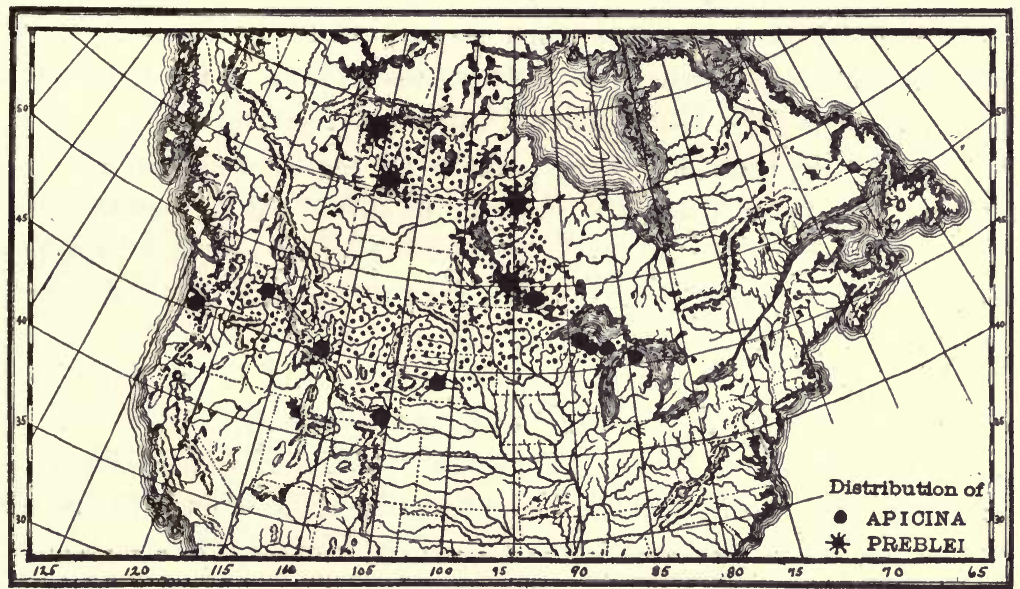

FIG. 50.

Apicina is an inhabitant of about the same drainage area as binneyi (Great Lakes, Columbia and Missouri rivers). It occupies the Canadian, Columbian and a part of the Upper Mississippian regions. It is also typical of the Boreal (Canadian) and Transition life zones. In fact, both binneyi and apicina may be said to occupy a strip of territory ten degrees in width from Michigan to Washington. The 41st parallel marks its known southern range while the 50th parallel marks its northern extension.

\section{RECORDS.}

\section{United States.}

Michigan: Union River, Ontonagon Co. (Ruthven; Walker); Mulletts Lake, Sheboygan Co. (Walker); shore of Lake Superior, Ontonagon Co.; Menominee River, Dickinson Co.; Twin Falls, Brule River and Michigamme River, Iron Co.; middle and lower beach, Lake Superior (Walker and Ruthven).

Montana: Madison Co. (G. P. Merrill).

OreGon: Willamette River, near its junction with the Columbia River, Columbia Co. (Lea; Nuttall). 
South Dakota: Grindstone Creek, Stanley Co. (Binney; Hayden).

Washington: Spokane, Spokane Co. (Olney).

Wyoming: Laramie, Albany Co. (Smith. Inst.).

British America.

Ontario: Lake of the Woods, Rainy River District (Dawson; Kennicott) ; north shore, Lake Superior, Thunder Bay District (Ferriss).

Geological Distribution: Unknown.

ECoLOGY: "It occurs here in great abundance chiefly in pools and along the sides of the stream where it may be found clinging tightly to the bare sandstone rocks and often in current so swift as to carry it rapidly down stream when its hold is disturbed." (Ruthven, Mich. Acad. Sci. VI, p. 189 ; Union River, Ontonagon Co., Mich.)

"The Lower Beach is that portion of the shore exposed to the action of the waves during the summer months. At the point studied, Station I, owing to the dip of the strata, the water deepens rapidly off shore, and the breaker line is brought near to the beach, the lower part of which is thus exposed to the full force of the waves. Exposed as it is alternately to the pounding of the waves and dessication in the sun the conditions are so severe that very little life can exist. The only form that is found here is the snail Limnca decollata (=apicina) that occurs occasionally behind projecting outcrops, where it is to some extent protected from the direct force of the waves. This snail seems to be adapted to habitats of this nature, for it was found elsewhere only in rapid water in the larger rivers." (Adams).

"Abundant on some parts of the shores of the Lake of the Woods, generally among rocks and boulders on an exposed coast, creeping over the stones even in the wash of the waves, with the habitat of a Littorina." (Dawson, Lake of the Woods specimen).

Remarks: Apicina may be known by its globose, tumid shell, rather short spirc and conspicuous columellar plait. It somewhat resembles both catascopium (short spired forms) and woodruffi but differs in having a more globose shell and a rounder aperture, and generally a broader and shorter spire. The shells agree well in the tumidity of the whorls, but the spire varies from broadly acutely-conic to tumidly depressed, and also varies one-half to nearly equal the length of the aperture. The columellar plait is almost always very prominent. It has been confounded with decollata, but that species is of a rhomboid shape, the spire is more regularly acute, the aperture is more ovate, the last whorl is disproportionately swollen at the periphery and the inner lip is more tightly appressed to the umbilical region leaving no sign of a chink. 
A comparison of the types of apicina with a large set of shells from Lake Superior shows that both are the same species. The Lake Superior forms are larger than the types but are otherwise the same. Lea's figure is wretched and gives no idea of the shape of the shell and his description is totally inadequate to recognize the species. Binney's figure 86 (catascopium?) represents apicina, the four figures showing something of the range of variation. Haldeman's fig. 5, on plate 14 is a good representation of apicina but is not related to decollata, as thought by Haldeman. Haldeman's fig. 12, on plate 11, is also this variety. The types of apicina (two specimens) are smaller than the Lake Superior and Michigan forms referred to this variety, but they are otherwise the same. (See plate XLVIII, fig. 1). Specimens from Oregon are identical and of the same size as the Michigan specimens. Conchologists have generally misunderstood this species, placing it as a synonym of solida and confounding it with decollata. The Michigan and other western references to decollata refer either to solida or apicina. The specimens examined from this region have nearly all proved to be apicina and not a single undoubted specimen of decollata has been detected among them. Apicina differs from the variety solida in being more regularly ovate or bulbous, having more tumid whorls, a slightly open umbilicus, a sharper and more conspicuous columellar plait and generally a more depressed and dome-shaped spire.

It is evident from a study of the types of binneyi Tryon that apicina is very closely related to that species. The chief differences are the more tumid shell with its short, depressed spire in apicina, which is long and more acute in binneyi; the closed or nearly closed umbilical chink in apicina is in strong contrast with the wide, flat inner lip and open umbilicus of binneyi. Individuals of one species vary toward the other, but on the whole these distinctions hold good. Some conchologists might consider these varieties of the same species, but while undoubtedly closely related, they are, apparently, specifically distinct. Young specimens of emarginata mighelsi somewhat resemble apicina, but the shape of the whorls, their less number and the large umbilicus, will distinguish them. The Michigan specimens vary greatly in size and form. Individuals from the Menominee River are small with a somewhat elevated spire and rather narrow shell, which is much eroded by the carbon dioxide in the water. Specimens from Iron County are larger and more tumid, with depressed, rotund spire and a well-marked columella plait. The forms from Union River are the same as those from Lake Superior.

The reference of Bell, Whiteaves, etc., to solida and apicina from 
the St. Lawrence River were all founded on specimens of catascopium (pinguis) a fact ascertained by an examination of some of the original specimens kindly sent to the writer by Dr. Whiteaves. A single specimen was detected among the shells collected by Mr. J. Macoun in the St. Lawrence River below the mouth of the Montmorency River, which was almost identical with the Lake Superior shells. As this may have been a case of parallel development in catascopium (to which species all of the other specimens belong) and in the absence of additional material it can scarcely be referred to apicina.

Galba apicina solida Lea. Plate XLVIII, figure 2; plate XLVII, figure 30 .

Limnea solida LEA, Trans. Amer. Phil. Soc., VI, p. 94, pl. 23, fig. 91, 1839 ; Obs., II, p. 94, pl. 23, fig. 91, 1839.-Wheatley, Sh. U. S., p. 24, 1845.-Jay, Cat. Ed. 4, p. 270, 1852.-Scudder, Bull. Nat. Mus., 23, pp. 20, 201, 1885.

Limnea solida Hald., Mon. Limn., p. 36, pl. 11, figs. 11, 13, 1842.

Limnaa solida DeKAY, Zool. N. Y., p. 75, 1843.-Binney, Check List., p. 12, 1860.-CPr., Rep. Brit. Assoc., p. 674, 1864.-Binney, L. \& F. W. Sh. N. A., II, p. 62, fig. 97, 1865.-CPR., Smith. Misc. Coll., p. 160, 1872.-SowB., Conch. Icon., XVIII, Lim., sp. 88, pl. 13, figs. 88 a, b, 1872.-Tryon, Con. Hald. Mon., p. 111 (85), 1872.-Clessin, Mal. Blatt., n. s., III, p. 82, 1881.

Limnophysa solida Tryon, Amer. Journ. Conch., I, p. 256, 1865.

Limnaus solidus Troschel, Archiv. für Natur., II, p. 224, 1839.

Limnaa bulimoides var. solida Cooper, Proc. Cal. Acad. Sci., IV, p. 96, 1870.

SHell: Acutely conic or elongate-ovate, very solid, periostracum pale horn varying to whitish; surface shining, presenting a polished appearance; lines of growth coarse and close-set, spiral striation marked; nuclear whorls as in apicina; whorls 4 to 5, rather rapidly increasing in size, body whorl somewhat flatly rounded; spire elongated, acutely conic; sutures impressed; aperture ovate, somewhat expanded, particularly at the anterior end; the aperture is about half the length of the shell; outer lip thickened with an internal, longitudinal varix; inner lip broadly reflected, completely closing the umbilicus, and forming a broad, flat expansion; parietal callus very thick and spreading over the parietal wall; axis slightly twisted, forming a distinct but not sharp plait.

\begin{tabular}{|c|c|c|c|c|c|}
\hline $\begin{array}{l}\text { Length. } \\
11.25\end{array}$ & $\begin{array}{l}\text { Width. } \\
7.00\end{array}$ & $\begin{array}{l}\text { Aperture length. } \\
\qquad 6.00\end{array}$ & $\begin{array}{l}\text { Width. } \\
3.25 \text { mill. }\end{array}$ & Type. & \\
\hline 13.00 & 8.00 & 8.00 & $4.75 \quad 6$ & Salmon & River, Idaho. \\
\hline 12.00 & 7.75 & 7.00 & 4.50 & & \\
\hline
\end{tabular}

TyPE: One specimen, Smithsonian Institution, No. $118 \% 13$.

Type Locality: Willamette (Wahlamat) near its junction with the Columbia River, Oregon. 
Animal, Jaw, Radula and Genitalia: Not examined.

RANGe: Idaho west to Oregon. A species of the Columbia River drainage (Columbian region) in the Transition life zone.

\section{RECORDS.}

IDAHO: Salmon River (Hemphill).

Oregon: Willamette (Wahlamat) near its junction with the Columbia River, Columbia Co. (Lea; Nuttall).

Geological Distribution: Unknown.

Ecology: Similar to that of apicina.

Remarks: Solida may be known by its somewhat oblique, acutely conic and imperforate shell, its wide and rather flat inner lip, its very solid shell and its somewhat patulous aperture. Students have generally misunderstood this race (and this is not strange, since the figures and descriptions are poor and meager), confounding it particularly with decollata. The Michigan references to decollata were founded on apicina and the western references on the present race. The figures of solida and apicina have been very unfortunate. Haldeman's are fairly good but Binney's are very poor and one can scarcely believe that the figure given by him and the photograph of the type in this monograph (pl. XLVIII, fig. 2) are intended to illustrate the same specimen. Solida differs from apicina in its more elongated spire, closed umbilical region, less tumid whorls, more oblique shape, patulous aperture and less acute columellar plait. It does not seem to be common and only one lot, besides the type, has been seen.

Notwithstanding the fact that Lea described solida on an earlier page than apicina, the writer has deemed it best to consider the earlier name a race of the later species.

Galba hinkleyi (Baker). Plate XLVII, figure 31-35.

Lymnaa hinkleyi BAKer, Nautilus, XIX, p. 142, April, 1906.

?Limnea catascopium Hald., Mon. Lim., p. 8, pl. 14, fig. 4, 184\%

Shell: Varying from ovate to globose, very thin; color of periostracum light greenish-horn; surface dull to slightly shining, rough, the growth lines uneven and raised at intervals to form fine ridges; the surface is sometimes malleated and occasionally ornamented by five or six heavy spiral ridges; fine impressed spiral lines present and very marked in some specimens; whorls 5, rounded, tumid in some specimens, the last whorl globose; spire of variable length, but generally shorter than the aperture, broadly conic; sutures well impressed; aperture roundly ovate, not expanded, acutely narrowed at the posterior angle; outer lip thin with an internal longitudizal varix; inner lip very 
lightly appressed to the parietal wall, where it shows as a very thin wash of callus; the anterior part of the lip is reflected over the umbilicus, leaving a very small chink, axis slightly twisted, forming a more or less distinct, ascending plait.

$\begin{array}{ccccll}\text { Length. } & \text { Width. } & \text { Aperture length. } & \text { Width. } & \\ 12.00 & 8.50 & 8.00 & 5.00 \text { mill. } & \text { Type. } \\ 11.50 & 7.50 & 7.25 & 4.50 & \text { “ } & \text { “ } \\ 12.00 & 7.75 & 7.00 & 4.00 & \text { “ } & \text { “ } \\ 11.00 & 6.75 & 6.25 & 3.75 & \text { “ } & \text { “ } \\ 15.25 & 9.25 & 10.50 & 3.50 & \text { “ } & \text { “ } \\ 11.00 & 6.75 & 6.50 & 3.75 & \text { “ } & \text { “ } \\ 15.10 & 10.00 & 10.00 & 5.00 & \text { “ } & \text { Spokane Falls. } \\ 14.00 & 8.50 & 8.80 & 4.50 & \text { “ } & \text { " }\end{array}$

Types: Chicago Academy of Sciences, five specimens, No. 23720; cotypes, Academy of Natural Science, Philadelphia; Coll. A. A. Hinkley.

Type Locality: North fork Snake River, East Idaho.

Animal, Jaw, Radula and Genitalia: Not examined.

RAnge: Idaho and Oregon. Columbia River drainage (Columbian region).

\section{RECORDS.}

IdAнo: North fork Snake River, Fremont Co. (H. O. Hinkley).

OrEGon: Snake (Lewis) River (Haldeman).

Geological Distribution: Unknown.

ECOLOGY: Not recorded.

REMARKS: Hinkleyi is related to both binneyi and apicina, but differs from both in being much thinner, more tumid, the inner lip is narrower, the umbilical chink smaller and the axis more twisted. The whole shell is more fusiform in outline. Hinkleyi varies somewhat in the elevation of the spire, but otherwise seems very uniform. The spire is decollated in most of the specimens examined. It was thought at first to be binneyi, but the shell is much smaller and thinner with no umbilicus.

The species is named in honor of Mr. A. A. Hinkley, Du Bois, Illinois, in whose collection the shells were found.

Galba preblei (Dall). Plate XXV, figures 7-10.

Lymnaa (binneyi var.?) preblei Dall, Alaska Mollusks, p. 70, pl. 1, figs. 1, 2, 1905.-PILSBRY, Nautilus, XIX, p. 95, 1895.

Lymnaa binneyi Dali, Alaska Moll., p. 69, 1905 (part).

Limnaa ampla Binney, Proc. Phil. Acad., p. 330, 1861; L. \& F.-W. Sh. N. A., II, p. 31, 1865 (part). 
Shell: Rather thin, convex, tumid; periostracum white or pale straw color; surface dull, with fine growth lines and minute spiral lines; often malleated; nuclear whorls as in emarginata; whorls 5 to 6 ; convex; rapidly increasing in size, the body whorl very convex; spire rather short, less than half the length of the shell, broadly acutely pyramidal; sutures impressed; aperture ovate or elongate-ovate, somewhat expanded and produced in front; peristome thin, sharp, with a light varix ; inner lip expanded to form a wide shelf which is reflected over the body whorl, leaving a rather wide, umbilical chink; the parietal callus is quite erect in some specimens; axis slightly twisted, but the pillar of the aperture is without a fold.

$\begin{array}{cccccc}\text { Length. } & \text { Breadth. Aperture length. } & \text { Breadth. } & \\ 37.00 & 23.00 & 22.50 & 13.00 \mathrm{mill} & \text { (Dall.) } \\ 38.00 & 26.00 & 26.00 & 19.00 \text { " } & \text { " } & \\ 23.00 & 15.00 & 15.00 & 8.00 \text { " } & \text { Isle La Crosse. } \\ 18.50 & 13.00 & 11.25 & 7.25 \text { " } & \text { " }\end{array}$

TYPES: Smithsonian Institution, No. 180333, one specimen; No. 110376, two specimens figured by Dr. Dall, plate 1, figures 1, 2.

Animal, Jaw, Radula and Genitalia: Unknown.

Range: (Figure 50). Central Keewatin to Central Athabaska, south to Manitoba. A species of the Hudsonian and Mackenzian regions and of the Boreal (Canadian) life zone.

\section{RECORDS.}

British America.

Athabaska: Clear Lake, N. Lat. 56 ${ }^{\circ}$ (Dall) ; Isle La Crosse Lake (Kennicott; W. A. Nason).

Keewatin: Knee Lake, near $55^{\circ}$ N. Lat. (Preble).

ManitoBa: English River (Kennicott).

Geological Distribution: Unknown.

ECOLOGY: Not recorded.

REMARKS: An examination of the type material has led the writer to consider preblei a good species and not a variety of binneyi. It will be recognized at once by its peculiar swollen form, raised inner lip and deep umbilical chink. Dr. Dall suggested a resemblance to L. megasoma and says this resemblance "is so marked that one wonders whether some of the records of the latter species from high northern localities may not have been based on specimens of this form." This similarity is only apparent in one or two specimens. The two species are totally unlike, particularly in color. Preblei is larger and thinner than binneyi, the whorls are more tumid, the spire is more acutely conical and the inner lip more erect and without a plait. Some ma- 
terial has been included in preblei which Dr. Dall places in binneyi, evidently from a misconception of the true binneyi. Binney (p. 31) has confused this species with Galba emarginata mighelsi. An examination of the axis of both species shows them to be true Stagnicolas and not rightly placed in Radix which has a distinctly gyrate axis. Preblei will doubtless be found to be a common species in the waters draining into Hudson Bay.

Galba randolphi (Baker). Plate XVIII, figure 6 ; plate XLVIII, figures 5-12; plate XLVI, figure 13.

Limncea ampla RANDoLPH, Nautilus, XII, p. 110, 1899.

Limncea emarginata var. mighelsi BAKER, Bull. Chi. Acad. Sci., II, No. 4, pp. 196, 198, 1900 (not of Binney).

Lymncea randolphi BAKER, Nautilus, XVIII, p. 63, Oct., 1904.

Lymncea (Radix) randolphi Dall, Alaska Moll., p. 71, pl. 1, figs. 3, 4, 1905.

Limnca randolphi Whiteaves, Ottawa Naturalist, XIX, p. 65, 1905; Nautilus, XIX, p. 3, 1905.

Shell: Large, thin, more or less inflated; whorls 5, inflated, distinctly angulated at the shoulder and constricted at the suture, frequently decollated; spire short, occupying less than half the length of the shell; in some specimens the first three and one-half whorls are small and regularly wound, and the last whorl abruptly enlarges to more than four times the diameter of the preceding whorls, sometimes causing the upper spire whorls to appear as though set upon a pedestal; nuclear whorls $1 \frac{1}{4}$ in number, the first part of the whorl is rounded and very small, the second very large, rounded; the nuclear whorls are very rough, with a satin finish sculpture; in certain lights there seem to be very fine spiral striations; (pl. XLIX, fig. Q); sutures deeply impressed, the whorls constricted near this region; sculpture consisting of close-set, regular lines of growth crossed by fine, impressed spiral lines; the surface is strongly malleated in many specimens and in some individuals raised spiral ridges are formed on the body-whorl; aperture very large, ovate, narrowed at the posterior end by the sutural constriction; the anterior end of the aperture is rounded and much produced; the aperture is made continuous by the elevation of the inner lip which is more or less reflected, thin and sharp; outer lip very thin, a trifle patulous in many specimens; in some specimens the inner lip is appressed to the body whorl while in others it scarcely touches it joining the outer lip at a sharp angle; pillar with a twisted axis, sometimes slightly sinuous; umbilical chink deep, rather widely open in some specimens; color pale horny, with sometimes a dark line at resting stages, dead specimens become chalky white. 


\begin{tabular}{|c|c|c|c|c|c|}
\hline $\begin{array}{l}\text { Length. } \\
29.50\end{array}$ & $\begin{array}{l}\text { Breadth. } \\
20.00\end{array}$ & $\begin{array}{c}\text { Aperture length. } \\
19.00\end{array}$ & $\begin{array}{l}\text { Brea } \\
12.00\end{array}$ & $\begin{array}{l}\text { dth. } \\
\text { mill. }\end{array}$ & 5 whorls. \\
\hline 35.00 & 27.00 & 21.00 & 12.50 & “ & Spire broken. \\
\hline 32.00 & 20.00 & 20.00 & 12.00 & “ & 4 whorls. \\
\hline 31.00 & 19.00 & 18.00 & $11: 00$ & “ & Dall, $3^{1} / 2$ whorls \\
\hline 41.00 & 23.00 & 24.00 & 15.50 & " & " 4 " \\
\hline 35.00 & 27.00 & 24.00 & 15.60 & “ & " 4 \\
\hline 16.00 & 10.00 & 9.50 & 6.00 & “ & (Juvenile.) \\
\hline 13.00 & 7.50 & 7.50 & 4.10 & “ & “ \\
\hline
\end{tabular}

Types: Chicago Academy of Sciences, one specimen, No. 23089; four specimens, No. 23090. Cotypes in Academy of Natural Sciences of Philadelphia, No. 88434.

Type Locality: Marsh Lake, near Dyea Valley, Yukon Territory.

Animal, Jaw, Radula and Genitalia: Unknown.

RANGE: (Figure 51). British Columbia north to Northern Alaska. Randolphi is a species of the Boreal life zone including the Arctic, Hudsonian and Canadian divisions. It is at present known from the drainage areas of the Yukon and Fraser rivers, which places it in the Alaskan, Yukonian and Columbian regions.

RECORDS.

Alaska and British America.

AlASKA: Nushagak River, lat. $59^{\circ}$ N., long. $159^{\circ}$ west (Arnheim); Kowak River (Dall; Stoney); lake near Cosmos River, north of the Kowak River, about lat. $68^{\circ}$ N. (Smith. Inst.); Alitah Lake, Alaska Peninsula (U. S. Fish Com.).

British Columbia: Lake La Hoche, Lillooet Dist. (Dall).

Yukon: Marsh Lake, near Dyea Valley; Lake Lindeman (Randolph); Francis Lake; Finleyson Lake; Lewes River (Whiteaves).

Geological Distribution: Unknown.

Ecology: In Marsh Lake (Randolph). The records show that this species is confined principally to lakes. Its habitat relations would seem to resemble those of Galba emarginata.

REMARKS: This is a very distinct species, not easily confounded with any other. It has a superficial resemblance to some forms of Galba emarginata mightlsi (Binney), but the angularity of the whorls, the constriction of the suture, the acute spire and the deep umbilical chink easily separates it from that species. From binneyi Tryon it differs in its angular whorls, constricted sutures and differently shaped aperture. In fully adult specimens the inner lip becomes very broad and erect and completely covers the axis, thereby obscuring the characteristic twist of the columella; but in young specimens the axis is 
slightly twisted, as is also the axis of the inner whorls of adult specimens. Young specimens resemble petersi but have a less number of whorls, besides differing in rotundity, the whorls of petersi being entirely without angularity. The umbilicus varies from a rather wide chink to a round hole, the aperture in specimens with this kind of an umbilicus being entire and almost separated from the body whorl. The

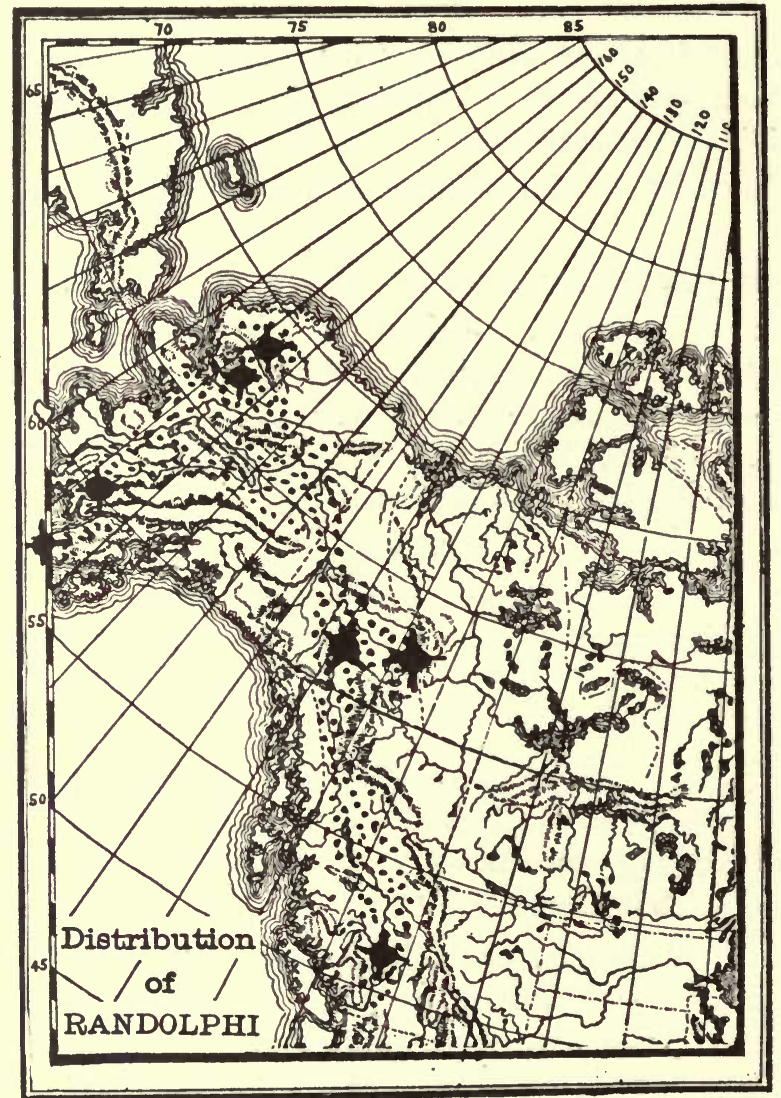

FIG. 51.

whorls vary greatly in angularity and in their general form. When perfect, randolphi is one of the finest of our American Lymnæas, attaining a length of an inch and a half ( 41 mill.).

The writer cannot agree with Dr. Dall in referring randolphi to Radix. Its affinities, judging by the shell alone, are entirely with the cmarginata group of the genus Galba. The specimens from near Coll- 
ville, mentioned by Dall (p. 71) are referred by the writer to binneyi (see page 443).

Galba alaskensis Baker. Plate XLVI, figures 14-15.

Limnaa scalaris Westerlund, Nach. Mal. Ges., IV, p. 165, 1883; Vega Exped., Vert. Iakt., IV, pp. 163, 170, 201, pl. 4, fig. 13, a, b, 1885 (not scalaris A. Braun, 1853, or Sowerby, 1872).

Lymnaa emarginata DALL, Alaska Moll., p. 69, 1905.

SHell: Elongated, thin, fragile, pellucid; periostracum light horn colored; surface shining, sculpture of coarse growth lines crossed by impressed spiral lines; whorls 6 , convex, especially the body whorl; sutures deeply impressed; spire long, acute; the spire whorls are abruptly narrowed and constricted above the body whorl; aperture long ovate or semicircular, a trifle shorter than the spire, roundly arched above, subtruncated below; inner lip narrow below, widening above to form the columellar callus which is heavy; the inner lip is appressed tightly at its junction with the parietal wall and forms a distinct ascending plait; the umbilical chink is narrowly open and is emargined by the inner lip.

$\begin{array}{cccc}\text { Length. } & \text { Breadth. Aperture length. } & \text { Diameter. } \\ 22.00 & 10.00 & 9.00 & 6.00 \text { mill. } \\ 23.00 & 12.00 & 10.50 & \ldots . .\end{array}$

TyPES: Location not ascertained.

Type Locality: Port Clarence, Alaska.

Animal, Jaw, Radula and Genitalia: Unknown.

RANGE: Alaska. A species of the Yukonian region and of the Arctic life zone.

\section{RECORDS.}

Alaska: Port Clarence (Westerlund).

Geological Distribution: Unknown.

Ecology: Not recorded.

Remarks: Alaskensis (scalaris) is undoubtedly a valid species and not a synonym of emarginata, as thought by Dr. Dall. Its narrow shell, acute spire, very deep sutures, causing tumid whorls, and its regularly long, ovate or semicircular aperture will at once separate it from any form of Galba emarginata canadensis, to which race it has a superficial resemblance. It is totally unlike Say's figure of emarginata besides which it occupies an entirely different river system. Young specimens might be confused with juvenile forms of randolphi, but could be easily distinguished by the more tumid whorls, deeper sutures and generally narrower shell and aperture. It somewhat resembles petersi, but may be known by its narrow shell and more tumid body whorl, besides differing in the form of the inner lip. 
Westerlund's original Latin description is as follows:

"Testa aperte rimata, elongata, tenuis, fragilis, pellucida, irregulariter striatula, pallide cornea, spira longa, supra anfractum penultimum tumidum abrupte angustata, valde contorta, apice acuta; anfr. 6 , perconvexi, sutura profundissima perobliqua disjuncti, superne subtruncati, tumidi, basin versus forte declivi, attenuati; apertura dimidiam testae non attingens, verticalis, subsemicircularis, margine exteriore forte arcuato, superne sinuato, medio producto, (columella cum) margine columellari substricto; verticali, late reflexo, umbilicum semitegente; columella incisura obliqua sat profunda, plica lata appressa."

Westerlund compares his species with Galba traski Tryon but is in error as that species belongs to a different group.

Galba petersi (Dall). Plate XXX, figure 29.

Lymnaa petersi Dall, Alaska Moll., p. 66, pl. 2, fig. 3, 1905.-Pilsbry, Nautilus, XIX, p. 95, 1905.

"Shell: Extremely thin, of five or more tumid rapidly enlarging whorls; spire acute, the sutures deep; whorls rounded, the periphery nearer the preceding suture; shell of a blackish brown, polished, finely, sharply, spirally striate; periostracum brownish, darker at resting stages; aperture oval, a thin wash of callus on the body; pillar very thin, gyrate, the gyrations pervious; the outer lip not thickened."

$\begin{array}{ccccc}\text { Height. } & \text { Breadth. Aperture length. } & \text { Breadth. } & \\ 16.00 & 8.00 & 8.50 & 5.20 \text { mill. } & \text { Type. }\end{array}$

Types: Smithsonian Institution, two specimens, No. 180332.

Type Locality: Koyukuk River, north of the Yukon in Alaska. Animal, Jaw, Radula and Genitalia: Unknown.

RANGE: Alaska, north of Yukon River; a species of the Yukonian region.

\section{RECORDS.}

Koyukuk River, north of the Yukon in Alaska (W. J. Peters).

Geological Range: Unknown.

Ecology: Not recorded.

REMARKs: "This very delicate and pretty species appears to belong to the typical Lymncea in spite of its small size; it has much the aspect of a minute $L$. randolphi, but has more whorls in less than half the height and is of quite a different color and without angularity to the whorls." (Dall).

Petersi can scarcely belong to the typical Lymnæas. Its close resemblance to young specimens of Galba randolphi would lead to the assumption that its proper position is near that species. A camparison 
of the type (plate XXX, fig. 29) with juvenile specimens of randolphi (plate XLVIII, figs. 7-8) well illustrates the relationship of the two species. Additional material of petersi is needed to satisfactorily determine its position. Until the animal of this species and that of atkaensis is examined the correct position of these species must remain purely conjectural. The form of the axis is that of the emarginata group of Galba rather than of typical Lymnca.

Galba atkaensis Dall. P1. XLVIII, figures 13-14.

Limncea ovata var. atkaensis DALL, Proc. Nat. Mus., VII, p. 343, 1884.

Limnaus atkinensis Clessin, Conch. Cab., p. 390, taf. LIII, fig. 11, 1886 (figure not typical).

?Limnaa ovata DalL, Report Fur Seal Inves., III, p. 544, 1866; Nautilus, XIII, p. 132, 1900.

Lymncea atkaensis DalL, Alaska Moll., p. 66, pl. 2, figs. 7, 9, 1905.

SHELL: "With about four ovate whorls rapidly increasing, of a ciark olive sometimes purplish tint, very thin, malleated, miscroscopically reticulated, with obscure revolving ridges; the aperture ovate, not expanded, the margins thin, that on the pillar narrowly reflected; pillar gyrate, pervious, in the early whorls widely so, a condition concealed in the adult." (Dall).

\begin{tabular}{|c|c|c|c|c|c|c|c|}
\hline Length. & Breadth. & Aperture length. & Bre & adth. & & & \\
\hline $\begin{array}{l}26.50 \\
24.00\end{array}$ & $\begin{array}{l}16.50 \\
1300\end{array}$ & $\begin{array}{l}16.50 \\
14.00\end{array}$ & $\begin{array}{r}10.50 \\
9.20\end{array}$ & $\underset{\text { mill. }}{ }$ & $\begin{array}{l}4 \\
3 \mathrm{I} /\end{array}$ & $\begin{array}{c}\text { whorls, } \\
\text { “" }\end{array}$ & Dall. \\
\hline 17.00 & 11.50 & 11.20 & 7.50 & “ & $41 / 2$ & “ & \\
\hline 22.00 & 16.00 & 15.50 & 9.00 & " & Тур & 29031 & \\
\hline
\end{tabular}

Types: Smithsonian Institution, two specimens, No. 29031.

Type Location: See records.

Animal, Jaw, Radula and Genitalia: Unknown.

RANGE: Aleutian Chain, Alaska; a species of the Alaskan region. RECORDS.

Lake on the Island of Atka, Aleutian Chain, near Korovin Bay (Dall).

Geological Distribution: Unknown.

Ecology: Not recorded.

REMARKS: "This form grows in a region containing little lime, and the shells are extremely thin and often eroded into holes, which exhibit the peculiarities of the axis by which the species is relegated to the typical Lymnæas though externally it has much the appearance of a small Radix." (Dall).

This is a wider species than petersi, with less rotund whorls and a shorter spire, and with a rounder aperture. The writer cannot agree with Dr. Dall in placing this species in Lymnca. The axis is more of 
the twisted type of Galba than of the gyrate.type of Lymncea, and the whole shell suggests the emarginata group of the genus Galba.

\section{Subgenus POLY̌RHYTIS Meek, 1876.}

1876. Polyrhytis Meek, Rep. U. S. Geol. Surv. Terr., IX, p. 532. (Limnaa kingii Meek.)

1877. Polyrhytis MeEk, Exp. 40th Parallel, Pal., pp. 192, 193.

1844. Polyrhytis TrYon, S. and S. Conch., III, p. 101.

1905. Polyrhytis Dall, Mollusks of Alaska, p. 64.

1908. Polyrhytis BAKer, Science, N. S. XXVII, No. 703, p. 943.

SHELL: With well-marked longitudinal folds or ribs; spire broadly acute, generally shorter than aperture; axis twisted; columella lip broadly expanded, obscuring the fold more or less; umbilical chink well marked.

Animal, Jaw, Radula and Genitalia: Unknown.

Distribution: Pliocene to recent fauna.

Meek's Polyrhytis would seem to be a well marked division of the Lymnæids, characterized by a longitudinally ribbed, ventricose shell. Call's Lymnea utahensis answers well to the diagnosis of Polyrhytis and is accordingly placed here. As remarked by Meek (Exp. 40th Parallel Pal., p. 193) Polyrhytis bears somewhat the same relation to Lymnaa that Costella Dall bears to Physa. No other recent Lymnca at all resembles utahensis in the possession of this peculiar sculpture which is probably produced by the unfavorable character of their habitat, as remarked by Call.

Polyrhytis is placed tentatively near Stagnicola. The genitalia and radula of utahensis are unknown and until these are published the group cannot be definitely placed.

Galba utahensis (Call). Plate XXII, figures 9-11; plate XXIV, figures 22-2\%.

Radix ampla var. utahensis CALL, Bull. U. S. Geol. Surv., II, pp. 373, 379, 381; p. 401, pl. 6, figs. 7-9, 1884.-KEeP, West American Sh., pp. 149, 314, 1904.

Radix utahensis Call, Proc. Davenport Acad. Sci., V, p. 5, pl. 1, figs. 7-9, 1886.

Limnca ampla var. utahensis Stearns, Proc. Nat. Mus., XXIV, p. 291, 1901.

?Limnaa catascopium Ingersoll, Proc. Daven. Acad. Sci., II, p. 132, 1877.

Radix ampla Gilbert, Mon. U. S. Geol. Surv., I, p. 298, 1890.

Lymnaa utahensis Sterki, Nautilus, XXII, p. 142, 1909.

SHell: "Globose, somewhat umbilicated, irregularly costate, light horn color, nearly pellucid; spire rather small, conical; whorls four to four and one-half, convex, rather flattened above, giving rather a 
shouldered appearance to the whorls, rapidly increasing in size, the last whorl being inflated with numerous rather marked transverse costæ, minutely wrinkled; suture somewhat deep, regularly impressed; aperture elongately ovate, effuse, approaching patulous, pearly white within; outer lip simple, the margin connected by a slight calcareous deposit ; columella somewhat twisted, but straight in front." (Call).

Length. Breadth. Aperture length. Breadth.

$\begin{array}{lllll}13.40 & 7.10 & 9.00 & 5.90 \text { mill. (Call.) } \\ 16.82 & 8.88 & \ldots . & \ldots . & \text { “ } \\ 13.40 & 7.10 & \ldots . & \ldots . & \text { average of } 9 \text { spec. (Call). } \\ & & \ldots & \end{array}$

Shell: Varying from globose to elongate-ovate, rather solid; color (of dead shells) white; surface dull, lines of growth heavy, wide, somewhat regular and in some cases equidistant; surface of body whorl with numerous heavy, rounded, irregularly placed ribs or costæ; the surface is minutely wrinkled but distinct spiral lines cannot be seen in the specimens examined; apex small, smooth, roundly flattened, spermaceti-white in color; whorls $4-4 \frac{1}{2}$, convex, rapidly enlarging, sometimes slightly shouldered; spire broadly or sharply conic, varying in length from one-third to one-half the length of the shell, flattened or pointed in different specimens; sutures deeply impressed; aperture varying from round to elongate-ovate, in some specimens somewhat effuse; peristome thin, sometimes internally thickened; parietal wall with a heavy callus which is more or less erect, leaving a well-defined umbilical chink; axis thickened, only slightly twisted and with a faint plait. (Phil. Acad. specimens).

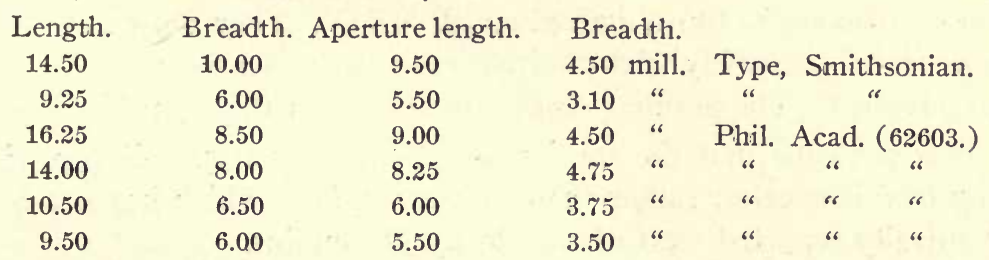

Types: Smithsonian Institution, four specimens, No. 31276.

Type Locality: Lake Utah, Lehi, Utah.

Animal, Jaw, and Genitalia: Not recorded.

RAdula: Call says, "The dentition differs from typical $R$. ampla Mighels very materially," but he does not say in what manner. In another place (T. c. pp. 47, 48) he says, "dentition unpublished."

RANGE: Utah. The relation of this species to the fauna of the ancient Lake Bonneville is not clearly known. There is reason to believe that it is a descendant of the Pliocene Lymnaa Kingii. From the records it would seem that it is a new species evolved since the dep- 
osition of the Bonneville beds. Further study is needed to satisfactorily elucidate the relationship of this curious species.

\section{RECORDS.}

Utah: Utah Lake, near Lehi, Utah Co. (Call); Bear Lake, Rich Co. (Hayden Survey; Walker); Spring Lake (Phil. Acad.); Utah Lake (Ingersoll).

Geological Range: Pleistocene.

\section{RECORDS.}

UTAH: Bear Lake, Rich Co. (Hayden Survey; Sterki).

Ecology: "Dredged in Utah Lake in August, 1883." (Call).

Remarks: This curious form, dwarfed and peculiarly sculptured by its unfavorable environment, seems to be a representative of Polyrhytis Meek. The species closely resembles, in many respects, the Lymnca kingii of Meek, from the Tertiary formation of Cache Valley, Utah, as pointed out by Call (T. c., p. 381). It has no relation, however, to Galba mighlesi (ampla) as stated by Call. The axial costæ are irregular, elevated and in many examples very conspicuous. The spire varies from long and pointed to short and wide and the aperture is modified correspondingly. The costæ are not always developed, some specimens (pl. XXIV, fig. 23) being almost smooth. The costæ, however, may be detected in all specimens, though the development is but slight in some individuals.

Call's figures (reproduced on pl. XXII, figs. 9-11) do not agree very well with the type specimens in the Smithsonian Institution, which correspond to those figured on pl. XXIV. They must have been drawn from extremely short-spired specimens, scarcely to be considered typical. The peculiar costæ will at once distinguish this species.

It is probable that the specimens recorded by Ingersoll (op. cit.) belong to this species, rather than to catascopium, which has not been authentically reported west of the Rocky Mountains.

\section{Subgenus LEPTOLIMNAEA Swainson, 1840.}

Leptolimncea Swainson, Malac., p. 338, 1840. Type, L. clongata, Sowerby $=$ L. glaber (Müller).

Leptolimnca Haldeman, Mon. Lim., p. 6, 1844 (part).

Leptolimncea Mörch, Vidensk. Meddel. Kjob., p. 298, 1864.

Leptolimnea Binney, L. \& F.-W. Sh. N. A., II, p. 67, 1865 (part).

Leptolimncea Tryon, Con. Hald. Mon., p. 87 (61), 1872 (part).

Leptolimncea TrYon, S. \& S. Conch., III, p. 101, 1884.

Leptolimncea Dall, Alaska Moll., pp. 62, 64, 1905.

Leptolimncea BAKer, Science, n. s., XXVII, p. 943, 1908.

Leptolimnaus Sandberger, Land U. Süssw. Conch. d. Vorwelt, p. 787, 1875 ; sole example cited $L$. glaber (Müller). 
Omphiscola Beck, Index, p. 110, 1833 (L. glabra Müller), H. \& A. Adams, Genera Rec. Moll., II, p. 255, 1855.

Omphiscola Meek, Rep. U. S. Geol. Surv. Tẹrr., IX, p. 533, 1876 (not of Raf.).

Shell: Very long, cylindrical; spire with numerous closely coiled whorls; aperture very small; axis twisted (plate XLVIII, figure 4).

Animal, Jaw, Radula and Genitalia: Not examined.

REMARKS: Leptolimnaa differs from Stagnicola in its cylindrical shell, numerous closely coiled whorls and comparatively small aperture. What its anatomical relations may be is not known, specimens of the animal not being available for study. Leptolimnea appears to constitute a group of subgeneric importance. So far as known, no representatives of this group have been found in America. 


\section{SPURIOUS AND UNIDENTIFIABLE SPECIES.}

The following pages include a list, with notes, of all the unidentifiable and spurious species of North American Lymnæas. Some of these names were founded on foreign species erroneously referred to America, several have been ascertained to belong to other families while a large number are nude names of which no description has ever been published. The list is quite extensive and it is believed that all of the questionable species are recorded.

\section{Limnæa bombycina Lunge.}

Limnca bombycina Lunge, Woon, Nautilus, V, p. 56, 1891.-KeEP, West Amer. Sh., p. 314, 1904.

Mr. William J. Raymond, of Oakland, California, has kindly given the following information concerning this reference:

"The name was inserted in our list of 'Mollusks of San Francisco County' by Mr. Wood. I do not know the species, but am under the impression that we thought it, or rather Mr. Wood, an oriental species, introduced into San Francisco, perhaps with living fish or aquatic plants. The describer was probably Dr. De Lunge, an eccentric collector, who died several years ago. His collection, or a part of it, is now in possession of the University of California, of which I am a member." No other information has been obtained concerning this species. As no description was published it must fall into the list of nude names.

Limnæa elliptica "Lea" Sowerby.

Limnca elliptica LeA, Sowerby, Conch. Icon., XVIII, Limn., sp. 61, pl. 9, fig. $61, \mathrm{a}, \mathrm{b}, 1872$.

Mr. E. A. Smith has informed Mr. Bryant Walker that the original specimens of this species, in the British Museum, quoted by Sowerby from Lake Madison, Michigan, are a form of Succinea from Lake Madison, Wisconsin. The name elliptica Lea is an error of Sowerby's, for Lea never described a Lymnæa of that name. There is a Physa clliptica Lea, and this is possibly the name Sowerby had in mind.

Lymnea heterostropha C. B. Adams.

Lymnea heterostropha, C. B. AdAms, Amer. Journ. Sci., XXXVI, p. 392, 1839.-Binney, L. \& F.-W. Sh. N. A., II, p. 70, 1865.

This may have been a lapsis pennæ for Physa heterostropha, but as the latter species is also mentioned, it is quite impossible to know just what species was in the mind of Prof. Adams. 


\section{Lymnea lubricoides Lea.} 1859.

Lymnea lubricoides LEA, Exp. in Nebraska, Warren's Rep., II, pt. 3, p. 724,

Limnaa lubricoides Binney, L. \& F.-W. Sh. N. A., II, p. 71, 1865.

This species is listed by Lea from Grindstone Creek, Nebraska. So far as known, it has not been described, nor are the specimens to be found. It is, therefore, a nude name.

Limnæa palmeri Dall.

Limnaa palmeri DALl, Amer. Journ. Conch., VII, p. 135, 1871.-FISCHER \& Crosse, Mis. Scient. Mex., Moll., II, p. 51, 1880.-Martens, Biol. Cent. Amer. Moll., p. 377, 1899.-Pilsbry, Proc. Phil. Acad., p. 777, 1903.

This species is now referred to the marine genus Recluzia by Dr. Dall.

Limnea platystoma Hald.

Limnea platystoma Hald., Suppl. to Mon., pl. 1, p. 2, 1840.

Lymnaa platystoma Wheatley, Cat. Sh. U. S., Ed. 2, p. 23, 1845.

Limnæa platystoma Binney, Check List, p. 12, 1860 ; L. \& F.-W. Sh. N. A., II, p. 72, fig. 116, 1865.-TRYoN, Amer. Journ. Conch., III, p. 196, 1867 ; Con. Hald. Mon., p. 115 (89), 1872.

This species is the common Lymncea ovata of Europe. The two criginal specimens in the Philadelphia Academy (No. 58461) are marked "Maine or Marseilles." A single specimen in the Smithsonian Collection (No. 9744) is the same. The specimens were either introduced or had become mixed with American shells.

Limnæa rugosa Valenciennes.

Limncea rugosa VAL., in Humb. \& Bonp., Rec. d. Obs., II, p. 250, pl. lvi, fig. 5, 1833.-HALd., Mon. Lim., p. 15, pl. 3, figs. 4-5, 1842.-DEKAY, Zool. N. Y., p. 75, 1843.-Binney, Check List, p. 12, 1860 ; L. \& F.-W. Sh. N. A., II, p. 71, fig. 115, 1865.-Tryon, Con. Hald. Mon., p. 114 (88), 1872.

Limnceus rugosus Küster, in Chemn., Ed. 2, p. 38, pl. viii, figs. 3, 4, 1862.

This species is the immature form of Otostomus dombeyanus Fer. (Bull. Zool., p. 33, 1835) vide Von Martens, Biol. Cent. Amer., p. 199, 1892.

Lymnæa virginiana Lamarck.

Lymnca virginiana LAM., An. Sans Vert., VI, pt. I, p. 160, 1822.-Desh., Lam., An. Sans Vert., VIII, p. 411, 1838.-ReEve, Elements of Conch., p. 179, 1860.

Lymnea virginiana Delessert, Rec. des. Coq., pl. 30, fig. 4, 1841.

Limnaa virginiana Desh., Encyc. Meth., II, p. 362, 1830.-BInNey, L. \& F.-W. Sh. N. A., II, p. 55, fig. 84, 1865.-Tryon, Amer. Journ. Conch., III, p. 196, 1867.

Lymnaa catascopium var. virginiana JAY, Cat., p. 268, 1852.

This species can scarcely be American. It was said to be an Asiatic species by Tryon. It seems to be the same as Lymnca spadicea 
Morelet, which occurs in Siam and Cochin China. A mixing of labels may have led Lamarck to refer it to "the fresh waters of Virginia." No specimens of American or European species have been seen at all comparable with it; it is of the type of shell occurring abundantly in Indo-China.

\section{Limnea vitrea Haldeman.}

Limnea vitrea HALD., Mon. Lim. pt. 4, cover p. 3, 1841; p. 47, pl. 13, figs. 14, 15, 1842.-DeKAY, Zool. N. Y., p. 75, 1843.

Limnca vitrea Binney, Check List, p. 12, 1860 ; L. \& F.-W. Sh. N. A., II, p. 60, fig. 93, 1865.-Sowв., Conch. Icon., XVIII, Lim., pl. 14, fig. 94, 1872 (poor figure).-Tryon, Con. Hald. Mon., p. 106 (80), 1872.

Limnophysa vitrea TRYON, Amer. Journ. Conch., I, p. 255, 1865.

Limnaus vitreus KüsteR, Conch. Cab., p. 50, taf. 11, figs. 11, 12, 13, 14, 1862.

"Shell ovate, extremely thin and delicate; surafce smooth and polished; lines of growth very fine; aperture ample; the labium presents a well marked fold, and is not appressed anteriorly; spire short.

"Geographical Distribution: Ohio? Missouri?

"Foreign analogue. L. tenuis, Bronn.

"This species presents us with a shell which is probably thinner in texture than that of any other we have. For the specimens figured I am indebted to Mr. G. B. Emerson, president of the Boston Society of Natural History." (Haldeman.)

Haldeman's types of this species are in the Philadelphia Academy (No. 598\% 2 , two specimens). Figure 15 of Haldeman's original plate scems to be a form of columella. Figure 14 is a different form and may have been an introduced Indian species. Figure 15 measures as follows : mill.

Length, 12.00 ; breadth, 6.00 ; aperture length, 6.75 ; breadth, 3.50

The species is a composite one, judging from the types. It might possibly be included in columella in part.

\section{Lymnæa Sp.}

Limnca desidiosa Sterki, An. Rep. Geol. Surv. Texas, III, p. 263, 1901.

"About ten small specimens, for the most part damaged, of a slender form, distinctly umbilicated, with well rounded, somewhat shouldered whorls and deeply impressed suture, can hardly be ranged under any other species, although, even when mature, they certainly were of small size."

In the absence of the specimens, which have not been obtainable by the writer, it is impossible to ascertain which one of the southern forms of Lymnæa this may have been. 


\section{Lymnæa Sp.}

Limncea sp. WatKer, An. Rep. Mich. Geol. Surv., 1908, p. 291, 1909.

Isle Royale: III, 3, Bulrush Zone at western end of Rock Harbor, No. 163 ; IV, 2, Island No. 14 in Tobin Harbor, No. 126.

At both of these localities occurred a few dead, fragmentary and more or less decayed specimens, which could hardly be referred to any of the species listed above, and yet were too imperfect to successfully identify. (Walker).

\section{Lymnæa pyramidata Sowb.}

Limnaa pyramidata Sowв., Conch. Icon., sp. 58, pl. 6, fig. 35, 1872.

No locality is mentioned for this species. The figure resembles Galba clodes jolietensis. Mr. E. A. Smith has expressed to Mr. Walker his belief that it is a monstrosity of reflexa.

\section{Limnæa terræ-novæ Lesson.}

Limnaa terranova Lesson, Rev. Zool., p. 356, 1840.-Binney, Journ. de Conch., XV, p. 428, 1867.

As remarked by Binney, the affinites of this species are very doubttul.

\section{Limnæa præcellens West.}

Limnaa pracellens West., Ann. Mus. St. Petersburg, p. 177, 1898.

No information has been obtained concerning this species.

Galba. Species indet. Plate XXX, figures 21-24.

SHELL: Small, ovate, turreted; periostracum yellowish horn color; surface shining; growth lines conspicuous, crowded; spiral lines absent; whorls 5, rapidly enlarging, the body whorl quite globose; spire short, broadly turreted, the whorls inclining to be shouldered; aperture ovate or roundly ovate, somewhat oblique, about as long as the spire; outer lip thin; inner lip evenly rounded, erect; umbilical chink widely open; there is no plait on the columella.

\begin{tabular}{ccccc} 
Length. & Breadth. Aperture length. & \multicolumn{2}{c}{ Breadth. } \\
6.00 & 3.25 & 3.00 & 2.00 mill. \\
6.00 & 3.25 & 3.00 & 1.75 " \\
6.00 & 3.25 & 2.75 & 1.75 "
\end{tabular}

TyPes: Chicago Academy of Sciences, four specimens, No. 24,545 .

Type Locality: Greenhouse, Boulder, Colorado.

Animal: "Greenish-gray, foot very pale; dorsum darkened and distinctly orange in the middle line; eyes black, large; tentacles short, triangular." (Cockerell).

Remarks: This peculiar little Lymnæa was found in a greenhouse in Boulder, Colorado, by Dr. T. D. A. Cockerell. It is unlike 
any American shell which the writer has seen and it is probably an introduced species. It somewhat approaches Galba parva, being distinguished, however, by its short, wide spire and by its widely open umbilical chink and very erect inner lip. The obliquity of the aperture is also peculiar. It has not been thought best to give a name to this Lymnæa, as it may have been previously named by some European malacologist. It bears a close resemblance to some European figures of Galba truncatula, but differs markedly from all specimens of that species which have been examined, in the shape of the body whorl and inner lip.

\section{NUDE NAMES.}

Limnaa alternata SAy, Berl, Rep. Prog. Can. Geol. Surv., p. 252, 1858.Binney, L. \& F.-W. Sh. N. A., II, p. 72, 1865.-Whiteaves, Can. Nat. \& Geol., VIII, p. 103, 1863. From Point Levis, Canada.

L̇imnca conoidea SAY, H. \& A. Adams, Genera Rec. Moll., II, p. 253, 1858.Binney, L. \& F.-W. Sh. N. A., II, p. 71, 1865.

Limnaa corrugata SowB., Tank Cat., p. 42, 1825.-Binney, L. \& F.-W. Sh. N. A., II, p. 71, 1865.

Limnca cygmata SAY, Christy, Journ. Conch., IV, p. 347, 1885. From Dufferin, Manitoba (Dawson).

Lymnea gracilis DeKAY, Cat. An. N. Y., p. 32, 1839.-BinneY, L. \& F.-W. Sh. N. A., II, p. 70, 1865.

Limnaa fossaria J. de C. SowB., Fauna Bor.-Amer., p. 316, 1836.-Binney, L. \& F.-W. Sh. N. A., II, p. 70, 1865.-Dall, Alaska Moll., p. 80, 1905.

Limnea lineata SAY, H. \& A. Adams, Gen. Rec. Moll., II, p. 253, 1858.Binney, L. \& F.-W. Sh. N. A., II, p. 71, 1865.

Limnca minuta C. B. AdAms, Cat., p. 32, 1847.

Lymnea nigrescens DeKAY, Cat. An. N. Y., p. 32, 1839.-BinneY, L. \& F.-W. Sh. N. A., II, p. 70, 1865.

Lymnca ovata LAM., Hiтch., Geol. Zool. Mass., p. 37, 1835.

Limncea petitii Beck, Index, p. 113, 1838.-Binney, L. \& F.-W. Sh. N. A., II, p. 71, 1865.-DALL, Alaska Moll., p. 80, 1905.

From Newfoundland.

Omphiscola pugio Beck, Index, p. 113, 1838.-Binney, L. \& F.-W. Sh. N. A., II, p. 71, 1865

From Mexico.

Lymnea reticulata DeKAY, Cat. An. N. Y., p. 32, 1839.-BINNEY, L. \& F.-W. Sh. N. A., II, p. 70, 1865.

The following species, described originally under Limncea, are now referred to other genera:

Limnaa decisa SAY, Nich. Encyc., Ed. 1 and 2, pl. ii, fig. 6=Campeloma decisa Say.

Limnea heterostropha SAY, 1. c., pl. i, fig. 6= Physa heterostropha Say.

Limnca subcarinata $\mathrm{SAY}$ 1. c., pl. i, fig. $7=$ Lioplax subcarinata Say. 
Limnca virginica SAY, 1. c., pl. ii, fig. 4=Goniobasis virginica Say.

Limncea vivipara SAY, 1. c., pl. i, fig. $5=$ Vivipara contectoides W. G. Binney.

In the Journal de Physique, de Chemie, et d'Histoire Naturelle, volume LXXXVIII, June, 1819, -occur the following descriptions of new genera by C. S. Rafinesque. These are not Lymnæas, nor any other of the fresh water pulmonates, but probably Succinea or some other marsh-loving pulmonate. The description of Espiphylla reads very like that of Succinea. For the sake of completeness the descriptions of these genera are reproduced, as given by Binney, Land and Fresh-Water Shells, II, p. 70.

"Espiphylla, 1. c., p. 423.-Differing from Lymnula (Lymnea, Auct.) by its rounded aperture and its claviform tentacles carrying the eyes at their end. Family Lymnida. Only one lacustrine species, E. nympheola.

"Cyclemis, 1. c., p. 424.-Differs from Lymnula by its rounded shell of two or three slightly oblique whorls. Aperture large, almost round. Animal like that of Espiphylla? Two lacustrine species, C. minutissima and C. olivacea.

"Lomastoma, 1. c.-Shell acute, pyramidal. Aperture oblong, base obtuse, summit sharp, entirely surrounded by a detached, marginal, acute lip, which is decurrent and inflected at the junction of the summit; no operculum or umbilicus. Animal unknown. Singular genus of the family Lymnida? One only known species, L. terebrina. Shell subulate, smooth, four whorls, pale red; aperture one-third the shell's length, breadth one-third of its length. Very rare. In brooks."

In a volume on "Sketches of Louisville," by Dr. McMurtrie, the following shells are listed by Rafinesque. These may not all be true Lymnæas. They occur on page 66 .

Lymnula eburnea Rafinesque.

Lymnula lithophila Rafinesque.

Lymnula retusa Rafinesque.

Lymnula turricula Rafinesque.

Lymnula ventricosa Rafinesque. 


\section{BIBLIOGRAPHY.}

The following list of references to North American Lymnæas is believed to be measurably complete. Absolute completeness cannot be claimed, as it is quite probable that some references have escaped the writer's notice, either because of inaccessible or obscure publication, or of oversight on the part of the author. It is believed, however, that the list includes all of the important references to this subject:

Adams, Charles B.

1839. Shells of Fresh Pond. Amer. Journ. Sci., O. S., XXXVI, No. 2, p. $392,1839$.

1840, a. Description of Shells. Amer. Journ. Sci., O. S., XXXIX, No. 2, pp. 373-375.

1840, b. Descriptions of Thirteen New Species of New England Shells. Bost. Journ. Nat. Hist., III, No. 3, pp. 318-331.

1841, a. Catalogue of the Mollusca of Middlebury, Vermont, and Vicinity; with Observations. Amer. Journ. Sci., O. S., XL, No. 2, pp. 266-277.

1841 , b. See Mighels.

1842, a. Fresh-water and Land Shells of Vermont. Thampson's History of Vermont, pt. 1, pp. 151-169; pamphlet, pp. 1-19.

1842, b. See Mighels, 1842.

1846. Memoir on Mollusca of Jamaica. Proc. Bos. Soc. N. Hist., II, p. 133.

1847. Catalogue of the Genera and Species of Recent Shells in the Collection of C. B. Adams, A. M., Middlebury, Vermont.

1849. Contributions to Conchology, No. 3, p. 45, Oct. Catalogue of the Fresh-Water Shells which Inhabit Jamaica; same title, No. 9, p. 187.

1852. Catalogue of the Fresh-Water Shells which Inhabit Jamaica. Ann. N. Y. Lyc. Nat. Hist., V, p. 111.

1854. Shells of the Exploration of the Red River of Louisiana, by Capt. Marcy, pp. 242-244.

Adams, Charles C.

1901. Baseleveling and its Faunal. Significance, with Illustrations from Southeastern United States. Amer. Nat., XXXV, pp. 839-852.

1902 , a. Postglacial Origin and Migration of the Life of the Northeastern United States. Journ. of Geography, I, pp. 303-310, 352-357.

1902, b. Southeastern United States as a Center of Geographical Distribution of Flora and Fauna. Biological Bulletin, III, pp. 115-131.

1905. The Postglacial Dispersal of the North American Biota. Biological Bulletin, IX, pp. 53-71.

1906. An Ecological Survey in Northern Michigan. Rep. State Board of Geological Survey, Michigan, 1905.

1909. Isle Royale as a Biotic Environment. Rep. Geol. Surv. Mich., 1908, pp. 1-53.

Aldrich, Truman $\mathrm{H}$.

1868. Partial List of Shells Found near Troy, New York. Rep. N. .Y. State Cab. N. H., XXII, pp. 17-24. 
Ami, Henry M.

1897. Contribution to the Palæontology of the Post Pliocene Deposits of the Ottawa Valley. Ottawa, Nat., XI, p. 20, 1897.

Anderson, Robert.

1907. See Arnold, Ralph.

Andre, Emile.

1901. Note sur une Limnée de la fauna profunde du lac Léman. Journ. Malac., VIII, p. 35.

Arnold, Ralph, and Anderson, Robert.

1907. Geology and Oil Resources of the Santa Maria Oil Distriot, Santa Barbara County, California. Bull. U. S. Geol. Surv., No. 322, 1907.

1908. New and Characteristic Species of Fossil Mollusks from the Oilbearing Tertiary Formation of Santa Barbara County, California. Smith. Mis. Coll., L, p. 419, 1908.

(Review in Nautilus, XXII, p. 36.)

Anonymous.

1837. Miscellaneous Observations made during a Tour in May, 1835, to the Falls of Cuyahoga, near Lake Erie; Extracted from the Diary of a Naturalist. Amer. Journ. Sci., O. S., XXXI, No. 1, pp. 35-36, January.

1857. Description of some of the Fresh-Water Gastropods Inhabiting the Lakes and Rivers of Canada. Can. Nat. \& Geol., II, pp. 195-215.

1872. List of Long Island Mollusca, Presented to the State Museum. An. Rep. N. Y. State Mus. N. H., XXV, pp. 35-38.

1875. List of Gould Types of Mollusca in the Collection of the State Museum. An. Rep. N. Y. State Mus. N. H., XXVII, pp. 47-55.

1876. New Shells from Colorado. Pop. Sci. Mon., X, p. 248.

1882, a. List of Shells Presented to the State Museum by Dr. James Lewis, March 15, 1875. An. Rep. N. Y. State Mus. N. H., XXXV, pp. 112-117.

1882, b. Parasite of Limnæa Truncatula, Journ. Conch., III, p. 329.

1883. The Circumpolar Distribution of Certain Fresh-Water Mussels, and the Identity of Certain Species. Amer. Nat., XVII, pp. 203-204.

1886. Deep-Water Fauna of Lake Léman. Amer. Nat., XX, p. 391.

1890. List of the Land and Fresh-Water Mollusca of Ottawa as Recorded in the Transactions of the Ottawa Field Naturalists' Club, up to April 1, 1890. Ottawa Nat., IV, p. 54.

1895. Casselman Shells. Ottawa Nat., IX, p. 156.

1898. A Preliminary Catalogue of the Collections of Natural History and Ethnology in the Provincial Museum, Victoria, British Columbia. Mollusca, pp. 83-106. Published by the Museum.

1900. The Mollusk Fauna of the Pribilof Islands. Review, Nautilus, XIII, p. 132.

1902. Limnæa Auricularia in America. Nautilus, XVI, p. 58, September.

1903. Niagara River Shells. Ottawa Nat., XVI, p. 205.

1906. Lymnea Megasoma Say. Nautilus, XX, p. 36.

Anthony, John G.

1843. List of Land and Fresh-Water Shells Found Chiefly in the Vicinity of Cincinnati. Cincinnati, Ohio. First edition, no date. Second edition, Jan. 1, 1843. 
Arango, Rafael.

1865. Catalogo de los Moluscos terrestres y fluviatiales de la Isla de Cuba. In Poey's Repertorio Fisico-Natural de la Isla de Cuba, I, p. 71.

1866. Conspectus familiarum et index Molluscorum terrestrium et aquarum dulcium insulæ Cubæ. L. c., II, p. 73.

1868. Apendice a los Moluscos terrestres y fluviales de la Isla de Cuba. L. c., II, p. 269.

Ashley, George H.

1900. See Blatchley, W. S.

Aughey, Samuel.

1876. The Superficial Deposits of Nebraska. An. Rep. U. S. Geol. \& Geog. Surv. Colo. and adjoining Territory, 1874, pp. 243-269.

1880. Sketches of the Physical Geography and Geology of Nebraska, 8vo., p. 326,1880 .

Baird, W.

1863. Descriptions of some New Species of Shells Collected at Vancouver Island and in British Columbia by J. K. Lord, Esq., Naturalist to the British North American Boundary Commission, in the Years 1858-1862. Proc. Zool. Soc. London, p. 66.

Bailey, Albert.

1891. Shells of Erie Canal. Nautilus, V, p. 23.

Baker, Frank Collins.

1895, a. The Geographical Distribution of the Mollusca. Science, N. S., II, pp. 179-183, August 16.

1895, b. A Naturalist in Mexico. Chicago, 1895.

1897, a. On the Pulsations of the Molluscan Heart. Journ. Cin. Soc. N. H., XIX, pp. 73-78.

1897, b. Notes on Radulæ. Journal Cin. Soc. N. H., XIX, pp. 81-92.

1897 , c. On a Collection of Mollusks from Grand Tower, Illinois. Nautilus, XI, pp. 28-30, July.

1897, d. Collecting about Chicago. Sports Afield, XIX, pp. 112-113, August; same, The Museum, p. 153.

1898; a. The Molluscan Fauna of Western New York. Trans. Acad. Sci. St. Louis, VIII, pp. 71-94.

1898, b. A Day on the Chicago Drainage Canal. Nautilus, XXII, pp. 63-65, October.

1899, a. Notes on the Mollusks of Lilycash Creek. Natitilus, XIII, pp. 30-31, July.

1899, b. Notes on the Mollusca of Owasco Lake, N. Y. Nautilus, XIII, pp. 57-59, September.

1900 , a. Notes on a Collection of Pleistocene Shells from Milwaukee, Wisconisin. Journ. Cin. Soc. N. H., XIX, pp. 175-177.

1900, b. The Gross Anatomy of Limnæa Emarginata, Say, var. Mighelsi, Binney. Bull. Chi. Acad. Sci., II, No. 3, pp. 189-224.

1900 , c. On a Collection of Fresh-Water Shells from Rhode Island. Nauti$\because$ lus, XIII, pp. 112-113, February.

1900, A. Shell Collecting near Rochester, N. Y. Nautilus, XIV, pp. 69-71, October. 
1901, a. A Revision of the Limnæas of Northern Illinois. Trans. Acad. Sci., St. Louis, XI, pp. 1-24.

1901, b. Description of a New Species of Limnæa. Bull Chi. Acad. Sci., II, No. 4, pp. 229-230.

1901, c. The Molluscan Fauna of the Genesee River. Amer. Nat., XXXV, pp. 659-664, August.

1901, d. New Varieties of Fresh-water Shells. Nautilus, XV, pp. 17-18, June.

1901, e. Limnæa Auricularia in America. Nautilus, XV, p. 59, September. 1902. The Mollusca of the Chicago Area. Part II, Gastropoda. Bull. Nat. Hist. Surv. Chi. Acad. Sci., No. III, pt. 2.

1903, a. Shells of Land and Water. A Familiar Introduction to the Study of Mollusks, Chicago.

1903, b. Shell Collecting on the Mississippi. Nautilus, XVI, pp. 102-105, January.

1903, c. Pleistocene Mollusks of White Pond, New Jersey. Nautilus, XVII, pp. 38-39, August.

1904, a. Mollusks of Cedar Lake, Indiana. Nautilus, XVII, p. 112-113, February.

1904, b. New Varieties of American Limnæas. Nautilus, XVIII, pp. 10-12, May.

1904, c. New American Limnæas, II. Nautilus, XVIII, pp. 62-63, October. 1904, d. The Molluscan Fauna of the Dells of Wisconsin. Trans. Acad. Sci., St. Louis, XIV, pp. 99-105.

1905 , a. Critical Notes on the Smaller Lymnæas. Nautilus, XVIII, pp. 125-127, March.

1905, b. New Species of Lymnæa. Nautilus, XVIII, pp. 141-142, April.

1905, c. Notes on a Collection of Shells from Bass Lake, Indiana. Nautilus, XIX, pp. 27-28, July.

1905, d. A New Species of Lymnæa from Ohio, with Notes on Lymnæa Parva, Lea. Nautilus, XIX, pp. 51-53, September.

1905, e. The Molluscan Fauna of McGregor, Iowa. Trans. Acad. Sci. St. Louis, XV, pp. 249-257.

1905, f. Notes on the Genitalia of Lymnæa. Amer. Nat., XXXIX, pp. 665679 , September.

1906, a. Application of DeVries Mutation Theory to the Mollusca. Amer. Nat., XL, pp. 327-334, May.

1906, t. Notes on a Collection of Mollusks from the Vicinity of Alpena, Michigan. Trans. Acad. Sci. St. Louis, XVI, pp. 1-15.

1906, c. A Catalogue of the Mollusca of Illinois. Bull. I11. State Lab. N. H., VII, No. 6, pp. 53-136.

1906, d. Lymnæa Hinkleyi N. Sp. Nautilus, XIX, No. 12, pp. 142-143, April.

1907, a. Descriptions of New Species of Lymnæa. Nautilus, XX, pp. 125127, March.

1907, b. Two New Species of Lymnæa. Nautilus, XXI, No. 5, pp. 52-55, September.

1908. Note on Lymnæa Desidiosa Say. Nautilus, XXII, pp. 20-23, June. 1909, a. A.New Species of Lymnæa. Nautilus, XXII, pp. 140-141, April. 
1909, b. Description of a New Fossil Lymnæa. Nautilus, XXIII, pp. 19-21, June.

1909, c. Range of Lymnæa Umbilicata. Nautilus, XXIII, p. 80, November. 1909, d. Mollusks from Kansas and Oklahoma. Nautilus, XXIII, pp. 9194, December.

1910, a. The Ecology of the Skokie Marsh Area, with Special Reference to the Mollusca. Trans. Ill. State Acad. Sci., III, pp. 106-108.

1910, b. A New Variety of Lymnæa Stagnalis. Nautilus, XXIII, pp. 112113, February.

1910, c. The Ecology of the Skokie Mansh Area, with special reference to the Mollusca. Bull. Ill. State Lab. Nat. Hist., VIII, pp. 437-499, 1910.

1910, d. Preliminary note on the Life of Glacial Lake Chicago. Science, n. s., XXXI, No. 801, pp. 715-717, May 6.

1910, e. Description of a New Lymnæa. Nautilus, XXIV, pp. 58-60, September.

1910, f. Mollusks of Unionville, Conn. Nautilus, XXIV, pp. 68-69, October. Baker, H. Barrington.

1909. Key to the Genera of Gastropoda of Michigan. An. Rep, Mich. Acad. Sci., XI, pp. 134-140.

1910. Variation in Lymnæa Reflexa Say, from Huron County Rep. Mich. Acad. Sci., XII, pp. 60-63.

Bartlett, John.

1866. Catalogue of Shells found in the Ponds of Haverhill, Mass., and in the Merrimack River near that Town. Proc. Essex. Inst., V, p. 45.

Bather, F. A.

1909. Visit to the Florissant Exhibition in the British Museum (Natural History). Proc. Geol's. Assoc., XXI, pp. 159-165.

Baudelot, M.

1863. Recharches sur l'appariel générateur des Mollusques Gastéropodes. Ann. des Sci. Nat. Zool., IV, XIX, pp. 135-222, 268-294.

Beauchamp, W. M.

1886. Land and Fresh-Water Shells of Onondaga County and New York State. Baldwinsville, N. Y.

Beck, H.

1837. Index Molluscorum Præsentis. Evi Musei Principis Augustissimi Cristiani Frederici. Hafinæ.

Beecher, Charles.

1876. See Walker.

Bell, Robert.

1859, a. Catalogue of Animals and Plants Collected and Observed on the Southeast Side of the St. Lawrence, from Quebec to Gaspé, and in the Counties of Rimouski, Gaspé and Bonaventure. Geol. Surv. Can., Rep. Prog., 1858, pp. 243-255.

1859, b. Notes on the Natural History of the Gulf of St. Lawrence and the Distribution of the Mollusca of Eastern Canada. Can. Nat. \& Geol., IV, pp. 197-220.

1861, a. On the Occurrence of Fresh-Water Shells in some of our Post Tertiary Deposits. Can. Nat. \& Geol., VI, pp. 42-51. 
1861, b. List of Recent Land and Fresh-Water Shells Collected Around Lakes Superior and Huron in 1859-1860. Can. Nat. Geol., VI, p. 268.

1880. List of Fresh-Water Mollusca from Manitoba and the Valley of the Nelson River. Geol. Surv. Canada. Report Progress for 1878-79. Appendix III, pp. 61-62 C.

1881. List of Land, Fresh-Water and Marine Mollusca. Rep. Geol. \& Nat. Hist. Surv. Can, 1879-1880, Appendix IV, pp. 75-76.

Betten, C.

1901. See Needham, J. G.

Berry, S. S.

1908. Molluscan Fauna of the San Bernardino Mountains, California. Nautilus, XXI, pp. 121-124, March.

1909. The known Mollusca of San Bernardino County, California. Nautilus, XXIII, pp. 73-79, November.

1910. Mollusks of Unity, Maine. Nautilus, XXIV, pp. 61-63, October. Beyer, S. W.

1898. Buried Lœss in Story County. Proc. Iowa Acad. Sci., VI, pp. 117121.

Binney, William G.

1860. Check List of the Shells of North America. Smith. Mis. Coll., 1860.

1861. Catalogue of Land and Fresh-Water Univalve Mollusks Collected in British America by Messrs. Ross, Kennicott and Drexler, and Deposited in the Smithsonian Collection. Proc. Acad. Nat. Sci. Phil., p. 330 .

1863. Bibliography of North American Conchology Previous to the Year 1860. Smith. Miss. Coll.

1865. Land and Fresh-Water Shells of North America. Part II, Pulmonata Limnophila and Thalassophila. Smith. Miss. Coll., No. 143, 1865.

1867. Notes sur quelques espèces de Mollusques fluviatiles de l'Amerique du Nord. Journ. de Conch., XV, p. 427.

1870. Edition of Gould's Invertebrates of Mass. See Gould.

1871. See Bland, Thomas.

1885. A Manual of American Land Shells. Bull. U. S. Nat. Mus., No. 28. Binney, W. G., and Bland, Thomas.

1870. Notes on Lingual Dentition of Mollusca, No. 1. Ann. N. Y. Lyc. Nat. Hist., IX, pp. 281-295.

Blake, W. P.

1856. Geology of the 35th Parallel. Pacific R. R. Reports, III, part IV, p. 11. Lœss Fresh-Water Shells mentioned on p. 22.

Bland, Thomas.

1862. Notice of Land and Fresh-Water Shells Collected by Dr. J. G. Cooper in the Rocky Mountains, etc., in 1860. Ann. N. Y. Lyc. Nat. Hist., VII, pp. 362-370.

1870. See Binney, W. G.

Bland, Thomas, and Binney, W. G.

1871. On the Lingual Dentition of Limnæa Appressa, Say, and Limnæa Megasoma, Say. Amer. Journ. Conch., VII, pp. 161-162. 
Blatchley, W. S.

1900. A List of the Mollusca Known to Occur in Lake Maxinkuckee. 25th Ann. Rep. Geol. \& Nat. Res. Ind., pp. 248-251.

Blatchley, W. S., and Ashley, Geo. H.

1900. The Lakes of Northern Indiana and Their Associated Marl Deposits. 25th An. Rep. Dept. of Geol. \& Nat. Res. Indiana, pp. 31-247.

Blatchley, W. S., and Daniels, L. E.

1902. On Some Mollusca Known to Occur in Indiana. An. Rep. Dept. Geol. and Nat. Res. Ind., XXVII, pp. 577-628.

Bourguignat, M. J. R.

1860. Aménités Malacologiques. Vol. II.

1862. Les Spiciléges Malacologiques. Paris, 1862 (Reprinted from Magasin de Zoologie).

Boyle, Cornelius Breckenridge.

1893. A Catalogue and Bibliography of North American Mesozoic Inveritebrata. Bull. U. S. Geol. Surv., No. 102.

Braun, M.

1888. Zur Frage der Selbstbefruchtung bei Zwitterschnecken. Nach. Deutsch. Mal. Gesell., XX, p. 146-148.

Broadhead, G. C.

1904. The Lœss. Amer. Geol., XXXIII, p. 393.

Brot, A.

1877. Proc. Verb. Soc. Mal. Belg., VI, p. xlviii.

Brown, Lewis B.

1903. Notes on the Land and Fresh-Water Shells of Barbadoes. Journ. Conch., X, pp. 266-273.

Bunker, Robert.

1880. Can Snails Mend their Shells. Amer. Nat.; XIV, p. 522.

Butler, A. W.

1885. See Moore, D. R.

Butterell, J. D.

1880. (Filaments on jaws of Limnæa stagnalis.) Journ. Conch., III, p. 150-151.

Byrnes, R. M.

1872. List of Land and Fresh Water Shells found in the Vicinity of Cincinnati; also the Unionidæ of the Ohio River an-1 its Northern Tributaries within the State of Ohio. December.

C., E: J.

1858. Alleged Discovery of a Fossil Conus in the Drift of Western Canada. The Canadian Journ., n. s., III, p. 516.

Calkins, William Wirt.

1874, a. The Land and Fresh Water Shells of La Salle County, Illinois. Proc. Ottawa Acad. Nat. Sci., 1874.

1874 , b. Notes on the Fresh-Water Mollusca, Found in the Vicinity of Chicago, Illinois. Cin. Quart. Journ. Sci., I, No. 3, pp. 242-247, July.

1874, c. Notes on the Molluscan Fauna of Northern Illinois. Cin. Quart. Journ. Sci., I, No. 4, pp. 321-325, October.

Call, R. Ellsworth.

1881, a. Fossils of the Iowa Lœss. Amer. Nat., XV, pp. 585-586, July.

1881, b. The Lœss in Central Iowa. Amer. Nat., XV, pp. 782-784, October. 
1882, a. The Lœss of North America. Amer. Nat., XVI, pp. 369-381, May; pp. 542-549, July.

1882, b. See McGee, W. J.

1884. On the Quaternary and Recent Mollusca of the Great Basin with Descriptions of New Forms. Bull. U. S. Geol. Surv., No. 11 (Vol. II, pp. 357-420).

1885-6. Contributions to a Knowledge of the Fresh-water Mollusca of Kansas. Bull. Wash. Coll. Lab. Nat. Hist.; I, pp. 51-54; 115-124, $1885 ; 177-184,1886$.

1886. On Certain Recent, Quaternary, and New Fresh Water Mollusca. Proc. Daven. Acad. Sci., V, pp. 1-8.

1887. Sixth Contribution to a Knowledge of the Fresh Water Mollusca of Kansas. Bull. Wash. Coll. Lab. N. H., II, pp. 11-25.

1893. A Contribution to a Knowledge of Indiana Mollusca. Proc. Ind. Acad. Sci., pp. 140-156.

1895, a. Second Contribution to a Knowledge of Indiana Mollusca. Proc. Ind. Acad. Sci., pp. 135-146.

1895, b. On a Small Collection of Mollusks from Northern Indiana. Proc. Ind. Acad. Sci., pp. 246-250.

1896. The Hydrographic Basins of Indiana and Their Molluscan Fauna. Proc. Ind. Acad. Sci., pp. 247-258.

1899. A Descriptive Illustrated Catalogue of the Mollusca of Indiana. An. Rep. Dept. Geol. \& Nat. Res. Ind., XXIV, pp. 335-535.

1902. The European Pond Snail. Science, n. s., XVI, p. 65, July 11. Canada.

1864. Commission Géologique du Canada. Rapport de Progrés depuis son commencement jusqua à 1863. Montreal.

Carlton, H. P.

1870, a. Shells of Antioch, Cal., and Vicinity. Proc. Cal. Acad. Sci., IV, pp. 50-52.

1870, b. Shells of Tucker River and Vicinity. Proc. Cal. Acad. Sci., IV, pp. 57-58.

Carpenter, Horace F.

1886-7. The Shell-bearing Mollusca of Rhode Island. Random Notes on Natural Hist., III, pp. 78-86. Conch. Exch., I, p. 76, 1886; II, pp. 2, $18,61,77,161,1887$.

1889. A Catalogue of the Shell-bearing Mollusca of Rhode Island. Ed. 2, Providence, R. I.

Carpenter, Phillip P.

1855-57. Catalogue of the Reigen Collection of Mazatlan Mollusca in the British Museum.

1856. Monograph of the Shells Collected by N, Nuttall, Esq., on the Californian Coast in the Years 1854-5. Proc. Zool. Soc. London, pp. 209-229.

1856. See Gould, A. A.

1857. Report on the Present State of our Knowledge with Regard to the Mollusca of the West Coast of North America. Extracted from the Report of the British Association for the Advancement of Science, 
pp. 159-368; separately printed with four preliminary leaves, London, 1857.

1864. Supplementary Report on the Present State of our Knowledge with regard to the Mollusca of the West Coast of North America. Report British Assoc. Advance. Science, pp. 517-686.

1872. The Mollusks of Western North America. Smith. Mis. Coll., X (No 252).

Chadwick, George $\mathrm{H}$.

1906, a. List of Wisconsin Shells. Nautilus, XX, pp. 22-24, June.

1906, b. Notes on Wisconsin Mollusca. Bull. Wis. Nat. Hist. Soc., IV, No. 3, pp. 67-99.

Chalmers, R.

1885. Report on the Surface Geology of Western New Brunswick. Rep. Prog. Geol. \& Nat. Hist. Surv. Can., 1882-84 GG.

Chamberlin, Thomas C.

1883. Geology of Wisconsin, Vol. I.

Chamberlin, Thomas C., and Salisbury, Rollin D.

1885. Preliminary Papers on the Driftless Area of the Upper Mississippi Valley. An. Rep. U. S. Geol. Surv., VI, pp. 199-322.

1906. Geology, III, pp. 327-405. Also Vol. II.

Chapman, E. J.

1861. Additional Note on the Occurrence of Fresh-Water Shells in the Upper Drift Deposits of Western Canada. Canadian Journal, n. s., VI, p. 497.

Chaster, George W.

1899. A Cross between Limnæa stagnalis and L. auricularia. Journ. of Conch., IX, p. 282.

Chenu, J. C.

1845. Bibliothèque Conchyliologique. Première Serie, Vol. III, Paris, 1845. Thomas Say, Conchyliologie Américaine ou Descriptions et Figures des Coquilles du Nord d l'Amérique, ouvrage traduit de l'Anglais, par J. C. Chenu.

Chickering, J. W., Jr.

1855 or 56. List of Marine, Fresh-Water and Land Shells Found in the Vicinity of Portland, Me.

Christy, Robert Miller.

1885. Notes on the Land and Fresh-Water Mollusca of Manitoba. Journ. Conch., IV, p. 339.

Clapp, F. G.

1903. See Fuller, M. L.

Clapp, George H.

1895. Mollusks of Allegheny Co., Pennsylvania. Nautilus, VIII, p. 116, February.

1900. Land Mollusca of Kennebunkport, Me. Nautilus, XIV, pp. 63-64, October.

Clessin, S.

1873. Anfressungen der Gehaüse. Nach. Mal. Ges., V, p. 28.

1877. Die Mollusken der Tiefenfauna unserer Alpenseen. Mal. Blätt., XXIV, pp. 159-185. 
1879. Limnæa truncatula Müller. Mal. Blätt., n. s., I, p. 20.

1880. Zur Biologie von Limnæa auricularia L. Mal. Blätt., ii, II, p. 199.

1881. Die Gruppe der Limnæa truncatula. Mal. Blätt., ii, III, p. 77.

1882. In Weissmanns Ueber die Dauer des Lebens, pp. 79-81.

1886. Die Familie der Limnæiden. Mart. \& Chem., Conch. Cab. A continuation of Küster's Monograph of $\mathbf{1 8 6 2 .}$

Cockerell, Theodore D. A.

1885. The Variation and Abnormal Development of the Mollusca. Science Gossip, XXI, p. 179.

1887. Notes on Some Species of Inland Mollusca. Ann. Mag. Nat. Hist., v, XIV, p. 174.

1889. The British Mollusca. Science Gossip, XXV, p. 44.

1889, a. Limnæa truncatula in Colorado. Nautilus, III, p. 9, May.

1889, b. Preliminary Remarks on the Molluscan Fauna of Colorado. Journ. Conch., VI, p. 60.

1889 , c. Mollusca of Colorado, Nautilus, III, p. 21, June.

1890. Critical Notes on some Land and Fresh-Water Mollusca. Journ. Conch., VI, p. 255.

1893. Notes on the Conchological Society's New List of British Mollusca. Science Gossip, No. 338, p. 25, February.

1900. See Pilsbry.

1902. Notes on Limnæa. Nautilus, XVI, pp. 95-96, December.

1906. The Fossil Mollusca of Florissant Colorado. Bull. Amer. Mus. Nat. Hist., XXII, p. 459.

1908. The Miocene Species of Lymnæa. Nautilus, XXII, p. 96.

Coleman, A. P.

1899. The Iroquois Beach. Trans. Can. Inst., VII, pp. 29-44.

1901. Glacial and Interglacial Beds near Toronto. Journ of Geol., IX, No. 4, pp. 285-310, May-June.

1906. Interglacial Periods in Canada. Mexico. Int. Geol. Congress.

Colton, Harold S.

1908. Some Effects of Environment on the Growth of Lymnæa Columella Say. Proc. Phil. Acad., pp. 410-448.

Conrad, T. A.

1846. Notices of Fresh-Water Shells, etc., of Rockbridge County, Virginia. Amer. Journ. Sci., ii, I, pp. 405-407.

1866. Descriptions of American Fresh-water Shells. Amer. Journ. Conch., II, pp. 278-279.

Cooke, A. H.

1895. Mollusca. The Cambridge Natural History. Vol. III, MacMillan Co.

Coolidge, William H., Jr.

1908. See Walker, R. D.

Cooper, J. G.

1862. See Bland, $T$.

1868. The Shells of Montana. Amer. Nat., II, pp. 486-487, November.

1869. Notes on the Fauna of the Upper Missouri. Amer. Nat., III, pp. 294-299, August.

1870, a. The West-Coast Fresh-water Univalves, No. 1, Proc. Cal. Acad. Sci., IV, pp. 92-100. 
1870, b. On Shells of the West Slope of North America. Proc. Cal. Acad. Sci., IV, pp. 150-154.

1872. On Shells of the West Slope of North America, No. II. Proc. Cal. Acad. Sci., IV, pp. 171-175.

1875. On Shells of the West Slope of North America, No. III. Proc. Cal. Acad. Sci., VI, pp. 14-27.

1888. Catalogue of Californian Fossils. An. Rep. Col. State Min. Bu., VII, pp. 221-308.

1890 , a. Notes on the Subalpine Mollusca of the Sierra Nevada, near lat. $38^{\circ}$. Additional Notes and Description of New Species. Proc. Cal. Acad. Sci., ii, III, pp. 61-91.

1890, b. Fresh-water Mollusca of San Francisco County. Zoe, I, p. 196.

1891, a. On Land and Fresh-water Shells of Lower California. Proc. Cal. Acad. Sci., ii, III, pp. 99-103.

1891, b. On Land and Fresh-water Shells of Lower California, No. 2. Proc. Cal. Acad. Sci., ii, III, pp. 207-217.

1892. Catalogue of the Land and Fresh-water Mollusca of Lower California. Zoe., III, p. 12.

1893. On Land and Fresh-water Mollusca of Lower California, No. 3. Proc. Cal. Acad. Sci,, ii, III, pp. 338-344.

1894, a. On Land and Fresh-water Mollusca of Lower California, No. IV. Proc. Cal. Acad. Sci., ii, IV, pp. 130-143.

1894, b. On Some Pliocene Fresh-water Fossils of California. Proc. Cal. Acad. Sci., ii, IV, pp. 166-172.

1894, c. Descriptions and Figures of New Species of Cretaceous and Cretaceous B (or Eocene) Fossils of California, with Notes on Tertiary Species. Bull. Cal. State Mining Bureau, IV, pp. 36-65.

1895. On West Mexican Land and Fresh-water Mollusca. Proc. Cal. Acad. Sci., ii, V, pp. 166-169.

Cooper, William.

1834. List of Shells Collected by Mr. Schoolcraft in the Western and Northwestern Territory. In Appendix to Narrative of an Expedition through the Upper Missouri to Itaska Lake, etc., under the Direction of Henry B. Schoolcraft, pp. 153-156.

1860. Report upon the Mollusca Collected on the Survey. Reports on the Natural History, etc., of Minnesota, Nebraska, Washington and Oregon Territories, made in connection with the Pacific Railroad Survey, XII, pt. 2, pp. 369-386.

Copeland.

1877. See Jordan.

Couper, J. Hamilton.

- Catalogue of the Recent Shells of Georgia. Appendix to Statistics of the State of Georgia; Sketch of the Geology of Georgia.

Crandall, O. A.

1893. Post Pliocene Shells. Nautilus, VI, p. 103.

Crosse, $\mathrm{H}$.

1870. See Fischer, Paul.

1874. See Fischer, Paul. 
1890. Faune Malacologique terrestre et fluviatile de l'ile de Cuba. Journ. de Conch., XXXVIII, p. 173, 1890.

1891. Faune Malacologique terrestre et fluviatile de l'ile de Saint Dominique. Journal de Conch., XXXIX, p. 69.

Crowther, Henry.

1896. (Mucus tracks of L. stagnalis seen through water.). Journ. Conch., p. 230.

Cummins, W. F.

1893. Notes on the Geology of Northwest Texas. Ann. Rep. Geol. Surv. Texas, IV, 18.92, pp. 179-238.

Currier, A. O.

1859. List of Shells Collected in the Grand River (Mich.) Valley. Printed at Grand Rapids by the Author.

1865. Catalogue of the Mollusca of Grand Rapids, Michigan. Amer. Journ. Conch., I, pp. 292-296.

1867. Description of New Species of Fresh-water Shells from Michigan. Amer. Journ. Canch., III, pp. 112-113.

1868. List of the Shell-bearing Mollusca of Michigan. Kent. Sci. Inst., Mis. Pub. No. 1.

- List of the Shell-bearing Mollusca of Michigan, Especially of Kent

Cuvier, G. and Adjoining Counties. Printed privately.

1816. Memoires pour servir a l'historie et a l'anatomie des Mollusques. Paris.

Dall, Wílliam $\mathrm{H}$.

1870 , a. Revision of the Classification of the Mollusca of Massachusetts. Proc. Bost. Soc. N. H., XIII, p. 240.

1870 , b. On the Genus Pompholy $x$ and its Allies, with a Revision of the Lymnæidæ of Authors. Ann. Lyc. Nat. Hist. N. Y., IX, pp. 333-360.

1881, a. Remarks on Limnæa megasoma. Bull. Phil. Soc. Wash., III, p. 75. Smith. Mis. Coll., XX, p. 75.

1881, b. (Sinistral shells in Sandwich Islands). Smith. Mis. Coll., p. 75.

1883. On a Collection of Shells sent from Florida by Mr. Henry Hemphill. Proc. Nat. Mus., VI, pp. 318-342.

1884. Contributions to the History of the Commander Islands. No. 3. Report on the Mollusca of the Commander Islands, Behring Sea, Collected by Leonard Stejneger in 1882 and 1883. Proc. U. S. Nat. Mus., VII, pp. 340-349.

1886. Report on the Mollusks Collected by L. M. Turner at Ungava Bay, N. Labrador, and from the Adjacent Arctic Seas. Proc. Nat. Mus., IX, pp. 202-208.

1896. Insular Landshell Faunas, especially as Illustrated by the Data Obtained by Dr. G. Baur in the Galapagos Islands. Proc. Phil. Acad., pp. 395-459.

1897. Report on the Mollusks Collected by the International Boundary Commission of the U. S. and Mexico. Proc. U. S. Nat. Mus., XIX, pp. 333-379.

1899. The Mollusk Fauna of the Pribilof. Report of Fur Seal Investigations, Part 3, pp. 539-546. 
1905, a. Land and Fresh-water Mollusks. Harriman Alaska Expedition, Vol. XIII.

1905, b. On the Relations of the Land and Fresh-water Mollusk Fauna of Alaska and Eastern Siberia. Popular Science Monthly, LXVI, pp. 362-366.

Dall, W. H., and Harris, G. D.

1892. Correlation Papers. Neocene. Bull. U. S. Geol. Surv., No. 84 (p. 286). Dall, W. H., and Simpson, C. T.

1900. The Mollusca of Porto Rico. Bull. U. S. Fish Com., XX, pt. 1, pp. 351-524.

Dana, James D.

1896. Manual of Geology, p. 966.

Daniels, L. E.

1902, a. A Check-List of Indiana Mollusca, with Localities. An. Rep. Dept. Geol. and Nat. Res. Ind., XXVII, pp. 629-652.

1902, b. See Blatchley.

1909. Records of Minnesota Mollusks. Nautilus, XXII, pp. 119-121.

Darton, N. H.

1908. Paleozoic and Mesozoic of Central Wyoming. Bull. Geol. Soc. Amer., XIX, p. 403.

Darton, N. H., and Siebenthal, C. E.

1909. Geology and Mineral Resources of the Laramie Basin, Wyoming. Bull. U. S. Geol. Surv., p. 364.

Davis, W. M.

1900. The Fresh-water Tertiary Formations of the Rocky Mountain Region. Proc. Amer. Acad. Arts \& Sci., XXXV, p. 345.

Dawson, George Mercer.

1875. Land and Fresh-water Mollusca Collected during the Summers of 1873-74, in the Vicinity of the Forty-ninth Parallel-Lake of the Woods to the Rocky Mountains. Report on the Geology and Resources of the Region in the Vicinity of the Forty-ninth Parallel, etc., British North American Boundary Commission. Appendix (E), pp. 347-350.

Dawson, J. W.

1857. On the Newer Pliocene and Post Pliocene Deposits of the Vicinity of Montreal, with Notices of Fossils Recently Discovered in Them. Can. Nat. \& Geol., II, pp. 401-426.

1859. Additional Notes on the Post Pliocene Deposits of the St. Lawrence Valley. Can. Nat. \& Geol., IV, pp. 23-39.

1860. Notice of Tertiary Fossils from Labrador, Maine, etc., and Remarks on the Climate of Canada in the Newer Pliocene or Pleistocene Period. Can. Nat. \& Geol., V, pp. 188-200.

1872. The Post Pliocene Geology of Canada. Can. Nat. \& Geol., n. s., VI, pp. 242-259.

Dean, George W.

1892. Catalogue of the Shell-bearing Mollusca of Portage Co., Ohio. Amer. Nat., XXVI, p. 11. 
DeCamp, W. H.

1881. List of the Shell-bearing Mollusca of Michigan. Kent Sci. Inst. Mis. Pub. No. 5.

DeKay, James E.

1839. Catalogue of the Animals belonging to the State of New York, as far as They have been Figured and Described. Assembly No. 50, January 1.

1843. Zoology of New York. Part V, Mollusca. Albany.

Delessert, M. Benjamin.

1841. Recuil de Coquilles décrites par Lamarck, etc., et non encore figurées. Paris.

Deshayes, G. P.

1830. Encyclopèdie Mèthodique., II, p. 362.

1838. Lamarck's Histoire Naturelle des Animoux sans Vertebrés, Ed. 2, VIII.

D'Urban, W. S. M.

1859. Catalogue of Animals and Plants Collected and Observed in the Valley of the River Rouge and the Neighboring Township, in the Counties of Argentevil and Ottawa. Geol. Surv. Can., Rep. Prog., pp. 241-243.

1859-60. Same in Canadian Naturalist, IV, pp. 252-276, 1859; V, pp. 81-99, 1860 .

DeVarigny, $\mathrm{H}$.

1894. Recherches sur le nanisme experimental. Contribution a l'etude de l'influence du milieu sur les organismes. Journ. Anat. Pyhsiol., XXX, pp. 147-188.

Dybowski, W.

1884. Studien über die Zahnplatten der Gattung Limnæa Lam. Bull. Imp. Soc. des Nat. de Moscou, LIX, ii, pp. 256-262.

1903. Beschreibung einer neuen Süsswasser-Schencke, Limnæa (Limnus) lagorii m. Bull. Acad. Imp. Sciences St. Petersburg, XVIII, No. 3, pp. 113-116.

1903. Bemerkungen über die gegenwärtige Systematik der SüsswasserSchnecken. Nach. Deutsch. Mal. Ges., XXXV, pp. 130-144.

Earle, John Milton.

1833. List of Land and Fresh-Water Shells of Massachusetts so far as They have been Ascertained. Hitchcock's Report on the Geology, Botany, and Zoology of Massachusetts, Ed. I, pp. 557-562.

1835. List of Land and Fresh-water Shells of Massachusetts so far as They have been Ascertained. Hitchcock's Report on the Geology, Botany, and Zoology of Massachusetts, Ed. 2, p. 22-23.

1835. Catalogue (of Mollusca) of the Boston Society of Natural History. Hitchcock's Report on the Geology, Botany and Zoology of Massachusetts, Ed. 2, pp. 25-28.

Eisig, Hugo.

1869. Beitrage zur Anatomie und Entwicklungsgeschichte der Geschlectsorgane von Lymnæus. Zeitsch Wissen. Zool., XIV, pp. 297-321. 
Elrod, Morton J.

1899. Limnological Investigations at Flathead Lake, Montana, and Vicinity, July, 1899. Trans. Amer. Micr. Soc., XXII, p. 63.

1902, a. Collecting Shells in Montana. Nautilus, XV, pp. 103-104; 110-112. 1902 , b. A Biological Reconnoissance in the Vicinity of Flathead Lake. Bull. Univ. Mont., Biol. Ser., No. 3.

1902, c. Montana Shells. Bull. Univ. Mont., Biol. Ser., No. 3, pp. 170-176. 1903. Montana Shells. Bull. Univ. Mont., Biol. Ser., V, pp. 255-262.

Englemann, Henry.

1876. Report on the Geology of the Country between Fort Leavenworth, K. T., and the Sierra Nevada near Carson Valley. Appendix I, Simpson's Exploration Across the Great Basin of Utah, in 1859, p. 243.

Evermann, Barton Warren, and Goldsborough, E. L.

1901. Notes on the Fishes and Mollusks of Lake Chautauqua, New York. Rep. U. S. Fish. Com., pp. 169-175. Mollusca, p. 175.

Evans, John, and Shumard, B. F.

1854. Descriptions of New Fossil Species from the Fresh Water Tertiary Formation of Nebraska, Collected by the North Pacific Railroad Expedition under Gov. J. J. Stevens. Proc. Acad. Nat. Sci. Phil., p. 164.

Fairchild, H. L.

1899. Glacial Waters in the Finger Lakes Region of New York. Bull. Geol. Soc. America, X, pp. 27-68.

1909, a. Drainage Evolution in Central New York. Science, n. s., XXIX, pp. 632-633, April 16.

1909, b. Glacial Waters in Central New York. Bull. N. Y. State Mus., CXXVII.

Ferriss, James $\mathrm{H}$.

1906, a. Mollusks of Oklahoma. Nautilus, XX, pp. 16-17.

1906, b. See Pilsbry.

Ferussac, Gervais.

1835. Bulletin Zoologique, ou Annonce et Analyse de touts les Ouvrages, etc., par F. E. Guerin, Paris.

Fischer, Paul, and Crosse, $\mathrm{H}$.

1874. Observations on effect of infected water on fresh-water Mollusca. Journ. de Conch., XXII, p. 332.

1880. Etudes sur les Mollusques terrestres et fluviatiles du Mexique et du Guatemala. Mission Scientifique au Mexique et dans l'Amerique Centrale. Part 7.

Fischer, Paul.

1883. Manuel de Conchyliologie et de Paléontologie Conchyliologique ou Histoire Natural des Mollusques Vivants et Fossiles. Paris, 1880-87.

Forbes, Edward.

1840. Report on the Distribution of Pulmoniferous Mollusca in the British Isles. Rep. Brit. Asso. Ad. Sci., VI, p. 127.

Forbes, Edward, and Hanley, Sylvanus.

1853. A History of British Mollusca and Their Shells, IV. 
Forbes, S. A.

1888. Preliminary Report upon the Invertebrate Animals inhabiting Lakes Geneva and Mendota, Wisconsin, with an Account of the Fish Epidemic in Lake Mendota in 1884. Bull. U. S. Fish. Com., VIII, pp. 473-487.

Forel, S. F. A.

1869. Introduction a l'étude de la faune profonde du lac Léman. Bull. de la Soc. vaudoise des Sci. Nat., Tome X, p. 217.

1874. Materiaux pour servir a l'étude de la faune profonde du lac Léman. T. c., Tome XIII, p. 1.

Fox, William J.

1891. List of Mollusca of Gloucester Co., N. J. Nautilus, IV, pp. 113-115.

Friedel, Ernest.

1870. Zur Kunde der Weichthiere Schleswig-Holsteins. Mal. Blätt., XVII, pp. 36-81.

Frierson, L. S.

1900. An Hour on the Great Raft. Nautilus, XIV, pp. 67-69.

Froebel, Charles.

1870. Notes on Some Observations made in Dakota, during Two Expeditions, under Command of General Alfred Sully against the Hostile Sioux, in the Years 1864 and 1865. Proc. N. Y. Lyc. Nat. Hist., I, pp. 64-73.

Fuller, M. L., and Clapp, F. G.

1903. Marl-Lœss of the Lower Wabash Valley. Bull. Geol. Soc. Amer., XIV, pp. 153-176.

Gabb, W. M.

1861. List of the Mollusoa inhabiting the Neighborhood of Philadelphia. Proc. Phil. Acad., 1861, pp. 306-310.

Geike, Sir Archibald.

1903. Text-book of Geology, Vol. II, Fourth Edition, London.

Gerstfeldt, G.

1859. Ueber Land-und Süsswasser-Mollusken Siberiens und des Amurgebietes. Mem. des savants étrangers, IX, pp. 507-548, pt. IX, June. Imp. Acad. Sci. St. Petersburg.

Gibbes, Lewis R.

1848. Molluscous Animals of South Carolina. Appendix to Geol. of South Carolina.

Gibbons, J. S.

1879. Notes on the Habits and Distribution, etc., af Certain West Indian Pulmonifera. Journ. Conch., II, p. 129.

Gilbert, G. K.

1875, a. Report upon the Geology of Portions of Nevada, Utah, California, and Arizona, Examined in the Years 1871 and 1872. Exp. and Surveys West of 100th Meridian, III, pp. 21-192.

$1875, \mathrm{~b}$. Report on the Geology of Portions of New Mexico and Arizona, Examined in 1873. L. c., pp. 503-570.

1890. Lake Bonneville. U. S. Geol. Surv. Mon., No. 1, 1890. 
Gill, Theodore.

1871. Arrangement of the Families of Mollusks. Smith. Mis. Coll., X, No. $227,1871$.

Girard, Charles.

1856. Catalogue of Recent Shells and other Mollusca Found in the District of Columbia, Prepared from Specimens in the Cabinet of Dr. E. Foreman. Proc. Nat. Inst., Washington, I, No. 2, pp. 79-82.

Gleason, Henry Allen.

1909. The Ecological Relations of the Invertebrate Fauna of Isle Royale, Michigan. An. Rep. Geol. Surv. Mich., 1908, pp. 57-78.

Goldsborough, Edmund Lee.

1901. See Evermann, B. W.

Gould, Augustus A.

1833. Lamarck's Genera of Shells with a Catalogue of Species; Translated from the French by Aug. A. Gould, M. D. Boston.

1837. Catalogue of Maine Shells. First Report on the Geology of the State of Maine, by Charles F. Jackson, M. D., p. 119.

1840. Limnæa Chalybea. Amer. Journ. Sci., XXXVIII, p. 196.

1841. Report on the Invertebrata of Massachusetts, Comprising the Mollusca, Annelida and Radiata. Cambridge.

1844. Results of an Examination of the Shells of Massachusetts, and Their Geographical Distribution. Bost. Journ. Nat. Hist., III, pp. 488-489.

1847. Descriptions of Shells from the Wilkes Exploring Expedition. Proc. Bost. Soc. N. H., II, pp. 142-170.

1850, a. Catalogue of Shells with Descriptions of New Species. Agassiz's Lake Superior. Boston.

1850, b. Proc. Bost. Soc. N. H., III, p. 181.

1852. Mollusca and Shells of the United States Exploring Expedition (Com. Wilkes), Boston.

1862. Otia Conchologica, Boston.

1870. Report on the Invertebrates of Massachusetts, Published Agreeably to an Order of the Legislature. Second Edition, comprising the Mollusca, Edited by W. G. Binney. Boston.

Gould, A. A., and Carpenter, P. P.

1856. Descriptions of Shells from the Gulf of California, Part II. Proc. Zool. Soc., p. 198.

Gray, J. E.

1857. Annals of Natural History; or, Magazine of Zoology, Botany, and Geology, etc., ser. 1, London. XIX, p. 408.

Gant, Ulysses S.

1886. Conchological Notes. An. Rep. Geol. \& Nat. Hist. Surv. Minn., XIV, p. 114.

1888. Notes on the Molluscan Fauna of Minnesota. An. Rep. Geol. \& Nat. Hist. Surv. Minn., XVI, p. 481.

Haldeman, S. S.

1840-44. A Monograph of the Limniades and other Fresh Water Univalve Shells of North America. Philadelphia.

1844, a. Rupp's History of Lancaster County, Penn. Mollusca, pp. 479-482. 
1844, b. Enumeration of the Recent Fresh Water Mollusca which are Common to North America and Europe, with Observations on Species and Their Distribution. Bost. Journ. N. H., IV, p. 468.

1867. Description of a New Species of Limnæa. Amer. Journ. Conch., III, p. 194.

Hankinson, Thomas L.

1908. A Biological Survey of Walnut Lake, Michigan. Rep. State Board Geol. Surv. Mich., 1907, pp. 153-288.

Hambach, G.

1890. A Preliminary Catalogue of the Fossils Occurring in Missouri. Bull. Geol. Surv. Missouri, I, pp. 60-85.

Hanham, A. W.

1899. A list of the Land and Fresh Water-shells of Manitoba. Nautilus, XIII, pp. 1-6.

Hanley, Sylvanus.

1853. See Forbes, Edward.

Hanna, G. Dallas.

1909. The Mollusca of Douglas County, Kansas. Gasteropoda. Nautilus, XXIII, pp. 94-96, December.

Hannibal, Harold.

1908. Formation of Epiphragm by Limnæa Palustris (Müller). Nautilus, XXII, p. 33.

Harper, Geo. W.

1895. Catalogue of Land and Fresh-water Shells found in the Vicinity of Cincinnati, Prepared for the Use of Beginners. Journ. Cin. Soc. N. H., XVIII, pp. 89-104.

Harper, Geo. W., and Wetherby, A. G.

1876. Catalogue of the Land and Fresh-water Mollusca Found in the Immediate Vicinity of Cincinnati. February.

Harris, G. D.

1892. See Dall, W. H.

Hartmann, W. D.

- A Classified Catalogue, with Synonyms, of the Terrestrial and Fluviatile Testaceous Mollusks of Chester Co., $\mathrm{Pa}$. (no date).

Hartmann, W. D., and Michener, E.

1874. Conchologia Cestrica. The Molluscous Animals and their Shells, of Chester County, $\mathrm{Pa}$. Philadelphia.

Hayden, F. V.

1856. See Meek, F. B.

1857. Notes on the Geology of the Mauvaises Terres of White River, Nebraska. Proc. Phil. Acad., p. 151.

1860. See Meek, F. B.

Hayden, F. V.

1871. Preliminary Report U. S. Geol. Surv. of Wyoming and Portions of Contiguous Territories. Second An. Rep. Progress.

1868. Notes on the Geology of Wyoming and Colorado Territories, No. 1. Proc. Amer. Phil. Soc., X, pp. 463-478.

Hayden, F. V., and Meek, F. B.

1861. Descriptions of New Lower Silurian (Primordial), Jurassic, Cretace- 
ous and Tertiary Fossils Collected in Nebraska, by the Exploring Expedition under Command of Capt. Wm. F. Reynolds, U. S. Top. Engrs., with some Remarks on the Rocks from which They were Obtained. Proc. Phil. Acad., p. 415.

Hazay, Julius.

1881. Die Mollusken Fauna von Budapest. Mal. Blätt., n. s., III, p. 161; also IV, p. 1.

1883. Die Limnaeen der Gruppe Gulnaria Leach. Mal Blätt., n. s., VII, p. 18.

Heilprin, Angelo.

1887. Explorations on the West Coast of Florida and in the Okeechobee Wilderness. Trans. Wagner Free Inst. Sci., I, pp. 38, 49.

Hemphill, Henry.

1890. New Forms of Western Limniades. Nautilus; IV, pp. 25-27, July.

Henderson, John B., Jr.

1894. List of Shells Collected in Jamaica. Nautilus VIII, pp. 31-33. July.

1907, a. Mollusks of Cazenovia, N. Y. Nautilus, XX, No. 9, pp. 97-98. January.

1907, b. A List of Land and Fresh Water Shells of Yemassee, South Carolina. Nautilus, XXI, pp. 7-8, May.

Henderson, Junius.

1907, a. The Mollusca of Colorado. Univ. Colo. Studies, IV, No. 2, pp. 77-96, No. 3, pp. 167-185.

1907, b. Scientific Expedition to Northeastern Colorado. Zoology: 5, List of Mollusks Collected. Univ. of Colorado Studies, IV, pp. 158-159.

1910, a. Mollusca Collected in Northwestern Colorado in 1909: Univ. Col. Studies, VII, pp. 125-126.

1910, b. Lymnæa bulimoides techella. Nautilus, XXIII, p. 144.

Heron, Gilbert C.

1880. On the Land and Fresh-water Shells of the Ottawa. Trans. Ottawa Field Nat. Club., I, p. 36.

Hershey, O. H.

1897. The Florencia Formation. Amer. Journ. Sci., iv, IV, pp. 90-98.

Heynemann, D. F.

1868. Begattung zwischen Limnæa auricularia und peregra. Nach. Mal. Gesell., I, p. 38 .

Higgins, Frank.

1858. A Catalogue of the Shell-bearing Species of Mollusca Inhabiting the Vicinity of Columbus, Ohio, with some Remarks Thereon. September.

Hind, Henry Youle.

1860. Narrative of the Canadian Red River Exploring Expedition of 1857 and of the Assiniboine and Saskatchewan Exploring Expedition of 1858. London, Vol. II, p. 8.

Hinkley, A. A.

1904. List of Alabama Shells Collected in October and November, 1903. Nautilus, XVIII, pp. 37-45, 54-57, August-September.

1906. Some Shells of Mississippi and Alabama. Nautilus, XX, pp. 40-44, August. 
1907. Shells Collected in Northeastern Mexico. Nautilus, XXI, pp. 76-80. November.

Hilbert, R.

1909. Neue Beitrage zur Kenntnis der Molluskenfauna von Ost-und Westpreussen. Schriften der Physikal-okonom. Gessellschaft Königsberg, XLIX, pp. 397-402.

Hjalmarson, J., and Pfeiffer, L.

1858. Beitrage zur Fauna von Westindien. Mal. Blätt., V, p. 135.

Hogg, Jabez.

1854. Observations on the Development and Growth of the Water-Snail (Limneus stagnalis). Trans. Microscopical Society, London, n. s., II, pp. 91-103.

1870. Cercariæ, Parasitic on Lymnæa Stagnalis. Monthly Microscopical Journal. Trans. Roy. Micer. Society, III, pp. 232-235.

Holzinger, John M.

1888. Notes on the Mollusca of Winona County. An. Rep. Geol. \& Nat. Hist. Survey Minn., XVI, p. 485, 1888.

Hubbard, Eber W.

- Catalogue of Terrestrial and Fluviatile Shells of Ohio, in the Collection of Eber W. Hubbard. Elyria, Ohio. (No date given.)

Hubbard, J. W.

1867. Catalogue of the Mollusca of Staten Island, N. Y. Ann. N. Y. Lyc. Nat. Hist., VIII, pp. 151-154.

Huett, J. W.

1898. Essay toward a Natural History of La Salle Co., Ills., Part II, Geol-

Ingersoll, Ernst. ogy and Zoology. Ottawa, Ills. Mollusca, pp. 93-120.

1875. Report on the Natural History of the U. S. Geol. \& Geog. Survey of the Territories, 1874. Special Report on the Mollusca. Bull. U. S. Geol. \& Geog. Surv., I, p. 121, 1875.

1876. Report on the Natural History of the United States Geological and Geographical Survey of the Territories, 1874. Geol. \& Geog. Surv. Terr., pp. 385-410.

1877. On a Collection of Mollusks from Utah and Colorado. Proc. Daven. Acad. Sci., II, pp. 130-134.

Jackson, C. T.

1844. List of Shells Found at Lake Superior. Proc. Bost. Soc. N. H., I, p. 198.

Jackson, Henry, Jr.

1908. The Mollusca of North Haven, Maine. Nautilus, XXI, pp. 142-144. April.

Jay, John C.

1836. A Catalogue of Recent Shells, with Descriptions of New or Rare Species, in the Collection of John C. Jay, M. D., Second Ed.

1839. A Catalogue of the Shells, Arranged According to the Lamarckian System; together with Descriptions of New or Rare Species Contained in the Collection of John C. Jay, M. D., Ed. 3. New York.

1846. Descriptions of New Species of Shells. Ann. N. Y. Lyceum Nat. Hist., IV, pp. 169-170. 
1852. A Catalogue of the Shells Arranged According to the Lamarckian System, etc., Contained in the Collection of John C. Jay. Ed. 4, with Supplement.

Jeffery, William.

1882. Authenticated List of Land and Fresh-water Mollusca of Western Essex. Journ. Conch., III, p. 305.

Jeffreys, J. G.

1869. On Some British Fresh-water Shells. Ann. \& Magazine Nat. Hist., November.

1872. The Mollusca of Europe Compared with Those of Eastern North America. Ann. Mag. N. H., iv, X, p. 237.

1874. The Mollusca of Europe Compared with Those of Eastern North America. Journ. Conch., I, p. 8.

Johnson, C. W.

1890. Annotated List of the Shells of St. Augustine, Fla. Nautilus, III, pp. 137-139. April.

1910. Shells of Mt. Equinox, Vermont. Nautilus, XXIV, p. 72.

Jones, J. Matthew.

187\%. List of the Mollusca of Nova Scotia.

Jones, K. Hurlstom.

1899. (Diseased Lymnæas leave shells.) Journ. Conch., IX, p. 164.

Jordan, David Starr, and Kellogg, Vernon Lyman.

1907. Evolution and Animal Life. An Elementary Discussion of Facts, Processes, Laws and Theories Relating to the Life and Evolution of Animals. New York. D. Appleton and Company.

Jordan, Hermann.

1883. Die Binnenmollusken der nördlich gemassigten Lander von Europa und Asien und der arktischen Lander. Nova Acta Ksl. Leop.-Carol.Deutschen Academie der Naturforscher, XLV, pp. 181-402.

Jordan and Copeland.

1877. (Food of Whitefish.) Amer. Nat., XI, p. 445.

Keep, Josiah.

1887. West Coast Shells. San Francisco.

1904. West American Shells. San Francisco, Cal.

Keferstein, Wilhelm.

1862-66. Bronn's Klassen und Ordnungen der Weichthiere; Malacozoa. Leipzic and Heidelburg.

Kennedy, W.

1893. Report on Grimes, Brazos and Robertson Counties. An. Rep. Geol. Surv. Texas, IV, pp. 1-84.

Kellogg, Vernon Lyman.

1907. See Jordan, David Starr.

Kennicott, Robert.

1855. Catalogue of Animals Observed in Cook County, Illinois. Trans. Ills. State Ag. Soc., I, Mollusca, p. 595.

Keyes, C. R.

1888, a. An Annotated Catalogue of the Mollusca of Iowa. Bull. Essex Inst., XX, pp. 61-83. 
1888, b. List of Fossil Mollusca from the Loss (Post Pliocene) of Iowa. Bull. Essex Inst., XX, p. 83.

King, Clarence.

1878. Systematic Geology. U. S. Geol. Surv. 40th Parallel, I, pp. 359-529.

Kirtland, J. P.

1838. Report on the Zoology of Ohio.

1854. New Locality of Limnea Megasoma Say. Annals of Science, etc., Including the Transactions of the Cleveland Academy of Natural Sciences, II, p. 6.

Knowlton, F. H.

1897. See Stanton, T. W.

1909. The Stratigraphic Relations and Paleontology of the "Hell Creek Beds," "Cereatops Beds" and Equivalents, and their reference to the Fort Union Formation. Proc. Wash. Acad. Sci., XI, pp. 179-238.

Kobelt.

1871. Zur Kenntniss der Europäịschen Limnäen, II, P. stagnalis Linné. Mal. Blätt., XVIII, p. 108.

1880. Schnecken der Hudsonbai. Nacht. Mal. Ges., XII, p. 32.

Küster, H. C.

1862. Die Familie der Limnæiden. Martini and Chemnitz Conch. Cab., Ed. 2.

Lacaze Duthiers, Henri de.

1872. Du Systeme Nervoux des Mollusques Gastropodes Pulmones Aquatiques et d'un nouvel organe d'innervation. In Archiv. de Zool. Exp., i, I, pp. 437-500, pl. 17-20. Paris.

Lamarck, J. B. de.

1799. Prodrome. Nouv. Clas. Coq.

1822. Histoire Naturelle des Animaux sans Vertebrés. VI, pt. 1. Paris.

Lankester, E. Ray.

1874. Observations on the Development of the Pond-snail (Lymnæus stagnalis) and on the Early Stages of Other Mollusca. Quart. Journ. Micr. Soc., XIV, p. 365.

1891. Zoological Articles Contributed to the Encyclopædia Britannica. Article Mollusca, pp. 95-158. Edinburgh and New York.

Lapham, J. A.

1852. A Systematic Catalogue of the Animals of Wisconsin, Mollusca. Trans. Wis. State Ag. Soc., II, pp. 367-370.

1860. A list of the Shells of the State of Wisconsin. Proc. Phil. Acad., pp. 154-156.

Latchford, Frank R.

1884. Shells of Anticosti. Amer. Nat., XVIII, p. 1051.

1889. Report of Conchological Branch, for the years 1887-88. Ottawa Nat., III, p. 65,

1892. Limnæa Stagnalis Albino (white as pear1). Ottawa Nat., VI, p. 118.

1893. Conchology. Ottawa Nat., VII, p. 114.

1896. Lymnæa .Megasoma. Nautilus, XX, p. 83, November. Ottawa Nat., $\mathrm{XX}$, p. 172. 
Latchford, F. R., and Poirier, Pascal.

1884. Report of Conchological Branch. Trans. Ottawa Field Nat. Club, p. 130.

1885. T. c. II, p. 263.

1886. T. c. III, p. 350.

Latchford, F. R., and Taylor, Geo. W.

1890. Report of the Conchological Branch. Ottawa Nat., IV, p. 51.

Lawson, Andrew, and Palache, Charles.

1902. The Berkeley Hills. A Detail of Coast Range Geology. Bull. Dept. Geol., Univ. Cal., II, pp. 349-450.

Lea, Isaac.

1837. Observations on Lamarck's Collection of Naiades. Trans. Amer. Phil. Soc., V, pp. 86-117.

1839. Descriptions of New Fresh-Water and Land Shells. Trans. Amer. Phil. Soc., VI, pp. 1-107.

1841. Continuation of Paper on Fresh Water and Land Shells. Proc. Amer. Phil. Soc., II, pp. 30-33.

1844. Continuation of Mr. Lea's paper on Fresh-water and Land Shells. Trans. Amer. Phil. Soc., IX, pp. 1-30.

1834-1874. Observations on the Genus Unio, etc. Philadelphia.

1856. Description of New Fresh-Water Shells from California. Proc. Phil. Acad., pp. 80-81.

1858. Descriptions of Twelve New Species of Uniones and Other Freshwater Shells of the U. S. Proc. Phil. Acad., pp. 165-166.

1859. Explorations in Nebraska. Preliminary Report of Lieut. G. K. Warren. Hayden's Report on Geology and Natural History. II, pt. 3, pp. 723-725. Executive Documents, 2nd Session, 35th Congress.

1860. Lymnæa and Physæ found in isolated places. Proc. Phil. Acad., p. 147.

1864. Descriptions of Five New Species of Lymnæa of North America. Proc. Phil. Acad., p. 113.

1866. New Unionidæ, Melanidæ, etc., chiefly of the United States. Journ. Phil. Acad., VI, pp. 113-187.

Leidy, Joseph.

1845. Notes taken on a Visit to White Pond, in Warren Co., New Jersey. Proc. Phil. Acad., II, pp. 279-281.

1877. On Flukes Infesting Mollusks. Proc. Phil. Acad., p. 200.

Lemond, Norman W.

1908. Shells of Maine. Thomaston, Maine. Privately printed, 1908.

Letson, Elizabeth J.

1901. Post-Pliocene Fossils of the Niagara River Gravels. Bull. Buff. Soc. Nat. Sci., VII, No. 1, pp. 238-252; Bull. N. Y. State Mus., Vol. IX, No. 45, pp. 238-252.

1905. Check-List of the Mollusca of New York. Bull. N. Y. State Mus., LXXXVIII.

1909. A Partial List of the Shells Found in Erie and Niagara Counties, and the Niagara Frontier. Bull. Buf. Soc. Nat. Sci., IX, pp. 239-245. 
Leverett, Frank.

1895. The Preglacial Valleys of the Mississippi and its Tributaries. Journ. Geol., III, pp. 740-763.

1897. The Pleistocene Features and Deposits of the Chicago Area. Bull. Geol. Nat. Hist. Survey, Chi. Acad. Sci., II.

1899. The Illinois Glacial Lobe. Monograph U. S. Geol. Surv., XXXVIII. 1902. Glacial Formations and Drainage Features of the Erie and Ohio Basins. Mon. U. S. Geol. Surv., XLI.

Lewis, James.

1854. Notes on Lymnæa Catascopium. Proc. Bost. Soc. N. H., V, p. 27.

1855. Proc. Bost. Soc. N. H., V, p. 121-124.

1856, a. List of Living Mollusca in Little Lakes, Otsego County, N. Y. Proc. Phil. Acad., VIII, pp. 259-260.

1856, b. Proc. Bost. Soc. N. H., V, pp. 296-298.

1856, c. List of Shell-bearing Mollusca Observed in Portions of Herkimer and Otsego Counties, N. Y. Proc. Bost. Soc. N. H., VI, pp. 2-4.

1860. Catalogue of the Mollusks in the Vicinity of Mohawk, N. Y. Proc. Phil. Acad., pp. 17-19.

1862. Letter in Proc. Bos. Soc. Nat. Hist., IX, p. 160.

1868, a. Notes on certain Fresh-Water Shells, Observed in the Vicinity of Mohawk, N. Y. Amer. Journ. Conch., IV, pp. 2-4.

1868, b. On the Shells of Michigan, Described by A. O. Currier on the 112th and 113th Pages of Vol. III, Journal of Conchology. Amer. Journ. Conch., IV, pp. 81-85.

1870. Note on Limnæa. Amer. Journ. Conch., VI, pp. 85-87.

1872, a. Shells of Herkimer and Adjacent Counties in the State of New York. Proc. Phil. Acad., pp. 97-107.

1872, b. Shells of Tennessee (No. 2). Proc. Phil. Acad., pp. 108-115.

1874. Land and Fresh-Water Shells of the State of New York. Bull. Buff. Soc. N. Sci., II, pp. 127-142.

Linden, Maria, Grafin von.

1891. Das Schwimmen der Schnecken am Wasserspiegel. Biol. Centr., XI, p. 763.

Linné (Linnæus), Carl von.

1758. Systema Naturæ, seu Regna tria Naturæ systematica proposita, per classes, ordines, genera et species. Edition X, 2 Vols. Holm, 17581759. .

1767. Syst. Nat. Ed. 12, p. 1249. (Lymnæa.)

Linsley, James $\mathrm{H}$.

1845. Catalogue of the Shells of Connecticut. Amer. Journ. Sci., XLVIII, pp. 271-286.

Lord, John Kearst.

1866. List of Shells Taken on the Eastern Side of Vancouver Island, Dredged in Ten Fathoms, and Collected from Rocks between Tide Marks. The Naturalist in British Columbia, II, Appendix, p. 356.

Marcou, John Belknap.

1885. A List of the Mesozoic and Cenozoic Types in the Collections of the U. S. National Museum. Proc. U. S. Nat. Mus., VIII, p. 290. 
Marsh, Wm. A.

1887. Brief Notes on the Land and Fresh-Water Shells of Mercer Co., Ills. Conch. Exchange, II, pp. 103, 110.

Marshall, William B.

1893. Land and Fresh-Water Shells of New York Exhibited at the World's Columbian Exposition, Chicago, Ills., 1893. An. Rep. N. Y. State Mus., XLVII, p. 49.

1894. Catalogue of New York Exhibits in Department M, Ethnology. Report on the Zoological Exhibit. Report Board Gen. Man. Exhibit State N. Y., at World's Columbian Exposition. p. 503. Albany.

1895. List of Shells Inhabiting the Vicinity of Albany and Troy, N. Y. An. Rep. N. Y. State Mus., XLVIII, p. 641.

Martens, Dr. Edward von.

1865. Ueber die Mexicanischen Binnen-Conchylien aus den Sammlungen von Deppe und Uhde im Berliner Museum. Mal. Blätt., XII, p. 1.

1865. Malak. Blätt., XII, p. 58.

1872. Conchylien aus Alaschka. Mal. Blätt., XIX, p. 78.

1898. Biologia Centrali Americana, Mollusca.

1899. (Variation in Mollusca.) Sitzungsberichte Gesell. Naturf. Freunde, Berlin. pp. 200-209.

McGee, W. J.

1891. The Pleistocene History of Northeastern Iowa. An. Rep. U. S. Geol. Surv., XI, pp. 199-577.

McGee, W. J., and Call, R. Ellsworth.

1882. On the Löss and Associated Deposits of Des Moines. Ann. Journ. Sci. (iii), XXIV, pp. 202-223.

Maury, C. J.

1898. Chautauqua Lake Shells. Elementary Natural History Series, No. 1. Ithaca, N. Y.

1908. An Interglacial Fauna Found in Cayuga Valley and its Relations to the Pleistocene of Toronto. Journ. Geol., XVI, pp. 565-567.

Meek, F. B.

1860. Descriptions of Fossil Remains Collected in Nebraska and Utah, by the Exploring Expedition, under the Command of Capt. J. H. Simpson, of U. S. Topographical Engineers (extracted from that officer's forthcoming report). Proc. Phil. Acad. Sci., p. 308.

1864. Check List of the Invertebrate Fossils of North America. Miocene. Smithsonian Miscellaneous Collections, No. 183.

1866. Conrad's Eocene Smithsonian Check-List, p. 9.

1873. Preliminary Paleontological Report, Consisting of Lists and Descriptions of Fossils, with Remarks on the Ages of the Rocks in which They were Found, etc., etc. Sixth An. Rep. U. S. Geol. Surv. Terr., p. 431.

1876. Report on the Palæontological Collections of the Expedition. Report of Explorations Across the Great Basin of the Territory of Utah, etc. Report of Capt. J. H. Simpson, 1876. Appendix J, p. 339.

1876. A Report on the Invertebrate Cretaceous and Tertiary Fossils of the Upper Missouri Country. U. S. Geol: Surv. Terr., IX, 1876.

1877. Paleontology. U. S. Geol. Surv. 40th Parallel, IV, p. 181. 
Meek, F. B., and Hayden, F. V.

1856, a. Descriptions of New Species of Acephala and Gasteropoda, from the Tertiary Formations of Nebraska Territory, with some General Remarks on the Geology of the Country about the Source of the Missouri River. Proc. Acad. Nat. Sci. Phil., p. 111, 1856; also in Amer. Journ. Sci. \& Arts, Ser. ii, XXII, p. 423, 1856.

1856, b. Descriptions of New Fossil Species of Mollusca Collected by Dr. F. V. Hayden in Nebraska Territory; together with a Complete Catalogue of all the Remains of Invertebrata hitherto Described and Identified from the Cretaceous and Tertiary Formations of that Region. Proc. Acad. Nat. Sci. Phil., 1856, p. 265.

1860. Systematic Catalogue with Synonyma, etc., of Jurassic, Cretaceous and Tertiary Fossils Collected in Nebraska by the Exploring Expeditions under the Command of Lieut. G. K. Warren, of U. S. Topographic Engineers. Proc. Acad. Nat. Sci. Phil., p. 417.

Merriam, C. Hart.

1890. Results of a Biological Survey of the San Francisco Mountain Region and Desert of the Little Colorado, Arizona. North American Fauna, No. 3, U. S. Dept. Agriculture.

1898. Life Zones and Crop Zones of the United States. Bull. U. S. Dept. Agric., Biol. Surv., No. 10.

1910. A. O. U. Check List.

Merriam, John C.

1896. Sigmogomphius Le Contei. A New Castoroid Rodent from the Pliocene near Berkeley, California. Bull. Dept. Geol., Univ. Cal., I, pp. 363-370.

Michaud, Andre Louis Gaspard.

1838. See Potiez.

Michener, E.

1874. See Hartmann.

Mighels, J. W., and Adams, C. B.

1841. Descriptions of Twenty-five New Species of New England Shells. Proc. Bos. Soc. N. H., I, pp. 48-50.

1842. Descriptions of Twenty-four Species of the Shells of New England. Bost. Journ. Nat. Hist., IV, pp. 37-54.

Mighels, J. W.

1843, a. Catalogue of the Marine, Fluviatile and Terrestrial Shells of the State of Maine and Adjacent Ocean. Bost. Journ. Nat. Hist., IV, pp. 308-344.

1843, b. Descriptions of Seven Species of Shells Regarded as New. Proc. Bost. Soc. N. H., I, p. 129.

1843, c. Descriptions of Six Species of Shells Regarded as New. Bost. Journ. Nat. Hist., IV, pp. 345-349.

Miles, M.

1860. A Catalogue of the Mammals, Birds, Reptiles and Mollusks of Michigan. Winchell's Geol. Surv. Mich., p. 219. Mollusca, pp. 235-241.

Miller, S. A.

1880-81. North American Mesozoic and Cænozoic Geology and Palæontology. Journ. Cin. Soc. Nat. Hist., III, pp. 9, 79, 245 ; IV, p. 93. 
1881. North American Mesozoic and Cænozoic Geology and Palæontology, etc. Cincinnati, 1881.

Mitchell, C. T.

1899. Notes on the Mollusca of Canandaigua Lake Region, N. Y. Nautilus, XIII, pp. 87-89. December.

Möller, H. P. C.

1842. Index Molluscorum Grœnlandica. Hafinæ.

Moquin-Tandon, A.

1855. Histoire Naturelle des Mollusques Terrestris et Fluviatiles de France. Two volumes and Atlas. Paris.

Moore, D. R., and Butler, A. W.

1885. Land and Fresh Water Mollusca Observed in Franklin County, Indiana. Bull. Brookville Soc. Nat. Hist., No. 1, pp. 41-44.

Mörch, O. A. L.

1857. Prodromus Fauna Molluscorum Grönlandiæ. Rink's Greenland, Appendix, p. 75. Second edition, revised and augmented, in Arctic Manual, London, p. 124, 1875.

1868, a. On the Land and Fresh-water Mollusca of Greenland. Amer. Journ. Conch., IV, pp. 25-40.

1868, b. On the Land and Fresh-water Mollusca of Iceland. Amer. Journ. Conch., IV, pp. 41-45.

1877. The Greenland Fauna, IV, Mollusca. Rink's Danish Greenland, London; Appendix, p. 435.

Morse, Edward S.

1863. Synopsis of the Fluviatile and Terrestrial Mollusca of the State of Maine. Published by the Author.

1864. Observations on the Terrestrial Pulmonifera of Maine Including a Catalogue of All the Species of Terrestrial and Fluviatile Mollusca Known to Inhabit the State. Journ. Port. Soc. Nat. Hist., I, No. 1, 1864

1870. Our Common Fresh-water Shells. Amer. Nat., III, pp. 648-651.

1880. The Gradual Dispersion of Certain Mollusks in New England. Bull. Essex Inst., XII, pp. 171-176.

Müller, O. F.

1774. Vermium terrestrium et fluviatilium sen animalium infusoriorum helminthicorum et testaceorum, non marinorum, succincta historia.

Needham, J. G., and Betten, Cornelius.

1901. Aquatic Insects in the Adirondacks. Bull. N. Y. State Mus., XLVII, p. 402.

Nelson, William.

1877. Note on Limnæa stagnalis. Journ. Conch., I, p. 216.

Newberry, J. S.

1851. Geographical Distribution of Certain Species of Fluviatile and Terrestrial Shells. Proc. A. Assoc. Ad. Sci., V, p. 105.

Nicholson, H. Alleyne.

1872. Preliminary Report on Dredgings in Lake Ontario. Ann. Mag. Nat. Hist., iv, X, p. 276.

Nordenskiöld, Erland.

1900. Ostersjöns Nutida Sötvattensmolluskfauna jämförd med Ancylussjöns. 
Bihang till Kong. Svenska Vetenskaps-Akademiens Handlingar, Band 26, Afd. IV, No. 11, 1900.

Norris, A. A.

1901. A List of the Mollusca of Eagle, Center and Pine Lakes, Kosciusko County, Indiana. Proc. Ind. Acad. Sci., pp. 118-119.

Nylander, Olof O.

1895. Shells of Aroostook Co., Maine. Nautilus, VIII, pp. 125-126, March.

1897. Fresh-water Shells in the Northeast of Maine. Nautilus, XI, pp. 9-12. May.

1900. A List of Shells from Northeast Maine. Nautilus, XIII, pp. 102-106. January.

1901, a. Shells of the Marl-Deposits of Aroostook County, Maine, as Compared with the Living Forms in the Same Locality. Nautilus, XIV, pp. 101-104. January.

1901, b. The Original Locality of Limnæa Ampla Mighels. Nautilus, XV, pp. 127-129. March.

1901, c. Distribution of Limnæa Emarginata, Say, and the var. Mighelsi, Binney, in Fish River, Aroostook Co., Maine. Printed by the Author.

1908. Additional Shells Found in Aroostook Co., Maine. Nautilus, XXII, p. 19. June.

1909. Fossil and Living Shells Found in Little Mud Lake, Westmanland, Aroostook Co., Maine. Nautilus, XXII, pp. 105-106. February.

Ortmann, A. E.

1909. The Destruction of the Fresh-water Fauna in Western Pennsylvania. Proc. Amer. Phil. Soc., XLVIII, pp. 90-110.

Osborn, Henry L.

1899. Pond Snails. Popular Science, XXXIII, p. 3.

Owen, David Dale.

1856. Geological Survey of Kentucky. Quaternary Deposits, pp. 17-29.

Packard, A. S.

1875. Life Histories of the Mollusca. Amer. Nat., IX, pp. 282-307.

Palache, Charles.

1902. See Lawson, Andrew C.

Pascal, L.

1891. (The Egg of Limnæa auricularia.) Journ. de Conch., XXXI, p. 9.

Pauly, A.

1877. Uber die Wasserathmung der Limnæiden. Gekrönte Preisschrift, 47 pp. München.

Peale, A. C.

1879. Report on the Geology of the Green River District. An. Rep. U. S. Geol. and Geog. Surv. Terr., XI, p. 511.

Perkins, George H.

1869. Molluscan Fauna of New Haven. A Critical Review of all the Marine, Fresh Water and Land Mollusca of the Region with Descriptions of Many of the Living Animals and of Two New Species. Part I, Cephalopoda and Gasteropoda. Proc. Bost. Soc. Nat. Hist., XIII, p. 109.

Pfeiffer, Dr. Louis.

1839. Wiegmann's Archiv. fur Naturg., p. 354. 
1858, a. Fernere Nachrichten über die Mollusken-Fauna der Insel Cuba. Mal. Blätt., V, p. 1.

1858, b. Zur Molluskenfauna der Insel Cuba. Mal. Blätt., V, p. 173.

Pfeiffer, L., and Hjalmason, J.

1858. Beiträge zur Faune von Westindien. Mal. Blätt., V, p. 135.

Pilsbry, H. A., and Roads, S. N.

1896. Contributions to the Zoology of Tennessee. No. 4, Mollusks. Proc. Phil. Acad., pp. 487-506.

Pilsbry, H. A.

1886, a. Notes on Some Eastern Iowa Snails. Amer. Nat., XX, p. 75.

1886, b. Notes on Some New Orleans Fresh-water Shells. Conch. Exch., I, p. 20.

1891, a. Land and Fresh-water Mollusks Collected in Yucatan and Mexico. Proc. Phil. Acad., pp. 310-334.

1891, b. Mollusca of Nantucket, Mass. Proc. Phil. Acad., pp. 406-407.

1894, a. Critical List of Mollusks Collected in the Potomac Valley. Proc. Phil. Acad., pp. 11-31.

1894, b. Guide to the Study of Helices. Manual of Conchology, Vol. IX, second ser. Philadelphia.

1896. Limnæa Bulimoides Lea Resisting Drought. Nautilus, X, p. 96. December.

1898, a. Note on the Florencia Formation. Amer. Journ. Sci., iv, V, pp. $232,233$.

1898, b. Shells of Redding, Shasta Co., California. Nautilus, XII, pp. 59-60. September.

1899, a. Mollusks collected by R. C. McGregor in Northern California. Nautilus, XIII, pp. 64-67. October.

1899, b. Note on Some New Mexican Shells. Nautilus, XIII, p. 79. November.

1899, c. Descriptions of New Species of Mexican Land and Fresh-water Mollusks. Proc. Phil. Acad., pp. 391-405.

1900, a. Land Shells from Rejectamenta of the Rio Grande at Mesilla, New Mexico, and of the Gallinas River at Las Vegas, N. M. Nautilus, XIV, pp. 9-10, May.

1900, b. On the Zoological Position of Partula and Achatinella. Proc. Phil. Acad., pp. 561-567.

1900, c. Notes on Certain Mollusca of Southwestern Arkansas. T. c., pp. 449-459.

1903, a. Mollusca of Western Arkansas and Adjacent States, with a Revision of Paravitrea. Proc. Phil. Acad., pp. 193-214.

1903, b. Mexican Land and Fresh-water Mollusks. Proc. Phil. Acad. Sci., pp. 761-789.

1903, c. Shells of Douglas Co., Central Washington. Nautilus, XVII, p. 84. November.

1903, d. A New Hawaiian Limnæa. Proc. Phil. Acad., 1903, p. 790.

1905. Land and Fresh-water Mollusks of Alaska and Adjacent Regions. (Review of Dr. Dall's paper.) Nautilus, XIX, pp. 93-95. December. 
1906. Shells of Grant, Valencia Co., New Mexico. Nautilus, XIX, p. 130. March.

1910. Lymnæa cubensis aspirans, n. subsp. Nautilus, XXIII, p. 120.. February.

Pilsbry, H. A., and Cockerell, T. D. A.

1900. Records of Mollusca from New Mexico. Nautilus, XIV, pp. 85-86. December.

Pilsbry, H. A., and Ferriss, J. H.

1906, a. Mollusca of the Southwestern States, II. Proc. Phil. Acad., XLVIII, pp. 123-175.

1906, b. Mollusca of the Ozarkian Fauna. Proc. Acad. Nat. Sci., Phil, XLVIII, pp. 529-567.

1909. Mollusks from around Albuquerque, New Mexico. Nautilus, XXII, pp. 103-104. February.

1910, a. Mollusca of the Southwestern States, III. The Huachuca Mountains, Arizona. Proc. Phil. Acad., 1909, pp. 495-518.

1910, b. Mollusca of the Southwestern States, IV. The Chiricahua Mountains, Arizona. Proc. Phil. Acad., 1909. pp. 44-14\%.

Pleas, Elwood.

1891. Nautilus, IV, p. 131. March.

Poirier, Pascal.

1883. Report of Conchological Branch. Trans. Ottawa Field Nat. Club., I, p. 74.

1884. See Latchford, F. R.

1885. See Latchford, F. R.

1886. See Latchford, F. R.

Prasch, A.

1843. Archiv. fur Naturges. pt. 1, p. 71.

Pratt, W. H.

1876. List of Land and Fresh Water Shells Found at Davenport, Iowa. Proc. Daven. Acad. Sci., I, pp. 165-168.

Presas, Manuel J.

1865. Moluscos terrestres y fluviatiles encontrados por Gundlach y Presas en una excursion de Ceiba Mocha al Pan y Palenque. In Poey, Repertorio Fisico-Natural de la Isla de Cuba, I, pp. 264.

Prescott, William.

1842. Catalogue of the Marine, Fluviatile and Terrestrial Shells of Massachusetts. Lynn.

Price, Sadie F.

1900. Mollusca of Southern Kentucky. Nautilus, XIV, pp. 75-79. November.

Prime, Henry.

1880. The Mollusca of Riverdale, New York City. Forest \& Stream, XV, p. 245.

Poey, Felipe.

1856-58. Molluscorum species novæ. Memorias sobre la Historia Natural de la Isla de Cuba, accompanadas de sumarios latinos y extractos en Frances. Havana, Cuba, II. 
Potiez, Vallery Louis Victor, et Michaud, A. L. G.

1838. Galerie des Mollusques, ou Catalogue, etc., etc., des Mollusques et Coquilles du Muséum de Donai. Vol. I, Paris.

Rafinesque, C. S.

1819. Podrome de 70 nouveaux genres d'animaux, etc. Journ. de Physique, de Chemie, et de Histoire Naturelle, LXXXVIII, p. 417. June.

_ Sketches of Louisville by Dr. McMurtrie. Shells by Rafinesque, p. 66.

Randolph, P. B.

1898. Shells of Seattle, King Co., Washington. Nautilus, IX, pp. 101-102. January.

1899. Collecting Shells in the Klondike Country. Nautilus, XII,.pp. 109112. February.

Ravenel, Edward.

1834. Catalogue of Recent Shells in the Cabinet of Edward Ravenel. Charleston, S. C.

Read, William.

1845. Catalogue of the Marine, Fluviatile and Terrestrial Shells of Massachusetts. Lynn, Mass.

Reeve, Lovell.

1850. On a New Species of Lymnæa from Thibet. Proc. Zool. Soc. London, p. 49.

1855. Account of the Shells Collected by Captain Sir Edward Beecher, C. B., North of Beechey Island. From the Last Arctic Voyages, being a Narrative of the Expedition of H. M. Ship "Assistance," Under the Command of Capt. Sir Edward Beecher, etc., .London. Vol. II, p. 392.

1860. Elements of Conchology; an Introduction to the Natural History of Shells and of the Animals which form Them. London, I.

1862. On a New Form of Physa, of the Section Ameria, received from George French Angas, Esq., of Angaston, South Australia, Corresponding Member of the Society. Proc. Zool. Soc., 1862, p. 105.

Rhoads, Samuel N.

1896. See Pilsbry, H. A.

1899, a. On a Recent Collection of Pennsylvanian Mollusks from the Ohio River System below Pittsburg. Nautilus, XII, pp. 133-138. April.

1899, b. Annotated List of Land and Fresh-water Shells Recently Collected in the Vicinity of Miami, Florida. Nautilus, XIII, pp. 43-48. August.

1904. A Glimpse of the Shell Fauna of Delaware. Nautilus, XVIII, p. 6367. October.

Roberts, S. R.

1871. Report on the Mollusca. Rep. U. S. Geol. Surv. of Wyoming and Contiguous Territory, 1870, pp. 467-469.

Roper, E. W.

1899. Collecting Land Shells in Southern California. Nautilus, III, pp. 77, 78. November.

Rossmässler, E. A.

1835. Iconographie der Land und Süsswassen-Mollusken, etc. Dresden \& Liepzig. Heft 1. 
Russell, Frances W.

1891. Preliminary Notes on the Geology of Central Nebraska. Amer. Geol., VII, p. 38.

1892. Notes upon Nebraska Tertiary. Amer. Geol., IX, p. 178.

Russell, Israel C.

1884. A Geological Reconnaissance in Southern Oregon. An. Rep. U. S. Geol. Surv., IV, pp. 431-464.

Russell, J. H.

1852. Conspectus of Shells Found in Essex County, etc. Journ. Essex Co. Nat. Hist. Soc., p. 126.

Ruthven, A. G.

1904. Notes on the Mollusks, Reptiles and Amphibians of Ontonagon County, Michigan. Report Mich. Acad. Sci., VI, pp. 188-192.

1906. An Ecological Survey in the Porcupine Mountains and Isle Royale, Michigan. Rep. State Board Geolog. Surv. Mich., 1905, pp. 17-55.

Safford, James M.

1869. Geology of Tennessee, p. 434.

Sager, Abraham.

1839. Report of Dr. Abm. Sager, Zoologist of the Geological Survey (of Michigan). Detroit.

Salisbury, R. D.

1885. See Chamberlin, T. C.

1902. The Glacial Geology of New Jersey. Geol. Surv. N. J., Final Report. Vol. V.

1906. See Chamberlin, T. C.

Samson, F. A.

1883. Notes on the Distribution of Shells, No. IV. Kansas City Rev. Sci., May, 1883, p. 22.

1885. Shells of Pettis County, Missouri. Bull. Sedalia Nat. Hist. Soc., No. 1, pp. 16-28.

1887. Notes on the Distribution of Shells. Amer. Nat., XXI, pp. 83-86.

1891. A Preliminary List of the Mollusca of Arkansas. Ark. Geol. Surv. An. Rep. II, pp. 177-199.

1893. Mollusca of Arkansas. Nautilus, VII, pp. 33-35. July.

Sargent, H. E.

1894. Shell Collecting in Northern Alabama. Nautilus, VII, pp. 121-122. March.

1895. Annotated List of the Mollusca Found in the Vicinity of Clearwater, Wright Co., Minnesota. Nautilus, IX, pp. 87-90. December.

Say, Thomas.

1816. Article "Conchology." American edition of Nicholson's Encyclopedia of Arts and Sciences, II, First Edition. Philadelphia, 1816. Second Edition, IV, 1818. Third Edition, IV, 1819.

1817. Description of Seven Species of American Fresh Water and Land Shells, not Noticed in the Systems. Journ. Phil. Acad., I, pp. 13-18.

1821. Descriptions of Univalve Shells of the United States. Journ. Phil. Acad., II, pp. 150-178.

1822. Descriptions "of Univalve, Terrestrial, and Fluviatile Shells of the United States. Journ. Phil. Acad., II, pp. 370-380. 
1824. Narrative of an Expedition to the Source of the St. Peter's River, etc., etc., under the Command of Major Stephen H. Long, II, Appendix, pp. 256-265. Reprint, pp. 29-32, 128-131.

1825. Descriptions of Some New Species of Fresh-Water and Land Shells of the United States. Journ. Phil. Acad., V, pp. 119-131.

1829. Descriptions of Some New Terrestrial and Fluviatile Shells of North America. New Harmony Disseminator, II, pp. 229-245.

1831. Descriptions of Some New Terrestrial and Fluviatile Shells of North America, 1829, 1830, 1831. Mrs. Say's Reprint, pp. 13-21.

1832-34. American Conchology; or, Descriptions of the Shells of North America. Illustrated by colored figures from original drawings executed from nature. New Harmony, Ind. Part IV, March, 1832; Part VI, April, 1834.

See Binney, complete writings.

Scharff, Robert F.

1907. European Animals.

1909. On the Evidences of a Former Land-bridge between Northern Europe and North America. Proc. Royal Irish Acad., XXVIII, sec. B, pp. 1-28.

Schuchert, Charles.

1905. Catalogue of the Type Specimens of Fossil Invertebrates in the Department of Geology, United States National Museum. Bull. U. S. Nat. Mus., No. 53, Part 1.

Scudder, Newton Pratt.

1885. The Published Writings of Isaac Lea, LL.D., Bull. U. S. Nat. Mus., 23. Semper, Carl.

1874. Ueber die Wachsthums-Bedingungen des Lymnæus stagnalis. Arbeiten aus dem Zoologisch-Zootomischen Institut in Wurzburg, I, 1874 .

1881. Animal Life as Affected by the Natural Conditions of Existence. International Scientific Series, XXX.

Shaffer, David H.

- A Complete List of Land and Fresh Water Shells Found in the Immediate Vicinity of Cincinnati, Ohio. No date.

Sheppard, Mrs.

1829. On the Recent Shells which Characterize Quebec and its Environs. Trans. Lit. \& Hist. Soc., Quebec, I, pp. 188-198.

Shick, Morris.

1895. Mollusk Fauna of Philadelphia and Environs. Nautilus, VIII, pp. 133-140. April.

Shimek, B.

1888. Notes on the Fossils of the Loss at Iowa City, Iowa. Amer. Geol., I, p. 149.

1890. The Mollusca of Eastern Iowa. Bull. Lab. Nat. Hist., Univ. Iowa, I, p. 56.

1893, a. Additional Notes on Iowa Mollusca. Proc. Iowa Acad. Sci., I, pt. IV, pp. 107-111.

1893, b. The Lœss and Its Fossils. Bull. Lab. Nat. Hist., Univ. Iowa, II, p. 89.

1898. Is the Lœss of Aqueous Origin? Proc. Iowa Acad. Sci., V, pp. 32-45. 
1901, a. The Lœss of Iowa City and Vicinity. Bull. Lab. Nat. Hist., Univ. Iowa, V, p. 195.

1901, b. Report of Professor B. Shimek on the Lœss Mollusks in Geology of Pottawattamie County, by J. A. Udden. Iowa Geol. Surv., XI, pp. 261-266.

1901, c. The Lœss of Iowa City and Vicinity. Amer. Geol., XXVIII, p. 344.

1903. Report of Professor B. Shimek on the Fossils from the Lœss of Mills and Fremont Counties. In Geology of Mills and Fremont Counties, by J. A. Udden. Iowa Geol. Surv., XIII, pp. 170-175.

1904. Evidences (?) of Water-deposition of Lœss. Bull. Lab. Nat. Hist., Univ. Iowa, V, No. 4, pp. 369-381.

Shiverick, C. E.

1840? See Taylor, W. K.

Shuttleworth, R. J.

1854. Beiträge Zur näheren Kenntniss der Land-und Süsswasser-Mollusken der Insel Portorico. Mittheilungen der Natur. Gesel. Bern, 1854.

Siebenthal, C. S.

1909. See Darton, N. H.

Siebold, C. Th. von.

1875. Ueber das Anpassungs-Vermögen der mit Lungen athmenden Süsswasser-Molluscen. Sitzungs. der Math. Phys. Classe der K. B. Acad. der Wiss. zu München. Band VI, heft 1, p. 39.

Simpson, C. T.

1886. Contributions to the Mollusca of Florida. Proc. Daven. Acad. Sci., V, pp. 45-72.

1887. On the Distribution of Land and Fresh-water Shells of the Tropics. Conch. Exch., II, pp. 37, 50.

1888. Notes on Some Indian Territory Land and Fresh-water Shells. Proc. Nat. Mus., XI, pp. 449-454.

1889. What is a Species? Nautilus, III, pp. 88-90. December.

1894. Distribution of Land and Fresh-water Mollusks of the West Indian Region, and their Evidence with Regard to Past Changes of Land and Sea. Proc. U. S. Nat. Mus., XVIII, pp. 423-450.

1895. The Classification and Geographic Distribution of the Pearly Freshwater Mussels. Proc. U. S. Nat. Mus., XVIII, pp. 295-343.

1900. Synopsis of the Naiades or Pearly Fresh-Water Mussels. Proc. U. S. Nat. Mus., XXII, pp. 501-1044.

Singley, J. A.

1893, a. List of Pleistocene and Recent Shells. Geol. Surv. Texas, Fourth An. Rep. for 1892, pp. 186-190.

1893, b. Contributicns to the Natural History of Texas. Part I, Texas Mollusca. An. Rep. Geol. Surv. Texas, IV, pp. 297-343.

Small, H. B., and Symes, P. B.

1882. Report of Conchological Branch. Trans. Ottawa Field Nat. Club, I, p. 57.

Smith, Maxwell.

1906. Shells of Richfield Springs, New York, and Vicinity. Nautilus, XX, pp. 89-91. December. 
Smith, Sanderson.

1867. See Hubbard, J. W.

Smith, S. I.

1874. Sketch of the Invertebrate Fauna of Lake Superior. Rep. U. S. Fish Com., 1872-73, pp. 690-707.

Smith, Sanderson, and Prime, Temple.

1870. Report on the Mollusca of Long Island, N. Y., and of its Dependencies. Ann. Lyc. Nat. Hist. N. H., IX, pp. 377-407.

Smith, S. I., and Verrill, A. E.

1871. Notice of the Invertebrata Dredged in Lake Superior in 1871, by the U. S. Lake Survey, under the Direction of General C. B. Comstock, S. I. Smith, Naturalist. Amer. Journ. Sci. Arts, iii, II, pp. 448-454.

Smith, W. Hilles.

1899. Shells and Mastodon. Nautilus, XIII, pp. 34-35. July.

Squyer, Homer.

1894. List of Shells from the Vicinity of Mingusville, Montana. Nautilus, VIII, pp. 63-65. October.

Snyder, W. E.

1896. Land and Fresh-water Shells of Dodge County, Wisconsin. The Museum, III, pp. 11-12.

Sowerby, James de Carle.

1836. Mollusca in Richardson's Fauna Boreali-Americana, III, London, 1836 .

Sowerby, G. B.

1825. A Catalogue of the Shells Contained in the Collection of the Late Earl of Tankerville. London.

Sowerby, G. B., Jr.

1872. Monograph of Limnæa. Reeves, Conch. Icon., XVIII.

Spengel, Dr. J. W.

1881. Die Geruchsorgane und das Nervensystem der Mollusken. In Zeits. fur Wissen. Zool., Vol. XXXV, pp. 333-409, taf. 17-19.

Stanton, T. W.

1909. The Age and Stratigraphic Relations of the "Ceratops Beds" of Wyoming and Montana. Proc. Wash. Acad. Sci., XI, pp. 239-293.

Stanton, T. W., and Knowlton, F. H.

1897. Stratigraphy and Paleontology of the Laramie and Related Formations in Wyoming. Bull. Geol. Soc. Amer., VIII, p. 127.

Standard Natural History.

1884. Edited by J. S. Kingsley. Vol. I, pp. 304-308.

Stearns, Robert E. C.

1891, a. List of North American Land and Fresh-water Shells Received from the U. S. Department of Agriculture, with Notes and Comments Thereon. Proc. U. S. Nat. Mus., IV, pp. 95-106.

1891, b. Notes on the Sculpture of American Limnæas, etc. Nautilus, IV, pp. 121-124. March.

1893, a. Notes on Recent Collections of North American Land, Freshwater, and Marine Shells Received from the U. S. Department of Agriculture. Proc. Nat. Mus., XIV, pp. 743-755.

1893, b. Report on the Land and Fresh-water Shells Collected in California and Nevada by the Death Valley Expedition, including a few Addi- 
tional Species obtained by Dr. C. Hart Merriam and Assistants in Parts of the Southwestern U. S. North American Fauna No. VII, pp. 269-283, U. S. Dept. Agric., Div. of Ornith. \& Mam.

1899. Mollusca Associated with Mastodon Remains. Nautilus, XIII, pp. 100-101. January.

1900. List of Shells Collected by Vernon Bailey in Heron and Eagle Lakes, Minnesota, with Notes. Proc. Nat. Mus., XII, pp. 135-138.

1901. The Fossil Fresh-water Shells of the Colorado Desert, Their Distribution, Environment and Variation. Proc. Nat. Mus., XXIV, pp. 271-299.

1902. Fossil Shells of the John Day Region. Science, n. s., XV, p. 153.

1906. Fossil Mollusca from the John Day and Mascall Beds of Oregon. Univ of Cal. Publication, Geology V, p. 67.

Steenstrup, Prof. Japetus.

1879. Bericht gung rücksichtlich der von Nrn. S. Clessin aufgestellten Limnæa steenstrupi aus Island. Mal. Blätt, n. s., I, p. 16.

Stein, Frederick.

1880. Synopsis of the Molluscous Fauna of Indiana. Ind. Bu. Stat. \& Geol.,

Sterki, Victor. pp. 453-467.

1886. Die Mollusken der Umgebung von New Philadelphia, O. Nach. Mal. Gesell, XVIII, p. 10.

1891, a. Food of Limnæidæ. Nautilus, V, p. 94. December.

1891, b. Odontophores of Limnæidæ. Nautilus, V, p. 95. December.

1893. Growth Changes of the Radula in Land Mollusks. Proc. Phil. Acad. Sci., pp. $388-400$.

1900. List of the Land and Fresh-water. Mollusca of Tuscarawas County, Ohio. An. Rep. Ohio State Acad. Sci., VIII, pp. 30-42. Reprint, pp. 1-13.

1901. Shells Collected in the Sand of a Dry Salt Lake near Eddy, New Mexico. List and Notes. An. Rep. Geol. Surv. Texas, III, pp. 261265.

1902. Some Additions and Corrections to the List of Land and Fresh-water Mollusca of Tuscarawas Co., Ohio. Ohio Naturalist, II, No. 8, p. 286.

1907. A Preliminary Catalogue of the Land and Fresh-water Mollusca of Ohio. Proc. Ohio State Acad. Sci., IV, Part 8, pp. 365-402. Special Papers, No. 12.

1909. Sphærium pilsbryanum, n. sp. Nautilus, XXII, pp. 141-142. April.

Stimpson, William.

1851. Shells of New England; a Revision of the Synonymy of the Testaceous Mollusks of New England, with Notes on Their Structure and Their Geographical and Bathymetrical Distribution, with Figures of New Species. Boston.

Strebel, Hermann.

1873. Ein Beitrag zur Fauna Mexikanisher Land-und Süsswasser Conchylien. Abhan. aus den Gebiete der Natur. hereausgegeben von dem Naturwissenschaftlichen Vereins in Hamburg, VI, 1 abth.

Strecker, John K., Jr.

1908. The Mollusca of McLennan County, Texas. Nautilus, XXII, pp. 63-67. November. 
Streng, L. H.

1896. A New Variety of Limnæa. Nautilus, IX, p. 123. March.

Stubbs, Arthur G.

1898. (Diseased Lymnæas leave shells.) Journ. Conch., IX, p. 112.

Stupakoff, S. H.

1894. Land and Fresh-water Shells of Allegheny County, Pa. Nautilus, VII, pp. 135-136. April.

Swallow, G. C.

1855. Second Annual Report, Geol. Surv. of Missouri, pp. 69-76, 215.

Sykes, E. R.

1894. Note on Limnæa auricularia. Journ. of Mal., III, p. 34.

Symes, P. B.

1882. See Small, H. B.

Taylor, Geo. W., and Latchford, F. R.

1890. See Latchford, F. R.

Taylor, Geo. W.

1892. Preliminary Check-list of the Land and Fresh-water Mollusca of Canada. Ottawa Nat., VI, p. 33.

1893. Land and Fresh-water Shells in the Rocky Mountains. Nautilus, VII, pp. 85-86. December.

1895. The Present Condition of Canadian Conchology. Ottawa Nat., VIII, p. 143.

1895. The Land and Fresh-water Shells of Alberta. Ottawa Nat., IX, p. 173. Taylor, John W.

1890. The Variation of Limnæa Peregra Müll. Journ. Conch., VI, p. 284.

Taylor, W. H., and Shiverick, C. F.

1840? Catalogue of Shells Found In and Near the County of Bristol, in the State of Massachusetts. New Bedford.

Tight, W. G.

1903. Drainage Modifications in Southeastern Ohio and Adjacent parts of West Virginia and Kentucky. U. S. Geol. Surv., Professional Papers, No. 13.

Todd, J. E.

1878. Richthofen's Theory of the Lœss, in the Light of the Deposits of the Missouri. Proc. Amer. As. Ad. Sci., XXVII, pp. 231-239.

Todd, J. E.

1896. The Moraines of the Missouri Coteau and Their Attendant Deposits.

Bull. U. S. Geol. Surv., No. 144.

1898. New Light on the Drift in South Dakota. Proc. Iowa Acad. Sci., VI, pp. 122-130.

1899. The Moraines of Southeastern South Dakota and Their Attendant Deposits. Bull. U. S. Geol. Surv., No. 158.

Todd, J. E., and H. Foster Bain.

1895. Interlœssial Till near Sioux City, Iowa. Proc. Iowa Acad. Sci., II, pp. 20-23.

Tristram, H. B.

1861. Catalogue of a Collection of Terrestrial and Fluviatile Molluscs, made by O. Salvin, Esq., M. A., in Guatemala. P. Z. S., p. 229. 
Troschel, F. H.

1839. Review of Molluscan Literature. Weigmann's Archiv. fur Natur., V, pt. 2, p. 224.

True, Joseph.

1857. Shells Gathered about Salem, Mass., by Joseph True, with Particular Localities Designated, and Remarks on the Species. Proc. Essex Inst., II, pp. 187-197.

Tryon, Geo. W., Jr.

1861. On the Mollusca of Harper's Ferry, Virginia. Proc. Phil. Acad., pp. 396-399.

1863, a. Descriptions of New Species of Fresh-water Mollusca, belonging to the Families Amnicolidæ, Valvatidæ and Limnæidæ, inhabiting California. Proc. Phil. Acad., pp. 147-150.

1863, b. Descriptions of Two New Species of Fresh-water Mollusca, from Panama. Proc. Phil. Acad., p. 146.

1865, a. Catalogue of Mollusca, Collected by Prof. D. S. Sheldon, at Davenport, Iowa. Amer. Journ. Conch., I, pp. 68-70.

1865, b. Descriptions of New Species of North American Limnæidæ. Amer. Journ. Conch., I, pp. 223-231.

1865, c. Catalogue of the Species of Limnæa inhabiting the United States. Amer. Journ. Conch., I, p. 247-258.

1866, a. Descriptions of New Fresh-water Shells of the United States. Amer. Journ. Conch., II, pp. 4-7.

1866, b. Descriptions of New Exotic Fresh-water Mollusca. Amer. Journ. Conch., II, pp. 8-11.

1866, c. Descriptions of New Fluviatile Mollusca. Amer. Journ. Conch., II, pp. 111-113.

1867. Review of Binney's Land and Fresh-water Shells of North America, Part II. Amer. Journ. Conch., III, pp. 195-197.

1868. Notes on Mollusca Collected by Dr. F. V. Hayden in Nebraska. Amer. Journ. Conch., IV, pp. 150-151.

1872. Continuation of Haldeman's Monograph of the Fresh-water Univalve Mollusca of the United States. Philadelphia; Limnæa, pp. 83-124.

1873. Land and Fluviatile Mollusca from Utah. Proc. Phil. Acad., 1873, pp. 285-286.

1882-84. Structural and Systematic Conchology, III, p. 100, 1884; also Vol. I.

Tufts, Samuel, Jr.

1856. A List of Shells Collected at Swamscot, Lynn and Vicinity. Proc. Essex Inst., I, pp. 25-32.

1859. Catalogue of Shells Deposited in the State Cabinet. Cat. Mass. State Cabinet, Appendix, pp. 85-88.

Tyrrell, J. B.

1887. Report on a Part of Northern Alberta and Portions of Adjacent Districts of Assiniboia and Saskatchewan. Rep. Geol. \& Nat. Hist. Surv. Can., n. s., II, E.

Udden, J. A.

1898. Some Preglacial Soils. Proc. Iowa Acad. Sci., V, pp. 102-104.

1901. Geology of Pottawattamie County. Iowa Geol. Surv., XI, pp. 199277. 
1902. Geology of Mills and Fremont Counties. Geol. Surv. Iowa, XIII, pp. $123-183$.

Ulffers, H. A.

1855. Mollusca of Southern Illinois. Trans. Ill. State Ag. Soc., I, 1853-54, pp. $610-612$.

Ullyett, Henry.

1886. Note on Limnæa stagnalis. Science Gossip, XXII, p. 214.

Upham, Warren.

1895. The Glacial Lake Agassiz. Monograph, XXV, U. S. Geol. Surv.

Valenciennes, M. A.

1833. Coquilles Univalves Terr. et Fluv., etc., Recueil d'Observations de Zoologie et d'Anatomie Comparée, etc., II.

Vaughan, T. Wayland.

1893. Notes on a Collection of Mollusks from Northwestern Louisiana, and Harrison County, Texas. Amer. Nat., XXVII, pp. 944-961.

Verrill, A. E.

1871. See Smith, S. I.

1873, a. Remarks on Certain Errors in Mr. Jeffrey's Article on "The Mollusca of Europe Compared with Those of Eastern North America." Ann. Mag. N. H., iv, XI, p. 206.

1873, b. Remarks on Certain Errors in Mr. Jeffrey's Article on "Mollusca of Europe Compared with Those of Eastern North America." Amer. Journ. Sci. (iii), V, pp. 465-472.

Wailes, B. L. C.

1854. Report on the Agriculture and Geology of Mississippi, Embracing a Sketch of the Social and Natural History of the State. Invertebrate Fauna, pp. 336-339.

Walker, Bryant, and Beecher, Chas.

1876. List of Land and Fresh-water Shells Found Within a Circuit of Four Miles about Ann Arbor, Mich. Proc. Ann Arbor Sci. Asso., p. 43.

Walker, Bryant.

1879. Catalogue of the Shell-bearing Mollusca of Michigan. Journ. Conch., II, p. 325 .

1892-3. The Shell-bearing Mollusca of Michigan. Nautilus, VI, pp. 31-36, July, 1892 ; pp. 135-141, April, 1893.

1894, a. Shells of the Saginaw Valley, Michigan. Nautilus, VII, pp. 125129. March.

1894, b. Review of Our Present Knowledge of the Molluscan Fauna of Michigan. Privately printed, 1894. Read before the Michigan Academy of Science, Dec. 27, 1894.

1895. A Month with the Michigan Fish Commission. Nautilus, IX, pp. 2-6. May.

1898. Mollusca Contemporaneous with the Mastodon. Nautilus, XI, pp. 121-122. March.

1899. Station of Limnæa Gracilis. Nautilus, XII, pp. 119-120, February; p. 131, March.

1900, a. Note on the Habits of Limnæa Mighelsi W. G. Binney. Nautilus, XIV, pp. 8-9. May. 
1900, b. The Origin and Distribution of the Land and Fresh-water Mollusca of North America. An. Rep. Mich. Acad. Sci., III, pp. 43-61.

1903. On the Shells of Marls. Geol. Surv. Mich., VIII, pt. 3, pp. 97-102. 1906, a. An Illustrated Catalogue of the Mollusca of Michigan. Part I, Terrestrial Pulmonata. Rep. Mich. Geol. Surv., 1905, pp. 427-531.

1906, b. A List of Shells from Nebraska. Nautilus, XX, pp. 81-83. November.

1907. Notes on Planorbis, -I. Nautilus, XXI, pp. 61-64. October.

1908, a. New Michigan Lymnæas. Nautilus, XXII, pp. 4-9. May.

1908, b. Lymnæa Umbilicata C. B. Adams in Canada. Ottawa Nat., XXII, pp. 89-91.

1909, a. On the Use of Certain Preoccupied Names for European Mollusca. Journ. of Conch., XII, pp. 238-240. January.

1909, b. Notes on Planorbis II, P. Bicarinatus. Nautilus, XXIII, pp. 1-10. May.

1909, c. Annotated List of the Mollusca of Isle Royale, Michigan. An. Report Mich. Geol. Surv., 1908, pp. 281-298.

1910. The Distribution of Margaritana Margaritifera (Linn.) in North America. Proc. Mal. Soc., IX, pt. ii, pp. 126-145.

Walker, Bryant, and Lane, A. C.

1900. Recent Shells of the Marl. Geol. Surv. Mich., VII, pt. 2, pp. 247-252.

Walker, Bryant, and Ruthven, A. G.

1906. Annotated List of the Molluses of the Porcupine Mountains and Isle Royale, Michigan. Rep. Geol. Surv. Mich., 1905, p. 93.

Walker, R. D., and Coolidge, Wm. H.

1908. Mollusca of Keene, New Hampshire. Nautilus, XII, p. 32. July.

Walter, Herbert E.

1906. The Behavior of the Pond Snail Lymnæus Elodes Say. Cold Spring Harbor Monographs, VI. (Brooklyn Inst. of Arts \& Sci.)

Walton, John.

1891. The Mollusca of Monroe County, N. Y. Proc. Roch. Acad. Sci., II, p. $3,18$.

1898. Mollusca of Monroe Co., N. Y. The Museum, IV, No. 9, pp. 132-134.

Ward, Henry B.

1895. A Biological Examination of Lake Michigan in the Traverse Bay Region. Bull. Mich. Fish. Com., No. 5, 1895.

Warren, G. K.

1875. Report of the Chief of Engineers, Part I, pp. 381-402.

Webster, Clement L.

1888. Notes on the Geology of Johnson County, Iowa. Amer. Nat., XXIJ, p. 408.

Wegemann, Carroll $\mathrm{H}$.

1909. Some Notes on River Development in the Vicinity of Danville, Illinois. The University Studies (Illinois), III, No. 2, pp. 27-43.

Westerlund, C. A.

1883. Malakologische Miscellen II, III. Nacheinige von der Vega-expedition gesammelte mollusken. Nacht. Mal. Ges., XV, p.' 164.

1885. Land och Sötvatter-Mollusker, insamlade under Vega-expeditionen. Vega Expd. Vetenskapliga Iakttagelser, IV, pp. 141-220. 
1886-90. Fauna der in der palærktischen Region lebenden Binnen-Conchylien. Two volumes with Supplements. Berlin.

Wetherby, A. G.

1879. Notes on Some New or Little Known North American Limnæidæ. Journ. Cin. Soc. Nat. Hist., II, pp. 93, 100.

1881. On the Geographical Distribution of Certain Fresh-water Mollusks of North America, and the Probable Causes of Their Variation. Journ. Cin. Soc. N. H., IV, pp. 156-166.

Wheat, Silas C.

1907, a. List of Long Island Shells. Bull. Brook. Conch. Club., I, p. 9.

1907, b. Shells in City Gardens and Ponds. L. c., p. 6.

Wheatley, Chas. M.

1845. Catalogue of the Shells of the United States, with Their Localities. New York, Ed. 2, 1845.

White, C. A.

1876. Invertebrate Paleontology of the Plateau Province. Powell's Rep. Geol. Uinta Mts., p. 74.

1877. Paleontological Papers No. 3. Catalogue of the Invertebrate Fossils hitherto Published from the Fresh- and Brackish-Water Deposits of the Western Portion of North America. Bull. U. S. Geol. \& Geog. Surv. Terr., III, p. 607.

1878. Paleontological Papers No. 6; Descriptions of New Species of Invertebrate Fossils from the Laramie Group. Bull. U. S. Geol. Surv. Terr., IV, p. 707.

1879. Report on the Paleontological Field-work for the Season of 1877. An. Rep. U. S. Geol. \& Geog. Surv. Terr., XI, p. 161.

1880, a. On the Antiquity of Certain Subordinate Types of Fresh-water and Land Mollusca. Amer. Journ. Sci. and Arts, ii, XX, p. 44. Also Ann. Mag. N. H., v, VI, p. 247.

1880, b. Descriptions of New Invertebrate Fossils from the Mesozoic and Cenozoic Rocks of Arkansas, Wyoming, Colorado and Utah. Proc. U. S. Nat. Mus., III, p. 157.

1883, a. A Review of the Non-Marine Fossil Mollusca of North America. 3rd An. Rep. U. S. Geol. Surv., p. 403.

1883, b. Contributions to Invertebrate Paleontology No. 4; Fossils of the Laramie Group. 12th An. Rep. U. S. Geol. and Geog. Surv. Terr., pt. 1, p. 49.

1886, a. On the Fresh-water Invertebrates of the North American Jurassic. Bull. U. S. Geol. Surv., No. 29.

1886, b. On the Relation of the Laramie Molluscan Fauna to that of the Succeeding Fresh-water Eocene and other Groups. Bull. U. S. Geol. Surv., No. 34.

1890. On the Biological and Geological Significance of Closely Similar Fossil Forms. Proc. Am. A. A. Sci., XXXIX, p. 239.

1895. The Bear River Formation and its Characteristic Fauna. Bull. U. S. Geol. Surv., No. 128.

White, J. J.

1899. Shells of Lake Worth, Florida. Nautilus, XII, pp. 142-143. April. 
Whiteaves, J. F.

1861. On the Land and Fresh-Water Mollusca of Lower Canada, with Thoughts on the General Geographical Distribution of Animals and Plants Throughout Canada. Can. Nat. \& Geol., VI, p. 452-459.

1863. On the Land and Fresh-water Mollusca of Lower Canada, part I, Can. Nat. \& Geol., VIII, pp. 50-65; part II, pp. 98-113.

1885. Report on the Invertebrata of the Laramie and Cretaceous Rocks of the Vicinity of the Bow and Belley Rivers and Adjacent Localities in the North-West Territory. Geol. and Nat. Hist. Surv. Can., Cont. Can. Paleont., I, pt. 1, p. 1.

1887. On some Fossils from the Cretaceous and Laramie Rocks of the Saskatchewan and its Tributaries Collected by Mr. J. B. Tyrrell in 1885 and 1886. Rep. Geol. \& Nat. Surv. Can., n. s., II, Appendix, p. $153 \mathrm{E}$.

1895. Recent Mollusca from the Headwaters of the Ottawa. Ottawa Nat., IX, p. 22.

1901. Notes on some Land and Fresh-water Mollusca from Fort Chimo, Ungava Bay, Ungava. Ottawa Nat., XIV, p. 221.

1902. Notes on some Fresh-water and Land Shells from Keewatin, Northern - Ontario and British Columbia. Ottawa Nat., XVI, p. 91.

1905, a. Notes on some Fresh-water Shells from the Yukon Territory. Ottawa Nat., XIX, pp. 63-65.

1905, b. List of a Few Species of Land and Fresh-water Shells from the Immediate Vicinity of James Bay, Hudson Bay. Ottawa Nat., XIX, p. 66 ; Nautilus, XIX, p. 4.

1906, a. List of Land and Fresh-water Shells from the District of Keewatin, collected by W. McInnes in 1904. Rep. Geol. Surv. Canada, 1905, pp. 160-164 A.

1906, b. List of some Fresh-water Shells from North-Western Ontario and Keewatin. Ottawa Naturalist, XX, pp. 29-32.

1906, c. Notes on some Land and Fresh-water Shells from British Columbia. Ottawa Naturalist, XX, pp. 115-119.

Whitfield, R. P.

1882. Description of Lymnæa (Bulimnæa) Megasoma, Say, with an Account of Changes Produced in the Offspring by Unfavorable Conditions of Life. Bull. Amer. Mus. N. H., I, pp. 29-37.

Whittemore, T. J.

1854. Notes on Lymnæa and Planorbis. Proc. Bost. Soc. Nat. Hist., V, p. 39.

1859. Notes on Mohawk Shells. Proc. Bost. Soc. N. H., VII, p. 151.

Wiedersheim, Prof.

1879. Zur Biologie von Limnæa auriculata. Zoölogischer Anzeiger, II, pp. 572-573.

Willem, Victor.

1896. Observations sur la Respiration Cutanée des Limnées et son Influence sur leur croissance. Bull. Acad. Roy. des Science, Belg., iii, XXXII, p. 563 . 
Williams, J. W.

1889. The Fluid Emitted by Limnæa Stagnalis, Journ. Conch., VI, p. 122.

hy — "Shell-Collectors' Handbook." Date not ascertained.

Williamson, A. E.

1861. Note on Land and Fresh Water Shells collected in the Environs of Toronto, C. W. Canadian Journ., n. s., VI, p. 327.

Willis, Bailey.

Paleogeographic Maps of North America, 13, Eocene-Oligocene North America. Journ. Geol., XVII, pp. 503-505.

Wiswall, Mrs. E. C.

1897. Shells of Southern Wisconsin. Nat. Sci. Journ., I, No. 2, pp. 47-48.

Witter, F. M.

187-. History of Muscatine County, Iowa. pp. 330-332, 187-.

1878. List of Mollusca Collected at Muscatine, Iowa, U. S. A., Journ. Conch., I, p. 383.

1879. Notes on the Lœess. Muscatine Tribune, 1879. Read before Muscatine Acad. Sci., Feb. 10, 1879.

1890. .Notes on some Shells, Ferns, etc., Collected in Decatur County, Iowa, and Lyon County, Kansas, in the Summer of 1886. Proc. Iowa Acad. Sci., I, pp. 17-18.

Wright, Fred Eugene.

1905. Report of Progress in the Porcupines. Rep. State Bd. of Geol. Surv. Mich., for 1903, p. 35.

Wolf, John.

1870, a. Descriptions of Three New Species of Shells. Amer. Journ. Conch., V, p. 198.

1870, b. Catalogue of the Shell-bearing Mollusca of Fulton County, Illinois. Amer. Journ. Conch., VI, pp. 27-29.

Wood, Williard M.

1891. Mollusks of San Francisco County. Nautilus, V, pp. 54, 58. September.

Woodward, S. P.

1856. On the Land and Fresh-water Shells of Kashmir and Tibet, Collected by Dr. T. Thomson. Proc. Zool. Soc. London, 1856, p. 185.

Woodworth, T. B.

1894. The Relation between Baseleveling and Organic Evolution. Amer. Geol., XIV, p. 209.

Yarrow, Dr. H. C.

1875. Report upon the Collections of Terrestrial and Fluviatile Mollusca made in Portions of Colorado, Utah, New Mexico and Arizona during the Years 1872, 1873 and 1874. U. S. Geog. Surv. West 100th Merid., V, p. 923-954.

Yung, E.

1878. Contributions a l'histoire de l'influence des milieux physiques sur les etres vivants. Arch. Zool. Exper. et Gen., VII, pp. 251-282. 


\section{DESCRIPTION OF PLATES.}

PLATE I.

Galba reflexa (SAY). Animal removed from shell, dissected, and the organs separated. 1, buccal sac; 2 , œsophagus; 3 , gizzard; 4, crop; 5 , intestine; 6, pyloric portion of stomach; 7, rectum; 8 , anus; 9 , liver or digestive gland; 10 , salivary gland; 11 , ducts of salivary-gland; 12 , spire portion of body, containing one lobe of the digestive gland; 13, penis-sac; 14, vas deferens; 15, anterior protractor muscles of penis-sac; 16, posterior protractor muscles of penis-sac; 17 , penis; 18 , retractor muscle of penis; 19 , retractor of penis-sac; 20 , penial opening ; 21 , vaginal opening; 22, duct of receptaculum seminis; 23 , receptaculum seminis; 24, first accessory albuminiparous gland; 25, second accessory albuminiparious gland; 26 , oviduct; 27 , uterine portion of oviduct; 28 , albuminiparous gland; 29, posterior portion of prostate; 30 , anterior enlarged portion of prostate; 31, prostatic portion of vas deferens; 32 , ovisperm duct; 33, ovotestis ; 34 , ventricle; 35 , auricle; 36 , pericardiac cavity; 37 , pulmonary vein; 38 , plexus of blood vessels on left lobe of kidney; 39 , pulmonary sac or rete; 40 , glandular portion of kidney, or renal organ; 41 , ureter; 42 , cut edge of muscles connecting head with velum; 43 , velum; 44 , muscular collar of velum; 45 , cut edge of head; 46 , tentacle; 47 , supra-esophageal ganglia; 48 , nerve to head or penis; 49 , nerve to penis-sac; 50 , nerve of female genital organs; 51 , columella muscles and foot retractor muscles; 52 , right retractor muscle of buccal sac.

\section{PLATE II.}

Figure A. Shell of Lymnaa, to illustrate different parts. Much enlarged. 1, spire; 2 , aperture; 3 , body whorl; 4 , suture; 5 , parietal wall; 6 , columella or inner lip; 7 , peristome or edge of outer lip; 8 , umbilical chink; 9 , sculpture of growth lines and spiral lines producing the characteristic decussated appearance of the surface.

B. Young Lymnea just previous to its escape from the egg.

C. Trochosphere stage of Lymnaa stagnalis LinNe. 1, mouth; 2, velum. (After Lankester.)

D. Veliger stage of Lymnaa stagnalis LiNNe. 1, mouth; 2, velum; 3, foot; 4 , tentacle; 5 , eye; 6 , shell (after Lankester).

\section{PLATE III.}

All figures are greatly magnified.

Figure A. One-half complete row of teeth of Galba reflexa (SAY); c, central tooth; $1-12$, lateral teeth; $13-15$, transition teeth; $16-33$, marginal teeth. X 300 .

B. Teeth of Lymnca stagnalis LinNe, to show position of central tooth in relation to lateral teeth. The first lateral to the left and the first three laterals to the right are shown. Also, the two rows and the median cusp of a third row. $X 516$.

C. Lateral tooth of Lymnaa showing named parts. 1, base of attachment; 2 , reflection; 3 , cutting portion of tooth; 4 , entocone or 
inner cusp; 5 , mesocone or middle cusp; 6, ectocone or outer cusp. X 516.

D. First lateral and a marginal (13) tooth of Galba reflexa, to show appearance when worn by use. X 516 .

E. Sculpture of Lymnaa consisting only of growth lines. (X 50.)

F. Sculpture of Lymnaa showing the breaking up of the rib-like growth lines to form pseudo-spiral lines. (X 50.)

G. Galba reflexa (SAY), showing position of openings into body. 1. respiratory opening; 2 , anus; 3 , orifice to female organs; 4 , ori fice of male organ.

H. Animal of Galba obrussa (SAY), from above.

I. Animal of Galba emarginata mighelsi (Binney), from the side.

J. The same, from below.

$\mathrm{K}$. The same, from above. 1 , eye; 2 , tentacle; 3 , velum; 4 , foot; 5 , respiratory siphon; 6 , edge of mantle forming the collar, which closely embraces the outer and inner lips.

\section{PLATE IV.}

Figure A. Galba pilsbryi (Hemphill). Type, drawn by H. A. Pilsbry. Enlarged.

B. Galba pilsbryi (Hemphill). Side view of last whorl. Drawn by H. A. Pilsbry. Enlarged.

C. Galba bakeri (WALkeR). Type, drawn by Bryant Walker. Enlarged.

D. Innervation of female organs of Lymnaa (after Lacaze-Duthiers).

1 , oviduct; 2 , penis; 3 , duct of receptaculum seminis; 4 , nerve;

5 , anterior pallial nerve; 6 , right pallial nerve.

E. Egg capsule of Lymnœa. (X 8.)

F. Retractor muscles of Galba reflexa. 1, buccal sac; 2, right and left retractors of buccal sac; 3 , penis-sac retractor; 4, penis retractor; 5, muscles protracting and depressing the buccal sac. (Greatly enlarged.)

G. Male organs of Lymnca. 1, penis partly everted in penis-sac; 2, penis fully inverted; $p$, penis; ps, penis-sac; vd, vas deferens. Note the different shape of the penis-sac in the two conditions.

H. Cross sections of penis of Galba reflexa ( $\mathrm{SAy}$ ), to show the longitudinal internal folding. The particular position of each section is indicated on the outline to the left.

I. Comparisons of the length of the penis and the penis-sac in four species of Lymnaa. 1, stagnalis; 2, emarginata; 3, palustris; 4, auricularia.

J. Penis of Lymnca stagnalis lillianc, as it appears in life during the breeding season( August). 1, front view; 2, side view.

PLATE V.

NERVOUS SYSTEM. ${ }^{1}$

Viewed from above; only the right tentacle and left large labial nerves are shown: 1, cerebral ganglia; 2 , pleural ganglion of right side; 3 , visceral gan'In the preparation of the nervous system of Galba reflexa, Lacaze-Du-
thiers' figure (pl. 17, fig. 2) in Archiv. Zool. Exp., has been closely followed as a guide, and the figure here presented differs little from the one in the work mentioned. 
glion of right side; 4, abdominal ganglion; 5 , visceral ganglion of left side; 6 , pleural ganglion of left side; 7 , pedal ganglia (separated and pulled away from their natural position); 8, buccal ganglia; 9, superior frontal nerve to labial region; 10 , eye; 11 , optic nerve; 12 , nerve to right tentacle; 13 , nerve to the neck; 14 , nerve to penis-sac; 15 , nerve to head of penis; 16 , inferior cervical nerve of right side; 17 , large labial nerve; 18 , superior cervical nerve; 19 , inferior cervical nerve to left side; 20 , lateral mantle nerve; 21 , anterior mantle nerve; 22 , aortic nerve; 23 , sub-intestinal nerve; 24 , right pallial nerve; 25 , osphradium or organ of smell; 26 , left, 27 , right columellar nerve; 28 , superior pedal nerve; 29 , central pedal nerve; 30 , inferior pedal nerve; 31 , otocyst or auditory vesicle; 32 , nerve to labial arteries; 33 , anterior pellial nerve.

\section{PLATE VI.}

Figure A. Superior and lateral jaws of Lymnca stagnalis appressa SAY. 1, superior jaw; 2, 2, right and left lateral jaws.

B. Superior jaw of Lymnca stagnalis sanctamarice WALKER.

C. Superior jaw of Pseudosuccinea columella (SAY).

D. Superior jaw of Radix auricularia (LINNE).

E. Superior jaw of Bulimnea megasoma (SAY).

F. Superior jaw of Galba obrussa (SAY).

G. Superior jaw of Galba cubensis (PFr.).

H. Superior jaw of Galba umbilicata (Adams).

I. Superior jaw of Galba palustris (MüLLER).

J. Superior jaw of Galba emarginata (SAY).

K. Superior jaw of Galba catascopium (SAY).

L. Superior jaw of Galba caperata (SAY).

M. Superior jaw of Galba catascopium (SAY). Worn.

N. Radula of Galba doddsi BAKER. 1, first lateral; 5, 7, 8, intermediate teeth; 9, 10, typical marginal teeth.

O. Galba obrussa plica (LEA). Intermediate or seventh tooth of the radula.

P. Radula of Galba hendersoni (BAKER). 9, intermediate tooth; 10, 11, lateral teeth.

\section{PLATE VII.}

RADULA.

Figure A. Lymnaa stagnalis appressa SAY. C, central tooth; 1, 2, lateral teeth; 16, 19, lateral teeth with a second cusp above the ectocone; 20,21 , intermediate teeth; $23,32,34$, marginal teeth; 38,44 , outer marginal teeth.

B. Pseudosuccinea columella (SAY). C, central tooth; 1, first lateral; 11, first intermediate; 13, 14, 15, 18, typical marginals; 27,30 , outer marginals.

C. Radix auricularia (LINNE). C, central tooth; 1 , first lateral (tricuspid) ; 2, 9, lateral teeth (bicuspid) ; 10, 11, 13, intermediate teeth; 15, 20, typical marginal teeth.

D. Bulimnea megasoma (SAY). C, central tooth; 1 , first lateral; 2, second lateral; 6 , modified lateral; 14 , outer lateral; 17 , intermediate tooth; 18, 19, 21, marginal teeth. 
E: Galba obrussa (SAY). C, central tooth; 1, 2, 7, lateral teeth; 9, transition tooth; 11, 13, first marginals; 15, 16, 21, typical marginals.

F. Galba cubensis (PFr.). C, central tooth; 1, 3, lateral teeth; 7, intermediate tooth; $9,13,21,22$, marginal teeth.

\section{PLATE VIII.}

RADULE.

Figure A. Galba umbilicata (AdAms). C, central tooth; 1, first lateral tooth; 3 , third lateral; 5 , intermediate tooth; 7, 8, 9, marginal teeth.

B. Galba umbilicata (AdAms). Seventh tooth (marginal) in one membrane.

C. Galba obrussa exigua (LEA). 1, 3, 6, lateral teeth; 7, intermediate tooth; 8,9 , true marginal teeth.

D. Galba obrussa exigua (LEA). Variation in first marginal on different membranes.

E. Acella haldemani ((Desh.) Binney). C, central tooth; 1, 2, 7, lateral teeth; 9 , intermediate tooth; 10, 11, 16, marginal teeth.

F. Galba palustris (MülLER). C, central tooth; 1, 2, lateral teeth; 10, 12, intermediate teeth; 14, 16, 17, 18, marginal teeth.

G. Galba elodes jolictensis (BAKER). 1, lateral tooth; 9, 10, intermediate teeth; 11, 13, 16, marginal teeth.

H. Galba palustris (MüLLER). First lateral tooth, with a split or bifed ectocone.

I. Galba palustris desidiosa ( $\mathrm{SAY}$ ). 1, first lateral; 10, 11, intermediate teeth; 14, 19, marginal teeth.

J. Galba bulimoides cockerelli (PILS. \& FERR.). 8, 10, intermediate teeth; 11, first marginal tooth.

\section{PLATE IX.}

RADUL王.

Figure A. Galba reflexa (SAY). C, central tooth; 1 , first lateral tooth; 12, last lateral tooth; 14 , transition tooth; 18 , first marginal ; 20, 21, 22, typical marginals.

B. Galba danielsi (BAKER). C, central tooth; 1, 8, lateral teeth; 10-11, intermediate teeth; 12, 13, 25, marginal teeth.

C. Galba danielsi (BAKER). Tenth tooth (intermediate) in one specimen.

D. Galba emarginata (SAY). C, central tooth; 1, 10, first and tenth lateral teeth; 11, 12, intermediate teeth; 13, 15, marginal teeth.

F. Galba emarginata (SAY). Thirteenth tooth (marginal in one specimen).

G. Galba emarginata mighelsi (BInNEY). 1, first lateral tooth; 12, 13, transition teeth; 17, 22, marginal teeth.

H. Galba emarginata angulata (SowB.). 11, 12, intermediate teeth; 13, marginal tooth.

I. Galba catascopium (SAY). C, central tooth; 1 , first lateral; 10, 11, 13, transition teeth; 14, 15, 26, 27, marginal teeth.

J. Galba caperata (SAY). C, central tooth; 1, first lateral; 9, 10, 12, intermediate teeth; 14, 15, 24, 28, marginal teeth. 


\section{PLATE $\mathrm{X}$.}

Figure A. Genitalia of Lymnca stagnalis appressa SAY. The organs are separated from each other to show their form. AL, albuminiparous gland; $\mathrm{A}^{1}$, first accessory albuminiparous gland; $\mathrm{A}^{2}$, second accessory albuminiparous gland; CM, columellar muscle; N, penis nerve; $\mathrm{O}$, ovotestis; OS, ovisperm duct; OV, oviduct; $\mathrm{OV}^{1}$, free portion of oviduct; $\mathrm{P}$, penis; $\mathrm{PM}^{1}$, posterior protractor muscle of penis-sac; $\mathrm{PM}^{2}$, anterior protractor muscles of penis-sac; PR, prostate; $\mathrm{PR}^{1}$, bulb-shaped portion of prostate; PRM, penis retractor muscle; PS, penis-sac; RM, retractor muscles of penis-sac; $S$, receptaculum seminis, or spermatheca; SD, its duct; U, uterine portion of oviduct; V, vagina; $\mathrm{VD}$, vas deferens; $\mathrm{VD}^{1}$, vas deferens to prostate; 2 , penis-sac showing attachment of retracting muscles. (Dissection from animal killed in August.)

B. Genitalia of Pseudosuccinea columella (SAY). (Animals killed in May and August.)

C. Genitalia of Radix auricularia (LiNNe). 1, side view of prostate. (Animal killed in April.)

D. Genitalia of Bulimnea megasoma (SAY). (Animals killed in September.)

\section{PLATE XI.}

GENITALIA.

Figure A. Galba cubensis (PFr.). (Animals killed in April.)

B. Galba umbilicata (Adams). 1, penis of one example.

C. Galba obrussa (SAY). (Killed in August.)

D. Galba parva (LEA).

E. Galba palustris (MüLLER). (Killed in August.)

F. Acella haldemani ((Desh.) Binney.) 1, side view of prostate. (Killed in October.)

\section{PLATE XII.}

GENITALIA.

Figure A. Galba reflexa (SAY). (Killed in September). A, side view of prostate.

B. Galba catascopium (SAY). (Killed in August.)

C. Prostate of Galba obrussa (SAY). 1, from above; 2, from side.

D. Lymncea stagnalis appressa SAY. Variation in penis retractor muscles. 1, with penis retractor split into two branches; 2, with unbroken retractor; $\mathrm{N}$, penis nerve; $\mathrm{P}$, penis retractor; $\mathrm{S}$, penissac retractor.

E. Galba reflexa (SAY). Prostate.

F. Radix auricularia (LINNE). Retractor muscles of male organs. 1, penis retractor; 2, minor, and 3, major branch of penis-sac retractor.

G. Galba emarginata (SAY). (Killed in September.)

H. Galba emarginata angulata (Sowв.). 


\section{PLATE XIII.}

Figure A. Genitalia of Planorbis trivolvis SAY. 1, pẹnis; 2, penis appendage; 3 , vas deferens; 4 , duct (portion of vas deferens) from penis appendage; 5 , nerve to penis appendage; 6 , protractor muscles of penis; 7, retractor muscles of penis; 8 , left retractor of buccal sac; 9 , duct from prostate; 10 , duct of receptaculum seminis; 11 , receptaculum seminis; 12 , oviduct; 13 , prostate; 14 , ovisperm duct; 15, ovotestis (the albuminiparous gland is omitted from this figure).

B. Radula of Planorbis trivolvis SAY. 1, central tooth; 2, lateral tooth; 3 , marginal tooth.

C. Genitalia of Galba danielsi (BAKER). (Animal killed in September.)

D. Genitalia of Galba caperata (SAY).

\section{PLATE XIV.}

Variation in retractor and protractor muscles of male organ in Lymnæa.

Figure A. Lymncea stagnalis appressa SAY. M, transverse muscles.

B. Lymnea stagnalis sanctamarice WALKer. From Siskowit Bay, Isle Royale.

C. Pseudosuccinea columella (SAY). 1-3, from Sea Breeze, near Rochester, N. Y.; 4, from La Porte, Ind.

D. Bulminea megasoma (SAY). 1, one penis-sac retractor; 2 , two retractors of penis-sac; pr, penis retractor; psr, penis-sac retractor; ps, penis-sac; psp, posterior penis-sac protractors; $\mathrm{psp}^{1}$, anterior penis-sac protractors.

E. Galba parva (LeA).

F. Galba umbilicata (AdAms). Cayuga Lake, N. Y.

G. Galba obrussa (SAY). 1, Sea Breeze, N. Y.; 2, Cayuga Lake, N. Y. G, 3. Galba obrussa peninsulace (WALKeR).

\section{PLATE XV.}

Variation in muscles of male organ.

Figure A. Galba reflexa (SAY). La Porte, Indiana.

B. Galba emarginata (SAY). From Isle Royale specimens.

C. Galba palustris (MüLleR). Colorado specimens. ap, anterior penissac protractors; cm, columellar muscle; pp, posterior penis-sac protractors; pr, penis retractor; psr, penis-sac retractor.

D. Galba reflexa (SAY). Calumet Lake, Illinois.

E. Acella haldemani ((Desh.) Binney.)

F. Galba catascopium adamsi BAKer. 1-3, St. Clair flats, Mich.

F. Galba catascopium (SAY). 4-6, Erie Canal, Rochester, N. Y.; 7-8, Genesee River, Rochester, N. Y.

G. Galba elodes jolietensis (BAKER).

PLATE XVI.

FOSSIL LYMNAAS.

Figure 1. Lymnaa ativuncula White. Bull. U. S. Geol. Surv., No. 29, pl. 4, fig. 10. Type. 
2. Lymnca ativuncula White. L. c. fig. 11. Type.

3. Lymnaa consortis White. L. c. fig. 8. Type.

4. Lymncea consortis WhITE. L. c. fig. 9. Type.

5. Lymnaa accelerata White. L. c. fig. 12. Type.

6. Lymnaa accelerata White. L. c. fig. 13. Type.

7. Lymnca accelerata White. L. c. fig. 14. Type.

8. Lymnca accelerata White. L. c. fig. 15. Type.

9. Lymnaa tenuicosta M. \& H. U. S. Geol. Surv. Terr., IX, pl. 44, fig. 13 a. Type specimen, natural size.

10. Lymnaa tenuicosta M. \& H. L. c. fig. 13 b. Enlarged figure of 13a. 11. Lymnaa tenuicosta M. \& H. L. c. fig. 13 c sculpture of body whorl.

12. Lymnaa vetusta MeEK, 3rd An. Rep. U. S. Geol. Surv., pl. 29, fig. 22. Type. Natural size.

13. Lymnca vetusta MeEk. L. c. fig. 23. Type. Enlarged.

14. Lymnaa similis MeEk. U. S. Geol. Surv. 40th Parallel, IV, pl. 17, fig. 3. Type.

15. Lymnaa similis Meek. L. c. fig. 3a. Type.

16. Lymnaa minuscula White. 3rd An. Rep. U. S. Geol. Surv., pl. 29, fig. 24. Type.

17. Lymnaa minuscula White. L. c. fig. 25. Type.

18. Lymnca similis MeEK. L. c. fig. 20. Type.

19. Lymnca similis Meek. L. c. fig. 21. Type.

20. Lymnaa nitidula MEEK. L. c. pl. 6, fig. 15.

21. Lymnca nitidula MEEK. L. c. pl. 6, fig. 16.

22. Lymnca nitidula Meek. Bull. 128, U. S. Geol. Surv., pl. 6, fig. 3, - from type specimen.

23. Lymnaa compactilis MeEK. 3rd An. Rep. U. S. Geol. Surv., pl. 26, fig. 14. Type.

24. Lymnca meekiana Evans \& Shumard. 3rd An. Rep. U. S. Geol. Surv., pl. 32, fig. 27.

25. Lymnaa meckiana E. \& S. L. c. fig. 26.

26. Lymnaa shumardi MEEK \& HAYDEN. L. c. fig. 29.

27. Lymnaa shumardi MeEK \& HAyden. L. c. fig. 28. (Holotype.)

\section{PLATE XVII.}

\section{FOSSIL LYMNAAS.}

Figure 1. Lymnca kingii Meek. 3rd An. Rep. U. S. Geol. Surv., pl. 32, fig. 30.

2. Lymncea kingii MeEk. L. c. fig. 31. Holotype.

3. Lymnaa sp. Bull. U. S. Geol. Surv., 34, pl. 2, fig. 13. Natural size.

4. Lymnaa micronema White. L. c. fig. 14. (= tenuicosta M. \& H.)

5. Lymncáa florissantica Cockerell. From a photograph supplied by Prof. Cockerell.

6. Lymnaa bonnevillensis Call. Bull. U. S. Geol. Surv., XI, pl. 6, fig. 10.

7. Lymnaa bonnevillensis CALL. L. c. fig. 13.

8. Lymnaa bonnevillensis CALL. L. c. fig. 12.

9. Lymnaa alamosensis ARnold. Smith. Mis. Coll., L, pl. 54, fig. 6 . Type.

10. Lymnca alamosensis Arnold. L. c. fig. 7. Type. 
11. Lymnaa maxima Stearns. Univ. Cal. Pub., Geol., V, p. 69, fig. 1. Type.

12. Lymnca contracosta J. G. Cooper. Proc. Cal. Acad. Sci., ii, IV, pl. 14, fig. 12. Type.

13. Lymnca scudderi Cockerel.. Bull. Am. Mus. N. H., XXII, p. 461, fig. 4, a. Type; b, narrow. variety of scudderi; $\times 4 \frac{1}{2}$.

14. Lymnaa sieverti Cockerell. L. c., fig. 3. Showing interior of shell and outside of a portion near the mouth; X 4 .

\section{PLATE XVIII.}

Section of shells to show axis.

Figure 1. Acella haldemani ('Desh.' Binney). 23936.

2. Galba bulimoides cockerelli (PILS. \& FERR.). 23940.

3. Galba obrussa (SAY). 24506.

4. Galba palustris (MüLleR). 23987.

5. Pseudosuccinea columella (SAY). 23931.

6. Galba randolphi (BAKER). 23675. Young.

7. Lymnca stagnalis appressa SAY. 23925.

8. Bulimnea megasoma (SAY). 23097.

9. Radix auricularia (LINNE). 23934.

10. Galba reflexa (SAY). 23988.

Figures Enlarged.

PLATE XIX.

Figures 1,2. Lymnaa stagnalis LINNE. Baden, Germany (23008).

3. Lymnca stagnalis Linne. Elba River, Germany (Coll. Walker).

4. Lymnaa stagnalis appressa SAY. Braddocks Bay, Lake Ontario, N. Y. (23035).

5-6. Lymncea stagnalis appressa SAy. Round Bay, Lake Ontario, N. Y. (23006).

7. Lymnaa stagnalis appressa SAY. Calumet Lake, Ills. (Coll. Ferriss).

8. Lymnca stagnalis appressa SAY. Pigeon Lake, Ontario (23046).

9. Lymnea stagnalis appressa SAY. Calumet River, Ills. (8113).

10. Lymnca stagnalis appressa SAY. Romeo, Ills. (23009). Figures Natural Size.

PLATE XX.

Figures 1,2,3. Lymnaa stagnalis appressa SAY. Squaw Island, Niagara River, N. Y. (Coll. Walker).

4. Lymnaa stagnalis appressa SAy. Calumet Lake near Pullman, Ills. (19584).

5. Lymnaa stagnalis appressa SAY. Bear Lake, Mich. (23014).

6. Lymnaa stagnalis appressa SAY. Batavia, N. Y. (23015).

7. Lymnaa stagnalis perampla WALKER. Houghton Lake, Mich. CoTYPE (23924).

8, 9. Lymnaa stagnalis perampla Walker. Douglas Lake, Mich. (Coll. Ferriss).

10-12. Lymnaa stagnalis wasatchensis HeмpHILL. Near Ogden, Utah. Types (Coll. Hemphill).

Figure 6, enlarged $11 / 3$; figure 5 , enlarged 2 diameters; balance natural size. 


\section{PLATE XXI.}

Figure 1. Lymnaa stagnalis higleyi BAKER. Michipicoten Island, Lake Superior. TYPE (23050).

2. Lymnaa stagnalis higleyi BAKER. Michipicoten Island, Lake Superior. (23052).

3. Lymnca stagnalis higleyi BAKER. Michipicoten Island, Lake Superior. Cotype (Coll. Ferriss).

4-5. Lymnaa stagnalis sanctamaria WALKER. Siskowit Lake, Isle Royale, Mich. (23927).

6-7. Lymnaa stagnalis sanctemarice WALKER. Specimens showing thickening of columella by callus, thus obscuring the gyrate character of the axis. Figure 7 shows the formation of the callus, while figure 6 shows the typical condition. The latter is a younger shell. (23926.)

8-9. Lymnca stagnalis lilliane BAKER. Lake Harriett, Minneapolis, Minn. (23049).

10-12. Lymnca stagnalis lilliance BAKER. Tomahawk Lake, Wisconsin. TYPES (24554).

Figures 4 to 7 , slightly reduced; figure 2, enlarged; balance natural size.

PLATE XXII.

Figures 1-2. Lymnea stagnalis appressa SAY. Nautilus, VI, pl. 1, figs. 2-3. $7 / 8$ nat. diam.

3. Lymnca stagnalis appressa SAy. Distortion. Nautilus, VI, pl. 1, fig. 1. $7 / 8$ nat. diam.

4. Lymnca stagnalis appressa SAY. Variety. Dredged from depth of 10 meters in Lake Michigan, at High Island Harbor, Beaver Island. (Photo by Walker.)

5. Lymnaa stagnalis perampla WalKer. Nautilus, VI, pl. 1, fig. 6 . $7 / 8$ nat. diam.

6. Lymnaa stagnalis lilliance BAKER. Minnehaha River, Minn. (Coll. Hemphill).

7-8. Lymnea stagnalis sanctemarie WALKer. TyPes. Nautilus, VI, pl. 1, figs. $4-5$. $7 / 8$ nat. diam.

9-11. Galba utahensis (CALL). Bull. U. S. Geol. Surv., II, p1. 6, figs. $7-9$ (x2).

12-15. Radix auricularia (Linne). .Greenhouse, Lincoln Park, Chicago (23087). Slightly enlarged.

\section{PLATE XXIII.}

Figures 1-3. Lymnaa stagnalis sanctamaria Walker. Sault Ste. Mariæ, Mich. (23051).

4-5. Lymnaa stagnalis occidentalis HemphilL. Lake Whatcom, Washington. Types (Coll. Hemphill).

6-7. Lymnaa lepida Gould. Tryon's Continuation Haldeman's Monograph, pl. 16, figs. 12-13.

8. Pseudosuccinea columella (SAY). Pennsylvania (23061).

9. Pseudosuccinea columella (SAY). Greenwood, S. C. (23060).

10-12. Pseudosuccinea columella (SAY). Bradford, Conn. (23063). Figure 11 is a typical macrostoma SAY. 
13. Pseudosuccinea columella (SAY). Blount Co., Tenn. (Walker Coll. 12876). Approaches var. chalybea in form.

14. Pseudosuccinea columella (SAY). Concord, Tenn. (Walker coll. 12877).

15. Pseudosuccinea columella (SAY). Schuylkill River, Tenn. (Coll. Walker).

16-19. Pseudosuccinea columella (SAY). Lincoln Park, Chicago (23054). 20. Pseudosuccinea columella (SAY). DuBois, Ills. (23055).

Figures 4-20, slightly enlarged; 1-3, natural size.

\section{PLATE XXIV.}

Figures 1, 2. Pseudosuccinea columella (SAY). Pass Christian, Miss. (Coll. Walker, 6157).

3. Pseudosuccinea columella (SAY). Lake Jessup, Manatee Co., Fla. (23053).

4. Pseudosuccinea columella (SAY). Washington, D. C. (Coll. Walker, 18301).

5. Pseudosuccinea columella chalybea (Gould). Pittsburgh, Penn. (23057).

6-7. Pseudosuccinea columella chalybea (Gould). Allegheny, Penn. (Coll. Walker, 10476).

8. Pseudosuccinea columella chalybea (Gould). Kent, Ohio (23062).

9. Pseudosuccinea columella chalybea (Gould). Cambridge, Mass. Type locality (Coll. Walker, 5893).

10-12. Pseudosuccinea columella chalybea (Gould). Cattaraugus Co., N. Y. (23067).

13. Pseudosuccinea columella chalybea (Gould). Cattaraugus Co., N. Y. (23065).

14-19. Pseudosuccinea columella casta (LEA). Bass Lake, Ind. (23064).

20. Pseudosuccinea columella championi (Von Martens). Palvon, Nicaragua. Coll. Walker (17317).

21. Pseudosuccinea francisca (PoEy). Pinar del Rio Province, Cuba (24627).

22-27. Polyrhytis utahensis (CALL). Bear Lake, Utah. Hayden Survey, Phil. Acad. Sci. (62603).

All figures enlarged about $1 \frac{1}{2} 2$ diameters (figure 21 enlarged 2 diameters).

\section{PLATE XXV.}

Figure 1. Bulimnea megasoma (SAY). Under surface of animal. Whitfield, Bull. Am. Mus. N. H., I, pl. 5, fig. 2.

2. Bulimnea megasoma (SAY). Animal seen from the side, 1.c. fig. 3.

3. Bulimnea megasoma (SAY). Oconto, Wis. (23095).

4. Bulimnea megasoma (SAY). St. Croix River, Wis. (23094).

5. Bulimnca megasoma (SAY), Manitowoc Co., Wis. (23100).

6. Bulimnea megasoma (SAY). Minnesota (23096).

7-8. Galba preblei (DALL). Lake Isle La Crosse, Athabaska (23717).

9-10. Galba preblei (DALL). Alaska Moll., pl. 1, figs. 1-2. Types.

Figures 7-8, enlarged about 2 diameters; $9-10$, slightly enlarged; balance natural size. 


\section{PLATE XXVI.}

Figures 1-2. Acella haldemani ( (Desh.) Binney). Grand Rapids, Mich. (23909).

3-4. Acella haldemani ( (Desh) Binney). Reed's Lake, Mich. (23910).

5-7. Galba bulimoides cockerelli (PILsbry and Ferriss). Chaco Canyon, New Mexico. (23227).

8-10. Galba obrussa (SAY). Monocacy Creek, Bethlehem, Pa. (24633).

11-13. Galba obrussa (SAY). Lebanon, Pa. (24630).

14-16. Galba petoskeyensis (Walker). Petoskey, Mich. (Cotypes, 23316).

17-20. Galba palustris (Müller). Sugar Island, Alpena, Mich. (23424).

21-26. Galba palustris (MüLler). Halma, Minn. (23381). Figures 17-26 are excellent examples of spire variation.

27-28. Galba palustris (MüLLER). Fort Erie, N. Y. (23421).

29-32. Galba palustris (MülLER). Braddock's Bay, near Charlotte, N. Y. (23415).

33-34. Galba palustris (MüLlER). Ebenezer, N. Y. (23412).

35-37. Galba palustris (MÜLLER). Windsor, Colo. (23451).

Figures 1-4, 8-13, enlarged $1 \frac{1}{2}$ diameters ; $5-7$, enlarged 2 diameters; other figures about natural size.

\section{PLATE XXVII.}

Figures 1-2. Galba truncatula (Müller). Roundhay, Leeds, England. (Phila. Acad., 58939).

3-4. Galba truncatula (MülLER). Park Lane, Burnley, England. (Phila. Acad., 66691).

5-8. Galba doddsi Baker. Hot Sulphur Springs, Colo. (Types 23937).

9-10. Galba cubensis (PFr.). Havana, Cuba (23318).

11. Galba cubensis (PFr.). Havana, Cuba (23319).

12. Galba cubensis (PFr.). Valles, Mexico (23320).

13-15. Galba cubensis (PFr.). Pujal Lake, Valles, Mexico (24634).

16. Galba cubensis (PFr.). Valles, Mexico (23886).

17-19. Galba cubensis aspirans (PILsBRy). Barbadoes (23224).

20. Galba bryanti BAKer. (=bulimoides, juv.). Alameda, Cal. (Type, coll. Walker, 1352).

21-24. Galba bulimoides (LEA). Menton Ranch, Santa Clara Co., Cal. (24536).

25. Galba bulimoides (LEA). Oregon (TYPE, Smith coll., 118647).

26-28. Galba bulimoides (LEA). San Luis Obispo Co., Cal. (Coll. Walker, 3760).

29. Galba bulimoides (LEA). Pajaro Valley, Cal. (24567). (=adelince TRYon.)

30. Galba bulimoides techella (HALd.). Bixby, Cal. (24509).

31. Galba bulimoides techella (HaLd.). Bardsdale, Ventura Co., Cal. (23946).

32. Galba bulimoides techella (HALD.). Rockwell Co., Texas (23323).

33-35. Galba bulimoides techella (HALd.). Bardsdale, Cal. (23942).

All figures enlarged about two diameters. 


\section{PLATE XXVIII.}

Figures 1-2. Galba bulimoides techella (HALdeman). Baird's Lake, Ventura Co., Cal. (23947).

3. Galba bulimoides techella (Haldeman). Near San Diego, Cal. (Coll. Hemphill).

4. Galba bulimoides cockerelli (PILSBRY \& FERrIss). Ogalalla, Neb. (23225).

5. Galba bulimoides cockerelli (PILsBry \& Ferriss). Chaco Canyon, New Mexico (23328).

6-7. Galba bulimoides cockerelli (P. \& F.). Bardsdale, Ventura Co., Cal. (23945).

8. Galba bulimoides techella (Haldeman). Albuquerque, N. Mex. (23222).

9-11. Galba bulimoides cassi BAKer. Rose Canyon, near Pacific Grove, Cal. (TyPES, 23948).

12. Galba sonomansis (Hemphill). Sonoma Co., Cal. (23229).

13-14. Galba sonomansis (Hemprill). Sonoma Co., Cal. (Cotypes, coll. Hemphill).

15-18. Galba hendersoni (BAKER). East of Fort Collins, Colo. (Types, 24537).

19. Galba perpolita (DALL). Nushagak, Bristol Bay, Alaska. Alaska Moll., pl. 2, fig. 8. TYPE.

20-22. Galba caperata (SAy). Des Moines, Iowa (23863).

23-24. Galba caperata (SAY). White Rock, Colo. (23864).

25. Galba caperata (SAy). North Platte City, Neb. (23865).

26-27. Galba caperata (SAY). Emerson, Manitoba (23866).

28-29. Galba caperata (SAY). Calumet Lake, Ills. (23869).

30. Galba caperata (SAY). Liverpool, Ind. (23870).

31. Galba caperata (SAY). Boulder, Colo. (23873).

32. Galba caperata (SAY). Near Salt Lake, Utah (Coll. Hemphill).

33. Galba caperata (SAY). Near Salt Lake, Utah. Scalar specimen.

Figures 12-14, enlarged about 3 diameters; 19, 11/2 diameters; balance enlarged 2 diameters.

\section{PLATE XXIX.}

Figures 1-2. Galba caperata (SAY). Mud Lake, Yukon Terr. (24704).

3. Galba ferrissi (BAKER) = caperata SAY. Joliet, Ills. (TyPe, 3458).

4. Galba holbollii ('Beck' MöLleR). Greenland (Coll. Walker).

5-7. Galba parva (LEA). Des Moines, Iowa (23136).

8-9. Galba parva (LEA). Des Moines, Iowa (23109).

10-11. Galba parva (LEA). Algonquin, Ills. (23141).

12. Galba parva (LEA). Canton, Ills. (23106).

13. Galba parva (LeA). Dyer, Ind. (23150).

14. Galba parva (LEA). Pittsburgh, Pa. (23107).

15. Galba parva sterkii (BAKER). Near Cleveland, Ohio (TYPE, 23156).

16-17. Galba parva sterkii (BAKER). Canton, Ills. (23158).

18. Galba parva sterkii (BAKER). Fox River, Ills. (23142).

19-20. Galba parva sterkii (BAKER). Goshen, Ohio (23163).

21-22. Galba parva sterkii (BAKER). Blickston, Ohio (23162). 
23-25. Galba owascoensis (BAKER). Owasco Lake, N. Y. (TYPES, 23137), 26-27. Galba humilis (SAY). Charleston, S. C. (Coll. Walker 12815).

28-30. Galba humilis (SAY). Mouth of Woodbury Creek, below Gloucester, N. J. (24542).

31-32. Galba humilis modicella (SAY). Oakland Co., Mich. (23105).

33-34. Galba humilis modicella (SAY). Macomb Co., Mich. (23152).

35. Galba humilis modicella ( $\mathrm{SAY}$ ). Des Moines, Iowa (23954).

36-37. Galba humilis modicella (SAY). Long Lake, Alpena, Mich. (23955).

Figures 1-4, 26, 27, 31-37, enlarged 2 diameters; 15-25, 27-30, enlarged $21 / 2$ diameters; $\mathbf{5 - 1 4}$, enlarged 3 diameters.

\section{PLATE XXX.}

Figures 1-2. Galba umbilicata (C. B. AdAms). Rhode Island (Coll. Walker). 3-7. Galba umbilicata (C. B. Adams). Aroostook Co., Maine (23148), 8. Galba cyclostoma (WALKeR). TyPe (Coll. Walker, 13599).

9-12. Galba parva (LEA). Des Moines, Iowa (23102).

13-15. Galba dalli (BAKER). Lake James, Steuben Co., Ind. (TyPes,. 23125).

16. Galba dalli (BAKER). Scalariform. Rockford, Ills. (23123).

17-18. Galba dalli (BAKER). Rockford, Ills. (23124).

19-20. Galba humilis (SAY). Vacant lot, Charleston, S. C. (23145).

21-24. Galba, species. Greenhouse, Boulder, Colo. (24545).

25-26. Galba catascopium (SAY). Say's original figures in Amer. Conch., pl. 55, fig. 2.

27-28. Galba emarginata (SAY). Say's original figures in Amer. Conch., pl. 55, fig. 1 .

29. Galba petersi (DAll). Alaska Moll., pl. II, fig. 3 (TYPE).

30-31. Galba reflexa (SAY). Say's figures, Amer. Conch., IV, pl. 31, fig. 2 .

32-33. Galba umbrosa (SAy). Say's figures, Amer. Conch., IV, pl. 31. fig. 1.

34. Galba elodes (SAY). Say's figure, Amer. Conch., IV, pl. 31, fig. 3.

Figures 1-12, 19-24, enlarged about $2 \frac{1}{2}$ diameters; figures 13-18, enlarged 4. diameters; figures 25-28, 30-34, natural diameter; figure 29, slightly enlarged.

\section{PLATE XXXI.}

Figure 1. Galba jamesii (LEA) =modicella (SAY). TyPE (Smith. Inst., 29106).

2-3. Galba humilis modicella (SAY). Silver Lake, Ills. (23958).

4. Galba humilis modicella (SAY). Montgomery, Ala. (23209).

5-7. Galba humilis modicella (SAY). Hamilton Co., Ohio (23212).

8. Galba humilis modicella (SAY). Pipe Creek, N. Y. Juvenile (23260).

9. Galba humilis modicella (SAY). La Porte, Ind. Striped form (23956).

10-13. Galba humilis rustica (LEA). Cedar Lake, Montcalm Co., Mich. (Coll. Walker).

14. Galba humilis rustica (LEA). Mohawk, N. Y. (23192).

15-19. Galba ferruginea (Haldeman). Near Ashford, Pierce. Co., Washington (24541). 
20-24. Galba obrussa (SAy). Abandoned quarry, Lemont, Ills. (23967). 25. Galba obrussa (SAY). Joliet, Ills. (Ferriss coll.). 26-31. Galba obrussa (SAy). Joliet, Ills. (23197).

32. Galba obrussa (SAy). Boulder, Colo. (23201).

33-34. Galba obrussa (SAY). Owasco Lake, N. Y. (23195).

35-37. Galba obrussa (SAY). Clear Lake, La Porte, Ind. Immature. (23257).

All figures enlarged about two diameters.

\section{PLATE XXXII.}

Figures 1-6. Galba obrussa peninsula (WALKer). TyPes (Walker Coll. 24269). 7-9, 13. Galba obrussa exigua (LEA). Aroostook Co. (23293).

10-12. Galba obrussa exigua (LEA). Near Des Moines, Iowa (23973).

14. Galba obrussa exigua (LeA). Near Charlotte, N. Y. (23972).

15. Galba obrussa decampi (Streng). Brooks Lake, Mich. Cotype (Walker Coll., 10847).

16-21. Galba obrussa decampi (Streng). Caribou, Maine (23307).

22. Galba obrussa decampi (Streng). Ann Arbor, Mich. (23303).

23-24. Galba galbana (SAY). Alpena, Mich. (23310).

25-27. Galba galbana (SAY). White Pond, N. J. (23311).

28-36. Galba galbana (SAY). Squaw Island, Niagara River, N. Y. (23313).

All figures enlarged about two diameters.

\section{PLATE XXXIII.}

Figure 1. Galba palustris (MülLER). Braddock's Bay, N. Y. (Long-spired specimen, 23612).

2-7. Galba palustris (Müller). Owasco Lake, N. Y. (23425).

8-10. Galba palustris (Müller). Owasco Lake, N. Y. (23518).

11. Galba palustris (Müller). Seattle, Wash. (23345).

12-13. Galba palustris (Müller). Madison Lake, Mont. (23387).

14-18. Galba palustris (MÜLleR). Florissant, Colo. (23511).

19. Galba palustris (MÜLlER). Goshen, Colo. (Pathologic, 23453).

20. Galba palustris (MÜLlER). Near Ward, Colo. (Immature, 23655).

21. Galba palustris (MÜller). North Platte City, Neb. (23388).

22. Galba nuttalliana (LEA) = palustris (MüLlER). California (23518).

23. Galba nuttalliana (LEA) =palustris (Müller). Brigham City, Utah. (Coll. Hemphill).

24. Galba nuttalliana (LEA) =palustris (MüLLER). California (23350).

25. Galba haydeni (LeA) =palustris (MülleR). California (Coll. Hemphill).

26-30. Galba palustris alpenensis BAKER. Thunder Bay Island, Alpena, Mich. (Types, 23486).

31. Galba palustris alpenensis BAKER. Whitefish Point, Alpena, Mich. (23492).

32-33. Galba palustris alpenensis BAKER. Long Island, Alpena, Mich. (23491). 
34-36. Galba palustris blatchleyi BAKER. Turkey Lake, Kosciusko Co., Ind. (TYPEs, 23626).

Figure 1, enlarged $1 \frac{1}{2}$ diameters; figures $20,22,23,24,25,34-36$, slightly enlarged; other figures about natural size.

\section{PLATE XXXIV.}

Figures 1-2. Galba palustris desidiosa (SAY). Say's figures, Amer. Conch., VI, pl. 55, fig. 3 .

3-7. Galba palustris desidiosa (SAY). Williamsville, N. Y. (23915).

8-9. Galba palustris desidiosa (SAY). Small stream under Western Wide Waters, Erie Canal, Rochester, N. Y. (23297).

10-12. Galba palustris desidiosa (SAY). Seneca Lake, N. Y. (23484).

13. Galba elodes shurtleffi (Tryon). Weatogue, Ct. (Cotype, Phil. Acad. Sci., 58160).

14-17. Galba elodes (SAY). White Co., Ind. (23517).

18. Galba elodes (SAY). (=michiganensis WALKER). Joliet, Ills. (23978).

19. Galba elodes (SAY). (=michiganensis WALKER). Tippecanoe Lake, Ind. (23505).

20. Galba palustris (Müller). East Saginaw, Mich. Form called "zebra" by Taylor (error for zebra TRYON. 23452).

21-22. Galba elodes (SAY). Madison, Wis. (24705).

23. Galba elodes (SAY). Madison, Wis. (23482).

24. Galba elodes (SAY). Winnebago Co., Ills. (23514).

25-28. Galba elodes jolietensis (BAKER). Joliet, Ills. (TYPES, 23606).

29-30. Galba elodes jolietensis (BAKER). Joliet, Ills. Showing variation toward elodes (23611).

Figures $3-13,18,19$, enlarged $1 \frac{1}{2}$ diameters; figures 24-28, slightly enlarged; figures 20-23, 29-30, natural size.

\section{PLATE XXXV.}

Figures 1-2. Galba elodes jolietensis (BAKER). Berry Lake, Chicago, Ills. (23608).

3. Galba reflexa (SAy). Robey, Ind. Young (23504).

4. Galba exilis (LEA). Skokie Marsh, near Glencoe, Ills. Young.

5-7. Galba reflexa (SAY). Near La Porte, Ind. (23635). Immature.

8. Galba reflexa (SAY). Winnebago Co., Ills. (23515).

9. Galba iowacnsis (BAKer). Muscatine, Ia. CotyPE =reflexa, SAY, immature (23520).

10. Galba reflexa (SAy). Calumet Lake, Ills. (23521).

11-13. Galba reflexa (SAY). Calumet River, Ills. (23519).

14. Galba reflexa (SAY). Lake Champlain, Vt. (Bos. Soc., N. H., 13592).

15-17. Galba reflexa (SAY). Romeo, Ills. (23522).

18. Galba reflexa (SAY). Lake Albert Lea, Minn. (23525).

19. Galba reflexa (SAY). Davenport, Ia. (23524).

20-21. Galba reflexa (SAY). Lockport, Ills. (23526).

22. Galba reflexa (SAY). Lockport, Ills. (23516).

Figures 3 and 4, enlarged $1 \frac{1}{2}$ diameters; the other figures are slightly enlarged. 


\section{PLATE XXXVI:}

Figures 1-6. Galba reflexa (SAY). Rock Run, Joliet, Ills. (23546). Pathologic forms.

7-11. Galba crystalensis (BAKER). Crystal Lake, Ills. (TyPes, 23634) $=$ reflex $a$, immature.

12. Galba reflexa walkeri (BAKER). Calumet River, Ills. (23572).

13. Galba reflexa walkeri (BAKER). Calumet Lake, Ills. (23570).

14. Galba reflexa walkeri (BAKER). Joliet, Ills. (23569).

15-16. Galba reflexa walkeri (BAKER). Wolf Lake, Ills. (23571).

17. Galba reflexa walkeri (BAKER). Silver Lake, Ills. (23527).

18. Galba reflexa walkeri (BAKER). Silver Lake, Ills. (23578). A form with spire resembling that of exilis.

19-20. Galba reflexa hemphilliana (BAKER). Lake Albert Lea, Minn. Types (Coll. Bryant Walker, 14037).

21-22. Galba exilis (LEA). Calumet River, Ills. (23577).

Figures 11 and 13 are enlarged 1/2 diameters; the other figures are about natural size.

\section{PLATE XXXVII.}

Figure 1. Galba exilis (LEA). Berry Lake, Chicago, Ills. (23583).

2. Galba exilis (LEA). Antrim Co., Mich. (23591).

3. Galba-cxilis (LEA). Winnebago Co., Ills. (23580).

4-6. Galba-exilis (LEA). Mercer Co., Ills. (23582).

7-10. Galba exilis (LEA). Des Moines, Ia. (23585).

11. Galba exilis (LEA). Des Moines, Ia. (23595).

12-13. Galba kirtlandiana (LEA). Crystal Lake, Ills. (23607).

14-16. Galba kirtlandiana (LEA). Mud Lake, Grand Crossing, Chicago, Ills. (23610).

17-18. Galba lanceata (Gould). Carp Lake, Emmet Co., Mich. (23592).

19-22. Galba lanceata (Gould). Tomahawk Lake, Wis. (23590).

23-24. Galba attenuata (SAY). Near City of Mexico (Coll. Walker).

Figure 4, enlarged about $11 / 2$ diameters; figures $1-3,11-24$, slightly enlarged; figures 5-10, natural size.

\section{PLATE XXXVIII.}

Figures 1-2. Galba danielsi (BAKER), Lake Maxinkuckee, Ind. (TYPES, 23622).

3. Galba danielsi (BAKER). Lake Maxinkuckee, Ind. Pathologic specimen. (Coll. Bartsch).

4-8. Galba danielsi (BAKER). Lake Maxinkuckee, Ind. (23624).

9-11. Galba proxima (LEA). San Francisco, Cal. (23642).

12. Galba proxima (LEA). San Mateo, Cal. (23641).

13. Galba californica (Sowerby) = proxima (LEA). Specimen compared with Sowerby's type in British Museum (Walker coll.).

14. Galba proxima rowellii (TRYON). San Francisco, Cal. (Coll. Hemphill).

15-18. Galba proxima rowellii (TRYoN). San Francisco, Cal. (23659). Showing variation toward proxima. 
19. Galba proxima rowellii (TRYON). San Francisco, Cal. (23647).

20-21. Galba proxima rowellii (TRYoN). San Francisco, Cal. (23648).

Figures 1-3, 13, enlarged $11 / 2$ diameters; 4-12, 14-21, about natural size.

\section{PLATE XXXIX.}

Figure 1. Galba leai (BAKer). San Francisco, Cal. (Type, 23653).

2-3. Galba leai (BAKer). San Francisco, Cal. (Coll. Nason).

4. Galba tryonii (LeA). Cotype. San Antonio, Cal. One of the type specimens. (Smith. Inst., 121470).

5. Galba tryonii (LEA). Vancouver Island (23654).

6. Galba traskii (TrYoN). San Francisco, Cal. Original locality. (Coll. Hemphill).

7-8. Galba traskii (TRYON). Black Rock Butte, Wyoming (Coll. Walker, 13506).

9-10. Galbi traskii (TrYoN). Banff, Alberta (24631).

11-16. Galba vahlii ("Beck" Möller). Near St. Michaels, Alaska (23656).

17-18. Galba vahlii ("Beck" Möller). Mud Lake, Yukon Territory (23657).

19. Galba vahlii arctica (LEA). Hudson Bay. (Walker coll.).

20-23. Galba vahlii arctica (LEA). Moose River, Hudson Bay. Part of original lot. (23660).

24-27. Galba vahlii pingellii ("Beck" MöLler). Near St. Michaels, Alaska (23658).

28. Galba neopalustris BAKer. Orange, Va. (Type, 23547).

Figures 1-3, natural size; figures 4-10, enlarged 2 diameters; figures 11-28, enlarged $1 \mathrm{r} / 2$ diameters.

\section{PLATE XL.}

Figures 1-5. Galba pallida (AdAms). Shoreham, Lake Champlain, Original locality. (Coll. Bos. Soc. N. H.).

6-10. Galba catascopium (SAY). Erie Canal, Rochester, N. Y. (23733).

11-12. Galba cotascopium (SAY). Lower Genesee River, Rochester, N. Y. (23732).

13-15. Galba catascopium (SAY). Between Upper and Middle Falls, Rochester, N. Y. (23731).

16. Galba catascopium (SAY). Third Point, Pine Lake, Mich. (23761).

17-19. Galba catascopium (SAy). Oyster Bay, Pine Lake, Mich. (23760).

20-22. Galba catascopium (SAY). Raspberry Bay, Pine Lake, Mich. (23762).

23-26. Galba catasiopium (SAY). St. Lawrence River, below mouth of Montmorency. =pinguis SAY. (Canadian Geol. Surv.)

27-28. Galba pinguis (SAY). =catascopium (SAY). Mohawk River, N. Y. (23775).

29-30. Galba pinguis (SAY). =catascopium (SAY). Seneca Lake, N. Y. (23779).

31. Galba intertexta (CURRIER). =catascopium (SAY). COTYPe, immature. (Walker coll., 17358). 
32-33. Galba intertexta (CURRIER). Black Lake, Holland, Mich., adult (23722).

34-35. Galba catascopium (SAy). Black Lake, Holland, Mich. (23723). Figures 1-5, 11, 12, 32-35, slightly enlarged; figure 31, enlarged about 2 diameters; figures $6-10,13-30$, natural size.

\section{PLATE XLI.}

Figure 1. Galba catascopium (SAY). Delaware River, near Burlington, N. J. (24632).

2. Galba catascopium (SAy). Delaware River, Philadelphia, Pa., near Say's original locality (24616).

3. Galba pinguis $(\mathrm{SAY})=$ catascopium $(\mathrm{SAY})$. Delaware River, Philadelphia, Pa. (24616).

4. Galba pinguis ( $\mathrm{SAY})=$ catascopium (SAY). Ohio (23771).

5. Galba davisi (Walker). Fish Point, Tuscola Co., Mich. Type (Coll. Walker, 20092).

6-7. Galba pseudopinguis (BAKER). Canarsie, Long Island, N. Y. (24535).

8-9. Galba decollata (Mighels). Maine. Bos. Soc. N. H., 24192).

10. Galba decollata (Mrghels). Maine. (Coll. Walker).

11-14. Galba sumassi (BAIRD). Types in British Museum. 11-12 and 13-14 back and front view of same specimen.

15-17. Galba sumassi (BAIRd). Echo Canyon, Utah (23879).

18. Galba emarginata (SAY). Lake Superior (23991).

19-20. Galba emarginata (SAY). Mackinac Island, Mich. (23676).

21-24. Galba emarginata (SAY). Seneca Lake, N. Y. (23680).

25. Galba emarginata mighelsi (Binney). Square Lake Inlet, Aroostook Co., Me. (23693).

Figures 1-17, enlarged about $1 \frac{1}{2}$ diameters; figures $18-25$, natural size.

\section{PLATE XLII.}

Figures 1-4. Galba catascopium niagarensis BAKER. Squaw Island, Niagara River, N. Y. (23743).

5-8. Galba catascopium adamsi BAKER. St. Clair Flats, near Detroit, Mich. (TYPES, 23730).

9-13. Galba pseudopinguis (BAKER). Crystal Brook, Long Island, N. Y. N. Y. (TYPES, 23800).

14-17. Galba nasoni (BAKER). Thunder Bay Island, Alpena, Mich. (TYPES, 23788).

18-20. Galba woodrufi (BAKer). Lake Shore, Oak St., Chicago, Ills. (TyPes, 3425).

21-22. Galba woodruffi (BAKER). Lake Shore, Chicago, Ills. (23791).

23-25. Galba decollata (Mighels). Maine (Walker Coll., ex Mighels, 1926).

26. Galba decollata (Mighels). Unity, Maine (23811).

27-31. Galba jacksonensis (BAKER). Jackson Lake, Wyoming. (TYPEs, 23806).

32-33. Galba gabbii (Tryon). Clear Lake, Cal. (Coll. Hemphill). 
34. Galba gabbii (Tryon). Clear Lake, Cal. (23810). From type lot, ex. Tryon.

35. Galba gabbii (Tryon). San Francisco, Cal. (Coll. Hemphill).

36. Galba gabbii (Tryon). San Francisco, Cal. (23332).

Figures 1-13, 18-25, slightly enlarged; figures 14-17, 32-36, enlarged 11/2 diameters; figures $27-31$, natural size.

\section{PLATE XLIII.}

Figures 1-3. Galba emarginata (SAY). Isle Royale, Lake Superior (23992)

4-8. Galba emarginata (SAy). Mud Lake, Aroostook Co., Maine (23670).

9. Galba emarginata (SAY). Mud Lake (Second Eagle Lake), Aroostook Co., Me. Juvenile (23694).

10-11. Galba emarginata (SAY). Square Lake Inlet, Aroostook Co., Maine (23993).

12. Galba emarginata (SAY). Square Lake Inlet, Aroostook Co., Maine (23700).

13. Galba emarginata mighelsi (BINNEY). Juvenile. Square Lake Inlet, Aroostook Co., Me. (23702).

14-21. Galba emarginata mighelsi (Binney). Square Lake Inlet, Aroostook Co., Me. (23698).

Figures natural size $(9,13$, slightly enlarged).

\section{PLATE XLIV.}

Figures 1-3. Galba emarginata angulata (SowB.). Houghton Lake, Mich. Specimens compared with Sowerby's type in British Museum (23704).

4-6. Galba emarginata angulata (Sowb.). Houghton Lake, Mich. (Coll. Walker).

7-9. Galba emarginata angulata (Sowb.). First of Four lakes, Madison, Wis. (23707).

10-18. Galba emarginata wisconsinensis (BAKER). Tomahawk Lake, Wis. Types (24504). Showing variation from elongated to depressed spire.

19-23. Galba emarginata canadensis (Sowв.). Crooked Lake, Emmet Co., Mich. (23712).

Figures natural size.

PLATE XLV.

Figure 1. Galba emarginata canadensis (SowB.). Immature. Owasco Lake, N. Y. (23679).

2-10. Galba emarginata canadensis (Sowb.). Owasco Lake, N. Y. Showing extremes of variation (23678).

11-13. Galba emarginata canadensis (Sowb.). Owasco River, N. Y. (23682).

14-15. Galba emarginata canadensis (SowB.). Bear Lake, Mich. (23713).

16-17. Galba emarginata canadensis (Sowb.). Bear Lake, Mich. (24548).

18-20. Galba emarginata canadensis (Sowв.). Bear Lake, Mich. (23714). 
21-23. Galba emarginata ontariensis ("MuhlF," KüSTER). Rose Hill Cemetery, Buffalo, N. Y. (23758).

24-25. Galba emarginata ontariensis ("MUhlF." KüSTER). Fort Erie Grove, near Buffalo, N. Y. (23688).

26-27. Galba emarginata ontariensis ("MuHLF." KüSTER). Stoney Island, Saginaw Bay, Mich. (24505).

28. Galba emarginata ontariensis ("MuhlF." Küster). Pigeon Lake, Ontario (23317).

29-30. Galba pilsbryana (WALKer). Isle Royale. Immature. Cotypes (23672.)

31. Galba pilsbryana (WALKER). Washington Harbor, Isle Royale, Mich. TYPE (Coll. Walker, 21345).

Figures 1, 16-28, a trifle enlarged; other figures natural size.

PLATE XLVI.

Figures 1-4. Galba contracta (CURrIER). Higgins Lake, Roscommon Co., Mich. (TOPOTYPES, 24538).

5-8. Galba montana (Elrod). Mission Mts., Montana. (Topotypes, 23709).

9-11. Galba binneyi (Tryon). Lake Louise, Alberta. (Coll. Phil. Acad. Sci., 91207).

12. Galba binneyi (Tryon). Sawtooth Lake, Idaho. (Coll. Smith. Inst.).

13. Galba randolphi (BAKER). Marsh Lake, Dyea Valley, Yukon Territory. (TYPE, 23089).

14-15. Galba alaskensis BAKER =scalaris West. Vega Exp., IV, pl. 4, figs. 13, a, b.

16-17. Galba anticostiana (DALL). Marl Lake, Anticosti Island. (CoTYPES, 23875).

18-24. Galba nashotahensis (BAKER). Marl beds, Nashotah, Wisconsin. (TYPES, 24539).

Figures 1-4, 9-24, slightly enlarged; figures 5-8, natural size.

\section{PLATE XLVII.}

Figure 1. Galba oronensis (BAKER). Orono, Maine, CotyPe (23784).

2-3. Galba oronensis (BAKER). Orono, Maine. TyPes (Coll. Walker, 7912).

4-8. Galba oronensis (BAKER). Aroostook River, Caribou, Maine (23786).

9. Galba oronensis (BAKer). Ottawa, Canada. (Coll. Walker, 2540).

10. Galba catascopium (SAY). Calumet River, Chicago (23875).

11-12, 14-18. Galba binneyi (TRYON). Lake Superior (23716).

13. Galba binneyi (TrYoN). Lake Superior (23715).

19-22. Galba apicina (LEA). Lake Superior (23718).

23-24. Galba apicina (LEA). Union River, Mich. (23719).

25. Galba apicina (LEA). Brule River, Iron Co., Mich. (Coll. Walker, 22924).

26-27. Galba apicina (LEA). Twin Falls, Iron Co., Mich. (Coll. Walker, 22934). 
28-29. Galba apicina (LeA). Menominee River, Mich. (Coll. Walker, 22891).

30. Galba apicina solida (LEA). Salmon River, Idaho. (Coll. Hemphill). 31-35. Galba hinkleyi (BAKER). North Fork Snake River, Idaho. TyPES (23720).

Figures 4-12, 14-17, natural size; figures 1-3, 13, 18-35, slightly enlarged.

\section{PLATE XLVIII.}

Figure 1. Galba apicina (LeA). Type. (Smith. Inst., 118626).

2. Galba apicina solida (LEA). TYPE. (Smith. Inst., 118713).

3. Galba binneyi (Tryon). East of Colville, Wash. (Part of No. 9320, Smith. Inst.).

4. Galba glabra (MülLer). Europe. (23681). Type of subgenus Leptolimnea.

5-8. Galba randolphi (BAKER). Lake Lindeman, Yukon Territory. Young and immature (23092).

Figures 9-12. Galba randolphi (BAKER). Marsh Lake, Dyea Valley, Yukon. (Types, 23090).

13-14. Galba atkansis (DALL). Alaska Moll., pl. II, figs. 7, 9. Types.

Figures 1-3, natural size; figures 4-8, enlarged 2 1/2 diameters; figures 9-12, enlarged 1 1/3 diameters; figures 13-14, enlarged 1 3/4 diameters.

\section{PLATE XLIX.}

PROTOCONCH OR NUCLEUS.

(Greatly magnified.)

A. Lymnca stagnalis appressa SAY.

B. Bulimnea megasoma (Haldeman).

C. Galba bulimoides techella (Haldeman).

D. Galba truncatula (LinNe).

E. Acella haldemani ((Desh.) Binney).

F. Lymnca stagnalis appressa SAY. View of whorls from above.

G. Galba petoskeyensis (WALKER).

H. Galba parva (LEA).

I. Galba bulimoides techella (HALD.).

J. Galba catascopium (SAY).

K. Galba palustris (MÜLLER).

L. Galba danielsi (BAKER).

M. Galba proxima (LEA).

N. Galba jacksonensis (BAKER).

O. Galba nasoni (BAKER).

P. Galba binneyi (TRYON).

R. Galba randolphi (BAKER).

PLATE L.

Small brook near Glencoe, Illinois. Habitat for Galba caperuta (SAY). Photograph by F. M. Woodruff (Bull. Ill. State Lab. N. H., plate XX). 


\section{PLATE LI.}

Figure 1. Open area in woods near Glencoe, Illinois. Habitat for Galba caperata ( $\mathrm{SAY}$ ), in the summer, when the woods are filled with small pools. Photograph by F. M. Woodruff (Bull. Ill. State Lab. N. H., plate XIV).

Figure 2. Summer-dry pond near Glencoe, Illinois. In the spring this pond contains water one to three feet in depth. Habitat for Galba reflexa (SAY). Photograph by F. M. Woodruff (Bull. Ill. State Lab. N. H., pl. XVII, fig. 1).

\section{PLATE LII.}

Figure 1. Small pond near Glencoe, Illinois. Habitat for Galba reflexa (SAy.) This pond is filled with cat-tails (Typha latifolia). Photograph by F. M. Woodruff (Bull. Ill. State Lab. N. H., pl. XII, fig. 1).

Figure 2. Small embayment in Tomahawk Lake, Wisconsin. Habitat for Galba lanceata (Gould) and Galba emarginata wisconsiensis (BAKER). Photograph by F. C. Baker.

\section{PLATE LIII.}

Figure 1. Marshy pond near Sander's Resort, Tomahawk Lake, Wisconsin. This pond was artificially made by damming a small brook emptying into the lake. Habitat for Galba lanceata (Gould). Photograph by F. C. Baker.

Figure 2. Thoroughfare between Tomahawk Lake and Little Tomahawk Lake, Wisconsin. Habitat for Bulimnea megasoma (SAY) and Pseudosuccinea columella (SAY). Photograph by F. C. Baker.

\section{PLATE LIV.}

Figure 1. East fork of the North Branch of the Chicago River, near Glencoe, Illinois. Habitat for Galba parva sterkii (BAKER). Photograph by F. M. Woodruff (Bull. I1l. State Lab. N. H., pl. XVII, fig. 2).

Figure 2. Shore of Canandaigua Lake, near Canandaigua, N. Y. Habitat for Galba modicella rustica (LEA). Photograph by F. C. Baker.

\section{PLATE LV.}

Figure 1. St. Lawrence River, near Thousand Island Park. Habitat for Lymnaa stagnalis appressa SAY. Photograph by F. C. Baker.

Figure 2. Quynoch Point, Tomahawk Lake, Wis. Galba lanceata (Gould) inhabits the marshy area near the shore, while Lymnca stagnalis lilliana BAKER occupies the sandy beach on the more exposed shore, in company with Galba emarginata wisconsinensis (BAKER). Photograph by F. C. Baker.

\section{PLATE LVI.}

Figure 1. Southern shore of Lake Michigan east of Millers, Indiana. The shore is bordered by large sand dunes. Habitat for Galba woodruffi (BAKER). Photograph by F. M. Woodruff.

Figure 2. Swamp east of Wide Waters, Erie Canal, Rochester, N. Y. Habitat for Galba catascopium (SAY). Photograph by F. C. Baker. 


\section{PLATE LVII.}

Figure 1. Manitou, near Charlotte, Lake Ontario. The pool back of the breakwater is caused by the water being thrown over the breakwater by the waves. Habitat for Galba catascopium (SAY). Photograph by F. C. Baker.

Figure 2. Small pond near Manitou, Lake Ontario. Habitat for Galba palustris (MÜLLER) and (rarely) Lymnaa stagnalis appressa SAY. Photograph by F. C. Baker.

\section{PLATE LVIII.}

Figure 1. North end Irondequoit Bay, near Sea Breeze, Lake Ontario, N. Y. Habitat for Pseudosuccinea columella (SAY). Photograph by F. C. Baker.

Figure 2. Genesee River, Rochester, N. Y., north of city, showing marked contamination of river by sewage. Former habitat for Galba catascopium (SAY). Photograph by F. C. Baker.

\section{ERRATA.}

Page 36, footnote 4, for Wasserathruna, read Wasserathmung.

Page 101, line 3, for Cockrell, read Cockerell.

Page 102, line 20, for those, read that; line 37 , for vrtical, read vertical

Page 103, line 4, take out "a" before "very."

Page 113, line 8 , should be placed above Harris, G. D.

Page 120, line 4, for, after shell, read;

Page 137, line 21, for (Say), read Say.

Page 151, line 6, for (Walker), read Walker.

Page 152, line 1, for (Hemphill), read Hemphill.

Page 153, line 2, from bottom, for (Baker), read Baker.

Page 154, line 27, for $\frac{18}{4}-4$, read $\frac{16}{4-5}$.

Page 156, line 21, for (Walker), read Walker.

Page 206, line 8 , for $\frac{3}{3}$, read $\frac{2}{3}$

Page 207, line 17, for Rhoods, read Rhoads.

Page 221, line 3, for Nov. Sp., read Nov. Var.

Page 238, line 12, for construction, read constriction.

Page 240, line 3, from bottom, for Molluska, read Mollusks

Page 246, place two last lines above last paragraph.

Page 310, line 6, for Murray, read Maury.

Page 322, insert line 3 on p. 323, above line 26.

Page 373, line 24, for placate, read plicate.

Page 376, line 17, for Dexter, read Drexler.

Page 395, line 17, for Baker, read (Baker).

Page 396, line 18, for "by," read "in."

Page 424, line 7 , for Kirtland, read Kirkland.

Page 438, line 6, from bottom, for $\frac{2}{5}-7$, read $\frac{22}{5-7}$.

Page 447, line 11, 12, for variety, read species.

Page 499, line 26, for Samson, read Sampson. 


\section{INDEX.}

New species and genera and new names are printed in SMall capitals; the page number indicating reference to a diagnosis is printed in italics.

abyssicola, 28, 36 .

accelerata, 88,89 .

Acella, 93, 108, 110, 122, 125, I26,

191, 198, 199, 347.

acuminata, 55, 166, 167.

acuta, 274, 275, 282.

ADAMSI, 393, 405.

adelinæ, 210, 211, 214, 220, 273, 408.

alamosensis, 104.

ALASKENSIS, 455.

ALPENENSIS, 3I5, 316, 321, 322.

alternata, 466 .

Amnicola, 21.

ampla, 182, 222, 223, 389, 409, 416, $417,420,421,428,440,441,450$, 452, 458-460.

Amphipeplea, 121, 123, I25, 225.

Amphipepleinæ, I25.

Amphipeplidæ, I24.

ampliata, 149.

Ancylidæ, 124.

Ancylus, 121.

Ancylus fuscus, 197. parallelus, 198.

angulata, 402, 413, 416, 419, 421, 423425, 427.

Anodonta grandis footiana, 25.

Anodonta marginata, 25.

anticostiana, 95, I06, 107.

apicina, 19, 22, 52, 53, 104, 106, 387,

$390,397-399,402,406,440,442-450$.

Aplexa, 121.

Aplexa hypnorum, 19, 54, 233, 240, 312.

appressa, 17, 19-21; 52, 53, I37, 141, $144-159,170,180$.

arctica, 366, 373-376.

Arion ater, 41.

“ hortensis, 41.

aspirans, 204, 208, 209.

ativuncula, 87 .

atkaensis, 457 .

atkinensis, 457.

attenuata, 313, 327, 343, 353-355.

Aucella piochii, 104.

Auricula, 84, 123, 134. auricularia, $1,2,8,9,13,15,28,39$ $41,45-46,51,54,55,88,178$, I79, 182, 411, 421.

bakeri, 107, 108.

barbadensis, 428, 431 .

bicolor, 149.

binneyi, 52, 53, 387, 406, 407, 421, 432,

$439,440-447,450-455$.

Bithinia tentaculata, 41.

BLATCHLEYI, 32I, 322.

bombycina, 462 .

bonnevillensis, I05, 106.

bottnica, 150 .

brownii, 382, 383, 390, 391, 444.

bryanti, 210, 211, 213.

Buccinum glutinosum, 125.

$$
\text { “ } \quad \text { palustre, 200, } 298 .
$$

Bulimnea, 122, 123, 125, I26, I83, 184, 199.

bulimoides, 2, 27, 53, 209, 211-214, 217, 220-224, 231, 233, 267, 396.

Bulimus, 84.

californica, 359, 360, 361 .

Campeloma, 84, 247.

$$
\text { “ } \quad \text { decisa, 84, } 466 .
$$

caperata, 2, 5, 6, 9, 19, 20, 52, 63, 95, $105,214,225-235,240,241,246,313$, 380,390 .

Cardium edule, 28.

“ rusticum, 28.

Carinifex, 121, 128.

CASSI, 221, 222, 264, 267.

casta, 172, I74-176.

catascopium, 4, 9, 21, 32, 33, 52, 55, $88,99,105,106,109,110,127,296$, $305,313,378,379,380,381-408,414$, $415,427,428,431-433,438,440,444$, $446-449,458,460$.

canadensis, $1,415,416,425,427,430$ $434,436,437,440$.

Cercaria furcata, 148.

chalybea, $I 7 I-176$.

championi, 171, I75-177. 
Charydrobia stachei, 90, 91.

Chilina, 121.

Chironemus, 41.

Choanomphalus, 128.

Circinaria vancouverensis, 160 .

clammys, 150 .

coarctata, 172-174.

cockerelli, 1, 40, 209, 211, 213, 217222.

cochlea, 134.

columella, $1,2,6,9,21,50,110,158$,

$162, I 63,164,165,167,169-177,320$,

332, 382, 464.

columellaris, 165, 167.

compactilis, 94.

compressa, 164 .

conidea, 466.

consortis, 87,88 .

contracta, 89, 108, 432, 433, 434, 435.

contracosta, 103 .

cornea, 382, 383, 391.

corrugata, 466.

corvus, 302, 314.

Costella, 458.

crystalensis, 334, 335, 337, 340.

cubensis, 100, 196, 202, 203, 204, 205209, 213, 216-219, 222, 224, 225, 227, 231-237, 240-242, 257, 262, 369.

curta, 203, 243, 244, 247, 248.

Cyclemis, 467 .

$$
\text { “ } \quad \begin{aligned}
& \text { minutissima, } 467 . \\
& \text { olivacea, } 467 .
\end{aligned}
$$

Cyclolimnæa, 123, 125 .

cyclostoma, 24I, 242.

cygmata, 466.

dalli, 1, 20, 248, 25I-254.

danielsí, 109, 355, 357-359.

davisi, 283, 394.

Dawsonella meekii, 80.

decampi, 127, 289-291, 295.

decidiosa, 273.

decisa, 466.

decollata, 314, 399, 400, 402, 403, 421, 422, 425, 438, 444, 446, 447, 449.

delicata, 409, 415 .

desidiosa (authors), 162, 203, 262, $271,273,285,288,295,319,320$, $332,378,379,392,464$. desidiosa (Say), 107, 283, 313, 3I6, $317,318,319,320,321$.

diaphana, 97, 98.

Distoma ascidia, 41.

“ endolabrum, 41.

distortus, 334, 341 .

DODDSI, 196, 203, 204.

doriana, 160.

Dytiscus, 44.

eburnea, 467.

elegans, 149.

elliptica, 462.

elodes (authors), 43, 55, 300, 301, 303 . 336, 340, 389.

elodes (Say), 2, 312, 316, 319, 320, $321,322,323,324,325-327,329,330$,

332, 340, 353, 362, 363, 378.

elongata (Sowb.), 39, 460.

elongata (Say), 322, 323, 370.

emarginata (authors), 101, 422, 425, 427, 428, 438, 440, 455.

emarginata (Say), 2, 3, 19, 24-27, 31, $45,46,127,130,296,305,316,369$. $389,398,399,402,408-416,417,418$, $420-434,436-440,442,443,451,453$, 454, 455, 457, 458.

Ephemera, 41.

Erinna, 123, 124, I28.

Erinna newcombi, 128.

Espiphylla, 467.

Espiphylla nympheola, 467.

Estheria mexicana, 40, 220.

Eulimneus, 134.

exigua, 250, 270, 285-289.

exilis, $1,20,94,332,343-350,352-355$.

expansa, 160, 301-305, 313.

Fasciola hepatica, 203.

ferrissi, 227-229, 234.

ferruginea, 53, 255, 256, 269.

florissantica, 101.

Fossaria (West.), 200.

fossaria (Sowb.), 466.

fragilis, 149, 302.

francisca, 148, I76.

fusca, 314.

fusiformis, 391, 392.

gabbii, 53, 406-408.

Galba, 95, 108, 124-127, 199, 200, 234236, 307, 311, 373, 396, 454, 457, 458. 
Galba, sp., 465 .

galbana, 63, 127, 203, 267, 269, 282, $291-295$.

geisercola, 28.

glaber, 460, 461.

glabra, 254, 461.

glutinosa, 125.

Goniobasis virginica, 388, 467.

gracilis, 81, 108, 191-193, 197, 198, 347. 464.

griffithiana, 236, 237, 241.

groenlandica, 370, 371.

Gulnaria, 178.

Gundlachia, 121.

haldemani ('Desh.' Binney), 1, 2, 33, I92-196, 198, 199, 347, 348.

haldemani (White), 81, IIO.

haydeni, 303-305, 313.

hawaiensis, 192, 195.

Helix, 81, 134.

hemphilliana, $342,343$.

hendersoni, 223, 224.

heterostropha, 462, 466.

higleyi, 156, 157, 159.

hinkleyi, 449, 450.

holbollii, 54, 234, 235.

humilis (authors), 236, 243, 246, 259, 260-263.

humilis (Say), 9, 20, 39, 90, 96, 97, 202-204, 208, 210, 233, 236, 239-242, $245,247,249,256,257-259,263,264$, 266, 267, 270, 282, 288, 294, 295, 379, 391.

Hydra viridis, 41.

Hydrobia, 84.

inæqualis, 370 .

interstriata, 359-36r.

intertexta, 382-384, 391.

involuta, 125.

iowaensis, 334, 335, 341 .

jacksonensis, 106, 398, 404, 405, 406$408,434$.

jamesii, 262, 263, 267.

jayi, 108, 193. jolietensis, 322, 327-329, 334, 350, 355,
465 .

jugularis, 137, 148, 149, 156. kingii, 84, I02, 103, 458-460.

kirtlandiana, 329, 332, 347, 348-353, 359.

lævigata, 370.

lagorii, 127.

Lampsilis, 21.

Lampsilis luteola, 25.

lanceata, 20, 45, 140, 343, 347, 349, 350-353.

Lantzia, 123.

Leachia, 134.

leai, 363,364 .

lecontii, 205, 206, 208.

lepida, 53, 140, I6r, 162.

Leptolimnæa, 95, 122-126, 200, 254, $460,461$.

leucostoma, 370, 373 .

lillianæ, 21, 24, 45, 46, r53-156, 159.

Limax agrestis, 41.

“ maximus, 41.

Limnæa, 122, 123, 134, 136, 372.

Limnæidæ, 124.

Limnæus, 134, 136.

Limnea, 134, 136.

Limneus, 134.

Limnophysa, 122-124, 127, 200, 298.

limosa, 391.

lineata, 466.

linsleyi, 382, 383, 391.

Lioplax subcarinata, 466.

lithophila, 467.

Littorina, 28, 446.

Lomastoma, 467.

“ terebrina, 467.

Lymnæa, 121, I25, 134, 136, 178, 179. 192, 199, 200, 456-458.

Lymnæa sp., rog, 464, 465.

Lymnæidæ, I2r, 125, 133.

Lymnæinæ, $125,133$.

Lymnæus, 134, 136.

Lymnea, 134, 136, 297, 467.

Lymneus, 134.

Lymnula, 134, 298, 467.

Lymnus, 134.

lubricoides, 463.

macrostoma, 165, 167, 170, 171, 176, 320.

malleata, 371, 373.

maxima, I02.

meekiana, 98, 99, 100. 
meekii, 99, 101.

megalosoma, 185.

megasoma, $1,2,3,5,7,20,47,183$, I84-191, 410, 451.

megastoma, 184.

Melania multistriata, 111.

Melanopsis, 89.

merostoma, 166.

mexicanus, 353-355.

michiganensis, 303, 321, 322, 324, 327, $334,362$.

micronema, 81, 92.

mighelsi, 1, 32, 400, 402, 409, 412-415, $4 I 6,427,432,440,447,452,453,460$.

mighelsianus, 417.

minor, $370,373$.

minuscula, 95 .

minuta, 466.

modicella, $6,19,20,27,52,53,63,199$, 210, 245, 246, 258, 259-270, 279, 281. 282, 283, 288, 294, 295.

mölleri, 370, 371.

montana, 436, 437.

multistriata, 111.

Musculium truncatulum, 20.

Mya arenaria, 28.

nashotahensis, 108, 109.

nasoni, 397, 398, 409.

navicula, $165,167$.

nebrascensis, 98 .

NEOPALUSTRIS, 358, 376, 377.

Neritina, 28, 84.

Neritostoma, 178.

niagarensis, 391, 392, 394.

nigrescens, 466.

nitens, 370, 373 .

nitida, 375 .

nitidula, 89, 91 .

nuttalliana, 302-305, 313, 363, 364 .

obrussa, $1,2,6,9,27,33,39,53,63$, $77,87,107,127,162,170-177,199$, 203, 233, 236, 240, 254, 263, 267, 270. 271, 275-292, 296, 312, 319-321, 378, $379,392$.

occidentalis, I60, 161.

Omphalia, 297.

Omphalobulimus, 127.

Omphiscola, 296-298, 461.

ontariensis, 416, 432, 433 . opacina, 382.

oronensis, $403,438-440$.

Otostomus dombeyanus, 463.

ovata, $32,41,457,463,466$.

owascoensis, 250, 251, 254.

Pachymelania, 84.

pallida (authors), 274, 282.

pallida (Adams), 162, 203, 282, 377,

$378,379$.

palmeri, 463.

Paludina, 41.

palustris, $1-7,15,19,21,22,27-29,32$,

$38,41-43,46,52-54,63,94,96,101$, $127,149,170,279,281,283,298-309$, $311-330,334-337,340,343,344,351$, $356,357,359,361-379,384-390$, 404407, 414, 432, 440, 442.

parva, $2,19,20,33,39,52,63,87,199$,

$202,204,236,239,241,242,243-254$,

$258,262,264,267,274,281,282,370$.

$373,466$.

pellucida, 165, 167.

peninsulæ, 283, 285.

perampla, ${ }_{5} 5$.

pereger, 15.

peregra, 28, 32, 39, 40-46, 54, 400.

Perla, 41.

perpolita, 222-224.

petersi, 454-456, 457.

petitii, 466.

petoskeyensis, 295, 296.

philadelphica, 273-275, 282.

Physa, 22, 25-27, 33, 44, 81, 84, 88, 121, 458.

Physa acuta, 28.

“ ancillaria, 388.

“ elliptica, 462.

" fontinalis, 41.

“ gyrina, 20.

“ heterostropha, 332, 462.

“ primeana, 35.

“ sayii, 24-27.

Physastra, 124, 128.

“ vestita, 128.

Physidæ, 124.

pilsbryana, 430, 435, 436.

pilsbryi, 254 .

pingelii, 54, 358, 374-376.

pinguis, 382, 383, 389-391, 398, 448.

Pisidium, 29, 372. 
Planorbis, 29, 84, 121.

albus, 54 .

arcticus, 54.

bicarinatus, 322, 388.

bicarinatus royalensis, 25.

binneyi, 20, 155 .

campanulatus, 25.

carinatus, 41 .

corneus, 41 .

marginatus, 41.

parvus, 247, 414.

rotundatus, 54 .

spirorbis, 41.

trivolvis, 20, 29.

vortex, 41.

Planorbidæ, I2I, 124.

planulata, 285, 286, 289.

platystoma, 463.

plebeia, 300, 305, 313.

Pleurolimnæa, 3, 93, 103, 123, 124, 198.

plica, 87, 282, 283, 285, 286, 289.

plicata, 285.

Polygyra albolabris, 340 .

thyroides, 340 .

Polyrhytis, 3, 103, 123, 124, 127, 458, 460.

Pompholyx, 121, 122, 128.

præcellens, 465 .

preblei, 445, 450-452.

proxima, 53, 337, 358-363, 367, 369.

Pseudosuccinea, I26, I62.

pseudopinguis, $366,395,396$.

pugio, 353, 466.

Pupa vermilionensis, 80 .

“ vetusta, 80 .

Pupilla muscorum, 247.

pyramidata, 465.

Pyrgulifera, 84.

Radix, 88, 122-125, I26, 162, 163, 178, 179, 199, 421, 443, 452, 454, 457.

randolphi, 1, 179, 441, 443, 452-457.

raphidia, 149.

Recluzia, 463.

reflexa, $1,2,4,6,7,9,17,20,22,46$, $50,51,94,95,109,298,312,323-329$. $332-345,347,348,351,353-357,359$ 361-363, 465.

reflexis, 333 . reticulata, 466.

retusa, 467.

Rissoa, 28.

roseolabiata, 149, 314 .

rowellii, 303, 323 337, 349, 362-364.

rugosa, 463.

rustica, $877,268-270,288$.

sanctæmariæ, 21, 24-27, 149, 154, I56160.

Sandria, 127.

scalaris (Walker), 341.

scalaris (West.), 455.

scudderi, 100, 311.

Segmentina armigera, 20.

senegalensis, 371 .

septentrionalis, 301, 305 .

sericata, 391.

serrata, 409, 410.

shumardi, 99, 101.

shurtleffi, 329, 330, 332.

sieverti, IOI, 311 .

similis, 91, 96, 101, 110.

Simpsonia, I26, 199, 200, 236, 296, 297.

smithsoniana, 227-229, 234.

solida, 203, 382, 390, 391, 407, 444, $447,448,449$.

solidula, 371,375 .

sonomænsis, 1, 213, 222, 223, 224, 225.

sordidus, 303, 305, 313 .

spadicea, 463.

speciosa, 137.

Sphærium, 21, 28.

“ occidentale, 19, 233.

Spirogyra, 20, 21.

Stagnalis, 1, 2, 4, 6, 7-9, 13, 15, 17, $27,28,32,33,39,41,42,44,46,48$, $52,54,63,67,84,102$, I36-157, 161, $162,166,168,180,191,200,357,384$, 431, 436.

Stagnicola, 94, 96, 105, 110, 124, I26, $127,163,179,199,234,235,296$, 297, 298, 307, 347, 369, 373, 403, 452, 458, 461.

STEARNSI, 53, 84, IO2, 146.

sterkii, 20, 241, 248-250, 258, 267.

Stolidoma, 89.

strigata, 382.

strigosa, 171-174, 382. 
subcarinata, 466.

subula, 149.

subulata (Sowb.), 93.

subulata (West.), 149, 153.

subulata (Dunker), 353-355.

succinea, 150.

Succinea, 462, 467.

“ grosvenori, 247.

“ pellucida, 165, 167.

“ putris, 41.

“ ovalis, 170 .

“ retusa, 166.

“ wilsoni, 165, 167.

succiniformis, $165,167$.

sufflatus, 302, 304, 305, 313 .

sumassi (authors), 303, 314, 359, 435, 440.

sumassi, (Baird), 53, 403-407.

Tanousia, 127.

tazewelliana, 243, 244, 248.

techella. 1, 2, 4, 84. 100, 207-209, 211,

213, 214-223, 231, 241, 396.

terebrina, 467 :

terræ-novæ, 465.

tenuicosta, 9I, 92, 93, 103.

tenuicostata, 91, 93, 198.

tenuis, 464.

Thaumastus, 94, 95.

“ californicus, 94 .

Tortacella, 81, 84 .

haldemani, 110.

traskii (Lea), 365, 367.

traskii (Tryon), 53, 203, 295, 346, $367,368,369,456$.

Triton tæniatus, 42.

truncatula, 39, 41, 54, 101, 127, 196, 199, 20I-204, 208, 234, 235, 243, 247, 255, 256, 274, 466.

tryoniana, 303, 365, 367.

tryonii, $365,366,367,372$.

Tubifex rivulorum, 37 .

turricula, 314, 467.

turritus, 353, 354.
Typha, 21, 170, 339, 352.

“ latifolia, 21.

umbilicata (authors), 205, 227, 234.

umbilicata (Adams), 2, 22, 208, 236242, 244, 245, 247, 258.

umbrosa, 300, 323, 324, 327, 331, 332, 347, 361, 362.

Unio, 81, 84 .

“ complanatus, 332 .

utahensis, 29, 53, 84, 103, 222, 223, 458.

vahlii, $54,235,303,307,346,370,371-$ 376.

Vallonia gracilicosta, 247.

Valvata, 21.

variegata, 149.

velutina, 128 .

Velutinopsis, 128.

ventricosa, 182, 467.

Vesica, 134.

vetusta, 95, 97, 101.

virginica, 467.

virginiana, 463.

vitrea, 464.

Vivipara, 41, 84, 467.

“ contectoides, 467.

“ decisa, 322.

vulgaris, $127,149$.

walkeri, $34 I, 342,355$.

WASATCHENSIS, I52, 153.

WHITEAVESI, 93.

wilsoni, 165, 167.

wisconsinensis, 1, 21, 155, 156-160,

413, 416, 421, 425, 426, 427.

woodruffi, $21,28,366,397,398-400$.

446.

wormskioldi, $370,371,373$.

wormskjoldi, 370 .

Zagrabica, 127.

“ $\quad$ brusiniana, 128.

zebra, 344, 345, 347.

zrmanjæ, 127. 


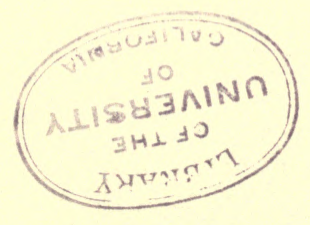





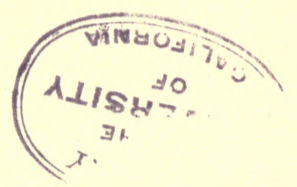




Pl.ate. I.

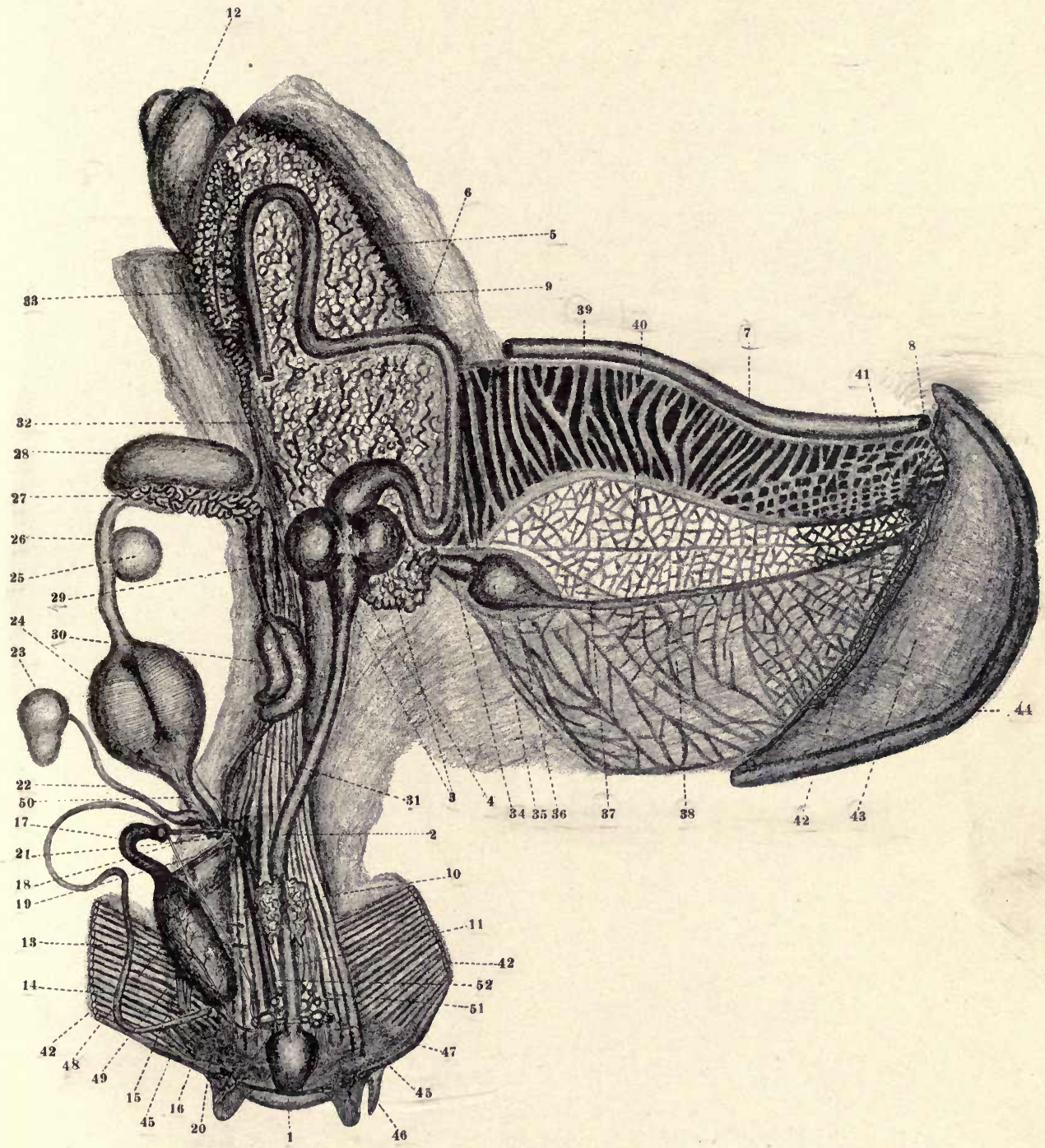




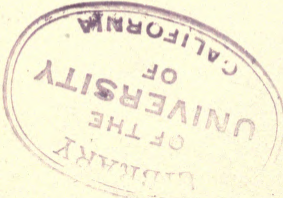


Plate II.
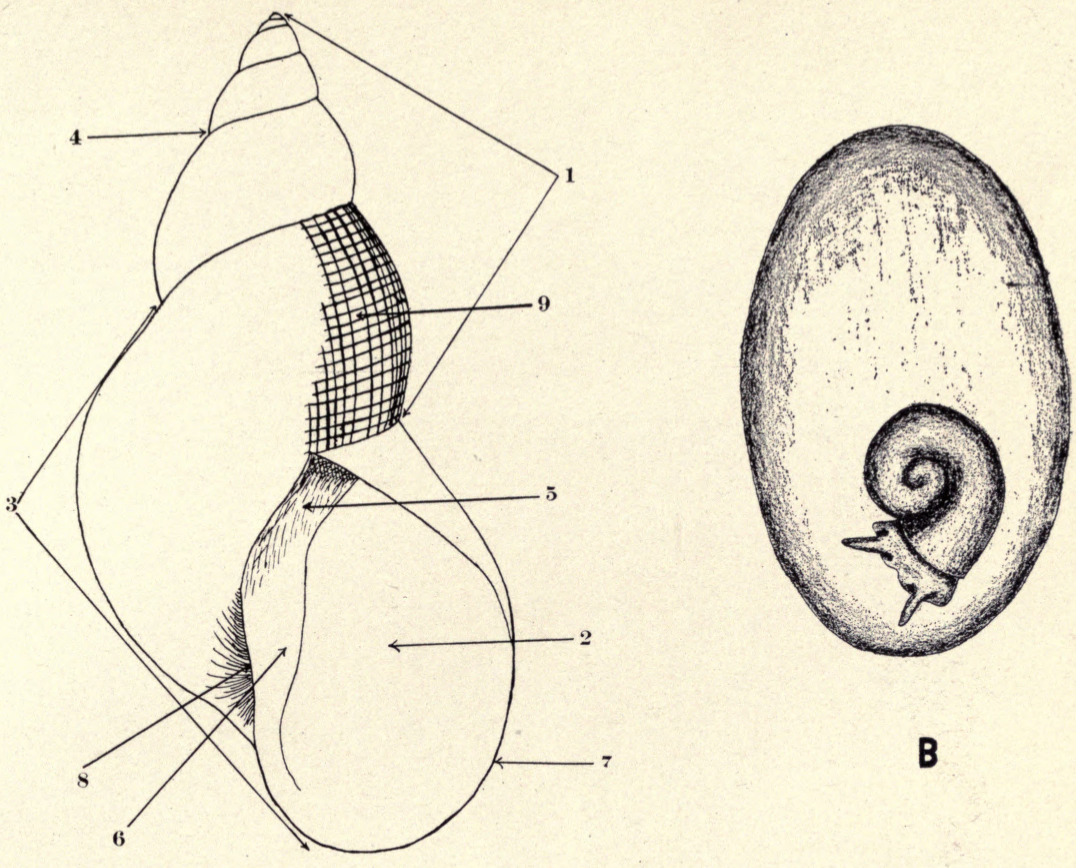

B
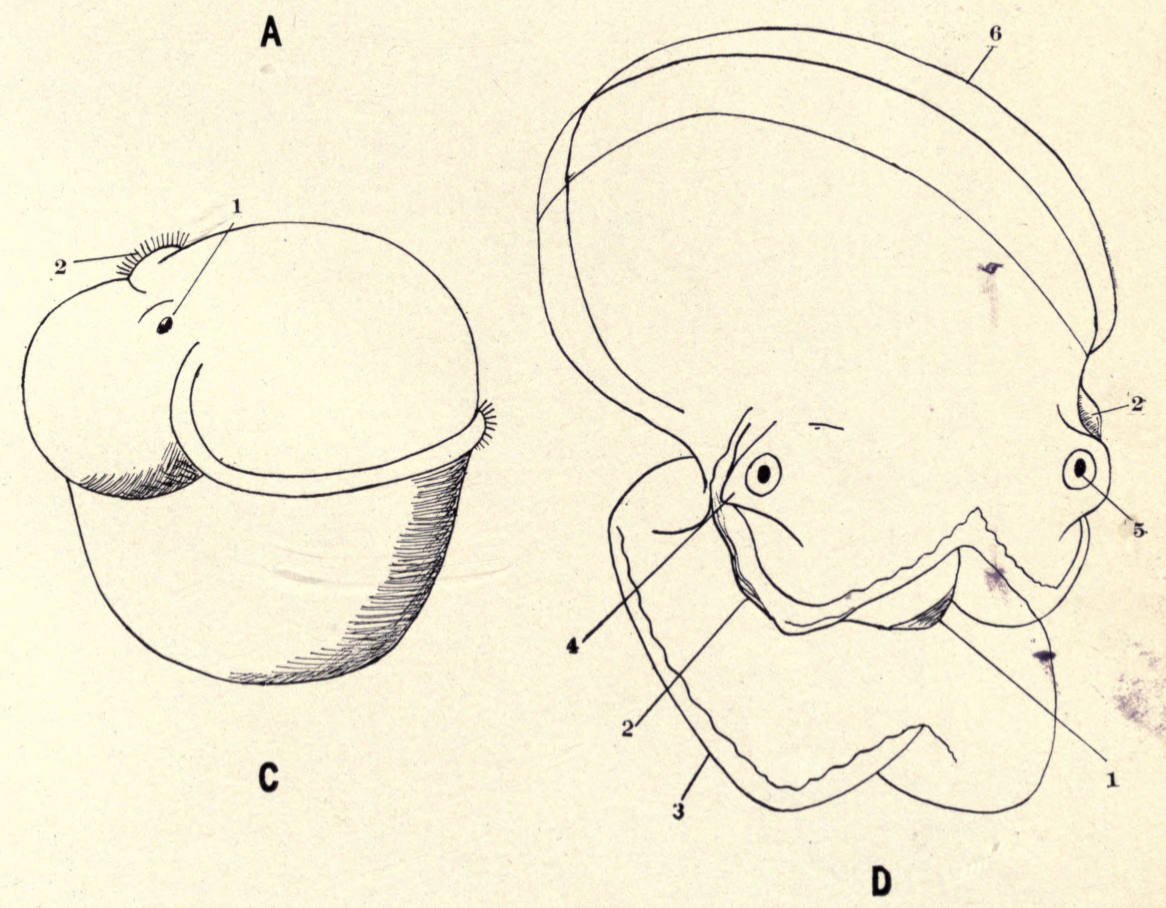


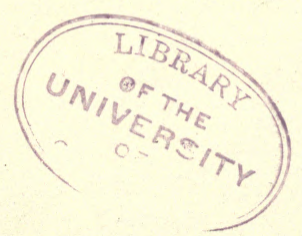


Plate III.

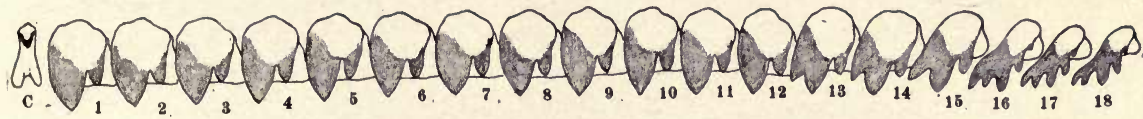
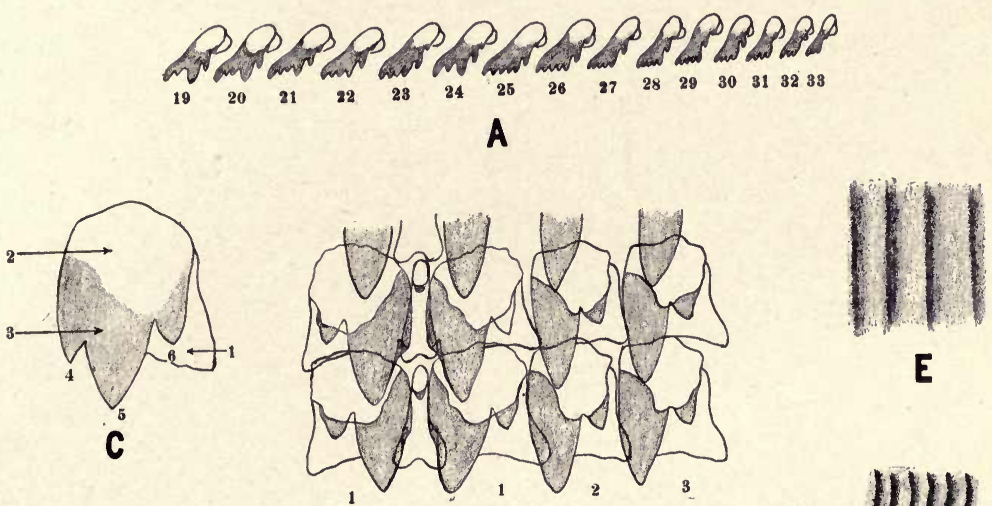

E

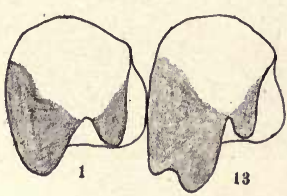

B

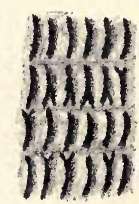

$\mathbf{F}$
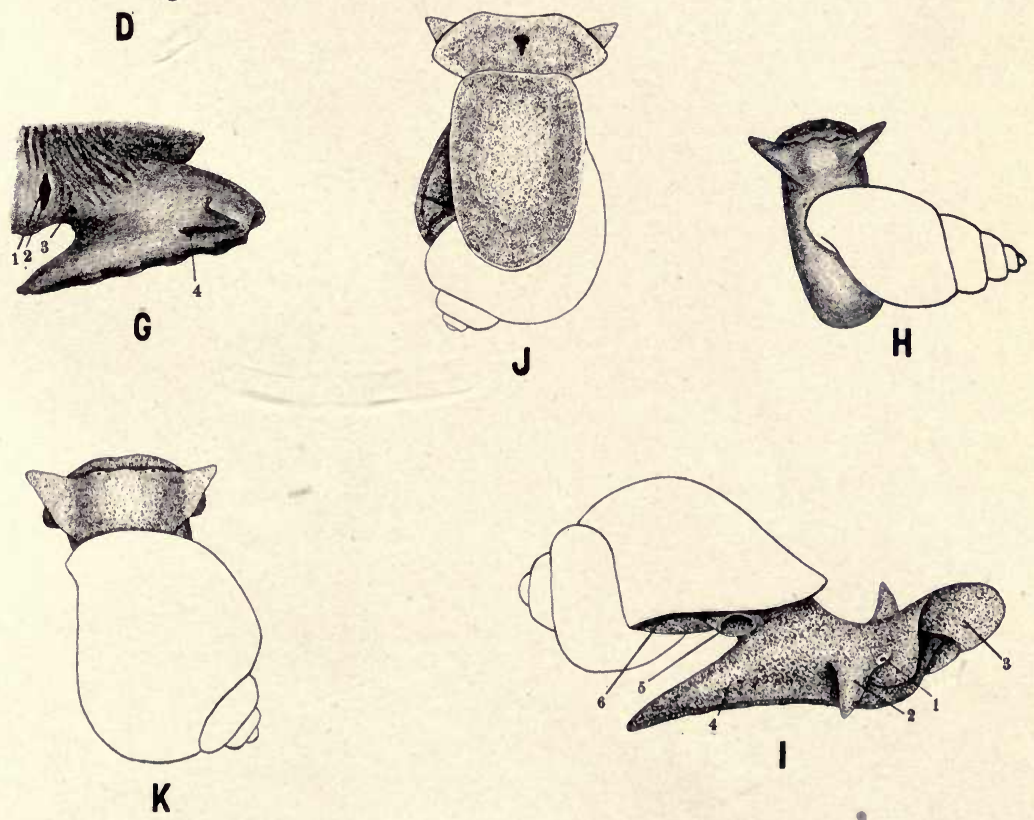


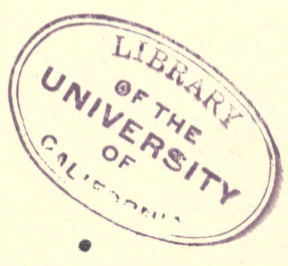


Plate IV.

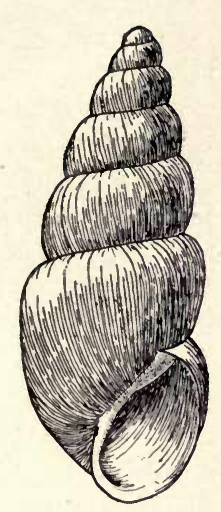

A
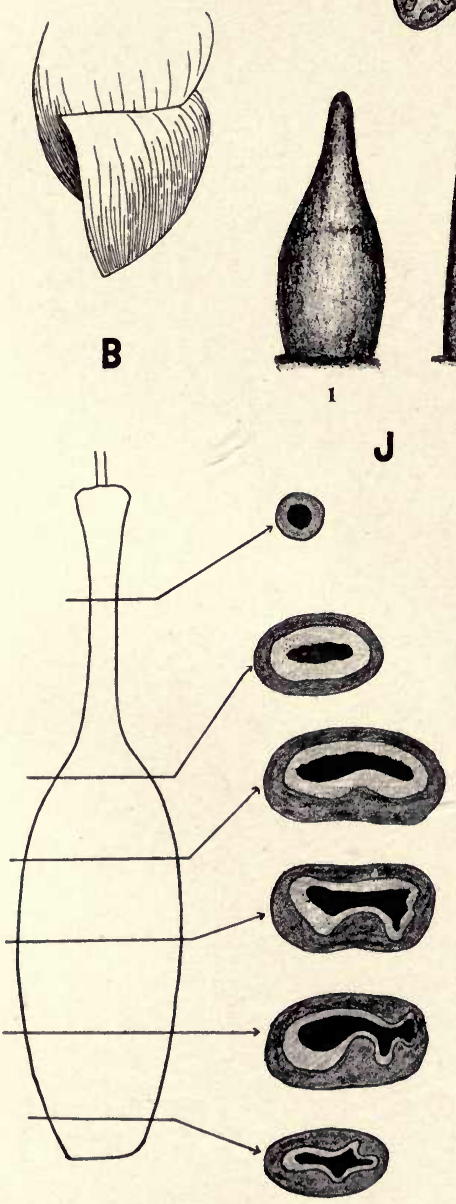

H

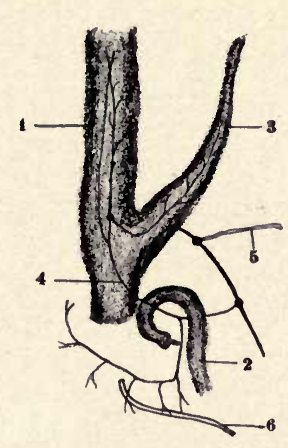

D
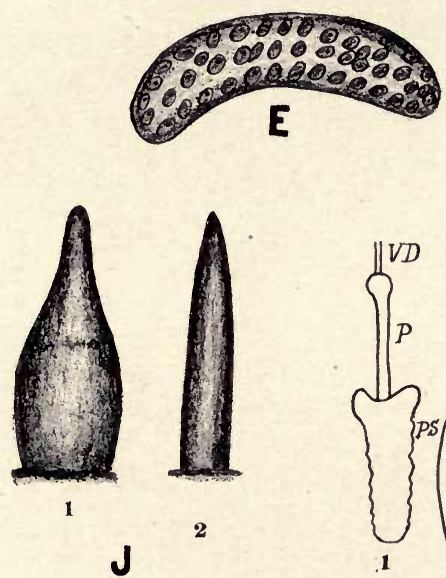

G

F
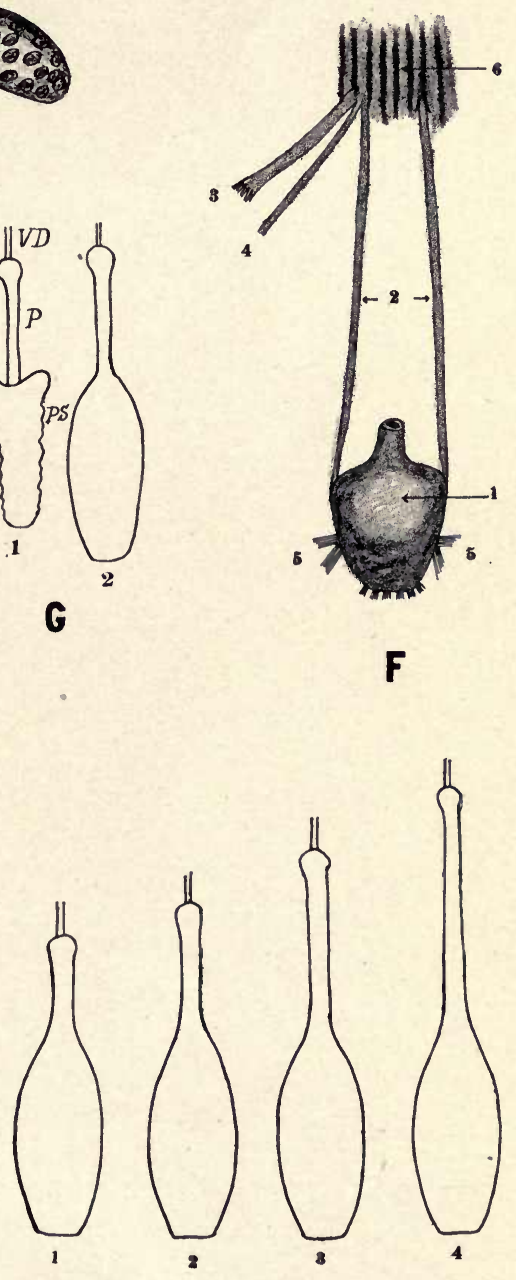

Plate V.

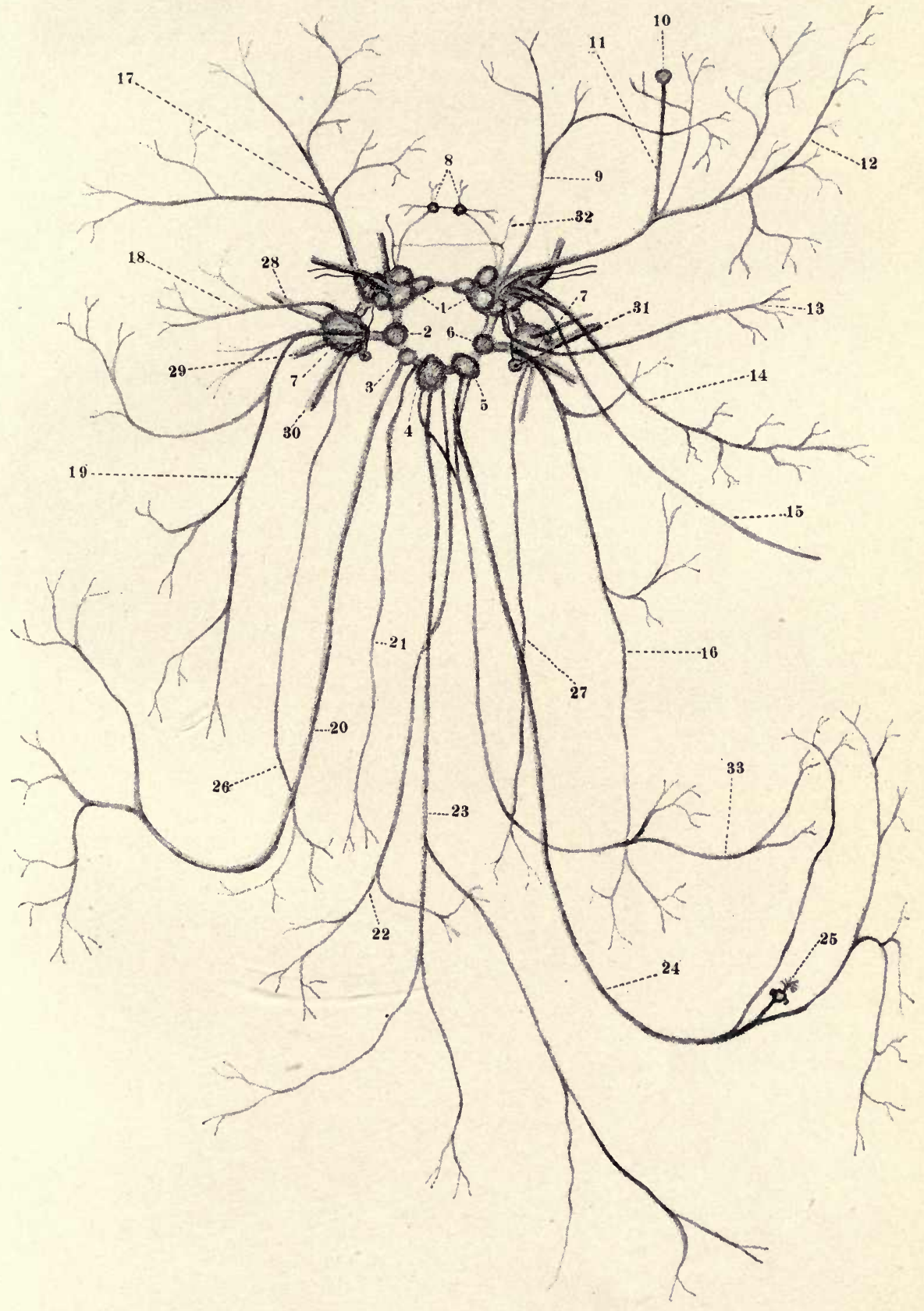



Plate VI.
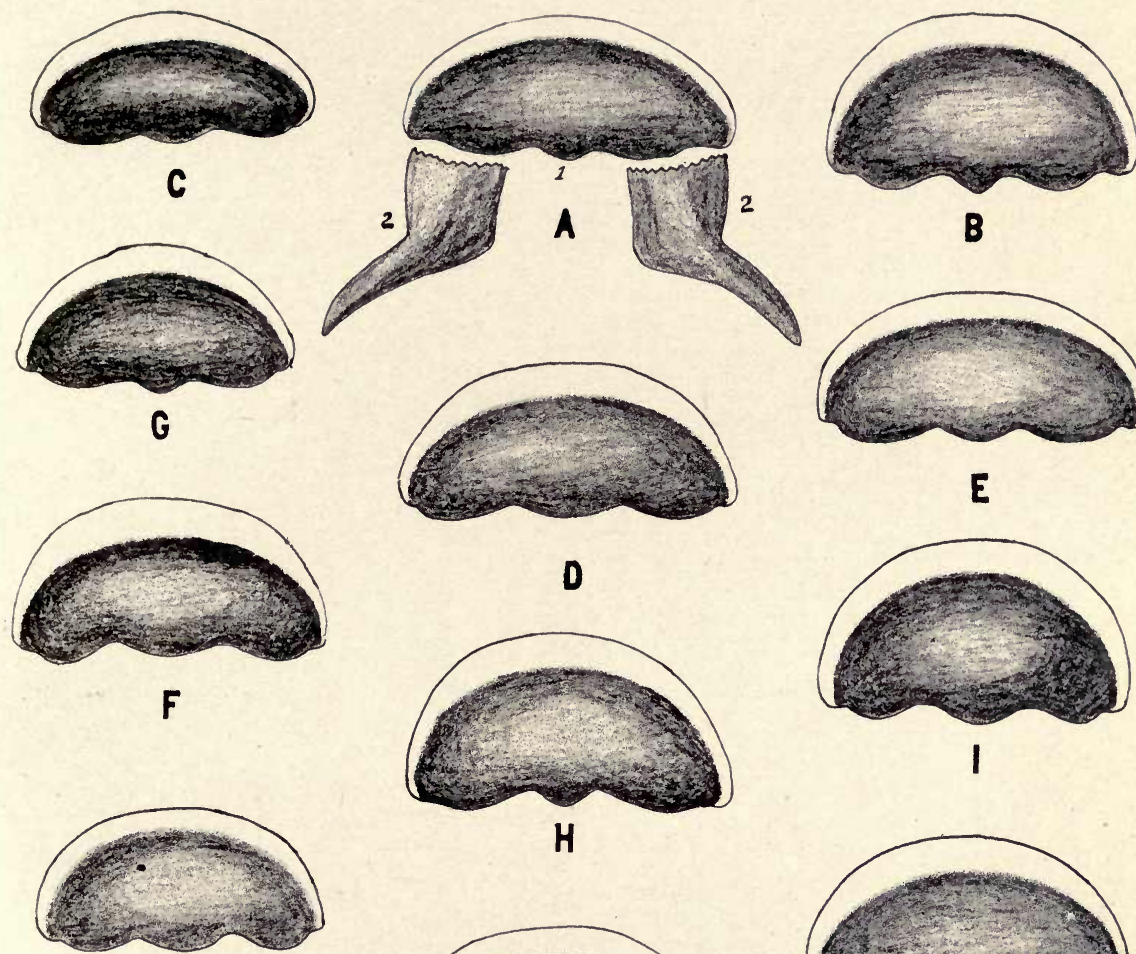

H

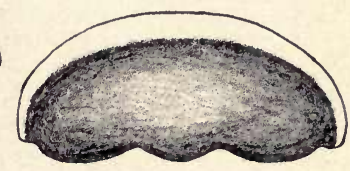

E
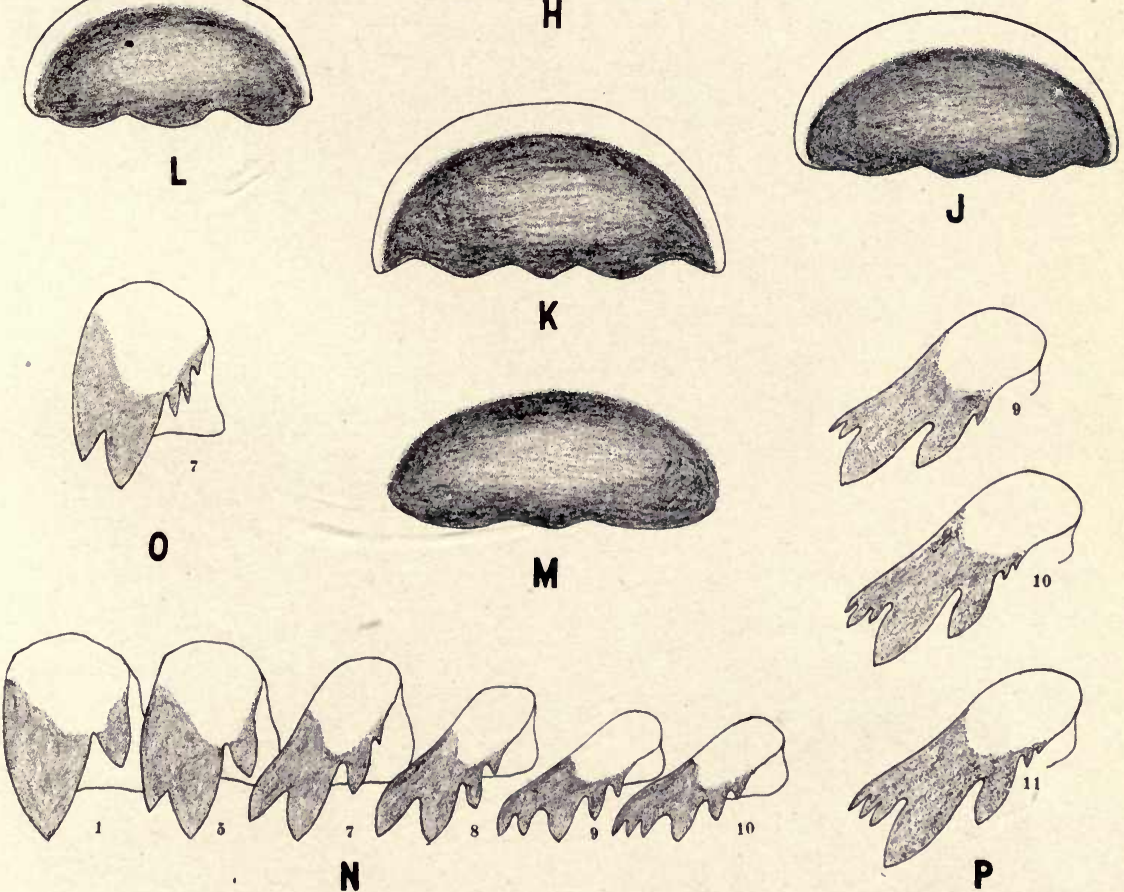

Plate VII.

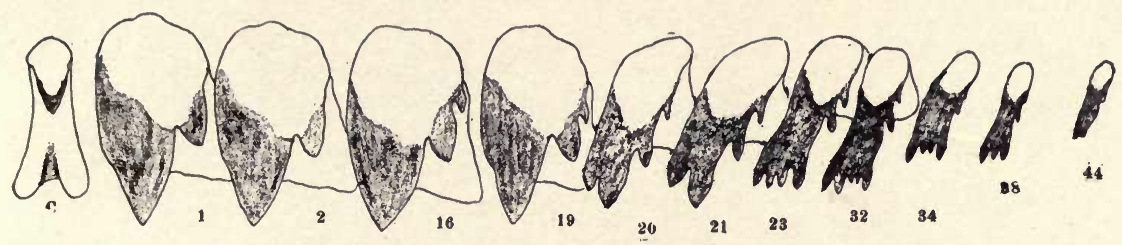

A
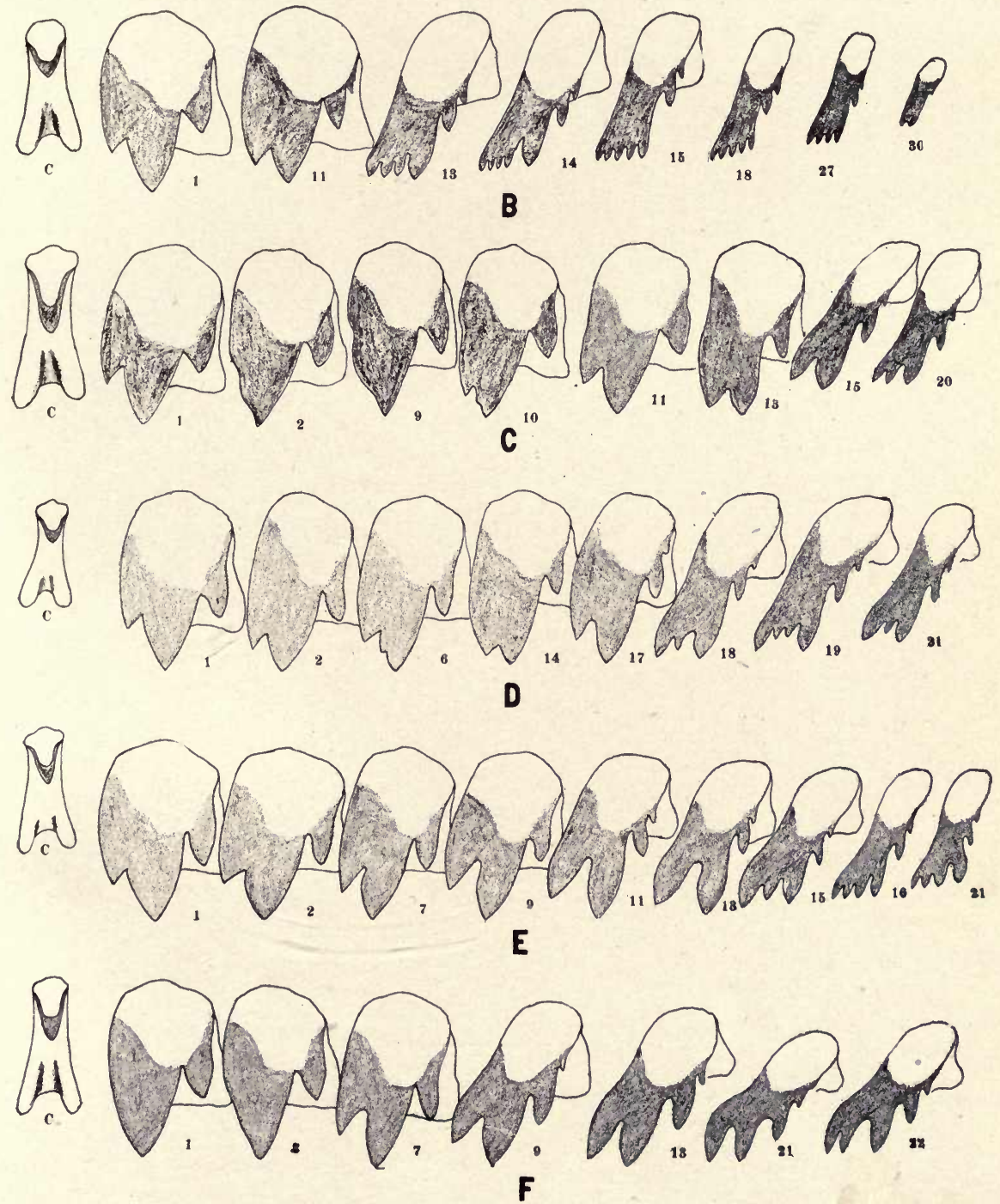


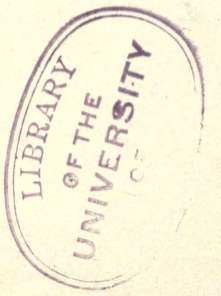


Plate VIII.

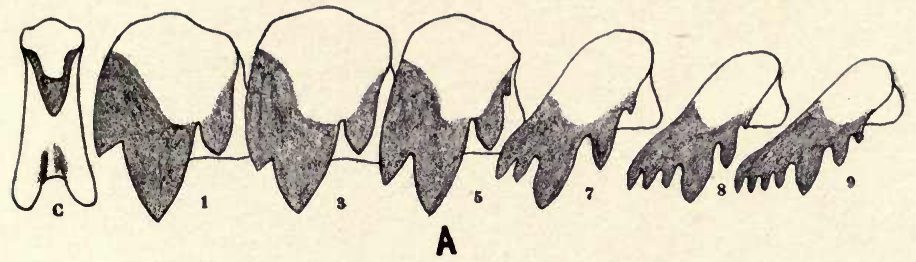

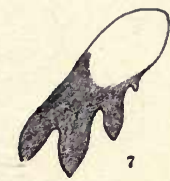

8
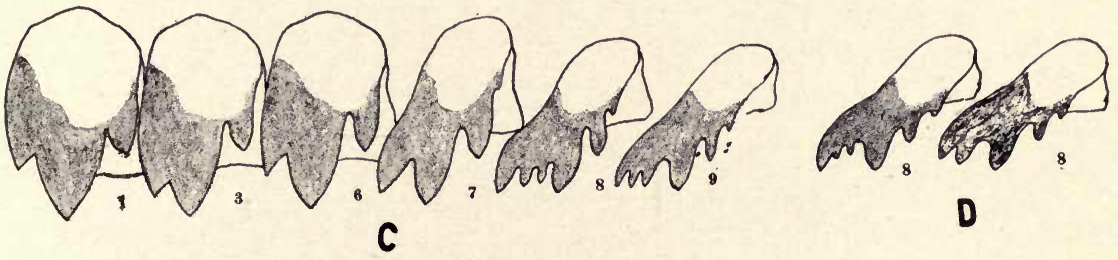

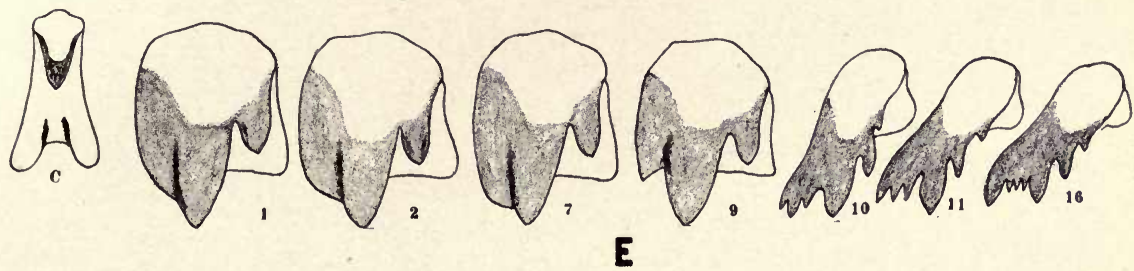
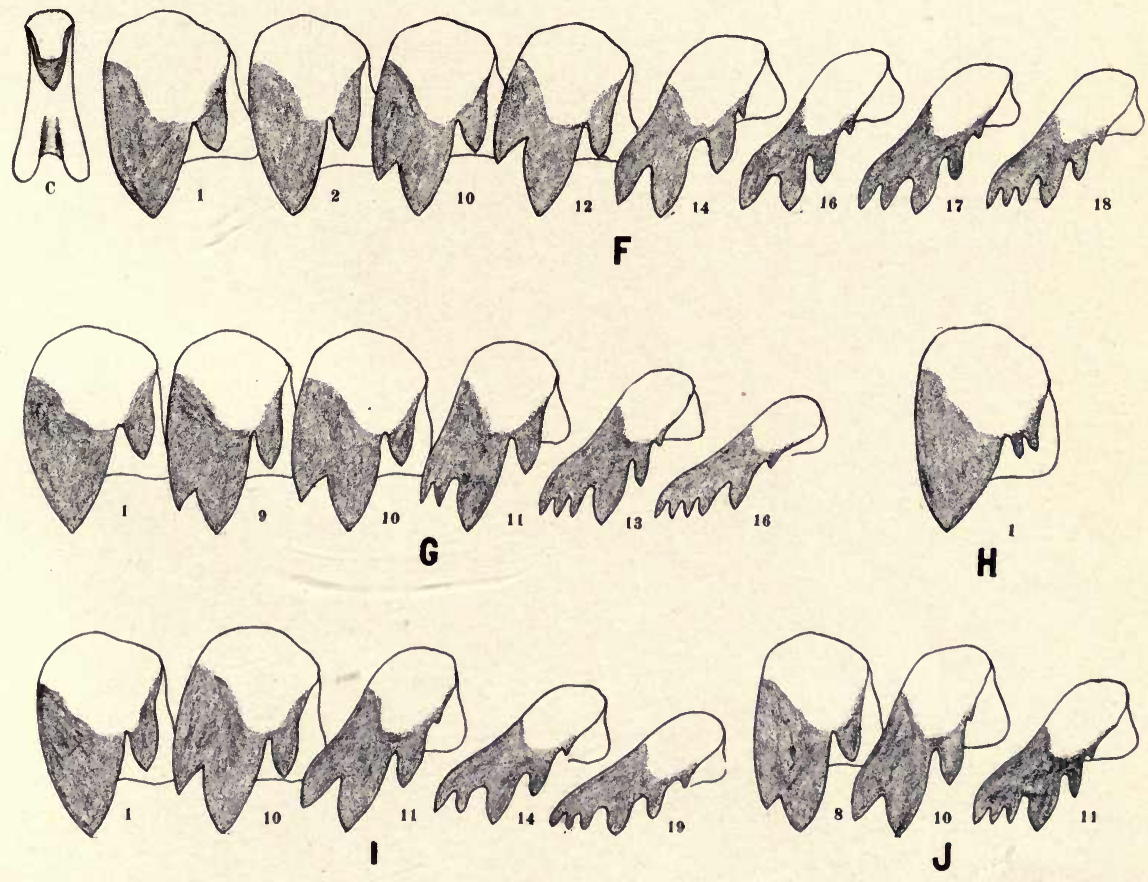

Plate IX.
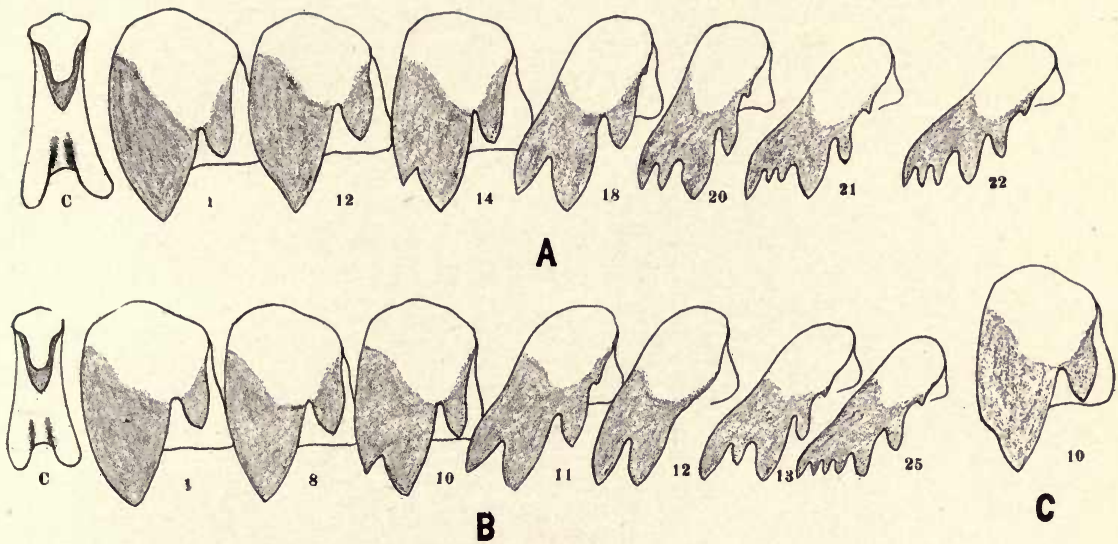

\section{B}

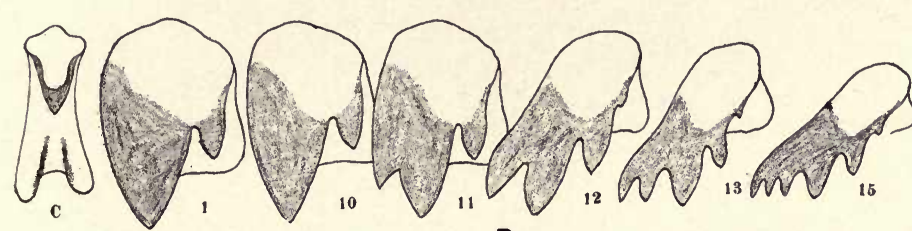

D

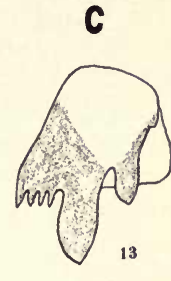

F
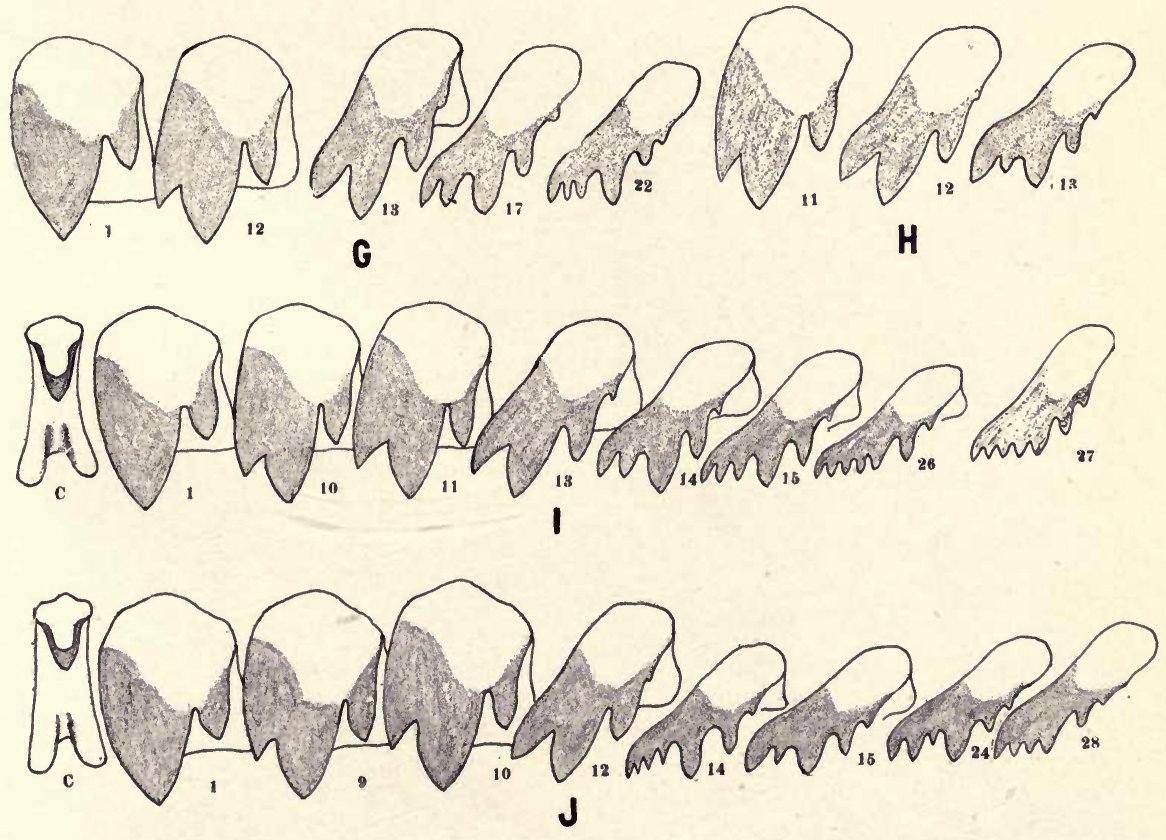

Plate X.

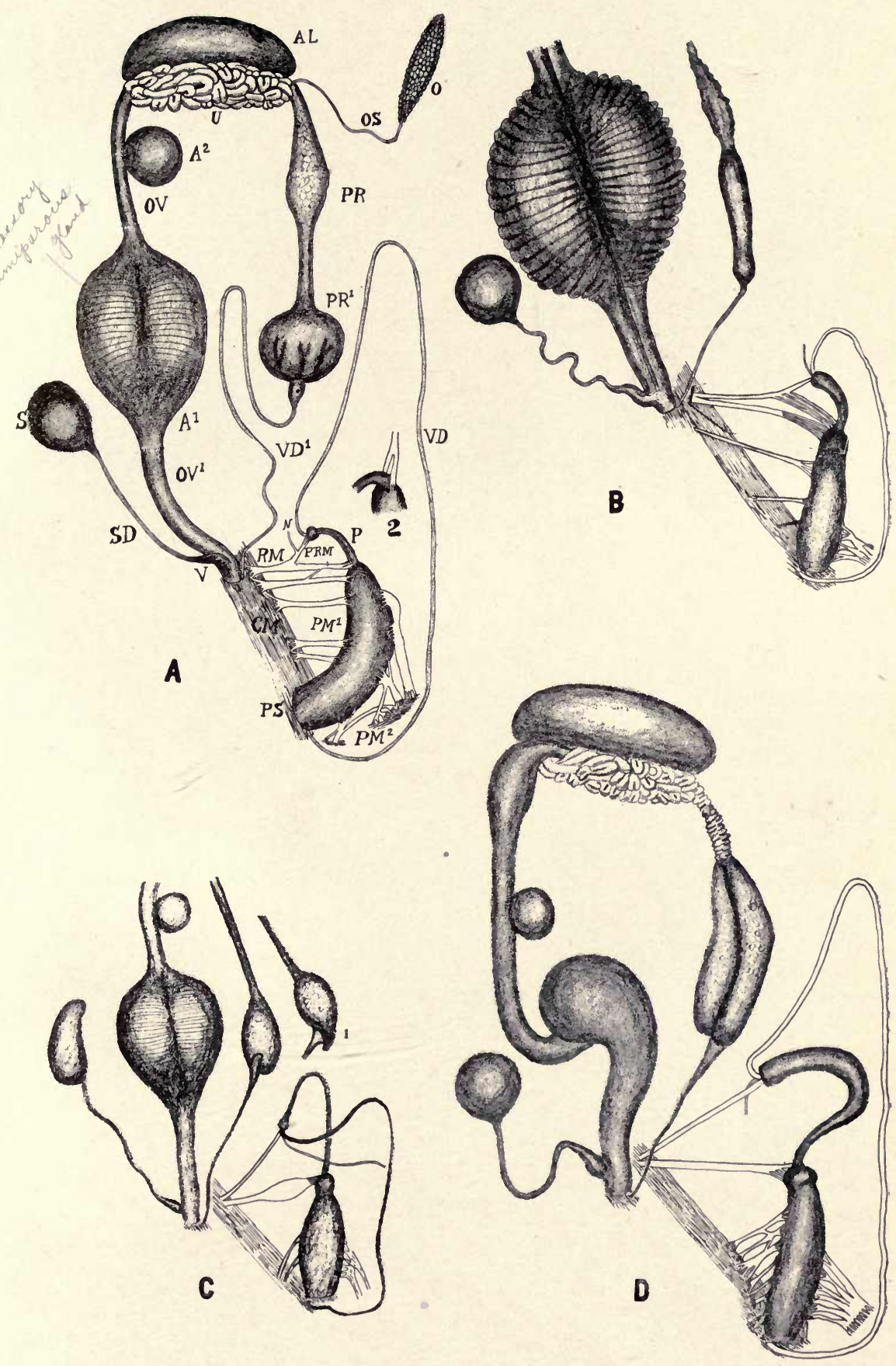



Plate XI.
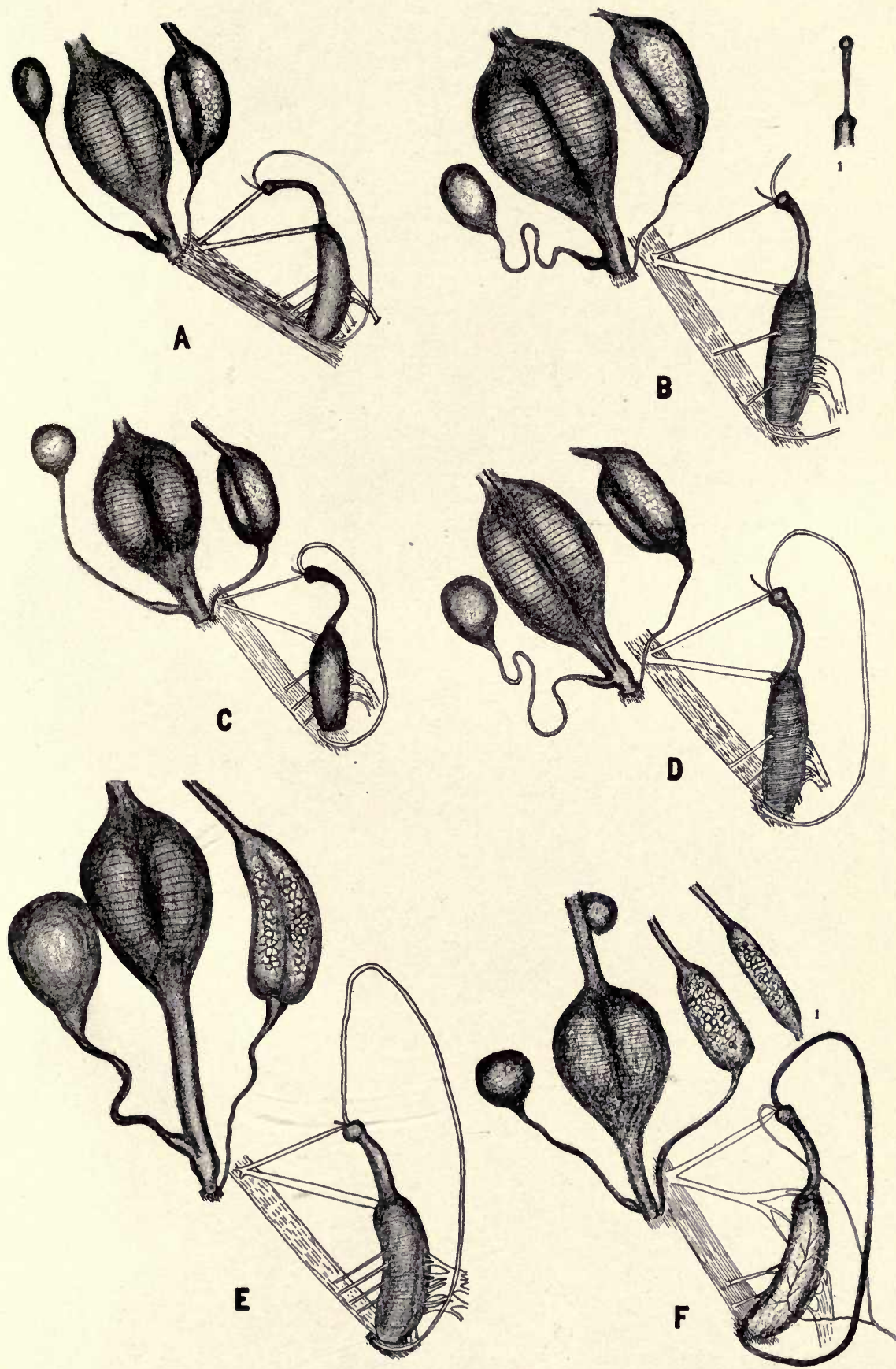


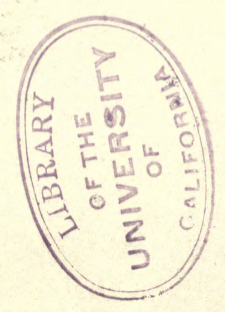


Plate XII.
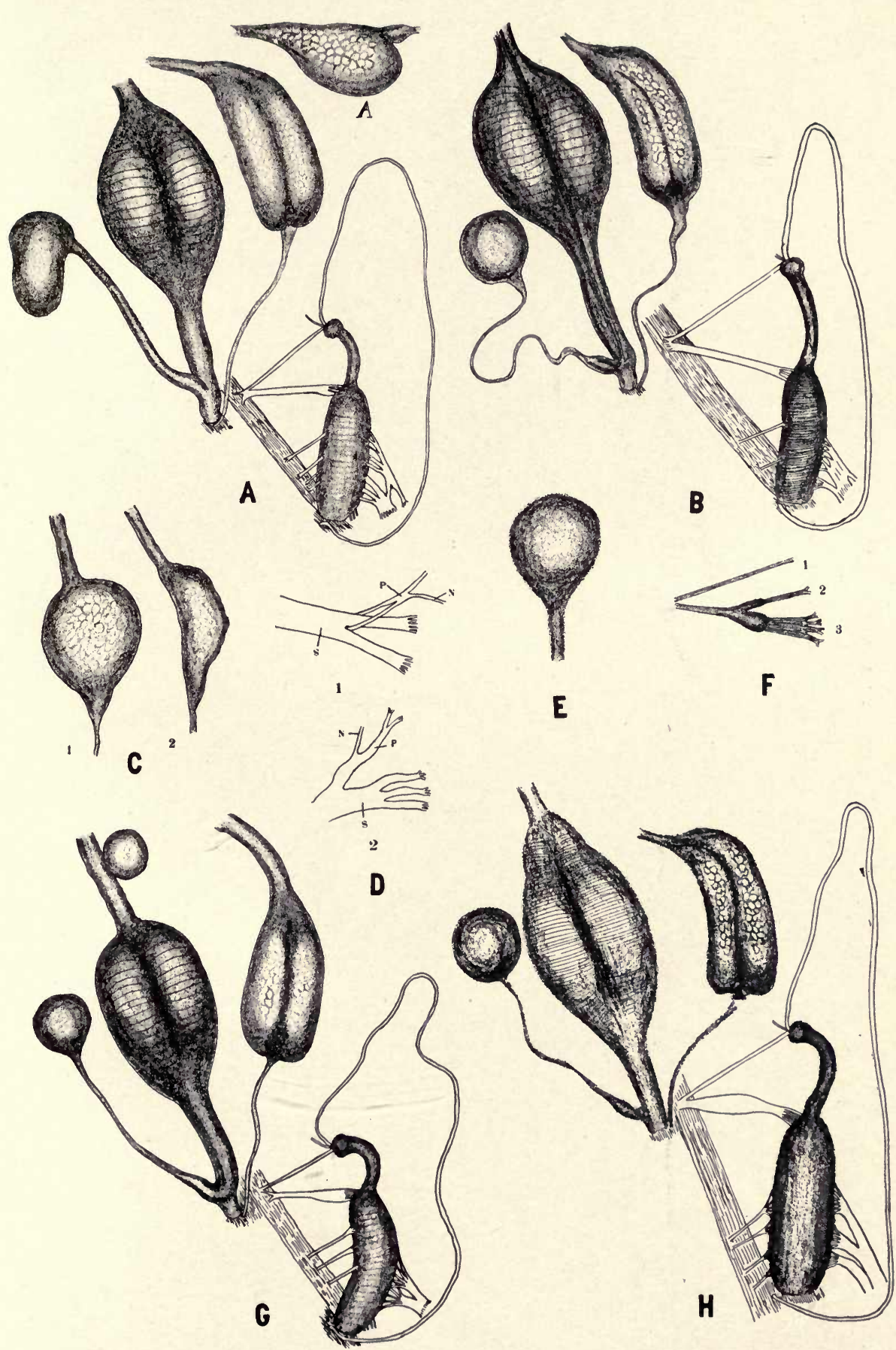

Plate XIII.

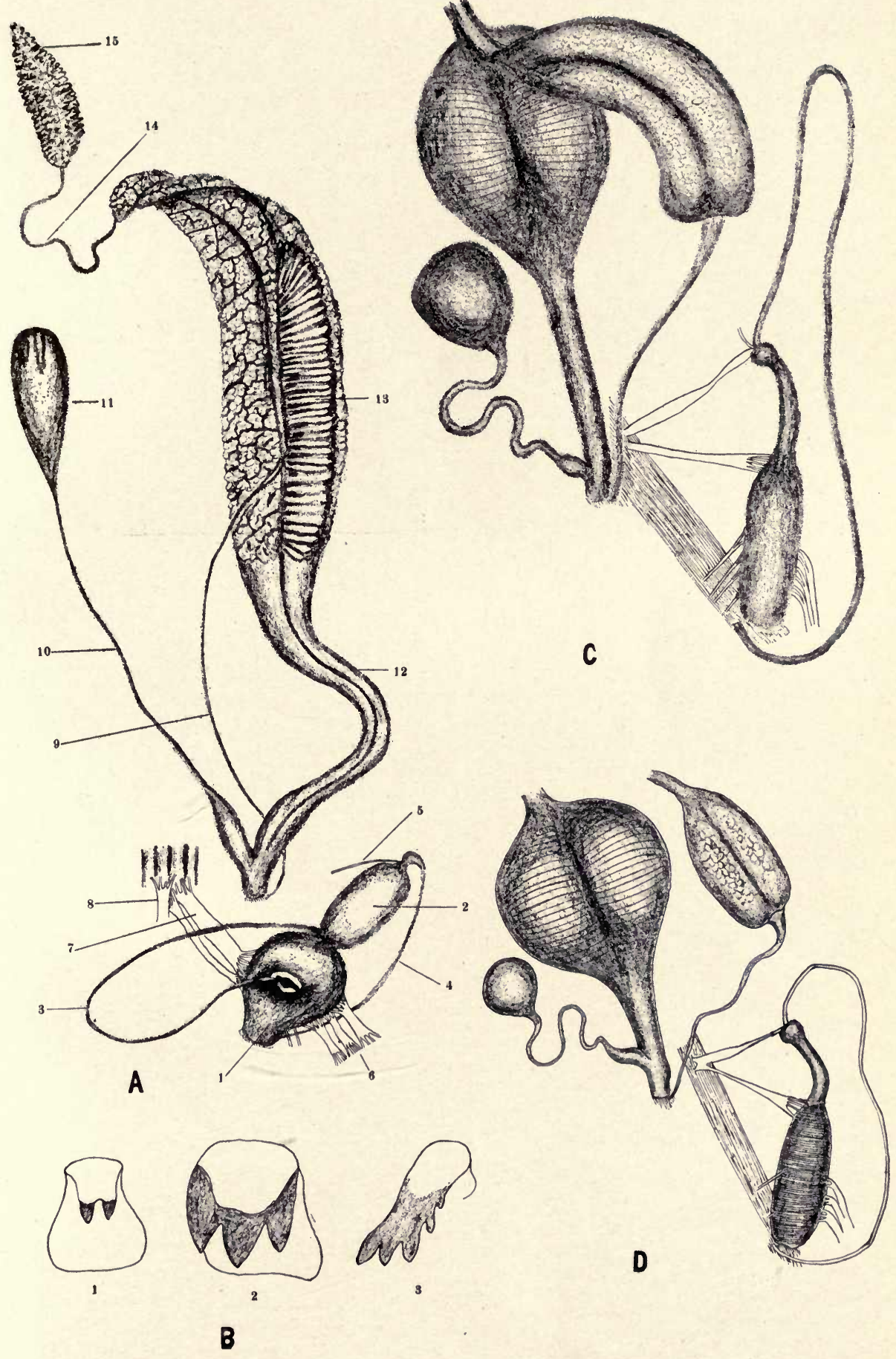




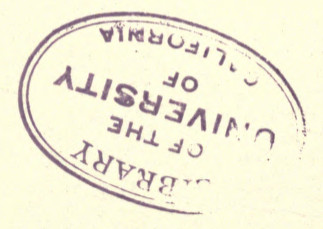


Plate XIV.
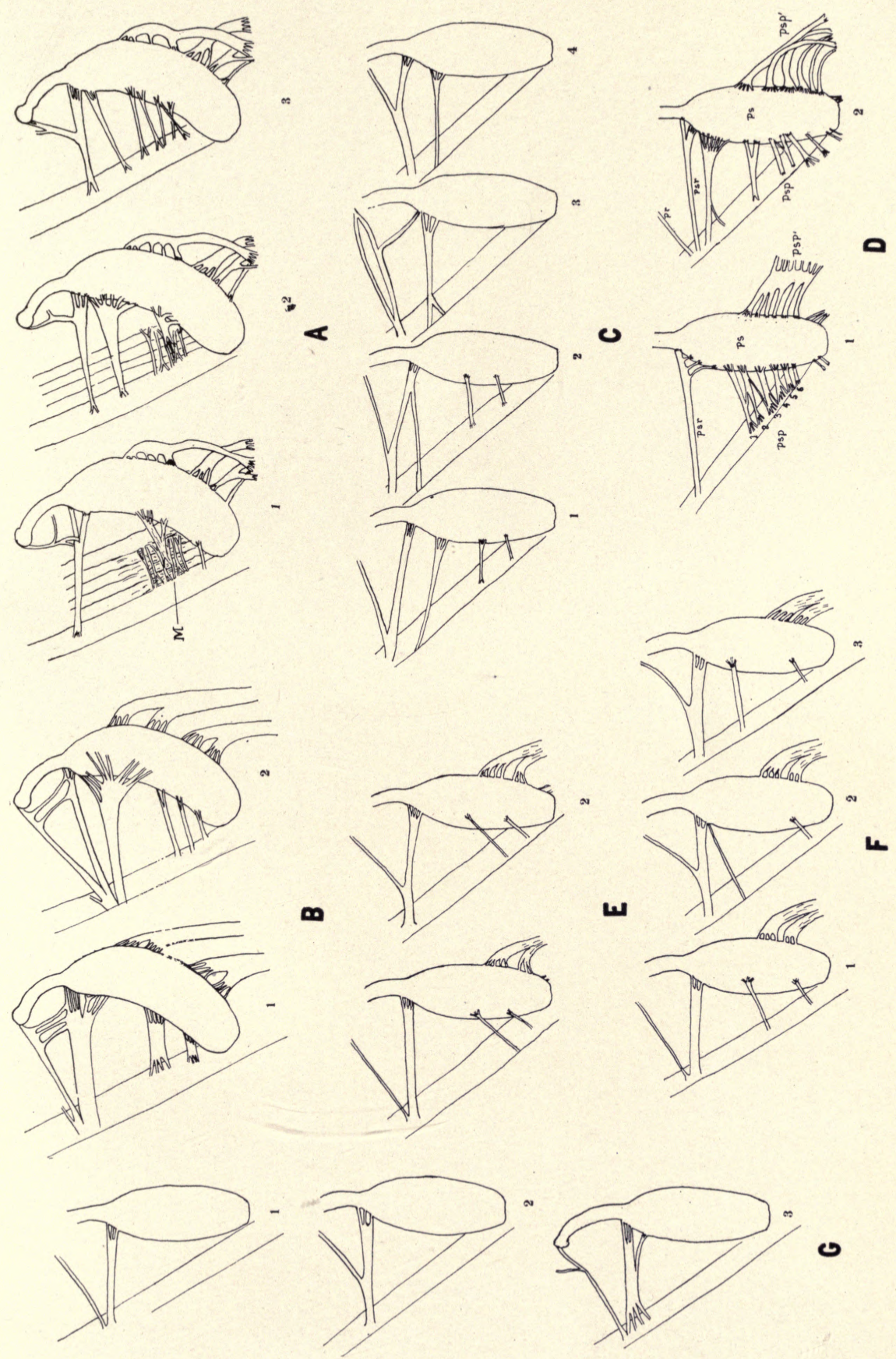


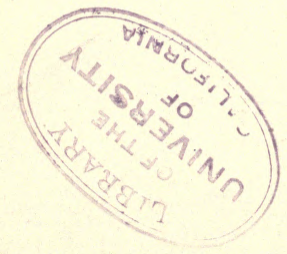


Plate XV.
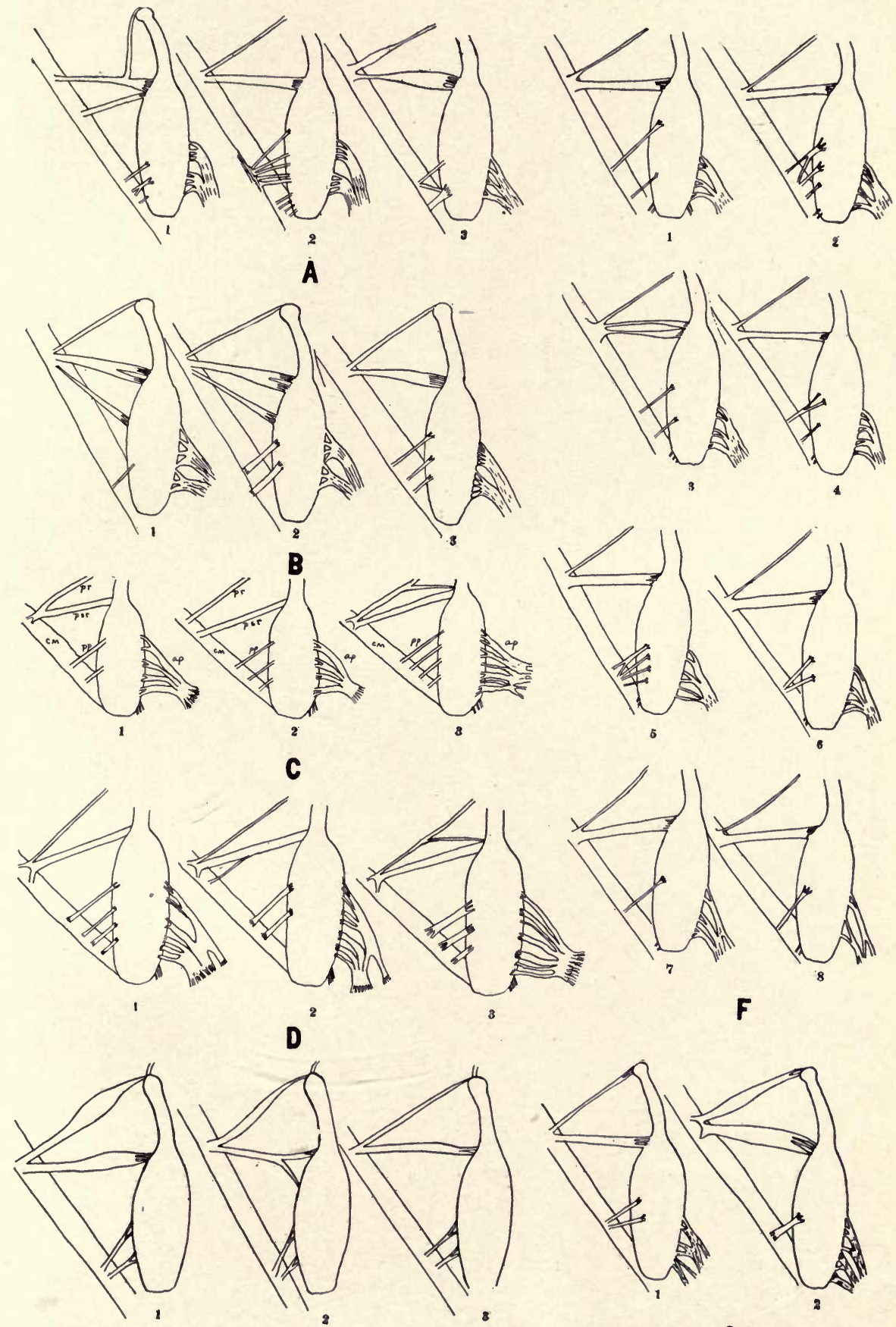

E

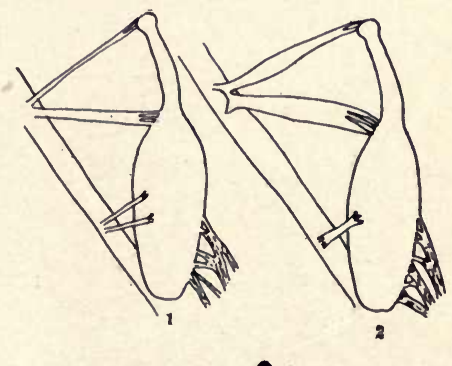



Plate XVI.
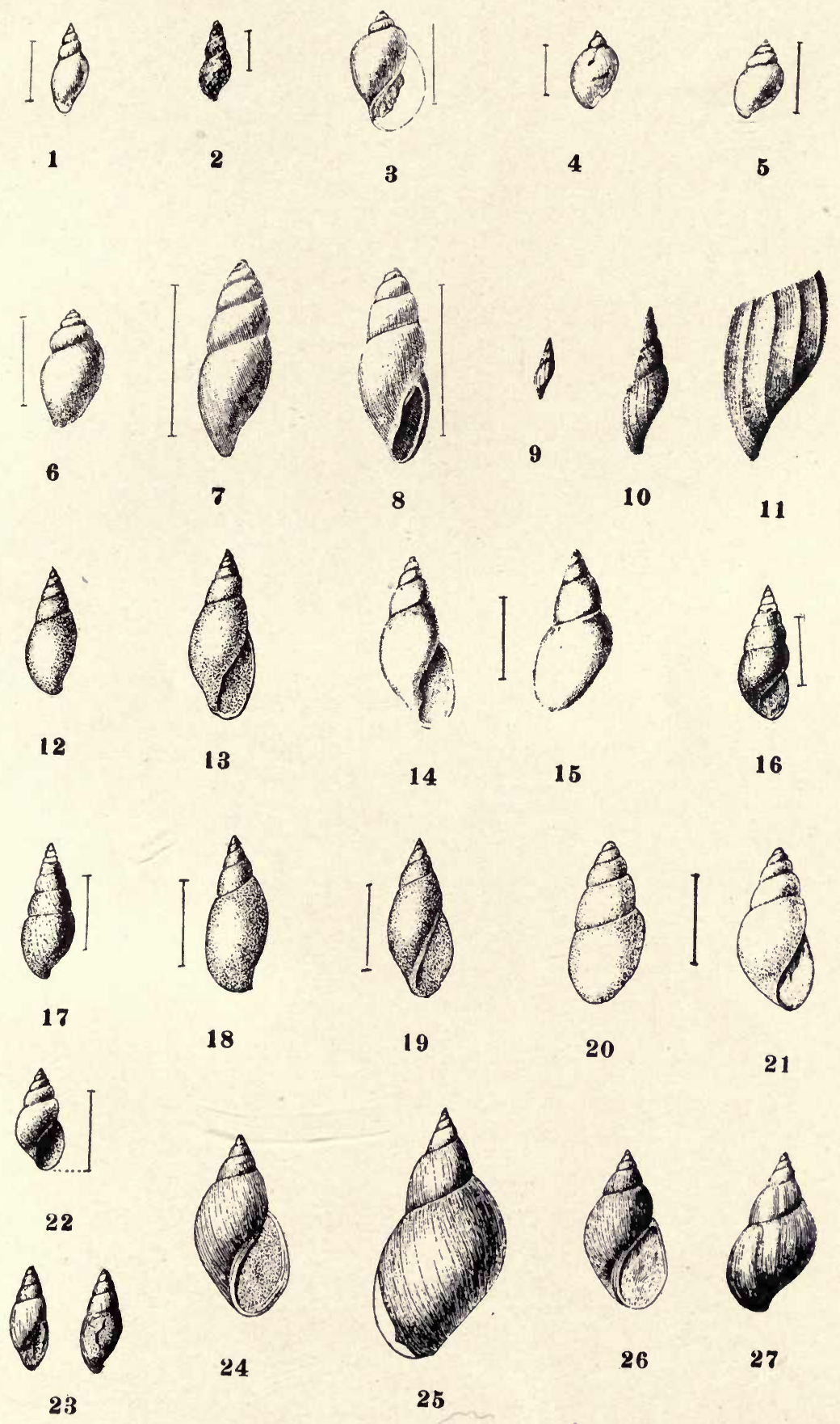


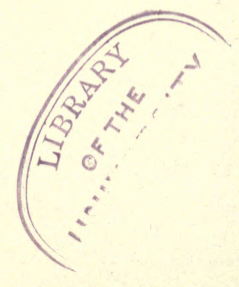


Plate XVII.

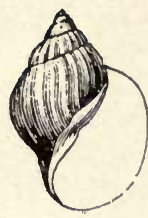

1

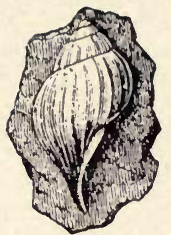

2

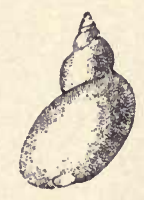

3

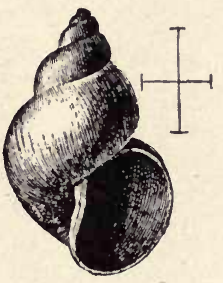

7

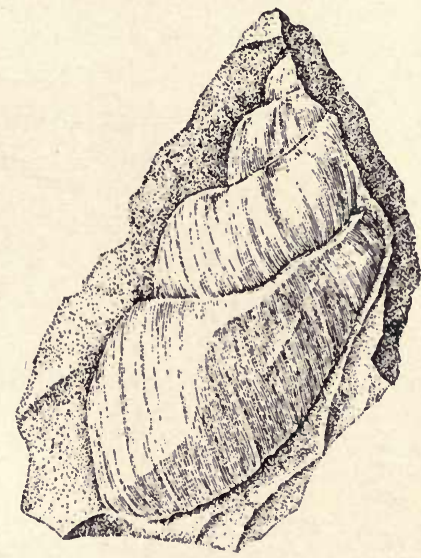

11

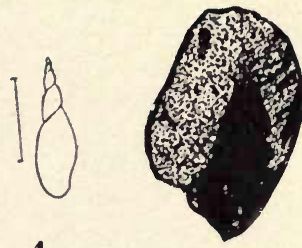

5

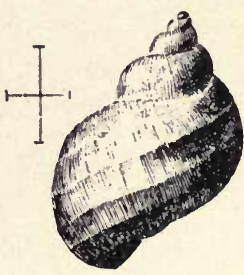

8

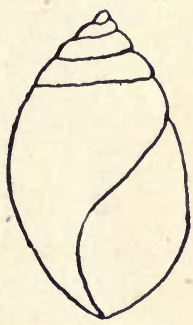

12

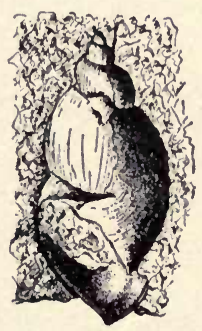

14 

Plate XVIII.

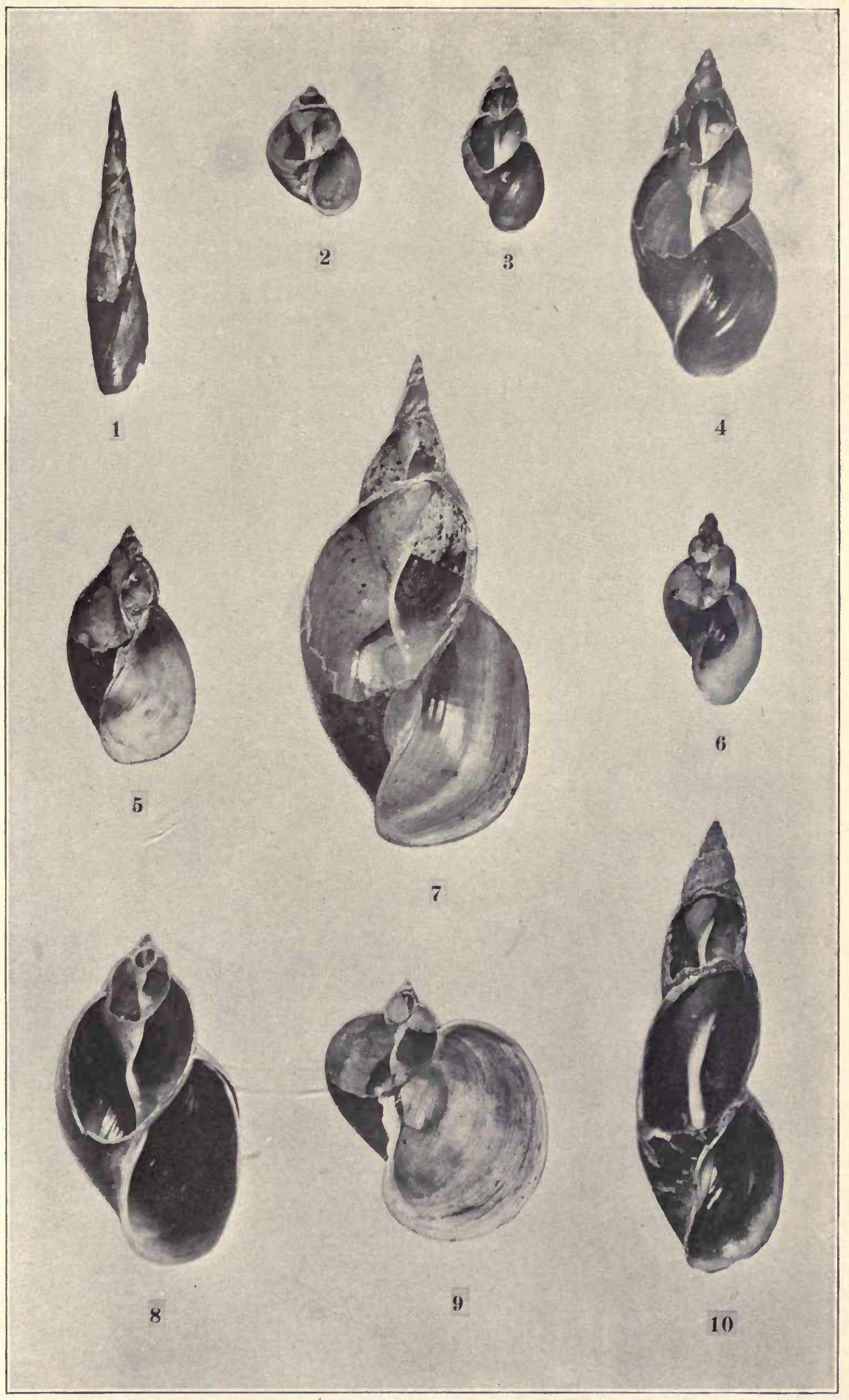




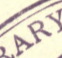


Plate XIX.

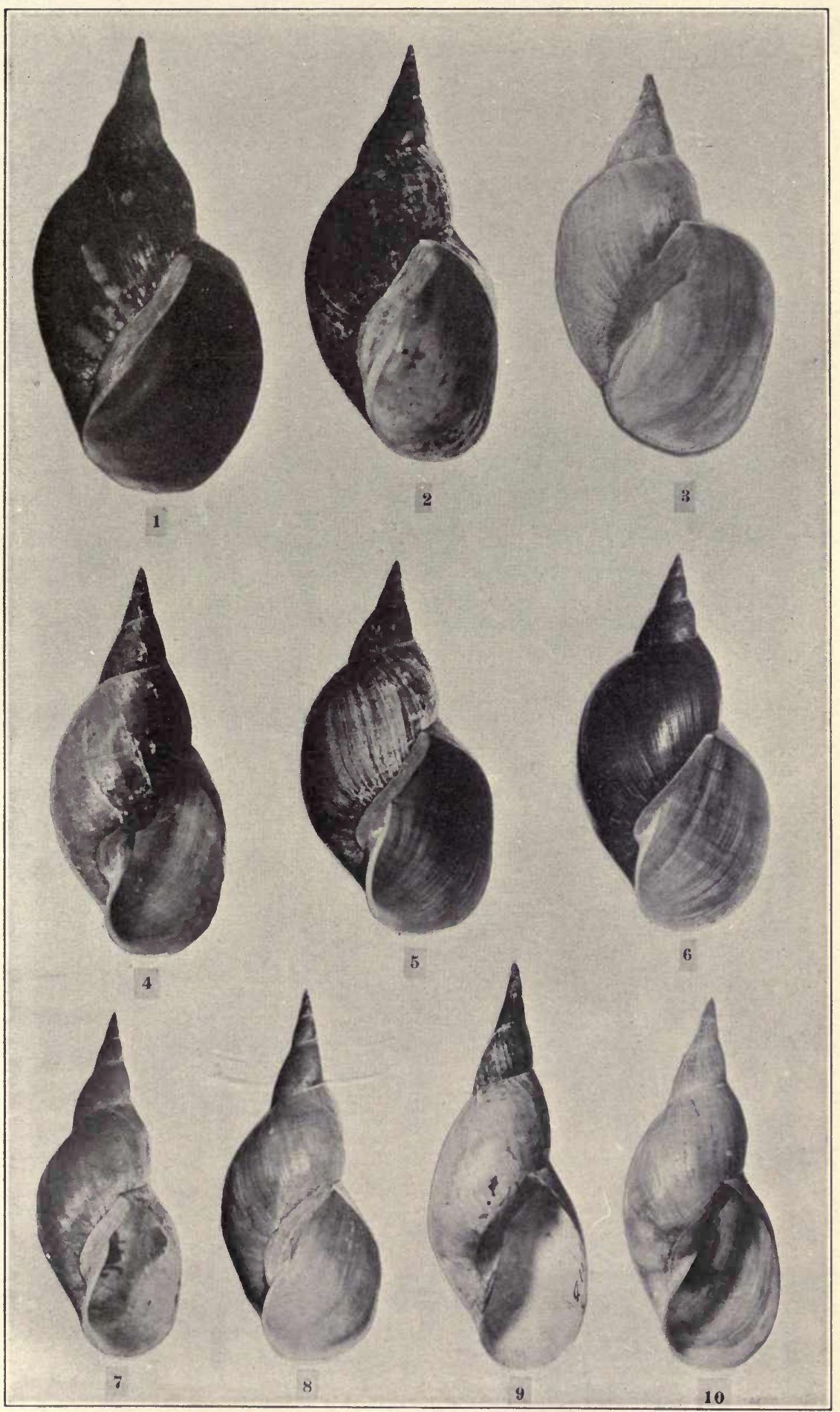



Plate XX.

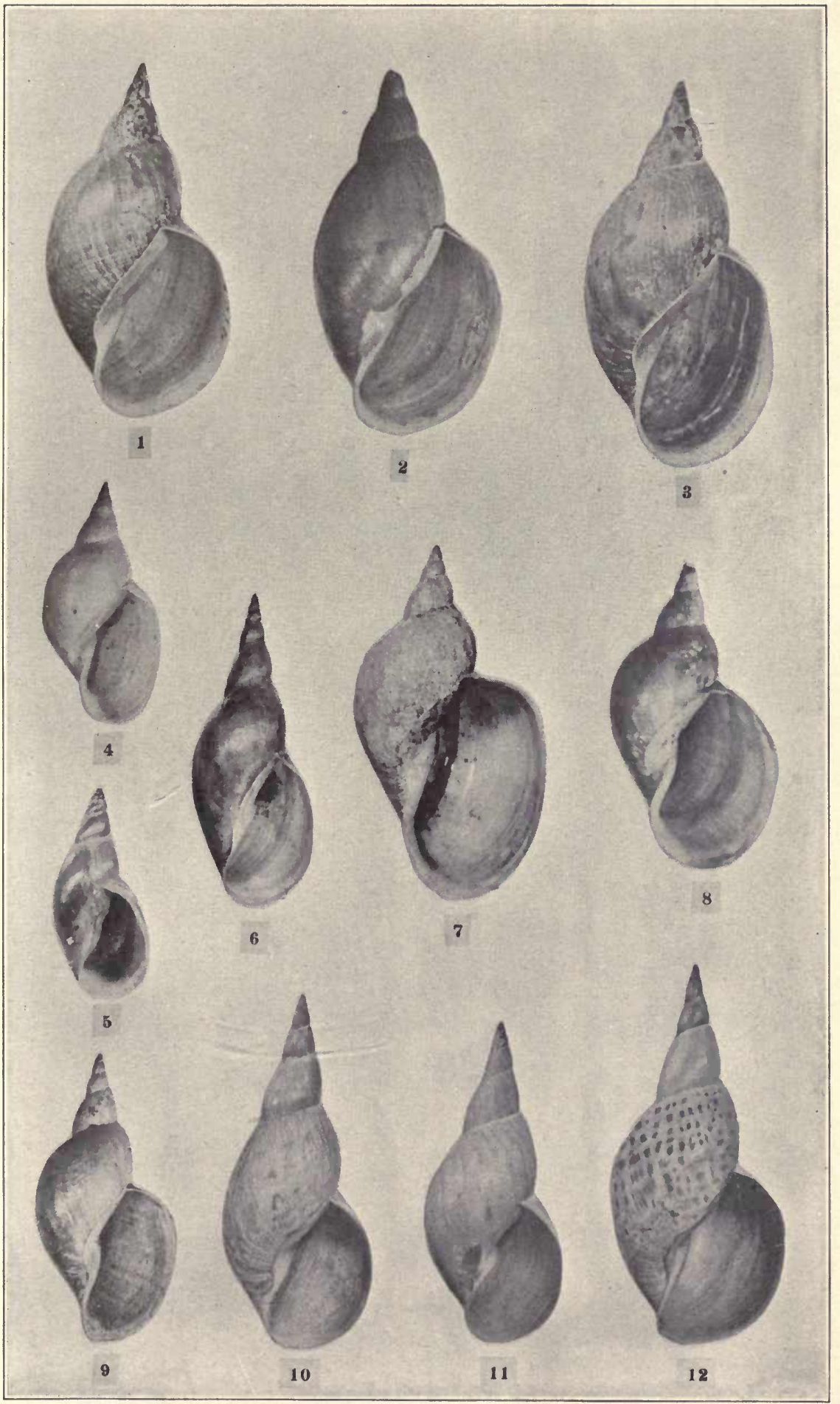


Plate XXI.

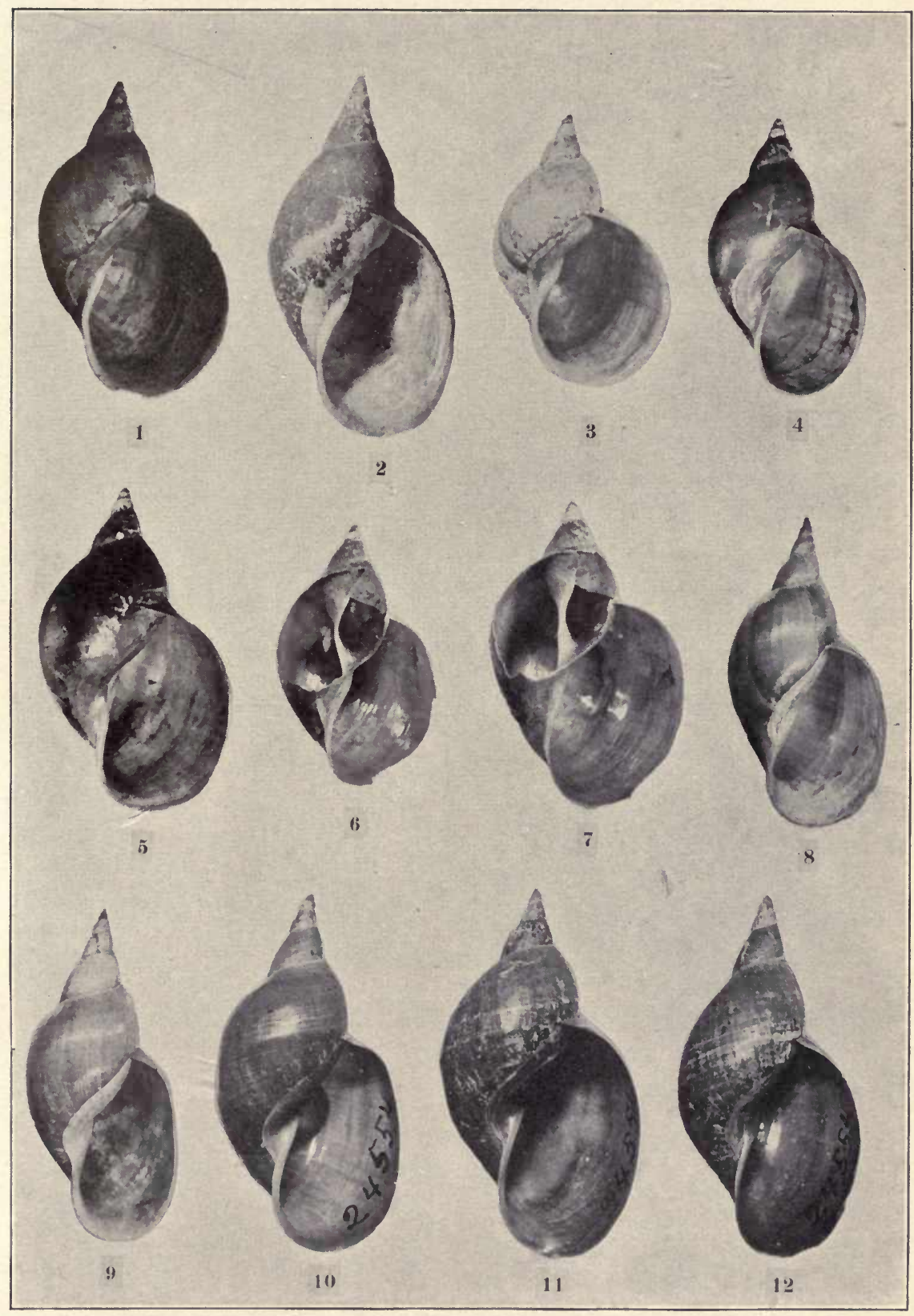



Plate XXII.

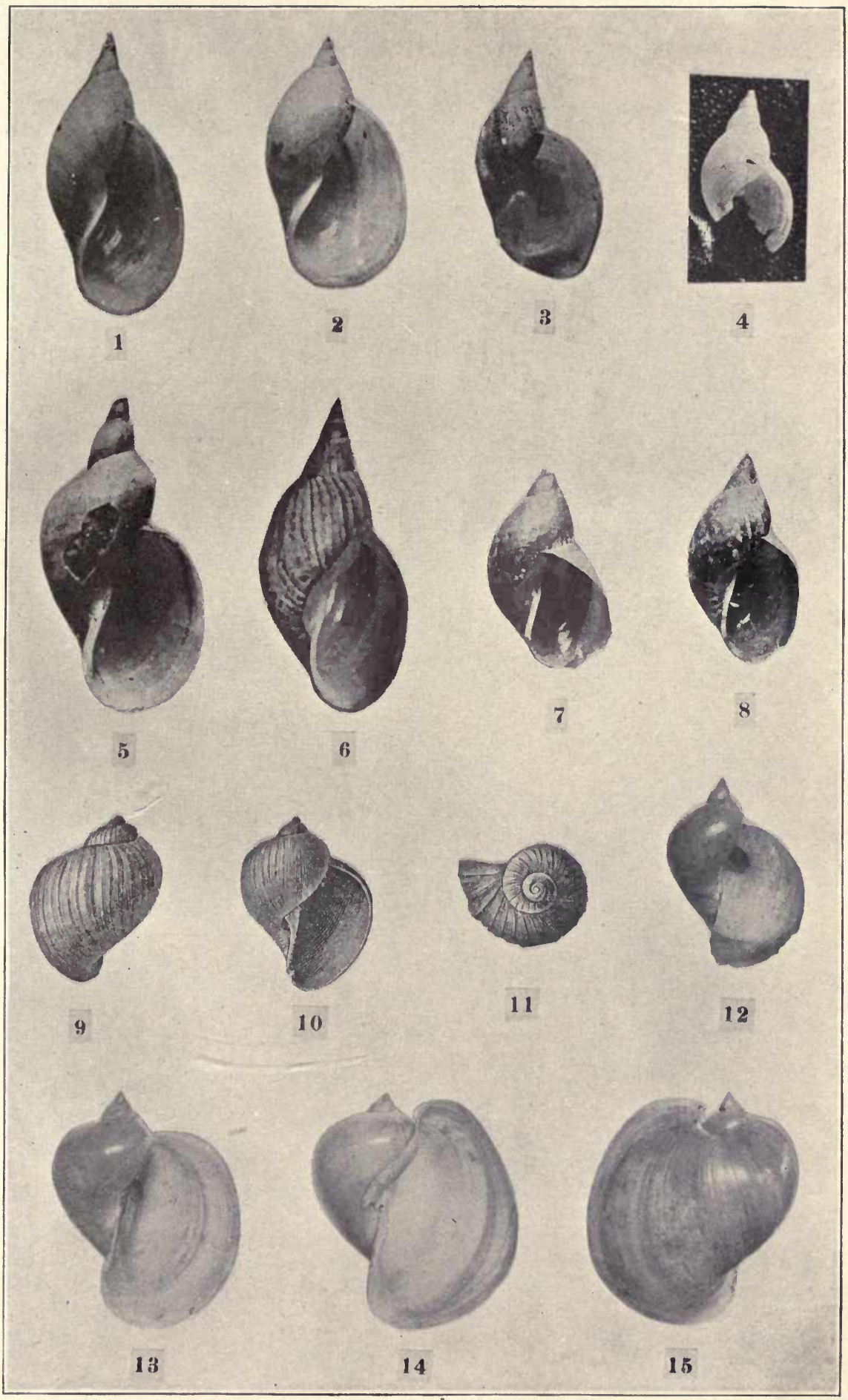



Plate XXIII.

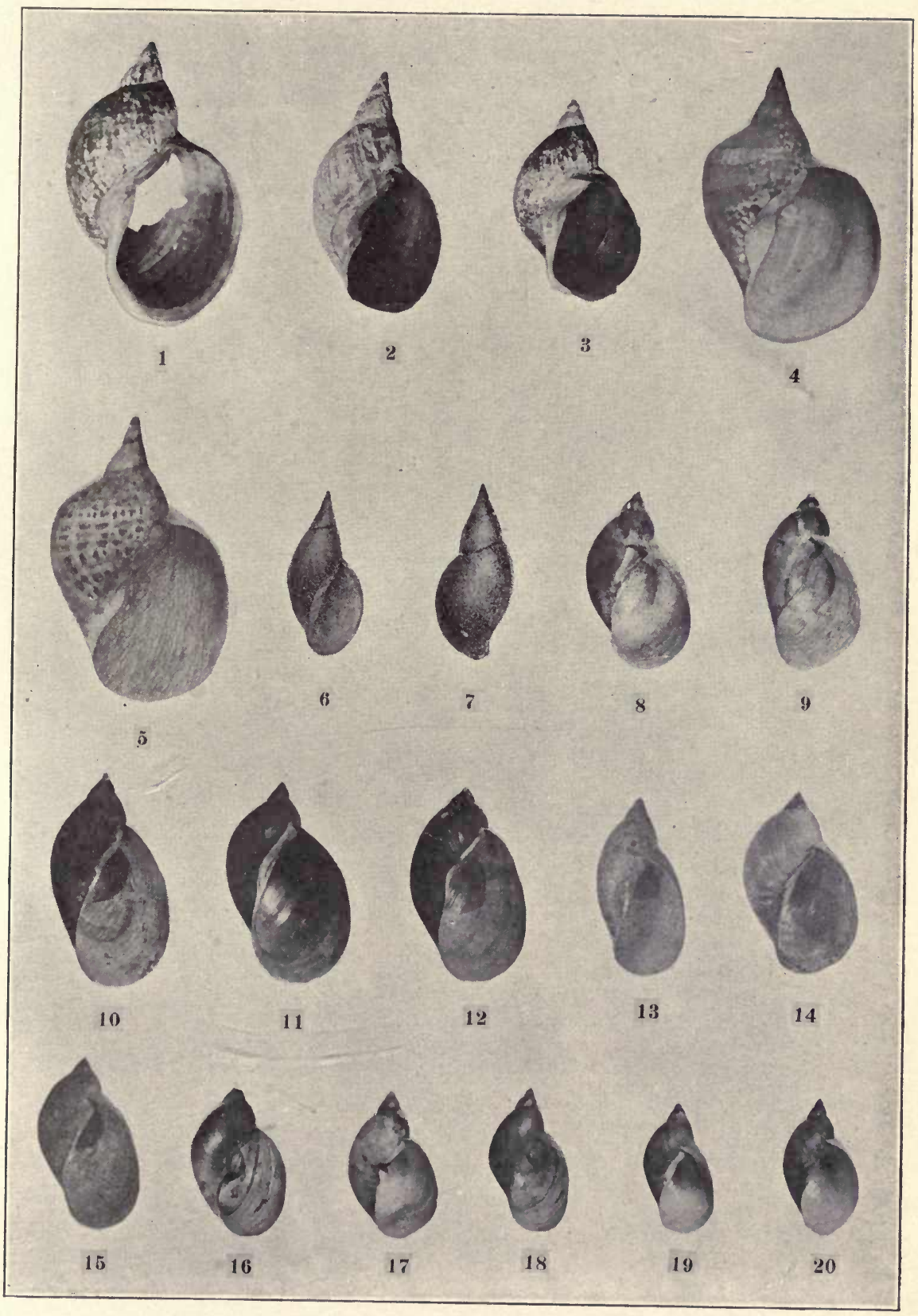





\section{Plate XXIV.}

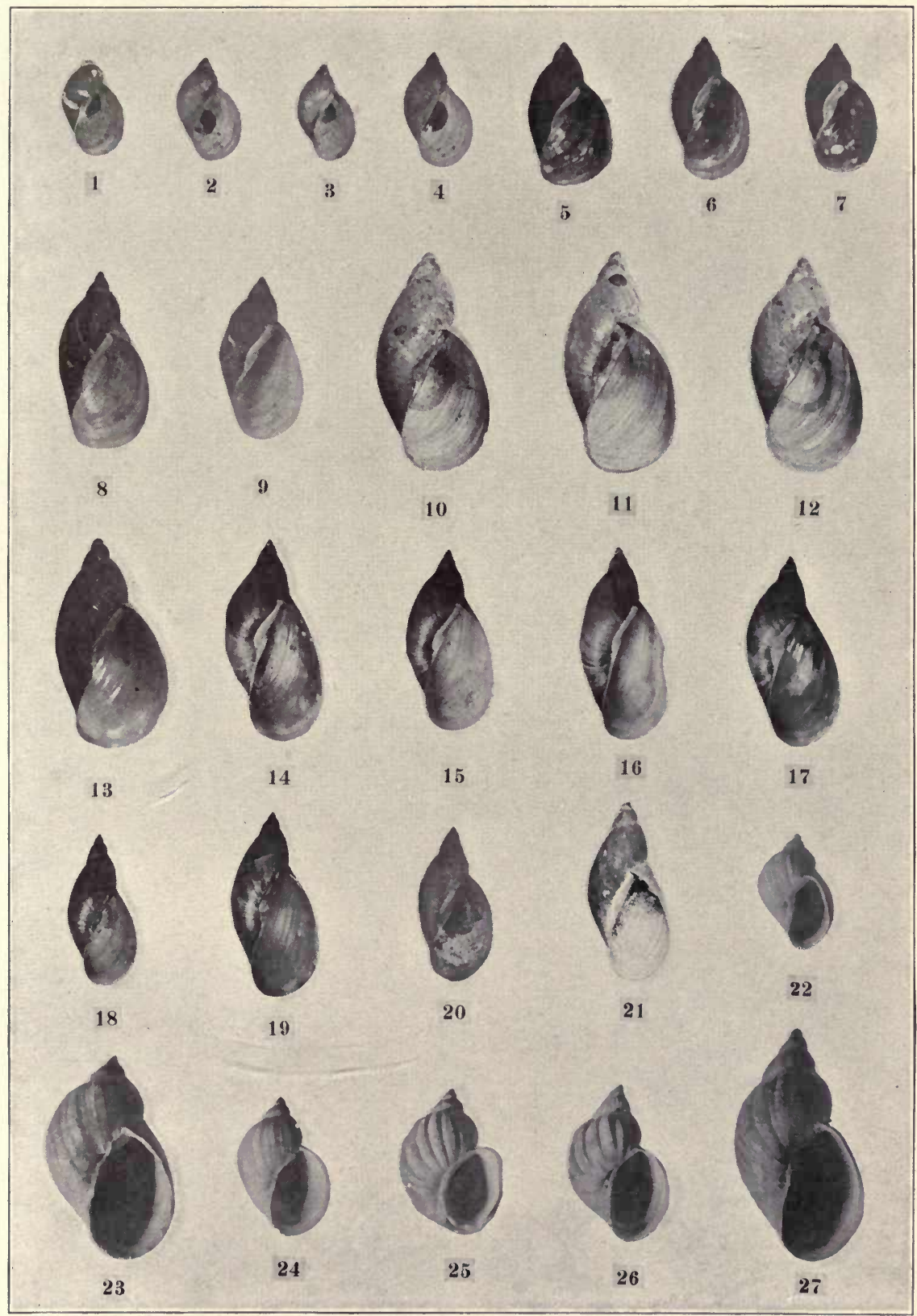




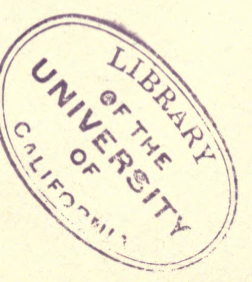


Plate XXV.

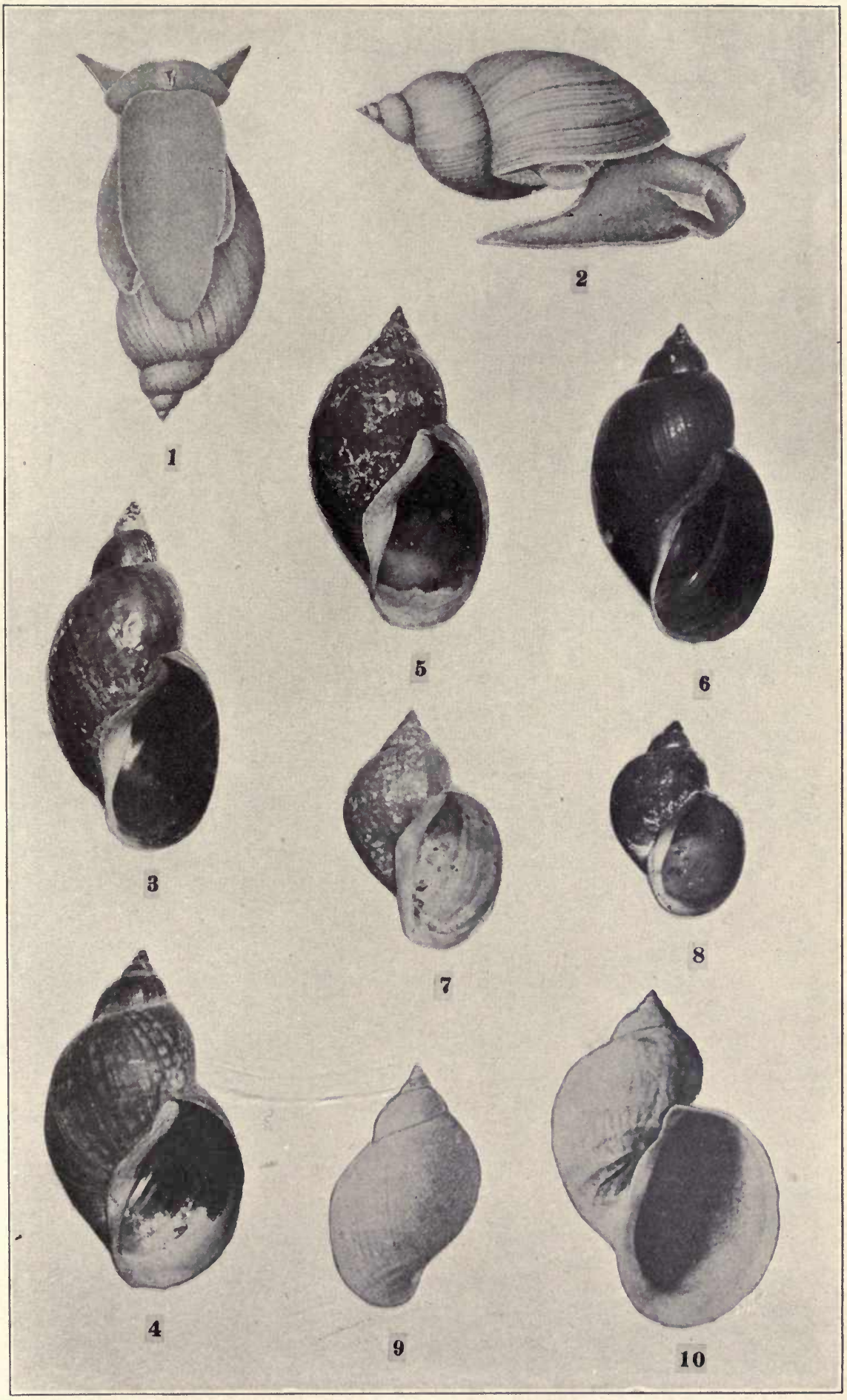



Plate XXVI.

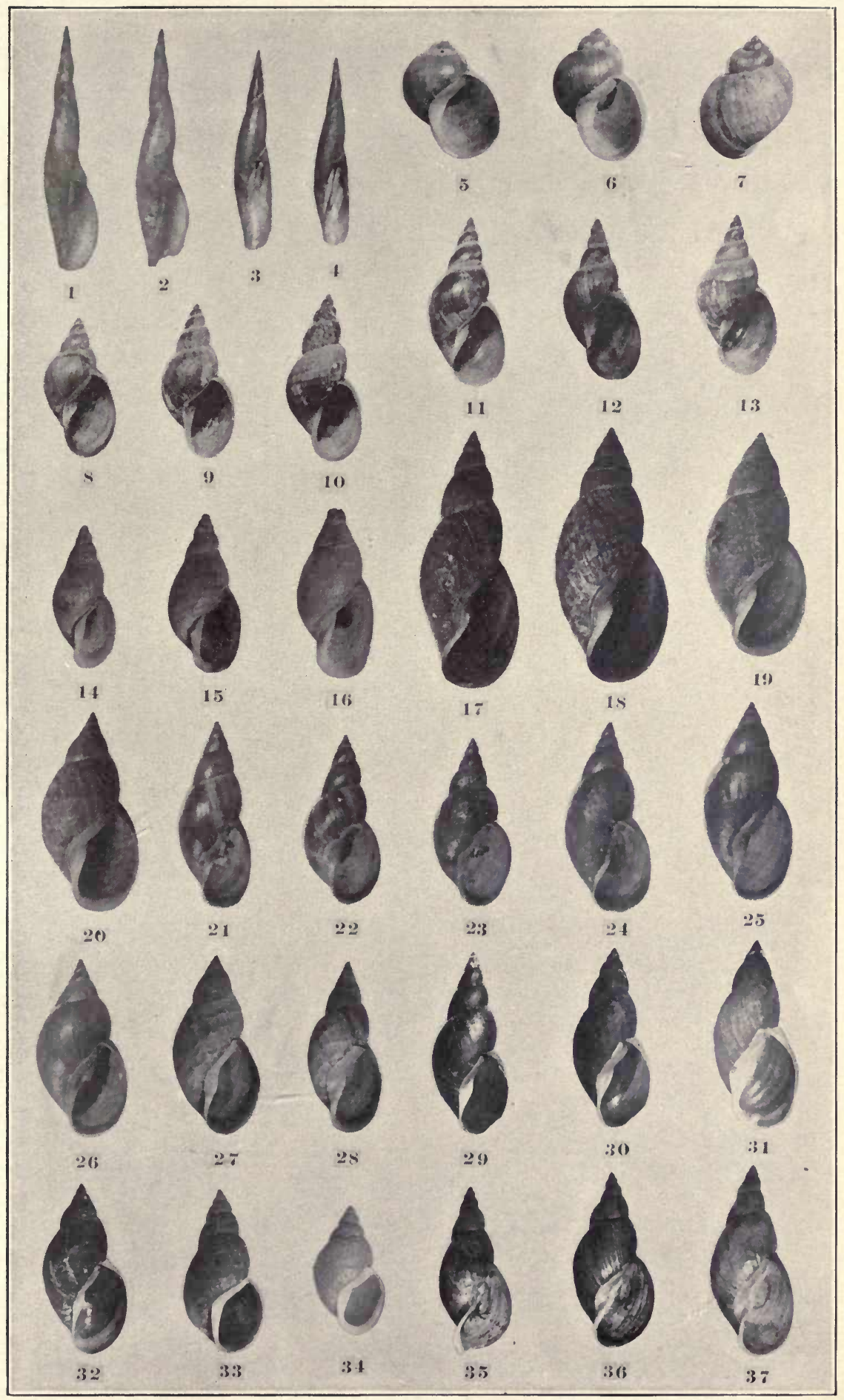



Plate XXVII.

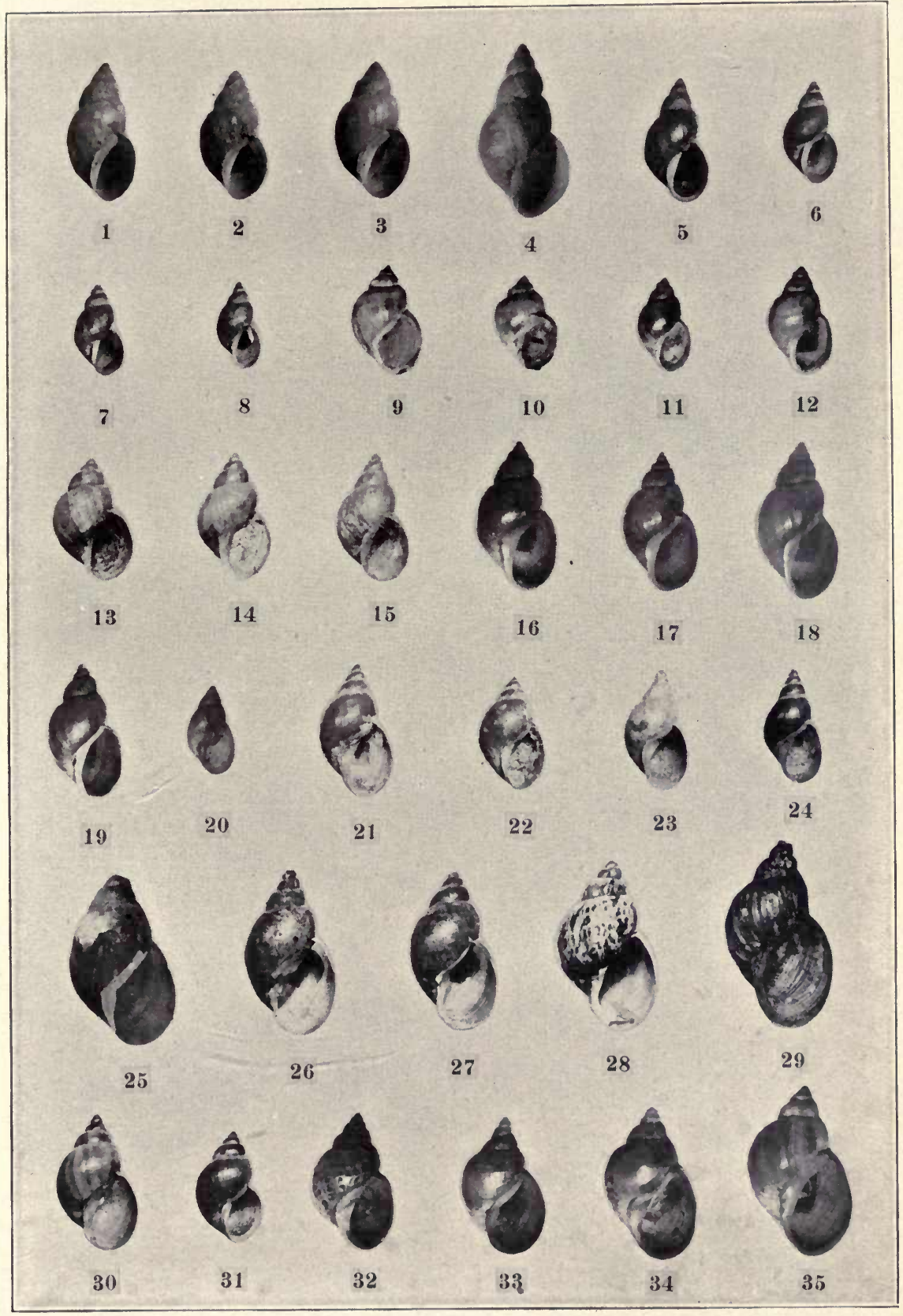



Plate XXVIII.

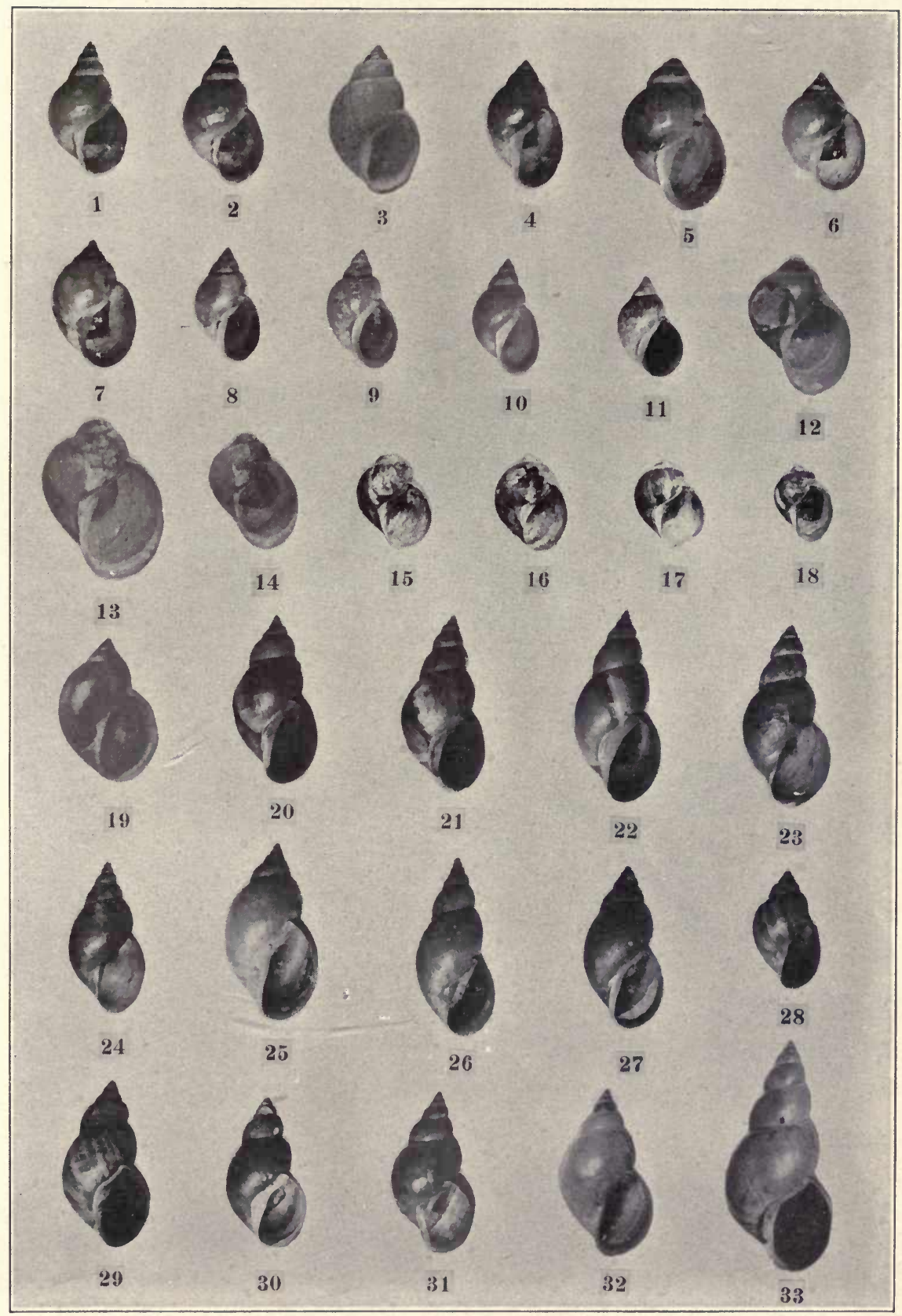



Plate XXIX.

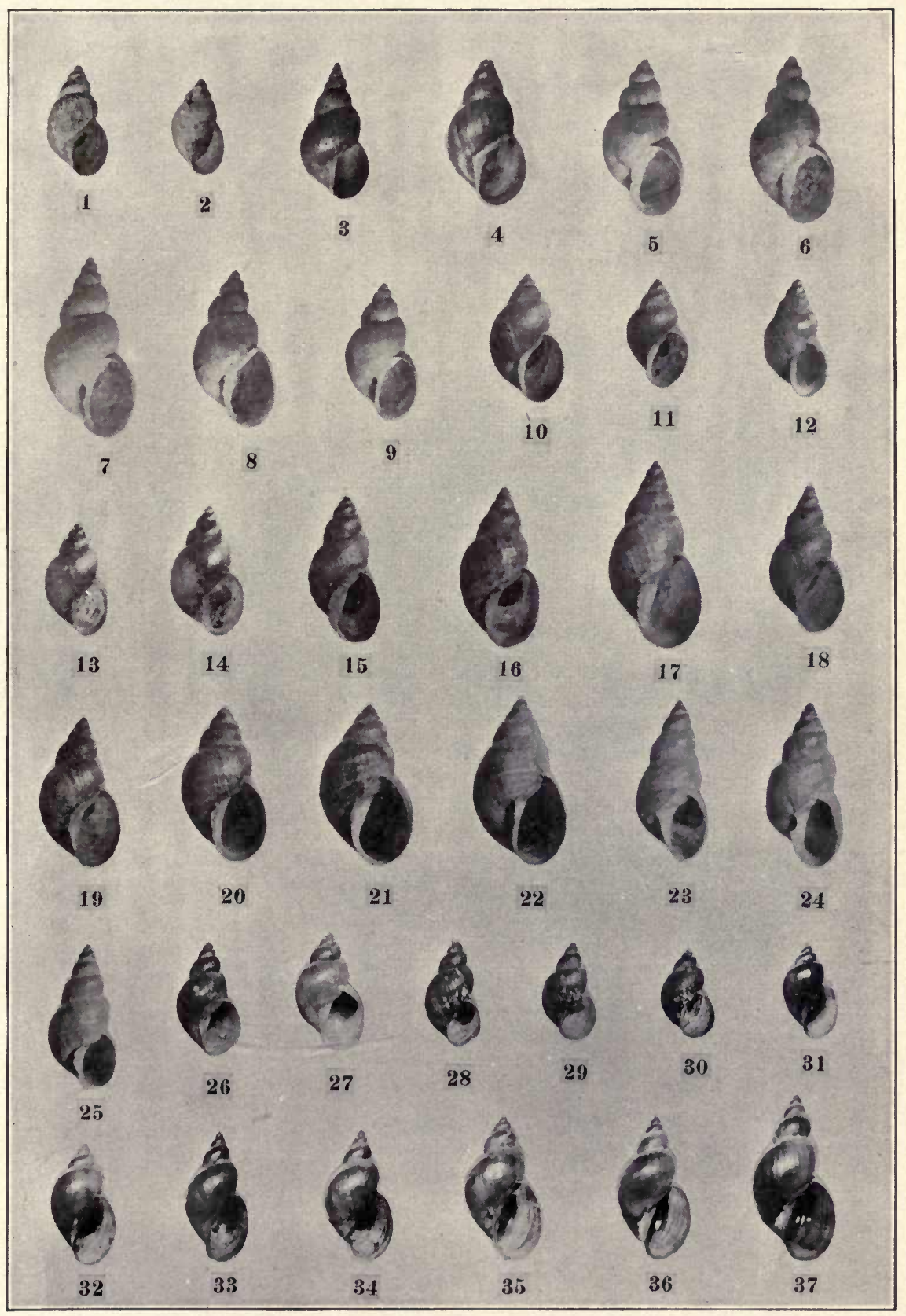



Plate XXX.

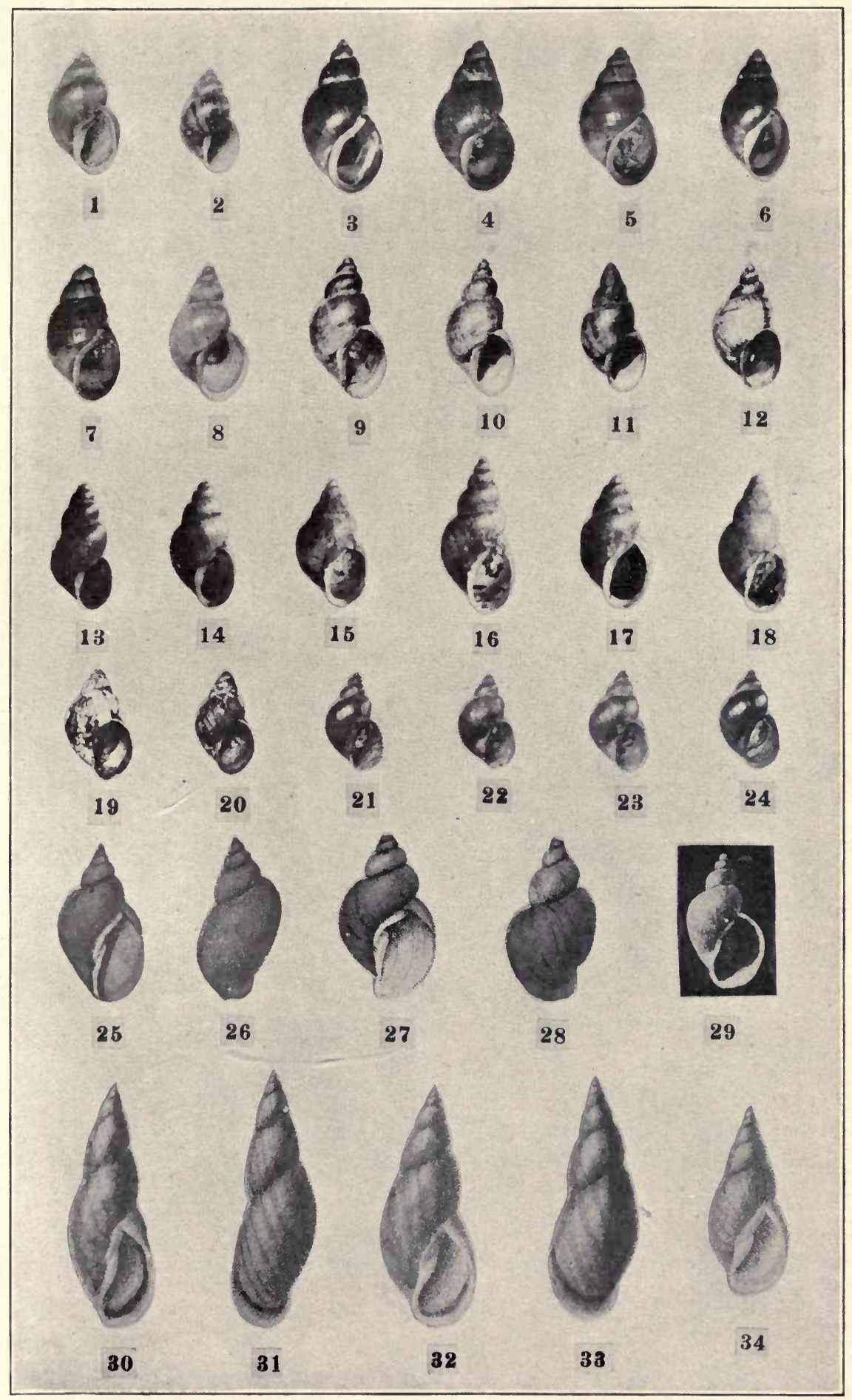



Plate XXXI.

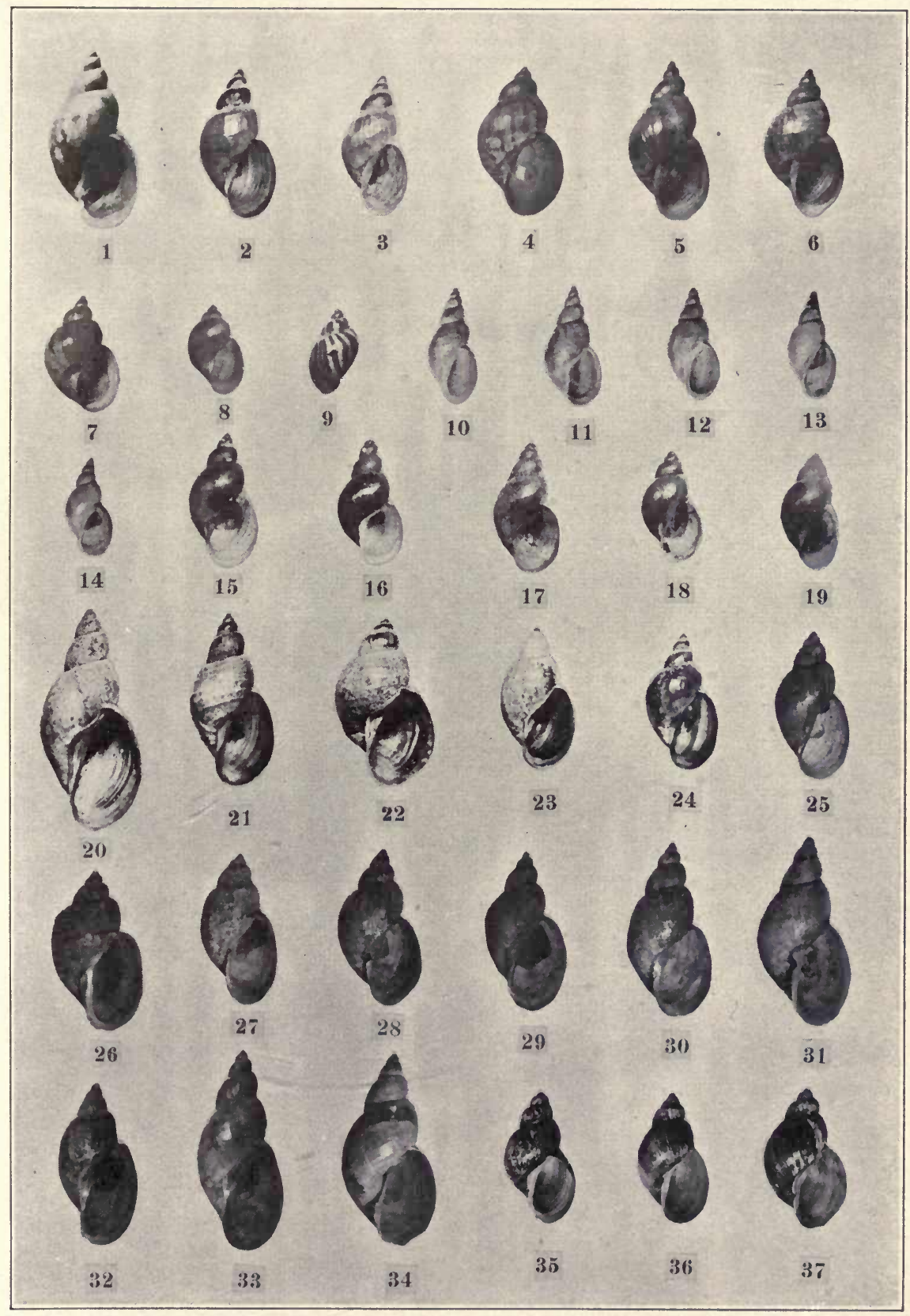


(8) 
Plate XXXII.

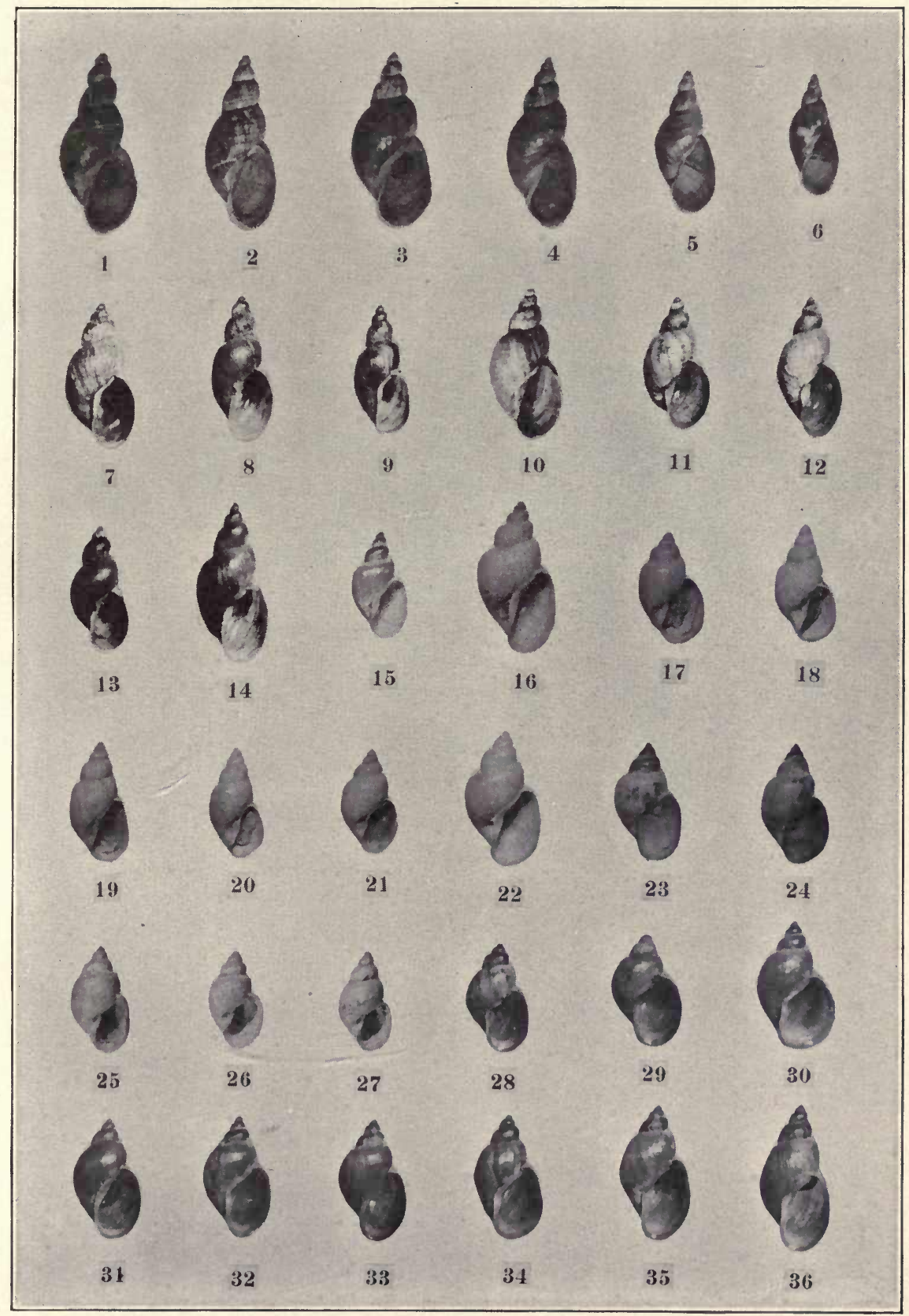





$$
\begin{aligned}
& 86000 \\
& 060100 \\
& 6000 \\
& 080100
\end{aligned}
$$



Plate XXXIV.

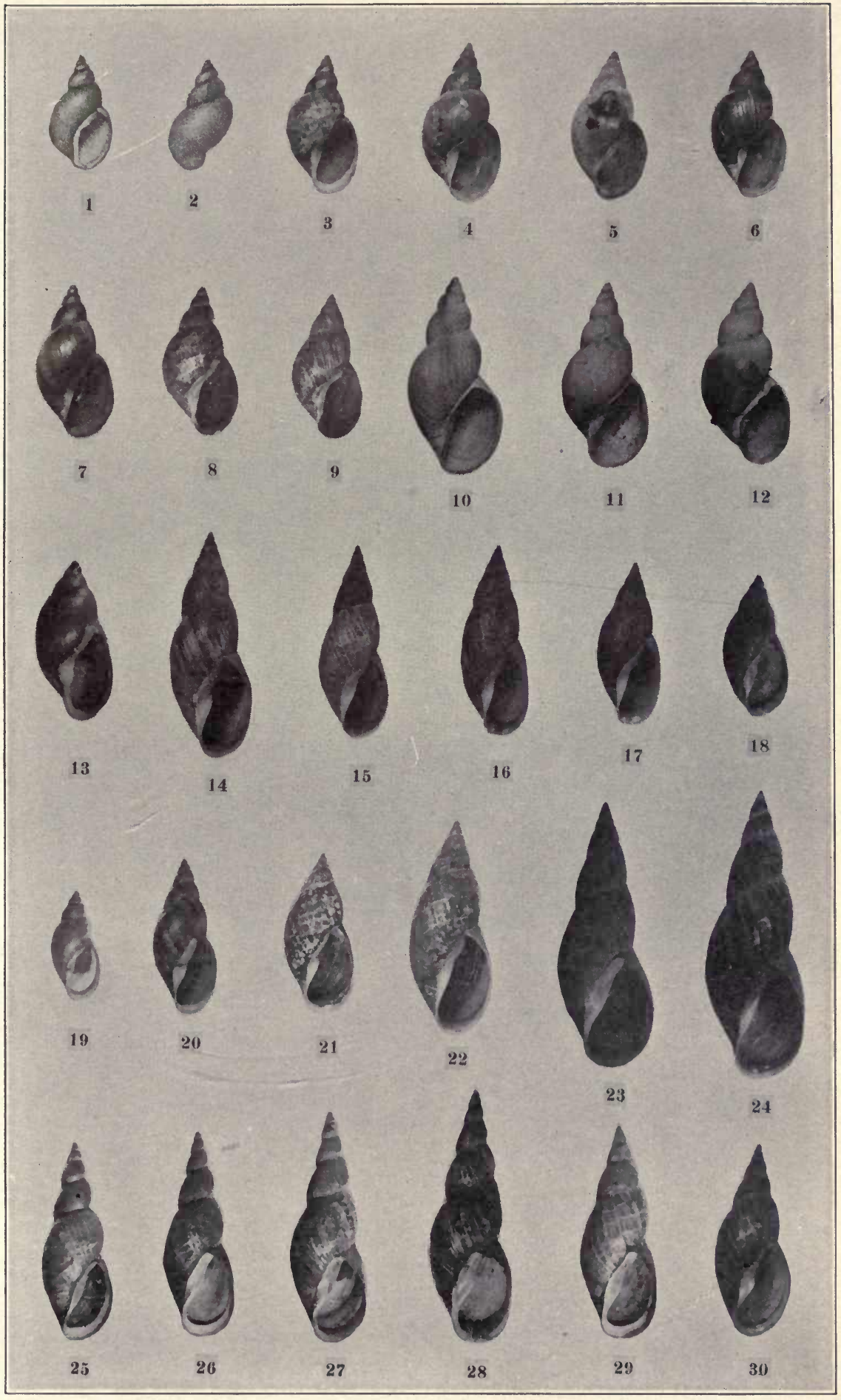




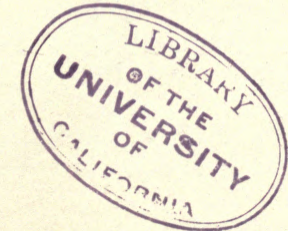




$$
\begin{aligned}
& 6600041 \\
& 60686 \\
& 68686 \\
& 66666
\end{aligned}
$$



Plate XXXVI.

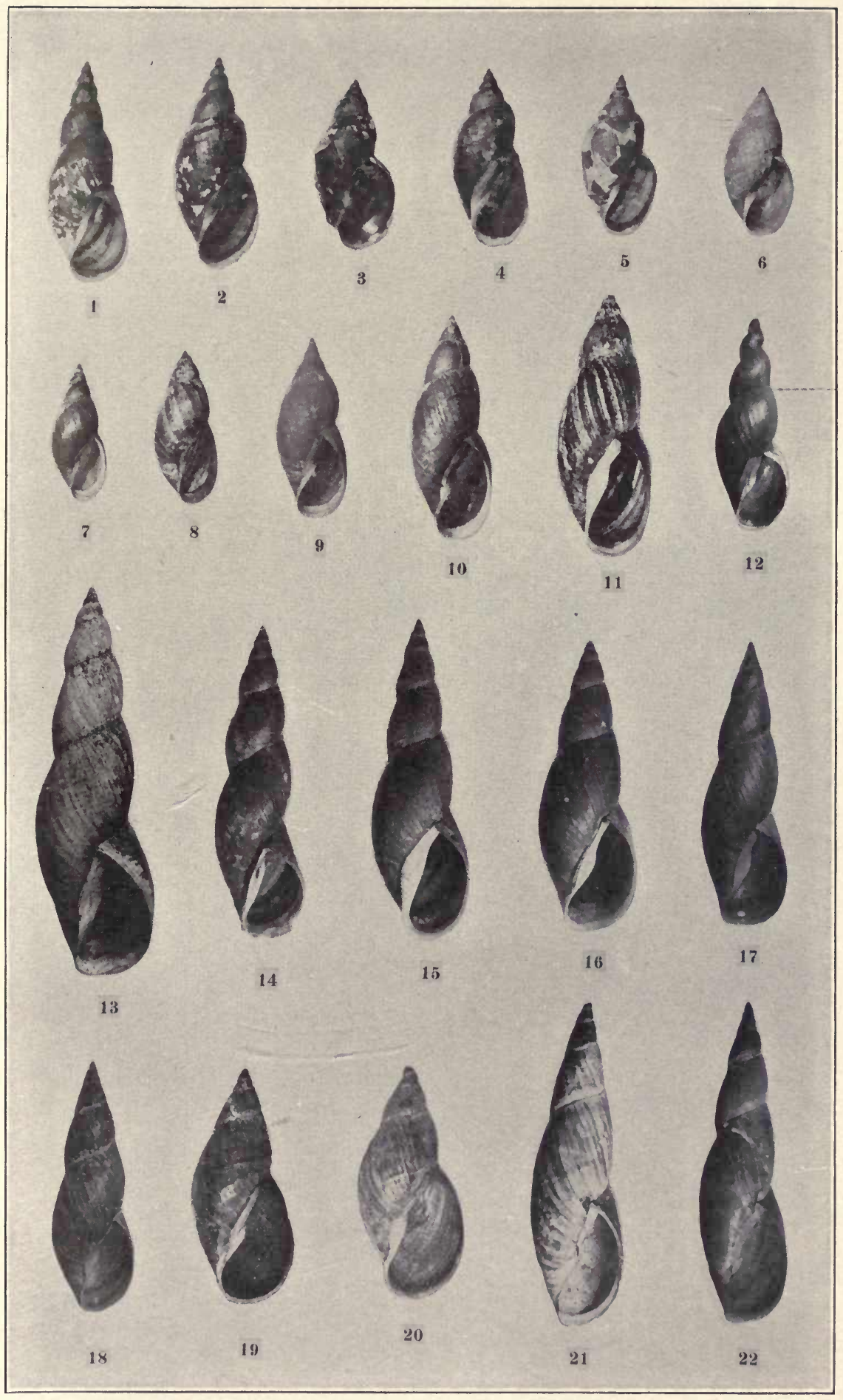





$$
\begin{aligned}
& 801066 \\
& 100608 \\
& 808060 \\
& 606016
\end{aligned}
$$




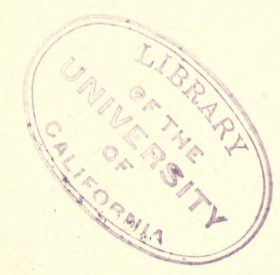




$$
\begin{aligned}
& 66606 \\
& 600006 \\
& 08061 \\
& 00001
\end{aligned}
$$





$$
\begin{aligned}
& 00030 \\
& 06060 \\
& 10000 \\
& 600000
\end{aligned}
$$





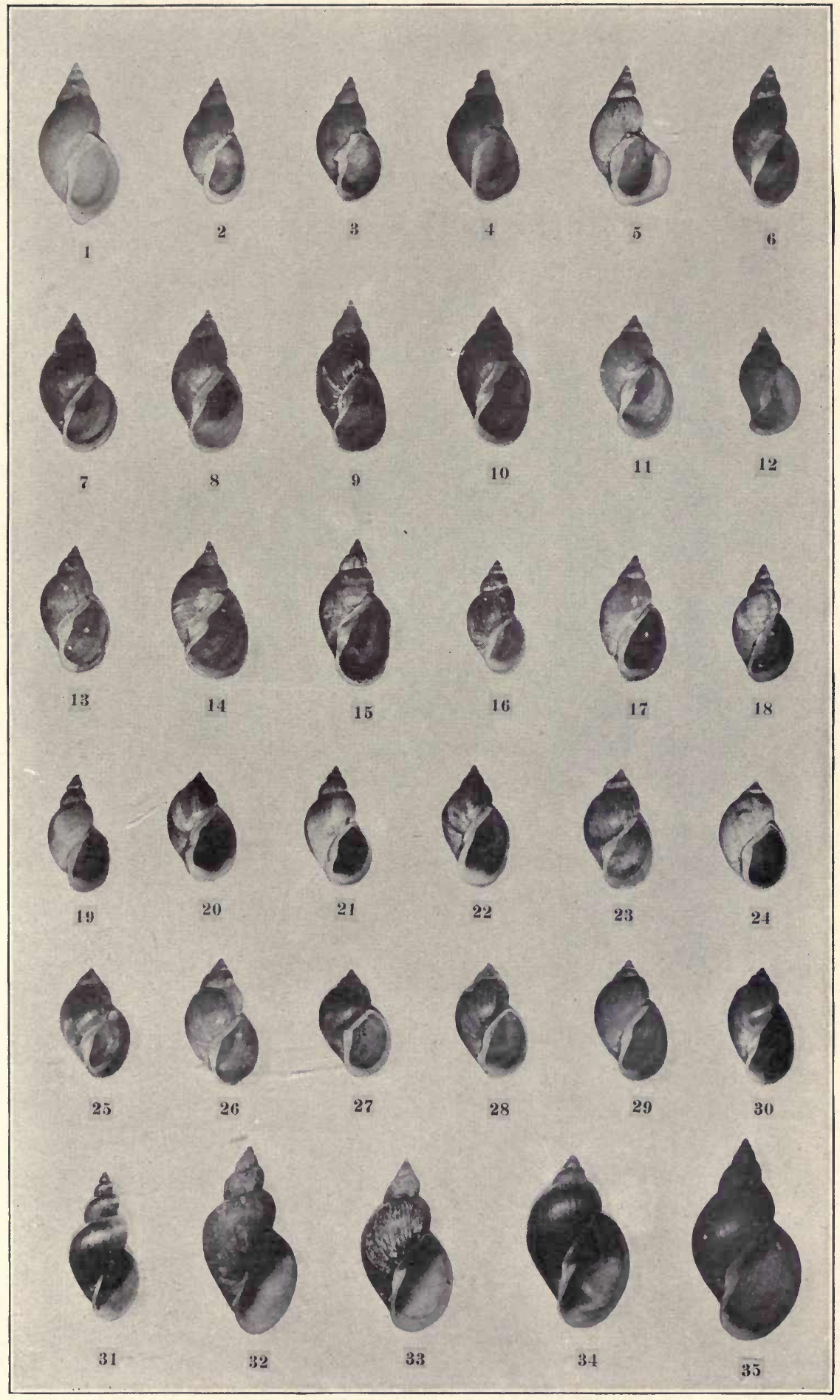




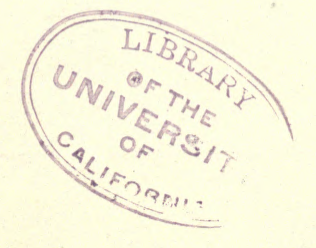


Plate Xli.

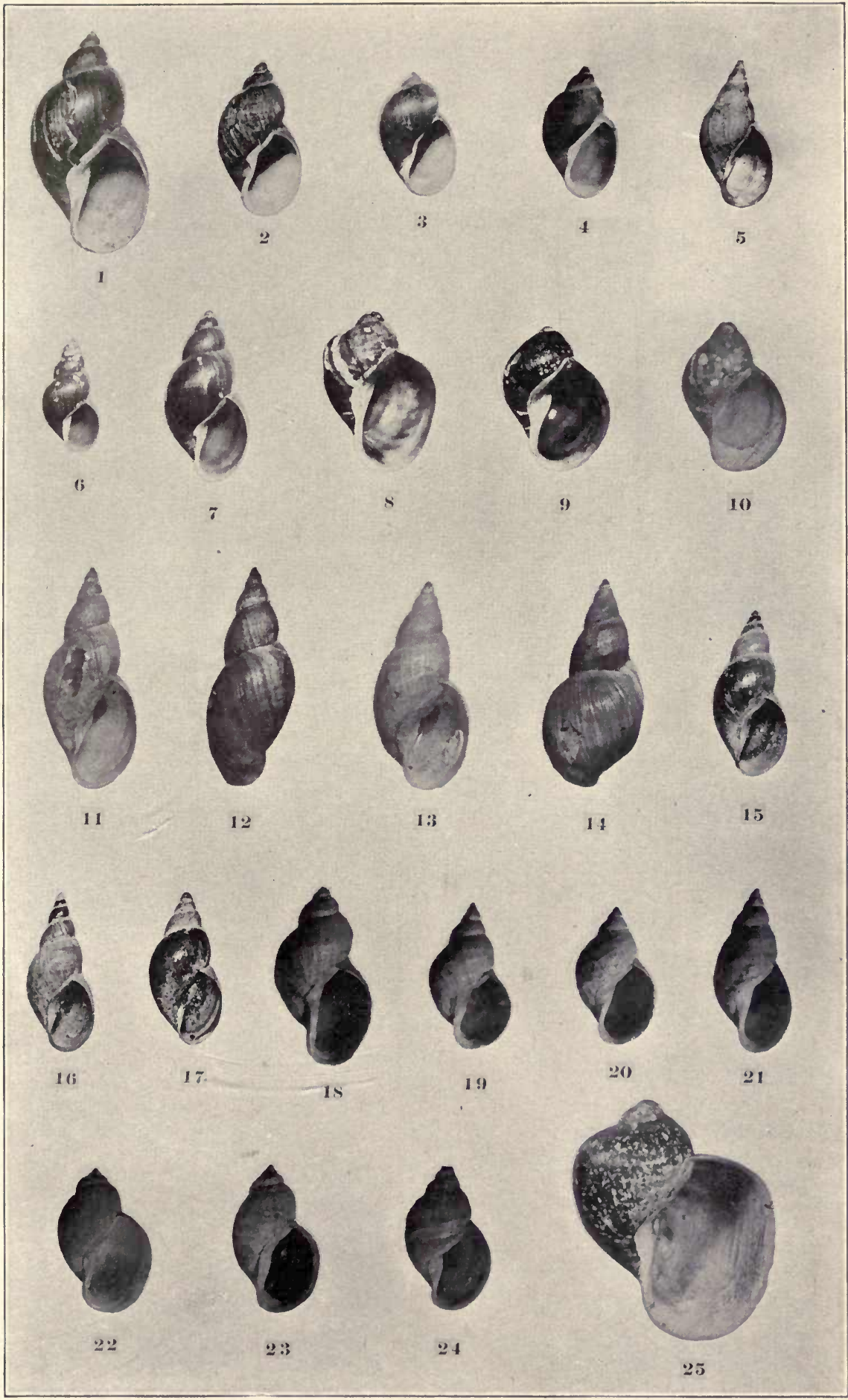



Plate XliI.

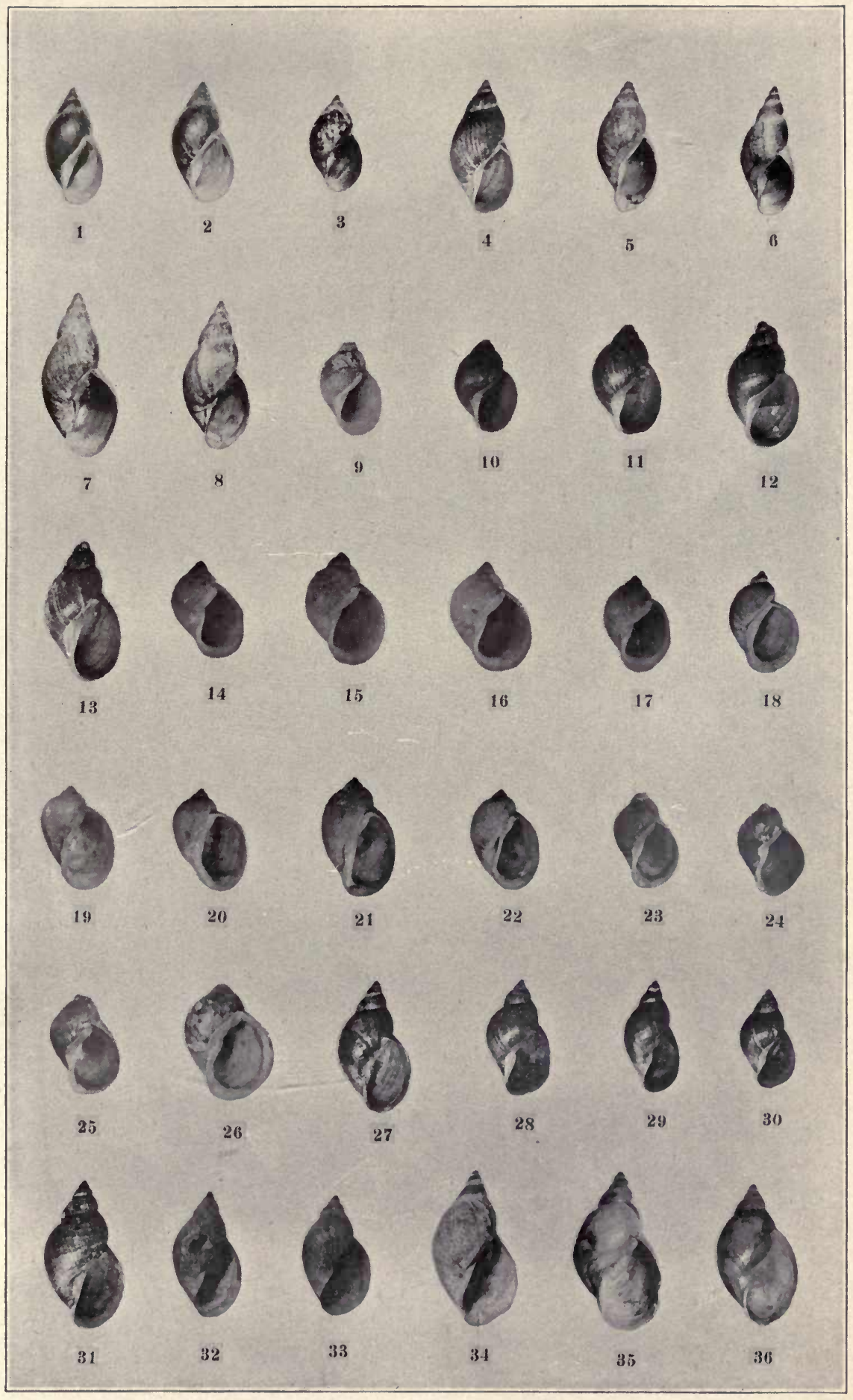




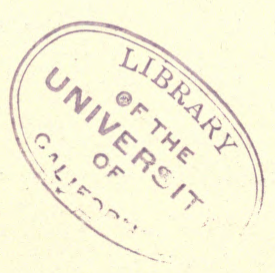


Plate XliII.

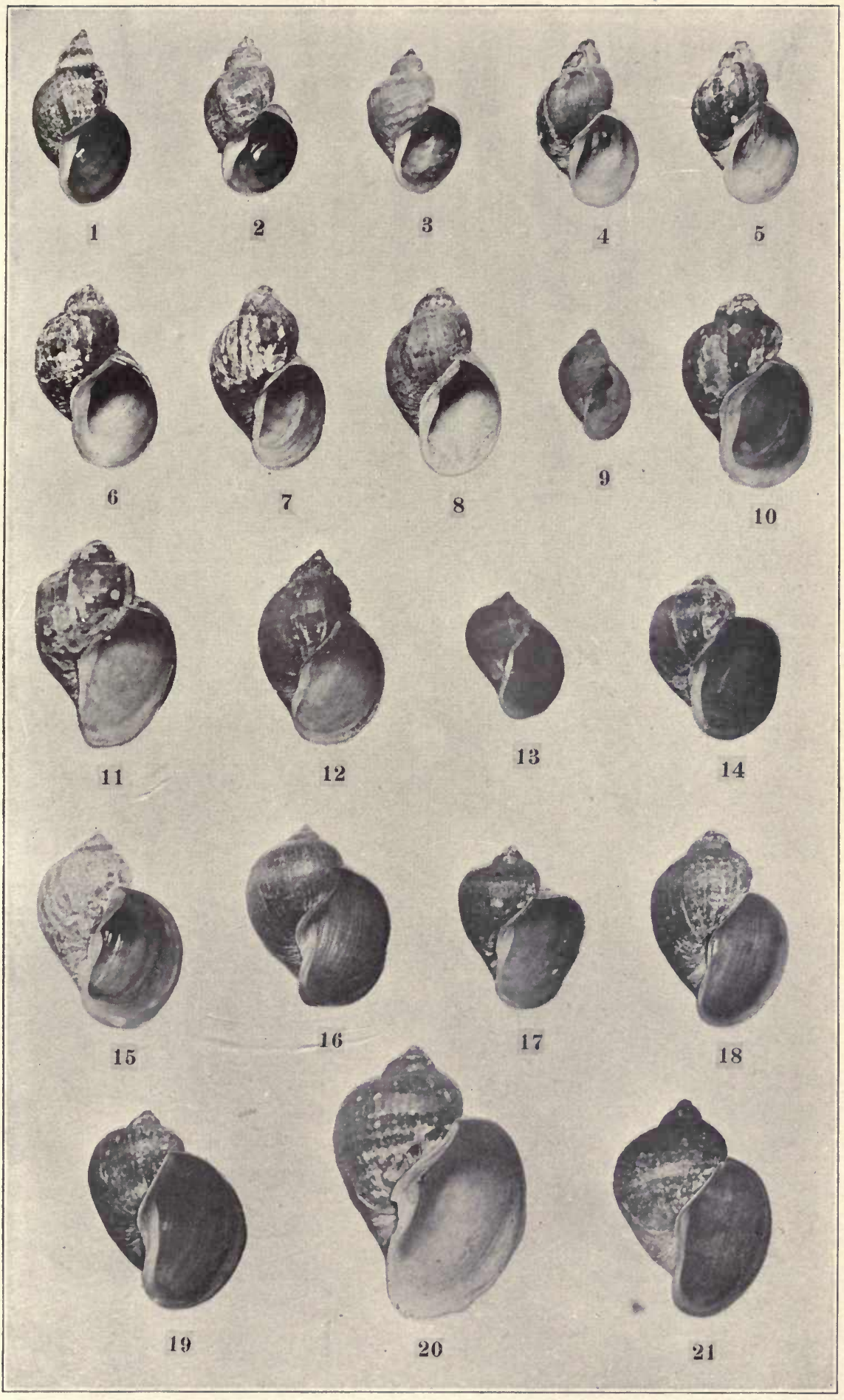



Plate XliV.

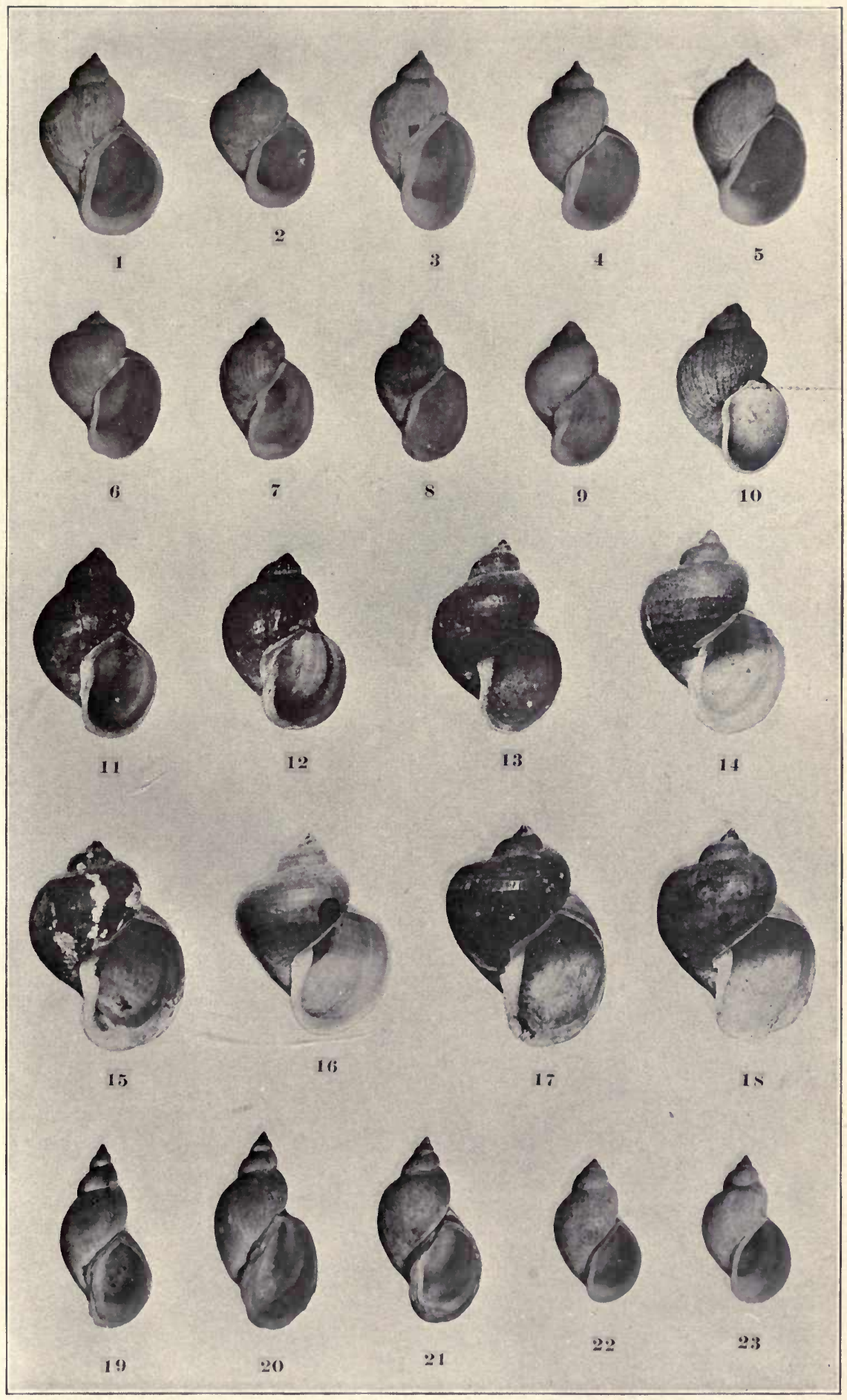




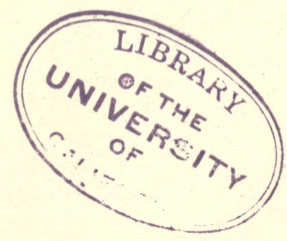


Plate XlV.

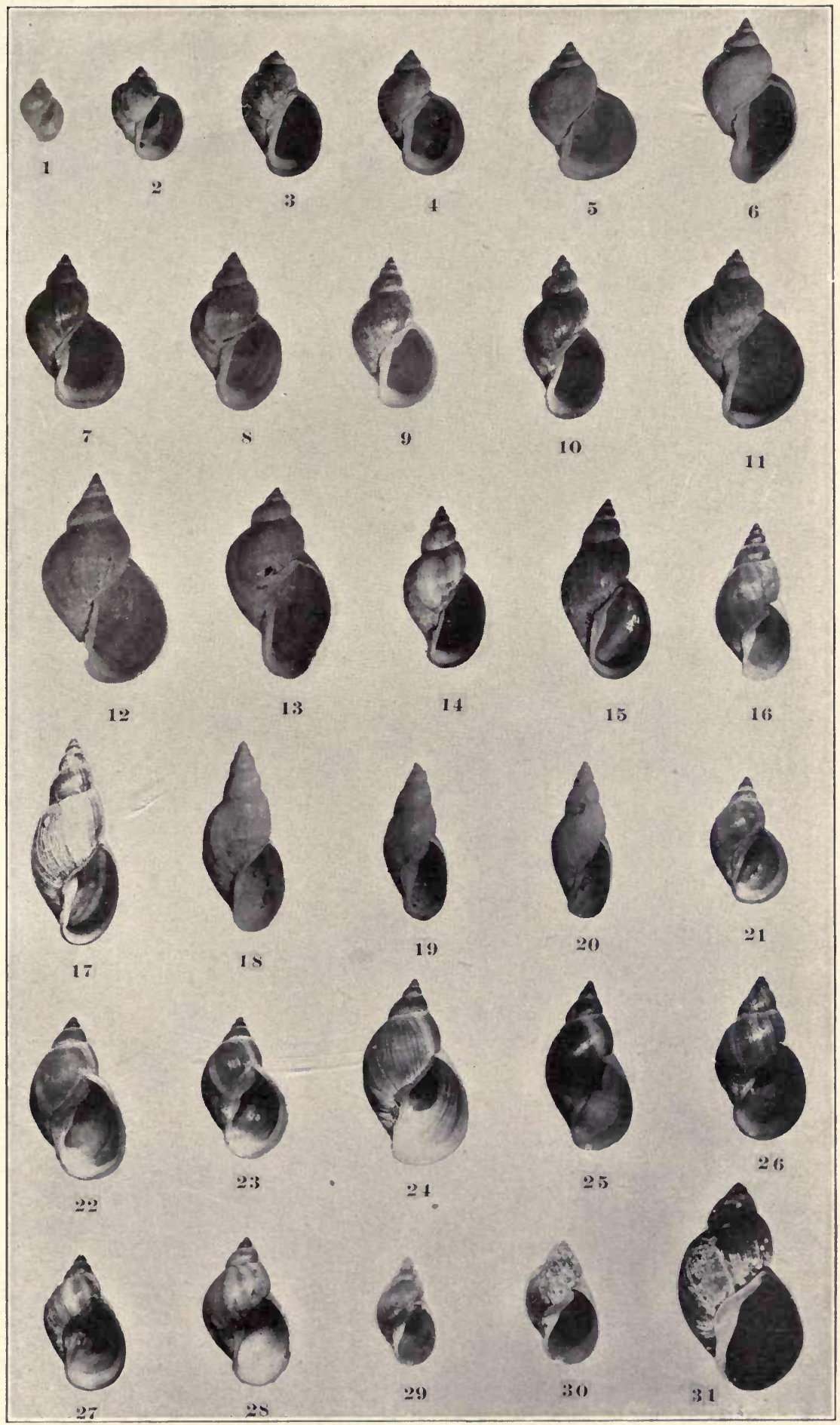



Plate XLVI.

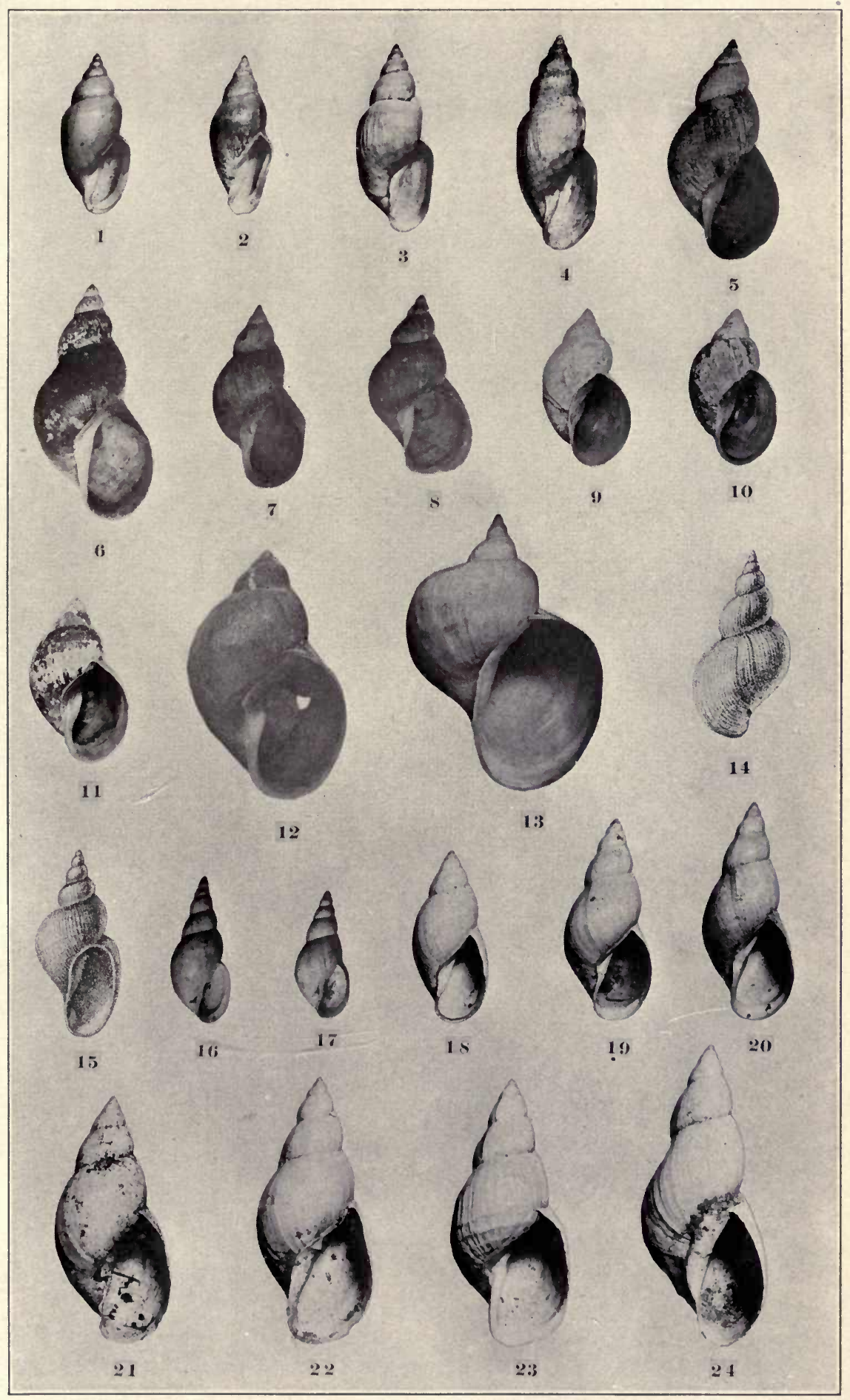




$$
\text { (2) }
$$


Plate XlViI.

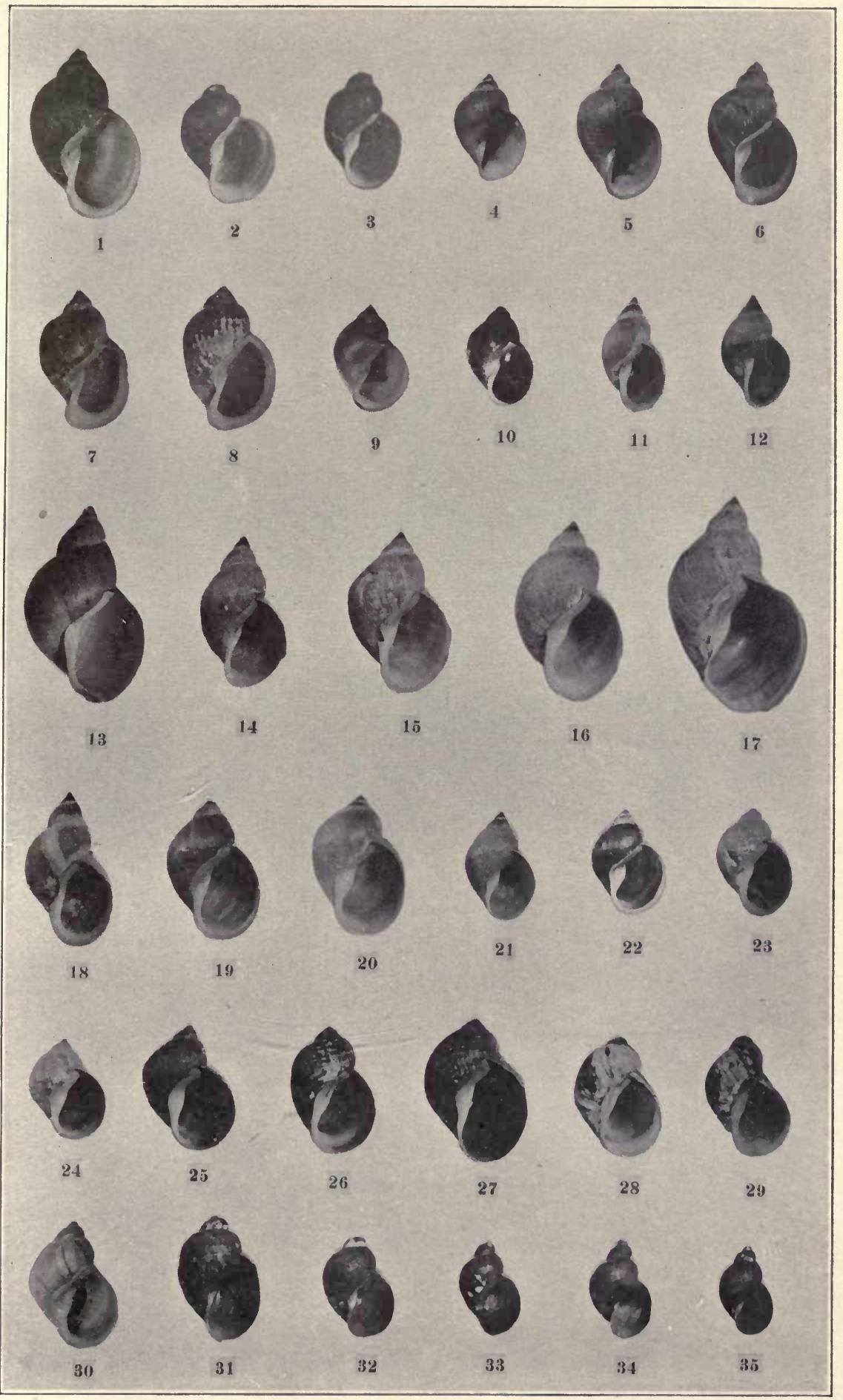




$$
\text { (1) }
$$


Plate XlVIII.

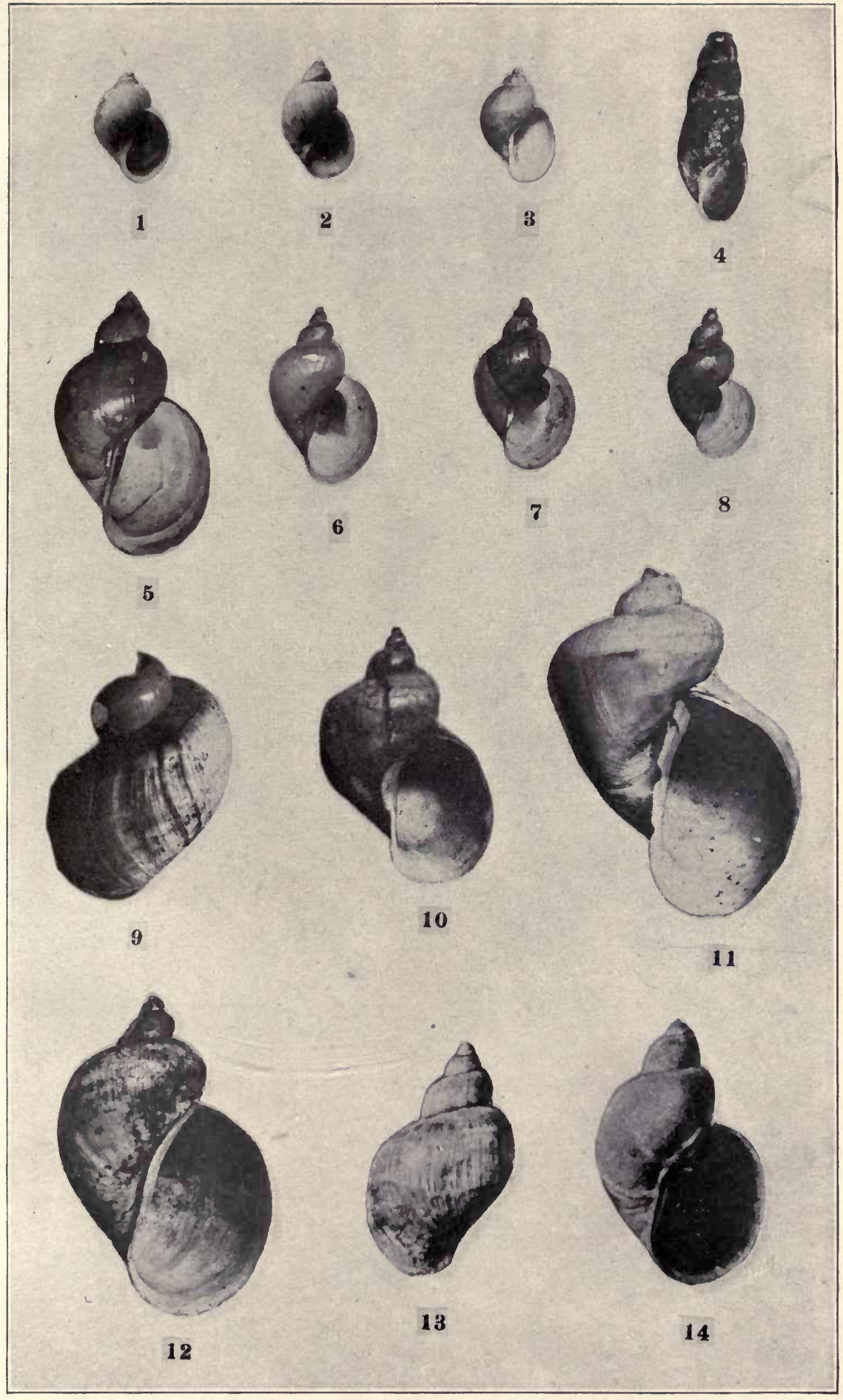




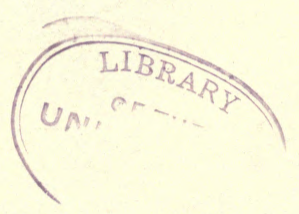


Plate XliX.

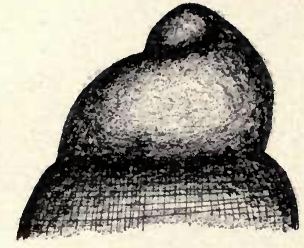

A

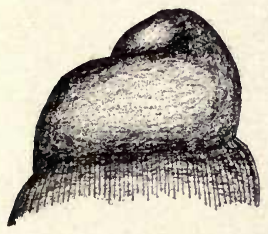

D

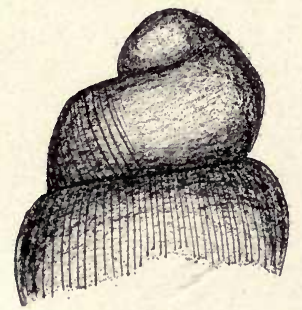

H

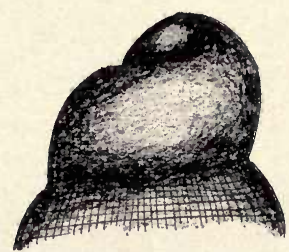

B

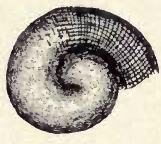

F

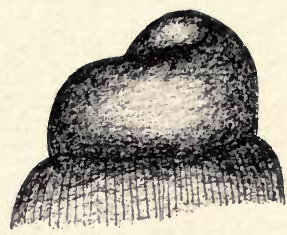

C

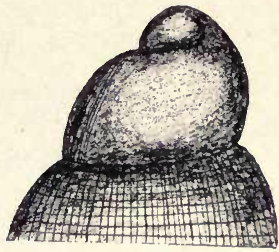

G
E
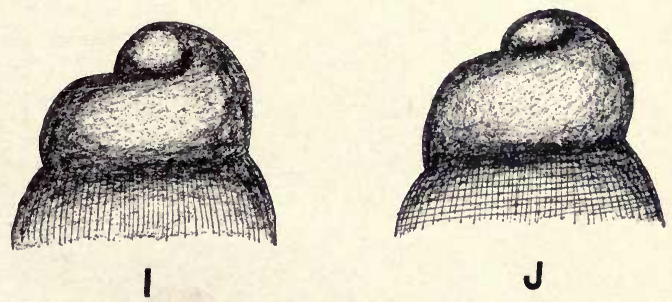

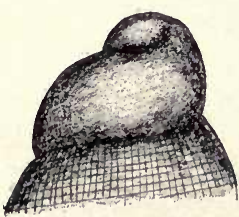

K

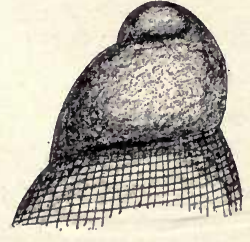

L

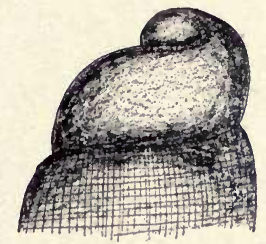

M

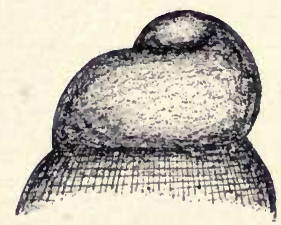

N

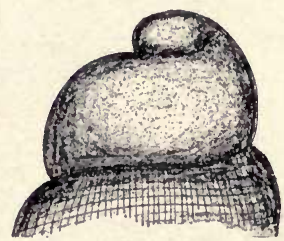

R 

Plate L.

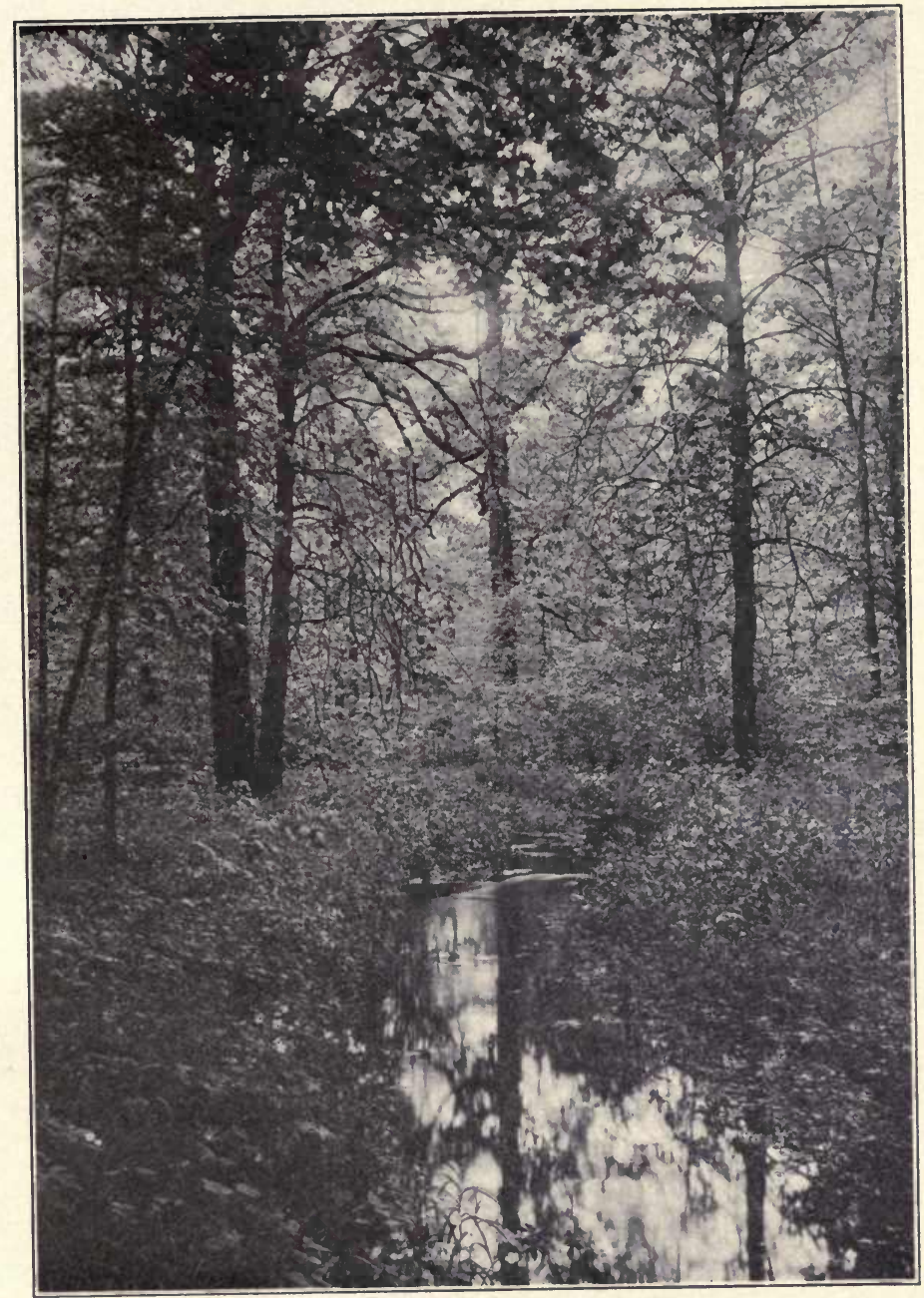



Plate Li.

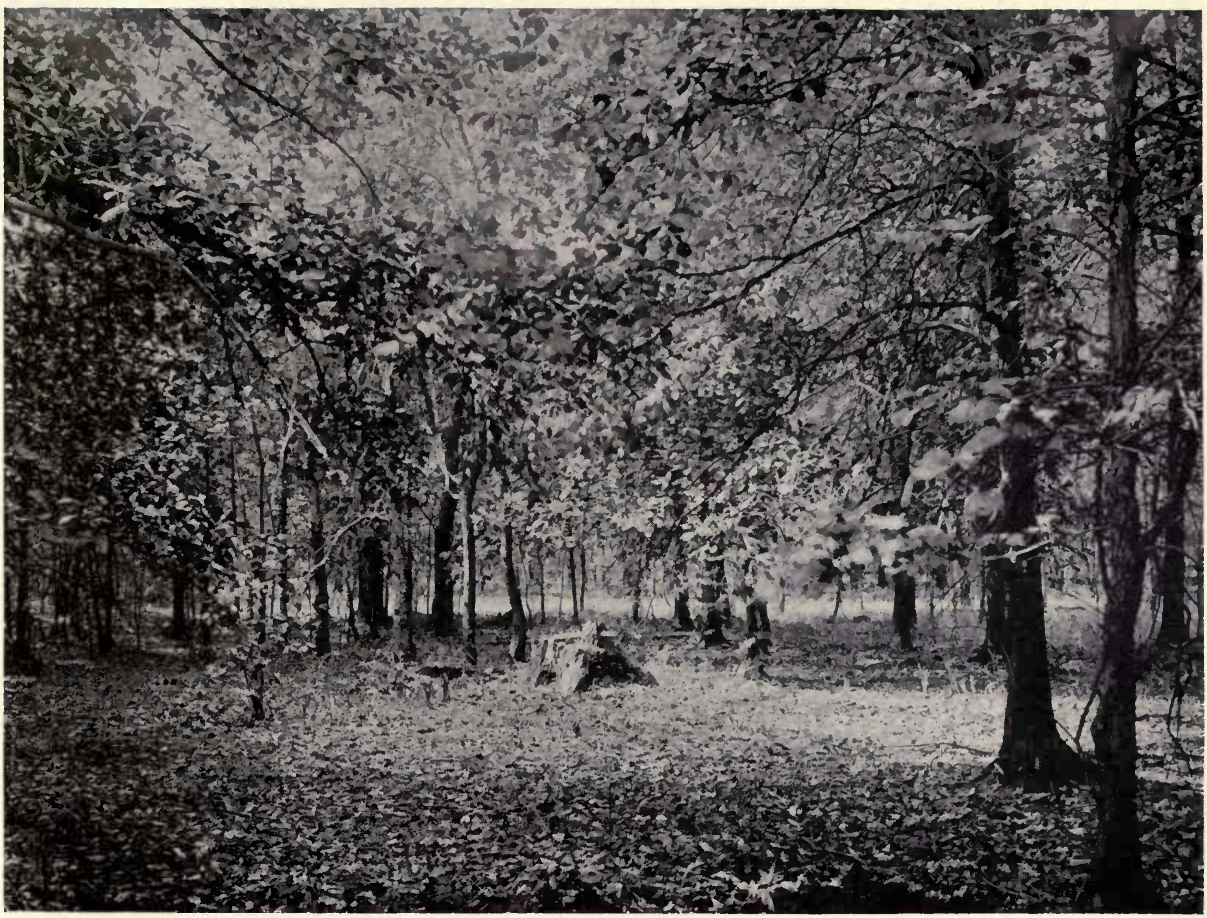

FIG. 1.

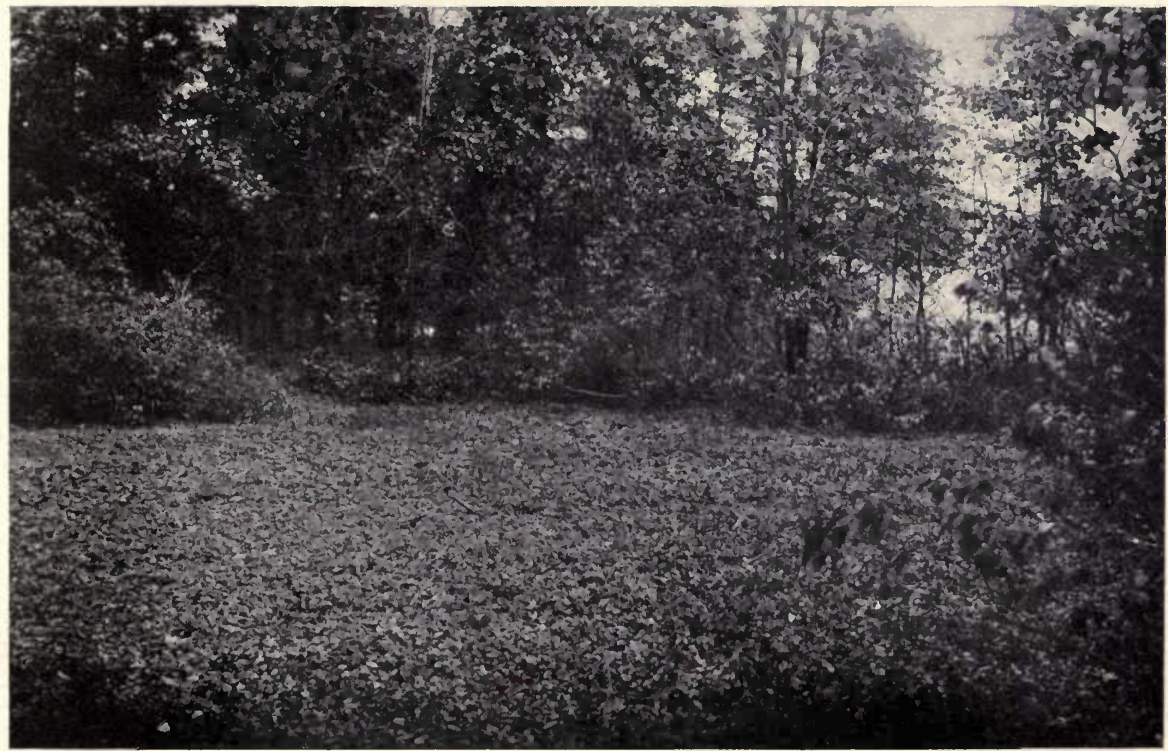

FIG. 2. 



\section{Plate LiI.}

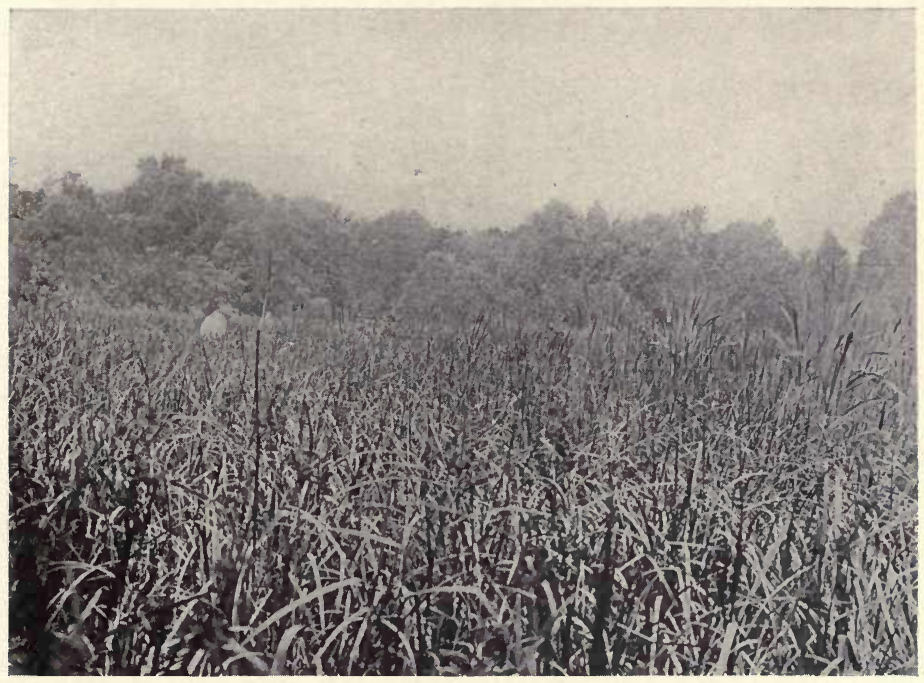

FIG. 1

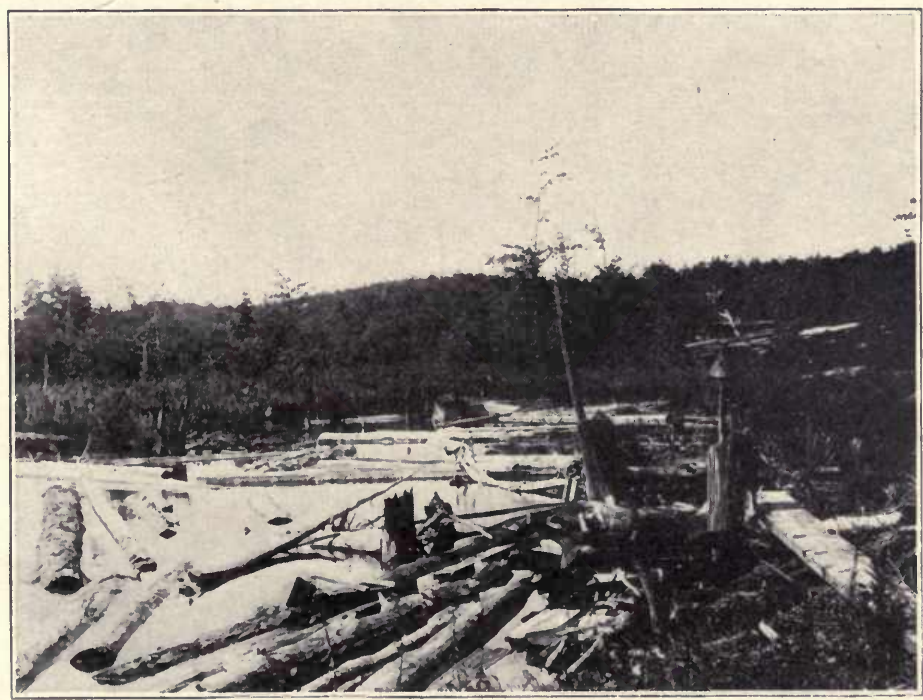

FIG. 2. 


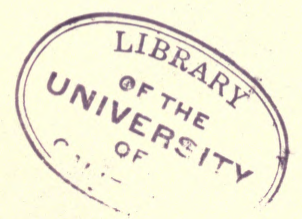


Plate LiII.

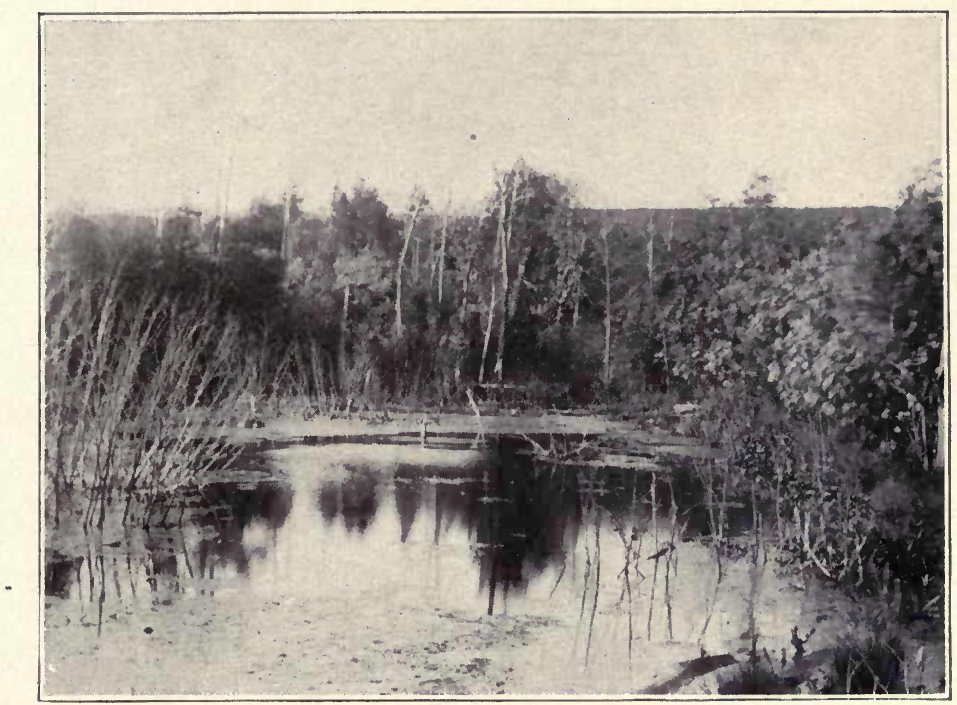

FIG. 1.

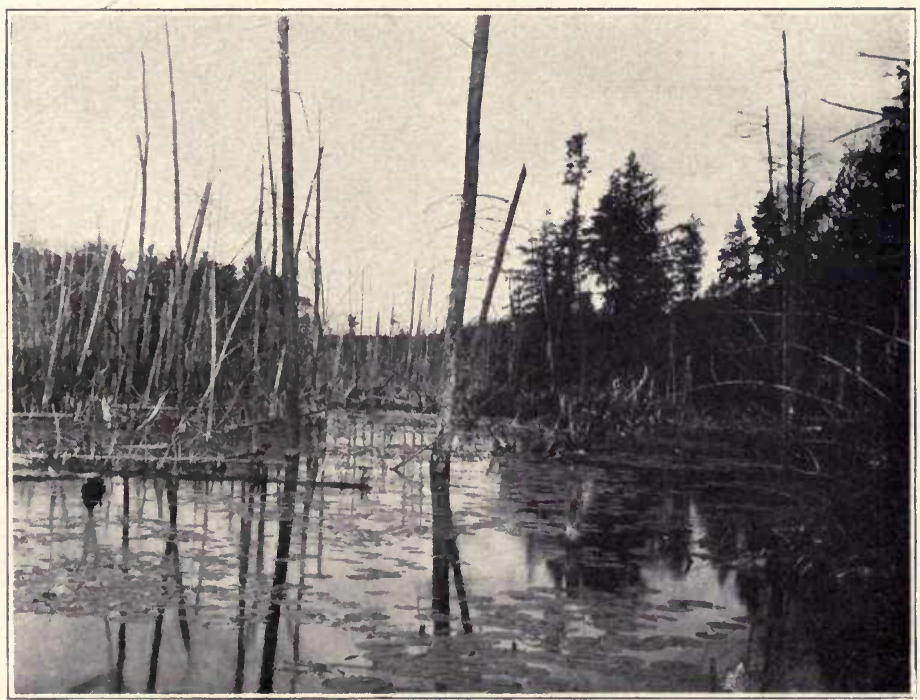

FIG. 2. 
JIBRARY
(अFTHE
MUMESITY 


\section{Plate LIV.}

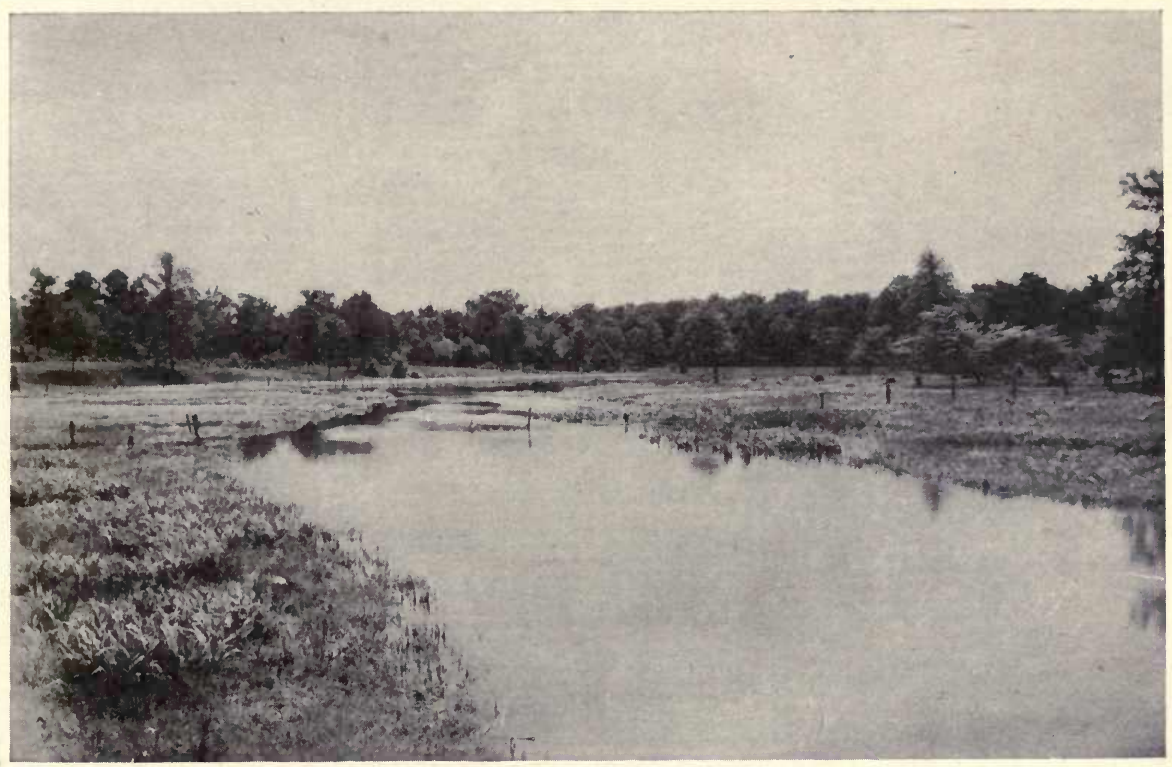

FIG. 1.

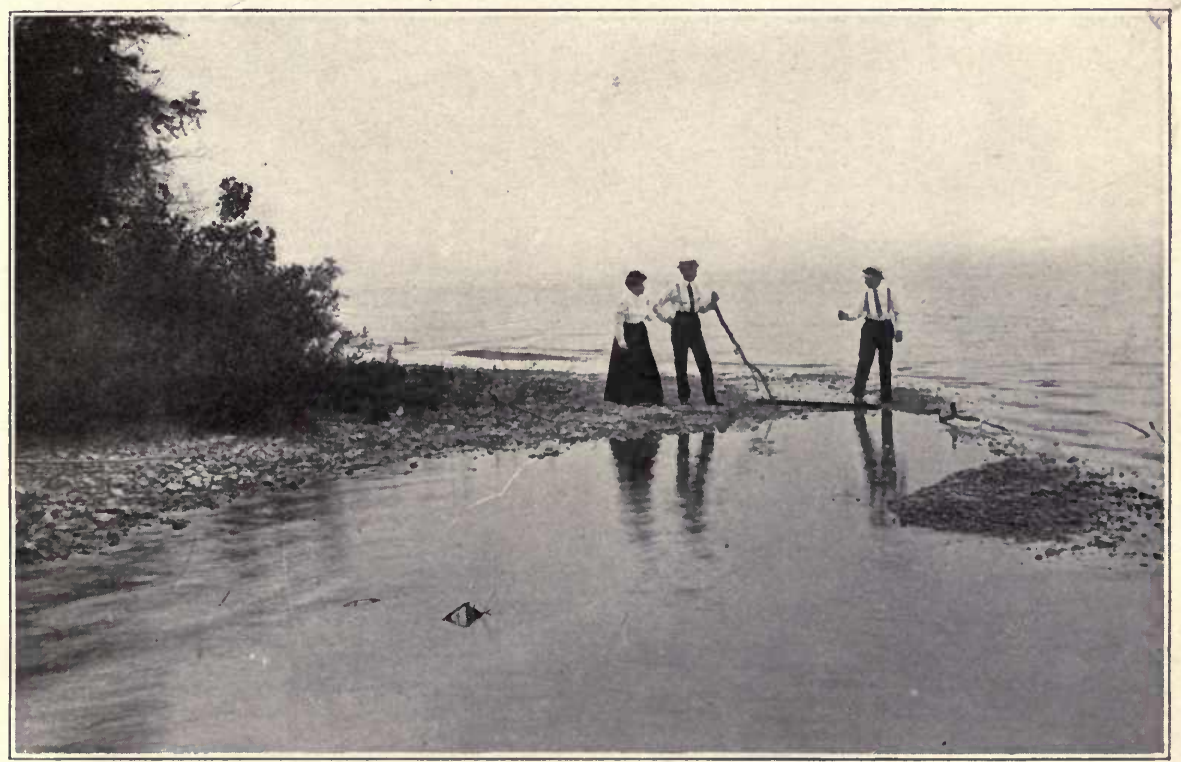

FIG. 2 


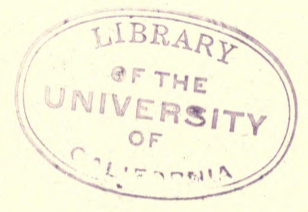


Plate LV.

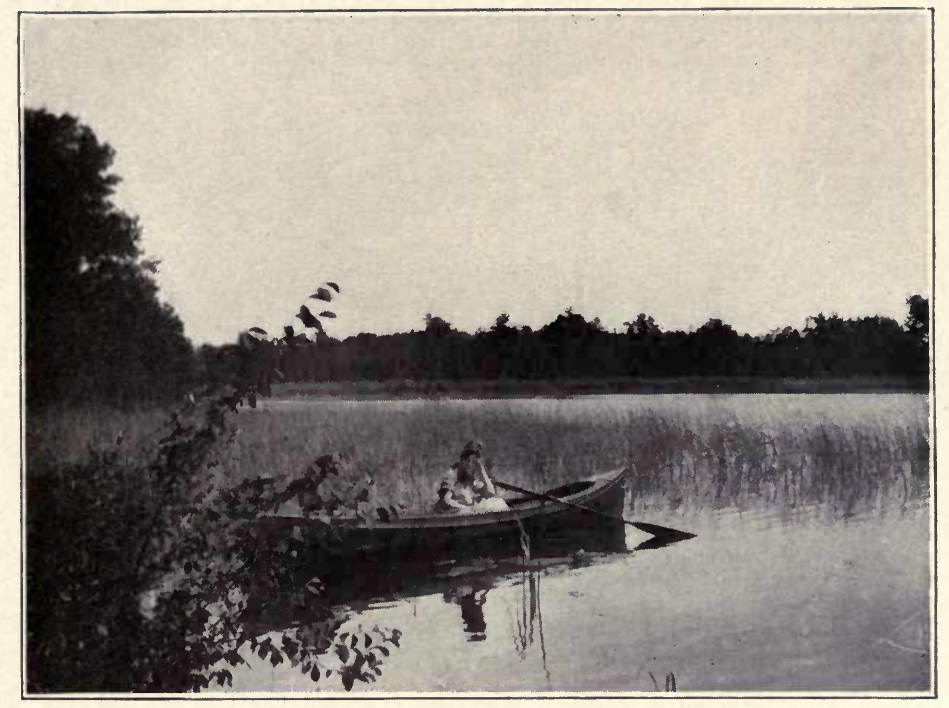

FIG. 1.

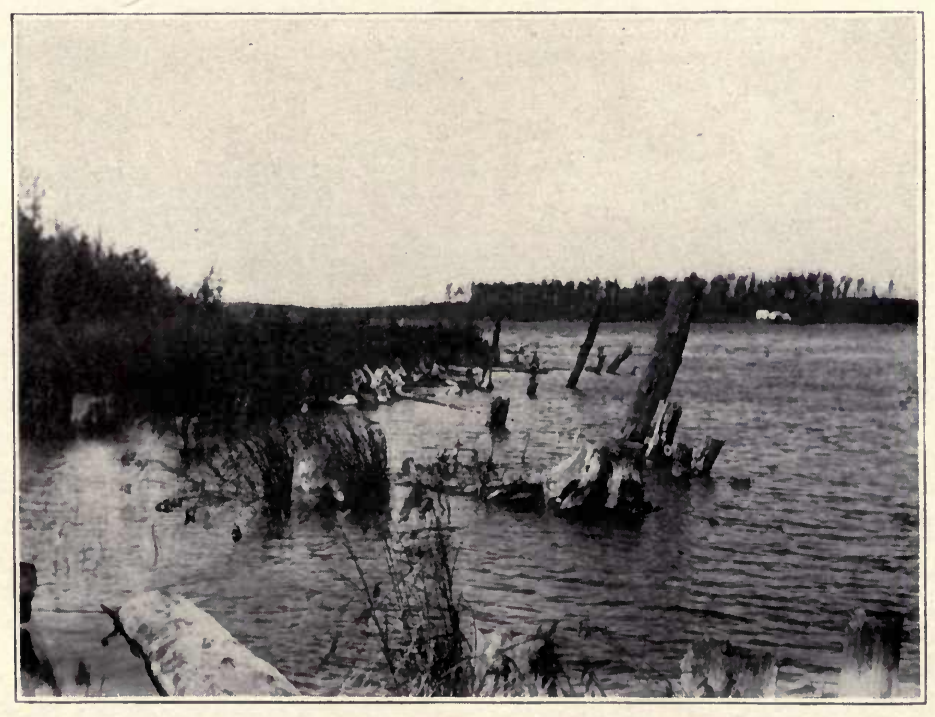

FIG. 2. 


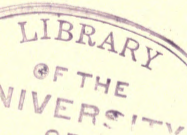




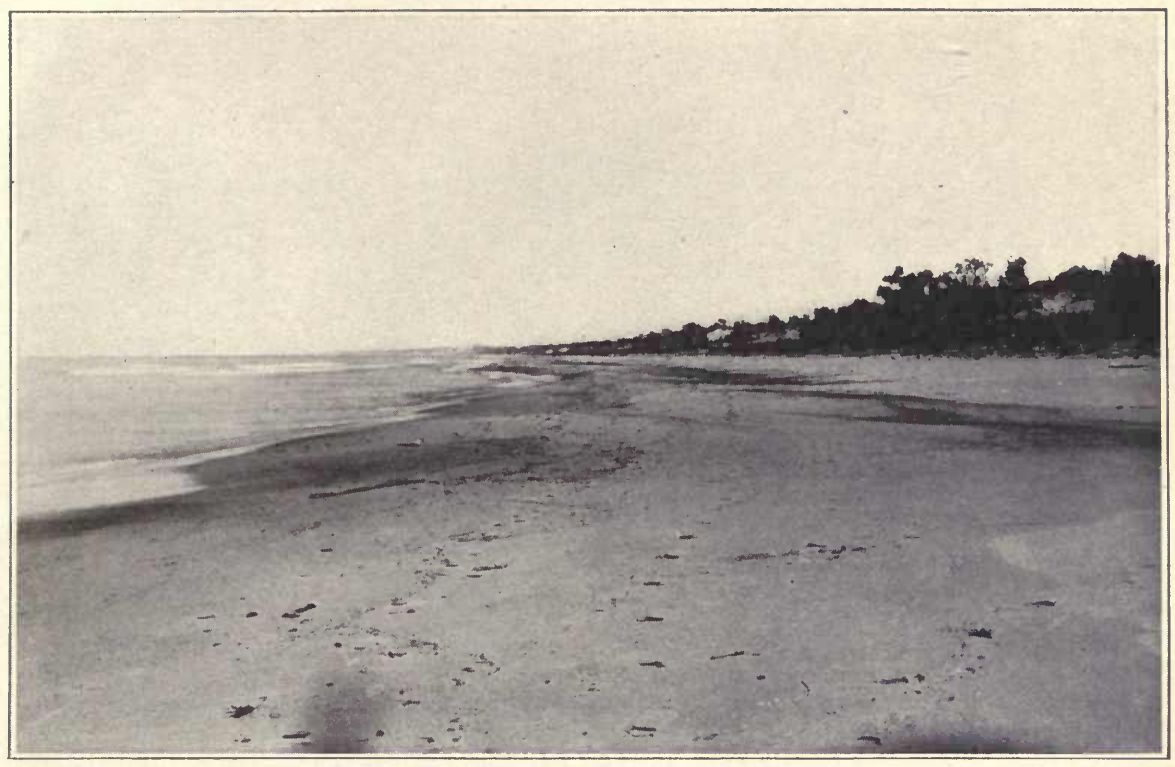

FIG. 1.

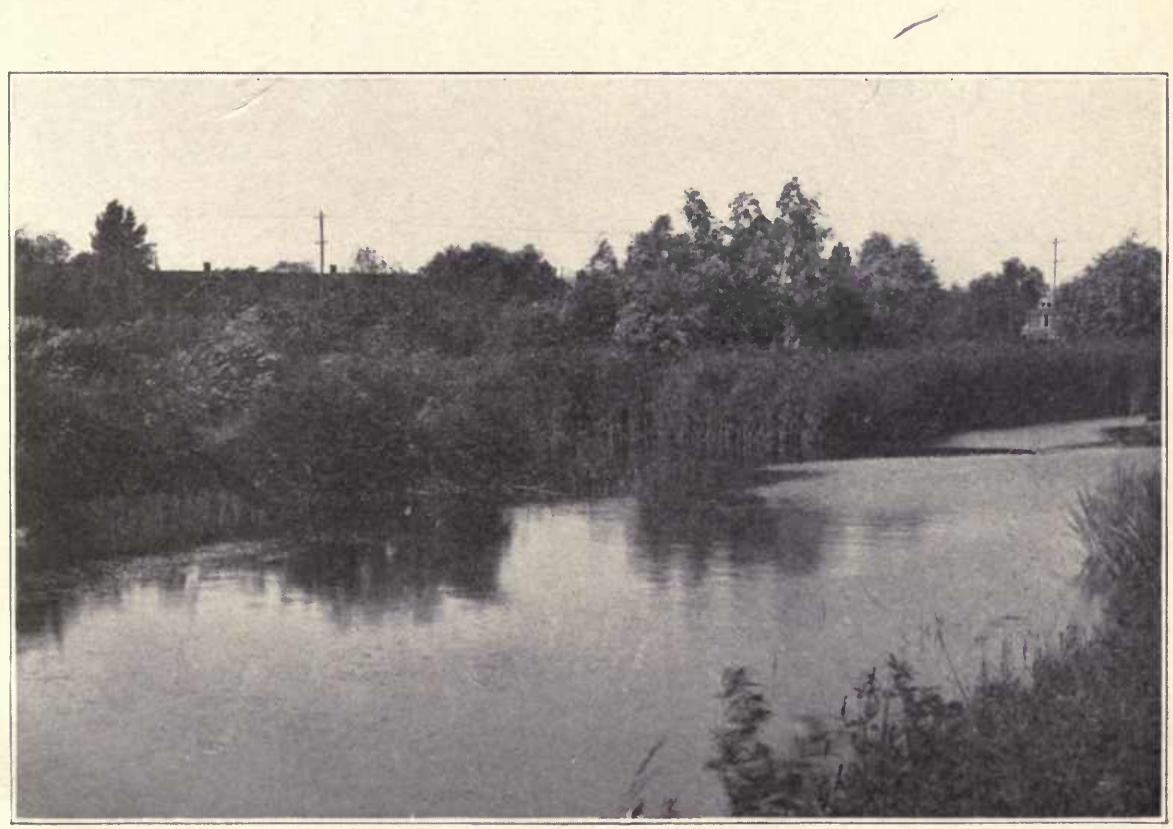

FIG. 2. 


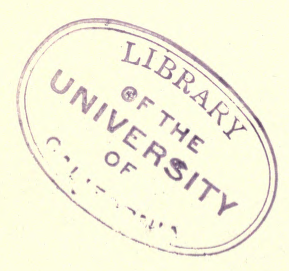


Plate LViI.

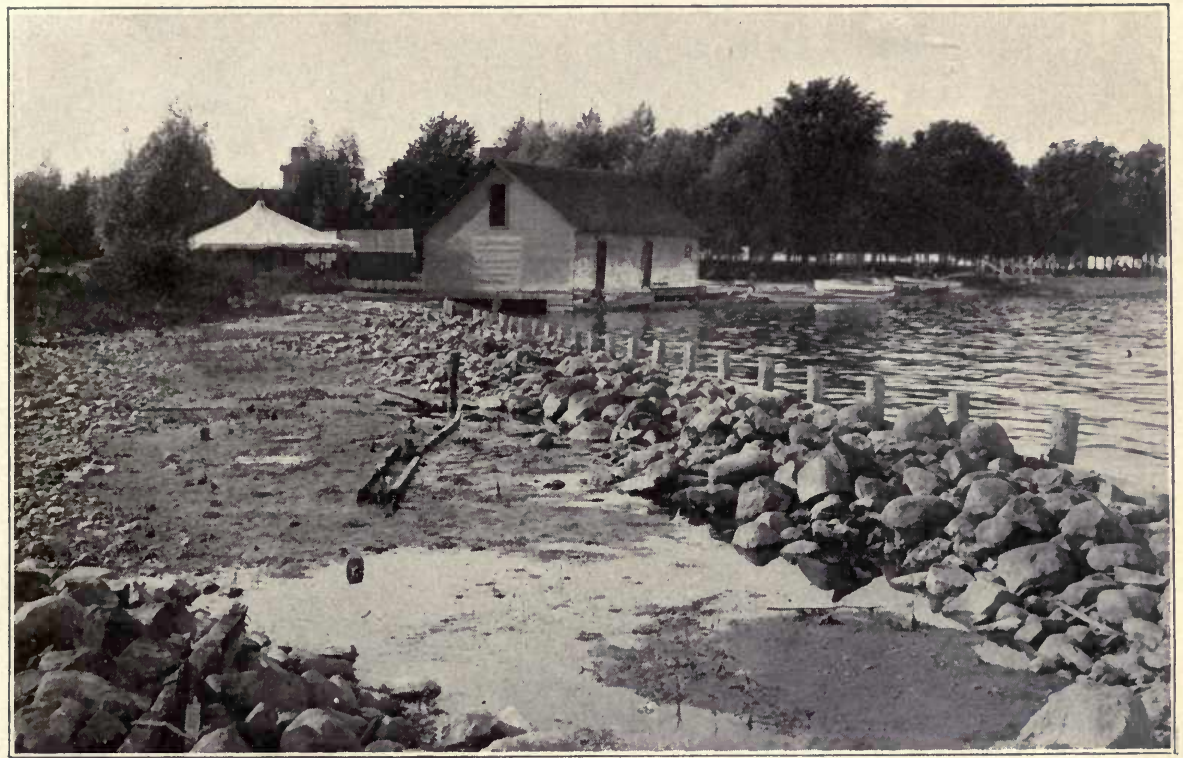

FIG. 1.

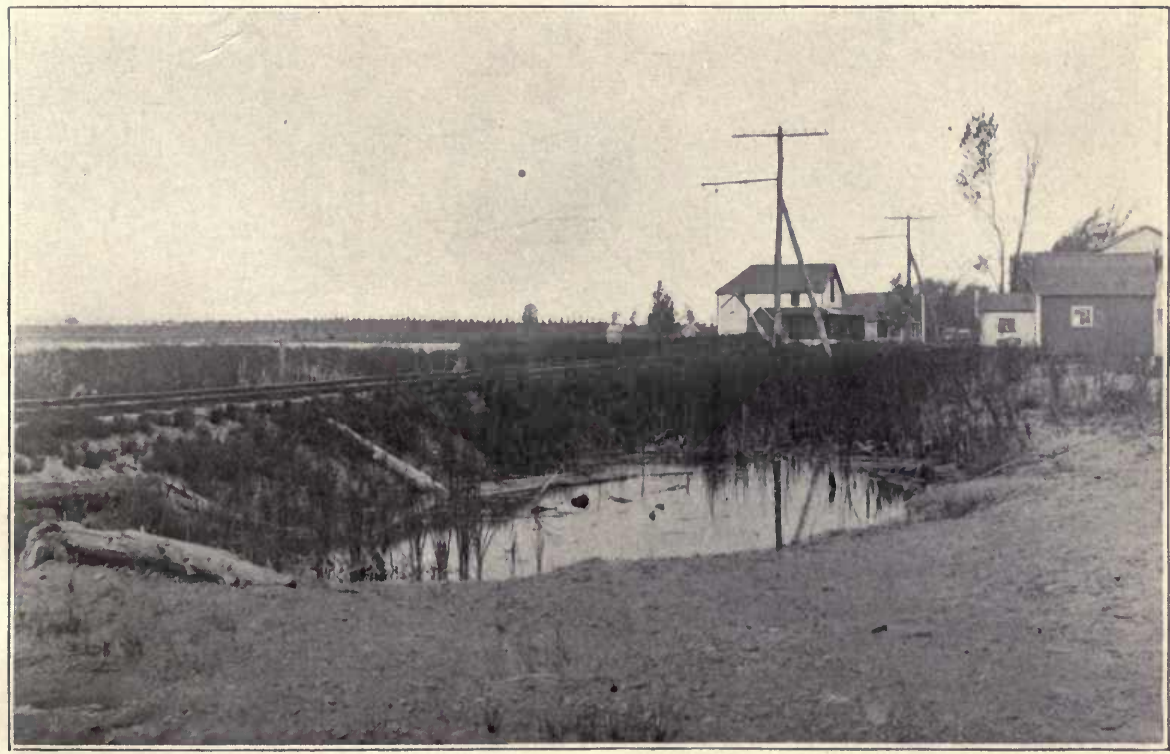

FIG. 2. 

Plate LVIII.

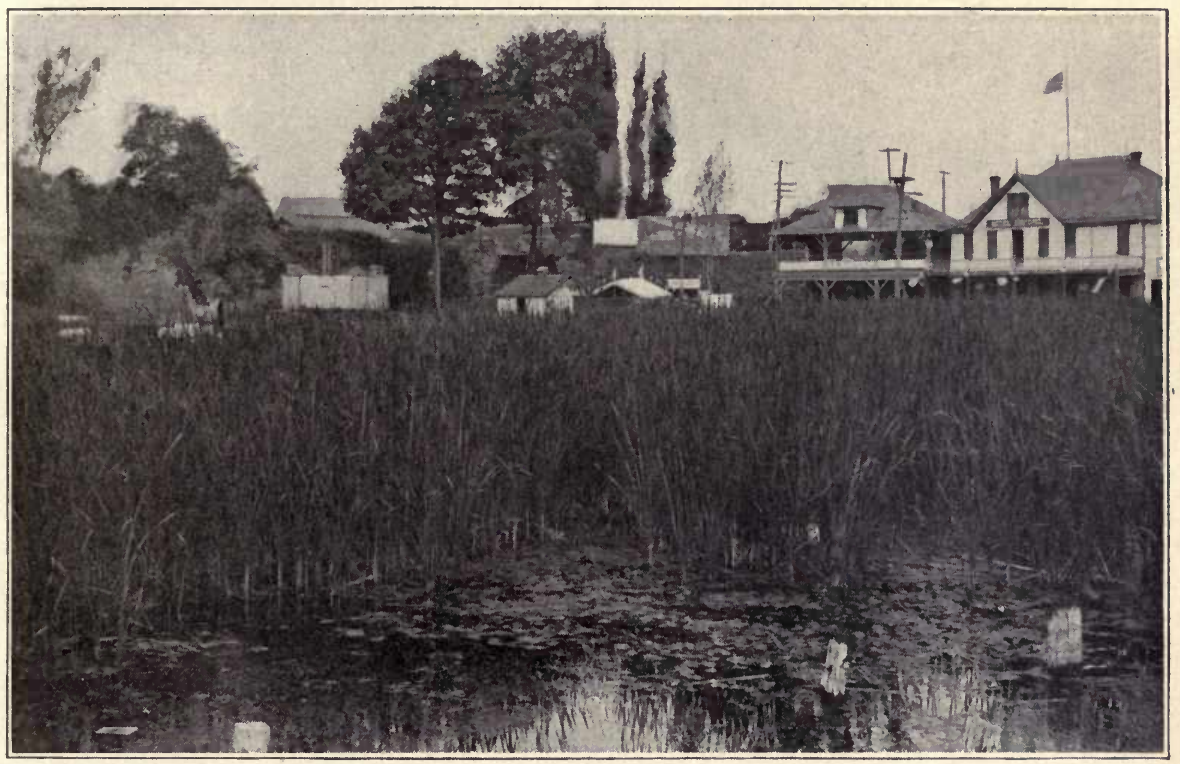

FIG. 1.

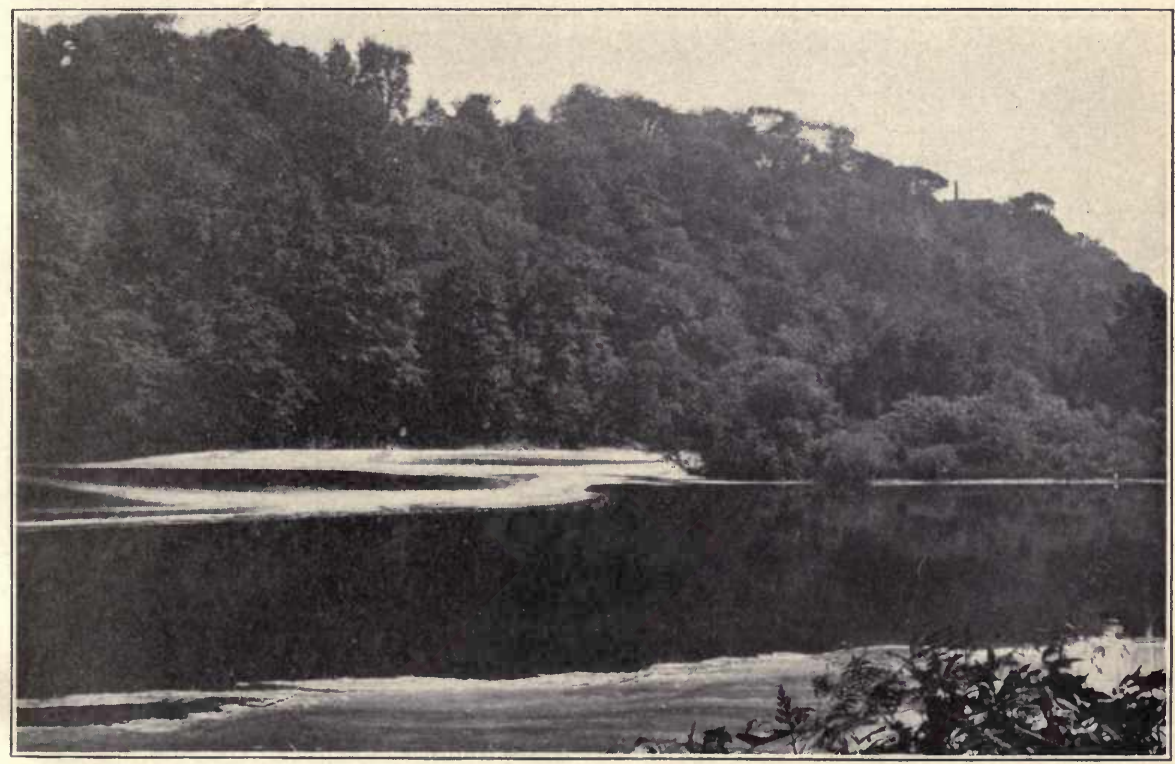

FIG. 2. 


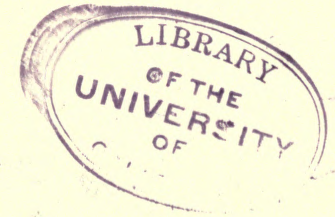





TWTT DRSTTY OF

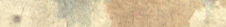

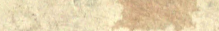

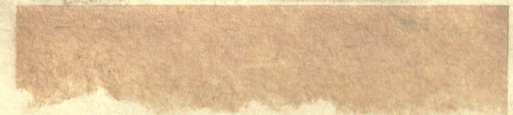




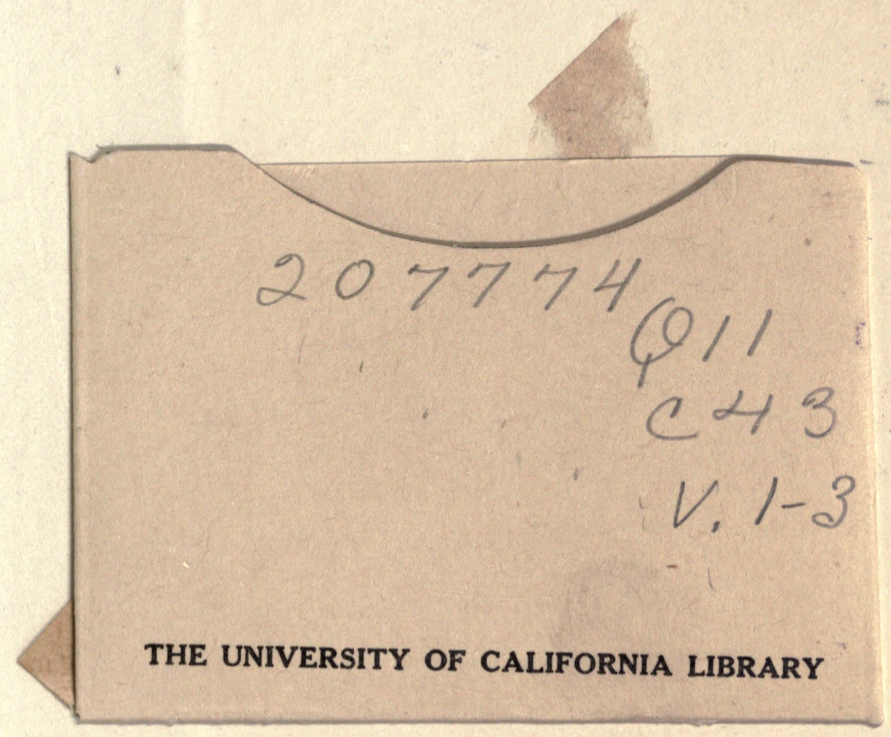


